Julia Thyroff

\title{
Aneignen in einer historischen Ausstellung
}

Eine Bestandsaufnahme von Elementen historischen Denkens bei Besuchenden der Ausstellung «14/18. Die Schweiz und der Grosse Krieg»

$\frac{O h}{12}$ Geschichtsdidaktik heute

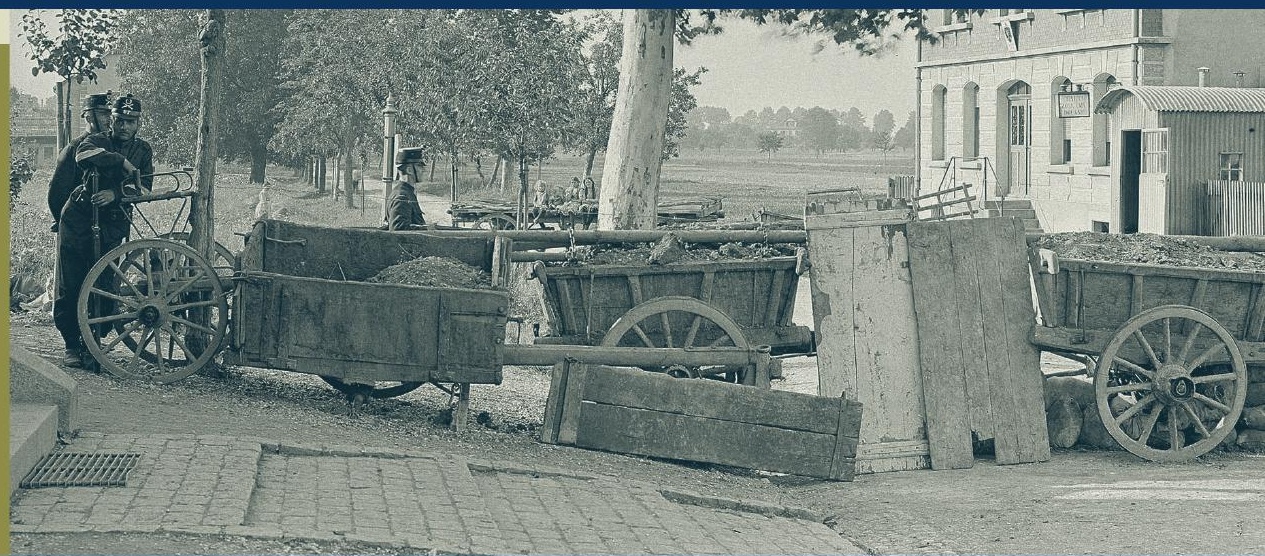


Oh Geschichtstidatikit heute

Un www.geschichtsdidaktik-heute.ch

12

In der Reihe "Geschichtsdidaktik heute» werden Arbeiten veröffentlicht, die sich mit innovativen Ansätzen und methodischer Klarheit der empirischen Erforschung theoretischer Konzepte sowie der Rückbindung empirischer Befunde an die Theoriebildung im Feld der Geschichtsdidaktik widmen.

Herausgeberschaft der Reihe «Geschichtsdidaktik heute» im hep verlag

Prof. em. Dr. Béatrice Ziegler

Politische Bildung und Geschichtsdidaktik,

Pädagogische Hochschule FHNW am ZDA Aarau

Prof. Dr. Marko Demantowsky

Professor für Neuere/Neueste Geschichte und Didaktik, Pädagogische Hochschule FHNW, Windisch

Prof. Dr. Markus Furrer

Professor für Geschichte und Geschichtsdidaktik an der

Pädagogischen Hochschule Luzern

Stephan Hediger

Bereichsleiter Geografie, Geschichte, Religion und Kultur,

Pädagogische Hochschule Zürich

Dr. Nadine Ritzer

Dozentin am Institut Sekundarstufe I,

Pädagogische Hochschule Bern 
Julia Thyroff

\section{Aneignen in einer historischen Ausstellung}

Eine Bestandsaufnahme von Elementen historischen Denkens bei Besuchenden der Ausstellung «14/18. Die Schweiz und der Grosse Krieg» 


\section{hep
kompetent bilden}

Publiziert mit Unterstützung des Schweizerischen Nationalfonds zur Förderung der wissenschaftlichen Forschung

Publiziert von

hep Verlag AG

Gutenbergstrasse 31

3011 Bern

hep-verlag.ch

Text (C) Julia Thyroff 2020

Umschlagbild: Barrikaden zwischen Hegenheimerstrasse und Allschwil, Schweizerisches Bundesarchiv, CH-BAR\#E27\#1000/721\#14095\#67*

ISBN (Print): 978-3-0355-1625-8

ISBN (E-Book): 978-3-0355-1626-5

DOI: https://doi.org/10.36933/9783035516258

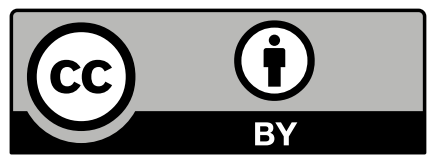

Dieses Werk ist lizenziert unter einer Creative Commons Namensnennung 4.0 International Lizenz.

Zusatzmaterialien und -angebote zu diesem Buch: http://mehr.hep-verlag.ch/geschichtsdidaktik-12 


\section{Inhaltsverzeichnis}

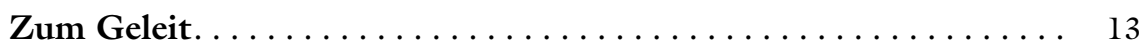

Vorwort der Autorin und Danksagung ............... 15

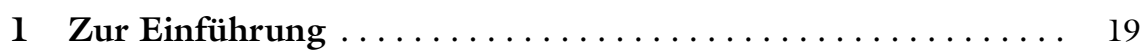

2 Theoretische Grundlegungen (I): Historisches Denken und dessen Relevanz für Gegenwart und Individuum. . . . . . . . . 29

2.1 Zu den Funktionen und Dimensionen einer

Beschäftigung mit Geschichte in der Gegenwart Theoretische Zugänge im Überblick . . . . . . ...... 30

2.2 Historisches Denken, Sinnbildung und Orientierung bei Jörn Rüsen...................... 39

2.3 Verknüpfungen von Zeitebenen: Bedeutung und Varianten ...................... 46

2.4 Gegenwarts- und Lebensweltbezug als geschichtsdidaktische Prinzipien und Normen . . . . . . . . . 50

$2.5 \quad$ Historisches Denken und Orientierung .......... 54

2.5.1 Historisches Denken und Orientierung im Rahmen von deutschsprachigen Kompetenzmodellen .......................... 54

2.5.2 Weitere theorie- und empiriebasierte Konzeptionen historischen Denkens . . . . . . . . 62

2.6 «Theoretische Sensibilität»: Zwischenfazit und Bemerkungen zum Verhältnis von Theorie und Empirie

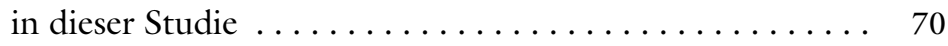

3 Theoretische Grundlegungen (II): Historische Museen und Ausstellungen und deren Besuchende ............. 81

3.1 Historische Ausstellung und historisches Museum:

Dimensionen, Konstruktionsbedingungen und Funktionen geschichtskultureller Manifestationen........... 81 
3.2 Besuchende: Lernen und Aneignen in Museum und Ausstellung $\ldots \ldots \ldots \ldots \ldots \ldots \ldots \ldots \ldots \ldots \ldots \ldots$

3.3 Historisches Denken, historisches Lernen und historische Kompetenzen in Museum und Ausstellung ......... 105

3.4 Ästhetik und Emotionen als Dimensionen historischen

Denkens und Lernens in einer historischen Ausstellung . . 115

3.4.1 «Nicht-nur-kognitive Momente» historischen Denkens und Lernens. . . . . . . . . . . . . . 116

3.4.2 Zum Stellenwert von Emotionen ......... 126

3.4.3 Zum Stellenwert von Ästhetik . . . . . . . . . . . 129

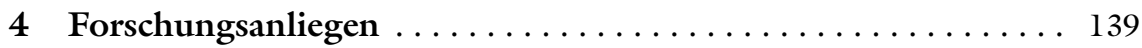

5 Besuchende in historischen Museen und Ausstellungen:

Zum Stand der empirischen Forschung. . . . . . . . . . 143

$5.1 \quad$ Forschungsgegenstände................. 146

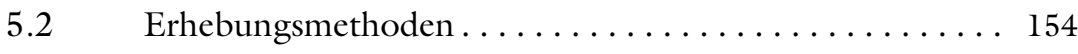

$5.3 \quad$ Befunde ausgewählter Studien $\ldots \ldots \ldots \ldots \ldots \ldots \ldots 163$

5.3.1 Befunde zur formalen Gestalt von Ausstellungsbesuchen: Bewegungs- und Aufmerksamkeitsmuster im Raum . . . . . . . . . . . . . . . . 165

5.3.2 Befunde zur inhaltlichen Gestalt von Ausstellungsbesuchen: Kategorisierungen von Besuchserfahrungen jenseits des Erwerbs von

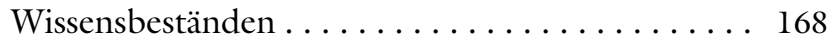

5.3.3 Befunde zu geschichtstheoretischen Zugängen: Vorstellungen der Besuchenden zur Manifestation Museum/Ausstellung und ihren Elementen .... 173

5.3.4 Befunde zum Nicht-nur-Kognitiven (1): Imagination und Empathie ............ 176

5.3.5 Befunde zum Nicht-nur-Kognitiven (2): Objektbegegnung, Emotion und Ästhetik...... 183

5.3.6 Befunde zur Lebenswelt- und Gegenwartsrelevanz von Ausstellungsbesuchen ............. 187 
5.3.7 Befunde zu Sinnbildung und historischem Denken in einer Ausstellung: Die Studie «Visitors encounter the dust. How People think with objects in a History Museum Exhibition» von Susie Wise . . . 188

5.4 Desiderate und Verortung des Projekts .......... 192

6 Methoden ............................... 195

6.1 Methode der Datenerhebung: Prozessbegleitendes

Lautes Denken......................... 195

6.1.1 Entstehung und Verwendung der Methode .... 196

6.1.2 «Verbal reports»- Theoretische und methodologische Fundierung bei K. Anders Ericsson und Herbert A. Simon . . . . . . . . . . . 197

6.1.3 Grenzen und Potenziale des Prozessbegleitenden Lauten Denkens als Erhebungsmethode ...... 202

6.1.4 Einsatzfelder Lauten Denkens ............ 210

6.1.5 Lautes Denken beim Besuch einer historischen Ausstellung. Begründung der Methodenwahl und Potenziale im Hinblick auf den Forschungsgegenstand .................... 214

6.2 Ablauf der Datenerhebung und Teilnehmende ...... 217

6.2.1 Anwerbung der Teilnehmenden........... 217

6.2.2 Ablauf der Erhebung: Lautes Denken in der Ausstellung $\ll 14 / 18 » \ldots \ldots \ldots \ldots \ldots \ldots \ldots 220$

6.2.3 Hintergründe der Teilnehmenden ......... 222

6.3 Transkription ........................... 229

6.4 Methode der Datenauswertung: Inhaltlichstrukturierende qualitative Inhaltsanalyse . . . . . . . . . 229

6.4.1 Zur Einordnung: Rekonstruktive und inhaltsanalytische Verfahren ........... 230

6.4.2 Prinzipien der inhaltlich strukturierenden Inhaltsanalyse und Vorgehen bei der Auswertung . . . . . 235

6.4 .3 Gütekriterien. . . . . . . . . . . . . . . . . 243 
7 «14/18. Die Schweiz und der Grosse Krieg». Ausstellung, historische Hintergründe und geschichtskultureller Kontext. . 249

7.1 Anliegen und Grundstruktur der Ausstellung ........ 250

7.2 Historische, historiografische und geschichtskulturelle Einordnung der Ausstellung . . . . . . . . . . . 252

7.2.1 Die Schweiz im Ersten Weltkrieg. Historische und historiografische Hintergründe, «Dominantes Narrativ» und Differenzierungen........... 253

7.2.2 Geschichtskulturelle Einordnung: Manifestationen und Erzählungen zur Schweiz im Ersten Weltkrieg.................... 258

7.2.3 Zum Narrativ der Ausstellung «14/18» und dessen Einordnung................. 265

7.3 Ästhetische Gestaltung und Exponate . . . . . . . . 268

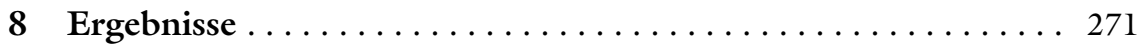

8.1 Erste Einblicke in Charakteristika des Datenmaterials und resultierende Herausforderungen für die Analyse. . . . . . 271

8.2 Struktur der Analysekategorien und Kapitelaufbau . . . . 274

8.3 Die Besuchenden in der Ausstellung: Zur

Oberflächenstruktur von Besuchsverläufen. . . . . . . . 277

8.3.1 Die Besuchenden im Raum: Laufwege und besuchte Abteilungen . . . . . . . . . . . . . . 278

8.3.2 Die Besuchenden im Kontakt mit Ausstellungselementen: Elementbezüge und Aktivitätsformen . . . . . . . . . . . . . 281

8.3.2.1 Varianten im Überblick ............ 281

8.3.2.2 Kleinschrittigkeit und unmittelbare Situationsbezogenheit der Äusserungen als wesentliche Strukturmerkmale . . . . . 288

8.3.2.3 Zum Verhältnis von lesenden und freien Äusserungen, von quellen- und darstellungsbezogenen Äusserungen. . . . 292

8.3.3 Übergreifende Befunde, Zwischenfazit und Einordnung. . . . . . . . . . . . . . . . . . . . 299 
8.4 Bausteine des Denkens in einer historischen Ausstellung:

Eine tiefenstrukturanalytische Inventarisierung. Die

Zugänge im Überblick . . . . . . . . . . . . . . . . . . . 304

8.5 Äusserungen im Fokus I: Geschehen . . . . . . . . . 314

8.5.1 Varianten im Überblick. .................. 314

8.5.2 Status der Äusserungen über Geschehen ...... . 317

8.5.3 Zeitebenen des Geschehens ............. 321

8.5.4 Varianten von Gegenwartsbezügen ........ 326

8.5.4.1 Gemeinsamkeiten zwischen

Vergangenheit und Gegenwart ...... . 329

8.5.4.2 Wurzeln und Vorläufer der Gegenwart . 337

8.5.4.3 Unterschiede zwischen Vergangenheit und Gegenwart ............. 340

8.5.4.4 Umgangsweisen der Gegenwart mit der Vergangenheit ............... 343

8.5.4.5 Überzeitliches und Allgemeingültiges. . . 347

8.5.4.6 Exkurs: Orte als zeitübergreifende Phänomene und Parameter........ 355

8.5.5 Übergreifende Befunde, Zwischenfazit und

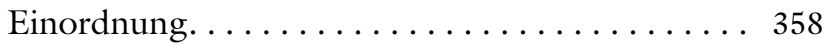

8.6 Äusserungen im Fokus II über die Ausstellung und ihre

Elemente und ihr Verhältnis zu geschehensbezogenen Äusserungen . . . . . . . . . . . . . . . . . 368

8.6.1 Varianten im Überblick. . . . . . . . . . . . . . . 368

8.6.2 Ausstellungsbezogene Äusserungen in Bezügen.

Zum Verhältnis von Fokus I und Fokus II zu

konstruktivistischen und positivistischen

Zugängen ...................... 371

8.6.2.1 Äusserungen über die Gemachtheit von Ausstellung und Geschichte . . . . . . . 374

8.6.2.2 Äusserungen über historische Wirklichkeit und Korrektheit der Darstellung . . . . . . . 387

8.6.2.3 Zwischen Abbild, Bild und Exponat:

Varianten von Äusserungen über Bildquellen.................. 
8.6.3 Identifizieren als zentraler Modus des Ausstellungsbesuchs ................ 403

8.6.4 Äusserungen der Besuchenden über Inhalt und Ästhetik der Ausstellung: Ästhetik als

Deutungshilfe und strukturgebendes Element ... 411

8.6.4.1 Zum Umgang der Besuchenden mit den «Blick ins Ausland»-Elementen und der Struktur der Ausstellung . . . . . . . . . 413

8.6.4.2 Zum Umgang der Besuchenden mit in der Ausstellung angelegten Verknüpfungen von Zeitebenen und Gegenwartsbezügen ............ 422

8.6.5 Übergreifende Befunde, Zwischenfazit und Einordnung. .................. 436

8.7 Äusserungen im Fokus III: Die eigene Person und Lebenswelt. . . . . . . . . . . . . . . . . . . 445

8.7.1 Varianten im Überblick. . . . . . . . . . . . . . . . 445

8.7.2 Kognitive und nicht-nur-kognitive Relationen . . 455

8.7.2.1 Erstaunen und Eindruck . . . . . . . . . 455

8.7.2.2 Interesse, Spannung und Faszination ... 465

8.7.2.3 Exkurs: Pläne und Massnahmen zur Weiterbeschäftigung ........... 467

8.7.2.4 Freude, Wohlgefühl, Dankbarkeit und positive Bewegung. . . . . . . . . . 469

8.7.2.5 Belustigung, Schmunzeln, Spott und Ironie . . . . . . . . . . . . . . . . 472

8.7.2.6 Betroffenheit, Entsetzen, Beunruhigung und negative Bewegung . . . . . . . 479

8.7.2.7 Sättigung, Überdruss und Anstrengung . 487

8.7.2.8 Desinteresse und Indifferenz. . . . . . . . 491

8.7.2.9 Urteile über Relevanz und Wichtigkeit. . 493

8.7.2.10 Exkurs: Implizite Relevanzen und Bedeutungen .............. 495

8.7.2.11 Urteile über Schlüssigkeit, Erwartbarkeit und Nachvollziehbarkeit ......... 500 
8.7.2.12 Positive und negative Urteile . . . . . 506

8.7.2.13 Vorwissen und neues Wissen........ 514

8.7.2.14 Vermutungen.................. 519

8.7.2.15 Fragen, Unklarheiten und Irritationen . . 522

8.7.3 Die eigene Lebenswelt . . . . . . . . . . . . . 540

8.7.3.1 Eigener Ort und Raum ............ 541

8.7.3.2 Eigenes Kollektiv . . . . . . . . . . . . . . 547

8.7.3.3 Eigene Familie ................ 555

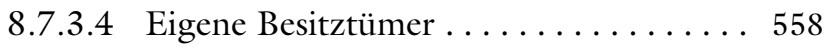

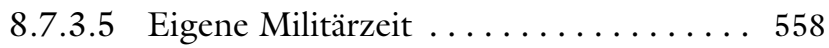

8.7.3.6 Eigene Ausbildung . . . . . . . . . . 560

8.7.3.7 Eigene Berufs- und

Vermittlungstätigkeit........... 561

8.7.3.8 Eigene Erfahrungen mit

Geschichtskultur .............. 564

8.7.3.9 Sonstige biografische Bezüge . . . . . 570

8.7.3.10 Abwesenheit von persönlichen

Bezügen................ 572

8.7.4 Die eigene Person in der Ausstellung. . . . . . . . 573

8.7.4.1 Die eigene Rolle als

Studienteilnehmende............ 573

8.7.4.2 Sich-Vorstellen und -Hineinversetzen,

Nähe und Ferne zum Geschehen ..... . 574

8.7.4.3 Eigene Geschichtsbilder und deren

Bestätigung oder Revision.......... 584

8.7.5 Übergreifende Befunde, Zwischenfazit und

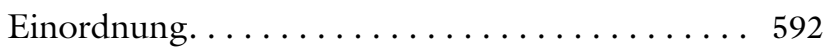

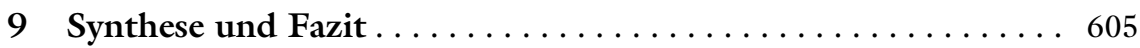

9.1 Dreierlei Fokussierungen: Zusammenfassung und

Modell ........................... 605

9.2 Theoretische Bezüge: Das Fokussierungsmodell im

Verhältnis zur «Sechs-Felder-Matrix» . . . . . . . . . . . . 609

9.2.1 Historisches vs. ahistorisches Denken ....... 610

9.2.2 Re-konstruktive und de-konstruktive Elemente .. 612

9.2.3 Stellung von eigener Person und Gegenwart.... 616 
9.3 Aneignen in einer historischen Ausstellung: Überlegungen zu manifestations- und methodenspezifischen Prägungen historischen Denkens. .................... 617

9.3.1 Kleinschrittigkeit und Momentbezogenheit des Denkens ....................6. 617

9.3.2 Nicht-nur-kognitive Elemente . . . . . . . . . . 619

9.3.3 Zur Einschätzung der Ausstellung und ihrer Elemente zwischen Abbild historischer Wirklichkeit und konstruiertem Raum ........... 626

9.3.4 Bezüge zur eigenen Person und Gegenwart und Rolle des Erhebungsortes ............ 629

10 Literaturverzeichnis . . . . . . . . . . . . . . . . 631

10.1 Artikel, Monografien, Sammelbände, Zeitschriften .... . 631

$10.2 \quad$ Websites.......................... 659

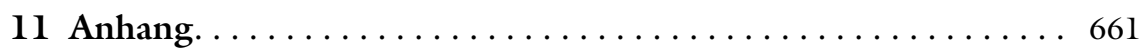

11.1 Hinweise zum Anhang und zur digitalen Ergänzung des Anhangs..........................661 661

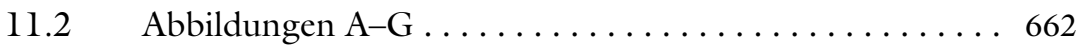

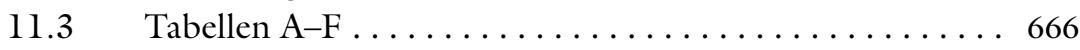




\section{Zum Geleit}

Ein Geleitwort für dieses Buch zu schreiben, verschafft mir doppeltes Vergnügen. Zum einen verdankt sich das Dissertationsprojekt einem glücklichen Zufall, zum andern das Ergebnis aber dem Können und dem Forschungswillen seiner Verfasserin. Dass es entstehen konnte und nun vorliegt, ist mir Grund zum Dank bei allen Beteiligten, aber insbesondere bei der Verfasserin selbst, die auf ihren Suchbewegungen zu begleiten mir eine Freude und intellektuelle Herausforderung war.

Der glückliche Zufall entstand, als das Team um das Sinergia-Forschungsprojekt «Die Schweiz im Ersten Weltkrieg. Transnationale Perspektiven auf einen Kleinstaat im totalen Krieg» die Idee zu einer Ausstellung zum Thema «14/18. Die Schweiz und der Grosse Krieg» verwirklichte und sich, genauso wie dann das Historische Museum Basel, gegenüber einer Besucherforschung aufgeschlossen zeigte. - Ausstellungen zu historischen Themen sind seit Längerem Gegenstand geschichtsdidaktischen Interesses, in erster Linie deshalb, weil Schulklassen wichtige Adressaten sind, Lehrpersonen ihre Schülerinnen und Schüler auch gerne mit Museen und ihren Ausstellungen vertraut machen, es aber durchaus nicht einfach klar ist, was der Gewinn des Ausstellungsbesuchs für das historische Wissen und Verständnis der Schülerinnen und Schüler tatsächlich ist. Zum glücklichen Zufall gehörte, dass Julia Thyroff kurz davor eine Masterarbeit eingereicht hatte, die sich mit Ausstellungskonzeptionen befasste, mit der Angebotsseite sozusagen, und nun nach kurzem Überlegen interessiert war, die Gelegenheit zu packen, um die Nutzendenseite in einer Dissertation näher zu beleuchten und dabei die noch relativ junge theoretische Forschung zu historischer Kompetenz zur empirischen Analyse dessen zu nutzen, was sich in den Köpfen von (erwachsenen) Besuchenden von «14/18. Die Schweiz und der Grosse Krieg» abspielte.

Das Können und die Freude an der Forschung zeigte sich dann unter anderem an der Arbeit mit einer überlegt gewählten und noch wenig genutzten Methode, dem Lauten Denken, aber auch an der Bewältigung und innovativen Strukturierung einer Unmenge von Material, das dabei anfiel. Die Arbeit ist eine Studie zur historischen Kompetenz bei Museumsbesuchenden und fügt sich damit in die aktuelle Kompetenzforschung in der Geschichtsdidaktik ein. Sie zeigt dabei aber auch eine breite Palette von Aussagen, die auf weitere Fragen Antworten liefern: Welches Wissen, welche Assoziationen, welche Erinnerungen, welche Fragen, welche Emotionen zeigen sich bei Besucherinnen und Besuchern unterschiedlichsten 
Alters und unterschiedlichster Erfahrungen? Wann werden diese geäussert, in Verbindung mit Bildern, Objekten, Texten? Welche Wege nehmen Besuchende durch die Ausstellung?

Wie schon frühere Arbeiten in dieser Reihe zu «Geschichtsdidaktik heute» dokumentiert die vorliegende so die Originalität, Innovationskraft und Forschungskompetenz in der noch jungen schweizerischen geschichtsdidaktischen Forschung. Dies lässt auf deren weitere Entwicklung und noch viele derartige Arbeiten in der Geschichtsdidaktik an schweizerischen Institutionen hoffen.

Bern im April 2020

Béatrice Ziegler 


\section{Vorwort der Autorin und Danksagung}

Die vorliegende Publikation basiert auf meiner Dissertationsschrift, die ich im Mai 2018 bei der Philosophisch-Historischen Fakultät der Universität Basel eingereicht und im Juli 2018 verteidigt habe. Mit dem Druck der Dissertation kommt ein vieljähriges Projekt zum Abschluss - begonnen im April 2013 mit meiner Anstellung als Assistentin bei Herrn Prof. Dr. Hans-Ulrich Grunder am damaligen Forschungs- und Studienzentrum für Pädagogik, später umbenannt in Institut für Bildungswissenschaften der Universität Basel. Ich bin dankbar dafür, dass ich die Möglichkeit hatte, die ersten vier Jahre meiner Dissertationszeit unter diesen sehr förderlichen institutionellen Bedingungen zu realisieren und zu finanzieren, bin dankbar für das am Institut herrschende allzeit wertschätzende Klima und das entgegengebrachte Vertrauen in meine Arbeit.

Eine Reihe von Personen hat im Lauf der Jahre mein Projekt massgeblich begleitet und gefördert. Ihnen gilt zu Beginn mein Dank. Zuvorderst danke ich meinen «Doktoreltern», Herrn Prof. Dr. Hans-Ulrich Grunder und Frau Prof. Dr. Béatrice Ziegler. Sie nahmen über viele Jahre hinweg konstant Anteil am Entwicklungsprozess meiner Arbeit, hatten stets ein offenes Ohr für Rückfragen aller Art und dachten sich konstruktiv in die Belange meines Projekts ein. Ich bin ausserordentlich dankbar für ihr Interesse an meiner Arbeit und für ihr Vertrauen in meine Arbeit, für die erfahrene Unterstützung, für wertvolle und weiterführende fachliche Ratschläge und für bestärkende, aber auch herausfordernde Kommentare, die für mein Projekt von unschätzbarem Wert waren.

Neben der Begleitung durch meine Betreuungspersonen wäre mein Projekt nicht in dieser Form zustande gekommen ohne das Interesse und Vertrauen der Akteurinnen und Akteure innerhalb des für meine Forschung relevanten geschichtskulturellen Feldes. Initialzündung für die vorliegende Studie war das Interesse der Verantwortlichen der Wanderausstellung «14/18. Die Schweiz und der Grosse Krieg», des Vereins «Die Schweiz und der Erste Weltkrieg», an einer begleitenden Forschung und eine diesbezügliche Kontaktaufnahme mit Béatrice Ziegler, die wiederum an mich dachte. Erst auf diesem Weg kam ich überhaupt auf die Idee, Besuchende dieser Ausstellung in den Blick zu nehmen, während ich mich bis dahin noch unspezifisch für die Erforschung des Umgangs mit geschichtskulturellen Manifestationen zu interessieren begonnen hatte.

Ich hatte das Glück, seitens des Vereins auf grosses Interesse zu stossen, gleichzeitig aber meine Forschungsfragen und mein Studiendesign vollkommen nach 
meinen Bedürfnissen entwickeln zu können. Ich danke den Angehörigen des Vereins für das mir entgegengebrachte Vertrauen, das Zurverfügungstellen von Materialien und dem Geschäftsführer, Herrn Severin Rüegg, überdies für das geduldige Beantworten zahlreicher Nachfragen zu Belangen der Ausstellung.

Ebenfalls essenziell für die Durchführung meiner Studie war das Entgegenkommen, das ich seitens des Historischen Museums Basel erfahren durfte. Ich erhielt die Möglichkeit, während der Station der Ausstellung in den Räumlichkeiten des genannten Museums meine Datenerhebung durchzuführen, und bin sehr dankbar dafür, dass das Museum bereitwillig seine Tore für meine Forschungsarbeit öffnete. Namentlich danke ich hierfür meiner Hauptansprechperson Frau Dr. Gudrun Piller, die sich sogleich für mein Forschungsvorhaben erwärmen konnte und mir die Unterstützung des Museums zusicherte. Ich erhielt in vielerlei Hinsichten wertvolle Hilfe von Mitarbeitenden des Museums, angefangen bei der Publikation meiner Ausschreibung auf Kanälen des Museums über unzählige Terminkoordinationen, um geeignete schulklassenfreie Besuchszeiten für die Erhebungen zu identifizieren, über die Gewährung freier Eintritte für «meine» Besuchenden bis hin zu der erlebten Anteilnahme bei Erhebungsterminen vor Ort. Während der rund zwei Dutzend, jeweils mehrstündigen Museumsaufenthalte im Herbst- und Winterhalbjahr 2014/15 sind mir das Museum und seine freundlichen Mitarbeitenden ausserordentlich ans Herz gewachsen.

Eine solche Studie wäre weiterhin natürlich undenkbar ohne die Studienteilnehmenden selbst. Insgesamt 30 Personen haben sich für meine Studie zur Verfügung gestellt. Auch wenn letztlich nicht alle erhobenen Daten in die Auswertung einfliessen konnten, danke ich jeder und jedem Einzelnen von ihnen für die Teilnahme. Sie alle haben einen erheblichen zeitlichen Aufwand in Kauf genommen, teilweise mehrstündig die Ausstellung besucht und überdies sehr viel Mut bewiesen. Lautes Denken während eines Ausstellungsbesuchs erfordert Überwindung und bedeutet ein Verlassen der persönlichen Komfortzone. Ich danke allen Teilnehmenden dafür, dass sie dieses Experiment gewagt und ihre Gedanken während des Ausstellungsbesuchs mit mir geteilt haben.

Weiterführende und inspirierende inhaltliche Hinweise erhielt ich auch als Teilnehmerin diverser Doktorandenkolloquien und Seminare. Ich hatte die Gelegenheit, meine Arbeit in regelmässigen Abständen im Rahmen des Doktorandenkolloquiums der Gruppe FUER Geschichtsbewusstsein sowie des Promotionskolloquiums von Herrn Prof. Dr. Hans-Ulrich Grunder zu präsentieren und zur Diskussion zu stellen. Daneben erlebte ich auch die Einbettung in die Graduate School Social Sciences (G3S) der Universität Basel und die damit verbundene Möglichkeit zur 
Teilnahme an Veranstaltungen, insbesondere Methodenseminaren, als inspirierend. Den Teilnehmenden all dieser Veranstaltungen danke ich für ihr engagiertes Hineindenken in die Belange meiner Arbeit und ihre konstruktiven Rückmeldungen.

Grosser Dank gilt weiter den Angehörigen des Zentrums Politische Bildung und Geschichtsdidaktik der PH FHNW in Aarau unter Leitung von Prof. Dr. Monika Waldis. In den letzten Monaten meiner Dissertationszeit nahm ich dort parallel eine Tätigkeit als wissenschaftliche Mitarbeiterin auf. Ich bin sehr dankbar dafür, dass ich unter diesen Bedingungen von «Doppelbelastung», gerade in der arbeitsintensiven Schlussphase meiner Dissertation, sehr viel Anteilnahme an meinem Projekt und Rücksicht erleben durfte.

Etliche Personen haben ihre Zeit und Energie investiert, um Teile der Arbeit zu lesen und zu kommentieren, mir weiterführende inhaltliche Hinweise und Literaturtipps zu geben, Baustellen zu diskutieren, Fragen zu beantworten. Hierfür danke ich neben vielen weiteren namentlich André Thyroff, Martin Nitsche, Philipp Marti und Samuel Burri. Meinen Teamkolleginnen Claudia Schneider und Franziska Hedinger danke ich dafür, dass sie mir in den Monaten vor der Einreichung der Arbeit den Rücken freihielten und Luft zum Schreiben verschafften. Mein besonderer Dank gilt ausserdem Yannick Hofmann, der mir eine wertvolle Unterstützung auf vielerlei Weisen und nicht zuletzt in allen technischen Belangen war, der ausgehend von meinen Bedürfnissen das Setup für die Aufnahmetechnik erdachte und zusammenstellte und überdies unermüdlich um die Aufbereitung und Sicherung sämtlicher entstandener Audio- und Videoaufnahmen besorgt war. Für ihre Unterstützung bei der Transkription des umfangreichen Datenmaterials danke ich Alix Hofmann. Ihre sorgfältige Arbeit und die dadurch gewonnene Entlastung und Zeitersparnis waren mir eine grosse Hilfe.

Für die Publikationsphase schliesslich richtet sich mein besonderer Dank an die Mitarbeitenden des hep Verlags in Bern, die die Veröffentlichung meiner Arbeit stets freundlich und zuvorkommend begleiteten.

So viele Menschen haben einen Anteil am Werden des Projekts, dass es mir unmöglich ist, sie alle namentlich zu nennen. Zuletzt und von Herzen möchte ich auch allen Menschen in meinem persönlichen Umfeld danken, die die Dissertationszeit und die damit verbundenen unausweichlichen Hochs und Tiefs mit Interesse, Einfühlungsvermögen, Geduld und Nachsicht begleitet und immer wieder für die nötige Ablenkung, Abwechslung und Entspannung gesorgt haben.

Basel im März 2020

Julia Thyroff 



\section{Zur Einführung}

Diese Studie handelt von Aneignungsweisen bei Besuchenden einer historischen Ausstellung. ${ }^{1}$ Sie ist in einer Geschichtsdidaktik verortet, die, über das historische Lehren und Lernen im Geschichtsunterricht hinaus, Weisen des individuellen und gesellschaftlichen Umgangs mit Historischem, namentlich «Geschichtsbewusstsein» und «Geschichtskultur», zu ihrem Gegenstand erklärt. ${ }^{2}$ Geschichte, die ich in meiner Arbeit als Erzählung über Vergangenes verstehe und begrifflich von der Vergangenheit selbst unterscheide ${ }^{3}$, ist im menschlichen Leben allgegenwärtig

$1 \quad \mathrm{Zu}$ meinem Dissertationsprojekt ist vorgängig bereits ein Artikel in der Printausgabe der Zeitschrift «Didacta Historica» erschienen (Thyroff 2017b) samt zugehörigem etwas ausführlicherem Pendant in der online verfügbaren Rubrik der Zeitschrift (Thyroff 2017c). Darin habe ich mich bereits einmal sehr knapp zur disziplinären Verortung der Studie geäussert, ausserdem die verfolgten Forschungsfragen formuliert, und, selbstverständlich sehr viel knapper als in der hier vorliegenden Arbeit möglich, theoretische Bezüge der Studie aufgezeigt, die gewählte Erhebungsmethode skizziert sowie in sehr begrenztem Umfang vorläufige Ergebnisse vorgestellt. Es handelte sich dabei um vorläufige, kondensierte Produkte aus dem laufenden Forschungsprozess.

2 Stellvertretend: Jeismann 1988; Rüsen 1994; Rüsen 1997a; Schönemann 2002a; Pandel 2009. Geschichtskultur fasse ich mit Rüsen als «praktisch wirksame Artikulation von Geschichtsbewusstsein im Leben einer Gesellschaft» (Rüsen 1994, S. 5), mit Pandel als «die Art und Weise, wie eine Gesellschaft mit Vergangenheit und Geschichte umgeht» (Pandel 2009, S. 86).

Die Begriffe «Vergangenheit» und «Geschichte» meinen nachfolgend Unterschiedliches (vgl. dazu und für den gesamten Abschnitt: Baumgartner 1997, S. 157; Lorenz 1997, S. If.; Rüsen 2003, S. 18 f.; Pandel 2005, S. 135 f.; Schreiber et al. 2007, S. 26; Borries 2009, S. 101). «Vergangenheit» bezeichnet eine Zeitebene (analog zu Gegenwart und Zukunft), sie bezeichnet vergangenes Geschehen, das in der Gegenwart nicht mehr anwesend und nicht mehr unmittelbar zugänglich ist, eben «vergangen» (Völkel 2009, S. 723) ist, das lediglich in einzelnen Relikten bzw. Versatzstücken, den Quellen, zugänglich ist. Mit «Geschichte» ist hier und nachfolgend eine Erzählung/Narration über Vergangenes (und ggf. Gegenwärtiges) gemeint. «Geschichte» wird dabei verstanden als Produkt der Zeit, in der sie erzählt wird, das bestimmt und geprägt ist durch bestimmte Perspektiven, Fragestellungen, zur Verfügung stehende Quellen aus der Vergangenheit usw., insofern kein Abbild der Vergangenheit sein kann und als «Geschichten» im Plural vorkommt.

Mit der Differenzierung in Vergangenheit und Geschichte geht ein narratives Geschichtsverständnis einher, das die narrative Struktur, sprachliche Verfasstheit und Gestaltetheit von Geschichte betont (Baumgartner 1997; Rüsen 1997b; Körber 2007, S. 127), wobei ich mich, einer Differenzierung Rüsens folgend, eines weiten Erzähl- bzw. Narrationsbegriffs bediene, der alles Denken und Reden über Vergangenes als Erzählung fasst (weit verstanden z. B. auch bei Pandel 2002, S. 40; Körber 2007, S. 127), wohingegen «Erzählung» gelegentlich auch im engeren Sinn als «Gegenbegriff» zu diskursiven, argumentativen, distanzierten, rationalen, abstrakten Darstellungen verwendet werde (Rüsen 1982, S. 129; sowie neu aufgegriffen bei: Rüsen 1997b, S. 57). Bisweilen werden, Baumgartner zufolge «irreführend», auch Erzählung und Theorie einander gegenübergestellt (Baumgartner 1997, S. 158). 
und tritt in vielfältigen Formen auf. Die Bandbreite geschichtskultureller Formen, die Bandbreite an «Manifestationen» ${ }^{4}$, reicht von Denkmälern, historischen $\mathrm{Mu}$ seen und Ausstellungen über Spielfilme und Fernsehdokumentationen bis hin zu historischen Festen, Living History, Games und vielem anderem. ${ }^{5} \mathrm{Zu}$ erforschen und zu beschreiben, was diese Manifestationen selbst ausmacht und wie die Nutzung solcher Manifestationen geschieht, also in welchen Formen Auseinandersetzung mit Geschichtskultur und den darin erzählten Geschichten geschieht und in welchem Verhältnis diese zu einem individuellen Geschichtsbewusstsein, zu Prozessen historischen Denkens und Lernens stehen, ist Teil einer breit verstandenen geschichtsdidaktischen Forschungsagenda. ${ }^{6}$

Die Annahme einer unhintergehbaren Differenz von Vergangenheit und Geschichte steht im Kontrast zu einer historistischen Vorstellung, derzufolge mittels quellenkritischen Vorgehens exakte Abbilder der Vergangenheit erzielt werden können und die Rüsen als «modern» fasst, während der hier gewählte Zugang die «post-moderne Antwort auf die Frage, wie wir mit der Vergangenheit umgehen», repräsentiere (Rüsen 2003, S. 18 f.).

Die hier verwendete Unterscheidung in Vergangenheit und Geschichte entspricht derjenigen in «the past» und «history» (Seixas/Morton 2013, S. v), in "res gestae» und «historia»/«historia rerum gestarum» (Jeismann 1985, S. 12; Nipperdey 1986, S. 7; Lorenz 1997, S. 1, Baumgartner 2015, S. 23), in «vergangene Geschichte» und «Geschichten, die wir von jener Vergangenheit berichten» (Nipperdey 1986, S. 7), wobei Jeismann wie auch Nipperdey und Lorenz auf einen entsprechenden «Doppelsinn"/eine «Doppelbedeutung»/die «zwei Bedeutungen» des Begriffs «Geschichte» verweisen (Jeismann 1985, S. 12; Nipperdey 1986, S. 7; Lorenz 1997, S. 1).

Die begriffliche Trennung in «Vergangenheit» und «Geschichte» wird dann problematisch, wenn beide Dimensionen integriert angesprochen werden sollen, etwa weil gleichermassen Erzählungen und das darin repräsentierte Geschehen gemeint sind. Den Begriff des Historischen verwende ich in meiner Arbeit in diesem Sinn als beide Perspektiven integrierend. Er bildet eine Alternative zu der zum Beispiel bei Hasberg und Schöner verwendeten Schrägstrich-Variante «Vergangenheit/Geschichte» (Hasberg 2012, S. 139; Hasberg 2013, S. 47; Schöner 2013a, S. 68) oder der bei Pandel zu findenden Doppelung «Vergangenheit und Geschichte» (Pandel 2009, S. 86).

4 Der Begriff der Manifestationen findet sich beispielsweise bei Pandel 2009, S. 86, und Kuhn/Ziegler 2013, S. 506. In der geschichtsdidaktischen Literatur ist er, so Kuhn/Ziegler, in Gebrauch für «Gattungen [...], in denen geschichtskulturelle Inhalte gesellschaftlich fassbar werden», wie etwa Filme, Denkmäler, Ausstellungen (Kuhn/Ziegler 2013, S. 506), bezeichnet also in irgendeiner Weise veräusserte, wahrnehmbare Formen des Umgangs mit Historischem.

5 Einen Überblick über die Vielzahl an Formen liefern etwa die Einträge im «Handbuch der Geschichtsdidaktik» (Bergmann et al. 1997), ausserdem Rüsen 1997a, S. 39 f., und Pandel 2009, S. 86.

Neben der Geschichtsdidaktik bestellen auch andere Disziplinen das Feld der «Geschichtskultur» bzw. «Erinnerungskultur», so etwa die Geschichtswissenschaften und die Kulturanthropologie. Insofern handelt es sich hierbei um ein multidiziplinär besetztes Forschungsgebiet, wobei meine Arbeit dezidiert aus geschichtsdidaktischer Perspektive verfasst ist. 
$\mathrm{Zu}$ den theoretischen Grundüberzeugungen zählt dabei die Annahme, dass die Allgegenwart von Geschichte in der Gegenwart durch diese Gegenwart selbst hergestellt und begründet ist, nämlich auf Bedürfnissen der Gegenwart nach Auseinandersetzung mit Historischem beruht. ${ }^{7}$ Als Begründungsmuster für diese Bedürfnisse finden sich in der Literatur mehrere. Virulent ist einerseits die Vorstellung, dass aus der Geschichte für die Gegenwart gelernt werden und dass Geschichte für die Gestaltung der Gegenwart dienen könne. ${ }^{8}$ Diesem eher nutzenorientierten Zugriff lassen sich weitere Dimensionen und Anlässe einer Beschäftigung mit Historischem hinzufügen, etwa ein von einer konkreten Nutzbarmachung losgelöstes Bildungsbedürfnis sowie ein Bedürfnis nach Unterhaltung und Erlebnis. 9

Jörn Rüsen macht überdies - neben einer ästhetischen und kognitiven - die politische Dimension einer Auseinandersetzung mit Historischem stark ${ }^{10}$ und differenziert mit seinen «vier Typen der historischen Sinnbildung» Varianten, wie Gegenwart und Vergangenes erzählend miteinander verknüpft werden können, und zwar immer orientiert an der Gegenwart, etwa zum Zweck der Legitimation oder De-Legitimation, der Erklärung oder Infragestellung gegenwärtiger Verhältnisse. ${ }^{11}$ Wiederum an der Nutzbarmachung einer Beschäftigung mit Geschichte für die Gegenwart, aber stärker an ihrer Bedeutung für Individuen als für Kollektive setzt ein verwandter Theoriezweig an, der von in der Gegenwart gründenden individuellen Orientierungsbedürfnissen oder Irritationen ausgeht und diese als Ausgangspunkt bzw. als Motor für Prozesse historischen Denkens bestimmt. ${ }^{12}$

Die genannten Zugänge eint die Vorstellung, dass Beschäftigung mit Geschichte in der Gegenwart begründet ist, dass Geschichte für die Gegenwart in irgendeiner Weise bedeutsam und funktionell ist und sich so die Zuwendung zur Geschichte erklären lässt. Nach welchen Prinzipien die dabei entstehenden Manifestationen funktionieren, wie sich der Umgang einzelner Akteurinnen und Akteure, Rezipientinnen und Rezipienten mit diesen gestaltet, wie sich dabei etwa das Wechselspiel aus individuellen und kollektiven Deutungen von Vergangenheit

7 Vgl. hierzu die detaillierteren Ausführungen in Kapitel 2.

8 Für einen Überblick zur Idee der «historia magistra vitae»: Koselleck 1989, S. 38 ff.

9 Bernd Schönemann unterscheidet als Leitmuster «Geschichte als Nutzen», «Geschichte als Bildung» und «Geschichte als Erlebnis» (Schönemann 2002a, S. 80 f.).

10 Zu den Dimensionen von Geschichtskultur: Rüsen 1994, Rüsen 1997a.

$11 \mathrm{Zu}$ den «vier Typen der historischen Sinnbildung»: Rüsen 2013, S. 209 ff., direktes Zitat S. 109; Rüsen 2012, S. $170 \mathrm{ff}$.

12 Z.B. Rüsen 1983; Hasberg/Körber 2003; Körber et al. 2007. 
vollzieht, ${ }^{13}$ wie sich im Umgang mit Geschichtskultur historisches Denken oder Lernen vollzieht, welche Potenziale die unterschiedlichen Formen im Hinblick auf dieses historische Denken oder Lernen haben, welche Bedeutung sie für das Geschichtsbewusstsein ihrer Adressatinnen und Adressaten entfalten, in welchem Verhältnis sie zum historischen Lernen im Geschichtsunterricht stehen - dies sind Fragen, denen sich eine für Geschichtskultur und deren Nutzung sensible Geschichtsdidaktik zuwenden kann.

Béatrice Ziegler unterscheidet insgesamt sieben Bereiche, im Rahmen deren sich geschichtsdidaktische Forschung bislang mit Geschichtskultur befasst hat, nämlich:

«a) Ausserschulisches Lernen angesichts der Spezifik von Angeboten geschichtskultureller Akteure und Institutionen für das schulische Lernen»,

«b) Einbezug des Konzepts der Geschichtskultur in die Lehr-Lernforschung im Fach Geschichte»,

«c) Analyse und Beschreibung der Ausprägung historischen Denkens bzw. Geschichtsbewusstseins und historischer Kompetenz unter Berücksichtigung der ausserschulischen Sozialisierung in der Geschichtskultur»,

«d) Forschung zu Lehrpersonen und ihrem Wirken im Kontext von Geschichtskultur»,

«e) Fragestellungen und Erkenntnisse der Schulbuchforschung» und

«f) Geschichtskultur: Gesellschaftliches Handeln in, durch und mit Geschichte». ${ }^{14}$

In diesen sieben Feldern werden Geschichtskultur und der Umgang mit ihr einmal stärker, einmal weniger stark auf das Geschehen im schulischen Geschichtsunterricht und dortige Lehr-Lern-Prozesse, Akteurinnen, Akteure und Medien bezogen, und es zeigt sich, dass der schulische Geschichtsunterricht zwar eine zentrale, jedoch nicht die ausschliessliche Bezugsgrösse der geschichtsdidaktischen Forschungsagenda bildet. So beanspruchen die von der Gruppe FUER Geschichtsbewusstsein modellierten Kompetenzen historischen Denkens etwa «Gültigkeit für die gesamte Domäne des Umgangs mit Vergangenheit» ${ }^{15}$ und sollten damit

13 Schönemann spricht beispielsweise von «zwei Seiten einer Medaille» (Schönemann 2002a, S. 79).

14 Ziegler 2017a, S. $10 \mathrm{ff}$.

15 Schreiber et al. 2007, S. 22. 
auch als Instrumente zur Beschreibung von Umgangsweisen mit ausserschulischer Geschichtskultur geeignet sein.

Angeregt durch diese Prämisse, interessiere ich mich in meinem Projekt für Elemente des Denkens und historischen Denkens im Umgang mit Geschichtskultur, die sich jenseits von Unterrichtssettings ereignen, und ordne mich mit meiner Forschung vorwiegend dem von Ziegler genannten Aspekt c) zu, wenngleich meine Arbeit überdies den Anspruch erhebt, dabei der unter a) angesprochenen «Spezifik» der zugrunde liegenden geschichtskulturellen Manifestation gerecht zu werden. Ich nehme dafür eine eher als klassisch zu bezeichnende ${ }^{16}$ geschichtskulturelle Manifestation in den Blick, nämlich die historische Ausstellung bzw. konkreter: Umgangsweisen von Besuchenden mit einer historischen Ausstellung. ${ }^{17}$

Historische Ausstellungen zeigen Exponate, vielfach Quellen aus der Vergangenheit, ergänzt um weitere Elemente wie Texte und eine Bandbreite anderer Bausteine, sie ordnen diese im Raum an und erzählen bzw. konstruieren auf diese Weise eine Geschichte. ${ }^{18}$ Besuchende kommen mit dieser Geschichte in Kontakt. Zu erschliessen, zu welchen Überlegungen es bei Besuchenden im Moment dieses Kontakts kommt, ist das Forschungsanliegen. Im Gegensatz zu älteren Forschungen zu Besuchenden, in denen diese als passive Empfängerinnen und Empfänger der in Ausstellungen angebotenen Deutungen betrachtet wurden, nehme ich Besuchende hierbei als aktive Konstrukteurinnen und Konstrukteure in den Blick, ${ }^{19}$

16 Klassisch meint in dem Fall: eine von der Geschichtsdidaktik üblicherweise fraglos als solche anerkannte geschichtskulturelle Manifestation. Wie Oliver Plessow feststellt, machen Museen, Archive und Gedenkstätten den Hauptanteil einer geschichtsdidaktischen Auseinandersetzung mit ausserschulischen Lernorten aus, obwohl in der ausserschulischen Lebenswelt wohl kaum annähernd relevant wie andere Manifestationen, er spricht vom «Sonderfall als Normalfall» (Plessow 2015, S. 24).

17 Weiter unten werde ich noch darlegen, dass ich den Begriff der historischen Ausstellung nicht synonym mit demjenigen des historischen Museums gebrauche, sondern Letzteren vielmehr bezogen auf die Institution Museum verwende. Ich folge dabei einer Kategorisierung Schönemanns, der als vier Dimensionen von Geschichtskultur Institutionen, Professionen, Medien und Adressaten/Publika unterscheidet (Schönemann 2000, S. 46f.) und das «Museum als Institution der Geschichtskultur» versteht (so der Aufsatztitel von Schönemann 2006). Den hier angedeuteten begrifflichen Klärungen und Abgrenzungen wende ich mich in Abschnitt $3.1 \mathrm{zu}$.

18 Zur Konstruktion von Geschichte im Museum bzw. in einer Ausstellung stellvertretend: Grütter 1997b, S. 668 ff., Grütter 1997c, S. 710 f. Zur Anordnung im Raum auch Schwan 2012, S. 46f. Auch zur Konstruktion von Geschichte in historischen Ausstellungen äussere ich mich weiter unten im genannten Abschnitt näher.

19 Zu Phasen und Zugängen der Besucherforschung: Hooper-Greenhill 2006; NoschkaRoos/Lewalter 2013; vgl. hierzu die weiteren Ausführungen in Abschnitt 3.2. 
die sich individuell und variabel in der vorhandenen räumlichen Struktur bewegen und dabei aus den in der Ausstellung bereitgestellten Versatzstücken mutmasslich zu eigenen Erzählungen und Deutungen kommen, sich das Gegebene aktiv-konstruierend aneignen. ${ }^{20}$ Ich verfolge das Anliegen, dieses Aneignen zu erhellen, indem ich Elemente des Denkens während des Besuchs einer historischen Ausstellung identifiziere und strukturiere.

Hierfür habe ich als Erhebungsmethode das Prozessbegleitende Laute Denken eingesetzt, ${ }^{21}$ das es ermöglicht, direkt auf die konkrete Situation eines Ausstellungsbesuchs zu blicken und Assoziationen im Moment ihres Entstehens einzufangen. Prozessbegleitendes Lautes Denken ist in der Forschung zu Museumsbzw. Ausstellungsbesuchenden bislang eher wenig gebräuchlich ${ }^{22}$ und begegnet einem Forschungsdesiderat, das sich im Bereich der prozessbegleitenden Erforschung von Besuchsverläufen eröffnet. Denn in der empirischen Forschung trifft ein zunehmendes Interesse an Prozessen des Besuchs derzeit nur bedingt auf eine adäquate Erhebungsmethodik. Oft werden zum Beispiel retrospektive Methoden eingesetzt, die nur vermittelt Rückschlüsse auf das vorausgegangene Erleben ermöglichen. ${ }^{23}$ Dabei bleiben relevante Fragen unbeantwortet, zum Beispiel, in welchen Situationen genau bestimmte Assoziationen und Überlegungen entstehen, welche Exponate, Texte usw. genau es sind, die zum Auslöser oder Gegenstand für bestimmte Überlegungen werden, welche dieser Ausstellungselemente namentlich eine Rolle in der Konstruktion von Bezügen zur eigenen Person und Gegenwart spielen. ${ }^{24}$ Prozessbegleitendes Lautes Denken erlaubt, solche Verbindungen zwischen Äusserungen der Teilnehmenden und der umgebenden räumlichen Struktur der Ausstellung unmittelbar zu erschliessen. ${ }^{25}$

20 Zum Begriff der Aneignung siehe Schorb 2009 sowie die Ausführungen in Abschnitt 3.2.

21 Vgl. zu den methodischen Hintergründen Lauten Denkens die Ausführungen in Abschnitt 6.1. Ich betrachte «Lautes Denken» hier und nachfolgend als Eigenname einer Erhebungsmethode und kennzeichne dies durch Grossschreibung des Adjektivs. Analog verfahre ich bei seiner Präzisierung als «Prozessbegleitendes Lautes Denken» oder «Nachträgliches Lautes Denken».

22 Zu Einsatzfeldern siehe die Ausführungen und Literaturverweise in Abschnitt 5.2 und Abschnitt 6.1.

23 Vgl. für weitere Ausführungen zum Forschungsstand Kapitel 5. Eine knappe entsprechende Einordnung findet sich auch bereits bei Thyroff 2017c, S. 3.

24 Einige solche Fragen habe ich ähnlich in Thyroff 2017c, S. 3, formuliert.

25 Wise 2011, S. $10 \mathrm{ff}$. 
Auf Basis des mittels Lauten Denkens erhobenen Datenmaterials frage ich danach, ${ }^{26}$ wie sich Aneignungsweisen während des Besuchs einer historischen Ausstellung gestalten, konkreter, welche Elemente und Strukturen des Denkens sich während des Besuchs einer historischen Ausstellung identifizieren lassen. Ein spezifischer Aspekt ist dabei wiederum von besonderem Interesse: Inspiriert von den bereits genannten theoretischen Modellierungen historischen Denkens, ${ }^{27}$ interessiere ich mich für die Rolle der aktuellen Gegenwart und Lebenswelt der Besuchenden als möglicher Bezugspunkt des Denkens beim Ausstellungsbesuch. Ich frage deshalb zweitens und insbesondere danach, inwiefern Besuchende während des Besuchs explizit ihre eigene Person und Gegenwart thematisieren und in ihre Überlegungen einbeziehen.

Mein Projekt verstehe ich dabei als empirische Grundlagenforschung in einem Feld, das bislang in der Geschichtsdidaktik schwergewichtig auf theoretischer Ebene erschlossen wurde. Die leitenden Forschungsfragen betrachte ich als heuristische Folie, die bewusst sehr offen gehalten ist und Elemente eines aus der Theorie bekannten historischen Denkens beinhalten kann, aber nicht darauf beschränkt ist.

Zur Verfolgung des Anliegens habe ich eine inbaltlich-strukturierende qualitative Inhaltsanalyse ${ }^{28}$ eingesetzt, die mehrheitlich induktiv erfolgte, um der Eigenlogik des Materials Rechnung tragen zu können, ohne es bereits durch die Brille theoretisch konzipierten historischen Denkens betrachten zu müssen, auch wenn « $[\mathrm{t}]$ heoretische Sensibilität» natürlich zwangsläufig auch einen materialbasierten Analyseprozess prägt. ${ }^{29}$ Auf das Verhältnis, in dem in meiner Arbeit Theorie und Empirie zueinander stehen, werde ich weiter unten noch differenzierter eingehen.

Auch wenn vorliegende Theorien nicht den Analyseprozess determinieren sollen, bilden sie doch den Bezugspunkt der vorliegenden Arbeit und ist es mein Anliegen, die identifizierten Elemente und Strukturen des Denkens und historischen Denkens in einer abschliessenden Synthese wieder an vorliegende Theorien

26 Die Forschungsfragen sind in ihrer Vorform, ähnlich wie hier, in Thyroff 2017c, S. If., und Thyroff 2017b, S. 111, benannt.

27 Z. B. Rüsen 1983; Hasberg/Körber 2003; Körber et al. 2007.

28 In Anlehnung an Kuckartz 2010; vgl. hierzu die weiteren Ausführungen in Abschnitt 6.4.

29 «Theoretische Sensibilität» wird zum Beispiel bei Strauss/Corbin thematisiert (Strauss/ Corbin 1996, S. 25, S. 30). Zum Thema auch: Kelle 1994, S. 341; Kelle/Kluge 2010, S. 18 ff.; Kruse 2014, S. 94 ff.; Strübing 2014, S. 52. Zum Forschungsprozess allgemein und zum Verhältnis von Theorie und Empirie in meiner Studie siehe ausserdem die weiteren Ausführungen in Abschnitt 2.4 und Kapitel 6. 
zurückzubinden und zu fragen, inwiefern sich Ergebnisse und vorliegende Überlegungen in Bezug setzen lassen. Diese Betrachtung zielt darauf, vorhandene Modellierungen auf ihre Passung hin zu befragen und in dieser Hinsicht erste Impulse für eine Erweiterung und Differenzierung zu setzen.

Bei den Teilnehmenden der Studie handelt es sich um 18 erwachsene Besuchende der Ausstellung «14/18. Die Schweiz und der Grosse Krieg», einer Wanderausstellung, die vom Verein «Die Schweiz im Ersten Weltkrieg» ${ }^{30}$ konzipiert und die im Zusammenhang mit der einhundertsten Jährung des Ersten Weltkriegs im Zeitraum zwischen 2014 und 2016 in historischen Museen der deutsch- und französischsprachigen Schweiz gezeigt wurde, ${ }^{31}$ wobei die Datenerhebung während der Station der Ausstellung im Museum für Geschichte in Basel durchgeführt wurde. Der Präsentation der Ausstellung, ihrer inhaltlichen Struktur und Ästhetik sowie ihrem geschichtswissenschaftlichen und geschichtskulturellen Kontext widme ich im Kapitel 7 eine nähere Betrachtung.

Zuvor beinhaltet meine Darstellung die folgenden Abschnitte: Die unmittelbar im Anschluss an die Einführung folgenden beiden Kapitel dienen der Aufarbeitung der theoretischen Hintergründe meiner Studie. Zwei theoretische Stränge betrachte ich als relevanten Referenzrahmen für mein Forschungsanliegen. Erstens sind dies Theorien zum historischen Denken und Überlegungen dazu, welche Bedeutung und Relevanz eine Auseinandersetzung mit Geschichte für die Gegenwart und das historisch denkende Individuum entfalten kann bzw. mit welchen Funktionen und in welchen Dimensionen eine solche Auseinandersetzung geschieht. Diesem Bereich widme ich mich in Kapitel 2.

Historische Ausstellungen und deren Besuchende werden dort noch nicht explizit behandelt. Dies ist vielmehr Gegenstand des darauffolgenden zweiten theoretischen Zugangs in Kapitel 3, bei dem ich Museen und Ausstellungen und deren Besuchende aus theoretischer Perspektive in den Blick nehme und danach frage, welche Vorstellungen zu Aneignungsvorgängen in Museen bzw. Ausstellun-

30 Dem Verein gehören folgende Personen an: Präsident: Thomas Buomberger; Geschäftsführer: Severin Rüegg; Projektleitung: Thomas Buomberger, Patrick Kury, Roman Rossfeld sowie zeitweise Heidi Witzig (2011) und Beatrice Schumacher (2011-2013). Umgesetzt wurde die Ausstellung von der Raumprodukt GmbH (www.ersterweltkrieg.ch/ ausstellung/, Zugriff am 25.8.2017).

31 Die Ausstellung wurde ab 2014 zunächst in Basel und Zürich gezeigt, später in St. Gallen, Neuenburg, Frauenfeld und Zug. Zudem ist im Jahr 2018 Solothurn als weiterer Standort geplant (www.ersterweltkrieg.ch/, Zugriff am 22.12.2017). 
gen $^{32}$ existieren. Mit dem Blick auf Konzeptionen historischen Denkens einerseits und historischer Museen und Ausstellungen sowie deren Nutzung und Aneignung andererseits nähere ich mich meinem Forschungsgegenstand aus zwei Richtungen theoretisch an, wobei in der Schnittmenge beider Perspektiven das Themenfeld meiner Studie - historisches Denken in einer historischen Ausstellung - liegt. Ausgehend von diesen theoretischen Annäherungen, mündet meine Darstellung in der Darlegung des eigenen Forschungsinteresses in Kapitel 4.

Im Anschluss daran wende ich mich in Kapitel 5 dem empirischen Forschungsstand in Bezug auf Museums- bzw. Ausstellungsbesuchende zu. Berücksichtigt sind dort noch Studien, wie ich sie für die Manuskriptfassung meiner Dissertation, eingereicht im Frühjahr 2018, verarbeitet habe. Ich gliedere die Darstellung in Kapitel 5 in drei Bereiche und skizziere Gegenstände, Erhebungsmethoden und ausgewählte Ergebnisse vorhandener Studien. Die gesonderte Betrachtung der eingesetzten Erhebungsformen dient dazu, ein Forschungsdesiderat nicht nur hinsichtlich der Gegenstände, sondern auch auf der Ebene der bislang eingesetzten Methoden zu konstatieren und zu zeigen, dass derzeit ein Mangel im Bereich der unmittelbaren Introspektion von Aneignungsvorgängen im Moment des Ausstellungsbesuchs besteht, was mir anschliessend erlaubt, meine eigene Forschung zu verorten.

In Kapitel 6 beschreibe ich anschliessend die für meine eigene Studie eingesetzten Methoden. Aufgrund des Einsatzes einer in diesem Feld bislang wenig gebräuchlichen Erhebungsmethode, des Prozessbegleitenden Lauten Denkens, verwende ich dort Raum für die Darstellung der Methode, ihrer Potenziale und Grenzen und der mit ihr verbundenen Hoffnungen im Hinblick auf das eigene Forschungsvorhaben. Des Weiteren äussere ich mich in diesem Kapitel zu den Charakteristika des Samples von Besuchenden und zu den eingesetzten Samp-

Da sowohl in der theoretischen als auch in der empirischen Literatur oft von Museen und nicht von Ausstellungen und analog dazu von Besuchenden in Museen und nicht in Ausstellungen die Rede ist, selbst dann, wenn es im engeren Sinn um die Besuche der Ausstellungsräumlichkeiten eines Museums geht, gebrauche ich in den dortigen Abschnitten beide Begriffe, um einerseits meiner eigenen Begriffssetzung, andererseits aber auch der geläufigen Selbstbezeichnung in der rezipierten Literatur gerecht zu werden.

Bislang nicht gebräuchlich ist im Bereich der «Besucherforschung» die genderneutrale und damit korrekte, aber phonetisch kompliziertere Bezeichnung als Besuchendenforschung. Um dem Anliegen der genderneutralen Schreibweise gerecht zu werden und zugleich sprachlich zumindest möglichst einfach zu bleiben, spreche ich vorzugsweise von Forschung zu Museums- bzw. Ausstellungsbesuchenden o. Ä., es sei denn, es soll die geläufigere Selbstbezeichnung des Forschungszweiges als Museumsbesucherforschung betont werden. 
lingstrategien und gehe auf die Auswertungsmethode, die inhaltlich-strukturierende qualitative Inhaltsanalyse, ein. Kapitel 7 dient dann, wie bereits angekündigt, dazu, den Erhebungsort, die Ausstellung «14/18. Die Schweiz und der Grosse Krieg» und ihre historischen, historiografischen und geschichtskulturellen Hintergründe vorzustellen.

Den Ergebnissen meiner Studie wende ich mich schliesslich in Kapitel $8 \mathrm{zu}$. Dort schildere ich zunächst erste Eindrücke zu den Charakteristika des Datenmaterials (Abschnitt 8.1) und beschreibe die Grundstruktur der verwendeten Analysekategorien bzw. Ebenen der Datenanalyse (Abschnitt 8.2). Anschliessend schildere ich in einem ersten Schritt Ergebnisse zur Oberflächenstruktur von Besuchsverläufen (Abschnitt 8.3), bevor ich mich einer tiefenstrukturellen Identifizierung der dabei vorkommenden Elemente des Denkens und deren Struktur und Bezügen untereinander zuwende (Abschnitt 8.4 bis 8.7), immer mit einem besonderen Fokus auf der Frage, inwiefern sich in den Überlegungen der Besuchenden Bezüge zu ihrer eigenen Person und Zeit manifestieren und wie sich diese in Auseinandersetzung mit der Ausstellung als räumliche Ermöglichungsstruktur ergeben. Ausgehend von den so identifizierten Elementen und Bezügen, schlage ich in der abschliessenden Synthese (Kapitel 9) eine zugehörige Modellierung vor. Diese wird ergänzt um Rückbindungen der Befunde an vorhandene geschichtsdidaktische und -theoretische Modelle und Überlegungen zu den bereichsspezifischen Charakteristika des Denkens und historischen Denkens in einer historischen Ausstellung.

Der Anhang dieser Arbeit schliesslich ist zweigeteilt und besteht aus einem gedruckten Anhang (Kapitel 10) sowie einem ergänzenden digital verfügbaren Anhang (siehe Hinweise in Abschnitt 10.1). Der Anhang innerhalb der Druckfassung beinhaltet die Abbildungen A-G und die Tabellen A-F. Der ergänzende digitale Anhang beinhaltet die Abbildungen 1-11, die Tabellen 1-6, den verwendeten Ausschreibungstext für die Akquise von Teilnehmenden, eine Übersicht der Hauptschritte bei der Materialanalyse, Beschreibungen der eingesetzten Analysekategorien mit Materialbeispielen, eine Übersicht über Prinzipien der Transkription und Transkriptdarstellung in dieser Arbeit, Transkriptauszüge aus einer ausgewählten Abteilung der Ausstellung sowie eine Übersicht über die in der Arbeit enthaltenen kategorienbasierten Falldarstellungen. 


\section{Theoretische Grundlegungen (I): Historisches Denken und dessen Relevanz für Gegenwart und Individuum}

In diesem Kapitel stelle ich dar, wie in der geschichtsdidaktischen und geschichtstheoretischen Literatur ${ }^{33}$ über das Verhältnis zwischen Gegenwart und Individuum einerseits und Vergangenheit bzw. vielmehr Geschichte ${ }^{34}$ andererseits nachgedacht wird. Welche Rolle und Bedeutung wird der Beschäftigung mit Historischem für die Gegenwart, insbesondere für das einzelne Individuum, zugeschrieben? Wie werden Weisen des Umgangs mit Historischem beschrieben und modelliert?

$\mathrm{Zu}$ Beginn steht zunächst die Einsicht, dass alles Gegenwärtige eine historische Dimension hat. ${ }^{35}$ Alles Heutige steht in einer historischen Entwicklung, ihm wohnt insofern per se eine Zeitlichkeit inne, die es zu dem gemacht hat, was es heute ist, oder wie Waltraud Schreiber formuliert: «Aspekte der Vergangenheit

sind [...] gegenwärtig in den konkreten Lebensumständen: Alles Gegenwärtige ist geworden und birgt deshalb notwendigerweise auch Vergangenes in sich.» ${ }^{36}$ Diese Einsicht soll als Hintergrundfolie für die folgenden Überlegungen dienen. Der für meine Arbeit interessierende Gegenstand ist innerhalb dessen jedoch spezifischer, nämlich geht es um die explizite Beschäftigung der Gegenwart mit Historischem, um die Aufmerksamkeit der Gegenwart für diese Historizität, es geht um Dimensionen der Auseinandersetzung mit Geschichte und um die Bedeutung, die eine Beschäftigung mit ihr für in der Gegenwart Lebende hat und zugeschrieben erhält.

Im Verlauf der folgenden Darstellung wird ein Spektrum aus eher deskriptiven und eher normativen Zugängen abgebildet, die einerseits von einem anthropologisch vorhandenen Bedürfnis von Menschen und Gesellschaften nach einer Be-

33 Sowie punktuell auch in der erziehungswissenschaftlichen, insbesondere bildungshistorischen Literatur.

34 Zur Unterscheidung der beiden Begriffe vgl. die Anmerkungen in Fussnote 3. Ausgehend davon, spreche ich nachfolgend in der Regel von «Geschichte» oder integrierend von «Historischem».

35 Oder anders gesagt: «Von ihrer realen «historischen Dimension» kommt also keine Zeit los; wir können nicht aus der Geschichte fallen» (Jeismann 1985, S. 12).

Schreiber 2007c, S. 236. 
schäftigung mit Geschichte ausgehen, andererseits solche Bezüge auch zur Zielgrösse und zum Qualitätsmerkmal erklären. ${ }^{37}$

\subsection{Zu den Funktionen und Dimensionen einer Beschäftigung mit Geschichte in der Gegenwart - Theoretische Zugänge im Überblick}

Unter den Überlegungen zu den möglichen Funktionen einer Beschäftigung mit Geschichte weist die längste Tradition wohl die Idee einer «historia magistra vitae» auf, also einer Geschichte als «Lehrmeisterin des Lebens», wie gelegentlich übersetzt wird, ${ }^{38}$ oder auch und vielleicht zutreffender einer «Lehrmeisterin für das Leben ${ }^{39}$. Der Topos ist alt, wie Reinhart Koselleck darlegt. Nämlich sei der Begriff, in Anlehnung an griechische Vorläufer, im Wesentlichen von Cicero geprägt worden, der die Vorstellung von einer Historie als «Beispielsammlung» zum Zweck der Belehrung eingeführt habe. ${ }^{40}$ Koselleck stellt die Begriffsgeschichte im Verlauf der Jahrhunderte zusammen und unterscheidet zwei Phasen der Begriffsverwendung, die sich seiner Einschätzung nach im 18. Jahrhundert mit der Aufklärung ablösen. ${ }^{41}$

«Die Historie kann die Mit- oder Nachlebenden klüger oder relativ besser zu werden anleiten, das aber nur, wenn und solange die Voraussetzungen dazu sich grundsätzlich gleich sind. Bis zum 18. Jahrhundert bleibt die Verwendung unseres Ausdrucks ein untrügliches Indiz für die hingenommene Stetigkeit der menschlichen Natur, deren Geschichten sich zu wiederholbaren Beweismitteln moralischer, theologischer, juristischer oder politischer Lehren eignen.» ${ }^{42}$

37 Die beschriebenen Theorien erfüllen dabei, wie in der Einleitung angedeutet, für mein Projekt die Funktion von sensibilisierenden Konzepten, sie lenken die Aufmerksamkeit auf einen Phänomenbereich und leiten die Wahl des Forschungsgegenstands.

Zur Idee der sensibilisierenden Konzepte: Kelle/Kluge 2010, S. 28 ff.; Blumer 1954, S. 7. Ich komme darauf und auf das meine Arbeit leitende Verhältnis von Empirie und Theorie weiter unten differenzierter zu sprechen (vgl. Abschnitt 2.6).

38 So etwa bei Koselleck 1989, S. 38; Tanner 2011, S. 271.

39 Unter alternativer und meines Erachtens eher einleuchtender Auslegung des «vitae» als Dativ, in dieser Variante beispielsweise gebraucht bei Nipperdey 1987, S. 8.

40 Koselleck 1989, S. 40 f.

41 Koselleck 1989, S. 40 ff., S. 46 ff., S. 62.

42 Koselleck 1989, S. 40. 
Mit der Aufklärung konstatiert Koselleck ein neues Geschichtsverständnis, das «die Modellhaftigkeit vergangener Ereignisse zertrümmerte[.], um an deren Stelle die Einmaligkeit geschichtlicher Abläufe und die Möglichkeit ihres Fortschritts aufzuspüren». ${ }^{43}$ Koselleck spricht für diese Phase von der «Entdeckung einer spezifisch geschichtlichen Zeit. Wenn man so will, handelt es sich um eine Verzeitlichung der Geschichte, die sich seitdem von der natural gebundenen Chronologie abhebt.» ${ }^{44}$

Koselleck weist zugleich auf eine Paradoxie hin, die mit diesem Wandel einhergeht: Indem die Geschichte nicht mehr zyklisch als Abfolge vergleichbarer Entwicklungen verstanden wird, indem stattdessen «sich die Zukunft der modernen Geschichte ins Unbekannte öffnet, wird sie planbar - und muss sie geplant werden». ${ }^{45}$ In beiden von Koselleck beschriebenen Phasen geht es somit darum, aus einer Beschäftigung mit der Vergangenheit Ideen für die Gestaltung von Gegenwart und Zukunft, also Handlungsmöglichkeiten, abzuleiten, sei es, dass diese auf der Idee eines zyklisch Wiederkehrenden und insofern Gleichbleibenden bestehen oder von der Unvorhersehbarkeit des Zukünftigen ausgehen. ${ }^{46}$

$\mathrm{Ob}$ aus der Geschichte tatsächlich unmittelbar Handlungsanweisungen für die Gegenwart ableitbar sind, dazu bestehen allerdings erhebliche Zweifel. ${ }^{47}$ So führt Hans-Ulrich Wehler aus, die Geschichtswissenschaft könne keineswegs Wissen «zur Verfügung stellen, das für die Lösung aktueller Probleme unmittelbar verwendet werden kann». ${ }^{48}$ Sie stelle lediglich «Orientierungswissen» bereit, das «sachkundig» mache und «eine heilsame Skepsis gegenüber den flotten Heilsversprechen

46 Auch bereits Nipperdey (1987) unterscheidet einen Wandel im Umgang mit Vergangenheit, den er etwa um 1800 festmacht. Einerseits führt er das Entstehen des Historismus an und die damit verbundene Idee, dass mit der Anwendung der historisch-kritischen Methode im Umgang mit Quellen «Wahrheit» (und «Falschheit») erschlossen werden könne. Zweitens verweist er wie Koselleck auf die neue Einsicht, «[d]ass die Vergangenheit anders ist als die eigene Zeit, dass das Individuelle wichtiger ist als das Typische und Allgemeine» und die damit verbundene Akzentverschiebung weg von der Betrachtung von Dauer hin zu derjenigen von Wandel (Nipperdey 1987, S. 8 ff.). Einen Überblick hierzu liefert unter dem Abschnitt «Krise der Tradition» auch Dressler 2012, S. $63 \mathrm{ff}$.

47 Nipperdey 1986, S. 16; Wehler 1988, S. 12 f.; Flöter 2009, S. 71; Groppe 2009, S. 76; Pilarczyk 2009, S. 81; Prondczynsky 2009, S. 82. Von einer möglichen Erweiterung von Handlungsoptionen spricht hingegen Matthes 2009, S. 81.

Wehler 1988, S. 12. 
und der flinken Erklärung aller Welträtsel» nähre, aber keineswegs «die Lösung gegenwärtiger Probleme wie auf einem Präsentierteller» anbiete. ${ }^{49}$

Jakob Tanner benennt hingegen als Ziel des Lernens aus der Geschichte nicht Orientierungswissen, sondern Problembewusstsein und Reflexivität:

«Geschichte hat nicht in erster Linie 〈Orientierungswissen〉 zu liefern. Ihre Aufgabe besteht in der Problemsensibilisierung. Diese läuft [...] über Irritationen, über selbstreflexive Nachdenklichkeit, über das Infragestellen von Selbstverständlichkeiten. Es gilt, auch im Geschichtsunterricht, zu zeigen, dass die Formel Historia magistra vitae selber einem Bedeutungswandel und einer wechselhaften Relevanzkonjunktur unterworfen war.» ${ }^{50}$

Andreas von Prondczynsky wiederum geht von der Möglichkeit von Schlussfolgerungen aus, differenziert allerdings nach der Möglichkeit wissenschaftlicher oder moralischer Schlussfolgerungen. So könne aus der Feststellung, «dass etwas in der Vergangenheit der Fall war, [...] nicht der Schluss gezogen werden, dass dies in Zukunft erneut oder nicht mehr eintreten solle», allerdings bezieht Prondczynsky dies auf wissenschaftlich hergeleitete Schlüsse, die nicht möglich seien, wohingegen moralische Appelle - er nennt das auf Adorno zurückgehende Diktum «Nie wieder Auschwitz» - durchaus aus der Geschichte ableitbar seien. ${ }^{51}$

Die Beispiele zeigen, dass die Diskussion eines möglichen Lernens aus der Geschichte intensiv geführt wird, wobei es durchaus Vorbehalte gegen das Ableiten von konkreten Handlungsanweisungen aus der Geschichte gibt. Was abgesehen davon zu lernen wäre, dem widmet sich unter den Leitmotiven «Lernen aus der Vergangenheit» ${ }^{52}$ oder «Lernen aus/an/mit der Geschichte»/ «Aus der Geschichte lernen ${ }^{53}$ gleich eine Reihe von Publikationen, wobei die Begriffe «Vergangenheit» und «Geschichte» vielfach synonym gebraucht zu werden scheinen. ${ }^{54}$ Lernen

49 Wehler 1988, S. 13.

50 Tanner 2011, S. 276; Kursivsetzung analog zum Original.

51 Prondczynsky 2009, S. $82 \mathrm{f}$.

52 Tanner 2011.

53 Wehler 1988; Meseth 2005; Grunder 2011; Dressler 2012. Ausserdem existiert eine Ansammlung von bildungsgeschichtlichen Beiträgen unter dem Titel «Aus der (Bildungs-) Geschichte lernen!?» im Diskussionsteil der «Zeitschrift für pädagogische Historiografie» (Koinzer/Loeffelmeier 2009, direktes Zitat S. 68), darunter etwa die Beiträge von Flöter 2009, Glaser 2009, Priem 2009, Tenorth 2009 und Wiegmann 2009.

54 Wie bereits angedeutet (vgl. Fussnote 3), unterscheide ich selbst die Begriffe «Vergangenheit» und «Geschichte» dahingehend, dass «Vergangenheit» vergangenes Geschehen meint, 
könne man demnach - nachfolgend in collagenhafter und unsystematischer Aufreihung von Vorschlägen zusammengestellt - Verständnis für vergangene Entwicklungen, ${ }^{55}$ Verständnis und Erklärung für gegenwärtige Entwicklungen, ${ }^{56} \mathrm{Di}$ stanz zur Gegenwart, ${ }^{57}$ Infragestellung «essentialistische[r] und verabsolutierte[r] Formeln», ${ }^{58}$ Verständnis für die Geschichtlichkeit und Kontextabhängigkeit gegenwärtigen Seins und Handelns, ${ }^{59}$ Verständnis für die «Grenzen und Möglichkeiten» der Gegenwart, ${ }^{60}$ «Problemsensibilisierung», «Irritationen» und «selbstreflexive Nachdenklichkeit», ${ }^{61}$ Distanz zur eigenen Person ${ }^{62}$ Selbstverständnis in Bezug auf die eigene Person ${ }^{63}$ und kollektive Zugehörigkeit ${ }^{64}$.

Ein Teil der genannten Aspekte, die Bezüge zur Person des denkenden Individuums, sind für mein Forschungsprojekt von besonderer theoretischer Relevanz. Ich greife sie deshalb differenzierter auf. Beispielsweise befassen sich Karl-Ernst Jeismann und Rolf Schörken mit der lebensweltlichen Bedeutung einer Auseinandersetzung mit Geschichte. Jeismann unterscheidet in diesem Zusammenhang eine «identitätsstiftende Funktion», eine «Legitimierungsfunktion» und eine «Orientierungsfunktion». ${ }^{65}$ Schörken differenziert drei «Bedürfnisgruppen», nämlich ein «Orientierungsbedürfnis», ein «Bedürfnis nach Selbsterkenntnis und Spiegelung» und ein «Bedürfnis nach Erweiterung der eigenen Lebensmöglichkeiten», darauf hinweisend, dass diese Bedürfnisse nicht zwingend ausgerechnet

Geschichte demgegenüber eine rückwirkende Rekonstruktion desselben darstellt. Nach diesem Verständnis ist Vergangenheit aus der Gegenwart nicht unmittelbar zugänglich, sondern stets nur vermittelt über Geschichte(n). Lernen kann man nach diesem Verständnis, genau genommen, nur aus «Geschichte». In der vorhandenen Literatur finden sich gleichermassen beide Begriffe, teilweise synonym gebraucht, wobei der Gebrauch des Begriffs «Vergangenheit» deshalb ebenfalls nachvollziehbar erscheint, weil er, im Gegensatz zu «Geschichte», als Zeitebene strukturgleich mit «Gegenwart» ist. Priem 2009, S. 82; Wiegmann 2009, S. 87.

56 Matthes 2009, S. 81.

57 Priem 2009, S. 82.

58 Priem 2009, S. 82.

59 Glaser 2009, S. 74; Priem 2009, S. 82; Tosch 2009, S. 86.

60 Nipperdey 1986, S. 16.

61 Tanner 2011, S. 276.

62 Groppe 2009, S. 76.

63 Groppe 2009, S. 76.

64 Nipperdey 1986, S. 17; Groppe 2009, S. 76.

65 Jeismann 1985, S. 13 ff. Die letztgenannte betrachtet er dabei als «von der unmittelbaren Indienstnahme zur Legitimation und Identifikation» losgelöst (S. 15). Jeismann bindet damit seinen Orientierungsbegriff weniger stark an aktuelle Bedürfnisse der Gegenwart, als dies in anderen Verwendungszusammenhängen des Orientierungsbegriffs (vgl. zu diesen Abschnitt 2.2) der Fall ist. 
durch Beschäftigung mit Geschichte befriedigt werden müssen, wohl aber, dass Geschichte ein hierfür «häufig aufgesuchtes Feld» darstellt. ${ }^{66}$

Orientierung versteht Schörken - und damit anschlussfähig oder umgekehrt abgrenzbar von obigen Überlegungen - «zum einen handfest als Regel- und Anwendungswissen [...], zum anderen als Antwort auf die grossen Sinnfragen». ${ }^{67}$ Inzwischen ist der Orientierungsbegriff zum festen Inventar geschichtsdidaktischer und geschichtstheoretischer Diskurse geworden, wenn es um die Frage geht, was der Antrieb für eine Beschäftigung mit Geschichte und der daraus zu ziehende Nutzen sein könnten, gelegentlich in Verbindung mit Prozessen historischen Denkens, wobei Orientierung als ein Teilbereich dieses historischen Denkens verstanden wird. ${ }^{68}$

Die geschilderten möglichen Zugänge gehen über die Idee einer Nachahmung von Exempla hinaus, sie zielen auf Welt- und Selbstverstehen, auf Formung der eigenen individuellen oder auch kollektiven Identität. Bernd Schönemann identifiziert denn auch neben einem Leitmuster «Geschichte als Nutzen», das mir kongruent zu dem von Koselleck beschriebenen Motiv einer «Historia magistra vitae» erscheint, ein Leitmuster "Geschichte als Bildung». ${ }^{69}$ Er verortet es zeitlich im Kontext der Entstehung des modernen Nationalstaats seit Ende des 18. Jahrhunderts. ${ }^{70}$ "Nicht Geschichtsgebrauch nach Massgabe des praktischen Nutzens also, sondern Erinnerung als geistiger Besitz, als Erkenntnis und Weisheit, war die Leitidee der modernen Gesellschaft», ${ }^{71}$ kombiniert mit einem Bemühen um staatlichen Zusammenhalt, Stiftung von Identität und Legitimation. ${ }^{72}$ Beschäftigung mit Geschichte dient damit sowohl individuellen als auch kollektiven Zwecken: sie trägt bei zur Persönlichkeitsbildung und zur Formung einer Gemeinschaft.

In diesem Sinn kann Geschichte auch legitimatorische, traditionsstiftende Funktion haben - ein Aspekt, den auch Jörn Rüsen akzentuiert, etwa im Rahmen seiner Ausarbeitung von Sinnbildungstypen ${ }^{73}$ oder wenn er in seinen Dimensionen von Geschichtskultur neben einer kognitiven und ästhetischen Dimension auch eine

66 Schörken 1981, S. $223 \mathrm{f}$.

67 Schörken 1981, S. 59.

68 Z.B. Körber et al. 2007; Rüsen 2013. Diesem Themenkomplex widme ich im Anschluss einen eigenen Abschnitt (Abschnitt 2.2).

69 Schönemann 2000, S. 47-49.

70 Schönemann 2000, S. 51.

71 Schönemann 2000, S. 49.

72 Schönemann 2000, S. 51; vgl. zum Aspekt der Legitimation und Identifikation auch: Schönemann 2002a, S. 79 f., sowie Baier 2000, S. 13.

Rüsen 2013, S. $209 \mathrm{ff}$. 
politische Dimension der Auseinandersetzung mit Geschichte benennt. ${ }^{74}$ Besonders augenfällig zeigt sich diese politische Dimension Rüsen zufolge bei nationalen Gedenktagen, die «an den Ursprung des politischen Gemeinwesens erinnern», ${ }^{75}$ sie ist aber auch in historischen Museen und Ausstellungen virulent. ${ }^{76}$ Die politische Dimension von Geschichte, ihre gemeinschaftsbezogene, identitätsrelevante und identitätsstützende, legitimierende und delegitimierende Bedeutung wird auch in Theoriesträngen rund um die Konzepte des kollektiven, kulturellen und kommunikativen Gedächtnisses bzw. der Erinnerungskultur berücksichtigt ${ }^{77}$ und ist in Begriffen wie «Vergangenheitspolitik» ${ }^{78}$ bzw. «Geschichtspolitik» ${ }^{79}$ offenkundig.

Umgekehrt sensibilisiert Holger Thünemann dafür, Geschichtskultur durchaus auch als nicht intentional zu verstehen, und schlägt ein Verständnis vor, das

«sowohl zufällige und ungewollte Repräsentationen umfasst als auch bewusste Rekonstruktionen von Vergangenheit sowie intentionale Inszenierungen von Geschichte, die nicht unbedingt einem bestimmten Niveau, Tendenzen oder gar Hauptsträngen von Geschichtsbewusstsein im Leben einer Gesellschaft entsprechen müssen». ${ }^{80}$

$74 \mathrm{Zu}$ den Dimensionen von Geschichtskultur und insbesondere der politischen Dimension: Rüsen 1994, v. a. S. 15 f.; Rüsen 1997a, v. a. S. 39 f. Mit seiner Veröffentlichung von 2013 fügte Rüsen der Trias noch eine moralische und religöse Dimension hinzu (Rüsen 2013, S. $234 \mathrm{ff}$.). Mit den drei von Rüsen entfalteten Dimensionen von Geschichtskultur habe ich mich im Rahmen meiner Masterarbeit bereits einmal beschäftigt einschliesslich Überlegungen zur Übertragung der drei Dimensionen auf Museen, und greife auf dortige Vorarbeiten zurück (Thyroff 2012, insb. S. 13 ff.). Auch einen Teil der im weiteren Verlauf dieses Kapitels beschriebenen theoretischen Zugänge zu Geschichtskultur und Konzeptionen von Erinnerungsorten (s. u.) habe ich dort bereits zusammengetragen (Thyroff 2012, S. $10 \mathrm{ff}$.) und baue nun darauf auf.

75 Rüsen 1994, S. 15.

76 Die politische wie auch die ästhetische und kognitive Dimension kondensieren sich auch in Gestalt historischer Museen und Ausstellungen, weshalb ich bei der näheren Zuwendung zu diesen Manifestationen detaillierter auf Rüsens Konzeption zurückkomme (vgl. Abschnitt 3.1). Hierzu: Hartung 2006, Thyroff 2012.

77 Assmann 2007, insb. S. 29-86; Cornelissen 2003, S. 555; für eine Metaübersicht über den Theoriezweig: Erll 2005; Pethes 2008; Für Überlegungen dazu, wie sich die stärker von der Geschichts- und Kulturwissenschaft kommenden Theorien des kollektiven/kulturellen/kommunikativen Gedächtnisses bzw. der Erinnerungskultur auf der einen Seite und in der Geschichtsdidaktik vorzugsweise verwendete Theorien von Geschichtskultur und Geschichtsbewusstsein auf der anderen Seite zueinander verhalten: Hasberg 2006.

78 Frei 2012.

79 Zum Begriff «Geschichtspolitik» einschliesslich Abgrenzung desselben von «Vergangenheitspolitik»: Schmid 2008, insb. S. 77.

80 Thünemann 2005, S. 21 f., direktes Zitat S. 22. 
Des Weiteren weckt Schönemann mit seinem dritten Leitmuster «Geschichte als Erlebnis» das Bewusstsein dafür, dass Beschäftigung mit Geschichte auch die Funktion der Unterhaltung erfüllen kann. ${ }^{81}$ Thomas Nipperdey streicht unter anderem die Bedeutung zweckungebundener «reiner[r] Neugier» im Umgang mit Historischem heraus. ${ }^{82}$ Und Klaus Bergmann verdeutlicht, dass Bedürfnisse nach Auseinandersetzung mit Geschichte nicht einmal zwingend vorab vorhanden sein müssen, sondern in Wechselwirkung mit einem entsprechenden Angebot entstehen können, dass sie «industriell-medial hergestellt werden» und somit (auch) eine geschäftliche, ökonomische Seite haben - kurzum: «Mit Geschichte werden Geschäfte gemacht.» ${ }^{83}$

Denkbare Gründe für die Zuwendung zu Geschichte werden somit vielerlei diskutiert, und auch die Ausprägungsformen sind vielfältig. Klaus Bergmann spricht entsprechend von einer «Allgegenwart von Geschichte» und titelt: «So viel Geschichte wie heute war nie.» ${ }^{84}$ Korrespondierend stellt Karl-Ernst Jeismann fest, dass «die Bildung historischer Vorstellungen in der Gesellschaft» wesentlich ausserhalb des Geschichtsunterrichts erfolgt. ${ }^{85}$

Hilfreich für eine Systematisierung des vielgestaltigen Feldes der Geschichtskultur ist Schönemanns Unterscheidung in «Institutionen», «Professionen», «Medien» und «Adressaten»/ «Publika» von Geschichtskultur, ${ }^{86}$ auf die ich weiter unten am Beispiel der historischen Museen und Ausstellungen zurückkomme. Schönemann lenkt damit den Blick verstärkt auf die Akteurinnen, Akteure und Instanzen innerhalb von Geschichtskultur(en). ${ }^{87}$

Er liefert damit erste Anstösse zur Differenzierung eines theoretischen Feldes, in dem als Träger von Geschichtskultur bislang vielfach abstrakte Kollektive, etwa

81 Schönemann 2000, S. 49f.; Schönemann 2002a, S. 81.

82 Nipperdey 1986, S. $17 \mathrm{f}$.

83 Bergmann 1998, S. 20.

84 Bergmann 1998.

85 Jeismann 1988, S. 4. Inwieweit Geschichtsunterricht als integraler Bestandteil von Geschichtskultur gedacht oder eher von einer Dichotomie zwischen Geschichtskultur auf der einen Seite und Geschichtswissenschaft und Geschichtsunterricht auf der anderen Seite ausgegangen wird, in dieser Frage gibt es divergierende Ansätze (vgl. hierzu weiter unten Abschnitt 3.3 und insb. Fussnote 468).

86 Schönemann 2000, S. $46 \mathrm{f}$.

87 Den Terminus «Geschichtskulturen» im Plural verwendet beispielsweise Schönemann 2002a, S. 79. Ich schliesse mich dem an, um dem Rechnung zu tragen, dass unterschiedliche Gruppen und Individuen je unterschiedliche Formen des Umgangs mit Geschichte pflegen können. Geschichtskultur im Singular lässt sich demgegenüber als übergeordnete Kategorie betrachten. 
nationale Kollektive, in den Blick geraten, wobei diese je nach Ansatz eher als homogene oder heterogene Kollektive behandelt werden, ${ }^{88}$ die Rolle einzelner Individuen aber in keinem der Fälle näher beleuchtet wird. In der Geschichtsdidaktik wird Geschichtskultur vielfach abstrakt als Gegenstück zu Geschichtsbewusstsein ${ }^{89}$ beschrieben. Schönemann begreift die Kategorien etwa als «zwei Seiten einer Medaille [...] - auf der einen Seite Geschichtsbewusstsein als individuelles Konstrukt, das sich in Prozessen der Internalisierung und Sozialisation aufbaut, auf der anderen Seite Geschichtskultur als kollektives Konstrukt, das auf dem entgegengesetzten Wege der Externalisierung entsteht» ${ }^{90}$. Eine ähnliche

88 Überlegungen zur Homogenität vs. Heterogenität von Geschichtskulturen und zu entsprechenden Zugängen verschiedener Forschungsansätze habe ich bereits im Rahmen meiner Masterarbeit dargelegt. Die Ausführungen in dieser Fussnote basieren auf der entsprechenden Darstellung in Thyroff 2012, S. $11 \mathrm{f}$.

Auf die Nation als Rahmen beziehen sich beispielsweise Projekte zu nationalen Erinnerungsorten, namentlich «Les lieux de mémoire» für den Fall Frankreichs (mir in der später erschienenen, deutschsprachigen und aufs einbändige Format gekürzten Ausgabe vorliegend: Nora 2005). Grundlegend ist die Idee eines nationalen kollektiven Gedächtnisses - in diesem Fall Frankreichs -, das sich an «Lieux de mémoire» als «Kristallisationspunkte» manifestiert (Nora 1995, S. 83). Erinnerungsorte sind dabei nicht zwingend geografische Orte, sondern beispielsweise auch Ereignisse, Ideen, Begriffe, Personen usw.

Für eine Reihe von Ländern existieren Anlehnungen und Nachahmungen des Konzepts (hierzu im Überblick Kreis 2010, S. 329 f.). Nachfolgeprojekte in Deutschland und der Schweiz bemühen sich dezidiert darum, mit ihrer Auswahl an Erinnerungsorten die $\mathrm{He}-$ terogenität der jeweiligen Geschichtskulturen zu berücksichtigen (Kreis 2010, S. 318 f; François/Schulze 2005, S. $10 \mathrm{ff}$.), bleiben aber gleichwohl allein durch ihre Buchtitel («Schweizer Erinnerungsorte», Kreis 2010; «Deutsche Erinnerungsorte», François/Schulze 2005) an der Nation als äusserem Rahmen orientiert.

Hingegen betont Simone Lässig die Heterogenität von nationalen Geschichtskulturen und weist auf die Gefahr von Vereinfachungen und Stereotypen hin, die verkennen, «dass es in jedem einzelnen der vorgestellten Länder nicht nur eine nationale Meistererzählung gab, sondern bestenfalls eine dominante, dass immer und überall verschiedene kulturelle Überlieferungen und Erinnerungen [...] existierten» (Lässig 2006, S. 198f., direktes Zitat S. 199). Massgeblich geprägt hat den Begriff des Geschichtsbewusstseins Karl-Ernst Jeismann (Jeismann 1988; Jeismann 1997), der es als Bewusstsein über «den Zusammenhang von Vergangenheitsdeutung, Gegenwartsverständnis und Zukunftsperspektive», als «Wissen um die Geschichtlichkeit» begreift (Jeismann 1997, S. 42). Als zentrale Aspekte des Geschichtsbewusstseins nennt Jeismann «Funktionen», "Intentionalität», "Reflexivität» und «historisches Lernen» (Jeismann 1988, S. 10 f., Kursivsetzung analog zum Original). Bernd Schönemann vertritt in Abgrenzung dazu ein erweitertes Konzept von Geschichtsbewusstsein, das «die ganze Breite individueller historischer Bewusstseinsbildungen in ihren unterschiedlichen Komplexitäts- und Reifegraden» umfasst (Schönemann 2000, S. 45). Jörn Rüsen schliesslich weist auf die Gefahr hin, durch die Wahl des Begriffes «Geschichtsbewusstsein» «von den Dimensionen menschlicher Mentalität [abzulenken], die nicht in der Zielgerichtetheit und Reflexivität von Bewusstsein aufgehen» (Rüsen 1994, S. 5).

Schönemann 2002a, S. 79. 
Vorstellung eines Aufeinanderbezogenseins findet sich bei Rüsen, der Geschichtskultur als "praktisch wirksame Artikulation von Geschichtsbewusstsein im Leben einer Gesellschaft» ${ }^{91}$ beschreibt, wobei in dieser Formulierung sogar das individuelle Geschichtsbewusstsein hinter demjenigen einer Gesellschaft verborgen bleibt. Expliziter in den Blick genommen wird demgegenüber das einzelne Individuum von Hans-Jürgen Pandel, auch hier gedacht als Wechselverhältnis:

«Das Geschichtsbewusstsein derer, die in einer Gegenwart leben, wird in der Geschichtskultur praktisch. Die geschichtskulturellen Objektivationen (z. B. Historienfilme, Belletristik, bildende Kunst) sind Ausdruck des Geschichtsbewusstseins derer, die sie machen. Es äussert sich in seinen verschiedenen kulturellen Formen und Gattungen. Geschichtskultur ist die Art und Weise, wie eine Gesellschaft mit ihrer Vergangenheit und ihrer Geschichte umgeht. Sie ist eine Produktion von Sinnbildungsangeboten, die sich auf Geschichte beziehen und die einer jeden Gegenwart spezifisch sind. Diese pluralen Sinnbildungsangebote werden dann von dem individuellen Geschichtsbewusstsein wieder verarbeitet.» ${ }^{92}$

Hier, bei der Verarbeitung von Angeboten durch das Individuum, setzt mein Forschungsprojekt an. Es lässt abstrakte, kollektive Weisen des Umgangs mit Geschichte beiseite und wendet sich vielmehr einzelnen Individuen und deren Auseinandersetzung mit Historischem in Gestalt einer geschichtskulturellen Manifestation zu, wenn ich danach frage, wie sich Denkprozesse im Kontakt mit einer historischen Ausstellung manifestieren, wie darin Aneignung abläuft. Mit dieser Untersuchung möchte ich einen Beitrag zur Klärung der Frage leisten, wie sich die theoretisch skizzierten Bezüge zwischen Geschichtskultur und Individuum im konkreten Fall manifestieren, und zwar am Beispiel einer konkreten Kontaktsituation, dem Ausstellungsbesuch.

Vorgängig wende ich mich jedoch derjenigen geschichtsdidaktischen und -theoretischen Literatur zu, die, unabhängig von der konkreten Situation eines Ausstellungsbesuchs bzw. darüber hinaus gehend, Prozesse des Denkens eines Individuums in Auseinandersetzung mit Historischem in den Blick nimmt. Unter

91 Rüsen 1994, S. 5.

92 Pandel 2013, S. 164. 
der Bezeichnung «historisches Denken» ${ }^{93}$, «historical thinking» ${ }^{94}$ bzw. «historical reasoning» ${ }^{95}$ existiert eine Reihe von Konzepten, die sich allerdings dahingehend unterscheiden, wen sie als Akteurinnen und Akteure dieses Denkens bestimmen (professionelle Historiker und Historikerinnen, ${ }^{96}$ Schüler und Schülerinnen ${ }^{97}$ oder alle Individuen ${ }^{98}$ ) und - damit verbunden - in welchen Zusammenhängen vom Auftreten dieses historischen Denkens ausgegangen wird. Den breitesten Anspruch in dieser Hinsicht weist das Kompetenz-Strukturmodell historischen Denkens aus, das 2007 von der Gruppe FUER Geschichtsbewusstsein vorgelegt wurde. ${ }^{99}$ Der Vorstellung dieses Konzepts und zunächst seiner Vorläufer gilt deshalb nachfolgend besondere Aufmerksamkeit.

\subsection{Historisches Denken, Sinnbildung und Orientierung bei Jörn Rüsen}

$\mathrm{Zu}$ den Autoren und Autorinnen, die systematisch den Zusammenhang zwischen Vergangenheit, Gegenwart und Zukunft in den Blick nehmen und über die Bedeutung der Beschäftigung mit Historischem für die Gegenwart nachdenken, gehört Jörn Rüsen. ${ }^{100}$ Rüsen hat einige Begriffe und Konzepte lanciert und geprägt, die in der deutschsprachigen Geschichtsdidaktik einflussreich geworden sind und auch für dieses Projekt als sensibilisierende Theorien fungieren.

Dazu zählen der Begriff der Orientierung und Rüsens Vorstellungen von Prozessen historischen Denkens bzw. einer Sinnbildung über Zeiterfahrung, wobei Orientierung einen Teilbereich innerhalb dessen darstellt. Ich gehe vom Allgemeinen zum Speziellen vor und schildere (a) zunächst Rüsens Idee einer Sinnbildung über Zeiterfahrung sowie (b) seine Modellierung historischen Denkens, das gewissermassen einen Spezialfall der zuvor behandelten Sinnbildung über Zeiterfahrung darstellt. Der anschliessende Abschnitt (c) dient dazu, über Anschlussmöglichkeiten zwischen Rüsens Theorie und meinem Forschungsvorhaben nachzudenken.

93 Körber et al. 2007.

94 Z. B. Seixas 1998; Wineburg 2001; Seixas/Morton 2013.

95 Drie/Boxtel 2008.

96 Wineburg 1991, 1998, 2001; Rüsen 2013.

97 Pandel 2005; Drie/Boxtel 2008; Gautschi 2009a.

98 Körber et al. 2007.

99 Körber et al. 2007.

100 Ich beziehe mich in diesem Kapitel auf Rüsen 1983, Rüsen 2008, Rüsen 2012 und Rüsen 2013, um einige Hauptgesichtspunkte seiner Überlegungen in synthetisierender Absicht herauszuarbeiten. 
$\mathrm{Zu}(\mathrm{a})$ : Ausgangspunkt für Rüsens Überlegungen ist die Annahme einer anthropologischen, universellen Notwendigkeit, sich aus der Gegegenwart heraus mit der Vergangenheit zu beschäftigen:

«Es gibt keine menschliche Lebensform, in der ein deutender Bezug auf die Vergangenheit nicht eine wichtige Rolle in der kulturellen Orientierung des jeweils gegenwärtigen Handelns und Leidens spielt. Überall und immer müssen Menschen sich auf die Vergangenheit beziehen, um ihre Gegenwart verstehen und Zukunft erwarten und vorentwerfen zu können.»101

Als Auslöser für eine Zuwendung zur Vergangenheit identifiziert Rüsen das Erleben von «Kontingenz», also das Erleben von Unerwartetem, von Brüchen, die erklärungsbedürftig seien und die in einen sinnhaften historischen Gesamtzusammenhang eingeordnet werden müssten. ${ }^{102}$ Rüsen spricht hierfür von «historischer Sinnbildung» ${ }^{103}$ oder auch von «Sinnbildung über Zeiterfahrung», ${ }^{104}$ die für ihn aus einer Reihe aufeinander aufbauender Teilschritte besteht. ${ }^{105}$ Ich beschreibe diese nachfolgend näher, Abbildung 1 im digitalen Anhang dient als begleitende Visualisierung.

Den Ausgangspunkt des beschriebenen Prozesses bildet bei Rüsen die erwähnte «[h]istorische Erfahrung», eine «Erfahrung von Zeitdifferenz, von der Unterschiedlichkeit von Zeiten». ${ }^{106}$ Rüsen nennt als Beispiele «eine tiefgreifende Veränderung von Herrschaftsverhältnissen» ${ }^{107}$ oder «Katastrophen», ${ }^{108}$ also Ereignisse, aufgrund deren Zeit «in ein Vorher und Nachher auseinander[-fällt], zwischen dem der erfahrene Wandel steht». ${ }^{109}$

In jedem Fall benötigt eine solche Erfahrung von Zeitdifferenz Rüsen zufolge zu ihrer Bewältigung eine «[h]istorischen Deutung». ${ }^{110}$ Bei der Deutung geht

101 Rüsen 2013, S. 29. Hinweis auf anthropologische Grundannahmen ausserdem bei Rüsen 2013, S. 29 f., S. 53, und Rüsen 2012, S. 8 f. Andernorts gesteht er allerdings ein, seine Ausführungen seien «durch und durch von westlichen Denktraditionen geprägt» (Rüsen 2012, S. 16).

102 Rüsen 2013, S. 30 ff., direktes Zitat: S. 30.

103 Rüsen 2013, S. 34.

104 Rüsen 2008, S. 16.

105 Rüsen 2013, S. 34 ff.; Rüsen 2008, S. 11 ff.

106 Rüsen 2013, S. 38.

107 Rüsen 2013, S. 38.

108 Rüsen 2008, S. 17.

109 Rüsen 2013, S. 38.

110 Rüsen 2013, S. 40. 
es darum, die erfahrene Zeitdifferenz «in eine übergreifende Zeitverlaufsvorstellung» einzuordnen, ${ }^{111}$ "die historische Erfahrung in ein Deutungsmuster einzuholen, das sie verständlich macht». ${ }^{112}$ Rüsen unterscheidet mehrere Formen bzw. Modi von Deutungen, so etwa nach Sinnbildungstyp eine «traditionale, exemplarische, kritische und genetische Form», ausserdem in bewusste und unbewusste, kognitive und emotionale Zugänge, «alltägliche Erscheinungsformen» und «elaborierte und komplexe Artikulation» sowie nach «Entwicklungsstadien» und Dimensionen («die ästhetische, die politische und die kognitive [... Dimension»). ${ }^{113}$

In gewissen Fällen kann Rüsen zufolge aus einer Deutung «[h]istorische Orientierung» erwachsen, nämlich dann, wenn in der Deutung «ein direkter Bezug zur Lebenspraxis, also eine innere Qualität von Lebensdienlichkeit» enthalten ist. ${ }^{114}$ Rüsen unterscheidet dabei nach zweierlei Bezugspunkten von Orientierung: Historische Orientierung «[n]ach aussen» oder in Bezug auf «die Welt» diene dazu, «die Welt in ihrer Zeitlichkeit dem Menschen so zu erschliessen, dass er sich in ihr zurechtfinden kann». ${ }^{115}$ Hierzu zählt Rüsen das Bestärken oder Brechen von Traditionen, die Einsicht in eine Verbesserbarkeit von Lebensumständen und die Mobilisation von Handlungsmöglichkeiten. ${ }^{116}$ Historische Orientierung «[n]ach innen» oder in Bezug auf «das Selbst» verschaffe dem denkenden Individuum Orientierung «in sich selbst» und diene zur «Gestaltung seiner inneren Zeit», liefere Antworten auf die Frage nach der eigenen historischen Identität mithilfe «einer erfahrungsbegründeten und aussichtsreichen Zeitvorstellung über das eigene Ich beziehungsweise Wir». ${ }^{117}$

Einen vierten Bereich bildet schliesslich die "Motivation». ${ }^{118}$ Rüsen zufolge ist es möglich, dass Orientierung zur Grundlage von «Handlungsmotivationen» wird, verstanden als «Willensimpulse», ${ }^{119}$ also Anregungen zu Handlungen, noch nicht die Handlungen selbst.

111 Rüsen 2013, S. 40.

112 Rüsen 2013, S. 40.

113 Rüsen 2008, S. 25 ff.; direkte Zitate: S. 25, S. 31, S. 33. Die drei Dimensionen entsprechen den von Rüsen vorgeschlagenen drei Dimensionen von Geschichtskultur (Rüsen 1994, S. 11 ff.; Rüsen 1997a, S. 39f.). Auf Rüsens Sinnbildungstypen komme ich weiter unten erneut zu sprechen und setze überdies die Befunde meiner Datenanalyse dazu in Bezug.

114 Rüsen 2013, S. 41.

115 Rüsen 2008, S. 21; Rüsen 2013, S. 41.

116 Rüsen 2013, S. 41.

117 Rüsen 2008, S. 21; Rüsen 2013, S. 41 f.

118 Rüsen 2013, S. 42.

119 Rüsen 2013, S. 42. 
Das Beschriebene zählt für Rüsen zu den «anthropologisch elementaren und allgemeinen Grundlagen des historischen Umgangs mit der Vergangenheit». ${ }^{120}$ Rüsen zufolge geht es um eine deutende Verbindung von Vergangenheit, Gegenwart und Zukunft, bei der die zeitlichen Grenzen der eigenen Biografie überschritten werden und eine «Geschichte» entsteht, verstanden als «das Sinngebilde eines Zeitzusammenhangs, in dem ein Vorgang der Vergangenheit als Abfolge von Geschehnissen so vergegenwärtigt wird, dass dabei Gegenwart gedeutet und Zukunft als Erwartungsperspektive entworfen wird. Es ist ein Zeitverlauf mit $\langle$ Sinn $\rangle.\rangle^{121}$

In Bezug auf die empirische Anwendbarkeit seiner Modellierung schränkt Rüsen allerdings ein, dass in der Praxis in den seltensten Fällen vollständige Geschichten in diesem idealtypischen Sinn entstehen, dass vielmehr «narrative Abbreviaturen» die Regel seien, die mit einzelnen Worten oder Symbolen zwar eine Geschichte repräsentieren oder auf eine dahinterstehende Geschichte verweisen, diese jedoch nicht selbst erzählen. ${ }^{122}$ Zudem verdeutlicht er, dass auch die vorgeschlagene Unterscheidung in mehrere Modi der historischen Sinnbildung idealtypischen Charakter habe, im empirischen Feld in dieser Reinform möglicherweise gar nicht vorkomme. ${ }^{123}$

$\mathrm{Zu}$ (b): Rüsen spezifiziert weiter eine besondere Form des Umgangs mit Historischem, die er als «historische[s] Denken» bezeichnet und dem Feld eines wissenschaftlichen Umgangs mit Vergangenheit zuordnet. ${ }^{124}$ Die Geschichtswissenschaft greift darin «Orientierungsbedürfnisse» der «Lebenspraxis» auf, verwandelt sie in Forschungsfragen und bearbeitet diese mit geschichtswissenschaftlichen Methoden, schliesslich stellt sie ihre Deutungen als Orientierungsangebote zur Verfügung. ${ }^{125}$ Bei Rüsen erscheint geschichtswissenschaftliche Arbeit zwar auch möglich ohne Anbindung an Orientierungsbedürfnisse der Lebenspraxis, jedoch nicht als wünschenswert. ${ }^{126}$ "Das Eine ist gleichsam die Kehrseite des Anderen; beide gehören aufs Engste zusammen, und zwar so, dass sie sich wechselseitig bedingen, ohne dass die eine von der anderen völlig determiniert würde.» ${ }^{127}$ Erst mit der Anbindung an die Lebenspraxis als Ausgangs- und Zielpunkt ist der Pro-

120 Rüsen 2013, S. 53.

121 Rüsen 2008, S. 15, S. 18, S. 21, direkte Zitate S. 18, im Original in Kursivsetzung.

122 Rüsen 2008, S. 19f., direktes Zitat S. 19.

123 Rüsen 2008, S. 25 ff., insb. S. 29.

124 Rüsen 2013, S. 53.

125 Rüsen 2013, S. 66 ff., direkte Zitate S. 68.

126 Rüsen 1983, S. 30; Rüsen 2012, S. 23 ff.; Rüsen 2013, S. 18 f., S. 68 ff.

127 Rüsen 2013, S. 69. 
zess historischen Denkens vollständig, lässt sich Rüsen zufolge überhaupt von historischem Denken sprechen. ${ }^{28}$

Mit dem beschriebenen Ablauf deutet sich bereits an, dass Rüsen historisches Denken in dynamischer Weise als Prozess begreift, bestehend aus aufeinander folgenden und aufbauenden Teilschritten. ${ }^{129}$ Rüsen selbst bezeichnet die Abfolge in einer älteren Publikation von 1983 als «Regelkreis des historischen Denkens» und als «disziplinäre Matrix der Geschichtswissenschaft», ${ }^{130}$ später als «Matrix historischen Denkens», ${ }^{131}$ davon ausgehend, dass die einzelnen Schritte zwar einerseits «zeitlich gerichtet» aufeinanderfolgen, aber zugleich «in einem systematischen Interdependenzverhältnis» zueinander stehen. ${ }^{132}$

$\mathrm{Zu}$ (c): Worin Rüsens Darstellung letztlich widersprüchlich und mehrdeutig bleibt, ist der Bereich der Akteurinnen und Akteure der beschriebenen Sinnbildung über Zeiterfahrung und des historischen Denkens. Historische Sinnbildung führt Rüsen, wie oben beschrieben, als universell-anthropologisch und typisch menschlich ein, insofern liegt zunächst der Schluss nahe, dass alle Menschen so Sinn bilden können und dies auch tun. Andererseits spricht Rüsen an anderer Stelle in Bezug auf unterschiedliche Typen von Sinnbildungen davon, dass es unterschiedliche «Entwicklungsstadien» gebe, ${ }^{133}$ was den Schluss nahelegt, dass Sinnbildung über Zeiterfahrung erlernt werden muss.

Ähnlich undeutlich führt Rüsen den Kreis der Akteurinnen und Akteure in Bezug auf historisches Denken aus. Er entfaltet es einerseits als Prozess, für den es die methodisch geleitete und regulierte Geschichtswissenschaft braucht. ${ }^{134}$ Jeder der Teilschritte sei «notwendig, ohne ihn würde also historisches Denken nicht erfolgen können». ${ }^{135}$ Da der Kreislauf historischen Denkens nach Rüsens Konzeption die Befähigung zum streng methodisch geleiteten und regulierten, forschenden Umgang mit Geschichte beinhaltet, der die eine Hälfte des dynamischen Modells ausmacht, ${ }^{136}$ erweckt historisches Denken damit den Anschein, professionellen Historikern und Historikerinnen vorbehalten zu sein.

128 Rüsen 2013, S. 68 f.

129 Rüsen 2013, S. $68 \mathrm{f}$.

130 Rüsen 1983, S. 31, S. 29.

131 Rüsen 2013, S. 68.

132 Rüsen 2013, S. 69.

133 Rüsen 2008, S. 33 f., direktes Zitat S. 33.

134 Rüsen 2013, S. 68 ff.

135 Rüsen 2013, S. 68, Kursivsetzung analog zum Original.

136 Rüsen 2013, S. 68, S. $71 \mathrm{ff}$. 
Andererseits sieht Rüsen den «Ursprung des historischen Denkens in der menschlichen Lebenspraxis», ${ }^{137}$ in universellen, anthropologischen Gegebenheiten des Menschseins. ${ }^{138}$ Rüsen beschreibt historisches Denken auch als innerhalb der Geschichtskultur vorkommend, ${ }^{139}$ wobei an mehreren Stellen deutlich wird, dass er unterschiedliche Grade der Güte historischen Denkens annimmt und dem geschichtswissenschaftlichen historischen Denken einen besonderen Stellenwert einräumt:

«Die Demokratisierungsabsicht kann also zu einer Anarchie führen, die unübersichtlich zu nennen untertrieben wäre. Selbstverständlich kann man nicht davon ausgehen, dass alle historischen Umgangsformen mit der Vergangenheit gleichberechtigt sind. Aber alle beanspruchen Geltung; deshalb kann ihre Berechtigung mit Gründen und Gegengründen verhandelt werden. Dies wiederum bringt die Geschichtswissenschaft auf den Plan, denn sie ist es, die die elaborierteste Form der Begründung im Umgang mit der Vergangenheit entwickelt hat. Sie steht kraftvoll als eigene gesellschaftliche Institution für eine besondere, nämlich rationale Begründbarkeit.» ${ }^{140}$

«Geschichte als Wissenschaft ist also eine spezifische Form der $<$ Rationalisierung> des in der Lebenspraxis immer schon tätigen historischen Denkens. Es unterscheidet und distanziert sich mit seinen eigenen Denkformen und -strategien vom alltäglichen historischen Denken und von vielen anderen Ausprägungen der Geschichtskultur.» ${ }^{141}$

Allerdings erklärt Rüsen das Erlernen der «Fähigkeit zu historischem Denken» auch als Gegenstand von «Erziehungs- und Bildungsprozessen». ${ }^{142}$ Welche Personenkreise genau jedoch im Zug einer Demokratisierung historischen Denkens als «historisch Denkende» infrage kommen, bleibt letztlich unklar. Rüsen benennt seine Akteure und Akteurinnen als Kollektivsingulare, spricht von «Wissenschaft» oder «Geschichtswissenschaft», «Lebenspraxis» und «Geschichtskultur» ${ }^{143}$ und

137 Rüsen 2013, S. 221.

138 Rüsen 2013, S. 29 f., S. 53; Rüsen 2012, S. 8 f.

139 Rüsen 2013, S. 221 ff., insbesondere S. 222.

140 Rüsen 2013, S. $222 \mathrm{f}$.

141 Rüsen 2013, S. 70.

142 Rüsen 2013, S. 254.

143 Rüsen 2013, S. 68 f., S. 221 f. 
geht dabei von einem Wechselverhältnis zwischen Geschichtswissenschaft und Lebenspraxis aus:

«Wissenschaft und Lebenspraxis hängen aufs Engste miteinander zusammen und sind doch zugleich klar getrennt. [...] Das Eine ist gleichsam die Kehrseite des Anderen; beide gehören aufs Engste zusammen, und zwar so, dass sie sich wechselseitig bedingen, ohne dass die eine von der anderen völlig determiniert würde.» ${ }^{144}$

Ob die allgegenwärtig gegebenen Kontingenzerfahrungen als mögliche Auslöserinnen historischen Denkens dann dazu führen, dass alle Menschen, ausgehend davon, auch den Prozess historischen Denkens durchlaufen oder ob dieser Prozess nach Rüsens Vorstellung lediglich von in der historisch-kritischen Methode ausgebildeten Personen vollzogen wird, während die Lebenspraxis lediglich dazu dient, Orientierungsbedürfnisse zu generieren und zur Bearbeitung an die Geschichtswissenschaft abzugeben, bleibt letztlich unklar.

Diese verkürzte Darstellung in Bezug auf lebenspraktische Formen historischen Denkens ist wohl Rüsens Zugang geschuldet. Es geht ihm letztlich um das geschichtswissenschaftliche historische Denken, um die Lebenspraxis hingegen nur insofern, um in ihr «die besondere Rolle» der «Geschichte als Wissenschaft» zu ergründen. ${ }^{145}$ Im Gegensatz dazu stehen für mein eigenes Forschungsanliegen lebenspraktische Formen des historischen Denkens im Zentrum des Interesses. So besteht der Kreis an Teilnehmenden für diese Studie zwar auch, aber nicht nur aus ausgebildeten Historikerinnen und Historikern. ${ }^{146}$ Insofern ist ein methodisch regulierter und geschichtswissenschaftlichen Standards entsprechender Umgang mit dem vorgefundenen Material weder erwartbar noch erwartet.

Wie sich die von Rüsen entwickelte Theorie hinsichtlich der beschriebenen Akteurinnen und Akteure demokratisieren lässt, weitgehender, als es Rüsen selbst ausformuliert hat, zeigt sich in der Rezeption und Weiterverarbeitung von Rüsens Theorie, auf die ich in Abschnitt 2.5 noch zu sprechen komme. Dort wird sein Ansatz um eine weitere relevante Perspektive ergänzt. Denn Rüsens historisches Denken bzw. seine Sinnbildung ist ein ausschliesslich aktiver, erzählungsgenerierender, nicht ein rezeptiver Prozess. Beim historischen Denken nach Rüsens Vor-

144 Rüsen 2013, S. 69.

145 Rüsen 2013, S. 221.

146 Zur Zusammensetzung des Samples siehe Abschnitt 6.2. 
stellung entstehen historische Narrationen über Geschichte. ${ }^{147}$ Historisch Denkende sind also diejenigen Personen, die aktiv diese Narrationen gestalten, nicht diejenigen, die diese fertigen Narrationen zur Kenntnis nehmen. Dies unterscheidet Rüsens Modellierung etwa von ihrer Weiterentwicklung im Rahmen des FUER-Projekts, die als eine Variante historischen Denkens auch das eher rezeptive Zur-Kenntnis-Nehmen und De-Konstruieren bereits existierender Narrationen kennt. ${ }^{148}$

\subsection{Verknüpfungen von Zeitebenen: Bedeutung und Varianten}

Ein wesentliches Verdienst Rüsens besteht darin, illustriert zu haben, dass die Beschäftigung mit Historischem in der gegenwärtigen Lebenspraxis gründen ( «Orientierungsbedürfnisse») und auch auf diese zurückbezogen werden kann bzw. sollte («Orientierungsfunktionen»). ${ }^{149}$ Für Rüsen sind diese Bezüge für einen vollständigen und gelungenen Prozess historischen Denkens sogar zwingend erforderlich: ${ }^{150}$ «Historisch ist eine narrative Form dann, wenn sie den Zeitzusammenhang zum Ausdruck bringt, der die Deutung der Vergangenheit systematisch mit einem Verständnis der Gegenwart und den Erwartungen der Zukunft zusammenbringt». ${ }^{151}$

$\mathrm{Ob}$ und inwieweit die explizite Verknüpfung von Zeitebenen konstitutiv für historische Darstellungen sein soll, wie von Rüsen nahegelegt, wird innerhalb der Geschichtsdidaktik und -theorie kontrovers diskutiert, etwa unter Verweis auf die historiografische Praxis. So stellt Waltraud Schreiber in Bezug auf geschichtswissenschaftliche Darstellungen fest:

«Bei der Analyse vorliegender historischer Narrationen erkennt man bald, dass in ihnen nur in den seltensten Fällen der Zusammenhang zwischen allen drei Zeitdimensionen explizit hergestellt wird. Über weite Teile werden in den 〈vorliegenden Geschichten〉 Entwicklungen und Veränderungen in der Vergangenheit bzw. historische Phänomene untersucht. [...] Der Autor bezieht in solchen Fällen die von ihm erarbeiteten Narrationen nicht explizit auf seine

147 Rüsen 2013, S. 75 ff.

148 Schreiber et al. 2007, v. a. S. 28 f.; hierzu ausserdem die Ausführungen in Abschnitt 2.5.

149 Rüsen 2013, S. 68 ff.; S. 77 f.; direkte Zitate S. 68.

150 Rüsen 2013, S. 68 u. S. 76.

151 Rüsen 2013, S. 76. 
eigene Gegenwart und/oder auf die für ihn offene Zukunft. Er nutzt seine Geschichte also weder explizit zur eigenen Orientierung noch macht er seinen Rezipienten ein deutlich erkennbares Orientierungsangebot.» ${ }^{152}$

Schreiber votiert dagegen, solchen Darstellungen allein aufgrund des mangelnden expliziten Gegenwartsbezugs «das Attribut 〈historisch〉 abzusprechen», ${ }^{153}$ eine Auffassung, die ich teile, um einerseits der Realität historiografischer Arbeit als auch derjenigen des schulischen Geschichtsunterrichts gerecht werden zu können. Schreibers Vorschlag, in solchen Fällen von «Orientierung in der Vergangenheit» zu sprechen, ${ }^{154}$ halte ich allerdings gleichwohl für ungünstig, da auf diese Weise der spezifische gegenwartsbezogene Gehalt des Orientierungsbegriffs verwässert wird.

Nicht nur hinsichtlich der Frage, ob für einen gelungenen Akt historischen Denkens und Erzählens die Gegenwart explizit einzubeziehen sei, scheiden sich die Geister. Dies gilt auch für die Frage, inwieweit historisches Denken bzw. Erzählen zwingend mehreve Zeitebenen innerhalb der Vergangenheit miteinander in Bezug setzen muss. Eindeutig positionieren sich in dieser Hinsicht Michele Barricelli und Hans-Jürgen Pandel. ${ }^{155}$ Letzterer äussert: «Erzählende Sätze verbinden mindestens zwei zeitlich unterschiedliche Ereignisse sinnhaft zu einer Geschichte». ${ }^{156}$ Jedoch stellt Pandel am Beispiel von Schulgeschichtsbüchern gleichzeitig auch fest, dass diesen eine solche Struktur oft fehlt, «dass diese Bücher keine kohärente narrative Darstellung, sondern eine Addition von Ereignisbeschreibungen liefern». ${ }^{157}$ Geschichtsunterricht sei «immer noch mehr ein Abfragen von Existenzaussagen als ein Narrativieren». ${ }^{158}$ Insofern lässt sich die Frage anschliessen, ob ein enger, auf Verknüpfung von mehreren Zeitebenen festgelegter Narrationsbegriff und entsprechende Konzeptionen von historischem Erzählen der Unterrichtsrealität angemessen Rechnung tragen.

152 Schreiber 2007c, S. 244.

153 Schreiber 2007c, S. 244.

154 Schreiber $2007 \mathrm{c}$, S. 243.

155 Barricelli 2005, S. 42; Pandel 2002, S. 41; Daneben ausserdem zu finden bei Schöner (2013c, S. 94), allerdings konträr dazu bei Schöner auch der Hinweis auf die Möglichkeit einer Beschreibung «vergangene[r] Zustände» und synchroner Zusammenhänge (2013a, S. 83).

156 Pandel 2002, S. 41.

157 Pandel 2002, S. 46.

158 Pandel 2002, S. 47. Dies schlussfolgert Pandel aus Ergebnissen einer Studie von Magull (2000, zit. n. Pandel 2002, S. 46f.). 
Die dem Kompetenz-Strukturmodell ${ }^{159}$ konzeptionell zugrunde liegende Sechsermatrix (siehe auch Abbildung 10 im digitalen Anhang) positioniert sich zurückhaltender, sieht nämlich als Varianten innerhalb der «Fokussierung auf Geschichte» neben den «diachrone[n] Kontextualisierungen (Zeitverläufe)» durchaus auch «synchrone Kontextualisierungen (Zustände)» vor. ${ }^{160}$ Alexander Schöner beschreibt diese als Bezüge innerhalb einer Zeitebene, z.B. räumlicher Art. ${ }^{161}$ Hierzu passt, dass Historiker wie Reinhart Koselleck auch die Beschreibung von Ereignissen und Strukturen zum geschichtswissenschaftlichen Gegenstand erklären, nicht nur die Beschreibung von Prozessen. ${ }^{162}$ Analog dazu unterscheidet auch Ulrich Baumgärtner als «Grundformen der Geschichtsschreibung» die Betrachtung von «Ereignis», «Struktur» und «Prozess» und sieht, ähnlich wie auch Hilke Günther-Arndt, als «thematische Strukturierungskonzepte» neben dem «Längsschnitt» auch «Querschnitt», «Falldarstellung», «Epochensequenz», «Vergleich» und «Biografie» vor, wovon einige ohne Bezüge zwischen mehreren Zeitebenen auskommen oder zumindest nicht darauf festgelegt sind. ${ }^{163}$

Für die Fälle, in denen tatsächlich mehrere Zeiten zueinander in Bezug gesetzt werden, gegebenenfalls auch einschliesslich der Gegenwart, existiert eine Reihe von theoretischen Überlegungen dazu, welcher Art diese Verknüpfungen zwischen den Zeiten sein können. Schöner nennt Narrationen mit kausalen, konzessiven, konditionalen oder finalen Argumentationsmustern, es könnten «Entwicklungen bzw. Veränderungen oder vergangene Zustände» im Fokus stehen, ${ }^{164}$ «Kontinuität und Wandel», «Diskontinuität und Abbruch», «Beschleunigung [und] Verlangsamung» dargestellt sein. ${ }^{165}$ Mit ähnlichen Begriffspaaren wie Schöner sprechen Peter Seixas und Tom Morton von «Continuity and Change» sowie «Cause and Consequence». ${ }^{166}$

159 Körber et al. 2007.

160 Körber et al. 2007, S. 863. Zur Idee der synchronen und diachronen Kontextualisierungen auch Schöner 2013b, S. 109. In der in dieser Arbeit verwendeten Abbildung der SechsFelder-Matrix aus Zabold/Schreiber 2004, S. 206, ist statt von Zuständen von Strukturen die Rede (vgl. Abb. 10 im digitalen Anhang).

161 Schöner 2013b, S. 109.

162 Koselleck 2003, S. 294 ff., sowie dessen Rezeption bei Schöner 2013c, S. 95.

163 Baumgartner 2015, S. 95. Günther-Arndt unterscheidet ähnlich als «Strukturierungskonzepte»: «chronologisch-genetisches Verfahren», «Längsschnitt», «Querschnitt», «Fallanalyse», «Konstellationsanalyse», «biografische[s] Verfahren» (Günther-Arndt 2014, S. $166 \mathrm{ff}$.).

164 Schöner 2013a, S. 83.

165 Schöner 2013c, S. 95.

166 Seixas/Morton 2013, S. 74, S. 102. 
Etliche Autoren widmen sich der Unterscheidung von Sinnbildungs- oder Erzählmustern, ${ }^{167}$ und hier geht es nun tatsächlich um den Einbzug der Gegenwart in die Erzählung. Jörn Rüsen differenziert etwa in «vier Typen der historischen Sinnbildung» bzw. «Erzählweisen»: traditional, exemplarisch, genetisch und kritisch, ${ }^{168}$ wobei das kritische Erzählen in der Rezeption Rüsens beispielsweise von Andreas Körber weiter ausdifferenziert wurde. ${ }^{169}$ Dirk Lange unterscheidet, auf Rüsen Bezug nehmend und sich von ihm abgrenzend, einen zirkulären, linearen und punktuellen Sinnbildungsmodus. ${ }^{170}$ Ich komme auf all diese Sinnbildungsmuster im Kontext meiner Ergebnisdiskussion näher zu sprechen, weil es dort darum gehen wird, die Befunde meiner eigenen Studie mit diesen Mustern in Abgleich zu bringen. ${ }^{171}$

Andere Autoren agieren weniger mit dem Begriff der Sinnbildungsmuster, sondern sprechen von Gegenwartsbezügen, differenzieren aber auch hier unterschiedliche Typen. Etwa unterscheidet Peter Gautschi «drei Grundtypen von Gegenwartsbezügen»: 172 Ein erster thematisiere Vergangenheit als «Vorgeschichte», z. B. «Ursache», und stelle ausgehend davon «Veränderungen oder Kontinuitäten» dar, ein zweiter verwende «vergangene Strukturen als Modell zur Erklärung von aktuellen Situationen», und ein dritter betrachte «vergangene Strukturen oder Ereignisfolgen als Kontrast zur Gegenwart». ${ }^{173}$

Klaus Bergmann benennt zwei Möglichkeiten der Herstellung von Bezügen. Eine Variante ist der «Gegenwartsbezug als Ursachenzusammenhang», in dem

167 Borries 1988, S. 60 f.; Pandel 2002, S. 40 ff.; Lange 2004, S. 24 ff., v. a. S. 32 ff.; Rüsen 2012, S. 171 ff.; Rüsen 2013, S. 209; Körber 2013; Körber 2016.

168 Rüsen 2012, S. 170 ff.; Rüsen 2013, S. 209. In seiner Veröffentlichung aus dem Jahr 2012 spricht Rüsen von «Erzählweisen» (Rüsen 2012, S. 170), 2013 von «Typen der historischen Sinnbildung» (Rüsen 2013, S. 209).

169 Körber 2013; Körber 2016.

170 Lange 2004, S. $24 \mathrm{ff}$, v. a. S. $32 \mathrm{ff}$.

171 Siehe Abschnitt 8.5.5.

172 Gautschi 2015, S. 37.

173 Gautschi 2015, S. 37. In Teilen lassen sich bei diesen drei Typen Anklänge an «[d]ie vier Typen der historischen Sinnbildung» bzw. «vier Erzählweisen» bei Rüsen entdecken (Rüsen 2013, S. 209 ff., direktes Zitat S. 209; Rüsen 2012, S. 170 ff., direktes Zitat S. 170), auf die ich in Abschnitt 8.5.5 noch näher zu sprechen komme. Rüsen unterscheidet "Traditionales Erzäblen", "Exemplarisches Erzäblen», "Kritisches Erzäblen» und "Genetisches Erzäblen» (Rüsen 2012, S. 171, S. 172, S. 175, S. 178, Kursivsetzungen analog zum Original), in seiner Publikation aus dem Jahr 2013 spricht er jeweils von «Sinnbildung» (Rüsen 2013, S. 209 ff.). Im Vergleich zwischen Gautschi und Rüsen ähnelt der erste von Gautschi genannte Typus der traditionalen oder auch genetischen Sinnbildung bei Rüsen, der zweite Typus weist Parallelen zur exemplarischen Sinnbildung auf. 
eine gegenwärtige Situation auf ihre unmittelbaren Ursachen hin befragt wird, was Bergmann zufolge nur für Rückblicke geringer Reichweite («Naherinnerung») möglich ist, die innerhalb der neuesten Geschichte bzw. Zeitgeschichte verbleiben. ${ }^{174}$ Über die Suche nach und die Benennung von Ursachen hinaus reicht das Konzept «Gegenwartsbezug als Sinnzusammenhang», was sich auch bei der Betrachtung grösserer historischer Zeiträume ( «Fernerinnerung») anbiete. ${ }^{175}$ Hier geht es nicht um die Feststellung eines kausalen Zusammenhangs, sondern um die Frage, «ob es in der Vergangenheit Situationen und Entwicklungen gegeben hat, die mit der gegenwärtigen Situation bedingt vergleichbar» sind, wobei «Kohärenz und Differenz» festgestellt werden. ${ }^{176}$

\subsection{Gegenwarts- und Lebensweltbezug als geschichts- didaktische Prinzipien und Normen}

Während Ansätze auf deskriptiver Ebene von einer nicht hintergehbaren Gegenwartsgebundenheit historischen Denkens ausgehen, dabei wie Rüsen auf anthropologischer Ebene Orientierungsbedürfnisse als notwendigen Auslöser dafür betrachten, dass überhaupt eine Hinwendung zu Vergangenheit bzw. Geschichte passiert ( Ohne historische Fragen keine Geschichte» ${ }^{177}$ ), oder wie Thomas Martin Buck «epistemologisch betrachtet» hervorheben, «dass die Gegenwart das unhintergehbare erkenntnistheoretische Fundament nicht nur aller historischen, sondern aller menschlichen Erkenntnis schlechthin ist», ${ }^{178}$ weist die Idee einer Gegenwartsbezogenheit historischen Denkens in der Geschichtsdidaktik neben der deskriptiven, anthropologischen und epistemologischen auch eine normative Dimension auf. Gegenwartsbezug gilt hier auch als leitendes didaktisches Prinzip und als Zielgrösse. Christian Heuer stellt diese Dimensionen nebeneinander, wenn er im «Wörterbuch Geschichtsdidaktik» Gegenwartsbezug einerseits als «die nicht hintergehbare Gebundenheit des historischen Denkens an Gegenwart und Zukunft» fasst, andererseits aber auch «die bewusste Konstruktion dieses Gegenwartsbezuges» als Aufgabe des schulischen Geschichtsunterrichts benennt. ${ }^{179}$

179 Heuer 2009, S. 76. 
Differenzierte Überlegungen zur didaktischen Dimension eines Gegenwartsbezugs, vielmehr sogar «Gegenwarts- und Zukunftsbezug[s]», finden sich vor allem bei Klaus Bergmann. ${ }^{180}$ Auch er betont zunächst die anthropologische Dimension: «Diese Gegenwarts- und Zukunftsbezogenheit ist eine grundlegende, nicht hintergehbare Voraussetzung allen historischen Denkens. Geschichte ist immer ein Nachdenken über Vergangenheit, das in einer Gegenwart stattfindet und von Zukunftserwartungen beeinflusst wird. ${ }^{181}$ Gleichzeitig formuliert er aber auch als Anforderung an den Geschichtsunterricht, «das Nachdenken über Vergangenes so anzulegen, dass den Schülerinnen und Schüler[n] erkennbar und nachvollziehbar ist, was dieses Nachdenken über Vergangenes mit ihrer Gegenwart und Zukunft zu tun hat». ${ }^{182}$

In dieser Unterscheidung deutet sich eine Differenzierung in unbewusste und bewusste, implizite und explizite Gegenwartsbezüge an. ${ }^{183}$ Auf der einen Seite steht das unbewusste, unreflektierte Einbringen von gegenwärtigen Perspektiven und Fragestellungen in die Zuwendung zu Historischem, das - wie bereits mehrfach thematisiert - als konstitutiv und unumgänglich angesehen wird. Auf der anderen steht das explizite, reflektierte Sich-Bewusstmachen oder gar aktive Herstellen dieser Bezüge, wobei Bergmann insbesondere im letztgenannten Bereich die Aufgabe von Lehrpersonen erkennt. ${ }^{184}$

Die Ausführungen Bergmanns und Heuers oder auch Gautschis ${ }^{185}$ verweisen auf ein angenommenes geschichtsdidaktisches Potenzial in der Herstellung von Gegenwartsbezügen. Gegenwartsbezüge verhindern, so Heuer, «Geschichte [...] als reinen 〈Stoff〉 zu konsumieren», und dienen stattdessen der «Förderung eines reflektierten Geschichtsbewusstsein». ${ }^{186}$ Sie zielen, so Bergmann, auf eine Ausrichtung des Unterrichts an «den Lebensperspektiven von Schülerinnen und Schülern» ${ }^{187}$ und klären die Frage,

180 Bergmann 2008 und Bergmann 2016; ausserdem bei Pandel 2013, S. 333-336.

181 Bergmann 2016, S. 91.

182 Bergmann 2016, S. 91f.

183 So auch bei Heuer 2009.

184 Bergmann 2016, S. 92.

185 Gautschi 2015, S. 36.

186 Heuer 2009, S. 76.

187 Bergmann 2016, S. 92. 
«welchen Nutzen und welchen Nachteil die Geschichte für ihr Leben in ihrer Gegenwart und für ihre Zukunft hat - und das ist eine Frage, die zu Recht immer wieder gestellt und beantwortet worden ist. [...] Die Frage gehört als Frage nach der Lebensdienlichkeit von Geschichte zu den Grundfragen der Geschichtsdidaktik. Sie ohne Begründung als banausisch abzutun heisst, die Bedürfnisse und berechtigten Ansprüche von Kindern und Jugendlichen zu missachten.» 188

Die Idee notwendiger Gegenwartsbezüge geht bei Heuer Hand in Hand mit der Idee eines notwendigen Lebensweltbezugs schulischen Geschichtsunterrichts, ${ }^{189}$ eine Verbindung, die sich in der geschichtsdidaktischen Literatur häufiger findet. Etwa titelt Thomas Martin Buck integrierend «Lebenswelt- und Gegenwartsbezug» ${ }^{190}$ und vermengt die Prinzipien auch in seinen Ausführungen:

«Sie [gemeint ist Geschichte, Anm. JT] hat etwas mit unserem Leben zu tun und sollte deshalb nicht nur ein ödes Abarbeiten von Faktenbeständen oder gar Auswendiglernen sein, sondern persönliche Bedeutung für die Lernenden haben. Geschichte geht uns etwas an, weil Geschichte Teil unserer Lebenswelt ist und wir selbst historisch bzw. zeitlich existieren. Das heisst: Aller Beschäftigung mit Geschichte ist zwar selbstverständlich ein Vergangenheitsbezug, aber auch ein Gegenwarts- und Zukunftsbezug inhärent.» ${ }^{191}$

Auch Hans-Jürgen Pandel neigt unter dem Stichwort "Gegenwartsorientierung» zu einer Integration beider Perspektiven, feststellend, dass «Gegenwarts- und Schülerorientierung [... weitgehend den gleichen Sachverhalt [meinen]». ${ }^{192} \mathrm{Hin}$ gegen differenziert er danach, ob von einem didaktischen, die Auswahl von Themen für den Unterricht leitenden Prinzip «Gegenwartsorientierung» oder vielmehr von einem methodischen Prinzip «Gegenwarts- und Zukunftsbezug» die Rede ist. ${ }^{193}$

188 Bergmann 2008, S. $10 \mathrm{f}$.

189 Grundsätzlich über das Verhältnis von historischem Lernen und Lebenswelt nachgedacht wird bei Schreiber (2005), Grunder widmet sich aus schulpädagogischer Perspektive dem Verhältnis von «Schule und Lebenswelt» (Grunder 2001).

190 Buck 2017.

191 Buck 2017, S. 293.

192 Pandel 2013, S. 333.

193 Pandel 2013, S. 333. 
Umgekehrt unterscheidet Ulrich Baumgärtner in zwei separate didaktische Prinzipien, nämlich «Gegenwartsorientierung» einerseits und «Lebenswelt- und Erfahrungsorientierung» andererseits. ${ }^{194}$ Bei Ersterer berücksichtigt auch Baumgärtner die anthropologische Dimension von Gegenwartsbezügen:

«Da jede historische Frage von der jeweiligen Gegenwart ausgeht, ist dieses Prinzip konstitutiv. So ist im Unterricht stets der Bezug historischer Sachverhalte zur heutigen Situation zu thematisieren, da dadurch der Blickwinkel auf die Vergangenheit vorgegeben ist und nur eine Reflexion dieser Perspektive eine belastbare historische Erkenntnis ermöglicht.» ${ }^{195}$

Dem stellt Baumgärtner das Prinzip der «Lebenswelt und Erfahrungsorientierung» gegenüber:

«Im Unterschied zur Gegenwartsorientierung spielt hier die Erfahrungs- und Lebenswelt der Kinder und Jugendlichen eine entscheidende Rolle. Im Unterricht kommt es darauf an, entsprechende Anknüpfungspunkte zu suchen. So kann im Zusammenhang der Industrialisierung auf die Verwendung von Plastik bei der Herstellung von Alltagsgegenständen Bezug genommen werden.» ${ }^{196}$

Diese Zweiteilung sensibilisiert dafür, dass Gegenwartsbezüge und Bezüge zur Lebenswelt der historisch Denkenden nicht zwingend identisch sind und dass Gegenwarts- auch ohne Lebensweltbezüge auftreten können ${ }^{197}$ - eine Unterscheidung, die sich später auch in dem von mir eingesetzten Kategoriensystem widerspiegelt und die ich bei der Darstellung meiner Ergebnisse erneut aufgreife. In der Theorie werden beide Prinzipien jedoch, wie dargestellt, häufig vermengt, und auch in den im folgenden Abschnitt beschriebenen Konzeptionen historischen Denkens wird eine entsprechende Differenzierung bisweilen verwässert.

Gegenwarts- und Lebensweltbezüge haben, so lässt sich zusammenfassend konstatieren, für die Geschichtsdidaktik, neben der Einsicht in ihren unhintergehbaren anthropologischen und dabei vielfach impliziten, unbewussten Charakter,

194 Baumgärtner 2015, S. 68.

195 Baumgärtner 2015, S. 68.

196 Baumgärtner 2015, S. 68.

197 Umgekehrt lassen sich Lebensweltbezüge immer auch als Gegenwartsbezüge verstehen, wenn man Lebenswelt als einen Teilbereich von Gegenwart versteht. Unter dieser Perspektive wären Lebensweltbezüge eine Teilmenge von Gegenwartsbezügen. 
auch einen didaktischen Wert, nämlich dann, wenn sie bewusst hergestellt und auf die Lebenswelt der historisch denkenden Personen bezogen werden. Sie sind damit zugleich normative Konzepte als didaktische Zielgrössen, die es im Unterricht zu verwirklichen gilt.

\subsection{Historisches Denken und Orientierung}

\subsubsection{Historisches Denken und Orientierung im Rahmen von deutschsprachigen Kompetenzmodellen}

Jörn Rüsens weiter oben vorgestellter Regelkreis historischen Denkens und seine Überlegungen zu einer Sinnbildung über Zeiterfahrung stellen wesentliche Theoriebausteine dar, auf denen das im Jahr 2007 publizierte geschichtsdidaktische Kompetenz-Strukturmodell der Gruppe FUER Geschichtsbewusstsein aufbaut. ${ }^{198}$ Die Kernidee des Modells besteht darin, aus einer Konzeption fachspezifischen historischen Denkens heraus entsprechende Kompetenzbereiche «abzuleiten». ${ }^{199}$

Die Entstehung des Modells fällt in eine Zeit intensiver kompetenzorientierter Theorie- und Modellbildung in den Fachdidaktiken, die in erster Linie auf eine Bereitstellung von Kompetenzmodellen für den schulischen Unterricht zielt, womit die Benennung erwünschter Lernergebnisse in Form von Kompetenzen und die kompetenzbasierte Modellierung von Lehr-Lern-Prozessen möglich wird. ${ }^{200}$ Innerhalb der Geschichtsdidaktik sind in diesem Rahmen eine Reihe von Kompetenzmodellen vorgelegt worden, die alle Vorstellungen von fachspezifischem historischem Denken und Lernen bzw. dessen Teilbereichen zum Ausgangspunkt einer Unterscheidung von Kompetenzbereichen machen. ${ }^{201}$

198 Körber et al. 2007. Als theoretisches «Bindeglied» zwischen beiden fungiert das von Hasberg und Körber unter Bezugnahme auf Rüsen vorgestellte «dynamische[.] Modell des historischen Denkens» (Hasberg/Körber 2003, S. 187). Zum Bezug der Theorien untereinander: Schreiber et al. 2007, S. $19 \mathrm{ff}$.

199 Schreiber et al. 2007, S. 22.

200 Zum Kontext des FUER-Projekts: Körber 2007.

201 Für Übersichten und vergleichende Darstellungen zu geschichtsdidaktischen Kompetenzmodellen: Körber 2007, S. 100 ff.; Gautschi 2009a, S. 54 ff.; Pandel 2013, S. 207 ff.

Weitere Kompetenzmodelle neben dem Kompetenz-Strukturmodell liegen in der deutschsprachigen Geschichtsdidaktik vor durch: Pandel 2005; Verband der Geschichtslehrer Deutschlands 2006; Gautschi 2009a, S. 48 ff.; Pandel 2013, S. $221 \mathrm{ff}$; sowie in enger Anbindung an das FUER-Modell: Kühberger 2015. 
Mein Forschungsprojekt zielt nicht unmittelbar auf die Erhebung von Kompetenzen, ich beobachte vielmehr die Performanz von Besuchenden im Rahmen eines einmaligen Ausstellungsbesuchs und die sich dabei ereignenden Denkvorgänge. Freilich können diese Denkvorgänge auch als Ausdruck vorhandener Kompetenzen verstanden werden, jedoch stellt «Kompetenz» kein Bezugskonstrukt meiner Studie dar. Insofern sind vorhandene Kompetenzmodelle nicht aufgrund ihres Status als solche relevant. Vielmehr interessieren für meine Zwecke die in den Modellen enthaltenen Überlegungen zu fachspezifischen historischen Denkprozessen und darunter, noch spezifischer, Überlegungen zur Bedeutung und Rolle einer Auseinandersetzung mit Historischem für Gegenwart und Lebenswelt sowie Überlegungen zum Umgang mit geschichtskulturellen Manifestationen, konkreter: mit historischen Museen und Ausstellungen.

Von herausgehobener Bedeutung für meine Studie ist das Kompetenz-Strukturmodell der Gruppe FUER, weil es historisches Denken dezidiert schulunterrichtsübergreifend begreift und den Anspruch erhebt, «für die gesamte Domäne des Umgangs mit Vergangenheit» gültig zu sein und «historisches Denken in allen Phasen von Lebensläufen und in allen Bereichen des Lebens kategorial fassen» zu können. ${ }^{202}$ Grundlage ist die Annahme, «dass historisches Denken in seiner Grundform anthropologisch notwendig ist und daher von Menschen auch ohne institutionalisierte Unterweisung vollzogen wird». ${ }^{203}$ In diesem Sinn sollte das Modell auch Denkvorgänge beim Besuch einer historischen Ausstellung modellieren und erhellen können. ${ }^{204}$

Auch Autoren weiterer deutschsprachiger Kompetenzmodelle berücksichtigen den kompetenten Umgang mit geschichtskulturellen Phänomenen ${ }^{205}$ oder weisen hierfür sogar eigene Kompetenzen aus, ${ }^{206}$ verlassen dabei aber nicht explizit wie das FUER-Modell den Geschichtsunterricht und das dort erlernte und praktizierte historische Denken als äusseren Bezugsrahmen.

202 Schreiber et al. 2007, S. 19 und S. 22. Zum schulunterrichtsübergreifenden Anspruch in Abgrenzung zu anderen Kompetenzmodellen ausserdem: Schreiber 2009, S. $46 \mathrm{f}$.

203 Körber 2006, S. 194.

204 Selbiges gilt für die im Kompetenzmodell von Hans-Jürgen Pandel vorgeschlagene «geschichtskulturelle Kompetenz» (Pandel 2005, S. 40 ff.; Pandel 2013, S. 232 f.), auf die ich im Rahmen von Abschnitt 3.3 näher zu sprechen komme. Zur Übertragbarkeit des Kompetenz-Strukturmodells auf Museums-/Ausstellungsbesuche haben Körber und von Borries bereits theoretische Überlegungen publiziert (Borries 2009; Körber 2009; Körber 2010a und 2010b), auf die ich ebenfalls weiter unten noch eingehe.

205 Z.B. Gautschi 2009a, S. 64 ff.

206 Pandel 2005, S. $40 \mathrm{ff}$. 
Aufgrund seiner Bedeutung für meine Studie stelle ich nachfolgend zunächst das Kompetenz-Strukturmodell vor. Ich schildere (a) den Aufbau des Modells und skizziere die vier darin enthaltenen Kompetenzbereiche, von denen drei zugleich Prozessschritte eines theoretisch konzipierten historischen Denkens bilden und Ideen über die Rolle von Individuen in Auseinandersetzung mit Historischem beinhalten. Im Anschluss fasse ich (b) zentrale Aspekte zusammen, die Anschlussmöglichkeiten für mein eigenes Projekt eröffnen.

$\mathrm{Zu}$ (a): Das Kompetenz-Strukturmodell unterscheidet insgesamt vier Kompetenzbereiche, worunter drei, nämlich die historischen Fragekompetenzen, Methodenkompetenzen und Orientierungskompetenzen, prozesshaft gedacht sind und sich an einem angenommenen idealtypischen Prozessverlauf historischen Denkens orientieren. ${ }^{207}$ Die theoretische Basis dieser Kompetenzbereiche ist ein narratives Geschichtsverständnis, in dem Geschichte nicht als identisch mit Vergangenheit verstanden wird, sondern als eine Narration über Vergangenes (und Gegenwärtiges). ${ }^{208}$

Prozesse historischen Denkens können dem Modell zufolge in zwei grundsätzlichen Modi bzw. «Basisoperationen» ablaufen, dem re-konstruierenden oder dekonstruierenden Modus. ${ }^{209}$ Während im re-konstruierenden Modus das Generieren von Erzählungen über Vergangenes im Fokus steht, geht es im de-konstruierenden Modus um den Umgang mit bereits vorliegenden Narrationen. ${ }^{210}$ Diese Unterscheidung in zwei Modi offenbart sich insbesondere im Bereich der Frage- und Methodenkompetenzen bzw. in deren Ausdifferenzierung in Teilbereiche.

Der Bereich der historischen Fragekompetenzen ${ }^{211}$ umfasst einerseits «die Fähigkeit, Fertigkeit und Bereitschaft, Fragen an die Vergangenheit/Geschichte zu stellen» - dies wäre der aktiv generierende, re-konstruktive Weg - und andererseits auch «die Fähigkeit, Fertigkeit und Bereitschaft [...], die Fragen, welche vorliegende historische Narrationen behandeln, zu erkennen, zu verstehen und auf die eigene Fragestellung zu beziehen». ${ }^{212}$ Als Ausgangs- und Bezugspunkt, um sich Fragen der Vergangenheit bzw. Geschichte zuzuwenden, gelten in der Gegenwart des Individuums liegende «Verunsicherungen/Interesse[n]» bzw. «Orientie-

207 Schreiber et al. 2007, S. 23.

208 Schreiber et al. 2007, S. 19; Körber 2007, S. 127; vgl. zur Unterscheidung von «Vergangenheit» und «Geschichte» sowie zum narrativen Geschichtsbegriff auch die Ausführungen in Fussnote 3.

209 Schreiber et al. 2007, S. 27 ff., direktes Zitat S. 27.

210 Schreiber et al. 2007, S. $28 \mathrm{f}$.

211 Schreiber et al. 2007, S. 24 ff.; Schreiber 2007a.

212 Schreiber et al. 2007, S. 25. 
rungsbedürfnisse». Diese «können aus erfahrenen Veränderungen entspringen, aus der Notwendigkeit, Position zu beziehen/sich zu verhalten/zu agieren, aus Unklarheiten über zeitliche Zusammenhänge, aus Irritationen angesichts der Darstellung bestimmter Zusammenhänge in historischen Narrationen, aus Neugierde an historischen Situationen oder Entwicklungen, aus Forschungsanliegen etc.». ${ }^{213}$ Analog zu den Überlegungen bei Rüsen wird also auch im FUER-Modell von einer Gegenwartsbezogenheit und -gebundenheit historischen Denkens ausgegangen. Im Gegensatz zu Rüsen, der mit Kontingenzerfahrungen ein eher enges Spektrum möglicher auslösender Momente für historisches Denken annimmt, ${ }^{214}$ erweist sich die hier zitierte Auflistung jedoch als sehr viel breiter und alltagsbezogener.

Dem Bereich der Fragen nachgelagert sind im idealtypischen Prozessverlauf historischen Denkens die historischen Methodenkompetenzen. ${ }^{215}$ Hierbei geht es, abhängig vom eingenommenen Modus, entweder um das Erstellen oder Erschliessen historischer Narrationen, also um das «Re-Konstruieren» als «Akt der Synthese» oder das «De-Konstruieren» als «ein analytischer Akt». ${ }^{216}$ Der erstgenannte Bereich basiert auf dem «Herausarbeiten von 〈Vergangenheitspartikeln»», auf Basis von Quellen und Quellenkritik - oder auch auf Basis von Befunden aus vorliegenden Darstellungen ${ }^{217}$ - und deren Synthese zu einer historischen Darstellung (einer «Geschichte»), die Zusammenhänge herstellt, «vergangene Entwicklungen erklärt» und «insbesondere auch Bezüge zu Gegenwart und Zukunft» entfaltet. ${ }^{218}$ Im zweitgenannten Bereich, dem «De-Konstruieren» steht demgegenüber der Umgang mit

213 Schreiber et al. 2007, S. $24 \mathrm{f}$.

214 Rüsen 2013, S. $30 \mathrm{ff}$.

215 Schreiber et al. 2007, S. 27 ff.; Schreiber 2007b.

216 Schreiber et al. 2007, S. 28.

217 An dieser Stelle verschwimmen meines Erachtens re-konstruktiver und de-konstruktiver Modus - ein Eindruck, der sich auch anhand meines Datenmaterials einstellt. Vgl. hierzu die Ausführungen im Schlusskapitel.

218 Schreiber et al. 2007, S. 28. Die Annahme, dass mit der Rede von Re-Konstruktion die Vorstellung von einer exakten, abbildhaften, objektiven Rekonstruierbarkeit der Vergangenheit einhergeht (so gefolgert bei Hellmuth/Klepp 2010, S. 125 f.), erscheint mir mindestens in Bezug auf das hier beschriebene Modell nicht nachvollziehbar, da sie eine theoretische Grundannahme des Modells, nämlich die erkenntnistheoretische Unterscheidung in Vergangenheit und Geschichte und die damit verbundene Einsicht in eine «Gegenwartsgebundenheit» von Geschichte, die «unhintergehbar» ist (Schreiber 2007c, S. 238; Schreiber et al. 2007, S. 25), ausblendet. 
bereits vorhandenen Narrationen im Fokus, die auf ihre «tiefer liegenden Strukturen hin» und auf ihre «Konstruktionsmuster» untersucht werden. ${ }^{219}$

Bei den historischen Orientierungskompetenzen ${ }^{220}$ schliesslich handelt es sich um denjenigen Kompetenzbereich, in dem

«historisches Denken und seine Ergebnisse lebensweltlich wirksam werden [...]. Es geht also um die Fähigkeit, Fertigkeit und Bereitschaft, die Erkenntnisse und Einsichten, die durch die Re- und De-Konstruktionsprozesse - auf der Basis eigener oder fremder Fragestellungen - gewonnen wurden, auf die eigene Person und Lebenswelt bzw. die eigene Weltsicht zu beziehen.»221

Orientierung meint hier mehr als die Historizität gegenwärtigen Seins; es ist nämlich

«[m]it der Kompetenz, sich historisch zu orientieren, [...] nicht die Geschichtlichkeit gemeint, der sich niemand entziehen kann, sondern die Fähigkeit, Fertigkeit und Bereitschaft, sich aktiv im Wandel der Zeit zurecht zu finden, indem zeitliche Erfahrungen als sinnvolle Zeitverläufe gedeutet und in die Form historischer Narrationen gebracht werden».222

Dem Wortsinn nach geht es bei Orientierung um ein «Sich-Ausrichten» bzw. ein «Sich-Zurecht-Finden». ${ }^{223}$ Als Bezugsgrössen, innerhalb deren Orientierung erfolgen kann, werden konkret das Geschichtsbewusstsein, Selbst-, Welt- und Fremdverstehen sowie die eigene Handlungsdisposition genannt, die mittels historischen Denkens neu organisiert, reflektiert oder erweitert werden können. ${ }^{24}$ Betrachtet man historisches Denken im Sinn Rüsens als zirkulären Prozess, der seinen Ausgangs- und Zielpunkt in der Lebenswelt hat, ${ }^{225}$ so vollendet der Bereich der Orientierung diesen Zirkelschluss oder kann ausgehend davon ein neuerlicher Prozess historischen Denkens angestossen werden.

219 Schreiber et al. 2007, S. 28.

220 Schreiber et al. 2007, S 29 ff.; Schreiber 2007c. Ähnlich findet sich auch im Kompetenzmodell von Gautschi eine «Orientierungskompetenz für Zeiterfahrung» (Gautschi 2009a, S. 52).

221 Schreiber et al. 2007, S. 29.

222 Schreiber 2007 c, S. 240.

223 Schreiber 2007c, S. 236.

224 Schreiber et al. 2007, S. $29 \mathrm{ff}$.

$225 \mathrm{Vgl}$. Abschnitt 2.2. 
Neben den historischen Frage-, Methoden- und Orientierungskompetenzen unterscheidet das FUER-Modell schliesslich noch einen vierten Kompetenzbereich, der nun nicht als prozessualer Teilschritt historischen Denkens konzipiert ist. ${ }^{226}$ Dies ist der Bereich der historischen Sachkompetenzen, ${ }^{227}$ der in der Konzeption des Modells die anderen drei Bereiche durchdringt und als «Bedingung und Folge des Umgangs mit Geschichte zugleich» verstanden wird, ${ }^{228}$ also gleichsam querliegend zu den anderen drei Kompetenzbereichen gedacht werden kann. Unter Sachkompetenzen firmieren Begriffs- und Strukturierungskompetenz, die das Verfügenkönnen über Prinzipien, Konzepte, Kategorien und Skripts beinhalten, ${ }^{229}$ nicht aber «schlichtes Daten- und Faktenwissen», das im FUER-Modell bewusst ausgeklammert wird, in der Annahme, dass für historisches Denken «Inhalte unerlässlich [sind], nicht aber bestimmte kanonisierte Inhalte». ${ }^{230}$

$\mathrm{Zu}$ (b): In der Zusammenschau lässt sich feststellen, dass dem KompetenzStrukturmodell - insbesondere den drei prozessbezogenen Kompetenzbereichen - die Idee einer Verbindung von Zeitdimensionen innewohnt. Als Ausgangs- und Zielpunkt historischen Denkens wird die Gegenwart und Lebenswelt des denkenden Individuums angenommen, aus der heraus Fragen generiert und an die Erkenntnisse aus Prozessen historischen Denkens zurückgebunden werden.

Im Kontrast zu den Ausführungen Rüsens, wo der Anspruchs- und Gültigkeitsbereich der Modellierung letztlich unklar erscheint und die Idee eines notwendigen Einbezugs geschichtswissenschaftlicher Instanzen virulent ist ${ }^{231}$ wird im FUER-Modell der Gültigkeitsbereich präzise benannt, nämlich als holistisch mit dem Anspruch, «historisches Denken in allen Phasen von Lebensläufen und in allen Bereichen des Lebens kategorial fassen» zu können. ${ }^{232}$ Auch wird allein durch den Kontext des Modells, nämlich seinen Bezug auf den schulischen Geschichtsunterricht (wenn auch nicht nur diesen), neu davon ausgegangen, dass die Elemente historischen Denkens potenziell auch bei Schülerinnen und Schülern

226 Schreiber et al. 2007, S. 24.

227 Schreiber et al. 2007, S. 31 ff.; Schöner 2007.

228 Schreiber et al. 2007, S. 34.

229 Schreiber et al. 2007, S. $32 \mathrm{f}$.

230 Schreiber et al. 2007, S. 33. An der Frage, in welchem Verhältnis Wissen und Kompetenzen stehen und welche Stellung Wissen innerhalb von Kompetenzmodellen einzuräumen sei, hat sich im letzten Jahrzehnt eine Debatte entfaltet, sowohl innerhalb der Geschichtsdidaktik (z. B. Borries 2012; Schreiber 2012; Ziegler 2012) als auch in der Politikdidaktik (für einen Überblick: Sander 2014, S. 120 f.).

231 Vgl. Abschnitt 2.2.

232 Schreiber et al. 2007, S. 19. 
vorkommen. Damit wird die von Rüsen mit Vorbehalten betrachtete Demokratisierung historischen Denkens ${ }^{233}$ zumindest auf theoretischer Ebene vorangetrieben. Dies erfolgt überdies auch dadurch, dass - wie weiter oben ausgeführt - auslösende Momente für historisches Denken breiter gefasst werden.

Breiter wird die Vorstellung historischen Denkens auch dadurch, dass das FUER-Modell neben dem Re-Konstruieren als zweiten möglichen Modus das De-Konstruieren vorsieht. Historisches Denken ist damit bewusst nicht nur als synthetisierender, narrationsgenerierender Akt verstanden, sondern kann auch im Umgehen mit bereits existierenden Erzählungen bestehen, in der Annahme, dass dies den sehr viel wahrscheinlicheren Fall im Kontakt mit Historischem darstellt. ${ }^{234}$ In dieser Hinsicht geht die Modellierung über die Überlegungen Rüsens und eines Teils der Kompetenzmodelle bzw. Modellierungen historischen Denkens und Lernens hinaus. ${ }^{235}$ Andere Kompetenzmodelle integrieren ebenfalls den Umgang mit Darstellungen ${ }^{236}$ oder Medien der Geschichtskultur, ${ }^{237}$ ohne jedoch zwei grundsätzliche, unterschiedliche Modi auszuweisen. Gerade für die Erforschung des Umgangs mit geschichtskulturellen Manifestationen ist die Erweiterung um dekonstruktive Elemente historischen Denkens besonders bedeutsam, da dort vielerlei Erzählungen bereits «fertig» vorliegen, etwa in Gestalt historischer Ausstellungen. ${ }^{238}$

Ähnlichkeiten mit dem Kompetenz-Strukturmodell zeigt das Kompetenzmodell Peter Gautschis. Zwar weist Gautschi nicht explizit einen re- und de-konstruktiven Modus aus, stellt jedoch «Quelle» und «Darstellung» ins Zentrum des von ihm modellierten Kreislaufs historischen Lernens ${ }^{239}$ und fasst seine «Erschliessungskompetenz» als «korrekten und kompetenten Umgang mit verschiedenen Gattungen». ${ }^{240}$ Wie auch das FUER-Modell beinhaltet Gautschis Modell vier Kompetenzbereiche: eine «Wahrnehmungskompetenz», die bereits erwähnte «Er-

233 Rüsen 2013, S. 221 ff., insbesondere S. 222; vgl. Abschnitt 2.2.

234 Hasberg/Körber 2003, S. 185 ff.; Körber 2007, S. 127 ff.

235 Z.B. über Drie/Boxtel 2008, Gautschi 2009a. Zur unterschiedlichen Betonung einer analytischen neben einer synthetischen Seite historischen Denkens in vorliegenden Modellierungen und Zugängen: Waldis et al. 2015, S. $64 \mathrm{f}$.

236 Gautschi 2009a, S. 49.

237 Pandel 2013, S. $232 \mathrm{f}$.

238 Zur Einstufung von Ausstellungen als Erzählungen siehe die Ausführungen in Abschnitt 3.1.

239 Gautschi 2009a, S. 49.

240 Gautschi 2009a, S. 51. 
schliessungskompetenz», eine «Interpretationskompetenz» und wie das FUERModell eine "Orientierungskompetenz», die auch bei Gautschi zirkelförmig angeordnet werden. ${ }^{241}$

Das Bindeglied der vier Bereiche, sein Kernkonstrukt, nennt Gautschi «historisches Erzählen» bzw. «narrative[.] Kompetenz», womit auch sein Modell einem narrativen Geschichtsverständnis Rechnung trägt. ${ }^{242}$ Aufschlussreich für mein Anliegen sind insbesondere die von Gautschi formulierten Komponenten von Orientierungskompetenz, die er aus der Rezeption bereits vorliegender Kompetenzmodelle extrahiert, "geschärft und präzisiert» hat und die unter anderem das Herstellen von Bezügen «von Phänomenen aus der Vergangenheit zur eigenen Person oder Gegenwart» beinhalten. ${ }^{243}$ Auch Gautschi geht also von einer Verknüpfung von Zeitebenen als Element historischen Lernens aus, wobei auffällt, dass er, anders als einige Publikationen zu Gegenwarts- und Lebensweltbezug als didaktischen Prinzipien, ${ }^{244}$ zwischen Bezügen zur eigenen Person einerseits und zur Gegenwart andererseits differenziert.

241 Gautschi 2009a, S. 51.

242 Gautschi 2009a, S. 48 ff., direkte Zitate S. 50 und 51. Zur narrativen Idee als Gemeinsamkeit vorliegender Kompetenzmodelle: Schreiber 2009, S. 46.

243 Gautschi 2009a, S. 63, S. 65 f., direktes Zitat S. 63.

Konkret lauten die Bestandteile von Orientierungskompetenz: «Lernende finden in der Geschichte Orientierung für die Bewältigung ihrer Gegenwart und die Gestaltung der Zukunft», «stellen einen Bezug von Phänomenen aus der Vergangenheit zur eigenen Person oder Gegenwart her», «erklären den Einfluss vergangener Phänomene für die Gegenwart», «erkennen in Erzählungen und Erklärungen Sinnbildungsmuster», «vergleichen und reflektieren ihre Werturteile mit anderen Werturteilen», «benennen den eigenen Lernfortschritt und Handlungsmöglichkeiten», «erklären den Nutzen der Beschäftigung mit Vergangenem», «finden Unterhaltung in der Geschichte», «analysieren Interesse und Werte, die bei Menschen eine Rolle spielten, die an vergangenen Ereignissen beteiligt waren", «schlagen verschiedene Wege und Lösungen vor, die für die Bewältigung von typischen Situationen und Fällen möglich sind, und beurteilen die Vorschläge», «begründen den Einfluss von vergangenen Phänomenen für die Gegenwart und schätzen deren Einfluss $a b »$, «überprüfen ihre Urteile anhand geltender Normen», «reichern eigene Erzählungen diskursiv an», «unterscheiden die einzelnen Prozessschritte beim historischen Lernen und bezeichnen und erklären die jeweiligen Produkte», «erklären den Nutzen der eigenen Beschäftigung mit Vergangenem» (Gautschi 2009a, S. 65 f.).

244 Vgl. Abschnitt 2.4. 


\subsubsection{Weitere theorie- und empiriebasierte Konzeptionen historischen Denkens}

Während die bislang vorgestellten Konzepte zu historischem Denken und historischer Orientierung theoriebasiert entwickelt wurden, gibt es auch Zugänge, die neben theoretischen Überlegungen auch Befunde aus empirischen Untersuchungen einbeziehen und aufgrund dieses Zusammenspiels zu Modellierungen historischen Denkens (bzw. des «Historical Thinking» ${ }^{245}$ oder «Historical Reasoning» ${ }^{246}$ ) gelangen. ${ }^{247}$ Ich stelle einige Konzepte vor und betrete damit das Feld der empirisch gesättigten Theorie, was Bezüge zu empirischen Befunden unvermeidlich macht, ohne aber grundsätzlich einen Überblick über empirische Forschungen zum historischen Denken jenseits historischer Museen und Ausstellungen geben zu können. ${ }^{248}$

Im Kern eint die Konzepte dasselbe Anliegen, nämlich zu ergründen und zu beschreiben, auf welchem Weg und basierend auf welchen Denkoperationen bzw. Arbeitsschritten sich Umgang mit Historischem ereignet. Die anvisierte Reichweite der Konzepte ist jedoch unterschiedlich. So zielen Jannet van Drie und Carla van Boxtel mit ihrem Konzept eines «Historical Reasoning» auf ein «theoretical framework $[\ldots]$, which can be used to describe and study historical reasoning in secondary education in terms of its constituting activities», ${ }^{249}$ und nehmen damit Schülerinnen und Schüler in den Blick - auch wenn die von den Autorinnen vorgeschlagene Modellierung durchaus geeignet erscheint, auf ein grösseres Spektrum von Situationen des Kontakts mit Historischem übertragen zu werden.

245 Z. B. Seixas 1998; Wineburg 2001; Seixas/Morton 2013.

246 Z.B. Drie/Boxtel 2008.

247 Z. B. Wineburg 1991, 1998, 2001; Drie/Boxtel 2008. Im Fall des FUER-Modells wurde ein umgekehrter Weg beschritten, dort folgt die Empirie der Theorie, etwa im Fall des Projekts «Historical Thinking - Competencies in History $(\mathrm{HiTCH})$ (Trautwein et al. 2017).

248 Das weite Spektrum an existierenden empirischen Arbeiten zum historischen Denken abbilden zu wollen, ist im Rahmen dieser Arbeit weder möglich noch sinnvoll. Mit meinem weiter unten folgenden Überblick über den Stand der Empirie (Kapitel 5) fokussiere ich auf Arbeiten zu Museums- bzw. Ausstellungsbesuchenden und komme dort auf die mit diesen spezifischen Manifestationen verbundenen Ausprägungen historischen Denken zu sprechen. Ein umfassender Blick auf Arbeiten zum historischen Denken jenseits von $\mathrm{Mu}$ seen und Ausstellungen würde die Möglichkeiten meiner Studie übersteigen und wäre zudem nicht zielführend, da gerade orts- bzw. medienbezogene Aneignungsweisen in einer Ausstellung in den Blick geraten sollen.

Drie/Boxtel 2008, S. 88. 
Die Autorinnen wählen den Begriff «Reasoning», um deutlich zu machen, dass es sich bei dem beobachteten Phänomen um einen aktiven, interpretierenden, konstruierenden Akt handelt. ${ }^{250}$ Sie identifizieren sechs Bausteine des «Historical Reasoning», nämlich «asking historical questions», «use of sources», «contextualization», «argumentation», «use of substantive concepts» und «use of metaconcepts», ${ }^{251}$ verstanden als idealtypische «analytical tools for describing the activity of historical reasoning», die jedoch «do not refer to entities that occur clearly separated in reality». ${ }^{252}$

Mit dem letztgenannten Aspekt, dem Einbezug von «meta-concepts», und der Idee, dass Historical Reasoning dreierlei Mustern folgen kann, nämlich «describing processes of change and continuity», «comparing historical phenomena» und «explaining historical phenomena», ${ }^{253}$ berühren die Autorinnen Bereiche, die Bruce

250 Drie/Boxtel 2008, S. 88.

251 Drie/Boxtel 2008, S. 90. Im Detail definieren sie:

- «asking historical questions [...] [as] asking descriptive, causal, comparative, or evaluative questions about historical phenomena and about the sources that give information about the past» (ebd., S. 92),

- «use of sources $[\ldots]$ as the evaluation of sources (e. g., their usefulness, trustworthiness) in relation to the question at hand and the selection, interpretation, and corroboration of information from sources in order to answer a historical question or to provide evidence for al claim about the past» (ebd., S. 94),

- «contextualization [...] as situating a historical phenomenon, an object, statement, text, or picture in a temporal, spatial, and social context in order to describe, explain, compare, or evaluate it» (ebd., S. 97),

- «argumentation [...] [as] putting forward a claim about the past and supporting it with sound arguments and evidence through weighing different possible interpretations and taking into account counterarguments» (ebd., S. 99),

- «use of substantive concepts [...] [as] the use of concepts that name historical phenomena, persons, and periods when organizing information about the past in order to describe, compare, and/or explain historical phenomena» (ebd., S. 101),

- «use of meta-concepts [...] [as] using heuristics related to

(a) the description of processes of historical change, for example distinguishing change and continuity, gradual and sudden changes, and political, economical, social, and cultural changes;

(b) the comparison of historical phenomena, for example distinguishing similarities and differences and unique and generic aspects;

(c) the explanation of historical events, for example the identification of multiple causes, types of causes, relationships between causes, and of long term and immediate consequences; and

(d) the use of sources providing information about the past, for example evaluating the trustworthiness of the source and corroborating information from different sources (see also the section about the use of sources)» (ebd., S. 103).

252 Drie/Boxtel 2008, S. 90.

253 Drie/Boxtel 2008, S. 90. 
VanSledright und Margarita Limón als «Second Order Conceptual Ideas and Knowledge» einerseits und als «Strategic Knowledge» andererseits bezeichnen. ${ }^{254}$ Sowohl Drie und Boxtel als auch Sledright und Limón sensibilisieren auf diese Weise dafür, dass historisches Denken oder Historical Reasoning sich nicht nur im prozeduralen Anwenden erschöpft, sondern dass darein auch Wissensbestandteile einfliessen, wobei «First Order Conceptual and Narrative Ideas and Knowledge» als Wissen auf «who, what, where, when and how questions», ${ }^{255}$ bei Drie und Boxtel keinen Bestandteil eines Historical Reasoning darstellt. In dieser Hinsicht ähnelt ihre Konzeption trotz unterschiedlicher Begrifflichkeiten in der Idee der Anlage des Kompetenz-Strukturmodells der Gruppe FUER, das, wie weiter oben bereits vorgestellt, eine «Sachkompetenz» ausweist und damit das Verfügenkönnen über Begriffe und Strukturierungsmöglichkeiten meint ${ }^{256}$, ohne abgesehen davon historischem Wissen im engeren Sinn einen Ort im Kompetenzmodell zuzuweisen.

In zwei weiteren Aspekten finden sich jedoch auffällige Abweichungen zwischen den Modellierungen von Drie und Boxtel einerseits, Körber et al. andererseits. So fällt zum einen auf, dass in der Modellierung der Autorinnen Drie und Boxtel ein Element fehlt, das bei den weiter oben beschriebenen Konzepten von Rüsen oder Körber et al. stark gewichtet wird, nämlich der Aspekt der Orientierung bzw. der Rückbindung historischen Denkens an die Lebenswelt und Gegenwart des denkenden Individuums. ${ }^{257} \mathrm{Da}$ die Autorinnen empiriebasiert zu ihrer

254 VanSledright/Limón 2006, S. 547.

Unter Erstgenanntem verstehen VanSledright/Limón «Knowledge of concepts and ideas that investigators impose on the past in the practice of interpreting and making sense of it», beispielsweise "causation, progress, decline, evidence, primary and secondary sources, historical context, author perspectives, source reliability, etc.» (ebd., S. 547). Auch die von Drie/Boxtel erwähnten Konzepte «change and continuity» oder «similarities and differences» (Drie/Boxtel 2008, S. 103) lassen sich diesem Bereich zurechnen.

Unter «Strategic Knowledge» fassen VanSledright/Limón «Knowledge of how to research and interpret the past», beispielsweise "Interpreting within historical context» (VanSledright/Limón 2006, S. 547). Während Drie/Boxtel in ihrer Modellierung die beobachtbare Aktivität selbst benennen, beispielsweise das Einbeziehen von Konzepten, widmen sich Sledright/Limón hingegen der Definition der für solche Prozesse notwendigen Wissensbestandteile.

255 VanSledright/Limón 2006, S. 547. Die Forschenden unterscheiden als dritte Form, neben den zwei oben genannten, "First-Order Conceptual and Narrative Ideas and Knowledge», verstanden als Wissen auf «who, what, where, when and how questions» (VanSledright/ Limón 2006, S. 547).

256 Schöner 2007, insb. S. 272.

257 So wird der Aspekt des «asking historical questions» nicht wie im Fall des FUER-Modells systematisch als das Stellen lebensweltlich und orientierungsrelevanter Fragen verstanden. Die Autorinnen unterscheiden vier Typen von Fragen, nämlich «descriptive questions», 
Modellierung gelangt sind, stellt sich insofern die Frage, welche Rolle die eigene Person und Gegenwart überhaupt in empirisch feststellbaren Phänomenen historischen Denkens spielt.

Zudem wird in der Modellierung Dries und Boxtels - in der Logik des FUERModells gesprochen - der re-konstruktive Modus betont. Die Autorinnen definieren

«skilled historical reasoning» als «reasoning which reflects contextualization or taking into account the historical period and setting, the use of substantive and meta-concepts to describe, compare, and explain historical phenomena, and sound argumentation based on a careful inspection and evaluation of available sources». ${ }^{258}$

Der nach Auffassung des FUER-Modells zweite Modus, der de-konstruierende Modus, bei dem historisches Denken im Umgang mit bereits vorliegenden historischen Narrationen besteht, ist in der Konzeption des Historical Reasoning nicht explizit ausgewiesen.

Passend dazu stellte Andreas Körber fest, dass sich historisches Denken im Kontext schulischen Unterrichts tatsächlich vorzugsweise im rekonstruierenden Modus vollzieht. ${ }^{259}$ Anhand einer Einzelfallanalyse zeigt er, dass Schülerinnen und Schüler nicht kategorial zwischen den Operationen Re-Konstruktion und DeKonstruktion unterscheiden und dass sie

«in Fällen nicht eindeutiger Klärung des jeweiligen Erkenntnisziels [...] automatisch zu ersterem tendieren - Re-konstruktives, synthetisches Denken scheint der Default-Modus ihres Denkens zu sein - zumindest im Unterricht. Die Analyse von Texten auf die in ihnen erkennbaren Sinnbildungsleistungen des Autors hin scheint nur dann wirklich ins Zentrum zu rücken, wenn sie explizit gefordert und angeleitet wird.» 260

«causal questions», «comparison questions» und «evaluative questions» (Drie/Boxtel 2008, S. 91). Ob und - falls ja - welche Rolle dabei die Gegenwart und Lebenswelt des denkenden Individuums spielen kann, etwa als eine Vergleichsebene für Vergleiche zwischen Zeitebenen, ist nicht Gegenstand der Betrachtung. Zudem enthält die Modellierung keinen zur Idee der Orientierung analogen Bereich.

258 Drie/Boxtel 2008, S. 105.

259 Körber 2006.

260 Körber 2006, S. 211. 
Körber stellt die Frage nach möglichen Ursachen dieser Tendenz und hält fest: «Das Übergewicht des Re-konstruktiven Denkens auf eine anthropologische Ursache zurück zu führen, halte ich vorläufig für nicht geboten.» ${ }^{261}$ Vielmehr sei es möglich, dass der «Geschichtsunterricht zumindest in seiner etablierten Form derart stabil den Eindruck [vermittle], dass es um die Erklärung vergangenen Geschehens gehe, dass anderweitige Fragestellungen und Operationen nur schwer zu initiieren sind». ${ }^{262}$ Für mein Projekt stellt sich deshalb die Frage, inwiefern der theoretisch modellierte de-konstruktive Modus überhaupt empirisch relevant ist bzw. ob sich das von Körber festgestellte Übergewicht re-konstruktiven Denkens womöglich auch bei Ausstellungsbesuchenden manifestiert. ${ }^{263}$

Neben möglichen empirischen Gründen ist der unterschiedliche Stellenwert, den der de-konstruktive Modus in den betrachteten Modellierungen historischen Denkens besitzt, allerdings auch auf theoretischer Ebene erklärbar und hängt mit einem unterschiedlichen Verständnis von «sources» im Fall von Drie und Boxtel ${ }^{264}$ und Quellen bzw. historischen Narrationen/Darstellungen im Fall des FUERModells ${ }^{265}$ zusammen. So fassen Drie und Boxtel unter «sources» «primary sources from the time of the event itself and secondary sources or historical accounts of the events. [...] When talking here about the sources, we refer to primary and secondary sources, written sources as well as images.» ${ }^{266}$ Anders als im FUERModell wird hier also nicht Quellen und historischen Darstellungen ein systematisch unterschiedlicher erkenntnistheoretischer Status zugewiesen, der wiederum unterschiedliche Vorgehensmodi historischen Denkens erforderlich macht. So wird im FUER-Modell dem Umgang mit Quellen in Form von Heuristik und Quellenkritik ein Ort innerhalb des Rekonstruktionsprozesses zugewiesen, der Umgang mit fertigen vorliegenden Narrationen erfolgt demgegenüber im Akt der

261 Körber 2006, S. 211.

262 Körber 2006, S. 211.

263 Ein Vergleich erscheint mir auch dann lohnenswert, wenn die äusseren Bedingungen der Datenerhebungssituation grundliegend verschieden sind. So handelt es sich bei meinen Studienteilnehmenden im Vergleich zu den von Körber untersuchten Schüler/innen um Erwachsenen aller Altersklassen. Körbers Studie hat das Geschehen im Geschichtsunterricht zum Gegenstand und damit eine Situation, in der historisches Denken künstlich initiiert wird und bei der die beteiligten Schülerinnen und Schüler obendrein möglicherweise (implizite) Vorstellungen davon mitbringen, was von ihnen in dieser Situation erwartet wird (Körber 2006, S. 192 f., S. 211).

265 Schreiber et al. 2007; Schreiber 2007b.

266 Drie/Boxtel 2008, S. 92. 
De-Konstruktion. ${ }^{267}$ Drie und Boxtel vereinen hingegen den kritischen Umgang mit «sources» unterschiedlicher Herkunft im Akt des «using sources». ${ }^{268}$

Analog dazu findet sich auch in den Veröffentlichungen Samuel Wineburgs keine Unterscheidung in zwei, zur Re- und De-Konstruktion analoge Modi. ${ }^{269}$ Wie auch bei Drie und Boxtel ist Wineburgs Verständnis des Historical Thinking in einem stärkeren Mass aus empirischen Studien abgeleitet, als dies für die Überlegungen Rüsens, der Gruppe FUER oder andere deutschsprachige Kompetenzmodelle gilt. Wineburg hat sich in mehreren Untersuchungen mit der Frage beschäftigt, welche Denkprozesse im Umgang mit historischen Materialien auftreten, wobei er diese Prozesse in den früheren Studien unter «Historical Problem Solving» oder «Historical Interpretation» führt, ${ }^{270}$ später in einer Synthese den Terminus «Historical Thinking» gebraucht. ${ }^{271}$

Typisch für Wineburgs Forschung sind Vergleiche zwischen Expertinnen und Experten einerseits, Novizinnen und Novizen andererseits, oder zwischen mehreren Expertinnen und Experten untereinander. Solche Vergleiche förderten interessante Einblicke in unterschiedliche Ausprägungsgrade des Historical Thinking sowie unterschiedliche Formen von Expertise im Umgang mit dem Material zutage. ${ }^{272}$ Ein wesentlicher Unterschied zwischen den teilnehmenden Schülerinnen

267 Schreiber 2007 b, insb. S. $200 \mathrm{ff} .$, S. $226 \mathrm{ff}$.

268 Drie/Boxtel 2008, S. 92.

269 Wineburg 1991, 1998, 2001.

270 Wineburg 1991, S. 73; Wineburg 1998, S. 320.

271 So im Titel einer Synthese verschiedener Forschungsarbeiten aus dem Jahr 2001: Wineburg 2001.

272 Wineburg konfrontierte etwa acht Historikerinnen und Historiker und acht Schülerinnen und Schüler mit einem Set aus Textquellen und Gemälden zur Schlacht von Lexington und forderte sie auf, diese zu lesen bzw. zu betrachten und dabei mittels Lauten Denkens zu kommentieren, schliesslich das Material einzuschätzen hinsichtlich der angenommenen «trustworthiness as sources for understanding what happened on Lexington Green» (Wineburg 1991, S. 74f., direktes Zitat: S. 75; eine jüngere Beschreibung des Projekts ausserdem bei Wineburg 2001, S. 64 ff.).

Dabei verfolgte Wineburg folgende Forschungsinteressen: «(a) How do people construct an understanding of historical events from a group of fragmented and contradictory documents? (b) What heuristics or rules of thumb help individuals fill in the gaps left by such documents? (c) What beliefs do people hold about history that help or hinder their ability to make sense of historical evidence?» (Wineburg 1991, S. 74).

Wineburg förderte etliche Zugänge zu den Bildern und Texten zutage, die er im Fall von Bildern als «Description», «Reference», «Analysis» und «Qualification», im Fall von Texten als «Corroboration», «Sourcing» und «Contextualization» kategorisiert, wobei er für Letztere vorschlägt, sie unter dem Dach der «Sense-Making Activities» zu fassen (Wineburg 1991, S. 75 ff., direkte Zitate S. 75, 76, 77, 79, 80). 
und Schülern, Expertinnen und Experten bestehe in den «beliefs about the nature of historical evidence». ${ }^{273}$ So hätten Erstere die vorgelegten Quellen binär beurteilt als glaubwürdig oder nicht glaubwürdig, in der Annahme, dass es «a single < correct answer»» gebe, hätten die gezeigten Texte zudem lediglich als Übermittler von Informationen eingestuft, ohne deren Entstehungskontext in die Betrachtung einzubeziehen, hätten allgemein wenig Bewusstsein darüber, «how historical knowledge is constructed». ${ }^{274}$ Das Vorgehen der beteiligten Historiker und Historikerinnen beschreibt Wineburg demgegenüber als Abwägen, als bewusstes und reflektiertes «exploring the limits of historical knowledge». ${ }^{275}$

In seiner Synthese von Forschungsarbeiten, in der «Historical Thinking» als Terminus auftaucht, ${ }^{276}$ wird deutlich, dass er lediglich die zweite Form, den elaborierten und konstruktionssensiblen Umgang mit Material, als Historical Thinking fasst. Wineburg prägt dort ein stark normatives und professionsbezogenes Verständnis des historischen Denkens, hält es nicht für etwas, «that springs automatically from psychological development». ${ }^{277}$

Merkmale der von den Historikerinnen und Historikern produzierten «sophisticated historical interpretations» ${ }^{278}$ sind für ihn die Einsicht in eine Verschiedenartigkeit von Gegenwart und Vergangenheit und die Gegenwartsbezogenheit eigener Deutungsmuster sowie die unauflösbare Begrenztheit historischer Erkenntnis angesichts dieser Andersartigkeit, ausserdem die Wahrnehmung von «textbooks» nicht als objektive Abbilder von Wirklichkeit, nicht nur als «just reporting the facts», sondern als konstruierte Geschichte unter Berücksichtigung und Sichtbarmachung der Rolle des Autors oder der Autorin. ${ }^{279}$ Historisches Denken beinhaltet Wineburg zufolge weiter das Bilden von Kontexten, das Zusammenfügen von Einzelteilen zu grösseren Zusammenhängen, das er als aktiven und kreativen Prozess beschreibt. ${ }^{280}$

Ein Begriff, der für mein eigenes Forschungsvorhaben zentral ist, derjenige der Orientierung als Ausgangs- und Zielpunkt historischen Denkens, taucht bei Wineburg nicht auf. Wohl aber wendet er sich an mehreren Stellen dem Phänomen

273 Wineburg 1991, S. 84.

274 Wineburg 1991, S. 83 f., direkte Zitate S. 83, S. 84.

275 Wineburg 1991, S. 83.

276 Wineburg 2001.

277 Wineburg 2001, S. 7.

278 Wineburg 2001, S. xii.

279 Wineburg 2001, S. 7 ff., 12 ff., 22 ff., S. 67 ff.; S. 75 ff., direkte Zitate: S. 68.

280 Wineburg 2001, S. 17 ff., v. a. S. 21: «Context, from the Latin contexere, means to weave together, to engage in an active process of connecting things in a pattern» (ebd., S. 21). 
zu. So stellt er in einer Studie fest, dass teilnehmende Historikerinnen und Historiker neben ihren Äusserungen unmittelbar zu den ihnen vorgelegten Materialien und deren Kontext (Kategorien «Text» und «Context») auch auf ihre eigene Person zu sprechen kommen, was Wineburg unter der Kategorie «Self» zusammenfasst. ${ }^{281}$

Darunter subsumiert er «self-referential statements that addressed aspects of the historians' beliefs, personal views, or opinions», ausserdem «metacognitive comments that pointed to aspects of confusion, emerging understanding, or the formulation of plans» sowie «comments addressing affective responses evoked by the texts». ${ }^{282}$ Er stellt also einerseits auf der Ebene seines Datenmaterials fest, dass Teilnehmende ihre eigene Person explizit in den Deutungsprozess einbringen und sogar Rückwirkungen der Beschäftigung mit Historischem auf ihre eigene Person konstatieren. Tiefer gehende Fragen dahingehend, welche Bedeutung die teilnehmenden Personen der behandelten Geschichte für ihre eigene Person und Zeit zumessen, verfolgt Wineburg allerdings nicht.

Zwar formuliert er punktuell immer wieder theoretische und normative Annahmen darüber, welche Funktion Geschichte für die Gegenwart erfüllen könnte. So spricht er von der «basic assumption that history teaches us a way to make choices, to balance opinions, to tell stories, and to become uneasy - when necessary - about the stories we tell», ${ }^{283}$ und geht davon aus, "that history holds the potential, only partly realized, of humanizing us in ways offered by few other areas in the school curriculum». ${ }^{284}$ Er führt diese Überlegungen allerdings nicht weiter aus bzw. integriert sie nicht systematisch in seine Vorstellung von Historical Thinking. Die von ihm vorgeschlagenen Bestandteile von historischem Denken sind stark auf die unmittelbare Arbeit mit dem Material bezogen, explizite Bezüge zur eigenen Person und Gegenwart in den entstehenden Narrationen sind demgegenüber, wie auch in der Modellierung Jannet van Dries und Carla van Boxtels, nicht konzeptionell als begründende Bestandteile historischen Denkens vorgesehen, ebenso wenig wie bei Peter Seixas und Tom Morton. ${ }^{285}$

281 Wineburg 1998, S. 324.

282 Wineburg 1998, S. 324.

283 Wineburg 2001, S. ix.

284 Wineburg 2001, S. 5.

285 Seixas/Morton 2013.

Peter Seixas unterscheidet ähnlich zu den drei bei Wineburg verwendeten Kategorien («text», «context», «self», Wineburg 1998, S. 324) in «historical texts», «historical contexts» und «current issues» und sensibilisiert für die Notwendigkeit, bei der Arbeit mit «sources» das dynamische Zusammenspiel aus diesen drei Dimensionen zu berücksichtigen bzw. zu realisieren, nämlich: «1. Text and context exist in dynamic tension in the const- 
Zusammenfassend geht es bei Wineburgs Begriff historischen Denkens, ähnlich wie in den Überlegungen des FUER-Modells, darum, Geschichte einerseits als gegenwartsgebundene Konstruktion zu erkennen und zu reflektieren, andererseits selbst unter Rückgriff auf vorhandene Materialien und den Einbezug von Kontexten solche Konstruktionen zu erschaffen. Bei Wineburg sind es vor allem Historikerinnen und Historiker, die hierzu in der Lage sind, weshalb bei ihm der Begriff des historischen Denkens eng mit demjenigen der Expertise verknüpft ist. ${ }^{286}$ Die bedeute nicht, dass Schüler und Schülerinnen per se nicht zu historischem Denken in der Lage seien, allerdings sei der aktuelle schulische Geschichtsunterricht aufgrund seiner wissensbasierten, instruktionalen Ausrichtung nicht in der Lage, historisches Denken zu fördern. ${ }^{287}$

Im Gegensatz zu Wineburg nehme ich einen breiteren Adressatenkreis als mögliche Akteure und Akteurinnen historischen Denkens in den Blick, erachte also den Begriff nicht auf professionell geschichtswissenschaftliche ausgebildete Ausstellungsbesuchende beschränkt. In einem weiteren Schritt wird jedoch der Abgleich mit den Befunden Wineburgs relevant, wenn ich frage: Zeigen sich auch in den gewonnenen Daten zum Denken beim Ausstellungsbesuch unterschiedliche Ausprägungsgrade dahingehend, inwieweit Besuchende das Ausgestellte als Konstruktion durchschauen, die Erzählung der Ausstellung und sich selbst als in der eigenen Gegenwart gebunden erkennen und reflektieren?

\section{6 «Theoretische Sensibilität»:288 Zwischenfazit und Bemerkungen zum Verhältnis von Theorie und Empirie in dieser Studie}

Ich habe eine Reihe von Theorien vorgestellt, die den Umgang mit Vergangenheit bzw. Geschichte thematisieren und dabei insbesondere die Funktionen und Dimensionen einer solchen Auseinandersetzung für Gegenwart und denkendes Individuum in den Blick nehmen. Welchen Zweck erfüllen diese Theorien für mein Forschungsvorhaben? Ich schliesse den ersten Teil der theoretischen Betrachtun-

ruction of historical knowledge. 2. We never have access to the historical context in direct or unmediated form: the construction of context is shaped not only through work with historical sources (texts), but also through present concerns and issues. [...]» (Seixas 1998, S. 310, S. 314, direkte Zitate: S. 314).

287 Wineburg 2001, S. 83.

288 Strauss/Corbin 1996, S. 25, S. 30. 
gen mit einigen Überlegungen darüber ab, in welchem Verhältnis sich Theorie und Empirie in meinem Forschungsprojekt zueinander verhalten, komme dabei auf die Idee der theoretischen Sensibilität zu sprechen und fasse schliesslich zusammen, welche Aspekte diese Sensibilität bislang in Bezug auf mein eigenes Forschungsvorhaben ausmachen.

Meine Studie verortet sich innerhalb des qualitativen Paradigmas. Qualitativer Analyse gehe es, so Jan Kruse, generell um «die umfassende und detaillierte, deskriptive Analyse stets sinnhafter sozialer Wirklichkeit». ${ }^{289}$ Im Gegensatz zu quantitativen Prozessen bestehe

«die Logik und das Ziel im qualitativen Sozialforschungsprozess nicht darin, mit fertigen Konzepten in den Datenerhebungsprozess einzusteigen - sondern darin, so weit wie möglich die originären Konzepte der Untersuchungsgegenstände herauszuarbeiten, zu rekonstruieren. Mit anderen Worten: der standardisierte Sozialforschungsprozess ist ein linearer Forschungsprozess, in dem Konzepte eingespeist werden, um zu Verteilungsaussagen und Korrelationen zu gelangen. Der qualitative Sozialforschungsprozess ist dagegen ein dynamisch-offener, iterativ-zyklischer Forschungsprozess [...], in dem so wenig wie möglich an Setzungen eingespeist werden soll, um so zu empirisch rekonstruierten, gegenstandsbegründeten Konzepten zu gelangen.» ${ }^{290}$

Ein qualitatives, offenes und der Eigenlogik des Datenmaterials Rechnung tragendes Vorgehen erscheint für meine Studie angezeigt, weil in der empirischen Forschung bislang sehr wenig über Elemente, Strukturen und Prozesse des Denkens und Aneignens bei Ausstellungsbesuchenden im Verlauf des Besuchs bekannt ist und sich darum eine explorative Auslegeordnung empfiehlt. Das genannte Forschungsdesiderat muss ich an dieser Stelle freilich zunächst behaupten, kann es aber erst weiter unten mit einer Übersicht über bereits existierende Forschungsarbeiten und deren Methoden differenzierter darlegen. ${ }^{291}$

Welche Funktion erfüllen unter diesen Umständen theoretische Vorüberlegungen, in welchem Verhältnis stehen in meiner Studie Theorie und Empirie? Hier kommt die Idee der theoretischen Sensibilität ins Spiel, die auf Ansätze der Groun-

289 Kruse 2014, S. 25

290 Kruse 2014, S. 46.

291 Vgl. Kapitel 5. 
ded Theory zurückgeht. ${ }^{292}$ Ich gehe nachfolgend auf die Idee der theoretischen Sensibilität näher ein, ohne mich jedoch abgesehen davon grundsätzlich im Paradigma der Grounded Theory zu verorten.

Da es hinsichtlich der theoretischen Sensibilität unter den Exponentinnen und Exponenten der Grounded Theory uneinheitliche Ansätze gibt und obendrein die Rezeption der Grounded Theory vielfältig und bisweilen widersprüchlich erfolgt, erscheint mir zunächst eine differenzierte Begriffsbestimmung notwendig. Eine Grundkontroverse betrifft die Frage, inwieweit theoretische Vorannahmen im qualitativen Forschungsprozess ausgeblendet werden sollen und können. In ihrem im Jahr 1967 erschienen Buch «The Discovery of Grounded Theory: Strategies for Qualitative Research» ${ }^{293}$, formulieren Barney G. Glaser und Anselm L. Strauss hierzu stellenweise eine relativ rigide Haltung:

«Eine materiale, der empirischen Situation treue Theorie kann unserer Ansicht nach nicht durch die blosse Anwendung einiger einer etablierten formalen Theorie entnommener Ideen auf den fraglichen Sachbereich formuliert werden. [...] Aber man kann (und wir meinen: sollte) den fraglichen Bereich auch ohne irgendeine vorgefasste Theorie untersuchen, die der eigentlichen Forschung vorweg die <relevanten〉 Konzepte und Hypothesen bestimmt.» ${ }^{294}$

Und: «Es ist eine wirksame und sinnvolle Strategie, die Literatur über Theorie und Tatbestände des untersuchten Feldes zunächst buchstäblich zu ignorieren, um sicherzustellen, dass das Hervortreten von Kategorien nicht durch eher anderen Fragen angemessene Konzepte kontaminiert wird. Ähnlichkeiten und Konvergenzen mit der Literatur können später, nachdem der analytische Kern von Kategorien aufgetaucht ist, immer noch festgestellt werden.» ${ }^{295}$

Glaser und Strauss vertreten in diesen Auszügen eine «radikal induktivistische Konzeption», ${ }^{296}$ nach der die auf das eigene Feld bezogene Literatur zu Beginn eines Forschungsprozesses auszublenden sei, um nicht die Entstehung von dem Gegenstand angemessenen Theorien zu gefährden. In der Rezeption der Groun-

292 Glaser/Strauss 2010; Strauss/Corbin 1996, z. B. S. 25, S. 30.

293 Mir in der späteren deutschen Übersetzung vorliegend: Glaser/Strauss 2010.

294 Glaser/Strauss 2010, S. 51.

295 Glaser/Strauss 2010, S. 55.

296 Kelle 1994, S. 341. 
ded Theory wird diese Vorstellung vielfach kritisiert als irreführende Vorstellung, dass sich Forschende voraussetzungslos einem Forschungsgegenstand nähern und dass dabei Kategorien aus dem Material emergieren könnten. ${ }^{297}$ Jedoch wird bisweilen auch hervorgehoben, dass es sich hierbei um eine einseitige Fehlinterpretation des Zugangs von Glaser und Strauss handle - tatsächlich distanzieren diese sich selbst bereits zu Beginn ihres Werks von der Idee einer tabula rasa ${ }^{298}$ und argumentieren insofern inkohärent - und dass sie sich der Uneinlösbarkeit einer theoretisch voraussetzungslosen Datenanalyse durchaus bewusst gewesen bzw. diesem Prinzip nicht einmal in ihrer eigenen Forschung gefolgt seien. ${ }^{299}$ Unter Verwendung eines Ausdrucks von Kelle ist deshalb gelegentlich von einem induktivistischen Selbstmissverständnis der Grounded Theory die Rede. ${ }^{300}$

Zur Erhellung des Verhältnisses von Theorie und Empirie und in Abgrenzung zur (zugeschriebenen) Idee einer tabula rasa wird in der Literatur bisweilen die Idee einer notwendigen und auch unausweichlichen theoretischen Sensibilität der Forschenden ins Feld geführt. Dieser Begriff wird bereits bei Glaser und Strauss eingeführt, dort aber teilweise anders aufgeladen gebraucht als in der Rezeption der Grounded Theory, was eine Begriffsdefinition erschwert. In den Texten von Glaser und Strauss bezieht sich die Idee der theoretischen Sensibilität eher auf den Aspekt des Theoriegenerierens: Dort meint Sensibilität eine Sensibilität für das Auffinden von gegenstandsangemessenen Kategorien:

«Der Soziologe sollte des Weiteren hinlänglich theoretisch sensibel sein, sodass er eine aus den Daten hervorgehende Theorie konzeptualisieren und formulieren kann. [...] Widmet der Soziologe sich ausschliesslich einer vorab erschlossenen Theorie (z. B. über formale Organisation), schränkt er seine theoretische Sensibilität zwangsläufig ein. Er wird dann zum Doktrinär und vermag weder zu der von ihm favorisierten noch zu sonst einer Theorie auf Distanz zu gehen. Er verliert die Sensibilität für Fragen, die seine Theorie in Zweifel stellen, oder er wird defensiv; er ist davon besessen, zu testen und zu modifizieren und alles aus seinem einmal festgelegten Blickwinkel zu betrachten.»301

297 Etwa bei Kelle 1994, S. 305.

298 Glaser/Strauss 2010, S. 21.

299 Kelle 1994, S. 305 f., 341 f.; Kruse 2014, S. 97 ff.; Strübing 2014, S. 52.

300 Kelle 1994, S. 341; Kelle/Kluge 2010, S. 18 ff.; Kruse 2014, S. 94 ff.; Strübing 2014, S. 52.

301 Glaser/Strauss 2010, S. 62. 
Anselm Strauss und Juliet Corbin greifen diese Idee in ihrer Weiterentwicklung des Ansatzes der Grounded Theory auf:

«Theoretische Sensibilität bezieht sich auf eine persönliche Fähigkeit des Forschers. Gemeint ist ein Bewusstsein für die Feinheiten in der Bedeutung von Daten. [...] Theoretische Sensibilität bezieht sich auf die Fähigkeit, Einsichten zu haben, den Daten Bedeutung zu verleihen, die Fähigkeit zu verstehen und das Wichtige vom Unwichtigen zu trennen.» ${ }^{302}$

Allerdings fügen Strauss und Corbin dieser kreativ verstandenen, theoriegenerierenden Seite des Terminus eine weitere Dimension hinzu, nämlich die Frage nach der Herkunft einer solchen Sensibilität ${ }^{303}$ :

«Theoretische Sensibilität hat zwei Quellen. Einerseits kommt sie daher, daß man sich in der Fachliteratur gut auskennt, und auch aus professioneller und persönlicher Erfahrung. Forscher bringen dieses komplexe Wissen mit in die Forschungssituation ein. Andererseits wird theoretische Sensibilität auch während des Forschungsprozesses durch die kontinuierliche Auseinandersetzung mit den Daten erworben - Erheben und Analysieren.» ${ }^{304}$

Deutlich stärker als Glaser und Strauss akzentuieren Strauss und Corbin, dass theoretische Vorannahmen im Forschungsprozess notwendig wie auch unausweichlich sind, und reflektieren die Ursprünge einer theoretischen Sensibilität. Wenn in der Rezeption der Grounded Theory auf das Konzept der theoretischen Sensibilität rekurriert wird, wird meines Erachtens namentlich diese zweite Dimension betont. So formulieren etwa Udo Kelle und Susanne Kluge:

«Auch wenn die Entwicklung von Kategorien und Konzepten nicht vor der Datenerhebung erfolgt, sondern auf der Basis des erhobenen Materials, benötigt der Forscher oder die Forscherin Vorwissen. Weder empirische Verallgemeinerungen noch theoretische Aussagen <emergieren〉 einfach aus dem Datenmaterial. ForscherInnen sehen die Realität ihres empirischen Feldes

302 Strauss/Corbin 1996, S. 25.

303 Bei Glaser/Strauss wird diese Dimension kaum thematisiert, wie Kelle feststellt (Kelle 1994, S. 305 f.).

304 Strauss/Corbin 1996, S. 30. 
stets durch die «Linsen> bereits vorhandener Konzepte und theoretischer Kategorien, sie benötigen eine bestimmte Perspektive, um ‘relevante Daten〉 zu «sehen`. Die Verfügbarkeit und flexible Verwendung dieser theoretischen Perspektive führt zu der von Glaser und Strauss $(1967 / 1998)^{305}$ beschriebenen 〈theoretischen Sensibilität〉, der Fähigkeit, über empirisch gegebenes Material in theoretischen Begriffen zu reflektieren». ${ }^{306}$

Nach diesem Verständnis steht theoretische Sensibilität in einem inhärenten Widerspruch zur Idee einer tabula rasa, eine Ambivalenz, die den Kern der an der Grounded Theory geäusserten Kritik ausmacht. Stellt man allerdings wie Glaser/ Strauss selbst und wie oben gezeigt gar nicht explizit die Frage nach der Herkunft einer solchen theoretischen Sensibilität, ist der Widerspruch weniger offenkundig.

Kelle und Kluge greifen zur Entfaltung der Idee eines Ineinandergreifens von theoretischem Vorwissen und empirischen Daten auf ein weiteres Konzept zurück, nämlich die von Herbert Blumer geprägte Idee der «sensitizing concepts». ${ }^{307} \mathrm{Blu}$ mer gebraucht diesen Begriff Kelle und Kluge zufolge, um «an einem zentralen Theorieproblem der Sozialwissenschaften [...], der Vagheit vieler ihrer theoretischen Konzepte», anzusetzen. ${ }^{308}$ So gebe es Konzepte, die «nur in der empirischen sozialen Welt selber präzisiert werden» könnten, ${ }^{309}$ wobei in der Vagheit dieser Konzepte eine Chance gesehen kann, oder wie Blumer selbst schreibt: «Whereas definitive concepts provide prescriptions of what to see, sensitizing concepts merely suggest directions along which to look.» ${ }^{310}$

Die in den vorangegangenen Abschnitten geschilderten Überlegungen greife ich für meine Arbeit auf. Auch in meinem Fall erfüllen die beschriebenen Theorien die Funktion von sensibilisierenden Konzepten, sie fungieren als «Linsen», 311 die - und selbiges gilt im Übrigen nicht nur für vorher bekannte Theorien, sondern auch im Hinblick auf den vorab und parallel zum Forschungsprozess rezipierten Forschungsstand zum Thema - die Aufmerksamkeit beim Blick auf das Material lenken, aber nicht determinieren sollen. So wurden Fragestellung und Perspektive meiner Arbeit wesentlich in Auseinandersetzung mit der theoretischen Literatur

305 Mir in anderer Ausgabe als bei Kelle/Kluge, nämlich als Glaser/Strauss 2010 vorliegend.

306 Kelle/Kluge 2010, S. 28.

307 Blumer 1954, S. 7; Kelle/Kluge 2010, S. 28 ff.

308 Kelle/Kluge 2010, S. 28; Kursivsetzung analog zum Original.

309 Kelle/Kluge 2010, S. 30.

310 Blumer 1954, S. 7; Rezeption Blumers nach Kelle/Kluge 2010, S. $28 \mathrm{ff}$.

311 Kelle/Kluge 2010, S. 28. 
entwickelt, gleichzeitig greife ich bei der Strukturierung der Analysekategorien nur teilweise auf aus vorliegenden Theorien bekannte Zugänge zurück. Dies soll dem Zweck dienen, bei der Analyse Offenheit für eventuell über die Theorien hinausgehende Denkstrukturen und -gegenstände zu gewährleisten.

Mit den Worten Andreas Körbers gesprochen, bestand das Vorhaben darin, die Äusserungen der Teilnehmenden nicht «in den Kategorien vorgängig erarbeiteter theoretischer Konzepte zu fassen, sondern die Kategorien der «Wirklichkeit〉 folgen zu lassen», um dabei «Sinnkonstruktionen und Bedeutungszuweisungen aus dem Feld genauer [...] erfassen» zu können. ${ }^{312}$ Erst in einem abschliessenden Schritt werden die entstandenen Kategorien deduktiv auf ihre Passung mit bereits existierenden Modellen hin befragt, ${ }^{313}$ mit dem Ziel, Übereinstimmungen und Abweichungen zu diagnostizieren und unter Umständen Impulse für eine Anpassung oder Erweiterung der vorhandenen Modelle geben zu können, ohne mit meiner Arbeit selbst bereits auf dieser Ebene theoriebildenden Anspruch zu verfolgen.

Das für die Analyse gewählte mehrheitlich induktive Vorgehen und die damit verbundene Lösung von theoretischen Vorannahmen über historisches Denken machte zugleich eine Lösung von Vorstellungen darüber notwendig, was überhaupt als Bestandteile historischen Denkens gelten könne und wann der Prozess historischen Denkens als «vollständig» zu betrachten sei. Wie durch Körber angeregt, soll für die Datenanalyse «der theoretische Begriff des vollständigen, authentischen historischen Denkens als der lebensweltlich funktionalen Orientierung zu Gunsten eines offeneren Begriffes zurückgestellt [werden] [...], welcher auch Teil- und Protoformen etc. umfasst». ${ }^{314}$

Wie schwierig ein solches Ansinnen in einem auf theoretischer und normativer Ebene derart dicht besetzten Feld sein kann, zeigt allerdings die Studie Körbers selbst, in der er sich letztlich offenbar doch auf ein deduktives Vorgehen fokussiert bzw. ausschliesslich in aus der Theorie bekannten Kategorien über seine Befunde spricht. ${ }^{315} \mathrm{Im}$ Unterschied dazu gilt für meine Studie das Ansinnen, theoretische Vorannahmen möglichst nur im Stil von interesseleitenden Linsen und als Hintergrundfolie einzusetzen und, wann immer sie die Kategorienbildung bei der Datenanalyse prägen, dies zu reflektieren.

312 Körber 2006, S. 190.

313 So, wie erwähnt, auch bei Glaser/Strauss angedacht: Glaser/Strauss 2010, S. 55.

314 Körber 2006, S. 193.

315 Körber 2006, S. $206 \mathrm{ff}$. 
Doch worin bestehen in meiner Arbeit die sensibilisierenden Konzepte, die aus der Auseinandersetzung mit den beschriebenen Theorien gewonnen wurden? Auf den vorangegangenen Seiten habe ich eine Reihe von Theorien vorgestellt, die den denkenden Umgang mit Vergangenheit bzw. Geschichte betreffen und dabei auch die Funktionen einer solchen Auseinandersetzung für die Gegenwart und das denkende Individuum in den Blick nehmen. Ich fasse zentrale Aspekte aus diesem Bereich, die für die weiteren Überlegungen und meine eigene Untersuchung prägend sind, in Form eines Zwischenfazits zusammen, bevor ich anschliessend zum zweiten Bereich von theoretischen Grundlegungen übergehe, den Überlegungen zu historischen Museen und Ausstellungen als Manifestationen und zu deren Besuchenden.

Die zentrale, aus der bisher beschriebenen Literatur extrahierte und für mein Projekt relevante Idee lautet, dass Auseinandersetzung mit Vergangenheit und Geschichte stets mit der Gegenwart bzw. den in der Gegenwart stehenden Individuen, deren Interessen und Lebenswelten zu tun hat, wobei diese entweder implizit für eine Beschäftigung mit Historischem leitend sein oder Bezüge explizit gesucht, hergestellt und angeregt werden können. Diese Idee übertrage ich auf die Situation des Ausstellungsbesuchs, wenn ich weiter unten danach frage, wie beim Besuch einer historischen Ausstellung diese gegenwarts- und lebensweltbezogene Bedeutung einer Auseinandersetzung mit Historischem sichtbar wird, wie sie sich in den Äusserungen der Besuchenden manifestiert.

Hinsichtlich der Akteurinnen und Akteure, die in den Blick genommen werden, erweist sich die vorliegende Literatur als unterschiedlich konkret. So wird bisweilen von Bedürfnissen und Interessen einer eher abstrakten, unpersonalen Gegenwart, von Grössen wie Geschichtskultur und Lebenswelt gesprochen, andernorts eher das einzelne, denkende Individuum und dessen historisches Denken in den Blick genommen. In meiner Studie nehme ich, indem ich mich mit den Äusserungen von einzelnen Museumsbesuchenden beschäftige, den zweitgenannten Blickwinkel ein.

Auf Ebene der Akteurinnen und Akteure und beim individuellen historischen Denken anzusetzen, bedeutet jedoch nicht, dass dafür die Gegenwart als abstrakte Grösse losgelöst vom Individuum vollständig irrelevant würde. Sie ist zwar nicht Gegenstand der Untersuchung, ist aber insofern relevant, als die Besuchenden über sie sprechen können, also die von der eigenen Person losgelöste Gegenwart zum Gegenstand ihrer Äusserungen machen.

Folgt man Rüsen, so können sich beide Dimensionen im historischen Denken und Sinnbilden einer einzigen Person widerspiegeln und hat Orientierung zwei- 
erlei Ebenen: Orientierung in Bezug auf die Person des denkenden Individuums und Orientierung in Bezug auf die das Individuum umgebende Welt. ${ }^{316}$ Auf Ebene der didaktischen Prinzipien finden sich die beiden Dimensionen verwirklicht als Lebensweltbezug einerseits und Gegenwartsbezug andererseits, wobei beide, wie ich gezeigt habe, vielfach integriert betrachtet werden. Wie dargestellt, gehe ich jedoch davon aus, dass Gegenwarts- nicht zwingend auch Lebensweltbezüge beinhalten, und betrachte beide Bereiche als separate, die Analyse sensibilisierende heuristische Kategorien.

Geht man vom Kompetenz-Strukturmodell historischen Denkens aus, so wären Bezüge zur eigenen Person darin namentlich im Bereich der Frage- und Orientierungskompetenzen aufgehoben. Bezüge zur Gegenwart könnten sich hingegen auch im Bereich der Methodenkompetenzen manifestieren oder - in der Terminologie Rüsens - im Moment der historischen Deutung, ${ }^{317}$ sofern eine Deutung zeitebenenübergreifend neben der Vergangenheit auch die Gegenwart umfasst. Ich berücksichtige beide Ebenen, wenn ich nachfolgend davon spreche, beim Ausstellungsbesuch hergestellte Bezüge zur eigenen Person und Gegenwart erforschen zu wollen, behandle sie jedoch als zwei voneinander zumindest theoretisch getrennte Ebenen.

Dabei fokussiere ich auf Äusserungen der Besuchenden, in denen solche Bezüge explizit hergestellt werden, während die unhintergehbare implizite Gegenwartsbezogenheit allen historischen Denkens zwar die theoretische Hintergrundfolie bildet, aber nicht eigentlich den Gegenstand der Analyse darstellt. Mit diesem Blickwinkel nehme ich eine Zuspitzung der Überlegungen des Kompetenz-Strukturmodells vor.

Bei Waltraud Schreiber für den Bereich der Frage- und Orientierungskompetenz angedacht sind nämlich auch implizite Formen von Bezügen, in denen Fragen und Orientierung auf eine «Fokussierung auf Vergangenes» abzielen und sich darin lediglich implizit die «Gegenwartsgebundenheit» des Individuums manifestiert bzw. - im Fall von historischen Fragen - «[e]ine spätere Aufladung mit persönlicher oder kollektiver Bedeutung» erfolgen kann. ${ }^{318}$ Mit dieser Ablösung des Orientierungsbegriffs von expliziten Bezügen zur eigenen Person und Zeit ist allerdings meines Erachtens zugleich seine Verwässerung verbunden, wird doch dann das Plus einer Orientierung im Vergleich zum Bereich der Methodenkom-

318 Schreiber 2007a, S. 161; Schreiber 2007c, S. 240. 
petenzen bzw. - in der Rüsen'schen Terminologie - der historischen Deutung nicht mehr unmittelbar deutlich, weshalb ich es vorziehe, von einem auf expliziten Bezugnahmen basierenden Orientierungsbegriff auszugehen.

$\mathrm{Zu}$ den sensibilisierenden Ideen meiner Studie gehört auf Basis des bisherigen Literaturüberblicks ferner die Idee, dass im denkenden Umgang mit Vergangenheit bzw. Geschichte unterschiedliche Modi denkbar sind, nämlich ein re-konstruktiver, Geschichte generierender Modus und ein de-konstruktiver Modus, in dem vorhandene Geschichten analysiert werden. Damit verbunden ist die Möglichkeit, dass unterschiedlich ausgeprägte Vorstellungen über die (Nicht-)Identität von Vergangenheit und Geschichte bzw. über die Eigenschaften von Geschichte als Konstruktion vorhanden sind. Dieser Aspekt ist insbesondere deshalb für meinen Gegenstand bedeutsam, weil es sich bei historischen Ausstellungen, wie ich nun zeigen werde, um Erzählungen handelt und Besuchende bei ihrem Besuch einerseits mit «fertigen» Narrationen, andererseits aber auch mit den darin enthaltenen Quellen und sonstigen Elementen in Kontakt kommen, was sowohl rekonstruktive als auch de-konstruktive Tätigkeiten ermöglicht, ohne dass ich diese Konzepte jedoch von Beginn an als die Datenanalyse strukturierende Konzepte einsetze. 



\section{Theoretische Grundlegungen (II): Historische Museen und Ausstellungen und deren Besuchende}

\subsection{Historische Ausstellung und historisches Museum: Dimensionen, Konstruktionsbedingungen und Funktionen geschichtskultureller Manifestationen}

In diesem Kapitel lege ich dar, welche Vorstellungen in Bezug auf Museen und Ausstellungen, spezifischer auf historische Museen und Ausstellungen, für meine Arbeit leitend sind. Über Merkmale, Konstruktionsbedingungen und Funktionen von historischen Museen und Ausstellungen zu reflektieren, ist notwendige Voraussetzung dafür, um in einem späteren Schritt über Formen der Aneignung im Kontakt mit diesen Manifestationen nachzudenken und sie zu erforschen. Nachfolgend verwende ich die Begriffe «Museum» und «Ausstellung» nicht synonym, obwohl dies im alltäglichen Sprachgebrauch bisweilen üblich ist. Nach einer Kategorisierung Bernd Schönemanns, der als vier Dimensionen von Geschichtskultur «Institutionen», «Professionen», «Medien» und «Publika» unterscheidet, ${ }^{319}$ lässt sich das «Museum als Institution der Geschichtskultur» ${ }^{320}$ begreifen, die historische Ausstellung hingegen als Medium der Geschichtskultur, ${ }^{321}$ auch wenn ich selbst den Begriff «Medium» aufgrund seiner vielfältigen Konnotationen und teilweise widersprüchlichen Verwendungsweisen vermeide. ${ }^{322}$

319 Schönemann 2014, S. 18 f.; Schönemann 2000, S. 46 f.

320 So der Aufsatztitel von Schönemann 2006; entsprechende Zuordnung ausserdem bei Schönemann 2014, S. 18.

321 In dieser Weise zugeordnet bei Schönemann 2014, S. 19.

322 Einerseits lassen sich Medien, so bei Baumgartner, als Bestandteile in Kommunikationsprozessen einordnen (Baumgartner 2015, S. 113f.). Dies kommt wohl auch der Rolle nahe, welche Medien im Schönemann'schen Begriffsnetz zugedacht wird. Mit dieser Verwendungsweise wird dem Medium, so meine ich, zugleich eine Fuktionalität und Intentionalität, die Absicht einer Botschaftsübermittlung, zugeschrieben.

Diese Konnotation ginge dann allerdings nur bedingt überein mit einer in geschichtsdidaktischen Einführungsbüchern geläufigen Verwendungsweise des Begriffs «Medium», wo Medium «alles enthält, was pri märe [sic] oder sekundäre Aussagen über Geschichtebeinhaltet [sic]» (Pandel/Schneider 2017a, S. 7; sich dem anschliessend: Baumgartner 2015, S. $114 \mathrm{ff}$.) und dort auch, aber nicht nur, Quellen beinhaltet (explizit so weit definiert bei 
Von historischem Museum spreche ich nachfolgend ausschliesslich dann, wenn ich mich auf die Institution beziehe, und favorisiere abgesehen davon den präziseren Begriff der historischen Ausstellung. Und dennoch gibt es Überschneidungen zwischen beiden Manifestationen, erfüllt doch die Institution Museum unter anderem die Funktion des Ausstellens und beinhaltet Ausstellungen. Auf den folgenden Seiten werde ich Gemeinsamkeiten und Unterschiede zwischen beiden Manifestationen ausloten und darlegen, in welchen Zusammenhängen sich welche Begriffe anbieten. Ich gehe in meiner Darstellung vom Allgemeinen zum Besonderen vor und wende mich zunächst Museum und Ausstellung als Typen generell und dann spezifischer dem historischen Museum und der historischen Ausstellung zu. Innerhalb dessen beginne ich meine Annäherung jeweils bei der Institution Museum und leite dann über zur Ausstellung.

Gemäss Definition des International Council of Museums (ICOM) gehören folgende Tätigkeiten in das Aufgabenspektrum von Museen:

- «Museums preserve, interpret and promote the natural and cultural inheritance of humanity.» ${ }^{323}$

- «Museums that maintain collections hold them in trust for the benefit of society and its development.» ${ }^{324}$

- «Museums hold primary evidence for establishing and furthering knowledge.» ${ }^{325}$

Pandel/Schneider 2017a, S. 7; in den Inhaltsverzeichnissen so ersichtlich bei: Baumgartner 2015, S. 6; Barricelli/Lücke 2017, S. 7; Pandel/Schneider 2017b, S. 5 f.).

Gerade im Hinblick auf Quellen erscheint mir der Medienbegriff aufgrund seiner oben angesprochenen funktionalen und intentionalen Konnotation problematisch, können Quellen doch auch nicht intentional überliefert sein (vgl. Abschnitt 3.1; Grütter 1997c, S. 708). Zudem findet insbesondere im Fall von Quellen keine unmittelbare Kommunikation zwischen Sender/in und Empfänger/in statt, können ursprüngliche mit der Erstellung verbundene Intentionen, spätere Verwendungsweisen und bearbeitete Fragestellungen voneinander abweichen, erschwert also historische Differenz eine klare Einordnung in einfache Sender-Medien-Empfänger-Systeme wie dasjenige bei Baumgartner (Baumgartner 2015, S. 114), auch wenn die grafische Darstellung bei Baumgartner mit dem sogar enthaltenen Hinweis auf «historische[n] Wandel» (ebd.) suggeriert, dass eine Einordnung möglich ist. In der Anwendung auf historische Ausstellungen erscheint der Medienbegriff zwar stimmiger, können Ausstellungen doch plausibler als «Medium der Kommunikation» (Michler 2004, S. 600) innerhalb eines geschichtskulturellen Systems verstanden werden. Dennoch vermeide ich den Medienbegriff aufgrund seiner komplexen Konnotationen. 
- «Museums provide opportunities for the appreciation, understanding and management of the natural and cultural heritage.»326

- «Museums hold resources that provide opportunities for other public services and benefits.»327

- «Museums work in close collaboration with the communities from which their collections originate as well as those they serve.» ${ }^{328}$

- «Museums operate in a legal manner.» ${ }^{329}$

- «Museums operate in a professional manner.» ${ }^{330}$

In der deutschsprachigen Museumsliteratur ist in Anlehnung daran die Unterscheidung der Aufgabenfelder Sammeln, Bewahren, Forschen, Dokumentieren, Ausstellen und Vermitteln überaus gebräuchlich. ${ }^{331}$ Aber was ist es, was von $\mathrm{Mu}$ seen gesammelt, bewahrt, erforscht, dokumentiert, ausgestellt und vermittelt werden soll? Der ICOM spricht von «natural and cultural inheritance of humanity». ${ }^{332}$ Im physischen Sinn sind es Objekte, die den Gegenstandsbereich von Museen bilden, die gesammelt und zugänglich gemacht werden. ${ }^{333}$ Und weiter noch:

«Das Museum lebt aus der Dialektik von Sammeln und Zeigen. Sammeln ist Speicherung und Vorratshaltung, Zeigen zielt auf die soziale Vergegenwärtigung von Zukunft. Was im Museum gesammelt wird, sind dinghafte Zeitzeugen, die uns über die Vergangenheit in Kenntnis setzen. Das Museum sammelt Relikte, Dinge der Vergangenheit, um sie zu Dingen für uns, zu Informationsträgern zu machen». ${ }^{334}$

326 ICOM 2017, S. 23

327 ICOM 2017, S. 27.

328 ICOM 2017, S. 31 .

329 ICOM 2017, S. 35.

330 ICOM 2017, S. 39.

331 So in Anlehnung an den International Council of Museums übernommen bei: Deutscher Museumsbund e. V. gemeinsam mit ICOM-Deutschland 2006, S. 5, S. 15 ff.; ausserdem in Gebrauch bei: Grütter 1997c, S. 707 ff.; Hein 2006, S. 342; Noschka-Roos/Lewalter 2013, S. 201; Heese 2014, S. 13.

Doris Lewalter und Annette Noschka-Roos sprechen an anderer Stelle sogar von einer «klassischen Quadriga», wobei sie die Kategorie «Bildung»statt des Ausstellens und Vermittelns verwenden (Lewalter/Noschka-Roos 2009, S. 527).

332 ICOM 2017, S. 1.

333 Korff 2002. Ausserdem: Noschka-Roos/Lewalter 2013, S. 201, und spezifisch für historische Museen: Grütter 1997b, S. 668; Grütter 1997c, S. 707.

334 Korff 2002, S. 141. 
Für meine Studie ist weniger die Funktion des Sammelns von Interesse, auch nicht diejenige des Bewahrens, Forschens und Dokumentierens. Im Zentrum der Aufmerksamkeit steht hingegen derjenige Tätigkeitsbereich, der sich auf das Zugänglichmachen für Besuchende, für die Öffentlichkeit und auf das Vermitteln bezieht. Museen besitzen zu diesem Zweck als wesentlichen Bestandteil Ausstellungsräumlichkeiten, in denen Teile der Sammlung präsentiert werden. ${ }^{335}$

Während jedes Museum eine Ausstellungsfläche benötigt, um seiner Aufgabe des Präsentierens und Vermittelns nachzukommen, gilt dies im umgekehrten Fall nicht zwangsläufig. So kann es durchaus Ausstellungen unabhängig von der Institution Museum geben, sei es in einem räumlichen Sinn, etwa weil es sich um Wanderausstellungen handelt, die losgelöst von einem Museumsstandort zirkulieren, oder sei es auch in einem organisatorischen Sinn. So gibt es Ausstellungen, die nicht von einem Museum als Träger konzipiert werden, sondern von Privatpersonen oder einem Verein. Dies gilt überwiegend auch für die in dieser Studie beforschte Wanderausstellung «14/18. Die Schweiz und der Grosse Krieg», die vom Verein «Die Schweiz im Ersten Weltkrieg» entwickelt wurde. ${ }^{336}$ Gezeigt wurde die Ausstellung jedoch in den Räumlichkeiten mehrerer historischer Museen in der Schweiz, und es wurden, ergänzend zur Kernausstellung, regionalspezifische Zusatzabteilungen von den jeweiligen Museen konzipiert.

Wenn ich also im Verlauf dieser Arbeit in Bezug auf den gewählten physischen Ort alternierend sowohl von Ausstellung als bisweilen auch von Museum spreche, so dient dies der sprachlichen Abwechslung und ist - im Fall der von mir untersuchten Ausstellung «14/18»- konzeptuell unproblematisch insofern, als von einer Ausstellung in einem Museum die Rede ist. In beiden Fällen sind in Anlehnung an den alltäglichen Sprachgebrauch im engeren Sinn die Ausstellungsräumlichkeiten und nicht die Institution Museum in ihrer Gesamtheit gemeint, da die Funktionen des Sammelns, Bewahrens, Erforschens und Dokumentierens für mein Forschungsvorhaben in den Hintergrund treten.

335 Mit Byung Jun Yi könnte man vielleicht sogar die Ausstellung selbst als pädagogischen Akteur begreifen: «Generell ist die Einrichtung der Ausstellung nicht die Sache der Pädagogen. Aber das Ausstellen selbst hat den Charakter einer pädagogischen Intentionalität. Die Ausstellung selbst ist das mediale pädagogische Handeln für die Vermittlung und Kommunikation durch die Dinge» (Yi 2013, S. 224). Doris Lewalter und Annette Noschka-Roos schreiben diese Funktion eher einzelnen Elementen innerhalb der Ausstellung zu. So rückt Lewalter mit Bezug auf das didaktische Dreieck «Ausstellungselemente und Objekte $[\ldots]$ an die Stelle des Lehrers» (Lewalter 2009, S. 46), Noschka-Roos bezeichnet Texte als «Vermittlungsträger[.]» (Noschka-Roos 1994, S. 150).

336 Vgl. hierzu die nähere Vorstellung der Ausstellung in Kapitel 7. 
Ich habe gezeigt, dass der Begriff «Ausstellung» beispielsweise eine Dauerausstellung innerhalb einer Institution Museum bezeichnen kann, eine Wanderoder Sonderausstellung, die in einem Museum gezeigt wird und vielleicht sogar von diesem konzipiert wurde, aber auch eine von einem Museum als Ort und Institution unabhängig gezeigte Ausstellung. In Bezug auf ihre Funktionen können sich diese Ausstellungstypen erheblich voneinander unterscheiden. So führt Hans-Ulrich Thamer aus:

«[D]as Museum ist die verfestigte und auf eine dauerhafte und möglichst umfassende Präsentation zielende Einrichtung, die Ausstellung arbeitet stärker exemplarisch, ausschnitthaft und ist sehr viel stärker auf Vergänglichkeit, aber auch auf die Möglichkeiten des Experiments angelegt - beide operieren mit originalen Objekten, die sie in einem bestimmten Raum und teilweise unter Verwendung anderer Medien und Inszenierungsformen präsentieren». ${ }^{337}$

Im Zitat wird deutlich, dass Thamer den Begriff «Museum» synonym mit der Dauerausstellung in einem Museum verwendet und den Begriff Ausstellung nur für vergänglichere Formen des Präsentierens anwendet, gemeint wohl Sonderausstellungen. Obwohl ich mich dieser Variante der Begriffsunterscheidung nicht anschliesse, lässt sich doch Thamers Ausführungen der weiterführende Hinweis entnehmen, dass Unterschiede in der Langlebigkeit von Ausstellungen auftreten können, je nachdem, ob es sich um Dauerausstellungen einer Institution Museum oder um Sonderausstellungen handelt.

Gleichzeitig lässt sich Thamers Ausführungen jedoch auch entnehmen, dass verschiedene Ausstellungstypen trotz ihrer unterschiedlichen Funktionen gleichen grundlegenden Konstruktionsbedingungen unterworfen sind. Indem ich mich nun nachfolgend diesen Konstruktionsbedingungen zuwende, verlasse ich zugleich die Ebene der Betrachtung von Museen und Ausstellungen als allgemeine Typen und fokussiere fortan auf historische Museen und historische Ausstellungen als fachspezifische Ausprägungen.

337 Thamer 2006, S. $34 \mathrm{f}$. 
Wie lauten nun die spezifischen Bedingungen, die ein Museum zu einem historischen Museum, eine Ausstellung zu einer historischen Ausstellung machen? Eine erste Annäherung an diese Frage ist mit Blick auf das historische Museum als Institution bzw. genauer auf die Art der von ihm gesammelten Objekte möglich. ${ }^{338}$ Gelegentlich ist die Rede davon, dass historische Museen, analog zur obigen Definition des ICOM, Zeugnisse der Vergangenheit sammeln, bewahren und erforschen und ihre gewonnenen Erkenntnisse an Besucher vermitteln. ${ }^{339}$ Eine solche Beschreibung erscheint allerdings als noch zu ungenau, wenn die Beschäftigung mit Objekten aus der Vergangenheit, folgt man den oben zitierten Richtlinien des ICOM, auch als generelles Merkmal von Museen gelten soll. Was macht dann ein Museum tatsächlich zu einem historischen Museum?

Eine Diversifizierung der Museumslandschaft in die heute gebräuchlichen Museumstypen lässt sich Hildegard Vieregg zufolge etwa ab dem früheren 19. Jahrhundert konstatieren. ${ }^{340}$ Bei Vieregg findet sich eine Unterscheidung in zwei grundlegende Typen von Museen, nämlich «Naturwissenschaftliche und Naturhistorische Museen» und «Museen der Kulturgeschichte und Kunst», ${ }^{341}$ analog zu der erwähnten Unterscheidung des ICOM in «natural and cultural inheritance». Historische Museen ordnet Vieregg den zweitgenannten zu, ${ }^{342}$ woraus sich schliessen lässt, dass historisch im engeren Sinn kulturhistorisch und nicht naturhistorisch meint ${ }^{343}$ und sich somit auf die Geschichte der Menschheit sowie auf die von Menschen hergestellten und benutzten materiellen Güter bezieht. ${ }^{344}$

338 Grütter 1997b, S. 668.

339 Heese 2014, S. 13; Grütter 1997c, S. 707 ff. Grütter spricht von «historischen Relikte[n]» (ebd., S. 707).

340 Vieregg 2008, S. 93 ff. Die Ursprünge des Museums reichen allerdings, so Vieregg, bis in die Sammlungstätigkeiten der griechischen Antike zurück (Vieregg 2008, S. 18 ff.).

341 Vieregg 2008, S. 94. Mit dieser Unterscheidung beruft sich Vieregg auf eine Differenzierung der Deutschen Forschungsgemeinschaft (1974, zit. n. Vieregg 2008, S. 94).

342 Vieregg 2008, S. $99 \mathrm{ff}$.

343 Die Unterscheidung in die Bereiche der Natur und Kultur wäre freilich dann problematisch, wenn sie mit europäisch-hegemonialem und kolonialistischem Impetus auf die Unterscheidung in sogenannte Kultur- und Naturvölker abzielte. Gebraucht man die Begriffe stattdessen zur Unterscheidung in einerseits die Gesamtheit der nicht menschlich belebten Welt in Flora und Fauna sowie andererseits die Gesamtheit menschlichen Lebensvollzugs, so können sie eine hilfreiche Annäherung an eine Abgrenzung unterschiedlicher Museumstypen und deren Sammlungsstrategien bilden.

344 Grütter 1997b, S. 668. 
Eine Vielzahl von Gütern kommt hierunter infrage. Man kann Quellen auf mehrerlei Weisen untergliedern, so beispielsweise

- anhand ihrer äusseren Form in Schrift-, Bild-, Film-, Ton- und Sachquellen, ${ }^{345}$

- $\quad$ anhand ihres Entstehungs-/Überlieferungszusammenhangs bzw. der (Nicht-) Intentionalität ihrer Überlieferung «zwischen der direkten Quelle, der Tradition, die eine Gesellschaft bewusst zur Überlieferung an die Nachwelt geschaffen hat, und der indirekten Quelle, dem Überrest, also allen Zeugnissen $[\ldots]$, die nur unabsichtlich und zufällige Informationen über Geschehnisse oder Situationen der Vergangenheit liefern». ${ }^{346}$

Sammlungen von Museen gründen auf originalen Exponaten. Jedoch kommen in Ausstellungen bisweilen auch Reproduktionen zum Einsatz, wenn Originale nicht vorhanden oder nicht zugänglich sind, aus konservatorischen Gründen hinter Verschluss bleiben müssen, oder, wie zum Beispiel im Fall von Fotografien, reproduziert oder vergrössert gezeigt werden sollen. Auch für Ausstellungen mit einem Anteil an reproduzierten Exponaten ist die Bezeichnung als «historisch» gebräuchlich, auch wenn es dann streng genommen Objekte aus der Gegenwart sind, die hier gezeigt werden.

In der museumstheoretischen Literatur ist es geläufig, die Anwesenheit originaler Exponate bzw. die Möglichkeit der Begegnung mit ihnen zum zentralen Element von Museen zu erklären. ${ }^{347}$ In Zusammenhang mit der Rede vom Wesen der Museumsobjekte fallen dabei vielfach die Begriffe «Aura» ${ }^{348}$ oder «Authentizität», Letzteres etwa bei Gottfried Korff:

345 So die in geschichtsdidaktischen Einführungswerken gebräuchliche Differenzierung, die in der Kapitelgliederung Niederschlag findet (so bei Günther-Arndt/Zülsdorf-Kersting 2014, S. 6; Baumgärtner 2015, S. 6; Pandel/Schneider 2017b, S. 5 f.), wobei in allen Fällen die Differenzierungen nicht nur Quellen, sondern in breiterem Sinn insgesamt Medien oder auch Darstellungen umfassen.

346 Grütter 1997c, S. 708. Grütter bezieht sich mit dieser Unterscheidung in indirekter Zitation auf Johann Gustav Droysen sowie auf Nora (1990, S. 26f., zit. n. Grütter 1997c, S. 708).

347 So etwa: Grütter 1997c, S. 707; Korff 2004, S. 81 ff.; Thiemeyer 2012, S. 56; Heese 2014, S. $14 \mathrm{f}$.

348 Den Begriff der Aura ist geprägt von Walter Benjamin (1996, insb. S. 316-319). Für einen Überblick zur Begriffsverwendung: Hartung 2009, S. $160 \mathrm{ff}$. 
«Das Museumsding gehört einer anderen Zeit an, bietet sich aber dem heutigen Betrachter face to face. Das Museumsding ist uns nah und fern zugleich. Von dieser Doppeleigenschaft gehen die Reizwirkungen aus, die die Museumsdinge seit jeher zu Objekten der Faszination gemacht haben. Die Faszination beruht auf der Authentizität der Dinge, und es mag vieles für sich haben, was manche Museumstheorie der Gegenwart vermutet, dass es nämlich gerade diese Authentizität ist, die dem Museum zu jener Karriere verholfen hat, von der in den letzten Jahren nicht selten voller Irritation die Rede war.» ${ }^{349}$

Thorsten Heese greift dieses von Korff beschriebene Spannungsverhältnis aus Nähe und Ferne auf und bringt es unter Einbezug von Zeitebenen auf den Punkt: «Das Museumsding befindet sich mit den es betrachtenden Subjekten in einer gemeinsamen Gegenwart, kommt aber aus einer für die Subjekte unzugänglichen Vergangenheit. Museumsobjekte befinden sich in einem zeitlich-räumlichen Schwebezustand zwischen Vergangenheit und Gegenwart.» ${ }^{350}$

Spezifisch historisch wird ein Museum neben der Art seiner Objekte aber zweitens und vor allem durch die Art und Weise, wie diese Objekte dargestellt, präsentiert, miteinander in Verbindung gesetzt werden. ${ }^{351}$ Hiermit verlasse ich nun die Ebene der Institution Museum und wende mich der historischen Ausstellung zu. Die nachfolgenden Bedingungen gelten in ähnlicher Weise für verschiedene Typen historischer Ausstellungen, seien es Dauerausstellungen in historischen Museen oder auch Wander-/Sonderausstellungen. ${ }^{352}$ Im Gegensatz zu Kunstausstellungen steht in historischen Ausstellungen in der Regel nicht das einzelne Objekt im Fokus der Aufmerksamkeit, sondern es wird in einen grösseren Gesamtzusammenhang eingebettet, eine "Geschichte», die mithilfe der zahlreichen Bestandteile einer historischen Ausstellung erzählt wird. ${ }^{353}$ Heinrich Theodor Grütter folgend,

349 Korff 2002, S. 141.

350 Heese 2014, S. 14.

351 Grütter 1997b, S. 669. Mit den in den folgenden drei Absätzen formulierten Überlegungen zu den Elementen historischer Ausstellungen und deren Kontextualisierung sowie der dabei durch die Anordnung im Raum entstehenden Geschichte baue ich auf einer früheren Darstellung im Rahmen meiner Masterarbeit auf (Thyroff 2012, S. $14 \mathrm{ff}$.).

352 Hierzu auch der weiter oben bereits zitierte Hinweis von Thamer 2006, S. $34 \mathrm{f}$.

353 Grütter 1997b, S. 668 f. Die Überlegungen zur Konstruktion von Geschichte im Museum hier und im folgenden Abschnitt sind wesentlich inspiriert durch Grütter 1997b, S. 668 ff.; Grütter 1997c, S. $710 \mathrm{f}$. 
gehe ich davon aus, dass «Geschichte in einer Ausstellung immer inszeniert wird, indem die Objekte nach bestimmten Kriterien im Raum angeordnet werden». ${ }^{354}$

$\mathrm{Zu}$ dieser Erzählung tragen nicht nur unterschiedliche Typen von (originalen) Exponaten bei. Dazu gehören zahlreiche weitere Bestandteile, wie interaktive Elemente, ${ }^{355}$ aber auch Ausstellungstexte auf unterschiedlichen Textebenen und mit unterschiedlicher Bezugsweite. ${ }^{356}$ Texte können sich entweder erläuternd auf einzelne Objekte beziehen, auf ganze Objektgruppen, Ausstellungsabteilungen oder gar die gesamte Ausstellung. Die Texte allein machen Ausstellungen wiederum noch nicht zu einer historischen Ausstellung, da erklärende Texte auch in anderen Museumstypen zu finden sind. Wiederum ist es wohl die Art der Kontextualisierung, die den Ausschlag gibt: In historischen Ausstellungen werden Geschichten erzählt, indem einzelne Elemente in (räumlichen) Bezug zueinander gesetzt werden. ${ }^{357}$ Eine historische Ausstellung kann dabei nie ein objektives, umfängliches Abbild von Vergangenheit zeigen, ${ }^{358}$ sondern immer nur partikulare Blickwinkel auf Vergangenheit einnehmen. In diesem Blick auf historische Ausstellungen kombiniert sich eine konstruktivistische mit einer narrativistischen Perspektive. $^{359}$

Die entstehende Geschichte kann, dafür sensibilisiert Volkhard Knigge, mehr oder weniger linear, mehr oder weniger kohärent strukturiert sein. ${ }^{360}$ Immer ist es nur eine mögliche Geschichte, die erzählt wird. Präziser betrachtet, handelt es sich sogar um mehrere historische Erzählungen zugleich: eine grosse Geschichte, die Gesamtausstellung als Anordnung aus vielerlei Elementen, und darin eingegliedert

354 Grütter 1997b, S. 669. Zur Anordnung im Raum auch: Schwan 2012, S. 46 f.

355 Für eine erhellende Annäherung an den Begriff der Interaktivität jenseits von einer Beschränkung auf die Benutzung von Multimediastationen: Witcomb 2006, v. a. S. $353 \mathrm{f}$.

356 Für eine erzähltheoretisch fundierte Systematisierung von Texttypen: Buschmann 2010, S. $166 \mathrm{ff}$.

357 Grütter 1997 c, S. 711.

358 Grütter 1997c, S. 710 f.

359 Unterscheidung in Anlehnung an Schröder, die zwischen «Argumenten einer konstruktivistischen Perspektive» und «Argumenten eines narrativen Ansatzes» unterscheidet (Schröder 2013, S. 26).

360 Volkhard Knigge unterscheidet idealtypisch «[n]arrative und dokumentierend-argumentierende Ausstellungen», wobei Erstere eine «chronologisch-semantische Entität [darstellen], die die Anordnung des Ausstellungsgutes im Sinne einer Metabotschaft regelt», Zweitere gerade «nicht nach einem vorgehenden Narrativ [...] geordnet» sind, sondern versatzstückhaft bleiben (Knigge 2002, S. 385 f.). Gemäss der von mir verwendeten Terminologie lassen sich allerdings beide Varianten als «Erzählung» verstehen, unter Verwendung eines weiten Erzählbegriffs, der auch argumentierende Formen einschliesst (Rüsen 1982, S. 129; vgl. hierzu auch die Erläuterungen in Fussnote 3). 
eine Vielzahl an kleineren Geschichten, beispielsweise die Ausstellungstexte, die ich, ungeachtet ihrer Reichweite, alle als Darstellungen, Narrationen oder Geschichte bezeichne.

Die im Museum erzählte(n) Geschichte(n) wird bzw. werden durch vielerlei Einflussgrössen geprägt, etwa durch den Auftrag des Museums, durch spezifische Anliegen und Fragestellungen der Ausstellungsmachenden, durch die Art der überhaupt für eine Ausstellung zur Verfügung stehenden Objekte oder durch Anliegen der Gesellschaft, die den äusseren Kontext einer Ausstellung bildet. ${ }^{361}$ Damit können Museen zugleich Einsichten gewähren in «gegenwärtige gesellschaftliche Selbstbilder, über Interpretationen der Vergangenheit und über Vorstellungen von der Zukunft». ${ }^{362}$ Museen und Ausstellungen sind Ausdruck von Geschichtskultur, zugleich aber auch Akteure innerhalb dieser Geschichtskultur. ${ }^{363}$

Beispielsweise beschreibt Sharon Maconald die identitätsstiftende Funktion, die historische Museen einnehmen, indem sie eine kollektiv bedeutsame Geschichte erzählen ${ }^{364}$ - sei es nun, dass nationale, sei es, dass andere Kollektive die Bezugsgrösse bilden. Historische Museen und Ausstellungen können in dieser Hinsicht eine politische Rolle einnehmen. Dies entspricht der «politische[n] Dimension» von Geschichtskultur bei Rüsen, einer von drei Dimensionen geschichtskulturellen Manifestationen neben der «ästhetischen Dimension» und der «kognitive [n] Dimension ${ }^{365}$, die alle drei auch in historischen Museen bzw. historischen Ausstellungen wirksam sind. ${ }^{366}$

361 Grütter 1997b, S. 669.

Für die Ausführungen in diesem sowie den drei folgenden Absätzen greife ich auf eine frühere Darstellung im Rahmen meiner Masterarbeit zurück. Dort habe ich bereits einmal mögliche Einflussfaktoren auf die Gestalt von Ausstellungen und ihr Verhältnis mit der umgebenden Geschichtskultur thematisiert bzw. zugehörige Literatur zusammengetragen. Auch habe ich mich dort mit dem Verhältnis von Museen und den drei Dimensionen von Geschichtskultur beschäftigt (Thyroff 2012, S. 13 ff.).

362 Köhr 2012, S. 32.

363 Pieper 2010, S. $199 \mathrm{ff}$.

364 Macdonald 2000, S. $123 \mathrm{ff}$.

365 Rüsen 1994, S. 12 ff., direkte Zitate S. 12, S. 15, S. 16, Kursivsetzungen analog zum Original; zu den Dimensionen auch Rüsen 1997a, S. 39 ff. Mit seiner «Historik» aus dem Jahr 2013 ergänzte Rüsen die drei Dimensionen um zwei weitere, eine «moralische[.] Dimension» und eine «religiöse Dimension» (Rüsen 2013, S. 238 ff., direkte Zitate S. 238, S. 240, Kursivsetzungen analog zum Original).

366 Dass sich die drei Rüsen'schen Dimensionen auf Museen übertragen lassen, diese Auffassung kommt etwa im Titel des von Hartung herausgegebenen Sammelbands «Museum und Geschichtskultur. Ästhetik - Politik - Wissenschaft» zum Ausdruck (Hartung 2006). Auch Pohl überträgt die drei Dimensionen auf Museen (Pohl 2013, S. 15 ff.). 
Als Elemente der politischen Dimension beschreibt Rüsen diejenigen Momente einer Auseinandersetzung mit Geschichte, die der «Identitätsbildung» oder auch «Traditionsbildung und -pflege» dienen. ${ }^{367}$ Als mögliches geschichtskulturelles Beispiel führt er Gedenktage an, ${ }^{368}$ jedoch haben auch Museen eine - mehr oder weniger stark ausgeprägte - politische Dimension, wenn sie beispielsweise, wie zuvor genannt, eine identitätsrelevante Geschichte erzählen. Die kognitive Dimension steht hingegen bei Rüsen für die rationale, wissenschaftliche Seite von Geschichtskultur. Dort geht es um «Wissen und Erkenntnis», um «Zustimmungsfähigkeit», es stehen Aspekte der «methodischen Regulierung» und «Objektivität durch intersubjektive Überprüfbarkeit» im Zentrum. ${ }^{369}$ Manche Arbeiten stellen mit Fokus auf der identitätsrelevanten Rolle von Museen und Ausstellungen deren politische Dimension ins Zentrum. ${ }^{370}$ Einzelne Arbeiten fokussieren ausserdem auf ihre wissenschaftliche Ebene als Orte einer rationalen Geschichtsdarstellung und damit auf ihre kognitive Dimension. ${ }^{371}$ Daneben machen jedoch auch die ästhetischen Prinzipien ein wesentliches Moment historischer Ausstellungen aus. In der ästhetischen Dimension geht es «um eine spezifische Wahrnehmungsqualität der Vergangenheit», «Faszinationskraft», «Imagination vergangener Lebenswelten und ihrer Veränderung». ${ }^{372}$ Diese Dimension steht - neben der politischen - etwa bei Denkmälern im Vordergrund, doch nicht zuletzt auch in historischen Museen und Ausstellungen. Gerade ihre gestalterischen Prinzipien machen die Eigenart historischer Ausstellungen als geschichtskulturelle Manifestationen aus: Zentrale Eigenschaften sind ihre «dreidimensionale[.] Anschaulichkeit und Begehbarkeit», ihre «besondere Form von Körperlichkeit», ${ }^{373}$ in der Besuchende gleichsam mit einem dreidimensionalen Text ${ }^{374}$ in Kontakt kommen. Es «entsteht ein Bild, das bestimmt ist durch die Architektur des Ausstellungsraumes, durch die Anordnung der Objekte im Raum, durch die Form ihrer Präsentation und durch begleitende

In meiner Masterarbeit habe ich beispielsweise drei Ausstellungen zum Thema Holocaust bzw. Nationalsozialismus unter dem Blickwinkel der ästhetischen, politischen und kognitiven Dimension betrachtet (Thyroff 2012).

367 Rüsen 1994, S. 15 f.

368 Rüsen 1994, S. 15; Rüsen 1997a, S. 39.

369 Rüsen 1997a, S. 40.

370 Z. B. Macdonald 2000.

371 So bei Borsdorf/Grütter, die Denkmäler und Museen als zwei entgegengesetzte Pole auf einer Achse zwischen «Ästhetisierung und Emotionalisierung» einerseits und «Historisierung und Rationalisierung» andererseits verorten (Borsdorf/Grütter 1999, S. 6).

372 Rüsen 1997a, S. 39.

373 Köhr 2012, S. 33.

374 Buschmann 2010, S. 168. 
Materialien, wie Text- und Schautafeln, Beschriftungen, etc.». ${ }^{375}$ Dieser spezifische Charakter einer Ausstellung als zugleich Text und Bild ermöglicht Besuchenden neben dem kognitiven auch ein sinnlich-ästhetisches Erlebnis. Ausstellungen setzen durchaus bewusst solche ästhetischen Mittel ein, etwa um Emotionen und Empathie bei den Besuchenden hervorzurufen, wiederum zu historischem Lernen führen sollen. ${ }^{376}$ Die Grenzen zwischen der ästhetischen Dimension sowie der politischen und kognitiven sind insofern fliessend.

Dass Ausstellungen dabei durchaus mehr sein können als Orte der intendierten kontemplativen Objektanschauung, dann nämlich, wenn Ausstellungen die Besuchenden aktiv einladen zum Generieren eigener Deutungen, merken Jens Andermann und Silke Arnold-de Simine an. ${ }^{377}$ Sie beschreiben den Typus des «inclusive museum» ${ }^{378}$,

«[that] seeks to recover the museum's social role as a purveyour of shared, collective meanings precisely in departing from its high-modern predecessor and in forging 〈open representations〉 that acknowledge the diversity of the interpretative community thus interpolated. Inclusive museums, in short, aim to offer a new, contemporary stage for negotiating and performing cultural citizenship $[\ldots][$,$] moving toward a horizontal$ peer-to-peer structure, in which visitors morph into <users invited to <complete the meanings of the object-technology interface through their own emotional and experience-based responses.» ${ }^{379}$

Einhergehend mit diesem Wandel, postulieren Andermann und Arnold-de Simine die Ablösung von der Fokussierung «on the aura of the authentic object as a window onto the past» und stattdessen eine Entwicklung hin zur Integration multimedialer Elemente und anderer Formen, die Besuchende zur Aktivität und Performanz einladen. ${ }^{380}$ Umgekehrt fordern andere dezidiert ein, Museen möchten sich auf ihr Kerngeschäft, das Sammeln und Präsentieren von Objekten fokussieren. ${ }^{381}$

375 Grütter 1997b, S. 670.

376 So für Ansätze in der Gedenkstättenpädagogik und dabei insbesondere für die Ansätze zur absichtsvollen Anbahnung von Empathie konstatiert bei Brauer 2013, S. 75 ff.; beispielhaft zu emotionalisierenden Darstellungsweisen in Ausstellungen zum Thema Holocaust bzw. Nationalsozialismus ausserdem Thyroff 2012, S. $50 \mathrm{ff}$., S. $91 \mathrm{ff}$.

377 Andermann/Arnold-de Simine 2012.

378 Rayner 1998, zit. n. Andermann/Arnold-de-Simine 2012, S. 1.

379 Andermann/Arnold-de Simine 2012, S. 1.

380 Andermann/Arnold-de Simine 2012, S. 2.

381 So Heese: «Die Ausrichtung am historischen Original muss die absolute Leitlinie bleiben» (Heese 2014, S. 18). 
Unabhängig von der Gewichtung der Bedeutung von Objekten sind historische Ausstellungen vieldeutig und laden zum Generieren von Bedeutungen ein - sowohl explizit aufgrund der Integration diskursanregender Elemente, wie von Andermann und Arnold-de Simine dargelegt, als auch mittels der sowieso vorhandenen Mehrdeutigkeit historischer Ausstellungen aufgrund ihrer spezifischen Konstruktionsbedingungen. Heinrich Theodor Grütter fasst die damit verbundene Bedeutungsvielfalt zusammen:

«Gerade die Anordnung der Objekte im dreidimensionalen Raum, der ja nach Standort und Perspektive unterschiedliche Sichtweisen und Kombinationen zulässt, garantiert die Mehrdeutigkeit und unterschiedliche Lesbarkeit der Exponate, die ja nicht nur innerhalb des Zusammenhanges, in den sie die Ausstellung einordnet, ihre Bedeutung haben. Sie setzt zumindest potentiell ihren Sinnüberschuss frei und ermöglicht die Multiperspektivität ihrer Deutung.» ${ }^{382}$

Eine historische Ausstellung ist also auf vielerlei Weisen lesbar. Zwar können Ausstellungen mittels ihrer spezifischen Auswahl, interpretierenden Anordnung und Kontextualisierung von Texten, Exponaten und anderen Gestaltungselementen Besuchenden aktiv eine Deutungslinie anbieten. ${ }^{383}$ Dies bedeutet jedoch keineswegs, dass Besuchende diese erzählte Geschichte in ihrer Gesamtheit und in der von den Ausstellungsgestaltern intendierten Art und Weise wahrnehmen und übernehmen. Im Gegenteil: Was den Besuchenden in physischer Hinsicht begegnet, ist zunächst einmal eine Vielzahl von einzelnen, in einer räumlichen Struktur angeordneten Elementen. Der Ausstellungsbesuch besteht nun darin, sich in dieser räumlichen Struktur zu bewegen, einen Weg zu wählen, bestimmte Elemente zur Kenntnis zu nehmen, andere möglicherweise nicht, dies in einer bestimmten Reihenfolge zu tun, die selbst gewählt sein kann, oder einem von den Ausstellungsmachern vorgegebenen Laufweg folgend, das Gesehene mit dem Gelesenen zu verbinden, Zusammenhänge zu erschliessen. Im Gegensatz zu Grütter

382 Grütter 1997 c, S. 711.

383 Überlegungen zu Möglichkeiten der Gestaltung von «Lernumgebungen»: Prenzel 2009, S. $139 \mathrm{f}$.

$\mathrm{Zu}$ Möglichkeiten der Steuerung von Aufmerksamkeit und Interesse durch die Ausstellungsgestaltung, etwa durch Platzierung von Objekten oder Einsatz des Mittels der Personalisierung: Schwan 2009, S. $38 \mathrm{ff}$.

$\mathrm{Zu}$ «Techniken [...] einer besucherorientierten Ausstellungsplanung»: Lewalter/NoschkaRoos 2009, S. 537. 
betrachte ich die Vieldeutigkeit von Ausstellungen nicht als «Problem», ${ }^{384}$ sondern als interessantes Forschungsfeld, um das Zustandekommen unterschiedlicher Lesarten zu beobachten und zu beschreiben. Meine Studie soll einen Beitrag zur Erhellung dieses komplexen Felds leisten.

Eine Dimension, die in diesen Beschreibungen der Konstruktionsbedingungen von historischen Ausstellungen deutlich wird, ist die räumliche Dimension. Thomas Thiemeyer erklärt sogar Raum neben den Dingen zum «Alleinstellungsmerkmal[.]» von Museen. ${ }^{385}$ Vielleicht könnte man ausgehend davon formulieren, dass die spezifische Kombination aus Dingen und Raum, nämlich die Anordnung von Dingen im Raum zum Zweck der Erzählung von Geschichte, historische Ausstellungen konstituiert.

In den drei Rüsen'schen Dimensionen von Geschichtskultur ist die räumliche Dimension nicht explizit beinhaltet, und es würde wohl zu kurz greifen, zu behaupten, dass die räumliche Dimension in der ästhetischen aufgeht, auch wenn es Überschneidungsbereiche geben mag. Saskia Handro und Bernd Schönemann konstatieren für die geschichtsdidaktische Forschung eine bislang unzureichende systematische Durchdringung von deren räumlicher Dimension - dies, obwohl mit Rüsens dreidimensionaler Konzeption von Geschichtskultur eine theoretische Grundlage bereitstehe, die «verhältnismässig leicht um weitere Dimensionen wie die ökonomische, die zeitliche oder eben die räumliche ergänzt werden kann, da es sich um vergleichbar ubiquitäre Phänomenklassen handelt». ${ }^{386}$ Waltraud Schreiber bestätigt das von Handro und Schönemann festgestellte Defizit, wenn sie auch 2017 noch feststellt, es geschehe selten, ««Raum» und Geschichtskultur theoretisch zusammen zu denken». ${ }^{387}$

Jedoch kann die Museumstheorie von dieser Feststellung mit guten Gründen ausgenommen werden. Wie die Ausführungen Thiemeyers und einer Reihe weiterer in diesem Kapitel zitierter Autorinnen und Autoren zeigen, ist dort ein Bewusstsein für die räumliche Dimension der Manifestation Ausstellung durchaus verbreitet. ${ }^{388}$ Was jedoch aus geschichtsdidaktischer Perspektive ein Desiderat dar-

384 Bei Grütter heisst es: «Damit ist aber ein gravierendes Problem angesprochen, das sich zumindest im historischen Museum stellt. Die Ausstellung erschliesst sich in ihrer Vielschichtigkeit - zumal beim einmaligen Besuch - nur zu Teilen von selbst und für jeden Besucher anders» (Grütter 1997c, S. 711).

385 Thiemeyer 2012, S. 56.

386 Handro/Schönemann 2014, S. 2.

387 Schreiber 2017, S. 49.

388 Knapp angeschnitten wird die Bedeutung von Räumlichkeit und Dreidimensionalität ausserdem bei Heese 2014, S. $15 \mathrm{f}$. 
stellt, ist, diese räumliche Dimension mit Prozessen der Nutzung solcher Manifestationen und den darin stattfindenden Prozessen historischen Denkens zusammenzubringen - ähnlich wie für den Bereich der ästhetischen und emotionalen Erfahrungen beim Ausstellungsbesuch. Da diese Aspekte nicht mehr nur angebotsseitig die Manifestation Museum bzw. Ausstellung, sondern auch ihre Nutzungsseite betreffen, stelle ich sie vorerst noch zurück und komme später erneut darauf zurück. ${ }^{389}$

\subsection{Besuchende: Lernen und Aneignen in Museum und Ausstellung}

Während ich mich bislang mit den Merkmalen historischer Museen und Ausstellungen beschäftigt und damit diese Manifestationen angebotsseitig betrachtet habe, frage ich nun, wie in theoretischer Hinsicht über die Nutzung von Museen und Ausstellungen durch Besuchende gedacht wird. Da in der Literatur zumeist von «Museumsbesuchenden» und nicht den «Besuchenden in Ausstellungen» die Rede ist, auch dann, wenn im engeren Sinn die Besuche der Ausstellungsräumlichkeiten gemeint sind, gebrauche ich nachfolgend beide Begriffe, wechselweise oder in Kombination, um je nach Verwendungszusammenhang meiner eigenen Begriffssetzung und der geläufigen Bezeichnung in der rezipierten Literatur gerecht zu werden.

Der vorzufindende Literaturbestand ist umfangreich, und nicht immer sind dabei theoretische Überlegungen und empirische Untersuchungen klar voneinander zu trennen. Ich versuche trotzdem eine Unterscheidung, indem ich mich nun zunächst den theoretischen Überlegungen zuwende, bevor ich später in einem separaten Abschnitt (Kapitel 5) die empirische Forschungslage in Bezug auf Museums- bzw. Ausstellungsbesuchende thematisiere.

Die Unterscheidung theoretischer und empirischer Zugänge empfiehlt sich nicht nur in systematischer Hinsicht, sondern auch, um zu verdeutlichen, dass ein grosser Bestand an theoretischen Annahmen darüber existiert, wie die Nutzung von Museen bzw. Ausstellungen abläuft, ${ }^{390}$ und dass diese zwar inzwischen auch von einem umfangreichen Bestand an empirischen Untersuchungen flankiert werden, gleichwohl aber bislang in manchen Bereichen empirischer Forschungsbedarf

389 Vgl. Abschnitt 3.4 sowie Kapitel 9.

390 So auch die Feststellung bei Kohler 2014, S. 83 f. 
besteht. Jedoch mangelt es bislang, wie Christian Kohler feststellt, an einer «Rückkopplung» zwischen neueren empirischen Untersuchungen und den oft ohne empirischen Bezug formulierten theoretischen und normativen Annahmen. ${ }^{391}$ Angesichts dieser Desiderate begründe ich anschliessend die Notwendigkeit meiner Untersuchung.

Museen werden in der didaktischen Literatur gelegentlich als «informelle Lernorte» ${ }^{392}$ oder «non-formale Lernorte» ${ }^{393}$, häufig auch als «ausserschulische Lernorte» ${ }^{394}$ thematisiert. Mit diesen Begriffen kann je nach Verwendungszusammenhang Unterschiedliches gemeint sein, wie Oliver Plessow für die Geschichtsdidaktik und deren Gebrauchsweisen des Begriffs des Ausserschulischen herausarbeitet. ${ }^{395}$ Plessow unterscheidet zwei Bedeutungsvarianten des Begriffs, nämlich eine schulbezogene und eine schulkomplementäre Verwendung, wobei Erstere «von der Schule verantwortete Lernaktivitäten ausserhalb des Klassenraums und Schulgeländes» umfasst, Zweitere «das Engagement nicht-schulischer Bildungsakteure» meint. ${ }^{396}$ Museen seien nach beiden Verwendungsweisen als ausserschulische Lernorte einzustufen, sie seien «hybride Einrichtungen», die einerseits zum Ziel im Rahmen des Schulunterrichts unternommener Exkursionen würden, gleichzeitig «als etablierte eigenständige Bildungsinstitutionen [...] keinesfalls zwingend allein an Schule gerichtete [...] professionelle pädagogische Angebote bereitstellen». ${ }^{397}$ Ungeachtet des jeweiligen Bedeutungsgehalts sei, so stellt Plessow fest, der «Terminus meist positiv konnotiert». ${ }^{398}$

Tatsächlich wird ausserschulischen Lernorten in der Literatur eine Reihe von Potenzialen zugeschrieben. So wird davon ausgegangen, dass ausserschulische Lernorte einen höheren Bezug zur Lebenswelt der sie Nutzenden haben, dass ihr Besuch entdeckendes und handlungsorientiertes Lernen begünstigt, «die Möglichkeit der unmittelbaren Begegnung mit einem Lerngegenstand und/oder Sachverhalt» bietet und sich diese Begegnung durch Originalität und Authentizität auszeichnet $^{399}$ - wobei Konzepte von Originalität und Authentizität ihrerseits als

391 Kohler 2014, S. 84.

392 Hartung 2009, S. 158; Lewalter 2009, S. 45; Pleitner 2008, S. 101.

393 Plessow 2015, S. 26.

394 Z. B. Messmer/Niederhäusern/Rempfler/Wilhelm 2011, S. 7; Plessow 2015, S. 24 f.

395 Plessow 2015.

396 Plessow 2015, S. 17.

397 Plessow 2015, S. 24.

398 Plessow 2015, S. 18.

399 Sauerborn/Brühne 2007, S. 15; Mayer 2009, S. $27 \mathrm{ff}$; Messmer/Rempfler/Wilhelm 2011, S. 139; Messmer/Niederhäusern/Rempfler/Wilhelm 2011, S. 7, direktes Zitat: ebd., Kursivsetzung analog zum Original. 
befragungswürdig gelten. ${ }^{400}$ Vielfach werden diese Potenziale vor dem Hintergrund eines Vergleichs mit dem Lernen im schulischen Klassenzimmer entfaltet. ${ }^{401}$

Der fachdidaktische und erziehungswissenschaftliche Diskurs um ausserschulische Lernorte, spezifischer um historische Museen als ausserschulische Lernorte, stellt für meine Arbeit relevante Bezugsliteratur dar. Allerdings thematisiere ich selbst Museen aus zweierlei Gründen begrifflich nicht als ausserschulische Lernorte.

Erstens ist dem Begriff «ausserschulisch» sprachlich als Referenz- und Vergleichspunkt das schulische Lernen inhärent ${ }^{402}$, selbst wenn er eigentlich in schulkomplementärer Weise gemeint wäre. Angesichts dessen, dass mein Projekt ausschliesslich mit erwachsenen Besuchenden durchgeführt wurde, die die Ausstellung nicht im Rahmen des schulischen Geschichtsunterrichts besuchten, könnte eine Verwendung des Begriffs des ausserschulischen Lernens zu irreleitenden Konnotationen führen.

Zweitens gilt es zu betonen, dass Lernen im engeren Sinn nur teilweise einen Gegenstandsbereich meines Forschungsprojekts bildet, nämlich dann nur bedingt, wenn Lernen erstens in einem engeren Sinn als feststellbarer Zuwachs von Wissen oder Fähigkeiten betrachtet wird, ${ }^{403}$ nicht breiter verstanden etwa als «Veränderung an und in der ‘Zielperson»», ${ }^{404}$ und damit zweitens genau genommen erst vom Ergebnis aus betrachtet konstatiert werden kann. Demgegenüber interessiere ich mich stärker für den Prozess des Ausstellungsbesuchs, weniger für dessen Resultate.

Gleichwohl ist mein Forschungsanliegen mit breiteren theoretischen Konzeptionen von Lernen in Deckung zu bringen. So regt George E. Hein an, «education as «meaningful experience〉 rather than «defined content outcome» zu verstehen. Ein solches Verständnis sei «broad enough to include enjoyment, satisfaction, and other outcomes from experiences». ${ }^{405}$ Eine ganze Reihe von Autorinnen und Autoren betont in diesem Sinn, dass Museumsbesuche mehr seien als der Erwerb von

400 Messmer/Rempfler/Wilhelm 2011, S. $139 \mathrm{f}$.

401 Einer entsprechenden Gegenüberstellung bedienen sich etwa: Sauerborn/Brühne 2007, S. 15; Thomas 2009, S. $284 \mathrm{ff}$.

402 Plessow 2015, S. 21. Dies gilt meines Erachtens auch dann, wenn ausserschulisches Lernen definitionsgemäss eigentlich sogar Erwachsene mit meinen soll, wie bei Messmer/Niederhäusern/Rempfler/Wilhelm, die ausserschulische Lernorte definieren als «Orte ausserhalb des Schulhauses, an denen Personen jeglichen Alters im Rahmen formaler, non-formaler oder informeller Bildung lernen können» (Messmer/Niederhäusern/Rempfler/Wilhelm 2011, S. 7).

403 Z.B. Dinkelaker 2011, S. 133.

404 Nieke 2016, S. 28.

405 Hein 2006, S. 348. 
Wissen oder Sachkenntnissen, ${ }^{406}$ wobei in diesen Kontexten mutmasslich eher ein enger Wissensbegriff im Sinn eines first-order knowledge $e^{407}$ leitend ist.

Einen solch engen Begriff überschreitend, listet Manfred Prenzel stattdessen ein ganzes Spektrum des Lernens im Museum auf, das «Formen des absichtlichen und beiläufigen Lernens» umfasse, verschiedene «Ausprägungen des kognitiven Lernens» wie etwa «Ebenen des konzeptuellen Verstehens, von episodischem Wissen, von prozeduralem oder strategischem Wissen», aber auch «Meta-Kognition und Reflexion» und neben dem kognitiven Bereich «das Lernen von Motiven, Überzeugungen, Gefühlen, Perspektiven oder Handlungsmustern», «Einstellungen und Überzeugungen». ${ }^{408}$ Zudem könne das Museum «ästhetische Empfindungen auslösen» und habe «als gemeinsames Erlebnis» auch eine «soziale Seite des Lernens», sodass Prenzel in der Summe zu dem Befund kommt, man könne «im Museum nicht nicht lernen». ${ }^{409}$

Einen breiteren Lernbegriff vertreten auch Annette Noschka-Roos und Doris Lewalter, wenn sie über Museen als Orte der «ästhetischen Erfahrung» und der «ästhetischen Bildung» schreiben. ${ }^{410}$ Es komme dabei darauf an, Bildung als Prozess und nicht vom Produkt her zu denken und Bildung zugleich breit zu konzeptualisieren: «Bildung wird als ein subjektives Vermögen, die Welt zu erschliessen, betrachtet und alle Formen - kognitive ebenso wie emotionale oder soziale - einbezogen». ${ }^{411}$

Mein Forschungsinteresse zielt also auf eine möglicherweise grosse Bandbreite von Erfahrungen beim Museums- bzw. Ausstellungsbesuch, die den Zuwachs von Wissen und Kompetenzen nicht ausschliessen, jedoch keineswegs darauf beschränkt werden, oder wie Sharon Macdonald, hier wiederum unter Annahme

406 So Stephan Schwan: «Zwar kann ein Museumsbesuch dazu beitragen, Sachkenntnisse zu erweitern und zu vertiefen. Er lässt sich jedoch nicht darauf reduzieren, denn er befriedigt noch eine Vielzahl weiterer Bedürfnisse» (Schwan 2012, S. 46).

407 Im Sinn der bereits weiter oben eingeführten Definition bei VanSledright/Limón, von welchen «First-Order Conceptual and Narrative Ideas and Knowledge», als Wissen auf «who, what, where, when and how questions» verstanden werden (VanSledright/Limón 2006, S. 547).

408 Prenzel 2009, S. 137 f.

409 Prenzel 2009, S. 138.

410 Noschka-Roos/Lewalter 2013, S. 199. Zur Idee der ästhetischen Bildung siehe die Ausführungen in Abschnitt 3.4.3. Die Unterscheidung von zwei grundlegenden Zugängen in der Museumsbesucherforschung habe ich bereits einmal in Thyroff 2017c, S. 2, angeschnitten.

411 Noschka-Roos/Lewalter 2013, S. 201. 
eines engen Lernverständnisses, formuliert: «[T]he ways in which visitors interact with museums cannot be confined to learning and education. ${ }^{412}$

Die geschilderten Positionen tragen einem Blickwinkel auf Museums- bzw. Ausstellungsbesuchende Rechnung, der einerseits die Aufmerksamkeit von definierten Ergebnissen des Besuchs ablöst und stärker Prozesse des Besuchs in den Blick nimmt, gleichzeitig die Individualität dieser Prozesse betont. Folgt man Noschka-Roos und Lewalter, so sind diese Perspektiven für jüngere Forschungen zu Besuchenden überwiegend. Die Autorinnen unterscheiden Untersuchungen zum Lernen im Museum nach zwei Phasen bzw. Zugängen, nämlich danach, ob sie eine «instruktionale Perspektive» oder eine «konstruktivistische Perspektive» auf Lernprozesse verfolgen. ${ }^{413}$ Die instruktionale Perspektive sei in einer ersten Phase der Besuchendenforschung ab den 1970er-Jahren vorherrschend gewesen, wobei das Forschungsinteresse darin bestand, herauszufinden, «inwieweit Besucher tatsächlich die präsentierten Inhalte mit der angestrebten Botschaft der Ausstellung wahrnehmen, verarbeiten und schliesslich erinnern können», um anschliessend «die instruktionale Seite der Informationspräsentation in Museen und Ausstellungen zu optimieren». ${ }^{414}$ Für diese Art der Forschung ist also ein Bild leitend, demzufolge Besuchende die vorgegebenen Deutungen der Ausstellungsmachenden idealerweise möglichst unverändert übernehmen. Dem stellen Noschka-Roos und Lewalter eine konstruktivistische Perspektive gegenüber, die der «Individualität und Vielfältigkeit von Lernprozessen im Museum» Rechnung trägt. ${ }^{415}$ Diese Perspektive erlaube im Gegensatz zur erstgenannten, «Lernprozesse im Museum [...] differenzierter zu betrachten und als wechselseitigen Prozess zu konzeptualisieren». ${ }^{416}$

John H. Falk, Lynn D. Dierking und Marianna Adams sowie Eilean HooperGreenhill kommen für die US-amerikanische und britische Forschung zu einem

412 Macdonald 2006, S. 320.

413 Noschka-Roos/Lewalter 2013, S. 206 ff. und $208 \mathrm{ff}$.

Knapp eingegangen auf diese zwei Phasen bin ich auch bereits in Thyroff 2017c, S. 2.

414 Noschka-Roos/Lewalter 2013, S. 206.

415 Noschka-Roos/Lewalter 2013, S. 208.

416 Noschka-Roos/Lewalter 2013, S. 208.

Nicht nur die «rezeptive Weltaneignung», sondern auch die «produktive Weltaneignung» im Museum zu ermöglichen, stellt Eckart Liebau zufolge eine allerdings gar nicht so neue, sondern reformpädagogische Forderung dar und solle nicht zuletzt auch dem Zweck dienen, weitere Adressatenkreise zu erschliessen (Liebau 2012, S. 43). Die Integration dieser Idee in die Museums(besuchenden)theorie und -forschung scheint allerdings erst in jüngerer Vergangenheit erfolgt zu sein. 
ganz ähnlichen Befund. Sie stellen einen Wandel von einem hier als behavioristisch bezeichneten Blick auf Besuchende bzw. Lernende hin zu einer konstruktivistischen Perspektive ab den 1980er- und 1990er-Jahren fest. ${ }^{417}$ So habe es einen Wechsel gegeben «from thinking about visitors as an undifferentiated mass public to beginning to accept visitors as active interpreters and performers of meaningmaking practices within complex cultural sites». ${ }^{418}$ Frühere Studien hätten «focused on whether the exhibitions visitor had understood the message that the exhibition intended to transmit». ${ }^{419}$ Das behavioristische Modell sei gekennzeichnet durch die Annahme, dass «all visitors to the museum will emerge having had the same experience and having learned exactly the same thing. The constructivist model, however, sees learning as a highly contextual process.» ${ }^{420}$

Falk, Dierking und Adams nehmen denn auch diese Kontexte in den Blick, die ihrer Ansicht nach individuelle Besuchsverläufe prägen, wobei sie in "personal, socio-cultural, and physical contexts» unterscheiden. ${ }^{421}$ Zum personal context zählen sie beispielsweise die individuelle Biografie, Vorwissen, Interessen, Überzeugungen, während der socio-cultural context Beeinflussungen aufgrund sozialer und kultureller Zugehörigkeiten meint, einschliesslich sozialer Interaktionen in der Besuchssituation, und der physical context die vorhandenen räumlichen Gegebenheiten in der besuchten Ausstellung, wie etwa Architektur, Beleuchtung, Grad der Informationsfülle. ${ }^{422}$ Die Forschenden tragen mit ihrer Modellierung der Einsicht Rechnung, dass beim Museums- bzw. Ausstellungsbesuch individuelle Bedeutungen generiert werden und dass dies, wie schon Grütter feststellte, «immer vor dem Hintergrund eigener Kenntnis und Erfahrung» ${ }^{423}$ geschieht.

Die auf den letzten Seiten vorgestellten Überlegungen wurden jüngst von Christian Kohler in ein «domänenspezifisches Modell des musealen Lernens» ${ }^{424}$

417 Falk/Dierking/Adams 2006, S. 325; Hooper-Greenhill 2006, S. 368.

418 Hooper-Greenhill 2006, S. 362.

419 Hooper-Greenhill (2006), S. 366. Falk/Dierking/Adams gehen davon aus, dass für die praktische Museumsarbeit nach wie vor eine behavioristische Lernvorstellung leitend ist (Falk/Dierking/Adams 2006, S. 325). Überlegungen dazu, welche Auswirkungen der Wandel von einer behavioristischen, instruktionalen Perspektive hin zu einem konstruktivistischen Blickwinkel für die Ausstellungsgestaltung und museumspädagogische Praxis hat, finden sich im selben Sammelband bei Hein (Hein 2006, v. a. S. 347 ff.).

420 Falk/Dierking/Adams 2006, S. 325.

421 Falk/Dierking/Adams 2006, S. 327, Kursivsetzung analog zum Original.

422 Falk/Dierking/Adams 2006, S. 327.

423 Grütter 1997b, S. 672; dazu auch: Falk/Dierking/Adams 2006, S. $326 \mathrm{ff}$.

424 Kohler 2016, S. 70. 
überführt, das ich andernorts bereits rezipiert habe ${ }^{425}$; ich greife hier auf meine dortige Beschreibung zurück. In seinem Modell nimmt Kohler

«einerseits Bezug auf vorliegende theoretische Überlegungen zum Medium Museum, zu seinen Konstruktionsbedingungen und lernortspezifischen Besonderheiten. Andererseits greift er auch auf Arbeiten der Museumsbesucherforschung zurück, namentlich und insbesondere auf das von Falk und Dierking entwickelte «Contextual Model of Learning〉, und rezipiert bzw. integriert deren Ergebnisse. Kohlers Modell nimmt einerseits museales Lernen in seiner Prozesshaftigkeit in den Blick und modelliert einen Dreischritt aus Lernvoraussetzungen, Besuchssituation und Lernergebnissen. Zugleich betrachtet es Lernen im Museum als individuellen Konstruktionsprozess, der in seiner Individualität doch einer Reihe von Bedingungen und Faktoren unterliegt, konkret den individuellen Lernvoraussetzungen, der aktuellen sozialen Situation und dem physisch vorhandenen Ausstellungskontext und dessen Dimensionen.» ${ }^{426}$

Aus der Modellierung Kohlers - und den Abschnitt insgesamt zusammenfassend - wird deutlich: Was beim Besuch einer historischen Ausstellung passiert, kann viel mehr sein als ein lediglich passives Zurkenntnisnehmen einer vorgefertigten, vorgegebenen Erzählung über Vergangenes. «From a constructivist perspective, learning in and from museums is not just about what the museum wishes to teach the visitor. It is as much about what meaning the visitor chooses to make of the museum experience.» ${ }^{427}$ Oder mit Heinrich Theodor Grütter gesprochen: «Der Besucher ist nicht nur Leser, er ist zugleich Produzent seines Textes.» ${ }^{428}$ Derartige Hinweise auf die aktive, erschliessende Rolle von Besuchenden in Abwendung von einer passiven Konsumentensicht sind vielerorts in der Literatur zu finden. So regen Annette Noschka-Roos und Doris Lewalter an, «Besucher im erschliessenden Umgang mit den Objekten nicht in der Rolle als passive Konsumenten, sondern als aktive Produzenten zu betrachten», ${ }^{429}$ und im Vorwort zum Sammelband

425 Vgl. Thyroff $2017 \mathrm{~d}$.

426 So von mir im Rahmen der genannten Rezension zusammengefasst (Thyroff 2017d, S. 285 f.), wobei ich mich mit den Ausführungen auf die Darstellung von Kohlers Modell in Kohler 2016, S. 70, beziehe.

427 Falk/Dierking/Adams 2006, S. 325.

428 Grütter $1997 \mathrm{c}$, S. 711.

429 Noschka-Roos/Lewalter 2013, S. 211, dazu auch S. 212. 
«Geschichte erfahren im Museum» heisst es: «Die Ausstellungsbesucher sind nicht nur Leserinnen und Leser, sie produzieren ihre eigene Narration.» ${ }^{430}$

Kristine A. Morrissey fasst die Grundannahmen der von ihr als postmodern deklarierten Perspektiven auf Besuchende in drei Punkten zusammen:

a) «the visitor is actively engaged in creating knowledge»,

b) «learning is a process, not a product» und

c) «knowledge is not transmitted from one person to another, but constructed and continually negotiated and renegotiated». 431

Um dieser Ausgangslage Rechnung zu tragen, bietet sich ein alternativer Begriff zum Lernbegriff an, obwohl der Lernbegriff, wie ich gezeigt habe, durchaus weit auslegbar ist. Aufgrund seiner bisweilen aber doch eng verstandenen Konnotation und zur Vorbeugung von Missverständnissen bevorzuge ich jedoch den Begriff der Aneignung. Dieser wird zum Beispiel in der Medienpädagogik verwendet und findet zunehmend Eingang auch in die Erforschung des Umgangs mit Museen und anderen ausserschulischen Lernorten. ${ }^{432}$

Bernd Schorb grenzt den Begriff «Medienaneignung» ab von den Begriffen «Medienkonsum», «Mediennutzung» und «Medienrezeption»: ${ }^{433}$

«Gemeinsam ist allen diesen Begriffen, dass sie das Verhältnis der Menschen zu den Medien beschreiben wollen. Unterschiedlich ist die Sichtweise, die sie auf die Stellung des Menschen in diesem Verhältnis haben. Medienkonsum wählt das Bild, dass Medien einverleibt werden wie beispielsweise Nahrung. Der Konsument ist dabei im Grunde passiv und die Medien entfalten ihre Wirkung mehr oder minder selbstständig in ihm, in seinem Denken und Handeln. Der Begriff Mediennutzung legt die Betonung auf den sichtbaren Akt

430 Grütter/Kuhn 2014, S. 12.

431 Morrissey 2002, S. 288.

432 Für die Medienpädagogik: Schorb 2009; für die Übertragung des Aneignungsbegriffs von Schorb auf die Nuztzung ausserschulischer Lernorte wurde ich durch die Ausschreibung für die Tagung "Aneignungspraktiken an ausserschulischen Lernorten» inspiriert (Sommer 2016), die am 9. und 10. Juni 2017 an der Pädagogischen Hochschule Luzern stattfand. Explizit erwähnt in Bezug auf Museumsbesuchende wird der Aneignungsbegriff ausserdem bei Noschka-Roos 2001, S. 89. Im Titel von museumsbezogenen Publikationen findet der Begriff Verwendung bei Borsdorf et al. 2004a sowie Kunz-Ott et al. 2009.

433 Schorb 2009, S. 182. 
des Gebrauchs von Medien [...]. Bei all diesen Begriffen ist das Verhältnis der Menschen zu den Medien dadurch gekennzeichnet, dass sie den Medien gegenüberstehen und diese auf sie einwirken.» ${ }^{434}$

Demgegenüber versteht Schorb «Medienaneignung» als einen Begriff, der der Idee Rechnung trägt,

«dass der Mensch aktiv ist und sich handelnd die Medien aneignet. Der Mensch wird grundsätzlich als ein bewusst handelndes Wesen gesehen. [...] Das bedeutet aber nicht, dass jeder Mensch während seines Medienhandelns immer diese Absicht aussprechen und/oder erklären kann, aber sehr wohl, dass er sie selbst erkennen und auch rekonstruieren kann und dass er für sein Medienhandeln grundsätzlich wie für jedes andere individuelle Handeln verantwortlich ist.»435

Ausgehend von diesem Begriffsverständnis, halte ich den Aneignungsbegriff für gut geeignet, um die oben ausgeführten Annahmen über die Aktivität von Museums-/Ausstellungsbesuchenden Rechnung zu tragen, wobei in diesem Fall der Begriff «Medium», sofern überhaupt noch verwendet, nicht eng gefasst und dann bezogen auf den «Medieneinsatz» ${ }^{436}$ in historischen Ausstellungen zu verstehen ist, sondern breiter in Bezug auf die gesamte geschichtskulturelle Manifestation, mit der die Besuchenden in Kontakt kommen. ${ }^{437}$

Der Aneignungsbegriff trägt zudem auch auf sprachlicher Ebene dem verfolgten Forschungsanliegen Rechnung, betont er doch durch den Begriffsbestandteil des Eigenen, dass es darum geht, einen Gegenstand auf die eigene Person zu beziehen, Bezüge zur eigenen Person herzustellen, sich einen Gegenstand eben anzueignen, und dabei auf durchaus individuelle, aktive, kreative, konstruktive Weise. Die Begriffswahl korrespondiert insofern insbesondere mit der zweiten verfolgten Forschungsfrage, die darauf zielt, herauszufinden, ob, wie und in welchen Hinsichten Besuchende beim Besuch einer historischen Ausstellung Bezüge zur eigenen Person und Zeit herstellen.

434 Schorb 2009, S. 182.

435 Schorb 2009, S. 182.

436 Eine solche mögliche Engführung des Begriffs im Zusammenhang mit ausserschulischen Lernorten wird in dem o. g. Call abgelehnt (Sommer 2016).

437 In Bezug auf ganze Ausstellungen wird der Begriff «Medium» verwendet bei Schönemann 2014, S. 19. Vgl. zu Vorbehalten gegenüber dem Medienbegriff die Hinweise im vorigen Abschnitt. 
Trotz Bevorzugung des Aneignungsbegriffs ist der Lernbegriff für mein Forschungsprojekt nicht völlig obsolet, ist doch das auf den letzten Seiten geschilderte Verständnis der beim Ausstellungsbesuch ablaufenden Prozesse insbesondere mit Konzeptionen informellen Lernens in Einklang zu bringen. Wie ich weiter oben bereits angedeutet habe, werden Museen neben ihrer Klassifizierung als ausserschulische Lernorte bisweilen auch als informelle Lernorte thematisiert. ${ }^{438}$ Der Begriff des informellen Lernens erlebt derzeit eine Hochkonjunktur ${ }^{49}$ und geht einher mit einer zunehmenden, auch bildungspolitisch forcierten, Beschäftigung mit lebenslangem Lernen als Phänomen und auch normative Zielgrösse. ${ }^{440}$ Die Aufmerksamkeit richtet sich dabei auf Lernen als Lernen jenseits formalisierter Bildungsinstitutionen und in allen Altersstufen, als selbst gesteuertes Lernen und als Lernen, das in der Lebenswelt und in unterschiedlichen sozialen Zusammenhängen stattfindet. ${ }^{441}$ Die mit der Rede vom informellen Lernen überdies verbun-

438 Hartung 2009, S. 158. Je nach Klassifikationssystem liessen sich Museen allerdings ebenso als Orte des non-formalen oder gar formalen Lernens begreifen, wie dies etwa Oliver Plessow tut (Plessow 2015, S. 26). So unterscheidet die «Classification of Learning Activities» (CLA) der Europäischen Union nicht nur zweipolig in formales und informelles Lernen, sondern differenziert «formal education», «non-formal education» und «informal learning», wobei «non-formal education» im Gegensatz zu «informal learning» an Institutionen erfolgt, diese institutionellen Angebote aber nicht, wie umgekehrt im Fall des «formal Learning» bestimmte Bedingungen erfüllen, wie etwa eine mindestens einsemestrige Dauer oder Anerkennung der Institution als Teil des nationalen Bildungssystems (Eurostat 2016, insb. S. 16-19). Nach dieser Unterscheidung käme es auf den Kontext und die konkrete Ausprägung an, welcher Form Lernprozesse im Museum zuzurechnen wären. Museumsbesuche im Rahmen des Schulunterrichts könnten wohl als Teil von «formal education» gelten, die individuelle Teilnahme an einer museumspädagogischen, organisierten Lehr-Lern-Situation wohl als non-formales Lernen.

Nina Kahnwahl bezeichnet solche Klassifikationssysteme, in der sich die unterschiedlichen Formen wechselseitig ausschliessen sollen, als «komplementäre Ansätze» (Kahnwald 2016, S. 347, Kursivsetzung analog zum Original). Aufgrund der am Beispiel des Museums angedeuteten Schwierigkeiten in der eindeutigen Zuordnung konkreter Lernformen scheint mir hierfür die zweite von Kahnwald genannte Variante, nämlich «dimensionale Ansätze» mit der Vorstellung eines Kontinuums zwischen den Lernformen (Kahnwald 2016, S. 347 f., direktes Zitat S. 347, Kursivsetzung analog zum Original), einleuchtender.

439 Dies kommt allein dadurch zum Ausdruck, dass im Jahr 2016 sogar zwei Handbücher zum informellen Lernen erschienen sind, nämlich das «Handbuch informelles Lernen» bei Beltz Juventa (Harring et al. 2016) und das «Handbuch Informelles Lernen» bei Springer VS (Rohs 2016). Eine vergleichende Rezension der beiden Sammelbände liegt vor von Rau/ Welser 2017.

440 Zum Begriff des lebenslangen Lernens, dessen zunehmender Relevanz als Phänomen und in bildungspolitischer Hinsicht: Hof 2011, insb. S. 116-118. Zum Zusammendenken von lebenslangem und informellem Lernen: Kahnwald 2016, S. $344 \mathrm{f}$.

441 Z. B. Kahnwald 2016, S. 345 ff.; Alkemeyer/Brümmer 2016, S. 493. 
dene Vorstellung von Lernen «als ein subjektiver Konstruktionsprozess» ${ }^{442}$ bzw. von «inhaltlich offenen Lernprozesse[n]» ${ }^{443}$ ist dabei durchaus anschlussfähig an die weiter oben skizzierten Überlegungen zu Museumsbesuchen als individuellen und selbst gesteuerten Aneignungsprozessen. Insofern ist das Konzept des informellen Lernens einerseits aufgrund seiner inhaltlichen Aufladung des Lernbegriffs brauchbar für mein Projekt, gleichzeitig aber auch aufgrund seiner zeitlichen Ausweitung des Lernbegriffs auf lebenslanges Lernen und damit auf Erwachsene, die im Fokus meiner Studie stehen. Museen und Ausstellungen verstehe ich mit Heese als Orte solch lebenslangen Lernens. ${ }^{44}$

\subsection{Historisches Denken, historisches Lernen und historische Kompetenzen in Museum und Ausstellung}

In den vorangegangenen Abschnitten wurde deutlich, dass Ausstellungsbesuche ausgesprochen komplexe und herausforderungsreiche Prozesse sind - einerseits durch die Vielschichtigkeit der Manifestation selbst, andererseits durch ebensolche Vielschichtigkeit der darin ablaufenden Aneignungsprozesse, die einerseits durch die räumliche Struktur der Ausstellung und ihrer Elemente, aber auch durch individuelle Bedingungsfaktoren aufseiten der Besuchenden geprägt werden können. Als Herausforderungen für Besuchende bzw. hier konkret Schülerinnen und Schüler identifiziert Olaf Hartung insbesondere den Umgang mit Objekten, in dem er eine Reihe von Schwierigkeiten und Fallstricken sieht, denn: «Das Betrachten authentischer Originale allein garantiert weder historisches Lernen noch die Ausbildung eines reflektierten Geschichtsbewusstseins.» ${ }^{445}$ Dinge könnten Fragen evozieren, ebenso gut aber auch schweigen und eine Kontextualisierung notwendig machen. ${ }^{446}$ Deshalb warnt Hartung vor einem «substantialistischen Dingbegriff» und der damit verbundenen Hoffnung, «über die Dinge einen Direktanschluss zur Geschichte» zu erhalten, während er das Ziel von Museen vielmehr in «der Aufklärung der Besucher über den Konstruktcharakter und die Deutungsperspektiven sowie über die in einer Ausstellung verwendeten Methoden histori-

442 Alkemeyer/Brümmer 2016, S. 493.

443 Berg 2016, S. 710.

444 Heese 2014, S. 13.

445 Hartung 2009, S. 169.

446 Hartung 2009, S. 168. 
scher Untersuchung und Erklärung» sieht, was umgekehrt nicht zwingend originale Objekte erfordere. ${ }^{447}$

Ausgehend von solchen und anderen Überlegungen zum «Konstruktcharakter ${ }^{448}$ von historischen Museen/Ausstellungen und zum manifestationsspezifischen Lernen ist im Rahmen der Kompetenzorientierung innerhalb der Geschichtsdidaktik in den letzten Jahren verstärkt auch darüber nachgedacht worden, welche Kompetenzen während eines Museums-/Ausstellungsbesuchs zum Einsatz kommen können. ${ }^{449}$ Es bietet sich an, dabei, ausgehend von Anregungen durch Bodo von Borries, Andreas Körber und Michael Sauer, idealtypisch zwei Bereiche von Kompetenzen zu unterscheiden: zum einen solche, die während eines Museumsbesuchs erlernt werden können, zum anderen solche, die bereits vorgängig vorhanden sein sollten und für die Nutzung von Museen nützlich sein bzw. dort zur Anwendung kommen können. ${ }^{450}$

Es gehe, so Körber, vorrangig um Zweitere, nämlich gerade

«nicht nur um die Frage, was an und in Museen «historisch gelernt» werden kann und muss, und wie das geschehen kann. $\mathrm{Zu}$ fragen ist vielmehr gerade auch danach, welche Einsichten, Konzepte, Begriffe und Fähigkeiten Lernende für die Nutzung und ggf. Gestaltung von Museen, Ausstellungen etc. erwerben bzw. ausbauen müssen.» ${ }^{451}$

Die Autoren konstatieren, dass in Museen eher von bereits vorhandenen Kompetenzen ausgegangen werde, mehr als dass die Kompetenzentwicklung während des Besuchs möglich sei und zum zentralen Gegenstand der Museumsarbeit er-

447 Hartung 2009, S. 168 ff., direkte Zitate S. 168 u. S. 169.

448 Der Terminus findet sich neben Hartung (Hartung 2009, S. 169) zum Beispiel auch bei Sauer (Sauer 2009, S. 87), losgelöst von historischen Ausstellungen ausserdem bei Schreiber et al. (Schreiber et al. 2007, S. 26).

$449 \mathrm{Zu}$ nennen ist insbesondere der Sammelband «Historische Kompetenzen und Museen» von Popp/Schönemann 2009, darin wiederum insbesondere die konzeptionell an Kompetenzmodellen ausgerichteten Beiträge von Borries 2009, Gautschi 2009b, Hasberg 2009, Körber 2009, Popp 2009, Sauer 2009; ausserdem die Beiträge von Zabold/Schreiber 2004 und Körber 2010b mit 2010a.

450 Körber 2009, S. 62; Borries unterscheidet diese beiden Perspektiven anhand der historischen Methodenkompetenzen (Borries 2009, S. 116 f.). Michael Sauer differenziert allgemein in Kompetenzen als "Ziel und Voraussetzung» (Sauer 2009, S. 81 f., direktes Zitat S. 81).

451 Körber 2009, S. 62, Kursivsetzung analog zum Original. 
klärt werde oder werden solle ${ }^{452}$ - wohingegen dies etwa Stefanie Zabold und Waltraud Schreiber dezidiert einfordern. ${ }^{453}$

Eine alternative Differenzierung der in der Geschichtsdidaktik diskutierten Kompetenzen lässt sich dahingehend vornehmen, ob diese als spezifisch für den Bereich der Museums-/Ausstellungs- bzw. allgemein Geschichtskulturnutzung angesehen werden oder ob in anderen Zusammenhängen, etwa für den Geschichtsunterricht, entwickelte und relevante Kompetenzen auf den Umgang mit ausserschulischer Geschichtskultur übertragen werden. Gemeinsamer Nenner der vorgeschlagenen Kompetenzen in Bezug auf Museen und Ausstellungen ist, dass sie von einem narrativen Geschichtsverständnis ${ }^{454}$ ausgehen und folglich historische Ausstellungen nicht als Abbild der Vergangenheit, sondern als Erzählung über Vergangenheit begreifen, die medienspezifischen Konstruktionsbedingungen folgt. ${ }^{455}$ Kompetenz beinhaltet in diesem Zusammenhang im weitesten Sinn das Umgehenkönnen mit dieser Manifestation und der von ihr erzählten Geschichte, nicht ein unreflektiertes Übernehmen der darin enthaltenen Aussagen über Vergangenes.

Die Perspektive der als Voraussetzung notwendigen und dabei zugleich spezifisch auf das geschichtskulturelle Feld bezogenen Kompetenzen nimmt HansJürgen Pandel ein, indem er eine «Geschichtskulturelle Kompetenz» ausweist. ${ }^{456}$ Pandel geht davon aus, dass die Geschichtskultur nach grundlegend anderen Prinzipien funktioniert als die Geschichtswissenschaft. ${ }^{457}$ Geschichtskultur ziehe «ihren Reiz ja gerade aus der Abweichung von historisch Triftigem», ${ }^{458}$ es gehe ihr «nicht um den erforschten bzw. erforschbaren historischen Gegenstand, sondern um die Präsentation».459 Der Geschichtsunterricht habe «zur Geschichtskultur

452 Borries 2009, S. 100, 117; Sauer 2009, S. 81 f.; Körber 2010b, S. 44. Ebenso wird diese Frage erörtert bei Hasberg 2009, S. $226 \mathrm{ff}$.

453 Die Autorinnen formulieren strengere Erwartungen an Museen: «Aus der Sicht von Geschichtstheoretikern und Geschichtsdidaktikern gehört zu einer gelungenen Ausstellung auch, dass sie Geschichte nicht als Abbild der Vergangenheit darstellt; dass sie zeigt, wie Geschichte entsteht, dass sie den Rezipienten zum Nachdenken anregt, ihn dazu befähigt, sich adäquat in der Geschichtskultur zu bewegen» (Zabold/Schreiber 2004, S. 215).

454 Hierzu allgemein in Bezug auf geschichtsdidaktische Kompetenzmodelle, unabhängig vom Museumsbereich: Schreiber 2009, S. 46.

455 Vgl. für theoretische Ausführungen zu diesem Geschichtsbegriff die Anmerkungen in Fussnote 3 .

456 Pandel 2005, S. 40 ff., direktes Zitat S. 40.

457 Pandel 2005, S. 128 ff., insb. S. 131 u. $135 \mathrm{ff}$.

458 Pandel 2005, S. 130.

459 Pandel 2005, S. 133. 
noch nicht den richtigen Zugang gefunden», beziehe sich vorrangig auf «das von der Geschichtswissenschaft bereitgestellte Wissen» und nehme die Geschichtskultur in der Alltagswelt der Schülerinnen und Schüler nur unzureichend zur Kenntnis. ${ }^{460}$

Um Nutzerinnen und Nutzern den reflektierten Umgang mit den vielfältigen Erscheinungen von Geschichtskultur in der Lebenswelt zu vermitteln, postuliert Pandel die Förderung von geschichtskultureller Kompetenz als wesentliche Aufgabe des Geschichtsunterrichts. ${ }^{461}$ Er versteht darunter die

«Fähigkeit, sich in dem durch Geschichte geprägten Teil der Kultur zu bewegen, d.h. sich in der Vielzahl von kulturellen Situationen, Inszenierungen, Tourismus, Verarbeitungen und auch Kommerzialisierungen bewusst - geschichtsbewusst - zu bewegen», ${ }^{462}$

und nennt als Bestandteile geschichtskultureller Kompetenz:

«Faktualität, Fiktionalität und Fiktivität unterscheiden; mit Erinnerungskonflikten umgehen; die ästhetische Dimension des Geschichtsbewusstseins wahrnehmen; kontrafaktische Aussagen erkennen und bewerten (Interessen, Lüge, Imagination); moralische und ästhetische Werturteile fällen». ${ }^{463}$

Pandels geschichtskulturelle Kompetenz ist somit stark von der Idee geprägt, dass Geschichtskultur systematisch anders mit Historischem umgehe als Geschichtswissenschaft und der übliche Geschichtsunterricht und dass dieser Unterschied unter anderem im Mass der Triftigkeit liege, wobei Pandel wohl vornehmlich die empirische Triftigkeit meint. ${ }^{464}$

460 Pandel 2013, S. 172.

461 Neben der geschichtskulturellen beinhaltet Pandels Kompetenzmodell eine «Narrative Kompetenz», «Interpretationskompetenz» und "Gattungskompetenz» (Pandel 2013, S. 221 ff., direkte Zitate S. 223 u. S. 226; Pandel 2005, S. 24 ff.).

462 Pandel 2013, S. 233.

463 Pandel 2013, S. 222.

464 Pandel 2005, S. 130. Zu den drei Formen von Triftigkeiten, der empirischen, narrativen und normativen Triftigkeit: Rüsen 2012, S. 90 ff.; in seiner Historik aus dem Jahr 2013 spricht Rüsen stattdessen von Plausibilitäten und unterscheidet vier Formen, nämlich Plausibilität im Hinblick «(a) auf Erfahrung, (b) auf Erklärung, (c) auf Bedeutung und (d) auf Sinn» (Rüsen 2013, S. 58 ff.). 
Pandel ist derzeit der einzige Geschichtsdidaktiker, dessen Kompetenzmodell explizit eine geschichtskulturelle Kompetenz aufführt. In anderen Modellen wird der Umgang mit ausserschulischer Geschichtskultur nicht separat ausgewiesen, da Modelle entweder in der angestrebten Reichweite auf den Geschichtsunterricht fokussieren ${ }^{465}$ oder da, wie im Fall von Körber et al. oder Gautschi, der Umgang mit Geschichtskultur in allgemeinere Kompetenzbereiche integriert wird. ${ }^{466}$

Die theoretische Frage, ob der Umgang mit Geschichtskultur eher als anderen Kompetenzen eingelagert zu betrachten sei oder ob der Umgang mit Geschichtskultur wie bei Pandel in eine eigenständige Kompetenz ausgegliedert werden sollte, hängt wesentlich damit zusammen, inwiefern historischem Denken im Geschichtsunterricht und im geschichtswissenschaftlichen Kontext auf der einen Seite und im Kontakt mit Geschichtskultur und spezifischer mit Museen auf der anderen Seite ein systematisch und wesentlich unterschiedlicher Charakter zugeschrieben wird ${ }^{467}$ bzw. inwieweit ein breiteres oder engeres Verständnis von Geschichtskultur zugrunde gelegt wird. ${ }^{468}$ Wolfgang Hasberg und Andreas Körber sprechen sich - und ich

465 Z.B. Drie/Boxtel 2008; Verband der Geschichtslehrer Deutschlands 2006, wobei Sauer hierzu eine nachträgliche Übertragung auf Museumsbesuchende erarbeitet hat (Sauer 2009).

466 Körber et al. 2007; Gautschi 2009a, S. 51, S. 64 ff.

467 Die Unterscheidung der beiden Varianten findet sich bei Hasberg 2009, S. 214.

468 Zur Unterscheidung eines engeren und weiteren Geschichtskultur-Begriffs: Plessow 2015, S. 26 ff., insb. S. 27.

Von einer wesentlichen Unterschiedlichkeit von Schule/Wissenschaft einerseits und Geschichtskultur andererseits geht neben Pandel etwa auch Bergmann aus (Bergmann 1998, S. 21 ff.). Differenzen zwischen Geschichtsschreibung und Lebenswelt zeigt auch Schörken auf (Schörken 1981, insb. S. 225, S. 59). Und spezifisch für Museen hält Pohl fest: «Historische Museen weisen Strukturen auf, die nur partiell denen von (Hoch)Schule und Wissenschaft gleichen. Insofern können die dort geltenden geschichtsdidaktische[n] Kategorien sicherlich nur ansatzweise auf sie übertragen werden» (Pohl 2013, S. 28). Umgekehrt definiert Schönemann «die Schule selbst [als] eine Institution der Geschichtskultur», ebenso wie Universitäten (Schönemann 2014, S. 18 ff., direktes Zitat S. 20).

Das Verhältnis von Geschichtswissenschaft, Geschichtsunterricht und Geschichtskultur ist in der geschichtsdidaktischen, -wissenschaftlichen und -theoretischen Literatur strittig und der zugehörige Literaturbestand umfangreich und unübersichtlich. Komplizierter wird das Feld noch dadurch, dass sich entsprechende Debatten vermengen mit denjenigen um Geschichts- vs. Erinnerungskultur, um Geschichte vs. Erinnerung und um Positivismus vs. Konstruktivismus. Letztgenannten drei Gegensatzpaaren rückt systematisierend Hasberg zuleibe (Hasberg 2006 , v.a. S. 55 f.), die terminologische Lage allerdings weiter verkomplizierend dadurch, dass er unter Erinnerungskultur offenbar vor allem Theorien des kollektiven Gedächtnisses subsummiert (ebd., S. 36 ff.) und diese einem begrifflichen Konglomerat aus Geschichtskultur, Geschichtsbewusstsein, historischem Bewusstsein und historischem Denken gegenüberstellt (ebd., S. 55).

Theorien zu Erinnerungskultur verstünden Geschichte positivistisch und als Gegensatz zu Gedächtnis (ebd., S. 55 f.), Geschichtskultur gehe umgekehrt von einem konstruktivistischen 
schliesse mich dem an - dezidiert gegen eine solche Trennung aus. ${ }^{469}$ Hasberg stellt fest: «Da Vergangenheit und Geschichte nicht anders als in Form geschichtskultureller Artikulationen zugänglich sind, können spezielle geschichtskulturelle Kompetenzen schlechterdings nicht ausgewiesen werden.» ${ }^{470}$

So stellt auch das Kompetenz-Strukturmodell der Gruppe FUER Geschichtsbewusstsein eine Unterschiedlichkeit infrage, indem es, wie weiter oben bereits erwähnt, den Anspruch erhebt, «historisches Denken in allen Phasen von Lebensläufen und in allen Bereichen des Lebens kategorial fassen» zu können. ${ }^{471}$ Übereinstimmungen mit den Überlegungen Pandels finden sich gleichwohl dahingehend, dass geschichtskulturelle Manifestationen als Medien ernst und in den Blick zu nehmen seien. So äussert Körber:

«Ein nach unserem Strukturmodell kompetenzorientiert angelegter Geschichtsunterricht in einem Museum oder einer Gedenkstätte nimmt jene als geschichtskulturelle Institution wahr und reduziert sie nicht auf die Funktion der Vermittlung vermeintlich perspektivneutraler Informationen. Er gibt sich nicht damit zufrieden, dass Schülerinnen und Schüler nach einem Besuch Einzelinformationen über den dargestellten Zusammenhang wiedergeben können, sondern zielt darauf ab, die gegenwärtige gesellschaftliche Funktion der geschichtskulturellen Institution in die Betrachtung und eigene Reflexion einzubeziehen.» ${ }^{472}$

Geschichtsbegriff aus, demzufolge Geschichte «im Prozess des Re-Konstruierens» entsteht (ebd., S. 55). Für den Stellenwert der Geschichtswissenschaft in diesem System schlussfolgert Hasberg: «Die strikte Dichotomie von Erinnerung/Gedächtnis auf der einen Seite entspricht nicht dem Modell des Geschichtsbewusstseins, das dem historischen Denken per se lebensweltliche Funktion zuschreibt und zwischen dem historischen Denken des in der Geschichtskultur sich bewegenden Laien und dem des der wissenschaftlichen Forschung obliegenden Historikers nur graduelle Unterschiede ausmachen kann» (ebd., S. 56).

Gewisse Unschärfen in Bezug auf die Auslotung dieser von Hasberg sogenannten «graduelle[n] Unterschiede» habe ich weiter oben bereits für Rüsen konstatiert (vgl. Abschnitt 2.2). Unentschlossen in der Einordnung bleibt auch Grütter. Einerseits konstatiert er: «Der Begriff ‘Geschichtskultur〉 synthetisiert so unterschiedliche Institutionen wie Universität, Schule, Archive, Museen, Denkmalpflege, Gedenkstätten und Geschichtsvereine [...]» (Grütter 1997a, S. 601). Wenig später scheint dann, trotz des beschriebenen Bedingungsgefüges, doch eine angenommene Dichotomie in seinen Ausführungen auf, wenn er schreibt: «Insofern bedingen sich Schule und Universität auf der einen und die Geschichtskultur einer Gesellschaft auf der anderen Seite» (ebd.). Hasberg 2009, S. 235; Körber 2009, S. 79 f.

470 Hasberg 2009, S. 235.

471 Schreiber et al. 2007, S. 19 und S. 22.

472 Körber 2009, S. 73. 
Allerdings geht Körber im Gegensatz zu Pandel nicht so weit, für den Umgang mit Geschichtskultur systematisch andere Aspekte historischen Denkens als relevant zu propagieren. Im Gegenteil stammen von Körber Vorschläge, die im Kompetenz-Strukturmodell ${ }^{473}$ enthaltenen Kompetenzen historischen Denkens auf Museums-/Ausstellungsbesuchende zu adaptieren. ${ }^{474} \mathrm{Er}$ unterscheidet jeweils in ein basales, intermediäres und elaboriertes Niveau, wobei ich auf eine detaillierte Wiedergabe der einzelnen Niveaus verzichte und stattdessen jeweils die Bandbreite zwischen den Polen wiedergebe. ${ }^{475}$

Im Bereich der historischen Sachkompetenzen unterscheidet Körber in einer Publikation aus dem Jahr 2009 die «Verfügung über ein Konzept der «Ausstellung〉 und des Museums» und über ein «Konzept des 〈Objekts»» sowie überdies eine «Strukturierungskompetenz» ${ }^{476}$ :

- Vorstellungen über Museen bzw. Ausstellungen können dabei reichen von einer Wahrnehmung als «Darstellung vergangener Wirklichkeit» über eine Einsicht in deren Bindung an Zeit und Forschungsstand bis hin zu einer Reflexion und Hinterfragung der «in einer Ausstellung verwendeten Kategorien». ${ }^{477}$

- Wahrnehmungen von Objekten reichen von einer Wahrnehmung der «ausgestellten Objekte nur als 〈Gegenstände»» über deren Betrachtung «als Repräsentanten eines historischen Zusammenhangs» und Unterscheidung «zwischen 〈Original〉 und 〈Fälschung〉» bis hin zu einer Reflexion des Konzepts von Originalität und der durch die Ausstellung getroffenen Objektauswahl. ${ }^{478}$

- Strukturierungskompetenz umfasst das Wahrnehmen des Ausstellungsaufbaus als «nicht wahllos» über das Wiedererkennen von bekannten Strukturierungsweisen mit zunehmender Fähigkeit zu deren Kommentierung bis hin zur Reflexion der Effekte einer bestimmten Präsentationsweise. ${ }^{479}$

473 Körber et al. 2007.

474 Körber 2009, Körber 2010a, Körber 2010b.

475 Ich bediene mich dabei eklektisch aus mehreren Veröffentlichungen Körbers mit ähnlicher Ausrichtung. In Körber 2009 wird nur ein Teil der Kompetenzbereiche in Niveaustufen ausdifferenziert, was in der späteren Variante bei Körber 2010b mit Anhang 2010a dann vollständig und in tabellarischer Form der Fall ist (Körber 2010a, S. 3 ff.), dabei in der Ausführung aber teilweise auch abweichend zur früheren Publikation aus dem Jahr 2009. In Körber 2010a sind neben Stufungen zur «Kompetenzdiagnostik» auch Fragen zur jeweils zugehörigen Förderung aufgelistet, ich beziehe mich jedoch nachfolgend bei Verwendung von Körber 2010a nur auf seine diagnostischen Überlegungen.

476 Körber 2009, S. 65, 66, 67.

477 Körber 2009, S. 65.

478 Körber 2009, S. $66 \mathrm{f}$.

479 Körber 2009, S. 67 f., direktes Zitat: S. 67. 
In einer späteren Veröffentlichung aus dem Jahr 2010 wählt Körber einen abweichenden Zugang zum Bereich der Begriffskompetenz. Dort nimmt er ein Verfügenkönnen und Reflektieren über diejenigen Begriffe und Konzepte in den Blick, mit denen eine konkrete Ausstellung arbeitet und die für deren Erschliessung notwendig sind (z. B. «Konzentrationslager», «Zeitzeuge»), verlässt also die Ebene der für alle Arten historischer Ausstellungen notwendigen Konzepte. ${ }^{480}$ Sinnvoll und der Idee einer Sachkompetenz Rechnung tragend erscheint mir eine Integration beider Perspektiven.

Im Bereich der historischen Fragekompetenzen, die im Kompetenz-Strukturmodell in das Entwickeln eigener Fragestellungen und das Erkennen von bereits vorliegenden Fragestellungen unterschieden werden, ${ }^{481}$ verweist Körber für den Fall von historischen Museen/Ausstellungen vor allem auf die Relevanz des zweiten Bereichs; denn Orientierungsbedürfnisse seien

«zunächst nur auf Seiten der Ausstellungsmacher, ihrer Auftraggeber und Berater aktiv, auch bei ihnen allerdings in der vermittelten Form, dass sie nicht nur ihre persönlichen Bedürfnisse einfließen lassen, sondern die von ihnen wahrgenommenen Bedürfnisse der 〈Gesellschaft〉 (oder relevanter Teile von ihr)». ${ }^{482}$

Ausgehend davon, sieht Körber einen Kompetenzbereich in der «Entzifferung des in der Ausstellung 〈bedienten〉 Interesses», weist daneben aber auch das Stellen eigener Fragen als Bereich aus. ${ }^{483}$

- Ersteres reicht vom Erkennen dessen, «dass der Ausstellung eine Form von Frage an die Vergangenheit zu Grunde liegt», über das Wahrnehmen einer «Absicht» und «Relevanz» der Ausstellung bis hin zur Reflexion und Hinterfragung vorhandener Fragestellungen und der Fähigkeit, diese «umzuformulieren, fortzuschreiben, Alternativen zu entwickeln». ${ }^{484}$

- Zweiteres umfasst «die Fähigkeit, das eigene Interesse in eine Frage zu <verwandeln»», und zwar zunächst auf eine «spontane und unsystematische» Weise über eine Übersetzung «in die Begriffe und Konzepte [...], mit denen die

480 Körber 2010a, S. 3 ff., direkte Zitate: S. 4.

481 Schreiber et al. 2007, S. 26.

482 Körber 2009, S. 68.

483 Körber 2009, S. 69. In seiner Systematisierung aus dem Jahr 2010 benennt Körber die beiden Bereiche als «Selbst Fragen stellen (können)» und «Fragen verstehen (können)» (Körber 2010a, S. 3 ff.).

484 Körber 2010a, S. 3 ff., direkte Zitate: S. 3, S. 4, S. 5. 
Ausstellung arbeitet», bis hin zur Reflexion darüber, «inwiefern eine solche Ausstellung überhaupt das eigene Bedürfnis befriedigen kann». ${ }^{485}$

Den Bereich der historischen Methodenkompetenzen unterscheidet Körber analog zum FUER-Modell in Re-Konstruktionskompetenz und De-Konstruktionskompetenz, wobei er wiederum für den konkreten Fall des historischen Denkens im Museum die besondere Bedeutung eines der beiden Bereiche, der De-Konstruktionskompetenz, hervorhebt. ${ }^{486}$ Dies erscheint nachvollziehbar, da eine Ausstellung in der Logik des Kompetenz-Strukturmodells eine Narration über Vergangenes darstellt, mit der die Besuchenden zwangsläufig durch ihren Besuch in Kontakt kommen.

- De-Konstruktion umfasst Körber zufolge, «überhaupt [...] das Dargestellte als eine heutige Aussage über Geschichte zu erkennen», und reicht über die Verwendung hierfür «gängiger Konzepte und Begriffe (‘Perspektive), ‘Interesse〉, 〈Inszenierung〉, 〈Auswahl〉, 〈Re-Kontextualisierung〉 ...)» bis hin zu einer Reflexion der «verwendeten Deutungs- und Erklärungsmuster». ${ }^{487}$

- Re-Konstruktion beinhaltet die Fähigkeit, «überhaupt aus dem Präsentierten Informationen zu entnehmen und zueinander in Beziehung zu setzen», diese «unter Rückgriff auf bekannte Vorbilder, Verfahren, Frageraster, Muster zu neuen Sinnzusammenhängen zu verbinden» und schliesslich sogar «Informationen zur Erschliessung eigener, innovativer oder spezieller Fragen zu nutzen, eigenständige Sinnbildungen zu erstellen». ${ }^{488}$

Im vierten und letzten Kompetenzbereich, bei den historischen Orientierungskompetenzen, differenziert Körber in Analogie zum Kompetenz-Strukturmodell in vier Bereiche, die er wiederum museumsspezifisch wendet. Da es sich bei dem Bereich der Orientierung um denjenigen handelt, der in besonderem Mass das Kerninte-

485 Körber 2009, S. 69f., Kursivsetzung analog zum Original. In der Fassung von 2010 spricht Körber stattdessen für das elaborierte Niveau davon, Besuchende seien «in der Lage, in Abgrenzung zu herkömmlichen Interessen eine eigene, ihrer eigenen Perspektive entsprechende Fragestellung zu formulieren, und diese in die gesellschaftliche Perspektive einzuordnen» (Körber 2010a, S. 3), sieht hier also keinen Abgleich mit dem Grad an Befriedigung der eigenen Frage durch die Ausstellung vor.

486 Körber 2009, S. 70. In den Überlegungen aus dem Jahr 2009 wird dann auch die ReKonstruktionskompetenz gar nicht ausdifferenziert, jedoch finden sich Überlegungen dazu in Körber 2010a, S. $3 \mathrm{ff}$.

487 Körber 2010a, S. 3 ff., Kursivsetzung analog zum Original.

488 Körber 2010a, S. 3 ff., Kursivsetzung analog zum Original. 
resse meines Forschungsvorhabens tangiert, weil sich vor allem darin die Bezüge historischen Denkens auf die eigene Person und Lebenswelt der Besuchenden manifestieren, gebe ich die von Körber vorgeschlagenen Niveauausprägungen im Anhang in ausführlicherer, tabellarischer Form wieder (siehe Tabelle A). Die Tabelle zeigt, dass das Spektrum an Aussagen in diesem Kompetenzbereich von überhaupt vorhandenen Äusserungen in Bezug auf die Veränderung eigener Konzepte, Vorstellungen und Verhaltensanregungen über das Kommunizieren dieser Veränderungen mittels Rückgriff auf «gängige» und «bekannte» Begriffe und Kategorien und im Abgleich mit Angeboten, die in der Ausstellung zum jeweiligen Thema vorhanden sind, bis hin zur innovativen Erweiterung oder kritischen Reflexion der Begrenztheit eigener Konzepte und Handlungsmöglichkeiten reicht.

Zusammenfassend definiert Körber «Kompetenz historischen Denkens in Bezug auf Ausstellungen und Museen» als die

«Fähigkeit, Fertigkeit und Bereitschaft, das in einer Ausstellung Dargebotene in seinen Einzelheiten wie in der durch die Auswahl der Exponate, das Arrangement und die Inszenierung getroffene Aussage wahrzunehmen und zu entschlüsseln und die so gewonnenen Informationen und Einsichten für eigene historische Orientierung zu nutzen». ${ }^{489}$

Körbers Übersicht stellt eine aufschlussreiche erste Auslegeordnung dessen dar, was in Anlehnung an das Kompetenz-Strukturmodell als historisches Denken bzw. als Kompetenzen historischen Denkens in einer Ausstellung gefasst werden könnte. In dreierlei Hinsichten erweist sich der Vorschlag jedoch als ergänzungsbedürftig.

Zum einen fällt auf, dass die vorgenommenen Stufungen stellenweise an Kohärenz vermissen lassen. So werden beispielsweise im Bereich der Orientierungskompetenzen nicht systematisch Reflexion und Veränderung eigener Konzepte und Handlungsdispositionen gestuft, Formulierungen beziehen sich nicht durchgängig auf den re-konstruktiven und de-konstruktiven Modus, und die Niveaustufen sind im Vergleich der verschiedenen Kernkompetenzen untereinander nicht durchgängig strukturgleich aufgebaut.

Zum anderen wird die Ausstellung als Manifestation und in ihrer Rolle in den Formulierungen stellenweise wenig sichtbar. Körber adressiert Veränderung und Reflexion eigener Konzepte, Vorstellungen und Handlungsdispositionen im Kon- 
takt mit einer Ausstellung, spezifische Konstruktionsbedingungen der Ausstellung als Manifestation spielen in diesen Überlegungen allerdings - mit Ausnahme der Formulierungen der historischen Sachkompetenzen - keine Rolle. Anders ausgedrückt, scheint die Manifestation, im Rahmen deren historisches Denken stattfindet, in dieser Konzeption weitgehend austauschbar, könnten sich die beschriebenen Kompetenzen doch beispielsweise auch auf eine historische Fernsehdokumentation beziehen. Diese Austauschbarkeit trägt einerseits eindrücklich der Idee des Kompetenz-Strukturmodells Rechnung, auf alle Situationen des Kontakts mit Historischem gleichermassen anwend- und übertragbar zu sein. Gleichwohl stellt sich die Frage, ob eine bereichsspezifische Anpassung nicht stärker auf die konkrete Manifestation Bezug nehmen müsste, wenn sie einen Mehrwert zu den bereits in allgemeiner Form existierenden Überlegungen zu historischem Denken im Rahmen des Kompetenz-Strukturmodells darstellen soll. Damit einher geht eine dritte Beobachtung, die sich als Kognitionslastigkeit der vorgelegten Modellierung unter Abwesenheit von Bezügen zu ästhetischen und emotionalen Komponenten des historischen Denkens im Museum bezeichnen lässt und die ich im Rahmen des nächsten Abschnitts weiter ausführe und in einen grösseren Kontext einbette.

\section{4 Ästhetik und Emotionen als Dimensionen historischen Denkens und Lernens in einer historischen Ausstellung}

Gelegentlich wird geschichtsdidaktischen Kompetenzmodellen, insbesondere dem Kompetenz-Strukturmodell der Gruppe FUER mit seiner starken Betonung von Reflexionsfähigkeit, eine (zu) starke Fokussierung auf kognitive Aspekte des historischen Denkens attestiert. ${ }^{490}$ Gerade bei der Übertragung der Modellierung auf historisches Denken beim Museums- bzw. Ausstellungsbesuch gilt es, diesen Einwand ernst zu nehmen, sind doch gerade Museen und Ausstellungen Orte, die, wie oben ausgeführt, wesentlich auch eine ästhetische Dimension aufweisen.

490 Etwa spricht Barricelli von einer «Alleinherrschaft des Rationalen» und von einer «Verabschiedung alles authentisch Emotionalen, Imaginativen und Affektiven aus der Beschäftigung mit Geschichte» (Barricelli 2008, S. 238). Borries widerspricht allerdings dezidiert der Annahme, dass diese Verkürzung ein Problem ausschliesslich des Kompetenz-Strukturmodells sei: «Es ist allerdings nicht so, dass ausgerechnet die Sechsfeldermatrix und das Kompetenzmodell von 〈FUER Geschichtsbewusstsein〉 die kognitivistische Verkürzung verursacht oder verschärft hätte. Diesem Verdacht gilt es zu widersprechen» (Borries 2009, S. 117). 
So konstatieren etwa Heinreich Theodor Grütter und Bärbel Kuhn: «Geschichte im Museum hat den besonderen Reiz der Anschaulichkeit, denn die Besucherinnen und Besucher erfahren die Vergangenheit im Museum zunächst einmal sinnlich, immer visuell, meist auch akustisch und immer häufiger auch haptisch oder als Geruch.» ${ }^{491}$ Kuhn et al. unterscheiden dabei die Begegnung mit Geschichte im Museum vom Geschichtsunterricht: «Die Materialität des Museums eröffnet durch das auf Anschauung beruhende Lernen in stärkerem Masse sinnliche und ästhetische Zugänge zu historischer Erkenntnis und Erfahrung als der schulische Unterricht.» ${ }^{492}$ Dessen ungeachtet lassen bislang vorgelegte Kompetenzmodelle und Modellierungen historischen Denkens wesentliche Aspekte von Geschichtskultur, namentlich deren Ästhetik und auch emotionale Relevanz, weitgehend unthematisiert. ${ }^{493}$

\subsection{1 «Nicht-nur-kognitive Momente ${ }^{494}$ historischen Denkens und Lernens}

Bodo von Borries stellt deshalb die Frage, ob am Beispiel des historischen Denkens im Museum über solche Blindstellen existierender Modellierungen nachgedacht werden könnte:

«Ist das Geschichtslernen im Museum geeignet, das Kompetenzkonzept auf Verkürzungen zu überprüfen oder solche gegebenenfalls abzustellen? Gab es z. B. bisher eine Verengung auf blosse Kognition? Fehlte die Einbeziehung der ästhetischen und der politischen Dimension (die freilich - seit Rüsen immer wieder gefordert wurde)? Im Museum ist ein sinnlich-ästhetischer Überschuss unverkennbar - aber im Kompetenzmodell?» ${ }^{495}$

491 Grütter/Kuhn 2014, S. 11.

492 Kuhn et al. 2014, S. 9. Zu den ästhetischen Bedingungen von Museen siehe im selben Band auch Heese 2014, S. 15.

493 Mit Ausnahme vielleicht der für diese Aspekte von Geschichtskultur stärker sensiblen geschichtskulturellen Kompetenz bei Hans-Jürgen Pandel (Pandel 2006; Pandel 2013).

494 Borries 2014, S. 167. Der Terminus bzw. vielmehr das zugehörige Adjektiv «nicht-nurkognitiv» wird von Borries näher erläutert in Borries 2014, S. 170 f., Kursivsetzung analog zum Original. Verwendet wird der Begriff z. B. bei Borries 2014, S. 17, S. $167 \mathrm{ff}$.

Borries 2009, S. 117. 
Borries selbst sieht Anknüpfungspunkte für die Integration emotionaler und ästhetischer Komponenten im FUER-Modell und verfolgt als Ziel «die weitere Auslegung und Präzisierung, nicht die Revision oder Sprengung» der existierenden Modellierung. ${ }^{496}$ So enthalte das Modell im Bereich der historischen Orientierungskompetenz über das Kognitive hinausgehende Aspekte, thematisiere diese jedoch nicht explizit. ${ }^{497}$

Johannes Meyer-Hamme sieht den Ort von Emotionen darüber hinaus wesentlich auch in der Fragekompetenz angesiedelt, etwa könne historisches Fragen aus dem «Erleben», vor allem aber auch aus den «Verunsicherungen dieser Emotionen» resultieren. ${ }^{498}$ Solche Dimensionen theoretisch zu fassen und in die Modellierung zu integrieren, beschreibt Borries als eine zukünftige Aufgabe. ${ }^{499}$ Und auch jenseits des FUER-Modells kommt Borries zu der Defizitfeststellung, dass die Rolle von Ästhetik und Emotionen in der geschichtsdidaktischen Theorie wie auch in empirischen Arbeiten und Unterrichtspraxis entgegen besserem Wissen bislang unzureichend berücksichtigt werde:

«Geschichtslernen stellt - das sagt unsere eigene Erfahrung - durchaus einen nicht-nur-kognitiven Prozess dar. Emotionen, Ästhetik, Moral, Politik, Imagination, Triebdynamik usw. haben ihren Anteil an Auslösung, Verlauf und Ergebnis; sie treiben also nicht nur Lernen (oder Lernverweigerung) an, sondern ändern sich auch durch Umgang mit Geschichte. Das ist trivial und wird von niemandem bestritten. Es wird aber meist auch überhaupt nicht ernst genommen, nicht nur in der Unterrichtspraxis (mit ihrer häufigen Stillstellung von Ästhetik und Emotion), sondern auch in Theoriebildung, Normsetzung und empirischer Erforschung im Rahmen akademischer Geschichtsdidaktik.» ${ }^{500}$

Während Borries' Urteil mit Blick auf die geschichtsdidaktische Theorie, konkret auf Kompetenzmodelle und Modellierungen historischen Denkens, einleuchtet, erscheint sein Urteil in Bezug auf die geschichtsdidaktische empirische Forschung doch pauschalisierend. Mindestens für die empirische Forschung zu Museumsbzw. Ausstellungsbesuchenden lässt sich bereits seit Längerem eine Sensibilität für

496 Borries 2014, S. 163.

497 Borries 2014, S. 233.

498 Meyer-Hamme 2013, S. 132.

499 Borries 2014, S. 158.

500 Borries 2014, S. 17. 
die in Abrede gestellten Aspekte konstatieren. Insofern halte ich auch das Urteil Kohlers, dass in der Museumsbesuchendenforschung «das Lernen im Museum auf seine kognitive Dimension verengt» und dabei zugleich «ästhetische, emotionale

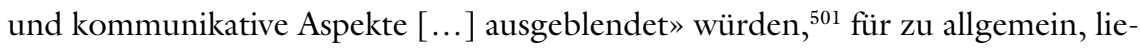
gen doch ganz im Gegenteil, wie im Rahmen des Forschungsüberblicks noch zu zeigen sein wird, einige Studien vor, die für die ästhetische, emotionale und sinnliche Dimension von Museums- bzw. Ausstellungsbesuchen sensibel sind. Sicherlich zuzustimmen ist Kohler allerdings dahingehend, dass empirische Ergebnisse bisher nicht systematisch Eingang in die geschichtsdidaktische Theorie historischen Lernens und Denkens gefunden haben. ${ }^{502}$ Insofern begegnen Borries' Überlegungen durchaus einem Desiderat.

Konkret beschreibt Bodo von Borries namentlich die Anwesenheit von Ästhetik und Emotion in der Geschichtsbegegnung als elementar, ${ }^{503}$ denn

«Historie, sei sie sprachlich oder bildlich präsentiert, kann nicht 〈ungestaltet〉 sein ${ }^{504}$ und

«Menschen können nicht «nicht-emotional〉 sein, so wenig wie sie «nicht-kommunizieren> können. Emotionen können, wenn sie denn auftreten, nicht einmal 〈un-authentisch〉, 〈verlogen〉, ‘falsch〉 oder <inhuman〉 sein, freilich sehr wohl 〈unerwünscht〉, 〈parasitär〉, 〈widersprüchlich〉 oder 〈aufklärungsresistent〉. Die Frage kann also nur sein, wie man in der Historie mit Emotionen umgeht, was man mit ihnen macht, welche Rolle sie spielen, nicht aber, ob man Emotionen hat.» ${ }^{505}$

Borries selbst wendet sich dezidiert der Rolle von Emotion und Ästhetik zu, verweist aber zugleich darauf, dass sich der Bereich jenseits des rein Kognitiven nicht in diesen beiden Dimensionen erschöpfe. ${ }^{506}$ Ganz im Gegenteil benennt er insgesamt acht «[m]entale Dimensionen des Geschichtslernens», die er jeweils in einen Bereich der Psyche und die zugehörige «Leistung für die Historische Identität» unterscheidet ${ }^{507}$

501 Kohler 2014, S. 85.

502 Kohler 2014, S. 84; vgl. dazu auch Abschnitt 3.2.

503 So ist sogar im Titel seines Bandes von «Ästhetik und Emotionalität als konstitutive[n] Momente[n] historischen Lernens» die Rede (Borries 2014).

504 Borries 2014, S. 155.

505 Borries 2014, S. 170.

506 Borries 2014, S. 150.

507 Borries 2014, S. 169. Die Kategorie «historische Identität» sei dabei allen Bereichen übergeordnet (Borries 2014, S. 170). 
und zugleich anmerkt, dass diese Dimensionen für alle Formen von «Geschichtsbeschäftigung» gelten, ${ }^{508}$ insofern auch auf den Besuch historischer Museen/Ausstellungen übertragbar sein sollten. Konkret unterscheidet Borries

- «Kognition»als «Intellektuelle Durchdringung»,

- «Motivation» als «Manifeste Interessen»,

- «Emotionalität» als «Erlebte Affekte»,

- «Ästhetizität» als «Gestalt(ungs)bedingtes Vergnügen»,

- «Moralität» als «Ethische Stellungnahme»,

- «Triebstruktur»als «Unbewusste Regungen»,

- «Fantasie» als «Imaginative Kräfte» und

- «Handlungsdisposition» als «Willensmässige Bereitschaft». ${ }^{509}$

Dass die einzelnen Dimensionen dabei durchaus nicht als trennscharf verstanden werden sollten, wird zum Beispiel deutlich, wenn Borries auf das Ineinandergreifen von moralischen Entscheidungen und Emotionen verweist. ${ }^{510}$ Dass die Grenzen des Emotionsbegriffs keineswegs eindeutig zu bestimmen seien, zeigt auch Wolfgang Hasberg. Er erwägt sogar, einige der Bereiche, die Borries separat ausweist, als in den Emotionsbereich integriert zu betrachten:

«Ohne Zweifel lassen sich Affekte und Motivationen als Emotionen begreifen [...]. Aber zählt auch das Interesse dazu, dass [sic] die Lernenden oder Lehrenden einem Gegenstand entgegenbringen? Und wie verhält es sich mit Einstellungen und Haltungen? Sind sie als Affekte zu betrachten? Schnell sprengt eine solche Gegenstandserweiterung die Grenzen eines auch nur vage abgesteckten Begriffshofs, der mit dem Terminus Emotion verbunden ist.» ${ }^{511}$

508 Borries 2014, S. 169.

509 Borries 2014, S. 169, Kursivsetzungen analog zum Original.

510 Borries 2014, S. $158 \mathrm{ff}$.

511 Hasberg 2013, S. 52, Kursivsetzung analog zum Original. Unter Rückgriff auf Differenzierungen der Pädagogischen Psychologie unterscheidet Hasberg vier Varianten von Emotionen, nämlich «topic emotions», «academic emotions», «epistemic emotions» und «social emotions», wobei innerhalb der Geschichtsdidaktik bislang der erstgenannte Bereich, die gegenstandsbezogenen Emotionen, schwerpunktmässig erforscht würden, nämlich «in Form von Untersuchungen zur Beliebtheit von und Motivation respektive Interesse für Geschichte und Geschichtsunterricht» (Hasberg 2013, S. 49, S. 54). 
Das Begriffsdickicht nicht gerade vereinfachend, aber zugleich das Bewusstsein für die Komplexität des Phänomens schärfend ist sicherlich die von Borries dezidiert vertretene Auffassung, dass das Vorhandensein von Dimensionen wie Emotion, Ästhetizität und anderen nicht zwangsläufig eine Abwesenheit von Kognition bedeutet, weshalb er vom Bereich des «Nicht-nur-Kognitiven» spricht:

«Die Terminologie von «Emotionen〉, 〈Moralentscheidungen〉 etc. als «nichtnur-kognitiv〉 - statt 〈nicht-kognitiv〉 - ist sehr bewusst gewählt. Die anderen Elemente müssen nämlich durchaus nicht <vernunftfeindlich〉, irrational', <anti-intellektuell〉 sein. Ein harmonisches Verhältnis ist durchaus denkbar; nur geht Geschichtsbewusstsein (〈Geschichtskultur〉, 〈historische Identität〉 und 〈Geschichtskompetenz〉) eben nicht im Bloss-Kognitiven auf». ${ }^{512}$

Mit seiner Rede von den «nicht-nur-kognitiven» Bestandteilen als «Dimensionen des Geschichtslernens» versucht Borries eine gebräuchliche Dichotomie zu überwinden, die bereits manchenorts als nicht weiterführend beschrieben wurde, nämlich eine Unterscheidung in die sich wechselseitig ausschliessenden Aspekte der Kognition auf der einen Seite und Emotion auf der anderen Seite. ${ }^{513}$ Gleichwohl hält Borries eine kategorieale Unterscheidung der Bereiche für notwendig, um überhaupt sensibel für die Rolle nichtkognitiver Bereiche für historisches Lernen zu werden-andernfalls resultiere aus der «Nicht-Trennung» eine «Nicht-Beachtung». ${ }^{514}$

Borries selbst widmet sich deren Aufklärung und tut dies auf zweierlei Ebenen. Zum einen lokalisiert er den Ort von Ästhetik und Emotionen in der Geschichtsbegegnung und betrachtet sie, dies wurde bereits erwähnt, als im Umgang mit Historischem zwangsläufig vorhandene Grössen. Neben diesem eher deskriptiven Zugang entfaltet er zweitens, wie ich nachfolgend zeige, auch normative Zielgrössen und denkt darüber nach, wie mit Ästhetik und Emotion als gegebenen Grössen im Prozess historischen Lernens umgegangen werden könne.

512 Borries 2014, S. $170 \mathrm{f}$.

513 Borries 2014, S. 168 ff., direkte Zitate S. 169. Zur nicht zielführenden Idee der Gegensätzlichkeit von Emotion und Kognition auch: Gies 1994, S. 27 f. und S. 38 f., sowie Brauer/Lücke 2013a, S. 15 ff., S. $18 \mathrm{ff}$.

514 Borries konstatiert für den Bereich der Emotion, «die Aufhebung der Besonderheit von Emotion» führe ansonsten «geradewegs wieder zu ihrer Leugnung (d.h. der alltäglichen Nicht-Berücksichtigung), jedenfalls im Bereich Geschichte bzw. Geschichtswissenschaft. Die Nicht-Trennung wird dann zum Alibi der Nicht-Beachtung» (Borries 2014, S. 150, im Original teilweise kursiv). 
Im Bereich der Ästhetik geht es Borries dabei um die Wahrnehmung dieser zwangsläufig gegebenen, «unvermeidlichen Gestaltetheit» von historischen Narrationen, eine Einsicht «in die immer schon wirksame Beeinflussung der eigenen Person durch die ästhetischen Werte von Geschichten» und um den «bewussten» und «verantworteten» Umgang mit - sowohl auf der Ebene der Rezeption vorhandener Narrationen als auch auf der Seite der aktiven Herstellung und Gestaltung von Erzählungen. ${ }^{515}$ Ästhetik erscheint somit bei Borries als eine Eigenschaft historischer Narrationen, mit der es möglichst reflektiert umzugehen gilt, deren Ort im denkenden Individuum aber ansonsten unausgefaltet bleibt.

Demgegenüber beschreibt Borries Emotionen als etwas, was einerseits den Gegenstand der Beschäftigung ausmachen kann, gleichzeitig und vornehmlich aber auch im denkenden Individuum selbst anwesend ist. $\mathrm{Zu}$ dieser Differenzierung unterscheidet Borries eine «Subjektseite» und eine «Objektseite» ${ }^{516}$ - eine Unterscheidung, die sich in der Literatur mehrfach findet. ${ }^{517}$ Während die Objektseite bei Borries «historische Emotionen» als Gegenstand bzw. Thema der Beschäftigung meint, bezieht sich die Subjektseite auf Emotionen des denkenden Individuums. ${ }^{518}$

Nur Zweitgenannte sind für meine Untersuchung im engeren Sinn von Interesse, allerdings in dem Wissen, dass es durchaus Wechselwirkungen zwischen beiden Bereichen geben kann, «weil durchaus bewusste und unbewusste Interdependenzen zwischen Affekten heute und Affekten damals auftreten können (〈Osmose $) » .{ }^{519}$ Vermutlich auf den Bereich der Subjektseite bezogen, regt Borries weiter an, sich darüber klar zu werden, über welche Rolle von Emotionen im jeweiligen Moment nachgedacht werde. Er unterscheidet eine Behandlung von Emotionen als «Begleiterscheinung», «Zielsetzung», «Diagnosefeld» und «Leistungsbereich», ${ }^{520}$ womit er

515 Borries 2014, S. 162.

516 Borries 2014, S. 162, Kursivsetzung analog zum Original.

517 So die Unterscheidung in «Objektebene» und «Subjektebene» bei Brauer/Lücke 2013a, S. 14, oder die Unterscheidung in «eine Objekt- und eine Subjektdimension» bei Gies 1994, S. 35. Auch Hasberg unterscheidet eine «Objektdimension der Emotionalität» als «Emotionen in Vergangenheit/Geschichte» und eine «Subjektdimension der Emotionalität» als «Emotionen des erkennenden Subjekts», als dritte Ebene dann jedoch noch den «Einfluss von Emotionen auf Vermittlung und Rezeption, Lehren und Lernen, von Vergangenheit/ Geschichte» (Hasberg 2013, S. 49). Mit dieser dritten Ebene bringt Hasberg eine weitere Dimension, nämlich die Lehrseite, in die Überlegungen ein, vermengt die dritte Dimension aber zugleich mit der Lernerseite, die bereits in der «Subjektdimension» bedacht ist, weshalb die Systematik insgesamt inkohärent wirkt.

518 Borries 2014, S. 162.

519 Borries 2014, S. 162.

520 Borries 2014, S. 233. 
zugleich ein Spektrum aus eher deskriptiven und eher normativen Zugängen aufspannt.

$\mathrm{Zu}$ den Lernzielen im Bereich der Emotionen zählt Borries «Wahrnehmung» und «Umgang mit eigenen und fremden Emotionen», deren «Offenlegung» sowie die «(Weiter-)Entwicklung von eigenen Emotionen». ${ }^{521}$ Gerade im Letztgenannten scheint Borries die eigentliche Zielgrösse historischen Denkens im Umgang mit Emotionen zu sehen. So beinhaltet das von ihm vorgeschlagene dreistufige Kompetenzraster im Umgang mit Emotionen

- «[n]aives 〈Zu-Hause-Sein〉 in den eigenen Empfindungen»,

- «(Distanzierung von den eigenen Emotionen» und

- «[s]elbst-reflexive 〈Wieder-Annäherung〉 an - u.U. revidierte, gewandelte eigene Emotionen ( $\langle$ Selbst-Versöhnung $\rangle$ ) unter Abgleich mit den gesellschaftlich dominanten Affekten», ${ }^{522}$

also eine «Rückkehr zum Selbst und zur eigenen - wenn auch hoffentlich gewandelten - Sichtweise», hingegen «nicht deren Vergessen oder Verschweigen». ${ }^{523}$ Historisches Denken im Umgang mit Emotionen zielt in der Vorstellung Borries' somit auf die Reflexion über Emotionen und gegebenenfalls deren Wandlung. ${ }^{524}$ Seine Zielvorstellung lautet, dass «die Ausgangsemotion nicht einfach unverändert wieder aufgenommen werden» solle, auch wenn dies häufig vorkommen dürfte. ${ }^{525}$

Ein alternativer, aber ebenfalls auf Reflexion zielender Vorschlag zur Stufung von Niveaus im Umgang mit Emotionen stammt von Johannes Meyer-Hamme. ${ }^{526}$ Dieser stuft den Umgang mit Emotionen dahingehend, ob man

- «intuitiv seine eigenen Emotionen auslebt»,

- «die gesellschaftlichen Konventionen unhinterfragt übernimmt» oder

- «die gesellschaftlich konventionellen Emotionen reflektiert und in seiner eigenen historischen Orientierung die dominanten Emotionen im Verhältnis $\mathrm{zu}$ den gesellschaftlichen Konventionen begründet». ${ }^{527}$

521 Borries 2014, S. 162.

522 Borries 2014, S. 234.

523 Borries 2014, S. 238.

524 Zum Primat der Reflexion auch Borries 2014, S. 159.

525 Borries 2014, S. 238.

526 Meyer-Hamme 2013, S. 133.

527 Meyer-Hamme 2013, S. 133. 
Sowohl Borries als auch Meyer-Hamme unterbreiten damit normative Vorschläge, denen zufolge die Reflexion und - im Fall von Borries auch Wandlung - von Emotionen erstrebenswert ist. Emotionen sind in dieser Sichtweise keineswegs lediglich zu erwartende Begleitphänomene historischen Denkens, sondern vielmehr Gegenstand einer notwendigen Bearbeitung und Weiterentwicklung. Meyer-Hamme zielt auf eine «analytische Distanz» zu den Emotionen. ${ }^{528}$ Borries spricht davon, dass «Kognition die Affekte klären und u.U. zähmen» solle, bedenkt jedoch auch die Möglichkeit eines umgekehrten Falls, denn «so einseitig und eindeutig fällt das Verhältnis nicht in allen Fällen aus. [...] Unsere Affekte müssen, sollen, können - jedenfalls manchmal - unsere Kognition genauso kontrollieren und humanisieren wie umgekehrt.» ${ }^{529}$

Trotz dieser Differenzierung erweist sich Borries' Zugang durch das geschilderte Primat der Reflexion ingesamt als stark kognitiv orientiert - dies, obwohl er selbst beklagt, dass in der Regel allzu schnell «doch wieder nur von intellektuellem Zugriff gesprochen und alles andere ausgeblendet wird». ${ }^{530} \mathrm{Ob}$ es auch Erkenntnisprozesse im Umgang mit Historischem geben könne, wenn Emotionen unbearbeitet gelassen werden und in unreflektierter Weise den Denkprozess begleiten und mit gestalten, diese Frage gerät nicht in den Blick.

Ein Primat des Kognitiven zeigt sich auch in Borries' Ausführungen über den Bereich der Ästhetik, die nach Borries' Vorstellung ebenfalls, wie oben bereits geschildert, zum Gegenstand von Reflexion werden soll. Als Ziel historischen Lernens sieht er zusammenfassend eine

«höhere Form der - auch ästhetischen, auch emotionalen - <Alphabetisierung>, die für sprachliche wie für bildliche Materialien, für Quellen wie für Darstellungen, für Kulturlandschaften wie für Objektgruppen, für Ausstellungen wie für Archive, für Gedenkstätten wie für Denkmäler, für argumentative Erörterungen wie für symbolische Ikonenbildungen, für imaginative Fiktionen wie für sachliche Rekonstruktionen, für historische Spielfilme wie für Fernseh-〈Dokumentationen $〉$ gilt bzw. aufgefächert wird. [...] Dabei sind verschiedene Teilleistungen zu erbringen ( $\langle$ Kernkompetenzen $>$ zu erwerben), in

528 Meyer-Hamme 2013, S. 134.

529 Borries 2014, S. 498.

530 Borries 2014, S. 169. 
denen das mental wie erkenntnislogisch beim Geschichtsumgang ohnehin Unvermeidliche - nämlich Gestaltwahrnehmung und Gefühlsverarbeitung jeweils explizit thematisiert und reflektiert wird.» ${ }^{531}$

Allerdings denkt Borries auch im Fall der Ästhetik einen umgekehrten Fall mit, in dem Ästhetik zur Klärung von Kognition beiträgt, nämlich sei Ästhetik «nicht unbedingt Verweichlichung und Verharmlosung von kognitiver Klarheit und verstörendem Realismus, sondern [könne] deren Transformation und Erweiterung, d.h. Zuspitzung, Erhöhung und Verwandlung zugleich, bedeuten». ${ }^{532}$

Ich gehe nachfolgend in Anlehnung an Borries von einem zwangsläufigen Vorhandensein emotionaler und ästhetischer Momente in der Begegnung mit Historischem aus und frage danach, wie sich diese in der konkreten Situation der Geschichtsbegegnung in Form eines Ausstellungsbesuchs manifestieren. Dass historische Ausstellungen wie alle geschichtskulturellen Manifestationen eine ästhetische Dimension haben, dies wurde unter Rückgriff auf die Überlegungen Rüsens und anderer bereits dargelegt. ${ }^{53}$ Dass neben ästhetischen auch von emotionalen Anteilen des Ausstellungsbesuchs ausgegangen werden kann, hierfür sensibilisieren die soeben dargestellten Überlegungen Borries'.

Bereits Rüsen bringt «Gefühl» als eine von «drei Grundmodi menschlicher Mentalität» in seine Überlegungen zum Umgang mit Geschichtskultur ein und ordnet es sogar systematisch der ästhetischen Dimension zu, während er der kognitiven und politischen Dimension die Modi «Wille» und «Verstand» zuweist. ${ }^{534}$ Damit unternimmt er eine Kombination, die sich in der Literatur vielfach findet, wenn Ästhetik und Emotionen in einem Atemzug genannt werden und damit suggeriert wird, dass beide Aspekte in irgendeiner Art aufeinander bezogen sind, wenn dieses Verhältnis auch nicht genauer ausbuchstabiert wird. ${ }^{535}$

531 Borries 2014, S. 500.

532 Borries 2014, S. $498 \mathrm{f}$.

533 Vgl. Abschnitt 3.1.

534 Rüsen 1994, S. 17.

535 Die Kombination beider Begriffe findet sich etwa im Titel der Veröffentlichungen von Borries 2014 und Borries 2016, ausserdem bei Heese, der von einer «ästhetischen und emotiven Kompetenz» spricht (Heese 2014, S. 15). Borsdorf et al. sprechen in Bezug auf Museen von einer «ästhetisch-affektive[n] Komponente des Zeigens von Dingen» (Borsdorf et al. 2004b, S. 7). In der empirischen Museumsbesucherforschung findet sich hierzu ein aktuelles Beispiel bei Kohler 2016. Vgl. für entsprechende Ausführungen zu Kohlers Studie Abschnitt 5.3 sowie Thyroff 2017d.

Neben den behelfsmässig anmutenden begrifflichen Integrationen von Emotion und Ästhetik finden sich ebensolche auch in Bezug auf Emotionen und sinnliche Wahrnehmung. 
Ein aktuelles theoretisches Desiderat kann deshalb sicherlich auch in der Hinsicht ausgemacht werden, die Bereiche des Ästhetischen und Emotionalen sauber voneinander zu unterscheiden oder umgekehrt über Bezüge zwischen beiden Bereichen systematisch nachzudenken. Inwiefern beide Dimensionen beim Ausstellungsbesuch zwingend zusammenhängen müssen, inwieweit also Emotionalität vorzugsweise mit der Begegnung der Ästhetik der Manifestation vorkommt oder beide Aspekte sich auch getrennt voneinander entfalten können, dies ist bislang kaum betrachtet worden.

In Abgrenzung zu Borries bediene ich mich bei der Betrachtung der Rolle von Ästhetik und Emotionen eines nur deskriptiven statt auch normativen $\mathrm{Zu}$ gangs. Den weiter oben genannten Differenzierungsvorschlag Borries' aufgreifend, ${ }^{536}$ spielen Ästhetik und Emotionen für das Projekt einerseits als zu erwartende Begleiterscheinung des Ausstellungsbesuchs eine Rolle, andererseits als Gegenstand der Diagnose bzw. besser Analyse, sie gelten hingegen weder als notwendiges und möglichst zu erreichendes Ziel noch als Ausdruck eines gelungenen Besuchs. Zwar kann in geschichtskulturellen Manifestationen die absichtsvolle Anbahnung von Emotionen eine Rolle spielen, ${ }^{537}$ eine entsprechende Analyse möglicher ausstellungsseitig vorhandener Absichten nehme ich jedoch weder vor noch gleiche ich bei den Besuchenden entstehende Emotionen mit selbigen ab. Stattdessen beschränke ich mich auf eine deskriptive Analyse der von den Besuchenden selbst thematisierten Emotionen. Dabei gilt es zu bedenken, dass das Forschungsprojekt mit Verbalisierungen der Besuchenden arbeitet und insofern nur diejenigen Emotionen und Umgangsweisen mit Ästhetik zur Kenntnis nehmen kann, über die die Besuchenden selbst sprechen wollen und derer sie sich in dem Masse bewusst sind, dass sie sie überhaupt explizit thematisieren können. ${ }^{53}$ Forschungsmethodisch spielt eine Bewusstheit bzw. ein gewisses Mass an Reflektiertheit über die eigenen Wahrnehmungen also zwangsläufig eine konstitutive Rolle, jedoch wird diese nicht normativ gewendet und als Zielgrösse formuliert.

So spricht etwa Elisabeth Erdmann von «sinnlich-emotionale[n] Erfahrungen» (Erdmann 1994, S. 155).

536 Borries 2014, S. 233.

537 So für Ansätze in der Gedenkstättenpädagogik und dabei insbesondere für die Ansätze zur absichtsvollen Anbahnung von Empathie konstatiert bei Brauer 2013, S. $75 \mathrm{ff}$.

538 Dies kann allerdings als Bedingung gelten, der jegliche mit verbalen Daten arbeitende Sozialforschung unterworfen ist. 


\subsubsection{Zum Stellenwert von Emotionen}

In Borries' Zugang manifestieren sich, wie weiter oben geschildert, letztlich ähnliche Anzeichen für ein Unbehagen gegenüber emotionalen Momenten einer Geschichtsbeschäftigung, wie er selbst dies für die geschichtsdidaktische Diskussion seit den 1970er-Jahren als kennzeichnend beschreibt und eigentlich zu überwinden sucht. ${ }^{539}$ Während bis in die 1970er-Jahre «emotionales Lernen durchaus als Hauptaufgabe des Geschichtsunterrichts» betrachtet und beispielsweise «zur Erzeugung der «richtigen〉 Identifikationen» genutzt worden sei, konstatiert Borries seither eine Fokussierung auf kognitive Zugänge. ${ }^{540}$

Juliane Brauer und Martin Lücke sprechen für diese Zeit von einem «Rationalitätsschub in der geschichtsdidaktischen Debatte», einem Unbehagen gegenüber emotionalen Zugängen aufgrund von deren vermeintlicher Unkalkulierbarkeit und Manipulierbarkeit - eine Ablehnung, die beide nicht zuletzt auch als Erbe aus der Zeit des Nationalsozialismus deuten. ${ }^{541}$ Über einige Jahrzehnte hinweg seien lediglich einzelne Protagonisten wie etwa Rolf Schörken mit seiner Idee der historischen Imagination ${ }^{542}$ oder auch Bodo von Borries dem entgegengetreten, bevor schliesslich im Jahr 1991 die Tagung «Emotionen und historisches Lernen» den Versuch unternommen habe, «Emotionen einen Ort in der Geschichtskultur zuzuweisen». ${ }^{543}$

Brauer und Lücke zeigen jedoch auf, dass gefühlsbasierten Zugängen durchaus schon vor der zeitweiligen kognitiv orientierten Phase eine wichtige Rolle im historischen Erkenntnisprozess zugestanden wurde. Namentlich verweisen sie auf Wilhelm Dilthey, dessen hermeneutisches Verfahren auf «Verstehen» und «Nacherleben fremder Gefühle» basiere und der «den Gefühlen im Prozess des Verstehens eine zentrale erkenntnistheoretische Bedeutung» zuschreibe. ${ }^{544}$ Dilthey könne somit «zu Recht am Beginn eines Nachdenkens darüber stehen, welche Bedeutung Emotionen bei der Begegnung mit Vergangenem und mit Geschichte zukommt». ${ }^{545}$

539 Borries 1994, S. 73 ff.; Borries 2014, S. 159.

540 Borries 1994, S. 73; Borries 2014, S. 233.

541 Brauer/Lücke 2013a, S. 15.

542 Brauer/Lücke beziehen sich mit ihrer Einschätzung auf Schörken 1994 und 1995.

543 Brauer/Lücke 2013a, S. 14 ff.; direktes Zitat: S. 16. Zur Programmatik der Tagung siehe auch die Einleitung im zugehörigen Tagungsband (Mütter/Uffelmann 1994b, S. 13f.), sowie insgesamt zur Tagung Mütter/Uffelmann 1994a.

544 Brauer/Lücke 2013a, S. 12 f., unter Bezug auf Dilthey, mir in der Ausgabe von 1924 vorliegend (Dilthey 1924, S. 317 ff.)

545 Brauer/Lücke 2013a, S. 14. 
Stärker als Borries betonen also Brauer und Lücke ein in den Emotionen selbst und nicht erst in deren Reflexion liegendes Potenzial, eine, um einen Ausdruck Christian Kohlers aufzugreifen, «erkenntnisleitende Funktion» ${ }^{546}$ von Emotionen. Etwas verengt, fassen sie historisches Lernen dabei allerdings als Kombination aus Erinnern und Erzählen, den darin enthaltenen Bestandteil des Erinnerns wiederum als «emotionale Praktik», die zunächst Verinnerlichen beinhaltet sowie das Zurückholen und Deuten des Erinnerten. ${ }^{547}$

Historisches Lernen ist nach diesem Verständnis geknüpft an eine biografische Erinnerung und insofern eng gefasst, setzt es doch zunächst einmal voraus, «dass der Sinnes- oder Gefühlseindruck sich beim Erinnernden selbst eingestellt hat». ${ }^{548}$ Wolfgang Hasberg verdeutlicht jedoch, dass Emotionen überdies auch in Bezug auf Gegenstände jenseits des Biografischen von Bedeutung sind:

«Wendet man den Blick auf die vorbiographische Vergangenheit, ist zu konstatieren, dass diese weder sinnlich wahrgenommen, noch emotional erlebt werden kann. Gleichwohl wird deren Rezeption, ob aus Quellen oder über Historiographie, mit den Sinnen vollzogen und von emotionalen Befindlichkeiten begleitet, die nicht ohne Folgen für die Qualität des Rezipierten bleiben. Nur von diesen Emotionen, die den Prozess des Umgangs mit Vergangenheit/Geschichte begleiten, kann an dieser Stelle die Rede sein.» ${ }^{549}$

Wie sich bei Hasberg andeutet, greift der Begriff historischen Lernens bei Brauer und Lücke auch deshalb zu kurz, weil er lediglich die Rolle von Emotionen bei aktiv konstruierten Narrationen in den Blick nimmt, nicht jedoch im de-konstruktiven Umgang mit vorhandenen Erzählungen. Gleichwohl sensibilisieren Brauer und Lücke in der Tradition Diltheys mit ihren Ausführungen für die möglicherweise erkenntnisfördernde Rolle emotionaler Praktiken im historischen Denken.

Brauer nimmt an anderer Stelle und inhaltlich durchaus anschlussfähig an die zuvor geschilderten Überlegungen sowie an Dilthey und Schörken den Begriff der Empathie in den Blick. Sie schlägt vor, Empathie als «emotionale Praktik» zu beschreiben, «als eine Gefühlswahrnehmung des historisch Fremden und eine Gefühlshaltung (im Sinne des Sich-selbst-dazu-ins-Verhältnis-Setzens)», die «den

546 So ein von Kohler in Bezug auf Imagination gebrauchter Ausdruck (Kohler 2016, S. 203).

547 Brauer/Lücke 2013a, S. 19 und S. 21.

548 Hasberg 2013, S. 47.

549 Hasberg 2013, S. 47. 
Betrachter mit dem historischen Sujet seiner Betrachtung» verbindet. ${ }^{550}$ Empathie in diesem Verständnis beinhaltet zwei Komponenten, einerseits die Imagination bzw. ein Sich-Hineinversetzen, gleichzeitig dann aber, «Grenzen zwischen Ähnlichkeit und Nicht-Ähnlichkeit zu ziehen, d.h., auch den Unterschied zwischen dem Selbst und dem Anderen erkennen zu können». ${ }^{551}$

Empathie kann nach dieser Vorstellung also Erkenntnis fördern - sie ermöglicht im Versuch des Sich-Hineinversetzens Wahrnehmung von Unterschiedlichkeit und "produktive Irritation», sie ermöglicht nicht nur, «Alterität zu überbrücken, sondern sie auch spürbar und erkennbar werden zu lassen. Empathie rechnet Alterität ein und fordert sie heraus.» ${ }^{552}$ Brauers Empathiebegriff weist damit charakteristische Schwachpunkte gerade nicht auf, die andernorts in Bezug auf das Konzept der Empathie festgestellt werden. Wolfgang Hasberg konstatiert nämlich die Gefahr eines nicht historisch sensiblen Empathieverständnisses, «das die Historizität emotionaler Befindlichkeiten, die Distanz zwischen historischem Akteur und historisch Erkennendem nicht hinreichend ins Kalkül zieht». ${ }^{553}$ Im Begriffsverständnis Brauers ist Alterität hingegen mitgedacht und macht die Attraktivität ihres Entwurfs aus. Ebenso begegnet Brauers Begriff der Feststellung Noa Mkaytons, «dass Empathie als Lernhaltung oft missverständlich mit einer Identifikationshaltung gleichgesetzt wird, was ein Sich-Hineinversetzen in den Anderen und damit zwangsläufig Mitfühlen oder Mitleiden bedeutet». ${ }^{554}$

550 Brauer 2013, S. 83.

551 Brauer 2013, S. $85 \mathrm{f}$.

552 Brauer 2013, S. $88 \mathrm{f}$.

553 Hasberg 2013, S. 61. Auf die durch Andersartigkeit bedingten «Grenzen des Fremdverstehens» weist auch Frank Baring hin (Baring 2009, S. 52).

554 Mkayton 2011, S. 31. Eine weitere mögliche Unterscheidung ist diejenige in eine kognitive und emotionale Dimension von Empathie, die sich bei Ekman findet (Ekman 2007) und von Mkayton rezipiert wird (Mkayton 2011, S. 31), wobei Ekman diesen Formen nicht den Status als Emotion zubilligt:

«Weder Mitgefühl (Empathie) noch Mitleid sind Emotionen: Sie bezeichnen unsere Reaktion auf die Emotion eines anderen Menschen. Kognitive Empathie lässt uns erkennen, was ein anderer fühlt. Emotionale Empathie lässt uns fühlen, was der andere fühlt, und das Mitleiden bringt uns dazu, dass wir dem anderen helfen wollen, seine Situation und seine Gefühle zu bewältigen» (Ekman 2007, S. 249; Kursivsetzung analog zum Original). Ekmans Empathiebegriff entspricht hier wohl dem Imaginationsbegriff Brauers, wobei im Sinn Brauers hinzuzufügen wäre, dass Empathie stets Nichtgelingen und Alterität mitdenkt, sei es im Bereich der kognitiven oder emotionalen Empathie. 
Den geschichtsdidaktischen Diskurs rund um den Begriff der Empathie umfassend abzubilden, ist hier nicht mein Ziel. ${ }^{555}$ Vielmehr habe ich Brauers Überlegungen beispielhaft herbeigezogen, um erneut anzudeuten, was ich weiter oben bereits für Borries' Überlegungen konstatiert habe: Emotionen gelten der Geschichtsdidaktik letztlich dann als wertvoll, wenn sie produktiv genutzt und in historische Erkenntnis umgemünzt werden können, sei es, dass diese Erkenntnis wie im Fall von Borries durch die Reflexion über Emotionen zustande kommt, sei es, dass Emotionen wie im Fall von Brauer selbst eine erkenntnisfördernde Rolle zugeschrieben wird. Insofern lässt sich ein überwiegend funktionaler Emotionalitätsbegriff konstatieren: Emotionen sind in theoretischen Zugängen Hilfsmittel auf dem Weg der Erkenntnisgewinnung.

Aus geschichtsdidaktischer Perspektive stellt sich somit die Frage, welche Rolle Emotionen innerhalb der Denkprozesse beim Ausstellungsbesuch einnehmen bzw. genauer, welche Rolle ihnen von den Besuchenden zugeschrieben bekommen und ob sie spezifische Funktionen erfüllen, namentlich Erkenntnisprozesse anbahnen. Gleichzeitig verfolge ich in meiner Studie das Anliegen, Emotionen nicht funktionalistisch verengt zu betrachten, sondern deskriptiv ihre Rolle im Prozess des Ausstellungsbesuchs in den Blick zu nehmen.

\subsubsection{Zum Stellenwert von Ästhetik}

Ein vergleichbares Anliegen verfolge ich auch in Bezug auf die Rolle der Ästhetik beim Ausstellungsbesuch. Auch der Ästhetik wird in der Literatur erkenntnisbefördernde Funktion zugeschriebe. Allerdings ist dieser Aspekt bislang weniger in der geschichtsdidaktischen, sondern stärker in der erziehungswissenschaftlichen Literatur unter dem Begriff der «Ästhetischen Bildung» behandelt worden, wobei Letztere innerhalb der Geschichtsdidaktik meines Erachtens bislang unzureichend rezipiert wird.

Hilfreich für eine Annäherung an den Begriff der Ästhetik einerseits und den der ästhetischen Bildung andererseits sind die Überlegungen bei Carl-Peter Buschkühle:

555 Einen Überblick über das geschichtsdidaktische Empathieverständnis im deutschen, britischen und US-amerikanischen Raum liefert Baring (Baring 2011, insb. S. 31 ff.), der zugleich darauf verweist, dass es sich bei Empathie nicht um eine genuin geschichtsdidaktische Kategorie handelt (ebd., S. 22 ff.). Vgl. zum Thema ausserdem den Artikel Barings im «Wörterbuch Geschichtsdidaktik» (Baring 2009). 
«Man muss kein Anhänger eines radikalen Konstruktivismus sein, um dem Gedanken zu folgen, dass alles, was wir für wirklich oder auch wahr halten, ästhetisch ist. Ästhetik wird hier nicht verstanden als die Lehre vom Schönen. Sie wird auch nicht gesehen als Wissenschaft der Künste. Ganz grundsätzlich wird dieser Begriff von der aisthesis her aufgefasst, von der Wahrnehmung, die in sich ein Zusammenwirken von Sinnestätigkeit und Kognition ist. Damit umfasst das Ästhetische die beiden Wurzeln, die Kant dem menschlichen Erkennen als konstitutiv nachgewiesen hat: Sinnlichkeit und Verstand. Wir wissen schlechterdings nichts, was nicht diesen beiden Wurzeln entspringt. Wohlgemerkt müssen dabei beide Wurzeln zusammen aktiv sein, die Tätigkeit nur einer reicht nicht zur Erkenntnis. ${ }^{556}$

Buschkühle vertritt hier die Auffassung, dass Wirklichkeit per se gestaltet ist - wie auch Borries für den Fall der erzählten Geschichte davon ausgeht, dass diese «nicht 〈ungestaltet〉 sein» kann. ${ }^{557}$ Zudem widerspricht Buschkühle einem Dualismus, der «das Künstlerische [...] als das Gegenstück zum Wissenschaftlichen» sieht, denn: «Erkenntnis mit Wahrheitsanspruch ist, wenn Empirie und Theorie zusammenfinden, wenn - und sei es instrumentell vermittelt - sinnliche Perzeption mit rationaler Erklärung zusammenstimmt. ${ }^{558}$ Ästhetische Bildung liegt nach diesem Verständnis also an der Schnittstelle zwischen sinnlicher Wahrnehmung und kognitiver Verarbeitung. ${ }^{559}$

Saskia Bender sensibilisiert dafür, dass ästhetische Bildung von der ästhetischen Erfahrung zu unterscheiden ist, und verortet die Schwelle zur ästhetischen Bil-

556 Buschkühle 2015, S. 467.

557 Borries 2014, S. 155.

558 Buschkühle 2015, S. $468 \mathrm{f}$. Zu unterscheiden ist ästhetische Bildung Buschkühle zufolge von der künstlerischen Bildung: «Bezieht ästhetische Bildung alles ein, was im Verhältnis von sensibler Wahrnehmung und Reflexion zu lernen ist, gibt künstlerische Bildung diesem Verhältnis eine Richtung, welche darin liegt, dass sie Lernen mit Schöpfung verbindet» (Buschkühle 2015, S. 476). Nur die künstlerische Bildung zielt also auf das aktive Produzieren, während ästhetische Bildung gleichermassen im rezeptiven Modus möglich ist. Nach diesem Verständnis ist ästhetische Bildung sehr weit zu fassen und bezieht im Prinzip alles Lernen mit ein, da «Lernen grundsätzlich ästhetisch ist, insofern sich Einsicht und Wissen auf den Fundamenten der Sinnlichkeit und des Verstandes gründen» (Buschkühle 2015, S. 483).

Auch Duncker und Niesseler gehen von Ästhetik als einem konstitutiven Element von Bildung aus (Duncker/Niesseler 2015, S. 461).

So auch bei Bender 2011, S. 321. 
dung dort, wo ästhetische Erfahrung bewusst wird. ${ }^{560}$ Wie in den weiter oben geschilderten geschichtsdidaktischen Überlegungen zur Rolle von Emotionen für historisches Lernen geht es also auch im Bereich der ästhetischen Bildung um das Bewusstmachen und wohl auch Reflektieren ästhetischer Erfahrungen, die konstitutiv sind für Lernprozesse und Erkenntnis befördern.

Ebenfalls unterscheiden Annette Noschka-Roos und Doris Lewalter in die zwei Bereiche ästhetische Erfahrung und ästhetische Bildung und beziehen beide Konzepte auf das Lernen im Museum. ${ }^{561}$ Im nachfolgenden Zitat scheinen beide Dimensionen allerdings fliessend ineinander überzugehen:

«Das Foto und die Formel werden erschlossen und dadurch erschliessen sich auch jeweils neue Sichtweisen auf die Welt. Die ästhetische Erfahrung> ist ein Innehalten, ein Nachdenken mit Empfindungen, eine neu entdeckte Erkenntnis über sich oder über die Welt; eine neue Begegnung mit der Betrachtung eines Kunstwerks, mit der je nach individueller Konstellation mehr oder weniger starker Impuls zur Aus-Ein-Ander-Setzung ausgelöst wird.» ${ }^{52}$

Über das erkenntnisfördernde Potenzial von ästhetischem Erleben beim Besuch denkt auch Thorsten Heese nach. Er schreibt dieses Potenzial dezidiert der Begegnung mit dem auratischen Objekt zu:

«Der durch die Aura des Originals angebahnte erste Schritt auf das Objekt zu, also die ästhetische Dimension, die geweckte Neugierde, wird durch die weitere Beschäftigung mit dem Exponat verlängert und in einen kognitiven Prozess überführt. Das befördert den «langen Blick», den das Objekt aufgrund seiner Fremdartigkeit auslöst. Im Gegensatz zum «schnellen Blick des Lesens», der zügig vom Text zum Verständnis führt, hält die «Gegenständlichkeit` des Objekts, d.h. das dem betrachtenden Subjekt Entgegenstehende, dessen Faszination aufrecht und fordert seine andauernde Betrachtung. Diese ermöglicht eine schrittweise Entwicklung hin zur historischen Erkenntnis.» ${ }^{563}$

560 Bender 2011, S. 333.

561 Noschka-Roos/Lewalter 2013, S. 199 f.

562 Noschka-Roos/Lewalter 2013, S. 199, die sich dabei auf Zacharias 2010, S. 316, beziehen.

563 Heese 2014, S. 15, mit seiner Formulierung Bezug nehmend auf Aleida Assmann. Dort lautet der Titel: «Die Sprache der Dinge. Der lange Blick und die wilde Semiose» (Assmann 1988). 
Heese sieht das Potenzial von Museen also einerseits in der Ermöglichung solcher Begegnungen mit auratischen Objekten, durch deren Anschauung Erkenntnis resultieren könne - wie dieser Schritt genau zu denken sei, hierzu schweigt er sich allerdings aus -, zweitens sieht er das Potenzial von Museen auch darin, als «Schule des Sehens» zu fungieren, in der der Umgang mit Visualität geübt werden könne:

«Im Zeitalter der Bilderflut kommt dem Museum bei der Medienerziehung eine Schlüsselrolle zu. Das unmittelbare〈Ansprechen〉 des Auges verschafft den Museen eine wichtige Rolle in der visuellen Kommunikation. Dabei vollzieht das Museum den iconic turn nicht einfach mit, sondern macht vertraut mit den historischen Entwicklungen von Bilderwelten. Anders als die modernen Medienwelten täglich im Fernsehen, auf Werbebildschirmen, am Flughafen oder selbst in der Imbissbude vormachen, bietet das Museum die Gelegenheit, die Bilderflut 〈stillzustellen〉, anzuhalten und durch Gegenüberstellungen mit anderen Bildern im Ausstellungskontext verstehbar zu machen. Hier werden Ikonografien entschlüsselt. Das Museum als Schule des Sehens ermöglicht eine ikonische Alphabetisierung.» ${ }^{564}$

Ebenfalls in Bezug auf das Museum, aber in der Spielart als aktiv gestaltende «künstlerische Bildung», ${ }^{565}$ kommt Umgang und Lernen mit Ästhetik in einer Studie von Waltraud Schreiber et al. zur Sprache. Die Autorinnen konstatieren dort einen Zusammenhang zwischen aktiver künstlerischer Betätigung und historischem Denken im Museum. Im untersuchten museumspädagogischen Programm habe die «kreativ-gestaltende Vertiefung», im konkreten Fall mit dem Konzept des Gedenkens, die Teilnehmenden neben nicht-historischem auch zu historischem Denken angeregt und Bezüge zur eigenen Lebenswelt evoziert. ${ }^{566}$

Es liegen also erste Ansätze vor, ästhetische Bildung und die Manifestationen Museum und Ausstellung zusammenzudenken, teilweise sogar ergänzt um den Aspekt des historischen Denkens. Aufseiten der Angebotsstruktur der Geschichtskultur steht mit Rüsen eigentlich seit Längerem ein Instrumentarium bereit, um über die ästhetische Dimension von Geschichtskultur nachzudenken. Dennoch gilt für den Fall der Museums- bzw. Ausstellungsnutzung nach wie vor Borries'

564 Heese 2014, S. 15, Kursivsetzung analog zum Original.

565 Buschkühle 2015, S. 476; vgl. hierzu auch Fussnote 558.

566 Schreiber et al. 2015, S. 91. 
Befund aus dem Jahr 2009: «Der besondere Surplus eines auch ästhetischen Geschichtslernens im Museums [sic] und der Gewinn beim ästhetischen Museumsgenuss durch spezifisch historische Betrachtungen bleiben noch näher zu analysieren.» ${ }^{567}$

Auch unabhängig von der Manifestation Museum steht eine systematische Integration von Modellen historischen Denkens und ästhetischer Erfahrung und Bildung bislang aus. Trotz der von Carl-Peter Buschkühle beschriebenen unhintergehbaren Ästhetik von Wirklichkeit tragen aktuelle geschichtsdidaktische Modellierungen historischen Denkens und Lernens sowie vorhandene Kompetenzmodellierungen der ästhetischen Dimension bislang unzureichend Rechnung.

Aktivitäten fokussieren sich bislang auf den Bereich des historischen Denkens im Umgang mit bildlichen Medien, etwa unter dem Stichwort «Visualität». ${ }^{568}$ Dabei werden Charakteristika von Bildquellen und der Umgang damit behandelt, etwa wird über medienspezifische Stärken und Schwächen von Bildquellen nachgedacht, wird einerseits ihre Anschaulichkeit hervorgehoben und ihnen ein imaginatives Potenzial zugeschrieben, wird andererseits auf ihre Subjektivität und Ausschnitthaftigkeit verwiesen. ${ }^{569}$ Von etlichen Autorinnen und Autoren werden vorliegende Kompetenzmodelle oder Vorstellungen historischen Denkens bereichsspezifisch für den Anwendungsfall des Umgangs mit Bildquellen gewendet. ${ }^{570}$ Diese Publikationen kreisen um die Frage, welche Rolle visuelle Medien für historisches Denken und Lernen spielen oder spielen können. Dabei geht es vornehmlich um die Frage des Umgangs mit diesen Medien, insbesondere deren Analyse und Interpretation als Quellen, für welche die geschichtsdidaktische Lite-

567 Borries 2009, S. 120. Einen Beitrag zur Aufklärung des Bereichs hat allerdings in jüngerer Vergangenheit Kohler mit seiner empirischen Forschung zu «Schülervorstellungen über die Konstruktion von Geschichte im Museum» (Kohler 2016) geleistet, der eines seiner Augenmerke auch darauf richtet, welche Rolle ästhetische und emotionale Erfahrungen im Museum für die beforschten Jugendlichen spielen. Auf seine Studie komme ich weiter unten im Rahmen des Forschungsüberblicks zur empirischen Museumsbesucherforschung näher zu sprechen.

568 So der von Saskia Handro und Bernd Schönemann herausgegebene Sammelband mit dem Titel «Visualität und Geschichte» (Handro/Schönemann 2011a) oder auch Christoph Hamanns «Visual History und Geschichtsdidaktik» (Hamann 2007).

569 Pandel 201 la, S. 13 ff., insb. S. 13, S. 24 ff.; Gautschi 2015, S. 122.

570 Schönemann 2002b; Hamann 2007; Binnenkade 2008; Krammer 2008; Bernhardt 2011; Hamann 2011; Pandel 201la; Pandel 2011b. 
ratur mehrschrittige Schemata bereithält. ${ }^{571}$ Allerdings wird der ästhetischen und emotionalen Bilderfahrung in diesen Zugängen nicht zwingend ein Eigenwert in der rationalisierenden Erkenntnisgewinnung eingeräumt. ${ }^{572}$

Auch die Erziehungswissenschaft erweist sich, so Buschkühle, trotz allgegenwärtiger «Ästhetisierungen der Lebenswelt» als «auf dem ästhetischen Auge blind», vernachlässige die Herausbildung ästhetischer Kompetenzen. ${ }^{573}$ Buschkühle führt diese Blindstelle auf den vorherrschenden ökonomisierten, auf Brauchbarkeit ausgerichteten Bildungsbegriff zurück und propagiert in Abgrenzung dazu selbst einen auf Persönlichkeitsbildung zielenden Bildungsbegriff. ${ }^{574} \mathrm{Nach}$ diesem Verständnis

571 Gleich etliche Autoren beziehen sich hierfür auf ein vielrezipiertes Schema von Erwin Panofsky, der seinerseits vorschlägt, bei der Bildanalyse nach «Phänomensinn», «Bedeutungssinn» und «Dokumentsinn» zu differenzieren (Panofsky 1991, S. 203). Entsprechend unterscheidet

- Klaus Bergmann in «Bildbeschreibung», «Bildanalyse», «Bildinterpretation» und «Bildüberschreitung» (Bergmann 2002, S. 16),

- Bodo von Borries in «Entstehungszusammenhang», "Verwendungszusammenhang», «Bedeutungszusammenhang» und «Erhaltungszusammenhang» einerseits sowie «präikonografische Analyse», «ikonografische Analyse» und «ikonologische Analyse» andererseits (Borries 2003, S. $108 \mathrm{f}$.),

- Reinhard Krammer in "(Vorikonographische) Beschreibung», «Ikonographisch-historische Analyse» und «Bewertung (Interpretation)» (Krammer 2006, S. 23; Krammer 2008, S. 46) und

- Hans-Jürgen Pandel in Analyse von «Erscheinungssinn», «Bedeutungssinn», «Dokumentensinn» und «Erzählsinn» (Pandel 2011b, S. 74 ff., direkte Zitate: S. 74, 75, 76).

Die ästhetische Erfahrung wird in diesen Schemata nicht explizit integriert, vielmehr erscheint der Zugang zu Bildquellen hier als geregelter Prozess rein kognitiver Erkenntnisgewinnung.

Dass Strategien des Umgangs mit Bildern durchaus auch auf die Rezeption von Denkmälern anwendbar seien, zeigt Holger Thünemann, wobei er darauf hinweist, dass Denkmäler gegenüber Bildern dreidimensional und damit per se multiperspektivisch seien und dass sie neben der visuellen «auch eine haptische Qualität haben» (Thünemann 2011, insb. S. 91 ff., direktes Zitat S. 93).

572 Vorgesehen ist dieser Bereich in Ansätzen bei Gautschi, der neben der in Schemata üblichen Beschreibung der Bildinhalte (vgl. vorige Fussnote) auch den Bereich «Empfindungen» berücksichtigt, also «Was fühlst du beim Anblick des Bildes? Woran erinnert dich das Bild?» (Gautschi 2015, S. 123).

573 Buschkühle 2015, S. 483.

574 Bei Nieke wird diese Dimension des Bildungsbegriffs gefasst als «Eigentätigkeit des SichBildenden», als «Eigentätigkeit zur Gewinnung eines Selbst- und Fremdverhältnisses» bzw. als «Selbst-Bildung» und stellt für ihn eine von drei Bedeutungsvarianten des Bildungsbegriffs dar. Daneben könne Bildung auch das «Ergebnis des [...] Enkulturationsprozesses» oder dessen «institutionalisierte Unterstützung» meinen (Nieke 2016, S. 36). 
«legt ästhetische Bildung, besonders in ihrer produktiven Form als künstlerische Bildung, Wert auf vieles, was einer systemischen Bildungstheorie und -praxis fremd bleibt, die Bildung als Ausbildung brauchbarer Kompetenzen für praktische Anwendungssituationen versteht. Ästhetische und künstlerische Bildung betrachtet den Menschen nicht als Funktionselement unter ökonomischen und gesellschaftlichen Anforderungen, sondern beschreibt und aktiviert ihn umfassend und grundlegend als leiblich-seelisch-geistiges Wesen. Bildung unter diesen Voraussetzungen strebt nicht eine variable Problemlösungskompetenz an, sondern die Förderung der existentiellen Kreativität. [...] Ästhetische, künstlerische Bildung ist inhaltlich und methodisch, theoretisch wie praktisch das Andere der Bildung gegenüber ihrer pragmatischen Zurichtung zur Ausbildung.» ${ }^{575}$

Ähnliche Überlegungen finden sich bei Michael Parmentier, der sich für ästhetische Bildung als Gegenentwurf zu einem «instrumentellen Bildungsbegriff» ausspricht. ${ }^{576}$ Dieser von Buschkühle und Parmentier vertretene und in der Tradition klassischer erziehungswissenschaftlicher und philosophischer Bildungstheorie stehende Begriff ${ }^{577}$ wäre unmittelbar anschlussfähig an geschichtsdidaktische Überlegungen zu Orientierungskompetenz als Ziel historischen Denkens. Auch dort steht letztlich die Persönlichkeit des denkenden Individuums, namentlich etwa dessen Selbst- und Fremdverstehen, im Vordergrund, ${ }^{578}$ auch wenn in der dortigen Literatur kaum einmal explizite Bezüge zur erziehungswissenschaftlichen Bildungstheorie hergestellt werden. ${ }^{579}$

Zum Abschluss des Kapitels wende ich mich neben der ästhetischen Dimension noch einer weiteren zu, die für Aneignungsprozesse beim Besuch historischer Ausstellungen relevant sein dürfte: der räumlichen Dimension. Für die Geschichtsdidaktik wird, wie oben bereits dargestellt und ähnlich wie in Bezug auf den Bereich des Ästhetischen und Emotionalen, eine bislang erst zaghafte und unzureichend systematische theoretische Durchdringung räumlicher Fragen, so etwa des

575 Buschkühle 2015, S. 484 f.

576 Parmentier 2013, S. 79 ff., direktes Zitat S. 79. Stärker als Buschkühle vertritt Parmentier dabei allerdings die Fokussierung ästhetischer Bildung auf selbsttätiges künstlerischen Tun (Parmentier 2013, v. a. S. 85 ff.).

577 Parmentier 2013, S. 82 ff.

578 Etwa bei Schreiber et al. 2007, S. $30 \mathrm{f}$.

579 In umgekehrter Richtung gilt dies etwa für Alena Berg, die pauschalisierend feststellt, der Kompetenzbegriff sei «noch zu unreflektiert», um den Ideen informellen Lernens bzw. informeller Bildung Rechnung zu tragen, «dass sich infolge von Lern- und Bildungsprozessen Selbstbilder und Weltverhältnisse aufbauen und transformieren» (Berg 2016, S. 715). 
Verhältnisses von Raum und Geschichtskultur - konstatiert. ${ }^{580}$ Eine ähnliche Defizitfeststellung wird auch für die Erziehungswissenschaft vorgenommen, ${ }^{581}$ und die dortigen Überlegungen scheinen mir auf die Geschichtsdidaktik übertragbar. Raum und Räumlichkeit seien, so Fabian Kessl, «konstitutive Dimensionen des pädagogischen Tuns», allerdings habe sich die Erziehungswissenschaft trotz der Zuwendung zu raumtheoretischen Fragen in Sozial- und Kulturwissenschaften («spatial turn») bislang «weitgehend der systematischen Analyse von Raum und Räumlichkeit enthalten». ${ }^{582}$

Ich halte auch in Bezug auf raumbezogene Fragestellungen in der Geschichtsdidaktik die Unterscheidung zweier Ebenen für hilfreich, einer Subjekt- und einer Objektseite, so wie dies Borries und andere Autoren für den Bereich der Emotionen differenzieren. ${ }^{583}$ Zum einen hat der Gegenstand, historisches Geschehen, selbst eine räumliche Dimension. "Jedes historische Geschehen besitzt [...] einen Handlungsraum und daneben einen Wirkungsraum. ${ }^{584}$ Diese Dimension wird in der Geschichtswissenschaft durch eine Vielzahl an räumlich orientierten Zweigen der Disziplin, etwa Regionalgeschichten, eingefangen. Von dieser räumlichen Dimension des Gegenstands scheint aber nicht die Rede, wenn Erziehungswissenschaft und Geschichtsdidaktik eine Blindheit gegenüber räumlichen Fragen attestiert wird. Vielmehr geht es dort um die räumliche Dimension von Aneignungs- und Lernprozessen.

Wie eine solche Integration raumbezogener Fragen in erziehungswissenschaftliche Forschung aussehen könnte, hierzu finden sich Anregungen bei Sabrina Schrammel, mittels deren stärker als bislang die Verknüpfung von lernendem oder lehrendem Subjekt und dem umgebenden Raum in den Blick genommen werden könnte. So liesse sich fragen:

«Welche Bedeutung wird Raum seitens Lehrender und Lernender zugeschrieben? Welche räumlichen Inszenierungen kommen als Lern- und Erziehungsraum seitens der Lernenden (nicht) in den Blick? Inwiefern wirkt Raum auf Lernprozesse? Mit welchen räumlichen Bedingungen sind Lernende und Lehrende konfrontiert? Welche Sozialräume, architektonischen Räume und geografischen Räume suchen Lernende für welche Lernzwecke auf und/oder inszenieren sie?» ${ }^{585}$

580 Handro/Schönemann 2014; Schreiber 2017; siehe hierzu auch Abschnitt 3.1.

581 Für die Erziehungswissenschaft: Kessl 2016; Kessl et al. 2016.

582 Kessl 2016, S. 5.

583 Siehe hierzu die Ausführungen in Abschnitt 3.4.1.

584 Schöner 2013c, S. 97.

585 Schrammel 2008, S. 95, am Beispiel lernbiografischer Forschung. 
Dies sind Fragen, die unmittelbar auf die Erforschung von Ausstellungsbesuchenden übertragbar sind. Die räumlichen Bedingungen und insbesondere die Auseinandersetzung der Besuchenden mit der räumlichen Struktur, ihre individuellen Bedeutungszuschreibungen und die Rolle von Raum im Prozess der subjektiven Aneignung in den Blick zu nehmen - dies sind Aspekte, die ich für meine eigene Datenanalyse als Hintergrundfolie im Blick behalte.

Was sich in dieser Auflistung möglicher Fragen bei Schrammel zaghaft andeutet, ist einerseits überhaupt eine Integration der räumlichen Dimension in die Analyse von Lehr-Lern-Prozessen und Aneignungsvorgängen. Gleichzeitig manifestiert sich darin auch eine Vervielfältigung der Bedeutungsdimensionen des Raumbegriffs, die für den Spatial Turn konstitutiv ist.

Neuere Raumkonzeptionen sind, wie bei Martina Löw et al. ausgeführt, ausgesprochen vielfältig, sie eint aber zumindest die Vorstellung, «banalisierende Container-Raumbegriffe als Erkenntnismittel zurückzuweisen». ${ }^{586}$ Waltraud Schreiber benennt ähnlich als gemeinsame Elemente des neuen Pradigmas raumsensibler Forschungen die Annahme, «dass Raum nicht als vorgegebener Container-Raum $[\ldots]$ zu verstehen ist», sowie ausserdem, «dass nicht von einem Geobzw. Raumdeterminismus auszugehen ist [und] dass Räume vielmehr immer (auch) konstruiert werden und deshalb grundsätzlich durch Veränderung gekennzeichnet sind». ${ }^{587}$

Eine Dichotomisierung von Perspektiven auf Raum als Container auf der einen Seite und Raum als konstruierter Raum auf der anderen Seite würde jedoch zu kurz greifen. So entfaltet Ed Soja in seinen Ausführungen zum «Thirdspace» ein Raumkonzept, das nicht in einem Entweder-oder zwischen beiden Dimensionen aufgeht, sondern diese überschreitet, und zum anderen nicht den Raum selbst, sondern das Verhältnis von Akteurinnen und Akteuren zu diesem Raum zum Ausgangspunkt seiner Kategorisierungen macht. ${ }^{588}$ Soja entwirft die Idee vom «Thirdspace» als einen «gelebten Raum, eine andere Art des Blicks auf raumbezogene Fragestellungen, der die geographische Betrachtungsweise über die bestehenden Dualismen hinaus erweitert». ${ }^{89}$

586 Löw et al. 2008, S. 51.

587 Schreiber 2017, S. 52.

588 Soja 2003, insb. S. $273 \mathrm{ff}$.

589 Soja 2003, S. 274, sich dabei beziehend auf Vorarbeiten von Lefebvre, mir in der Ausgabe von 2004 vorliegend. 
Übertragen auf die Forschung zu Besuchenden historischer Ausstellungen bedeutet dies, Aspekte des «gelebten Raums» in den Blick zu nehmen, wie sich diese beim Besuch manifestieren. Weder ist die Ausstellung lediglich ein vorgegebener, physischer Container (bzw. im konkreten Fall: eine vorgegebene, physisch vorhandene erzählte Geschichte) noch lediglich ein Wahrnehmungsraum, sondern möglicherweise entfalten sich durch das Sein und die Bewegung der Besuchenden im Raum neue Bedeutungen, die zwischen diesen Dimensionen changieren oder sie auch überschreiten. Diese in ihrem möglichen Zusammenhang mit Elementen und Prozessen historischen Denkens und Aneignens zu bringen, ist ein Anliegen, das ich im Rahmen meiner Forschung nur am Rande berühren kann, das aber für künftige geschichtsdidaktische Forschungen zum Umgang mit der räumlichen Dimension von Geschichtskultur relevant sein dürfte.

Daneben gilt es selbstverständlich auch die andere angesprochene räumliche Dimension zu berücksichtigen, nämlich die des behandelten Gegenstands, des historischen Geschehens. In dieser Betrachtung fliessen Objekt- und Subjektseite des Räumlichen ineinander. Zusammenfassend ist Raum in mindestens zweierlei Hinsichten für meine Studie relevant: erstens Raum als Faktor in den beobachteten Aneignungsvorgängen: Dabei geht es etwa um die Auseinandersetzung der Besuchenden mit dem Ausstellungsraum und der auf räumliche Weise strukturierten und erzählten Geschichte, um Raum als prägendes und konstituierendes Element des Aneignens. Zweitens Raum als Raum des behandelten Gegenstands, des historischen Geschehens: Auch dort geht es letztlich aber nicht um den Raum als historisch relevante Grösse, sondern um die Bedeutung dieses Raums für die Besuchenden und ihre Deutungen desselben, um die Rolle, die der Raum historischen Geschehens in ihren Aneignungsvorgängen spielt. In beiden Fällen geht es mittelbar um eine Objektseite des Räumlichen, aber um die Wahrnehmung, Deutung, Erzählung dieser Objektseite durch die beobachtenden Subjekte. 


\section{Forschungsanliegen}

Ich komme nun auf die mein Projekt leitenden Forschungsfragen zu sprechen. Dies erfolgt im Anschluss an die Schilderung der theoretischen Grundlagen, weil das Forschungsinteresse massgeblich aus einer Beschäftigung mit der Theorie entstanden ist. Selbstverständlich ebenfalls notwendige Bedingung für die Wahl des genauen Forschungsgegenstandes ist die Feststellung eines korrespondierenden Desiderats in der empirischen Forschung zu Museums- bzw. Ausstellungsbesuchenden, das ich im nächsten Kapitel aufzeigen werde.

Mit meinem Projekt strebe ich einen Beitrag zur Klärung der Frage an, welche Elemente und Strukturen des Denkens und welche Aneignungsweisen sich bei Besuchenden im Verlauf des Besuchs einer historischen Ausstellung identifizieren lassen. Dabei ist ein spezifischer Aspekt wiederum von besonderem Interesse: Angeregt von theoretischen Modellierungen, interessiert die Rolle der aktuellen Gegenwart und Lebenswelt als Gegenstand der Äusserungen, als möglicher Bezugspunkt des historischen Denkens beim Ausstellungsbesuch. ${ }^{590}$ Ich frage also weiter, inwiefern Besuchende bei ihren Äusserungen während des Ausstellungsbesuchs die eigene Person und Zeit thematisieren und einbringen.

Bei diesen Fragen geht es, auch wenn sie mit prozessorientierter Methodik erhoben werden, «weniger um die Repräsentation der kognitiven Prozesse als vielmehr um die Erfassung der Inhalte des Denkens und der gedanklichen Organisation dieser Inhalte». ${ }^{591}$ Es geht also in erster Linie um eine Strukturierung und Systematisierung der Äusserungen der Besuchenden. Nur in sehr begrenztem Mass werden daneben auch die den Äusserungen zugrunde liegenden, von den Besuchenden vollzogenen Operationen sichtbar und berücksichtigt. Beispielsweise beobachte ich, ob Besuchende über ihre eigene Lebenswelt sprechen, ob und wie sie $\ddot{u} b e r$ Verbindungen zwischen Vergangenheit und Gegenwart sprechen, erschliesse jedoch nicht, inwiefern sie dabei «Erzählen», «Nacherzählen» oder

590 Rüsen 1983; Hasberg/Körber 2003; Körber et al. 2007. Vgl. auch die Ausführungen in Kapitel 2.

591 Litten 2017, S. 180. Litten stellt dies so für ihr eigenes Forschungsinteresse fest, die Feststellung lässt sich analog aber auch auf mein Projekt übertragen. Vgl. hierzu weiter Abschnitt 6.1.5. 
«Umerzählen» ${ }^{592}$, und nicht grundsätzlich, inwiefern sie dabei Re- oder De-Konstruieren. Da Fragen des «Was» und «Wie» nur idealtypisch zu trennen sind, ${ }^{593}$ wobei ich zu Zweitgenannten auch zugrunde liegende Denkoperationen zähle, scheinen einzelne, die zugrunde liegenden Operationen betreffende Beobachtungen immer wieder auf. Kerngegenstand der Analyse ist jedoch die Systematisierung der expliziten Äusserungsebene.

Bei den beiden formulierten Forschungsfragen handelt es sich absichtsvoll um relativ breite und offene Fragen, die erlauben sollen, ausgehend vom Datenmaterial zu Strukturierungen zu gelangen, die den Äusserungen der Besuchenden selbst Rechnung tragen, ohne bereits mit einem über eine theoretische Sensibilität hinausgehenden Vorverständnis von historischem Denken das Datenmaterial begutachten zu wollen. Dabei ist es ein dezidiertes Anliegen, die Interaktion der Besuchenden mit der Ausstellung in den Blick zu nehmen und die gemachten Äusserungen an die Ausstellung und ihre Elemente zurückzubinden, also dafür sensibel zu sein, welche Rolle die Ausstellung als gestalteter Raum und als erzählte Geschichte und die darin befindlichen Elemente in den Überlegungen der Besuchenden spielen, sowohl implizit als vorhandene Struktur und Impulsgeber als auch explizit als Gegenstand der Auseinandersetzung.

Damit trage ich der Einsicht Rechnung, dass die konkrete Ausstellung als Umgebung massgeblich die darin stattfindenden Aneignungsweisen mitgestaltet. ${ }^{94}$ Obwohl die Forschungsfragen themen- und ausstellungsunabhängig formuliert sind und mit Besuchenden jeder historischen Ausstellung bearbeitet werden könnten, wird auf diese Weise auch der Ausstellungsabhängigkeit des beobachteten Geschehens Rechnung getragen. ${ }^{595}$

592 Pandel 2002, S. 49 f. Pandel unterscheidet als vierten Typ noch ein «Rezensierendes Erzählen», bei dem es sich um eine «Metanarration», eine "Bewertung erzählter Geschichten» handle, bei der «eine Geschichte auf empirische und narrative Triftigkeit geprüft» wird (Pandel 2002, S. 50). Der Logik der Basisoperationen Re-Konstruktion und De-Konstruktion folgend, liegt diese Operation meines Erachtens allerdings auf einer anderen Ebene als die übrigen drei, nämlich gehört sie dem de-konstruktiven Modus an.

593 Vgl. Abschnitt 6.4 .

594 So die Idee bei der Benennung eines «Physical Context» als Teil des «Contextual Model of Learning» bei Falk/Dierking (Falk/Dierking 2000, S. $10 \mathrm{ff}$., S. 53 ff., direkte Zitate S. 10 und S. 53), der bei Kohler als «Ausstellungskontext» aufgegriffen und rezipiert wird sowie «domänenspezifisch gewendet» für den Fall des historischen Lernens im Museum (Kohler 2016, S. 42 ff., S. 70, direkte Zitate S. 43 und 44).

595 Dies ist auch der Grund, weshalb ich mich in Kapitel 7 ausführlich der Darstellung der Ausstellung und ihrer Charakteristika widme. 
Die formulierten Anliegen sind dezidiert situationsbezogen und nehmen den Ausstellungsbesuch «in actu ${ }^{596}$ in den Blick. Ich verfolge hingegen nicht das Anliegen eines Vorher-nachher-Vergleichs in dem Sinn, dass zu einem Erhebungszeitpunkt vor und nach dem Museumsbesuch Ausprägungen von Geschichtsbewusstsein, Wissensbestände usw. erfragt würden. Veränderungen werden nur dann sichtbar, wenn sie während des Ausstellungsbesuchs von den Besuchenden selbst thematisiert werden.

Auch geht es nicht um eine Aufklärung der Frage, warum sich die Besuchenden so verhalten und äussern, wie sie es tun. Das Forschungsinteresse ist dezidiert auf die Situation des Besuchs fokussiert und bezieht Kontextinformationen zu den Besuchenden nur sehr zurückhaltend in die Analyse ein. Informationen, die über den Besuch selbst hinausreichen, beispielsweise zu Interessen und Motivationen der Besuchenden, kommen dann ins Spiel, wenn sich die Besuchenden während des Besuchs selbst explizit über diese äussern. ${ }^{597}$

Schliesslich geht es im Anschluss an die vom Datenmaterial ausgehende Systematisierung und Strukturierung der Befunde und zur Abrundung der Ergebnisdarstellung in einem letzten Schritt auch darum, Rückbindungen an vorhandene Theorien vorzunehmen, insbesondere an vorhandene Theorien historischen Denkens, aber auch an theoretische Vorstellungen des Lernens und Aneignens in einer historischen Ausstellung. Im Rahmen der Zwischenfazits und einer abschliessenden Synthese stelle ich deshalb, neben einer Rückbindung der Befunde an Ergebnisse empirischer Studien zu Museums-/Ausstellungsbesuchenden, auch dar, wie sich die festgestellten Aneignungsweisen und Elemente des Denkens beim Ausstellungsbesuch mit vorhandenen theoretischen Überlegungen in Bezug setzen lassen.

Dies zielt darauf, vorliegende Modellierungen auf ihre ausstellungsspezifische Passung hin zu befragen und in dieser Hinsicht erste Impulse für eine Erweiterung und Differenzierung zu setzen, ohne in dieser Hinsicht mit meiner Arbeit bereits theoriebildenden Anspruch zu verfolgen. ${ }^{598}$ Ich folge darin einem Einwand Koh-

596 Eine entsprechende Aufforderung ergeht generell in Bezug auf die Erforschung historischen Denkens bei: Körber 2006, S. 191.

597 «Individuelle Lernvoraussetzungen», wie diese bei Kohler neben dem «Ausstellungskontext» als weiterer Einflussfaktor im Rahmen der «Museumserfahrung» in den Blick genommen werden (Kohler 2016, S. 70), spielen in meiner Studie insofern dann eine Rolle, wenn sie von den Besuchenden wäbrend ihres Besuchs explizit verbalisiert werden.

598 So gehört auch die Ausarbeitung von Niveaustufen des historischen Denkens in einer historischen Ausstellung nicht zu meinen Anliegen, auch wenn ich auf vorliegende theoretische Überlegungen dazu (Körber 2009, Körber 2010a mit 2010b; vgl. Abschnitt 3.3) in den Fazits Bezug nehme. 
lers, der empfiehlt, die Passung vorhandener Modellierungen empirisch zu klären, «statt im deduktiven Zugriff geschichtsdidaktische Kompetenzmodelle samt -graduierung auf das Museum zu übertragen». ${ }^{599}$ Auch wenn ich nicht Kohlers pauschale Feststellung teile, dass ein deduktiver Zugriff «schlussendlich scheitern muss» ${ }^{600}$ halte ich doch eine stärkere Ergänzung theoretischer um empirische Zugänge bzw. eine stärkere Verzahnung beider für sinnvoll, wobei ich dem bislang vorhandenen Übergewicht theoretischer Überlegungen mit meiner Arbeit nun eng am Material orientierte, empiriegesättigte Befunde an die Seite stelle.

599 Kohler 2016, S. 20 f., direktes Zitat S. 21; Kohler bezieht sich mit diesem Hinweis auf bislang vorliegende, vor allem deduktive Ansätze namentlich auf die Beiträge von Gautschi 2009b, Körber 2009, Sauer 2009 sowie Körber 2010b, die von mir teilweise in Abschnitt 3.3 thematisiert wurden.

600 Kohler 2016, S. 21. 


\section{Besuchende in historischen Museen und Ausstellungen: Zum Stand der empirischen Forschung}

In diesem Kapitel äussere ich mich zum Stand der Forschung zu Museums- bzw. Ausstellungsbesuchenden. Dabei einen auch nur annähernd vollständigen Überblick über das grosse Spektrum bereits existierender Arbeiten geben zu wollen, wäre ein aussichtsloses Unterfangen. Es handelt sich um ein multidisziplinär besetztes Forschungsfeld, das aufgrund der Vielzahl an beteiligten Disziplinen unübersichtlich ist und «nicht gut koordiniert». ${ }^{601}$ Als beteiligte Disziplinen führt Sharon Macdonald «vor allem Psychologie, Soziologie, Architektur und Sozialanthropologie» an, ${ }^{602}$ wobei in diese Auflistung mindestens die Kulturwissenschaften und nicht zuletzt die Bildungswissenschaften, eine Reihe von Fachdidaktiken einschliesslich der Geschichtsdidaktik zu ergänzen wären. Daneben gibt es auch im ausserakademischen Bereich Studien zu Besuchenden, die etwa von den Museen selbst oder von mit der Befragung beauftragten Unternehmen durchgeführt werden. $^{603}$

Umfang und Vielfalt des Feldes, sowohl angesichts jahrzehntelanger Forschungen als auch im Hinblick auf die Zahl der beteiligten Disziplinen, macht Einschränkungen der Betrachtung unabdingbar. So beziehe ich mich auf Studien aus dem deutschsprachigen und daneben aus dem angloamerikanischen ${ }^{604}$ Raum. Neben einem einführenden Gesamtüberblick berücksichtige ich insbesondere Studien aus der jüngeren deutschsprachigen Geschichtsdidaktik, da der dortige Diskurs den Hauptbezugspunkt meiner Arbeit darstellt, integriere aber darüber hinaus für relevant befundene Studien aus angrenzenden Bereichen. ${ }^{605}$

601 Macdonald 2011, S. 237; rezipiert bei Noschka-Roos/Lewalter 2013, S. 205.

602 Macdonald 2011, S. 237.

603 Zu diesem Bereich: Macdonald 2011, S. 240.

604 Dass hier Forschungen stattfinden, die nicht nur von empirischer, sondern auch von theoretischer Relevanz für meine Arbeit sind, wurde bereits in Kapitel 3 deutlich.

605 Es stellt sich die Frage, inwiefern angesichts der Vielzahl von beteiligten Disziplinen im Fall der Museumsbesuchendenforschung überhaupt in disziplinären Kategorien gedacht werden sollte. Durchaus sinnvoll erscheint mir der integrierende Terminus «Museum Studies», der beispielsweise an der University of Leicester gebraucht wird (www2.le.ac.uk/ uol/departments/museumstudies/, letzter Zugriff am 29.7.2017). 
Im Zentrum stehen Forschungsarbeiten zu Besuchenden von historischen $\mathrm{Mu}$ seen und Ausstellungen, punktuell ergänzt um museumstypübergreifende Arbeiten und solche zu Besuchenden von anderen Museumstypen und Gedenkstätten, ${ }^{606}$ sofern ich den dabei gewonnenen Befunden über den jeweiligen Institutionstyp hinausgehende und für meine eigene Studie relevante Bedeutung beimesse. Weiter beinhaltet die Darstellung Studien zu Museumsbesuchenden sowohl mit als auch ohne Teilnahme an museumspädagogischen Programmen, da Letztere zumindest teilweise innerhalb von Ausstellungsräumlichkeiten stattfinden $^{607}$ bzw. mutmasslich auf die Ausstellung und die darin enthaltenen Elemente Bezug nehmen, insofern relevant für mein Projekt sein können, wenn auch Stu-

606 Die punktuelle Erweiterung des Forschungsüberblicks auf Studien zu Gedenkstättenbesuchenden rührt daher, dass ich Gedenkstätten als einen in Teilen dem historischen Museum bzw. der historischen Ausstellung verwandten Typus betrachte. Gedenkstätten enthalten in der Regel auch Ausstellungsräumlichkeiten, auch wenn ich Volkhard Knigge folge, der deutlich macht, dass Gedenkstätten - hier bezogen auf Gedenkstätten an Orten nationalsozialistischer Konzentrationslager - nicht nur «historische Museen und Lernorte» sind, sondern auch «Tatorte», «herausgehobene Orte des Leidens», «symbolisch und konkret Friedhöfe», «politische Denkmale», «Ort für Projektionen» und «Palimpseste», d.h. «weder ursprünglich noch authentisch, sondern vielfach überschriebene Denkmale aus der Zeit an die Zeit» (Knigge 2004, S. 17, S. 26 ff.; direkte Zitate: S. 26, 27). Bert Pampel bemerkt zudem, dass in Gedenkstätten ein stärkerer Fokus auf der historisch-politischen Bildung liege, etwa im Streben nach der «Förderung demokratischer Einstellungen», und dass sich dort weniger als in Museen «Bildung und Unterhaltung» miteinander verbinden lasse (Pampel 2007, S. 64f.).

Volkhard Knigge kommt zu dem Schluss, dass sich aufgrund der Differenzen zwischen den Institutionen «Konzepte museumsbezogener Besucherforschung nicht ohne weiteres auf Gedenkstätten übertragen lassen» (Knigge 2004, S. 17). Hingegen denke ich, dass für die Besucherforschung im Museum eine Berücksichtigung von Studien zu Gedenkstättenbesuchenden ertragreich sein kann (für den umgekehrten Fall: Pampel 2007, S. 157). Dies gilt insbesondere für solche Studien, die Aufschlüsse über den Besuch der in Gedenkstätten befindlichen Ausstellungsräumlichkeiten gewähren. Zudem gilt es zu bedenken, dass beide Institutionen trotz der genannten Differenzen die Räumlichkeit, Begehbarkeit und Dreidimensionalität gemeinsam haben (für Museen: Köhr 2012, S. 33) und den Besuchenden beim Besuch räumliche und ästhetische Erfahrungen ermöglichen können, ebenso wie ein Neben- oder Miteinander aus kognitiven und emotionalen Erfahrungen (für Gedenkstätten in den Blick genommen bei Pampel 2007), die es für beide Institutionen zu ergründen gilt. Auch in diesen Bereichen empfiehlt sich eine Berücksichtigung der im jeweils anderen Institutionstyp gewonnenen Befunde, die allerdings notwendigerweise kontextsensibel sein und «simple Analogien» (Pampel 2007, S. 157) vermeiden sollte.

607 Wenn auch die Untersuchung von Felicitas Iris Klingler den überraschenden Befund zutage fördert, dass von insgesamt 237 analysierten museumspädagogischen Angeboten (in diesem Fall zum Thema «Mittelalter») nur 56 Prozent innerhalb von Ausstellungsräumlichkeiten stattfinden, während die übrigen Angebote in Werkstätten, im Stadtraum bzw. an historischen Orten oder im Klassenzimmer durchgeführt werden (Klingler 2017, S. 77). 
dien zu Besuchenden ausserhalb von Programmen den Schwerpunkt des Forschungsüberblicks bilden. Nicht berücksichtigt werden dabei solche Studien, die ausschliesslich Analysen von museumspädagogischen Angeboten vornehmen. ${ }^{608}$ Hingegen sind solche Studien relevant, die Einsichten in Wahrnehmung, Denkweisen, Rezeption und Aneignungsprozesse der am Programm teilnehmenden Besuchenden gewähren. ${ }^{609}$

Mein Forschungsüberblick gliedert sich nachfolgend nach drei Perspektiven. Zunächst stelle ich in Abschnitt 5.1 bislang behandelte Gegenstände im Überblick vor und unterscheide dort nach ausgangslagen-, ergebnis- und prozessorientierten Forschungsanliegen. Daran anschliessend wende mich in Abschnitt 5.2 den eingesetzten Erhebungsmethoden zu, die ich nach prospektiven, retrospektiven und prozessbegleitenden Methoden differenziere.

Die ersten beiden Abschnitte dienen dazu, einen relativ breiten Überblick über Anliegen und zugehörige Forschungswege der Forschung zu Besuchenden zu geben und ausgehend davon Desiderate zu bestimmen - sowohl im Bereich der beforschten Themen als auch insbesondere der dabei zum Einsatz kommenden Erhebungsmethoden. ${ }^{610}$ Ausgehend davon, wird es später möglich, mein eigenes Projekt sowohl im Hinblick auf den Gegenstand als auch auf die gewählte Erhebungsform zu verorten und zu begründen.

608 Dies gilt etwa für die Studie von Felicitas Iris Klingler, die museumspädagogische Angebote hinsichtlich der «Relevanz 〈authentischer Objekte»» beforscht und dabei Websites analysiert bzw. in der Museumspädagogik tätige Personen befragt (Klingler 2017, S. 72 ff.), oder für die Untersuchung von Bettina Alavi, die das Angebot einer Museumspädagogin danach befragt, «welche (professionellen) historischen Kompetenzen sie für die Erstellung und Durchführung einer Führung von Schüler/innen durch eine historische Ausstellung anwendet und welche Kompetenzen sie bei den Schüler/innen fördern möchte» (Alavi 2009, S. 237, Kursivsetzung analog zum Original).

609 Z.B. Schreiber et al. 2015.

610 Das im Bereich der Erhebungsmethoden festgestellte Desiderat ist der Grund, weshalb ich bei meinem Forschungsüberblick gesondert auf die eingesetzten Erhebungs-, nicht aber auf die Auswertungsmethoden zu sprechen komme, auch wenn diesen nach streng systematischem Vorgehen ebenfalls eine Übersicht zu widmen wäre. Ich verzichte darauf, da ich die Ergänzung des bisherigen Forschungsfelds durch meine Arbeit im Bereich des Gegenstands und der Erhebungsform sehe und vorrangig diese in der Forschungslandschaft verorten möchte, zweitens aber auch deswegen, weil sich eine Reihe der nachfolgend zitierten Literatur zwar zu den Wegen der Datenerhebung äussert, bisweilen aber die konkret gewählten Auswertungs- bzw. Analyseverfahren unthematisiert lässt (z. B. Franz/ Siegele/Warmbold 2011, Lenz/Talsnes 2014, Pleitner 2011) oder keine Auswertung des erhobenen Materials vornimmt (Buttkereit et al. 2014). 
In Abschnitt 5.3 widme ich mich schliesslich der Darstellung von ausgewählten Forschungsergebnissen. Dort wird das Spektrum der rezipierten Arbeiten dann deutlich verengt und beschränkt sich auf diejenigen Arbeiten mit grösster Relevanz als Referenzpunkte für mein eigenes Projekt, die später auch herangezogen werden, um meine eigenen Ergebnisse abzugleichen und anzuschliessen. Abgerundet wird der Überblick zum Forschungsstand in Abschnitt mit einem Fazit, in dem ich Desiderate zusammenfasse und meine eigene Untersuchung verorte.

\subsection{Forschungsgegenstände}

Wenn ich nun die Gegenstände von Studien im Bereich der Besuchendenforschung systematisiere, so meine ich mit Gegenständen in erster Linie zugrunde liegende Forschungsfragen/-anliegen, bei ausgesprochen weiten Forschungsfragen im Rahmen qualitativer Vorhaben bisweilen jedoch auch die thematischen Bereiche, in denen sich anschliessend die Analyse bewegt. ${ }^{611}$ In der Literatur werden verschiedene Wege beschritten, um die Vielfalt an bearbeiteten Forschungsgegenständen zu systematisieren. Einer davon ist die von Annette Noschka-Roos vorgeschlagene Differenzierung in «Besucherstrukturanalysen», «Evaluationsstudien» und «Besucherforschung als Grundlagenforschung». ${ }^{612}$

Erstgenannte Studien zielen auf die Erhebung soziodemografischer und weiterer mitgebrachter Merkmale der Besuchenden, um Einblicke darüber zu geben, «welche Besucher kommen bzw. fernbleiben, welche Motive dem zugrundeliegen, oder welche Interessen und Vorkenntnisse Besucher zu einem bestimmten Ausstellungsthema haben». ${ }^{613}$ Vielfach werden solche Besucherstrukturanalysen von Museen selbst oder von zu diesem Zweck engagierten Marktforschungsunternehmen durchgeführt. ${ }^{614}$ Insbesondere in den USA haben die «marketingorientierten

611 Beispielsweise nennt Victoria Bishop Kendzia in Bezug auf Besuchende des Jüdischen Museums in Berlin zunächst recht allgemein das Anliegen, «to understand how Berlin-based high school students approach this museum and the history it presents», dem sie sich mittels Grounded Theory zuwendet und auf diesem Weg schliesslich auf den Umgang der Besuchenden mit Architektur, Objekten, interaktiven Elementen und Informationsfülle zu sprechen kommt (Bishop Kendzia 201 1, S. 51 und S. 54 ff.; direktes Zitat: S. 51). In solchen Fällen einer zunächst recht unspezifischen Forschungsfrage erscheint es mir hilfreich, für die Identifizierung behandelter Themen auch die Bereiche der Datenanalyse zu berücksichtigen, ohne dabei im engeren Sinn bereits Ergebnisse zu rezipieren. Dies ist erst Gegenstand von Abschnitt 5.3.

612 Noschka-Roos 1994, S.163, 168, 172. Nach Besucherstrukturanalysen und Evaluationsforschung differenziert auch Hoffrichter 1998, S. 109.

613 Noschka-Roos 1994, S. 168.

614 Macdonald 2011, S. 240. Beispielhaft für Museen der Stadt Köln: Hoffrichter 1998. 
Besucherstrukturanalysen» eine bis in die 1920er-Jahre zurückreichende Tradition, ${ }^{615}$ wie Horst Hoffrichter zeigt, ergänzt um einen weiteren Zweig, «dessen Ziel es ist, die kulturellen Vermittlungsprozesse in Museen zu fördern», und die «der sozialwissenschaftlichen Evaluationsforschung (Wirkungsforschung) zugeordnet» werden könnten. ${ }^{616}$ Diese Studien entsprechen dem zweiten von NoschkaRoos benannten Bereich. Hierzu zählt sie «Untersuchungen, welche die Wirkung von Ausstellungselementen auf Besucher erforschen und damit u.a. die Wirksamkeit methodischer Massnahmen beantworten». ${ }^{617}$ Während sie den beiden bereits beschriebenen Studientypen «den Charakter einer wissenschaftlichen Begleitforschung von Ausstellungen» zuweist, sei neben «dieser anwendungsbezogenen Funktion» noch eine dritte Gruppe von Besucherstudien festzustellen, nämlich eine Gruppe, «die explizit im Sinne einer Grundlagenforschung arbeitet, um die Bedingungen des Lernens an diesem Ort wissenschaftlich aufzuklären». ${ }^{618}$

Die Unterscheidung in Besucherstrukturanalysen, Evaluationsstudien und Grundlagenforschung stellt einen möglichen Weg dar, um das Feld empirischer Arbeiten zu systematisieren und zu strukturieren. In einem jüngeren Beitrag von Annette Noschka-Roos, gemeinsam mit Doris Lewalter, finden sich Anregungen für zwei weitere mögliche Unterscheidungen. Zum einen unterscheiden die Autorinnen Studien dahingehend, ob ihnen ein instruktionales/behavioristisches oder eher konstruktivistisches Verständnis des Lernens und Aneignens im Museum zugrunde liegt. ${ }^{619}$ Eine entsprechende Differenzierung erscheint mir allerdings für einen aktuellen Forschungsüberblick derzeit nicht zielführend, da erstgenannte Zugänge aus der aktuellen Forschungslandschaft nahezu vollständig verschwunden zu sein scheinen. ${ }^{620}$

615 Im Vergleich zur verhältnismässig langen Tradition der Besucherforschung in den USA sieht Hoffrichter den «Aufschwung» der Besucherforschung in Deutschland in den 1970er-Jahren und assoziiert diesen vor allem mit den Soziologen Heiner Treinen und Hans-Joachim Klein sowie dem Berliner Institut für Museumskunde (Hoffrichter 1998, S. 109). Zu einem ähnlichen Gesamteindruck kommt Noschka-Roos (Noschka-Roos 1994, S. 165).

616 Hoffrichter 1998, S. 109.

617 Noschka-Roos 1994, S. 168.

618 Noschka-Roos 1994, S. 172.

619 Analog zu den weiter oben bereits vorgestellten theoretischen Überlegungen zum Lernen bzw. Aneignen im Museum (vgl. Abschnitt 3.2). Diese Unterscheidung findet sich, wie im genannten Abschnitt differenzierter dargelegt, bei: Falk/Dierking/Adams 2006; HooperGreenhill 2006; Noschka-Roos/Lewalter 2013.

620 So formuliert Eckart Liebau etwa den Eindruck, dass behavioristische Zugänge «heute als geradezu rührend altmodisch und überholt» eingeschätzt würden (Liebau 2012, S. 39). Ebenfalls festgestellt wird eine deutliche Verschiebung bei Macdonald 2009, S. 242. 
Weiter regen die Autorinnen an, danach zu unterscheiden, ob eher Prozesse oder Ergebnisse der Museumsnutzung in den Blick genommen werden. ${ }^{621}$ Diese Differenzierung greife ich für meinen nachfolgenden Forschungsüberblick auf, da sie mir später erlaubt, mein eigenes Forschungsvorhaben innerhalb der prozessorientierten Anliegen zu verorten. Allerdings ergänze ich die von Noschka-Roos/ Lewalter vorgeschlagene Unterscheidung in Prozesse und Ergebnisse der Museumsnutzung um eine dritte Variante, die mir ausgehend von einem Blick in die Forschungssituation notwendig erscheint. So interessieren sich viele konstruktivistisch angelegte Studien statt oder neben Prozessen und Ergebnissen auch für die Ausgangslage der Museumsnutzung, also für Voraussetzungen auf Ebene der Besuchenden.

Die beschriebene Dreiteilung von Anliegen entspricht dem jüngst von Christian Kohler vorgelegten und weiter oben bereits beschriebenen domänenspezifischen Modell des musealen Lernens, ${ }^{622}$ in dem er den Prozess musealen Lernens in drei Aspekte bzw. Phasen untergliedert: die «Lernvoraussetzungen», den «Rezeptions- bzw. Lernprozess» und schliesslich die «Lernergebnisse». ${ }^{623}$ Kohler selbst möchte es als «Rahmenmodell für die Untersuchung und Analyse des gesamten Lernprozesses oder einzelner Aspekte» verstanden wissen. ${ }^{624}$ Das von ihm vorgeschlagene Modell ist nicht nur geeignet, um Aneignungsprozesse in einzelne Phasen bzw. Dimensionen zu segmentieren, sondern gleichzeitig auch die zugehörige empirische Forschung nach den jeweils schwerpunktmässig verfolgten Interessen zu systematisieren.

Eine entsprechende Dreigliederung stellt eine systematischere Alternative zu der weiter oben genannten Differenzierung in Besucherstrukturanalysen, Evaluationsstudien und Grundlagenforschung dar bzw. ist geeignet, diese Typen in sich aufzunehmen. So liessen sich Besucherstrukturanalysen tendenziell der ausgangslagen-/voraussetzungsorientierten Forschung zuordnen, Evaluationsstudien mit

621 Noschka-Roos/Lewalter 2013, S. 206 ff. Allerdings gehe ich in Abgrenzung zu NoschkaRoos und Lewalter davon aus, dass eine Fokussierung auf Lernergebnisse nicht per se gleichbedeutend sein muss mit einem instruktionalen Lernverständnis, vor allem aber umgekehrt eine Fokussierung auf Lernprozesse nicht gleichbedeutend mit einem konstruktivistischen Lernverständnis sein muss.

622 Kohler 2016, S. 70; vgl. Abschnitt 3.2.

623 Kohler 2016, S. 70. In Abweichung zu Kohler spreche ich selbst allerdings nicht von Lernvoraussetzungen, sondern lediglich von Voraussetzungen usw., um den weiter oben ausgeführten bedingten Vorbehalten gegenüber dem Lernbegriff im Kontext meines Projekts Rechnung zu tragen (vgl. Abschnitt 3.2).

Kohler 2016, S. 69. 
ihrem Blick auf Effekte der ergebnisorientierten Betrachtung. Grundlagenforschung kann innerhalb von allen drei Perspektiven erfolgen und sich Voraussetzungen, Prozessen oder Ergebnissen von Museums- bzw. Ausstellungsbesuchen zuwenden.

Tabelle 1 im digitalen Anhang stellt die drei möglichen Fokussierungen einander gegenüber, zergliedert sie weiter in Teilbereiche und nennt jeweils zugehörige Studien. Dass sich Studien mehr als einer der drei Ebenen zuordnen lassen, erweist sich dabei eher als Regel denn als Ausnahme. Die einzelnen Bereiche werden nachfolgend näher beschrieben.

$\mathrm{Zu}$ Studien mit Interesse für Ausgangslage und Voraussetzungen des Museumsbesuchs gehören zunächst einmal Erhebungen, in denen die soziodemografischen Daten von Besuchenden erfasst werden, beispielsweise um einen Überblick über Alters- und Geschlechtsverteilung oder Bildungshintergründe zu erhalten. In vielen wissenschaftlichen Studien liegt die Erhebung von soziodemografischen Daten allerdings nicht im Zentrum des Forschungsinteresses, sondern dient der Einordnung eines Samples, an das weitere Fragen herangetragen werden. ${ }^{625}$

Studien zu den Voraussetzungen von Besuchen interessieren sich ausserdem beispielsweise dafür, welches Wissen, Vorverständnis, welche Konzepte oder Einstellungen Besuchende in Bezug auf ein ausgestelltes Thema mitbringen, welche Erwartungen, Gründe und Motivation dem Besuch eines Museums oder einer Gedenkstätte zugrunde liegen oder welche Einstellungen gegenüber der Manifestation Museum bzw. Vorstellungen von der Manifestation Museum Besuchende mitbringen. ${ }^{626}$ Häufig beziehen sich die Untersuchungen dabei auf Besuchende einer spezifischen Einrichtung. ${ }^{627}$

625 So auch in meiner Untersuchung. Ich komme auf ausgewählte Befunde von Besucherstrukturanalysen weiter unten zu sprechen, wenn ich mein eigenes Sample charakterisiere und einordne (vgl. Abschnitt 6.2).

626 In diesen Feldern bewegen sich beispielsweise folgende Studien: Adams 1999, zit. n. Falk/ Dierking/Adams 2006; Falk 2006; Falk/Dierking/Adams 2006; Höge 2006; Pampel 2007; Pleitner 2008; Christmeier/Reither 2009, S. 135; Christmeier 2011, S. 313; Marx/ Sauer 2011; Schönert/Weckwerth 2011, S. 294 ff.; Lenz/Talsnes 2014, S. 99 f.; PauflerGerlach 2014; Kohler 2016. Für eine differenzierte Zuordnung der einzelnen Studien zu den genannten Feldern siehe Tabelle 1 im elektronischen Anhang.

627 So beforschen beispielsweise Martina Christmeier und Ingmar Reither Besuchende des Dokumentationszentrums Reichsparteitagsgelände in Nürnberg (Christmeier 2011; Christmeier/Reither 2009), Volker Schönert und Susanne Weckwerth Besuchende des Deutschen Hygiene-Museums in Dresden (Schönert/Weckwerth 2011). 
Studien, die sich mit der Ausgangslage des Museums- bzw. Ausstellungsbesuchs beschäftigen, erweisen sich als sensibel dafür, dass Besuchende weder eine tabula rasa sind noch alle Besuchenden identische Voraussetzungen mitbringen - eine Vorstellung, die für eher behavioristisch und instruktionistisch orientierte Arbeiten leitend wäre. ${ }^{628}$ Stattdessen kommen die vielfältigen Bedingungen in den Blick, die das Erlebnis des Besuchs prägen können. Wie weiter oben bereits eingeführt, schlagen John F. Falk und Lynn D. Dierking, teilweise mit Marianna Adams, eine Systematisierung für diese zahlreichen Faktoren vor, nämlich unterscheiden sie nach "Personal Context», «Sociocultural Context» und «Physical Context» des Lernens im Museum, ${ }^{629}$ wobei der zweit- und der drittgenannte Faktor in der von mir verwendeten Dreigliederung bereits den Prozess des Museumsbesuchs berühren. Konkret differenzieren Falk und Dierking innerhalb dieser drei Bereiche insgesamt acht Schlüsselfaktoren, nämlich

- innerhalb des Personal Context in «Motivation and expectations», «Prior knowledge, interests, and beliefs» und «Choice and control»,

- innerhalb des Sociocultural Context in «Within-group sociocultural mediation» und «Facilitated mediation by others» und

- innerhalb des Physical Context in «Advance organizers and orientation», «Design» und «Reinforcing events and experiences outside the museum». ${ }^{630}$

Wird, wie weiter oben angeführt, von Studien beispielsweise nach dem von Besuchenden mitgebrachten Vorverständnis, ihren Interessen und Erwartungen gefragt, so wären diese Forschungsinteressen nach dieser Kategorisierung dem personal context zuzurechnen.

Die Vielfalt von Bedingungsfaktoren eines Museums-/Ausstellungsbesuchs im Blick zu behalten, ist, so bemerkt Sharon Macdonald, gleichzeitig geboten wie auch herausforderungsreich: «Trying to understand this variability and the factors that may influence it is a major task of current museum eduational research. [...] Trying to incorporate even some of these factors into an analysis is clearly extremely difficult.» ${ }^{631}$ So erscheint es nicht verwunderlich, dass sich empirische Studien in der Regel lediglich auf Teilbereiche des Bedingungsgefüges fokussieren.

\footnotetext{
628 Vgl. hierzu die Ausführungen in Abschnitt 3.2.

629 Falk/Dierking 2000, insb. S. 15 ff. und 135 ff., direkte Zitate: S. 137, Kursivsetzung ana$\log$ zum Original. Hierzu ausserdem: Falk/Dierking 1997; Falk/Dierking/Adams 2006, S. 327.

630 Falk/Dierking 2000, S. 136f., direkte Zitate S. 137.

631 Macdonald 2006, S. 321.
} 
Neben den an der Ausgangslage interessierten Forschungsarbeiten bilden eine zweite Gruppe, nun am Ende des Besuchsverlaufs angesiedelt, solche Arbeiten mit Blick auf die Ergebnisse von Museumsbesuchen. In dieser Gruppe fällt auf, dass die Erhebung von deklarativem Wissen in Bezug auf das ausgestellte Thema oder auf Geschichte im Allgemeinen nur für einen geringen Teil der rezipierten Studien überhaupt eine Rolle spielt ${ }^{632}$ oder dass sie anders benannt wird. ${ }^{633}$ Erhoben werden stattdessen etwa Einstellungen in Bezug auf Geschichte oder ein Thema und der Umgang der Besuchenden damit, ${ }^{634}$ Konzepte, ${ }^{635}$ Motivation oder Interesse an einem Thema, ${ }^{636}$ allgemein gemachte Erfahrungen mit oder Wahrnehmungen der Ausstellung. ${ }^{637}$ Weiter geht es um die Bewertung von besuchten Museen, Ausstellungen oder Programmen durch die Besuchenden, ${ }^{638}$ auch im Kontext von erfüllten oder unerfüllten Erwartungen, ${ }^{639}$ und um die Reflexion der Besuchenden über eigene Lern-/Aneignungsprozesse. ${ }^{640}$

Nur idealtypisch abgrenzbar von den geschilderten ergebnisorientierten Anliegen sind solche, die sich den Prozessen eines Museums- bzw. Ausstellungsbesuchs widmen. Stark vereinfacht ausgedrückt, geht es ergebnisorientierten Forschungsvorhaben um die Klärung des «Was?», prozessorientierten Anliegen demgegenüber um die Frage des «Wie?» der Rezeption und Aneignung, wobei beide Perspektiven selbstredend in einem wechselseitigen Interdependenzverhältnis stehen, in der Praxis miteinander verwoben sind und von vielen Studien gemeinschaftlich behandelt werden. Allerdings gibt es durchaus Unterschiede dahingehend, wie unmittelbar Studien ihre Befunde über entstehende Sinnbildungen, Einstellungen, Konzepte usw. an den konkreten Verlauf des Museumsbesuchs und an die Ausstellung als Manifestation zurückbinden. Prozessbezogene Forschung ist sensibel für die Interaktion der Besuchenden mit dem jeweiligen

632 Christmeier/Reither 2009, S. 136; Marx/Sauer 2011, S. 62.

633 Volker Schönert und Susanne Weckwerth fragten Besuchende des Hygiene-Museums in Dresden unter anderem danach, was sie «Neues erfahren» hätten (Schönert/Weckwerth 2011, S. 302). An anderer Stelle heisst es allerdings, es gehe nicht darum, das Gelernte zu erheben (ebd., S. 293).

634 Marx/Sauer 2011; Klein 2011.

635 Adams 1999 zit. n. Falk/Dierking/Adams 2006; Falk/Dierking/Adams 2006.

636 Lewalter 2009; Marx/Sauer 2011; Schönert/Weckwerth 2011.

637 Klein 2011; Pleitner 2011; Schönert/Weckwerth 2011.

638 Christmeier 2011, S. 311 f.; Franz/Siegele/Warmbold 2011, S. 332 f.; Schönert/Weckwerth 2011, S. 284, S. 297 f.; Klein 2011.

639 Lenz/Talsnes 2014, S. $99 \mathrm{ff}$.

640 Pleitner 2011; Lenz/Talsnes 2014. 
physical context, für die ausstellungsseitig vorhandenen Bedingungen des Aneignens. ${ }^{641}$ Mit eng prozessbezogenen Anliegen liesse sich dann etwa fragen: Wie und auf welchem Weg gehen Besuchende durch eine Ausstellung? Welche Elemente wecken dabei ihre Aufmerksamkeit und warum? Welche Elemente führen zu welchen Deutungen? Welche Elemente evozieren Vorwissen?

So betrachten manche Studien Verhalten im Raum, etwa die Bewegungsmuster bzw. Laufwege von Besuchenden, ${ }^{642}$ teilweise verstanden als Indizien für Interesse oder Strategien der Auseinandersetzung, und fragen nach der Bedeutung von Raum und Architektur im Besuchsverlauf. ${ }^{643}$ Zahlreiche Arbeiten interessieren sich für die Rolle von Ausstellungselementen, u. a. Quellen, und den Umgang der Besuchenden mit diesen Elementen, ${ }^{644}$ teilweise verbunden mit der Frage nach der

641 Interessanter Ausgangspunkt hierfür könnten im Übrigen Arbeiten sein, die im Bereich der Museumsanalysen entstehen und dort die ausstellungsseitig vorhandene Angebotsstruktur in den Blick nehmen und die bislang kaum systematisch mit einer Erforschung der Nutzungsseite zusammengedacht werden. Museumsanalysen stellen (wie im Übrigen auch Denkmalsanalysen) ein stetig wachsendes und heterogenes Forschungsfeld dar, auf das ich an dieser Stelle nicht näher eingehe, obwohl es nach der hier vorgestellten Systematik der Analyse des physical context zugerechnet werden kann und insofern durchaus erwähnenswert ist. Da ich mich mit meinem Forschungsüberblick jedoch auf die Nutzungsperspektive, weniger die Angebotsperspektive von Museen fokussieren möchte, verweise ich lediglich auf einige einschlägige Publikationen. Für Einblicke in Methoden und Zugänge der Museumsanalyse empfiehlt sich der Sammelband von Baur 2010. Ausgewählte Analysen konkreter Museen finden sich beispielsweise bei: Hass 2002; Pieper 2006; Köhr 2012; Pohl 2013.

642 Wolf 1980, zit. n. Noschka-Roos 1994, S. 155; Serrell/Associates 2010; Bishop Kendzia 2011; Heikkilä et al. 2011; Wise 2011, S. 21 ff.; Röttele 2017.

Ein Bereich, den ich in meinem Forschungsüberblick nur am Rande berücksichtigen kann, sind Studien, welche Steven S. Yalowitz und Kerry Bronnenkant im Rahmen einer Metadarstellung unter dem Dach «timing and tracking» zusammenfassen (Yalowitz/Bronnenkant 2009, S. 47). Die Anfänge dieser Forschung verorten Yalowitz/Bronnenkant - vermutlich bezogen auf die USA - in den 1920er-Jahren und konstatieren dann ab den 1980er-Jahren einen rasanten Anstieg (ebd., S. 47). Zum Feld des «Timing and Tracking» ordnen sie Studien mit Interesse für unter anderem folgende Aspekte zu: «Total time in area», «Total number of stops», «Proportion of visitors who stop at a specific element», «Time (min:sec) of a stop at a specific element», «Down time» or non-exhibit related behaviors», «Visitor path» (ebd., S. 49 f.). Derartigen Studien liegt somit ein formales Interesse an Verweilzeiten und -häufigkeiten zugrunde. Eine Metaanalyse empirischer Studien zum Thema findet sich bei Beverly Serrell (Serrell 1998, zit. n. Rounds 2004, S. 401; Rounds 2004, S. 401). Da in meiner Forschung das gesprochene Wort der Besuchenden bzw. die geäusserten Gedanken im Fokus stehen und nicht das non-verbale Verhalten im Raum - auch wenn ich zur Einordnung der Daten knapp auch auf diese Aspekte zu sprechen komme (vgl. Abschnitt 8.3) -, verzichte ich auf die detaillierte Aufarbeitung des zugehörigen Forschungsfelds.

643 Christmeier 2011; Bishop Kendzia 2011.

644 Rowe 2002; Bishop Kendzia 2011; Christmeier 2011, S. 320 ff.; Wise 2011, S. 9, v. a. S. $90 \mathrm{ff}$; Wagner 2013; Röttele 2017. 
Bedeutung von Echtheit/Originalität/Authentizität von Objekten. ${ }^{645}$ Manche Studien interessieren sich für Fragen der Objekt-/Informationsauswahl bzw. des Umgangs mit Informationsfülle. ${ }^{646}$ Eine ganze Reihe von Studien betrachtet das Vorkommen oder die Rolle von Emotionen und Empathie ${ }^{647}$ oder (sinnlicher) Wahrnehmung ${ }^{648}$ beim Museums-, Ausstellungs- oder Gedenkstättenbesuch. Viele Studien gehen noch nicht mit einem stark gerichteten Interesse in die Erhebung, sondern fragen möglichst offen etwa nach den beim Besuch auftretenden Erfahrungen $^{649}$ oder «sense-making processes», ${ }^{650}$ die dann ausgehend vom Datenmaterial ausdifferenziert werden. Eine kleine Anzahl von Studien widmet sich zudem namentlich dem historischen Denken beim Ausstellungsbesuch ${ }^{651}$ oder spezifischer noch der Anwendung von Kompetenzen historischen Denkens. ${ }^{652}$

Am Besuchserlebnis und -verlauf interessierte Forschungen, zu denen auch meine Arbeit gehört, scheinen mit Blick auf das breite Spektrum der bearbeiteten Themen bereits umfangreich erforscht zu sein. ${ }^{653}$ Das eigentliche Forschungsdesiderat offenbart sich erst mit Blick auf die für die Bearbeitung der jeweiligen Anliegen ausgewählten Methoden. Für die Bearbeitung solcher eng am Besuchserlebnis orientierter Anliegen wird nämlich, wie ich im nächsten Abschnitt zeigen werde, nur bedingt auf eine prozessorientierte Erhebungsmethodik gesetzt, werden viele Aspekte ganz im Gegenteil retrospektiv im Anschluss an den Besuch oder lediglich auf beobachtendem Weg erhoben.

645 Bishop Kendzia 2011.

646 Bishop Kendzia 2011; Christmeier 2011; Röttele 2017.

647 Erdmann 1994; Ameln-Haffke/Schuster 2006; Höge 2006; Schuster/Ameln-Haffke 2006; Bishop Kendzia 2011; Christmeier 2011; Heikkilä et al. 2011; Klein 2011; Schönert/Weckwerth 2011.

648 Erdmann 1994; Röttele 2017.

649 Pampel 2007, S. 18 f., S. 235 ff.; Bishop Kendzia 2011.

650 Wise 2011, S. 9 , S. $90 \mathrm{ff}$.

651 Wise 2011.

652 Schreiber et al. 2015.

653 Etwas anders stellt sich die Lage offenbar für empirische Studien zu Gedenkstättenbesuchenden dar. So findet sich in einer Auflistung von Bert Pampel, der in Form eines Literaturreviews die Gegenstände von insgesamt 21 Studien in diesem Bereich zusammenstellt, lediglich ein einziges Forschungsinteresse, das im weitesten Sinn als prozessbezogen bezeichnet werden könnte, nämlich die «Interaktion zwischen Schülern, Lehrern und Gedenkstättenmitarbeitern» (Pampel 2011, S. 27 f., direktes Zitat: S. 28). Die Darstellung von Befunden im Bereich «Lerneffekte» nimmt entsprechend in Pampels Artikel den weitaus grössten Anteil ein (ebd., S. 35 ff., direktes Zitat: S. 35). 


\subsection{Erhebungsmethoden}

Neben den thematischen Zugängen wende ich mich in meinem Forschungsüberblick den gewählten Erhebungsmethoden zu, die ich ebenfalls in drei Bereiche unterteile: prospektive, retrospektive und prozessbegleitende Methoden. Für diese Gliederung greife ich auf zwei Vorschläge in der Forschungsliteratur zurück. So unterscheidet Susie Wise Erhebungsmethoden in der Museumsbesuchendenforschung anhand zweier Dimensionen, und zwar erstens dahingehend, ob sie Individuen oder Gruppen in den Blick nehmen, und zweitens dahingehend, ob die Erhebung innerhalb der Ausstellungsräumlichkeiten durchgeführt wurde oder ausserhalb davon. ${ }^{654}$ In eine ähnliche Richtung wie die zweitgenannte Differenzierung zielt eine Unterscheidung bei Marcel V. Veenman. Dieser systematisiert Erhebungsmethoden danach, ob die Erfassung interessierender kognitiver Prozesse «[p]rospective», «[c] oncurrent» oder «[r] etrospective» sei. ${ }^{655}$ Ich greife diese Unterscheidung auf, ergänze allerdings die drei von Veenman vorgeschlagenen Erhebungszeitpunkte um einen vierten, indem ich die retrospektiven Erhebungsmethoden nach unmittelbar retrospektiven Methoden im Anschluss an den Ausstellungsbesuch und retrospektiver Erhebung mit zeitlichem Abstand unterteile, ausgehend von der Feststellung von Falk, Dierking und Adams, dass auch mit zeitlichem Abstand zum Besuch und in Abhängigkeit von den nachfolgenden Umständen Lernprozesse stattfinden können. ${ }^{656}$

Tabelle 2 im digitalen Anhang zeigt, dem geschilderten Prinzip folgend, eingesetzte Erhebungsformen im Überblick (prospektiv, prozessbegleitend, ${ }^{657}$ retrospektiv $I$, retrospektiv II) und differenziert überdies, auf dem Vorschlag von Wise aufbauend, nach den dabei interessierenden Personenkreisen (Individuen oder Gruppen, Schülerinnen und Schüler oder Erwachsene). Innerhalb der in der Ge-

654 Wise 2011, S. 17.

655 Veenman 2005, S. 78 ff., direkte Zitate: S. 78, 80, 83, am Beispiel von Methoden zur Erfassung von Metakognitionen. Diese Unterscheidung wird aufgegriffen von Maria Bannert, die «Prospektive Methoden», «Online-Methoden» und «Retrospektive Methoden» unterscheidet (Bannert 2007, S. 128 ff., direkte Zitate: S. 129, 131, 132). Günter L. Huber und Heinz Mandl differenzieren Methoden in «präaktional», «periaktional» und «postaktional» (Huber/Mandl 1982, S. 23).

656 Falks/Dierking/Adams 2006, S. 327.

657 In Analogie zu «[c] oncurrent» bei Veenman (Veenman 2005, S. 80, s. o.), unter Entwendung der Begrifflichkeit von einer spezifischen online erhebenden Methode, nämlich dem Prozessbegleitenden Lauten Denken (z. B. Wallach/Wolf 2001), das in meiner Studie zum Einsatz kommt. 
schichtsdidaktik verorteten Forschungsarbeiten zeigt sich dabei ein naheliegender Schwerpunkt auf Schülerinnen und Schüler und dabei wiederum auf Gruppen, der in meiner Studie nun durch eine Perspektive auf erwachsene Einzelbesuchende ergänzt wird.

$\mathrm{Zu}$ den prospektiven Erbebungsvarianten zählen all diejenigen Formen der Datenerhebung, die zeitlich vor dem Besuch durchgeführt werden. Wichtig ist dabei zunächst die Feststellung, dass nicht alle Studien, die sich - wie im vorigen Abschnitt beschrieben - für Voraussetzungen und Vorbedingungen des Besuchs interessieren, dies auch mit prospektiven Erhebungsmethoden tun. So werden beispielsweise Vorverständnis oder Erwartungen zum Museumsbesuch gelegentlich erst im Anschluss an diesen Besuch erfragt. ${ }^{658}$ Es stellt sich damit zugleich die Frage, inwiefern die erhobenen Erwartungen, Interessen und Vorverständnisse tatsächlich vor Besuch in der von den Besuchenden geschilderten Form vorlagen oder wesentlich auch durch das Besuchserlebnis selbst mitgeprägt wurden. ${ }^{659}$ Andererseits ist ein Verzicht auf eine vor dem Besuch stattfindende Erhebung insofern sinnvoll, als diese das Besuchserlebnis unbeabsichtigt und unkontrolliert vorstrukturieren und mitprägen kann. ${ }^{660}$

Werden prospektive Erhebungen durchgeführt, kommen methodisch dabei in erster Linie Fragebogenerhebungen vor Eintritt in die Ausstellung zum Einsatz ${ }^{661}$ bisweilen auch Interviews. ${ }^{662}$ Beispielsweise befragte Bert Pampel Besuchende von Gedenkstätten vor Eintritt mittels eines mündlichen Fragebogens zu ihren «Motiven und Erwartungen» hinsichtlich des Besuchs, ${ }^{663}$ ebenso erhoben Alexandra Marx und Michael Sauer Einstellungen von Gedenkstättenbesuchenden unter anderem in einer Vorabbefragung per Fragebogen. ${ }^{664}$

Für sämtliche erwähnten Studien stellt die prospektive Erhebung nicht den einzigen Erhebungszeitpunkt dar, sondern wird ergänzt um weitere Erhebungszeitpunkte bzw. auch um andere Methoden, die zu späteren Zeitpunkten des

658 So erheben beispielsweise Christmeier und Schönert/Weckwerth entsprechende Aspekte retrospektiv (Christmeier 2011, S. 313; Schönert/Weckwerth 2011, S. 294).

659 Darüber reflektiert Pampel 2007, S. $207 \mathrm{f}$.

660 So befürchtet von Pampel, der in seiner prospektiven Befragung bewusst auf Fragen nach dem Vorwissen zum besuchten Ort verzichtet, um den Teilnehmenden nicht das Gefühl zu geben, «dass ihre historischen Kenntnisse geprüft werden» (Pampel 2007, S. 207).

661 Ameln-Haffke/Schuster 2006; Falk 2006; Höge 2006; Pampel 2007; Bishop Kendzia 2011; Marx/Sauer 2011; Buttkereit et al. 2014.

662 Pleitner 2011.

663 Pampel 2007, S. 164.

664 Marx/Sauer 2011. 
Besuchs zum Einsatz kommen: entweder während des Besuchs oder in einer retrospektiven Erhebung im Anschluss daran. ${ }^{665}$ Dies veranschaulicht Tabelle 2 im digitalen Anhang, in der eine Reihe von Studien innerhalb mehrerer Kategorien genannt werden. Die Kombination mehrerer Erhebungszeitpunkte erlaubt es insbesondere, Veränderungen während des Besuchs in den Blick zu nehmen.

Dies ist ein Zugang, der etwa auch mit der am Institute for Learning Innovation entwickelten und bei Falk et al. beschriebenen Methode des "personal meaning mapping», kurz «PMM», verfolgt wird. ${ }^{666}$ Bei PMM handle es sich demnach um eine weiterentwickelte Form des Concept-Mapping, die ergebnisoffen gedacht sei und den individuellen Erfahrungen der Besuchenden Rechnung tragen solle. ${ }^{667}$ Die Methode erlaube,

«to measure how a specified learning experience uniquely affects each individual's understanding or meaning-making process. It does not assume that all learners enter with comparable knowledge and experience, nor does it require that an individual produce a specific 〈right \answer in order to demonstrate learning.» ${ }^{668}$

Mit dieser Sensibilität für individuelle Voraussetzungen und Lern- bzw. Sinnbildungsprozesse während des Besuchs verorten sich Falk et al. innerhalb einer konstruktivistischen Lernvorstellung. ${ }^{669}$ Immer in Kombination mit weiteren Erhebungszeitpunkten im Anschluss an den Museumsbesuch soll diese Methode ermöglichen, nachzuvollziehen, «how an educational experience uniquely affects the public's personal, conceptual, attitudinal, and emotional understanding across four, semi-independent learning dimensions», nämlich «the extent of a visitor's knowledge and feelings», "the breadth of a visitor's understanding», "the depth of understanding» und «the mastery an individual possesses of the topic». ${ }^{670}$

665 Die jeweilige Kombination aus Methoden und Erhebungszeitpunkten für einzelne Studien herauszuarbeiten, ist hier allerdings nicht mein Anliegen.

666 Falk/Dierking/Adams 2006, S. 333.

667 Falk/Dierking/Adams 2006, S. $332 \mathrm{f}$.

668 Falk/Dierking/Adams 2006, S. 333.

669 Falk/Dierking/Adams 2006, S. 325.

670 Falk/Dierking/Adams 2006, S. 333; Kursivsetzungen analog zum Original. 
Zugrunde liegt dem die Annahme,

«that it is the norm, rather than the exception, that free-choice learning experiences have an effect on the underlying structure of an individual's understanding. $[\ldots]$ The focus of PMM is not exclusively on the nature of change but equally on the degree of change in learning.» ${ }^{671}$

Mit dem Einsatz von PMM verbindet sich dabei die Idee einer langfristigen Perspektive mit Messzeitpunkten mit zeitlichem Abstand zum Besuch, ${ }^{672}$ der weiter oben bereits erwähnten Einsicht folgend, dass sich auch im weiteren Nachgang noch relevante Konzeptänderungen ergeben können:

«[O]ne should expect that learning from museums will not only rely on the confirmation and enrichment of previously known intellectual constructs but equally depend upon what happens subsequently in the learner's environment. All learning occurs over time in a cumulative process of acquisition and consolidation.» ${ }^{673}$

Dem Ansatz einer langfristigen Untersuchungsanlage folgen auch andere Studien mit in zeitlichem Abstand zum Besuch eingesetzten Methoden, üblicherweise in Form von Fragebögen, ${ }^{674}$ oder Interviews. ${ }^{675}$ Für den überwiegenden Anteil an Studien bedeutet retrospektiv jedoch, dass die Datenerhebung unmittelbar im Anschluss an den Besuch oder die Teilnahme an einem museumspädagogischen Programm durchgeführt wurde. Die bei Weitem verbreitetsten Methoden stellen dabei wiederum Fragebogenerhebungen ${ }^{676}$ und Interviews, insbesondere Einzelinterviews, ${ }^{677}$ dar. Eine spezielle Form bilden Gruppeninterviews, ${ }^{678}$ etwa wenn

671 Falk/Dierking/Adams 2006, S. 333.

672 Beispielsweise dreimalig, nämlich einmal vor der Besuchserfahrung sowie zweimalig im Anschluss daran, davon einmal unmittelbar nach dem Besuch und ein weiteres Mal im zeitlichen Abstand einiger Wochen, wie offenbar eingesetzt in einer Studie von Adams (Adams 1999, zit. n. Falk/Dierking/Adams 2006, S. 334).

673 Falk/Dierking/Adams 2006, S. 327.

674 Schuster/Ameln-Haffke 2006; Pampel 2007; Marx/Sauer 2011.

675 Pampel 2007; Pleitner 2008; Pleitner 2011.

676 Erdmann 1994; Ameln-Haffke/Schuster 2006; Falk 2006; Höge 2006; Bishop Kendzia 2011; Franz/Siegele/Warmbold 2011; Schönert/Weckwerth 2011; Buttkereit et al. 2014; Schreiber et al. 2015.

677 Klein/Wüsthoff-Schäfer 1990; Christmeier/Reither 2009; Lewalter 2009; Christmeier 2011.

678 Unmittelbar retrospektiv: Bishop Kendzia 2011; Klein 2012. Mit zeitlichem Abstand: Franz/Siegele/Warmbold 2011; Pleitner 2011. 
weniger individuelle Perspektiven als das gemeinsame Aushandeln von Besuchserfahrungen im Gespräch von Interesse sind. ${ }^{679}$

Eine bislang in der Besuchendenforschung nicht stark verbreitete Erhebungsform wählten, mit unterschiedlichen zeitlichen Abständen zum Besuch eingesetzt, unter der Bezeichnung «stimulated recall» Claudia Lenz und Anne Talsnes. ${ }^{680}$ Diese Methode zielt auf das Reflektieren über eine vorausgegangene Lehr- oder Lernsituation, wobei dieses Reflektieren durch einen Stimulus ausgelöst wird. ${ }^{681}$ So wurde die Methode unter anderem bei Schülerinnen und Schülern angewandt, die Ausstellungen zum Thema Holocaust im HL Center in Oslo besuchten. Vor dem Besuch wurden sie aufgefordert, ihre Erwartungen auf Kärtchen festzuhalten. Selbige dienten im Anschluss als Gesprächsanreiz, um über den Grad der Erfüllung bzw. Nichterfüllung von Erwartungen beim Besuch zu reflektieren. ${ }^{682}$ Beim Stimulated Recall handelt es sich um eine Methode, die eine Verwandtschaft mit dem (Nachträglichen) Lauten Denken besitzt. ${ }^{683}$

Neben den gesprächsbasierten Erhebungsformen wie Einzelinterviews und Gruppendiskussionen finden sich darüber hinaus vereinzelt Studien, die sich für Besucherbucheinträge interessieren. ${ }^{64}$ Ich zähle diese ebenfalls zu den retrospektiven Erhebungsmethoden, weil die Einträge aller Wahrscheinlichkeit nach von den Besuchenden am Ende ihres Museumsaufenthalts verfasst werden.

Wie die erwähnten Untersuchungen von Lenz und Talsnes oder auch Pampel sowie Falk, Dierking und Adams arbeiten viele Studien mit einer Kombination aus verschiedenen Erhebungsmethoden und -zeitpunkten. Werden mehrere Zeitpunkte miteinander kombiniert, so liegt die Frage nach möglichen Veränderungen im Verlauf des Besuchs nahe, so etwa die Frage nach Wissenszuwächsen oder Konzeptänderungen. Pampel macht allerdings darauf aufmerksam, wie schwierig es ist, Befunde unmittelbar auf den vorausgegangenen Besuch als Auslöser zurückzuführen. Am Beispiel der Forschung zu Gedenkstättenbesuchenden stellt er fest:

\footnotetext{
679 So bei Klein 2012, S. $84 \mathrm{ff}$.

680 Lenz/Talsnes 2014.

681 Lenz/Talsnes 2014, S. 97, S. 113.

682 Lenz/Talsnes 2014, S. $99 \mathrm{ff}$.

683 Vgl. dazu Abschnitt 6.1.

684 Christmeier 2011, S. 312, erwähnt diesen Datentyp, geht jedoch nicht näher auf ihr Vorgehen ein.
} 
«Von besonderem Interesse waren und sind Hinweise auf eine Veränderung politischer Einstellungen oder auf einen Zuwachs an historischem Wissen. Derartige Wirkungen lassen sich aus verschiedenen Gründen allerdings sehr schwer genauer bestimmen. Erstens ist der Nachweis «wahrnehmbarer〉 Veränderungen schwierig. Zweitens ist ihre eindeutige Zuordnung zum Besuch, das heisst ihre Isolierung von anderen Einflussfaktoren, schwer. Drittens entziehen sich Ziele historisch-politischer Bildung wie $<$ Sensibilisierung für Demokratiegefährdungen〉 oder 〈Anregung zur Selbstreflexion〉 überwiegend einer exakten Messung. Viertens erfordern entsprechende Untersuchungen einen vergleichsweise grossen Aufwand. Fünftens besteht bei solchen Fragen und bei diesem Thema besonders die Gefahr, dass durch die Fragetechnik Bekenntnisse produziert werden, die man wegen des Phänomens der sozialen Erwünschtheit nicht für bare Münze nehmen kann. Die meisten bisherigen Studien geben daher weniger Auskunft über solche Wirkungen, als über die Schwierigkeiten, diese zu messen.» ${ }^{685}$

Inwiefern Befunde unmittelbar an den vorausgegangenen Besuch kausal zurückgebunden werden können, darin unterscheiden sich die Studien somit jenseits vom Forschungsinteresse nicht zuletzt auch in Abhängigkeit vom gewählten Erhebungssetting. Beschränken sich Studien auf retrospektive Erhebungsmethoden, ist kaum eine Einsicht möglich, ob und inwiefern Effekte unmittelbar auf den Besuch zurückzuführen sind. Retrospektive Methoden sind stets abhängig davon, welche Auskünfte die untersuchten Personen in der Rückschau zu geben imstande sind und wie sie ihre Erlebnisse in der Rückschau bewerten. Andererseits können freilich auch im Nachhinein getroffene Selbstauskünfte der befragten Personen als Indizien für durch den Besuch ausgelöste Änderungen verstanden werden. ${ }^{686}$

Um Wirkungen eines Museums- bzw. Ausstellungsbesuchs unmittelbar im Moment ihres Entstehens in den Blick zu nehmen, ebenso wie für die Bearbeitung einer Reihe weiterer am Besuchsverlauf orientierter Anliegen bieten sich prozessbegleitende Erhebungsmethoden an. Sie versprechen Antworten auf Fragen wie:: ${ }^{67}$ In welchen Momenten genau entstehen bestimmte Assoziationen? Welche Objekte oder sons-

685 Pampel 2007, S. 106.

686 So argumentiert etwa Pampel 2007, S. 207. Er kommt zu seinem Set an «Besuchserfahrungen» mittels retrospektiver Befragungen (Pampel 2007, S. $163 \mathrm{ff}$., S. 235 ff., direktes Zitat: S. 235).

687 Einige der nachfolgend genannten Fragen habe ich ähnlich auch aufgelistet in Thyroff 2017 c, S. 3. 
tigen Ausstellungselemente sind es, die dabei eine Rolle spielen, die zum Beispiel Konzeptänderungen anstossen, Vorwissen evozieren, Emotionen auslösen? Welche Rolle spielt dabei sinnliches und ästhetisches Erleben? Wie gestaltet sich der Prozess, in dem Präkonzepte, Vorwissen usw. mit dem Gesehenen in Verbindung gebracht, sich ergänzen oder revidieren? Wie funktioniert Orientierung in der Ausstellungsstruktur - sowohl in räumlicher als auch inhaltlicher Hinsicht? Und in Anlehnung an vorherige Ausführungen mit konstruktivistischem Blickwinkel formuliert: Wie «konstruieren» Besuchende während des Besuchs Geschichte? Wie «konstruieren» sie Bezüge zu sich selbst, zu Gegenwart und Lebenswelt?

Das Anliegen prozessbegleitender Erhebungsmethoden besteht darin, solche Aspekte im Moment ihres Auftretens und an Ort und Stelle in der umgebenden Ausstellungsstruktur zu erfassen und damit die Forschung näher an den Prozess des konkreten Besuchsverlaufs zu bringen. Sie kommen in der Erforschung von Besuchenden neben retrospektiven Methoden bislang vergleichsweise wenig zum Einsatz. Dominierend sind dabei Formen der Beobachtung in unterschiedlichen Varianten, sowohl von einzelnen Besuchenden ${ }^{688}$ als auch von Gruppen. ${ }^{689}$ Eine weitere Zugangsmöglichkeit ist die Auswertung von Audioguidedaten, sofern diese Auskünfte über den Verlauf des individuellen Museumsbesuchs zu geben imstande sind. ${ }^{690}$

Mit Blick auf mein eigenes Forschungsanliegen folge ich Eilean HooperGreenhill, wenn sie darauf hinweist, dass beobachtende Methoden allein nicht ausreichend sind, wenn die Genese von Sinnbildungsprozessen während des $\mathrm{Mu}$ seumsbesuchs von Interesse ist:

«If meaning-making processes are contingent, variable, and fluid, then how can they be researched? In order to understand the sense that visitors make in museums, it is not enough to observe what people do, and it is not enough to ask demographic questions.» ${ }^{691}$

688 Bishop Kendzia 2011; Danker/Schwabe 2011; Schreiber et al. 2015; Wagner 2013; Klein/ Wüsthoff-Schäfer 1990. Zu Vorgehensweisen im Bereich des «Timing and Tracking» siehe Yalowitz/Bronnenkamp 2009, S. $50 \mathrm{ff}$. Als Spezialform innerhalb dieser Gruppe verstehe ich die Methode des Eye-Tracking (Eghbal-Azar/Widlok 2013).

689 Franz/Siegele/Warmbold 2011, S. 333; Röttele 2017.

690 Christmeier erwähnt diese Methode, geht jedoch nicht näher darauf ein (Christmeier 2011, S. 312).

691 Hooper-Greenhill 2006, S. 373. 
In diesem Forschungsbereich sind ganz im Gegenteil solche Forschungsmethoden hilfreich, die mit Verbalisierungen der Besuchenden arbeiten. So verfolgen Shawn Rowe wie auch Hannah Röttele die Gespräche zwischen besuchenden Gruppen, im Fall von Rowe «natürliche» Gruppen, im Fall von Röttele Arbeitsgruppen innerhalb einer an einem museumspädagogischen Programm teilnehmenden Schulklasse, wobei es sich in beiden Fällen um eine natürliche und nicht zu Forschungszwecken geführte Konversation handelt. ${ }^{692}$

Prozessbegleitende Verbalisierungen von Einzelbesucher/innen können ausserdem über den Einsatz Prozessbegleitenden Lauten Denkens gewonnen werden, das bislang allerdings eher selten zum Einsatz kommt. Erste Hinweise auf den Einsatz Lauten Denkens im Museum finden sich in den 1990er-Jahren. ${ }^{693}$ So interessiert sich Colette Dufresne-Tassé dafür, ohne hierfür allerdings den Terminus «think aloud» explizit zu gebrauchen, «what the visitor says in front of the objects being looked at», aufgenommen von einer Begleitperson «at a comfortable distance». ${ }^{694}$

Ein Beispiel für den Einsatz Lauten Denkens stellt die Dissertationsschrift von Susie Wise aus dem Jahr 2011 dar. Sie interessiert sich für «sense-making processes», die bei Besuchenden während ihres Gangs durch die Ausstellung des Chelsea Jeans Memorial in New York auftreten, und für die Rolle, die dabei die körperliche Bewegung im Raum spielt, und beobachtet diese mittels Lauten Denkens und gleichzeitiger Videoaufzeichnungen beim Ausstellungsbesuch. ${ }^{695}$ Die Studie von Wise ist aufgrund sowohl thematischer als auch methodischer Verwandtschaft von grosser Bedeutung für mein Projekt, und ich widme ihr weiter unten einen eigenen Abschnitt. ${ }^{696}$

Im deutschsprachigen Raum findet sich der Einsatz Lauten Denkens zur Erforschung von Museumsbesuchenden in der Dissertation von Gun-Brit Thoma zum Thema «Was lernen Besucherinnen und Besucher im Museum? Eine Untersuchung von Lerngelegenheiten einer Museumsausstellung und ihrer Nutzung»,

692 Rowe 2002; Röttele 2017.

693 So im Überblick von Heikkilä et al. konstatiert (Heikkilä et al. 2011, S. 14f.), die Arbeiten von Dufresne-Tassé erwähnen (Dufresne-Tassé 1995, ausserdem Dufresne-Tassé/Lefebvre 1994, zit. n. Heikkilä et al. 2011, S. 15). Ähnlich führt auch Hein unter dem Stichwort «Protocol Analysis» einzelne Studien aus diesem Zeitraum an (Hein 1998, S. $130 \mathrm{f}$.).

694 Dufresne-Tassé 1995, S. 249.

695 Wise 2011, S. 9f., S. 21, S. 27.

696 Vgl. Abschnitt 5.3.7. 
für die Besuchende der Ausstellung «Foto und Film» im Deutschen Museum in München beforscht wurden. ${ }^{697}$

Lautes Denken kommt als Erhebungsform ausserdem in einer Studie von Buttkereit et al. zum Einsatz, die im Rahmen einer Veranstaltung an der Universität Passau mit Studierenden im Oberhausmuseum Passau durchgeführt wurde. ${ }^{698}$ Dort geht es um Klärung der Frage, «wie die Besucherinnen und Besucher auf eine Ausstellung, auf Museumsobjekte reagieren», und darum, «Anhaltspunkte dafür zu gewinnen, warum bestimmte Objekte Interesse wecken, während andere erst gar nicht in den Fokus der Wahrnehmung gelangen». ${ }^{699}$ Zur Studie von Buttkereit et al. sind lediglich eine Beschreibung der angewendeten Methode sowie die Transkripte des Lauten Denkens veröffentlicht, aber es wurde keine Auswertung und Interpretation des Materials durchgeführt. ${ }^{700}$

Ebenfalls von Lautem Denken gesprochen wird im Kontext eines in Finnland durchgeführten Evaluationsworkshops zur Ausstellung «Ötzi - Iceman of the Alps». ${ }^{701}$ Allerdings besuchten dort die Teilnehmenden die Ausstellung in Gruppen $^{702}$, insofern bleibt unklar, inwiefern dort tatsächlich individuelles Lautes Denken oder vielmehr Gruppengespräche stattfanden. Zudem wurden die Gruppen begleitet von Personen, die das gesprochene Wort schriftlich festhielten, fand also keine Audioaufnahme statt. ${ }^{703}$

In Kunstmuseen wurde Lautes Denken von Forschergruppen um Eilean Hooper-Greenhill eingesetzt, und zwar einerseits in der Wolverhampton Art Gallery ${ }^{704}$ und andererseits im Nottingham Castle Museum sowie Art Gallery. ${ }^{705}$ Auch dort erfolgten die Besuche als «accompanied visit $[s] »{ }^{706}$ nun mit besuchenden Einzelpersonen und Begleitung. Zwar bezeichnen auch diese Autorinnen und Autoren die eingesetzte Methode als Lautes Denken, jedoch wurden die Besuchenden von den begleitenden Personen während des Besuchs auch punktuell nach bestimmten Aspekten gefragt oder aufgefordert, gewisse angesprochene

697 Thoma 2009.

698 Buttkereit et al. 2014.

699 Buttkereit et al. 2014, S. 6.

700 Buttkereit et al. 2014, S. $5 \mathrm{ff}$.

701 Heikkilä et al. 2011.

702 Heikkilä et al. 2011, S. 7.

703 Heikkilä et al. 2011, S. 5 f.

704 Hooper-Greenhill et al. 2011, zur Methode: ebd., S. 4.

705 Hooper-Greenhill/Moussouri 2011, zur Methode: ebd., S. 3.

706 Hooper-Greenhill et al. 2011, S. 4; Hooper-Greenhill/Moussouri 2011, S. 3. 
Themen weiter auszuführen ${ }^{707}$, es finden sich also auch Erhebungsmomente im Stil von Interviews und waren die Besuchenden im Gegensatz zu meiner Studie oder etwa derjenigen von Wise nicht vollständig sich selbst überlassen.

Im Gesamteindruck existieren noch relativ wenige Studien, in denen das Prozessbegleitende Laute Denken als Erhebungsform zum Einsatz kommt, um den Verlauf eines Ausstellungsbesuchs und die dabei auftretenden Assoziationen unmittelbar erheben zu können. Ebensowenig wird dieses Anliegen mittels anderer methodischer Zugänge verfolgt. Ich schliesse diesen Abschnitt deshalb mit der Feststellung eines Forschungsdesiderats, und zwar dahingehend, eine konstruktivistische Perspektive auf Aneignungsprozesse mit einer tatsächlich auch prozessbezogenen und dabei Verbalisierungen generierenden Forschungsmethodik zu kombinieren. ${ }^{708}$ In diesem Forschungsdesiderat liegt die Wahl der für mein Forschungsprojekt verwendeten Erhebungsmethodik, des Prozessbegleitenden Lauten Denkens, begründet.

\subsection{Befunde ausgewählter Studien}

Ich stelle nun Ergebnisse ausgewählter Studien vor, sofern sie als Referenzpunkte für mein eigenes Projekt von herausgehobener Bedeutung sind. ${ }^{709}$ Hierfür lege ich einen Schwerpunkt auf die Darstellung unmittelbar prozessbezogener Einsichten über Besuchsverläufe. Dabei verzichte ich auf die Repetierung zentraler Grundannahmen, wie etwa, dass Besuchende aktiv Bedeutungen generieren, ${ }^{710}$ Ausstel-

707 Hooper-Greenhill et al. 2011, S. 4; Hooper-Greenhill/Moussouri 2011, S. 3. Auch in der Studie von Thoma wurden die Besuchenden begleitet, allerdings dort von einer «stumme[n] Gesprächspartnerin", deren Funktion es war, die Exponate zu notieren, auf die die Besuchenden Bezug nahmen (Thoma 2009, S. 91).

708 Ebenfalls von untergeordneter Bedeutung scheinen prozessorientierte Erhebungsmethoden bislang in empirischen Studien zu Besuchenden von Gedenkstätten, wie ich einem Literaturreview von Bert Pampel entnehme (Pampel 2011; Pampel 2007, S. 126). Eine jüngere Ausnahme hierzu stellt die aktuell laufende Forschung von Christian Mehr statt, von der er am 10. Juni 2017 an der Tagung «Aneignungspraktiken an ausserschulischen Lernorten» an der PH Luzern berichtete. Unter dem Vortragstitel «Die Gedenkstätte Buchenwald aus Sicht der Schülerinnen und Schüler. Unterwegs mit der Helmkamera» berichtete Mehr dort aus der laufenden Datenerhebung und vom Einsatz ebendieser «Helmkamera» während des Gedenkstättenbesuchs der Schülerinnen und Schüler. Publikationen zum Projekt sind zum Zeitpunkt der Einreichung meiner Dissertation meines Wissens noch nicht entstanden.

709 Relevante Befunde zu soziodemografischen Hintergründen von Museumsbesuchenden lasse ich an dieser Stelle allerdings noch beiseite und komme darauf zu sprechen, wenn ich mein eigenes Sample vorstelle und einordne (vgl. Abschnitt 6.2).

710 Grütter 1997c, S. 711; Noschka-Roos/Lewalter 2013; Grütter/Kuhn 2014, S. 12. 
lungsbesuche also aktive, individuelle und kontextabhängige Konstruktionsprozesse darstellen. ${ }^{711}$ Lediglich auf das zentrale und bereits mehrfach erwähnte «Contextual Model of Learning» von Falk und Dierking sei an dieser Stelle nochmals verwiesen, weil es mit der Benennung eines personal context, physical context und sociocultural context dafür sensibilisiert, welche Vielfalt von Faktoren auf Aneignungsprozesse im Museum einwirkt und dass sowohl individuelle Bedingungen aufseiten der Besuchenden als auch ausstellungsseitig vorhandene Faktoren und die soziale Besuchssituation das Erleben prägen. ${ }^{712}$

Dies bedeutet im Umkehrschluss, dass Studienergebnisse in hohem Masse abhängig von der Erhebungssituation sind - von den beforschten Personen, der konkreten Ausstellung und der Besuchskonstellation - und dass Befunde, die anhand einer spezifischen Einrichtung gewonnen wurden, nur mit Vorsicht auch auf andere Museen übertragbar sind. ${ }^{713}$ Holger Höge kommt dazu passend zu dem radikalen Schluss, es bleibe «keine andere Wahl, als für die jeweils infrage stehende Ausstellung bzw. das jeweils zu evaluierende Museum eine eigene Untersuchung zu konzipieren». ${ }^{714}$

Trotz dieser Grenzen und der konstruktivistischen Annahme einer Individualität und Kontextabhängigkeit von Besuchsverläufen bemüht sich die Besuchendenforschung gleichwohl um Systematisierungen des Feldes. Eine Möglichkeit hierfür stellt der Einbezug von Besuchenden mehrerer Einrichtungen in eine Studie dar, was in gewissem Mass generalisierbare Aussagen erlaube, wie etwa Bert Pampel auf Basis der Daten von Besuchenden mehrerer Gedenkstätten mit Vorsicht formuliert. ${ }^{715}$ Doch auch der Abgleich mit anderen Studien kann zur Einordnung von Befunden beitragen - dies ist der Weg, den ich mit meiner eigenen Studie beschreite.

Für die folgende Gliederung zentraler Forschungsergebnisse gehe ich vom Allgemeinen zum Besonderen vor. In den ersten beiden Abschnitten stelle ich Befunde zur formalen und inhaltlichen Gestalt von Museumsbesuchen in ihrer

711 Vgl. hierzu die Ausführungen in Abschnitt 3.2.

712 Falk/Dierking 1997; Falk/Dierking 2000.

713 Zweifel an einer Übertragbarkeit werden etwa angemeldet bei Höge (Höge 2009, S. 208) sowie bei Noschka-Roos am Beispiel von Studien zum Leseverhalten bei Besuchenden und in Bezug auf die dabei ausstellungsseitig vorhandenen Variablen (Noschka-Roos 1994, S. 160).

714 Höge 2009, S. 208.

715 Pampel 2007, S. 172, S. 181. In Berit Pleitners Studie, die nach «Einstellungen zum und Vorstellungen vom Museum» fragt, besuchten umgekehrt dieselben Schülerinnen und Schüler nacheinander zwei Museen (Pleitner 2011, S. 36 f., direktes Zitat: S. 36). 
Gesamtheit vor und schildere dort Erkenntnisse über Bewegungsverläufe/-muster sowie über die Gesamtheit möglicher Besuchserfahrungen (Abschnitt 5.3.1 und 5.3.2). Im Anschluss daran gehe ich spezieller auf Teilaspekte der inhaltlichen Auseinandersetzung ein. Dort stelle ich Befunde vor, die Vorstellungen von Besuchenden zur Manifestation Museum und ihren Elementen betreffen (Abschnitt 5.3.3), Befunde zu den über den kognitiven Bereich hinausgehenden Dimensionen eines Museumsbesuchs, nämlich einerseits zur Rolle von Imagination und Empathie beim Museumsbesuch (Abschnitt 5.3.4) und andererseits zum Themenkomplex der Objektbegegnung, Emotion und Ästhetik (Abschnitt 5.3.5) sowie dann zur Lebenswelt- und Gegenwartsrelevanz von Museums-/Ausstellungsbesuchen aus Sicht der Besuchenden (Abschnitt 5.3.6). Zum Abschluss stelle ich die bereits erwähnte Studie von Susie Wise vor, die etliche der zuvor genannten Dimensionen vereint, weshalb ich ihr einen eigenen Abschnitt widme (Abschnitt 5.3.7).

\subsubsection{Befunde zur formalen Gestalt von Ausstellungsbesuchen: Bewegungs- und Aufmerksamkeitsmuster im Raum}

Eine Möglichkeit, zu generalisierenden Aussagen über Besuchende zu gelangen, stellt die Identifizierung von Typen von Besuchenden dar. Manche Studien unterscheiden Typen nach den spezifischen Interessenlagen, ${ }^{716}$ kombiniert mit der unterschiedlichen Art und Weise, wie Besuchende sich durch die Ausstellungsräumlichkeiten bewegen. So habe Robert L. Wolf, so rezipiert bei Annette Noschka-Roos, «[j]e nach Ausprägungsgrad des Interesses» vier Arten von Besuchenden identifiziert,

«den 〈Pendler〉, der rasch durch die Ausstellung eilt, sie mehr als Durchgang nutzend, den 〈Nomaden〉, der ohne spezielles Interesse eine Ausstellung betritt, in der er sich dann durch das eine oder andere Exponat aufhalten lässt, den 〈Cafeteria-Typ〉, einen allgemein interessierten Besucher, der sich selektiv verschiedenen Bereichen der Ausstellung zuwendet, die hoch interessierte Person (very interested person $=\langle\mathrm{VIP}\rangle$ ), die sich langsamer, sorgfältiger und kritischer durch die Ausstellung bewegt». ${ }^{717}$

716 So Wolf 1980, zit. n. Noschka-Roos 1994, S. 154 f.

717 Noschka-Roos 1994, S. 155; Kursivsetzung analog zum Original. Noschka-Roos bezieht sich in dieser Textstelle in indirekter Zitation auf vier Besuchertypen bei Wolf (Wolf 1980, zit. n. Noschka-Roos 1994, S. 155). 
Susie Wise unterscheidet ähnlich drei Formen des Fortbewegens, «Doing the museum with linear exploration», «Deep viewing and re-viewing for further understanding» und "Camping out in topical zones», die sie personalisiert einzelnen Besuchenden zuweist. ${ }^{718}$ Sharon Macdonald warnt umgekehrt, «dass man $[\ldots]$ Stile nicht personalisieren, sondern als Bewegungstypen begreifen sollte», weil Besuchende während eines Besuchsverlaufs zwischen den Stilen wechseln. ${ }^{719}$

Die vorgestellten Bewegungstypen deuten bereits an, dass sich viele Besuchende selektiv durch die Ausstellung bewegen und dabei nur einen Bruchteil der ausgestellten Elemente näher betrachten. Eine Metaanalyse von über hundert Besucherstudien ergab, dass «visitors typically stop at between 20 percent and 40 percent of an exhibition», ${ }^{720}$ einige Jahre später ergänzt um eine Folgestudie zu weiteren 50 Ausstellungen. ${ }^{721}$ In Letzterer stellt Beverly Serrell einen gewissen Zusammenhang zwischen Besucherverhalten und Museumstypen fest. Den «Sweep rate index» und den Prozentsatz an «Diligent visitors» betrachtend und auf dieser Basis vier Quadranten bestimmend, ${ }^{722}$ kommt sie zu dem Befund, dass die «least-thoroughly used exhibitions were found in natural history and general museums as well as in living collections; three-quarters of those were in science museums/centers». ${ }^{723}$ Hingegen scheint der Typus der «exceptionally thoroughly used ${ }^{724}$ Ausstellungen weniger eindeutig bestimmbar. Zwar zeigte sich Serrell zufolge, dass diese Gruppe «proportionately fewer science museum exhibitions» ${ }^{725}$ beinhalte, aber abgesehen davon

718 Wise 2011, S. $67 \mathrm{ff}$.

719 Macdonald 2011, S. $251 \mathrm{f}$.

720 Serrell 1998, S. 21 , zit. n. Rounds 2004, S. 391; Studie rezipiert bei Rounds 2004, S. 391, und ausserdem beschrieben bei Serrell 2010.

721 Serrell 2010, S. 1, S. 5 f.

722 Serrell 2010 , S. 5 f.; «Sweep rate index (SRI) is calculated by dividing the exhibition's square footage by the average total time spent there for a tracked sample of casual visitors. A lower sweep rate means that visitors spent more time in the exhibition and were engaged in more learning-related behaviors. Diligent visitors (\%DV) is the percentage of visitors in the tracked sample who stopped at more than one-half of the exhibit elements in the exhibition. Higher percentages of diligent visitors mean that more people were paying attention to more exhibits, and fewer exhibit elements were being ignored, skipped, or missed» (Serrell 2010, S. 5).

723 Serrell 2010, S. 6.

724 Serrell 2010, S. 9.

725 Serrell 2010, S. 8. 
«ran the gamut of exhibition characteristics: large and small spaces (from 1,200 to 12,000 square feet); content involving science, nonscience, and science fiction; real objects and no objects; and free and ticketed shows. The one characteristic they shared in common was having relatively fewer exhibit elements compared to the exhibitions in the other quadrants.» ${ }^{726}$

Es deuten sich also je nach Museumstyp gewisse Unterschiede in der Sorgfalt von Museumsbesuchen an. Wie sich spezifisch historische Museen in dem geschilderten Spektrum verorten lassen, geht aus den Ausführungen Serrells nicht eindeutig hervor.

Über Besucherverhalten im Hinblick auf unterschiedliche Ausstellungselemente finden sich Hinweise bei Sharon Macdonald, auf eigene Untersuchungen im Londoner Science Museum Bezug nehmend. ${ }^{727}$ Sie kommt zu dem Schluss, dass «Lesen vor allem zu Beginn der Ausstellung geschieht», aber dass «physische Ausstellungsobjekte insgesamt mehr Aufmerksamkeit auf sich ziehen als Texte und dass sie die Narrative, die Besucher_innen unmittelbar nach Abschluss ihres Rundgangs formulieren, auch deutlich mehr prägen». ${ }^{728}$

Annette Noschka-Roos kommt, Bezug nehmend auf einige Studien zu Besuchenden in mehrheitlich technischen bzw. Science-Museen zu der zusammenfassenden Einschätzung, «dass sich Besucher in einer Ausstellung hauptsächlich objektorientiert bewegen, und die Lektüre der Texte davon abhängig ist», wobei sich ausserdem «eine mit zunehmender Besichtigungsdauer nachlassende Intensität in der Betrachtung der Exponate und in der Lektüre der Texte» beobachten lässt. ${ }^{729}$

Die geschilderten Befunde eines objektorientierten Vorgehens beim Ausstellungsbesuch decken sich mit den Befunden Christian Kohlers, der auf Basis der von ihm erhobenen Schülervorstellungen in Bezug auf historische Ausstellungen zu dem Schluss kommt: «Der Rezeptions- und Verstehensprozess geht [...] immer

726 Serrell 2010, S. 9.

727 Macdonald 2011, S. 245, S. 247.

728 Macdonald 2011, S. 247.

729 Noschka-Roos 1994, S. 155 f.; Noschka-Roos bezieht sich in indirekter Zitation auf Studien von Borun/Miller, Serrell und Diamond, die mir nicht im Original vorliegen (Borun/ Miller 1980, zit. n. Noschka-Roos 1994, S. 155; Serrell 1980, zit. n. Noschka-Roos 1994, S. 155 f.; Diamond 1986, zit. n. Noschka-Roos 1994, S. 155 f.). Bei den beachteten Studien handelt es sich gemäss Titeln um Studien zu Besuchenden von technischen bzw. Science-Museen sowie Zoo und Aquarium, die Übertragbarkeit in Bezug auf historische Museen wäre insofern zu prüfen. 
von den Objekten aus, was deren Bedeutung als zentrale Präsentationsmedien unterstreicht.» ${ }^{730}$ Auch in dem von Susie Wise beschriebenen «basic script for exploring a museum» steht die Objektbetrachtung vor der Beschriftungslektüre, bleibt aber unklar, inwiefern sie damit eine feste Reihenfolge verbindet. ${ }^{731}$

Andernorts stellen Doris Lewalter und Annette Noschka-Roos fest, die Fortbewegung Erwachsener durch eine Ausstellung verläufe «meist nicht linear und [folge] selten den vorgeschlagenen Besuchspfaden. Vielmehr lassen sich die Besucher visuell leiten und werden hauptsächlich durch Interessen, durch Neugier weckende oder zur Erkundung und Manipulation einladende Elemente, durch Phantastisches oder durch soziale Interaktion gelenkt.» ${ }^{732}$

Ausgehend von diesen Befunden, die allerdings mehrheitlich Aufschlüsse über das Besuchsverhalten in naturwissenschaftlichen Museen geben, ist von einer hohen Individualität des Verhaltens von Besuchenden im Raum auszugehen, bei dem durch die Ausstellung selbst vorgegebene Pfade eher verlassen und viele Elementen übersprungen werden, während andere, basierend auf diversen individuellen Gründen, aufgesucht werden, wobei sich der Ausstellungsbesuch vor allem objektorientiert gestaltet. Auf Befunde zum Umgang von Besuchenden mit Objekten und zur Anziehungskraft von Objekten komme ich weiter unten erneut zu sprechen. ${ }^{733}$

\subsubsection{Befunde zur inhaltlichen Gestalt von Ausstellungsbesuchen: Kategorisierungen von Besuchserfahrungen jenseits des Erwerbs von Wissensbeständen}

Was passiert nun in inhaltlicher Hinsicht im Verlauf von Ausstellungsbesuchen? Dass diese mehr beinhalten als den Erwerb von deklarativen Beständen eines firstorder knowledge und dass sie von der empirischen Besuchendenforschung auch nicht mehr auf diese Funktion reduziert werden, wurde bereits ausgeführt. ${ }^{734}$ Mehrere Studien versuchen entsprechend, die ganze Bandbreite der beim Ausstellungsbesuch möglichen Erfahrungen in ihrer Vielfalt in den Blick zu nehmen.

730 Kohler 2016, S. 209.

731 Wise 2011, S. 75. Kurz darauf beschreibt sie den Zeitpunkt, wann eine Beschriftung gelesen wird, als variabel (ebd., S. 75).

732 Lewalter/Noschka-Roos 2009, S. 532; ähnlich auch bei Noschka-Roos 2001, S. 89.

733 Vgl. Abschnitt 5.3.5.

734 Vgl. insb. Abschnitt 3.2. 
Bereits 1995 stellte Colette Dufresne-Tassé, offensichtlich von einem sehr engen Lernbegriff ausgehend, fest, dass

«for an adult, the most obvious benefit of a visit to the museum is not learning, but a cognitive and intense affective functioning because this determines a series of pleasures not afforded by lerning. The benefit may be:

- Aesthetic pleasure, resulting from the observation of beautiful or important objects;

- pleasure of recognizing and identifying oneself with what is beautiful, valuable, rare;

- pleasure of using one's intellectual skills to imagine, remember, acquire knowledge, extend it, reflect, modify one's ideas;

- pleasure of easily overcoming a major difficulty;

- pleasure of coming into contact with something new, internalizing it or having new ideas.» ${ }^{735}$

Eine ganze Bandbreite von Erfahrungen nehmen auch Andrew J. Pekarik, Zahava D. Doering und David A. Karns in den Blick, die sich mit «Satisfying Experiences in Museums» beschäftigen. ${ }^{736}$ Aus Interviews und Umfragen mit Besuchenden von Smithonian Museums, darunter das Museum of Natural History und das Museum of American History, entwickelten sie, startend mit einem induktiven Vorgehen und anschliessendem mehrstufigem Prozess, ein Set von befriedigenden Besuchserfahrungen, die Besuchende entweder vor einem Besuch erwarten oder im Anschluss an diesen rückblickend als befriedigend erlebt feststellen. ${ }^{737}$ Sie unterscheiden vier Cluster, nämlich «Object Experiences», «Cognitive Experiences», «Instrospective Experiences» und «Social Experiences» und ordnen diesen jeweils zwischen zwei und fünf Erfahrungsdimensionen zu. ${ }^{738}$ Konkret unterscheiden sie folgende Erfahrungen:

735 Dufresne-Tassé 1995, S. 251.

736 Pekarik et al. 1999.

737 Pekarik et al. 1999, insb. S. 152-156, S. 161, explizite Unterscheidung der zwei Varianten auf S. 152.

738 Pekarik et al. 1999, S. 155 f. 


\section{«Object Experiences}

Seeing «the real thing>

Seeing rare/uncommon/valuable things

Being moved by beauty

Thinking what it would be like to own such things

Continuing my professional development

\section{Cognitive Experiences}

Gaining information or knowledge

Enriching my understanding

\section{Introspective Experiences}

Imagining other times or places

Reflecting on the meaning of what I was looking at

Recalling my travels/childhood experiences/other memories

Feeling a spiritual connection

Feeling a sense of belonging or connectedness

\section{Social Experiences}

Spending time with friends/family/other people

Seeing my children learning new things.» ${ }^{739}$

Jeweils zwei der Cluster werden als sich tendenziell gegenseitig ausschliessend betrachtet, nämlich zum einen Object Experiences vs. Cognitive Experiences, weil Ausstellungen entweder objekt- oder informationsfokussiert sein könnten, zum anderen Introspective Experiences vs. Social Experiences, da Erstere «enhanced by a quiet environment and inner space»» seien, Zweitere «enhanced by activity and engagement with others». ${ }^{40}$

Welche Erfahrungen Besuchende tatsächlich in einem Museum als befriedigend erleben, hänge von einer Kombination aus drei Faktoren ab, «the availability of particular experience or type of experience», "the quality or intensity of that experience» und «individual preference», wobei Letztere unter anderem in Abhängigkeit von Alter und Geschlecht variiere. ${ }^{741}$ Ähnlich wie im Contextual Model 
of Learning ${ }^{742}$ wird also auch bei Pekarik et al. die Vielfalt der Einflussfaktoren auf die Erfahrungen im Museum betont und werden in der Person der Besuchenden liegende wie auch ausstellungsseitige und den sozialen Kontext der Besuchssituation einbeziehende Dimensionen genannt.

Die Liste von Erfahrungen beinhaltet mit «Feeling a sense of belonging or connectedness» auch einen Aspekt, den Berit Pleitner in ihrem Datenmaterial als «identitätsstiftende Funktion» erkennt ${ }^{743}$ und der in den weiter oben dargestellten theoretischen Überlegungen zu den Dimensionen von Geschichtskultur im Allgemeinen und historischen Museen im Speziellen als ein möglicher Effekt eingeführt wurde. ${ }^{74}$ Sowohl bei Pleitner als auch bei Pekarik et al. werden in den jeweils beispielhaft angeführten Äusserungen von Besuchenden Bezüge zu regionaler oder nationaler Zugehörigkeit bzw. Herkunft genannt. ${ }^{745}$

In einer Forschergruppe um Eilean Hooper-Greenhill wurde am Research Center for Museums and Galleries an der Universität Leicester ein ganz ähnliches holistisches Anliegen wie bei Pekarik et al. verfolgt, nämlich die aus Besuchen von Museen (sowie Archiven und Bibliotheken) resultierenden Lernergebnisse in ihrer Gesamtheit abzubilden. ${ }^{746}$ Im Gegensatz zu Pekarik et al. ist dieses Projekt stärker an Lernergebnissen und weniger an im Besuchsverlauf gemachten Erfahrungen interessiert, verfolgt aber einen ähnlich ganzheitlichen Zugriff. Das Projekt zeitigte, unter Einbzug von 15 als repräsentativ eingestuften Institutionen bzw. deren Besuchenden, ${ }^{747}$ ein Set von «Generic learning outcomes», ${ }^{748}$ nämlich

\section{Falk/Dierking 2000.}

743 Pleitner 2011, S. 41.

744 Vgl. Abschnitt 3.1.

745 Bei Pleitner lautet das gewählte Materialbeispiel: «It's about where we come from, really» (Pleitner 2011, S. 41). Bei Pekarik et al. wird als Beispiel genannt: «This is my favourite museum. I like it because it has American artists. I like it because they have Californian artists represented. It's where I'm from» (Pekarik et al. 1999, S. 159).

746 Research Center for Museums and Galleries 2003.

747 Research Center for Museums and Galleries 2003, S. 18. Dort ist von nach Institutionen unterschiedlichen Vorgehensweisen die Rede, unter anderem von der Auswertung bereits durch die Institutionen gesammelter Daten und Neuentwicklung von Evaluationsinstrumenten.

748 «Generic learning outcomes» werden wie folgt definiert: «Learning outcomes can also be defined as specific or generic. Specific learning outcomes are related to specific programmes of study and are more tightly focused than generic learning outcomes which consist of broader categories. For example, after a programme of study in art history, participants might gain some specific knowledge about the names and styles of different artists. The generic outcomes of this learning would be an increase in knowledge and (possibly) understanding» (Research Center for Museums and Galleries 2003, S. 11). 
- «Increase in knowledge and understanding»,

- «Increase in skills»,

- «Change in attitudes or values»,

- «Evidence of enjoyment, inspiration and creativity»,

- «Evidence of activity, behaviour, progression». ${ }^{79}$

Auch Christian Kohler entwickelte im Rahmen seiner Dissertationsschrift eine Typologie von Zugangsweisen. ${ }^{750}$ Seinem Interesse an «Schülervorstellungen über Präsentation von Geschichte im Museum» entsprechend, unterscheidet er fünf Vorstellungen, nämlich

- «Typus 1: Geschichte wird erlebt - Die emotionale Zeitreise- und Alteritätserfahrung»,

- «Typus 2: Geschichte wird entdeckt - Die von Eigenaktivität geprägte Erfahrung»,

- «Typus 3: Geschichte wird gefühlt - Die kontemplative Objekterfahrung»,

- «Typus 4: Geschichte wird rezipiert - Die museale Erfahrung als Informationsentnahme»,

- «Typus 5: Geschichte wird angelesen - Der Museumsbesuch als Leseerfahrung». ${ }^{751}$

An Berichten der Besuchenden über tatsächlich gemachte Erfahrungen mit einer zuvor besuchten Gedenkstätte setzt demgegenüber Bert Pampel an und liefert ebenfalls eine Typologie von Besuchserfahrungen. Pampel unterscheidet

- «emotionale Erfahrungen»,

- «kognitive Erfahrungen»,

- «Vorstellungen (Imaginative Erfahrungen)»,

- «Einfühlung (Empathische Erfahrungen)»,

- «Erinnerungen (Memorierende Erfahrungen)»,

- «Ortserfahrungen»,

- «Soziale Erfahrungen»,

749 Research Center for Museums and Galleries 2003, S. 12. Ausführungen zu den fünf Bereichen von generic learning outcomes ausserdem bei Hooper-Greenhill 2007, S. $53 \mathrm{ff}$.

750 Kohler 2016, S. $223 \mathrm{ff}$., insb. S. $230 \mathrm{ff}$.

751 Kohler 2016, S. $230 \mathrm{ff}$. 
- «Selbst-Erfahrungen» und

- «Dissonanzerfahrungen».752

In sämtlichen vorgestellten Systematisierungen zeigt sich, dass Museums-/Ausstellungs- wie auch Gedenkstättenbesuche in den Erwartungen und Vorstellungen der Besuchenden wie auch in den konkret gemachten Erfahrungen über einen eng verstandenen kognitiven Wissenserwerb hinausgehen, stattdessen um ein ganzes Spektrum weiterer Erfahrungen ergänzt werden, wozu auch emotionale Erfahrungen zählen.

Eine spezifisch räumliche Erfahrung durch Bewegung in der Dreidimensionalität des Ortes findet demgegenüber interessanterweise nur bei Pampel Berücksichtigung. Andere Systematisierungen beinhalten zwar die Begegnung mit dem einzelnen Objekt und in dieser Hinsicht durchaus eine physische Erfahrung, nehmen daneben aber nicht die gesamte Ausstellungsfläche als räumliche Struktur in den Blick, innerhalb deren spezifische Erfahrungen möglich werden.

\subsubsection{Befunde zu geschichtstheoretischen Zugängen: Vorstellungen der Besuchenden zur Manifestation Museum/Ausstellung und ihren Elementen}

In der kompetenzorientierten geschichtsdidaktischen Literatur wird die Notwendigkeit deutlich gemacht, mit Museen und Ausstellungen als Manifestationen umgehen zu können, ihre Konstruktionsprinzipien zu verstehen und zu entschlüsseln, eine Ausstellung also als «gemachten» Ort und die Aussagen in Ausstellungen als eine mögliche Geschichte zu erkennen. ${ }^{753}$ Leitend ist dafür die Ansicht, dass Museen, wie Christian Kohler formuliert, «nicht nur Lernumgebung, sondern auch Lerngegenstand» sind ${ }^{754}$ - oder anders ausgedrückt, dass es neben den Kompetenzen, die beim Besuch selbst erworben werden können bzw. die aus dem Besuch resultieren, auch solche für die Nutzung von Museen und Ausstellungen braucht, weil sie als Manifestationen mit spezifischen Konstruktionsbedingungen auch spezifischer Fähigkeiten bedürfen. ${ }^{755}$ Im Kern geht es dabei unter anderem

752 Pampel 2007, S. 236, S. 248, S. 257, S. 262, S. 267, S. 269, S. 276, S. 283, S. 288.

753 Vgl. Abschnitt 3.3.

754 Kohler 2014, S. 85 .

755 Körber 2009, S. 62; Borries 2009, S. 116 f.; Sauer 2009, S. 81 f. Vgl. Abschnitt 3.3. 
auch darum, am Beispiel einer Ausstellung den Unterschied zwischen Vergangenheit und Geschichte wahrzunehmen und Letztere zu de-konstruieren. ${ }^{756}$

Wie denken nun Besuchende über die Manifestation Museum bzw. Ausstellung, inwieweit sind sie sensibel für ihre Konstruktionsbedingungen? Sharon Macdonald kommt zu dem Schluss, Museen würden «verbreitet als autoritative Einrichtungen» betrachtet ${ }^{757}$ und Besuchende des von ihr selbst beforschten Science-Museums neigten dazu, «in diesem Museum eine Einrichtung zu sehen, die ihnen neutrale, wertfreie Fakten präsentiert, auch wenn sie sich an anderer Stelle kritisch zu dem geäussert hatten, was sie die 〈Verzerrung〉 durch «andere Medien $>$ nannten» ${ }^{758}$

Der aus Macdonalds Einschätzung herauslesbare Befund, dass medienkritische Einsichten nicht zwingend auf den Umgang mit der Manifestation Museum umgemünzt werden, knüpft an einen Befund an, den auch Kohler in seiner Studie $\mathrm{zu}$ «Schülervorstellungen über die Konstruktion von Geschichte im Museum» berichtet. ${ }^{759}$ Kohler stellt fest, «dass knapp die Hälfte der befragten Jugendlichen tendenziell ein konstruktivistisches Geschichtsverständnis» besitze, bemerkt aber auch, dass sich eine solche konstruktivistische Grundhaltung nicht zwangsläufig im Umgang mit einer konkreten historischen Ausstellung und im Durchschauen von deren Konstruktcharakter niederschlägt. ${ }^{760}$

Kohler arbeitet heraus - und zu ganz ähnlichen Befunden kommt auch Pleitner ${ }^{761}$ - dass die Schülerinnen und Schüler analog zu Grundannahmen der Museumstheorie Objekte für die zentralen Bestandteile von Museen halten, dass sie damit allerdings weder zwingend Quellen meinen noch über ein differenziertes Quellenverständnis verfügen. ${ }^{762}$ Ausstellungen würden, so Kohler, von den Schülerinnen und Schülern vor allem als «Ansammlung einzelner Objekte» betrachtet. ${ }^{733}$ Sie könnten sich nicht vorstellen, «dass eine Abteilung in einem Museum

756 Zur Differenz zwischen Vergangenheit und Geschichte siehe Fussnote 3. Zur Idee der De-Konstruktion: Schreiber 2007b, S. $224 \mathrm{ff}$.

757 Macdonald 2011, S. 246, darin Bezug nehmend auf «verschiedene Studien», namentlich genannt Usherwood et al. 2004, mir als Usherwood et al. o. J. vorliegend.

758 Macdonald 2011, S. 246.

759 Kohler 2016. Zur Studie von Kohler habe ich eine Rezension verfasst (Thyroff 2017d). Meine hier und im Folgenden formulierten Einschätzungen zu Kohlers Studie habe ich dort dargelegt und beziehe mich nun darauf.

760 Kohler 2016, S. 150, S. 193 ff., S. 226 ff., direktes Zitat: S. 150.

761 Pleitner 2008, S. 109; Pleitner 2011, S. 39.

762 Kohler 2016, S. $172 \mathrm{ff}$.

763 Kohler 2016, S. 226. 
eine Einheit bildet und dies durch die Raumgestaltung ausgedrückt werden kann», ${ }^{764}$ und ebenso wenig, «dass die einzelnen Elemente der Abteilung zusammen eine historische Narration formen». ${ }^{75}$ Den chronologischen Aufbau der Ausstellung beschreibt Kohler hingegen als den meisten Schülern und Schülerinnen «fast wie selbstverständlich», ${ }^{766}$ er sei «in ihren Vorstellungen typisch für den Aufbau historischer Ausstellungen». ${ }^{767}$

Kohler zeigt, dass die beforschten Schüler und Schülerinnen dabei insbesondere den in der Ausstellung enthaltenen Texten Glaubwürdigkeit attestieren und deren Inhalte als «Verständnishilfen» oder gar als «gesichertes Wissen» betrachten. ${ }^{768}$ Lernen und Wissenserwerb assoziieren die Schülerinnen und Schüler Kohler zufolge mit der «klassischen Objekt-Text-Vermittlung». ${ }^{769}$

«Die kognitive Dimension der musealen Erfahrung besteht für die Schüler [...] darin, sich Informationen über die Objekte oder das Ausstellungsthema anzueignen, und dies geschieht massgeblich unter Rückgriff auf schriftliche Präsentationsmedien. Als Präsentationsmedien scheinen Texte somit in den Augen der Schüler eine zentrale Bedeutung für die Vermittlung der Ausstellungsinhalte zu besitzen.» ${ }^{770}$

Hingegen würden in der Ausstellung enthaltene Rekonstruktionen - im konkreten Fall von Kohlers Studie die Inszenierung eines Kaufmannstisches mit darauf befindlichen Objekten aus dem Arbeitsbereich eines Kaufmanns ${ }^{771}$ - demgegenüber als Anlass für «historische Imagination und ein bisweilen emphatisches Nachvollziehen des Lebens in der Vergangenheit» empfunden. ${ }^{772}$ Kohler stellt fest, «dass rekonstruierende Präsentationsformen den Eindruck vermitteln können, das Museum zeige die Vergangenheit, wie sie vermeintlich wirklich war». ${ }^{73} \mathrm{Z}$ war würden

764 Kohler 2016, S. 197.

765 Kohler 2016, S. 227.

766 Kohler 2016, S. 197.

767 Kohler 2016, S. 226.

768 Kohler 2016, S. 208 f.

769 Kohler 2016, S. 226.

770 Kohler 2016, S. 168.

771 Kohler 2016, S. 86, S. 202. Kohler beschreibt die Ausstellungseinheit wie folgt: «Auf dem Tisch liegen unter Glas einzelne Utensilien, die ein Kaufmann für seine Arbeit benötigte. Originale aus mehreren Jahrhunderten und Repliken werden hier zusammen inszeniert. Die Beschriftung ist an der Wand angebracht» (ebd., S. 86).

772 Kohler 2016, S. 226.

773 Kohler 2016, S. 203. 
derartige Vorstellungen bei den Schülerinnen und Schülern vielfach nicht expliziert, jedoch auch nur in wenigen Fällen ein Wissen «um die Künstlichkeit der Inszenierung» zum Ausdruck gebracht. ${ }^{774}$

Der zuletzt angesprochenen Punkt, die Wahrnehmung von rekonstruierenden Präsentationsformen und die Idee eines Nachvollziehens oder Sich-Hineinversetzens in historische Gegebenheiten, leitet über zu einem Aspekt, den ich im nächsten Abschnitt betrachte, nämlich Befunde zu den «nicht-nur-kognitiven» Dimensionen eines Ausstellungsbesuchs.

\subsubsection{Befunde zum Nicht-nur-Kognitiven ${ }^{775}$ (1): Imagination und Empathie}

Die Schülerinnen und Schüler in der Studie Kohlers verstehen, wie soeben erwähnt, rekonstruierende Präsentationsformen als Anlass für «Imagination» und «empathisches Nachvollziehen» ${ }^{776}$ bzw. historische Museen generell als Orte, in denen «eine ästhetisch-emotionale Erfahrung von Geschichte durch die Anregung historischer Imagination» möglich ist. ${ }^{777}$ Mit den Begriffen der Imagination und Empathie berührt Kohler die emotionale Seite und damit den unter Verwendung einer Terminologie Bodo von Borries' in meiner Arbeit als nicht-nur-kognitiv bezeichneten Bereich des Museumsbesuchs.

Ebenfalls über Imagination, aber in Bezug auf den Kontakt von Schülern und Schülerinnen mit Inszenierungen in britischen Living-History-Museen, spricht Berit Pleitner. ${ }^{778}$ Sie stellt aufseiten der Beforschten «ein grosses Bedürfnis nach diesem Sich-Einfühlen, Sich-Einlassen» fest und konstatiert, «dass ihnen durch die Living History quasi ein Schlüssel gereicht wird, mit dem sie zumindest die erste Tür zum Verständnis vergangener Zeiten öffnen können». ${ }^{779}$ In einer anderen Untersuchung kommt Pleitner zu dem Befund, dass Schüler und Schülerinnen

774 Kohler 2016, S. 203.

775 Der Terminus des Nicht-nur-Kognitiven geht, wie erwähnt, zurück auf Borries (2014, S. $167 \mathrm{ff}$.). Vgl. zur theoretischen Betrachtung dieses Bereichs auch die Ausführungen in Abschnitt 3.4.1.

776 Kohler 2016, S. 226

777 Kohler 2015, S. 68.

778 Pleitner 2008.

779 Pleitner 2008, S. $108 \mathrm{f}$. 
Exponate dann als positiv einschätzen, wenn sie anschaulich sind und «das historische Vorstellungsvermögen anregen». ${ }^{780}$

Stärker, als dies für die Schüler und Schülerinnen aus Kohlers Studie zuzutreffen scheint, beschreibt Pleitner die Teilnehmenden ihrer Studie zu Living-History Museen als sich der Gemachtheit des Dargestellten - hier in Bezug auf Inszenierungen - durchaus bewusst und sieht gerade in dieser Bewusstheit ein produktives Moment:

«Dieses Wissen darum, dass es sich nicht um eine tatsächliche «Zeitreise in das Mittelalter>, sondern um eine Inszenierung handelt, lässt den Schülern den nötigen Raum für die Distanz, die die historische Imagination benötigt, um sich fruchtbar zu entfalten. Auf die Frage, ob man bei Living History auch etwas über die Gefühle der Menschen erfahren könne, antworten sie mit nein. Das zeigt doch sehr deutlich, dass sie zwar die Anschaulichkeit schätzen, sich aber darüber im Klaren sind, dass hier eben nicht ein allumfassendes, gar 〈wahres〉 Bild von der Vergangenheit (bzw. von den Menschen aus der Vergangenheit) gezeichnet werden kann. [...] Die Schüler bewegen sich mental zwischen der realen und der inszenierten Lebenswelt. ${ }^{781}$

Pleitners Analyse lässt sich damit nahtlos anschliessen an den weiter oben bereits vorgestellten Empathiebegriff Juliane Brauers, die die in der Empathie liegende Gleichzeitigkeit von Imagination und dem Erkennen von «Nicht-Ähnlichkeit» hervorhebt und diese als «produktive Irritation» beschreibt, die ermögliche, «nicht nur [...] Alterität zu überbrücken, sondern sie auch spürbar und erkennbar werden zu lassen. Empathie rechnet Alterität ein und fordert sie heraus», ${ }^{782}$ ist also mehr als blosses Imaginieren.

Während Pleitner den Teilnehmenden eine Einsicht in die Konstruiertheit von Inszenierungen zuschreibt, stellt sie umgekehrt - und darin wieder ähnlich zu den Befunden Kohlers $^{783}$ - allerdings auch fest, dass die Schülerinnen und Schüler

780 Pleitner 2011, S. 39.

781 Pleitner 2008, S. 110.

782 Brauer 2013, S. 84 ff., direkte Zitate: S. 86, S. 88, S. 89. Vgl. hierzu auch die Ausführungen in Abschnitt 3.4.

783 Kohler 2016, S. 172 ff., insb. S. 175. 
«keinen Unterschied zwischen Quelle und Darstellung [machen]. Alles ist gleichermassen «evidence> für vergangene Ereignisse: ein Exponat im Museum (sei es Original oder Replik), eine CD der horrible histories, ein Schulbuch, eine Burgruine. $\rangle^{784}$

Angesichts dessen benennt Pleitner - nun nicht mehr auf der Ebene der deskriptiven Beschreibungen von Untersuchungsergebnissen, sondern auf Ebene der Empfehlungen - als Aufgabe des Geschichtsunterrichts, über unterschiedliche Formen von «evidence» zu reflektieren und diese einzuordnen, wobei sie Living History für einen besonders geeigneten Gegenstand der Reflexion hält. ${ }^{785}$ Pleitner thematisiert Living History damit einerseits normativ als möglichen Gegenstand der Analyse im Unterricht, andererseits aber auch deskriptiv als möglichen Auslöser für Imagination, für die es «Vorlagen» brauche, «entweder aus der eigenen Erfahrung oder aus uns sinnlich zugänglichen Vorlagen - Bildern, Filmen, Objekten, Gerüchen [...]. Da Geschichte nicht erfahren werden kann, bleibt nur der Umweg über verschiedene Medien.» ${ }^{786}$

Neben den geschichtsdidaktischen Studien Pleitners und Kohlers komme ich weiter auf eine dritte, nun psychologische Studie zu sprechen, die die Bedeutung einer Imagination und eines Sich-Hineinversetzens für Museumsbesuchende feststellt, allerdings unter anderem Begriff. Holger Höge befragte Besuchende des Museumsdorfes Cloppenburg in Eingangs- und Ausgangsbefragungen nach ihren Erwartungen und anschliessendem Befinden ${ }^{787}$ wobei im letztgenannten Bereich unter anderem ein «nostalgisch[es]» Empfinden geäussert wurde. ${ }^{788}$ Höge wendet sich nachfolgend unter dem Begriff «Nostalgie» diesem Bereich näher zu und beschreibt ihn innerhalb des Spektrums an Grundemotionen als eine "Form einer Sehnsucht», als «Erwartung des Nacherlebens, d.h. der Einfühlung in frühere Lebensumstände», als ein «Sich-in-die-Lebensumstände-Hineinversetzen». ${ }^{789} \mathrm{Ab}$ -

784 Pleitner 2008, S. 109.

785 Pleitner 2008, S. 109.

786 Pleitner 2008, S. 109. Dass als imaginationsauslösende bzw. Einfühlung bewirkende Medien auch die Architektur eines Museums eine Rolle spielen kann, hierzu finden sich erste vereinzelte Hinweise bei Bishop Kendzia am Beispiel des Jüdischen Museums in Berlin (Bishop Kendzia 2011, S. 55 f.).

787 Höge 2006, S. 210, 215.

788 Höge 2006, S. 215. Höge schreibt, dies sei «das einzige Gefühl, das in die Liste der Selbstbeschreibungsadjektive aufgenommen wurde» (ebd., S. 216), was vermutlich bedeutet, dass es sich hierbei um einen von den Besuchenden selbst gewählten Terminus handelt.

Höge 2006, S. $218 \mathrm{f}$. 
gesehen von dem Aspekt der Sehnsucht, der in den Überlegungen Höges neu auftaucht, scheint mir der beschriebene Bereich verwandt mit dem zu sein, was in der Geschichtsdidaktik unter Imagination oder auch Empathie verhandelt wird, und es zeigt sich, wie lohnenswert ein wechselseitiges Sich-zur-Kenntnis-Nehmen zwischen psychologischen und geschichtsdidaktischen Arbeiten sein könnte. ${ }^{790}$

Über die Bedeutung von Empathie und Sich-Vorstellen, nun am Beispiel von Besuchenden von Gedenkstätten an Orten ehemaliger nationalsozialistischer Konzentrationslager, finden sich auch Ausführungen bei Bert Pampel. Er unterscheidet innerhalb seines bereits weiter oben vorgestellten Sets von Besuchserfahrungen zwei zum Thema passende Bereiche, nämlich - und in deren Unterscheidung begrifflich vordergründig anschlussfähig etwa an die Differenzierung Juliane Brauers $^{791}$ - «Vorstellung (Imaginative Erfahrungen)» und «Einfühlung (Empathische Erfahrungen)». ${ }^{792}$

Pampel kommt in einer Analyse von Besuchsmotiven zu dem Schluss, die Besuchenden erhofften sich «von ihrem Aufenthalt in Gedenkstätten eine Vorstellung davon, «wie es früher war〉, den Nachvollzug des historischen Geschehens oder sogar eine Zeitreise in die Vergangenheit». ${ }^{793}$ «[E]rlebnisorientierte Erwartungen» besässen grössere Bedeutung für die Besuchenden als Wissenserwerb. ${ }^{794}$ Pampel widmet sich nun der Frage, inwieweit den Besuchenden «eine solche gedankliche Rekonstruktion> gelingt», ${ }^{795}$ und kommt dabei zu differenzierten Ergebnissen.

790 In der deutschsprachigen Geschichtsdidaktik scheint mir der Begriff der Nostalgie bislang kaum geläufig. Allerdings widmete die Internationale Gesellschaft für Geschichtsdidaktik im Jahr 2016 ihre Zeitschrift dem Thema «Nostalgia in Historical Consciousness and Culture» (Popp et al. 2016). Im einführenden Beitrag entfalten Elisabeth Erdmann und Arja Virta die Vielschichtigkeit des Begriffs und fassen zusammen: «In the context of history, nostalgia is understood as a sentimental relationship to the past, embellishing the past with devotion and admiration. It is not only about the place, the home that has been lost - but can deal with the time that has been lost. People's subjective images of the past are often represented as the glorfication of «the good old times», heritage and tradition» (Erdmann/Virta 2016, S. 13). Eine künftige geschichtsdidaktische Aufgabe könnte es sein, Konzepte von Nostalgie mit denjenigen der Empathie und Imagination zusammenzubringen und über Gemeinsamkeiten und Differenzen nachzudenken sowie hierzu auch Beiträge der psychologischen Forschung zu berücksichtigen.

791 Brauer 2013.

792 Pampel 2007, S. 262 ff. und S. $267 \mathrm{ff}$.

793 Pampel 2007, S. 257.

794 Pampel 2007, S. 248.

795 Pampel 2007, S. 258. 
Er gliedert seine Befunde in Äusserungen über «Vorstellungen (Imaginative Erfahrungen)» und «Einfühlung (Empathische Erfahrungen)» und schildert sowohl gelingende Fälle des Sich-Vorstellens und Sich-Einfühlens, aber auch durch die Besuchenden berichtete Schwierigkeiten, sowohl dahingehend, sich den «Ort des Geschehens» vorzustellen, als auch, «sich in die Opfer hineinzuversetzen». ${ }^{796}$ Pampel kommt zu dem Befund, dass ein Nicht-Gelingen des Sich-Vorstellens oder -Einfühlens von den Besuchenden im erstgenannten Fall vor allem auf die örtlichen Gegebenheiten zurückgeführt wird, nämlich auf das inzwischen veränderte Aussehen des Ortes, im zweiten Fall auf einen «Mangel an Anschaulichkeit oder an Information», in beiden Fällen also "praktisch» begründet werde, hingegen nur selten «wahrnehmungstheoretisch» oder «geschichtstheoretisch - mit der unaufhebbaren Distanz zwischen Vergangenheit und Gegenwart - oder psychologisch - mit der unüberwindlichen Differenz zwischen Subjekten». ${ }^{797}$

Umgekehrt finden sich auch Hinweise auf gelingendes Sich-Einfühlen. Sofern empathisches Sich-Einfühlen gelingt, das von nahezu allen Besuchenden versucht werde, seien «Gegenstand der Empathie [...] fast ausschliesslich Opfer, teilweise Angehörige bzw. Verwandte». ${ }^{798}$ Pampel bringt solches Sich-Einfühlen mit der Erfahrung des Ortes in Verbindung:

«Die Distanz zum historischen Geschehen wird auch dadurch verringert, dass man den Ort der Ereignisse 〈hautnah〉 erleben kann, dass man aus der Nähe erfährt, was dort Schreckliches geschehen ist. In dem Eindruck, die Leiden der Opfer nacherleben zu können, wird Distanz schliesslich gänzlich aufgehoben.» ${ }^{799}$

Im Fall von Pampels Studie kann Empathie somit auch ein Aufheben der historischen Distanz meinen, während in den weiter oben genannten Empathiedefinitionen die Differenzerfahrung als integraler Bestandteil von Empathie betont wird.

Pampel stellt weiter die Frage, ob Imaginieren historisches Verstehen befördern könne, ${ }^{800}$ und generell, «wie sich [...] Gefühle auf die kognitive Verarbeitung von Wahrnehmung auswirken», insbesondere angesichts von Einsichten der Psy- 
chologie, dass « $[\mathrm{n}]$ egative Gefühle $[\ldots]$ logisches Denken und rationale Entscheidungsfindung beeinträchtigen». ${ }^{801}$ Er kommt auch hier zu differenzierten Befunden, es fänden sich nämlich «sowohl Beispiele für Besucher mit reichhaltigen Vorstellungsbildern ohne nachhaltige Denkprozesse wie auch Beispiele dafür, dass trotz fehlenden Vorstellungsvermögens Einsichten gewonnen werden. Umgekehrt genauso.» ${ }^{802}$ Die der Gedenkstättenpädagogik zugeschriebene Annahme, dass Empathie die Besuchenden «nach Erklärungen für die historischen Geschehnisse» suchen lasse oder «weitergehendes Interesse an den Opfern» wecke, kann Pampel nicht stützen. ${ }^{803}$ Gleichwohl stellt er im Resümee seiner Arbeit ein in Gedenkstätten mögliches, «auf unmittelbaren nicht-kognitiven Erfahrungen» beruhendes Lernen fest, nämlich ein «Lernen durch unmittelbare Anschauung», ein «Lernen durch physische Aneignung des Ortes» und ein «Lernen durch Einfühlung und Imagination». 804

In der Zusammenschau der rezipierten Studien zeigt sich, dass Imagination/ Sich-Vorstellen einerseits und Sich-Hineinversetzen/Sich-Einfühlen/Empathie andererseits sowohl Bedürfnisse von Museumsbesuchenden sind wie auch dass sie von Besuchenden als tatsächlich erlebt berichtet werden. ${ }^{805}$ Der Bereich der Imagination und Empathie steht dabei an der Schnittstelle zwischen Emotion und Kognition, da er einerseits auf Einfühlung und Sich-Vorstellen basiert, ihm andererseits auch erkenntnisfördernde Kraft zugeschrieben wird - dies einerseits in der theoretischen geschichtsdidaktischen Literatur, ${ }^{806}$ andererseits von etlichen empirischen Studien. ${ }^{807}$

Wohl dieser Schnittstellenposition ist es geschuldet, dass Christian Kohler die eindeutige Zuordnung dieses Bereichs zu kognitiven oder emotionalen Anteilen des Museumsbesuchs offenbar Schwierigkeiten bereitet - so von mir folgendermassen andernorts bereits festgehalten: ${ }^{808}$

801 Pampel 2007, S. 245.

802 Pampel 2007, S. 261.

803 Pampel 2007, S. 265.

804 Pampel 2007, S. 352 f.; erstes Zitat im Original in Kursivsetzung.

805 Differenzierung in erwartete und erlebte Aspekte in Anlehnung an Pekarik et al. 1999, S. 152.

806 Vgl. Abschnitt 3.4 .

807 Pleitner 2008, S. 110; Kohler 2016, S. 164, S. 203; bedingt: Pampel 2007.

808 Ich habe dies im Rahmen einer Rezension bereits ausgeführt (Thyroff $2017 \mathrm{~d}$ ) und beziehe mich auf die dortige Darstellung. 
«Wie dieses Imaginieren, Nachvollziehen, Abtauchen, Hineinversetzen innerhalb der theoretischen Pole der Kognition und Emotion einzuordnen sei, in dieser Frage bleibt Kohlers Darstellung unentschlossen bzw. variantenreich. So kommt er zum Ende seiner Analyse zu dem Fazit, dass gefühlsmässiges Hineinversetzen von den Probandinnen und Probanden selbst nicht als Lernen konnotiert wird, ${ }^{809}$ während er im Rahmen einer Hauptkomponentenanalyse die Intentionen des Abtauchens und Mitreissenlassens als Elemente einer 〈Lernintention〉 im Kontrast zu einer 〈Erlebnisintention〉 identifiziert hat ${ }^{810}$ bei den konkreten berichteten Besuchserfahrungen jedoch dann wieder in eine <emotionale Alteritätserfahrung〉 und eine 〈kognitive Lernerfahrung〉 unterscheidet. $^{811}$ Kohlers eigene Erklärung, dass es wohl eine Diskrepanz zwischen Besuchsintentionen und konkreten Erfahrungen gebe, ${ }^{812}$ vermag die theoretische Unschärfe der gewählten Kategorien nicht vollends aufzulösen [...]. Die offenbar disparate Datenlage kann gleichzeitig auch als Indiz dafür verstanden werden, wie verwoben emotionale und kognitive Erfahrungen beim Museumsbesuch in den Vorstellungen der Besuchenden sein können. Kohler selbst macht denn auch die Notwendigkeit deutlich, beide Aspekte stärker zusammenzudenken, [...] [beschränkt sich aber auf die Feststellung], dass Imagination und Hineinversetzen auch eine <erkenntnisleitende Funktion> haben könne. ${ }^{813}$ Ebenfalls wenig ausdifferenziert wird die Rolle, die dabei die ästhetische Dimension von Museen in den Vorstellungen spielt. Eher als Notbehelf erscheint die gewählte Bindestrichvariante <ästhetisch-emotionale Komponente> oder ein lediglich additives Aneinanderhängen als «ästhetische und emotionale Erfahrung>. ${ }^{814}$ Eine weitere Ausdifferenzierung des Verhältnisses von kognitiver, ästhetischer und emotionaler Dimension der Museumserfahrung steht insofern noch aus $[\ldots] » .{ }^{815}$

813 Kohler 2016, S. 164, S. 171, S. 203, S. 236; direkte Zitate: S. 164, S. 203

814 Kohler 2016, S. 127, S. 167, S. $170 \mathrm{f}$.

815 Thyroff 2017 d, S. 287 f.; ähnlich wie auch bereits im Theorieteil meiner Arbeit festgestellt, vgl. Abschnitt 3.4. 


\subsubsection{Befunde zum Nicht-nur-Kognitiven (2): Objektbegegnung, Emotion und Ästhetik}

Nicht-nur-kognitive Dimensionen des Ausstellungsbesuchs manifestieren sich neben dem Bereich der Imagination und Empathie, der im Zusammenhang mit unterschiedlichsten Medien- und Präsentationsformen stehen kann, auch generell in der Begegnung zwischen Besuchenden und Objekten. Einige Studien beschäftigen sich etwa mit der Frage, wie Besuchende auf Objekte aufmerksam werden und aufgrund welcher Beweggründe sie sich diesen zuwenden. Dass Besuchende oft selektiv durch eine Ausstellung gehen, wurde weiter oben bereits deutlich. Insofern müssen sie eine Auswahl treffen, die, so zeigen Studien, auf mehreren Faktoren beruht.

Bernd Wagner beschäftigt sich in einer Studie mit Kindern im Berliner Museum für Gebrauchsgegenstände mit Kriterien der Zuwendung zu Objekten. Anziehend für die Kinder seien zum einen «Dinge, die emotionale Reaktionen hervorrufen», einhergehend «mit körperbezogenen, sinnlichen Erfahrungen». ${ }^{816}$ Zum anderen seien die Kinder «an ungewohnten Dingen sehr interessiert», ${ }^{817}$ wobei es hier auf die richtige Passung zwischen Fremdheit und Vertrautheit ankomme:

«Die drei Museumsbesuche zeigen, dass Dinge, die zwar noch in ihren Gebrauchszusammenhängen erkennbar sind, aber befremden, sich Kategorisierungen entziehen, eine Anziehungskraft auf die Kinder unseres kleinen Samples ausüben. Die Lieblingsdinge sind ihnen nicht völlig fremd, aber gleichzeitig irritieren sie und sind nicht in gewohnte lineare Dingkombinationen einordbar.» ${ }^{818}$

Wagner schreibt den an der Schwelle zwischen Vertrautheit und Fremdheit befindlichen Dingen ein didaktisches Potenzial zu. «Historisches Lernen kann diese produktive Verunsicherung aufgreifen, Verbindungen zu heute noch gebräuchlichen Nutzgegenständen aufzeigen und Empathie für die Lebensbedingungen in historisch gewachsenen Dingwelten wecken.» ${ }^{819}$

816 Wagner 2013, S. 213.

817 Wagner 2013, S. 215.

818 Wagner 2013, S. 213.

819 Wagner 2013, S. 215. 
Auf ein produktives Moment in der Objektbegegnung weist dezidiert auch Hannah Röttele hin. Im Rahmen ihrer Beobachtung von Teilnehmenden eines museumspädagogischen Programms im Historischen Museum Hannover stellt sie fest, dass

«Schülerinnen und Schüler auf Gegenstände, Bild- oder Modellelemente reagieren, die sie entweder als «bekannt identifizieren oder die sie in irgendeiner Weise irritieren oder ihnen als ungewöhnlich erscheinen. Der Identifikation von 〈Bekanntem〉 folgt in vielen Fällen keine weitere Beschäftigung; es sei denn, es knüpft sich an die Identifikation ein weiteres inhaltliches Interesse. In der Irritation kann hingegen ein verlängerter Wahrnehmungsmoment stecken und die Frage, wie die Wahrnehmungsirritation zu begründen ist.» ${ }^{820}$

Im Gegensatz zu Wagner stellt Röttele also keine Gleichzeitigkeit von Bekanntheit und Fremdheit fest, sondern unterscheidet nach zwei verschiedenen Formen der Objektbegegnung. Im Fall von Irritation sieht Röttele ähnlich wie Wagner ein Potenzial für die Anregung historischen Denkens. ${ }^{821}$ Innovativ an Rötteles Ansatz ist hierbei, den Moment der Wahrnehmung eines Objekts und das Entstehen einer historischen Frage integrativ zu denken. Bei der Objektbegegnung aufgrund von Irritation sei bereits «die historische Frage im Wahrnehmungsakt selbst angelegt». ${ }^{822}$

Die Ansätze Rötteles und Wagners unterscheiden sich mit ihrer Betonung der Bedeutung von (bedingter) Fremdheit ihrerseits von Überlegungen Heiner Treinens, der davon ausgeht, es werde lediglich sowieso Bekanntes betrachtet. ${ }^{823}$ Treinen vergleicht den Museumsbesuch mit der Nutzung von Massenmedien und bezeichnet ihn als «kulturelles window-shopping» bzw. als «aktives Dösen»: 824

«Wir verweilen vor allem vor solchen Objekten, mit denen wir bereits vorweg, vor dem Museumsbesuch also, zu tun hatten. Sofern unser Wissen über die dahinterstehenden Objektklassen, über die Struktur der ausgestellten Objekte also, ausgedehnt ist, genügen vielleicht wenige Blicke, um einen Merkmalposten abzuhaken, Gedanken anzuregen, Wissen zu vervollständigen. Alles andere wird 〈mitgenommen〉, das heisst: als blanke Abwechslung behandelt.» ${ }^{825}$ 
Auf ein Vorgehen im Stil eines Abhakens deutet auch ein Befund von Susie Wise hin, die allerdings nicht drauf eingeht, inwiefern dabei die Bekanntheit von Objekten eine Rolle spielt. Sie stellt fest: «The basic script for exploring a museum exhibition with its objects on display is to walk in to the space, look at an object, read its label, and move to a next object. This is repeated multiple times until the visit is $\left\langle\right.$ done ${ }^{8}{ }^{826}$

Auf eine Bedeutung der Auseinandersetzung mit bereits Bekanntem statt Irritierendem können meines Erachtens auch die Befunde Gun-Brit Thomas hindeuten, die sie mittels Fragebogen und Lautem Denken bei einer Vitrine innerhalb der Ausstellung «Film und Fotografie» im Deutschen Museum in München gewonnen hat ${ }^{827}$ - auch wenn sie selbst ihre Ergebnisse nicht in dieser Hinsicht in einen grösseren Zusammenhang einordnet und diskutiert. Gemäss Thomas Fragebogenerhebung gehörte das Wiedererkennen von Apparaten zu einem von drei am ehesten von Besuchenden selbst geschilderten kognitiven Verarbeitungsprozessen. ${ }^{828}$ Aus den mittels Lauten Denkens erhobenen Daten folgert Thoma, dass die Exponate «am ehesten dazu an[regen], das eigene Vorwissen zu aktivieren [...]. Am seltensten werden durch die Exponate Fragen bei den Besucherinnen und Besucher[n] aufgeworfen.» ${ }^{829}$ Ergänzt um die Kategorien «Wiedererkennung» und «Nennung von Alltagsbeispielen», die Thoma neben dem Vorwissen separat ausweist, was aber anhand der im Anhang befindlichen Ankerbeispiele nicht überzeugend ist, da sich diese für alle drei Kategorien in ihrer Struktur auffallend ähneln oder gar gleichen, ${ }^{830}$ wird die Bedeutung der Auseinandersetzung mit bereits Bekanntem zusätzlich unterstrichen. ${ }^{831}$

Sofern überhaupt von den Besuchenden Fragen während der Exponatbetrachtung aufgeworfen werden, sind diese Thoma zufolge nie komplex, sondern «ausschliesslich einfach», ${ }^{832}$ was gemäss Kategorienbeschreibung bedeutet, dass das

826 Wise 2011, S. 75. Wie bereits erwähnt, verwendet Wise allerdings einen breiten Objektbegriff und zählt dazu etwa auch ein «text panel» (ebd., S. 92).

827 Thoma 2009, S. $82 \mathrm{ff}$.

828 Thoma 2009, S. 120. Die zwei anderen Aspekte sind das Entdecken von «Gemeinsamkeiten und Unterschiede[n] zwischen den Apparaten» und das Sich-Vorstellen, «wie Leute zu den verschiedenen Zeiten mit den einzelnen Apparaten fotografiert haben» (ebd., S. 120).

829 Thoma 2009, S. 137.

830 Thoma 2009, S. $221 \mathrm{f}$.

831 Entsprechende quantitative Befunde für die Kategorien im Vergleich sind ersichtlich in Thoma 2009, S. 137.

832 Thoma 2009, S. 138. 
Fragen darauf zielt, "was das für ein Exponat ist und was seine Funktion ist». ${ }^{83}$ Und auch generell stellt Thoma fest, «dass alle kognitiven Prozesse eher in einfacher als in komplexer Form vollzogen werden», ${ }^{834}$ wobei in der einfachen Form von Thoma gemäss Ankerbeispielen in mehreren Fällen identifizierende Tätigkeiten oder entsprechende Fragen/Vermutungen erfasst werden, ${ }^{835}$ ohne dass Thoma diese auffallende Parallele zwischen den einzelnen Kategorien reflektieren würde. Sie verpasst auf diese Weise die Gelegenheit, auf eine offensichtlich hohe Bedeutung der Auseinandersetzung mit bereits Bekanntem einerseits und identifizierender Aktivitäten andererseits hinzweisen. Inwieweit diese Befunde der spezifisch zugrunde liegenden Ausstellung geschuldet sind oder vielleicht generell ein Charakteristikum von Ausstellungsbesuchen darstellen, lässt sich freilich auf Basis einer einzelnen Studie nicht aufzeigen.

Eine Reihe der von mir vorgestellten Ansätze geht weiter davon aus, dass Objektwahrnehmung stark durch individuelle Bedingungen der Besuchenden strukturiert wird. So beschreibt Hannah Röttele Objektwahrnehmung als individuell, da sowohl Bekanntheit als auch Irritation «vom Standpunkt des Subjekts» abhängen. ${ }^{836}$ Allerdings benennt sie noch eine Reihe weiterer Faktoren, die den Verlauf eines Ausstellungsbesuchs und die Objektwahrnehmung beeinflussen, neben Objekten und Beschriftungen

«die Interaktion der Schülerinnen und Schüler untereinander, die Konstitution bestimmter räumlicher Verhältnisse über die Bewegung bzw. die Wahl des Standpunkts, der die Sicht auf das Objekt ermöglicht oder zum Teil verhindert, sowie der Aspekt der Zeitlichkeit (die Zeitlichkeit der Objektwahrnehmung; die Prozesshaftigkeit des Ablaufs)». ${ }^{837}$

Erneut zeigt sich also neben den persönlichen Voraussetzungen der Besuchenden die Bedeutung des physischen und sozialen Kontexts der Besuchssituation und manifestieren sich die drei von Falk und Dierking festgestellten Bedingungsfaktoren eines Ausstellungsbesuchs. ${ }^{838}$

833 Thoma 2009, S. 223.

834 Thoma 2009, S. 138.

835 Thoma 2009, S. $221 \mathrm{ff}$.

836 Röttele 2017, S. 122 f., direktes Zitat: S. 122.

837 Röttele 2017, S. 117.

838 Falk/Dierking 1997; Falk/Dierking 2000. 
Ein ähnliches Ineinandergreifen von persönlichen und objektseitig vorhandenen Faktoren stellen auch Martin Schuster und Hildegard Ameln-Haffke fest, die Studierende eines Seminars nach «grosse $[\mathrm{m}]$ Kunsterleben» in der Begegnung mit Werken der Bildenden Kunst befragten, d.h. nach Begegnungen «mit starker innerer Angerührtheit». ${ }^{839}$ Sie stellen «drei 〈Aufschliesser〉 des grossen Kunsterlebnisses» fest, nämlich «das Interesse an Bildender Kunst, das Museum als Ort und die Urlaubsstimmung», und formulieren als Fazit, dass «das grosse Kunsterlebnis nicht allein durch das Kunstwerk erzeugt [ist]. Es zeigt sich, dass solche grossen Kunsterlebnisse fast immer aus einer Passung zwischen Erlebnissen der individuellen Biographie und dem Kunstwerk entstehen». ${ }^{840}$

\subsubsection{Befunde zur Lebenswelt- und Gegenwartsrelevanz von Ausstellungsbesuchen}

Mit meiner Studie ziele ich schwerpunktmässig darauf, festzustellen, inwiefern Besuchende beim Besuch einer historischen Ausstellung Bezüge zu ihrer eigenen Person und Lebenswelt sowie Gegenwart herstellen. In einem weiteren Sinn gehören zur Lebensweltrelevanz viele der bereits geschilderten Befunde, etwa zu den emotionalen Dimensionen und Auswirkungen eines Museumsbesuchs. In einem engeren Sinn wende ich mich nun jedoch noch Studien zu, die Auskünfte über explizite Bezugnahme der Besuchenden auf ihre eigene Lebenswelt und Gegenwart in den Blick nehmen. Hierzu gibt es bislang einen überschaubaren Kreis von empirischen Studien, die relevante Referenzpunkte bereitstellen.

$\mathrm{Zu}$ nennen ist erneut die bereits mehrfach zitierte Studie von Bert Pampel zu Besuchenden von Gedenkstätten. ${ }^{841}$ Pampel erhob in einer retrospektiven Befragung von Besuchenden unter anderem, «welche konkreten Verbindungen zwischen Vergangenheit und Gegenwart» die Besuchenden sahen, ${ }^{842}$ und stellt sowohl von den Besuchenden genannte Themenbereiche wie beispielsweise «Sterbehilfe», «Todesstrafe», «Rechtsextremismus» vor $^{843}$ als auch die Struktur der Bezüge zwischen den Zeitebenen. So würden «[w]eit überwiegend [...] Parallelen bzw. Kontinuitäten gesehen und Unterschiede nivelliert» ${ }^{844}-$ ein Befund, der den

839 Schuster/Ameln-Haffke 2006, S. 280 f., direkte Zitate: S. 281.

840 Schuster/Ameln-Haffke 2006, S. 287 f.

841 Pampel 2007.

842 Pampel 2007, S. 312.

843 Pampel 2007, S. $312 \mathrm{ff}$.

844 Pampel 2007, S. 319, dazu ausserdem S. 312 ff., S. 358. 
meinigen ähnelt, wie ich später noch zeigen werde. Pampel kommt zu dem Schluss, und auch darin ähneln sich die Befunde, «dass viele Gesprächspartner den historischen Ereignissen durchaus Bedeutung für die Gegenwart beimassen. Gegenwartsbezüge gingen allerdings nur selten mit gründlichen Reflexionen oder gar persönlichen Schlussfolgerungen einher, sondern trugen oftmals den Charakter von flüchtigen Assoziationen, die nicht systematisch durchdacht werden». ${ }^{845}$

An Bezügen zur Gegenwart der Besuchenden stellt Pampel weiter fest, dass der Gedenkstättenbesuch in unterschiedlichem Mass «Interesse am Thema bzw. an einer weiteren Beschäftigung» wecke und von den Besuchenden tendenziell als Anlass zur «Bestätigung des eigenen Geschichtsbildes» und nicht als Anlass von dessen Hinterfragung gedeutet werde. ${ }^{846}$ Unter der Überschrift «Bekräftigung und Veränderung von historischen und politischen Einstellungen» schildert Pampel, die meisten der von ihm beforschten Personen hätten

«sich durch den Besuch im Grossen und Ganzen in ihrer Deutung bzw. Bewertung des historischen Geschehens bestätigt [gezeigt]. [...] Informationen, die den eigenen Deutungsmustern widersprachen, wurden ignoriert, passend gemacht oder als nicht der Wahrheit entsprechend kritisiert, führten aber nicht zu einer grundsätzlichen Veränderung der eigenen Haltung. [...] Vereinzelt wiesen Gesprächspartner aber auch auf Korrekturen an ihrem Bild von der Vergangenheit hin.» ${ }^{847}$

Auch auf die hier angesprochenen Aspekte, mögliche Bestätigungen oder Differenzierungen von Geschichtsbildern, werde ich im Rahmen meiner eigenen Datenanalyse noch zu sprechen kommen, dort allerdings die Befunde Pampels differenzieren.

\subsubsection{Befunde zu Sinnbildung und historischem Denken in einer Ausstellung: Die Studie «Visitors encounter the dust. How People think with objects in a History Museum Exhibition» von Susie Wise}

Die engste Verwandtschaft zu meiner eigenen Untersuchung weist die Dissertationsschrift von Susie Wise aus dem Jahr 2011 auf. ${ }^{848}$ Wise' Studie liegt in ihren

845 Pampel 2007, S. 319.

846 Pampel 2007, S. 323, S. 348.

847 Pampel 2007, S. 328 ff., direkte Zitate S. 328 u. 330.

848 Wise 2011. 
thematischen Bezugspunkten quer zu einer Reihe der bislang in meinem Forschungsüberblick berücksichtigten Bereiche, behandelt etwa körperliche Praktiken im Raum, Formen der Objektbegegnung, Vorstellungen von der Manifestation Museum/Ausstellung und ihren Elementen, auftretende Emotionen und Bezüge zur eigenen Person, weshalb ich sie an den Schluss der Darstellung stelle und ihr einen gesonderten Abschnitt widme. Dies bietet sich zweitens auch deshalb an, weil Wise mit ihrer Studie noch einen weiteren Aspekt berücksichtigt, der bislang nicht Gegenstand des Forschungsüberblicks war, nämlich die Frage, wie und auf welche Weisen im Prozess eines Ausstellungsbesuchs durch die Besuchenden Sinn gebildet und historisch gedacht wird. Bei der Studie von Wise handelt es sich um die einzige mir bislang bekannte, die wie die meinige Elemente des historischen Denkens und Sinnbildens bei Einzelpersonen im Verlauf des Besuchs einer historischen Ausstellung in den Blick nimmt. ${ }^{849}$

Unter dem Titel «Visitors encounter the dust. How People think with objects in a History Museum Exhibition» untersucht Wise, welche Gedanken der Besuch einer historischen Ausstellung, insbesondere der Kontakt mit den darin befindlichen Objekten auslöst. ${ }^{850}$ Ort ihrer Untersuchung ist eine Ausstellung in New York. Diese zeigt einerseits das sogenannte Chelsea Jeans Memorial, Teile eines Jeansgeschäfts, das beim Einsturz des World Trade Center im September 2001 verstaubte und in diesem Zustand in die genannte Ausstellung transferiert wurde, wo neben dem Memorial Fotografien der Ereignisse rund um den 11. September gezeigt werden. ${ }^{851}$

Wise interessiert sich nun für «sense-making processes», ${ }^{852}$ die bei Besuchenden während ihres Gangs durch diese Ausstellung auftreten, und für die Rolle, die dabei die körperliche Bewegung im Raum spielt: «I show how visitors embody their interpretations as they move through the exhibition space.» ${ }^{853}$ Als Erhebungsmethode verwendet Wise das Prozessbegleitende Laute Denken während

849 Nachträglich mittels Stimulated Recall fragen danach Lenz/Talsnes 2014, im Kontext eines museumspädagogischen Programms ausserdem Schreiber et al. 2015.

850 Wise 2011, S. iv. Anzumerken ist, dass Wise einen breiteren Objektbegriff verwendet, als er in der deutschsprachigen Museumstheorie gebräuchlich ist. So fasst sie darunter kategorial auch Ausstellungstexte (Wise 2011, S. 92). In der Ergebnisdarstellung selbst (ebd., S. 37 ff.) geht sie dann allerdings nicht auf Texte, sondern konkret auf den Umgang mit den ausgestellten Fotografien sowie dem Chelsea Jeans Memorial ein, das zuvor von ihr eingeführte weite Objektsverständnis macht sich also in der Auswertung selbst nicht bemerkbar.

851 Wise 2011, S. $1 \mathrm{ff}$.

852 Wise 2011, S. 32.

853 Wise 2011, S. 9. 
des Ausstellungsbesuchs und ergänzt dieses um Videoaufzeichnungen mittels Kameras, an den Köpfen der Probandinnen und Probanden befestigt. ${ }^{854}$

Wise arbeitet insgesamt vier verschiedene Strategien des sense-making heraus. Drei davon gewinnt sie mehrheitlich aus einer Analyse des gesprochenen Wortes des Besuchenden («interpreting», «emoting», «remembering»), eine vierte über den ergänzenden Einbezug der Laufwege und Körperhaltungen («embodied interpretative practices»), wobei sie gleichzeitig deutlich macht, dass alle vier Formen überhaupt erst durch die Bewegung im Raum, den Gang durch die Ausstellung möglich werden: ${ }^{855}$ «The space shapes their interaction.» ${ }^{856}$

Als grundlegende Form des sense-making führt Wise das «Interpreting» ein, verstanden als «fundamental building block of the exhibition experience», das sie am häufigsten in ihren Daten identifiziert. ${ }^{857}$ Leider liefert Wise keine prägnante Definition der Kategorie, aber sie fasst darunter «Identifying and describing», «Offering an opinion», «Employing gallery-based resources», «Requesting more information» und «Adding an interpretative layer», also eine Bandbreite von Aktivitäten, die von einem nah an das einzelne Objekt gebundenen Identifizieren und Beschreiben des Gesehenen über das Äussern von Meinungen bis hin zu weitreichenderen, übergreifenden Deutungen und Einordnungen reichen. ${ }^{858}$

Sofern Annäherungen an das Gesehene ganz unmittelbar in Zusammenhang mit körperlichem Verhalten gebracht werden, spricht Wise von «Embodied interpretative practices» und unterscheidet dabei «Leaning in to look closely», «Juxtaposing», «Walking a path of understanding» und «Changing vantage point». ${ }^{859}$ Alternative Sinnbildungsstrategien neben interpreting stellen Wise zufolge einerseits das «Remembering» dar, wobei Besuchende «use remembering for sensemaking in real time during their visit» ${ }^{860}$, sowie andererseits «Emoting», also das Äussern von Emotionen. ${ }^{861}$

Quer liegend zu diesen vier Formen der Sinnbildung analysiert Wise, auf welchen Fokus die Besuchenden ihre Aufmerksamkeit richten. Sie identifiziert auch hier vier Varianten: «Object», «Exhibition», also die Ausstellung als Ganzes,

854 Wise 2011, S. 10, S. 21, S. 27.

855 Wise 2011, S. 89.

856 Wise 2011, S. 142.

857 Wise 2011, S. 95 , S. 97 ff., direkte Zitate: S. 98.

858 Wise 2011, S. $98 \mathrm{f}$.

859 Wise 2011, S. $74 \mathrm{ff}$.

860 Wise 2011, S. $113 \mathrm{ff}$., direkte Zitate: S. 113.

861 Wise 2011, S. 123 ff., direktes Zitat: S. 123. 
die darin befindlichen Elemente und ihre Beziehungen, «Self», also die eigene Person der Besuchenden, sowie «Outside», alle ausserhalb der Ausstellung liegenden Dinge, Ereignisse und Erfahrungen. ${ }^{862}$ Sie kommt zu dem Ergebnis, dass ein Grossteil des Besuchs aus Objektfokussierung besteht, wobei sie einen breiten Objektbegriff verwendet und dazu etwa auch ein «text panel» zählt. ${ }^{863}$

Wise zeigt im Verlauf ihrer Ergebnisdarstellung anhand von zahlreichen Beispielen, wie bestimmte Objekte unterschiedliche Sinnbildungsstrategien auslösen können. ${ }^{864}$ Dabei stellt sie beispielsweise fest, dass «Emoting» vor allem durch einen bestimmten Objekttyp, nämlich Fotografien, ausgelöst wird ${ }^{865}$ Eine systematische Übersicht darüber, welche Typen von Objekten zusammen mit welchen Typen von Sinnbildungen auftreten, bleibt Wise allerdings - trotz Ankündigung ${ }^{866}$ - schuldig.

Bei Wise handelt es sich mit dem 11. September um ein Thema der unmittelbaren Zeitgeschichte, an das alle Teilnehmenden, mindestens vermittelt durch Medien, eine persönliche Erinnerung haben, bei dem sie zum Teil auch selbst unmittelbar von den Ereignissen betroffen waren. ${ }^{867}$ Dort kann der Besuch der Ausstellung potenziell autobiografische Erinnerungen anregen und Emotionen hervorrufen und tut dies auch, wie Wise feststellt. ${ }^{868}$ Ausgehend von Wise' Befunden stellt sich die Frage, wie sich die Situation demgegenüber bei Besuchenden der Ausstellung «14/18» darstellt. Die dort behandelte Periode, die Zeit des Ersten Weltkriegs, liegt sehr viel weiter zurück. Persönliche Erinnerungen an diese Zeit haben die Besuchenden keine. Gerade deshalb ist die Frage interessant, ob Besuchende dem Gesehenen dennoch Bedeutung für ihre eigene Gegenwart beimessen.

Das Verdienst von Wise besteht vor allem darin, anhand von prozessbezogenen empirischen Daten unterschiedliche Strategien des sense-making bei Ausstellungsbesuchenden herausgearbeitet $\mathrm{zu}$ haben. $\mathrm{Zu}$ aufschlussreichen Befunden kommt Wise weiter aufgrund der Zusammensetzung ihres Samples. Wise achtete auf theoretisch kontrastierende Fälle und suchte gezielt nach Novizinnen und Novizen, Expertinnen und Experten im Hinblick auf das dargestellte Thema, den 11. September, und im Hinblick auf den Umgang mit Objekten und Ausstellun-

862 Wise 2011, S. 92.

863 Wise 2011, S. 92 f., direktes Zitat: S. 92.

864 Wise 2011, S. $90 \mathrm{ff}$.

865 Wise 2011, S. 125.

866 Wise 2011, S. 94.

867 Wise 2011, S. 34.

868 Wise 2011, S. $113 \mathrm{ff}$. 
gen, wobei jeder der Typen von jeweils zwei bis drei der insgesamt sieben untersuchten Personen repräsentiert wird. ${ }^{869}$

Das gewählte vergleichende Setting erwies sich als durchaus fruchtbar. So kommt Wise unter anderem zu dem Ergebnis, dass sich die Formen der Interpretation zwischen den an der Studie beteiligten Touristen und einer Historikerin auffällig unterscheiden.

«Whereas the tourists interpreted in order to understand what they were seeing in the first place, the historians, who were no more familiar with the exhibition's specific content, interpreted to create wider reaching narratives about what was happening either at the level of the object or the exhibition.» ${ }^{870}$

So beschränkte sich etwa ein Tourist im Umgang mit Objekten auf das Identifizieren des Gesehenen und versuchte zu verstehen, "what the museum wanted him to see». ${ }^{871}$ Einer Historikerin war stattdessen daran gelegen, die Bedeutung des Objekts und seinen Symbolgehalt zu erschliessen, sie habe die Ausstellung betrachtet als «constructed space filled with objects that were chosen» und «revealed her knowledge that curators and designers created the exhibition and placed the objects, and that in so doing they also created potential meanings», das heisst, «she understood that curatorial choices have shaped the interpretations she has made». ${ }^{872}$ Diese Form des Umgangs mit Objekten und der Ausstellung als konstruiertem Raum bezeichnet Wise als «object-based historical thinking», angelehnt an das Konzept des Historical Thinking bei Sam Wineburg. ${ }^{873}$ Für Wise ist historisches Denken damit ein normatives Konzept, über das manche Besuchende als Expertinnen und Experten verfügen, andere hingegen nicht. ${ }^{874}$

\subsection{Desiderate und Verortung des Projekts}

Aus dem Forschungsüberblick wurde deutlich, dass bislang verhältnismässig wenige Studien existieren, die mit verbalen Äusserungen von Einzelbesuchenden während des Ausstellungsbesuchs arbeiten. Wenn Ausstellungsbesuchende als ak-

869 Wise 2011, S. 33

870 Wise 2011, S. 99

871 Wise 2011, S. 100 f., direktes Zitat S. 101.

872 Wise 2011, S. 101 f., direkte Zitate S. 102, Kursivsetzungen analog zu Original.

873 Wise 2011, S. 103 ff., direktes Zitat S. 103, sich beziehend auf Wineburg 1991 und 1998.

874 Wise 2011, S. 103. 
tive Generatorinnen und Generatoren von Bedeutung verstanden werden, wie ich dies weiter oben ausgeführt habe, so ist ein prozessorientierter Blick auf Aneignungsweisen eigentlich naheliegend, und es erstaunt, dass eine konstruktivistische Perspektive auf Aneignungsprozesse bislang noch selten mit einer tatsächlich auch prozessbezogenen und dabei Verbalisierungen generierenden Forschungsmethodik kombiniert wird. ${ }^{875}$

An unmittelbar prozessbezogenen Erhebungsmethoden gibt es daneben Beobachtungsstudien oder solche, die Gespräche von Besuchenden beim Besuchsverlauf analysieren. Bei Gruppengesprächen handelt es sich um einen Datentypus, der sich eignet, um beispielsweise das Aushandeln eines Gegenstandes in der Gruppe zu beobachten und ko-konstruierte Aneignungsweisen in den Blick zu nehmen. Sind demgegenüber individuelle Umgangsweisen mit einer Ausstellung, individuelle Sinnbildungen im Zentrum des Interesses, so erweist sich das von Wise eingesetzte Prozessbegleitende Laute Denken als gewinnbringend.

In dem genannten Forschungsdesiderat verorte ich mein eigenes Projekt und versuche damit zugleich zur Erhellung eines zweiten Bereichs beizutragen. So sind bislang nicht nur in Bezug auf Aneignungsweisen innerhalb einer Ausstellung prozessbegleitende Einsichten rar, Analoges gilt auch für Prozesse des historischen Denkens - unabhängig von der konkreten Einsatzsituation. Systematisch dargelegt wird das dortige Feld bei Andreas Körber. Er unterscheidet danach, ob empirische Forschung eher auf Ausprägungen von Geschichtsbewusstsein «als eine latente mentale Struktur» achtet oder es «in seiner prozessualen Funktion, Orientierung zu steuern», in den Blick nimmt, ${ }^{876}$ also anders gesagt, ob sie zustandsoder prozessinteressiert ist. Körber fordert dazu auf, nicht nur Studien durchzuführen, in denen «aus der Analyse der Ergebnisse eines Denkprozesses auf die ihm zu Grunde liegenden Strukturen des Geschichtsbewusstseins zurückgeschlossen» wird, sondern auch «Prozesse des historischen Denkens in actu in den Blick [zu] nehmen», so etwa «Tonband- und Videoaufzeichnungen von Prozessen, in denen solches Denken stattfindet». ${ }^{877}$ Auch wenn seit dieser Diagnose mehr als zehn Jahre vergangen sind, so hat Körbers Aufforderung nach wie vor ihre Berechtigung und fasst mein Forschungsprojekt die Aufgabe, Einsichten über Ausstel-

875 Hier lehne ich mich an Kohler an, der Verwunderung darüber äussert, dass zwar ein «konstruktivistisches Lernverständnis» in Bezug auf Museumsbesuchende vorliege, aber kaum Forschung zu Lernprozessen und insbesondere Lernvoraussetzungen stattfinde (Kohler 2014, S. 85).

876 Körber 2006, S. $190 \mathrm{f}$.

877 Körber 2006, S. 191. 
lungsbesuche mit Einsichten in das in actu dort stattfindende historische Denken zu kombinieren.

Inspirierend in diesem Zusammenhang sind die weiter oben bereits vorgestellten Arbeiten von Wineburg ${ }^{878}$ wie auch, mit konkretem Bezug zu historischen Ausstellungen, diejenige von Wise. Während Wise auf das «historical thinking» eher als Nebenprodukt ihrer Analyse zu sprechen kommt, bildet es für meine Untersuchung hingegen eine zentrale theoretische Bezugsgrösse und stelle ich die Frage ins Zentrum, was historisches Denken bei Ausstellungsbesuchenden bedeuten kann. Im Gegensatz zu Wineburg oder Wise verstehe ich historisches Denken dabei nicht als elaboriertes Denken, über das lediglich bestimmte Personen verfügen. Vielmehr gehe ich zunächst von einem vagen Konzept historischen Denkens aus, zu dem ich prinzipiell alle Ausstellungsbesuchenden in der Lage betrachte und das unabhängig von den konkreten Ausprägungsgraden ist.

878 Wineburg 1991, 1998, 2001. 


\section{Methoden}

Bei meinem Projekt handelt es sich um eine qualitativ-empirische Studie. Die Datenerhebung erfolgte auf dem Weg des Prozessbegleitenden Lauten Denkens. ${ }^{879}$ Hierzu besuchten die Studienteilnehmenden unbegleitet die Ausstellung «14/18». Sie wurden darum gebeten, alles ihnen während des Besuchs in den Sinn Kommende zu äussern. Gesprochenes Wort und Laufwege sowie die dabei durchschrittenen Ausstellungsteile wurden mittels Audio- und Videoaufnahme aufgezeichnet, transkribiert und anschliessend einer inhaltlich-strukturierenden qualitativen Inhaltsanalyse unterzogen. Auf den folgenden Seiten stelle ich die Erhebungsmethode des Lauten Denkens vor (Abschnitt 6.1), äussere mich zur Transkription (Abschnitt 6.2), zur eingesetzten Samplingstrategie bei der Suche nach Teilnehmenden und zu Merkmalen des Samples (Abschnitt 6.3) und komme schliesslich auf das Vorgehen bei der Datenanalyse zu sprechen (Abschnitt 6.4).

\subsection{Methode der Datenerhebung: Prozessbegleitendes Lautes Denken}

Zur Datenerhebung wurde das Prozessbegleitende Laute Denken beim Ausstellungsbesuch eingesetzt. Ich wende mich nun zunächst der allgemeinen Beschreibung dieser Methode, ihres Entstehungs- und Verwendungszusammenhangs sowie ihrer Grenzen und Potenziale zu, bevor ich dann spezifischer auf die Potenziale der Methode für mein eigenes Projekt und die konkreten Einsatzumstände zu sprechen komme. Prozessbegleitendes Lautes Denken ist bislang weder in der empirischen Forschung zu Ausstellungsbesuchenden noch in der deutschsprachigen geschichtsdidaktischen Forschung besonders geläufig, und auffallend

879 Ergänzend zum Prozessbegleitenden Lauten Denken habe ich mit den Besuchenden im Anschluss an den Ausstellungsbesuch auch leitfadengestützte, fokussierte Interviews geführt, in denen der vorangegangene Besuch und das Erleben zum Gegenstand wurden (zu diesem Interviewtyp: Merton/Kendall 1993, S. 171 ff.; Hopf 2009, S. 353 ff.). Auf die Auswertung der Interviews habe ich für mein Dissertationsprojekt zugunsten einer vertieften, detaillierten Analyse der prozessorientiert entstandenen Daten verzichtet. Die Interviews wurden allerdings insofern verwendet, als die am Ende der Interviews erfragten soziodemografischen Daten der Besuchenden aus diesen extrahiert wurden. Der Hinweis auf die Interviews ist auch deshalb wichtig, weil sie den Charakter der Gesamterhebungssituation mitprägen, etwa den zeitlichen Aufwand der Besuchenden erhöhen. 
ist, dass in diesen Feldern bislang nur wenig über die Hintergründe, Implikationen, Chancen und Grenzen der Methode reflektiert wird. ${ }^{880}$ Mein Anliegen ist hingegen, die Methode nicht nur einzusetzen, sondern «nach Erklärungskraft und Leistungsfähigkeit der Methode im Rahmen des neuen Anwendungsfeldes» ${ }^{881} \mathrm{zu}$ fragen.

\subsubsection{Entstehung und Verwendung der Methode}

Die Methode des Lauten Denkens besteht im Kern darin, dass Probanden für einen gewissen Zeitraum nach Möglichkeit alles ihnen durch den Kopf Gehende versprachlichen sollen, so etwa während der Bewältigung einer Situation oder während der Lösung einer Aufgabe. ${ }^{882}$ Lautes Denken wird eingesetzt, um über die dabei auftretenden kognitiven Vorgänge Aufschluss zu erhalten, etwa Verstehensprozesse oder Problemlösestrategien zu erheben. ${ }^{883}$

Lautes Denken als Methode stammt ursprünglich aus der psychologischen Forschung. ${ }^{84}$ In den 1920er-Jahren zum Zwecke der Selbstbeobachtung und -beschreibung kognitiver Vorgänge eingesetzt, geriet die Methode aufgrund der an ihr vermissten Intersubjektivität zunächst für einige Jahrzehnte ausser Gebrauch. ${ }^{885}$ Den lange Zeit in der Psychologie dominierenden Behaviorismus interessierten Zusammenhänge zwischen Reiz und Reaktion, nicht aber die dazwischen ablaufenden kognitiven Prozesse, die erst später ins Blickfeld rückten. ${ }^{886} \mathrm{Ab}$ den 1960er/70er-Jahren erlebte Lautes Denken dann eine Renaissance in der Problemlöseforschung, es begegnete dort dem zunehmenden Bedürfnis, «prozedurale und dynamische Aspekte kognitiver Prozesse sichtbar» zu machen. ${ }^{887}$ Lautes Denken ermöglicht Einblicke in Strategien, die bei der Lösung einer Aufgabe

880 So äussert sich zum Beispiel Wise zwar eingehend über die Potenziale der Methode für ihr Forschungsprojekt (Wise 2011, S. 20 ff.), reflektiert jedoch kaum über methodologische Grundlagen oder mögliche Grenzen. Auf nähere methodische Einlassungen verzichten beispielsweise Litten 2013, die mit Prozessbegleitendem Lautem Denken arbeitet, oder Lenz/Talsnes 2014, die die Methode des Stimulated Recall einsetzen.

881 Thyroff 2017 c, S. 3.

882 Buttkereit et al., S. 7.

883 Konrad 2010, S. 477, S. $482 \mathrm{ff}$.

884 Zur Entstehungsgeschichte der Methode siehe Konrad 2010, S. 477 f.; Someren 1994, S. $29 \mathrm{ff}$.

885 Konrad 2010, S. 477.

886 Ericsson/Simon 1980, S. 215 f.; Ericsson/Simon 1984, S. 1.

887 Konrad 2010, S. 477. Eine Übersichtsdarstellung zur Funktion Lauten Denkens in der Problemlöseforschung liefern Someren et al. 1994. 
angewendet werden, und Einblicke in beigezogenes Wissen und Argumentationsverläufe. 888

Gegenstand der Problemlöseforschung ist das Lösen von Aufgaben oder Anforderungssituationen, «for which one does not directly have an answer available. This can be because the answer cannot be directly retrieved from memory but must be constructed from information that is available in memory or that can be obtained from the environment.» ${ }^{889}$ Und weiter: «Problem-solving can be characterized as a cognitive process that is goal directed and requires effort and concentration of attention. The solution is not found directly in a single step but via intermediate reasoning steps, some of which may later appear useless or false.» ${ }^{890}$ Der Begriff des Problemlösens kann dabei durchaus breit gefasst werden. Er bezieht sich nicht nur auf das Lösen gestellter Aufgaben unter Testbedingungen, sondern beinhaltet auch die Bewältigung von alltäglichen Anforderungssituationen. ${ }^{891}$

Lautes Denken eignet sich für all diejenigen Forschungsvorhaben, in denen kognitive Abläufe im Zentrum der Aufmerksamkeit stehen, und kann in diesen Fällen beispielsweise dazu beitragen «to validate or construct theories of cognitive processes, in particular of problemsolving». ${ }^{892}$ Und auch jenseits der Problemlöseforschung kommt Lautes Denken gegenwärtig in einer Reihe von Forschungsfeldern zum Einsatz, etwa in der Spracherwerbs- und Leseforschung, Unterrichtsforschung und Entscheidungsforschung. ${ }^{893}$

\subsection{2 "Verbal reports» ${ }^{894}$ - Theoretische und methodologische Fundierung bei K. Anders Ericsson und Herbert A. Simon}

Die Psychologen K. Anders Ericsson und Herbert A. Simon haben sich in den 1980er-Jahren systematisch sowohl mit den theoretischen als auch mit den methodologischen Grundlagen Lauten Denkens auseinandergesetzt, das sie als

888 Someren et al. 1994, S. 4.

889 Someren et al. 1994, S. 8.

890 Someren et al. 1994, S. 13.

891 Someren et al. 1994, S. $13 \mathrm{f}$.

892 Someren et al. 1994, S. 9.

893 Konrad 2010, S. 482 f. Er nennt dort noch weitere Forschungsfelder. Speziell zur Unterrichtsforschung auch: Weidle/Wagner 1983, S. 81 f., S. 91 ff. Ich komme auf einige ausgewählte Einsatzfelder Lauten Denkens innerhalb von Geschichtsdidaktik und Erziehungswissenschaft weiter unten noch zu sprechen (vgl. Abschnitt 6.1.4).

894 So im Titel bzw. Untertitel bei Ericsson/Simon 1980 u. 1984 verwendet. 
eine Form verbaler Daten (verbal reports) klassifizieren. ${ }^{895}$ Ericsson und Simon haben der Methode zugrunde liegende Vorstellungen vom Ablauf kognitiver Informationsverarbeitung sowie Vorstellungen von der Struktur des Gedächtnisses ausgeführt und ausgehend davon verschiedene Formen verbaler Daten bestimmt.

Als Ausgangspunkt für ihre Arbeiten benennen Ericsson und Simon die Feststellung, dass verbale Daten zwar in der psychologischen Forschung zur Anwendung kämen, diesen aber einerseits der Ruf als informelle, «weiche» («soft» ${ }^{896}$ ) Daten subjektiver Natur anhafte, andererseits bestehe keine systematische Theorie und werde keine entsprechende Methodologie angewendet. ${ }^{897}$ Dies sei dem bislang induktiven Verwendungszusammenhang der Methode geschuldet: «If the purpose of obtaining verbal reports is mainly to generate hypotheses and ideas, investigators need not to concern themselves $[. .$.$] with methodological questions about data$ collection.» ${ }^{898}$ Ericsson und Simon setzen sich zum Ziel, das bestehende theoretische und methodologische Desiderat zu beheben, verbale Daten als «harte» ( «hard» ${ }^{899}$ ) Daten einsatzfähig zu machen und zugleich in Abgrenzung zur bisherigen Forschung den Wert verbaler Daten für deduktive Zugänge unter Beweis zu stellen, nämlich für «situations where the theoretical terms are fixed before the actual encoding begins». ${ }^{900}$ In meiner Studie verfolge ich im Gegensatz zu Ericsson und Simon ein exploratives, mehrheitlich induktives Vorgehen. Doch auch für dieses ist selbstverständlich der Blick auf die theoretischen Grundannahmen Lauten Denkens und auf die methodologischen Qualitäten dieser Erhebungsform sinnvoll, um ausgehend davon Potenziale und Fallstricke identifizieren zu können.

Ericsson und Simon beginnen ihre Ausführungen damit, dass sie ihre Vorstellung vom Ablauf kognitiver Informationsverarbeitung sowie, damit verbunden, vom Aufbau des Gedächtnisses explizieren. ${ }^{901}$

«[I]nformation is stored in several memories having different capacities and accessing characteristics: several sensory stores of very short duration, a shortterm memory (STM) with limited capacity and/or intermediate duration, and

895 Ericsson/Simon 1980; Ericsson/Simon 1984.

896 Ericsson/Simon 1984, S. 2.

897 Ericsson/Simon 1984, S. $1 \mathrm{ff}$.

898 Ericsson/Simon 1984, S. 3.

899 Für sie bedeutet dies: «Data are 〈hard when there is intersubjective agreement that they correspond to the facts of the observed behavior» (Ericsson/Simon 1984, S. 3).

900 Ericsson/Simon 1984, S. 1 ff., direktes Zitat: S. 6.

901 Ericsson/Simon 1984, S. 9 ff.; Ericsson/Simon 1994, S. 9 ff. 
a long-term memory (LTM) with very large capacity and relatively permanent storage, but with slow fixation and access times compared with the other memories.»902

Diese Dreiteilung in sensorische Register, Kurzzeit- und Langzeitgedächtnis entspricht dem «Dreispeichermodell», das Andreas Helmke zufolge «das anschaulichste und bekannteste Gedächtnismodell» darstellt ${ }^{903}$ und vielfach auch in der Methodenliteratur zum Lauten Denken abgebildet und beschrieben wird, etwa bei Konrad. ${ }^{904}$ Maria Bannert fasst in Rezeption von Ericsson und Simon den Ablauf der Informationsverarbeitung innerhalb dieses Schemas folgendermassen zusammen:

«Nach diesen Modellvorstellungen werden Informationen aus der Umwelt über die Sinnesorgane aufgenommen und in den sensorischen Registern für wenige Sekunden modalitätsspezifisch gespeichert. Über Aufmerksamkeitsprozesse gelangt nur ein Bruchteil dieser Information in kodierter Form in das Kurzzeitgedächtnis mit stark begrenzter Aufnahmekapazität und Speicherdauer. Zwar können darin die aktuellen Informationen durch stetige Wiederholung theoretisch beliebig lang gehalten werden, in der Regel werden sie jedoch entweder durch neue Informationen aus dem Kurzzeitspeicher verdrängt oder aber weiter verarbeitet. Wird die Information zum Beispiel entsprechend lange wiederholt, erfolgt eine Speicherung im Langzeitgedächtnis mit unbegrenzter Speicherkapazität und -dauer. [...] Nach diesen Modellvorstellungen lassen sich nur die bewussten Inhalte aus dem Kurzzeitgedächtnis verbalisieren. Inhalte des Langzeitgedächtnisses können folglich nicht direkt verbalisiert, sondern müssen hierfür zuerst in das Kurzzeitgedächtnis transferiert werden.» ${ }^{905}$

Ericsson und Simon gehen also davon aus, dass Verbalisierungen nur Aufschluss über die Inhalte des Kurzzeitgedächtnisses geben können. «This is the

902 Ericsson/Simon 1994, S. 11.

903 Dreispeichermodell beschrieben und abgebildet bei Helmke (Helmke 2015, S. 59 f.) und von Helmke auf Atkinson und Shiffrin zurückgeführt (Atkinson/Shiffrin 1968, zit. n. Helmke 2015, S. 59).

904 Konrad 2010, S. 478. Konrad spricht von «Gedächtnismodell» bzw. «Drei-Speicher-Modell». Die Darstellung findet sich ganz ähnlich auch bei Someren et al. 1994, S. 19, und Wallach/Wolf 2001, S. 13.

905 Bannert 2007, S. $134 \mathrm{f}$. 
information that is heeded or attended to.» ${ }^{906}$ In welcher Form die im Kurzzeitgedächtnis befindlichen Informationen verbalisiert werden, in dieser Hinsicht unterscheiden Ericsson und Simon mehrere Varianten (siehe Tabelle 3 im digitalen Anhang) und treffen eine Unterscheidung verbaler Daten unter anderem anhand des Zeitpunkts ihrer Verbalisierung.

Nach dieser Unterscheidung findet simultanes oder prozessbegleitendes Verbalisieren («concurrent verbal reports») zeitgleich zum kognitiven Prozess statt, beispielsweise während des Durchlaufens einer Situation oder des Erledigens einer Aufgabe, retrospektives Verbalisieren («retrospective reports») hingegen unmittelbar danach, wobei im zweiten Fall Informationen bereits teilweise aus dem Langzeitgedächtnis beigezogen werden müssen. ${ }^{907}$ Die zweitgenannte Form wird auch mit der Bezeichnung Nachträgliches Lautes Denken oder Stimulated Recall verwendet und kommt beispielsweise in der Unterrichtsforschung, ${ }^{908}$ vereinzelt auch in Bezug auf Museums-/Ausstellungsbesuchende ${ }^{909}$ zum Einsatz. Für diese Arbeit ist hingegen prozessbegleitendes Verbalisieren von Interesse.

Das prozessbegleitende Verbalisieren wird von Ericsson und Simon wiederum in zwei Typen unterteilt. Je nachdem, ob die zu verbalisierende Information unmittelbar in der im Kurzzeitgedächtnis gespeicherten Form versprachlicht werden kann oder ob ein oder mehrere Encodierungsvorgänge der Versprachlichung vorgeschaltet sind, sprechen Ericsson und Simon entweder von direkter oder encodierter Verbalisierung ( «direct or Level 1 verbalization», «encoded Level 2 or Level 3 verbalization»). ${ }^{910}$ Direkte oder Level-1-Verbalisierung liegt dann vor, wenn die Information bereits in verbaler Form im Kurzzeitgedächtnis vorhanden ist und lediglich ausgesprochen werden muss. ${ }^{911}$ Eine encodierte Verbalisierung kann in zweierlei Varianten auftreten, nämlich als Level-2-Verbalisierung, wenn der Inhalt des Kurzzeitgedächtnisses in nicht verbaler Form vorliegt und vor der Verbalisie-

906 Ericsson/Simon 1984, S. 14, Kursivsetzung analog zum Original.

907 Ericsson/Simon 1984, S. 16. Die Übersetzung mit «simultan» findet sich bei Konrad (2010, S. 481), von «prozessbegleitend[.]» sprechen z. B. Wallach/Wolf (2001, Titel). Zur Unterscheidung der beiden Formen auch: Konrad 2010, S. 476 f., S. 481; Someren et al. 1994 , S. $20 \mathrm{ff}$.

908 Zur Methode allgemein und zu deren Einsatz in der Unterrichtsforschung: Weidle/Wagner 1982 , S. 81 f., S. $91 \mathrm{ff}$.

909 Lenz/Talsnes 2014.

910 Ericsson/Simon 1984, S. 16; Ericsson/Simon 1980, S. 219, direktes Zitat ebd., Kursivsetzung analog zum Original.

911 Ericsson/Simon 1984, S. 16. 
rung in verbale Form encodiert werden muss. ${ }^{912}$ Von Level-3-Verbalisierung sprechen Ericsson und Simon dann, wenn die Aufgabenstellung es erfordert, dass die Teilnehmenden ausschliesslich Informationen einer bestimmten Art verbalisieren oder aber solche Informationen verbalisieren, die sich üblicherweise der Aufmerksamkeit entziehen würden. ${ }^{913}$ Level-3-Verbalisierung tritt dann ein, wenn die Verbalisierung durch gezielte Hinweise der forschenden Person thematisch gesteuert und in eine bestimmte Richtung gelenkt wird, während die Levels 1 und 2 freies Verbalisieren beinhalten. ${ }^{914}$

Für mein eigenes Forschungsvorhaben spielen lediglich Verbalisierungen der Ebenen 1 und 2 eine Rolle. ${ }^{915}$ Dies liegt in der Aufgabenstellung begründet, mit der die Studienteilnehmenden gebeten wurden, alles während des Ausstellungsbesuchs in den Sinn Kommende laut zu äussern, also keine Beschränkung auf bestimmte Themen gefordert wurde. Ebene 2 tritt dabei auf, wenn die Besuchenden Bilder, Filme oder überhaupt ästhetische Gestaltungsmittel wahrnehmen, und diese Wahrnehmung vor einer sprachlichen Äusserung zunächst encodieren müssen. Ebene 1 tritt hingegen im Fall der Rezeption von sprachlichem Material wie Ausstellungstexten oder Schriftquellen auf. Hier erfolgt die Wahrnehmung des Inhalts bereits in sprachlicher Form, kann somit ohne Encodierung verbalisiert werden. ${ }^{916}$

912 Ericsson/Simon 1984, S. 17.

913 Ericsson/Simon 1984, S. 17.

914 Konrad 2010, S. 479.

915 Ericsson und Simon bezeichnen Ebene 1 auch als «talk aloud», Ebene 2 als «think aloud» (Ericsson/Simon, S. 16f.). Sie verwenden den Begriff des Lauten Denkens also eigentlich im engeren Sinn für diejenigen Fälle, in denen nichtsprachliche Informationen zunächst in sprachliche Form encodiert werden müssen (Wallach/Wolf 2001, S. 16). In meiner Arbeit, darin Wallach und Wolf folgend (Wallach/Wolf 2001, S. 16), findet der Terminus des Lauten Denkens hingegen auch für Verbalisierungen der Ebene 1 Anwendung. Dies beruht zum einen auf der in dieser Hinsicht gebräuchlichen Begriffsverwendung in der aktuellen Forschungsliteratur, die keine Unterscheidung in «talk aloud» und «think aloud» vornimmt (so etwa bei Deffner 1984; van Someren et al. 1994; Wallach/Wolf 2001, S. 16; Konrad 2010; Buttkereit et al. 2014). Auch erscheint der von Ericsson/Simon gewählte Terminus «talk aloud» irreführend, da es in der Ebene 1 wie auch Ebene 2 nicht lediglich um Reden, sondern um die Versprachlichung von Gedächtnisinhalten geht.

916 Diese Zuordnung der verschiedenen Ausstellungselemente zu den beiden Verbalisierungsformen beruhen auf Buttkereit et al. 2014, S. 7. 


\subsubsection{Grenzen und Potenziale des Prozessbegleitenden Lauten Denkens als Erhebungsmethode}

Verwendet man die Methode des Lauten Denkens, so sind Überlegungen darüber sinnvoll, welche Art von Daten diese Erhebungsform zu generieren vermag und was zum Gegenstand von Äusserungen wird oder umgekehrt nicht. Lautes Denken als Erhebungsmethode besteht, wie bereits ausgeführt, darin, dass die Untersuchten beim Bearbeiten einer Aufgabe oder Bewältigen einer Situation parallel ihre Gedanken laut mitteilen. ${ }^{917}$ Es sind damit also zweierlei Anforderungen, die an die Versuchspersonen herangetragen werden: einerseits das Erledigen der gestellten Aufgabe, andererseits das zeitgleiche Verbalisieren. ${ }^{918}$

Ausgehend von diesen Grundbedingungen, stellt sich die Frage, ob und inwieweit erstens die Aufgabe des Verbalisierens möglicherweise Verhalten und Kognition beim Erledigen der Anforderungssituation beeinträchtigt, inwieweit die Verbalisierungen Rückschlüsse über die stattfindenden kognitiven Prozesse erlauben und welche Informationen überhaupt der Auftrag zur Verbalisierung zu generieren vermag. Someren et al. bezeichnen derartige Überlegungen als «verbalization theory». Es gehe darum, sich zu fragen: «What can we expect to find in the protocols», ${ }^{919}$ also "which information can be obtained directly from the protocols, which cannot be obtained at all and which can be obtained partially or indirectly». ${ }^{920}$

Eine Frage in diesem Zusammenhang lautet, inwiefern Lautes Denken Rückschlüsse auf «tatsächliches» Denken zulässt, also inwieweit es ein Abbild der zugrunde liegenden kognitiven Vorgänge liefert. In ihren Veröffentlichungen aus den Jahren 1980 und 1984 gehen Ericsson und Simon davon aus, dass bei Level-1und Level-2-Verbalisierungen ${ }^{921}$ die zeitliche Abfolge und Struktur der kognitiven Aktivitäten durch das Verbalisieren unbeeinflusst bleiben, wobei jedoch Lautes Denken mit Verbalisierungen der Ebene 2 die Aufgabenbearbeitung verlängert. ${ }^{922}$

917 Someren et al. 1994. S. 25.

918 Wallach/Wolf 2001, S. 12.

919 Someren et al. 1994, S. 123.

920 Someren et al. 1994, S. 118. Die beim Lauten Denken entstehenden Daten werden oft als Protokolle bezeichnet, so auch im Titel von Ericsson/Simon 1980 und 1984.

921 Da für meine Arbeit lediglich Verbalisierungen dieser Ebenen von Relevanz sind, beschränke ich die Darstellung nachfolgend auf diese und erörtere zugehörige Grenzen und Potenziale der Erhebungsmethode.

922 Ericsson/Simon 1980, S. 229; Ericsson/Simon 1984, S. 106. 
Klaus Konrad bemerkt, die Autoren würden «die durch die Verbalisierung auf Niveau 1 und 2 hervorgerufene Information als unmittelbare Repräsentation der kognitiven Prozesse des Kurzzeitgedächtnisses» betrachten. ${ }^{923}$

Dass Lautes Denken der Ebenen 1 und 2 als unmittelbares Abbild des «tatsächlichen» Denkens gelten könne und die Struktur des kognitiven Prozesses unbeeinflusst lasse, wird allerdings immer wieder infrage gestellt. Dieter Wallach und Christiane Wolf unterscheiden zwei Formen von Einwänden, die die «Non-Veridikalität» oder «Reaktivität» Lauten Denkens betreffen. ${ }^{924}$ Erstere bezeichnet «das nicht wahrheitsgetreue Berichten über den Denkprozess», also die nicht exakte Wiedergabe kognitiver Vorgänge, Zweitere bezieht sich darauf, «dass der Prozess, während dessen verbalisiert wird, sich durch die Verbalisierung ändert», etwa verlängert wird oder eine Störung erfährt.9 ${ }^{925}$

Im Bereich der Non-Veridikalität finden sich Befunde zum Beispiel bei Maarten W. Someren et al. Sie gehen davon aus, dass sich manche Gegenstände des Kurzzeitgedächtnisses einer Verbalisierung entziehen könnten, nämlich dass «information that resides in working memory for a very short time, that is difficult to verbalize because of complexity or because of its non-verbal character, may not appear in a protocol». ${ }^{926}$ Mindestens brauche das Arbeitsgedächtnis in diesem Fall zusätzliche Kapazität. ${ }^{927}$

Ausgehend davon, liegt - übertragen auf den Ausstellungsbesuch - die Vermutung nahe, dass bereits sprachlich codierte Informationen, die beispielsweise aus Ausstellungstexten stammen, möglicherweise leichter von den Teilnehmenden versprachlicht werden können, während die Versprachlichung von Informationen, die nichtsprachlich wahrgenommen werden, so etwa im Zusammenhang mit der sinnlichen Wahrnehmung von Objekten, Ästhetik der Ausstellung usw., grössere Mühe bereiten. Den Bereich der Non-Veridikalität betrifft ausserdem der bei Wallach und Wolf zu findende Hinweis, dass Lautes Denken «als Externalisierung

923 Konrad 2010, S. 479. Konrad bezieht sich dabei aber auf eine Neuausgabe von Ericsson/ Simon (Ericsson/Simon 1993), in deren Vorwort eine Relativierung dieser Annahmen formuliert ist (Ericsson/Simon 1993, S. xix. Der Hinweis auf diese Relativierung findet sich bei Wallach/Wolf 2001, S. 18 f.; vgl. hierzu auch die Ausführungen weiter unten).

924 Wallach/Wolf 2001, S. 17. Sie führen diese Unterscheidung auf Russo und Deffner zurück (Russo et al. 1989, zit. n. Wallach/Wolf 2001, S. 17; Deffner 1989, zit. n. Wallach/Wolf 2011, S. 17).

925 Wallach/Wolf 2001, S. 17.

926 Someren et al. 1994, S. 122.

927 Someren et al. 1994, S. 33. 
deklarativen Wissens» betrachtet werden kann, während prozedurales Wissen nicht unmittelbar beobachtet werden kann. ${ }^{928}$

Einschätzungen der Veridikalität Lauten Denkens stehen vor der Herausforderung, «tatsächliche» kognitive Prozesse bestimmen und sie anschliessend mit Verbalisierungen abgleichen zu müssen. Gerhard Deffner wählte zu diesem Zweck zweierlei Zugangsweisen. ${ }^{929}$ Mit seiner Arbeit verfolgt er das Ziel, die Annahmen Ericssons und Simons über den Zusammenhang von lautem und stillem Denken zu prüfen. ${ }^{930}$ Er tut dies zum einen unter der Formel «Einbeziehung des Subjekts», indem er Personen, die zuvor beim Lösen einer Aufgabe selbst Lautes Denken praktiziert hatten, im Rahmen von Einzel- und Gruppengesprächen über das Verhältnis von eben diesem lauten und stillen Denken nachdenken lässt. ${ }^{931}$ Zweitens sucht Deffner den «Zugang zum Denken mit den Mitteln der Experimentalpsychologie», indem er Lautes Denken mit aufgezeichneten Blickbewegungen vergleicht und Letztere als Ausdruck des eigentlichen Denkens fasst, ausgehend von der Annahme, «dass jeweils solche Stellen des Sichtfeldes angeblickt werden, an denen Information aufgenommen werden kann, die für den augenblicklichen Ablauf der Informationsverarbeitung erforderlich ist». ${ }^{932}$

Aus den Einzel- und Gruppengesprächen mit den betroffenen Probanden folgert Deffner Diskrepanzen. So sei Lautes Denken «weniger vielschichtig und umfangreich», führe gleichzeitig «zu mehr Denkaufwand», habe eine erhöhte Konzentration, Sorgfalt und Strukturiertheit bei der Aufgabenbearbeitung zur Folge, gelinge besser mit zunehmender Übung und sei unangenehm in Gegenwart anderer. ${ }^{933}$ Die Blickbewegungsaufzeichnungen Deffners ergaben demgegenüber eine «hohe Übereinstimmung der in Verbalisierungen erwähnten Teile von Aufgabenvorlagen und den durch die Blickrichtung indizierten Inhalten des Kurzzeitgedächtnisses», verbunden mit «einer geringen zeitlichen Verschiebung», sie ergaben zudem eine Übereinstimmung zwischen Blickbewegungen und den mittels Lauten Denkens geäusserten Strategien der Aufgabenbearbeitung. ${ }^{934}$ Die Aufgabenbearbeitung dauere bei Lautem Denken «wesentlich länger als die stille Bear-

928 Wallach/Wolf 2001, S. 11.

929 Deffner 1984, S. 3.

930 Deffner 1984, S. 29 ff., insb. S. $33 \mathrm{ff}$.

931 Deffner 1984, S. 3, S. $11 \mathrm{ff}$., insb. S. 15 ff., direktes Zitat S. 3.

932 Deffner 1984, S. 3, S. 37 ff., direkte Zitate S. 3 und 37.

933 Deffner 1984, S. 20 ff., direkte Zitate S. 20 und S. 21.

934 Deffner 1984, S. 143. 
beitung», jedoch beeinflusse Lautes Denken nicht die Qualität des Ergebnisses. ${ }^{935}$ Zusammenfassend, kommt Deffner zu dem Ergebnis, dass kaum Indizien gegen die Gültigkeit der Annahmen von Ericsson und Simon sprächen. ${ }^{936}$ Lautes Denken als Erhebungsinstrument erfülle «wesentliche Anforderungen in Bezug auf a) die Erfassung des zu Messenden und b) die möglichst unverzerrte Wiedergabe des zu Messenden». ${ }^{937}$

Einige Befunde Deffners berühren bereits den zweiten Bereich an Einwänden, die die Reaktivität Lauten Denkens betreffen, also Veränderungen der zugrunde liegenden kognitiven Prozesse durch die Aufgabe des Lauten Denkens. ${ }^{938}$ Auch Someren et al. gehen davon aus, dass kognitive Prozesse eine längere Zeit in Anspruch nehmen, wenn gleichzeitig Lautes Denken praktiziert wird. ${ }^{939}$ Sofern die kognitiven Prozesse trotzdem in ihrer üblichen Geschwindigkeit ablaufen, drohe hingegen eine unvollständige Verbalisierung, da in diesem Fall nach Bericht von Teilnehmenden das Tempo der Verbalisierung nicht mit den kognitiven Prozessen mithalten könne. ${ }^{940}$ So stellen auch Renate Weidle und Angelika C. Wagner fest: «Manche Kognitionen, Bilder und Gefühle scheinen fast gleichzeitig aufzutauchen, so dass man notwendigerweise auswählen muß, um darüber zu berichten, und während ein Gedanke ausgesprochen wird, gehen manche andere Kognitionen schon wieder verloren.» ${ }^{941}$

Neben einer Verlangsamung in der Bearbeitung der zugrunde liegenden Aufgabe können im Bereich der Reaktivität zudem Verlaufsveränderungen eintreten, etwa das längere Beibehalten von Strategien. ${ }^{942}$ Zusammenfassend, finden sich Wallach und Wolf zufolge etliche «ernstzunehmende empirische Hinweise auf eine Reaktivität Lauten Denkens», die Anlass zu einer Relativierung der ursprünglichen Annahmen von Ericsson und Simon gäben. ${ }^{943}$ So äussern diese in der neueren Ausgabe ihres Bandes «Protocol Analysis» aus dem Jahr 1993:

935 Deffner 1984, S. 143 f.

936 Deffner 1984, S. 147.

937 Deffner 1984, S. 148.

938 Wallach/Wolf 2001, S. 17.

939 Someren et al. 1994, S. 33.

940 Someren et al. 1994, S. 33.

941 Weidle/Wagner 1982, S. 84.

942 Dieses wurde gemäss Wallach/Wolf von Deffner festgestellt (Deffner 1989, zit. n. Wallach/Wolf 2001, S. 19).

943 Wallach/Wolf 2001, S. 18f., direktes Zitat S. 18. Den Hinweis auf die nachfolgend zitierte Passage von Ericsson/Simon habe ich Wallach/Wolf entnommen (Wallach/Wolf, S. 19). 
«In our earlier review $[\ldots]$ we found that instructions to verbalize influenced the end state of the cognitive process (accuracy of the responses) only in the case of Type 3 verbalization, or in cases where subjects were pushed to maintain a very high rate of verbalization, as in rehearsing aloud while learning lists. However since the publication of our paper in Psychological Review several investigators have designed experiments to show that thinking aloud can influence and change the cognitive processes even with Type 1 or Type 2 verbalization.» ${ }^{944}$

Die empirischen Befunde und damit verbundenen Einschätzungen der Qualität Lauten Denkens sind durchaus weit gestreut und auch widersprüchlich, ${ }^{945}$ wobei es möglicherweise auch den Aufgabentyp als Einflussfaktor in Betracht zu ziehen gilt. ${ }^{946}$ Unterschiede in der Performanz des Lauten Denkens können weiter auch in den Fähigkeiten der teilnehmenden Versuchspersonen begründet sein. So spricht Dörte Saaman im Fall des Problemlösens von «eine[r] Differenzierung zwischen 〈guten〉 und «schlechten〉 Laut-Denkern» und meint im ersten Fall Versuchspersonen, die «wissensdiagnostisch gehaltvollere» Daten produzieren, also die nicht nur problem- und selbstbezogene Aussagen machten, sondern auch metakognitive Aussagen, welche Forschenden «einen höheren Aufschlussgewinn über das Lösungsvorgehen» ermöglichten. ${ }^{947}$

In Saamans Fall besteht somit bereits vor der Datenanalyse eine Vorstellung davon, was aufschlussreiche oder weniger aufschlussreiche Daten sind, und ausgehend davon das Bestreben, die entsprechenden Personen bereits im Vorfeld einer Studie mittels Persönlichkeitstests zu identifizieren. ${ }^{948}$ Für meine eigene Studie gilt dieses Bestreben nicht. Aufgrund des induktiven, kategoriengenerierenden Vor-

944 Ericsson/Simon 1993, S. xix.

945 Wallach/Wolf 2001, S. 18f; Bannert 2007, S. 137 f.

946 Wallach/Wolf nennen eine Reihe von Studien, die dies nahelegen (Wallach/Wolf 2001, S. 19). Ein Grossteil der im aktuellen Kapitel zitierten Studien basiert auf Experimenten, bei denen die Teilnehmenden Aufgaben gestellt bekommen und während der Bearbeitung laut denken. Im Zentrum des Forschungsinteresses steht dann der Prozess der Aufgabenbearbeitung. Die gestellten Aufgaben können dabei durchaus unterschiedlich sein. So beziehen sich Someren et al. mit ihren Einschätzungen auf eine Studie, im Rahmen deren das Verhalten von Architekten beim Bearbeiten einer gestellten Planungsaufgabe untersucht worden sei (Someren et al. 1994, S. 2, sich beziehend auf eine Studie von Hamel [Hamel 1990, zit. n. Someren et al. 1994, S. 2]). Die Teilnehmenden in einer Studie von Saaman lösten hingegen Analogieaufgaben sowie das Knobelspiel «Turm von Hanoi» (Saamann 2001, S. 129). Zu den Aufgaben bei Deffner siehe ausserdem: Deffner 1984, S. 50 ff.

947 Saamann 2001, S. 125, S. 128 f., S. 135, direkte Zitate S. 125 u. S. 135.

948 Saamann 2001, S. 125. 
gehens werden zunächst alle entstehenden Daten als prinzipiell gleichwertig angesehen, es ist somit kein Vorverständnis über gehaltvolle oder weniger gehaltvolle Elemente leitend. Weiterführend ist gleichwohl die durch Saamann angeregte Annahme, dass die später bei der Analyse festgestellten Unterschiede in der Performanz Lauten Denkens in der Person der Teilnehmenden begründet sein können.

Sowohl eine persönlichkeitsbezogene Performanz als auch eine mögliche und nicht abschliessend zu ergründende Diskrepanz zwischen verbalen Äusserungen und ablaufenden kognitiven Prozessen stellen Bedingungen dar, die nicht spezifisch für Lautes Denken gelten, sondern generell für alle Formen der Datenerhebung, die es mit verbalen oder schriftlichen Äusserungen der beforschten Subjekte zu tun haben. In all diesen Fällen gilt, dass es die entstandenen verbalen Daten sind, anhand deren die Forschungsfrage bearbeitet werden kann, nicht das Denken der beforschten Subjekte selbst. ${ }^{949}$ Auf der Ebene dieser Bedingungen ist Lautes Denken ein Erhebungsinstrument von ähnlicher Qualität, wie es beispielsweise Interviews oder Gruppendiskussionen darstellen. Auch prozessbezogene Methoden können nicht, so stellt Andreas Körber spezifisch auf historisches Denken bezogen fest, «die mentale Operation des historischen Denkens selbst erfassen, sondern zunächst lediglich die in ihrem Verlauf stattfindenden Verhaltensweisen dokumentieren: körperliche Reaktionen sowie verbale und nonverbale kommunikative Äusserungen». ${ }^{950}$

Es kann also nicht darum gehen, die genannten Einschränkungen auszuschalten, sondern vielmehr bewusst zu machen und zu reflektieren. Hierzu gehört auch die Einsicht, dass beim Lauten Denken, ähnlich wie bei anderen Formen der verbalen Datenerhebung, Verbalisierungen abhängig davon sind, was die Teilnehmenden überhaupt versprachlichen wollen und können. Lautes Denken liefert lediglich einen «Ausschnitt intermediärer, bewusstseinsfähiger Produkte des Denkens», ${ }^{951}$ das Feld unbewusster kognitiver Vorgänge entzieht sich hingegen einer expliziten Verbalisierung. ${ }^{952}$

949 So etwa Huber/Mandl in Bezug auf die Erforschung von handlungsleitenden Kognitionen: «Verbalisation einer befragten Person erschliesst der fragenden Person nicht die Gedanken selbst, die der/dem Befragten im Handlungszusammenhang durch den Kopf gingen, sondern ist nur Rede über Kognitionen, aus der erst wieder Schlüsse gezogen werden müssen» (Huber/Mandl 1982, S. 20).

950 Körber 2006, S. $191 \mathrm{f}$.

951 Wallach/Wolf 2001, S. 14.

952 Zur Frage der Bewusstheit: Konrad 2010, S. 486; Weidle/Wagner 1982, S. 83. 
Lautes Denken bleibt also zwangsläufig unvollständig. Doch: «Incompleteness of reports may make some information unavailable, but it does not invalidate the information that is present.» ${ }^{953}$ Der Wert Lauten Denkens besteht vielmehr darin, dass es Zugang zu Informationen ermöglicht, «die anders nicht erhoben werden könnten». ${ }^{94}$ So generiert es prozessbezogene Einblicke in Strategien und Informationsverarbeitung im Verlauf einer Aufgabenbearbeitung oder einer Situationsbewältigung. ${ }^{955}$

Lautes Denken liefert dabei sogar mehr, als der Begriff des Denkens zunächst nahelegt. "Strenggenommen ist die Bezeichnung «Lautes Denken» nicht vollständig zutreffend, da neben Produkten des Denkens auch Wahrnehmungen, Gefühle, Empfindungen und Gedanken über das eigene Denken und Handeln (Metakognitionen) verbalisiert werden» - dies, obwohl die Methode keine explizite Aufforderung zur Reflexion über die eigenen Gedanken beinhaltet. ${ }^{956}$ Ähnlich schätzen auch Weidle und Wagner das Potenzial Lauten Denkens breiter ein, als der Terminus zunächst vermuten lässt, ihnen zufolge sprechen laut Denkende

«oft nicht nur ihre Gedanken laut aus, sondern berichten auch über ihre Wahrnehmungen ( (ich sehe gerade ...〉) und Gefüble oder Empfindungen (〈jetzt ärgere ich mich ... >). Hinzu kommt, dass sie oft ihre eigenen Gedanken und ihr Verhalten kommentieren [...]. Genau genommen handelt es sich also bei der Methode des Lauten Denkens um die Aufforderung an die Befragten, das, was ihnen von den ablaufenden kognitiven Prozessen bewusst ist, auszusprechen.» ${ }^{957}$

Ich fasse zum Abschluss des Abschnitts die Potenziale und Grenzen Lauten Denkens zusammen. Die Grenzen Lauten Denkens liegen in folgenden Bereichen:

953 Ericsson/Simon 1980, S. 243.

954 Konrad 2010, S. 481.

955 Konrad 2010, S. 485 f.

956 Wallach/Wolf 2001, S. 9.

957 Weidle/Wagner 1982, S. 82, Kursivsetzungen analog zum Original. 
- Lautes Denken gibt möglicherweise keine exakten Hinweise auf die Inhalte des Kurzzeitgedächtnisses ( Non-Veridikalität» ${ }^{958}$ ). So gelingt möglicherweise

- die Verbalisierung bereits sprachlich codierter Informationen besser als diejenige nichtsprachlicher oder sehr komplexer Informationen, 959

- die Verbalisierung deklarativen Wissens besser als diejenige prozeduralen Wissens, ${ }^{960}$

- die Verbalisierung generell unvollständig, sofern die zugrunde liegenden kognitiven Prozesse sehr schnell ablaufen, ${ }^{961}$ und

- die Verbalisierung unterschiedlich je nach Fähigkeit der Probandinnen und Probanden. ${ }^{962}$

- Lautes Denken kann überhaupt nur Einblicke in bewusste kognitive Vorgänge geben, während sich unbewusste einer Erhebung entziehen. ${ }^{963}$

- Lautes Denken führt möglicherweise zu einer Veränderung der Situationsbewältigung im Vergleich mit stillem Denken ( «Reaktivität» ${ }^{964}$ ). So wird möglicherweise

- die Aufgabe langsamer bearbeitet ${ }^{965}$ und

- die Struktur der Aufgabenbearbeitung durch Lautes Denken verändert. ${ }^{966}$

Die Potenziale Lauten Denkens liegen demgegenüber in folgenden Bereichen:

- Lautes Denken vermag trotz Berücksichtigung der oben angeführten Einwände Einblicke in Inhalte des Kurzzeitgedächtnisses zu gewähren. ${ }^{967}$

- Das Potenzial Lauten Denkens liegt dabei, im Vergleich zu anderen Erhebungsformen, in seiner Prozessbezogenheit, es rückt die unmittelbar auftretenden kognitiven Vorgänge ins Blickfeld. ${ }^{968}$

- Lautes Denken ist geeignet, um nicht nur Denken im engeren Sinn, sondern daneben auch Wahrnehmungen, Emotionen und Metakognitionen zur Sprache zu bringen. ${ }^{969}$

958 Wallach/Wolf 2001, S. 17.

959 Someren et al. 1994, S. 122.

960 Wallach/Wolf 2001, S. 11.

961 Weidle/Wagner 1982, S. 84; Someren et al. 1994, S. 33.

962 Saamann 2001, S. 125, S. 128 f., S. 135.

963 Weidle/Wagner 1982, S. 83; Wallach/Wolf 2001, S. 14; Konrad 2010, S. 486.

964 Wallach/Wolf 2001, S. 17.

965 Deffner 1984, S. 143.

966 Deffner 1984, S. 143; Deffner 1989, zit. n. Wallach/Wolf 2001, S. 19; Ericsson/Simon 1993, S. xix; Wallach/Wolf 2001, S. $18 \mathrm{f}$.

967 Deffner 1984, S. 143, S. 148.

968 Konrad 2010, S. 477, S. 482 ff.

969 Weidle/Wagner 1982, S. 82; Wallach/Wolf 2001, S. 9. 


\subsubsection{Einsatzfelder Lauten Denkens}

Ich skizziere in loser und beispielhafter Folge einige Einsatzfelder, im Rahmen deren Lautes Denken bislang in Geschichtsdidaktik und Erziehungswissenschaft mit Pädagogischer Psychologie eingesetzt wird, um das mögliche Verwendungsspektrum in einigen mit meiner Arbeit verwandten Feldern aufzuzeigen. Wallach und Wolf verweisen etwa auf die Bedeutung Lauten Denkens als Methode in der Wissensdiagnostik, und zwar für diejenigen Fälle, in denen nicht statusdiagnostisch Wissen zu einem spezifischen Zeitpunkt erhoben werden solle, sondern vielmehr prozessdiagnostisch die «Rekonstruktion einer Trajektorie von Wissenszuständen eines Probanden über aufeinanderfolgende Zeitpunkte» angestrebt wird. ${ }^{970}$

Ein weiteres Verwendungsfeld Lauten Denkens stellen Forschungen zu Metakognitionen dar. Maria Bannert erforschte etwa «Metakognition beim Lernen mit Hypermedien». ${ }^{971}$ Die Instruktion beinhaltet in diesem Fall, «über die eigenen Lernprozesse nachzudenken, und aktiviert hierdurch sein [des Probanden, Anm. d. Verf.] Repertoire an verfügbarem metakognitivem Wissen sowie metakognitiven Kontrollprozessen, welche das Lernen insgesamt fördern sollen». ${ }^{972} \mathrm{Im}$ Zentrum des Interesses stehen bei dieser Forschung - im Gegensatz etwa zu meinem eigenen Projekt - lediglich Verbalisierungen der Ebene 3, also solche Verbalisierungen, die auf Aufforderung hin lediglich bestimmte Inhalte des Kurzzeitgedächtnisses versprachlichen, was Bannert zufolge dem Forschungsinteresse an Metakognitionen geschuldet ist. ${ }^{973}$ Ebenfalls mit Metakognitionen, nämlich selbstregulativen Lernstrategien, befasste sich Klaus Konrad, der unter Rückgriff auf «das Laute Denken im Partnergespräch» «kooperatives Lernen bei Studierenden» erforscht. ${ }^{974}$

Eine dem Lauten Denken verwandte Methode kommt in der Dissertation von Jan Hodel zum Einsatz, in der er sich für die Verwendung digitaler Netzmedien durch Schülerinnen und Schüler bei der Erstellung von Referaten interessiert und hierfür ein als «Teachback» bezeichnetes Verfahren einsetzt, wobei die Schülerinnen und Schüler eine Recherche im Internet durchführen und dabei der beobachtenden Person ihr Vorgehen erklären. ${ }^{975}$

970 Wallach/Wolf 2001, S. 10 f., direktes Zitat S. 11, Bezug nehmend auf eine Unterscheidung in status- und prozessdiagnostische Verfahren bei Tergan 1988.

971 Bannert 2007.

972 Bannert 2007, S. 136.

973 Bannert 2007, S. 136.

974 Konrad 1998, S. 25 ff., direkte Zitate S. 25 und S. 28.

975 Hodel 2013, zur Datenerhebung: S. 154 ff.; zur Methode: Wallach/Wolf 2011, S. 25. 
Renate Weidle und Angelika C. Wagner beschreiben insbesondere das Nachträgliche Laute Denken als Möglichkeit, um «herauszufinden, welche Kognitionen das Handeln von Lehrern und Schülern steuern», und «Handlungspläne und -strategien» aufzudecken. ${ }^{976}$ So werden dazu Schülern und Schülerinnen sowie Lehrpersonen videografierte Unterrichtslektionen vorgespielt, bei deren Betrachtung sie ihre Gedanken rekonstruieren sollen. ${ }^{977}$

Innerhalb der deutschsprachigen Geschichtsdidaktik kam Lautes Denken bislang einerseits in dieser retrospektiven Form zum Einsatz. ${ }^{978}$ Mit Prozessbegleitendem Lautem Denken arbeitete hingegen Katharina Litten, um das Planungsverhalten von Geschichtslehrpersonen bei der Vorbereitung einer Geschichtslektion zu erforschen. ${ }^{979}$ Ebenfalls setzte Manfred Seidenfuss Lautes Denken für die Beforschung der Unterrichtsplanung bei Geschichtslehrpersonen ein..$^{980}$

Dezidiert zur Erfassung historischen Denkens dient (Nachträgliches) Lautes Denken in Studien von Andreas Körber, Sam Wineburg sowie Claudia Lenz und Anne Talsnes. Körber untersuchte historisches Denken von Schülerinnen und Schülern in Geschichtslektionen und ging dazu ähnlich vor wie Weidle und Wagner; die Teilnehmenden wurden nämlich beim anschliessenden Betrachten von videografierten Unterrichtslektionen aufgefordert, die Lektionen «laut denkend» zu kommentieren und den Fokus dabei darauf zu legen, was ihnen in der jeweils gezeigten Unterrichtssituation durch den Kopf gegangen sei». ${ }^{981}$

Auch Lenz und Talsnes arbeiten mit nachträglicher Verbalisierung. Sie bezeichnen ihre Methode als «stimulated recall», ${ }^{92}$ sehen den Kern der Methode dabei allerdings weniger im nachträglichen Rekonstruieren von Gedanken, sondern vielmehr im Reflektieren über eine vorausgegangene Lehr- oder Lernsituation, der durch einen Stimulus ausgelöst wird. ${ }^{983}$ So wurde die Methode unter anderem mit Schülerinnen und Schülern als Besuchende des HL Centers in Oslo

976 Wagner/Weidle 1982, S. 91.

977 Wagner/Weidle 1982, S. 81 f., S. 91 ff. Ein ähnlicher methodischer Zugang in Bezug auf Sportlehrpersonen findet sich bei Messmer 2015.

978 Den Einsatz von Stimulated Recall erwähnt Monika Fenn, allerdings ohne weitere methodische Einordnung der mit dem Einsatz von Stimulated Recall verbundenen Absichten (Fenn 2015, S. 521).

979 Litten 2017, insb. S. 169 f., 179 ff.; Litten 2013, S. 84, S. 87.

980 Seidenfuss 2002, insb. S. $64 \mathrm{f}$.

981 Körber 2006, S. 199; Kursivsetzung analog zum Original.

982 Lenz/Talsnes 2014.

983 Lenz/Talsnes 2014, S. 97, S. 113. 
angewendet. ${ }^{984}$ Vor dem Besuch wurden sie aufgefordert, ihre Erwartungen auf Kärtchen festzuhalten, und selbige dienten im Anschluss als Gesprächsanreiz, um über den Grad der Erfüllung bzw. Nichterfüllung von Erwartungen beim Besuch zu reflektieren. ${ }^{985}$

Dabei stellen die Autorinnen Elemente historischen Denkens fest, nämlich könne die Herangehensweise, «itself boost narrative competence», ${ }^{986}$ wobei die Autorinnen offenbar «narrativity» synonym mit «reconstruction» bzw. Rekonstruktionskompetenz gebrauchen. ${ }^{987}$ Die Autorinnen schätzen die Methode aber generell als geeignet ein für alle Forschungsvorhaben, in denen es um die Erhebung historischen Denkens geht.

«[I]t is this narrative approach and focus on reflection as regards one's own assumptions and opinion-forming processes that makes the method particularly well suited to the type of history teaching which is located within the theoretical and didactic framework of historical thinking, historical consciousness and historical use.»988

Im Bereich der Erforschung historischen Denkens sind weiter die bereits erwähnten Arbeiten Samuel Wineburgs relevant, der beispielsweise Historikerinnen und Historiker, Schülerinnen und Schüler mit einem Set aus Textquellen und Gemälden zur Schlacht von Lexington konfrontierte und sie aufforderte, diese zu lesen bzw. zu betrachten und dabei mittels Lauten Denkens zu kommentieren und einzuschätzen, ${ }^{989}$ um Folgendes herauszufinden:

«(a) How do people construct an understanding of historical events from a group of fragmented and contradictory documents? (b) What heuristics or rules of thumb help individuals fill in the gaps left by such documents? (c) What beliefs do people hold about history that help or hinder their ability to make sense of historical evidence?» ${ }^{990}$

984 Lenz/Talsnes 2014, S. $99 \mathrm{ff}$.

985 Lenz/Talsnes 2014, S. 99.

986 Lenz/Talsnes 2014, S. 114.

987 Lenz/Talsnes 2014, S. 98 f., direkte Zitate S. 99.

988 Lenz/Talsnes 2014, S. 114.

989 Wineburg 1991, S. 74 f. Eine jüngere Beschreibung des Projekts findet sich auch bei Wineburg 2001, S. $64 \mathrm{ff}$.

990 Wineburg 1991, S. 74. 
Wineburg kommt dabei zu sowohl inhaltlich als auch methodologisch aufschlussreichen Befunden in Bezug auf Strukturen des Problemlösens im Fach Geschichte. Er ordnet seine Forschungsarbeiten zwar der Problemlöseforschung zu, im Bereich deren er für das Fach Geschichte ein Forschungsdesiderat ausmacht, ${ }^{991}$ sensibilisiert aber gleichzeitig dafür, dass Problemlöseprozesse durchaus disziplinär bedingte Charakteristika aufweisen können, konkret, dass der Terminus «problem solving» im Fall von Geschichte eine spezifische Prägung hat, gar den Gegenstandbereich historischen Arbeitens nur unzureichend fassen könne:

«Historical inquiry differs considerably from problem solving in well-structured domains. For example, in domains such as geometry or physics, goals are given to individuals, who then transform problems to arrive at solutions. But in history, goals remain vague and indefinite, open to a great deal of personal interpretation.» ${ }^{992}$

«There is no sproblem isomorph〉 for the Battle of Lexington; what happened on that April morning was a unique combination of circumstances and conditions that will never be repeated. Certainly, many schemata were activated by historians in the course of reading these documents. But the activation of schemata did not lead to the type of automatic, schema-driven processing described in the literature on physics problem solving. To be able to reason thoughtfully about the accuracy of these documents, historians needed to build - node by node - an elaborate model of this event.» ${ }^{993}$

Wineburg macht zudem deutlich, dass für diesen kreativen, konstruktiven Prozess des Bedeutung-Generierens nicht zwingend umfangreiches Hintergrundwissen zum behandelten Gegenstand erforderlich ist. ${ }^{994}$

991 Wineburg 1991, S. 73.

992 Wineburg 1991, S. 73 f.; zur Erläuterung dieses Unterschieds auch Wineburg 1998, S. $319 \mathrm{f}$.

993 Wineburg 1991, S. 83, Kursivsetzung analog zum Original.

994 Wineburg 1991, S. 84; ausserdem: Wineburg 2001, S. 66. Dies leitet Wineburg nicht nur aus dem geschilderten Vergleich aus dem Jahr $1991 \mathrm{ab}$, sondern auch aus einer kleineren, im Jahr 1998 publizierten Studie, im Rahmen deren er zwei Historiker mit sieben Textquellen von und über Abraham Lincoln konfrontierte, wobei einer der beiden Historiker als Experte für Abraham Lincoln und die Zeit des Amerikanischen Bürgerkriegs ausgewählt wurde, der zweite Historiker zwar mit der amerikanischen Geschichte, jedoch nicht spezifisch mit dieser Periode professionell befasst war (Wineburg 1998, S. $321 \mathrm{ff}$.). Auch in 


\subsubsection{Lautes Denken beim Besuch einer historischen Ausstellung. Begründung der Methodenwahl und Potenziale im Hinblick auf den Forschungsgegenstand}

Auch der Besuch einer Ausstellung lässt sich mit einem solchen erweiterten Begriffsverständnis als Problemlöseprozess begreifen. Beim Ausstellungsbesuch bewegen sich die Teilnehmenden in einer dreidimensionalen Struktur mit einer Vielzahl an darin befindlichen Elementen, müssen selbstständig ihren Weg durch diese finden. Sie werden konfrontiert mit einem reichhaltigen Sortiment an Texten, Bildern, dreidimensionalen Objekten, ästhetischen Gestaltungs- und weiteren Elementen, die sie zur Kenntnis nehmen können, aber nicht müssen. Welche Gedanken sind dabei leitend? Welche Elemente wecken ihre Aufmerksamkeit und wie, welche wiederum nicht? Welche Assoziationen löst die Ausstellung aus? Wie deuten Besuchende das Gesehene, wie bringen sie die einzelnen Elemente in einen Zusammenhang untereinander und mit sich selbst, mit der eigenen Gegenwart? Welche Bedeutung messen sie dem Gesehenen bei? ${ }^{995}$ Um solche Fragen zu klären, halte ich Lautes Denken für eine geeignete Erhebungsmethode, gibt es doch Einblicke, die anderen gebräuchlichen Methoden verwehrt bleiben. ${ }^{996}$

Das grösste Potenzial ${ }^{997}$ Lauten Denkens liegt in seiner unmittelbaren Ausstellungsbezogenheit. Eindücklich beleuchtet wird dieses Potenzial bei Wise. ${ }^{998}$ Die Methode gewähre, so Wise, «an opportunity to ride along with visitors as they

dieser Studie sollten die Probanden die Quellen lesen und dabei laut denken, hierbei zu verstehen versuchen, welche Perspektive die Dokumente auf "Lincoln's views on race» einnehmen (ebd., S. 323). Wineburg verfolgte mit dieser Studie das Ziel, unterschiedliche Formen von Expertise herauszuarbeiten, abhängig vom «level of factual and conceptual knowledge brought to the task» (ebd., S. 321). Im Vergleich zwischen beiden Teilnehmern kommt Wineburg zu dem Ergebnis, dass der thematisch spezialisierte Historiker mehr Assoziationen, deklaratives Wissen und sogar vorgefertigt scheinende Interpretationen in den Deutungsprozess einbrachte (ebd., S. 335 f.). Nichtsdestotrotz sei auch dem zweiten Teilnehmer gelungen, was Wineburg als «at the heart of historical expertise» bezeichnet, nämlich «creating a context to explain this diverse collections of texts» (ebd., S. 337). Wineburg fasst das beobachtete Verstehen zusammen als «dialectical process between the questions he asks and the textual materials he encountered», in dem also im Vergleich zu anderen Konzeptionen von «Expert problem-solving» Wissen nicht unbedingt Voraussetzung des Problemlösens ist (ebd., S. 337).

995 Ähnliche Fragen sind auch formuliert in Thyroff 2017c, S. 3.

996 Vgl. hierzu die Ausführungen in Kapitel 5 sowie Wise 2011, S. 11 ff., S. $20 \mathrm{ff}$.

997 Die nachfolgend aufgeführten Potenziale Lauten Denkens für meinen Forschungsgegenstand habe ich auch bereits knapp zusammengestellt in Thyroff 2017 c, S. 3.

998 Wise 2011, S. $20 \mathrm{ff}$. 
interact with the exhibition environment». ${ }^{999}$ Sie erlaube, «to hear what visitors were thinking in real time as well as to observe [...] how their thinking interacts with the objects on display in the gallery space». ${ }^{1000}$ Damit wird es möglich, einen direkten Bezug zwischen den gemachten Äusserungen und der Ausstellung bzw. den darin befindlichen Elementen herzustellen.

Für mein Forschungsvorhaben ist diese unmittelbare Ausstellungsbezogenheit des Denkens von grosser Relevanz, gilt doch die Ausstellung hier ganz dezidiert als möglicher Auslöser von Gedanken, mindestens aber als der «physical context» ${ }^{1001}$ derselben. Wie sie das tut, welche Elemente dabei eine massgebliche Rolle spielen, kann mittels Lauten Denkens erfasst werden. Um dieses Potenzial Lauten Denkens für den Ausstellungsbesuch ausschöpfen zu können, haben sich allerdings die ergänzend zum Lauten Denken erstellten Videoaufnahmen als von eminenter Wichtigkeit erwiesen. Vor allem mit deren Hilfe und nicht allein aufgrund des Lauten Denkens konnten die geäusserten Assoziationen im Nachhinein in der vorgegebenen räumlichen Struktur der Ausstellung, den darin befindlichen Exponaten, Texten usw. verortet werden. ${ }^{1002}$

Eng mit der Ausstellungsbezogenheit verbunden ist die Prozessbezogenheit Lauten Denkens. Es trägt der bereits einmal zitierten Forderung Andreas Körbers Rechnung, dass empirische Forschung zum historischen Denken notwendig auch «Prozesse des historischen Denkens in actu in den Blick nehmen» müsse, so etwa «Tonband- und Videoaufzeichnungen von Prozessen, in denen solches Denken stattfindet». ${ }^{1003}$ Das bedeutet noch nicht zwingend, dass dabei auch Abfolgen aus Denkoperationen in den Blick genommen werden wüssen, auch wenn sich angesichts der - wohlgemerkt idealtypisch gemeinten - Zirkel- bzw. Spiralförmigkeit theoretischer Konzeptionen historischen Denkens und Lernens ${ }^{1004}$ mittelfristig

999 Wise 2011, S. 10.

1000 Wise 2011, S. 21.

1001 Falk/Dierking 2000, S. 53.

1002 Ergänzende Videoaufnahmen kommen auch in der Studie von Wise zum Einsatz (Wise 2011). Eine mögliche Alternative zu Videoaufnahmen findet sich bei Thoma. Dort wurden die Besuchenden von einer «stumme[n] Gesprächspartnerin» begleitet, die parallel notierte, über welche Exponate die Besuchenden sprachen (Thoma 2009, S. 91). Allerdings schildert Thoma trotz der Notizen Schwierigkeiten, bei der Analyse die gemachten Äusserungen eindeutig Exponaten zuzuordnen, und erklärt ausgehend davon den Einsatz von Videoaufnahmen für sinnvoll (Thoma 2009, S. 192 ff.). Zudem gilt es zu bedenken, dass die Anwesenheit einer weiteren Person den Charakter der Erhebungssituation verändert und sich Videoaufnahmen auch aus diesem Grund empfehlen.

1003 Körber 2006, S. 191.

1004 Rüsen 1983; Hasberg/Körber 2003; Körber et al. 2007; Drie/Boxtel 2008; Gautschi 2009a. 
einmal auch solche Zugänge für empirische Forschung zum Thema empfehlen, etwa um herauszufinden, ob bestimmte Operationen grundsätzlich aufeinanderfolgend oder in Zusammenhang zueinander eintreten oder ob sie umgekehrt vereinzelt und punktuell auftauchen.

Im Rahmen meines Projekts stehen allerdings die Abfolgen selbst nicht im Zentrum des Interesses. Vielmehr interessieren Elemente und inhaltliche Strukturen des Geäusserten. Es geht also, wie von Katharina Litten für ihr eigenes Forschungsprojekt festgestellt, auch wenn mit prozessorientierter Methodik gearbeitet wird, weniger um «die Repräsentation der kognitiven Prozesse als vielmehr um die Erfassung der Inhalte des Denkens und der gedanklichen Organisation dieser Inhalte». ${ }^{1005}$

Ein weiteres Potenzial Lauten Denkens liegt darin, dass es den Ausstellungsbesuch allein ohne Anwesenheit der Untersuchungsleiterin ermöglicht, wie ebenfalls bereits bei Susie Wise dargelegt: «Unlike the other techniques for gathering verbal data, there are no interruptions or suggestive prompts or questions as the subject is encouraged to give a concurrent account of his thougths.» ${ }^{1006}$ Lautes Denken erlaube, so Wise, den Besuchenden, «to explore and in essence to create their own prompts», ${ }^{1007}$ und fördert dabei Gedanken zutage, die in einem Interview möglicherweise gar nicht zur Sprache kämen.

«It captures the interstitial moments that a questioner or observer might not ever know to ask about. Moreover, it allows for individual idiosyncrasiers to come through because it is an individual making his or her way through an exhibition. The thoughts and actions of the participant determine what the camera captures, not the preset hypotheses of the researcher.» ${ }^{1008}$

Im Zentrum des Interesses steht bei Lautem Denken ganz unmittelbar «the visitor's point of view». ${ }^{1009}$

1005 Litten 2017, S. 180. Litten stellt dies so für ihr eigenes Forschungsinteresse fest, die Feststellung lässt sich analog aber auch auf mein Projekt übertragen. Vgl. hierzu weiter Abschnitt 6.1.5.

1006 Someren et al. 1994, S. 25.

1007 Wise 2011, S. 20.

1008 Wise 2011, S. 25.

1009 Wise 2011, S. 26. 


\subsection{Ablauf der Datenerhebung und Teilnehmende}

\subsubsection{Anwerbung der Teilnehmenden}

Zielgruppe meiner Studie waren Einzelbesuchende aller Altersklassen. Im Gegensatz zu vielen anderen geschichtsdidaktischen Studien zielte ich mit meiner Suche also nicht auf Schüler und Schülerinnen, sondern es war mir ein Anliegen, mit den Besuchenden ein breites Altersspektrum abzudecken. ${ }^{1010}$ Die Suche nach Teilnehmenden erfolgte mittels einer Ausschreibung (siehe Text im digitalen Anhang), mit dem Ziel, Personen bereits im Vorfeld des Besuchs zu kontaktieren. Diese Ausschreibung wurde auf mehreren Wegen gestreut: durch Veröffentlichung auf der Website des Museums für Geschichte, via Twitter-Account des Museums ${ }^{1011}$ sowie über Verteilung der Ausschreibung im persönlichen und beruflichen Umfeld per E-Mail und Facebook, verbunden mit der Bitte, diese wiederum weiterzuverbreiten.

Gesucht wurde im Ausschreibungstext nach Personen, die Interesse hätten, die Ausstellung zu besuchen und dabei ihre Gedanken mitzuteilen sowie im Anschluss daran ein Interview zu führen. Als Anforderungen wurden genannt, dass es sich um einen Erstbesuch der Ausstellung und um einen Besuch als Einzelperson handeln solle. Genannt wurde weiter, dass keine Vorbereitung des Besuchs nötig sei, ebensowenig Vorwissen über Geschichte oder über das Ausstellungsthema, und dass an der Studie Personen unterschiedlichen Alters und Geschlechts, unterschiedlicher Herkunft und Interessen teilnehmen könnten. Daraufhin meldeten sich Personen, um sich für die Studie zur Verfügung zu stellen, wobei aus fast allen Kontaktaufnahmen tatsächlich eine Terminvereinbarung für die Datenerhebung resultierte. Letztlich in die Datenauswertung eingeflossen sind daraus Ausstellungsbesuche von 18 Personen. ${ }^{1012}$ Ich beziehe mich im Folgenden stets auf diese 18 Personen.

1010 Schülerinnen und Schüler wurden nicht kategorisch ausgeschlossen, jedoch finden sich im letztlich in die Datenanalyse eingeflossenen Sample nur Erwachsene.

1011 Für die dargebotene Hand bei der Bekanntmachung meiner Studie und Publikation der Ausschreibung auf den genannten Kanälen danke ich den Mitarbeitenden des Historischen Museums sehr herzlich.

1012 Tatsächlich im Kontext meiner Studie das Museum besucht haben insgesamt 30 Personen. Davon sind 12 Personen aus verschiedenen Gründen nicht in die Auswertung eingeflossen. Zum einen sind dies zwei Personen, welche zum Zweck einer Testerhebung angefragt wurden. Die Aufnahme einer weiteren Person wurde aufgrund von grossen Anteilen unverständlicher Passagen auf der Audioaufnahme aus der Analyse ausgeklammert. Eine weitere Person hatte offensichtlich Unbehagen gegenüber der Aufgabe des Lauten Denkens 
Der Einsatz einer Ausschreibung im Vorfeld des Ausstellungsbesuchs und die dadurch bedingte Notwendigkeit einer Selbstrekrutierung war vorrangig aus pragmatischen Gründen erforderlich, da eine ebenfalls denkbare Ansprache von möglichen Teilnehmenden beim Eintritt in das Museum nicht realisierbar war ${ }^{1013}$ und überdies wenig sinnvoll erschien. Die gewählte Form der Datenerhebung stellte einen erheblichen Eingriff in einen üblichen Museumsbesuch dar. Lautes Denken während eines Ausstellungsbesuchs ist atypisch und erfordert - insbesondere im laufenden Museumsbetrieb - mutmasslich Überwindung. Zudem erforderte die Teilnahme einen erheblichen Zeitaufwand von den Besuchenden, da neben dem eigentlichen Besuch der Ausstellung, der für sich genommen unter den Bedingungen der Studienteilnahme mutmasslich länger als üblich dauerte, ${ }^{1014}$ eine Installation der Aufnahmetechnik und Einweisung notwendig war sowie im Anschluss an den Besuch ein Interview durchgeführt wurde. ${ }^{1015}$ Besuchende beim Eintritt in das Museum ad hoc anzusprechen und unter den genannten Bedingungen zu einer Teilnahme bewegen zu wollen, erscheint wenig aussichtsreich und zudem vermessen.

bzw. stellte mir gegenüber zu Beginn der Erhebung die Aufschlusskraft solcher Daten infrage, was schliesslich darin resultierte, dass ich mit ihr einen «stillen» Museumsbesuch vereinbarte. Acht weitere Personen besuchten die Ausstellung, entgegen der ursprünglich angedachten Anforderungen, aber in meinem Interesse, zu mehreren, darunter zwei Zweiergruppen und eine Vierergruppe. Die Gruppenbesuche dienten dem Zweck, auch Kinder bzw. Jugendliche als Teilnehmende in die Studie aufzunehmen, welche die Ausstellung jeweils in Begleitung eines Elternteils besuchten. Bei den Gruppenbesuchen handelt es sich insofern um Spezialfälle, als hier während des Ausstellungsbesuchs Gespräche zwischen den Teilnehmenden stattfanden und aufgezeichnet wurden, hingegen nicht Lautes Denken von Einzelpersonen stattfand. Im Angesicht des insgesamt entstandenen umfangreichen Datenmaterials habe ich auch diese Gruppenbesuche aus der Analyse ausgeklammert, was vor allem auch deshalb als sinnvoll und begründbar erscheint, da der differente Datentypus gesonderter Berücksichtigung seiner Bedingungen bedurft und einen unmittelbaren Vergleich erschwert hätte.

1013 Museumsbesuchende direkt bei ihrem Eintritt in das Museum anzusprechen und für die Teilnahme an der Studie anzuwerben, war auf Wunsch des Museums nicht möglich, was angesichts der nachfolgend angeführten Überlegungen und Umstände der Datenerhebung mehr als nachvollziehbar erscheint.

1014 Vgl. hierzu die weiter oben ausgeführten Überlegungen, dass Lautes Denken die Bearbeitung einer Aufgabe verlängert (Abschnitt 6.1). Zudem lasen die meisten Besuchenden die gelesenen Texte laut vor, worauf ich weiter unten noch eingehe, was ebenfalls die Besuchsdauer verlängert haben dürfte.

1015 Letzteres ist, wie erwähnt, nicht in die Datenauswertung eingeflossen. Ich erwähne es hier gleichwohl, um die Rahmenbedingungen der Studienteilnahme angemessen abbilden zu können. 
Der alternativ eingeschlagene Weg, sowieso am Besuch interessierte Personen im Vorfeld zu gewinnen, wobei sich diese in Ruhe mit den Bedingungen der Teilnahme auseinandersetzen und sich über ihre Bereitschaft klarwerden sowie genügend Zeit für den Besuch einplanen konnten, erwies sich hingegen als plausible Variante. Das in Bezug auf die Zusammensetzung des Samples angestrebte Hauptanliegen, solche Personen zu gewinnen, die sowieso einen Besuch der Ausstellung planten, konnte auch auf dem Weg einer vorgängigen Ausschreibung realisiert werden. Dieses Kriterium war deshalb entscheidend, weil in den relevanten Bezugstheorien von einem in der Lebenswelt und Gegenwart gründenden Interesse an bzw. Bedürfnis nach Auseinandersetzung mit Geschichte ausgegangen wird. ${ }^{1016}$ Am Ausstellungsbesuch interessierten Personen unterstellte ich hypothetisch ein solches Interesse und Bedürfnis und hielt sie folglich für geeignete Teilnehmende, um Verbalisierungen dieser Dimension beim Ausstellungsbesuch zu beobachten.

Die angewendete Samplingstrategie lässt sich als «sekundäre[.] Selektion» beschreiben, insofern, als die «an der Untersuchung Teilnehmenden [...] sich selbst aktivieren» müssen, die Fälle also nicht anhand bestimmter Kriterien von der Studienleiterin ausgewählt werden. ${ }^{1017}$ Lediglich wurden zwei Personen aus dem beruflichen und privaten Umfeld um eine Teilnahme gebeten, die in gewissen Merkmalen zu einer stärkeren Varianz des Samples beitrugen. Diese beiden Personen waren mir vor der Studie bekannt sowie darüber hinaus zwei weitere Personen, die sich jedoch freiwillig auf die Ausschreibung hin meldeten. Die übrigen 14 Personen waren mir im Vorfeld der Studie nicht bekannt. Unter diesen kamen zwei

\section{Vgl. Kapitel 2.}

1017 Merkens 2009, S. 288 f., sich beziehend auf die Unterscheidung in primäre und sekundäre Selektion bei Janice M. Morse, das Unterscheidungskriterium zwischen beiden Formen allerdings etwas anders gewichtend.

Bei Morse heisst es: «Primary selection of participants describes the opportunity for the researcher to sample informants using these criteria. Secondary selection of participants takes place if the researcher cannot select participants according to these criteria and obtains participants by some other means, such as through advertising» (Morse 1994, S. 228f.; Kursivsetzung analog zum Original). Mit «these criteria» bezieht sich Morse auf die Auswahl von «appropriate informants», etwa im Hinblick auf für die Untersuchung erforderliches Wissens oder erforderliche Erfahrung, die bei primärer Selektion möglich ist, bei sekundärer nicht (S. 228).

Merkens betont demgegenüber noch den Akt der Selbstaktivierung als Kriterium für sekundäre Selektion, der für mich den entscheidenderen Aspekt für die Zuordnung des Begriffs zu meiner Samplingstrategie darstellt. Die Unterscheidung nach mehr oder weniger «appropriate» Teilnehmenden ist für mich hingegen nicht relevant, da ich ausgehend von einem offenen Forschungsinteresse alle Besuchenden als grundsätzlich geeignete Studienteilnehmende eingestuft habe. 
Kontakte nicht direkt auf die Ausschreibung hin zustande, sondern auf eine nicht durch mich angeregte Vermittlung durch zwei Personen, die ihrerseits bereits an der Studie teilgenommen hatten oder dies planten. Insofern handelt es sich bei dem Sample um eine im kleineren Teil geklumpte Stichprobe. ${ }^{1018}$ Die übrigen Personen reagierten mehrheitlich auf die auf der Website des Museums aufgeschaltete Ausschreibung.

\subsubsection{Ablauf der Erhebung: Lautes Denken in der Ausstellung «14/18»}

Mit denjenigen Personen, die sich auf die Ausschreibung hin meldeten, vereinbarte ich Termine für den Ausstellungsbesuch. Am vereinbarten Termin fand ein Treffen in den Eingangsräumlichkeiten des Historischen Museums statt und wurden die Teilnehmenden in die Aufgabe eingewiesen und wurde die Aufnahmetechnik installiert. ${ }^{1019}$

Die Datenaufnahme erfolgte mittels kombinierter Audio- und Videoaufnahme. Zu diesem Zweck wurde eine GoPro-Kamera an einem Brustgurt um den Oberkörper der Besuchenden befestigt, ergänzt um ein kleines externes Ansteckmikrofon in Kragennähe. Obwohl den eigentlichen Forschungsgegenstand das gesprochene Wort der Teilnehmenden darstellte, erschien die ergänzende Videoaufnahme erforderlich, um später die gemachten Aussagen innerhalb der Struktur

1018 Merkens 2009, S. 293.

1019 Die Einweisung und Installation der Technik erfolgte im Untergeschoss des Museums und dort im Vorraum der Ausstellung «14/18». Dieser Ort wurde gewählt, weil er im Gegensatz zur Eingangshalle des Museums relativ ruhig und weniger mit anderen Besuchenden frequentiert war und deshalb ein konzentriertes Gespräch ermöglichte. Allerdings befanden sich die Besuchenden an diesem Ort räumlich bereits hinter dem Einstieg der Ausstellung, nämlich hinter einem Teil der zur Ausstellung gehörigen regionalspezifischen Ergänzungsteile (vgl. Abschnitt 7.1). Diese Ergänzungsteile befanden sich teilweise im Vorraum, in dem die Einweisung stattfand, teilweise aber auch schon in einer Zone im Erdgeschoss um den Treppenabgang herum sowie in der Treppenzone selbst. Der Einweisungsort mag dazu beigetragen haben, dass manche Besuchende die im Erdgeschoss befindlichen Teile nicht aufgesucht, sondern direkt am Ort der Einweisung ihren Besuch gestartet haben (vgl. Abschnitt 8.3). Allerdings ging ich, nachdem nach den ersten Besuchenden die Problematik deutlich geworden war, dazu über, die Besuchenden bei der Einweisung noch gezielt auf die im Erdgeschoss befindlichen Teile hinzuweisen, wobei dem Hinweis teilweise gefolgt wurde. Jedoch wurden nicht alle Besuchenden in dieser Weise auf den Ausstellungsteil im Erdgeschoss aufmerksam gemacht. Die verhältnismässig geringen Besuchszahlen für diesen Bereich (vgl. Abschnitt 8.3.1) sind insofern sehr wahrscheinlich durch das Erhebungsdesign beeinflusst. 
der Ausstellung und in ihren Beziehungen zu den einzelnen Elementen wie Bildern, Texten usw. verorten zu können. Es zeigte sich später, dass die Äusserungen ohne den ergänzenden Einbezug der Videoaufnahmen in vielen Fällen nicht eindeutig verortbar gewesen wären. Insofern empfiehlt sich Lautes Denken zur Erforschung von Besuchsverläufen vor allem in der Variante mit kombinierter Videoaufnahme.

Der Besuch der Teilnehmenden in der Ausstellung fand während der regulären Öffnungszeiten des Museums statt, wobei nach Möglichkeit darauf geachtet wurde, weniger frequentierte Phasen, etwa die Mittagszeit, auszuwählen. Zeiten mit parallelen Besuchen von Schulklassen wurden bei der Planung der Termine explizit vermieden. Um einen möglichst störungsfreien Ablauf des Museumsbetriebs zu gewährleisten und den Teilnehmenden möglichst geringe Unannehmlichkeiten zu bereiten, wurde ein Mikrofon mit sehr guter Aufnahmequalität ausgewählt, das den Teilnehmenden auch leises Sprechen erlaubte.

Für die Instruktion der Teilnehmenden orientierte ich mich an Someren et al.: «The essence of the instruction is: Perform the task and say out loud what comes to your mind.» ${ }^{1020}$ Die Kerninstruktion für die Teilnehmenden lautete also, sich die Ausstellung anzusehen und dabei möglichst alles laut zu äussern, was ihnen währenddessen in den Sinn kommen würde. ${ }^{1021}$ Ich machte den Besuchenden weiter deutlich, sie sollten sich in Bezug auf Dauer und Ablauf des Besuchs frei fühlen, also beispielsweise nur diejenigen Ausstellungsteile betrachten, für die sie sich interessierten bzw. die sie üblicherweise betrachten würden, und sollten sich umgekehrt nicht verpflichtet fühlen, nur aufgrund der Studienteilnahme die Aus-

1020 Someren et al. 1994, S. 42 f., direktes Zitat S. 42. Someren et al. empfehlen ausserdem, das Laute Denken vor Beginn der eigentlichen Aufgabe zunächst einzuüben (Someren et al. 1994, S. 43). Darauf wurde nach Abwägung verzichtet. So ist zu bedenken, dass die Teilnahme an der Studie mit Besuch der Ausstellung sowie anschliessendem Interview bereits einen erheblichen Zeitaufwand für die Teilnehmenden darstellte, der durch ergänzende Übungen nochmals verlängert worden wäre. Zudem gehen Someren et al. davon aus, dass nach einer kurzen Eingewöhnungsphase das Laute Denken innerhalb von einigen Minuten nahezu selbsttätig stattfindet (ebd., S. 43), insofern erscheint der Verzicht auf eine Aufwärmphase durchaus vertretbar. Zudem ist zu bedenken, dass auch Einüben des Lauten Denkens nicht vollständig personenbedingte unterschiedliche Dispositionen zum Lauten Denken reduzieren kann (Someren et al. 1994, S. 35 f.).

1021 Bei einigen Teilnehmenden ergänzte ich präzisierend den Hinweis, dass wirklich alles für mich interessant sein könnte, und/oder die Bitte, nichts zu verschweigen, nur weil sie es für zu wenig mitteilsam, uninteressant usw. hielten. 
stellung vollständig zu betrachten. ${ }^{1022}$ Zudem bat ich die Teilnehmenden darum, Texte leise vorzulesen oder zumindest das Lesen kurz anzukündigen. ${ }^{1023}$ Dieser ergänzende Auftrag erschien mir notwendig, um bei der späteren Analyse lesende Aktivitäten identifizieren bzw. Phasen von Stille im Material deuten zu können.

Auf einschränkende Hinweise hinsichtlich des zu Äussernden verzichtete ich entgegen einem anderen Vorschlag von Someren et al. Die Autoren empfehlen, die Probanden darauf hinzuweisen, zwar laut denken, dabei aber nicht ihr eigenes Denken zu interpretieren oder ihr eigenes Verhalten zu analysieren, sich vielmehr auf das eigentliche Bearbeiten der Aufgabe zu konzentrieren. ${ }^{1024}$ Im Hinblick auf mein Forschungsinteresse schien mir eine solche Einschränkung kontraproduktiv, da auch Deutungen des eigenen Denkens und Handelns interessant schienen. Mit den genannten Instruktionen ausgestattet, wurden die Teilnehmenden dann in die Ausstellung entlassen, konnten dort selbstständig über den Ablauf und die Dauer des Besuchs sowie über die dabei zur Kenntnis genommenen Elemente entscheiden.

\subsubsection{Hintergründe der Teilnehmenden}

Ich gehe nachfolgend auf die soziodemografischen und fachlichen Hintergründe der 18 Teilnehmenden ein. Der Einsatz sekundärer Selektion in Kombination mit einer insgesamt kleinen Fallzahl kann zu Auffälligkeiten in der Verteilung soziodemografischer Merkmale innerhalb eines Samples führen. Dies ist auch in der vorliegenden Studie der Fall. Da es sich um eine explorative, qualitative Studie handelt, die sich der Erkundung eines bislang wenig beforschten Feldes zuwendet und dabei keinen Anspruch auf Repräsentativität anstrebt, etwa keine Übereinstimmung der Samplestruktur mit den soziodemografischen Daten der Gesamtbevölkerung, ist dies nicht grundsätzlich problematisch, sollte jedoch reflektiert werden.

1022 Die Instruktion erfolgte frei formuliert, nicht mittels Vorlesen. Ich achtete anhand einer Checkliste darauf, den Besuchenden die zentralen Botschaften zu übermitteln, jedoch konnten die gewählte Formulierung und die Reihenfolge von Fall zu Fall unterschiedlich sein und gestalteten sich in Abhängigkeit vom sonstigen Gesprächsverlauf mit den Teilnehmenden. Auch stellten die Besuchenden während der Instruktion teilweise präzisierende Zwischenfragen, die dann unmittelbar geklärt wurden.

1023 Die zweite Option nannte ich nur bei einem Teil der Teilnehmenden, zum Beispiel, wenn ich bei der Instruktion den Eindruck hatte, dass sie die Aufgabe des Vorlesens als beschwerlich empfanden.

1024 Someren et al. 1994, S. 25, S. 44. 
Eine Auffälligkeit in der Struktur des Samples betrifft die Geschlechterverteilung. So befinden sich unter den 18 Teilnehmenden lediglich vier weibliche und demgegenüber 14 männliche Personen. ${ }^{1025}$ Über Gründe für diese Verteilung lässt sich lediglich mutmassen. So sind etwa Zusammenhänge mit der teilgeklumpten Stichprobe denkbar, insofern, als zwei männliche Teilnehmende wiederum männliche Kontakte aus ihrem Umfeld auf die Studie aufmerksam machten. ${ }^{1026}$ Für meine Auswertungen spielen geschlechtsbezogene Fragestellungen keine Rolle, das heisst, ich betrachte nicht, ob es Zusammenhänge zwischen bestimmten Ausprägungen von Phänomenen und Geschlechtszugehörigkeit gibt. Aus diesem Grund wähle ich bei der späteren Beschreibung von einzelnen Besuchenden durchgängig geschlechtsneutrale Formulierungen. ${ }^{1027}$

Hinsichtlich der Altersstruktur (siehe Tabelle B) wird eine grosse Bandbreite von Altersstufen von jungen Erwachsenen bis hin zu Pensionisten abgedeckt, wobei die Gruppen der 30- bis 39-Jährigen und der 60- bis 69-Jährigen übervertreten sind. In Bezug auf ihre geografische Zugehörigkeit ist die Mehrheit der Teilnehmenden in der unmittelbaren Region verankert, viele sind in den Kantonen Basel-Stadt und Basel-Landschaft wohnhaft und/oder beruflich tätig. Eine Person lebt in einer anderen grossen Stadt in der Schweiz, eine Person in Frankreich, vier Personen in der süddeutschen Region Baden, eine Person im weiteren Süddeutschland und eine Person in Norddeutschland. Die regionale Zugehörigkeit kommt in zahlreichen Äusserungen der Besuchenden zum Ausdruck, weshalb ich im Rahmen der Ergebnisdarstellung an mehreren Stellen auf diesen Aspekt zurückkomme.

Auf Ebene der Bildungshintergründe (siehe Tabelle C) zeigt sich im Sample ein sehr hoher Anteil von sehr gut ausgebildeten Teilnehmenden. So verfügen mit elf Personen knapp zwei Drittel der Teilnehmenden über einen Abschluss auf Tertiär-A-Stufe, also ein Universitäts- oder Fachhochschulstudium, teilweise einschliesslich eines laufenden oder abgeschlossenen Doktorats. Eine weitere Person

1025 Die Einteilung erfolgte nachträglich durch mich, korrespondierend mit den Vornamen. Möglicherweise davon sowie von der binären Zuteilung abweichende geschlechtliche Identitäten der Besuchenden wurden leider nicht explizit von mir erfragt, allerdings spielt die Geschlechtszugehörigkeit für die weitere Auswertung generell keine Rolle.

1026 Ein deutlich stärker ausgeglichenes Geschlechterverhältnis ergäbe sich unter Einbezug all derjenigen Personen, die aus der Auswertung ausgeschlossen wurden (vgl. Fussnote 1012).

1027 Beispielsweise spreche ich gemäss dem jeweiligen Personenkürzel von Person P3, P4 usw. und zugehörig «sie»/«die Person» und wähle als Personalpronomen Formulierungen wie «er oder sie». 
hat eine ältere schweizerische Ausbildung zur Lehrperson absolviert. ${ }^{1028}$ Die sechs übrigen Personen verfügen über eine abgeschlossene Gymnasial- und/oder Berufsausbildung, zwei von ihnen studieren aktuell in einem geistes- und sozialwissenschaftlichen Feld.

$\mathrm{Ob}$ es sich mit dieser Verteilung von Bildungshintergründen und der Übervertretung der sehr gut Ausgebildeten im Vergleich mit der schweizerischen Gesamtbevölkerung ${ }^{1029}$ um ein Abbild des «typischen» Museumspublikums handelt, lässt sich auf Basis der mir zur Verfügung stehenden Untersuchungen nicht zufriedenstellend beurteilen. So kommen Besucherstrukturanalysen zu durchaus differenzierten Ergebnissen hinsichtlich der Bildungshintergründe von Museumsbesuchenden, etwa in Abhängigkeit vom besuchten Museumstyp, was den Schluss nahelegt, dass es «den typischen Besucher»/«die typische Besucherin» gar nicht gibt und dass zumindest für historische Museen die Annahme eines hohen Anteils sehr gut ausgebildeter Besuchender nicht zwingend zutreffen muss. ${ }^{1030}$

1028 Die an Vorgängerinstitutionen der heutigen pädagogischen Hochschulen in der Schweiz absolvierten Ausbildungen zur Lehrperson stellen eine Herausforderung in der Klassifizierung dar, da zum Erwerbszeitpunkt am ehesten als Abschluss auf Sekundarstufe II einzustufen, wohingegen heute an einer pädagogischen Hochschule erworbene Lehrdiplome als Abschlüsse auf Tertiär-A-Ebene eingestuft würden (vgl. zur Einstufung von Lehrdiplomen: Kraus/Schmid/Thyroff 2013, S. 19). Ich wähle zur Umgehung der Klassifizierungsproblematik den Weg, die am Lehrerseminar erworbene Ausbildung als gesonderte Kategorie auszuweisen, wohingegen zwei weitere im Sample befindliche Person mit in Deutschland erworbenen, universitären Ausbildungen zur Gymnasiallehrperson unter den Abschlüssen auf Ebene Tertiär A erfasst werden.

1029 In der schweizerischen Gesamtbevölkerung gestaltete sich die Verteilung von Bildungsabschlüssen im Jahr 2016 gemäss Bundesamt für Statistik wie folgt: 12,6\% obligatorische Schule, 37,8\% Sekundarstufe II (Berufsbildung), 8,4\% Sekundarstufe II (Allgemeinbildung), 14,3\% Tertiärstufe (höhere Berufsbildung), 27,0\% Tertiärstufe (Hochschulen) (Bundesamt für Statistik 2017).

1030 In einer Sekundäranalyse aus dem Jahr 1994 kommt Christa Schulze - allerdings mit äusserst lückenhaftem Ausweis der zugrunde liegenden Studien, Daten und beforschten $\mathrm{Mu}-$ seen und vermutlich in Bezug auf Deutschland - zu den Aussagen, vier Fünftel der Bevölkerung gingen nie oder selten ins Museum, die tatsächlichen Besuchenden seien im Vergleich mit der Gesamtbevölkerung eher männlich und besser ausgebildet, wobei insbesondere in historischen Museen eher niedrigere Bildungsniveaus, in kunst- und kulturhistorischen eher höhere Bildungsniveaus anzutreffen seien (Schulze 1994, S. 108 f.). Eine ähnliche Abhängigkeit der Bildungsniveaus vom Museumstyp ergibt sich auch aus dem Überblick bei Doris Lewalter und Annette Noschka-Roos. Die Autorinnen kommen zu dem Schluss, «die Annahme eines durchgängig relativ hoch gebildeten Museumspublikums» bestätige sich nicht und erwachsene Lernende seien «keine homogene Gruppe» (Lewalter/Noschka-Roos 2009, S. 532). 
Aufschlussreicher erscheint mir in diesem Zusammenhang ein Abgleich des Samples mit Strukturerhebungen, die konkret in Bezug auf Besuchende der Ausstellung «14/18» vorliegen. Zu diesem Zweck habe ich mich bei den Museen, die in der deutschsprachigen Schweiz als Standorte der Ausstellung beteiligt waren, nach erhobenen Daten zu Besuchenden erkundigt. Alle Standorte erfassen Daten zu ihren Besuchenden, jedoch teilweise nicht spezifisch bezogen auf die konkrete Ausstellung oder nur bezogen auf die Gesamtzahl von Besuchenden der Ausstellung. ${ }^{1031}$ Differenzierte Strukturdaten speziell zu Besuchenden der Ausstellung «14/18» wurden vom Historischen Museum Thurgau in Frauenfeld erhoben und mir freundlicherweise zur Verfügung gestellt.

Von den insgesamt in Frauenfeld befragten 225 Besuchenden $^{1032}$ besuchten 68 und damit rund 30 Prozent die Ausstellung als Einzelpersonen, was zeigt, dass Einzelbesuche zumindest für die von mir beforschte Ausstellung durchaus verbreitet sind ${ }^{1033}$ und dass das meiner Studie zugrunde liegende Setting eines Besuchs als Einzelperson insofern nicht ungewöhnlich ist. Der Anteil von Akademikerinnen und Akademikern lag unter den befragten Besuchenden in Frauenfeld bei 25 Prozent $(\mathrm{N}=57)$, also erheblich niedriger als in meinem Sample, wobei zu bedenken ist, dass das Frauenfelder Museum, da in einer kleineren Ortschaft und zudem nicht einer Universitätsstadt liegend, möglicherweise generell ein zu Basel verschiedenes Publikum aufweist. Wie auch in meinem Sample waren unter den Besuchenden in Frauenfeld die männlichen Besuchenden übervertreten $(\mathrm{N}=131$ bzw. 58,2\% gegenüber 93 Nennungen für weibliche und 1 Nennung für andere Geschlechtszugehörigkeit), wenn auch nicht in dem Mass wie in dem meiner Studie zugrunde liegenden Sample. Stark vertreten waren in Frauenfeld die älteren

1031 Ich danke sämtlichen kontaktierten Museen in Basel, Frauenfeld, St. Gallen, Zürich und Zug, die sich die Zeit nahmen, um meine Anfrage zu beantworten. Für St. Gallen liegt die Gesamtzahl von Besuchenden vor, die im Ausstellungszeitraum von Mai 2015 bis Februar 2016 die Ausstellung besuchten, nämlich 10746 Personen.

1032 In Frauenfeld wurde die Ausstellung «14/18» von April bis Oktober 2016 gezeigt. Möglichkeiten zum Ausfüllen der Umfrage bestanden, so ergab meine Nachfrage, per Formular am Empfang, online via iPad sowie zu Hause mittels eines Links. Die Besuchenden wurden möglichst flächendeckend vom Besucherservice aufgefordert, an der Umfrage teilzunehmen. Wie sich die Merkmale der 225 die Umfrage ausfüllenden Personen zur Grundgesamtheit der insgesamt die Ausstellung besuchenden Personen verhalten, hierüber sind mir allerdings keine Aussagen möglich.

1033 Dies steht im Widerspruch zu Falk/Dierking, die davon ausgehen, Museumsbesuche erfolgten zumeist in Gruppen, und die dementsprechend die soziale Dimension des Museumsbesuchs stark machen (Falk/Dierking 1997, S. 41). 
Besuchenden. So machten Personen über 45 Jahre zwei Drittel der Besuchenden aus. ${ }^{1034}$ Im Vergleich dazu erweisen sich in meinem Sample die jüngeren Besuchenden als tendenziell etwas übervertreten, wobei ein unmittelbarer Vergleich aufgrund der unterschiedlichen Stufungen der Alterskategorien erschwert wird.

In der Zusammenschau erweist sich der Anteil sehr gut ausgebildeter Personen in meinem Sample als auffallend hoch. Ein möglicher Grund hierfür mag in der für die Akquise von Teilnehmenden gewählten Strategie liegen. Die Aussicht, während des Ausstellungsbesuchs Gedanken mitteilen zu sollen, verbunden mit dem Prinzip der Selbstrekrutierung, mag dazu geführt haben, dass sich nur solche Personen überhaupt für die Studie meldeten, die glaubten, etwas zur Thematik beitragen zu können. Dies erscheint wahrscheinlich, obwohl in der Ausschreibung explizit darauf hingewiesen wurde, dass Vorwissen für die Teilnahme keine Rolle spiele.

Bei aller notwendigen Berücksichtigung der soziodemografischen Hintergründe der Besuchenden ist der in der Literatur immer wieder anzutreffende Hinweis relevant, dass soziodemografische Hintergründe allein wenig aussagekräftig sind in Bezug auf das, was Besuchende tatsächlich aus einem Ausstellungsbesuch machen, welches Lernen dort stattfindet, mit welchen Interessen sie eine Ausstellung aufsuchen usw. ${ }^{1035}$ So stellt etwa Stephan Schwan fest, man habe es im Museum «mit einer grossen Heterogenität der Voraussetzungen zu tun, die sich eben nicht in äusserlichen, demographischen Variablen wie Alter, Geschlecht oder Bildungsstand erschöpfen, sondern die vor allem auch lernpsychologisch bedeutsame mentale Dimensionen umfassen». ${ }^{1036}$ Und ähnlich konstatiert Manfred Prenzel:

«So praktisch Differenzierungen nach Alter, Geschlecht, globalen Besuchsmotiven (Schul- oder Familienkontext) oder sozialer Herkunft sind, bleiben diese oft allgemein und blass, weil sie kaum aussagekräftige Unterschiede in

1034 Konkret waren die verschiedenen Altersstufen in Frauenfeld wie folgt vertreten:

- Unter 18 Jahre: 11 Personen bzw. 5\%

- 19-25 Jahre: 25 Personen bzw. 11\%

- 26-35 Jahre: 14 Personen bzw. 6\%

- 36-45 Jahre: 26 Personen bzw. $12 \%$

- 45-59 Jahre: 73 Personen bzw. $32 \%$

- 60-75 Jahre: 64 Personen bzw. $28 \%$

- Über 75 Jahre: 11 Personen bzw. $5 \%$

- Andere: 1 Person

1035 Wolf 1980, zit. n. Noschka-Roos 1994, S. 155; Prenzel 2009, S. 139; Schwan 2009, S. 35 f.

1036 Schwan 2009, S. $35 \mathrm{f}$. 
Vorwissen und Interesselage erkennen lassen. Für Lernen besser interpretierbar sind Differenzierungen zum Beispiel auf einer (themenbezogenen) Skalierung, die von Laien bis Experten/Freaks reicht». ${ }^{1037}$

An dem von Prenzel zuletzt angesprochenen Aspekt, der Differenzierung in Laien und Experten, anzuknüpfen, erlaubt auch das Sample meiner Studie. Obwohl mehrheitlich auf dem Weg der sekundären Selektion und insofern ohne kriteriengeleitete Fallauswahl zustande gekommen, erlaubt das Sample, hinsichtlich der Bildungshintergründe der Teilnehmenden eine Differenzierung in zwei Gruppen vorzunehmen. Gemeint ist damit nicht in erster Linie eine Differenzierung hinsichtlich der Niveaus der erreichten Abschlüsse, sondern vielmehr eine Unterscheidung der Besuchenden hinsichtlich ihrer fachlichen Hintergründe.

Vergleiche zwischen Expertinnen und Experten, Novizinnen und Novizen sind namentlich aus den bereits vorgestellten Studien von Sam Wineburg und Susie Wise bekannt und erwiesen sich dort als ertragreich, um Kontraste in Denkund Verhaltensweisen herauszuarbeiten. ${ }^{1038}$ Wise unterschied dabei zudem nach Expertise im Hinblick auf das in der beforschten Ausstellung dargestellte Thema, den 11. September, und im Hinblick auf den Umgang mit Objekten und Ausstellungen. ${ }^{1039}$

Eine ähnliche Zusammenstellung des Samples ergibt sich auch in meiner Studie (siehe Tabelle D). Darin verfügen exakt die Hälfte der teilnehmenden Personen weder über einen professionellen geschichtswissenschaftlichen noch einen geschichtsdidaktischen oder museumsbezogenen Hintergrund, die andere Hälfte verfügt hingegen über solche Hintergründe. Unter diesen neun Besuchenden haben die meisten ein Studium aus dem geschichtswissenschaftlichen Spektrum ${ }^{1040}$ absolviert, zwei unter ihnen haben ausserdem Erfahrung in der Museumsmitarbeit/Museumspädagogik. Drei haben eine universitäre oder lehrerseminaristische Ausbildung zur Geschichtslehrperson absolviert und sind aktuell als Lehrpersonen oder in der Geschichtsdidaktik an einer Hochschule tätig. Eine weitere Person hat zwar kein geschichtswissenschaftliches Studium absolviert, übt jedoch eine Tätigkeit in diesem Bereich aus und brachte in ihren Äusserungen profunde fachliche

1037 Prenzel 2009, S. 139.

1038 Wineburg 1991 und 1998; Wise 2011.

1039 Wise 2011, S. 33.

1040 Dazu zählen diverse geschichtswissenschaftliche Disziplinen sowie in Einzelfällen auch kultur-/kunstgeschichtliche und archäologische Hintergründe. 
Kenntnisse ein, weshalb ich mich dazu entschlossen habe, sie ebenfalls dem Kreis der Personen mit geschichtswissenschaftlichen Hintergründen zuzurechnen. Ich zähle alle neun Personen zu denjenigen mit geschichtswissenschaftlichen Hintergründen ${ }^{1041}$ und differenziere innerhalb dessen nach zwei Gruppen, nämlich diejenigen Personen mit einem nur geschichtswissenschaftlichen Hintergrund (4 Fälle) und diejenigen Personen mit einem überdies auch geschichtsdidaktischen und/ oder museumsbezogenen Hintergrund (5 Fälle), wobei sich im Sample keine Expertinnen oder Experten explizit zur Geschichte der Schweiz im Ersten Weltkrieg befanden.

Ein solches Sample weist entfernte Bezüge zu Ideen der Grounded Theory auf. Eine dort propagierte Variante der Datenerhebung und -auswertung besteht darin, absichtsvoll kontrastierende Fälle zu suchen und einander gegenüberzustellen. ${ }^{1042}$ Ein Theoretical Sampling im strengen Sinne von Glaser und Strauss, das eines Prozesses aus paralleler Datenerhebung und -auswertung mit wechselseitiger Beeinflussung und dabei eines gezielten Auswählens von Vergleichsfällen bedurft hätte, ${ }^{1043}$ wurde allerdings nicht durchgeführt. Im Forschungsalltag ist dieses, wie Strauss und Corbin darlegen, oft auch gar nicht umsetzbar:

«Das [... Vorgehen dürfte sich als schwierig herausstellen, wenn Sie den Ort, die Person oder das Dokument nicht bereits vor der Beobachtung oder vor dem Interview gut genug kennen, um eine solche Entscheidung zu treffen. Das Vorgehen kann auch dann schwierig sein, wenn Sie keinen unbegrenzten Zugang zu Orten, Personen oder Dokumenten haben. Realistisch gesehen, müssen Sie auf Basis dessen auswählen, zu dem Sie Zugang haben oder auf das Sie stossen.» ${ }^{1044}$

Strauss und Corbin vertreten vielmehr die Auffassung, dass auch innerhalb eines nicht absichtsvoll durch das Prinzip der Kontrastierung zusammengestellten Samples sinnvoll vergleichend vorgegangen werden kann. ${ }^{1045}$ In diesem Sinn bietet

1041 Freilich sind die geschichtswissenschaftlichen Anteile in den unterschiedlichen Ausbildungsgängen unterschiedlich ausgeprägt, unterscheiden sich mutmasslich namentlich zwischen «reinen» geschichtswissenschaftlichen Studiengängen und Ausbildungsgängen zur Lehrperson. Eine dahingehende weitergehende Differenzierung des Samples erschien mir jedoch nicht gewinnbringend.

1042 Strauss/Corbin 1996, S. $155 \mathrm{ff}$.

1043 Glaser/Strauss 2010, S. 61 ff.; Strauss/Corbin 1996, S. 157.

1044 Strauss/Corbin 1996, S. 157.

1045 Strauss/Corbin 1996, S. 157, S. 164. 
auch das meiner Studie zugrunde liegende Sample eine sinnvolle Ausgangslage für Vergleiche, auch wenn ich keine systematischen Fallkontrastierungen vornehme. Hauptgegenstand der Analyse sind, wie ich weiter unten noch zeigen werde, nicht die einzelnen Fälle im Sinn von einzelnen Personen und deren Charakteristika, sondern eine inhaltlich strukturierende Erfassung der insgesamt zu findenden Elemente des Denkens im Museum über viele Besuchende hinweg, wobei entdeckte Ausprägungsweisen aber immer wieder auch anhand einzelner Personen veranschaulicht werden und Phänomene in ihrer Tragweite und im Vergleich zu anderen Phänomenen eingeordnet sowie teilweise an fachliche Hintergründe der Besuchenden zurückgebunden werden.

\subsection{Transkription}

Für die Transkription des Materials wurde «[e]in einfaches Transkriptionssystem» in Anlehnung an Thorsten Dresing und Thorsten Pehl ${ }^{1046}$ inklusive individueller Erweiterungen und Anpassungen verwendet, und es erfolgte eine vollständige Transkription des gewonnenen Materials. Die Transkripte wurden von mir selbst und einer weiteren Person angefertigt. Im digitalen Anhang der Arbeit sind entsprechende Prinzipien der Transkription zu finden, ebenso Hinweise auf geltende Prinzipien für die Transkriptdarstellung im Rahmen dieser Arbeit.

\subsection{Methode der Datenauswertung: Inhaltlich- strukturierende qualitative Inhaltsanalyse}

In Abschnitt 2.6 habe ich mich zum Verhältnis geäussert, in dem sich in meinem Forschungsvorhaben Theorie und Empirie zueinander befinden. Ich habe dargelegt, dass auch eine vom Material ausgehende Analyse notwendigerweise theoretisch informiert bzw. theoretisch sensibel ist, dass also die Kenntnis der theoretischen Ausgangslage - wie auch des Forschungsstandes zum Thema - in die Analyse einfliessen.

An dieser Stelle greife ich die dortigen Überlegungen auf und führe sie weiter, indem ich mein Vorgehen bei der Datenauswertung vorstelle. Darin war es mein dezidiertes Anliegen, dem Material in seiner Eigenlogik Rechnung zu tragen und theoretisch bekannte Kategorien lediglich behutsam und möglichst reflektiert zum

1046 Dresing/Pehl 2013, S. 20 ff., direktes Zitat S. 20. 
Einsatz zu bringen. ${ }^{1047}$ Methodisch habe ich mich hierfür für ein inhaltsanalytisches Vorgehen in Anlehnung an Kuckartz entschieden, ${ }^{1048}$ computergestützt durchgeführt mit Verwendung des Programms MAXQDA. Nachfolgend begründe ich die Entscheidung für ein inhaltsanalytisches Vorgehen und grenze es von rekonstruktiven Verfahren ab, beschreibe, welche Arbeitsschritte die inhaltlich strukturierende Inhaltsanalyse beinhaltet, und runde die Darstellung schliesslich mit einigen Hinweisen zu Gütekriterien qualitativer Forschung ab.

\subsubsection{Zur Einordnung: Rekonstruktive und inhaltsanalytische Verfahren}

Eine mögliche Unterscheidung textanalytischer Verfahren ist diejenige in inhaltsanalytische Verfahren auf der einen Seite und rekonstruktive Verfahren auf der anderen Seite. ${ }^{1049}$ Bisweilen wird diese Unterscheidung mit einer Trennung in quantitative und qualitative Zugänge oder einer Unterscheidung in deduktive und induktive Zugänge vermengt. ${ }^{1050}$ Allerdings müssen inhaltsanalytische Verfahren keineswegs zwingend deduktiv und quantitativ orientiert sein, vielmehr folge ich Jan Kruse und seiner Auffassung, dass inhaltsanalytische und rekonstruktive Verfahren nicht als dichotome Pole und Vertreter konträrer Paradigmen zu betrachten seien, sondern dass sich verschiedene methodische Zugänge vielmehr auf einem Kontinuum anordnen lassen. ${ }^{1051}$ Worin dieses Kontinuum besteht und wo ich mein eigenes Forschungsvorhaben darin einordne, dem gehe ich nachfolgend nach.

Meine Forschung verortet sich innerhalb des qualitativen Paradigmas. Qualitativer Analyse gehe es, so Kruse, generell um «die umfassende und detaillierte,

1047 In der Methodenliteratur zum Lauten Denken findet sich gelegentlich der pauschale Hinweis, dass sich für die Auswertung der Protokolle Lauten Denkens ein theoriegeleitetes, deduktives Vorgehen empfiehlt (so bei Wallach/Wolf 2001, S. 22). Dabei wird übersehen, dass die Entscheidung für eine Auswertungsmethode nur auf Basis des jeweiligen Forschungsinteresses sinnvoll getroffen werden kann. Für mein eigenes Vorhaben erschien mir, wie bereits weiter oben ausgeführt, ein Beharren auf dem deduktiven Paradigma nicht sinnvoll.

1048 Kuckartz 2014.

1049 So zum Beispiel bei Kruse 2014, s. u.

1050 Beispielsweise unterscheidet Bohnsack rekonstruktive und hypothesenprüfende Verfahren (Bohnsack 1999, S. 12) und suggeriert damit, dass nicht rekonstruktiv zwangsläufig auch hypothesenprüfend bedeutet.

1051 Idee einer Anordnung als Kontinuum bei Kruse 2014, einerseits bezogen auf rekonstruktive Verfahren (S. 25) wie andererseits auch auf inhaltsanalytische Verfahren (S. 407). 
deskriptive Analyse stets sinnhafter sozialer Wirklichkeit», ${ }^{1052}$ und sie unterscheide sich im Forschungsprozess von quantitativen Zugängen:

«So bestehen die Logik und das Ziel im qualitativen Sozialforschungsprozess nicht darin, mit fertigen Konzepten in den Datenerhebungsprozess einzusteigen - sondern darin, so weit wie möglich die originären Konzepte der Untersuchungsgegenstände herauszuarbeiten, zu rekonstruieren. Mit anderen Worten: der standardisierte Sozialforschungsprozess ist ein linearer Forschungsprozess, in dem Konzepte eingespeist werden, um zu Verteilungsaussagen und Korrelationen zu gelangen. Der qualitative Sozialforschungsprozess ist dagegen ein dynamisch-offener, iterativer-zyklischer Forschungsprozess [...], in dem so wenig wie möglich an Setzungen eingespeist werden soll, um so $\mathrm{zu}$ empirisch rekonstruierten, gegenstandsbegründeten Konzepten zu gelangen.» ${ }^{1053}$

Kruse unterscheidet also in der beschriebenen Weise quantitative und qualitative Zugänge und ordnet diesen in gebräuchlicher Weise Vorgehensweisen zu, die entweder stärker von bereits vorhandenen Konzepten oder von einer Eigenlogik des Gegenstandes ausgehen. Aufschlussreich für mein eigenes Vorhaben ist nun eine weitere Differenzierung, die Kruse innerhalb des Spektrums der qualitativen Zugänge vornimmt. Er widmet sich der Unterscheidung "Qualitative versus rekonstruktive Forschung», ${ }^{1054}$ wobei schnell klar wird, dass es ihm dabei eigentlich nicht um eine dichotome Gegenüberstellung geht, sondern dass er rekonstruktive Verfahren als Teilmenge innerhalb von qualitativen Zugängen betrachtet: «Alle Forschenden, die rekonstruktiv arbeiten, nutzen qualitative Methoden. Aber nicht alle Forschenden, die qualitative Methoden nutzen, forschen rekonstruktiv.» ${ }^{1055}$ Dass Kruse die rekonstruktiven Verfahren als Teilbereich innerhalb der qualitativen Zugänge verortet, bedeutet zugleich, dass es daneben auch «nicht-rekonstruktive» qualitative Verfahren geben muss. Was macht nun diese aus, und wie unterscheiden sie sich von den rekonstruktiven?

1052 Kruse 2014, S. 25.

1053 Kruse 2014, S. 46, sich beziehend auf Darstellungen bei Bohnsack 2000, S. 20 ff., mir in der Ausgabe von 1999 vorliegend, und Bohnsack 2012, S. 13-30.

1054 Kruse 2014, S. 24.

1055 Kruse 2014, S. 24, Kursivsetzung analog zum Original. 
Kruse nimmt eine Unterscheidung von Verfahren dahingehend vor, ob sie eher "Äusserungen» oder "Aussagen" der beforschten Personen in den Blick nehmen, und weiter bzw. in Verbindung damit, ob sie eher die "WIE-EBENE» oder die «WAS-EBENE» des Gesagten betrachten, ${ }^{1056}$ und verbindet diese Unterscheidung mit der Zuordnung zu rekonstruktiven oder inhaltsanalytischen Zugängen: «Mit der Unterscheidung von 〈Äusserungen〉 und 〈Aussagen $\rangle$ könnte eine sinnvolle Differenzierung qualitativer Analyseansätze in inhaltsanalytische (äusserungsbezogene) und rekonstruktive (aussagenbezogene) Verfahren vorgenommen werden.» ${ }^{1057}$

Demnach lassen sich inhaltsanalytische Zugänge - Kruse bezieht sich namentlich auf den inhaltsanalytischen Ansatz von Mayring ${ }^{1058}$ - als Verfahren verstehen, die sich der "〈Inventarisierung〉 der Äusserungsebene» annehmen. ${ }^{1059}$ «Die Analyse von 〈Inhalt〉 meint hier die Analyse von Äusserungen, also der Menge des Gesagten. 〈Inhalt> meint hier eben nicht die Ebene eines spezifischen Ordnungssystems des Gesagten.»1060

Rekonstruktive Verfabren lassen sich hingegen als Verfahren betrachten, die zwar notwendigerweise auch an der Ebene der Äusserungen ansetzen, darüber hinaus aber «auf die Rekonstruktion eines dokumentarischen Sinnsystems» abzielen und dazu «die Ebene des 〈WIE〉, der Form, d.h. des herstellenden Vollzugs in die Analyse ein[beziehen]», also darauf zielen, ein «unter dem 〈WAS〉 liegendes Aussagen- bzw. Sinnsystem rekonstruieren zu können». ${ }^{1061}$ Sowohl die Gruppe der inhaltsanalytischen Zugänge als auch die der rekonstruktiven Verfahren lassen sich Kruse zufolge allerdings ihrerseits als Kontinuum verstehen. ${ }^{1062}$

Für mein eigenes Forschungsanliegen steht vornehmlich die Was-Ebene, stehen die Äusserungen der Besuchenden im Zentrum des Interesses. Es geht um die

1056 Kruse 2014, S. 407 ff., S. 545 ff.; direkte Zitate S. 408 u. 546. Bührmann und Schneider, auf die sich Kruse unter anderem beruft (Kruse 2014, S. 408), fassen Äusserungen «als Ereignisse [...], die nicht wiederholt werden (können), da sie nur zu einem bestimmten Ort und zu einer bestimmten Zeit auftreten», demgegenüber seien Aussagen «konstitutive systematische Bestandteile diskursiver Formierungen bzw. Diskurse», sie stellten «vielmehr eine Funktion dar, die wiederholbar ist, da sie im Diskurs in der Form sprachlicher Zeichen etwas zu etwas anderem in Beziehung setzt. Insofern bezeichnen Aussagen die 〈regelmässigen〉, wiederkehrenden zeichenhaften Verkettungen von Bedeutungsrelationen» (Bührmann/Schneider 2008, S. 25 f.).

1057 Kruse 2014, S. 409.

1058 Mayring 2010.

1059 Kruse 2014, S. 409, Kursivsetzung analog zum Original.

1060 Kruse 2014, S. 409, Kursivsetzung analog zum Original.

1061 Kruse 2014, S. 409 f., Kursivsetzung analog zum Original.

1062 Kruse 2014, S. 25, S. 407. 
Frage, worüber die Besuchenden sprechen, auf welche Aspekte sie überhaupt ihre Aufmerksamkeit richten. Da über während eines Ausstellungsbesuchs auftretende Gedanken und Assoziationen bislang noch wenig bekannt ist, erscheint es mir sinnvoll, sich zunächst dieser Ebene zuzuwenden und sich an eine Systematisierung der auftretenden Äusserungen zu wagen. Den für den Titel meiner Arbeit gewählten Begriff der Bestandsaufnahme verwende ich analog zu Kruses Rede von einer "Inventarisierung». ${ }^{1063}$

Allerdings zeigt sich im konkreten Analyseprozess, dass die Unterscheidung in ein «Was» und «Wie» des Gesagten nur idealtypisch trennscharf ist. Analysiert man zum Beispiel die von den Besuchenden geäusserten Gedanken danach, welche Begriffe sie in den Mund nehmen («Quelle», «Neutralität» ...), so ist dies zwar vordergründig eine Betrachtung der oberflächlichen Äusserungsebene der Besuchenden, gleichzeitig manifestieren sich in der Begriffsverwendung aber auch Fragen des «Wie», nämlich Weisen, über ein bestimmtes Ausstellungselement oder beschriebenes Phänomen zu sprechen und es zu kategorisieren. Mit der Verwendung eines Begriffs verbinden sich zugleich hinter dem Begriff liegende Vorstellungen und Konzepte der Besuchenden, wobei sich - um beim genannten Beispiel zu bleiben - aus der Verwendung desselben Begriffs «Quelle» durch mehrere Besuchende nicht folgern lässt, dass alle auch vom selben zugrunde liegenden Quellenverständnis ausgehen. ${ }^{1064}$ Verschiedene textanalytische Verfahren gehen nun unterschiedlich weit in die Tiefe, um diese hinter den äusserlich verwendeten Begriffen liegenden Konzepte zu rekonstruieren.

Für derartige Manifestationen eines «Wie» im «Was», einer «Aussage» in der «Äusserung» sensibel zu sein, gehört trotz der Entscheidung für ein inhaltsanalytisches Vorgehen zu den Prinzipien meiner Datenanalyse und trägt der auf Kruse basierenden Annahme Rechnung, dass sich verschiedene textanalytische Verfahren und ihre Perspektiven nicht bipolar gegenüberstellen lassen. Gleichwohl gilt für meine Analyse ein vorrangiges Interesse an der Systematisierung des auf einer Äusserungsebene Gesagten, weshalb für mein Forschungsvorhaben ein inhaltsanalytisches Vorgehen die Methode der Wahl darstellt. Mein Vorgehen orientiert sich dabei an der qualitativen Inhaltsanalyse nach Udo Kuckartz, ${ }^{1065}$ deren Prinzipien ich nachfolgend beschreibe.

1063 Kruse 2014, S. 409, Kursivsetzung analog zum Original.

1064 Für dieses Phänomen sensibilisiert Schröder am Beispiel des Begriffs «Chronologie» (Schröder 2013, S. 204).

1065 Kuckartz 2014; Kuckartz 2016. 
Inhaltsanalytische Verfahren werden bisweilen als per se deduktiv und quantitativ vorgehende Verfahren verstanden. ${ }^{1066}$ Ihnen haftet der Ruf an, Äusserungen der Beforschten anhand vorher festgelegter, fixer Kriterien zu systematisieren und dann in erster Linie zu quantifizieren. Wie Mayring aufzeigt, liegen die Anfänge der Inhaltsanalyse tatsächlich auch im quantifizierenden Bereich, nämlich in den USA der 1920er-Jahre und den dort durchgeführten quantifizierenden Analysen der Inhalte von Massenmedien. ${ }^{1067}$ Aktuell gängige Ausprägungen der qualitativen Inhaltsanalyse weichen allerdings in vielerlei Hinsicht von der Fixierung auf ein deduktives Vorgehen ab. Udo Kuckartz nennt eine Reihe von Aspekten, welche die qualitative von einer klassischen Inhaltsanalyse unterscheiden, nämlich

- sei «die Formulierung von Hypothesen zu Beginn in der Planungsphase nicht zwingend, sondern im Bereich der qualitativen Inhaltsanalyse eher selten anzutreffen» (auch macht Kuckartz an anderer Stelle deutlich, dass zwar am Anfang der Analyse eine Forschungsfrage stehe, diese sich aber in Auseinandersetzung mit dem Material und innerhalb bestimmter Grenzen verändern könne $\left.{ }^{1068}\right)$,

- könnten Auswertung und Erhebung durchaus parallel zueinander stattfinden und es gegebenenfalls Rückkopplungen zwischen beiden geben,

- sei «die Codierung des Datenmaterials stärker hermeneutisch-interpretativ orientiert»,

- blieben «auch nach der Codierung das Ursprungsmaterial, sprich die verbalen Daten, von grossem Interesse, d.h., sie haben sich nicht durch die Codierung <erledigt〉 und sind nicht etwa überflüssig geworden»,

- hätten «die Kategorien bei einigen Methoden der qualitativen Inhaltsanalyse mehr eine strukturierende und systematisierende Bedeutung und nicht die Bedeutung der Transformation von Daten aus dem empirischen ins numerische Relativ» und

- laufe «die Analyse nicht notwendigerweise auf statistische Datenanalyse hinaus». ${ }^{1069}$

1066 So etwa die deduktive Vorstellung bei Huber/Mandl: «Die Grundidee dieser Analyse besteht darin, sprachliche Äusserungen (z. B. Worte, Ausdrücke, Sätze, Abschnitte) nach vorher festgelegten Kategorien auszuwerten» (Huber/Mandl 1982, S. 27).

1067 Mayring 2009, S. 469.

1068 Kuckartz 2014, S. 51.

1069 Kuckartz 2014, S. 51 f. 
Eine einfache Gleichsetzung von inhaltsanalytischen mit quantitativ oder deduktiv arbeitenden Verfahren greift insofern zu kurz, und inhaltsanalytische Verfahren erweisen sich als durchaus geeignet für die Bearbeitung offener Fragestellungen. $\mathrm{Zu}$ den Grundprinzipien des Verfahrens nach Kuckartz gehört es etwa, dass Kategorien, selbst im Fall einer bereits vorgängig bestehenden Hypothese, «während des Analyseprozesses verfeinert und ausdifferenziert» werden bzw. das Kategoriensystem ergänzt wird. ${ }^{1070}$

\subsubsection{Prinzipien der inhaltlich strukturierenden Inhaltsanalyse und Vorgehen bei der Auswertung}

Bevor ich anschliessend näher auf die eingesetzte Variante der inhaltlich-strukturierenden Inhaltsanalyse eingehe, sind vorab einige Begriffsklärungen angebracht. Den Begriff Kategorie verwende ich in meiner Analyse in Übereinstimmung mit Kuckartz als «Ergebnis der Klassifizierung von Einheiten», ${ }^{1071}$ in dem Wissen, dass unter diesen Umständen «das Spektrum dessen, was man unter Kategorie verstehen kann, sehr weit» ist. ${ }^{1072}$ Kategorien können beispielsweise näher oder ferner zu den Äusserungen der Teilnehmenden stehen («Natürliche»vs. «Analytische Kategorien»), sie können als «Formale Kategorien [...] die zu analysierende Einheit» klassifizieren, als «Inhaltliche Kategorien» angesprochene Themen oder Argumente systematisieren oder als «Evaluative Kategorien» bereits Aussagen über Ausprägungsgrade eines Phänomens beinhalten. ${ }^{1073}$ In meinem eigenen Projekt kommen nach dieser Kategorisierung formale, inhaltliche, natürliche und analytische Kategorien zum Einsatz, hingegen keine evaluativen Kategorien. Um welche Form von Kategorie es sich im Einzelfall handelt, wird während der Ergebnisdar-

1070 Kuckartz 2014, S. 52, Kursivsetzung analog zum Original.

1071 Kuckartz 2014, S. 41.

1072 Kuckartz 2014, S. 43.

1073 Kuckartz 2014, S. 43 f. Als sechste Form nennt Kuckartz «Fakten-Kategorien [...], die sich auf eine bestimmte objektive oder vermeintlich objektive Gegebenheit beziehen, beispielsweise einen Beruf klassifizieren (jemand ist 〈Politiker〉, jemand sagt: 〈Ich bin Bäcker〉) oder einen Ort bezeichnen (‘wohne in Wilmersdorf`, ‘wohne in einem Sanierungsgebiet))» (ebd., S. 43). Je nach Fragestellung könnten derartige Äusserungen allerdings durchaus auch mit inhaltlichen oder analytischen Kategorien abgedeckt werden, eine gesonderte Ausweisung von «Fakten-Kategorien» erscheint mir deshalb nicht überzeugend oder notwendig. Zudem wäre zu klären, was überhaupt als «objektiv» oder «vermeintlich objektiv» zu gelten hat, und die Frage zu stellen, ob sich nicht sehr viele zu analysierende Äusserungen auf mindestens «vermeintlich objektive» Gegebenheiten beziehen. Diese sechste Kategorie halte ich insofern für weder theoretisch noch empirisch überzeugend. 
stellung ersichtlich, nämlich immer dann, wenn ich die jeweiligen Kategorien einführe und ihr Zustandekommen beleuchte.

Kategorien unterscheiden sich von Codes dadurch, dass die «Klassifizierung von Einheiten» in ihnen «bereits einen gewissen «Reifegrad e erreicht hat und nicht lediglich vorläufig ist. In diesem Sinn gibt es also im Auswertungsprozess ein 〈offenes Codieren〉, aber kein 〈offenes Kategorisieren〉». ${ }^{1074}$ Das heisst, im Prozess einer offenen Datenanalyse entstehen in einem ersten Schritt Codes, später werden sie zu Kategorien verdichtet, erhalten eine Definition und werden mit typischen Textbeispielen als Indikatoren versehen, den «Ankerbeispiele[n]». ${ }^{1075}$

Kuckartz unterscheidet drei Varianten qualitativer Inhaltsanalysen, nämlich

- die «inhaltlich strukturierende qualitative Inhaltsanalyse», im Rahmen deren «die Identifizierung von Themen und Subthemen, deren Systematisierung und Analyse der wechselseitigen Relationen» von Interesse ist, ${ }^{1076}$

- die «evaluative qualitative Inhaltsanalyse», die auf «die Einschätzung, Klassifizierung und Bewertung von Inhalten durch die Forschenden» zielt, ${ }^{1077}$ und

- die «typenbildende Inhaltsanalyse», die häufig im Anschluss an eine der beiden anderen Formen «nach mehrdimensionalen Mustern, die das Verständnis eines komplexen Gegenstandsbereichs oder eines Handlungsfeldes ermöglichen», sucht. ${ }^{1078}$

Ich habe die erstgenannte Form, die inhaltlich strukturierende Analyse, eingesetzt. Kuckartz listet hierfür folgende Arbeitsphasen auf, jeweils in Abhängigkeit und Wechselwirkung mit der Forschungsfrage:

- «l) Initiierende Textarbeit, Markieren wichtiger Textstellen und Schreiben von Memos»,

- «2) Entwickeln von thematischen Hauptkategorien»,

- «3) Codieren des gesamten bisher vorhandenen Materials mit den Hauptkategorien»,

- «4) Zusammenstellung aller mit der gleichen Hauptkategorie codierten Textstellen»,

- «5) Induktives Bestimmen von Subkategorien am Material»,

1074 Kuckartz 2014, S. 45 f.

1075 Kuckartz 2014, S. 46.

1076 Kuckartz 2014, S. 77, S. 98.

1077 Kuckartz 2014, S. 98, Kursivsetzung nicht aus Original übernommen.

1078 Kuckartz 2014, S. 115. 
- «6) Codieren des kompletten Materials mit dem ausdifferenzierten Kategoriensystem»,

- «7) Kategorienbasierte Auswertung und Ergebnisdarstellung». ${ }^{1079}$

Zwar legt die Nummerierung der Phasen vordergründig nahe, dass Kuckartz von einer festgelegte Reihenfolge der Arbeitsschritte ausgeht, allerdings betont er andernorts, er verwende den Begriff «Phase» gerade deshalb, um «zum Ausdruck [zu] bringen, dass es sich nicht um einen starr fixierten Ablauf von Schritten handelt». ${ }^{1080}$ Diese Variabilität in der Reihenfolge der einzelnen Arbeitsschritte enspricht den in meinem eigenen Forschungsprozess gemachten Erfahrungen und überzeugt auch auf methodologischer Ebene. Nämlich erschiene ein starrer Ablauf, in dem gemäss Schema gleich zu Beginn des Forschungsprozesses die Hauptkategorien entwickelt und anschliessend ausdifferenziert werden, mit den Prinzipien eines offenen, an der Logik des Material orientierten und nicht durch theoretisch vorhandene Kategorien determinierten Analysevorgangs nicht in Einklang zu bringen, sondern vielmehr einer deduktiven Vorgehensweise entsprechend. Ein frühes Finden von Hauptkategorien mag bei induktivem Vorgehen zufällig eintreten, jedoch ist es nicht zwingend erwartbar, sondern ebenso ist denkbar, dass sich Hauptkategorien erst zu einem späteren Verlauf des Prozesses herauskristallisieren, indem sich beispielsweise ein Kondensat aus einer Anzahl bis dahin verwendeter Codes ergibt.

In Bezug auf meinen Analyseprozess lässt sich vielmehr von einem parallelen Finden von über- und untergeordneten Kategorien berichten. Die Analyse erfolgte als Prozess, in dem bisweilen Textstellen bereits zuvor gefundenen Codes oder Kategorien zugeordnet werden konnten, in anderen Fällen Codes oder Kategorien neu gebildet wurden, dabei immer wieder Systematisierungen aus Über- und Unterordnungen versucht wurden, aufgrund von Anpassungen bisweilen mehrmalige Materialdurchläufe nötig waren, bis schliesslich ein relativ stabiles Set von Kategorien vorhanden war, zu dem keine substanziell neuen Kategorien mehr aus der Beschäftigung mit dem Datenmaterial hinzukamen, sodass insofern von einer «Sättigung» ${ }^{1081}$ gesprochen werden konnte. ${ }^{1082}$

1079 Kuckartz 2014, S. 78.

1080 Kuckartz 2014, S. 51. Auch an anderer Stelle seiner Darstellung erweist sich Kuckartz als für die Iterativität, Variabilität und Flexibilität des Prozesses der Kategorienbildung durchaus sensibel (Kuckartz 2014, S. $63 \mathrm{ff}$.).

1081 Kuckartz 2014, S. 64; Kuckartz 2016, S. 85.

1082 Kuckartz beschreibt diesen Prozess ähnlich in Kuckartz 2014, S. 63 ff., sowie etwas ausführlicher in der überarbeiteten Ausgabe bei Kuckartz 2016, S. $84 \mathrm{ff}$. 
Gleichwohl ist - auch anknüpfend an meine Ausführungen zum Verhältnis von Theorie und Empirie und zur theoretischen Sensibilität ${ }^{1083}-$ zu betonen, dass sich trotz der geschilderten bedingten Unvorhersehbarkeit des Analyseprozesses die Kategorien nicht «zufällig» ergeben. Hierzu Kuckartz:

«Der Begriff <induktiv〉 sollte [...] nicht zu der Annahme verleiten, dass bei dieser Art der Kategorienbildung die Kategorien quasi aus dem Material hervorsprudeln und wie die Nachrichten bei einem Nachrichten-Ticker von den Forschenden nur noch aufgefangen werden müssen. Dies ist (leider) nicht der Fall; auch die induktive Kategorienbildung verlangt aktives Zutun und ist ohne das Vorwissen und die Sprachkompetenz derjenigen, die mit der Kategorienbildung befasst sind, nicht denkbar.» ${ }^{1084}$

«Obwohl es vielleicht so erscheinen mag, als geschähe die induktive Kategorienbildung gewissermassen voraussetzungslos am Material, sollte man eine solche naive Sichtweise, dass Kategorien quasi aus dem Material emergieren, vermeiden.» 1085

Um gleichwohl der Gefahr eines «sich nur allzu leicht einstellende[n] Anekdotismus» entgegenwirken zu können, habe ich, einer Anregung Kuckartz' folgend, eine Totalanalyse der Äusserungen der 18 Besuchenden durchgeführt. ${ }^{1086}$ Dabei wurde das Material vollständig codiert, und dies sogar nacheinander mit mehreren und in ihrer Struktur parallel zueinander liegenden Kategorienebenen. Welche Ebenen dies sind, um welche Form von Kategorien es sich jeweils handelte, ob diese von Fall zu Fall stärker auf induktivem oder bisweilen auch auf deduktivem Weg gewonnen wurden, darauf gehe ich erst im Rahmen der Ergebnisdarstellung näher ein, da diese Ausführungen bereits stark in eine inhaltliche Auswertung des Datenmaterials überführen.

1083 Vgl. Abschnitt 2.7.

1084 Kuckartz 2016, S. 72.

1085 Kuckartz 2014, S. 65.

1086 Kuckartz 2014, S. 25, dazu auch S. 77. Um eine Totalanalyse zu ermöglichen, können für zunächst nicht zuordenbare Textstellen Restkategorien geschaffen werden (zu diesen: Kuckartz 2014, S. 61) und die darin befindlichen Textstellen nach Gemeinsamkeiten und Potenzialen für die Bildung neuer Kategorien befragt werden. 
Kleinstmögliche Texteinheit für die Vergabe eines Codes war stets das einzelne Wort. Nach oben hin wurde die Textmenge einer Codiereinheit durch die Länge des Andauerns eines Phänomens bestimmt, das durch den gewählten Code oder die gewählte Kategorie bezeichnet werden sollte, bzw. durch den Beginn eines anderen, das vorangehende ausschliessenden Phänomens. ${ }^{1087}$ Die Codierung des Materials erfolgte also grundsätzlich anhand von auftretenden Ereignissen, d. h. event- und nicht zeitbasiert. ${ }^{1088}$ Im Verlauf der Analyse und in enger Auseinandersetzung mit dem Material kristallisierte sich eine Kategorienstruktur heraus, in der sich manche Kategorien wechselseitig ausschliessen sollten und in anderen Bereichen bewusst Überschneidungen vorgesehen wurden. Auch hierauf werde ich erst bei einer differenzierteren Beschreibung der Kategorien im Ergebnisteil der Arbeit von Fall zu Fall näher eingehen.

Im Verlauf des Analyseprozesses immer wieder vorgenommene Anpassungen des Kategoriensystems machten an verschiedenen Punkten der Analyse nochmalige Durchgänge durch das bis dahin codierte Material notwendig. ${ }^{1089}$ So wurde das Kategoriensystem in seiner letztendlichen Grundstruktur in Auseinandersetzung mit etwa zwei Dritteln der analysierten Dokumente gewonnen und bedurfte dort teilweise mehrerer Materialdurchgänge. Etwa ein weiteres Drittel von Dokumenten wurde anschliessend mit dem weitgehend fixierten Kategoriensystem bearbeitet. Die im Verlauf dieses Prozesses immer mehr verfeinerten und präzisierten Codebeschreibungen sind in ihrer letztlichen Form im digitalen Anhang einsehbar, ebenso wie zugehörige Materialbeispiele.

Das eingesetzte Kategoriensystem beschreibe ich weiter unten näher und kombiniere dies mit der Darstellung der Ergebnisse meiner Studie. Ein kombiniertes Abhandeln ist vor allem deshalb sinnvoll, weil die Kategorienstruktur zugleich die Gliederung der Ergebnisdarstellung und auch die Struktur der aus der Analyse generierten Modellierung grundlegend prägt. Einige Beschreibungen zum Vorgehen und dazu, wie aus einzelnen Codierungen und Kategorien schliesslich eine Ergebnisdarstellung wird, sind dennoch an dieser Stelle bereits sinnvoll.

1087 Innerhalb eines Phänomens enthaltene Pausen sowie den Transkripttext ergänzende Kommentare wurden dabei mitcodiert, sofern die davor und danach stehenden Textteile ansonsten zusammengehörig schienen.

1088 Zur Unterscheidung der beiden Formen: Brückmann/Duit 2014, S. $191 \mathrm{f}$.

1089 So auch der Hinweis bei Kuckartz 2014, S. 88. 
Einen Überblick über mögliche Auswertungswege gibt eine von Kuckartz verwendete Matrix, ${ }^{1090}$ die ich in Tabelle 4 im digitalen Anhang in leicht angepasster Form wiedergebe. Daraus wird ersichtlich, dass die Zusammenschau von Textstellen für Kuckartz entweder auf Ebene von Personen oder auf Ebene von Themen möglich ist. Im Fall der thematischen Ebene spricht Kuckartz dann von einer «Kategorienbasierte[n] Auswertung», ${ }^{1091}$ womit deutlich wird, dass bei dieser Betrachtungsweise eigentlich die Äusserungen innerhalb von Kategorien massgeblich sind, wohingegen ich den Begriff des Themas in diesem Zusammenhang selbst vermeide, da in meiner Arbeit für eine bestimmte Kategorienebene verwendet ${ }^{1092}$ und insofern spezifischer besetzt.

In meiner Studie stellte die kategorienbasierte Auswertung das zentrale Element dar und ist auch für die Ergebnisdarstellung leitend, wo die Gliederung nach Kategorien zugleich das Grundgerüst der Kapitelgliederung bildet. Innerhalb der einzelnen kategorienbasierten Darstellungen kommen punktuell auch personenbezogene Beschreibungen vor, von mir als Brennpunkte bezeichnet. Dabei handelt es sich um kategorienbasierte Falldarstellungen. Sie fokussieren auf die Äusserungen einzelner Personen innerhalb einzelner Kategorien oder auch innerhalb mehrerer, inhaltlich zusammengehöriger Kategorien. Insgesamt finden sich 20 derartige Brennpunkte im Verlauf der Ergebnisdarstellung, die Äusserungen von 11 der 18 Besuchenden näher in den Blick nehmen, wobei einzelne Besuchende mit mehreren Darstellungen vertreten sind (siehe Übersicht der kategorienbezogenen Falldarstellungen im digitalen Anhang).

Personenbezogene Falldarstellungen über alle Kategorien hinweg kommen hingegen in meiner Studie nicht vor. Umfassende Fallprofile zu entwickeln, ist dezidiert nicht mein Anliegen. Das Hauptanliegen der Analyse ist vielmehr die Betrachtung vorkommender Strukturelemente und deren Systematisierung über alle Besuchenden hinweg. Konkrete Merkmalsausprägungen und -kombinationen bei Einzelfällen treten demgegenüber in den Hintergrund. Gleichwohl können Personenbetrachtungen innerhalb einzelner Kategorien bisweilen aufschlussreich sein, indem sie entweder etwas Typisches oder umgekehrt etwas Besonderes aufzeigen. In meiner Studie setze ich Fallbetrachtungen überwiegend dann ein, wenn sich bestimmte Phänomene bei einzelnen Besuchenden in besonders ausgeprägter

1090 Kuckartz 2014, S. 74.

1091 Kuckartz 2014, S. 74.

1092 Vgl. Abschnitt 8.4. 
Weise zeigen. In welcher Hinsicht Einzelfälle in der konkreten Situation dargestellt werden, wird von Fall zu Fall gesondert eingeordnet.

Einordnungen nehme ich mitunter auch im Hinblick auf die Breite des Vorkommens von Phänomenen vor. Auch für qualitative Forschung ist es durchaus von Interesse, sich über die Tragweite von Befunden Gedanken zu machen. In diesem Zusammenhang kann es aufschlussreich sein, einzuschätzen, ob bestimmte Phänomene vergleichsweise häufig oder selten im Material vertreten sind, ob sie bei vielen oder nur bei einzelnen beforschten Personen vorkommen. Kuckartz ordnet den Stellenwert dieser Art von Quantifizierungen im Rahmen qualitativer Inhaltsanalysen an einem Beispiel ein:

«Sofern thematische Subkategorien gebildet wurden, wie oben beim Beispiel der Kategorien 〈Grösste Weltprobleme〉 und 〈Aktuelles persönliches Verhalten im Klimaschutz>, werden diese Subkategorien dargestellt, wobei durchaus auch Zahlen berichtet werden können, denn (nicht nur) für die Leserinnen und Leser kann es durchaus relevant sein, ob etwa nur 3 von 39 oder 29 von 39 Forschungsteilnehmenden 〈Umwelt- und Klimaprobleme〉 als die derzeit grössten Weltprobleme bezeichnen. Es kommt aber bei der Darstellung im Ergebnisbericht darauf an, keinesfalls nur die Häufigkeiten der Themen und Subthemen darzustellen, sondern die inhaltlichen Ergebnisse in qualitativer Weise zu präsentieren, wobei durchaus auch Vermutungen geäussert und Interpretationen vorgenommen werden können. D.h., es ist nicht nur von Interesse, dass nur neun Befragte 〈Wirtschafts- und Finanzprobleme〉 als grösste Weltprobleme nennen, sondern mindestens genauso interessant ist, welche Wirtschaftsprobleme in welcher Form und mit welchen Worten genannt werden.»1093

Quantifierende Einschätzungen bilden also keineswegs das Kernanliegen qualitativer Inhaltsanalyse. Vielmehr gilt es, deren Wert von Fall zu Fall zu betrachten: «Welche Aussagekraft Zahlen haben können, sollte [...] für jede qualitative Inhaltsanalyse sorgfältig reflektiert werden. Dabei geht es vor allem um die Frage 〈Bedeutet häufig auch wichtig?»» ${ }^{1094}$

1093 Kuckartz 2016, S. 118 f.

1094 Kuckartz 2016, S. 54. 
In meiner Arbeit kommen einordnende Aussagen über die Verbreitung von Phänomenen als Ergänzung und Kontextualisierung der strukturanalytischen Befunde vor. So halte ich etwa fest, wenn bestimmte Arten von Äusserungen im Verhältnis zu anderen auffallend häufig oder sehr selten im Material vorkommen, oder gebe in dem von Kuckartz beschriebenen Sinn Auskunft darüber, bei welchen Besuchenden sich ein bestimmter beobachteter Aspekt überhaupt zeigt, mitunter ergänzt um Hinweise, wenn sich Phänomene bei einzelnen Personen im Vergleich mit anderen in besonders ausgeprägter Weise zeigen. ${ }^{1095}$ Einschätzungen über

1095 Führt man eine Inhaltsanalyse wie in meinem Fall programmgestützt unter Verwendung von MAXQDA durch, so sind Quantifizierungen, selbst wenn sie für die eigene Arbeit nicht im Zentrum stehen, doch eine Begleiterscheinung des Analyseprozesses, nämlich auf Ebene des Codebaums, wenn für jeden Code und Subcode zugleich die aktuelle Häufigkeit seiner Verwendung angezeigt wird. Leicht können solche Hinweise Einfluss auf den Analyseprozess gewinnen, zum Beispiel, indem allein aufgrund der schieren Menge an Textstellen innerhalb einer Kategorie der Impuls entsteht, diese Gruppe weiter in Subformen auszudifferenzieren. Aufseiten des Forschers oder der Forscherin gilt es gleichwohl, möglichst darauf zu achten, welche Ausdifferenzierungen inhaltlich sinnvoll sind.

Neben den Angaben von Codehäufigkeiten bietet MAXQDA eine Fülle weiterer Funktionen für eine quantifizierende Bearbeitung des Materials. Je nach gewähltem Verfahren und verfolgter Forschungsfrage ist darunter unter Umständen nur ein kleiner Teil von Relevanz. In meinem Fall beruhen Einschätzungen in Bezug auf das Vorkommen von Phänomen ausschliesslich auf einfachen deskriptiven Funktionen, konkret a) Betrachtungen von Häufigkeiten von Codings (in meinem Fall zugleich: Anzahl von vorkommenden Ereignissen), entweder über alle Besuchenden hinweg oder auch gegliedert nach einzelnen Besuchenden, oder b), falls explizit als solches angegeben, Betrachtungen von Anteilen am Textvolumen im Vergleich zwischen mehreren (Sub-)Kategorien derselben Ebene bei einzelnen Besuchenden. Letztere, die Anteile am Textvolumen, wurden mit der Funktion «Dokument-Portrait» und darin wiederum der Angabe «Anzahl Kacheln» betrachtet, die für das Einschätzen tendenzieller Bedeutungen wertvolle Dienste liefert (zur Beschreibung der gewählten Funktion: VERBI Software 2014, S. 98 ff.). In der Funktion «Anzahl Kacheln» wird ein Dokument in 1200 Segmente zerlegt, die je nach Länge des Dokuments unterschiedlich viel Textvolumen umfassen können. Jede Kachel entspricht einem Segment und wird mit der Farbe des dort (mehrheitlich) vergebenen Codes versehen, sodass sich eine farbliche Visualisierung der Verhältnisse verschiedener Codes zueinander ergibt, ergänzt um entsprechende Angaben zu prozentualen Verteilungen, entweder für alle Codes des Codesystems oder, wie in meinem Fall, für von Fall zu Fall ausgewählte Codes innerhalb derselben Ebene. Anteil am Textvolumen meint also hier den Anteil von Kacheln innerhalb eines Dokuments. Zu beachten gilt es, dass die beiden Angaben, nämlich Vorkommen von Ereignissen und aufgewendetes Textvolumen, nur bedingt in einem Zusammenhang stehen. So erzielt langes, zusammenhängendes SichÄussern innerhalb einer Kategorie nur eine Nennung, nimmt aber im Volumen viel Raum ein. Weiterführende statistische Berechnungen über diese deskriptiven Einschätzungen hinaus habe ich nicht vorgenommen. Die beschriebenen deskriptiven Funktionen benutze ich als Hilfsmittel, um Eindrücke von der ungefähren Tragweite von beobachteten Phänomenen zu erhalten und strukturanalytische Befunde dahingehend zu kontextalisieren, jedoch nicht mit dem Anspruch, exakt belastbare Quantifizierungen zu erzielen. In meinem Fall dient die Nutzung deskriptiver Funktionen, anknüpfend an das weiter oben beschriebene Phä- 
Häufigkeiten des Vorkommmens sind dabei stets als Tendenzen zu verstehen. ${ }^{1096}$ Sie stehen nicht im Zentrum der Analyse, deren Hauptgegenstand vielmehr eine präzise und detaillierte Strukturierung und Systematisierung der überhaupt und insgesamt beim Ausstellungsbesuch auftretenden Elemente des Denkens und Aneignens ist.

\subsubsection{Gütekriterien}

Die Debatte um Gütekriterien, die für qualitative Forschung Gültigkeit beanspruchen sollen und dürfen, wird kontrovers geführt, wie Ines Steinke aufzeigt. ${ }^{1097}$ Sie unterscheidet drei Positionen innerhalb dieser Debatte: Von einer Position würden «Kriterien der quantitativen auf qualitative Forschung übertragen [...]. Zentrale Kriterien sind Objektivität, Reliabilität und Validität aus der experimentell-statistischen und der hypothesenprüfenden Forschung und aus der Psychometrie.»1098 Eine zweite Gruppe ziehe «grundsätzlich die Übertragbarkeit quantitativer Kriterien auf qualitative Forschung» in Zweifel und formuliere eigene Kriterien. ${ }^{1099}$ Eine dritte, von Steinke als postmodern klassifizierte Position argumentiere «generell gegen die Möglichkeit, Qualitätskriterien für qualitative Forschung zu formulieren». ${ }^{1100}$

Im Verlauf ihrer Ausführungen wird deutlich, dass Steinke selbst der zweiten Position angehört ${ }^{1101}$ - der ich mich nachfolgend ebenfalls anschliesse -, tritt sie

nomen der theoretischen Sensibilität (vgl. Abschnitt 2.6), zudem einer Schärfung des Blicks auf das Material. So können die beschriebenen Funktionen vertieftere Blicke ins Material anregen, also die qualitative Analyse schärfen. Zudem lenken Feststellungen von personenspezifischen Häufigkeiten bestimmter Kategorien die Auswahl dieser Personen für vertiefte, kategorienbezogene Fallbetrachtungen. Beispielsweise führte die Beobachtung, dass sich die Person P8 auffallend häufig über von der Ausstellung vorgenommene Deutungen äussert, dazu, im Rahmen einer Fallbetrachtung näher zu erschliessen, wie diese Person das tut, worüber sie genau in diesen Momenten spricht usw. (vgl. Abschnitt 8.6.2.1).

1096 Aussagen zum Vorkommen von Phänomenen bedienen sich der in Fussnote 1095 geschilderten Zugänge und beruhen stets auf den Codierungen des Datenmaterials durch mich als Einzelperson. Die von mir gewählten Massnahmen zur Herstellung von Nachvollziehbarkeit stelle ich im folgenden Abschnitt vor. Ein über das untersuchte Sample von 18 Besuchenden in der spezifischen Ausstellung hinausgehender Anspruch auf Repräsentativität der Angaben verbindet sich mit den formulierten Einschätzungen zu keinem Zeitpunkt.

1097 Steinke 2009.

1098 Steinke 2009, S. 319.

1099 Steinke 2009, S. 320.

1100 Steinke 2009, S. 321.

1101 Ebenfalls dieser Gruppe zuordnen lässt sich Kruse (Kruse 2014, S. 54 ff., insb. S. 55). 
doch für die Notwendigkeit der Formulierung von Gütekriterien auch für qualitative Forschung ein, um sie nicht der «Gefahr der Beliebigkeit und Willkürlichkeit» auszusetzen, ${ }^{1102}$ vertritt aber auch dezidiert die Auffassung, dass «[q]uantitative Kriterien $[\ldots]$ nicht für die Bewertung qualitativer Forschung geeignet» seien:

«Sie wurden für ganz andere Methoden (z. B. Tests, Experimente) entwickelt [...]. Da deren Grundannahmen kaum mit qualitativer Forschung vereinbar sind, ist es nicht gerechtfertigt, von ihr zu erwarten, dass sie den Kriterien quantitativer Forschung entsprechen kann oder soll. Quantitative Kriterien können insbesondere aufgrund der vergleichsweise geringen Formalisierbarkeit und Standardisierbarkeit qualitativer Forschung nicht unmittelbar auf diese übertragen werden.» ${ }^{1103}$

Anschlussfähig an die Überlegungen Steinkes, und in diesem Fall nun konkret bezogen auf die induktiv vorgehende qualitative Inhaltsanalyse und dabei den Aspekt der Kategorienbildung, formuliert Udo Kuckartz:

«Weil die Kategorienbildung aber nun von der individuellen Kategorienbildungskompetenz und dem aktiven Tun abhängig ist, lässt sich für den Akt der Konstruktion eines Kategoriensystems keine intersubjektive Übereinstimmung, keine Reliabilität, postulieren. Der möglicherweise bestehende Anspruch, dass sich beim induktiven Codieren durch mehrere Personen oder Mitglieder eines Teams die gleichen Kategorien ergeben würden, lässt sich nicht erfüllen. Deshalb ist es auch nicht sinnvoll, für die Kategorienbildung Koeffizienten der Übereinstimmung oder generell die Intercoder-Reliabilität zu berechnen. In vielen Workshops habe ich den Versuch gemacht, einzeln und/oder in Gruppen Kategorien am Material bilden zu lassen. Fast immer finden sich Bereiche, in denen sich die vorgeschlagenen Kategoriensysteme überlappen, d.h., es werden dieselben oder sehr ähnliche Kategorien vorgeschlagen. Aber genauso regelmässig finden sich nicht überlappende Bereiche, und es ist nicht selten, dass sogar Kategoriensysteme gebildet werden, die völlig anders strukturiert sind, teilweise auch sehr originell sind und durchaus eine Umsetzung der Forschungsfrage darstellen. Kategorienbildung am Ma-

1102 Steinke 2009, S. 321.

1103 Steinke 2009, S. 320. 
terial ist ein aktiver Konstruktionsprozess, der theoretische Sensibilität und Kreativität erfordert. Hierfür gelten nicht die Massstäbe der Übereinstimmung von Codierenden und der Anspruch von Intracoder- und IntercoderÜbereinstimmung.»1104

Steinke schlägt alternativ eine Reihe von Gütekriterien vor, die spezifisch auf das qualitative Paradigma zugeschnitten sind, unter anderem «intersubjektive Nachvollziehbarkeit». ${ }^{105}$ Hierzu rechnet sie einerseits die "Anwendung kodifizierter Verfahren» ${ }^{1106}$ - in meinem Fall der Arbeitsschritte der inhaltlich strukturierenden Inhaltsanalyse. Intersubjektive Nachvollziehbarkeit im Sinne Steinkes beinhaltet weiter, und dies sieht sie als die «zentrale Technik» in der Herstellung von Nachvollziehbarkeit, den Forschungsprozess transparent zu machen. ${ }^{1107}$ Dies löse ich ein, indem ich beispielsweise das theoretische Vorverständnis darlege, die Erhebungssituation beschreibe, Materialien offenlege, eingesetzte Erhebungs- und Auswertungsschritte dokumentiere.

$\mathrm{Zu}$ diesem Bereich zählt Steinke nicht zuletzt auch «die Dokumentation von Widersprüchen, die in der Analyse aufgetreten sind und nicht gelöst werden». ${ }^{1108}$ In meiner Arbeit rechne ich hierzu Reflexionen darüber, dass es bei der Analyse nicht in allen Fällen gelungen ist, sowohl Gegenstandsangemessenheit als auch Reduktion und Trennschärfe von Kategorien herzustellen. Die empirische Wirklichkeit erweist sich vielfach als komplexer als jedes noch so ausdifferenzierte Kategoriensystem. Immer wieder kommt es vor, dass Phänomene mehreren definierten Kategorien zugleich oder aber keiner davon entsprechen. Bisweilen können in solchen Fällen Mehrfachcodierungen Abhilfe schaffen, sofern der eigene Codierleitfaden diese gestattet. Bisweilen erweist sich auch die Neubildung weiterer Kategorien als angezeigt, um systematisch auftretenden Grenz- und Sonderfällen einen Ort zuzuweisen. Doch ist es wenig sinnvoll, für jedes Einzel- und Sonderphänomen eine neue Kategorie zu schaffen, da aus der Komplexität von Wirklichkeit sonst eine potenziell unendliche Parzellierung des Kategoriensystems resultiert, die ihrerseits im Wider-

1104 Kuckartz 2016, S. 72 f.

1105 Weitere genannte Aspekte sind: «Indikation des Forschungsprozesses», «Empirische Verankerung», «Limitation», «Kohärenz», «Relevanz» und «Reflektierte Subjektivität» (Steinke 2009 , S. $324 \mathrm{ff}$.).

1106 Steinke 2009, S. 326.

1107 «Die Dokumentation des Forschungsprozesses ist die zentrale Technik» (Steinke 2009, S. 324; Kursivsetzung analog zum Original).

1108 Steinke 2009, S. 325. 
spruch steht mit der Notwendigkeit einer Reduktion, um Ergebnisse intersubjektiv nachvollziehbar und lesbar aufbereiten zu können.

Auch wenn es der inhaltlich strukturierenden Inhaltsanalyse grundsätzlich um eine möglichst präzise Identifizierung und Abgrenzung von Phänomenen und um Formulierung von möglichst treffenden zugehörigen Kategorien geht, erscheint es mir als ebenso notwendig, den zugehörigen Prozess als womöglich nicht abschliessbar anzuerkennen. Als Qualitätsmerkmal qualitativer Forschung betrachte ich es auch, diejenigen Phänomene, die sich einer eindeutigen Kategorisierung nachhaltig widersetzen, anzuerkennen und überdies sogar produktiv zu nutzen. Möglicherweise stecken gerade in den Grenzregionen und Überschneidungsbereichen zwischen zwei Kategorien relevante Erkenntnisse ${ }^{1109}$ - die Lösung bestünde dann gerade nicht darin, Eindeutigkeit zu erzwingen, sondern über Überschneidungen und Abgrenzungsschwierigkeiten zu reflektieren, nach deren Gründen zu fragen oder gar ein möglicherweise in ihnen ruhendes Potenzial zur Theoriebildung zu identifizieren. Im Rahmen der Ergebnisdarstellung werde ich von Zeit zu Zeit auf solche Grenzfälle eingehen.

Aus der quantitativen Forschung importierte Verfahren zur Herstellung von Güte, namentlich die Berechnung von Intercoderreliabilität, stehen mit einem solchen Anliegen im Widerspruch. Sie bedürfen einer möglichst exakten Definition und Abgrenzung von Kategorien, um handhabbar zu sein, sind also zwangsläufig angewiesen auf Reduktionen und Nivellierungen und damit Aufhebung von Grautönen. Die Gefahr, der Komplexität des Materials nicht ausreichend gerecht zu werden, erscheint mir bei einem solchen Verfahren ausgesprochen hoch, wird aber häufig ignoriert.

Für meine Arbeit wähle ich in Abgrenzung dazu bewusst den von Steinke aufgezeigten Weg und versuche, intersubjektive Nachvollziehbarkeit herzustellen, indem ich nicht nur geglättete Ergebnisse präsentiere, sondern auch Einblicke in die Forschungswerkstatt, Unwägbarkeiten und getroffene Entscheidungen gebe, Materialien dokumentiere, zahlreiche Textbeispiele herbeiziehe und auf diese Weise eine aufgerauhte Ergebnisdarstellung präsentiere, um Leserinnen und Leser dieser Arbeit in die Lage zu versetzen, sich beim Lesen en passant selbst einen detaillierten Eindruck vom Forschungsprozess und den dabei entwickelten Kategorien verschaffen zu können.

1109 Diesen für meine weitere Arbeit sehr zentralen und wegweisenden Hinweis verdanke ich einem Teilnehmer des Doktorandenkolloquiums der Gruppe FUER Geschichtsbewusstsein. 
Weiter zählt Steinke zu den Bausteinen intersubjektiver Nachvollziehbarkeit auch Interpretationen zu mehreren. ${ }^{1110}$ In meinem Fall habe ich das verwendete Kategoriensystem in seiner allgemeinen, dreiteiligen Struktur in Form der daraus resultierenden Modellierung und zugehörige Materialbeispiele bei diversen Gelegenheiten, beispielsweise im Rahmen von Präsentationen auf Tagungen und in Kolloquien oder im sonstigen, interpersonellen Austausch mit Geschichtsdidaktikerinnen und Geschichtsdidaktikern vorgestellt. ${ }^{111}$

Zudem habe ich im Abstand von einigen Monaten für kleine Teile des Materials und Kategoriensystems erneute Codierungen vorgenommen und diese mit den eigenen älteren Codierungen verglichen, um auf diesem Weg die Stabilität eigener Einschätzungen zu beobachten und Abweichungen zu reflektieren.

«Bei der qualitativen Analyse strebt man eine möglichst hohe Zuverlässigkeit der Codezuordnungen an. Im Vergleich mit den üblichen Messungen der Reliabilität in der quantitativ orientierten Forschung geht es aber nicht um die Ermittlung eines Koeffizienten, der die Güte gewissermassen statistisch angibt, sondern es geht primär um eine praktische Verbesserung der Güte der Codierungen.»1112

Im Rahmen des Abgleichs festgestellte Abweichungen in den Codierungen waren insofern aufschlussreich, als sie teilweise bereits bekannte Eindrücke von der nicht eindeutigen Zuordenbarkeit bestimmter Passagen verstärkten und mich dazu animierten, gerade solchen Bereichen bei der Datenauswertung besondere Aufmerksamkeit zu widmen. ${ }^{1113}$

1110 Steinke 2009, S. 326.

1111 Überdies wurden ausgewählte Hauptkategorien von einer zweiten Person im Rahmen eines Gesprächs an einem Materialbeispiel angewendet und besprochen. Der Austausch umfasste die Hauptkategorien innerhalb der Kategorienbereiche «Themen» sowie «Fokussierungen», im zweiten Fall identisch mit den drei Hauptdimensionen des entwickelten Modells (Fokus I auf Geschehen, Fokus II auf die Ausstellung und ihre Elemente und Fokus III auf die eigene Person und Lebenswelt), die ich weiter unten noch genauer vorstellen werde. Diese Hauptdimensionen bzw. die zugehörige Modellierung in ihren Grundzügen wurden bei dem genannten Austausch und auch andernorts als einleuchtend und nachvollziehbar eingeschätzt.

1112 VERBI Software 2014, S. 146.

1113 Mayring fasst die Intracoderreliabilität als «Reliabilität im engeren Sinn», wohingegen die Intercoderreliabilität eigentlich Objektivität, «die Unabhängigkeit der Ergebnisse von der untersuchenden Person» messe (Mayring 2010, S. 117). Auch ohne Fokussierung auf entsprechende Reliabilitätswerte erscheint mir die reflektierte Auseinandersetzung mit den eigenen Codierungen als sinnvolle Massnahme zur Erhöhung der Kohärenz eines Kategoriensystems und zur Verbesserung der Nachvollziehbarkeit, weil dabei Aspekte ins Blickfeld geraten, die einer vertieften Klärung oder Präzisierung bedürfen. 



\section{7 «14/18. Die Schweiz und der Grosse Krieg". Ausstellung, historische Hintergründe und geschichtskultureller Kontext}

Bevor ich im nächsten Kapitel auf die Befunde meiner Studie zu sprechen komme, stelle ich nun zunächst den Ort der Datenerhebung, den "physical context»1114 der zu beforschenden Aneignungsvorgänge, vor. Neben der Beschreibung der eigentlichen Ausstellung, ihrer inhaltlichen Struktur und ästhetischen Gestaltung gehe ich dabei schlaglichtartig auch auf die historischen, historiografischen und geschichtskulturellen Kontexte der Ausstellung ein. Es geht nachfolgend darum, was die Situation der Schweiz im Ersten Weltkrieg ausmachte, wie diese Situation in der Geschichtswissenschaft thematisiert wird und welchen Platz das Thema in vergangenen und gegenwärtigen Geschichtskulturen einnimmt. Geschichtswissenschaft verstehe ich dabei als einen Teilbereich von Geschichtskultur, ${ }^{1115}$ widme ihr aber einen eigenen Abschnitt.

Ich beschreibe das genannte Feld, weil auch die Besuchenden, deren Äusserungen ich analysiere, Teil dieser Geschichtskulturen sind. Sie kommen mutmasslich, ob bewusst oder unbewusst, mit gesellschaftlich vorhandenen Vorstellungen über die Rolle der Schweiz im Ersten Weltkrieg in Kontakt. Die Beschreibung dieser Vorstellungen stellt somit eine wichtige Hintergrundfolie dar, um die Äusserungen der Besuchenden einordnen zu können, auch wenn der Umgang der Besuchenden mit geschichtskulturell wirksamen Deutungen nicht unmittelbar den Forschungsgegenstand meiner Studie bildet.

1114 Falk/Dierking 2000, S. 53. Vgl. Kapitel 3.

1115 In Übereinstimmung mit Schönemann 2014, S. 18 ff.; vgl. hierzu auch die Ausführungen in Abschnitt 3.3 sowie insbesondere Fussnote 468. 


\subsection{Anliegen und Grundstruktur der Ausstellung}

Bei der Ausstellung «14/18. Die Schweiz und der Grosse Krieg» handelt es sich um eine Wanderausstellung, die von dem von Historikerinnen und Historikern gegründeten Verein «Die Schweiz im Ersten Weltkrieg» konzipiert wurde. ${ }^{1116}$ Ziel der Ausstellung sei es, so lautet eine Positionierung der Ausstellungsmachenden, «auf allgemein verständliche Art die Geschichte der Schweiz im Ersten Weltkrieg aufzuarbeiten. Er hat zu Umwälzungen und Erschütterungen geführt wie kaum ein anderes Ereignis zuvor. Dennoch ist er vielen Schweizerinnen und Schweizern weitgehend fremd.» ${ }^{1117}$

Die Ausstellung wurde anlässlich der hundertsten Jährung des Ersten Weltkriegs in mehreren historischen Museen der deutschsprachigen und teilweise auch französischsprachigen Schweiz gezeigt. ${ }^{1118}$ Im Zeitraum zwischen August 2014 und Februar 2015 war die Ausstellung im Historischen Museum Basel, an dessen Standort in der Barfüsserkirche, zu sehen. Dort habe ich meine Datenerhebung durchgeführt. Neben der eigentlichen Wanderausstellung wurde in Basel eine regionalspezifische Ergänzung gezeigt, die vom Museum vor Ort selbst entwickelt wurde. ${ }^{1119}$ Meine folgenden Beschreibungen der Ausstellung beziehen sich, sofern ortsabhängig, auf den Zustand der Ausstellung am Standort in Basel und umfassen die Kernausstellung und die regionalspezifischen Ergänzungen. ${ }^{1120}$

Gegenstand der Ausstellung ist, dem oben zitierten Anliegen entsprechend, die Situation der Schweiz während des Ersten Weltkriegs. Das Geschehen in den krieg-

$1116 \mathrm{Zu}$ den Personen des im Jahr 2011 gegründeten Vereins gehören: Präsident: Thomas Buomberger, Geschäftsführer: Severin Rüegg, Projektleitung: Thomas Buomberger, Patrick Kury, Roman Rossfeld sowie zeitweise Heidi Witzig (2011) und Beatrice Schumacher (2011-2013). Szenografisch umgesetzt wurde die Ausstellung von der Raumprodukt $\mathrm{GmbH}$ (www.ersterweltkrieg.ch/ausstellung/, Zugriff am 21.2.2018).

1117 www.ersterweltkrieg.ch/ausstellung/, Zugriff am 21.2.2018.

1118 Die Ausstellung wurde an folgenden Orten gezeigt, jeweils als Sonderausstellung in einem geschichtlichen Museum vor Ort: Zürich, St. Gallen, Neuenburg, Zug, Frauenfeld, Solothurn (www.ersterweltkrieg.ch und www.ersterweltkrieg.ch/ausstellung/, Zugriff am 21.2.2018).

1119 Die Beschreibung der Ausstellung im Ausstellungsarchiv der Museumswebsite findet sich unter: www.hmb.ch/14/18.html, Zugriff am 21.2.2018.

1120 Für meine folgende Beschreibung der Ausstellungsräumlichkeiten stütze ich mich neben der angegebenen Literatur auf eigene Beobachtungen während meiner Besuche, auf von mir von der Ausstellung oder einzelnen Elementen angefertigte Fotografien sowie auf den mir zur Verfügung gestellten Grundrissplan (vgl. Abb. 6 im digitalen Anhang). Fotografien von der Ausstellung liegen dem Anhang nicht bei. In diese kann zum Beleg meiner Aussagen über die Ausstellung bei Bedarf bei mir Einsicht genommen werden. 
führenden Ländern steht demgegenüber nicht im Zentrum der Darstellung, wird aber immer wieder einbezogen, indem in regelmässigen Abständen Stellwände unter dem Titel «Blick ins Ausland» das zeitgleiche Geschehen im Ausland knapp zusammenfassen. Die Gliederung der Ausstellung folgt in ihrer Grundstruktur einem chronologischen Prinzip, bildet aber innerhalb dieser Struktur auch thematische Einheiten. Einblicke in die räumliche und inhaltliche Struktur der Ausstellung und eine Übersicht über die Ausstellungsabschnitte geben Tabelle E im Anhang sowie ein im digitalen Anhang befindlicher Grundrissplan (siehe Abbildung 6).

Die in Tabelle E ersichtliche Auflistung der Themen entspricht im Wesentlichen auch ihrer räumlichen Aneinanderreihung in der Ausstellung. Die eigentliche Kernausstellung befand sich im Raum für Sonderausstellungen im Untergeschoss des Museums. Die regionalspezifischen Ergänzungen wurden der Kernausstellung räumlich vor- und nachgeschaltet, teilweise im selben Stockwerk, teilweise auch bereits im Bereich der dorthinab führenden Treppe und in einer Zone am oberen Treppenabsatz. Auf diesem Weg ergab sich eine Dreigliedrigkeit der Ausstellung in einen regionalspezifischen Teil, die gesamtschweizerisch orientierte Kernausstellung sowie erneut einen regionalspezifischen Teil. Auch die Kernausstellung selbst kann ihrerseits wiederum als dreiteilig gedeutet werden, indem sie der Darstellung der eigentlichen Kriegsjahre Abteilungen unter dem Motto «Vor dem Krieg» und «Nach dem Krieg» in räumlich und optisch leicht abgetrennten Abteilungen vor- bzw. nachschaltete, sodass sie, zumindest im Fall eines linearen Abarbeitens der Räume, in chronologischer Folge durchschritten wurden.

Allerdings erlaubte die Ausstellung den Besuchenden durchaus Abweichungen von einer strengen Chronologie, was insbesondere für den Mittelteil der Kernausstellung gilt. Die dort befindlichen Abschnitte «Krieg!», «Mitten im Krieg», «Wachsende Not» sowie «Kriegsende und Streik» waren beidseitig entlang eines langgezogenen U-förmigen Ganges (siehe Abbildung 6 im digitalen Anhang) sowie teilweise auch inmitten desselben angeordnet, ohne dass eine Nummerierung der Abschnitte eine bestimmte Reihenfolge des Durchlaufs nahegelegt hätte. So blieb es den Besuchenden selbst überlassen, ob sie die Aussen- und Innenseite des U beispielsweise getrennt hintereinander ablaufen wollten, zwischen Aussen- und Innenseite hin- und herwechseln und sich auf diesem Weg durch das U arbeiten - dies der ideale Fortbewegungsmodus, wollte man der zugrunde liegenden Chronologie folgen - oder weitere völlig freie Formen des Durchgangs wählen wollten. Auf welche Weise die beforschten Besuchenden tatsächlich ihre Wege durch die Ausstellung nahmen, werde ich im Verlauf der Ergebnisdarstellung noch beleuchten. 


\subsection{Historische, historiografische und geschichtskulturelle Einordnung der Ausstellung}

Auf der zur Ausstellung gehörigen Website formulieren die Ausstellungsmachenden die inhaltliche Ausrichtung der Ausstellung wie folgt:

«Der Erste Weltkrieg war die erste mit allen technischen und propagandistischen Mitteln geführte militärische Auseinandersetzung von globalem Ausmass. Obwohl die Schweiz von Kampfhandlungen verschont blieb, erschütterte der Krieg das Land und veränderte es grundlegend. Die vier Kriegsjahre führen in der Schweiz zu zunehmenden Spannungen zwischen den sozialen Klassen, zwischen der Romandie und der Deutschschweiz, zwischen Arbeiterschaft und Bauern, Offizieren und Soldaten. Im Landesstreik von 1918 eskalieren diese Konflikte. Die Ausstellung zeigt diese zunehmende Erschütterung nicht nur thematisch in den Bereichen Wirtschaft, Gesellschaft, Militär und Politik, sondern auch durch die visuellen [sic] Gestaltung. Hunderte von Fotos, Dokumenten, Filmen und Objekten erzählen die Geschichte einer Schweiz, die zwar nicht vom Krieg militärisch betroffen ist, aber vor grossen Herausforderungen steht.» ${ }^{1121}$

Wie dieses Anliegen mithilfe der «visuellen Gestaltung» umgesetzt wird, darauf werde ich weiter unten noch zu sprechen kommen, wenn ich mich der ästhetischen Aufmachung der Ausstellung zuwende. Im aktuellen Kapitel ordne ich die Ausstellung inhaltlich ein und tue dies mit Blick auf ihre historischen, historiografischen und geschichtskulturellen Hintergründe.

Inhaltlich deuten sich im zitierten Anliegen Elemente eines «[d]ominante[n] Narrativ[s]» an, wie dieses von Konrad Kuhn und Béatrice Ziegler für historiografische Darstellungen zur Schweiz im Ersten Weltkrieg herausgearbeitet wurde. ${ }^{1122}$ Auf den folgenden Seiten stelle ich zunächst Elemente dieses Narrativs sowie Ansätze für seine Differenzierung und Erweiterung vor. Anschliessend öffne ich den Fokus und nehme insgesamt geschichtskulturelle Umgangsweisen mit dem Thema in den Blick. Zum Schluss wende ich mich der Erzählung der Ausstellung zu und zeige, wie sich in dieser das bekannte Narrativ einerseits wiederspiegelt, aber auch differenziert und erweitert wird.

1121 www.ersterweltkrieg.ch/hintergrund/, Zugriff am 21.2.2018.

$1122 \mathrm{Kuhn} /$ Ziegler 2011, direktes Zitat: Titel. 


\subsubsection{Die Schweiz im Ersten Weltkrieg. Historische und historiografische Hintergründe, "Dominantes Narrativ»"123 und Differenzierungen}

Im Historischen Lexikon der Schweiz (HLS) findet sich im Artikel zum Ersten Weltkrieg der folgende einführende Überblicksabschnitt zur Situation der Schweiz während der Kriegsjahre:

«Zwar blieb die Schweiz von militär. Angriffen verschont, doch war sie von der Länge des Kriegs und insbesondere von der Blockade der Alliierten und den daraus resultierenden wirtschaftl. Schwierigkeiten betroffen. Dazu kam die massive Ausweitung des Militärbudgets. Trotzdem konnte sich die Schweiz in dieser Zeit als Finanzplatz entwickeln. Die Bevölkerung war entlang der Sprachregion gespalten: Während die Deutschschweizer mehrheitlich mit den Mittelmächten sympathisierten, standen die Westschweizer zu grossen Teilen auf Seiten der Alliierten. Die sozialen Probleme kulminierten im Landesstreik von 1918, der zum Ende der Hegemonie des Freisinns führte. Während des Konflikts bemühte sich die Eidgenossenschaft, ihre seit Beginn des 20. Jh. betriebene Politik der Neutralität und der Guten Dienste weiterzuführen (Haager Konventionen).»1124

Dieser Abschnitt steht beispielhaft für ein «[d]ominantes Narrativ», das Kuhn und Ziegler in historiografischen Überblicksdarstellungen der letzten 70 Jahre zur Schweiz im Ersten Weltkrieg identifiziert und beschrieben haben. ${ }^{1125}$ Als fünf zentrale Elemente dieses Narrativs benennen Kuhn und Ziegler folgende Deutungen:

- Der Erste Weltkrieg sei «eine kulturell bedingte Zerreissprobe zwischen der Deutschschweiz und der Romandie» gewesen,

- $\quad$ er sei überdies «eine soziale Zerreissprobe» gewesen, sich manifestierend unter anderem in «der Teuerung, der schwierigen wirtschaftlichen Lage der Soldatenfamilien und [...] mangelhaften Vorsorgeleistungen des Staats» sowie in Form von Landesstreik und Spanischer Grippe,

$1123 \mathrm{Kuhn} /$ Ziegler 2011.

1124 www.hls-dhs-dss.ch/textes/d/D8926.php, Zugriff am 21.2.2018.

$1125 \mathrm{Kuhn} /$ Ziegler 2011, S. $123 \mathrm{f}$; Kuhn und Ziegler konstatieren dies für eine Version des HLS-Artikels aus dem Jahr 2009 (Kuhn/Ziegler 2011, S. 137, dortige Fussnote 4), wobei der von mir vorgefundene und zitierte Einführungsabschnitt aus der Version von 2015 immer noch zu dem von ihnen Festgestellten passt. 
- in Gestalt des Landesstreiks habe die Schweiz «vor einer Revolution» gestanden, aber den «Weg zum Friedensabkommen» gewählt,

- im Ersten Weltkrieg habe die Schweiz die Neutralität erklärt, jedoch sei es «zu Neutralitätsverletzungen durch Regierungsmitglieder und öffentliche Personen» gekommen und hätten «Versorgungsfragen» eine «Herausforderung für die Neutralitätspolitik» dargestellt,

- der «Verteidigungswille und die Verteidigungsfähigkeit der Armee» gälten als «nicht diskutabel», jedoch würden Probleme in «der Person von General Ulrich Wille, in seiner Auffassung von der Armeeführung und seiner Deutschfreundlichkeit» gesehen. ${ }^{1126}$

Kuhn und Ziegler konstatieren eine relative Stabilität dieser Elemente in Überblicksdarstellungen, eine «Beharrlichkeit des Narrativs», wobei «sich die zentralen Elemente des Topos entgegen neuerer Erkenntnisse halten». ${ }^{1127}$

Welche Erkenntnisse sind es, die zu einer Anpassung des klassischen Narrativs führen könnten? Seit der Feststellung Kuhns und Zieglers im Jahr 2011 sind sogar noch weitere solche Erkenntnisse hinzugekommen, wird doch die Geschichte der Schweiz im Ersten Weltkrieg seit einigen Jahren intensiv erforscht, namentlich im Rahmen des vom Schweizerischen Nationalfonds geförderten Sinergia-Projekts «Die Schweiz im Ersten Weltkrieg. Transnationale Perspektiven auf einen Kleinstaat im totalen Krieg». ${ }^{1128}$ In jüngster Vergangenheit aus dem Projekt hervorgegangene Publikationen ${ }^{1129}$ lasse ich an dieser Stelle allerdings unberücksichtigt, auch wenn ihre Erkenntnisse zur Erweiterung und Differenzierung der bisherigen Perspektiven auf die Schweiz im Ersten Weltkrieg beitragen könnten. ${ }^{1130}$ Vielmehr gebe ich den Forschungsstand etwa in dem Stadium wieder, wie er für die Ausstellung vorlag.

Auch dann bieten sich bereits Differenzierungen des traditionellen Narrativs an. In Bezug auf den «kulturellen Graben» legen Kuhn und Ziegler die Möglichkeit dar, eben jenen «Graben» weniger als kulturell und sprachlich bedingt zu verstehen und weniger als Gefährdung für die nationale Einheit aufgrund unterschiedlicher Solidaritäten mit den kriegführenden Nachbarländern zu deuten,

$1126 \mathrm{Kuhn} /$ Ziegler 2011, S. $123 \mathrm{f}$.

1127 Kuhn/Ziegler 2011, S. 128.

1128 http://p3.snf.ch/Project-141906, Zugriff am 21.2.2018.

1129 Weber 2016; Elsig 2017.

1130 Dies entnehme ich den Rezensionen von Ziegler zu beiden Publikationen: Ziegler 2017b, insb. S. 3; Ziegler 2017c, S. If. 
sondern stattdessen und umgekehrt «die intensive Auseinandersetzung um die Positionierungen der jeweils anderen Sprachgruppe [gerade] aus einem dezidierten nationalen Engagement heraus zu erklären». ${ }^{131}$

Weiter verweisen Kuhn und Ziegler auf die Notwendigkeit einer differenzierten Betrachtung des Phänomens:

«Die über Jahrzehnte postulierte kulturelle Kluft zwischen der Deutsch- und Westschweiz erfährt [...] in den regionalen Darstellungen einen erheblichen Komplexitätszuwachs, ja geradezu eine Korrektur. Zwar finden sich für mehrere Deutschschweizer Kantone enge Bande zu Deutschland und den Mittelmächten [...] [,] gleichwohl differenziert sich das pauschale Bild der politischen Parteinahme für die Mittelmächte deutlich.»1132

Zudem werde nicht bedacht, «dass die untersuchte Publizistik über die Stimmung und die Überzeugungen in der Bevölkerung wenig auszusagen vermag». ${ }^{1133} \mathrm{Zu}$ ergänzen ist hier noch die bei Alexandre Elsig oder Jakob Tanner zu findende Deutung, dass die Schweiz zu einer «Propagandaplattform» für kriegführende Mächte, ${ }^{1134} \mathrm{zu}$ einem durch den Einkauf schweizerischer Medien von den kriegführenden Mächten bestimmten «Austragungsort des Medienkrieges» wurde ${ }^{1135}$ - eine Deutung, die die Rede vom angeblichen kulturellen Graben ergänzen oder relativieren kann. ${ }^{136}$

$1131 \mathrm{Kuhn} /$ Ziegler 2011, S. 128 f. Letzteres werde durch die Arbeit von DuBois nahegelegt (DuBois 1983, zit. n. Kuhn/Ziegler 2011, S. 128 f.). Andernorts, aber thematisch daran anknüpfend, weisen Kuhn/Ziegler darauf hin, «dass die Kritik und die Ängste, die sich in der Öffentlichkeit der Romandie artikulierten, häufig politische Positionierungen der weitgehend deutschsprachig dominierten Armeeführung und Landesregierung und von Teilen der Eliten betrafen. Dies konnte kaum als Ausdruck kultureller Differenz verstanden werden» (Kuhn/Ziegler 2014b, S. 375).

$1132 \mathrm{Kuhn} /$ Ziegler 2011, S. 132.

1133 Kuhn/Ziegler 2011, S. 128. Darauf, dass bislang vor allem Presseerzeugnisse untersucht wurden und diese keine Schlüsse auf einen «Graben» in der Bevölkerung zulassen, weist auch Mauro Cerutti, der Autor des Abschnitts «Innenpolitik» im weiter oben genannten HLS-Artikel, hin (Cerutti 2015).

1134 Elsig 2014, S. 73.

1135 Tanner 2015, S. 128.

1136 Elsig spricht davon, die Propagandamassnahmen hätten «das sensible Gleichgewicht der Sprachen [gestört] und [...] den Graben [vertieft], der sich seit dem Kriegsbeginn zwischen den Deutschschweizern und den West- und Südschweizern auftat» (Elsig 2014, S. 73). Ziegler deutet später seinen Artikel als Beginn des Versuchs, die unglückliche Rede vom 〈Röstigraben» «in ein weitgehend neues Licht [zu] stellen» (Ziegler 2017b, S. 3, inkl. dortige Fussnote 5). 
In Bezug auf die soziale Spaltung und die in diesem Zusammenhang häufig vorgenommene Verknüpfung des Landesstreiks mit dem Ersten Weltkrieg konstatieren Kuhn und Ziegler, Autorinnen und Autoren gingen

«in der Regel davon aus, dass die (kriegsbedingten) sozialen Probleme im Ersten Weltkrieg zum 〈Landesstreik〉 geführt haben. Die Haltung des Staats und der Bürgerlichen gegenüber den sozialen Problemen wird dabei nicht grundsätzlich angesprochen und deshalb auch nicht in Erwägung gezogen, dass sich darin eine Politik manifestierte, die bereits vor dem Krieg feststellbar war - eine Interpretation, die Jost bereits 1983 nahe gelegt hatte.» ${ }^{1137}$

Neben einer diesbezüglich möglichen Korrektur bzw. Differenzierung des Narrativs verweisen Kuhn und Ziegler komplementär auch auf das sich zunehmend vervollständigende «Bild der konkreten Versorgungsprobleme und der im Lauf des Kriegs überdeutlich werdenden Überforderung der Bundesbehörden». Eine dem Rechnung tragende Erzählung spreche eher von einer «Krise des gesamten Staatswesens. Sie erachtet nicht kulturelle und soziale Spannungen als zentral, sondern identifiziert die Verantwortung bei den versagenden politischen wie wirtschaftlichen Steuerungssystemen.» ${ }^{1138}$

Weiter beschreiben Kuhn und Ziegler das dominante Narrativ als nicht sensibel für Befunde der Geschlechtergeschichte. ${ }^{1139}$ So lasse sich die Zeit des Ersten Weltkriegs auch deuten als ein «Handlungsraum, den einzelne Angehörige oder spezifische Gruppen und Verbände der Frauenbewegung mit ihren karitativen Bemühungen nutzten, um Frauen ein nationales Betätigungsfeld und nationale Aufmerksamkeit zu verschaffen», wie etwa Else Züblin-Spiller und deren Engagement in Form von Soldatenstuben. ${ }^{1140}$

Wie lässt sich aber nun die Situation in der Schweiz zur Zeit des Ersten Weltkriegs knapp und zusammenfassend beschreiben? Ich gehe nachfolgend auf einige Aspekte ein, sofern diese nicht ohnehin schon in den letzten Absätzen als Bestandteile, Ergänzungen oder Differenzierungen des bekannten Narrativs angespro-

1137 Kuhn/Ziegler 2011, S. 130. Kuhn/Ziegler beziehen sich hier auf Jost 1983, S. 116-119, 136-140.

1138 Kuhn/Ziegler 2011, S. 132.

1139 Neben Kuhn/Ziegler 2011 finden sich Ausführungen zu «Forschungslücken und verpasste[n] Chancen» in Bezug auf die Rolle von Frauen und die wirtschaftlichen Verflechtungen der Schweiz ausserdem bei Kuhn/Ziegler 2013, S. 516 ff.

1140 Kuhn/Ziegler 2011, S. 134 f., direktes Zitat S. 135. 
chen wurden. Zu nennen ist sicherlich die Mobilisierung von etwa 200000 Wehrmännern, von Fall zu Fall mit unterschiedlicher Dauer und Häufigkeit, die gleichzeitigen Verdienstausfall bedeutete und Frauen neue Möglichkeiten eröffnete - einerseits als Versorgerinnen ihrer Familien, andererseits im Rahmen von Frauenvereinen, deren Engagement im zivilen Bereich und bei der Betreuung von Soldaten. ${ }^{1141} \mathrm{Zu}$ nennen ist in diesem Zusammenhang auch der für die schweizerische Wirtschaft relevante Verlust von ausländischen Arbeitskräften, die zu Kriegsbeginn in ihre Herkunftsländer zurückkehrten. ${ }^{1142}$

Die wirtschaftliche Lage erweist sich in der Schweiz während des Ersten Weltkriegs insgesamt als vielschichtig, differenziert und im Zeitverlauf unterschiedlich. Roman Rossfeld und Tobias Straumann schlagen hierfür ein «Phasenmodell für die schweizerische Volkswirtschaft im Krieg» vor. ${ }^{1143}$ In einer ersten und kurzen Phase nach Kriegsbeginn habe die Wirtschaft zunächst nahezu stillgestanden, «weil die Einfuhr blockiert war und bedeutende Teile des männlichen Personals - nicht nur Schweizer, sondern auch zahlreiche ausländische Arbeitskräfte - mobilisiert wurden», was zu Betriebsschliessungen und einem «Ansturm auf Lebensmittelläden» geführt habe. ${ }^{1144}$ In einer zweiten Phase sei ab Frühling 1915 der Abschluss von Handelsabkommen mit den kriegführenden Ländern gelungen und habe «eine eigentliche Kriegskonjunktur» eingesetzt, was zu einem deutlichen Anstieg von Exportmengen geführt habe, wobei «[r] und zwei Drittel der Exporte von kriegswichtigen Industrien, der Textil-, Metall-, Maschinen- und der Uhrenindustrie getätigt» worden seien. ${ }^{1145} \mathrm{Ab}$ Juni 1916 sei jedoch mit der «Verschärfung des Wirtschaftskriegs durch die Entente» die Wirtschaft «dramatisch» geschrumpft und hätten Importe und Exporte in den Jahren 1917 bis 1918 deutlich abgenommen, etwa im Bereich von Lebensmitteln und Rohstoffen. ${ }^{146} \mathrm{Zu}$ sammenfassend kommen Rossfeld und Straumann allerdings zu dem Befund,

1141 Kuhn/Ziegler 2014c, S. 8 ff.

$1142 \mathrm{Kuhn} /$ Ziegler 2014c, S. 8.

1143 Rossfeld/Straumann 2008, S. 23 ff., direktes Zitat S. 23, sich mit ihren Ausführungen zu den Phasen auf Geering beziehend (Geering 1928, zit. n. Rossfeld/Straumann 2008, S. 23).

1144 Rossfeld/Straumann 2008, S. 23.

1145 Rossfeld/Straumann 2008, S. 23 f., S. 26, direkte Zitate S. 23 u. S. 26. Nachdem zu Kriegsbeginn vom Bundesrat ein «Verbot der Munitionsausfuhr» erlassen worden war, wurden von Privatunternehmen in der Folge stattdessen «in grossem Stil Munitionsbestandteile» exportiert (Tanner 2015, S. 137).

1146 Rossfeld/Straumann 2008, S. $24 \mathrm{f}$. 
«dass die industriellen Exportunternehmen den Ersten Weltkrieg gut überstanden und einzelne von ihnen sogar überdurchschnittlich hohe Gewinne erzielten. [...] Die von der Politik vorgegebene Neutralität des Landes ermöglichte es den Unternehmen, an alle oder zumindest viele Fronten zu liefern und im Krieg neue Märkte zu erschliessen.» ${ }^{1147}$

Mit dem Verweis auf die wirtschaftliche Situation der Schweiz während des Ersten Weltkriegs ist lediglich ein kategorialer Zugriff unter vielen angeschnitten, ${ }^{1148}$ den ich exemplarisch auch deshalb herausgegriffen habe, weil der Blick auf die schweizerische Wirtschaft, neben einer Reihe weiterer Themen, auch für die Ausstellung von herausgehobener Relevanz ist. Meine Ausführungen zur Situation der Schweiz während des Ersten Weltkriegs müssen gleichwohl punktuell und holzschnittartig bleiben und können nicht alle Themen aufgreifen, die für eine differenzierte historische Betrachtung relevant wären oder in der Ausstellung von Bedeutung sind, wie etwa die ebenfalls behandelten Fragen des Umgangs mit Ausländern und Ausländerinnen in der Schweiz einschliesslich des Endes der Personenfreizügigkeit und der Angst vor «Überfremdung». ${ }^{1149}$ Einige der bislang noch nicht behandelten Themen tauchen im Verlauf meiner Arbeit auf Umwegen auf, wenn ich die Äusserungen der Besuchenden zu bestimmten Themen zitiere.

\subsubsection{Geschichtskulturelle Einordnung: Manifestationen und Erzählungen zur Schweiz im Ersten Weltkrieg}

Bevor ich im nächsten Abschnitt die Erzählung der Ausstellung und ihren Umgang mit dem bekannten Narrativ in den Blick nehme, werfe ich vorgängig noch einen Blick in den geschichtskulturellen Kontext der Ausstellung. ${ }^{1150}$ Ein systema-

1147 Rossfeld/Straumann 2008, S. 53.

1148 Wenn auch dabei viele Aspekte notwendigerweise aussen vor bleiben, so etwa die Überwachungen und Restriktionen wirtschaftlicher Abläufe in der von Importen abhängigen Schweiz durch die kriegführenden Nationen (dazu Tanner 2015, S. 136 ff.).

1149 Ein Überblick zum Thema findet sich bei Kury 2014.

1150 Auch hier fokussiere ich wieder, wie schon in der historischen Einordnung und in Übereinstimmung mit dem Thema der gewählten Ausstellung, auf Manifestationen mit Bezug zur Schweiz. Das Spektrum geschichtskultureller Thematisierungen des Ersten Weltkriegs in den kriegführenden Ländern und mit Bezug auf die dortigen Ereignisse (z. B. Schlachtfeldreisen, hierzu: Brandt 2008) lasse ich aussen vor.

Einen hilfreichen, systematisierenden Überblick über das vielfältige Feld der Geschichtskultur zum Ersten Weltkrieg liefert, mit Schwerpunkt auf den kriegführenden Ländern, 
tischer Überblick über Umgangsweisen mit der Schweiz im Ersten Weltkrieg in vergangenen und gegenwärtigen Geschichtskulturen liegt erstmals mit einem von Konrad J. Kuhn und Béatrice Ziegler herausgegebenen Sammelband vor. ${ }^{1151}$ Unter dem programmatischen Titel «Der vergessene Krieg» verfolgt der Band das Ziel, sich auf die Suche nach «Spuren» zu begeben, nach Erzählungen über die Schweiz im Ersten Weltkrieg, dabei der Idee folgend, dass zwar der Erste Weltkrieg allgemein in den Vorstellungen virulent, jedoch «die Schweiz im Ersten Weltkrieg in den Köpfen der schweizerischen Bevölkerung eine Leerstelle sei» bzw. im «Schatten des Zweiten Weltkriegs» stehe. ${ }^{1152}$ Trotz dieses Schattendaseins versammelt sich im Band eine ganze Bandbreite geschichtskultureller Manifestationen, in denen die Situation der Schweiz während des Ersten Weltkriegs virulent war oder noch ist, angefangen von Bildpostkarten über Erinnerungsfotografien und Tageszeitungen bis hin zu Geschichtslehrmitteln und Internet, in Form von politischen Reden, Denkmälern, Filmen und auch Ausstellungen. ${ }^{1153} \mathrm{Zu}$ den heute noch im öffentlichen Raum sichtbarsten Manifestationen zählen sicherlich die zahlreichen Wehrmännerdenkmäler. ${ }^{1154}$

Tobias Arand (2006). Er regt an, geschichtskulturelle Erzeugnisse zum Ersten Weltkrieg nach drei Dimensionen zu systematisieren (ebd., S. 3 ff.),

- erstens in zeitlicher Hinsicht (ebd., S. 4f.), wobei Arand nach «der aktuellen Dimension» und «der historischen Dimension» unterscheidet (ebd., S. 4; im Original z. T. unterstrichen), wobei er die aktuelle Auseinandersetzung für den Fall von Deutschland als «weitgehend emotionsfrei und sachlich» (ebd., S. 4) klassifiziert,

- zweitens in nationaler Hinsicht nach jeweiliger nationaler Zugriffsweise zum Thema (ebd., S. 5 f.), wobei in bestimmten Ländern - und wohl im Gegensatz zu der obigen Vorstellung in Bezug auf Deutschland formuliert - der Erste Weltkrieg «weder historisiert noch entpolitisiert» (ebd., S. 5) sei, sondern vielmehr «[i]m öffentlichen wie privaten Gedenken an die Opfer des Ersten Weltkriegs [...] diese Nationen bis heute Selbstbild und Gründungsmythen [entwickeln]» (ebd., S. 6),

- drittens in Form einer «Kategorisierung der Produkte und Sphären der Geschichtskultur des Ersten Weltkriegs» (ebd., S. 6 ff., direktes Zitat S. 6), wobei Arand nach «Dingwelt» und «Gruppen» unterscheidet, ausserdem nach «private[r] Geschichtskultur» und «institutioneller Geschichtskultur», dabei Letztere in eine «ungelenkte institutionelle Seite» und «gelenkte institutionelle Seite» differenziert, bei Ersterer hingegen Produkte «nichtkommerziell[er]» und «kommerzieller Herkunft», Produkte der «Alltagskultur» und «Hochkultur» unterscheidet (ebd., S. 7 ff.), insgesamt allerdings in dem Bewusstsein von «Grenzen der Zuordbarkeit» (ebd., S. 11).

$1151 \mathrm{Kuhn} /$ Ziegler 2014a.

$1152 \mathrm{Kuhn} /$ Ziegler 2014c, S. 8.

1153 Vgl. das Inhaltsverzeichnis zum genannten Band von Kuhn/Ziegler 2014a.

1154 Kuhn/Ziegler 2014b, S. 377 ff. Zu einem spezifischen, im Zusammenhang mit der Grenzbesetzung im Ersten Weltkrieg entstandenen Denkmal, dessen Umdeutung und politischer Aufladung unter dem Stichwort «Aktionen gegen die Sentinelle»: Kreis 2008, S. 405 ff. 
Der genannte Sammelband folgt mit seiner Gliederung den unterschiedlichen Typen geschichtskultureller Manifestationen, also der physischen Ausprägungen von Geschichtskultur. Über diese sind vermittelt Rückschlüsse auf gesellschaftliches und individuelles Geschichtsbewusstsein möglich. Allerdings liegt derzeit meines Wissens keine empirische Studie vor, die dezidiert nach aktuell in der Bevölkerung vorherrschenden Vorstellungen von der Rolle der Schweiz im Ersten Weltkrieg fragen würde - anders als hinsichtlich der Rolle der Schweiz im Zweiten Weltkrieg bzw. während des Holocaust. ${ }^{1155}$ Auch sind mir keine Untersuchungen dazu bekannt, wie die Thematik im Geschichtsunterricht behandelt wird. Allerdings liegen Analysen von Geschichtslehrmitteln vor, die nach der dortigen Thematisierung der Schweiz im Ersten Weltkrieg in Lehrmitteln fragen ${ }^{1156}$ und Auskünfte über eine medienseitig vorhandene Angebotsstruktur geben, aber weder Rückschlüsse auf die Art von deren Einsatz im Unterricht noch auf die Rezeption des Themas durch die mit den Lehrmitteln in Kontakt kommenden Schülern und Schülerinnen ermöglichen.

Die genannten Lehrmittelanalysen zeigen, dass es, ähnlich wie in der Historiografie zur Schweiz im Ersten Weltkrieg, auch in Lehrmitteln bestimmte stabile Elemente gibt, die sich bisweilen über Jahrzehnte hinweg, teilweise bis in die vorletzte Lehrmittelgeneration, identifizieren lassen. ${ }^{1157}$ Markus Furrer nennt in Bezug auf die Darstellung der Rolle der Schweiz in den beiden Weltkriegen drei Motive, den «Neutralitätsmythos», den «Réduitmythos» und den «Samaritermythos». ${ }^{1158}$ Erzählt wird darin, zusammengefasst, von einer neutralen, wehrhaften und humanitären Schweiz, wohingegen eine Infragestellung oder Relativierung der Neutralitätsidee im Hinblick auf innen- und aussenpolitische Entwicklungen nur sehr begrenzt

1155 Vorstellungen zur Rolle der Schweiz im Zusammenhang mit dem Holocaust erhoben Peter/Burgermeister 2012.

1156 Furrer 2004; Furrer 2009; Morgenthaler 2009; Schultheiss/Thyroff 2014a; Schultheiss/ Thyroff 2014b; Thyroff 2017a.

1157 Die folgenden beiden Abschnitte stellen eine verkürzte Zusammenfassung meiner früheren Ausführungen zum Forschungsstand in Bezug auf Lehrmittel dar (Thyroff 2017a, S. $161 \mathrm{ff}$. und S. 179 f.). Die derzeit jüngste Generation von Lehrmitteln, namentlich, «Durchblick», "Gesellschaften im Wandel» und «Zeitreise», die sich am neuen deutschschweizerischen Lehrplan 21 orientieren, sind von keiner der erwähnten Studien mehr berücksichtigt.

1158 Furrer 2004, S. 258 ff., 260 ff., 263 ff.; direkte Zitate S. 258, S. 260, S. 263. Vergleichbar damit identifiziert Jonas Morgenthaler in Bezug auf Lehrmitteldarstellungen zum Ersten Weltkrieg «drei Leitmotive», nämlich « Neutralität», «Wehrhaftigkeit» und «Barmherzigkeit» (Morgenthaler 2009, S. 49 ff., direkte Zitate S. 49, S. 50, S. 55). 
stattfinde. ${ }^{1159}$ Neutralität werde in den Lehrmitteln gar nicht eigentlich als Thema behandelt, sondern punktuell und schlagwortartig eingeworfen, erscheine statisch und gegeben und bleibe insgesamt «an einem Oberflächenphänomen haften, das leicht mythologisierbar wird». ${ }^{1160}$

Die genannten drei Motive sind, wie Markus Furrer oder auch Jonas Morgenthaler zeigen, in Lehrmitteln über etliche Jahrzehnte hinweg vorzufinden, wenn auch mit punktuellen Akzentuierungen, und erfahren erst mit jüngeren Lehrmitteln eine Erosion, etwa wird die bis dahin unhinterfragte Neutralität zum Diskussionsgegenstand, wobei Furrer die öffentlichen Debatten um die Rolle der Schweiz im Zweiten Weltkrieg in den 1990er-Jahren als wichtigen Einschnitt deutet. ${ }^{1161}$ Jüngere Lehrmittel lassen einerseits Elemente einer Repetierung, andererseits aber auch Ansätze zur De-konstruktion solcher stabilen Erzählungen erkennen. ${ }^{1162}$

Ich erwähne Lehrmittel an dieser Stelle zum einen, weil ich sie als Manifestationen einer breit verstandenen und auch den Geschichtsunterricht einbeziehenden Geschichtskultur verstehe. Lehrmittel können als Indikatoren für gesellschaftlich verbreitete und anerkannte Geschichten verstanden werden und zugleich als Ausdruck dessen, was von dieser Gesellschaft als lernenswert für Schüler und Schülerinnen angesehen wird. ${ }^{1163}$ Zudem gehe ich davon aus, dass die Teilnehmenden meiner Studie teilweise im Rahmen ihres eigenen Geschichtsunterrichts mit diesen Lehrmitteln und Erzählungen in Kontakt gekommen sind. Das Wissen um die in Lehrmitteln virulenten Erzählungen sensibilisiert für mögliche auch in den Äusserungen der Besuchenden auftretenden Motive - selbstverständlich ohne dass diese kausal auf Ursprünge wie etwa einen Lehrmittelkontakt zurückgeführt werden könnten.

Die in den Lehrmitteln identifizierten Motive lassen sich durchaus in einen grösseren gesellschaftlichen Kontext einordnen, handelt es sich doch um Motive eines kollektiven Gedächtnisses, die sich mit Jakob Tanner bis in die Schweiz des

1159 Furrer 2004, S. 238, S. 260.

1160 Furrer 2004, S. 232 ff., S. 238, S. 258, S. 260, direktes Zitat S. 238.

1161 Furrer 2004, S. 260 f., S. 266; Furrer 2009, S. 149, S. 152 ff., S. 157 ff.; Morgenthaler 2009, S. 49 ff., S. 55; Furrer identifiziert je nach Zeit vier Akzentuierungen: den «Souveränitätsdiskurs», «Bedrohungsdiskurs», «Bewährungsdiskurs» und «Krisendiskurs» (Furrer 2009, S. 152 ff., direkte Zitate S. 150, S. 154, S. 155, S. 157).

$1162 \mathrm{Vgl}$. hierzu meine Ausführungen in Thyroff 2017a, zusammenfassend S. $179 \mathrm{ff}$., wobei auch darin die Lehrmittel der jüngsten Generation, beispielsweise «Durchblick», "Gesellschaften im Wandel» oder "Zeitreise», nicht mehr berücksichtigt sind.

1163 Furrer 2004, S. 64; Handro/Schönemann 2011b, S. 4f.; diesen Zusammenhang habe ich andernorts schon ähnlich beschrieben: Thyroff 2017a, S. $164 \mathrm{f}$. 
ausgehenden 19. Jahrhundert zurückführen lassen. Im Rahmen der Erfindung einer nationalstaatlichen Identität seien dort Demokratie, Föderalismus, Eigenständigkeit, Neutralität, Wehrhaftigkeit nach aussen und Zusammenhalt ins Innere zu Bestandteilen einer «imaginierte[n] Gemeinschaft der Confoederatio helvetica» geworden. ${ }^{1164}$

Mit der Geistigen Landesverteidigung ab den 1930er-Jahren bis in die Zeit des Kalten Kriegs hinein wurden ähnliche Deutungen angesichts einer empfundenen Bedrohungslage bewusst genährt. ${ }^{1165}$ Als Elemente der für die Geistige Landesverteidigung prägenden Denkweise lassen sich nach Kuhn und Ziegler folgende bestimmen: die Unterordnung des Einzelnen unter gesellschaftliche Erwartungen und Bestimmungen, der Vorzug des Bäuerlichen vor dem Städtischen, die Bedeutung der Wehrtauglichkeit und Vorrangstellung der Armee vor der Zivilgesellschaft, die Unterordnung von Frauen unter Männer, der Blick auf das Moderne, Städtische und Weltoffene als unschweizerisch und schliesslich der historische Bezug auf die Ursprungsgeschichten der Eidgenossenschaft. ${ }^{1166}$ Kurzum: «In dieser Selbstdefinition eines wehrhaften Kleinstaats diente der Erste Weltkrieg zum einen zur Begründung bewährter Strategien und Haltungen, zum anderen geriet er zur Negativfolie aktueller Verhältnisse», vorerst zur «Negativfolie für das Selbstbild der Schweiz im Zweiten Weltkrieg» ${ }^{1167}$ - ein Narrativ, das durchaus paradox ist, wie Kuhn und Ziegler andernorts feststellen. ${ }^{1168}$

Sie nennen drei Elemente einer solchen während der Geistigen Landesverteidigung stattfindenden Abgrenzung von einer Negativfolie: Die Erinnerung an den Ersten Weltkrieg sei nämlich von staatlicher Seite genutzt worden für erstens die Selbstinszenierung «als fürsorglicher Staat», der aus seinen Fehlern im Ersten Weltkrieg gelernt habe, ebenso wie zweitens für den Nachweis, dass die Armee aus der damaligen problematischen sozialen Spaltung zwischen Soldaten und Offizie-

1164 Tanner 1999, S. 28. Ähnlich habe ich Tanner bereits in Thyroff 2017a, S. 161, rezipiert. Zur De-konstruktion eines solchen Schweizbildes jüngst auch Maissen 2015, S. $104 \mathrm{ff}$., S. $162 \mathrm{ff} .$, S. $172 \mathrm{ff}$.

1165 Kuhn/Ziegler 2014b, S. 368 ff. Zur Geistigen Landesverteidigung und deren Erzählung über die Rolle der Schweiz im Ersten Weltkrieg ausserdem Kuhn/Ziegler 2016, S. 3 ff.

$1166 \mathrm{Kuhn} /$ Ziegler 2014b, S. 369.

1167 Kuhn/Ziegler 2014b, S. 369, S. 374.

1168 Nämlich: «On the one hand, the First World War, as a history of conflict, represented a negative foil against which the Swiss state and the army could present itself as capable of learning from the past by not repeating the errors made. At the same time, state and military activities were described - quite paradoxically - as the very factor responsible for ensuring that Switzerland was spared from the horrific war» (Kuhn/Ziegler 2016, S. 7). 
ren gelernt habe, und drittens sei versucht worden, stärker «den nationalen $\mathrm{Zu}$ sammenhalt über die Sprachgrenzen hinweg zu sichern», wobei die Rede vom kulturellen Graben allerdings überhaupt erst zementiert worden sei. ${ }^{1169}$

Die Geschichtskultur zur Schweiz im Ersten Weltkrieg ist insofern ausgesprochen vielschichtig und wird überlagert durch Umgangsweisen mit dem Zweiten Weltkrieg und dem Kalten Krieg. Kuhn und Ziegler konstatieren «eine hintergründige Präsenz des Ersten Weltkriegs, die sich in einer Vielfalt von verschiedenen Spuren und Erzählungen offenbart», wobei «neben der mehrfach überlagerten nationalen Geschichtskultur» eine Vielzahl von themen-, region- und gruppenabhängigen Erzählungen vorhanden seien. ${ }^{1170}$

In diesem vielschichtigen geschichtskulturellen Feld müssen sich nun auch aktuelle historische Museen und Ausstellungsprojekte zur Schweiz im Ersten Weltkrieg ihren Platz suchen. Einen Überblick über die insgesamt spärliche museale Auseinandersetzung mit dem Ersten Weltkrieg in schweizerischen Museen und Ausstellungen liefern Carol Nater Cartier ${ }^{1171}$ sowie, eingebettet in eine breitere Betrachtung geschichtskultureller Manifestationen zum Thema, Kuhn und Ziegler. ${ }^{1172}$ Nater Cartier beginnt ihre Darstellung mit der Ausstellung «Vor 75 Jahren ... eine Mobilmachung», die in den Jahren 1989 bzw. 1990 zunächst im Museum Altes Zeughaus in Solothurn und später im Historischen Museum Luzern gezeigt wurde und die in ihrer Objektauswahl einen Schwerpunkt auf Militaria gesetzt, daneben in langen Ausstellungstexten «soziale, politische und wirtschaftliche Missstände» während des Krieges abgedeckt habe. ${ }^{1173}$

Auch in der 2009 eröffneten Dauerausstellung «Geschichte Schweiz» im Landesmuseum Zürich liege der Schwerpunkt bei den dreidimensionalen Objekten auf militärischen Objekten, werde in der thematischen Gewichtung dem militärischen Bereich aber weniger Raum zugestanden. ${ }^{1174}$ Dort fällt Nater Cartier hingegen auf, dass die beiden Weltkriege «nur reduziert unterhalb der Holzrampe

1169 Kuhn/Ziegler 2014b, S. 374

$1170 \mathrm{Kuhn} / Z$ iegler 2014b, S. 377. Zu gruppenspezifischen Erinnerungen äussern sich ausserdem Kuhn/Ziegler 2016, konkret am Fall der Truppen, Arbeiterschaft und der bürgerlichen Frauenbewegung (Kuhn/Ziegler 2016, S. 5 f.).

1171 Nater Cartier 2014.

$1172 \mathrm{Kuhn} /$ Ziegler 2015, S. $54 \mathrm{ff}$.

1173 Nater Cartier 2014, S. 307 ff., direktes Zitat S. 308.

1174 Nater Cartier 2014, S. 309. 
thematisiert [werden], welche die Geschichte der Schweiz \Durch Konflikt zur Konkordanz> veranschaulicht». ${ }^{1175}$

«Die Ausstellungsszenografie dominiert die Erzählung, die gestalterisch umgesetzte Aussage basiert auf einem von Modernisierungs- und Fortschrittsglauben geprägten Geschichtsverständnis im Sinn der traditionellen Nationalgeschichtsschreibung: Die Geschichte der demokratischen «Errungenschaften〉 wird auf der aufsteigenden Rampe erzählt, und die zwei Weltkriege des 20. Jahrhunderts - 〈die Krisen〉, aus denen 〈nichts〉 hervorgegangen ist - werden unterhalb der aufsteigenden Rampe versteckt. Das ausgestellte Bild- und Dokumentationsmaterial behandelt militärische, zivile, soziale, gesellschaftliche, wirtschaftliche und politische Aspekte zum Ersten Weltkrieg zwar knapp, aber gleichwertig, indem sie nebeneinandergestellt werden. In den Haupttiteln auf den erklärenden Ausstellungstafeln finden sich die bekannten Stichworte zum Ersten Weltkrieg, die im Artikel des Historischen Lexikons der Schweiz (HLS) stehen und zum grossen Teil auch schon vor 25 Jahren in Solothurn anzutreffen waren, so zum Beispiel 〈Mobilmachung〉, 〈Grenzbesetzung〉, 〈Manöverkritik〉, 〈Neutralitätserklärung〉, 〈Der Graben〉, 〈Die Friedensinsel〉, 〈Soziales Elend〉, 〈Neutralitätsverletzung〉, 〈Rationierung〉.»1176

Sich beziehend auf Elemente des dominanten Narrativs, wie es von Kuhn und Ziegler herausgearbeitet wurde, ${ }^{1177}$ identifiziert Nater Cartier dieses also auch in historischen Ausstellungen zum Ersten Weltkrieg. Allerdings werde in Zürich, anders als in der Solothurner Ausstellung, der Landesstreik nicht in den Erzählstrang des Ersten Weltkriegs eingewoben, abgesehen davon seien aber «Parallelen - insbesondere was die Objektauswahl, die thematischen Stichworte und die Erzählung der Geschichte betrifft - augenfällig». ${ }^{1178}$

Nater Cartier fragt auch nach aktuellen Ausstellungsprojekten in Zusammenhang mit der einhundertsten Jährung des Ersten Weltkriegs in den Jahren 2014 bis 2018 und nennt darunter einige Projekte, auf die auch ich im Rahmen meiner Beobachtungen der geschichtskulturellen Aktivitäten in diesen Jahren gestossen

1175 Nater Cartier 2014, S. 309.

1176 Nater Cartier 2014, S. $311 \mathrm{f}$.

$1177 \mathrm{Kuhn} /$ Ziegler 2011.

1178 Nater Cartier 2014, S. 312. 
bin. ${ }^{1179}$ Von den grösseren Museen zeigte das Landesmuseum in Zürich im Jahr 2014 eine Sonderausstellung unter dem Titel «1900-1914. Expedition ins Glück», die sich der Phase des Aufbruchs vor Beginn des Ersten Weltkriegs zuwendete. ${ }^{1180}$ In der Region um Basel wurden namentlich im Rahmen des Netzwerks Museen am Oberrhein insgesamt 35 Ausstellungen zum Thema lanciert. ${ }^{1181}$ Eine davon ist die Ausstellung «Der Erste Weltkrieg - Die zerrissene Region», die im Jahr 2014 im Dreiländermuseum in Lörrach gezeigt wurde und die es sich zur Aufgabe machte, «einen vergleichenden Überblick über die Situation im Elsass, in Baden und der Nordwestschweiz während der Kriegsjahre 1914 bis 1918» zu geben. ${ }^{1182}$ Das Spielzeugmuseum in Riehen zeigte in den Jahren 2014 und 2015 die Ausstellung «Krieg im Kinderzimmer. spielen kämpfen träumen», verstanden als «Streifzug durch die unterschiedlichen Facetten des Krieg-Spielens anhand von historischem und zeitgenössischem Spielzeug aus 150 Jahren». ${ }^{1183}$ Ich greife exemplarisch diese beiden Ausstellungen heraus, weil sie auch vereinzelt von Studienteilnehmenden im Rahmen ihres Besuchs erwähnt und mit der Ausstellung «14/18» in Bezug gesetzt werden.

Neben diesen regional oder auf einzelne Manifestationen bezogenen Ausstellungen zur Zeit des Ersten Weltkriegs gab es daneben eine Sonderausstellung, die sich in holistischem Anliegen der Situation und Rolle der gesamten Schweiz während des Ersten Weltkriegs zuwendete, nämlich die meiner Studie zugrunde liegende Ausstellung «14/18. Die Schweiz und der Grosse Krieg».

\subsubsection{Zum Narrativ der Ausstellung «14/18» und dessen Einordnung}

Mit ihrem weiter oben bereits zitierten Anliegen, beispielsweise der Deutung des Ersten Weltkriegs als Zeit zunehmender sozialer und kultureller Spannungen, spiegelt die Ausstellung «14/18» Elemente des durch Kuhn und Ziegler bekannten Narrativs wieder, geht aber gleichzeitig auch darüber hinaus und differenziert

1179 Nater Cartier 2014, S. $313 \mathrm{ff}$.

1180 http://1914.landesmuseum.ch/, Zugriff am 21.2.2018.

1181 Moehring 2014, S. 14.

1182 www.dreilaendermuseum.eu/de/Ausstellungen/Sonderausstellungen/Erster-Weltkrieg, Zugriff am 21.2.2018.

1183 www.spielzeugmuseumriehen.ch/Ausstellungen/Sonderausstellungen2014/\$/Kriegim-Kinderzimmer/209, Zugriff am 21.2.2018. 
dieses. ${ }^{1184}$ So integriert die Ausstellung beispielsweise eine geschlechtergeschichtliche Perspektive als wesentliches Element in ihre Erzählung und richtet den Blick auf die Rolle von Frauen und die sich in der Zeit des Ersten Weltkriegs für diese eröffnenden Tätigkeitsfelder. Auch ergänzt die Ausstellung das Bild des kulturellen Grabens um eine Perspektive, in der ausländischer Einfluss auf Presseorgane und Propagandamassnahmen eine wesentliche Rolle in der Zeichnung des Grabenbildes spielen. Neu ist überdies die ausgesprochen differenzierte und «in einer bisher kaum je vollzogenen Deutlichkeit» erfolgende Aufarbeitung der wirtschaftlichen Situation und aussenwirtschaftlicher Beziehungen der Schweiz während des Krieges. ${ }^{1185}$ Und ganz generell bricht die Ausstellung durch Aufzeigen der vielfältigen Verbindungen mit den Nachbarländern - etwa in Form wirtschaftlicher $\mathrm{Zu}$ sammenarbeit - und der Auswirkungen des Krieges auf die Schweiz - etwa in Form sozialer Spannungen und wirtschaftlicher Not - mit dem Klischee einer Schweiz als einer Insel, einer «Schweiz als historischer Sonderfall», ${ }^{1186}$ die als Eiland die Weltkriege unbehelligt überstanden hat. ${ }^{1187}$

Hingegen ähnlich wie für das dominante Narrativ in der Geschichtsschreibung ${ }^{1188}$ und auch für Lehrmittel ${ }^{1189}$ festgestellt, findet in der Ausstellung «14/18» ein eher zaghaftes Zusammendenken von wirtschaftlicher Zusammenarbeit mit den Nachbarländern und daraus resultierender Profite auf der einen Seite und einer Reflexion über die Bedeutung und Reichweite von Neutralität auf der anderen Seite statt. Zwar enthält die Ausstellung unter dem Schlagwort «Neutral von Fall zu Fall» eine Problematisierung der schweizerischen Neutralität, Neutralität

1184 Das Verhältnis der Erzählung der Ausstellung «14/18» zum bekannten Narrativ beleuchten auch Kuhn/Ziegler 2015, identifizieren dabei aber, stärker als in meiner folgenden Darstellung, vor allem traditionelle und reproduzierende Elemente, bemängeln beispielsweise, dass die Ausstellung trotz Aufarbeitung wirtschaftlicher Verflechtungen dabei «unhinterfragt wiederum die Nation zugrunde» legt und dass sie verpasst, der «Internationalität der schweizerischen Gesellschaft vor 1914» Rechnung zu tragen «und transnationale Kontinuitäten in den Blick» zu nehmen (Kuhn/Ziegler 2015, S. 55).

$1185 \mathrm{Kuhn} /$ Ziegler 2015, S. 55. Wie die Ausstellung mit diesem Thema umgeht, hierzu finden sich einige weitere Ausführungen in Thyroff $2017 \mathrm{c}, \mathrm{S}$. $5 \mathrm{f}$.

1186 Aufarbeitung der Sonderfall-Idee bei: Maissen 2015, S. 12 f., S. 172 ff., S. 185, direktes Zitat S. 12.

1187 Ein solches Inselmotiv findet sich vielfach auf Bildpostkarten (für ein Beispiel, das auch in der Ausstellung Verwendung findet: Moos 2014, S. 222 f.) und diese wiederum - allerdings zunehmend weniger oder mit de-konstruktivem Zugriff - in manchen Lehrmitteln (Schultheiss/Thyroff 2014b; Thyroff 2017a). Ähnlich wie hier wurde die Ausstellung von mir bereits eingeordnet in Thyroff 2017c, S. 5, und Thyroff 2017b, S. 113.

1188 Kuhn/Ziegler 2011, S. 129.

1189 Thyroff 2017a, S. 172, S. 179. 
wird dort jedoch eher im Zusammenhang mit (militär-)politischen Affären, der Oberstenaffäre und der Hoffmann-Grimm-Affäre, thematisiert und steht unverbunden neben den zuvor gemachten wirtschaftsgeschichtlichen Betrachtungen.

Eine diesbezüglich weiterführende Darstellung findet sich im Begleitband zur Ausstellung, wo Carlo Moos verschiedene Dimensionen von Neutralität aufzeigt, nämlich eine militärische Neutralität, eine politische Neutralität, eine wirtschaftliche Neutralität und eine Gesinnungsneutralität. ${ }^{1190}$ Darunter sei die militärische Nentralität die «klassische Form» der Neutralität und definiere sich seit den Haager Abkommen «als Nichtteilnahme an Kriegen anderer Staaten und als Gleichbehandlung aller Krieg führenden». ${ }^{1191}$ Die politische Neutralität sei «schillernd, zumeist mit einem hohen Anspruch versehen» und «zeitbedingt». ${ }^{1192}$ Wirtschaftliche Neutralität sei «real nicht praktikabel, wie das Verhalten der Schweiz schon im Ersten und noch deutlicher im Zweiten Weltkrieg als Finanzdrehscheibe, Gotthard-Transitland, Rüstungsexportland und so weiter gezeigt hat». ${ }^{1193}$ Die Gesinnungsneutralität schliesslich sei «in demokratischen Gesellschaften streng genommen undenkbar, kann aber - wie im Ersten Weltkrieg - in Bezug auf öffentliche Äusserungen mit Zensurmassnahmen erzwungen werden». ${ }^{194}$

Eine entsprechend explizite Auffächerung der diversen Facetten von Neutralität findet in der Ausstellung selbst nicht statt, wenn auch punktuell einzelne Begriffe wie etwa «Gesinnungsneutralität» vorkommen und die Ausgestaltung der einzelnen Themenbereiche, wie etwa hinsichtlich der wirtschaftlichen Verflechtungen mit dem Ausland oder der Sympathien mit den kriegführenden Nationen, durchaus die Voraussetzungen bietet, um über Dimensionen, Reichweite und Grenzen von Neutralität nachzudenken. Die explizite Verknüpfung bleibt aber, namentlich im Wirtschaftsbereich, den Besuchenden überlassen, und die Ausstellung bleibt insofern deutungsoffen. ${ }^{1195}$ Zusammenfassend lässt sich feststellen, dass durch die Ausstellung einerseits gewisse Elemente überkommener Erzählungen aufgegriffen und repetiert werden, gleichzeitig auch differenziert und um weitere Perspektiven und neuartige Zugänge ergänzt.

1190 Moos 2014, S. 217.

1191 Moos 2014, S. 217.

1192 Moos 2014, S. 217.

1193 Moos 2014, S. 217.

1194 Moos 2014, S. 217.

1195 Zur unverblümten, aber letztlich in Bezug auf eine moralische Dimension deutungsoffenen Darstellung im Wirtschaftsbereich siehe auch bereits meine Ausführungen in Thyroff 2017b, S. 113. 


\section{3 Ästhetische Gestaltung und Exponate}

Zum Abschluss des Kapitels wende ich mich noch der Beschreibung der ästhetischen Gestalt der Ausstellung und ihrer Exponatauswahl zu. Die Ausstellung findet in ihrer ästhetischen Gestaltung, wohl ihrer Konzeption als Wanderausstellung geschuldet, mehrheitlich auf schlanken, transportablen Stellwänden Platz. Die Stellwände sind einerseits mit Ausstellungstexten, andererseits mit Bildquellen und deren Beschriftungen bedruckt. Jeweils etwa drei dieser Stellwände bilden thematische Einheiten. Korrespondierend mit dieser Grundanlage beinhaltet die Ausstellung als Exponate hauptsächlich Bildquellen, die in oft stark vergrösserter Form, auf den Stellwänden abgebildet sind.

Dreidimensionale Objekte oder originale Flachware werden demgegenüber verhältnismässig selten eingesetzt und finden beispielsweise in den vereinzelt vorkommenden Zylindern oder Vitrinen Platz. Dass Ausstellungen zur Schweiz im Ersten Weltkrieg mit einer relativen Armut überlieferter Objekte bzw. einem diesbezüglichen Schwerpunkt auf militärischen Objekten zu kämpfen hätten, wie andere Ausstellungen zum Thema, etwa im Zeughaus in Solothurn oder auch im Landesmuseum Zürich, vermuten lassen, bestätigt sich gleichwohl nicht, kommen doch in der Ausstellung «14/18» beispielsweise Gesellschaftsspiele aus der Zeit des Krieges zum Einsatz. ${ }^{1196}$ Insofern scheint hier der weitgehende Verzicht auf dreidimensionale Objekte stärker logistischen Überlegungen geschuldet. ${ }^{1197}$ Hingegen soll die Ausstellung

«eine multimediale Zeit-Raumerfahrung bieten und neben Sachinformationen auch Stimmungen vermitteln. Sie wird vor allem Fotos, Film- und Tondokumente präsentieren. Die Fotobestände des Bundesarchivs, der kantonalen Archive, des Schweizerischen Sozialarchivs, des Landesmuseums, der Nationalbibliothek sowie einiger Firmenarchive sind ausserordentlich reich. Etwas weniger zahlreich, aber dennoch in guter Qualität, erhalten sind auch verschiedene Filme in der Cinémathèque in Lausanne.»1198

1196 Nater Cartier 2014, S. 319, sich dabei auch auf eine entsprechende Befragung von Severin Rüegg, einem der Ausstellungsmacher, beziehend.

1197 Dies geht auch aus einer Broschüre zur Ausstellung hervor: Verein «Die Schweiz im Ersten Weltkrieg» 2012, S. 14.

1198 Verein «Die Schweiz im Ersten Weltkrieg» 2012, S. 14. 
Die vorwiegend in der Ausstellung vorhandenen Exponattypen sind damit benannt. ${ }^{1199}$ Jedoch ist die Ausstellung nicht nur Ort der Exponatpräsentation, sondern bietet aufgrund der zahlreichen visuellen Materialien und auch aufgrund der farblichen Gestaltung und räumlichen Anordnung der Ausstellungselemente ein gesamtheitliches ästhetisches und sinnliches Erlebnis.

Die Ausstellung ist, wie viele Ausstellungen mit Kriegsthematik, mehrheitlich in den Farben Rot, Schwarz und Weiss gehalten, wobei Texte auf rotem Hintergrund, die übergeordneten Abschnittstexte jeweils auf gänzlich roten Säulen zu finden sind und die schwarz-weisse Farbgebung demgegenüber durch die zahlreichen Bildmaterialien zustande kommt. Aus diesem Prinzip brechen die an einigen Stellen dort zwischengeschobenen «Blick ins Ausland»-Elemente aus, die durch grüne statt rote Texthintergründe gekennzeichnet und auf diesem Weg optisch von den übrigen, auf die Schweiz bezogenen Ausstellungsteilen zu unterscheiden sind. Inwiefern Besuchende diese veränderte Farbgebung zur Kenntnis nehmen und die damit verbundene veränderte inhaltliche Ausrichtung bemerken, gehört zu den Gegenständen der weiter unten folgenden Ergebnisdarstellung.

Die dem Ausstellungsnarrativ zugrundeliegende Idee zunehmender Spannungen im Verlauf der Kriegsjahre wird symbolisiert, indem die Stellwände im Ausstellungsverlauf in eine zunehmende Schieflage geraten. So heisst es in einer Medieninformation zur Ausstellung:

«Die zunehmende Erschütterung der Schweizer Gesellschaft zeigt sich in der Ausstellung nicht nur thematisch in den Bereichen Wirtschaft, Gesellschaft, Militär und Politik, sondern auch in der visuellen Gestaltung. Hunderte von Fotos, Dokumenten, Filmen und Objekten erzählen die Geschichte einer Schweiz, die zwar nicht vom Krieg militärisch betroffen war, aber aufgrund der Spannungen auseinanderzubrechen drohte». ${ }^{1200}$

1199 Ich komme weiter unten nochmals auf die in der Ausstellung enthaltenen Exponattypen zu sprechen, wenn ich mich im Ergebnisteil den Elementbezïgen der Besuchenden zuwende, also frage, in Bezug auf und ausgehend von der Beschäftigung mit welchen Elementtypen die Besuchenden Äusserungen formulieren. Dort definiere ich eingangs die dem Kategorienschema zugrunde liegenden Elementtypen im Hinblick auf die konkreten Bedingungen in der Ausstellung «14/18» (vgl. Abschnitt 8.3.2).

1200 Verein «Die Schweiz im Ersten Weltkrieg» 2014, S. 3. 
Auf die geschilderten Weisen und auf weiteren Wegen werden in der Ausstellung unter Rückgriff auf ästhetische Gestaltungsmittel inhaltliche Botschaften vermittelt. Ich gehe an dieser Stelle nicht differenziert auf alle in diesem Sinn eingesetzten Gestaltungsmittel ein, komme aber im Rahmen der Ergebnisdarstellung auf ausgewählte Gestaltungsmittel zu sprechen, wenn ich zeige, dass die Besuchenden die ästhetische Gestaltung wahrnehmen, kommentieren oder gar in einen Bezug zu damit verbundenen inhaltlichen Deutungen setzen. 


\section{Ergebnisse}

\subsection{Erste Einblicke in Charakteristika des Datenmaterials und resultierende Herausforderungen für die Analyse}

Ich beginne die Ergebnisdarstellung damit, dass ich ein Beispiel aus dem transkribierten Datenmaterial zeige. Dies dient dem Zweck, einen ersten Eindruck von der Gestalt des Materials zu geben und einige materialspezifische Herausforderungen zu benennen, die sich bei der Datenanalyse ergaben. Im Anschluss daran werde ich aufzeigen, welchen Weg ich zum Umgang mit diesen Materialeigenschaften und Herausforderungen bei der Analyse gewählt habe.

Das gewählte Beispiel enthält Äusserungen von P19, die einem frühen Zeitpunkt des Ausstellungsbesuchs entstammen. Im Vorfeld der zitierten Passage hielt sich die Person beim regionalspezifischen Ergänzungsteil der Ausstellung im Eingangsbereich auf und betritt zu Beginn des Zitats die Kernausstellung. Linker Hand befindet sich eine grossformatige Abbildung einer Grenzbefestigung im Raum Basel. Rechter Hand befinden sich unter anderem vier gläserne Säulen, jeweils bestückt mit Objekten und Texten, wobei jede Säule einer Person gewidmet ist, die sich in der Schweiz während des Ersten Weltkriegs in irgendeiner Weise politisch oder sozial betätigt hat. Eine fünfte derartige Säule, im Vorraum der Ausstellung platziert, wurde von P19 bereits im Vorfeld der zitierten Passage zur Kenntnis genommen. In der nachfolgenden Textstelle wendet sich P19 zunächst linker Hand der Fotografie zu, anschliessend rechter Hand einer der Säulen, dem Agronomen Ernst Laur gewidmet.

"Ich ${ }^{1201}$ komm jetzt rein in die Ausstellung (...) und kann gleich mal die grossen Bilder da bestaunen, (...) ähm, (...) in Übergrösse. Sujets von der damaligen Zeit da. (...) Wo ich wirklich sehr gelungen finde. (...) Also direkt so aus dem Alltag gegriffen (lacht) der (...) paar Kinder auf dem Wagen hinten, auf dem Hen-

1201 Ich zitiere Beispiele aus dem Datenmaterial nachfolgend in der Regel wie hier dargestellt, nämlich eingerückt und in Kursivschrift, um Datenbeispiele einerseits optisch vom Fliesstext und andererseits auch von Zitaten aus der Forschungsliteratur abzuheben. In einfachen Anführungs- und Schlusszeichen erscheinen innerhalb dieser Zitate solche Passagen, in denen die Besuchenden Texte lesen. Diese Passagen sind nicht zwingend identisch mit dem Wortlaut der Textgrundlagen in der Ausstellung, sondern mit dem durch die Besuchenden gewählten Wortlaut. Bisweilen werden innerhalb der Zitate Passagen von mir durch Fett- 
wagen, vorne die Soldaten, die sich (angelehnt) finden. Es kommt wirklich sehr realistisch rüber. (...)

Der < Ernst Laur, Agronom, Direktor des Schweizerischen Bauernverbandes. Der in Leipzig promovierte Agronom ist über 40 Jahre lang Direktor des 1870 gegründeten Bauernverbandes und Dozent an der ETH Zürich. Laur gilt als achter Bundesrat. Er führt betriebswirtschaftliche Grundsätze in die Landwirtschaft ein und profiliert sich als Modernisiever. Unter seiner Führung wird die Position der Bauernorganisation während des Krieges markant gestärkt und das Einkommen der Bauern erhöht.> (...)

Ja, ich find's interessant, so Personen, die eigentlich heute in Vergessenheitgeraten sind, die so herausgegriffen werden und ihre Leistungen oder ibr, ja ihr Wirken zu der Zeit erklärt wird. Find ich (...) find ich interessant, weil man kann sich dann so bineindenken, wie, wie die politischen Gegebenheiten in der damaligen Zeit gewesen sind. (...)

Dann lese ich da mal kurz die Thesen, die wabrscheinlich, die der Ernst Laur aufgestellt hat. (...)

Schon mal erstaunlich, dass ein Präsident vom Bauernverband so Themen aufstellt, zum Beispiel <Die nationale Erziehung des Schweizer Volkes muss mit Erziehung der Lehrer und Fübrer und der Gebildeten beginnen.> (...) Hm. (...)» (P19, Absatz 13-18)

Ich nehme an dieser Stelle keine systematische Interpretation der gezeigten Passage vor. ${ }^{1202}$ Vielmehr geht es zunächst darum, anhand dieser Textstelle einige erste Beobachtungen zur formalen und inhaltlichen Gestalt des Datenmaterials zu formulieren, wobei ich die gezeigte Passage als in vielerlei Hinsicht typisch und

schrift hervorgehoben, nämlich dann, wenn ich auf einzelne Elemente eines Zitats besonders hinweisen bzw. diejenigen Zitatbestandteile optisch hervorheben möchte, auf die sich die von mir formulierte Deutung bezieht. Werden Datenbeispiele im Fliesstext oder in Fussnoten eingebaut, erscheinen sie dort ebenfalls in Kursivschrift. Die Herkunftsangabe am Ende der Zitate, z. B. Absatz 13, bezieht sich auf die Absatznummer der Transkripte.

1202 Einige der enthaltenen Ideen werden im Verlauf der Darstellung wieder aufgegriffen, so etwa die von P19 formulierte Beschreibung der gezeigten Fotografie als «realistisch» und "aus dem Alltag gegriffen» oder die formulierte Idee eines möglichen Sich-Hineindenkens in historische Gegebenheiten. 
stellvertretend für den gesamten Transkriptbestand betrachte. ${ }^{1203}$ Folgende Beobachtungen lassen sich festhalten:

a) Zunächst einmal lässt sich festhalten, dass es überhaupt zu Äusserungen während des Ausstellungsbesuchs kommt. Offensichtlich gelingt es, mit der gestellten Aufgabe des Lauten Denkens in irgendeiner Weise umzugehen. ${ }^{1204}$ Dies ist für sich genommen bereits eine wesentliche Erkenntnis, gibt es doch bislang verhältnismässig wenige Erfahrungen mit dem Einsatz unbegleiteten Lauten Denkens beim Ausstellungsbesuch.

b) Die Besuchenden reagieren mit ihren Äusserungen auf die Ausstellung, sie nehmen Bezug auf das, was sie sehen, treten also in Interaktion mit der Ausstellung bzw. den darin befindlichen einzelnen Elementen. ${ }^{1205}$ In der gezeigten Passage wird deutlich, dass dies in schneller und variabler Abfolge unterschiedliche Elemente sein können, wie im konkreten Fall eine Fotografie, ein Einführungstext in die Biografie Ernst Laurs und eine Textquelle mit den von Ernst Laur formulierten Thesen, wobei die Elemente teilweise gelesen und teilweise frei kommentiert werden. Diese Kleinschrittigkeit ist typisch für das Datenmaterial. Die Bezüge zu systematisieren und hierfür eine hilfreiche Kategorienstruktur zu finden, war eine zentrale Aufgabe des Analyseprozesses, sollte doch der Rolle der Ausstellung und ihrer Elemente als mögliche Impulsgeber und als räumliche Struktur, innerhalb deren die Denkprozesse der Besuchenden ablaufen, Rechnung getragen werden.

c) Das Datenmaterial ist auch in weiteren Hinsichten vielschichtig. Abgesehen von der eher formalen Frage, ob die Besuchenden mit ihren Äusserungen auf Ausstellungselemente Bezug nehmen und auf welche Elemente, deutet sich weiter bereits an, dass sie dabei Aussagen in unterschiedlichsten Bereichen und Gegenstandsfeldern machen. Eine zentrale Herausforderung bei der Datenanalyse

1203 Ähnlichkeit Merkmale weisen nach einem ersten Eindruck auch die Transkripte Lauten Denkens auf, die zu der bereits erwähnten Untersuchung von Buttkereit et al. online zur Verfügung gestellt wurden (Buttkereit et al. 2014).

1204 Im ursprünglichen Sample von 30 Personen und darunter 22 Einzelbesuchenden gab es lediglich eine einzige Person, die ihren Ausstellungsbesuch in Stille durchführte und insofern nicht in die Datenanalyse einbezogen werden konnte. Allerdings lässt auch dieser Fall nicht auf eine Schwierigkeit mit der Aufgabe des Lauten Denkens schliessen, stellte die Person doch vielmehr schon bei der Einweisung mir gegenüber den Wert eines solchen Datentyps infrage und bot ich ihr alternativ einen stillen Besuch an (vgl. hierzu auch Fussnote 1012).

1205 Dafür sensibilisiert Wise und gebraucht hierfür den Begriff der Interaktion, spricht nämlich von «Visitor-Object Interactions» (Wise 2011, S. 22 ff., direktes Zitat S. 22). 
bestand darin, ein Kategoriensystem zu entwickeln, das dieser Vielschichtigkeit gerecht wird und dabei ein nützliches Instrumentarium darstellt, die gemachten Aussagen zu strukturieren.

d) Im Speziellen deutet sich dabei im gezeigten Beispiel bereits an, dass sich verschiedene Formen von Bezügen zur eigenen Person der Besuchenden finden lassen. So spricht die zitierte Person beispielsweise über eigene Interessen, äussert Urteile, zeigt sich belustigt und spricht davon, man könne sich in etwas «bineindenken». All dies sind Äusserungen, in denen sich P19 in irgendeiner Weise als besuchende Person selbst sichtbar macht. Aufgabe der Datenanalyse war es, diese Bezüge zu identifizieren und strukturieren.

Nachfolgend erläutere ich, ausgehend von den beschriebenen Charakteristika und Herausforderungen des Datenmaterials, die Grundstruktur des eingesetzten Kategorienschemas, wobei ich die Kategorienstruktur bereits als Ergebnis meiner Studie betrachte. Sie dient als Grundlage für die Modellierung der Äusserungen während eines Ausstellungsbesuchs und stellt gleichzeitig einen Vorschlag dar, wie mit diesem für die Ausstellungsbesuchendenforschung vielschichtigen und reichhaltigen Datentypus, den Transkripten Lauten Denkens, umgegangen werden kann.

\subsection{Struktur der Analysekategorien und Kapitelaufbau}

Für die Analyse des Datenmaterials habe ich ein mehrdimensionales Kategorienschema verwendet, um der bereits angedeuteten Vielschichtigkeit des Datenmaterials gerecht werden zu können. Das gesamte vorhandene Textmaterial wurde entsprechend mit mehreren, parallel übereinanderliegenden Zugriffen bearbeitet. ${ }^{1206}$

Ausgehend von meiner Fragestellung, war es mir ein Anliegen zu systematisieren, worüber die Besuchenden inhaltlich sprechen («Tiefenstruktur»), und insbesondere, inwiefern sie dabei ihre eigene Person und Zeit thematisieren, während sie die Ausstellung besuchen. Gleichzeitig wollte ich dabei aber auch stets die Ausstellung und ihre Elemente im Blick zu behalten, innerhalb deren diese Äusserungen zustande kommen. Es war also zugleich ein Anliegen, in formaler Hinsicht nach Formen der Aktivität der Besuchenden in der Ausstellung zu fragen

1206 In knapper Form sind einige Analyseebenen auch aufgeführt in Thyroff 2017b, S. $112 \mathrm{f}$., und Thyroff 2017c, S. 4. 
(«Oberflächenstruktur»). ${ }^{1207}$ Grundstruktur und Ebenen des verwendeten Kategorienschemas sind in Abbildung $A$ in Anhang dargestellt. Die Abbildung dient zur Veranschaulichung der folgenden Ausführungen.

Ausgangsbasis für die Datenanalyse bildete zunächst der gesamte Transkriptbestand aller Äusserungen der Besuchenden während ihrer Besuche. ${ }^{1208}$ Für das gesamte Textmaterial wurden Fragen der Oberflächenstruktur bearbeitet. Dort erhob ich, auf welchen Laufiwegen die Besuchenden sich durch die Ausstellung bewegen und welche Ausstellungsabteilungen sie dabei aufsuchen. Ausserdem wurde betrachtet, mit welchen Elementen sich die Besuchenden wie beschäftigen, also welche Elementbezüge und Aktivitätsformen auftreten. Diese Analyseebenen dienten dazu, herauszufinden, was die Besuchenden in formal-struktureller Hinsicht mit der Ausstellung tun und welche Teile der Ausstellung sie überhaupt zur Kenntnis nehmen. Diese Ebene dient als Hintergrundfolie, um in einem späteren Schritt die gemachten Aussagen kontextualisieren, einordnen und in Beziehung zur Struktur der Ausstellung setzen zu können. Auf die konkrete Gestalt der verwendeten Kategorien und Befunde der oberflächenstrukturellen Analyse komme ich in Abschnitt 8.3 zu sprechen. An dieser Stelle genügt vorerst die Feststellung, dass bei der Betrachtung der Aktivitätsformen grundsätzlich nach lesenden und nicht lesenden Äusserungen unterschieden wurde, Letztere von mir bezeichnet als freie Äusserungen.

Diese Unterscheidung war notwendig, sollte doch die zweitgenannte Gruppe, die freien Äusserungen, anschliessend Grundlage für weitere analytische Zugriffe werden. Für diese Passagen betrachtete ich weiter die Tiefenstruktur der Äusserungen (Abschnitte 8.4 bis 8.7), fragte hierfür danach, worüber Besuchende eigentlich sprechen, wenn sie aufgefordert sind, beim Ausstellungsbesuch laut zu denken. Dort wurde danach unterschieden, auf welche Themen die Besuchenden zu sprechen kommen und welche Fokussierungen sie bei ihren Äusserungen einnehmen.

1207 Die Wahl der Begriffe «Oberflächenstruktur» und «Tiefenstruktur» ist inspiriert durch einen Beitrag von Schöner, der die Begriffe im Kontext «kategorialer Inhalts- und Strukturanalysen» von Geschichtslehrmitteln gebraucht (Schöner 2013a). Die Betrachtung der Oberflächenstruktur meint dort das «Identifizieren und Klassifizieren» der Elemente von Schulbüchern und beinhaltet eine Unterscheidung in Autorentexte und Materialien und deren weitere Ausdifferenzierung (ebd., S. 71 f.). Die Analyse der Tiefenstruktur umfasst dann stärker inhaltliche Zugänge auf unterschiedlichen Analyseebenen (ebd., S. 77 ff.), die Entschlüsselung des «Strickmusters» (ebd., S. 77) der im Schulbuch enthaltenen Erzählung.

1208 Damit gemeint ist das gesamte Datenmaterial, in dem die Besuchenden individuell und monologisierend die Ausstellung durchschreiten. Ebenfalls aufgezeichnete Gespräche der Teilnehmenden mit mir, zum Beispiel während der Installation der Technik, wurden von der Analyse ausgeschlossen. Nicht codiert wurde zudem ein Zwischengespräch, das eine Person im Verlauf ihres Besuchs mit einer Aufsichtsperson führte. 
Die Erschliessung von angesprochenen Themen orientierte sich im Gegensatz zur Analyse der besuchten Abteilungen nicht mehr an den durch die Ausstellung selbst gesetzten Themenbereichen, sondern systematisierte die angesprochenen Themen nun absichtlich losgelöst davon. Die Kategorisierung erfolgte dort in gemischt deduktivem und induktivem Zugriff einerseits unter Rückgriff auf gebräuchliche Grosskategorien (z. B. «Wirtschaft», «Politik», «Militär») und andererseits mit deren induktiver Ergänzung und Ausdifferenzierung anhand des Datenmaterials.

Weiter wurde nach den gewählten Fokussierungen unterschieden. Dieser Bereich bildet das Kernstück der Analyse, weil dort dezidiert auch die gemachten Bezüge zur eigenen Person und Gegenwart identifiziert und strukturiert werden. Die Ebene der Fokussierungen liegt quer zu derjenigen der behandelten Themen, geht es hier doch unabhängig von den konkreten angesprochenen Themen um die Frage, aus welchen inhaltlich-strukturellen Bausteinen Äusserungen bestehen, zum Beispiel inwiefern sich Besuchende selbst als Person sichtbar machen, auf welche Aspekte von Wirklichkeit sie ihre Aufmerksamkeit richten. An dieser Stelle sei bereits vorweggenommen, dass ausgehend vom Datenmaterial drei zentrale Fokussierungsbereiche identifiziert werden konnten, die die Besuchenden während ihres Ausstellungsbesuchs einnehmen, nämlich erstens die Fokussierung auf Geschehen, ${ }^{1209}$ zweitens die Fokussierung auf die Ausstellung und ihre Elemente und drittens die Fokussierung auf die eigene Person und Lebenswelt. Diese drei Bereiche wurden jeweils weiter ausdifferenziert.

Die Befunde zu den skizzierten Analysebereichen werden nachfolgend vorgestellt. Die Kapitelgliederung orientiert sich dabei an der Gliederung des Kategorienschemas und folgt dem Prinzip einer «kategorienbasierte[n] Auswertung entlang der Hauptkategorien», ${ }^{1210}$ wobei innerhalb der Hauptkategorien jeweils auch die identifizierten Subkategorien vorgestellt werden sowie Bezüge zwischen Subund Hauptkategorien, auch über die Grenzen von Hauptkategorien hinweg, zur Sprache kommen. ${ }^{1211}$ Im Fall der Fokussierungen dient die Kapitelgliederung dann zugleich als Grundlage für die Entwicklung eines Modells, in dem Strukturelemente der Äusserungen der Besuchenden und deren Bezüge zueinander visualisiert werden (Abschnitt 9.1).

1209 Vgl. zur Begründung für die Wahl dieses positivistisch konnotierten Begriffs die Ausführungen in Abschnitt 8.5.1.

1210 Kuckartz 2016, S. 118.

1211 Zur Betrachtung von Zusammenhängen: Kuckartz 2016, S. 119. 
Ich stelle nachfolgend jeweils zu Beginn eines Abschnitts die verwendeten Kategorien vor und äussere mich zu deren Herleitung, anschliessend schildere ich die zugehörigen Befunde. Bisweilen werden dabei Querbezüge zu anderen Analyseebenen hergestellt. Die parallele Mehrfachcodierung des Materials, die auch als mehrdimensionaler Zugriff vorstellbar ist (siehe Abbildung 2 im digitalen Anhang), ermöglicht es, gleichzeitiges Vorkommen von Kategorien unterschiedlicher Ebenen zu beobachten. Dies wurde punktuell für ausgewählte Bereiche des Kategorienrasters realisiert, insbesondere dann, wenn sich damit die während des $\mathrm{Mu}$ seumsbesuchs hergestellten Bezüge zur eigenen Person und Gegenwart, die den Schwerpunkt des Forschungsanliegens bilden, in ihrer Struktur und ihren Zusammenhängen weiter erhellen lassen.

\subsection{Die Besuchenden in der Ausstellung: Zur Oberflächenstruktur von Besuchsverläufen}

Anliegen meines Forschungsvorhabens war es, nicht nur das von den Teilnehmenden Geäusserte inhaltlich zu strukturieren, sondern gleichzeitig auch im Blick zu behalten, was sie dabei in struktureller Hinsicht mit der Ausstellung tun, welche Rolle die Ausstellung in ihren Äusserungen spielt. In einem ersten Schritt geht es deshalb in formaler Perspektive um die Oberflächenstruktur des Ausstellungsbesuchs. Damit ist einerseits physische Aktivität durch Bewegung im Raum gemeint, vor allem aber auch beobachtbare, kognitive Auseinandersetzung mit Elementen der Ausstellung. Den erstgenannten Bereich, das physische Verhalten im Raum, berühre ich mit meiner Untersuchung dezidiert lediglich am Rande ${ }^{1212}$ und frage danach, welche Laufwege Besuchende durch die Ausstellung wählen und welchen Ausstellungsteilen sie sich dabei zuwenden (Abschnitt 8.3.1). Neben der Betrachtung der Laufwege der Besuchenden gehe ich in einem weiteren Schritt stärker ins Detail und betrachte, auf welche Elemente bzw. vielmehr Elementtypen der Ausstellung Besuchende mit ihren Wortäusserungen eingehen oder reagieren (Abschnitt 8.3.2).

Die Bearbeitung solcher Aspekte der Oberflächenstruktur weist entfernt Bezüge zu dem auf, was in der Unterrichtsforschung als die Erhebung von «Sicht- bzw.

1212 Eine tiefergehende Analyse von körperlichen Praxen nehme ich dabei im Unterschied zu anderen Studien wie etwa denjenigen von Wise oder Röttele (Wise 2011; Röttele 2017) nicht vor, da dies einen sehr viel stärker beobachtungsorientierten methodischen Zugriff erfordert hätte, wohingegen die Hauptdatenquelle für mein Forschungsanliegen, sogar für die Erschliessung der Laufwege, dezidiert die Verbalisierungen der Teilnehmenden darstellen. 
Strukturmerkmale[n]» bezeichnet wird. ${ }^{1213}$ In meinem Fall geht es um die Beschreibung der äusserlichen Erscheinungsform des Ausstellungsbesuchs, die auf einem gedachten Kontinuum zwischen formalen und inhaltlichen Zugängen zum Material stärker der formalen Seite zuneigt, während ich mich im Verlauf der weiteren Darstellung dann stärker den inhaltlichen Betrachtungen zuwenden werde.

\subsubsection{Die Besuchenden im Raum: Laufwege und besuchte Abteilungen}

Die Besuchsdauer ${ }^{1214}$ betrug im Durchschnitt über alle Besuchenden knapp 90 Minuten pro Person, variierte erheblich zwischen den einzelnen Besuchenden und betrug zwischen einer knappen Stunde im Fall von P7, P13 und P30 bis hin

1213 Waldis 2016, S. 128 f.; direktes Zitat ebd.; Lotz et al. 2013, S. 359 f.; Brückmann/Duit 2014, S. 16. Bei solchen niedrig-inferenten Verfahren sei Waldis zufolge «[d]ie Inferenz, d.h. das Mass der schlussfolgernden Interpretationen, [...] eher gering; das Urteil lässt sich über Indikatoren fällen, die der direkten Beobachtung zugänglich sind» (Waldis 2016, S. 128; zur Unterscheidung der Verfahren auch Lotz et al. 2013, S. 359). Niedrig-inferente Codierungen beziehen sich auf Merkmale des Unterrichts, die «in linearer Abfolge» auftreten (Waldis 2016, S. 129) und folglich auch Schritt für Schritt im Datenmaterial festgestellt werden können, wohingegen in hoch-inferenten Codierungen die ganze Unterrichtsstunde zum Gegenstand einer Gesamteinschätzung wird, der dann eine Vielzahl von Merkmalen zugrunde liegen kann (Lotz et al. 2013, S. 360; Waldis 2016, S. 129). Die Unterscheidung in niedrig- und hoch-inferente Verfahren lässt sich nicht gänzlich auf mein Projekt übertragen, da in meinem Fall ein zu den hoch-inferenten Verfahren äquivalenter Arbeitsschritt fehlt, in dem Sinn, dass ich keine holistische Gesamteinschätzung von Datensätzen vornehme. Wohl gibt es aber in meinem Fall Unterschiede in den Codierungen dahingehend, welchen Grad an Interpretation sie enthalten. Eine Bezeichnung für all diejenigen Codierungen, die sich nicht unmittelbar auf die Sichtstruktur des Geschehens beziehen und die höhere Grade an interpretativen Folgerungen enthalten, aber dennoch nicht eine Gesamteinschätzung des Materials darstellen, ist allerdings in der vorgestellten Unterscheidung niedrig- und hochinferenter Verfahren für die Unterrichtsforschung offenbar nicht vorgesehen. Zudem ist die dortige Unterscheidung auch deshalb nur bedingt auf mein Projekt übertragbar, weil sie zumindest im Fall von Lotz et al. 2013 und Waldis 2016 - letztlich die Quantifizierung von Befunden über Unterrichtsgeschehen und -qualität als Zielhorizont hat und hierfür mögliche unterschiedliche Gütegrade der jeweiligen Verfahren in den Blick nimmt (Lotz et al. 2013, S. $360 \mathrm{ff}$.; Waldis 2016, S. $130 \mathrm{ff}$.). Relevant für mein Projekt ist die Unterscheidung in niedrig- und hoch-inferente Verfahren in der Hinsicht, dass sie für die unterschiedlichen Möglichkeiten der Betrachtung von Datenmaterial sensibilisiert, die stärker formal oder inhaltlich orientiert sein kann, wobei ich diese Bereiche, wie erwähnt, durch die Bezeichnungen Oberflächenstruktur und Tiefenstruktur unterscheide.

1214 Die Angaben beziehen sich auf die Dauer der erstellen Audio- und Videoaufnahmen abzüglich derjenigen Zeit, die zu Beginn der Aufnahme jeweils noch für die Installation der Technik, einführende Hinweise bzw. Gespräche verwendet wurde. Es wurde auf ganze Minuten gerundet. 
zu über zweieinhalb Stunden im Fall von P5, P12 und P28 (siehe Tabelle 5 im digitalen Anhang). Auf welchen Wegen schritten die Besuchenden innerhalb dieser Zeiträume durch die Ausstellung? Während die Datenanalyse, wie oben beschrieben, prinzipiell auf dem Weg der Codierung der Transkripte erfolgte, habe ich für die Erfassung der eingeschlagenen Laufwege ein anderes Vorgehen gewählt. So wurden die Laufwege der Besuchenden per Eintragung in einen Grundrissplan der Ausstellung erfasst und visualisiert. Dabei hielt ich fest, auf welche Ausstellungselemente und in welcher Reihenfolge die Besuchenden mit ihren Wortäusserungen Bezug nehmen. ${ }^{1215}$ Die kleinste hierfür berücksichtigte Ausstellungseinheit bildete in diesem Arbeitsschritt eine thematische Stellwand-Einheit oder anderweitig klar abgegrenzte räumliche Einheit (Vitrine, solitär stehende Hörstation usw.), während ich im nächsten Kapitel dann sogar bis zur Ebene der Elementtypen weiter differenziere. Auf dieser Basis wurde für alle Teilnehmenden ein individuelles Bewegungsprofil erstellte, und die einzelnen Profile wurden miteinander verglichen.

Dabei zeigt sich eine Grundform des Sich-Bewegens durch die Ausstellung, die je nach Besucher und Besucherin entweder ausschliesslich auftritt oder mit weiteren Bewegungsmustern ergänzt und kombiniert wird. Bei der Grundform handelt es sich um ein einmaliges, lineares Abschreiten des durch die Ausstellungsräumlichkeiten vorgegebenen u-förmigen Weges bzw. der an dessen Rändern angeordneten Ausstellungselemente. Hierbei wählen alle Besuchenden einen Zickzackkurs, indem sie wechselweise Ausstellungseinheiten linker und rechter Hand aufsuchen und dabei sukzessive durch die Ausstellung voranschreiten. Dabei werden häufiger einzelne Einheiten ausgelassen, ${ }^{1216}$ aber abgesehen von diesen Auslassungen und Seitenwechseln keine grösseren räumlichen Sprünge vollzogen und

1215 Ausstellungselemente, die möglicherweise still zur Kenntnis genommen wurden, ohne dass dies durch Wortäusserungen im Datenmaterial nachvollziehbar wäre, flossen hingegen nicht in die Erfassung der Laufwege ein. Wohin überall sich beispielsweise die Blicke der Besuchenden richten, wäre ohne den Einsatz von Eyetracking-Verfahren (z. B. EghbalAzar/Widlok 2013) sowieso nicht nachvollziehbar.

1216 Die Videoaufnahmen deuten darauf hin, dass vereinzelt das Überspringen von Elementen durch die Anwesenheit anderer Besuchender begründet sein mag, explizite verbale Hinweise darauf durch die Besuchenden selbst finden sich aber nur in zwei Fällen, nämlich: "Ich gehe einfach vorbei, weil ich die Leute nicht stören will» (P30, Absatz 48) und "Ich geh etwas nach vorne, damit ich die anderen Leute nicht störe, wenn ich spreche» (P21, Absatz 49). In einem weiteren Fall scheint die Anwesenheit anderer dazu zu führen, dass die Betrachtung einer Einheit vorzeitig beendet wird: "Das ist dann unbequem, wenn andere Leute herumstehen» (P30, Absatz 4). Ich stelle diejenigen Äusserungen der Besuchenden, in denen sie über ihre Situation als Studienteilnehmende reflektieren, weiter unten noch vor (vgl. Abschnitt 8.7.4.1). 
auch keine auffallenden Vorwärts- oder Rückwärtsbewegungen durchgeführt. Abbildung 7 im digitalen Anhang mit dem Laufweg von P25 zeigt exemplarisch einen dieser Grundform entsprechenden linearen Besuchsverlauf, mit dem zugleich der der Ausstellung inhärenten chronologischen Struktur gefolgt wird.

Dieser anhand von P25 gezeigte idealtypische lineare Besuchsverlauf zeigt sich bei 6 Besuchenden in ausschliesslicher Form, ${ }^{1217}$ bei weiteren 12 Besuchenden kombiniert er sich mit anderen Bewegungsmustern. ${ }^{1218}$ So springen diese Besuchenden etwa vereinzelt während des Besuchs oder im Anschluss an den einmaligen Durchgang zu deutlich früher liegenden Elementen zurück und vollziehen somit einzelne Rückwärtsbewegungen, folgen ansonsten aber dem linearen Grundmodell.

Bei drei Besuchende zeigen sich auffallende weitere Bewegungsmuster (P5, P7, P28). Sie springen ab einem bestimmten Punkt des Besuchs zum Ende der Ausstellung und schreiten die Ausstellung von dort kommend in umgekehrt-linearer Reihenfolge $\mathrm{ab}$ (P5, P7) oder springen von dort aus wieder zu einem früheren Teil zurück (P28). ${ }^{1219}$ Zwei von ihnen weisen ausserdem auffallend lange und grossflächige Phasen des nichtlinearen Kreuzens durch die Ausstellung auf, indem sie Vor- und Rückwärtsbewegungen variabel aneinanderreihen. Dieselben beiden Personen fallen überdies durch ein mehrmaliges Durchkreuzen der gesamten Ausstellung auf (P5, P28).

Der wohl auffallendste und gleichzeitig möglicherweise fast selbstverständlich anmutende Befund besteht somit darin, dass die meisten Besuchenden die Ausstellung in der Regel im Modus eines einzigen, linearen Gesamtdurchgangs durchschreiten, sei es, dass dies den ausschliesslichen oder zumindest überwiegend gewählten Bewegungsverlauf darstellt, wohingegen gravierende Abweichungen von diesem linearen Grundmodus, wie konkret in Form eines nichtlinearen Kreuzens, Rückwärtsoder Mehrfachdurchgangs, nur bei einzelnen Besuchenden vorkommen.

Im Zusammenhang mit dem Nachvollzug der individuellen Bewegungsverläufe wurde auch erhoben, von welchen und wie vielen Besuchenden sich Wortäusserungen zu einzelnen thematischen (Stellwand-)Einheiten und ganzen Abteilungen finden. Dabei zeigte sich, dass die Besuchenden bei ihrem Durchgang, wie erwähnt, zwar häufiger einzelne Stellwandeinheiten, jedoch kaum einmal ganze

1217 Dies ist der Fall bei: P3, P13, P18, P19, P22, P25.

1218 Dies ist der Fall bei: P4, P5, P6, P7, P8, P12, P20, P21, P26, P27, P28, P30.

1219 Im Fall von P7 wird dieser Sprung erklärt durch die Anwesenheit anderer Besuchender: "Ich tu jetzt, damit ich die anderen nicht störe, von hinten anfangen» (P7, Absatz 24). Der Wechsel ans Ausstellungsende stellt hier einen Versuch dar, nicht störend aufzufallen, steht also in einem unmittelbaren Zusammenhang mit dem gewählten Erhebungssetting. 
Abteilungen überspringen, sondern die Ausstellung von Beginn bis zum Ende hin durchschreiten (siehe Abbildung 8 und Tabelle 6 im digitalen Anhang). ${ }^{1220}$ Der einmalige, lineare Durchgang unter Berücksichtigung aller oder nahezu aller vorhandenen thematischen Abteilungen und unter regelmässigem Überspringen einzelner Einheiten stellt somit den typischen Besuchsverlauf dar. Ich werde diese Befunde im Rahmen des Zwischenfazits diskutieren und einordnen.

\subsubsection{Die Besuchenden im Kontakt mit Ausstellungselementen: Elementbezüge und Aktivitätsformen}

\subsubsection{Varianten im Überblick}

Im vorangegangenen Abschnitt habe ich unter einer noch groben formalen Perspektive danach gefragt, welche Wege Besuchende durch die Ausstellung wählen und in welcher Reihenfolge sie sich dabei einzelnen Ausstellungseinheiten zuwenden. Dieser Zugang ermöglicht noch keine Aussagen darüber, welche spezifischen Ausstellungselemente innerhalb dieser Einheiten von den Besuchenden mit ihren Äusserungen berücksichtigt werden. Das vorliegende Kapitel dient nun der Betrachtung dieser Elementbezüge.

Ich arbeite nachfolgend mit einem breiten Elementbegriff und fasse darunter in einem ersten Schritt sowohl Quellen als auch Darstellungen, ${ }^{1221}$ differenziere die Elementtypen erst später aus. In diesem zunächst breiten Sinn ist der von mir

1220 Einzige Ausnahme von dem formulierten Befund des Nichtüberspringens ganzer Abteilungen stellt ein Teil des regionalspezifischen Einblicks in die Situation Basels während des Krieges dar, nämlich derjenige Teil, der im Eingangsbereich des Museums im Erdgeschoss bzw. im Treppenbereich und damit in einem anderen Stockwerk als die übrigen Ausstellungsteile gezeigt wurde. Dieser Teil wurde von etlichen der 18 Besuchenden ausgelassen, wobei die Gründe hierfür in der Anlage des Forschungsdesigns gesucht werden müssen. So erfolgte die Einweisung der Teilnehmenden und die Installation der Aufnahmetechnik jeweils im Untergeschoss und damit aus Sicht eines linearen Ausstellungsdurchgangs bereits hinter dem im Erdgeschoss und Treppenbereich platzierten Teil, und die Teilnehmenden wurden nur teilweise von mir auf den übersprungenen Teil aufmerksam gemacht (vgl. Fussnote 1019). Die festgestellten sehr geringen Besuchszahlen in diesem Bereich sind also zweifellos durch das Erhebungsdesign beeinflusst.

Die Codierung der Abteilungen diente, abgesehen davon, auch einem pragmatischen Zweck, ermöglichte sie doch ein schnelleres Sich-Zurechtfinden im Datenmaterial. Zudem ermöglichte sie im Fall von Äusserungen der Besuchenden in Bezug auf die Schlussräumlichkeiten die direkte Gegenüberstellung aller überhaupt in diesen Abteilungen gemachten Äusserungen (vgl. Transkriptauszüge im digitalen Anhang).

1221 Zur Unterscheidung von Quellen und Darstellungen: Grosch 2014, S. 74 ff.; Schreiber 2007b, S. 194, S. $200 \mathrm{ff}$. 
verwendete Elementbegriff ähnlich zu dem in geschichtsdidaktischen Einführungswerken gebräuchlichen Begriff des Mediums, ${ }^{1222}$ soll einer Gleichsetzung mit Quellen vorbeugen ${ }^{1223}$ und zudem in einem allerersten Schritt Ausstellungselemente physisch bezeichnen, nicht automatisch als Bestandteile eines kommunikativen Systems. ${ }^{1224}$

Eine Sichtung des Materials hatte früh ergeben, dass sich die Aussagen der Besuchenden in aller Regel an Elemente der Ausstellung als Bezugspunkt zurückbinden lassen. Dies kann entweder bedeuten, dass von den Besuchenden explizit über ein Element gesprochen wird oder aber, dass eine Äusserung ausgehend von der Beschäftigung mit diesem Element erfolgt, weil in dieser Äusserung Aspekte aufgegriffen werden, die an das Element anknüpfen, ohne dass das Element selbst explizit thematisiert würde. Ich zeige nachfolgend drei Textbeispiele, die diese Varianten verdeutlichen.

«Okay, da hat's noch einzelne weitere Archivalien.»(P6, Absatz 13)

"Also das fürbt auch auf die Kinder ab, jetzt hat's hier ein Zitat, dass schon ein Vierjähriger anfüngt, Barrikaden zu bauen im, im Garten, also wie der Krieg dann auch die Kinder prägt und man natürlich ganz anders aufwächst.» (P3, Absatz 16)

«Zwischen dem 3. und 7. August '14 rïcken zweibundertzwanzigtausend Mann und fünfundvierzig Pferde ein.> Ah, das ist offenbar eine sebr gute Organisation gewesen, dass in so kurzer Zeit so viele Männer unter Waffen haben beordert werden können.» (P25, Absatz 27)

In den ersten beiden Beispielen wird explizit über Elemente der Ausstellung gesprochen ( «weitere Archivalien» und «ein Zitat»), im zweiten und dritten Beispiel

1222 Pandel/Schneider zufolge ist «Medium» gegenüber «Quelle» «der breitere Begriff, der alles enthält, was pri märe [sic] oder sekundäre Aussagen über Geschichtebeinhaltet [sic]», ist also nicht nur auf Quellen beschränkt (Pandel/Schneider 2017b, S. 7; sich dem anschliessend: Baumgartner 2015, S. 114f.). Diese breite Verwendung des Medienbegriffs zeigt sich in den Inhaltsverzeichnissen/-strukturierungen diverser Werke: Baumgartner 2015, S. 6, S. 114 ff.; Barricelli/Lücke 2017, S. 7, S. 85 ff.; Pandel/Schneider 2017b, S. 5 f.

1223 Pandel/Schneider zufolge wird Medium fälschlicherweise häufig mit Quelle gleichgesetzt (Pandel/Schneider 2017a, S. 7; rezipiert bei Baumgartner 2015, S. 114 f.).

1224 Entsprechende mögliche Konnotationen des Medienbegriffs stellt Baumgartner dar (Baumgartner 2015, S. $113 \mathrm{f}$.). Vgl. hierzu die Ausführungen in Fussnote 322. 
formulieren die Besuchenden ausgehend von der Lektüre dieses Zitats bzw. eines Ausstellungstexts eigene, weiterführende Überlegungen, die sich jedoch inhaltlich in irgendeiner Weise als zurückgebunden an die Ausstellungselemente erweisen, wobei insbesondere für die Zuordnung von Elementen und Äusserungen in der zweiten Variante bis zu einem gewissen Grad interpretative Schlussfolgerungen notwendig werden.

Wenn ich von Aktivitäten in Bezug auf ein bestimmtes Ausstellungselement spreche, dann meine ich nachfolgend zunächst unterschiedslos dieses gesamte Spektrum an Äusserungen, wohingegen weitere Differenzierungen erst zum Gegenstand der später erfolgten tiefenstrukturellen Analyse wurden. Bei der Frage nach Elementbezügen geht es darum, zu identifizieren, wann welche Elemente, genauer welche Elementtypen, ${ }^{1225}$ in den beschriebenen Weisen die Aufmerksamkeit der Besuchenden auf sich ziehen, also worüber bzw. ausgehend von welchen Elementtypen Äusserungen erfolgen.

Eine Differenzierung nach Elementtypen erscheint mir weiterführend, da diesen in der geschichtsdidaktischen und -theoretischen Literatur einerseits unterschiedliche Potenziale im Hinblick auf Aneignungsvorgänge, andererseits auch ein unterschiedlicher Stellenwert in erkenntnistheoretischer Hinsicht beigemessen wird. Aus erkenntnistheoretischer Perspektive unterscheide ich zwei Typen von Ausstellungselementen: Es sind dies zum einen Quellen als Elemente aus der Vergangenheit und darin wiederum verschiedene Quellentypen. Zum anderen sind dies darstellende Ausstellungselemente, die von den Ausstellungsmachenden verfasst und erstellt sind und die die Quellen kontextualisieren und übergreifende Erzählungen entfalten. Darunter zähle ich vornehmlich Ausstellungstexte, aber auch weitere Elemente wie durch die Ausstellungsmachenden erstellte Statistiken oder Kartenmaterial. Die Kategorienstruktur wurde ausgehend von diesen Überlegungen entwickelt - in diesem Bereich ausnahmsweise mehrheitlich deduktiv und unterscheidet die Äusserungen der Besuchenden danach, auf welche Elementtypen sie sich beziehen.

Ich definiere nachfolgend diese Elementtypen und gehe dabei auch auf ausstellungsspezifische Besonderheiten ein, da im Hinblick auf die konkrete Quellenauswahl in der Ausstellung «14/18» einige erläuternde Präzisierungen angebracht

1225 Der Umgang mit konkreten einzelnen Elementen wird erst weiter unten exemplarisch näher beleuchtet. 
sind. Im Bereich der Quellen unterscheide ich ihrer äusseren Form nach Bildquellen, Textquellen, dreidimensionale Dingquellen sowie Tonquellen. ${ }^{1226}$

- Als Bildquellen fasse ich historische, bildliche Elemente wie Fotografien, Filme und Zeichnungen, also sowohl stillgestellte als auch bewegte Bilder. Fotografien machen in der Ausstellung die überwiegend gewählte Quellenform aus, wobei es sich überwiegend nicht um originale Fotografien, sondern um Reproduktionen und dabei zugleich starke Vergrösserungen handelt, die auf den Stellwänden abgedruckt sind. Ich fasse hier also auch Reproduktionen als Quellen. Ergänzt wird in der Ausstellung der Schwerpunkt auf Fotografien um einige filmische Zeugnisse sowie Gemälde, Postkarten und Karikaturen. Für meine Klassifizierung fasse ich dabei auch solche Elemente als Bildquellen, die ihrer äusseren Form nach Kombinationen aus Bild und Text darstellen, wie etwa Propagandapostkarten oder Karikaturen.

- Die Ausstellung enthält neben den bildlichen Zeugnissen auch Textquellen, wobei es sich hierbei im Gegensatz zu den Bildquellen im Verhältnis häufiger um Originale handelt. Ich fasse unter Textquellen sämtliche ausgestellte historische Flachware, die in sprachlicher Form verfasst ist (mit Ausnahme derjenigen Elemente, die neben dem Text auch bildliche Elemente enthalten, wie etwa Karikaturen, und daher als Bildquellen eingestuft werden, s.o.), und auch hier rechne ich wieder reproduziert auf Stellwänden abgedruckte Textquellen der Gruppe der Quellen zu.

- Unter Dingquellen fasse ich dreidimensionale historische Objekte, die in der Ausstellung im Vergleich mit den Bildquellen und im Kontrast mit anderen historischen Ausstellungen sehr zurückhaltend vertreten sind. Ich klassifiziere auch solche Elemente als Dingquellen, die ihrer äusseren Form nach Kombinationen aus Ding und Text darstellen, wie etwa beschriftetes Geschirr, Kissen usw.

- Die vierte Gruppe bilden die in der Ausstellung an Hörstationen verfügbaren Tonaufnabmen, ein Spezialfall, weil es sich um aktuelle Aufnahmen von historischen Dokumenten handelt, ${ }^{1227}$ also nicht um Tonquellen im eigentlichen Sinn, sondern um nachträglich vertonte Textquellen. Gleichwohl werte ich

1226 In Anlehnung an eine in der geschichtsdidaktischen Literatur gebräuchliche Differenzierung von Typen, die etwa in der Kapitelgliederung bei Günther-Arndt/Zülsdorf-Kersting 2014, S. 6, Baumgärtner 2015, S. 6, Pandel/Schneider 2017b, S. 5 f., Verwendung findet, wobei in allen Fällen die Differenzierungen nicht nur Quellen, sondern in breiterem Sinn Medien oder auch Darstellungen umfassen.

1227 Gemäss Auskunft von Herrn Severin Rüegg. 
diese Elemente als separaten Typus, um zu berücksichtigen, dass der Umgang mit gehörten Texten im Vergleich zu gelesenen Texten einen anderen Aktivitätstypus darstellt.

Die Entscheidung dafür, Aktivitäten von Besuchenden nach diesen genannten Quellentypen zu unterscheiden, beruht auf geschichtsdidaktischen Überlegungen im Hinblick auf den möglicherweise unterschiedlichen Status der Quellentypen im Rahmen von Aneignungsvorgängen bzw. Lernprozessen. Gerade mit bildlichen Quellen verbinden sich, wie ich gezeigt habe, in der Geschichtsdidaktik Vorstellungen über medienspezifische Stärken und Schwächen, die deren Anschaulichkeit und imaginatives Potenzial, aber auch Subjektivität und Ausschnitthaftigkeit betonen. ${ }^{1228}$ Um diesen Potenzialen auch im hier betrachteten Datenmaterial nachspüren zu können und anknüpfungsfähig an die geschilderten Debatten zu sein, empfiehlt sich eine Unterscheidung von Aktivitätsformen nach unterschiedlichen Quellentypen.

Sie empfiehlt sich jedoch überdies aufgrund der gewählten Erhebungsmethodik. Lautes Denken gilt, so wurde weiter oben bereits ausgeführt, als womöglich unterschiedlich gut gelingend in Abhängigkeit davon, ob Teilnehmende mit bildlichen oder textlichen Informationen konfrontiert werden, die es zu verarbeiten gilt. ${ }^{1229}$ Übertragen auf Ausstellungen bedeutet dies, dass Verbalisierungen in der Auseinandersetzung mit Ausstellungstexten sowie Textquellen möglicherweise anders und besser gelingen als diejenigen im Kontakt mit Bildquellen. Um diese Problematik bei der Analyse im Blick behalten zu können, erachtete ich es als hilfreich, die unterschiedlichen Beschäftigungsmodi unterscheiden zu können.

Zur zweiten Gruppe der darstellenden Elemente fasse ich zunächst einmal Ausstellungstexte. Hierunter verstehe ich Darstellungen der Ausstellungsmachenden, in denen in textlicher Form Geschichte erzählt wird, Abteilungen eingeordnet, Kontexte hergestellt usw. Diese lassen sich nach ihrer Reichweite unterscheiden, also je nachdem, auf welche Gliederungsebene der Ausstellung sie sich beziehen. Eine entsprechende Differenzierung vorzunehmen, erschien mir für das Anliegen meiner Studie jedoch nicht als notwendig. Deshalb spreche ich synthetisierend allgemein von Ausstellungstexten, die sich in diesem Fall auf thematische Einheiten

1228 So bei Pandel 201 la, S. 13 ff., insb. S. 13, S. 24 ff.; Gautschi 2015, S. 122. Vgl. Abschnitt 3.4.3.

1229 Vgl. Abschnitt 6.1. 
unterschiedlicher Grösse beziehen können, und unterscheide davon nur die dezidiert auf einzelne Elemente gerichteten Quellenbeschriftungen als separate Gruppe.

$\mathrm{Zu}$ den sonstigen Elementen zähle ich solche Ausstellungsbestandteile, die weder Quellenmaterial noch Ausstellungstexte sind, aber wie Letztere von den Ausstellungsmachenden erstellt und zur Kontextualisierung und Erzählung einer Geschichte eingesetzt werden. In der konkreten Ausstellung zählen hierzu vornehmlich Statistiken, die zur Darstellung der Import- und Exportmengen während des Ersten Weltkriegs zum Einsatz kommen, sowie Karten, die im Rahmen der verstreut vorkommenden «Blick ins Ausland»-Elemente die Kriegsschauplätze weltweit darstellen.

Während ich in den vorhergehenden Abschnitten dargelegt habe, wie ich den Elementbestand der Ausstellung systematisiere, dient die Frage nach Aktivitätstypen im engeren Sinn der Aufklärung der Frage, welche Aktivitäten die Besuchenden mit diesen Elementen vornehmen. Hierbei unterscheide ich zwei Formen, nämlich lesende und freie Äusserungen. Lesende Äusserungen umfassen alle eindeutig als Vorlesen identifizierbaren Passagen. ${ }^{1230}$ Unter freie Äusserungen fallen demgegenüber alle übrigen Wortäusserungen, die neben den lesenden Aktivitäten während des Ausstellungsbesuchs erfolgen. Nicht immer war die Unterscheidung zwischen lesenden und freien Äusserungen eindeutig zu treffen, da es eine grosse Bandbreite von Möglichkeiten gibt, wie Texte paraphrasiert oder zusammengefasst werden können und dabei dennoch eigene, freie Deutungen der Besuchenden zum Tragen kommen. Ich werde mich diesen Abgrenzungen weiter unten noch zuwenden.

Für die Entwicklung des Kategorienschemas wurden nun alle denkbaren Paarungen aus den möglichen Elementtypen und Aktivitätsformen vorgenommen. Tabelle F zeigt die eingesetzte Kategorienstruktur, die in diesem Fall mehrheitlich deduktiv aus den soeben geschilderten Überlegungen entwickelt wurde sowie induktiv um einzelne weitere Aspekte ergänzt, nämlich freie Äusserungen in Bezug

1230 Ich habe bereits weiter oben darauf hingewiesen, dass die Besuchenden aus forschungspraktischen Gründen darum gebeten wurden, entweder Texte laut vorzulesen oder - bei manchen Besuchenden - ihr Lesen anzukündigen (vgl. Abschnitt 6.2.2). Diese Aufforderung diente dem Anliegen, lesende Tätigkeiten überhaupt im Datenmaterial nachvollziehbar machen zu können. Die entstandenen Videoaufnahmen legen den Schluss nahe, dass der Aufforderung überwiegend nachgekommen wurde. Gelegentlich finden sich im Material jedoch Situationen, in denen sich die Besuchenden länger stillschweigend vor Texten aufhalten, ohne dass es verbale Indizien für lesende Aktivitäten gibt. Hier liegt der Schluss nahe, dass zwar gelesen, das Lesen aber nicht verbalisiert wurde. Mangels Nachvollziehbarkeit wurden solche Fälle nicht als Lesen erfasst. 
auf eine ganze Abteilungs- oder die gesamte Ausstellungsebene sowie eine Kategorie für Äusserungen, die keinem Bezugspunkt eindeutig zuordenbar waren. Wenn sich Äusserungen zugleich auf mehrere, aber für sich je eindeutig identifizierbare Elemente bezogen, wurden hingegen Doppelcodierungen vorgenommen.

Vollkommen abschweifende und weder mit der Ausstellung und dem eigenen Besuch noch der dargestellten Thematik irgendwie in Verbindung zu bringende Überlegungen (z. B. anstehende Termine und Einkäufe, Wochenendpläne, Hungergefühl, zu erledigende Dinge usw.) kamen im gesamten Datenmaterial kein einziges Mal zur Sprache. Das heisst, dass die Besuchenden entweder solche Gedanken während des Besuchs nicht hatten oder, was wahrscheinlicher sein dürfte, sie als nicht relevant für die Studie erachteten und nicht äusserten, ihre Aufgabe des Lauten Denkens also als fokussiert auf die unmittelbare Ausstellung und deren Thematik wahrnahmen. Inwiefern dabei zum Beispiel auch Lebensweltbezüge verschwiegen wurden, die aus Forschungsperspektive aufschlussreich gewesen wären, lässt sich nicht exakt feststellen. Ein expliziter Hinweis darauf, dass etwas verschwiegen wurde, weil womöglich nicht für mitteilenswert oder nicht zur Sache gehörig erachtet, findet sich in einem Fall, nämlich bei P13:

"Hm, spannend, dass eben die (...) Zweiseitigkeit aufgezeigt wird, eigentlich von (...) dass es ein humanitärer Antrieb gewesen ist, die Hilfe zu leisten, aber gleichzeitig eben auch den Handlungsspielraum vergrössert hat und das Ansehen im Ausland, und weil das Anseben im Ausland steigt, eben auch die Handlungsspielräume wieder. (...) Mir kommt da in den Sinn, dass ich auch mal mit Leuten (...). Ab, nein.» (P13, Absatz 64)

Wie in allen Erhebungsformen, die mit Verbalisierungen der Beforschten arbeiten, lässt sich auch in diesem Fall die Menge und das Spektrum des nicht Geäusserten nicht ermessen, sind Forschungsergebnisse vielmehr auf das tatsächlich Ausgesprochene angewiesen. Für die Strukturierung dieses tatsächlich vorliegenden Spektrums an Äusserungen kam schliesslich das in Tabelle F ersichtliche Kategorienset zum Einsatz, das eine vollständige Betrachtung des Materials erlaubte, weil alle Äusserungen der Besuchenden einer Kategorie zuordenbar waren.

Die Identifizierung der Elementbezüge und Aktivitätsformen erwies sich allerdings als ausgesprochen aufwendig und voraussetzungsreich, nämlich von einer genauen Kenntnis der Ausstellung und ihrer Elemente, insbesondere der vorhandenen Texte, abhängig. In vielen Fällen war ein ergänzender Einbezug des Videomaterials und der von der Ausstellung angefertigten Fotografien notwendig, etwa 
ein Einbezug der von mir abfotografierten Texte, um lesende Passagen im Abgleich mit den Texten als solche identifizieren zu können. Dabei auftretende Abgrenzungsschwierigkeiten zwischen lesenden Aktivitäten und freien Äusserungen stelle ich weiter unten noch vor.

\subsubsection{Kleinschrittigkeit und unmittelbare Situationsbezogenheit der Äusserungen als wesentliche Strukturmerkmale}

Zur Veranschaulichung der beschriebenen Codestruktur und zur Darlegung zentraler zugehöriger Befunde gehe ich auf drei Beispiele aus dem Datenmaterial ein. Es handelt sich um Auszüge aus den Äusserungen der Besuchenden P3, P6 und P18. Der Ausstellungsteil, in dem diese Äusserungen zustande gekommen sind, ist in allen drei Fällen identisch. Es handelt sich um eine im Vorraum der Ausstellung befindliche Vitrine, in der die Situation Basels während des Ersten Weltkriegs dargestellt wurde. Die Vitrine war nach vier Themenbereichen gegliedert («Wohlstand», «Profite», «Not», «Mobilisierung»), jeweils vertreten durch einen einführenden Ausstellungstext auf der Vitrinenscheibe und durch in der Vitrine befindliche, zugehörige Exponate. Die Besuchenden arbeiteten sich in der Regel der Reihe nach durch diese Abschnitte, von rechts («Wohlstand») beginnend, so auch die drei betrachteten Besuchenden. Die Abbildungen 3, 4 und 5 im digitalen Anhang zeigen die Äusserungen der drei Besuchenden in diesem Bereich, und zwar ab Eintreffen bei der Vitrine bis einschliesslich des dritten Abschnitts «Not». Mittels Farben unterschieden, sind darin die diversen vorkommenden Aktivitätsformen und Elementbezüge gekennzeichnet.

Auffällig ist in allen drei Beispielen ein überwiegend kleinschrittiges Aufeinanderfolgen von unterschiedlichen Aktivitätsformen. ${ }^{1231}$ Durch die farblich unterschiedliche Kennzeichnung der einzelnen Aktivitätsformen ist dies bereits ohne eine detaillierte Lektüre der Textbeispiele auf den ersten Blick erkennbar. Mitunter etwas längere Einheiten des Lesens von Ausstellungstexten, im Fall von P6 im Mittelteil des gezeigten Ausschnitts und im Fall von P18 zu Beginn, werden gerahmt und ergänzt durch zahlreiche weitere Aktivitätsformen, die in kurzer und variabler Abfolge miteinander kombiniert werden. Im Fall von P3 fehlen solche längeren, wörtlich lesenden Passagen und findet insgesamt eine ausgewogene und vielgestaltige Durchmischung von Formen statt. In dieser Kleinschrittigkeit stehen

1231 Diese Kleinschrittigkeit wird auch angesprochen in Thyroff 2017b, S. 116, und Thyroff 2017c, S. 11. 
die drei Beispiele stellvertretend für den im gesamten Datenmaterial überwiegend gefundenen Modus. ${ }^{1232}$

Ich nehme an dieser Stelle eine rein formale, nicht eine inhaltliche Analyse der gezeigten Textbeispiele vor, auch wenn sich bemerkenswerte inhaltliche Beobachtungen unmittelbar an die formalen anschliessen liessen. So deutet sich etwa im Fall von P6 an, dass für das Identifizieren von Objekten das Aufsuchen der zugehörigen Beschriftungen ein probates Mittel darstellt, was im konkreten Beispiel zunächst fehlgeleitet wird, indem P6 auf die Frage "Was zeigt denn das Foto?» (Ende des Abschnitts 4) zunächst die Beschriftung zu einer anderen Dingquelle findet ( Koblekessel»). Welche Rolle identifizierende Tätigkeiten beim Museumsbesuch spielen und wie durch die Besuchenden mit Irritationen umgegangen wird, wird jedoch erst weiter unten Gegenstand der Darstellung sein. ${ }^{1233}$ Vorerst dienen die gezeigten Beispiele dem Zweck, oberflächenstrukturelle Befunde zu veranschaulichen, nämlich auf die relativ kleinschrittige Abfolge von Aktivitätsformen hinzuweisen.

$\mathrm{Zu}$ diesem Eindruck gehört nicht nur, dass die einzelnen Beschäftigungseinheiten oft sehr kurz sind, sondern auch, dass sich die Besuchenden in aller Regel auf diejenigen Elemente konzentrieren, bei denen sie sich in diesem Moment befinden, und sich über diese oder ausgehend von diesen äussern. Rückgriffe auf bereits betrachtete, weiter zurückliegende Elemente und Themen und damit thematische oder strukturelle Querverbindungen über den Besuchsverlauf hinweg kommen hingegen verhältnismässig selten vor.

Für die drei gezeigten Beispiele ist dies allein schon deshalb erwartbar, weil es sich um Ausschnitte aus der Anfangsphase des Ausstellungsbesuchs handelt. Jedoch ändert sich das Bild auch im weiteren Verlauf der Besuche nicht gravierend. Nur in einem kleinen Teil aller betrachteten freien Äusserungen der Besuchenden finden sich Rückbezüge zu anderen, bereits früher in der Ausstellung bemerkten Elementen oder Themen: ${ }^{1234}$ vielfach, wenn Besuchende feststellen, dass ein The-

1232 Weniger kleinschrittig geht in der beschriebenen Eingangszone hingegen P19 vor. Sein oder ihr Kontakt mit der Vitrine besteht im Grundmuster darin, die auf der Vitrinenscheibe angebrachten Ausstellungstexte jeweils in Gänze und ohne Unterbruch zu lesen, sich anschliessend dazu frei zu äussern und dann zum nächsten Text weiterzugehen. Es finden sich also längere zusammenhängende und insgesamt weniger verschiedene Aktivitätsformen als bei anderen Besuchenden.

1233 Vgl. Abschnitte 8.6.4 und 8.7.2.15.

1234 Nicht beinhaltet sind darin Passagen, in denen die Besuchenden Bezug auf ein unmittelbar zuvor betrachtetes Element nehmen oder kleinräumig über Kohärenzen zwischen Ausstellungselementen unmittelbar vor ihnen nachdenken. 
ma wiederkehre, oder auch, wenn Besuchende eigene frühere Äusserungen aufgreifen, wiederholen und fortführen. Zudem zeigen sich dort individuelle Unterschiede zwischen den Besuchenden. Während einzelne Besuchende gar keine oder nur vereinzelte grossflächige Querbezüge herstellen, fällt demgegenüber insbesondere P12 durch ein im Vergleich zu anderen Besuchenden extensives Herstellen von Querverbindungen auf und erweist sich überdies auch als sensibel für die Strategie der Ausstellung, solche Bezüge herzustellen. Diese Beobachtungen werden weiter unten noch im Rahmen einer Fallbetrachtung vertieft. ${ }^{1235}$

Ich zeige nachfolgend Beispiele für solche Rückbezüge, in denen Besuchende auf zuvor bereits behandelte Themen oder gesehene Elemente rekurrieren und P12 überdies sogar thematische Bezüge als Strategie der Ausstellung kommentiert.

"Ja, also der Krieg wirkt trennend, da viele davon profitieren und andere noch weiter in die Not gestü/, gestürzt werden. (...) Was eigentlich da vorne durch die Karikatur auch ganz gut zum Ausdruck gebracht wird, die man jetzt natürlich besser verstehen kann.» (P8, Absatz 49)

"Im Eingangsbereich der Ausstellung konnte ich schon (...) lesen, dass die (...) chemische Industrie durch den Export von Farbstoffen nach England (...) zu den Profiteuren des Krieges und der wirtschaftlichen Änderung gehörte, (...) und sebe hier weitere Beispiele wie Herstellung von Munitionsbestandteilen.»(P28, Absatz 46)

«Blick ins Ausland. Am 12. November 1918 weist der Bundesrat die Angehörigen der russischen Sowjet-Gesandtschaft aus Bern aus.>

Unter anderem die Angelika Balabanoff, die Frau von der Stele vorbin. Das ist eigentlich sehr spannend zu sehen, wie die (...), wie die Ausstellung am Anfang so exemplarisch ein paar Sachen buchstäblich in den Raum stellt und an die Wand bängt, und dann nach und nach die Ausstellung die Informationen gibt und unterfüttert und evgänzt und vertieft und man mehr und mehr wirklich so einen, ein, ein, ein, einen Setzkasten hat, das man mit hier mit Wissen, Informationen füllt.» (P12, Absatz 178)

1235 Vgl. Abschnitt 8.7.2.15. 
Wie P12 selbst feststellt, enthält die Ausstellung selbst eine ganze Reihe solche thematischen Querbezüge, beispielsweise indem einzelne Personen im Verlauf mehrfach auftauchen oder indem sich gewisse Themen querschnittartig durch die Ausstellung ziehen. Der von mir beobachtete überwiegende Grundmodus der Besuchenden besteht nichtsdestotrotz darin, Station für Station abzuarbeiten und für sich genommen zu betrachten und zu kommentieren.

Die einzelnen Elementtypen werden dabei im Normalfall variabel aneinandergereiht und vermischt. Nur vereinzelt konnte ich feststellen, dass sich Besuchende über längere Phasen ihres Besuchs hinweg auf bestimmte Elementtypen fokussieren und sich nur mit diesen beschäftigen. Im Besuchsverlauf von P22 finden sich einzelne längere Phasen, in denen er oder sie sich von Abbildung zu Abbildung fortbewegt und diese beschreibt, ohne andere Ausstellungselemente wie etwa Bildbeschriftungen zur Kenntnis zu nehmen, sich also ausschliesslich bildbezogen fortbewegt. Das folgende Beispiel verdeutlicht dies. Darin signalisiert jeder Absatz die Zuwendung zu einer neuen Abbildung:

"Und da, das ist halt, das sind bereits die ersten (...) auch, da sieht man ein trauriges Kapitel mit (...) Gas, wo sie müssen, vielleicht ist das einfach die (Mache), hintendran sieht man auch einen Offizier, der eine höhere, höheren Offizier, der einfach, eben das ist eine Übungsleitung, nehme ich mal an, das ist kein, kein echter Gasalarm. (...)

Und da sieht man auch (...), wie sie (...) Milch bringen und (...). Die Pferde, und das sind recht Wägen, wo sie recht viel Milch in die Milchzentrale bringen. Da ist das Brot, das auch gemacht worden ist von den Leuten, das dann auch verteilt wird und zum Teil sicher auch verkauft. (...)

Das sind auch wieder militärische Sachen, wabrscheinlich, die (...) im Büro, wo die schreiben müssen, was gegangen ist, oder (...) einfach aufnebmen, Telefonzentrale, höhere Leute, die das Kommando haben.

Und da sieht man wieder mal ein bisschen Schwingen, das hat jetzt glaube ich weniger mit dem Krieg, also sicher auch, aber da im Moment, da geht's mehr wieder mehr um die Freude, und das finde ich gut, wenn es das zwischendurch gibt. (...) Dass nicht nur alles extrem ernst ist.

Da (...) wabrscheinlich eine Art Grenzbewachung. Da siebt man auch einen durch den Feldstecher schauen, ob da Leute über die Grenze herüberkommen, Schmuggler, und so weiter. (...) 
Da sieht man Frauen, Schwestern, mit so weissen Tüchern. (...) Die auch wieder die Küche zum Teil machen oder nähen, Wäsche, das muss alles auch gemacht werden. (...)

Da sieht man etwas die Erste Hilfe (...), wenn etwas passiert ist, dass man, so gut es möglich, das wieder einigermassen instand tun kann. (...)» (P22, Absatz 44-50)

Bei P26 zeigt sich phasenweise ein ähnliches Verhaltensmuster in Bezug auf Ausstellungstexte, indem er oder sie lesend mehrere Texte aneinanderreiht. Phasen wie die zitierte, in denen sich Besuchende eine längere Zeit am Stück auf einen bestimmten Elementtyp fokussieren und den Besuchsverlauf in dieser Phase auf die Beschäftigung mit diesem Elementtyp hin ausrichten und strukturieren, sind jedoch im Datenmaterial selten. Sehr viel typischer ist das Abarbeiten von unterschiedlichen Elementtypen in variabler Abfolge, unabhängig davon, ob es sich um ein Exponat oder ein darstellendes Element handelt, und vielmehr wohl abhängig davon, was als Nächstes ins Blickfeld gerät und Aufmerksamkeit generiert.

\subsubsection{Zum Verhältnis von lesenden und freien Äusserungen, von quellen- und darstellungsbezogenen Äusserungen}

Wie erwähnt, traten bei der Codierung immer wieder Grenzfälle bei der Zuordnung von Textstellen zutage. Insbesondere betrifft dies etwa den breiten Bereich der textparaphrasierenden und -zusammenfassenden Tätigkeiten der Besuchenden, der ein Kontinuum aus lesenden Passagen und freien Äusserungen darstellt. Dieses Kontinuum beinhaltet die nahezu textidentische Wiedergabe von Ausstellungstexten, reicht über die beim Lesen erfolgende Auslassung einzelner Sätze und Worte unter zeitgleicher Berücksichtigung und Betonung anderer, umfasst die Zusammenfassung von Texten und Extraktion von Kernaussagen, das Ergänzen einzelner eigener und nicht wörtlich im Text vorkommender Worte, Konzepte und Deutungen bei ansonsten textidentischer Wiedergabe, wobei mal mehr und mal weniger «Eigenes» der Besuchenden in das Wiedergeben von Texten einfliesst. Kurzum: Dieser Bereich stellt eines der angekündigten Beispiele dar, in denen sich die Komplexität des Datenmaterials einer exakten und trennscharfen Codierung nachhaltig widersetzt. Um der Komplexität des Materials Rechnung zu tragen, widme ich gerade solchen Bereichen von Schattierungen meine Aufmerksamkeit.

Da die als «frei», also «nicht lesend», identifizierten Äusserungen anschliessend einer differenzierteren Analyse unterzogen wurden, zeige ich nachfolgend, 
welches Spektrum von Aussagen dieser Bereich beinhalten kann. Ich greife hierzu auf Äusserungen der Besuchenden in der bereits zuvor herangezogenen Eingangsabteilung zurück, mehrheitlich von den drei bereits zitierten Besuchenden P3, P6 und P18 und im Zusammenhang mit dem Ausstellungstext zum Thema «Profite». Ich gebe zunächst den Ausstellungstext wieder:

«In Basel verhalf der Erste Weltkrieg der chemischen Industrie zum Durchbruch. Vor 1914 wurden $85 \%$ der Farbstoffe für den globalen Markt in Deutschland hergestellt, in Basel nur gerade $10 \%$. Als die deutschen Unternehmen die Lieferungen an ihre Kriegsgegner einstellten, eröffneten sich den Basler Chemiefirmen grosse neue Märkte und sie konnten umfangreiche Lieferverträge abschliessen. Hergestellt wurden vor allem die kriegsrelevanten Farbtöne Feldgrau, Feldgrün und Hechtgrau. Die wichtigste Abnehmerin war die damals führende englische Textilindustrie. 1917 exportierte z. B. die Firma Sandoz 40\% ihrer Farbstoffe nach England. Die Gewinne waren immens: Vom Jahr 1914 zum Jahr 1918 gelang es, den jährlichen Gewinn zu versechsfachen. Auch das Pharmageschäft wurde während des Ersten Weltkriegs weiter ausgebaut und eine eigene Pharmaforschung in Angriff genommen.»

Im folgenden Materialbeispiel liest P18 extrahierend den gezeigten Ausstellungstext und nimmt dabei Textergänzungen vor mit der Bemerkung, die im Text genannten Farbtöne seien für Uniformen gedacht.

"Eben ja, Chemie, rgrosse neue Märkte), ‘und sie konnten umfangreiche neue Lieferverträge abschliessen > (...)<Farbtöne〉, eben für die Uniformen (...), ‘Feldgraw ২Feldgrün > (...).»(P18, Absatz 6)

Einschübe wie den markierten habe ich dem Bereich der freien Äusserungen zugerechnet. Selbiges geschah mit Textstellen im Stil des folgenden Beispiels, in dem P3 den Inhalt desselben Textes mit überwiegend eigenen Worten wiedergibt und zusammenfasst, lediglich das Wort «versechsfacht» übernehmend:

"Also ich lese nur so grob, dass hier eben die Pharmaindustrie in dieser Zeit sebr gewachsen ist und dass ja die Schweiz eigentlich dann profitieren konnte, weil es Material brauchte. Sehr viel Gewinn, versechsfachst, versechsfacht.»(P3, Absatz 13) 
Als freie Äusserungen habe ich auch erfasst, wenn Besuchende Inhalte von Texten wiedergeben und dabei beispielsweise mit einer eigenen Wertung versehen, auf eigenes Vorwissen oder neues Wissen in Bezug auf das Gelesene verweisen, Passagen auffällig, z. B. überrascht, betonen und kommentieren oder auf einer Metaebene darlegen, dass es die Ausstellungstexte sind, aus denen etwas Bestimmtes hervorgeht.

"Und da, das hab ich gewusst, da von der chemischen Industrie (...), wie sie viel Farbstoffe produziert haben.» (P18, Absatz 5)

«[...] HECHTgrau〉, das klingt gut.» (P6, Absatz 4)

"Es heisst hier auch, dass die chemische Industrie in Basel profitiert hat vom Ersten Weltkrieg [...].» (P3, Absatz 12)

Demgegenüber habe ich nahezu textidentisches Paraphrasieren, das Ankündigen von Lesen sowie überfliegendes, abkürzendes, aber im Gebrauch der Wörter sehr textnahes Lesen den lesenden Aktivitäten zugeordnet (siehe Abbildung 3-5 im digitalen Anhang: z. B. P6, Absatz 2 und 4, P18, Absatz 6).

Die Transkription basiert dabei stets auf dem von den Besuchenden gewählten Wortlaut und kann bei den als «lesend» markierten Passagen von der in der Ausstellung enthaltenen Textgrundlage durchaus vereinzelt abweichen. Bisweilen werden lesende Passagen auch durchsetzt durch den Einschub einer freien Äusserung, wie im nächsten Beispiel: ${ }^{1236}$

"(Gerigi/) Kriegsgewinne in allen Industriezweigen, und so weiter. Angenehmes Leben, Kaffeehaus, woblhabende Familie〉. Ah ja, okeh, alles klar, ich verstehe das. (...) <Schweizer Mustermesse Basel (unv.), Profite, Wohlstand. In Basel verhalf der Erste Weltkrieg der chemischen Industrie zum Durchbruch.»»(P6, Absatz 4)

1236 Als Lesen mitcodiert wurden kurze, zwischen dem Lesen eingeschobene Laute wie «Hm», «Okay», «und so weiter», sofern diese keinen weiteren inhaltlichen Gehalt aufwiesen. Im Gegensatz dazu wäre beispielsweise ein überraschtes «Oh!» während des Lesens als freie und inhaltstragende Äusserung erfasst und in einem späteren Schritt als Äusserung von Erstaunen klassifiziert worden (vgl. Abschnitt 8.7.2.1). 
Schwierig einzuordnen waren Fälle, in denen Besuchende Exponate identifizieren und hierzu auf Begriffe zurückgreifen, die so oder ähnlich auch in der Exponatbeschreibung Verwendung finden. Nicht immer wurde aus dem Kontext restlos klar, ob sie diese Begriffe soeben selbst gewählt oder der Beschriftung entnommen haben.

"Hmm, ich schaue jetzt da den Essnapf an, die Rationierungsmarken. (...) Oder was das sind.» (P18, Absatz 9)

"Ah Rationierung ist hier noch mit diesen Marken, da werd ich sicher die Schülerinnen und Schüler darauf aufmerksam machen, ein Essnapf, wo man da ansteht, um Essen zu bekommen, und diese Marken, was man da bekommt [...].» (P3, Absatz 14)

"Schau ich mal, schicke Schube in Rosa, und weiss nicht, ob das Seide ist, ein Abendkleid, Haarbürsten.» (P3, Absatz 12)

Im Gegensatz dazu ist in der folgenden Passage das Vorlesen von Exponatbeschriftungen eindeutig als solches zu identifizieren bzw. wird nicht ergänzt oder eingebaut in freie Äusserungen:

« Farbmuster Eriochrom Verdon〉 (...), 〈Farbmuster für Eriochrom für den britischen Markt>.» (P8, Absatz 3)

Ein ähnliches Phänomen des Einbauens von Textbestandteilen aus der Ausstellung in eigene freie Äusserungen zeigt sich, wenn Besuchende über die inhaltliche Gliederung der Ausstellung oder einer Abteilung sprechen und hierzu Begriffe verwenden, die mit den inhaltlichen Überschriften der Abteilungen identisch sind:

"Ja, ich bin also jetzt da im Vorraum (...) und bei Mobilisation, Misere, Profit. Ist also offensichtlich eine grobe Einteilung.»(P5, Absatz 2)

"Zum einen geht es um Woblstand und Not. (...) Das könnten soziale Konflikte sein. Und es geht um Profite und Mobilisierung.» (P8, Absatz 3) 
Solche Äusserungen wurden gesamthaft als freie Äusserungen erfasst und, bisweilen bzw. je nach Kontext, parallel dazu einzelne lesende Elemente innerhalb dessen erfasst.

Welche Befunde ergeben sich nun aus der Betrachtung von Elementbezügen und Aktivitätsformen im Hinblick auf die Bedeutung der einzelnen Kategorien und ihr Verhältnis zueinander? Angesichts des Spektrums an Äusserungen, die sich im Graubereich zwischen Kategorien bewegen, und der methodischen Gesamtanlage der Studie ${ }^{1237}$ verbietet sich eine Darlegung der Befunde in Form von exakten Quantifizierungen. Jedoch erscheint eine vorsichtige Formulierung von Gesamteindrücken in Form von Tendenzen möglich und sinnvoll.

Nämlich zeigt sich ein nach einzelnen Besuchenden differenziertes Bild in der Hinsicht, dass für einen Teil der Besuchenden im Umfang die lesenden Passagen deutlich überwiegen, für andere Besuchende hingegen die freien Äusserungen und sich für eine dritte Gruppe sowie in der Gesamtschau ein recht ausgewogenes Verhältnis zwischen lesenden Passagen und freien Äusserungen ergibt. ${ }^{1238}$ Innerhalb der Gruppe der lesenden Aktivitäten fällt auf, dass darin insbesondere dem Lesen von Ausstellungstexten eine herausragende Bedeutung zukommt. ${ }^{1239}$

Für die in den nachfolgenden Kapiteln vorgestellte Feinanalyse der Elemente des Denkens beim Ausstellungsbesuch spielen die lesenden Anteile selbst dann nur noch eine untergeordnete Rolle, weil eigentlicher Analysegegenstand nur die freien Wortäusserungen der Besuchenden sind. Gleichwohl sind die gelesenen Texte insofern relevant, als sie als mögliche Impulsgeber für geäusserte Assoziationen betrachtet werden und Texte zum Gegenstand von freien Äusserungen werden können. Jedoch sind die lesenden Aktivitäten selbst nicht Teil des Forschungsinteresses, und denkbare zugehörige Fragestellungen werden nicht weiterverfolgt. ${ }^{1240}$

1237 Vgl. insb. Abschnitt 6.4.

1238 Die Einschätzung bezieht sich auf das Textvolumen und erfolgte auf Basis der in MAXQDA verfügbaren Funktion «Dokument-Porträt» (vgl. Fussnote 1095). Als Schwelle für die Einordnung als «überwiegend» habe ich in dem hier genannten Fall einen Anteil von mehr als drei Fünfteln des Textvolumens für eine Kategorie gegenüber der anderen festgelegt.

1239 Innerhalb der lesenden Aktivitäten macht das Lesen von Ausstellungstexten im Volumen allein mehr als zwei Drittel aus. In Ereignissen stellt das Lesen von Ausstellungstexten für über die Hälfte der Besuchenden die am häufigsten vorkommende Aktivitätsform überhaupt dar. Textvolumen und Vorkommen von Ereignissen stehen dabei allerdings nur bedingt in einem Zusammenhang. So erzielt langes und ununterbrochenes Vorlesen von Ausstellungstexten pro Ereignis lediglich eine Nennung, kann aber viel Raum einnehmen.

1240 Beispielsweise könnte man noch systematischer untersuchen, wie gelesen wird, ob und wann beispielsweise die Texte vollständig oder auszugsweise gelesen werden und welche 
Innerhalb der näher betrachteten Gruppe der freien Äusserungen fällt auf, dass es dort Unterschiede dahingehend gibt, ob sich Besuchende eher im Zusammenhang mit den in der Ausstellung befindlichen darstellenden Elementen oder mit Quellen äussern. ${ }^{1241}$ Auch hier zeigen sich im Wesentlichen wieder drei Gruppen von Besuchenden, nämlich solche, bei denen darstellungsbezogene Äusserungen deutlich mehr Raum einnehmen, solche, bei denen quellenbezogene Äusserungen deutlich mehr Raum einnehmen, und eine dritte Gruppe, in der sich die Besuchenden verhältnismässig ausgewogen im Zusammenhang mit darstellenden Elementen und Quellen äussern. ${ }^{1242}$

Im Hinblick auf eine zentrale Prämisse der theoretischen Museumsliteratur, die Quellen als zentrale Elemente oder gar Alleinstellungsmerkmal von historischen Museen bzw. Ausstellungen thematisiert, ${ }^{1243}$ was auch durch empirische Befunde unterstützt wird, ${ }^{1244}$ signalisieren die gemachten Befunde somit - zumindest für die konkrete zugrunde liegende historische Ausstellung und für einen Teil der Besuchenden - tendenziell Anlass zur Relativierung, erweist sich doch das Lesen von Ausstellungstexten sowie die Auseinandersetzung mit darstellenden Elementen als neben den Quellen keineswegs unbedeutend.

Für die Einordnung dieses Befundes gilt es jedoch, auch mögliche durch das Erhebungsdesign bewirkte Effekte in Betracht zu ziehen: Erstens gilt es zu bedenken, dass Lautes Denken möglicherweise in Bezug auf schriftlich vorliegendes

Passagen bei auszugsweisem Lesen herausgegriffen werden. Diese Fragen werden im Folgenden nicht behandelt. Hingegen sind die durch die Besuchenden im Rahmen ihrer freien Äusserungen formulierten Äusserungen $\ddot{u} b e r$ diese Texte sehr wohl von Interesse.

$1241 \mathrm{Zu}$ den quellenbezogenen Aktivitäten zähle ich das Sich-Äussern im Zusammenhang mit allen Arten von in der Ausstellung enthaltenen Quellen inkl. deren Quellenbeschriftungen. $\mathrm{Zu}$ den darstellungsbezogenen Aktivitäten zähle ich das freie Sich-Äussern zu oder ausgehend von Ausstellungstexten, ergänzt um Äusserungen im Zusammenhang mit sonstigen Elementen und damit «Nicht-Quellen», wie etwa Statistiken oder Kartenmaterial. Äusserungen der Besuchenden, die sich in einem grösseren Kontext auf die besuchten Abteilungen oder gar die ganze Ausstellung beziehen, werden nicht zu den darstellungsbezogenen Aktivitäten gerechnet, da die Besuchenden hier nicht konkret über einzelne, darstellende Elemente sprechen.

1242 Auch hier bezieht sich die Einschätzung wieder auf das Textvolumen, und es wurde als Schwelle ein Anteil von mehr als drei Fünfteln für eine Kategorie gegenüber der anderen festgesetzt.

1243 Vgl. Abschnitt 3.1.

1244 Vgl. z. B. Kohler 2016, S. 158, wobei Kohler auch feststellt, dass in den Augen der beforschten Schüler und Schülerinnen daneben Texten eine wichtige Rolle als Informationslieferanten zukommt (ebd., S. 168); vgl. zur Bedeutung von Objekten auch die Ausführungen in Abschnitt 5.3.5. 
Material leichter gelingt als in Bezug auf bildliches. ${ }^{1245}$ Zweitens kann nicht ausgeschlossen werden, dass die an die Teilnehmenden ergangene Aufforderung, gelesene Texte vorzulesen, möglicherweise überhaupt erst zu einer verstärkten Aufmerksamkeit für Texte oder gar einer Fixierung auf solche geführt haben könnte. Drittens und damit verbunden gilt es anzunehmen, dass lautes Lesen leichter fallen dürfte als lautes Denken und von den Besuchenden auch deshalb bereitwillig als Form gewählt wurde.

Möglicherweise zeigt das Interesse für Ausstellungstexte und insgesamt darstellende Elemente aber auch ein Bedürfnis der Besuchenden nach Kontextualisierung - ein Befund, der sich auch mit den von Christian Kohler erhobenen Schülervorstellungen decken würde, stellt Kohler doch fest, dass diese zwar den Ausstellungsbesuch als vom Objekt ausgehend verstehen, dass dabei jedoch in den Vorstellungen «den Texten und Medienstationen [...] eine zentrale Rolle $\mathrm{zu}[$ kommt]» und dass Ausstellungstexte «in den Augen der Schüler eine zentrale Bedeutung für die Vermittlung der Ausstellungsinhalte besitzen». ${ }^{1246}$ Weiter unten werde ich diese Überlegungen aufgreifen und zum Beispiel zeigen, dass die Besuchenden Ausstellungstexte, aber auch Quellenbeschriftungen mitunter als Antwortgeber auf während des Ausstellungsbesuchs entstehende Fragen und Irritationen behandeln.

Spezifischer für die freien Äusserungen im Zusammenhang mit Quellen fällt auf, dass dort Äusserungen im Zusammenhang mit Bildquellen die grösste Bedeutung zukommt, was angesichts des sehr hohen Anteils von Bildquellen in der Ausstellung naheliegend ist, höchstens in der Hinsicht überrascht, dass Lautes Denken im Zusammenhang mit bildlich vorliegenden Informationen als tendenziell weniger gut gelingend gilt. ${ }^{1247}$ Der Effekt der Methode kann selbstverständlich in meiner Arbeit nicht exakt beziffert werden, offenbar bereitet Lautes Denken den Besuchenden, so viel lässt sich feststellen, jedoch nicht derart Schwierigkeiten, dass es sie vom Sich-Äussern im Zusammenhang mit Bildquellen generell abhalten würde - im Gegenteil.

Mit der Unterscheidung in quellen- und darstellungsbezogene Aktivitäten ist noch nichts darüber ausgesagt, ob die Besuchenden selbst über einen Quellenund Darstellungsbegriff verfügen oder Vorstellungen von deren Funktion im Ausstellungskontext und deren unterschiedlichem erkenntnistheoretischem Stellen-

$1245 \mathrm{Vgl}$. Abschnitt 6.1.

1246 Kohler 2016, S. 168.

1247 Vgl. Abschnitt 6.1. 
wert haben. Wie Besuchende während ihres Durchgangs über die unterschiedlichen Elementtypen in Ausstellungen denken bzw. sprechen, welche Funktion sie diesen im Prozess des Besuchsverlaufs beimessen, diesen Fragen wird erst weiter unten im Rahmen der tiefenstrukturellen Betrachtungen differenzierter nachgegangen.

\subsection{3 Übergreifende Befunde, Zwischenfazit und Einordnung}

Mit der festgestellten, zumindest verhältnismässigen Bedeutung des Lesens von Ausstellungstexten sowie des freien Sich-Äusserns im Zusammenhang mit darstellenden Elementen steht eine weitere Beobachtung in Zusammenhang. Nämlich zeigt sich, dass sich ein in anderen Studien festgestelltes mehrheitlich objektorientiertes Organisieren des Ausstellungsbesuchs, bei dem das Lesen von Texten der Objektzentrierung nachgeordnet ist, ${ }^{1248}$ für die Teilnehmenden meiner Studie nicht feststellen lässt. Dies mag einerseits damit zusammenhängen, dass die dreidimensionalen Objekte in der konkreten Ausstellung nur einen geringen Anteil ausmachen. Doch auch für die zahlreichen in der Ausstellung enthaltenen Bildquellen lässt sich mehrheitlich kein vergleichbares Muster feststellen.

Nur vereinzelt zeigt sich bei Besuchenden über längere Phasen eine ausschliessliche Fokussierung auf bestimmte Elementtypen - im Fall von P22 die Bildquellen und deren Beschreibung - und eine entsprechende Strukturierung des Besuchsverlaufs. Abgesehen davon, ergibt sich jedoch mehrheitlich ein Bild, in dem sich die Besuchenden alternierend all dem zuwenden, was ihre Aufmerksamkeit weckt, wobei Ausstellungstexte bei der Mehrheit der Besuchenden eine mindestens ebenbürtige Rolle einnehmen.

Zentraler Befund ist in dem Zusammenhang weiter, dass Besuchsverläufe überwiegend ausgesprochen kleinschrittig strukturiert sind und einer momentbezogenen Logik folgen. ${ }^{1249}$ Besuchende beziehen sich in der Regel auf das, was sie unmittelbar vor sich haben, äussern sich darüber oder ausgehend davon und gehen anschliessend über zu einem nächsten Element. Die einzelnen Beschäftigungseinheiten reihen sich variabel und oft unverbunden aneinander und sind tendenziell kurz, explizite Rückbezüge zu weiter entfernt liegenden, früher betrachteten Elementen und eigenen früher angestellten Überlegungen kommen im Vergleich wenig vor.

1248 Noschka-Roos 1994, S. 155, S. 159; Kohler 2016, S. 168, S. 209; vgl. hierzu auch Abschnitt 5.3.1.

1249 Auf das festgestellte kleinschrittige und momentbezogene Abarbeiten gehe ich auch ein in Thyroff 2017b, S. 116, und Thyroff 2017c, S. 11. 
Dieser Befund ist aufschlussreich angesichts dessen, dass historisches Denken auf theoretischer Ebene zumindest idealtypisch als Prozess aus aufeinander aufbauenden, miteinander verknüpften Denkschritten bzw. Teiloperationen konzipiert wird. ${ }^{1250}$ Auf Basis der bislang erfolgten oberflächenstrukturellen Betrachtung entsteht der Eindruck, dass für das Denken während des Ausstellungsbesuchs hingegen von einer Vielzahl momentbezogener, kurzer und nicht zwingend untereinander in Bezug stehender Erzähleinheiten auszugehen ist, jedoch weniger von grossen, den gesamten Besuchsverlauf übergreifenden, miteinander vernetzten und aufeinander aufbauenden Erzähllinien. ${ }^{1251}$ Diese Überlegungen gilt es weiter unten anhand tiefenstruktureller Betrachtungen weiterzuverfolgen, wo ich dann aber auch Beispiele für durchaus auftretende, den Besuchsverlauf überspannende Erzähllinien anführen werde.

Die festgestellte Momentbezogenheit des Ausstellungsbesuchs ist mit Bezug auf Theorien des Lernens und Aneignens im Museum aufschlussreich, zeigt sich doch daran, dass die Besuchenden während des Besuchs keineswegs völlig losgelöst von der Ausstellung assoziieren, sondern dass die Elemente der Ausstellung als Impulsgeber fungieren bzw. die Besuchenden sie als solche gebrauchen. Der Befund unterstreicht so die schon von Falk und Dierking oder Kohler hervorgehobene Bedeutung des «Physical Context» ${ }^{1252}$ oder «Ausstellungskontexts» ${ }^{1253}$ auf den Verlauf individueller Aneignungsprozesse. Zwar ist einerseits die Auswahl von Elementen, mit denen sich die Besuchenden überhaupt beschäftigen, und sind andererseits die aus der Beschäftigung resultierenden Assoziationen höchst individuell, grundlegende formale Strukturen und Rhythmen des Sich-Beschäftigens und Aneignens einer Ausstellung sind aber über die einzelnen Besuchenden hinweg ähnlich. Darin reihen sich Zuwendungen zu Elementen der Ausstellung und davon ausgehende Überlegungen zumeist alternierend aneinander und wechseln sich in oft kurzer Folge ab.

Damit werden in meiner Studie Elemente des von Heiner Treinen fesgestellten "window shopping» sichtbar, in dem Sinn, dass sich Besuchende von dem leiten lassen, was gerade ins Blickfeld rückt, dass sie dies lesen oder betrachten und sich dazu äussern und anschliessend zum nächsten Element weitergehen, wobei die einzelnen Elemente bzw. Ausstellungsteile nacheinander abgehakt werden, im

1250 Vgl. Kapitel 2, v. a. Abschnitt 2.2 und 2.5.

1251 Dazu in Ansätzen auch Thyroff 2017c, S. 11.

1252 Falk/Dierking 2000, S. $53 \mathrm{ff}$.

1253 Kohler 2016, S. 70. 
Stil der Befunde Treinens, dass oft «wenige Blicke [genügen], um einen Merkmalposten abzuhaken, Gedanken anzuregen, Wissen zu vervollständigen». ${ }^{1254}$

Zusammenfassend erweist sich, mit Ausnahme der Reihenfolge aus Objektbetrachtung und Beschriftungslektüre, das von Susie Wise festgestellte «basic script for exploring a museum exhibition» auch in Bezug auf meine Daten als stimmig, wobei es für die Einordnung des folgenden Zitats zu beachten gilt, dass Wise einen breiten Objektbegriff verwendet, ${ }^{1255}$ also wohl das gesamte Spektrum in einer Ausstellung befindlicher Elemente meint:

«The basic script for exploring a museum exhibition with objects on display is to walk in to the space, look at an object, read its label, and move to a next object. This is repeated multiple times until the visit is 〈done〉. Even with this basic script we can see multiple decision points: what object to look at first, whether and when to read any adjacent text, what object look at next, how to know when I am done. And these are not just decisions made in the head, but are interactions with the exhibition space and its design.» ${ }^{1256}$

Dass beim Ausstellungsbesuch lediglich die Dinge betrachtet werden, die bereits bekannt sind, wie Treinen bemerkt, kann ich allerdings auf Basis meines Datenmaterials so nicht feststellen. Vielmehr zeigt sich ähnlich zu den Ergebnissen Rötteles ${ }^{1257}$ ein Nebeneinander aus Interesse für bereits bekannte Themen und Dinge und deren Identifizierung, andererseits auch die Zuwendung zu irritierenden, unbekannten Elementen. Auf diesen Aspekt komme ich weiter unten differenzierter zu sprechen, wenn ich inhaltliche Zugangsweisen der Besuchenden beschreibe.

Die Feststellung eines Abarbeitens des Museums von Element zu Element korrespondiert auch mit den festgestellten Bewegungsmustern im Raum. Wie beschrieben, lässt sich feststellen, dass der lineare Durchgang unter Berücksichtigung aller oder nahezu aller vorhandenen thematischen Abteilungen und unter regelmässigem Überspringen einzelner Einheiten den mehrheitlich beobachteten Besuchsverlauf darstellt. Die Besuchenden entsprechen somit wohl am ehesten dem Typus der «hoch interessierte[n] Person», die mit Sorgfalt die Ausstellung

1254 Treinen 1988, S. $33 \mathrm{f}$.

1255 Sie fasst darunter nämlich auch «text panel[s]» (Wise 2011, S. 92).

1256 Wise 2011, S. 75.

1257 Röttele 2017. Vgl. hierzu auch die Ausführungen in Abschnitt 5.3.5. 
durchschreitet, ${ }^{1258}$ oder dem bei Wise festgestellten Modus eines «Doing the museum with linear exploration». ${ }^{1259}$

Wenn also Doris Lewalter und Annette Noschka-Roos - und ähnlich weitere bereits vorgestellte Studien zu Besuchsverläufen ${ }^{1260}$ - feststellen, dass die Fortbewegung Erwachsener durch eine Ausstellung «meist nicht linear [verläuft] und [...] selten den vorgeschlagenen Besuchspfaden [folgt]», dass sich Besuchende vielmehr «visuell leiten [lassen] und [...] hauptsächlich durch Interessen, durch Neugier weckende oder zur Erkundung und Manipulation einladende Elemente, durch Phantastisches oder durch soziale Interaktion gelenkt [werden]», ${ }^{1261}$ so gilt es, diesen Befund für meine Studie zu relativieren und festzustellen, dass es vielmehr beides gleichzeitig ist, das sich beobachten lässt: ein in grosser Linie lineares Abarbeiten der vorgesehenen Wege unter individueller Fokussierung auf einzelne Elemente innerhalb dieser grossen Linie bei gleichzeitiger Auslassung anderer.

Die Befunde zu den Laufwegen lassen sich in dreierlei Hinsicht diskutieren, einordnen und weiterführen: Zunächst einmal sollte die Möglichkeit erwogen werden, dass die Besuchenden nicht zuletzt auch aufgrund ihrer Studienteilnahme mit verhältnismässig grosser Sorgfalt die Ausstellung betrachtet haben. Dies gilt möglicherweise trotz des Hinweises, nur diejenigen Ausstellungsteile zu betrachten, für die sie sich interessieren bzw. mit denen sie sich unter normalen Bedingungen, also ohne Teilnahme an der Studie, beschäftigen würden. Inwiefern das Wissen darum, an einer Studie teilzunehmen und im Anschluss an den Ausstellungsbesuch noch im Rahmen eines Interviews zum Besuch befragt zu werden, dazu geführt haben mag, dass die Besuchenden die Ausstellung trotz der eingangs formulierten Aufforderung mit relativer Sorgfalt betrachtet haben, lässt sich nicht abschliessend beurteilen. ${ }^{1262}$ Überdies kann der Befund eines sorgfältigen Durchschreitens auch in einem Interesse an der Thematik und hoher Besuchsmotivation begründet sein, die die Besuchenden überhaupt erst zur Meldung für die Studie bewogen haben mögen.

1258 Noschka-Roos 1994, S. 155, sich dabei auf einen von vier Besuchertypen beziehend, die Robert L. Wolf festgestellt habe (Wolf 1980, zit. n. Noschka-Roos 1994, S. 155); vgl. dazu auch Abschnitt 5.3.1.

1259 Wise 2011, S. 67.

1260 Vgl. Abschnitt 5.3.1.

1261 Lewalter/Noschka-Roos 2009, S. 532.

1262 Die Interviews wurden, wie bereits erwähnt, nicht in die Datenauswertung einbezogen, werden jedoch an dieser Stelle nochmals erwähnt, da sie in relevanter Weise den Charakter der Gesamterhebungssituation prägen. Über eine Beeinflussung der Besuchssituation durch das Wissen um eine anschliessende Befragung reflektiert auch Pampel (Pampel 2007, S. 167). 
Naheliegend erscheint mir zweitens die Deutung, dass die Besuchenden mit diesem typischen Bewegungsmuster das sowieso in den Räumlichkeiten der Ausstellung angelegte Potenzial realisieren, das eine lineare Bewegung entlang des u-förmigen Ausstellungsaufbaus nahelegt bzw. mangels Abkürzungsmöglichkeiten ein variables Hin- und Herspringen zwischen verschiedenen Abteilungen erschwert. Sollte ein derartiger linearer Ausstellungsdurchlauf bei der Konzeption der Ausstellung als Ideallinie angelegt und intendiert gewesen sein, was auch deshalb einleuchtend erscheint, weil dabei zugleich der der Ausstellung unterliegenden chronologischen Struktur gefolgt wird, so lässt sich folglich konstatieren, dass dieses Ziel erreicht wurde und die eingesetzten gestalterischen und architektonischen Mittel die Besuchenden in die gewünschte Laufrichtung lenken.

Umgekehrt und drittens wecken einzelne von dieser angenommenen Ideallinie abweichende Besuchsverläufe gleichwohl die Aufmerksamkeit dafür, dass Alternativen in den Laufbewegungen durchaus denkbar wären und möglich sind, aber offensichtlich von der Mehrheit der Besuchenden nicht realisiert werden. Deshalb stellt sich die von der konkreten räumlichen Gestaltung der Ausstellung unabhängige Frage, ob Besuchende durch lineares räumliches und thematisches Abarbeiten einer Ausstellung - trotz genannter gegenteiliger Befunde aus anderen Studien - möglicherweise das verwirklichen, was sie in einem Museum bzw. in einer Ausstellung für selbstverständlich geboten halten.

Insbesondere auf den spezifischen Fall historischer Museen übertragen, die in ihrer Erzählung häufig chronologisch strukturiert sind, kann lineares Abarbeiten zugleich bedeuten, einer Chronologie zu folgen und sich gleichsam mit der Entwicklung historischen Geschehens durch eine Ausstellung zu bewegen. Daraus leite ich die These ab, dass gerade in historischen Ausstellungen das Festhalten an einer gegebenen Reihenfolge für die Besuchenden eine besondere, weil zeitlich orientierende Bedeutung besitzt. Viele der erwähnten Studien, die bislang eine Nicht-Linearität oder Sprunghaftigkeit von Museumsbesuchen konstatieren, stellen dies für naturwissenschaftliche Museen fest. ${ }^{1263} \mathrm{Um}$ möglicheweise spezifische Umgangsweisen mit historischen Museen zu erhellen, bedarf es weiterer, vergleichend angelegter Studien, die einerseits unterschiedliche Museumstypen einander gegenüberstellen, aber auch neben dem Museumstyp weitere Merkmale variieren und überdies die Umgangsweisen von Besuchenden mit unterschiedlichen Darstellungs- und Strukturierungsweisen, so etwa noch stärker thematischen

1263 Vgl. Abschnitt 5.3.1. 
Zugängen, auch innerhalb von historischen Museen und Ausstellungen vergleichend betrachten.

Im Rahmen der Betrachtung von Besuchsverläufen anhand einer einzigen Ausstellung kann ich dem nur begrenzt nachgehen und meine Aufmerksamkeit lediglich darauf richten, ob und wie die Besuchenden der chronologischen Struktur in der hier untersuchten Ausstellung «14/18» Bedeutung beimessen. Ich greife diese Überlegungen weiter unten nochmals auf, wenn ich darstelle, wie die Besuchenden mit den wiederkehrenden und chronologisch strukturierten «Blick ins Ausland»-Elementen in der Ausstellung umgehen. ${ }^{1264}$

\subsection{Bausteine des Denkens in einer historischen Ausstellung: Eine tiefenstrukturanalytische Inventarisierung. Die Zugänge im Überblick}

Die bisherige oberflächenstrukturelle Betrachtung der Besuchsverläufe wird nachfolgend um eine tiefenstrukturelle Betrachtungsweise ergänzt und auf diesem Weg inhaltlich angereichert. Die im vorigen Kapitel beschriebene Codierung des gesamten Datenmaterials im Hinblick auf die darin befindlichen Aktivitätsformen liefert die Ausgangsbasis, um weitere Untersuchungen durchzuführen, erlaubt sie doch, lesende Aktivitäten der Besuchenden von freien Äusserungen zu unterscheiden und Letztere einer vertieften inhaltlichen Analyse zu unterziehen. Datengrundlage bilden nachfolgend nur noch diejenigen Äusserungen, die zuvor als freie Äusserungen identifiziert wurden und deren «Inventarisierung» ${ }^{1265}$ anschliessend erfolgte.

Bei der Betrachtung dieser Textstellen zeigte sich, dass sich die Äusserungen der Besuchenden in mindestens zwei parallel zueinander liegenden Ebenen strukturieren lassen, nämlich nach vorkommenden Themen und den dabei eingenommenen Fokussierungen. Ich zeige die Unterscheidung der beiden Ebenen anhand eines Beispiels aus dem Datenmaterial auf. In der nachfolgenden Passage beschäftigt sich P8 mit einer in der Ausstellung enthaltenen Textquelle, einem Aushang mit empfohlenen Massnahmen zur Eindämmung der während des Ersten Weltkriegs in der Schweiz grassierenden Grippeepidemie.

$1264 \mathrm{Vgl}$. Abschnitt 8.6.4.1.

1265 Kruse 2014, S. 409, Kursivsetzung analog zum Original. 
«Mitbürger (...) zur Einschränkung schränkt Besuche in den Wirtschaften, unterlasst Besuch von Kinos.> Also Menschenmassen sollten (...) nicht besucht werden, nicht auf die Strasse spucken, das empfeble ich grundsätzlich. (...) Händedruck unterlassen, na das sind ähnliche Plakate, wie heute bei grossen Grippewellen ausgehängt werden.» (P8, Absatz 79)

Unter der Perspektive einer Betrachtung von Aktivitätsformen, die ich im vorigen Abschnitt vorgestellt habe, liesse sich in dem gezeigten Beispiel mehrerlei identifizieren, nämlich zunächst das zusammenfassende, nicht exakt wortgetreue Vorlesen von Teilen der Textquelle und anschliessend ein freies Äussern in Bezug auf bzw. ausgehend von dieser Textquelle - wobei auch darin Bausteine aus der zugrunde liegenden Textquelle einfliessen und wiederum deutlich wird, dass die Grenzen zwischen lesenden und freien Äusserungen aufgrund eines grossen Spektrums paraphrasierender Varianten mitunter schwierig bestimmbar sind.

Unter tiefenstruktureller Perspektive werden jedoch nun noch weitere Zugriffe auf die Passage denkbar. So lässt sich das gewählte Thema, der (historische) Gegenstand, betrachten und feststellen, dass es in der Äusserung um das Thema Grippe bzw. Krankheiten geht. Parallel dazu liegend ist jedoch mindestens eine weitere Analyseebene denkbar, die ich als Fokussierungen bezeichne und die das Kernstück der Datenanalyse darstellt. Dabei geht es um die Frage, worüber die Besuchenden, jenseits von den konkret behandelten Themen, sprechen, wenn sie beim Ausstellungsbesuch ihre Gedanken äussern, also worauf sie ihren Fokus richten.

Der Fokussierungsbegriff wird hierbei in breiterem Sinn verwendet, als dies etwa in der Sechs-Felder-Matrix historischen Denkens der Fall ist, integriert aber teilweise deren Perspektiven. ${ }^{1266}$ Im gezeigten Beispiel lässt sich etwa feststellen, dass P8 mehrere Zeitebenen thematisiert, dass er oder sie nämlich aus der Beschäf-

1266 Das Bild des Richtens bzw. Einnehmens eines Fokus erscheint mir für das von mir betrachtete Phänomen ausgesprochen passend, weshalb ich für diesen Kategorienbereich mit dem Begriff der «Fokussierungen» operiere, auch wenn sich dadurch die Gefahr einer Verwechslung mit der beispielsweise dem Kompetenz-Strukturmodell der Gruppe FUER konzeptionell zugrunde liegenden Sechsermatrix des historischen Denkens ergibt (Körber et al. 2007, S. 862 f.; beschrieben auch bei Zabold/Schreiber 2004, S. 203; zu diesem Fokussierungsbegriff ausserdem: Schöner 2013a, S. 82 f.). In der Sechsermatrix wird der Begriff der Fokussierung als Fokussierung auf erstens Vergangenes, zweitens Geschichte oder drittens Gegenwart/Zukunft gebraucht. Diese Betrachtungsweise geht als Teilbereich in meinem Fokussierungsbegriff auf, allerdings beziehe ich darüber hinaus noch weitere Perspektiven ein, verwende also einen im Vergleich zur Sechsermatrix breiteren Fokussierungsbegriff. Ich komme auf Unterschiede und Gemeinsamkeiten in der abschliessenden Diskussion meiner Ergebnisse (Kapitel 9) zu sprechen. 
tigung mit dem gezeigten Plakat heraus einen Vergleich mit der Gegenwart herstellt und sagt, es gebe "ähnliche Plakate [...] heute bei grossen Grippewellen». Des Weiteren fällt auf, dass P8 neben Aussagen über die damalige historische Situation, bei der er oder sie zugleich Empfehlungen des Aushangs wiedergibt ("Menschenmassen sollten (...) nicht besucht werden»), auch auf das gezeigte Element eingeht ("na das sind ähnliche Plakate») sowie die eigene Person thematisiert ("das empfeble ich grundsätzlich»).

Auf engem Raum lässt sich also eine ganze Reihe von Strukturelementen identifizieren, die unabhängig von dem konkreten angesprochenen Thema, nämlich dem Thema Krankheiten bzw. Grippe, betrachtet werden können. Gerade die von den Besuchenden hergestellten Bezüge zur eigenen Person und Gegenwart $\mathrm{zu}$ identifizieren und $\mathrm{zu}$ beschreiben, stellt dabei ein zentrales Anliegen meines Forschungsprojektes dar. Anliegen ist allerdings auch, diese nicht isoliert zu betrachten, sondern sie in ihren strukturellen Bezügen mit weiteren Fokussierungen sowie mit den von den Besuchenden angesprochenen Themen und zugrunde liegenden Aktivitätsformen und Elementbezügen zu beleuchten.

Im Zentrum der Datenanalyse steht also der Bereich der Fokussierungen, die Betrachtung von Themen wie auch Aktivitätsformen dient jedoch als Hilfsmittel zur Anreicherung der fokussierungsbezogenen Befunde. Aus diesem Grund widme ich der Darstellung von themenbezogenen Befunden kein eigenes Kapitel, gehe vielmehr im Rahmen der Auseinandersetzung mit Fokussierungen immer wieder auch auf themenspezifische Aspekte ein und äussere mich an dieser Stelle nur in Bezug auf das für die Erschliessung von Themen verwendete Kategorienset.

Die Identifizierung von Themen erfolgte auf gemischt deduktivem und induktivem Weg. Einerseits wurde deduktiv auf einige gängige thematische Grosskategorien zurückgegriffen (z. B. Politik, Gesellschaft, Wirtschaft). Solche Kategorien werden zwar, wie Alexander Schöner feststellt,

«vorwiegend von anderen Disziplinen entwickelt und strukturieren bzw. systematisieren deren Domänen. Von der Geschichtswissenschaft aber werden sie zur Beschreibung und Erklärung historischer Phänomene, Gegebenheiten und Begebenheiten bzw. zur Strukturierung und Systematisierung der Domäne des Historischen herangezogen. Dabei werden sie mit der genuin historischen Kategorie Zeit korreliert.» ${ }^{1267}$

1267 Schöner 2007, S. 299 f.; dazu ausserdem Schöner 2013a, S. 78, und Schöner 2013c, S. 97 f. 
Absichtsvoll verwende ich gleichwohl nicht das Suffix -geschichte (z. B. als Wirtschaftsgeschichte, Sozialgeschichte), um der Möglichkeit Rechnung zu tragen, dass die Besuchenden auch Themen ohne Bezüge zur Vergangenheit zur Sprache bringen, und um diese Äusserungen ebenfalls fassen zu können. Mein Anliegen war es, mit dieser Kategorie die zur Sprache gebrachten Themen zu erfassen, ohne sie zugleich im Hinblick auf ihre (Nicht-)Historizität zu beurteilen. Welche Zeitebenen die Besuchenden thematisieren, wurde im Rahmen einer anderen Analyseebene betrachtet.

Das unter Rückgriff auf Grosskategorien erstellte Set, das zugleich Schwerpunktthemen der Ausstellung ähnelt, wurde um weitere in der Ausstellung selbst relevante Schwerpunktthemen ergänzt (z.B. Ausländer, Neutralität). Bewusst habe ich allerdings darauf verzichtet, die Gegenstände analog zu den Titeln der Ausstellungsabteilungen zu strukturieren. Zum einen wird die Struktur der Ausstellungsabteilungen bzw. genauer der Aufenthalt der Besuchenden in den einzelnen Abteilungen bereits mit einer anderen Kategorienebene abgebildet, ${ }^{1268}$ zum anderen sollte die Analyse möglichst offen für die seitens der Besuchenden selbsttätig zur Sprache gebrachten Gegenstände bleiben. ${ }^{1269}$ Hierzu wurde das Themenset auf induktivem Weg durch Subkategorien ausdifferenziert bzw. um weitere übergeordnete Kategorien ergänzt.

Im Rahmen der Datenanalyse wurde nun der Bestand an freien Äusserungen der Besuchenden nach darin vorkommenden Themengebieten systematisiert, ${ }^{1270}$

\section{$1268 \mathrm{Vgl}$. Abschnitt 8.3.1.}

1269 Fraglos steht das Vorkommen von Themen in der Ausstellung und in den Äusserungen der Besuchenden in einem gewissen Zusammenhang. Allerdings kann es hier nicht um eine exakte Einschätzung oder gar Bezifferung dieser Relation gehen. Eine Quantifizierung der Themen der Ausstellung wäre - wenn überhaupt - nur mit erheblichem Aufwand sinnvoll und vergleichbar zu bewerkstelligen, gerade auch deshalb, weil in vielen Texten, Objekten usw. mehrere Themenbereiche zugleich angelegt sind und zu einer Beschäftigung einladen. Ich kann somit stets nur vage qualifizierend einschätzen, welchen Anteil die Ausstellung selbst am Vorkommen der von den Besuchenden angesprochenen Gegenstände hat. Unabhängig davon geben die Befunde einen Eindruck davon, worüber die Besuchenden überhaupt sprechen, während sie sich in der Ausstellung befinden, und über Themenbereiche mit Relevanz oder Unbedeutsamkeit für einzelne oder eine ganze Reihe von Besuchenden.

1270 Dabei wurden bei Bedarf Textstellen mehreren Hauptkategorien zugeordnet, innerhalb deren aber jeweils nur einer Subkategorie, sodass die Subkategorien innerhalb einer Hauptkategorie sich gegenseitig ausschliessen. Die Länge der codierten Textstellen war dabei variabel und abhängig von der Dauer der Behandlung eines bestimmten Themas durch die Besuchenden. Anders als bei der Analyse der vorkommenden Interaktionsformen und Fokussierungen wurde im Bereich der Themen nicht zwingend der komplette Bestand an freien Äusserungen zugeordnet. So gab es eine Reihe von nicht thematisch zuordenbaren 
wobei Vorkommen eines Themas entweder bedeutete, dass die Besuchenden diesen Gegenstand völlig selbsttätig zur Sprache bringen oder dass sie einen Gegenstand der Ausstellung aufgreifen und sich dazu äussern. Das für die Betrachtung der Themen verwendete Kategorienset ist im digitalen Anhang einsehbar.

Für die Bearbeitung der Fokussierungen wurden analog zur Erfassung der Themen ebenfalls nur diejenigen Äusserungen der Besuchenden betrachtet, in denen sie sich frei äussern, also nicht lesen. Die Kategorienbildung erfolgte in einem Prozess aus zum Teil mehreren Materialdurchgängen und dabei mehrheitlich induktiver, jedoch theoretisch sensibler, paralleler Entwicklung von über- und untergeordneten Kategorien, im Verlauf dessen sich sukzessive die nachfolgend beschriebene Struktur herauskristallisierte. ${ }^{1271}$

Ich habe drei Fokussierungen in den Aussagen der Studienteilnehmenden identifiziert. ${ }^{1272}$ Es sind dies erstens Äusserungen über Geschehen (Fokus I), zwei-

Äusserungen, die bei der Analyse dieses Bereichs ausgeklammert wurden, wie beispielsweise rein formal besuchsstrukturierende Aussagen oder Aussagen über die Ästhetik der Ausstellung, sofern darin nicht zugleich auch die in der Ausstellung behandelte Thematik angesprochen wird.

1271 Mehrheitlich materialbasiert bedeutet in diesem Fall, dass die Kategorienstruktur zu Beginn des Analyseprozesses noch nicht feststand, sondern sich aus der Auseinandersetzung mit dem Material ergab, wohl aber die Identifizierung und Benennung von Kategorien aufgrund einer nicht hintergehbaren theoretischen Sensibilität (Strauss/Corbin 1996, S. 25; Kelle/Kluge 2010, S. 28) theoretisch inspiriert ist. Vgl. zum Verhältnis von Theorie und Empirie und der Rolle von theoretischer Sensibilität in meiner Studie ausserdem meine Ausführungen in Abschnitt 2.6. Für eine grundlegende Beschreibung des Ablaufs des Analyseprozesses unter Anlehnung an das Verfahren der inhaltlich-strukturierenden Inhaltsanalyse bei Kuckartz verweise ich auf meine Ausführungen in Abschnitt 6.4.

1272 Ähnlich betrachtete auch Wise in ihrer Studie, worauf Besuchende ihren Fokus richten, und bezeichnet die vier identifizierten Bereiche als "Object», «Exhibition», «Self» und «Outside» (Wise 2011 , S. 92; vgl. zu Wise auch Kapitel 5.3.7). Bis zu einem gewissen Grad wurde ich bei der Identifizierung und Benennung der Fokussierungen von der Arbeit von Wise inspiriert, allerdings weichen die letztlich von mir ausgewiesenen drei Fokussierungen in Struktur und Inhalt doch von dem Vorschlag Wise' ab. «Object» und «Exhibition» ähneln dem Fokus II auf die Ausstellung, «Self» und "Outside» ähneln dem Fokus III auf die eigene Person und Lebenswelt. Allerdings vermisse ich bei Wise eine weitere Dimension, in der das Sich-Äussern über historisches Geschehen eingefangen würde, das in meiner Kategorisierung im Fokus I Platz findet und das auch in Wise' Datenmaterial vorhanden sein dürfte. Wise scheint dieses mit einer gänzlich separaten Betrachtungsebene, den Strategien des sense-making einzufangen, im Rahmen deren sie ebenfalls vier unterscheidet («interpreting», «emoting», «remembering» und «embodied interpretative practices») (Wise 2011, S. 89). Das Interpreting führt sie als am häufigsten vorkommenden Modus des Sich-Äusserns im Museum ein und weist ihm verschiedene Subtypen zu, nämlich «Identifying and describing», "Offering an opinion», «Employing gallery-based resources», «Requesting more information» und "Adding an interpretative layer» (Wise 2011, S. 95 ff.; Zitate S. 98 f.). Es scheint somit, dass im Interpreting Äusserungen, die in meiner 
tens über die Ausstellung und ihre Elemente (Fokus II) und drittens über die eigene Person und Lebenswelt (Fokus III) (siehe in zunächst noch vereinfachter Darstellung Abbildung B). Es folgt ein Beispiel aus dem Datenmaterial, in dem sich alle drei Fokussierungen finden lassen und das insofern einen ersten Eindruck von deren Gestalt vermitteln kann. Das Beispiel enthält Aussagen einer Person bei der Betrachtung der Fotografie eines Grenzpostens (vgl. Umschlagbild):

"Hier ist ein schönes schwarzweisses Wandbild. Was seh ich denn hier? ২Provisorische Barrikaden am Zollposten - Nein! - «zwischen Hegenheim und Allschwil 1914.

Das ist ja (...), jetzt bin ich aber platt. Weil ich fahre ja fast täglich an diesem Zollhäuschen hier vorbei. Ich versuch mich gerade zu orientieren. Das ist zwischen Hegenheim und Allschwil, aber welcher der beiden Zollposten? Das sieht aus wie das (...). Klar, das ist, das ist der, an dem ich vorbeifabre. Muss ich gerade am Wochenende mal gucken.

Das Haus rechts scheint noch das gleiche zu sein. Die Bäume scheinen alle gefällt worden zu sein. Die Strasse ist breiter. Und ich frag mich, ob diese, dieses Gutshaus, diese Villa da rechts auf Allschwiler Seite, ja, was da wohl ist. Ich glaub, da ist beute alles Industrie und Wohngebiet. (unv.) wobl da von der französischen Seite zu. (...) Das ist ja eindrücklich. Ich hoffe, ich seh noch mehr von diesen Bildern.» (P12, Absatz 38-39)

Was macht nun die drei Fokussierungen aus, ${ }^{1273}$ und in welcher Gestalt sind sie im gezeigten Textbeispiel enthalten?

Fokus I beinhaltet Aussagen über Geschehen. ${ }^{1274}$ Hier berichten Besuchende darüber, was ihrer Ansicht nach war und sich ereignet hat oder was ist und sich ereignet, über das, was als gegeben angenommen wird und ihrer Meinung nach Gültigkeit hat. Die typische Grundstruktur von Aussagen im Fokus I lautet «x war

Kategorisierung in geschehens- und ausstellungsbezogene Äusserungen unterschieden wären, vermengt werden. Emoting und Remembering passt wiederum eher zu dem, was ich im Rahmen des Fokus III auf die eigene Person und Lebenswelt betrachte.

1273 In Grundzügen beschrieben und anhand von Datenbeispielen veranschaulicht (dort spezifisch anhand von Äusserungen der Besuchenden zu den exportwirtschaftlichen Verflechtungen der Schweiz) sind die drei Fokussierungen auch in Thyroff 2017b, S. $112 \mathrm{ff}$., und Thyroff 2017c, S. 4 f., S. 8 ff.

1274 Vgl. zur Begründung für die Wahl dieses positivistisch konnotierten Begriffs die Ausführungen in Abschnitt 8.5.1. 
so / $/ \mathrm{x}$ ist passiert ${ }^{1275}$ oder 〈y ist so / $\mathrm{y}$ passiert . Äusserungen im Fokus I können sich auf Geschehen in unterschiedlichen Zeitebenen beziehen. Im gezeigten Transkript-Auszug finden sich Beispiele für diesen Fokus etwa in Form der Äusserungen "Das ist zwischen Hegenheim und Allschwil», "Die Strasse ist breiter», «da ist heute alles Industrie und Wohngebiet» $\mathrm{u} . \mathrm{v} . \mathrm{m}$.

Äusserungen im Fokus II richten sich hingegen auf die Ausstellung und ihre Elemente. Im gezeigten Beispiel macht P1 2 diese sichtbar, indem er oder sie konkret eines dieser Elemente benennt und kommentiert ("Hier ist ein schönesschwarzweisses Wandbild»). Im Fokus II sprechen Besuchende über die Ausstellung, entweder in ihrer Gesamtheit oder über einzelne in der Ausstellung befindliche Bausteine. Sie entschlüsseln Merkmale und Gestaltungsweise der Ausstellung oder auch die Art der darin erzählten Geschichte. In unterschiedlichen Ausprägungsgraden wird dabei die Ausstellung als ein gemachter Ort sichtbar.

Auf den ersten Blick mag es so scheinen, als würde in den Fokussierungen I und II, zumindest in ihren idealtypischen Ausprägungen, ein positivistischer bzw. konstruktivistischer Blickwinkel auf Vergangenheit bzw. deren Konstruktion als Geschichte repräsentiert und gegenübergestellt. Diesem Aspekt werde ich weiter unten noch vertiefter nachgehen und dort darlegen, dass die Unterscheidung zwischen Äusserungen im Fokus I und II zwar teilweise übereinstimmend, jedoch nicht deckungsgleich mit einer Differenzierung in positivistische und konstruktivistische Zugänge ist. ${ }^{1276}$

Ebenfalls nicht deckungsgleich ist die Unterscheidung zwischen Fokus I und Fokus II mit derjenigen zwischen Vergangenheit und Geschichte ${ }^{1277}$ bzw. gilt es deren Verhältnis differenziert zu beleuchten. Aus der Perspektive einer konstruktivistischen Geschichtstheorie und mit analytischem Blick von aussen auf die Äusserungen der Besuchenden stellen ihre Äusserungen im Fokus I über Geschehen eine Geschichte dar bzw. mindestens Äusserungen über «Vergangenheitspartikel» ${ }^{1278}$ und «synchrone Kontextualisierungen», ${ }^{1279}$ wenn auch durchaus nicht

1275 Ich verwende hier und im Folgenden einfache Anfangs- und Schlusszeichen immer dann, wenn ich die idealtypische sprachliche Grundstruktur einer Aussage darlegen möchte und dabei nicht wörtlich aus dem eigentlichen Datenmaterial zitiere.

1276 Vgl. Abschnitt 8.6.3.

1277 Siehe zur Unterscheidung von Vergangenheit und Geschichte die Ausführungen in Fussnote 3 .

1278 Schreiber 2007b, S. 207.

1279 Zabold/Schreiber 2004, S. 206. 
immer Verknüpfungen von Zeitebenen ${ }^{1280}$ - auf diese Aspekte komme ich weiter unten differenzierter zu sprechen. Äusserungen im Fokus II über die Ausstellung und ihre Elemente sind aus analytischer Perspektive zunächst einmal nichts weiter als Äusserungen über die Gestalt eines gegenwärtigen Mediums. Äusserungen über die Ausstellung als konstruierte Erzählung über Vergangenes, also als $G e$ schichte, machen darin einen Teilbereich aus.

Inwiefern sich aus Perspektive der Besuchenden die Ausstellung und ihre Elemente als konstruierte Geschichte darstellen und von den Besuchenden als solche thematisiert werden, ist mit der Zuordnung von Äusserungen zum Fokus II allein also noch nicht ausgedrückt. Ebenfalls gibt die Zuordnung einer Äusserung zum Fokus I allein keinen Aufschluss darüber, ob die Besuchenden ihre eigene Äusserung selbst als Konstruktion wahrnehmen oder möglicherweise als Abbild von Vergangenheit.

Neben den Fokussierungen auf das Geschehen und die Ausstellung habe ich einen Fokus III identifiziert. In diesem Fokus machen die Besuchenden sich selbst als Person sichtbar, beziehen ihre Lebenswelt und den damit verbundenen Erfahrungsraum ein und stellen Relationen zwischen sich selbst und dem Geschehen oder der Ausstellung her. In der oben gezeigten Textpassage ist dies beispielsweise der Fall, indem P12 Überraschung äussert ("Nein! [...] - jetzt bin ich aber platt»), aus ihrer täglichen Lebenswelt berichtet ("ich fahre ja fast täglich an diesem Zollhäuschen hier vorbei»), eigene Fragen formuliert ("ich frag mich [...] was da wobl ist») oder Wünsche und Erwartungen an die Ausstellung formuliert ("Ich hoffe, ich seh noch mehr von diesen Bildern»).

Ich vertrete die Auffassung, dass sich das gesamte Spektrum an während des Ausstellungsbesuchs vorkommenden freien Äusserungen mit diesen drei Dimensionen abbilden lässt, dass also jede Äusserung mindestens einer der drei Dimensionen zugeordnet werden kann. Im weiteren Verlauf des Kapitels 8 werde ich diese drei Grunddimensionen, die entfernt an Darstellungen des didaktischen Dreiecks erinnern mögen, aber auf einer anderen Ebene liegen, ${ }^{1281}$ differenzierter vorstellen.

$1280 \mathrm{Vgl}$. für deren Bedeutung auch die Ausführungen in Abschnitt 2.3.

1281 Man kann in dieser dreipoligen Modellierung Anklänge des didaktischen Dreiecks erkennen, dessen Kenntnis sicherlich im Sinne einer theoretischen Sensibilität bei der Identifizierung der drei Fokussierungen eine Rolle gespielt haben dürfte, wobei mir der Zusammenhang erst im Nachhinein bewusst wurde. Das didaktische Dreieck weist als drei Pole Gegenstand, Lernende und Lehrperson aus (vgl. stellvertretend die Abbildung bei Gautschi 2009a, S. 34), die freilich nur bedingt zu den drei von mir benannten Fokussierungen 
Die Gliederung der Kapitel folgt dabei in ihrer Grundstruktur den drei identifizierten Fokussierungen. Überdies bildet die Gliederung auch die Grunddimensionen des im Verlauf der Analyse entwickelten und später noch vorzustellenden Fokussierungsmodells ab. Damit werden durch die Kapitelstruktur notwendigerweise wesentliche Befunde vorweggenommen und folgen meine Ausführungen nicht synchron dem Gang des ursprünglichen Analyseprozesses, bei dem sich die Kategorienstruktur und damit die Grundlage für die Modellbildung erst im Verlauf der Analyse verdichtete. ${ }^{1282}$

passen. «Gegenstand» entspräche in meinem Fall den Äusserungen über historisches Geschehen, «Lehrperson» den Äusserungen über die Ausstellung und «Lernende» den Äusserungen über die eigene Person. Allerdings geht es in meinem Modell, was die Formulierung «Äusserungen über» bereits deutlich macht, nicht um die Bezeichnung der Akteure und Akteurinnen innerhalb eines pädagogischen Feldes, sondern vielmehr auf einer Metaebene um die Äusserungen der Besuchenden über diese Dimensionen. Zudem konzipiere ich, wie weiter oben bereits dargelegt (vgl. Abschnitt 3.2), den Ausstellungbesuch nicht im engeren Sinn als eine Lehr-Lern-Situation.

Eine Zeit lang habe ich mit einer vierten Fokussierung gearbeitet, die Äusserungen über Geschichtskultur beinhaltete (vgl. hierzu auch Kapitel 9) und die, sofern der obige Vergleich mit dem didaktischen Dreieck fortgeführt wird, dort am ehesten dem «Umfeld» (Gautschi 2009a, S. 34) entspricht, aber in meinem Fall auch hier nicht das Umfeld selbst, sondern die Äusserungen der Besuchenden $\ddot{u} b e r$ dieses Umfeld bezeichnet. In dieser Kategorie enthalten waren beispielsweise Bezüge, die Besuchende zu anderen besuchten Ausstellungen herstellen, oder sonstige Berichte über ihre Erfahrungen aus dem Feld der Geschichtskultur, wie etwa besuchte Denkmäler oder gesehene Fernsehsendungen.

Ginge es darum, die Hintergrundfolie abzubilden, vor der alle Äusserungen der Besuchenden zustande kommen, wäre die Geschichtskultur als vierte Ebene des Modells stimmig. Jedoch geht es um die Strukturierung und Systematisierung der explizit hergestellten Bezüge durch die Besuchenden. Explizite Bezugnahmen auf diese Geschichtskultur durch die Besuchenden tauchen im Datenmaterial im Vergleich mit den übrigen drei Fokussierungen deutlich seltener auf, sodass ich an der Gleichwertigkeit dieser Fokussierung gegenüber den übrigen dreien zweifelte. In den Äusserungen der Besuchenden schienen mir geschilderte Erfahrungen mit Geschichtskultur vielmehr als ein Lebensweltbezug unter vielen, sodass ich entsprechende Textstellen schliesslich der Fokussierung III auf die eigene Person und Lebenswelt zuordnete und überdies hergestellte Bezüge zwischen der Ausstellung «14/18» mit anderen besuchten Ausstellungen als ausstellungsbezogene Aussagen im Fokus II wertete, aber nicht mehr Bezüge auf Geschichtskultur als ganz separaten Fokus auswies.

1282 Hierbei handelt es sich im Übrigen um eine generelle Problematik in der Darstellung der Ergebnisse qualitativer, vom Material ausgehender Forschungsprozesse, die meiner Einschätzung nach bislang zu wenig diskutiert wird. Die übliche inhaltliche Gliederung wissenschaftlicher Arbeiten in Theorie, Forschungsstand, Methode und Ergebnisse widerspiegelt nur bedingt den eigentlichen Forschungsprozess, in dem sich Ergebnisse in einem zyklischen Prozess und vielfältigen Miteinander aus Materialsichtung und -analyse, Finden und Festhalten von Zwischenergebnissen, Einbezug von Theorie und Forschungsstand, Verdichten von Ergebnissen, unter Umständen auch Erhebung weiterer Daten usw. abwechseln und in einem Wechselspiel generisch entwickeln. Diesen komplexen Prozess bis in kleinste Verästelungen zu dokumentieren und für Leser und Leserinnen nachvollziehbar 
Im nachfolgenden Abschnitt 8.5 widme ich mich nun zunächst dem Fokus I aufGeschehen und differenziere aus, worüber die Besuchenden sprechen, wenn sie Geschehen thematisieren. Zu diesem Zweck unterscheide ich zwei parallel zueinander liegende Analyseebenen. Ich frage einerseits danach, welcher Status diesem Geschehen beigemessen wird, und andererseits danach, welche Zeitebenen zur Sprache kommen, wenn Besuchende über Geschehen sprechen.

Der anschliessende Abschnitt 8.6 beschäftigt sich dann mit dem Fokus II auf die Ausstellung und ibre Elemente. Dort differenziere ich aus, worüber Besuchende genau sprechen, wenn sie die Ausstellung in den Blick nehmen. Beinhaltet sind dort weiter auch Überlegungen zum Verhältnis zwischen den beiden Fokussierungen I und II und zu ihrem Verhältnis mit positivistischen und konstruktivistischen Zugängen.

In Abschnitt 8.7 nehme ich schliesslich den Fokus III in den Blick, in dem die Besuchenden in irgendeiner Weise sich selbst als Person thematisieren. Auch innerhalb dieses Fokus habe ich im Verlauf der Analyse Subdimensionen ausdifferenziert. Es geht dort zum einen um Relationen, im Rahmen deren sich die Besuchenden in ein Verhältnis zu Geschehen oder Ausstellung setzen, ausserdem um Bezüge zur eigenen Lebenswelt sowie um Reflexionen über die Rolle der eigenen Person in der Ausstellung.

Auf die daraus resultierende dreipolige Modellierung komme ich schliesslich in Kapitel 9 zu sprechen, wo ich dann zum Abschluss meiner Arbeit auch die Befunde zusammenfasse und über Anschlusspunkte bzw. Überschneidungsbereiche mit vorhandenen theoretischen Modellierungen historischen Denkens reflektiere.

Ein besonderes Augenmerk gilt nachfolgend der Rolle der von den Besuchenden hergestellten Bezüge zur eigenen Person und Zeit. Deren Identifizierung und systematische Betrachtung und die Erhellung ihrer Struktur gehören zu den Hauptanliegen meines Forschungsprojekts. Ich frage also nach deren Auftreten

zu machen, ist schlechterdings unmöglich und mag ein Grund dafür sein, warum qualitativer Forschung gelegentlich vorgeworfen wird, ihr Prozess der Ergebnisgewinnung sei undurchsichtig. Ich betrachte dieses komplexe Ineinander von Arbeitsschritten hingegen als Qualitätsmerkmal und Konstitutiv qualitativer Forschung. Freilich muss trotz allem der Anspruch gelten, die eigene Vorgehensweise bestmöglich zu reflektieren und zu dokumentieren. Aus diesem Grund lege ich nachfolgend zu Beginn jedes Abschnitts dar, auf welche Weise Kategorien zustande gekommen sind, verweise auf theoretische Bezüge, differenziere die Kategorien anschliessend aus und reichere die Darstellung durch Beispiele aus dem Datenmaterial an, um eine möglichst enge Rückbindung der Darstellung an das Material zu erzielen. 
und Gestalt, nach ihrer Verortung innerhalb der entwickelten Modellierung und nach Anknüpfungspunkten zu vorhandenen Theorien historischen Denkens und Konzeptionen von Orientierung. Gemäss der Logik der Kategorienstruktur finden sich Personenbezüge im Fokus III wieder, dessen Darstellung im Vergleich mit den anderen beiden Fokussierungen deshalb mehr Raum gewidmet wird. Bezüge zu gegenwärtigem Gescheben finden sich demgegenüber, so viel sei an dieser Stelle vorweggenommen, auch im Fokus I wieder. Und auch in den Äusserungen über die Ausstellung kommen Gegenwartsbezüge zum Tragen, dort nämlich dann, wenn die Besuchenden über die von der Ausstellung hergestellten Gegenwartsbezüge sprechen.

\section{5 Äusserungen im Fokus I: Geschehen}

\subsubsection{Varianten im Überblick}

Bei Aussagen im Fokus I sprechen Besuchende darüber, was ihrer Ansicht nach 〈war〉 oder <ist〉, ${ }^{1283}$ beispielsweise:

"Alle haben ja gedacht, das würde ein kurzer Krieg (...) und sei in ein paar Wochen vorbei. Und niemand hat geabnt, dass das (...) von 1914 bis 1918 dauern wird.» (P25, Absatz 25)

"Also damals hat man schon geschaut für die Ärmsten. Man hat dann also Mietzins- und Krankenkassenbeiträge ausgezablt oder reduziert. Also ähnlich wie auch heute in der Sozialleistung.» (P20, Absatz 27)

Äusserungen im Fokus I sind Äusserungen über Sein und Werden, vergangen oder gegenwärtig, das als gegeben angenommen wird. Der Begriff Geschehen trägt dem Rechnung. Im Bewusstsein um seine positivistisch anmutende Konnotation halte ich gerade diesen Begriff für geeignet, um zu fassen, was Besuchende innerhalb des Fokus I tun, nämlich - in Abstufungsgraden mehr oder weniger unhinterfragt - über eine aus ihrer Sicht gültige Wirklichkeit zu sprechen. Der Begriff des Geschehens umfasst hier, was Hans-Jürgen Pandel als «Geschehene Geschichte» bezeichnet,

1283 Eine knappe Beschreibung des Fokus I mit anderen Materialbeispielen findet sich auch in Thyroff 2017 c, S. 4, S. 8. 
nämlich die «Totalität alles Geschehens in seiner absoluten Tatsächlichkeit», ${ }^{1284}$ und in meinem Fall genauer das Reden der Besuchenden über diese aus ihrer Sicht geschehene Geschichte. Anders als Pandel verwende ich allerdings, einem konstruktivistischen Geschichtsbegriff folgend, ${ }^{1285}$ absichtsvoll gerade nicht den Begriff der geschehenen Geschichte, sondern spreche von Geschehen und dabei genauer von vergangenem oder gegenwärtigem Geschehen, ${ }^{1286}$ ebenso wie auch Pandel den Begriff der geschehenen Geschichte nach Zeitebenen differenziert. ${ }^{1287}$ Geschehen nach meinem Begriffsverständnis integriert Sein und Werden, Ereignis, Zustand, Struktur und Prozess, Wandel und Gleichbleibendes. ${ }^{1288}$ Die Kategorie beinhaltet Äusserungen der Besuchenden über all diese Aspekte.

Die Begriffswahl für den Fokus I und die Zuordnung von Äusserungen orientiert sich eng an den expliziten Verbalisierungen der Besuchenden. Geschehen fungiert als heuristische Kategorie. Was die Besuchenden als vergangenes oder gegenwärtiges Geschehen thematisieren, wird auch als das erfasst, unabhängig davon, inwiefern das Gesagte empirisch, narrativ oder normativ triftig bzw. plausibel ist, ${ }^{1289}$ inwiefern es mit Aussagen der Ausstellung in Deckung zu bringen ist und welche zugrunde liegenden Operationen zu der formulierten Annahme über Wirklichkeit

1284 Pandel 2013, S. 53.

$1285 \mathrm{Vgl}$. hierzu die Ausführungen in Fussnote 3.

1286 In gewisser Hinsicht mag «Geschehen» damit als Totalkategorie anmuten, da alle menschlichen Äusserungen sich in irgendeiner Weise auf Wirklichkeit und Sein beziehen. Allerdings nehme ich in meinem Kategorienset davon strukturell Äusserungen aus, in denen sich Besuchende über die Ausstellung (Fokus II) oder ihre eigene Person (Fokus III) äussern, auch wenn Ausstellung und eigene Person natürlich, streng genommen, auch als Bestandteile gegenwärtigen Seins und gegenwärtiger Wirklichkeit verstanden werden können. Ein derart erweiterter Geschehensbegriff ist jedoch für das hier verfolgte Forschungsanliegen nicht zielführend, weil er die analytisch getrennten drei Fokussierungsbereiche verwässert. "Geschehen» meint im hier verwendeten Fall und in seiner idealtypischen Ausprägung vorrangig historisches Geschehen und daneben auch gegenwärtiges Geschehen, aber nicht das Erzählen über dieses Geschehen durch die Ausstellung und ihre Gestalt als heutige geschichtskulturelle Manifestation und nicht die eigene Person als Bestandteil von Geschehen. Diese beiden Bereiche sind vielmehr Gegenstand separater kategorialer Betrachtung, wobei es aber punktuell zu Überschneidungen zwischen dem Fokus I auf Geschehen und Fokus III auf die eigene Person kommen kann (s. u.).

1287 Pandel 2013, S. 53.

$1288 \mathrm{Vgl}$. für das Spektrum von Gegenstandsfeldern historischer Betrachtungen: Koselleck 2003, S. 294 ff.; Schöner 2013c, S. 95; Seixas/Morton 2013, S. 74, S. 102; Günther-Arndt 2014, S. 166 ff.; Baumgartner 2015, S. 95; sowie die Ausführungen dazu in Abschnitt 2.3.

1289 Zu den drei Triftigkeiten: Rüsen 2012, S. 90 ff.; in seiner Historik aus dem Jahr 2013 spricht Rüsen stattdessen von Plausibilitäten und unterscheidet vier Formen, nämlich Plausibilität von Geschichte im Hinblick auf Erfahrung, Erklärung, Bedeutung und Sinn (Rüsen 2013, S. $58 \mathrm{ff}$.). 
geführt haben mögen - sei es ein auf Quellen basierendes Re-Konstruieren, das Berichten von Vorwissensbeständen oder einer in einem Ausstellungstext gefundenen Aussage über Geschehen, sei es, in der Unterscheidung Pandels, ein «Erzählen», «Nacherzählen» oder «Umerzählen», ${ }^{1290}$ seien es in der Terminologie Hodels «NeuNacherzählungen» ${ }^{1291}$ oder in der Unterscheidung von Waldis et al. «Nacherzählung» oder «Interpretation». ${ }^{1292}$ Auch Rückschlüsse auf bei den Besuchenden möglicherweise vorhandene positivistische oder konstruktivistische Grundhaltungen, auf vorhandene oder abwesende Differenzierungen zwischen Vergangenheit und Geschichte sind damit noch nicht automatisch verbunden.

Wenn ich oben von der Grundstruktur oder der idealtypischen Ausprägung dieses Fokus I gesprochen habe, so deutet sich damit bereits an, dass es innerhalb der Kategorie Spielraum für Differenzierungen gibt. Konkret gibt es beispielsweise durchaus Unterschiede dahingehend, mit welchem Grad von Sicherheit oder «Wahrheits-/Wahrscheinlichkeitsgehalt» Besuchende über Geschehen sprechen, inwiefern sie ihre Aussagen auf Grundlagen zurückbinden und inwiefern sie deutende Instanzen in diesem Blick auf Geschehen sichtbar machen. Diesen Differenzierungen gehe ich nachfolgend unter dem Stichwort Status der Äusserung über Geschehen nach (Abschnitt 8.5.2).

Zweitens lassen sich die Textstellen, wie soeben angedeutet, auch dahingehend differenzieren, auf welche Zeitebenen Besuchende mit ihren Aussagen Bezug nehmen, also ob sie beispielsweise ausschliesslich vergangenheitsbezogene Aussagen über Geschehen machen oder, wie in einem der obigen Beispiele, die Gegenwart in ihre Überlegungen einbinden (Abschnitt 8.5.3). Diese Analyseebene ist für mein Forschungsanliegen deshalb von eminenter Bedeutung, weil sie erlaubt, im Material enthaltene Passagen mit gegenwartsbezogenen Geschehensaussagen zunächst zu identifizieren und anschliessend einer vertieften Feinanalyse zu unterziehen (Abschnitt 8.5.4).

1290 Pandel 2002, S. 49f. Pandel unterscheidet als vierten Typ noch ein «rezensierendes Erzählen», bei der es sich um eine «Metanarration», eine «Bewertung erzählter Geschichten» handle, bei der «eine Geschichte auf empirische und narrative Triftigkeit geprüft» wird (Pandel 2002, S. 50). Der Logik der Basisoperationen Re-Konstruktion und De-Konstruktion folgend, liegt diese Operation meines Erachtens allerdings auf einer anderen Ebene als die übrigen drei, nämlich gehört sie dem de-konstruktiven Modus an. In der Logik meines Kategoriensystems gehören Äusserungen über die in der Ausstellung vorgefundenen Erzählungen in den Bereich der Fokussierung II.

1291 Hodel 2014, S. 17.

1292 Waldis et al. 2015, S. 77, S. 80 f., direkte Zitate S. 80. 


\subsubsection{Status der Äusserungen über Geschehen}

Wenn ich von Status spreche, dann meine ich damit einerseits den Grad von Sicherheit und Wahrscheinlichkeit oder den «Wahrheitsgehalt», den die Besuchenden ihrem Reden über Geschehen zuschreiben, andererseits den Grad der expliziten Rückbindung von Äusserungen an eine Herkunft bzw. Grundlagen - seien es Quellen, Darstellungen, eigenes Vorwissen usw.

Im bereits beschriebenen Grundmodus ( $<\mathrm{x}$ ist passiert $>$ bzw. «x passiert $>$ ) stellt Reden über Geschehen eine von den Besuchenden unangezweifelte und auch unbelegte Äusserung über Sein und Wirklichkeit dar, etwa:

"Also sie haben den Lohnausfall, der Mann ist nicht da, und der Sold ist auch noch jämmerlich.»(P12, Absatz 69)

"Auch noch in den 50er-Jahren hat es solche Pflüge gegeben mit einem Pferd.» (P18, Absatz 60)

"Ciba ist ja noch unabbängig gewesen damals von Geigy. Das hat ja dann erst später fusioniert.»(P20, Absatz 26)

«Kupfer blieb eigentlich auf hohem Niveau.»(P27, Absatz 30)

"Also die Schweiz ist ja heute bekannt, dass sie eben manchmal vermittelt (...).» (P3, Absatz 57)

Nur ein Teilbereich der Äusserungen der Besuchenden über Geschehen entspricht diesem Grundmodus. Daneben existiert eine Reihe von Varianten, bei denen die Besuchenden ebenfalls über Geschehen sprechen, aber in verschiedenen Hinsichten vom Grundmodus abweichen. Zum einen gibt es Abweichungen in der Hinsicht, dass Besuchende eine eingeschränkte Sicherheit über die Gültigkeit ihrer Äusserung über Geschehen zum Ausdruck bringen, beispielsweise in der Form eines 〈vermutlich/möglicherweise/scheinbar ist $\mathrm{x}$ 〉. Zudem machen sie auch sich selbst oder die Ausstellung sowie die darin befindlichen Elemente als deutende und eine bestimmte Sicht auf Geschehen nahelegende Instanzen sichtbar oder tun auf irgendeine andere Weise eine persönliche Involvierung in Bezug auf ihre Äusserungen über Geschehen kund, etwa im Stil eines «ich vermute, dass $\mathrm{x}$ war), ‘aus dem Text geht hervor, dass $\mathrm{x}$ passiert ist oder 〈hier steht, dass $\mathrm{x}$ war〉. 
Mit derartigen Aussagen sprechen Besuchende nach wie vor über vergangenes oder gegenwärtiges Geschehen und äussern sich damit im Fokus I, bringen aber gleichzeitig auch Perspektiven ein, die einerseits die Ausstellung und andererseits sie selbst als Personen sichtbar machen. Beispielhaft zeige ich hierfür nachfolgende Überlegungen einer Person, vor einer Diashow mit Bildquellen stehend, im Zuge deren sie Äusserungen über historisches Geschehen formuliert und dabei zugleich explizit deutlich macht, dass ihre Überlegungen zu diesen Bildquellen durch ihr Vorwissen inspiriert sind ("das erinnert mich (...) dran, wie») bzw. durch eine weitere Abbildung in der Diashow bestätigt werden ("genau, da kommt's auch»):

"Was haben wir denn hier? ‘Soldaten am Pflug. Schweizerisches Bundesarchiv〉. Soldaten am Pflug, ja das evinnert mich vor allen Dingen dran, wie wabrscheinlich so wie im Zweiten Weltkrieg so eine Anbauschlacht existierte. Dass man angesichts von Lebensmittelrationalisierung, genau, da kommt's auch, diese Kartoffelsäcke, dass man überall angebaut hat, was man konnte. (...) Vor allen Dingen eben Kartoffeln und alles was eben irgendwie nährend war und satt machte und jeder Garten und jedes Feld und (...).»(P12, Absatz 105)

In der räumlichen Logik des von mir entwickelten dreipoligen Fokussierungsmodells ausgedrückt, fallen derartige Formulierungen in Randzonen der Fokussierung $I$ und integrieren Spuren einer Fokussierung II auf die Ausstellung und ihre Elemente oder einer Fokussierung III auf die eigene Person und Lebenswelt, ohne diese Fokussierung jedoch bereits zum alleinigen Hauptmodus der jeweiligen Äusserung werden zu lassen. Ich gehe nachfolgend näher auf diese Rand- bzw. Überschneidungszonen ein. Abbildung $\mathrm{C}$ visualisiert diese Randzonen.

Innerhalb der Äusserungen über das Geschehen mit Tendenz zur Sichtbarmachung der eigenen Person wurden Kategorien unterschieden, in denen die Besuchenden sich selbst als Urheber von Äusserungen sichtbar machen, unterschiedliche Abstufungen ihrer eigenen Sicherheit über die Tatsächlichkeit des Geschehens zum Ausdruck bringen oder sich anderweitig selbst in Relationen zu dem Geschehen setzen.

Unterschiedliche Grade an Sicherheit und Benennung der Herkunft von Äusserungen kommen in Vermutungen, Fragen und Unklarheiten sowie in Thematisierungen von Wissen in Bezug auf Geschehen zum Ausdruck. Damit sind vier Bereiche benannt, im Rahmen deren Besuchende zwar über Geschehen sprechen, sich dabei aber zugleich als Personen in Relation zu diesem Geschehen sichtbar 
machen, nämlich als Personen, die sich über die Tatsächlichkeit dieses Geschehens nur bedingt sicher sind, sich gar im Unklaren darüber sind, neues Wissen über Geschehen erwerben oder umgekehrt zu Vorwissen über Geschehen verfügen. Für die hier vorgestellte Modellbildung wurden derartige Überschneidungsbereiche zwischen eigener Person und Geschehen mit dem Begriff der Relationen übertitelt.

Äusserungen von neuem Wissen und Vermutungen in Bezug auf Geschehen finden sich beispielsweise in nachfolgenden Beispielen:

"Aber das ist für mich neu, dass doch schon im Dezember 1914 hunderttausend Soldaten wieder entlassen worden sind.»(P18, Absatz 26)

«Den Familien fehlt oft der Ernährer». Na und den Bauern der Arbeiter, nehm ich mal an.» (P5, Absatz 22)

«Firmengelände der Sandoz bei der Gasfabrik» (...). Die sind glaube ich noch lange gestanden, da, die, die komischen Gasbehälter, die, kann ich mich als Kind noch erinnern.» (P20, Absatz 119)

$\mathrm{Zu}$ den Relationen zählen kognitive, aber auch nicht-nur-kognitive Relationen, ${ }^{1293}$ etwa Äusserungen von Emotionen und Wertungen in Bezug auf Geschehen. Hierzu können beispielsweise Äusserungen von Überraschung oder Betroffenheit in Bezug auf Geschehen zählen:

"Das hätte ich jetzt nie gedacht, dass, so wie es die Arbeiterunruben und revolutionären Umtriebe in Deutschland gab, im November 1918, dass es zwar unter anderen Vorzeichen, aber eine Entsprechung in der Schweiz gab.» (P12, Absatz 183)

"Ja, hätt ich jetzt nicht gedacht, dass es so viele italienische Arbeiter da gab.» (P12, Absatz 53)

«ja, wie viele Leute da gestorben sind, bewegt einen, bewegt einen, wenn man das sieht, hm (seufzend).»(P19, Absatz 70)

1293 Vgl. zur Einführung dieses auf Borries zurückgehenden Begriffs Abschnitt 3.4.1 sowie später Abschnitt 8.7.2. 
Hier geht es nun nicht mehr um unterschiedliche Grade von Sicherheit in Bezug auf die Gültigkeit einer Aussage über Geschehen, sondern um eine persönliche emotionale Involvierung in Bezug auf Geschehen. In beiden Fällen handelt es sich um Berührungsbereiche zwischen dem Fokus I und III. Ich werde mich weiter unten, im Zusammenhang mit der Beschreibung des Fokus III, eingehender mit diesen kognitiven und nicht-nur-kognitiven Relationen beschäftigen und die zugehörigen Befunde differenzierter darstellen (Abschnitt 8.7.2). Für das Anliegen des aktuellen Abschnitts genügt hingegen zunächst der Befund, dass es neben der weiter oben beschriebenen Grundform des Sich-Äusserns über Geschehen auch ein variantenreiches Spektrum an Äusserungen gibt, im Rahmen deren Besuchende über Geschehen sprechen und sich zugleich als Person selbst explizit sichtbar machen.

Neben den Äusserungen über Geschehen mit Sichtbarmachung der eigenen Person gibt es des Weiteren auch Aussagen, in denen die Besuchenden über Geschehen sprechen und dabei zugleich die Ausstellung oder die darin befindlichen Elemente sichtbar machen (siehe Abbildung C). Eine Variante ${ }^{1294}$ liegt strukturell auf einer ähnlichen Ebene wie diejenigen, bereits beschriebenen Äusserungen, in denen die Besuchenden Vermutungen, Fragen, Vorwissen und neues Wissen in Bezug auf Geschehen äussern. In allen Fällen geht es darum, Seinsaussagen nicht einfach als gegeben in den Raum zu stellen, sondern deren Herkunft bzw. den Grad von deren Gewissheit zum Ausdruck zu bringen. Während Besuchende in den weiter oben beschriebenen Varianten mit Bezug zur eigenen Person sich selbst als Instanzen sichtbar machen, tun sie dies im hier beschriebenen Fall nun mit der Ausstellung bzw. den darin befindlichen Elementen. Die Besuchenden sprechen in diesen Passagen über Geschehen und geben zugleich an, diese Aussagen einem in der Ausstellung befindlichen Element entnommen zu haben. Idealtypische Formulierungen sind 〈hier geht hervor, dass $\mathrm{x}$ gewesen ist〉, 〈offenbar ist $\mathrm{x}$ gewesen〉, «dem Text zufolge ist $x$ gewesen». Die nachfolgenden Beispiele geben einen Eindruck hiervon:

"Es heisst hier auch, dass die chemische Industrie in Basel profitiert hat vom Ersten Weltkrieg.» (P3, Absatz 12)

"Ja, da sehe ich gerade schon wieder, dass die Exportindustrie Konjunktur hatte.» (P19, Absatz 65)

1294 Auf weitere Überschneidungsbereiche zwischen Fokus I und II komme ich am Beispiel des Umgangs der Besuchenden mit Bildquellen erneut zu sprechen (vgl. Abschnitt 8.6.3.3). 


\subsubsection{Zeitebenen des Geschehens}

Äusserungen über Geschehen lassen sich neben dem Status, den die Besuchenden ihrer Äusserung beimessen, also dem «Wahrheits»-/Wahrscheinlichkeitsgehalt, dem Grad der Rückbindung, dem Grad einer persönlichen Involvierung bzw. Sichtbarmachung der eigenen Person oder der Ausstellung, auch dahingehend unterscheiden, welche Zeitebenen bei einer Äusserung über Geschehen thematisiert werden. Geschehen ist, wie weiter oben bereits erwähnt, als Terminus zunächst einmal zeitebenenübergreifend gemeint, wird aber im Rahmen der hier beschriebenen Analyseebene im Hinblick auf die vorkommenden Zeitebenen ausdifferenziert.

Ausgehend von Theorien historischen Denkens bzw. Erzählens, gehe ich davon aus, dass Erzählen von Geschichte als Verknüpfung mehrerer Zeitebenen organisiert sein kann, wobei entweder mehrere Zeitebenen innerhalb der Vergangenheit (tl, $\mathrm{t} 2, \ldots)$ verbunden oder Bezüge zwischen Vergangenheit und Gegenwart oder $\mathrm{Zu}$ kunft hergestellt werden können. ${ }^{2295}$ Ohne zwingend dem Postulat folgen zu müssen, dass eine entsprechende Verknüpfung von Zeitebenen, womöglich gar unter Einbezug der Gegenwart, das Konstitutiv historischer Erzählungen sei, ${ }^{1296}$ ist es doch im Hinblick auf das Forschungsanliegen, die Suche nach Gegenwartsbezügen, notwendig, nach verschiedenen vorkommenden Zeitebenen zu differenzieren.

Ausgehend von der Literatur habe ich das Kategoriensystem deshalb zunächst nach den drei Zeitebenen Vergangenheit, Gegenwart (und Zukunft ${ }^{1297}$ ) gegliedert und innerhalb der Vergangenheit nach verschiedenen Zeitebenen tl und t2 unterschieden, um herauszufinden, auf welche dieser Ebenen die Besuchenden $\ddot{u} b e r-$ baupt zu sprechen kommen, und - im Falle des Einbezugs von Gegenwart - welcher Form die Verknüpfungen zwischen den verschiedenen Zeitebenen sind. Ich spreche explizit von Bezügen oder Verknüpfungen, keinesfalls von Vergleichen, ausgehend von der Überlegung, dass sich Bezüge zwischen Zeitebenen nicht nur als Feststellung von Gemeinsamkeiten und Unterschieden manifestieren, sondern auch nach anderen Erzählmustern strukturiert sein können, etwa, wie bei Peter Seixas und Tom Morton formuliert, als «Cause and Consequence», «Continuity

1295 Die Benennung der vergangenen Zeitpunkte als tl und t2 übernehme ich von Schöner 2013c, S. 94. Vgl. für theoretische Hintergründe zu den Verknüpfungen von Zeitebenen als mögliche oder auch notwendige Eigenschaft historischer Erzählungen die Ausführungen in Abschnitt 2.3.

1296 So postuliert bei: Pandel 2002, S. 41; Barricelli 2005, S. 42; Rüsen 2013, S. 76.

1297 Die Zukunft als Zeitebene taucht lediglich sehr vereinzelt auf. Ich behandle diese Textstellen weiter unten im Zusammenhang mit der Betrachtung von Gegenwartsbezügen. 
and Change» ${ }^{1298}$, oder, wie bei Alexander Schöner zu finden, als «Entwicklungen bzw. Veränderungen», ${ }^{1299}$ «Kontinuität und Wandel», «Diskontinuität und Abbruch», «Beschleunigung vs. Verlangsamung». ${ }^{1300}$

Neben der genannten und deduktiv aus der historischen Erzähltheorie abgeleiteten Kategorienstruktur wurde ausgehend vom Material eine weitere Kategorie eingeführt, mit der sich als überzeitlich und universell gültig formulierte Äusserungen fassen lassen, sowie eine weitere Kategorie, die nicht zeitliche, sondern räumliche Bezüge fasst, ausgehend von der Feststellung, dass diese neben den zeitlichen Bezügen eine weitere relevante Grösse innerhalb der Äusserungen der Besuchenden darstellen. Sämtliche Kategorien, sowohl die deduktiv gesetzten als auch die ausgehend vom Datenmaterial identifizierten, wurden in Auseinandersetzung mit dem konkreten Material präzisiert und definiert und dabei materialspezifische Besonderheiten und Prägungen der einzelnen Kategorien festgehalten. Das Ergebnis dieser materialbasierten Konkretisierung stelle ich nachfolgend vor. ${ }^{1301}$ Anschliessend gehe ich vertieft auf die von den Besuchenden hergestellten Gegenwartsbezüge ein, die im Zentrum des Forschungsinteresses stehen.

Eine erste und grösste Gruppe bilden Äusserungen, in denen die Besuchenden Geschehen in der Vergangenheit thematisieren und dabei innerhalb einer Zeitebene $t 1$ bleiben oder Fälle, in denen die gewählte Zeitebene nicht eindeutig feststellbar ist. Bezüge zwischen mehreren Zeitebenen kommen in dieser Kategorie nicht vor. Tl kann dabei variabel für unterschiedliche vergangene Zeiten stehen. In der Regel meint es die Zeit des Ersten Weltkriegs oder einen Ausschnitt daraus, ist jedoch nicht ausdrücklich darauf beschränkt. In der Regel wird die Zeit, auf die Bezug genommen, von den Besuchenden nicht explizit benannt, ist aber aus dem Zusammenhang zu erschliessen, wie im nachfolgenden Beispiel:

"Auf der einen Seite kann man sagen, die Schweiz hat Soldaten und private Leute interniert, hat sie gepflegt (...), hat ihnen Unterschlupf gegeben (...). Auf der anderen Seite haben sie Kosten von rund 140 Millionen Franken (...) an die kriegfübrenden Staaten verrechnet. Wie ist eigentlich das vonstatten gegangen?» (P25, Absatz 89)

1298 Seixas/Morton 2013, S. 74, S. 102.

1299 Schöner 2013a, S. 83.

1300 Schöner 2013c, S. 95. Vgl. hierzu auch die Ausführungen in Abschnitt 2.3.

1301 Eine noch detailliertere Beschreibung der Kategorien sowie eine grössere Anzahl von zugehörigen Textbeispielen sind im digitalen Anhang einsehbar. 
Die Kategorie beinhaltet zudem Äusserungen, in denen Besuchende sich im Präsens äussern, aber aus dem Inhalt der Äusserung anzunehmen ist, dass Geschehen in der Vergangenheit gemeint ist, wie im nachfolgenden Beispiel:

"Und man sieht, wie arm die Leute sind und beziehungsweise und auch völlig unterschiedliche Schichten, möglicherweise. Und alle Altersgruppen.»(P12, Absatz 174)

Ich rechne dieser Kategorie Beschreibungen von Phasen unterschiedlicher Dauer $\mathrm{zu}$, von der Beschreibung eines Moments bzw. Ereignisses bis hin zu einer mehrere Wochen, Monate oder Jahre andauernden Phase oder Situation, sofern diese durch die Besuchenden in irgendeiner Weise als gleichbleibende, einheitliche Episode thematisiert wird, ohne Anfangs- und Endpunkt zu benennen und in ihrer Unterschiedlichkeit zu betrachten, etwa:

"Weil die Schweiz hat ja im Prinzip vier Jahre lang auf einen Feind gewartet, der nie gekommen ist, das muss sicher sehr, muss ja wirklich langweilig gewesen sein, ja.»(P19, Absatz 36)

Im Kontrast dazu erfasst eine zweite Kategorie Äusserungen, in denen Bezüge zwischen mehreren (zwei oder mehr) Zeitebenen hergestellt werden, und zwar in diesem Fall zwischen mehreven Zeitebenen innerbalb der Vergangenheit. T1 und $\mathrm{t} 2$ können dabei für unterschiedliche vergangene Zeiten stehen. In der Regel betrifft im Material mindestens eine der beiden die Zeit des Ersten Weltkriegs, jedoch nicht zwingend. Vielfach werden auch mehrere Zeitpunkte innerhalb der Kriegsjahre miteinander verknüpft. Die nachfolgende Person stellt etwa einen Vergleich zwischen den frühen und späten Kriegsjahren her:

"Was ist wohl da mit dieser Zabl an Soldaten, der grossen Zabl 1914, und dann der kleinen Zahl gegen Ende des Krieges, September 1918, auf sich hat, das wär spannend. Vielleicht kommt das ja noch. Vielleicht auch einfach, weil am Anfang die Sorge gross war und man nicht wusste und 1918 dann aber klar war, dass niemand die Schweiz angreifen würde, und der Krieg ja sich dann auch langsam dem Ende neigt.» (Pl2, Absatz 48)

Immer wieder kommen auch Äusserungen vor, in denen eine Entwicklung oder Veränderung in der Vergangenheit thematisiert wird, auch wenn dabei nicht ex- 
plizit der Ausgangs- und/oder Endpunkt der Entwicklung benannt würde, wie etwa in den nachfolgenden Beispielen:

"Ah, Kakao. (...) Der ist fast gleich geblieben, aber hat sich (...). Ne, sogar gestiegen, aber hat sich extrem verteuert. (...) Mehr als verdoppelt.» (P27, Absatz 31)

«Am 5. November bietet der Bundesrat 800 Soldaten [eigtl. 8000] und Offiziere für die Besetzung Zürichs auf.> Okay, jetzt scheint sich hier die Situation tatsächlich noch mebr zuzuspitzen.» (P8, Absatz 75)

«Gasmasken, ganz neu, (...) dass es Gas gibt.»(P3, Absatz 50)

"Ja es ist doch krass, dass der Krieg direkt in eine, in so eine aufsteigende Phase gekommen ist, wo alles immer sich am Verbessern gewesen ist, wo (...) ja sich die Lebensumstände massiv verbessert haben. Und dann ist der Wabnsinn gekommen, das Massensterben. Ist irgendwie unvorstellbar, ja?» (P19, Absatz 26)

Von mehreren Zeitebenen spreche ich auch dann, wenn eine der beiden aufeinander bezogenen Ebenen durch die Ausstellung (z.B. einen Ausstellungstext) thematisiert und dazu eine andere Zeit in freier Formulierung in Bezug gesetzt wird.

"Wäbrend Milch zu Beginn des Kriegs noch im Überfluss produziert wird, besteht beim Brotgetreide von Anfang an ein krasses Missverhältnis zwischen Bedarf und Produktion> (...). Hm (lacht bitter), das ist sehr wenig. (...)

Da kommt mir jetzt auch gerade in den Sinn, dass dann im Zweiten Weltkrieg ja dann die Anbauschlacht gefübrt worden ist, wo man dann eben dann auch (unv.) da innen quasi, Kartoffeln angepflanzt hat.» (P13, Absatz 42-43)

Eine dritte Kategorie erfasst schliesslich hergestellte Bezüge zur Gegenwart, wie etwa im nachfolgenden Beispiel:

"Das ist ja schon auch spannend, dass eigentlich der Streik und grundsätzlich die Forderungen auch bis heute so negativ angesehen werden, und gleichzeitig eigentlich haben sie uns so, hat das uns eigentlich die AHV und weitere soziale Absicherungen gebracht.» (P13, Absatz 107) 
Als Indikatoren für die Thematisierung der Gegenwart wurden Schlüsselwörter wie 〈heute〉, 〈jetzt〉 usw. verwendet. Eine Präsensformulierung allein genügt hingegen noch nicht für die Identifizierung von Gegenwartsbezügen, da dieses Tempus, wie oben gezeigt, von den Besuchenden auch für Berichte über vergangenes Geschehen verwendet wird.

Von Bezügen zur Gegenwart spreche ich auch dann, wenn eine der beiden aufeinander bezogenen Ebenen allein durch die Ausstellung thematisiert (hier die Vergangenheit) und dazu ein Bezug zu einer anderen Zeit frei formuliert wird (hier die Gegenwart). ${ }^{1302}$ Aufgrund dieses erweiterten Verständnisses von Bezügen zwischen Vergangenheit und Gegenwart gibt es keine Textstellen, die ausschliesslich als gegenwartsbezogen ohne Vergangenheitsbezüge eingestuft wurden. Stets liegt ein vergangenheitsbezogenes Element durch den Gegenstand der Ausstellung vor, anhand dessen ein Bezug hergestellt wird.

Induktiv ergänzt wurde schliesslich eine vierte Kategorie, ausgehend von der Feststellung, dass die Besuchenden in gewisser Häufigkeit auch als überzeitlich oder allgemeingültig formulierte Äusserungen über Geschehen formulieren. Die Besuchenden thematisieren Geschehen dabei als immer wieder vorkommend, wesenhaft und universell gültig. Sie nehmen dabei auf keine der drei Zeitebenen explizit, aber gleichermassen doch auf alle Zeiten implizit Bezug. Als sprachliche Indikatoren für diese Ebene fungieren z.B. 〈immer〉, 〈überall〉, 〈natürlich〉. Das nachfolgende Beispiel steht stellvertretend für diese Kategorie:

«Von jedem Krieg gibt's ja Parteien, die direkt oder indirekt profitieren.»(P25, Absatz 9)

Den zuletzt genannten beiden Kategorien, den Bezügen zur Gegenwart sowie den Äusserungen über Überzeitliches und Allgemeingültiges, wende ich mich im Anschluss differenzierter zu und führe dort auch weitere Materialbeispiele an. Obwohl ich diesem Bereich besondere Aufmerksamkeit widme, gilt es doch festzuhalten, dass diese Textstellen in der Häufigkeit ihres Vorkommens zurücktreten hinter derjenigen Gruppe von Äusserungen, in denen Besuchende keine Bezüge zwischen Zeitebenen herstellen. Die bei Weitem am stärksten im Datenmaterial vertretene Gruppe sind diejenigen Äusserungen, in denen Besuchende über eine

1302 Den für meine Arbeit sehr relevanten Hinweis, dass durch die Anwesenheit der Besuchenden in der Ausstellung bzw. durch die dort erzählte Geschichte bereits automatisch eine weitere Zeitebene als Bezugshorizont vorliegt, verdanke ich Béatrice Ziegler. 
definierte Zeitebene bzw. nicht exakt feststellbare Zeitebene sprechen. Ergänzt noch um diejenigen Äusserungen, in denen die Besuchenden räumliche statt zeitlicher Bezüge herstellen, lässt sich festhalten, dass das Verbleiben innerhalb einer Zeitebene den bedeutendsten Modus des Sich-Äusserns über Geschehen bildet. Gleichwohl schenke ich, ausgehend von einer der zugrunde liegenden Forschungsfragen, nachfolgend explizit den hergestellten Gegenwartsbezügen besondere Beachtung.

\subsubsection{Varianten von Gegenwartsbezügen}

Auf Basis einer blossen Identifizierung der verwendeten Zeitebenen lassen sich noch keine qualifizierenden Aussagen machen, welcher Art die hergestellten Bezüge sind. Für den Fall der Gegenwartsbezüge und der in diese Kategorie als eingeschlossen betrachteten Äusserungen über Überzeitliches und Allgemeingültiges habe ich deshalb - ausgehend vom Material, aber zugleich theoretisch sensibel, vor allem im Wissen um bereits theoretisch beschriebene Varianten der Verknüpfung von Zeitebenen ${ }^{1303}$ - eine Ausdifferenzierung in Subkategorien vorgenommen.

Die Ausstellung selbst bot explizite Gegenwartsbezüge in den letzten beiden Räumlichkeiten der Ausstellung an. Einer der beiden Räume gehörte hierbei zum Kernbereich der Wanderausstellung und behandelt unter dem Titel «Nach dem Krieg» einige an die Zeit des Ersten Weltkriegs anknüpfende Entwicklungslinien, bezogen auf die ganze Schweiz. Räumlich daran anschliessend wurde im regionalspezifischen Ergänzungsteil der Ausstellung die Relevanz des Ersten Weltkriegs in Bezug auf die Stadt Basel aufgezeigt. Was Besuchende äussern, während sie sich in diesen beiden Abteilungen befinden, werde ich weiter unten gesammelt beleuchten und einer Feinanalyse unterziehen, wo ich dann die Möglichkeit nutzen kann, auch ausstellungsbezogene Aussagen im Fokus II in die Analyse einzubeziehen. ${ }^{1304}$ Für die nun folgend vorgestellte Systematik sind hingegen sämtliche formulierten Gegenwartsbezüge relevant, die Besuchende während ihres Ausstellungsbesuchs herstellen - auch unabhängig von den beiden genannten Räumlichkeiten und einer expliziten Anbahnung durch die Ausstellung.

1303 Vgl. Abschnitt 2.3.

1304 Vgl. Abschnitt 8.6.5. 
Die grosse Mehrheit der Besuchenden stellt im Verlauf ihres Besuchs solche Gegenwartsbezüge im Fokus I her, allerdings mitunter nur vereinzelt bis einige Male, während sich bei einzelnen anderen Besuchenden im Kontrast dazu im Verlauf ihres Besuchs durchaus um die zwei Dutzend Gegenwartsbezüge identifizieren lassen. Auffallend in dieser Hinsicht sind P12, P18, P19, P20 und P27. Ich liste die identifizierten Varianten von Bezügen nachfolgend zunächst im Überblick auf, bevor in den anschliessenden Abschnitten dann eine nähere Beschreibung und Veranschaulichung mit Beispielen folgt: ${ }^{1305}$

So bezieht sich ein verhältnismässig grosser Bereich von Äusserungen darauf, in irgendeiner Weise Gemeinsamkeiten zwischen Vergangenheit und Gegenwart festzustellen. Die Besuchenden tun dies, indem sie formulieren, etwas sei heute ähnlich oder genauso wie damals, mindestens andernorts heute noch genauso oder könne zumindest potenziell heute wieder genauso eintreten. Diesen Argumentationsfiguren ist gemeinsam, dass sie die Vergangenheit als eine Zeitebene und die Gegenwart als eine andere Zeitebene nebeneinanderstellen und Gemeinsamkeiten konstatieren, dabei jedoch nicht im engeren Sinn das Gewordensein der Gegenwart thematisieren.

Die Idee von einem Gewordensein der Gegenwart ist hingegen bei anderen Äusserungen inhärent. In diesen sprechen Besuchende über Ursprünge von Phänomenen und über Entwicklungsschritte zwischen zwei Zeitabschnitten. Sie argumentieren dann, die Wurzeln/Vorläufer eines heutigen Phänomens lägen in der Vergangenheit, oder berichten - sehr selten vorkommend - über Entwicklungsschritte, die zwischen Vergangenheit und Gegenwart passiert seien.

Eine dritte Kategorie von Äusserungen stellen Verweise auf die Unterschiedlichkeit zwischen Vergangenheit und Gegenwart dar. Diese Kategorie stellt den Gegenpol zur erstgenannten dar, in der über Gemeinsamkeiten zwischen Vergangenheit und Gegenwart gesprochen wird. Auch hier spielt wiederum das Gewordensein dieser Unterschiedlichkeit nicht notwendigerweise eine Rolle, vielmehr werden zwei Zeitebenen isoliert nebeneinandergestellt und deren Differenz konstatiert. In dieser Kategorie stellen Besuchende fest, heute sei etwas anders als damals.

1305 Theoretisch inspirierend für die hier unterschiedenen Formen, wenn auch nicht vollständig deckungsgleich mit den hier gewählten Kategorien, war einerseits die Kenntnis der Rüsen'schen Sinnbildungstypen (Rüsen 2012, S. 171 ff.; Rüsen 2013, S. 209 ff.) sowie andererseits der von Pampel in Bezug auf Gedenkstättenbesuchende identifizierten Formen der Verknüpfung von Zeitebenen (Pampel 2007; vgl. Abschnitt 5.3.6), auf die ich in der abschliessenden Diskussion noch genauer und vergleichend mit meinen Ergebnissen zu sprechen komme (vgl. Abschnitt 8.5.5). 
Eine vierte Kategorie stellen solche Äusserungen dar, in denen Besuchende über den heutigen Umgang mit vergangenem Geschehen sprechen. Für diese Textstellen ist ebenfalls eine Differenzfeststellung massgeblich, sei es eine zeitliche oder inhaltliche Differenz, und die Frage, in welchem Verhältnis sich die Gegenwart zur Vergangenheit unter diesen Umständen positioniert. In dieser Kategorie finden sich Äusserungen darüber, es lasse sich rückblickend in Bezug auf die Vergangenheit etwas Bestimmtes sagen, heute werde mit der Vergangenheit auf bestimmte Weise umgegangen oder - sehr selten vorkommend - es lasse sich aus der Vergangenheit eine Lehre für die Gegenwart ziehen.

Des Weiteren gibt es eine kleine Anzahl von Textstellen, in denen die Besuchenden ein heutiges Phänomen neben ein vergangenes stellen, und sich beide zwar in einer inhaltlichen Relation befinden, aber diese Relation nicht explizit gemacht wird und die Textstellen insofern keiner der oben genannten Kategorien zugeordnet werden können. Beispielhaft hierfür steht die folgende Textstelle, in der sich P26 zunächst dazu äussert, dass zur Zeit des Ersten Weltkriegs die Basler Mustermesse ins Leben gerufen wurde, wie er oder sie gerade einem Ausstellungstext entnommen hat. Daran anschliessend bringt er oder sie den Neubau des Basler Messeareals zur Sprache. Welche Art der Verknüpfung zwischen beiden P26 sieht, also ob er oder sie beispielsweise eher eine Kontinuitätslinie oder eine Differenz feststellt, lässt sich nicht erschliessen.

\begin{abstract}
"Ah ja, (...) das ist ja interessant, dass die (...) Mustermesse da (...) erstmals stattfand. (...) Kann man sich vorstellen, (...) klingt plausibel. (...)

Das neue Gebäude ist natürlich sehr (...) imposant. (...) Ich muss oft da umsteigen, am Messeplatz, von der einen Tram in die andere, (...) find ich immer gar nicht schlecht, wenn ich da (...) ein bisschen mir die (...) das schöne neue Gebäude anschauen kann, die (unv.).»(P26, Absatz 46)
\end{abstract}

Ebenso dem Bereich der Bezüge zwischen Vergangenheit und Gegenwart rechne ich Äusserungen zu, in denen Besuchende Äusserungen im Impetus des Überzeitlichen und Allgemeingültigen machen. Hier äussern die Besuchenden beispielsweise, etwas sei immer so, überall so, typischerweise oder natürlicherweise so. Ebenfalls zugerechnet werden diesem Bereich überzeitlich formulierte Lehren aus der Vergangenheit sowie das Einbringen von überzeitlichen Weisheiten bzw. Bonmots durch die Besuchenden.

Ich gehe auf die soeben in Kürze beschriebenen Varianten nachfolgend differenzierter ein und konkretisiere sie mit Datenbeispielen. 


\subsubsection{Gemeinsamkeiten zwischen Vergangenheit und Gegenwart}

In zahlreichen Äusserungen formulieren Besuchende Parallelen oder Ähnlichkeiten zwischen Vergangenheit und Gegenwart oder konstatieren vereinzelt, dass zumindest die Möglichkeit einer ähnlichen Entwicklung bestehe oder dass etwas heute zumindest andernorts noch so der Fall sei. Diese vier Themenbereiche betrachte ich als Varianten von festgestellten Gemeinsamkeiten zwischen Vergangenheit und Gegenwart. Sie machen neben den ebenfalls häufig vorkommenden überzeitlich und allgemeingültig formulierten Äusserungen die grösste Gruppe von Gegenwartsbezügen aus und kommen bei zwei Dritteln der Besuchenden vor.

Das Zustandekommen solcher Äusserungen folgt dabei in der Regel einer ähnlichen Struktur: Die Besuchenden entnehmen der Ausstellung eine Auskunft über Vergangenes und erklären anschliessend daran, dass etwas heute immer noch〉 so oder «jetzt auch wieder〉 so sei, dass es etwas «damals auch schon〉 gegeben habe, dass etwas 〈aktuell〉 und aus der Gegenwart 〈bekannt〉 sei und «auch wieder〉 passieren könne.

In thematischer Hinsicht lassen sich für diese Feststellungen von Ähnlichkeiten und Gleichheiten Schwerpunkte identifizieren. So finden sich etliche solche Äusserungen im Bereich der wirtschaftlichen Prozesse, Importe und Exporte, Profite und damit verbundenen moralischen Überlegungen. Gleich mehrere Besuchende stellen etwa Parallelen zwischen Vergangenheit und Gegenwart für die Thematik der Waffenexporte fest, teilweise äussern sie in dem Zusammenhang zudem moralische Bedenken:

«1917 beschäftigt die Schweizer Industrie mehr als 30000 Personen für die Herstellung von Munition.> Da wird wabrscheinlich auch beute noch so, gell, mit Munition und Riustungsindustrie.»(P12, Absatz 93)

"Was steht hier? 'L'Arbalète verweist auf die Doppelmoral von Waffenexporten einerseits und dem humanitären Engagement andererseits.> Tja, wie sich die Dinge gleichen. 1917 und die Diskussion heute. Bezïglich dem Widerspruch von humanitärem Einsatz der Schweiz und Rïstungsexporten.» (P12, Absatz 118)

"Also ich finde pervers, dass die Schweiz damals dreissigtansend Beschäftigte für die Herstellung von Munitionsbestandteilen hatte. Wenigstens auf das hätte man verzichten können. (...) Und nicht noch direkt mit Munition den Tod exportie- 
ren. Das tu ich übrigens heute noch kritisieren, dass die Schweiz Waffen exportiert. Pervers.» (P25, Absatz 66)

"(Den einen) Vorteil der Neutralität, mit niemand verfeindet zu sein, (sollte die) die schweizerische (...) Industrie ausnützen können.> (...) Ist nach wie vor (...) praktisch bis heute. (...) Verkanfe beiden die Waffen. (...) Du wirst sicher bei der Sieger(...)macht dabei sein.» (P27, Absatz 28)

Neben den Waffenexporten sind es aber auch weitere Fragen der wirtschaftlichen Prozesse, so etwa des Imports und Exports zu Kriegszeiten, woraufhin die Besuchenden Parallelen feststellen:

«Gastrol, gibts heute noch.» (P20, Absatz 55)

"Aber es zeigt auch, wie damals, wie heute die Schweiz halt vom Export abbängig ist. (...) Was sich auch im Krieg nicht geändert hat, hä?» (P19, Absatz 55)

Vor einem Ausstellungstext stehend, der über die Versorgungsengpässe zur Zeit des Ersten Weltkriegs berichtet, formuliert eine Person:

«Ja, wenn die Grenzen heute zu wären (...), bätten wir auch ein Problem in der Schweiz.» (P18, Absatz 85)

Ein zweiter grosser Themenbereich innerhalb der festgestellten Parallelen und Ähnlichkeiten zwischen Vergangenheit und Gegenwart sind Überlegungen zum Umgang mit ausländischen Personen in der Schweiz, konkret zu Überfremdungsangst und Abschottungstendenzen sowie zur Anwesenheit und Notwendigkeit ausländischer Arbeitskräfte. Einige Äusserungen zur Thematik werden nachfolgend aufgelistet:

"Also hier wird jetzt noch beschrieben, dass es erwünschte und unerwünschte Personen, also Ausländer gibt, die wohlhabenden Touristen und die Militärs sind willkommen, andere aber nicht, unerwünschte. Überfremdung ist ein neues Schlagwort, das ist auch interessant, Überfremdungsbekämpfung. (...) Also ein aktuelles Thema, (...) wer darf in die Schweiz, ist wieder hochaktuell, und wer nicht.» (P3, Absatz 68) 
"ZZu Beginn des Kriegs kehren Zehntausende von ausländischen Arbeitskräften in ibre Heimatländer zurück. Danach schränkt die vom Bundesrat erlassene Grenzsperre den Perso/, Personenverkehr ein.> (...) Das erinnert mich etwas an die heutige Zeit, wo man die Ausländer auch wieder beimschickt (...) und (unv.) einigelt. (...) Von Überfremdung bat man geredet (...) und hat die Fremdenpolizei gegründet [dabei Text paraphrasierend]. (...)

Also man hat sebr gern Gewinn gemacht an ausländischen Staaten (...), aber bat Ausländer nicht unbedingt hier baben wollen, wenn sie nicht vor allen Dingen Geld ausgegeben haben. Kommt mir irgendwie bekannt vor.» (P25, Absatz 92-94)

«Das bis 1914 weitgehend praktizierte System der Personenfreizügigkeit bricht zusammen.> Das ist ja glaub ich mal der ultimative Satz hier. ‘Für viele〉, dass es eine Personenfreizügigkeit gab und erst, und eben (...) wenn ich an dieses erste Wandbild mit den vielen italienischen Arbeitern in der Schweiz denke, von 1914, und die vielen Ausländer, also viele in Anfübrungszeichen, die es schon in der Schweiz gab, dann (...) ist es genau entgegen diesen Meinungen, die beute so sind, dass die Schweiz irgendwie erst jetzt so viel Fremdenzulauf bekommt und wie auch immer.» (P12, Absatz 195)

«Ich höre jetzt mal noch da, was da ist. (...) Wie funktioniert das? (...) [längeres Hören von Audioquelle] Oh, das, das macht mir aber Mühe. (...) Ist das auch ein Herr Blocher, ist das ein Vorfahr, ein Vorfabre vom heutigen Blocher? (...) [längeres Hören von Audioquelle].

Das ist extrem. (...) Die Blocher-Ansprache. (...) Macht mir auch (...) den Gedanken: Sind wir heute weiter? Was jetzt auch gevade wieder in Deutschland passiert. Einfach (...) Extremismus gegen Fremdenfeindlichkeit (...). Überbevölkerung, Ausländer, mit diesen Bewegungen, diesen Demonstrationen (...). Das ist, ist sebr ungut.» (P18, Absatz 39-41)

"[Audiotext der Tonquelle: <...] Die Fremdenfrage ist deswegen die erste vaterländische Frage, weil unsere nationale Selbstständigkeit in höchster Gefährdung sich befindet und diejenigen, die dafür Verständnis haben, in schwindender Minderbeit sind und ungehört bleiben. Unser national lauer und national lauer Kosmopolitismus, unser Allerweltsbürgertum ist auf dem Sprunge, das Schweizertum gänzlich aufzulösen>] (...)

Tönt fast wie eine beutige SVP-Propaganda. (...) Sind wir also noch nicht viel weiter. (...) Oder es wird wieder frisch hervorgebolt. (...)» (P18, Absatz 120) 
«schränkt die vom Bundesrat erlassene Grenzsperre Personenverkehr ein (...) kritischeres Bild von Ausländern. (...) Zwischen erwünschten und unerwünschten [liest Textteile zusammenfassend, paraphrasierend].> (...)

Hört man beute in (...) Deutschland mit Pegida. (...)

〈woblhabende Touristen [lässt Textteil aus] sind willkommen. (...) Ostjuden werden als unerwünscht bezeichnet. (...) Während des Krieges verändert, Begriff Überfremdung.> (...)

Ist wie heute.» (P27, Absatz 62)

Die zuletzt genannten Beispiele zeigen, dass Besuchende stellenweise aktuelle Ereignisse aus Politik und Zeitgeschehen in ihre Deutungen einbringen, wie beispielsweise die Verweise von P18 auf «bentige SVP-Propaganda» oder auch der Bezug von P27 auf die Pegida-Bewegung in Deutschland. Hierbei handelt es sich um Einbezüge von Ereignissen aus der aktuellen Gegenwart bzw. unmittelbaren Vergangenheit. P25 nimmt im nächsten Beispiel nach ähnlichem Prinzip Bezug auf die Masseneinwanderungsinitiative. Bei dieser Textstelle handelt es sich zugleich um eine der ganz wenigen, in denen ein/e Besucher/in auch die Zukunft einbezieht, nämlich wisse er oder sie nicht, "[w] as dann am Schluss draus [...] kommen wird».

«1970. Migration.> Da kann ich mich noch erinnern, Abstimmung zu der Schwarzenbach-Initiative. Schwarzenbach hat eine eigene Zeitung herausgegeben, wenn's mir recht ist. (...)

Damals ist die Initiative mit 54 Prozent Nein-Stimmen abgelehnt worden, knapp. Im (...) im Januar, vor'm letzten Jahr, also vor einem Jabr, ist eine äbnlich gelagerte Initiative sehr knapp angenommen worden. (...) Die Masseneinwanderungsinitiative. Was dann am Schluss draus hinaus, draus kommen wird, habe ich keine Abnung.» (P25, Absatz 107-108)

Ein weiterer Bereich, in dem gegenwärtiges Geschehen von den Besuchenden in die Deutungen eingebracht wird, stellt der Bereich der Epidemien und allgemein der Krankheiten dar. Zur Zeit der beginnenden Datenerhebung im Herbst 2014 grassierte in Westafrika eine Ebola-Epidemie. Zwei Besuchende kommen auf diese zu sprechen und stellen Bezüge mit der in der Ausstellung thematisierten Spanischen Grippe zur Zeit des Ersten Weltkriegs her. 
"Spanische Grippe. 50 Millionen sind gestorben, das ist wahnsinnig. (...) Da sind die Dimensionen schon noch anders. (...) Ebola ist auch schlimm, aber (...) da sind (...) zum Glück viel weniger bis jetzt gestorben.» (P18, Absatz 129-130)

Die hier zitierte Textstelle ist interessant auch als seltenes Beispiel, in dem trotz der festgestellten Parallele zwischen Zeitebenen zugleich auch eine inhärente Differenz identifiziert und benannt wird. ${ }^{1306}$ Auch P3 greift das Thema Grippe für einen Zeitenbezug heraus, nämlich habe das Thema Aktualität und werde deshalb wohl die eigene Klasse beim geplanten Ausstellungsbesuch ansprechen:

"Also hier sind noch Themen wie, (...) dass an Grippe gestorbene Soldaten Kriegsopfer werden, aber dami/ das hat ja eigentlich gar nichts miteinander zu tun. (...)

Aber beute jetzt mit Ebola, ist das sicher wieder etwas, was die Schïlevinnen auch interessiert. (...) Wenn man das alles noch liest.» (P3, Absatz 77)

Auch das zu Beginn von Kapitel 8 bereits einmal vorgestellte Zitat von P8 fügt sich in diese Kategorie ein. Darin stellt P8 nach Lektüre einer Textquelle, die Massnahmen zur Einschränkung von Ansteckung mit Grippe auflistet, Bezüge zu heutigen Grippewellen her.

"Mitbürger (...) zur Einschränkung schränkt Besuche in den Wirtschaften, unterlasst Besuch von Kinos.> Also Menschenmassen sollten (...) nicht besucht werden, nicht auf die Strasse spucken, das empfeble ich grundsätzlich. (...) Händedruck unterlassen, na das sind äbnliche Plakate, wie beute bei grossen Grippewellen ausgebängt werden.» (P8, Absatz 79)

Einen Sonderbereich von festgestellten Gemeinsamkeiten zwischen Vergangenheit und Gegenwart bilden diejenigen Äusserungen, in denen Besuchende einen

1306 Bei einer weiteren Person findet sich eine Gleichzeitigkeit der Feststellung von Gemeinsamkeiten und Unterschieden im Zusammenhang mit einem räumlichen Vergleich: «Wachsende Not». Brutal starke Parallele zu Deutschland. Die Not wird grösser, allerdings ist's natürlich anders, den Text hab' ich da nebenher schon gelesen, wäbrend ich die Tonstation gehört hab» (P6, Absatz 35) (vgl. hierzu auch Abschnitt 8.7.3.1). 
Bezug herstellen zu einem Phänomen, das heute noch, aber andernorts existiere. In diesen Fällen werden zeitliche mit räumlichen Bezügen verbunden. Eine Person äussert im Zusammenhang mit der Betrachtung einer Bildquelle und/oder deren Beschriftung, die Ausgabe von Lebensmittelmarken darstellend:

"Notabene, ich bin vor zwei Jabren in Kuba gewesen, und dort werden immer noch Lebensmittelmarken ausgegeben und verwendet, (...) und das seit 1959.» (P25, Absatz 80)

Dieselbe Person und eine weitere äussern sich in ähnlicher Struktur in der Abteilung «Mobilisierung», in der in Form einer Sachquelle sowie auf einer im Hintergrund abgebildeten Fotografie eine Kinderuniform gezeigt wird. P25 erinnert sie an "Kindersoldaten in der heutigen Zeit in Afrika»:

"Denke mir, an (...) Kindersoldaten in der beutigen Zeit in Afrika. (...) Wobei ich mir nicht vorstellen kann, dass die Kinder haben kämpfen müssen. (...) Sondern dass man probiert hat, sie (...) zu interessieren an der Armee.» (P25, Absatz 14)

P20 denkt in derselben Situation zunächst an "Hitlerdeutschland», später bemerkt er oder sie, Kinderuniformen seien in ähnlicher Form heute noch «in (...) kommunistischen Ländern» im Einsatz.

"Dann kommen wir zur Mobilisierung (...). Das ist noch lustig, das kennt man jetzt eigentlich, was ich da sehe, das sind kleine Buben in (...) in Uniform.

Also kennt man eigentlich von, von, von Hitlerdeutschland her, wo sie da die Kinder in so Uniformen gesteckt haben. Also nicht zum Kämpfen, sondern einfach kleine Kinder als Soldaten angezogen, das hat man schick gefunden damals. (...) Offensichtlich ist das etwas, das bei uns in der Schweiz auch gewesen ist. (...) Sie haben auch alle irgendso eine kleine Flinte. (...) Einen Sübel (...) oder Bajonett, (unv.-)Messer. Hm (zustimmend), Kadettengewehr 19/, 1897. (...)

Und Knabenuniform, eben genau. Knabenuniform (...). Zwei Sterne, das wär ein Oberleutnant gewesen, hm? Aber das ist eine Kinderuniform, genau das meine ich eben, heute noch zum Teil in (...) kommunistischen Ländern, wo (...) Kinder so (...) eingekleidet werden. (...)»(P20, Absatz 31-32) 
In allen Fällen werden zugleich zeitliche wie auch räumliche Bezüge hergestellt, nämlich zu Phänomenen, die aus Sicht der Besuchenden heute noch, aber andernorts existieren. P25 bringt mit "Hitlerdeutschland» überdies eine weitere vergangene Zeitebene ins Spiel, wobei nicht deutlich wird, ob er oder sie die zeitliche Differenz im Vergleich zur Zeit des Ersten Weltkriegs in diesem Fall wahrnimmt. Die Einordnung der Uniform als "[o]ffensichtlich [...] etwas, das bei uns in der Schweiz auch gewesen ist», deutet eher darauf hin, dass P20 in diesem Fall nicht über eine die räumliche Differenz ergänzende auch zeitliche Differenz zwischen der Zeit des Ersten Weltkriegs in der Schweiz und "Hitlerdeutschland» nachdenkt. ${ }^{1307}$

Mindestens im Fall der Kinderuniformen erscheinen die Phänomene als von den Besuchenden negativ konnotiert, wie die Assoziationen "Hitlerdeutschland» und «Kindersoldaten» zeigen. P25 gelangt im Verlauf seiner oder ihrer Äusserung allerdings offenbar zu der Einsicht, dass die Verknüpfung zwischen «Kindersoldaten in der heutigen Zeit in Afrika» und der schweizerischen Situation problematisch ist, korrigiert nämlich mit dem Hinweis, er oder sie könne sich nicht vorstellen, "dass die Kinder», gemeint sind nun vermutlich die damaligen Kinder in der Schweiz, "haben kämpfen müssen». Damit kombiniert sich in dieser Aussage eine erste Assoziation und dabei zunächst implizit gezogene Parallele mit der anschliessenden ebenfalls impliziten Feststellung einer Unterschiedlichkeit, wodurch P25 die schweizerische Situation zugleich moralisch zu rehabilitieren versucht.

Ansätze für eine Rehabilitation angesichts der Einsicht, es auch mit einem schweizerischen Phänomen zu tun zu haben, finden sich auch bei P20 mit dem Hinweis, die Uniform sei «schick» und "nicht zum Kämpfen» gewesen. Möglicherweise handelt es sich bei den gezeigten Passagen um Akte des «Exterritorialisieren[s]», ${ }^{1308}$

1307 Überhaupt finden sich im Datenmaterial sehr vereinzelt Hinweise darauf, dass einzelne Besuchende bisweilen die Zeit des Ersten und Zweiten Weltkriegs vermengen. Neben dem zitierten Beispiel aus den Äusserungen von P20 finden sich auch in den Äusserungen von P25 an zwei Stellen Hinweise auf eine Verwechslung bzw. Vermengung. So glaubt P25 in dem in der Ausstellung gezeigten Film zur Mobilisierung der Schweizer Armee im Ersten Weltkrieg General Guisan zu erkennen (P25, Absatz 36). Die auf einer «Nebelspalter»Karikatur aus dem Jahr 1918 gezeichnete Menschenmenge zeigt seiner oder ihrer Ansicht nach den Hitlergruss (P25, Absatz 47). Da ich im Rahmen meiner Studie auf Bezüge zur Gegenwart fokussiere und dabei Bezüge zwischen mehreren vergangenen Zeitebenen nicht im Detail betrachte, habe ich solche Textstellen allerdings nicht tiefergehend analysiert.

1308 Diesen Begriff entlehne ich von Rüsen (Rüsen 2001), der ihn allerdings in einem anderen Zusammenhang gebraucht, nämlich als Bezeichnung für die erste von «[d]rei Formen generationeller Praktiken des Erinnerns» (ebd., S. 243) an den Holocaust in der deutschen Geschichtskultur der Nachkriegszeit. Er bezeichnet diese Phase als «Beschweigen und 
im Zuge deren irritierende Elemente wie die Kinderuniform als heute ausserhalb der schweizerischen Grenzen und damit im übertragenen Sinn ausserhalb des eigenen Kollektivs verortet werden.

Eine weitere Variante von Äusserungen über Gemeinsamkeiten zwischen Vergangenheit und Gegenwart stellen solche Aussagen dar, in denen zwar nicht von tatsächlich existierenden, wohl aber von möglichen Parallelen gesprochen wird. Vergangenes Geschehen wird als potenziell wiederholbar thematisiert, wie beispielsweise in der folgenden Passage, in der sich P18 ausgehend von dem zu Ausstellungsbeginn gezeigten Film zur geografischen Verbreitung des Kriegsverlaufs äussert:

"Eigentlich lokal, Serbien (...) mit Österreich-Ungarn (...) und dann, ja da kommt mir schon in den Sinn, könnte heute auch wieder so sein. Russland, Serbien. (...) Plötzlich in, innert einem Jahr so eine (...) Ausdehnung, das ist extrem. (...)

Da boffe ich schon auch, dass der Ukraine-Konflikt nicht so etwas auch wieder auswirken kann. Dann ist es dann noch viel grösser und umfassender. (...)» (P18, Absatz 15-17)

Den vier geschilderten Argumentationsfiguren ist gemeinsam, dass sie die Vergangenheit als eine Zeitebene und die Gegenwart als eine andere Zeitebene nebeneinanderstellen und Gemeinsamkeiten konstatieren, dabei jedoch nicht die Verbindungslinie zwischen diesen beiden Zeitpunkten und damit im eigentlichen Sinn Historizität mitdenken, also Veränderbarkeit, Wandelbarkeit historischen Geschehens und damit in irgendeiner Weise das Gewordensein der Gegenwart thematisieren. Dies ist demgegenüber in der nachfolgend beschriebenen Gruppe von Äusserungen der Fall.

Exterritorialisieren» (ebd., S. 245), gekennzeichnet von der Auffassung, dass «Nationalsozialismus und Holocaust [...] keine historischen Ereignisse [waren], die in unsere Geschichte gehörten. Sie wurden vielmehr dezidiert mit der Qualität des Andersseins behaftet, des Fremden, des von aussen Hereinbrechenden» (ebd., S. 246). «Die Nazis wurden dämonisiert und aus der deutschen Geschichte exterritorialisiert» (ebd., S. 249). In den von mir beschriebenen Fällen hat Exterritorialisieren allerdings stärker noch als bei Rüsen tatsächlich eine geografische Dimension, indem irritierende Elemente als ausserhalb der schweizerischen Grenzen liegend eingeordnet werden. 


\subsubsection{Wurzeln und Vorläufer der Gegenwart}

In vergleichsweise starkem Mass in der Ausstellung selbst angelegt sind Überlegungen dazu, wie die Vergangenheit die Gegenwart geprägt hat, welche Folgen der Erste Weltkrieg in der Schweiz hatte und welche späteren Entwicklungen und Bedingungen in der Zeit des Ersten Weltkriegs ihren Ausgangspunkt genommen haben. In der Ausstellung selbst geschieht dies in den beiden bereits erwähnten Schlussräumen. Erwartungsgemäss kommt ein Teil der Äusserungen der Besuchenden über Wurzeln und Vorläufer von heute in diesen Räumlichkeiten zustande, ist allerdings keineswegs ausschliesslich dort anzutreffen.

Bei zwei Dritteln der Besuchenden finden sich Äusserungen darüber, dass und wo sie Wurzeln und Vorläufer einer heutigen Situation sehen. Sie bringen damit ein Bewusstsein darüber zum Ausdruck, dass heutige Phänomene und Bedingungen nicht immer schon> so gewesen sind, sondern irgendwann ihren Ausgang genommen haben müssen.

Im engeren Sinn historisches Werden als Nachvollzug einer Entwicklung zwischen der Vergangenheit und Gegenwart findet sich allerdings nur vereinzelt:

"Das ist ja schon auch spannend, dass eigentlich der Streik und grundsätzlich die Forderungen auch bis heute so negativ angesehen werden, und gleichzeitig eigentlich haben sie uns so, hat das uns eigentlich die AHV und weitere soziale Absicherungen gebracht.» (P13, Absatz 107)

"Zugleich verbringen auf Initiative des IKRK des Vatikans》, man höre, man höre, <und der Schweizer (unv.) insgesamt 67000 Kranke und Verwundete Kriegs/ einige Monate in der Schweiz. Die Internierten werden nach Ländern getrennt in Hotels, Pensionen und Sanatorien untergebracht. Pflegen regen Kontakt zur Bevölkerung und gehen (sowie es ibre Gesundheit zulässt) einer Arbeit nach.>

Da kamen also ziemlich viel ausländische Verwundete und was auch immer in die Schweiz. Das wär noch spannend zu erfahren, wie dass die Kontakte waren, und ob sich die einen oder eine Ehe da angebahnt hatte oder, ja, ob Leute blieben. So wie vielleicht dieser eine Familie von den [Familienname], wo der Gross- oder Urgrossvater als Kriegsgefangener dann einfach im [Ort] blieb und die (...) dann Schweizer natürlich sind.»(P12, Absatz 156)

Es finden sich lediglich vereinzelte Passagen, in denen Besuchende einen Zeitverlauf zwischen einem Ausgangspunkt in der Vergangenheit bis in die Gegenwart 
hinein nachzuzeichnen versuchen und dabei mehrere Entwicklungsschritte, also im engeren Sinn das Gewordensein im Zeitverlauf thematisieren. Viele andere Textstellen sind dadurch gekennzeichnet, dass die Besuchenden Vorläufer und Ausgangspunkte von heutigen Situationen benennen und darüber sprechen, dass ein heutiges Phänomen zu einem Zeitpunkt seinen Ursprung hat, nicht aber auch über die Verbindungslinien zwischen beiden Zeitpunkten reflektieren.

Thematisch lassen sich gewisse Häufungen dahingehend feststellen, in welchen Bereichen die Besuchenden Vorläufer von heutigen Bedingungen entdecken. Es sind dies oft Themen aus dem Bereich der Wirtschaft, nämlich wirtschaftspolitische Interventionen und Regulierungen, Güter/Prozesse/Importe/Exporte sowie wirtschaftliche Gewinne und Moral. Im Bereich der wirtschaftlichen Prozesse und Gewinne ist es vor allem die Pharmaindustrie (jedoch auch andere Industriezweige), der sich die Besuchenden zuwenden, indem sie den Ursprung von deren Erfolg in der Zeit des Ersten Weltkriegs verorten. So formuliert etwa P19, in der Abteilung zu den Nachwirkungen der Kriegszeit auf die Stadt Basel stehend:

«Da geht's um Life Science, (...) und eben, dass die Exporte im Ersten Weltkrieg dazu geführt haben, dass heute Basel so eines von den absoluten Zentrum ist von Life Science, Biotech und Pharma (...) und heute noch wichtigste Export, also heute mit 30 Prozent zu den wichtigsten Exportschlager der Schweiz ist. Ja, da kann man sich Gedanken machen, dass das auf den Ersten Weltkrieg zurïckzufübren ist, und da kann man ja auch dankbar sein, weil heute haben so viele Leute da ibre Arbeit da. Und machen Riesengewinn damit, also (...) es gibt nicht nur schlechte Sachen im Krieg. (...) Ja.» (P19, Absatz 147)

Ähnliche Überlegungen stellt auch die nachfolgend zitierte Person an, sich mit der Entwicklung der Import- und Exportzahlen während des Weltkriegs befassend:

«Das sieht ja so aus, als ob eigentlich der, die, die, die Marktfübrerschaft der Schweizer Produkte und Dienstleistungen, seh ich jetzt so, wie Banken und Versicherungen, die Chemie und damit auch die pharmazeutische Industrie auch ja Textil eben sowieso nicht mehr, aber auch immerhin die Schokoladenindustrie zusammen mit Uhr- und Metall- und Maschinenindustrie, so alles was hier eigentlich im Ersten Weltkrieg einen grossen Sprung nach vorne macht, und eben ausnutzen kann, dass es hier friedliche Bedingungen gibt und die Industrie produzieren kann und auch, ja, jetzt versteh ich das noch besser, vor dem Hinter- 
grund der wirtschaftspolitischen Massnahmen unter Kriegsbedingungen, diese Industriezweige relativ florieren.

Und eben, jetzt kommt eigentlich das Fazit, die bis beute wabrscheinlich ibve Marktfübrerschafterklären, oder einfachzeigen, dass das dieser grosse Sprung nach vorne war, der sie sogar beute noch weiterbin bei allem Know-bow und Weiterentwicklung vorne in der Weltspitze sein lässt.» (P12, Absatz 92)

Auch ausserhalb der Schlussabteilungen stellen Besuchende somit, wie die zuletzt zitierte Person, immer wieder Bezüge zwischen Vergangenheit und Gegenwart her, indem sie Vorläufer von heute identifizieren. Sie tun dies, indem sie weiterführendes Wissen einbringen, das sie ausserhalb der Ausstellung oder im früheren Verlauf der Ausstellung erworben haben, und auf dieser Basis Zeitverlaufsvorstellungen konstruieren, die in der Ausstellung selbst nicht in der Form angelegt sind. So äussert etwa P8 in Auseinandersetzung mit einem Ausstellungstext zur Spanischen Grippe:

«Nach dem Krieg versuchen armeenahe Kreise, an der Grippe gestorbene Soldaten zu Kriegsopfern zu stilisieren.> (...) Ha, das scheint ibnen relativ gut gelungen zu sein.

Hab ich glaub ich hier auch schon teilweise durchschimmern sehen. Dass irgendwie diese Toten im Zusammenhang mit dem Krieg und dem Militär gesehen werden. Also da wird wohl ein Mythos geschaffen, der es bis heute überlebt hat.» (P8, Absatz 78)

Im Themenbereich der wirtschaftspolitischen Interventionen ist es etwa die zur Zeit des Krieges vom Bundesrat eingeführte Kriegsgewinnsteuer, für die sich die Besuchenden interessieren und die sie als Ursprung der heutigen direkten Bundessteuer thematisieren - eine Verbindungslinie, die in dem Fall auch durch einen Ausstellungstext nahegelegt wird.

"Das hab ich auch nicht gewusst, dass eigentlich die direkte Bundessteuer eigentlich eine Kriegssteuer gewesen ist. (...) Interessant.» (P18, Absatz 89)

"Hehe (schmunzelt), das ist auch noch interessant, dass die Stener, die es beute noch gibt, auf damals, auf eine Kriegsstener zurückgeht, und wahrscheinlich hat es geheissen, jaja, die wird dann wieder abgeschafft, aber (...) wir wissen ja alle, die gibt's beute noch.» (P19, Absatz 83) 
Ebenfalls durch die Ausstellung selbst angeregt wird eine Verknüpfung von Zeitebenen im Bereich der Sozialpolitik, der im Abschnitt «Nach dem Krieg» ein eigener Abschnitt gewidmet wird. Dort äussert dann auch P13 im Hinblick auf die schweizerische Sozialversicherung AHV, wie bereits zitiert:

"Das ist ja schon auch spannend, dass eigentlich der Streik und grundsätzlich die Forderungen auch bis heute so negativ angesehen werden, und gleichzeitig eigentlich baben sie uns so, hat das uns eigentlich die AHV und weitere soziale Absicherungen gebracht.» (P13, Absatz 107)

\subsubsection{Unterschiede zwischen Vergangenheit und Gegenwart}

Während in den vorigen beiden Abschnitten die von den Besuchenden aufgezeigten Gemeinsamkeiten oder Ähnlichkeiten im Vergleich aus Vergangenheit und Gegenwart thematisiert wurden und Äusserungen über das Gewordensein der Gegenwart und Verbindungslinien zwischen den Zeitebenen im Vordergrund standen, stehen nun umgekehrt die aufgezeigten Unterschiede im Fokus der Aufmerksamkeit. Im Wesentlichen handelt es sich dabei schlicht um Feststellungen, dass in der Vergangenheit etwas anders gewesen sei, als dies heute der Fall ist. Diese Variante findet sich ebenfalls bei zwei Dritteln der Besuchenden.

Auf thematischer Ebene finden sich gewisse Häufungen einerseits mit Äusserungen zu Basel und der Region, ausserdem, etwas weniger bedeutsam, zu technischen Belangen, darunter insbesondere Fortbewegungsmitteln, sowie in auffallender Häufung in der Summe der gesellschaftsbezogenen Fragen, die das Leben der Bevölkerung betreffen, nämlich konkret vor allem soziale Not und Sozialhilfe, ergänzt um Kleidung und Aussehen, Alltagspraktiken und Weiteres.

Auffallend ist ausserdem, dass derartige Differenzen häufig im Zusammenhang mit der Betrachtung von Bildquellen, konkreter Fotografien, festgestellt werden. Die folgende Person stellt bei Betrachtung einer Fotografie etwa Unterschiede in der Haarmode fest, die sie davon abhalten, die abgebildeten Personen für «hentige Basler» zu halten:

"Und die Gesichter sehen echt aus, wie, wär, wär, wär die Schnurvbartmode nicht, und die Haarschnitte, und die (...) Hemdenkragen, hätte man das Gefühl, das sind heutige Basler, die da sitzen.» (P12, Absatz 173)

Ebenfalls durch Betrachtung einer Fotografie kommt eine andere Person zu einer Äusserung über die «damals» wohl übliche Bekleidung für Velofahrer: 
"Da sind wir auf der Mittleren Rheinbrücke. Das Café Spitz sehe ich. Also ist das die Mittlere Rheinbrïcke. Ein Soldat mit geschultertem Gewehr. Dann (...) Velofabrer mit Gamaschen und Knickerbocker. Das ist damals wabrscheinlich die ïbliche Bekleidung gewesen für Velofabrer.» (P20, Absatz 7)

Einerseits Kleidung, aber auch Alltagspraktiken sind Gegenstand der folgenden Äusserung, entstanden bei Betrachtung einer Diashow mit Fotografien. Zunächst argumentiert P25 darin auf der Ausstellungsebene (Fokus II), indem er oder sie darüber nachdenkt, was der Sinn und Zweck der Fotografien sei, nämlich Eindrücke vom damaligen Leben in der Schweiz zu vermitteln. Dann wechselt er oder sie die Fokussierung und argumentiert weiter auf der Geschehensebene, stellt fest, was genau «damals» anders gewesen sei.

"Das ist sehr eindrücklich, ein Bild, was ich da sehe (...) (und das) einen allgemeinen Einblick gibt, wie man damals gelebt hat. (...)

Damals ist es üblich gewesen, dass man im See, im offenen Wasser gewaschen hat und keine Waschmaschine gehabt hat. (...)

Die weiblichen Badegäste am See haben sich voll verhüllt.» (P25, Absatz 56-58)

Ebenfalls mit dem Alltagsleben der damals lebenden Bevölkerung beschäftigen sich die Besuchenden, wenn sie Unterschiede in den Ernährungspraktiken oder den Transportmitteln feststellen. So äussert die folgende Person, in diesem Fall nicht ausgehend von einer Fotografie, sondern von in der Ausstellung zu sehenden Einmachgläsern:

"Wir können einfach in den Laden gehen und etwas kaufen, und dort musste man Vorräte ansammeln (...) für den Winter, Einmachgläser, ich weiss nicht, wie viele [evtl. gemeint: von den eigenen Schülerinnen und Schülern ${ }^{1309}$ ] das überhaupt noch kennen, dass man mit diesen Einmachgläsern für den Winter Früchte und Gemüse sterilisiert.» (P3, Absatz 66)

1309 P3 bezieht zahlreiche Äusserungen auf die Lebenswelt der Schülerinnen und Schüler, mit denen P3 einen Ausstellungsbesuch plant. Siehe hierzu näher Abschnitt 8.7.3.7. 
Eine weitere Person äussert in Bezug auf Praktiken des Reisens, in diesem Fall wieder in Reaktion auf eine Fotografie, die gemäss Beschriftung «evakuierte Zivilpersonen auf dem Elsässer Bahnhof» und im Hintergrund einen Zug zeigt:

"Man sieht Drittklasswagen, das hat es damals noch gegeben, nicht nur erste und zweite Klasse, sondern Drittklasswägen. Und kein Gang in den Abteilungen, so wie das aussieht, sondern für jedes Abteil ein eigener Eingang, Trittbrett, eigener Eingang.

Also nichts mit (...) während der Fahrt schnell aufstehen und in den Speisewagen gehen. Abgeseben davon, dass es den da gar noch nicht gegeben hat.» (P20, Absatz 11)

Fragen der technischen Ausstattung bzw. Fortbewegungsmittel sind auch Gegenstand der folgenden Vergleiche von Zeitebenen, in denen die Besuchenden, ausgehend von Fotografien, zur Feststellung von Unterschieden kommen:

"Pikettstellung der Armee, der Pferde, Maultiere und Motorwagen〉. Also Motorwagen hat es dort sicher noch sebr, sebr wenige gegeben.» (P22, Absatz 19)

«Das sieht man auch nicht mehr, Maultiere, heutzutags.» (P18, Absatz 65)

Die Feststellung der Andersartigkeit im Vergleich zwischen Vergangenheit und Gegenwart ist in den zuletzt gezeigten Textstellen angelegt, wird aber - wie auch im übrigen Datenmaterial - in unterschiedlichem Ausmass explizit. Häufig sprechen Besuchende davon, dass etwas 〈damals〉 anders oder auffällig gewesen sei die Gegenwart als zeitliche Vergleichsebene wird dabei aber nicht explizit benannt, sondern schwingt lediglich unausgesprochen als Vergleichsmassstab in den Äusserungen mit.

Neben Themen des vergangenen Alltags wie etwa Aussehen, Kleidung, Ernährung und Transport sind es auch Örtlichkeiten, in Bezug auf die von den Besuchenden Unterschiede zwischen Vergangenheit und Gegenwart festgestellt werden. Häufig sind es Orte aus Basel und der Region, welche die Besuchenden kennen; anhand dieser Kenntnis gelangen sie zu dem Befund, es sehe heute anders aus. 
"Da sieht einfach den Bahnhof, nehme ich jetzt an, das ist der (...) [dreht Karte, um Beschriftung zu sehen] JA, das ist der Badische, das ist der Badische Bahnhof. (...)

Und das ist in Basel, beute natürlich ganz anders, aber (...) ein sehr schöner Bahnhof mit dem Baslerstab oben drauf.» (P22, Absatz 5)

"Die Bäume scheinen alle gefällt worden zu sein. Die Strasse ist breiter. Und ich frag mich, ob diese, dieses Gutshaus, diese Villa da rechts auf Allschwiler Seite, ja, was da wobl ist. Ich glaub, da ist heute alles Industrie und Wohngebiet.» (P12, Absatz 38)

\subsubsection{Umgangsweisen der Gegenwart mit der Vergangenheit}

Eine weitere Form, in der Besuchende auf die Gegenwart Bezug nehmen und die bei etwa einem Drittel der Besuchenden, insgesamt aber seltener als die übrigen Varianten, vorkommt, stellen Überlegungen darüber dar, wie in der Gegenwart mit der Vergangenheit umgegangen wird, umgegangen werden kann oder umgegangen werden sollte. Bei der erstgenannten Kategorie handelt es sich in einem theoretischen Sinn um Beschreibungen von gegenwärtiger Geschichtskultur ohne dass die Besuchenden aber explizit von Geschichtskultur sprechen würden.

Eine relativ lange zusammenhängende Passage innerhalb der Thematik «Geschichtskultur» stellt die folgende Äusserung von P20 dar. Konfrontiert mit einer Bildquelle und -beschriftung, die die Einlagerung von Sprengsätzen in den Pfeilern der Mittleren Brücke in Basel zu Beginn des Weltkriegs darstellt, kommt ihm oder ihr ein aktueller Bezug in den Sinn:

"Ja, das ist noch bis relativ lang so gewesen, dass in den Brückenpfeilern Sprengstoffeingelagert worden ist. Wir haben (...) jetzt erst kürzlich ist ein Fall gewesen in (...) Rbeinfelden, wo das badische Rbeinfelden einen Aufschrei hatte, weil herausgekommen ist, dass die Schweizer die Brücke mit Sprengstoff gefüllt hatten, die Brückenpfeiler von der alten Rheinbrücke in Rheinfelden. (...)

Und das ist jetzt als Kriegslast erst irgendwie so vor ein paar Monaten dann (...) ent/, wie soll man sagen, (...) ausgeräumt worden, und (...) das hat irgendein findiger Journalist, hat das (...) publik gemacht im Deutschen. Die Deutschen haben gar nix davon gewusst. (...) Also, die offizielle Stadtverwaltung von Badisch-Rheinfelden vielleicht schon, aber die anderen nicht. Und da ist ein bisschen ein Aufschrei durch (...) die Presse gegangen. Also ist das immer noch so ein bisschen aktuell gewesen.» (P20, Absatz 7-8) 
Eine andere Person interessiert sich im nächsten Beispiel für die Frage des Gedenkens an das Kriegsende, vor einer Texttafel mit Datum des Kriegsendes stehend:

«11.11.1918〉. Jetzt fällt mir gerade ein, dass das ja dann der Dienstag ist, nächste Woche, und dass ich heut Morgen in Frankreich überall die Fähnchen an den Gebäuden gesehnt, gesehen hab, und dass man eben, obne dass ich jetzt in Deutschland geguckt hatte, und logisch in Basel sowieso nicht, fällt mir ein eben, dass der 11.11. in Frankreich und in eigentlich fast allen sonstigen Ländern, bis auf die Schweiz und bis auf Deutschland, ein Feiertag ist. Die Feier zu Ende des Ersten Weltkrieges und auch der Sieg im Ersten Weltkrieg. (...)

Ja. Eigentlich müsste auch die Schweiz diesen 11.11. prägnanter feiern. Eigentlich unklar, warum das bei denen kein Feiertag ist, oder zumindest Gedenktag.»(P12, Absatz 194-195)

Auffällig bei beiden Beispielen ist, dass diese Assoziationen deutlich über das in der Ausstellung Thematisierte hinausgehen. Weder ist in der Ausstellung von den aktuellen Ereignissen rund um die Brückenpfeiler in Rheinfelden die Rede, noch werden Fragen des heutigen Gedenkens an das Kriegsende thematisiert. Die Besuchenden bringen diese Themen vielmehr frei ein, indem sie auf aktuelles Tagesgeschehen oder auf eigene Beobachtungen rekurrieren.

In der zuletzt gezeigten Passage findet sich zudem ein Aspekt, der im analysierten Material höchst selten vorkommt, nämlich Handlungsempfehlungen für die Gegenwart, konkret die Feststellung, dass eigentlich «auch die Schweiz diesen 11.11. prägnanter feiern» sollte.

Lehren bzw. Handlungsempfehlungen stellen neben den Beschreibungen von Geschichtskultur einen zweiten Bereich von Äusserungen dar, in denen Besuchende den tatsächlichen oder möglichen Umgang der Gegenwart mit der Vergangenheit thematisieren.

Formulierte Lehren finden sich im Datenmaterial nur äusserst vereinzelt. So konnte ich, neben der bereits zitierten Passage bei P12, lediglich in den Äusserungen von zwei weiteren Teilnehmenden Handlungsanweisungen identifizieren. In einem Fall verknüpft P19 Vergangenheit und Gegenwart, nachdem er oder sie durch einen Ausstellungstext mit den Ausmassen der Spanischen Grippe in der Schweiz und der Opferzahl konfrontiert wurde:

"Da überlegt man sich schon, ja, ob nicht auch heute wieder so eine Pandemie auftreten könnte und wie das heute wäre, weil wir uns eigentlich schon daran 
gewöhnt haben, dass es so etwas nicht mehr gibt, aber dass ja (...) das genau hundert Jahre oder nicht ganz hundert Jahre her ist, wo eine letzte grosse Pandemie Zehntausende Todesopfer gefordert hat und (...) dass man irgendwo, man kann auch sagen, ja wir sind nicht von dem gefeit, und (...) man darf sich da nicht in einer falschen Sicherbeit wiegen. Und ich denke, es ist gut, wenn man sich auch, ja, mit DEM auseinandersetzt und sich ïberlegt, wie sind die Leute damals damit umgegangen und was für Lebren kann man für beute zieben. Aber (...) ich bin doch sehr dankbar, dass wir von dem jetzt eigentlich nicht mebr betroffen sind, oder im Moment nicht betroffen sind.» (P19, Absatz 135)

Während P19 in dieser Passage explizit auf ein «heute» Bezug nimmt und formuliert, was man im Heute angesichts vergangenen Geschehens tun solle, zieht er oder sie an anderer Stelle eine Schlussfolgerung in Form einer überzeitlichen, allgemeingültigen Aussage. ${ }^{1310}$ Nämlich leitet P19 aus der Beschäftigung mit den während des Ersten Weltkriegs in der Schweiz bestehenden unterschiedlichen Sympathien mit den kriegführenden Nationen eine Schlussfolgerung für eine gelungene demokratische Praxis ab:

"Finde ich eindrücklich, wie, wie das natürlich zu Spannungen gekommen ist, weil die Deutschschweiz mehr auf Deutschland und die Welschschweiz mehr natürlich zu den Franzosen gestanden ist, und wie das zu einer echten Zerreissprobe für unser Land geworden ist und ich bin wirklich da sebr dankbar, dass man, dass man die Einigkeit, den Weg gehen konnte, und macht einem auch bewusst, dass man, dass wir einfach in einem Land sind, wo, wo die Gegensätze sehr gross sind, und dass man durch Demokratie auch miteinander immer wieder einen Weg suchen muss. Aber immer auch dem anderen zubören muss und gemeinsam als Land den Weg finden muss.» (P19, Absatz 41)

Ebenfalls über die Gestaltung des Zusammenlebens innerhalb einer Gesellschaft denkt eine weitere Person, P25, angesichts der Beschäftigung mit Arm-ReichGegensätzen nach, auch hier wieder als überzeitlich gültige Aussage formuliert:

1310 Derartige Aussagen würden der Systematik nach im nachfolgenden Kapitel zu überzeitlichen und allgemeingültigen Aussagen behandelt gehören, werden jedoch aufgrund der insgesamt sehr geringen Anzahl von Textstellen über gezogene Lehren an dieser Stelle mit erwähnt. 
"Also mir geht so durch den Kopf (...) dass (...) damit Frieden herrscht, eine Balance muss finde/, gefunden werden (...) zwischen den woblhabenden Leuten und den arbeitenden, nicht so woblhabenden Leuten. Das Schlimmste ist (...), wenn die einen viel und die anderen nichts haben.» (P25, Absatz 20)

Abgesehen von den drei zitierten Beispielen finden sich kaum ${ }^{1311}$ Hinweise darauf, dass Besuchende aus der Beschäftigung mit vergangenem Geschehen Handlungsempfehlungen ableiten würden.

Eine dritte Kategorie bilden Äusserungen der Besuchenden darüber, dass vergangenes Geschehen aus gegenwärtiger Perspektive anders eingeschätzt werde, als dies von Zeitgenossen getan worden sei. Mit diesen Äusserungen bringen die Besuchenden ein Verständnis für die Differenz zwischen Vergangenheit und Gegenwart zum Ausdruck. Ich habe zwei Besuchende gefunden, die sich in dieser Hinsicht äussern. So äussert eine Person auf die in einem Ausstellungstext enthaltene Formulierung, dass der Bundesrat zu Kriegsbeginn von einer kurzen Kriegsdauer ausgegangen sei:

"Aus heutiger Perspektive wirkt das vielleicht auch etwas naiv. Wobei natürlich auch viele Deutsche ausgerückt sind und dem festen Glauben, dass sie an Weihnachten wieder zu Hause sein wollen. (...) Viel mehr trifft es natürlich die Formulierung 〈europäischer Krieg von ungeheurer Ausdehnung〉.» (P21, Absatz 30)

Auch folgende Person stellt fest, rückblickend sei die Kriegsdauer besser einzuschätzen. Auch sie reagiert auf einen Ausstellungstext, der von der zunehmenden Not angesichts eines zum «Dauerzustand» werdenden Krieges spricht:

"Ja, alles wie sich das jetzt steigert, wie die Not langsam schlimmer wird, (...) weil der Krieg zum Dauerzustand wird, und man weiss ja gar nicht, wie lange der geht.

Jetzt im Rückblick wissen wir ja, wie lange der Krieg gedauert hat, aber mitten nach drei Jabren, was man da fühlt, wenn man nicht weiss, wann das endlich vorbei ist, das können wir uns auch überhaupt nicht vorstellen.» (P3, Absatz 65)

1311 Eine weitere Äusserung, ebenfalls von P25, stelle ich weiter unten im Zusammenhang mit Bezügen zur eigenen Lebenswelt vor. 
Dieselbe Person rekurriert auch andernorts auf die Unterschiedlichkeit der Blickwinkel. Während in den zuvor genannten Beispielen die Auffassung vertreten wird, dass von Zeitgenossen die Kriegsdauer zu optimistisch eingeschätzt worden sei, spricht P3 nun davon, dass umgekehrt im Rahmen des Landesstreiks die eigene Situation in der Schweiz als unverhältnismässig belastend eingestuft wurde:

"Ich heute empfinde das als sehr un/ als grosse Unzufriedenheit, dass die Menschen überhaupt nicht merken, was rundherum alles viel Schlimmeres passiert, aber (...) im Nachbinein kann ich das jetzt schon im Überblick sagen, aber für die Menschen damals war es ihre Situation.»(P3, Absatz 74)

Die zitierte Person P3 beschäftigt sich generell sehr viel damit, dass es Deutungsunterschiede zwischen Vergangenheit und Gegenwart gebe, thematisiert diese ansonsten aber eher in Bezug auf die eigene Person und ihre Unfähigkeit, sich in Sachverhalte hineinzuversetzen, wobei letztgenannte Äusserungen in den Fokus III entfallen und dort behandelt werden, wo P3 eine eigene Falldarstellung gewidmet wird. ${ }^{1312}$

\subsubsection{5 Überzeitliches und Allgemeingültiges}

Einen Sonderbereich der hergestellten Bezüge zwischen Vergangenheit und Gegenwart stellen überzeitliche Äusserungen dar. Solche überzeitlichen Äusserungen kommen bei über zwei Dritteln der Besuchenden vor und stellen neben den Feststellungen von Ähnlichkeiten und Gemeinsamkeiten die am stärksten vertretene Gruppe dar. Darin werden von den Besuchenden allgemeingültige Aussagen über Wirklichkeit gemacht.

Sie werden an dieser Stelle im weitesten Sinn den Gegenwartsbezügen zugerechnet, weil die Besuchenden mit ihren Äusserungen Gültigkeit für alle Zeitebenen und insofern auch für die Gegenwart beanspruchen. Diese Äusserungen sind dadurch gekennzeichnet, dass die Besuchenden davon sprechen, etwas sei <immer〉, ‘grundsätzlich〉, ‘typischerweise〉 oder 〈überall〉 so. Teilweise entsteht auch ohne diese Indikatorworte aufgrund der inhaltlichen Ausrichtung einer Äusserung der Eindruck, dass sie auf ein allgemeingültiges Prinzip rekurrieren soll. Präsensformulierungen allein genügen auch hier wieder nicht zur Klassifizierung als über-

1312 Vgl. Abschnitt 8.7.4. 
zeitliche Aussagen, da Besuchende auch über vergangenes Geschehen vielfach im Präsens sprechen. ${ }^{1313}$

Thematische Schwerpunkte bilden einerseits Äusserungen über Wesen und Schrecken von Kriegen sowie andererseits gesamthaft das Themenspektrum aus sozialer Not einerseits und wirtschaftlichen Profiten andererseits, verbunden noch mit Thematisierungen von Gegensätzen zwischen Arm und Reich. Eine Reihe von entsprechenden Äusserungen finden sich in der Auseinandersetzung von Besuchenden mit dem regionalspezifischen Eingangsbereich der Ausstellung, in dem unter den Stichworten «Wohlstand», «Profite», «Not» und «Mobilisierung» Bezüge des Ersten Weltkriegs zur Stadt Basel aufgezeigt werden, entsprechende Gegenüberstellungen zwischen Arm und Reich also auch durch die Ausstellungsgliederung selbst vorgenommen werden, wobei die Ableitung angenommener überzeitlicher Prinzipien durch die Besuchenden selbst erfolgt.

Ich zeige nachfolgend zunächst eine längere Passage aus den Äusserungen von P27, der/die sich von rechts nach links an der Vitrine entlangarbeitet, die jeweiligen thematischen Texte liest oder auszugsweise liest und dazwischen einige Äusserungen mit dem Impetus überzeitlicher Gültigkeit formuliert:

«Der Ausbruch des Ersten Weltkrieges bedeutete für die reichen Basler Familien noch nicht das Ende der Belle Époque. (...) Kriegsgewinne (...) und familiäres Vermögen ermöglichen der Oberschicht weiterhin ein (angenehmes) Leben.> (...) Tja, so ist das. (ironischer/spöttischer Tonfall) (...)

Selbst als es (...) vermehrt zu Demonstrationen und Streiks kommt, konnte der Offizier und Geschäftsmann> (...).

Tja. (...) It's (...) the rich who fight war and the poor who die. (...)

‘Chemische Industrie zum DURCHBRUCH (überraschter Tonfall)! (...) Lieferungen an (Kriegs) (unv.) (eröffnen Basler Firmen grosse newe Märkte. (...) Kriegsrelevanten Farbtöne FELDGRAU, FELDGR ÜN und HECHTGRAU> (schmunzelt) (...)

«und eigene Pharmaforschung〉, ah! Die Pharmaforschung ging zum Ersten Weltkrieg los. (...)

Tja. (...) Der Mensch war leider schon immer gut darin, (...) sich selbst umzubringen. (...) Schön ist, dass damals selbst der Chemielaborant Krawatte trug

1313 Vgl. für differenziertere Ausführungen zur Zuordnung von Textstellen zu Kategorien die Kategorienbeschreibungen im digitalen Anhang. 
(spöttischer Tonfall) (...). Ja, und f/, für die Massen gab's ‘Hunger, Not und Verarmung〉 (...). 〈Die feblende Marktregulierung und die kriegsbedingten Importschwierigkeiten.> (...)

Die Löbne wurden natürlich NICHT angepasst. (ironischer Tonfall) (...) Ah okay, Militärdienst hat noch keinen Lohn (...)ausgleich gebracht. (...)<Mietzins und Krankenkassenbeiträge ausbezahlt.> (...)» (P27, Absatz 2-6)

In den Äusserungen von P27 finden sich mehrere Facetten von überzeitlichen Feststellungen. Manche Dinge scheint er oder sie für 〈typisch〉 zu halten («Tja, so ist das", "Die Löhne wurden natürlich NICHT angepasst»), ohne dass hier ein explizites Indikatorwort auf eine überzeitlich gültige Annahme hinweist. Noch expliziter und verallgemeinernder formuliert er oder sie ein scheinbar als überzeitlich gültig angenommenes Prinzip im Mittelteil der Passage: "Der Mensch» sei «schon immer gut darin» gewesen, "sich selbst umzubringen». Ergänzt wird das Set überzeitlicher Feststellungen durch den Einsatz eines Bonmots: "It's (...) the rich who fight war and the poor who die.» Neben den Äusserungen der Besuchenden, dass etwas schon immer, überall oder typischerweise geschehe, habe ich auch solche Sprichwörter, die im Stil von allgemeingültigen Weisheiten formuliert sind, den Äusserungen von Überzeitlichem zugerechnet.

Ein Beispiel hierfür findet sich auch bei P20, sich wie P27 im Eingangsbereich befindend und dort den Text zum Thema «Wohlstand» lesend:

«Der Ausbruch des Ersten Weltkriegs ist für die reichen Basler Familien noch nicht das Ende der Belle Époque. Kriegsgewinne in einigen Industriezweigen und familiäres Vermögen ermöglichen der Oberschicht weiterhin ein angenehmes Leben. So konnte 1916 das Kaffeehaus Singer am Marktplatz eröffnet werden. Ein moderner Bau mit grossstädtisch-mondänem Interieur, wo sich die wohlhabenden Familien an Kaffee, Tee, Süssigkeiten und Konzerten erfreuten.>

Also wir haben damals die einen, die um ibre Existenz bangen müssen und jeden Rappen umkehren haben müssen, weil der Mann, der Ernäher ist an der, an der, an der Grenze gewesen. Keinen (...) Lohnersatz bekommen hat. Haben die einen schauen müssen, und die anderen sitzen bei Kaffee, Kuchen und Konzert im Singerhaus. So GERECHT ist die Welt. (...)»(P20, Absatz 23) 
Den Text zum Thema «Profite» über zunehmende Gewinne der Pharmabranche während des Kriegs lesend, äussert sich ähnlich auch P19, auch hier ein Bonmot gebrauchend:

«Da zeigt sich ja, des einen (...) Leid ist des anderen Freud.» (P19, Absatz 20)

Sich im selben Abschnitt zum Thema «Profite» befindend, werden auch zwei weitere Besuchende zu überzeitlichen Feststellungen veranlasst:

«In Basel verhall/, verhalf der Erste Weltkrieg der chemischen Industrie zum Durchbruch.> (...) Bevor ich das überhaupt lese, denke ich, dass die (...) Chemie (...) profitiert hat (...) vom Krieg. (...) Von jedem Krieg gibts ja Parteien, wo divekt oder indivekt profitieren. Und jetzt lese ich den ganzen Text, wo dazu gehört.» (P25, Absatz 9)

"Also ich lese nur so grob, dass hier eben die Pharmaindustrie in dieser Zeit sehr gewachsen ist und dass ja die Schweiz eigentlich dann profitieren konnte, weil es Material brauchte. Sehr viel Gewinn, versechsfachst, versechsfacht, in dieser Zeit also fa/ färben und hat es schöne Beispiele mit Farbkarten von der Ciba-Geigy die früber, also das war die frühere Chemie, die Namen haben ja immer gewechselt und es ist, vielleicht wollen wir das nicht so gerne sehen, dass wir da profitiert haben vom Krieg. Aber das ist ein wichtiger Aspekt, finde ich, auch zu sehen, dass immer jemand ein Interesse hat, sonst müsste man ja sagen, warum gibt es überbaupt Krieg? Weil es ja, niemand will Krieg sozusagen.» (P3, Absatz 13)

In den zitierten Äusserungen von P25 und P3 verbinden sich Überlegungen zum Wesen und Schrecken von Kriegen mit Hinweisen auf die durch Kriege zu machenden Profite. Von P3 werden diese Profite sogar explizit als Kriegsgründe benannt.

Das Nachdenken darüber, was Kriege im Kern ausmacht und warum es überhaupt Kriege gibt, findet sich bei mehreren Besuchenden. Beispielsweise wird es, so im Fall der zitierten Äusserungen von P25 und P3, verbunden mit dem Hinweis, es gebe Gruppen, die vom Krieg profitieren.

P25 bringt etwas später darüber hinaus einen weiteren Erklärungsansatz ein. Sich nun in der Abteilung «Vor dem Krieg» befindend und den dortigen einführenden Text betrachtend, in dem "von einem beispiellosen wirtschaftlichen Aufschwung», aber auch von einer «Arbeiterschaft in schwierigen sozialen Verhältnis- 
sen» und von «Spannungen und Bruchstellen zwischen sozialen Klassen» die Rede ist, äussert er oder sie, wie weiter oben in anderem Zusammenhang bereits zitiert:

"Off/, offensichtlich ist vor dem Ersten Weltkrieg eine Zeit gewesen von Aufschwung, von Erfindungen, grosse Mobilität. (...) Die Arbeiter haben aber nicht mehr gehabt, und das hat (...) zu Spannungen geführt (...) zwischen Mittelstand und der Oberschicht auf der einen Seite und der Arbeiterschaft auf der anderen Seite. (...)

Also mir geht so durch den Kopf (...), dass (...), damit Frieden berrscht, eine Balance muss finde/, gefunden werden (...) zwischen den woblbabenden Leuten und den arbeitenden, nicht so woblbabenden Leuten. Das Schlimmste ist (...), wenn die einen viel und die anderen nichts haben.» (P25, Absatz 20)

Die zitierten Aussagen beinhalten eine interessante Vermengung, in der P25 Aspekte der von der Ausstellung behandelten schweizerischen Situation während des Ersten Weltkriegs (namentlich soziale Gegensätze und wirtschaftliche Profite) weiterdenkt und zu möglichen Kriegsursachen erklärt, obwohl in der Schweiz selbst in der Folge dieser Umstände, abgesehen vom Landesstreik, keine militärischen Auseinandersetzungen stattfanden.

Auch in anderen Passagen der Ausstellung kommt es immer wieder zu Äusserungen der Besuchenden über das Wesen von Kriegen und insbesondere die mit Kriegen verbundenen Schrecken und Nöte. Vor einem Film über die Mobilmachung der Schweizer Armee stehend, wird P18 zu folgender Aussage veranlasst - dabei nicht berücksichtigend, dass schweizerische Soldaten gar nicht unmittelbar in das kriegerische Geschehen des Ersten Weltkriegs einbezogen waren:

"Der Mensch, Kronik von, Krone der Schöpfung, sagt man, und sie bringen sich gegenseitig um.» (P18, Absatz 36)

Ein Bild des Künstlers Frans Masereel betrachtend, äussert P22:

"Da sieht man (...) auch mit Zeichnungen wieder gefallene Leute. (...) Das ist halt, das, ein Krieg ist halt einmal nun so. Das ist immer etwas, wo es (...) einfach sehr viele (...) Sachen gibt, die halt eben nicht so toll sind und (...), dass man eben (...) Krieg ist: man tut sterben. Das ist der Krieg, kann man nichts anderes machen. Zum Teil nicht ganz alle, aber ein grosser Teil. Und Trauer ist halt immer ganz gross geschrieben (...).» (P22, Absatz 57) 
Weitere Themenbereiche neben Äusserungen über das Wesen von Kriegen und über Not und Profite decken Äusserungen ab, in denen sich Besuchende eher gesamthaft der Rolle und Situation der Schweiz zuwenden oder über Neutralität sprechen, teilweise allerdings auch hier wieder verbunden mit wirtschaftsbezogenen Überlegungen. In Bezug auf die Rolle der Schweiz äussert P13, sich wie die bislang zitierten Besuchenden im Eingangsbereich aufhaltend und dort den Text zum Thema «Wohlstand» lesend:

«Der Ausbruch des Ersten Weltkriegs bedeutete für die reichen Basler Familien noch nicht das Ende der Belle Époque> (...).

Die Schweiz einmal mehr Profiteur vom Krieg.» (P13, Absatz 8-9)

Bei P8 finden sich überdies zwei Äusserungen, in denen er oder sie Einsichten über wirtschaftliche Aktivitäten der Schweiz mit allgemeingültig formulierten Aussagen über spezifische Bedingungen, Anforderungen und Restriktionen in einem neutralen Land verbindet:

«So, dann betreten wir mal die Hauptausstellung. (...) <Alfred Frey. Wirtschaftspolitiker und Präsident des Schweizerischen Handels- und Industrievereins.' (...) [lautes Rauschen]

¿Der Völkerbundvertrag enthält an zwei Stellen ausdrückliche Bestimmungen über wirtschaftliche Fragen, nämlich in Artikel 23 und Artikel 16. Von Artikel 23 lauten die in Betracht fallenden Bestimmungen.>

Jetzt wird's französisch, ich versuch's mal zu entschlüsseln. (...) [lautes Rauschen] Okay, also Frey, also ein bedeutender Wirtschaftspolitiker, der es schafft, Handelsabkommen zwischen verschiedenen kriegführenden Staaten zu schliessen.

Das wirft natürlich die Frage auf, inwiefern ein neutrales Land Handel fübren kann (...) mit verfeindeten Nationen.» (P8, Absatz 7)

« Schon im Februar 1915 bält die Neue Zürcher Zeitung fest: ‘Den einen Vorteil der Neutralität, mit niemandem verfeindet zu sein, sollte die schweizerische Industrie ausnützen können.> Als einzigem neutralen Land gelingt es der Schweiz, Handelsverträge mit den kriegführenden Staaten auszubandeln. Gleichzeitig wollen diese Länder verhindern, dass die Schweiz kriegswichtige Produkte an den Feind liefert. Die wirtschaftlichen Aktivitäten der Schweiz werden daber immer genauer und restriktiver kontrolliert.' 


\section{Ab, das liegt natürlich nabe, dass ein Land miteiner gutentwickelten (unv.) überwacht wird, da es so den Boden der Neutralität auch schnell wieder ver- lassen kann.» (P8, Absatz 36)}

Ebenfalls im allgemeingültigen, überzeitlichen Impetus kommt P25 auf das Thema «Neutralität» zu sprechen, sich in der Abteilung «Neutral von Fall zu Fall» befindend und dabei über die Dehnbarkeit eines Neutralitätsbegriffs sprechend:

"Ich stehe vor dem Bild (...) 〈Neutral Apotheke. Man spricht nur deutsch〉. Aha. (...) Da wird also die Deutschfreundlichkeit von gewissen Kreisen (...) in der Schweiz angeprangert. Man hat also wobl gewusst, dass Neutralität (...) ein dehnbarer Begriff ist und dem Land und der Situation anpassen kann.» (P25, Absatz 82)

Sich in derselben Abteilung befindend und mutmasslich, weil still davorstehend, den dortigen Ausstellungstext über die Obersten-Affäre lesend, äussert P18 anschliessend im ironischen Tonfall:

"Ja, das ist eben neutral, dass man einfach für die eine Seite ist (...). Eben ‘Neutral von Fall zu Fall> (...). Ja.»(P18, Absatz 105)

Ich rechne die gezeigten Äusserungen dem Bereich der überzeitlichen, allgemeingültigen Aussagen zu, auch wenn spezifische Indikatorworte wie <immer> usw. fehlen. Jedoch legen Bezeichnungen wie "ein neutrales Land» (P8, Absatz 7) oder «ein Land» (P8, Absatz 36) oder die inhaltlichen Ausrichtungen der Äusserungen gleichwohl nahe, dass die Besuchenden in diesen Fällen von der spezifischen Situation und Zeit zumindest ein Stück weit losgelöste, allgemeingültige Überlegungen anstellen. ${ }^{1314}$

1314 Allerdings erweist sich eine auf dieser Ebene erfolgende Identifizierung von allgemeingültigen Aussagen ohne Vorhandensein expliziter Indikatorworte als herausfordernd, sprechen die Besuchenden doch häufig über vergangenes Geschehen im Präsens. Oft erscheinen solche Äusserungen jedoch stärker auf eine konkrete historische Situation bezogen und wurden deshalb als Äusserungen innerhalb der Zeitebene «Vergangenes» erfasst, so etwa: «[...] Der Versuch von Bundesrat Artur Hoffmann, (unv.) deutsch-russischen Separatfrieden zu vermitteln, SCHEITERT.> Das ist natürlich ein deutlicher Verstoss gegen die Neutralität.» (P8, Absatz 54). Oder: "Na also, das stützt jetzt wieder diese Position als neutraler Staat, dass eben ausländische Künstler hier weiterbin austoben können»(P8, Absatz 63). 
Insgesamt gibt es kaum Äusserungen, in denen Besuchende in gegenwartsbezogenen freien Äusserungen die Begriffe «neutral» oder «Neutralität» in den Mund nehmen - am ehesten, wie hier gezeigt, im Rahmen der Formulierung von Überzeitlichem und Allgemeingültigem, wobei Sensibilitäten für die grundsätzlichen Herausforderungen von Neutralität aufscheinen, allerdings von den Besuchenden nicht weiter ausgeführt werden. Eine weitere neutralitäts- und gegenwartsbezogene Äusserung lässt sich überdies in der Kategorie «Wurzeln und Vorläufer der Gegenwart» verorten. Darin fragt P3 nach dem Ursprung der offiziellen schweizerischen Neutralität und führt Neutralität dabei zugleich als ein seither bestehendes Konzept ein:

"Also die Neutralität wird anerkannt, heisst es hier. Muss ich nochmals anschauen, seit wann die Schweiz ïberhaupt neutral ist offiziell, ich glaube das ist seit 1815.» (P3, Absatz 60)

Die gegenwartsbezogenen Überlegungen der Besuchenden zum Thema «Neutralität» beschränken sich jeweils auf die knappen hier zitierten Passagen und werden nicht weiter ausgeführt. Es scheint für die Besuchenden nicht naheliegend, in diesem Bereich Bezüge zur heutigen Situation der Schweiz, zu Dimensionen des Neutralitätsbegriffs ${ }^{1315}$ und zu mit Neutralität verbundenen aktuellen Herausforderungen anzustellen, wie sich überhaupt Neutralität als ein in den Äusserungen der Besuchenden verhältnismässig selten vorkommendes Thema erweist. ${ }^{1316}$

1315 Moos 2014; vgl. dazu auch die Ausführungen in Abschnitt 7.2.

1316 Auch abgesehen von den hier betrachteten Bezügen zur Gegenwart erscheint «Neutralität» geradezu als eine Leerstelle in den Äusserungen etlicher Besuchender. Obwohl das Thema an einigen Stellen der Ausstellung explizit zur Sprache kommt und sich durch andere Teile - namentlich den wirtschaftsgeschichtlichen Bereich - als subtiler, unterliegender, wenn auch nicht explizit benannter roter Faden zieht (vgl. Kapitel 7), wird es von den Besuchenden selten explizit zur Sprache gebracht - sowohl in der Menge von Nennungen als auch in der Zahl der Besuchenden, die sich überhaupt zu diesem Thema äussern.

Für die Identifizierung dieses Gegenstands habe ich nach expliziter Verwendung der Begriffe «neutral» oder «Neutralität» durch die Besuchenden gesucht. Während die Bereiche «Kriegsverlauf und (Kampf-)Geschehen im Ausland», "Güter/Prozesse/Import/Export» und «soziale Not/Ernährungskrise/Sozialhilfe» bei (fast) allen Besuchenden in irgendeiner Weise behandelt werden, finden sich explizite Thematisierungen von Neutralität demgegenüber überhaupt nur bei 10 von 18 Besuchenden und insgesamt deutlich seltener. Von 4 Personen wird die Schweiz als neutrales Land benannt und thematisiert (P3, P8, P12, P21), dieselben 4 sowie 5 weitere Personen (P13, P18, P19, P25, P28) thematisieren Herausforderungen der Neutralität. Punktuell finden sich daneben ausserdem Äusserungen, in denen Neutralität abstrakt als Thema der Ausstellung benannt wird, ohne dass die 


\subsubsection{Exkurs: Orte als zeitübergreifende Phänomene und Parameter}

Ich wende mich abschliessend einem Bereich zu, der in der Systematik des Kategoriensystems nicht den Gegenwartsbezügen zugerechnet wurde, sondern dem grossen Bereich der Äusserungen über Geschehen innerhalb einer Zeitebene einschliesslich der nicht eindeutig zeitlich zuordenbaren Äusserungen, der aber gleichwohl auch im Zusammenhang mit Gegenwartsbezügen und überzeitlichen Äusserungen bedenkenswert ist. Die Rede ist von solchen Äusserungen, in denen sich Besuchende mit der Verortung historischen Geschehens beschäftigen.

Häufig treten derartige Äusserungen in Zusammenhang mit der Betrachtung von Bildquellen auf. Die Besuchenden äussern sich dann dazu, wo das Abgebildete «ist», oder fragen sich genau dies.

«Wo ist das? Ist das in Basel?» (P6, Absatz 15)

"Ist ein ‘Warenlager des Kriegsfürsorgeamts in Basel>. Wo das wohl war? ‘Staatsarchiv〉. Das wär noch nett gewesen, wenn irgendwo, das ist wahrscheinlich, $j a$ wenn irgendwo stehen würde, wo das, welcher Ort das ist, welche Adresse.»(P12, Absatz 136)

«Ich betrachte das Bild, frage mich, wo es ist.» (P21, Absatz 39)

"Da gucken sie alle in die Kamera. (...) Wo ist das? ‘Ein Esslokal der Volkshüche. Kriegsfïrsoge (abends) in der Turnballe in Basel, Dreirosen`. Okay.»(P6, Absatz 54)

Wie in den Beispielen ersichtlich, erfolgen solche Einordnungen vielfach im Präsens, was, wie weiter oben berichtet, ein generelles Merkmal vieler Äusserungen der Besuchenden ist, wenn sie über vergangenes Geschehen sprechen, und noch nicht per se von mir als Indikator für Bezüge zur Gegenwart gewertet wurde. ${ }^{1317}$

Aussagen einem der oben genannten Bereiche zuordenbar wären. Hingegen sprechen 16 von 18 Personen über die mit den Import- und Exportpraktiken während des Krieges verbundenen Gewinne und/oder moralischen Fragen. Aus diesem Befund lässt sich schlussfolgern, dass die Beschäftigung mit wirtschaftlichen Bezügen der Schweiz mit dem kriegführenden Ausland bei den Besuchenden nicht zwingend einhergehen muss mit neutralitätsbezogenen Überlegungen, und das deckt sich mit der nur zaghaften expliziten Verknüpfung der Aspekte im Narrativ der Ausstellung wie auch der Abwesenheit einer Verknüpfung in geschichtswissenschaftlichen Überblicksdarstellungen und Geschichtslehrmitteln (Kuhn/Ziegler 2011, S. 129; Thyroff 2017a, S. 172, S. 179; vgl. hierzu Kapitel 7).

1317 Vgl. Abschnitt 8.5.3. 
Im Zusammenhang mit der Verortung historischen Geschehens gilt es, das Verhältnis aus von den Besuchenden gewähltem Tempus und damit möglicherweise bezeichneter Zeitebene gleichwohl zu reflektieren. Denkbar ist nämlich auch, dass Besuchende den identifizierten Orten mit der Wahl des Präsens implizit eine überzeitliche Konnotation geben. Vielfach kombiniert sich das Identifizieren von Orten mit Hinweisen darauf, dass die Besuchenden selbst diese Orte kennen - ein Bereich, den ich auch weiter unten im Rahmen der Lebensweltbezüge noch vertiefen werde ${ }^{1318}$ - und dass sie damit zwangsläufig auch gegenwärtige Orte meinen. So zeigt sich in den folgenden Beispielen, dass Besuchende Orte identifizieren können, weil sie diese selbst kennen oder einordnen können.

"Das wär jetzt spannend zu sehen, wo, wo das jetzt in Basel ist. Beziehungsweise wenn ich genau hingucken würde, könnt ich's vielleicht, nee, ich erkenn's nicht (...). Ich weiss nicht, wo es ist.» (P12, Absatz 181)

"Und das ist (...). Ah, Hartmannsweilerkopf, das ist im Elsass, gar nicht so weit weg.» (P22, Absatz 2)

"Das ist Bern, glaube ich. Jaja, das ist Bern. Auf der rechten Seite ist das Bundeshaus.»(P22, Absatz 36)

"Ah, jetzt seh ich hier (...) auf diesem schwarz-weissen Foto hier, mit den italienischen Arbeitern an der Margarethenstrasse, da sieht man oben den Margarethenhügel und links die schönen Häuser, die da stehen, die zum Gundeldinger Quartier gehören. Und das ist wahrscheinlich ein Stück weit auch diese grosse Wiese, diese Matte, die da ist, wo es rechts zum Kreisel nach Binningen und Oberwil geht und zum Hintereingang vom Zolli.» (P12, Absatz 53)

Der in den genannten Beispielen mitschwingende - hier implizite - Bezug zur eigenen Lebenswelt und Gegenwart lässt zweifeln, ob in diesen Fällen das Präsens noch als Bezeichnung einer vergangenen Zeitebene gemeint ist oder ob nicht vielmehr Orte von den Besuchenden in diesem Fall als überzeitliche, damals und immer noch vorhandene Grössen eingeführt werden. Vielfach bleiben die Konnotationen allerdings uneindeutig, wie im nachfolgenden Beispiel:

$1318 \mathrm{Vgl}$. Abschnitt 8.7.3.1. 
"Wo das wobl ist, das Hauptzollamt in Basel? Vielleicht beim SBB irgendwo, SNCF.» (P12, Absatz 51)

Darin fragt P12 zunächst danach, wo das Hauptzollamt in Basel «ist», wobei unklar bleibt, ob er oder sie damit ausschliesslich den ehemaligen Standort meint oder auch die Möglichkeit einbezieht, dass das Hauptzollamt heute immer noch an dieser Stelle sein könnte, der Standort nach wie vor Gültigkeit habe. P12 vermutet dann, es sei möglicherweise «beim SBB irgendwo, SNCF» zu finden. SBB und SNCF stehen als Abkürzungen für die schweizerische und französische Eisenbahngesellschaft, bezeichnen gleichzeitig aber auch die schweizerisch und französisch betriebenen Bahnhöfe "Basel SBB» und «Basel SNCF", unmittelbar nebeneinander angesiedelt. P12 vermutet also, das Hauptzollamt könnte in der Nähe dieses binational genutzten Bahnhofsareals zu finden sein. Inwiefern er oder sie dabei vom heutigen Bahnhofsareal spricht oder davon ausgeht, dass dieses zur Zeit des Ersten Weltkriegs in der Form auch bereits bestanden habe und das Hauptzollamt damals an dem Ort zu finden war, lässt sich nicht letztgültig entscheiden, sprachlich wird durch die gewählte Präsensformulierung jedoch die Vorstellung einer zeitebenenübergreifenden Gültigkeit von Örtlichkeiten mindestens nicht ausgeschlossen.

Die beispielhaft angeführten Äusserungen der Besuchenden zeigen, dass in Fragen der Verortung historischen Geschehens die Grenzen zwischen Vergangenheit und Gegenwart aufgelöst werden können. Orte werden mitunter als zeitübergreifende Phänomene eingeführt und als Konstanten gehandelt - dies allerdings auf implizite Weise, lediglich angedeutet und gedeutet auf Basis der von den Besuchenden gewählten Präsensformulierungen.

Bisweilen werden Orte auch explizit von den Besuchenden zum Gegenstand von Vergleichen zwischen Zeitebenen gemacht und wird dann zum Beispiel festgestellt, dass sie sich in ihrem Aussehen gewandelt haben. Entsprechende Äusserungen werden dann als festgestellte Unterschiede zwischen Vergangenheit und Gegenwart erfasst; das wurde weiter oben bereits vorgestellt. ${ }^{1319}$ Unabhängig davon, ob implizit Gleichbleibendes suggeriert wird oder Zustände von Orten explizit miteinander verglichen werden, scheinen Orte für die Besuchenden Parameter zu sein, anhand deren man Bezüge zwischen Vergangenheit und Gegenwart organisieren und Relationen zwischen Zeitebenen herstellen kann.

1319 Vgl. Abschnitt 8.5.4.3. 
Ebenso als Parameter fungieren vereinzelt neben den Ortsbezügen auch $D a$ tumsbezüge bzw. Anniversarien, in zwei Fällen bei P12 festgestellt, wobei sich darin, im Gegensatz zu vielen der gezeigten Ortsbezüge, zugleich explizite Hinweise auf die Gegenwart bzw. unmittelbare Zukunft finden («übermorgen», «nächste Woche»).

"Oh je, jetzt kommt's erst. <Eine balbe Million deutscher Soldaten erkrankt an der Spanischen Grippe, die sich als Pandemie über den ganzen Globus verbreitet. In Kiel meutern die Matrosen, was eine Reihe von (unv.) in deutschen Städten bildet. Nach Massendemonstrationen dankt Wilhelm am 9. November 1918 ab.> Das ist ja praktisch übermorgen.» (P12, Absatz 180)

«11.11.1918〉. Jetzt fällt mir gerade ein, dass das ja dann der Dienstag ist, nächste Woche.» (P12, Absatz 194)

Ausgehend von konkreten Daten historischer Ereignisse zur Zeit des Ersten Weltkriegs, formuliert P12 in diesen Beispielen, die genannten Termine stünden in der unmittelbaren Zukunft bevor. Durch die in beiden Fällen gewählte Präsensformulierung führt er oder sie Datumsbezüge als zeitübergreifende Konstanten ein und schafft somit Verbindungen zwischen den Zeitebenen.

Ortsbezüge der Besuchenden werden weiter unten erneut aufgegriffen, weil sich auch im Rahmen der Äusserungen der Besuchenden zu ihrer eigenen Person (Fokus III) eine besondere Bedeutung der Verortung andeutet, nämlich in Form räumlich orientierter Lebensweltbezüge.

\subsection{5 Übergreifende Befunde, Zwischenfazit und Einordnung}

Ich fasse zum Abschluss des Kapitels die erzielten Befunde zusammen und diskutiere sie unter Bezug auf vorhandene Theorien, insbesondere Konzeptionen von Sinnbildungs- bzw. Erzähltypen, also theoretischen Überlegungen dazu, wie sich Vergangenheit und Gegenwart erzählend miteinander verknüpfen lassen. Vorab ist allerdings erneut festzuhalten, dass Äusserungen mit Bezügen zur Gegenwart in ihrem Vorkommen zurücktreten hinter derjenigen Gruppe von Äusserungen, in denen Besuchende zwar über Geschehen sprechen, aber keine Bezüge zwischen Zeitebenen herstellen. Mit Blick auf eine Anbindung an Theorien historischen Denkens lässt sich also feststellen, dass der Hauptmodus des geschehensbezogenen Sich-Äusserns beim Museumsbesuch zunächst einmal im Feststellen von 
«Vergangenheitspartikeln» ${ }^{1320}$ besteht sowie - in der Terminologie der Sechsermatrix historischen Denkens gesprochen - damit verbundenen «synchrone[n] Kontextualisierungen», ${ }^{1321}$ also Verknüpfungen innerhalb einer Zeitebene. ${ }^{1322}$ Informationen werden dabei gleichermassen und strukturgleich aus Ausstellungstexten, Quellenmaterialien oder auch dem Vorwissen der Besuchenden gewonnen. Nicht zwingend verbinden sich Feststellungen von Vergangenheitspartikeln und synchrone Zustandsbeschreibungen auch mit «diachrone[n] Kontextualisierungen ${ }^{1323}$ in dem Sinn, dass die festgestellten Partikel explizit in Zeitverlaufsvorstellungen eingebunden würden.

Obwohl Bezüge zur Gegenwart nicht den Hauptmodus des Sprechens über Geschehen ausmachen, interessieren für mein Projekt doch dezidiert diejenigen Äusserungen, in denen solche Bezüge vorkommen, weshalb ich ihnen auch im Rahmen der Zusammenfassung besondere Aufmerksamkeit widme. Auf den vorausgegangenen Seiten habe ich insgesamt fünf strukturelle Bereiche herausgearbeitet, innerhalb deren Besuchende Verknüpfungen zwischen Vergangenheit und Gegenwart herstellen. Dies waren

- Äusserungen über Ähnlichkeiten und Gemeinsamkeiten zwischen Vergangenheit und Gegenwart,

- Äusserungen über Wurzeln und Vorläufer der Gegenwart,

- Äusserungen über Unterschiede zwischen Vergangenheit und Gegenwart,

- Äusserungen über den Umgang der Gegenwart mit der Vergangenheit und

- Äusserungen über Überzeitliches/Universelles/Allgemeingültiges,

Letztere noch verbunden mit einem Exkurs über Raum und Zeit als überzeitliche Parameter.

Innerhalb dieser Aufreihung lassen sich zwei verschiedene Gruppen von Deutungsstrukturen unterscheiden. Auf der einen Seite gibt es Äusserungen, die zwar in verschiedenen Ausprägungen, aber doch alle in irgendeiner Weise von einer Konstanz bzw. Kontinuität historischer Zustände ausgehen. Dies ist der Fall, wenn Besuchende universell gültige Aussagen über Geschehen formulieren, wenn Ähnlichkeiten bzw. Gemeinsamkeiten zwischen Vergangenheit und Gegenwart formuliert werden und wenn Besuchende über Wurzeln und Vorläufer der Gegenwart sprechen. Zwar implizieren die letztgenannten beiden Kategorien nicht zwingend

1320 Schreiber 2007b, S. 207.

1321 Körber et al. 2007, S. 862 f.

1322 Schöner 2013b, S. 109.

1323 Körber et al. 2007, S. 863. 
eine durchgehende Kontinuitätslinie zwischen Vergangenheit und Gegenwart bzw. über alle Zeiten hinweg, jedoch werden mögliche Brüche zumindest nicht thematisiert. Und auch obwohl das Sprechen über Wurzeln und Vorläufer der Gegenwart die Vorstellung impliziert, dass Zustände zumindest nicht immer so gegeben waren, sondern irgendwann entstanden sein müssen, thematisieren die Besuchenden bei diesen Äusserungen stärker das gleich Gebliebene als mögliche in der Zwischenzeit geschehene Verwerfungen.

Die dieser Gruppe zugehörigen Äusserungen machen den deutlich grössten Anteil an hergestellten Gegenwartsbezügen aus, was sich mit den Befunden Bert Pampels in Bezug auf Gedenkstättenbesuchende deckt. Von diesen hergestellte Gegenwartsbezüge seien Pampel zufolge nämlich «vor allem durch Analogiebildung, Kontinuität und Gemeinsamkeiten charakterisiert, Unterschiede werden tendenziell nivelliert». ${ }^{1324}$ Ein Zusammendenken von Gemeinsamkeiten/Ähnlichkeiten und Unterschieden findet sich nur sehr vereinzelt, eine Einsicht in die Gleichzeitigkeit und systematische Verschränkung von «Continuity and Change», wie dies Peter Seixas und Tom Morton als einen Baustein historischen Denkens postulieren, ${ }^{1325}$ kommt insofern in den expliziten Äusserungen der Besuchenden im Zusammenhang mit Gegenwartsbezügen ${ }^{1326}$ praktisch nicht zum Tragen.

Einen zweiten Bereich bilden all diejenigen Äusserungen, in denen die Andersartigkeit zwischen Vergangenheit und Gegenwart betont wird, entweder indem die Besuchenden aus einem Vergleich von Vergangenheit und Gegenwart zur Feststellung von Unterschieden kommen oder indem sie über gegenwärtige Umgangsweisen der Gegenwart mit der Vergangenheit sprechen. Auch dieser zuletzt genannten Kategorie ist wiederum noch nicht die Feststellung einer Unterschiedlichkeit zwingend inhärent, jedoch wird sie im konkreten Datenmaterial überwiegend in dieser Art und Weise verwendet, nämlich indem die Besuchenden feststellen, die Vergangenheit könne aus der Perspektive der Gegenwart mit Abstand bzw. mit anderen Augen betrachtet werden.

Betrachtet man die jeweils angesprochenen Themen und vergleicht diese miteinander, so ergibt sich ein bemerkenswerter Befund. Je nach Art der Verknüpfung zwischen den Zeitebenen kommen nämlich unterschiedliche Gegenstände zur Sprache beziehungsweise werden dieselben Gegenstände unterschiedlich eingeordnet und gewertet. Parallelen, Ähnlichkeiten, Konstanten oder Kontinuitäten

1324 Pampel 2007, S. 358, dazu ausserdem S. 312 ff., S. 319.

1325 Seixas/Morton 2013, S. 76 ff., insb. S. 79, S. 81 f., direktes Zitat S. 77.

1326 Für die übrigen geschehensbezogenen Äusserungen wäre dies zu prüfen. 
zwischen Vergangenheit und Gegenwart werden von den Besuchenden vornehmlich in Bezug auf Aspekte festgestellt, die sich als problematisch oder mindestens diskussionswürdig ansehen lassen. Nach diesen Argumentationen tauchen Proble$m e$, die damals bestanden haben, heute auch noch oder wieder auf, so etwa Überfremdungsangst, Differenzen zwischen Arm und Reich, Epidemien, moralisch zweifelhafte Waffenexporte, wirtschaftliche Profite durch den Krieg und deren Nachwirkungen, internationale Konflikte.

In Bezug auf das Aussehen von Orten werden sowohl Konstanten als auch Unterschiede festgestellt. Vorrangig Unterschiede kommen in Bezug auf Alltagsleben und -ausstattung, wie etwa Kleidung, Technik oder Ernährungssituation, zur Sprache. Veränderung wird in diesen Äusserungen entweder neutral gewertet oder positiv konnotiert als Weiterentwicklung oder Fortschritt, so etwa in Form technischer Fortschritte, Entwicklungen in der Sozialhilfe und Verbesserung der Ernährungsgrundlagen ( Wir können einfach in den Laden gehen und etwas kaufen, und dort musste man Vorräte ansammeln (...) für den Winter», P3, Absatz 66). Nostalgische Rückblicke auf eine bessere Vergangenheit finden sich demgegenüber lediglich vereinzelt.

Zusammenfassend lässt sich deshalb feststellen: Wenn Besuchende Aspekte vergangenen Geschehens auch in der Gegenwart zu sehen glauben, so handelt es sich hierbei vornehmlich um Problemfelder, die aus ihrer Perspektive nach wie vor Bestand haben. Wenn Besuchende Unterschiede und somit überhaupt historische Veränderung konstatieren, so wird diese tendenziell als Weiterentwicklung und Verbesserung gedeutet. Den Deutungen der Besuchenden liegen insofern Vorstellungen eines sozialen und technischen Fortschritts bei umgekehrt Fortbestand von gesellschaftlichen Problemfeldern zugrunde. Die Zeit des Ersten Weltkriegs wird dabei von den Besuchenden in jedem Fall tendenziell negativ gewertet. Im Vergleich mit der Gegenwart sind dann diese negativen Aspekte immer noch oder wieder vorhanden oder haben sich zum Besseren hin entwickelt.

Auffallend ist dabei allerdings, dass die Besuchenden kaum einmal selbst Entwicklungsverläufe darstellen, wenn sie Vergangenheit und Gegenwart aufeinander beziehen. Entweder gehen sie im Rahmen von überzeitlichen Aussagen von etwas sowieso immer Gleichbleibendem aus. Oder sie greifen zwei Zeitebenen heraus, eine Zeitebene innerhalb der Vergangenheit und die Gegenwart, stellen diese singulär gegenüber und kommen zur Feststellung von Gemeinsamkeiten oder Unterschieden. Entwicklungsverläufe im eigentlichen Sinn, nämlich in der Gestalt, 
dass Verbindungslinien zwischen Vergangenheit und Gegenwart aufgezeigt würden, finden sich im Datenmaterial kaum. ${ }^{1327}$

Inwiefern lassen sich diese Befunde nun an vorhandene Theorien anbinden? Jörn Rüsen unterscheidet «vier Typen der historischen Sinnbildung» ${ }^{1328}$ bzw. «Erzählweisen»: «Traditionales Erzäblen», «Exemplarisches Erzäblen», "Genetisches Erzäblen» und «Kritisches Erzäblen». ${ }^{1329}$ Nachfolgend lege ich diese Typen dar und erörtere, inwiefern die von mir gemachten Befunde mit diesen kongruent sind, abweichen oder möglicherweise ergänzende Perspektiven eröffnen.

In der traditionalen Sinnbildung bzw. im traditionalen Erzäblen ${ }^{1330}$ wird Rüsen zufolge Geschichte als Kontinuität erzählt, als «Dauer einer Lebensordnung», wobei die Gegenwart in dieser Hinsicht als Fortschreibung des bereits Gewesenen thematisiert und auch die Zukunft als solche intendiert wird. ${ }^{1331}$

Auch die exemplarische Sinnbildung bzw. das exemplarische Erzäblen ${ }^{1332}$ geht von einem regelhaft ablaufenden historischen Geschehen aus. Allerdings geht es hier weniger als in der traditionalen Sinnbildung um ein regelhaft ablaufendes, bewährtes Modell, das fortgeschrieben werden soll, sondern vielmehr um ein ganzes Set aus - hier nun sowohl guten als auch schlechten - Varianten, aus dem sich Geschehen bedient, wobei die Aufgabe der Gegenwart darin besteht, dieses Set an Regeln zu kennen und sich unter Rückgriff auf diese Beispiele zu orientieren und zu handeln. ${ }^{1333}$

Die genetische Sinnbildung oder das genetische Erzählen ${ }^{1334}$ integriert Aspekte der zuvor genannten Sinnbildungstypen und wandelt sie gleichzeitig ab. Genetische Sinnbildung begreift im Gegensatz zur traditionalen Sinnbildung Veränderung «positiv als Chance und nicht als Bedrohung», geht aber gleichwohl vom Fortschreiben vorhandener Strukturen aus, wobei die fortzuschreibende Struktur

1327 Möglicherweise sind solche Darstellungen von Entwicklungsverläufen im Datenmaterial dort enthalten, wo die Besuchenden zwei Zeitebenen innerhalb der Vergangenheit (tl und t2) in Bezug zueinander setzen. Da für mein Forschungsvorhaben die Bezüge zur Gegenwart interessieren, wurden jedoch nur die Gegenwart thematisierende Textstellen überhaupt einer derartigen Feinanalyse unterzogen.

1328 Rüsen 2013, S. 209 ff., direktes Zitat S. 209.

1329 Rüsen 2012, S. 170 ff.; direkte Zitate S. 170, S. 171, S. 172, S. 175, S. 178, Kursivsetzungen analog zum Original; zu den vier Formen auch Rüsen 2013, S. 209 ff. In seiner Veröffentlichung aus dem Jahr 2012 spricht Rüsen jeweils von Erzählen, 2013 von Sinnbildung.

1330 Rüsen 2012, S. 171 ff.; Rüsen 2013, S. 210 f.

1331 Rüsen 2012, S. 171 ff.; Rüsen 2013, S. 210 f.; direktes Zitat: Rüsen 2013, S. 210.

1332 Rüsen 2012, S. 172 ff.; Rüsen 2013, S. 211 f.

1333 Rüsen 2012, S. 172 ff.; Rüsen 2013, S. $211 \mathrm{f}$.

1334 Rüsen 2012, S. 178 ff.; Rüsen 2013, S. 212 f. 
hier der Wandel ist, also die «Vorstellung eines kontinuierlichen Übergangs von der einen Qualität zur andern» zugrunde liegt und Kontinuität «als eine Richtung von Veränderungen» verstanden wird. ${ }^{1335}$ «Die Ereignisse der Vergangenheit in ihrer zeitlichen Bewegtheit erscheinen nicht mehr auf der Folie unbewegter praktischer Gesetzmässigkeiten der menschlichen Lebensform. Sie manifestieren vielmehr eine Dynamik der Veränderung.» ${ }^{1336}$

Von Andreas Körber stammt der hilfreiche Versuch, diese Sinnbildungsformen - am Beispiel der Fragekompetenz - in einem Satz auf den Punkt zu bringen. Unter traditionaler Sinnbildung versteht er, «nach den Ursprüngen gegenwärtig gültiger Normen und Werte bzw. zutreffender Zustände, Strukturen etc. zu fragen», unter exemplarischer Sinnbildung versteht er, «nach zeitübergreifenden Regeln zu fragen», und unter genetischer Sinnbildung versteht er, "grundsätzliche, gerichtete Veränderungen gesellschaftlicher und geistiger Verhältnisse, Lebens- und Denkweisen zu denken». ${ }^{1337}$

Beim vierten der von Jörn Rüsen genannten Typen, der kritischen Sinnbildung oder dem kritischen Erzäblen, ${ }^{1338}$ geht es, sehr allgemein gesprochen, um die Kritik an bestehenden Erzählungen. Dieser Modus ist allerdings am schwierigsten eindeutig zu fassen. Zum einen hat Rüsen selbst der kritischen Sinnbildung im Verlauf der Zeit unterschiedlichen Stellenwert beigemessen und weist diesem Typus nun eine «Sonderstellung» ${ }^{1339} \mathrm{zu}$ : "Er steht nicht für sich selber, sondern realisiert sich durch einen negierenden Bezug auf die drei anderen.» ${ }^{1340}$

Das Konzept der kritischen Sinnbildung ist aber zum anderen auch deshalb komplex, weil es, wie Körber darlegt, zwei verschiedene Dimensionen beinhaltet $^{1341}$ und die Thematisierung der «Sonderstellung» bei Rüsen sowie in dessen Rezeption «zu kurz» greife. ${ }^{1342}$ Nach Unterscheidung Körbers, aufbauend auf

1335 Rüsen 2012, S. 179.

1336 Rüsen 2013, S. 212.

1337 Körber 2016, S. 38 f. Körber betrachtet die Sinnbildungstypen als dritte Dimension neben den vier historischen Kompetenzbereichen und deren Stufen liegend (Körber 2016, S. 35), führt aber seine Überlegungen nur anhand der Fragekompetenz weiter aus.

Körber grenzt sich damit von Hasberg ab, der die vier Sinnbildungstypen als mit Niveaustufen identisch betrachtet (Hasberg 2012, S. 142; rezipiert bei Körber 2016, S. 29 ff.).

1338 Rüsen 2012, S. 175 ff.; Rüsen 2013, S. 213.

1339 Körber 2016, S. 28.

1340 Rüsen 2013, S. 213.

1341 Körber 2013, S. 3 ff.; Körber 2014, S. 28.

1342 Körber 2014, S. 28. 
Überlegungen Bodo von Borries', ${ }^{1343}$ kann kritisches Erzählen zwei Ebenen betreffen. Es kann einerseits Erzählungen erschüttern, dabei aber im selben Sinnbildungsmodus bleiben, beispielsweise eine traditionale Erzählung erschüttern und durch eine alternative traditionale Erzählung ersetzen. Oder aber es kann andererseits auf einer Metaebene das eingesetzte Erzählmuster erschüttern, beispielsweise den Modus traditionalen Erzählens infrage stellen. Ersteres wäre bei Körber «kritisch-traditionales Erzählen: eine bestimmte Tradition kritisierend, aber in der Logik traditionalen Erzählens verbleibend». ${ }^{1344}$ Zweiteres wäre «[t]raditionalitätskritisches-Erzählen: die Logik traditionaler Sinnbildung kritisierend». ${ }^{1345}$ Analog dazu differenziert Körber kritisches Erzählen auch in Bezug auf die anderen beiden Sinnbildungstypen. ${ }^{1346}$

Folgende Definition Rüsens aus dem Jahr 2013 lässt sich dem zweitgenannten Bereich zuordnen:

«Der vierte Typ des historischen Erzählens, der kritische, nimmt eine Sonderstellung ein. Er steht nicht für sich selber, sondern realisiert sich durch einen negierenden Bezug auf die drei anderen. Kritisches Erzählen destruiert und dekonstruiert jeweils kulturell vorgegebene traditionale, exemplarische und genetische Deutungsmuster.» ${ }^{1347}$

Andernorts neigt Rüsen eher dem erstgenannten Bereich zu, wenn er etwa schreibt, Gegengeschichten würden «die Bildung neuer Kontinuitätsvorstellungen durch Wegarbeiten der andern» möglich machen. ${ }^{1348}$ Ich schliesse mich nachfolgend der Unterscheidung Körbers an, wenn ich beide Dimensionen als mögliche Ausprägungen kritischer Sinnbildung im Auge behalte.

Rüsen unterscheidet diese vier Sinnbildungsmuster idealtypisch und analytisch, geht aber gleichwohl davon aus, dass sie sich im historischen Erzählen miteinander auf variantenreiche Weise kombinieren können. ${ }^{1349}$ Für meine Überlegungen stellt

1343 Borries 1988, S. 60 f. Borries legte dort bereits dar, dass sich jeder der Sinnbildungsmodi für sich genommen kritisch wenden lässt. Diese Idee, dass alle Erzählmodi kritisch gewendet werden können, wurde neben Körber auch bereits von Pandel aufgegriffen (Pandel 2002, S. 45).

1344 Körber 2013, S. 4.

1345 Körber 2013, S. 4.

1346 Körber 2013, S. 4 f.; Körber 2016, S. 28 f., S. 38 f.

1347 Rüsen 2013, S. 213. Kursivsetzungen analog zum Original.

1348 Rüsen 2012, S. 175 f., direktes Zitat S. 176.

1349 Rüsen 2013, S. 214; Rüsen 2012, S. 182. 
sich also einerseits die Frage, ob die von mir festgestellten Bezüge zwischen Vergangenheit und Gegenwart sich den skizzierten Sinnbildungsmustern zuordnen lassen, ob sie möglicherweise eine Kombination aus mehreren Mustern darstellen oder hingegen davon abweichende weitere Dimensionen und Perspektiven enthalten.

Die wohl auffallendste Abweichung besteht darin, dass Rüsens Sinnbildungsmuster sehr viel stärker auf eine Orientierung in der Gegenwart abzielen, als dies in den von mir im Datenmaterial identifizierten Textstellen der Fall ist. Für Rüsen ist der Bezugspunkt historischen Denkens und Sinnbildens die Lebenspraxis und Gegenwart, ${ }^{1350}$ und dies manifestiert sich auch in den von ihm vorgeschlagenen vier Sinnbildungstypen. Es geht darin um die Legitimierung oder Delegitimierung, die Stützung oder Kritik gegenwärtiger Verhältnisse. Rückgriffe auf vergangenes Geschehen dienen dem Zweck, für die Gegenwart Orientierung zu stiften und Handlungsmöglichkeiten aufzuzeigen, sei es in Form eines Fortschreibens des immer schon so Gewesenen, wie im Fall der traditionalen Sinnbildung, sei es als Gestalten der Gegenwart unter Rückgriff auf ein durch ein bekanntes Set an guten und schlechten Beispielen, wie im Fall der exemplarischen Sinnbildung, sei es durch radikale Infragestellung vorhandener Sinnbildungsmuster, wie im Fall der kritischen Sinnbildung, oder sei es durch Einsicht in bzw. Realisierung einer Dauer durch Wandel, wie im Fall der genetischen Sinnbildung. Immer hat der Rückgriff auf vergangenes Geschehen funktionelle Bedeutung im Hinblick auf aktuelle Anliegen der Gegenwart und deren Gestaltung und geht von diesen aus.

Explizites Ausgehen von Anliegen der Gegenwart kann ich in der Weise hingegen in dem von mir analysierten Material nicht ausfindig machen. Zwar stellen die Besuchenden, wie ich weiter oben ausführlich dargestellt habe, vielerlei Bezüge zwischen Vergangenheit und Gegenwart her. Sie tun dies aber ausgehend von einer Einsicht in Bezug auf vergangenes Geschehen und stellen dann gleich gebliebenes oder Verändertes fest. Dass daraus systematische Schlüsse für die Gestaltung der Gegenwart abgeleitet werden, lässt sich überhaupt nur in einer kleinen Anzahl von Äusserungen feststellen, in denen Besuchende Handlungsempfehlungen bzw. Lehren für die Gegenwart formulieren. Aber auch in diesen Fällen wird argumentativ nicht von der Gegenwart und einer aktuellen Herausforderung ausgegangen und zu deren Lösung bewusst auf die Vergangenheit zurückgegriffen, sondern die Schlussfolgerungen für die Gegenwart entstehen aus einer Beschäftigung mit

1350 Kondensiert sichtbar bei Rüsen 2013, S. 68. Diesen Aspekt habe ich weiter oben bereits ausführlicher dargelegt, vgl. Abschnitt 2.2. 
historischem Geschehen heraus. Daneben finden sich Beschreibungen heutiger Geschichtskultur, also heutigen Umgangs mit Vergangenem, die allerdings nur teilweise in Wertungen oder Schlussfolgerungen münden, in anderen Fällen deskriptiven Charakter haben.

Zusammenfassend lässt sich feststellen, dass die Gegenwart in den Äusserungen der Besuchenden über Geschehen (Fokus I) überwiegend in vergleichender Perspektive eine Rolle spielt. Es wird festgestellt, dass etwas heute anders oder genauso sei wie damals, aber es werden darüber hinaus kaum einmal weitergehende Schlüsse gezogen, wie etwa Handlungsüberlegungen abgeleitet.

Gleichwohl finden sich Teilaspekte der Rüsen'schen Sinnbildungsmuster auch in meinem Datenmaterial. So klingen in den von den Besuchenden gemachten Äusserungen zu überzeitlich gültigen Mustern Elemente einer traditionalen Sinnbildung an, auch wenn die Besuchenden nicht auf eine Fortschreibung der beschriebenen Strukturen in der Gegenwart abzielen, aber doch, indem sie überhaupt von der Existenz zeitübergreifend gültiger, gleichbleibender Muster ausgehen. Noch besser zu diesen Phänomenen scheint mir allerdings ein weiterer Sinnbildungsmodus zu passen, der sich bei Andreas Körber findet und als «Konstanz-Erzählen» betitelt wird, als «Behaupten anthropologischer Konstanz». ${ }^{1351}$

Feststellungen von Gemeinsamkeiten zwischen Vergangenheit und Gegenwart können sich hingegen sowohl aus einer traditionalen als auch einer exemplarischen Sinnbildung speisen. Dass etwas von den Besuchenden als in der Gegenwart <auch wieder so〉 erkannt wird, kann einerseits auf Vorstellungen von zeitübergreifenden Mustern hindeuten oder aber auf die Vorstellung, dass eine von vielen möglichen historischen Varianten, die sich in der Vergangenheit ausgeprägt hat, in der Gegenwart ebenfalls wieder verwirklicht.

Feststellungen von Unterschieden zwischen Vergangenheit und Gegenwart und darin eingelagerte Vorstellungen von einem Fortschritt bzw. einer Weiter-/Höherentwicklung lassen sich am ehesten dem genetischen Sinnbildungstypus zuordnen, für den es kennzeichnend ist, "Zeitverläufe als Fortschritt [zu] deuten», ${ }^{1352}$ auch wenn die Erzählungen der Besuchenden nicht das in der Rüsen'schen Idealform vorgesehene Nachdenken über die Notwendigkeit eines solchen Wandels ${ }^{1353}$ beinhalten und in der Konzeption Rüsens meines Erachtens Wandel weit weniger zwingend Wandel zum Besseren meint, als dies in meinem Datenmaterial der Fall ist. 
Und auch Elemente einer kritischen Sinnbildung finden sich im Datenmaterial, und zwar auf beiden Ebenen: in dem Sinn, dass die Besuchenden in der Ausstellung enthaltene Deutungen, aber auch Deutungsmuster erkennen und infrage stellen. Entsprechende Äusserungen lassen sich in der Systematik des dreipoligen Fokussierungsmodells allerdings als Äusserungen im Fokus II in Bezug auf die Ausstellung klassifizieren und wurden aus diesem Grund bislang noch nicht näher in den Blick genommen. ${ }^{1354}$

Neben Ansätzen einer traditionalen, exemplarischen, genetischen und kritischen Sinnbildung finde ich im Datenmaterial Anklänge an eine Typologie von Sinnbildungen, die Dirk Lange vorschlägt. Lange unterscheidet, auf Rüsen Bezug nehmend und sich von diesem abgrenzend, einen «zirkuläre[n] Sinnbildungsmodus», einen «lineare[n] Sinnbildungsmodus» und einen «punktuelle[n] Sinnbildungsmodus». ${ }^{1355}$ Während ich in der Konzeption des zirkulären und linearen Modus weitreichende Anklänge an die traditionale, exemplarische und genetische Sinnbildung bei Rüsen sehe, erscheint mir doch mindestens Langes Idee einer punktuellen Sinnbildung als geeignet, um neue Perspektiven zu eröffnen und einige meiner Befunde einordnen zu können.

Punktuelle Sinnbildung besteht Lange zufolge darin, dass keine zusammenhängenden Zeitverläufe aus mehreren aneinandergereihten Zeitebenen erzählt werden, sondern Gegenwart und einzelne, singuläre Phänomene der Vergangenheit aufeinander bezogen werden ${ }^{1356}$ :

«Die Sinnbildung gleicht dabei einer Punktion, durch die der Vergangenheit einzelne Erfahrungseinheiten entnommen werden. Diese werden so verzeitlicht, dass sie als Analogien von Gegenwartsphänomenen erscheinen. Der zeitverbindende Zusammenhang kann dabei sowohl durch das Aufzeigen von Gleichem als auch durch das Erkennen von Differentem hergestellt werden. Somit resultiert die Kontinuitätsvorstellung aus dem Vergleich und nicht aus der Gleichsetzung differenter Phänomene. [...] Im Unterschied zur zirkulären und linearen Sinnbildung, die beide danach streben, sämtliche Perlen zu einem historischen Sinnganzen auf dem roten Faden zu vereinen, bleiben die punktuellen Sinnbezüge fragmentarisch.» ${ }^{1357}$

1354 Vgl. hierzu den folgenden Abschnitt 8.6.

1355 Lange 2004, S. 24 ff., v. a. S. 32 ff., direkte Zitate S. 32 u. S. 33.

1356 Lange 2004, S. 33.

1357 Lange 2004, S. $33 \mathrm{f}$. 
Auch wenn Langes Ausführungen offenlassen, inwiefern festgestellte Differenzen zwischen Zeitebenen als «Analogien» fungieren und in eine «Kontinuitätsvorstellung» eingebaut werden können, seine Argumentation insofern meines Erachtens fragmentarisch bleibt, erscheint mir seine Überlegung doch hilfreich insofern, als sie einer Form des Bezugs zwischen Gegenwart und Vergangenheit Rechnung trägt, die sich auffallend auch in dem von mir analysierten Datenmaterial findet, nämlich «das Aufzeigen von Gleichem» bzw. von «Analogien» sowie «das Erkennen von Differentem» ohne Berücksichtigung der dazwischenliegenden Entwicklungsschritte. ${ }^{1358}$

In der punktuellen Form, wie Gegenwartsbezüge in dem von mir analysierten Material erscheinen, weisen sie zugleich Ähnlichkeiten mit dem auf, was andernorts Bert Pampel für die von Gedenkstättenbesuchenden hergestellten Gegenwartsbezüge konstatiert hat, nämlich «dass viele Gesprächspartner den historischen Ereignissen durchaus Bedeutung für die Gegenwart beimassen», dass diese Bezüge «allerdings nur selten mit gründlichen Reflexionen oder gar persönlichen Schlussfolgerungen» verbunden waren, im Gegenteil «oftmals den Charakter von flüchtigen Assoziationen [trugen], die nicht systematisch durchdacht werden». ${ }^{1359}$

\section{6 Äusserungen im Fokus II über die Ausstellung und ihre Elemente und ihr Verhältnis zu geschehensbezogenen Äusserungen}

\subsubsection{Varianten im Überblick}

Während im vorigen Abschnitt Äusserungen der Besuchenden über Geschehen systematisiert und strukturiert wurden, steht nun die zweite von drei Fokussierungen im Mittelpunkt der Darstellung, in der sich Besuchende der Ausstellung zuwenden und in irgendeiner Weise über die vorhandene physische Struktur sprechen, ${ }^{1360}$ sei es, dass sie sich über die Ausstellung als Ganzes, oder die Räum-

1358 Lange 2004, S. 33.

1359 Pampel 2007, S. 319.

1360 Diese Äusserungen sind nicht deckungsgleich und insofern nicht zu verwechseln mit denjenigen, die bei der Betrachtung der Elementbezüge und Aktivitätsformen (Abschnitt 8.3.2) als freies Sich-Äussern im Zusammenhang mit diversen Elementtypen und in Bezug auf Abteilungen und Ausstellung identifiziert wurden. Dort ging es um die Frage, welche Äusserungen in Bezug auf oder ausgehend von der Beschäftigung mit einem Element zustande kommen. Dies bedeutet aber nicht zwangsläufig, dass die Besuchenden dabei 
lichkeiten, einzelne Elemente innerhalb der Ausstellung usw. äussern. ${ }^{1361}$ Die Ausdifferenzierung der Kategorie erfolgte, wie generell bei der Analyse der gewählten Fokussierungen, in enger Anbindung an das Datenmaterial. Ich liste nachfolgend zunächst die gefundenen Kategorien auf, um einen Gesamtüberblick über das Spektrum möglicher Äusserungen zu geben. Einzelne Kategorien darunter greife ich im Anschluss heraus und stelle sie differenzierter vor.

Einen Grossbereich der Äusserungen stellen solche dar, mit denen sich Besuchende in irgendeiner Weise über den Elementbestand der Ausstellung äussern, also über einzelne Quellen oder sonstige Elemente sprechen, die sie innerhalb der Ausstellung vorfinden. Genauer handelt es sich hierbei um Äusserungen, in denen die Besuchenden

- die vorgefundenen Elemente benennen und identifizieren, ${ }^{1362}$

- $\quad$ sie explizit in ihrem Status als Quellen/Originale/Reproduktionen usw. identifizieren,

- die Funktion des jeweiligen Elements in der Ausstellung benennen,

- die Elementauswabl bzw. -präsentation durch die Ausstellung ansprechen,

- die Elementbeschriftung bzw. -erläuterung durch die Ausstellung thematisieren,

- Elementzusammenhänge und -kobärenzen ${ }^{1363}$ thematisieren,

- $\quad$ sich zur Textgestaltung äussern oder

- über die (technische) Funktionsweise von Elementen sprechen.

auch explizit im Fokus II $\ddot{u} b e r$ dieses Element als Element sprechen. Explizite Äusserungen über Elemente als Elemente bilden insofern einen Teilbereich innerhalb der Elementbezïge.

1361 Knapp beschrieben und mit anderen Materialbeispielen veranschaulicht wird der Fokus II auch in Thyroff 2017c, S. 4, S. 8 f.

1362 Für die Ausweisung des Identifizierens als eigene Kategorie wurde ich durch die Arbeit von Wise inspiriert, die als einen Teilbereich des Sinnbildungsmodus «Interpreting» unter anderem «Identifying and describing» benennt (Wise 2011, S. 97 f.).

1363 Der Begriff der Kohärenz ist inspiriert durch das bereits weiter oben erwähnte Eichstätter Projekt zur Schulbuchanalyse. Dort werden Kohärenzen, bezogen auf Schulbuchdarstellungen, als «Zusammenhänge verschiedener Elemente der Oberflächenstruktur und deren Zusammenspiel mit den verschiedenen Ebenen der Tiefenstruktur» verstanden (Schöner 2013a, S. 81). Übertragen auf Ausstellungen, meinen Kohärenzen dann die Zusammenhänge zwischen einzelnen Elementen der Ausstellung, seien diese Zusammenhänge formaler und/oder inhaltlicher Art, und geht es um die Frage, wie und inwieweit die Besuchenden über diese Kohärenzen sprechen. 
Den zweiten Grossbereich an Äusserungen bilden diejenigen zur inhaltlichen und thematischen Struktur der Ausstellung. Darin kommen Äusserungen vor, in denen die Besuchenden

- von der Ausstellung behandelte Themen identifizieren/benennen,

- spezifischer übergreifende Themen/Leitthemen identifizieren/benennen,

- $\quad$ sich zu von der Ausstellung vorgenommenen Deutungen äussern,

- $\quad$ sich darin spezifischer zu in der Ausstellung angelegten Gegenwartsbezügen äussern,

- $\quad$ sich zu Leerstellen/ «Nicht-Themen» der Ausstellung äussern,

- $\quad$ sich zur von der Ausstellung gewählten Reihenfolge und Struktur der Thematisierung äussern,

- sich zu vorkommenden Wiederholungen äussern,

- $\quad$ sich in eher abstrakter Weise zur Gesamtstruktur der Ausstellung äussern.

Neben den genannten zwei grossen und stark ausdifferenzierten Bereichen, den Äusserungen zum Elementbestand und der inhaltlich-thematischen Struktur der Ausstellung, konnte noch eine Reihe weiterer Äusserungen der Besuchenden hinsichtlich der Ausstellung festgestellt werden, nämlich

- zur ästhetischen und räumlichen Gestaltung der Ausstellung,

- zum Zusammenhang aus dargestelltem Inhalt und gewählter ästhetischer Form,

- $\quad$ zu der in der Ausstellung vorhandenen Informationsfülle/Dichte/Komplexi$t \ddot{a} t$,

- zu (potenziellen) Adressatinnen und Adressaten und deren Rezeption der Ausstellung, den Bezug der Ausstellung zu diesen sowie die gewählte Besuchendenführung,

- zu Intentionen der Ausstellung,

- zu an der Ausstellung beteiligten Personen wie Ausstellungsmachende und Museumspersonal,

- zu anderen besuchten Ausstellungen, die vergleichend herangezogen werden.

Im späteren Verlauf des Abschnitts greife ich ausgewählte Bereiche der genannten ausstellungsbezogenen Aussagen differenzierter auf, beispielsweise wenn sich diese als auffallend oft vorkommend erwiesen haben, so konkret die element- und themenidentifizierenden Tätigkeiten, oder wenn sie zur Erhellung der Frage dienen, wie Besuchende mit in der Ausstellung angelegten Gegenwartsbezügen um- 
gehen. ${ }^{1364}$ Zuvor wende ich mich jedoch der Auslotung von Verhältnissen zu: zwischen ausstellungs- und geschehensbezogenen Äusserungen einerseits sowie deren Verhältnis mit positivistischen und konstruktivisitischen Zugängen andererseits.

\subsubsection{Ausstellungsbezogene Äusserungen in Bezügen. Zum Verhältnis von Fokus I und Fokus II zu konstruktivistischen und positivistischen Zugängen}

Ausgehend von dem oben geschilderten Spektrum von Kategorien, in denen Besuchende $\ddot{u} b e r$ die Ausstellung sprechen, stellt sich die Frage, inwiefern sich in Äusserungen über die Ausstellung zugleich ein Bewusstsein über die Gemachtheit von Geschichte und insofern konstruktivistische Grundhaltungen widerspiegeln, während Äusserungen im Fokus I über Geschehen demgegenüber eher positivistische Überzeugungen entsprechen würden. Diesem Verhältnis gehe ich im vorliegenden Kapitel näher nach. Zudem widme ich mich den Grenzen zwischen ausstellungsund geschehensbezogenen Äusserungen und deren Verhältnis zueinander.

Ein vergleichender Blick auf alle 18 Besuchenden zeigt, dass es auffallende Unterschiede zwischen ihnen dahingehend gibt, wie viel Raum sie den beiden Fokussierungen im Verhältnis zueinander einräumen. So gibt es Personen, die den Ausstellungsbesuch in deutlich überwiegender Weise geschehensfokussiert angehen (P5, P18, P20, P22, P25, P26, P27), umgekehrt eine andere Person, die sich beinahe ausschliesslich ausstellungsbezogen äussert (P4). Wieder andere Personen bewegen sich stärker ausgewogen in beiden Dimensionen. ${ }^{1365}$

1364 Ich verzichte somit darauf, systematisch zu jeder der angeführten Kategorien Beispiele aus dem Datenmaterial zu zeigen, und verweise zu diesem Zweck auf die im digitalen Anhang unter den entsprechenden Analysekategorien zu findenden Beispiele.

1365 Die Rede ist hier vom aufgewendeten Textvolumen. Als sauffallend bezeichne ich hier Personen, die mindestens dreimal so viel Raum, vereinzelt auch mehr, für Äusserungen über Geschehen (Fokus I) gegenüber denjenigen über die Ausstellung und ihre Elemente (Fokus II) verwenden oder umgekehrt. Die genannte Schwelle wurde so gewählt, dass nur wirklich ausgeprägte Fälle erfasst werden und zugleich die Zuordnung möglichst vieler Besuchender eindeutig ausfällt. Personen, die sich ausschliesslich auf der Ebene des Geschehens oder der Ausstellung äussern würden, kommen nicht vor, wohl aber zeigen sich in der beschriebenen Weise individuelle Schwerpunkte. Aufgrund der Studienanlage und der bei der Codierung festgestellten Schwierigkeiten in der exakten Zuordnung von Äusserungen zwischen dem Fokus I und II, auf die ich an verschiedenen Stellen der Arbeit zu sprechen komme (z. B. Abschnitt 8.6.2.3), sind die hier formulierten Angaben selbstverständlich als vorsichtige Tendenzen zu betrachten. 
Die Unterscheidung in stärker geschehens- oder ausstellungsfokussierte Besuchende ist dabei keineswegs gleichbedeutend mit einer Zuordnung zu konstruktivistischen Zugängen. Vielmehr gilt es, das Verhältnis differenzierter zu beleuchten. Zur Einordnung der Konzepte des Konstruktivismus und Positivismus greife ich auf Arbeiten aus geschichtsdidaktischem Blickwinkel zurück, nämlich von Martin Nitsche und Bärbel Völkel.

Nitsche unterscheidet empirie- und theoriegestützt nicht nur zwei, sondern gar drei geschichtstheoretische Positionen: «Positivismus», «Skeptizismus», "Narrativer Konstruktivismus». ${ }^{1366}$ Für erstgenannte Position führt er als Kennzeichen ein Nicht-Vorhandensein der Differenzierung in Vergangenheit und Geschichte an. ${ }^{1367}$ Es werde davon ausgegangen, «dass historisches Wissen in den Quellen der Vergangenheit direkt erschlossen werden könne, da dort die Vergangenheit direkt wahrnehmbar sei». ${ }^{1368}$ Nitsche spitzt diese Haltung mit den Formeln «Vergangenheit ist Geschichte» und «Darstellung als Abbildung» zu. ${ }^{1369}$ Demgegenüber würden Skeptizistinnen und Skeptizisten verneinen, dass überhaupt «Aussagen über Vergangenes aus Quellen erschlossen werden können», vielmehr gelte Geschichte als individuell und «Ansichtssache», und es werde davon ausgegangen, dass «Geschichtsschreibung nichts über die Vergangenheit aus[sagt], sondern nur über ihre Entstehungszeit». ${ }^{1370}$ Der narrativ-konstruktivistischen Position weist Nitsche dazwischen eine «Mittlerposition» zu:

«Sie erkennt die Standortgebundenheit, Selektivität und Partialität der Vergangenheitswahrnehmungen der Quellenproduzent/innen und die Retrospektivität der Geschichtsschreibung an. Deshalb unterscheidet sie Vergangenheit von Geschichte als Erzählung über Vergangenes, die sowohl etwas über die Vergangenheit, von der sie handelt, als auch die Zeit, in der sie geschrieben wurde, berichtet..$^{1371}$

In dieser Position wird davon ausgegangen, dass man basierend auf Quellen zu einer «Rekonstruktion von Zusammenhängen durch Verstehen und Erklären» gelangen könne, wobei die entstehende Erzählung eine «intersubjektiv geprüfte

1366 Nitsche 2016, S. 171 ff., direkte Zitate S. 174, Kursivsetzung analog zum Original.

1367 Nitsche 2016, S. 174.

1368 Nitsche 2016, S. 171.

1369 Nitsche 2016, S. 174.

1370 Nitsche 2016, S. 172 und S. 174, direkte Zitate S. 172 u.S. 174.

1371 Nitsche 2016, S. $172 \mathrm{f}$. 
Perspektive» darstelle. ${ }^{1372}$ In alternativer Kategorisierung lassen sich die letztgenannten Positionen meines Erachtens beide dem konstruktivistischen Spektrum zuordnen und respräsentieren dort eine Bandbreite aus einem radikalen oder massvollen Konstruktivsmus. ${ }^{1373}$

Innerhalb der Geschichtswissenschaft ist der Konstruktivismus, so Völkel,

«heute wohl unumstritten. Geschichte existiert, da ihr Objektbereich vergangen ist und nur noch über Quellen und Artefakte in die Gegenwart hineinreicht, ausschliesslich als Erzählung - eben als eine Geschichte. Geschichten jedoch sind stets konstruiert - selbst wenn sie strengsten Konstruktionsrichtlinien, wie z. B. wissenschaftlichen Verifizierungskriterien, unterworfen sind.» ${ }^{1374}$

Ungeachtet dessen, bedarf praktischer menschlicher Lebensvollzug, so macht Völkel gleichwohl deutlich, positivistischer Annahmen, um überhaupt Handlungsfähigkeit zu gewinnen. ${ }^{1375}$ Trotz des Wissens «um den Konstruktcharakter und die mögliche Vorläufigkeit unseres Wissens um die Welt» sei es im alltäglichen Lebensvollzug unumgänglich, «die Komplexität der vagen, vielfach konstruierten Welt zu reduzieren». .1376

Auch wenn auf theoretischer Ebene Einsichten in den Konstruktcharakter von Geschichte vorhanden sind, kann es notwendig sein, so lässt sich aus Völkel schlussfolgern, diese in der Lebenspraxis auszublenden. ${ }^{1377}$ Für den alltäglichen Umgang mit geschichtskulturellen Manifestationen wie historischen Ausstellungen lässt sich, ausgehend von diesen Überlegungen, ein Vorhandensein positivistischer Zugangsweisen erwarten, wobei es Unterschiede dahingegend geben dürfte, inwieweit neben diesen sich auch konstruktivistische Zugänge manifestieren bzw. zumindest eine theoretisch vorhandene Einsicht in den Konstruktionscharakter von Geschichte vorhanden ist.

1372 Nitsche 2016, S. 174.

1373 Mit einer «radikalen Version» des Konstruktivismus beginnt auch Völkel ihre Darstellung und deutet damit implizit an, dass es eine Bandbreite konstruktivistischer Zugänge gibt (Völkel 2009, S. 720).

1374 Völkel 2009, S. $723 \mathrm{f}$.

1375 Völkel 2009, S. 723.

1376 Völkel 2009, S. 723.

1377 Passend dazu stellt Kohler bei Schülern und Schülerinnen folgendes fest: «Das Vorhandensein entsprechend ausgepräger historischer Meta-Konzepte bedeutet [...] nicht automatisch, dass sie auf die museale Präsentation von Geschichte angewandt werden» (Kohler 2016, S. 228). 
Ich gehe diesem Verhältnis anhand meines Datenmaterials nachfolgend differenzierter nach. Ich habe bereits die These vertreten, dass die Unterscheidung in Aussagen über Geschehen und die Ausstellung zwar Anklänge einer Differenzierung zwischen positivistischen und konstruktivistischen Zugängen aufweist, jedoch nicht in eins zu setzen ist. So habe ich etwa bereits dargestellt, dass Besuchende in ihren Äusserungen über Geschehen (Fokus I) durchaus unterschiedliche Sicherheitsgrade über die «Korrektheit» ihrer Aussagen zum Ausdruck bringen und sich selbst oder die Ausstellung bis zu einem gewissen Grad als erzählende Instanzen sichtbar machen, verbunden mit der Feststellung, dass sich daraus noch nicht zwingend Rückschlüsse auf positivistische oder konstruktivistische Grundhaltungen ziehen lassen.

Zur Erhellung des bislang noch nicht beleuchteten Verhältnisses zwischen Äusserungen über die Ausstellung (Fokus II) und geschichtstheoretischen Grundhaltungen wähle ich einen Zugang über Einzelfallbetrachtungen. So hat sich gezeigt, dass in den Äusserungen der Besuchenden über die Ausstellung durchaus unterschiedliche geschichtstheoretische Überzeugungen aufscheinen können, die ich kontrastiv aufzeigen werde. Konkret geht es um Positionierungen der Besuchenden zwischen der Vorstellung einer gültigen historischen Wirklichkeit, die in der Ausstellung repräsentiert werden kann, und umgekehrt der Vorstellung, dass die Ausstellung mit spezifischen Mitteln diese Geschichte auf ihr eigentümliche Art und Weise erzählt und konstruiert.

\subsubsection{1 Äusserungen über die Gemachtheit von Ausstellung und Geschichte}

Ich beginne die Darstellung mit einigen Fallbeispielen, von mir nachfolgend stets als Brennpunkte überschrieben, ${ }^{1378}$ in denen deutlich wird, dass Besuchende in unterschiedlichen Varianten Vorstellungen über die Ausstellung als gestalteten Raum und konstruierte Erzählung zum Ausdruck bringen.

1378 Bei den folgenden personenbezogenen Darstellungen handelt es sich stets um die in Abschnitt 6.4 angekündigten Abschnitte, in denen Äusserungen einzelner Personen innerhalb einzelner Kategorien oder innerhalb mehrerer, inhaltlich zusammengehöriger Kategorien vorgestellt werden. Es handelt sich dabei nie um umfassende Falldarstellungen zu Personen über alle Kategorien hinweg. Diese personenbezogenen Darstellungen werden stets optisch abgehoben in Kästen dargestellt, bilden aber Teilbereiche des jeweils aktuellen Abschnitts. 


\section{Im Brennpunkt: P8}

"Also sehr negative Erzäblung vom zunehmenden staatlichen Einfluss» - Bewusstsein für die Ausstellung als erzählende und deutende Instanz

Eine auffällige Sensibilität für die Gemachtheit von Geschichte zeigt P8, eine Person aus der Gruppe derjenigen mit sowohl geschichtswissenschaftlichem als auch geschichtsdidaktischem und/oder museumsbezogenem Hintergrund. So beschäftigt sich P8 im Verlauf des Besuchs wiederholt mit der von den Ausstellungsmachenden geleisteten Elementauswabl sowie mit den von der Ausstellung vorgenommenen Deutungen.

Ich zeige zunächst eine längere Passage, in der beides mehrfach vorkommt. Darin befindet sich P8 in dem bereits mehrfach für Beispiele herangezogenen baselbezogenen Eingangsbereich der Ausstellung. Sich bei den Themenabschnitten «Not» und anschliessend «Mobilisierung» befindend, kommentiert P8 die jeweils zugehörigen Exponate:

"Da hat einer die Rationalisierungsmarken gesammelt, das bedeutet, dass es wobl eine recht prägende Zeit für ihn war und er irgendwie damit fertig werden wollte oder die verarbeiten. (...)

‘Koblekessel mit einer kleinen Schaufel’. Okay, da seh ich jetzt nicht ganz, wie das in die Narration passt.

Dann wird's jetzt hier sehr nationalistisch, da (wohl) ein klassisches Exponat. Schweizer Krenz. ‘Grenzbesetzung Weihnachten 1914'. Wirkt auf mich irgendwie ein bisschen lächerlich, dass man eine Grenzbesetzung, die militärisch relativ unspektakulär ist, durch solche Trophäen feiern muss. (...) Passt aber irgendwie in das Bild des Schweizer Militarismus, das ich so habe. (...) ‘ Baumwolle bedruckt. Ist also nicht handgemacht und scheint mir eine Massenware gewesen zu sein. Das jeder, der bei dieser legendären Grenzbesetzung beteiligt war, als ewiges Andenken mitgenommen hat.

‘Stricknadelset der Marke Germania〉. (...) Da könnten natürlich schon Anspielungen durch die Wabl des Exponats in gewisse Beziehungen von Soldaten zum Deutschen Reich dargestellt werden. Die es ja durchaus gab.

‘Kadettengewehr', gut, das darf natürlich nicht fehlen, wenn es darum geht, das Militär darzustellen. Und eine ‘Knabenuniform. Basel zwischen 1915, 1920 . (...) Feldgrau, kennt man so eigentlich auch aus deutschen Ausstellungen, dass auch die Kinder frïh vom Militär begeistert werden sollten. (...)» (P8, Absatz 5) 
Wie im gezeigten Beispiel, operiert P8 an einigen Stellen mit dem Fachbegriff «Exponat(e)» (Absatz 5, 38, 58, 61). Ein Schwerpunkt in den ausstellungsbezogenen Äusserungen von P8 sind solche über die in der Ausstellung zu findende Auswabl von Elementen. Auffallend ist dabei einerseits die Häufigkeit, andererseits auch die Art und Weise, wie P8 sich dem Thema widmet. So findet sich an etlichen Stellen, wie auch im zitierten Ausschnitt, die Feststellung, ein bestimmtes Ausstellungselement sei «klassisch»(Absatz 4, 5, 27, 29, 35, 41, 61).

Mit derartigen Feststellungen scheinen sich mehrere Bedeutungsdimensionen zu verbinden: dass ein bestimmtes Exponat typisch für seinen historischen Kontext ist, dass es sich gut eignet, um ein bestimmtes Thema zu repräsentieren, dass es demzufolge bewusst ausgewählt wurde oder auch aus anderen Ausstellungen in diesem Zusammenhang bekannt sind. Die folgenden Textbeispiele verdeutlichen diese Facetten:

"Hier sehen wir klassische Propagandaplakate.» (P8, Absatz 29)

"Film leicht beschleunigt, klassisches Filmmaterial zum Ersten Weltkrieg.»(P8, Absatz 27)

"Ach, das sind jetzt die ausländischen Propagandapostkarten, von denen drüben die Rede war (...), die die Neutralität stören sollten. ‘Hilfsbund für deutsche Kriegsfürsorge in der Schweiz〉 (...), 〈Verhöhnung der britischen Kolonialtruppen> (...). Das sind die klassischen Bilder, die dann wohl auch in der Schweiz verbreitet wurden. (...) Ah schön gemischt, die verschiedenen Propagandakarten, die ein relativ umfassendes Bild malen.» (P8, Absatz 35)

"Kadettengewehr, gut, das darf natürlich nicht fehlen, wenn es darum geht, das Militär darzustellen. Und eine Knabenuniform. [...], kennt man so eigentlich auch aus deutschen Ausstellungen, dass auch die Kinder früh vom Militär begeistert werden sollten.» (P8, Absatz 5)

Neben oder in Kombination mit Äusserungen zur getroffenen Exponatauswahl beschäftigt sich P8 auch intensiv mit den durch die Ausstellungsmachenden vorgenommenen Deutungen, stellt hier die auffallendste Person im untersuchten Sample dar. Er oder sie operiert mit in der Geschichtswissenschaft und -didaktik gebräuchlichen Begriffen wie "Sinnbildung» (Absatz 7), "Narration» (Absatz 5, 13, 19, 67, 86, 89), "Darstellung» (Absatz 15, 18, 24, 41 60), «Erzählung» (Absatz 45), die alle in unterschiedlichen Bedeutungsfacetten auf die Gemachtheit von Geschichte anspielen und Bewusstheit für diese deutlich machen. 
Ich zeige nachfolgend eine längere Passage, in der sich P8 in einem ästhetisch abgehobenen Teilbereich der Ausstellung befindet, nämlich einem kreisförmigen, betretbaren Bereich mit roten Wänden, der sowohl von der Innen- wie auch auf der Aussenseite mit Texten und Bildquellen bestückt ist. P8 befindet sich im gezeigten Beispiel bereits in der zweiten von insgesamt zwei derart gestalteten kleinen Abteilungen und liest den dortigen Ausstellungstext, dabei immer wieder unterbrechend, um den Text und die Deutungen der Ausstellungsmachenden zu benennen und zu kommentieren, die er oder sie zu entdecken glaubt.

"Dann gibt's hier ja so einen Kreis, der vermutlich auf Nationalismus zielen wird, (wenn das) (...) wenn das Element so fortgefïhrt wird.

¿Die kriegsbedingten neuen Bundesaufgaben führen zu einem starken Anstieg der Staatsausgaben. Während der Kriegsjahre nimmt diese rund das Zweieinhalb/, rund das Zweieinhalbfache zu. Zur Finanzierung der (Kriegskosten führt der Bund eine) Kriegsstener - die heutige direkte Bundesstener - ein. Zugleich tritt er als Akteur /..

Hier werden wieder Verweise auf heute gemacht, (mit der) Kriegsstener, Bundesstener (...) (die dadurch) natuirlich nicht besonders gut wegkommt. ¿Der Personalbestand steigt auf mehreve Tausend Beschäftigte an. Mit der Ausweitung der Staatstätigkeit wird die Entwicklung hin zum modernen INTERVENTIONSSTAAT BESCHLEUNIGT> (...).

Aba, ein Interventionsstaat. (...) Na gut. Dasklingt irgendwie nach Bedauern ïber den Abschied von der Freibeit.

¿Die Zentralisierung der Aufgaben bedeutet für die Verwaltung grössere Entscheidungskompetenz und Machtzuwachs.>

Das klingt ja fast schon, als steuern die auf ein kommunistisches Regime zu. ¿Zur Sicherung der Versorgung mit Lebensmitteln und Robstoffen werden ‘Zentralstellen' gegründet, wie die [liest ab hier bruchstückhaft] schweizerische Zentral/ Einfuhr Eidgenössische Ernährungsamt steigt auch der Einfluss organisierter Interessen.

Also sebr negative Erzählung vom zunehmenden staatlichen Einfluss. (...)» (P8, Absatz 45)

Wie im zitierten Beispiel identifiziert P8 an vielen Stellen des Besuchs vorgenommene Deutungen und äussert sich lobend oder kritisierend darüber. So empfindet P8 etwa die Darstellung der Ursachen des Ersten Weltkriegs und des beginnenden Kriegsgeschehens als vereinfachend dargestellt, wie er oder sie an mehreren Orten der Ausstellung, jeweils in Reaktion auf einen Ausstellungstext, feststellt: 
"Weltenbrand 1914 bis 18. Das Attentat entwickelt eine Dynamik, die schon bald zu einem alle Lebensbereiche umfassenden Krieg fübrt. So wird aus einem militärischen Mord der (zuerst) totale Krieg.>

Ist für mich eine etwas zu simple Sinnbildung bier. (...) Vom Attentat die Dynamik abzuleiten, die zu einem Weltkrieg fübrt. Da seh ich doch auch andere Entwicklungen, die da eine wichtige Rolle spielten.» (P8, Absatz 7)

Und etwas später, anhand eines weiteren Textes erneut darauf zurückkommend: "'Mit der Kriegserklärung von Österreich-Ungarn an Serbien beginnt der Erste Weltkrieg. Deutschland erklärt daraufhin Russland (das mit Serbien verbündet ist) den Krieg. Gegenseitige Bündnisverpflichtungen führen zum Kriegseintritt.>

\section{Die alte Domino-Geschichte.}

‘Was als lokaler Konflikt auf dem Balkan beginnt, weitet sich rasch zu einem globalen Krieg aus.>

Hier im Passiv. Der Krieg wird als etwas bescbrieben, das sich von allein entwickelt, wofiur die Menschen keinerlei Verantwortung übernebmen müssen. (...) Passt zu der Darstellung am Anfang.

'Unter Verletzung der Neutralität überfällt Deutschland im August Belgien.' Die Schuldfrage wäre damit geklärt.» (P8, Absatz 24)

Wie auch in Bezug auf die Exponatauswahl bezeichnet P8 vorgenommene Deutungen als «klassisch[.]» (Absatz 19) und inszeniert sich selbst als Kenner oder Kennerin in Bezug auf verschiedene mögliche Deutungen und deren Verbreitung, so etwa:

«Der Bundesrat geht von einer kurzen Kriegsdauer aus, ist sich aber bewusst, dass ein europäischer Krieg von ungeheurer Ausdehnung bevorstehen könnte.>

Die klassische Narration. Jeder abnt einen grossen Krieg, plant aber trotzdem mit einem kurzen.» (P8, Absatz 19)

«Deutschland eröffnet als Reaktion [fehlt: 〈auf die britische Seeblockade〉] den U-Boot-Krieg〉. Jetzt erzäblen sie die Geschichte, wie die USA in den Krieg eintreten werden.» (P8, Absatz 44)

Darauf, dass die USA entgegen den Erwartungen anschliessend gar nicht im Text vorkommen und insofern die eigentlich erwartete klassische Narrationslinie von der Ausstellung durchaus aufgebrochen wird, kommt P8 allerdings nicht zu sprechen. 
Umgekehrt äussert sich P8 am Beispiel der Darstellung der sozialen Konflikte in der Schweiz während des Weltkriegs lobend über die sich durch die gesamte Ausstellung ziehenden Deutungslinien sowie die dabei vorgenommene Verzahnung von schweizspezifischen und globalen Perspektiven:

"Ah, das (...) ist hier relativ stringent durchgezogen, dieses Thema der sozialen Spaltung. Zum einen kulturell und zum anderen eher wirtschaftlich.

Finde ich überzengend gemacht, wie da immer wieder darauf gewiesen wird. Im Grossen und Ganzen find ich auch schön den Schwerpunkt auf die Schweiz gesetzt und trotzdem immer (...) ein Blick auf das Globale, der natürlich stark vereinfacht sein muss in diesem Fall. Solange er nicht ganz so stark vereinfacht ist wie eben zu Beginn der Ausstellung, wenn es um die Kriegsursachen geht.» (P8, Absatz 57)

Auch an anderen Stellen kommt P8 auf die Narration einer sozialen oder auch kulturellen Spaltung zu sprechen:

"Das vertieft jetzt hier diese Spaltung der Gesellschaft (...), die man vorher schon auf sozialer Ebene gesehen hat, hier eben auf kultureller Ebene.» (P8, Absatz 31)

"Lebensmittel werden ständig knapper und teurer, und die Verbitterung in der Bevölkerung zeigt sich in Demonstrationen und Streiks. (...) Bürgertum und Ei/, Arbeiterschaft stehen sich immer unversöhnlicher entgegen.) Also, Narration ist natürlich: Am Anfang gibt es schon, schon Spannungen, und die spitzen sich durch die (...) Lage im Krieg, durch die Gewinner und Verliever weiter zu.» (P8, Absatz 67)

Mit diesen Äusserungen erweist sich P8 einerseits als sensibel dafür, dass die Ausstellung auf spezifische Weise Geschichte erzählt und konstruiert. Gleichzeitig entsteht der Eindruck, dass P8 spezifisches Hintergrundwissen über die Geschichtsschreibung zur Schweiz im Ersten Weltkrieg mitbringt und ihm oder ihr das darin zu findende Narrativ geläufig ist - der Erste Weltkrieg als «eine kulturell bedingte Zerreissprobe» $u$ und «eine soziale Zerreissprobe $»^{1379}$ - was dazu führt, dass P8 Elemente des Narrativs dann auch in der Ausstellung identifiziert.

1379 Kuhn/Ziegler 2011, S. 123; vgl. dazu ausführlicher Abschnitt 7.2.1. 
Im Zusammenhang mit dieser Sensibilität für Narrative fällt weiter auf, dass P8 die sich durch die Ausstellung ziehenden Erzähllinien auch mit der ästhetischen Gestaltung des Raumes in Verbindung bringt:

"Hier sieht man jetzt von der Inszenierung ber einen deutlichen Bruch. Der Krieg ist vorbei, irgendwie dieser bedrückende Korridor endet auch, wenn man diesen Raum hier [zeigt auf vorletzten Säulenraum] betritt, füblt man sich schon so, als könnte man freier atmen.» (P8, Absatz 86)

Eine ganze Reihe von Besuchenden nehmen wie P8 die am Ende der Ausstellung abweichende ästhetische Gestaltung zur Kenntnis und führen sie auf einen veränderten inhaltlichen Zugang zurück, nämlich den am Ende der Ausstellung enthaltenen Verknüpfungen von Zeitdimensionen und Ausblicken bis in die Gegenwart. Dem Umgang der Besuchenden mit diesen Schlussräumlichkeiten gehe ich weiter unten noch differenzierter nach.

\section{Im Brennpunkt: P4}

«Immer wieder die Originalbilder»-Sensibilität für Elementwahl und ästhetische Gestaltung

Ähnlich wie bei P8 kommt auch in den Äusserungen von P4 ein Bewusstsein und Interesse für die Ausstellung als ästhetisch gestalteten Raum und für die darin eingesetzten Elemente zum Vorschein. Auch bei P4 handelt es sich um eine Person aus der Gruppe derjenigen mit sowohl geschichtswissenschaftlichem als auch geschichtsdidaktischem und/oder museumsbezogenem Hintergrund, die zudem dadurch auffällt, dass sie sich im Verhältnis der ausstellungs- und geschehensbezogenen Äusserungen nahezu ausschliesslich im erstgenannten Bereich bewegt.

In den Äusserungen von P4 manifestieren sich - neben den element- und themenidentifizierenden Aktivitäten, die bei nahezu allen Besuchenden einen zentralen Stellenwert einnehmen und weiter unten noch näher vorgestellt werden - zwei Schwerpunkte von Äusserungen, nämlich solche über die ästhetische Gestaltung der Ausstellung und solche über die geleistete Elementauswabl. Im erstgenannten Bereich beschäftigt sich P4 beispielsweise mit der ästhetischen Anordnung der verschiedenen Elemente im Raum sowie mit der gewählten Farbgebung und identifiziert die hierfür gewählten Muster. Die folgenden Textbeispiele geben einen Eindruck hiervon: 
"Ich finde, der Raum ist gut (genug), der ist eigentlich auch gut aufgeteilt, und diese (...) schräg an die Wand gestellten (...) Ausstellungsflüchen (...), die geben dem Raum Struktur, (unv.) die Vitrinen (...) finde ich gut, dass man die nicht weggelassen hat. (...) Denn sonst ist es nur (...) sonst ist zu textlastig fast, finde ich.»(P4, Absatz 96)

«Das ist echt gut, dass (unv.) (unter) jedem Text noch mal (...) ein kleines (Bild ist). (...) Bis auf die Texte auf den roten (...) (Stelen) sind die Texte eigentlich nicht (...) stehen die Texte nie alleine. (...) Okay doch, bei Zitaten. (schmunzelt) Ja okay, Zitate kann man nicht illustrieren, (...) oder nicht immer gut. (...)» (P4, Absatz 52-53)

«Das ist echt schön, dass keins (dieser) grossen Bilder auch wirklich obne (...) obne Bildunterschrift dasteht.» (P4, Absatz 107)

"Also ich finde (unv.) bübsch Gestaltung (von den) Schwarz-Weiss-Bildern in dem Rot immer, (...) das fin/das gefällt mir, finde ich (...) gut gemacht. (...) Da weiss man eigentlich immer, wo man genau hinschauen muss. Die Sachen auf den (...) Schwarz-Weiss-Bildern (...) gehen ein bisschen unter, (...) aber nicht (weil) man's (vielleicht mal) gemerkt hat.» (P4, Absatz 27)

Wichtig scheint P4 in Bezug auf die ästhetische Gestaltung auch die Ansprache verschiedener Sinnesorgane zu sein:

"Okay, also da hat man ja auf den ersten Metern gleich mal für alle Sinne was, das finde ich echt nicht schlecht.» (P4, Absatz 17)

"Es ist sehr auf die Sinne ausgerichtet, mit viel Medien.» (P4, Absatz 66)

Viele Äusserungen von P4 zur ästhetischen Gestaltung der Ausstellung verbleiben auf dieser rein ästhetischen Ebene, teilweise wird diese Ebene jedoch auch überschritten, wenn er oder sie über die Korrespondenz zwischen gewählter ästhetischer Darstellung und den damit repräsentierten Aussagen über das historische Geschehen nachdenkt. Wie im Fall von P8 tritt dies namentlich im Zusammenhang mit dem Ausstellungsabschnitt «Nach dem Krieg» auf und wird, im Vergleich mit Äusserungen von weiteren Besuchenden in dieser Abteilung, weiter unten erneut aufgegriffen.

Zweitens drückt sich bei P4, wie auch im Fall von P8, eine starke Sensibilität für die von der Ausstellung geleistete Elementanswabl aus. P4 zeigt ein starkes Interesse an der Einordnung der in der Ausstellung gezeigten Elemente. Er oder sie 
operiert im Vergleich mit anderen Besuchenden extensiv mit dem Begriff oder Begriffsbestandteil «Original» (Absatz 13, 34, 54, 55, $4 \times 66,2 \times 92,100,108$ ) und interessiert sich dafür, ob er oder sie es in der Ausstellung mit solchen Originalen zu tun habe. Der Einsatz von Originalen scheint P4 wichtig, wie etwa in folgenden Textstellen zum Ausdruck kommt:

"Immer wieder die Originalbilder, das finde ich nicht schlecht. (...) Finde ich sehr gut. (...) Also vor allem bewegte Originalbilder.» (P4, Absatz 92)

"Ich les also schon gern auch mal irgendwas im Original, ist nicht schlecht.» (P4, Absatz 55)

Warum P4 den Einsatz von Originalen begrüsst, macht er oder sie dabei allerdings nicht deutlich, bringt zwar zum Ausdruck, dass er oder sie Originale als Gegengewicht zu einem ansonsten sehr darstellenden Charakter der Ausstellung sowie zu den zahlreichen grossformatigen Fotografien schätzt, äussert sich darüber hinaus aber nicht dazu, worin dieses Gegengewicht genau besteht und warum Originale für historische Ausstellungen bedeutsam oder interessant sein könnten, bleibt vielmehr auf der identifizierenden Ebene:

"Also hier haben wir jetzt mal ('ne) Vitrine mit lauter Originalen (...), das find ich ganzgut. (...) Verbältnis dazu istes nämlichsonst (...) (sebr darstellend) (...). (Muss mich mal) noch mal vergewissern (schmunzelt), aber ansonsten nicht so arg viele (...) Originale. (...) Es ist sehr auf die Sinne ausgerichtet, mit viel Medien, (...) diese Vitrine hier (hat doch jetzt eher mal) (...) (ach ja) sind das auch (nur Reproduktionen), ich bin mir nicht ganz sicher, aber (...) Teil davon sehen schon original aus. (...) <(Kleidungs)stücke der Krankenschwestern von der Front>. (...) Also Originale (unv.) [Lärm im Hintergrund] (ganz anderen) (...) Eindruck als (...) als nur die beeindruckenden Darstellungen von den grossen Bildern. (...) Ja, aber nicht unbedingt (...) also, soll nicht wertend sein.» (P4, Absatz 66)

Auch abgesehen vom Original-Begriff beschäftigt sich P4 mit der Klassifizierung der in der Ausstellung enthaltenen Elemente, identifiziert diese beispielsweise als «Zitatquellen» (Absatz 16) oder als "Alltagsgegenstände» (Absatz 10), äussert sich aber nicht grundlegend auf erkenntnistheoretischer Ebene zur Bedeutung, die Originalen oder Quellen in der Darstellung der Ausstellung zukommt.

Auch ist auffallend, dass sich bei P4 zwar eine grosse Sensibilität für ästhetische Mittel und die Art der in der Ausstellung enthaltenen Elemente zeigt, dass sich allerdings 
bei dieser Person, trotz nahzu ausschliesslicher Ausstellungsfokussierung im Vergleich mit sehr wenigen geschehensbezogenen Äusserungen, dennoch keinerlei Äusserungen über die von der Ausstellung vorgenommenen Deutungen finden. Einsicht in den Konstruktcharakter der Ausstellung manifestiert sich bei P4 also auf Ebene der Analyse der Elementwahl, nicht jedoch mit Blick auf übergreifende, von der Ausstellung mithilfe dieser Elemente vorgenommene Erzählungen.

Äusserungen über die von der Ausstellung geleistete Elementauswahl und -präsentation gehören zu den relativ häufig vorkommenden ausstellungsbezogenen Äusserungen ${ }^{1380}$ und lassen sich darunter eher dem konstruktionssensiblen Spektrum zuordnen. Manche Äusserungen beziehen sich unter diesen auf die ästhetische Darstellungsweise von Elementen:

"Hm, das ist ein bisschen seltsam, dass da die Karikatur so gut versteckt ist, dort binten. (...) Offenbar hatten sie nicht mehr Platz.» (P7, Absatz 23)

"Das wär jetzt noch spannend, diese, diese. Eigentlich ist das ganz gut gemacht, aber dieses, die schweizerische Bundesanwaltschaft, diese Quelle, hier ein bisschen besser zu sehen. Hier ist das schade, da ist sie umgekippt.»(P12, Absatz 192)

... oder wie im nachfolgenden Beispiel und ähnlich zu den bereits anhand von P4 und P8 gezeigten Äusserungen auf die Auswahl von Elementtypen:

"Weil Ausstellungsobjekte an sich haben sie gar nicht so viele, so, so ein bisschen Flachwaren, aber sonst (...).

In der Eingangsvitrine haben sie ein bisschen aus dem Depot ein bisschen Sachen aus dem Depot geholt, aber sonst ist es eigentlich eine sehr (...) sehr eine objektarme Ausstellung, wenn man so will, bis jetzt.» (P7, Absatz 37-40)

"Ein Objekt wie diese (...) Kochkiste (...) wird auch in anderen Ausstellungen gezeigt, (...) selbst wenn man Lebensmittel (...) erwerben konnte, scheiterte, oder

1380 Die bedeutendste Gruppe bilden die identifizierenden Tätigkeiten, genauer die elementund themenidentifizierenden Äusserungen, auf die ich weiter unten noch gesondert eingehe (vgl. Abschnitt 8.6.4). 
fehlte oft (...) das nötige Brennmaterial. (...) Also ein sebr charakteristisches Objekt (...) für die Zeit des Evsten Weltkrieges.» (P28, Absatz 127)

Eng verwandt und teilweise verschwimmend sind Fragen einerseits der Elementauswahl, insbesondere der thematischen Einordnung von Elementen, und andererseits Äusserungen über die Funktion von Ausstellungselementen. Ich zeige einige Beispiele aus diesem Spektrum:

"So, da stehen wir jetzt vor der Vitrine, die (...) scheinbar ein bisschen die Reicheren (...) mit ihren Accessoires vertreten sind.» (P20, Absatz 22)

"Mir gefällt die Auswahl der Objekte, sie ist ziemlich stimmig und vermittelt auch noch ein gutes Bild. (...) Und womit dem man sich ein bisschen besser vorstellen kann, (mit den ganzen) Gegenständen, damals die durchschnittlichen Wohnzimmer ausgerïstet waren.» (P21, Absatz 9)

"Was ist denn hier? 〈Milchanlieferung bei Nestlé in Vevey, ca. 1900〉. Das find ich jetzt noch gut, dass die so ein älteres Bild hier reinnehmen, weil sie einfach irgendwie zeigt, wie so in Friedenszeiten alles hier so (...) florierte und funktionierte.» (P12, Absatz 110)

"Die Bilder, die ich da sehe, sind sebr eindrücklich und (will) mir (...) eine Idee, Bild vermitteln vom damaligen Leben in der Schweiz.» (P25, Absatz 54)

Sensibilität für die Gemachtheit einer Ausstellung kann, abgesehen von einem Reflektieren über die getroffene Exponatauswahl und gewählte ästhetische Gestaltung, wie dies im Rahmen der vorherigen Fallbeispiele dargestellt wurde, beispielsweise auch dadurch ausgedrückt werden, dass Besuchende über Nicht-Themen bzw. Leerstellen der Ausstellung nachdenken, also darüber, was die Ausstellung neben dem Gezeigten umgekehrt auslässt und nicht zeigt. Es ist dies ein Bereich, der im Verhältnis allerdings eher selten vorkommt und nur von einem kleineren Teil der Besuchenden überhaupt angesprochen wird.

Ein Beispiel für die Benennung einer solchen Leerstelle findet sich bei der bereits vorgestellten Person P8, die zunächst eine Zitatquelle liest und sich dann dazu äussert: 
«Was wird von allem übrig bleiben, wenn der Kampf zu Ende sein wird? Ein Leichenbaufen, ein Trümmerhaufen, ein Irrenbaus.> Ja, also hier (...) wird man jetzt tatsächlich mal angeregt, darüber nachzudenken, warum da überhaupt Krieg geführt wird, durch solche Zitate. Kommt in dieser Ausstellung relativ kurz, was aber (...) dem geschuldet ist, dass hier natürlich die Schweizer Perspektive eingenommen wird, die eben mit anderen Problemen zu kämpfen hat als eben die Frage nach dem Sinn dieses Krieges.» (P8, Absatz 72)

In der Textstelle benennt P8 ein Thema, das er oder sie als in der Ausstellung wenig bis gar nicht repräsentiert erachtet, nämlich die Beschäftigung mit den Gründen bzw. dem Sinn von Kriegen. P8 führt die Abwesenheit des Themas auf den spezifischen Blickwinkel der Ausstellung zurück, mit dem «die Schweizer Perspektive eingenommen wird, die eben mit anderen Problemen zu kämpfen hat». Mit dieser Aussage erweist sich P8 als ausgesprochen bewusst darüber, dass Ausstellungen je spezifische Blickwinkel einnehmen, Fragestellungen verfolgen und dass ausgehend davon bestimmte Themen relevant sind, andere hingegen nicht. Im Vergleich dazu werden in anderen Beispielen Leerstellen festgestellt, ohne dass sich die/der fragliche Besuchende explizit zu möglichen Gründen für das Fehlen äussern würde:

"Ich vermisse einen Text, der sich allgemein mit (...) der Rolle der Frauen beschäftigt.» (P28, Absatz 68)

«Burgfrieden». Was ist jetzt eigentlich genau der Burgfrieden, das müsste man vielleicht ausführen.» (P13, Absatz 59)

Und P8 äussert, nachdem er oder sie einen Ausstellungstext über die Massnahmen des Bundesrats zur Bewältigung des Landesstreiks gelesen hat:

"Was ich noch schade finde, ist irgendwie, der Bundesrat bleibt hier relativ blass, also. Ich weiss nicht, ob ich es nur übersehen habe, aber ich weiss jetzt nicht, welche Menschen da drin sitzen, wie die Stimmenverteilung ist, oder, ja, hätte man vielleicht noch ein bisschen mehr drüber erzählen können. Da er doch eine sehr entscheidende Rolle hier spielt.» (P8, Absatz 75)

Im zuletzt gezeigten Beispiel begründet P8 sein Bedürfnis nach ergänzenden Informationen damit, dass der Bundesrat "eine sehr entscheidende Rolle hier spielt». 
Im Kontext der sonstigen Äusserungen von P8 und der darin zum Ausdruck kommenden hohen Sensibilität für die Gemachtheit der Ausstellung und die von ihr vorgenommenen Deutungen kann diese Aussage einerseits darauf abzielen, dass der Bundesrat als Akteur in der Ausstellung immer wieder thematisiert wird und deshalb ausführlicher vorgestellt werden sollte. Umgekehrt kann die Aussage jedoch auch darauf anspielen, dass der Bundesrat eine wesentliche Rolle im historischen Geschehen gespielt habe und P8 deshalb als unterrepräsentiert in der Ausstellung erscheint.

Im gezeigten Beispiel deutet sich an, dass in der Feststellung von Nicht-Themen und Leerstellen der Ausstellung nicht zwingend im konstruktivistischen Modus und mit Sensibilität für die spezifischen Intentionen, Fragestellungen, Perspektiven der Ausstellung geschehen muss, sondern auch aus einem Abgleich der Darstellung der Ausstellung mit einer (angenommenen) historischen Wirklichkeit resultieren kann, wobei dann festgestellt wird, dass die Ausstellung diese Wirklichkeit nicht angemessen repräsentiere. Im nachfolgenden Beispiel kommt diese Dimension noch deutlicher zum Vorschein:

"Ja, kurz erklärt, wie es zum Kriegsausbruch gekommen ist (...). Ja, es ist ganz kurz dargestellt, auch da auf der Weltkarte, wer zu wem gehört hat. Finde ich jetzt, ja, ist ein bisschen diurftig, weil doch noch sebr viele andere Faktoren mitgespielt baben, aber so für einen guten Ü/, kurzen Überblick langt es sicher mal.

Da feblt es ein bisschen, dass, Deutschland hat ja Belgien überfallen, und das ist ja der ganz grosse (...), das ist ja der ganz grosse Skandal gewesen, auch weil die Bibliothek in Leu, Leuwen ja Raub von Flammen geworden ist. Und vor dem Film hat man gesehen, dass das bei der, gerade bei der Romandie sehr schlecht angekommen ist und Deutschland sehr unbeliebt gemacht hat. Das kommt für meinen Geschmack da ein bisschen wenig zum Tragen.» (P19, Absatz 45)

Im Beispiel zeigt sich, dass sich Aussagen über die Ausstellung und die darin vorkommenden Themen durchaus kombinieren können mit Vorstellungen von einer historischen Wirklichkeit, die in der Ausstellung zu repräsentieren sei, und mit einer darauf beruhenden Einstufung der Korrektheit der Ausstellung. 


\subsubsection{2 Äusserungen über historische Wirklichkeit und Korrektheit der Darstellung}

Gerade bei der zuletzt zitierten Person P19 finden sich etliche Äusserungen, in denen er oder sie die Darstellung der Ausstellung in Abgleich mit historischem Geschehen bringt. Ich stelle die Äusserungen dieser Person zum Thema wiederum in Form einer Fallbetrachtung vor. ${ }^{1381}$

\section{Im Brennpunkt: P19}

«da vermisse ich dann doch manchmal die Sachebene» - Vorstellungen von historischer Korrektheit und Ausgewogenheit

Bei P19 handelt es sich um eine Person ohne geschichtswissenschaftlichen und ohne geschichtsdidaktischen oder museumsbezogenen Hintergrund, die über eine Berufsausbildung verfügt und zum Zeitpunkt des Ausstellungsbesuchs ein geisteswissenschaftliches Studium absolviert. P19 bringt an etlichen Stellen des Ausstellungsbesuchs Vorstellungen von der Existenz historischer Wirklichkeit und Korrektheit zum Ausdruck und denkt ausgehend davon darüber nach, inwiefern diese Wirklichkeit sachgemäss in der Ausstellung repräsentiert wird. An einer Stelle spricht P19 beispielsweise davon, im Besuchsverlauf von einer neuen «interessante [n] historische [n] Tatsache» Kenntnis erlangt zu haben:

"Ha (bitter). Dass man sich dann auch noch beschuldigt hat, mit den Truppenaufgeboten Grippetote in Kaufgenommen zu h/, ist auch eine interessante (...) so ein interessanter Gedanke, den ich auch noch nie gehört habe vorher. Also interessante historische Tatsache, ist wirklich, ja.» (P19, Absatz 134)

Der Ausdruck «historische Tatsache» legt nahe, dass P19 von einer gültigen historischen Realität ausgeht, über die die Ausstellung in Kenntnis setzt. An anderer Stelle und im Zusammenhang mit der Darstellung exportwirtschaftlicher Tätigkeiten der Schweiz während des Kriegs beklagt sich P19 umgekehrt darüber, dass die Ausstellung nicht hinreichend deutlich mache, was «wirklich» gewesen ist:

1381 Ein Teil der nachfolgend zitierten Äusserungen von P19 wurde auch bereits andernorts vorgestellt und eingeordnet, dort unter der thematischen Perspektive des Umgangs von Besuchenden mit exportwirtschaftlichen Aktivitäten der Schweiz während des Ersten Weltkriegs (Thyroff 2017b, S. 116 f., und Thyroff 2017c, S. 10 f.). 
"Jaa, es ist da schon etwas die Frage, was ist da ethisch gewesen, was ist Doppelmoral, was ist wirtschaftlich notwendig gewesen? (...) Ich hab jetzt das Gefübl, aus, ja der, in der Ausstellung wird es eher etwas kritisch gesehen (...), aber (...) ich frage mich halt auch ein bisschen, was ist wirklich notwendig gewesen, was ist in der, was ist wirklich nur Kriegsgewinnlertum gewesen. So ein bisschen die Pro-und Contra-Stellung zu der Thematik fehlt mir jetzt da ein wenig.»(P19, Absatz 75)

Mit diesen Aussagen vertritt P19 die Haltung, man könne überhaupt herausfinden, wie etwas "wirklich» gewesen ist, was "historische Tatsache», und entwirft damit die Idee einer zweifellos gültigen historischen Wirklichkeit, die als solche erkannt und auch dargestellt werden kann.

Ein zweiter Strang von Überlegungen deutet sich im gezeigten Beispiel ebenfalls an. Dieser besteht aus Äusserungen, in denen P19 eine politisch ausgewogene Darstellung historischen Geschehens durch die Ausstellung einfordert. Wie sich in den nachfolgenden Beispielen zeigt, geht dieser Argumentationsstrang nur teilweise mit den weiter oben erläuterten Vorstellungen von einer gültigen historischen Wirklichkeit überein. Für P19 ist es nämlich auch wichtig, dass die Ausstellung in aus seiner oder ihrer Sicht angemesser Weise "die Pro- und Contra-Stellung» (Absatz 75), "Pro- und Contra-Seite» (Absatz 77), "Pro- und Contrapositionen» (Absatz 97), "Pro- und Contrasichten von der damaligen Zeit» (Absatz 151) berücksichtigt.

So beklagt er oder sie, wenn dies nicht der Fall sei, namentlich in Bezug auf die Darstellung der schweizerischen Exporttätigkeiten (Absatz 75, 77), benennt aber umgekehrt Freude darüber, wenn er oder sie Pro- und Contraperspektiven repräsentiert sieht, wie etwa in der Darstellung des Landesstreiks (Absatz 97). Was genau jeweils diese Pro- und Contrapositionen beinhalten könnten, hierzu wird P19 selten explizit, das zuletzt zitierte Beispiel (P19, Absatz 75) liefert jedoch einen Hinweis.

Die zitierte Textstelle macht zum einen deutlich, dass P19 ein in der Ausstellung angelegtes kritisches Potenzial in Bezug auf wirtschaftliche Aktivitäten der Schweiz zur Zeit des Ersten Weltkriegs erkennt. Zugleich mahnt P19 an, den aus seiner oder ihrer Sicht in der Ausstellung enthaltenen kritischen Blick auf die schweizerischen Exporttätigkeiten zu ergänzen um eine Prüfung der möglichen wirtschaftlichen Notwendigkeit dieser Exporte.

Politische Ausgewogenheit ist für P19 wichtig, wie auch eine längere Passage zu einem früheren Zeitpunkt des Ausstellungsbesuchs deutlich macht, wo er den 
Begriff der «Sachebene» einbringt. P19 unterscheidet darin danach, historisches Geschehen auf der «Sachebene» oder aber «emotional» und "politisch gefürbt» (Absatz 112) zu betrachten, und unterstellt der Ausstellung zugleich, den zweitgenannten Blickwinkel eingenommen zu haben und damit die notwendige Sachlichkeit vermissen zu lassen, konkret:

"Ja, da geht es etwas um Fremdenfeindlichkeit. (...) Was ein bisschen impliziert, ob man das nicht heute, auf eine heutige, man sollte das auf eine heutige Situation beziehen (...). Weil begründet wird das da eigentlich nicht, ja. Es macht ein bisschen, argh. Es macht ein bisschen einen politisch gefärbten Eindruck anf mich. (...)

[...] und da (...) da sehe ich, dass ¿ Zu Beginn des Kriegeskehren Zehntausende von ausländischen Arbeitskräften in ibre Heimatländer zurück. Rasch schränkt die vom Bundesrat erlassene Grenzsperre den Personenverkehr ein. Medien und amtliche Texte zeichnen nach und nach ein kritischeres Bild von Ausländern. Sie unterscheiden vermehrt zwischen erwünschten und unerwünschten Personen. Woblhabende Touristen und internierte Militärpersonen sind willkommen, Deserteure, Kriegsgewinnler und Bolschewisten und Ostjuden werden als Unerwünschte bezeichnet. Während des Krieges verändert sich das Verhältnis zwischen In- und Ausländern nachbaltig. Der Begriff Überfremdung steigt zum beherrschenden Schlagwort auf. Die neu geschaffene Fremdenpolizei sieht ibre Hauptanfgabe in der Überfremdungsbekämpfung und versteht es, den Anteil der Ausländer nach dem Krieg mit verschiedenen Mitteln zu senken. Zugleich schafft sie damit neue politische und humanitäre Probleme, die über Jahrzehnte nachwirken.> (...)

Ja, ähm (...), es zieht natürlich eine Parallele zu einer heutigen Ausländerdiskussion, (...) wo, ja wo manchmal. wo mich manchmal dünkt, das hat so der, den, die Sachebene verlassen und wird sebr emotional, was offensichtlich damals schon emotional gewesen ist (dort) (...). Ich habe einfach immer so ein bisschen den Eindruck (als) (...), was ist, ist die historische Darstellung der Situation (denn) (unv.) politisch gefärbt mit der, mit der Brille aus der heutigen Situation. Und das gibt für mich halt immer so einen Touch von - argh - dass man mit, mit der Historie in der heutigen Zeit Politik machen will. Und das ist für mich hal - argh - (...), da vermisse ich dann doch manchmal die Sachebene.» (P19, Absatz 108-112)

Mit dieser Aussage vertritt P19 die Auffassung, dass ein nicht perspektivischer, sachlicher Blick auf vergangenes Geschehen überbaupt möglich ist, dass dieser Blickwinkel jedoch in dem Fall nicht angemessen durch die Ausstellung eingenom- 
men werde. Die Textstelle macht deutlich, dass für P19 einerseits die ausgewogene Darstellung verschiedener Perspektiven wünschenswert ist, andererseits aber auch die Ausblendung aktueller politischer Fragen. Er oder sie reflektiert dabei nicht darüber, inwieweit nicht perspektivische Blickwinkel auf vergangenes Geschehen überhaupt möglich sind, inwiefern die Ausstellung heutiger Geschichtskultur sich überhaupt aktuellen Fragen und Perspektiven verschliessen kann.

Umgekehrt gibt es auch einen Moment während des Ausstellungsbesuchs, in dem P19 politisierte Elemente lobt, allerdings bezieht sich dies auf Quellenmaterial und nicht auf Ausstellungstexte. So äussert P19 im Abschnitt zum Landesstreik Freude über Textquellen, die dort die politischen Haltungen der streikenden Parteien widerspiegeln:

«Flugschriften und Plakate aus folgenden Archiven» (...), da machen wir einfach schnell, da lesen wir mal schnell, was mit der roten Fahne steht. Finde ich eben spannend, wenn es so ein bisschen politisch aufgeladen ist. So etwas ein Diskurs stattfindet. (...) Ja, ‘Aufruf zum Streik〉. Das finde ich wieder, ja, das finde ich, finde ich, das finde ich cool, so etwas.» (P19, Absatz 128)

Von Ausstellungstexten fordert P19 allerdings offenbar - ohne diese Unterscheidung selbst explizit zu formulieren - politische Ausgewogenheit und Sachlichkeit ein.

In den Äusserungen von P19 fliessen, zusammenfassend betrachtet, somit mehrere Argumentationsstränge ineinander, ohne dass diese vollständig ineinander aufgehen oder miteinander in Deckung zu bringen wären. Zum einen geht er oder sie, dies wurde eingangs deutlich, von einer gültigen, historischen Realität aus, die im Heute zugänglich ist und in der Ausstellung abgebildet werden kann. Zum anderen fordert er oder sie ein, historische Wirklichkeit durch eine angemessene Gegenüberstellung von Pro- und Contrapositionen und damit mehreren Perspektiven angemessen und sachlich zu repräsentieren und keineswegs politisch oder emotional gefärbte, im Jetzt gründende Positionen einzunehmen. Unklar bleibt dabei indes, wie durch eine sachliche Gegenüberstellung von Positionen zu einer gültigen Aussage über historische Wirklichkeit gelangt werden soll. Unthematisiert bleibt ebenso die Frage, inwiefern eine Ausstellung der Gegenwart überhaupt in der Gegenwart gründende Perspektiven und Fragestellungen ausblenden kann.

Allerdings lässt P19 andernorts, und dies verstärkt den Eindruck einer durchaus ambivalenten und disparaten Datenlage im Fall dieser Person, durchaus eine Sensibilität dafür erkennen, dass Reden über Vergangenes selektiv bestimmte Schwer- 
punkte setzen und andere Themen ausblenden kann. So stellt P19 an einzelnen Stellen des Besuchs Vergleiche zwischen dem in der Ausstellung Thematisierten und aktuellen Diskursen über die Zeit des Ersten Weltkriegs an. P19 stellt dann fest, dass bestimmte Themen, die in der Ausstellung behandelt werden, in der Form in aktuellen Diskursen nicht debattiert werden und ihm oder ihr insofern neu sind. So etwa in Bezug auf einen Überblickstext zur Spanischen Grippe:

"Die Spanische Grippe. Da hab ich Leute, kenne ich Leute, die selber noch Angehörige verloren haben, und das interessiert mich jetzt sehr, weil es doch (...) eigentlich ein sehr heftiges Kapitel ist, das aber im Zug vom Ersten Weltkrieg irgendwo etwas den Tisch gefallen ist. (...) Eben, es sind mehr Opfer, hat es gegeben, als im ganzen Krieg. (...) Woah. In der Schweiz ist die Hälfte der Bevölkerung erkrankt. Das hab ich noch nie gehört im Leben, das ist wirklich sehr, sehr interessant. (...)»(P19, Absatz 132)

In Reaktion auf einen Ausstellungstext, in dem von der Seeblockade Englands gegenüber Deutschland sowie von Engpässen in der wirtschaftlichen Versorgung in der Schweiz die Rede ist, formuliert P19:

"Eben, das trifft mich jetzt, dass (...) über das redet ja keiner heute, dass die Wirtschaftsseeblockade von England zum Tod von Hunderttausenden von Zivilisten gefübrt hat.

Ein Gedanke, der eigentlich (...) ja (...) der gar nicht diskutiert wird, wo ich mir auch nie Gedanken darüber gemacht habe. Und auf der anderen Seite die Blutmüble von Verdun, das kennt ja faktisch jeder, oder?

Und das finde ich jetzt echt zum Nachdenken, wie sehr doch auch ein Wirtschaftskrieg zusammen mit dem Militärischen, (weil/wenn) das zusammen verlinkt ist, und eben auch ein Wirtschaftskrieg zum Tod von, von Hunderttausenden fübren kann. (...)

Was aber kaum diskutiert und auch nicht irgendwo gross reflektiert oder, man bat auch nicht gross drïber nachgedacht, ja. Finde ich jetzt einen sehr spannenden Gedanken.»(P19, Absatz 92)

Mit derartigen Aussagen erweist sich P19 als sensibel dafür, dass Debatten über Historisches selektiv sein können. $\mathrm{Ob}$ sich damit die Auffassung verbindet, dass erzählte Geschichte per se selektiv ist, kann nicht abschliessend festgestellt werden. Denkbar im Kontext der weiteren vorgestellten Äusserungen ist auch, dass P19 Selektivität vielmehr als durchaus ausschaltbaren «Fehler» von Diskursen betrachtet. 
Am Beispiel von P19 zeigt sich, dass ausstellungsbezogene Äusserungen im Fokus II nicht zwingend gleichbedeutend sein müssen mit einer konstruktivistischen Grundhaltung. Ganz im Gegenteil können auch innerhalb von Äusserungen im Fokus II Vorstellungen von historischer Tatsächlichkeit und einer entsprechenden Korrektheit der Darstellung der Ausstellung zum Ausdruck gebracht werden. Insofern greift eine Gleichsetzung von Äusserungen im Fokus II mit konstruktivistischen und Äusserungen im Fokus I mit positivistischen Grundhaltungen zu kurz. Gleichwohl lassen sich die beiden Fokussierungen zumindest in ihren Extrempolen als mit positivistischen und konstruktivistischen Zugangsweisen übereinstimmend betrachten.

Die gesamthafte Zuordnung von Personen zu den jeweiligen erkenntnistheoretischen Positionen ist dabei nicht das Anliegen der Analyse. Diese zielt vielmehr auf eine Systematisierung und Strukturierung der insgesamt bei allen 18 Besuchenden vorkommenden Äusserungen; personenbezogene Befunde treten demgegenüber jedoch in den Hintergrund und kommen lediglich in Form der mitunter zu findenden Fallbetrachtungen im Rahmen einzelner Kategorien zum Tragen, umfassende Fallprofile werden hingegen nicht entwickelt.

Zudem sensibilisieren die Befunde für P19 dafür, dass Besuchende mit ihren Äusserungen durchaus auch zwischen verschiedenen Ausprägungen changieren können, das Datenmaterial insofern auch deswegen keine Identifizierung von reinen Konstruktivistinnen und Konstruktivisten, Positivistinnen und Positivisten nahelegt, sondern - wenn überhaupt - nur die Zuordnung einzelner Äusserungen zu bestimmten geschichtstheoretischen Überzeugungen möglich ist. Das Potenzial der Analyse liegt weniger in einer eindeutigen Zuordenbarkeit von Fällen, sondern vielmehr in einer Auslotung das variantenreichen Spektrums zwischen verschiedenen Polen, einerseits zwischen geschehens- und ausstellungsbezogenen Aussagen in den Fokussierungen I und II, andererseits, und, dazu nicht als deckungsgleich zu verstehen, zwischen positivistischen und konstruktivistischen Zugängen.

\subsubsection{Zwischen Abbild, Bild und Exponat: Varianten von Äusserungen über Bildquellen}

Das angedeutete Spektrum an Zugangsweisen der Besuchenden zwischen einerseits der Sensibilität für die Ausstellung und ihre Elemente als Konstruktion und andererseits der Vorstellung, dass die Ausstellung oder einzelne ihrer Elemente historische Wirklichkeit zu repräsentieren imstande sind, kondensiert sich in einem Bereich auf besonders eindrückliche Weise, nämlich im Umgang der Besuchenden mit den in der Ausstellung enthaltenen Bildquellen. Ich zeige nachfolgend Äusse- 
rungen der Besuchenden im Kontakt mit Fotografien und Filmen, Karikaturen sowie punktuell Gemälden. ${ }^{1382}$ Dabei unterscheide ich drei grundsätzliche Varianten. Nämlich behandeln die Besuchenden von Fall zu Fall Bildquellen entweder (1) als Abbilder historischen Geschehens, (2) als konstruierte Bilder oder (3) in ihrer Funktion als Exponate innerhalb der Ausstellung.

Auf einer Skala zwischen positivistischen und konstruktivistischen Zugangsweisen zähle ich die erstgenannte Form eher dem positivistischen und zähle die zweite und dritte Form stärker dem konstruktivistischen Spektrum zu. Im Hinblick auf die Unterscheidung von Äusserungen über Geschehen (Fokus I) und über die Ausstellung und ihre Elemente (Fokus II) rechne ich allerdings nur den dritten Bereich, die Thematisierung von Bildquellen als Exponate, dem Fokus II $\mathrm{zu}$, während ich die anderen beiden Bereiche den geschehensbezogenen Äusserungen zuschlage. Ich stelle die drei genannten Varianten und zugehörige Überlegungen nachfolgend vor.

$\mathrm{Zu}$ (1): Nachfolgend wende ich mich zunächst dem stärker positivistischen Teil des Spektrums im Umgang mit Bildquellen zu, der sich vor allem im Umgang mit Fotografien und Filmen beobachten lässt. Stellvertretend und gleichsam idealtypisch für diesen Bereich steht folgende Aussage von P18, zustande gekommen bei Betrachtung einer Filmquelle zur Mobilisation der schweizerischen Armee, wobei die Aussagen in dieser Explizitheit der darin formulierten Einschätzung im Datenmaterial einmalig ist:

"So Filmzengnisse faszinieren mich sehr (...). Einfach wie es damals gewesen ist.» (P18, Absatz 33)

Im zweiten Teil dieser Textstelle manifestiert sich die Vorstellung, dass es eine gültige vergangene Wirklichkeit gibt und dass diese in einem Element der Ausstellung, im konkreten Fall in einer Filmquelle, widerspiegelt wird bzw. über dieses Element zugänglich ist. Einer bei Christoph Hamann verwendeten Unterscheidung folgend, wird hier das bildliche Element als «Abbild» historischen Geschehens thematisiert, nicht jedoch als gestaltetes und konstruiertes «Bild», ${ }^{1383}$ ebenso wenig wie die Kontextualisierung des Bildes, seine Auswahl durch die Ausstellungsmachenden, seine Funktion innerhalb der Ausstellung Berücksichtigung findet.

1382 Vgl. für eine entsprechende Beschreibung der in der Ausstellung enthaltenen Bildquellen Abschnitt 8.3.2.

1383 Hamann 2007, S. 65 f. 
Gottfried Boehm, auf den Hamann mit seiner Differenzierung in «Bild» und «Abbild» Bezug nimmt, geht von diesbezüglich im Bild selbst angelegten Potenzialen aus, nämlich einerseits von der

«Möglichkeit, dass Bilder ganz selbstvergessen in der Illusionierung von etwas Dargestelltem aufgehen oder - umgekehrt - ihr bildliches Gemachtsein betonen. In extremis verleugnet sich das Bild als Bild ganz, um die perfekte Repräsentation einer Sache zustandezubringen. Dieses Ziel erreicht es, wenn wir als Betrachter getäuscht werden, das Bild für das Dargestellte selbst halten, es als Bild gleichsam übersehen.» ${ }^{1384}$

Für meine Arbeit ist weniger die von Boehm beschriebene in den Bildern selbst liegende Eigenschaft von Interesse als vielmehr die Beobachtung, dass Besuchende in der Art und Weise, wie sie sich über Bilder äussern, deren Dimension als Abbilder in den Vordergrund stellen. Ob sie dabei das Bild als Bild vollkommen vergessen, lässt sich nicht feststellen, mindestens aber, dass sie bei ihren Äusserungen in vielen Fällen auf das Abgebildete fokussieren, während das Bild als Konstruktion demgegenüber in den Hintergrund rückt. Im Datenmaterial liegt ein breites Spektrum von Äusserungen vor, in denen das Bild als gestaltetes Bild oder als Element der Ausstellung entweder gar nicht oder nur in gewissem Ausmass sichtbar gemacht wird. Letzteres geschieht in der idealtypischen Struktur eines 〈das Bild zeigt x〉, 〈auf dem Bild sieht man x〉, durch die das Bild als Ausstellungselement sichtbar wird, ohne dass dabei allerdings bereits im engeren Sinn auf die Konstruiertheit des Bildes selbst oder auf seine Rolle als Element in der Ausstellung eingegangen wird. Die nachfolgenden Beispiele decken das geschilderte Spektrum ab, wobei in den ersten beiden Äusserungen das betrachtete Medium überhaupt nicht sichtbar wird, in den darauffolgenden in gewissem Mass.

"Oh, jetzt bekommen sie noch Nummern eingebrannt, wiuini, (...) ich glaube das macht dem Pferd Schmerzen, oh weh. (...) Die Truppen übernehmen jetzt die Pferde. (...) Es sind sehr viele Pferde.» (P3, Absatz 41-42)

"Alle winken sie mit Taschentüchern.» (P27, Absatz 56)

1384 Boehm 2001, S. 34. 
«Die Entente, die Mittelmächte, die Kriegsschauplätze. Und da sieht man eigentlich geradehin, wie eklig eigentlich die Position der Schweiz hier ist. Mittendrin, zu Österreich-Ungarn und zum Deutschen Reich in engster Nachbarschaft, immerhin, Frankreich, Entente im Westen, und dann im Süden Italien.» (P12, Absatz 56)

«Der Film hier zeigt Demonstrationen (...), und langsam (...) wollen die Menschen anscheinend da nicht mehr mitmachen.» (P3, Absatz 67)

"Einige Abbildungen zeigen Frauen (...), wie sie Wäsche nähen, (...) oder flicken, wie sie (...) Brot verpacken, (...) in einem Casino (...) Soldatenwäsche sortieven.» (P28, Absatz 60)

"Ah, jetzt seh ich hier (...) auf diesem schwarz-weissen Foto hier, mit den italienischen Arbeitern an der Margarethenstrasse, da sieht man oben den Margarethenhïgel und links die schönen Häuser, die da stehen, die zum Gundeldinger Quartier gehören.

Und das ist wahrscheinlich ein Stück weit auch diese grosse Wiese, diese Matte, die da ist, wo es rechts zum Kreisel nach Binningen und Oberwil geht und zum Hintereingang vom Zolli. Das ist eine wahnsinnig grosse Zabl.» (P12, Absatz 53)

Die bislang gezeigten Beispiele resultieren aus einem Beschreiben des Gesehenen, andere, strukturgleich klingende Aussagen in Bezug auf Bildquellen integrieren Informationen aus beigefügten Quellentexten bzw. Bildbeschriftungen, die der räumlichen und zeitlichen Einordnung des Abgebildeten dienen, wobei auf diese Beschriftungen wie auch zuvor auf die Bilder als Medien mit unterschiedlichem Grad an Explizitheit Bezug genommen wird.

«Und das ist (...) hm (...) Bielersee in dem Fall.» (P22, Absatz 40)

«Das ist zwischen Hegenheim und Allschwil.»(P12, Absatz 38)

«Ah, das ist 1919, nach dem Krieg.»(P6, Absatz 38) 
"Da gucken sie alle in die Kamera. (...) Wo ist das? ‘Ein Esslokal der Volksküche. Kriegsfürsoge (abends) in der Turnhalle in Basel, Dreirosen〉. Okay.» (P6, Absatz 54)

Gemeinsam ist all diesen zitierten Beispielen, dass in ihnen Besuchende das auf Bildquellen Abgebildete beschreiben oder benennen, das Abgebildete räumlich oder zeitlich einzuordnen versuchen, wobei teilweise auch das Bild in seiner Rolle als Element der Ausstellung mit aufscheint, ansonsten jedoch nicht auf die Konstruktion des Dargestellten eingegangen wird.

Thematisierungen von Bildern als Abbilder finden sich im Material vorwiegend im Zusammenhang mit Fotografien und Filmen. Jedoch findet sich auch eine Textstelle, in der sich dieses Muster im Umgang mit einem Gemälde zeigt. So äussert sich P22, vor einem Gemälde von Niklaus Stöcklin und der zugehörigen Bildbeschriftung stehend:

"Das ist (...) 〈Erschütternde Leere〉 (...). Und das ist (...) Ah, 〈Hartmannsweilerkopf $>$, das ist im Elsass, gar nicht so weit weg. Das geht gegen (...) ah, wie heisst jetzt (...) 1919, Niklaus Stöcklin, er hat gelebt von 1896 bis 1982. (...)

Jetzt weiss ich den Berg dummerweise nicht mehr, wie er heisst. Aber da bin ich schon selber gewesen. (...) Also gut, dort hat es natürlich ganz, jetzt siehts natürlich ganz anders aus, da sind natürlich Schnee (...), und dann da der gebrochene (...) Stamm, den man da sieht. (...) Und da siebt man aber doch wieder eine Art, ein Aufkeimen vom Bild, wo wieder etwas Neues entstehen könnte, also ein Baum oder irgendeine Art, und ein Mann, der drüber läuft, und ein paar Kreuze sieht man drauf. Also es ist sehr eindrücklich, scheint mir persönlich.» (P22, Absatz 2-3)

In diesem Beispiel findet sich ein Ineinandergreifen mehrerer Zugänge: Anfänglich fokussiert P22 stärker auf das Bild als Exponat und als gestaltetes Bild, benennt mithilfe der Bildbeschriftung Titel und Maler des Bildes. Auch am Ende der Textstelle macht P22 mit dem Hinweis «sieht man drauf» deutlich, ein Bild vor sich zu haben, dessen Elemente er oder sie beschreibt. In der dazwischenliegenden Passage thematisiert P22 das Bild stärker als Abbild. Er oder sie vergleicht die dargestellte Szenerie mit den eigenen Erfahrungen bei einem Besuch am Hartmannsweilerkopf und mit einem «jetzt». Der Hinweis «jetzt siehts natürlich ganz anders aus» bringt die implizite Annahme zum Ausdruck, dass es damals so ausgesehen 
habe, wie auf dem Bild dargestellt. P22 thematisiert in diesem Moment das Bild als Abbild vergangener Realität, die mit heutiger Realität vergleichbar ist. Abgesehen von diesem Beispiel, findet sich in den Äusserungen der Besuchenden eine Fokussierung auf das Abgebildete als Spiegel vergangener Wirklichkeit jedoch in der Regel im Zusammenhang mit Fotografien und Filmen.

$\mathrm{Zu}$ (2): Dass die Besuchenden die in der Ausstellung gezeigten Fotografien und Filme im Sinn Boehms oder Hamanns tatsächlich als «Bild» thematisieren, also auf ihre Konstruiertheit als Bild zu sprechen kommen, kommt in der Auseinandersetzung mit Fotografien und Filmen demgegenüber eher selten vor. Ansätze hierfür finden sich etwa in den Äusserungen von P8:

"Hier (...) wird das romantische Soldatenleben dargestellt. Muntere Soldaten, die sich auf ibren Karren stützen, martialische Symbole auf der Mütze. Kinder, die sich des Anblicks erfreuen. Insgesamt so, wie ich mir die Schweiz vorstelle. Ein rubiges Bild. (...). Eine Idylle.» (P8, Absatz 12)

"Ja, (unv.), Darstellung des Soldatenlebens. (...) Das hier mehr als Zeit erscheint, in der man sich die Langeweile irgendwie vertreiben muss, indem man Briefe schreibt, Gedichte schreibt, was auch immer. (...) Indem man Karten spielt, im Stroh rumsitzt, was einen aber nicht daran hindert, hochpatriotische Bilder zu verfassen. (...) Mit einer für alle und alle für einen in Musketiermanier. (...)» (P8, Absatz 15)

"Film leicht beschleunigt, klassisches Filmmaterial zum Ersten Weltkrieg. Ich denk (...), der Film zeigt die Schlagkraft der Schweizer Armee. (...) Marschbereitschaft, immer in Abwebrbereitschaft. (...) Schweizer Kavallerie.» (P8, Absatz 27)

Deutlich häufiger - und offenbar naheliegender - kommen Besuchende in Auseinandersetzung mit Karikaturen auf den Konstruktcharakter von Bildern zu sprechen. In der Ausstellung «14/18» wurden unter anderem Karikaturen aus kriegführenden Staaten gezeigt, die zu Propagandazwecken auch in der Schweiz verbreitet wurden und klischeehafte, stereotype Darstellungen, Verhöhnungen des jeweiligen Kriegsgegners beinhalten. Ich zeige nachfolgend eine Auswahl von Äusserungen der Besuchenden in Bezug auf diese Karikaturen, in denen sie sich für die Dimension als gestaltete, konstruierte Bilder als sensibel erweisen. 
"Und (...) hier sehe ich auch die (...) angekündigten (...) Propagandabemühungen (...) aus (...) Deutschland, (...) Grossbritannien (...) oder Frankreich. (...) Die Entente-Staaten (...) stellen (...) die deutsche Kriegsfübrung als sebr brutal dar, die Zerstörungen in Belgien oder (...) der Kathedrale von Reims (...) werden aufgegriffen, um Deutschland in der Weltöffentlichkeit (...) in ein schlechtes Licht zu rïcken, (...)

während eine deutsche Postkarte die (...) Blockadepolitik (...) Grossbritanniens (...) kritisiert. (...)» (P28, Absatz 39-41)

"Karikaturen als (...) Propagandawerkzenge. (...) Kommt dann der jeweilige (...) Gegner immer sehr schlecht weg. (...) Die Russen als wodkasüchtig. (...) Deutschland muss nach allen Seiten (...) sich (...) erwehren, (so) (...) sieht das hier aus.» (P26, Absatz 21)

«Ausländische Propagandapostkarten gegen die Zentralmächte〉. Also gut (...). Man sieht hier diesen, diesen Stier mit Pickelhaube. (...) Und ich weiss jetzt gar nicht, ist es ein ungarischer Soldat? Österreich-Ungarn oder (...) hm, so ein bisschen Erklärung wär jetzt nicht schlecht. (...)

Das ist wahrscheinlich Belgien, dieses Kind, also würde zumindest zeigen, der erste deutsche Sieg, und das war ja unter anderem die, diese feige Tat, die Neutralität Belgiens zu missachten, und das zeigt ja vielleicht gevade dieses Kind, das, ein Kind per se ist webrlos, dieses hier ist auch noch fest verschnürt und könnte sich gav nicht webren. Wenn da so symbolisch schon eine Waffe davan bängt, ja, macht sich somit zu Recht über die deutsche vermeintliche Siegestaktik hier lustig und lächerlich, weil es ja wirklich mehr als perfide ist, hier Wehrloses anzugreifen.

[...]

〈Verhöhnung der britischen Kolonialtrupppen〉, genau.

[...] [hier geht P12 auf spezielles Vorwissen zum Thema und dessen Herkunft ein; wegen Anonymisierung nicht zitiert]

und genau dass, dass, dass die deutsche Propaganda, obwobl sie ja selber auch afrikanische Kolonien hatten, sich hier lustig macht und (...) sich hier lustig macht über Afrikaner und Häuptlinge und sie so als Buschmänner (tangiert). Ich frage mich, 〈das stolze England, genau, über die hatten sie sich ja auch lustig gemacht und ibre Kolonialtruppen aus Indien und von überall. 〈Das stolze England weiss für sich und seine Alliierten noch eine Hilfe. Es wendet sich flehend andie (...) Bantu〉-wahrscheinlich-〈Neger. Der Häuptling Billi Billi〉, 
das ist auch wieder so 'verspricht mit 500000 Mann in Marseille zu landen.' Genau, totale Verböhung. Häuptling Billi Billi ist ja auch so was. Und 500000 Mann ist nicht nur natïrlich mega absurd, sondern auch so eine Verböhung der Truppen, die anscheinend so eine ganze Division zur Untersützung bräuchten.» (P12, Absatz 97-98, 101)

Insbesondere die zuletzt zitierte Person P12 ist im untersuchten Sample auffallend, da er oder sie viel Aufmerksamkeit für die in der Ausstellung enthaltenen Karikaturen verwendet und sich als sensibel für die entsprechende "Bildsprache» (P12, Absatz 123) erweist, dabei aber auch feststellt, an die eigenen Grenzen zu stossen:

"Das find ich hier hochspannend, aber da muss man schon grosser Fachmann sein, um hier die volle Bildsprache zu verstehen, wenn es nicht noch ein bisschen Text gäbe.»(P12, Absatz 123)

Eine explizite Äusserung darüber, dass die gezeigten Karikaturen eine «Bildsprache» aufweisen, ist in dieser Weise im Datenmaterial einmalig.

$\mathrm{Zu}$ (3): Äusserungen über die Art der Darstellung stellen eine Möglichkeit dar, um konstruktionssensibel mit den in der Ausstellung enthaltenen Bildmedien umzugehen. Auf einer anderen Ebene zeigen sich konstruktivistische Zugangsweisen auch dann, wenn Besuchende sich über die von der Ausstellung geleistete Bildauswahl äussern und über die Rolle, die Bilder als Exponate in der Erzählung der Ausstellung spielen. Dass Besuchende bisweilen durchaus in konstruktionssensibler Art und Weise über die Exponatauswahl der Ausstellung sprechen, wurde bereits andornorts deutlich. ${ }^{1385}$ Ich zeige nun noch einige Beispiele, in denen sich Besuchende spezifisch über die Auswahl von bildlichen Quellen, deren Funktion und über damit verbundene Deutungen Gedanken machen:

"Giftgas in (unv.) (...) und dazu passend eine Abbildung (...) mit einer Übung (...) mit Gasmasken.» (P28, Absatz 55)

«Das Fallbeispiel (...) um die Obersten-Affäre (...) wird mit Karikaturen dokumentiert. (...)

1385 Vgl. Abschnitt 8.6.3.1. 
und soll die These belegen, (...) dass das - Zitat - <Land zwischen den Sprachregionen und den sozialen Geschicht/ Schichten tief gespalten> war.» (P28, Absatz 117-118)

"Also die Originalbilder (...) hier (...), das finde ich sehr gut. (...) Ich frage mich nur, warum hier so (...) auf die Pferde Wert gelegt wird.» (P4, Absatz 34)

Wie die zuletzt zitierte Person P4 verbinden gleich mehrere Besuchende die Betrachtung des in der Ausstellung gezeigten Films über das Einrücken der Pferde in die schweizerische Armee mit der Feststellung oder Frage, dass bzw. warum Pferde in der Ausstellung eine besondere Rolle einnehmen. Neben der Filmquelle werden Pferde auch in zwei Ausstellungstextelementen erwähnt und dort die Zahlen der für die Armee mobilisierten Pferde genannt. Auch P8 kommt bei Betrachtung der Filmquelle auf die Bedeutung der Pferde zu sprechen, in seinem Fall zum wiederholten Mal ("Wieder die Pferde»), nachdem er kurz zuvor bereits im Zusammenhang mit einem Ausstellungstext festgestellt hat, dass Pferde «hier» - gemeint ist wohl die Erzählung der Ausstellung - «öfters auftauchen»:

«Zwischen dem 3. und 7. August rücken 220000 Mann und 45000 Pferde ein.' Die 45000 Pferde scheinen wobl eine sehr grosse Bedeutung zu haben, da sie hier öfters auftauchen. Ist auch eine beeindruckende Zabl.

[...]

〈Unsere Armee〉 (...). Wieder die Pferde, die hier eine herausragende Rolle spielen.»(P8, Absatz 20 und 27)

Angesichts des Kontexts und der im ersten Fall vermutlich ausstellungsnarrativbezogenen Feststellung einer Bedeutung der Pferde liegt der Schluss nahe, dass P8 sich auch in der zweiten Äusserung auf das Narrativ der Ausstellung bezieht, wenn er oder sie von der Bedeutung der Pferde spricht. Denkbar, wenn auch nicht wahrscheinlich, wäre aber auch, dass P8 dabei die Bedeutung der Pferde im Film selbst anspricht, womit er oder sie sich über die Konstruktion des Films als Medium und nicht die Konstruktion der Ausstellung äussern würde.

Wie ich gezeigt habe, gibt es ein grosses Spektrum von Varianten, in denen sich Besuchende in Bezug auf oder ausgehend von den in der Ausstellung enthaltenen Bildquellen äussern. Dabei wir ein Element teilweise stärker (1) als Abbild historischen Geschehens, teilweise stärker (2) als konstruiertes Bild oder teilweise stärker (3) als Exponat innerbalb der Ausstellung thematisiert, und es kommen 
wechselweise stärker positivistische oder konstruktivistische, stärker geschehensoder ausstellungsbezogene Zugangsweisen zum Zug. Abbildung D verdeutlicht die Schnittstellenposition des Umgangs mit Bildquellen am Übergang zwischen geschehens- und ausstellungsbezogenen Zugängen, an der sich das komplexe Datenmaterial häufig einer exakten Kategorisierung und Zuordnung widersetzt.

Im Sinn einer strukturierenden Inhaltsanalyse mit dem Anliegen, das Spektrum geschehens- und ausstellungsbezogener Äusserungen möglichst klar voneinander zu unterscheiden, versuchte ich mich gleichwohl an der Formulierung von Regeln für eine eindeutige Zuordnung der Äusserungen. Ich entschied mich dazu, sämtliche Äusserungen, in denen Besuchende bildlich Dargestelltes als Abbild historischen Geschebens (1) thematisieren, als Aussagen über historisches Geschehen (Fokus I) zu behandeln, selbst wenn darin bis zu einem gewissen Grad auch ein Element als Exponat thematisiert wird (z. B. "Der Film hier zeigt Demonstrationen, (...) und langsam (...) wollen die Menschen anscheinend da nicht mehr mitmachen.", P3, Absatz 67). Umgekehrt wurden Äusserungen, in denen das Identifizieren oder sonstige Sprechen über ein Bild als Exponat in der Ausstellung (3) in diesem Moment die Hauptaussage darstellt, dem Fokus II und damit den Äusserungen über die Ausstellung und ihre Elemente zugerechnet (z.B. "Ich sehe Bildquellen (...) zum Landesstreik», P28, Absatz 86).

Eine Schnittstellenposition nehmen all diejenigen Äusserungen ein, in denen Besuchende Bilder als konstruierte Bilder (2) thematisieren, als Bilder, die bestimmte Dinge beabsichtigen oder ausdrücken sollen. Bei derartigen Äusserungen handelt es sich um konstruktivistische Zugriffe, die sich allerdings nicht auf die Erzählung der Ausstellung beziehen und nicht das Bild in seiner Rolle als Exponat der Ausstellung sichtbar machen, sondern in seiner Rolle als historisches Element, in seiner historischen Intention und damit als Teil vergangenen Geschehens. Derartige Äusserungen rechne ich deshalb, wie auch räumliche und zeitliche Einordnungen von bildlich Dargestelltem, dem Fokus I zu.

Generell befinden sich jedoch quellenkritische Einordnungen von Elementen im Schnittstellenbereich zwischen geschehens- und ausstellungsbezogenen Äusserungen. Ich habe mich dazu entschieden, diejenigen Äusserungen, in denen Besuchende Quellen als Teil historischen Geschehens thematisieren, sie beispielsweise zeitlich und räumlich einordnen und im Hinblick auf ihren Entstehungsund Verwendungskontext thematisieren, als geschehensbezogene Äusserungen zu fassen. Allerdings zeigt sich immer wieder, dass solche geschehensbezogenen Einordnungen von Elementen fliessend übergehen können in explizite Thematisierungen eines Elements als Quelle oder in Äusserungen über seine Position als 
Exponat innerhalb der Ausstellung, die ihrerseits dann den ausstellungsbezogenen Äusserungen im Fokus II zuzurechnen wären. Die folgende, bereits teilweise zitierte Äusserung von P8 bringt diese Grauzone zum Ausdruck:

«Unsere Armee» (...). Wieder die Pferde, die hier eine herausragende Rolle spielen (...). Film leicht beschleunigt, klassisches Filmmaterial zum Ersten Weltkrieg. Ich denk (...), der Film zeigt die Schlagkraft der Schweizer Armee. (...) Marschbereitschaft, immer in Abwehrbereitschaft. (...) Schweizer Kavallerie. (...)» (P8, Absatz 27)

In der Äusserung von P8 zeigt sich ein Ineinandergreifen von mehreren Ebenen des Umgangs mit Bildern. Im ersten Teil bringt P8 den Film - mutmasslich, wie oben beschrieben - in Zusammenhang mit der Erzählung der Ausstellung und der darin zu beobachtenden Bedeutung der Pferde. Damit behandelt P8 den Film als Teil des Ausstellungsnarrativs, also in seiner Rolle als Exponat. Im zweiten Teil äussert sich P8 allerdings mutmasslich auch über die Konstruktion des gezeigten Films selbst, stellt nämlich fest, der Film zeige «die Schlagkraft der Schweizer Armee». Auch hier wäre allerdings umgekehrt denkbar, wenn auch nicht wahrscheinlich, dass sich P8 nicht auf die Konstruktion des Films als historisches Element bezieht, sondern stattdessen der Ausstellung die Absicht zuschreibt, mit dem Film "Schlagkraft», "Marschbereitschaft» und "Abwehrbereitschaft» darzustellen.

In der dazwischenliegenden Passage ordnet P8 den Film als «klassisches Filmmaterial zum Ersten Weltkrieg» ein. Insbesondere in dieser Passage kondensiert sich das oben festgestellte Ineinanderfliessen von geschehens- und ausstellungsbezogenen Aussagen. Ich fasse die Äusserung als ausstellungsbezogene Äusserung über die in der Ausstellung zu sehende Exponatauswahl und damit als Äusserung im Fokus II. Ebenso wäre sie jedoch mit guten Gründen den geschehensbezogenen Äusserungen zuzurechnen, weil darin ein Element als aus einem historischen Zusammenhang stammend thematisiert wird.

Gerade im Umgang der Besuchenden mit Bildquellen, aber auch anderen Quellentypen zeigt sich in dieser Weise immer wieder ein Ineinandergreifen der Fokussierungen und erweisen sich Versuche einer Herstellung von Trennschärfe zwischen dem Fokus I und II als offensichtlich konstruiert. Weiter unten wird sich darüber hinaus zeigen, dass sich im Umgang mit Bildquellen überdies auch zahlreiche Äusserungen in Bezug auf die eigene Person und Lebenswelt der Besuchenden (Fokus III) ergeben. Dort werde ich unter anderem an der Idee von Bildquellen als Abbilder historischer Wirklichkeit anknüpfen und Überlegungen der 
Besuchenden skizzieren, wie sie sich selbst als Person über Abbildungen in historisches Geschehen hineinversetzen können - ein Bereich, der in der Systematik des der Kapitelgliederung zugrunde liegenden Fokussierungsmodells dem Fokus III auf die eigene Person zugehört und deshalb erst dort beschrieben wird. Bildquellen erweisen sich insgesamt als Elemente, die an der Schnittstelle zwischen allen drei Fokussierungen platziert sind. In den Äusserungen der Besuchenden im Zusammenhang mit Bildquellen liegen insofern besondere Potenziale, um über Abgrenzungen, aber auch über Überschneidungen zwischen den drei Fokussierungen nachzudenken.

\subsubsection{Identifizieren als zentraler Modus des Ausstellungsbesuchs}

Den nun noch verbleibenden Teil von Abschnitt 8.6 verwende ich darauf, ausgewählte Bereiche von Äusserungen differenzierter in den Blick zu nehmen. Innerhalb des Fokus II als insgesamt auffallend vorkommend haben sich identifizierende Tätigkeiten der Besuchenden erwiesen, und zwar einerseits element- und andererseits themenidentifizierende Äusserungen, die in der Gesamtschau die mit Abstand am häufigsten vorkommenden beiden Varianten innerhalb der Äusserungen im Fokus II darstellen. ${ }^{1386}$ Identifizieren lässt sich deshalb gesamthaft als ganz wesentlicher Modus des Ausstellungsbesuchs beschreiben.

Als Beispiele für das Identifizieren von vorhandenen Elementen dienen die nachfolgenden drei Textstellen:

«Dann haben wir hier ein Plakat von der Basler Volksküche.» (P8, Absatz 4)

"Auch noch eine Propaganda-Postkarte.» (P4, Absatz 42)

"Hier stehe ich vor einer Vitrine mit (...) den Ausrüstungsgegenständen der Soldaten.»(P28, Absatz 33)

1386 Die Rede ist hier wiederum von der Anzahl vorkommender Ereignisse. Zu den identifizierenden Äusserungen zähle ich hier Äusserungen in den Kategorien Elemente identifizieren/ benennen und Themen identifizieren/benennen. Als verwandt damit lassen sich zudem Äusserungen in den angrenzenden Bereichen Übergreifende Themen/Leitthemen identifizieren und Elemente als Quelle/Original/Beleg/Exponat benennen betrachten, die das Spektrum identifizierender Aktivitäten noch erweitern. 
Themenidentifizierende Aussagen treten wie in den nachfolgenden Beispielen auf: «Ah, das gehört noch zum, zum Bereich Hilfe und Not.»(P12, Absatz 155) «Okay, jetzt kommt das Rote Kreuz ins Spiel.» (P6, Absatz 43) "Also die humanitäre Hilfe ist ein Thema hier, Menschlichkeit und auch (...) das Ansehen im Ausland von der Rolle der Schweiz.» (P3, Absatz 62)

"Ja, das ist etwa da, die verschiedenen Säulen, die Nationalismus, nationalistische Tendenzen und (...) Protektionismus symbolisieren oder thematisieren.»(P7, Absatz 33)

Inwiefern bei diesen themen- und elementidentifizierenden Aktivitäten die Ausstellungselemente und vorkommenden Themen plausibel benannt, erkannt, identifiziert werden oder mit den Intentionen der Ausstellungsmachenden übereinstimmen, spielt für die Kategorisierung keine Rolle und wird auch nicht beurteilt. Ausschlaggebend für die Kategorisierung war vielmehr herauszufinden, in welchem Modus sich die Besuchenden in diesem Moment befinden, und dies ist in den genannten Beispielen der identifizierende Modus.

Unmittelbar verwandt sind damit auch all diejenigen Äusserungen der Besuchenden, in denen sie das auf Bildquellen Dargestellte identifizieren und dieses als Abbild historischen Geschehens thematisieren. ${ }^{1387}$ Diese Äusserungen wurden gemäss meinen Ausführungen im vorigen Kapitel strukturell dem Fokus I zugerechnet, lassen sich aber in systematischer Hinsicht ebenfalls als identifizierende Aktivitäten verstehen.

Für eine allgemeine Einschätzung der Bedeutung von identifizierenden Tätigkeiten überdies zu bedenken wären all diejenigen Äusserungen, in denen Besuchende Ausgestelltes nur durch das Vorlesen von Exponatbeschriftungen identifizieren, wobei diese Äusserungen im Rahmen der vorliegenden Analyse als lesende Aktivitäten klassifiziert und nicht näher betrachtet wurden, aber als identifizierende Aktivitäten ebenfalls in Betracht zu ziehen sind. In der Berücksichtigung all

1387 Aus dem von ihr angeführten Materialbeispiel entnehme ich, dass Wise derartige Aktivitäten gesamthaft unter der Kategorie «Identifying and describing» einordnet (Wise 2011, S. 98). 
dieser Aspekte lässt sich konstatieren, dass Identifizieren insgesamt einen ganz zentralen Modus innerhalb des Ausstellungsbesuchs darstellt.

\section{Im Brennpunkt: P20}

\section{«Das Café Spitz seh ich. Also ist das die Mittleve Rheinbrïcke.»- Identifizieren- de Tätigkeiten}

Eine Person, die sich mit auffallendem Schwerpunkt im identifizierenden Modus durch die Ausstellung bewegt, ist P20. Innerhalb der ausstellungsbezogenen Äusserungen erweisen sich element- und themenidentifizierender Aktivitäten hier als der bei Weitem überwiegende Modus. Hinzu kommen identifizierende Aktivitäten bei der Bildbetrachtung, deren Bedeutung sich ebenfalls stellvertretend anhand von P20 illustrieren lässt und auf die ich nachfolgend zunächst eingehe.

Bei P20 zeigt sich ein auffälliges, sich wiederholendes Muster, das sich gleich zu Beginn des Besuchs erstmals manifestiert, als P20 einen grossformatigen Basler Stadtplan betrachtet, auf dem in Form von Klappkarten Fotografien aus der Zeit des Ersten Weltkriegs in Basel angebracht sind. Zum Lesen der zugehörigen Bildbeschriftungen müssen Besuchende die Karten umklappen und deren Rückseite konsultieren. P20 geht damit dergestalt um, dass er oder sie in vielen Fällen zunächst das auf den Fotografien Abgebildete beschreibt und zu identifizieren versucht und sich anschliessend der Beschriftung auf der Rückseite zuwendet. P20 tut dies mit dem Impetus des Bestätigens, Ergänzens bzw. Falsifizierens der vorher geäusserten Vermutungen über das Dargestellte. Seine oder ihre Äusserungen können also nicht nur als Beispiele für die in diesem Kapitel relevanten identifizierenden Tätigkeiten, sondern zugleich auch für die weiter unten noch zu beschreibenden Vermutungen dienen.

Die folgenden Äusserungen zeigen das angesprochene Muster des Identifizierens und Vermutens und anschliessenden Verifizierens oder Falsifizierens der eigenen Annahmen:

"Da sind wir auf der Mittleren Rheinbrücke. Das Café Spitz sehe ich. Also ist das die Mittlere Rheinbrücke. Ein Soldat mit geschultertem Gewehr. Dann (...) Velofahrer mit Gamaschen und Knickerbocker. Das ist damals wahrscheinlich die übliche Bekleidung gewesen für Velofahrer. (...) Sücke, ich weiss nicht, reparieren die da irgendwas? (...) Mal schauen. Aha. ‘Verminung der Mittleren Brücke [...].» (P 20, Absatz 7) 
"Das nächste Bild (...) das sieht aus (...) nach einer Werkstatt. (...) Auf dem Tisch, das kann ich nicht unbedingt identifizieren, aber es könnte (...) Zündhölzer sein, die sie einpacken. Die werden, die Schachteln werden in einzelne Papiere eingeschlagen. (...) Es sind vorwiegend (...), nein eigentlich nur Männer (...), und zwar bis auf einen Bub, der da am Pfeiler steht, eigentlich alles mehr oder weniger Ältere, scheint mir. (unv.) (...) Aha, okay, also hab ich nicht recht gehabt mit meinen Zündhölzern. (...) <Arbeiter beim Verpacken von Farbstoffen für den ausländischen Markt. [...]>» (P20, Absatz 13-14)

"Auf dem nächsten Bild sieht man (...) Schweizer Offiziere und Soldaten, und wenn ich das richtig anschaue, haben die alle so Rotkreuzarmbinden, aber den Uniformen nach würde ich jetzt mal irgendwie (...) auf französische Soldaten tippen. (...) RICHTIG! ‘Französische Sanitütsmannschaft auf dem Weg zum Bundesbahnhof $[\ldots]>$.» (P20, Absatz 17)

Das in den Beispielen sichtbare Verhaltensmuster der Person - zunächst Betrachten, Beschreiben, Vermuten, Identifizieren, anschliessend erst Lesen der Beschriftungen - entspricht an dieser Stelle mutmasslich den Intentionen der Installation, die durch Anbringung der Beschriftungen auf der Rückseite der Karten zunächst zum Schauen anregt, und wird also durch die Ausstellung selbst gefördert. Dennoch zeigt sich auch hier ein Fall, in dem P20 zuerst die Beschriftung liest und sich anschliessend der Abbildung zuwendet - mutmasslich aus der Einsicht heraus, das Dargestellte nicht selbsttätig erkennen zu können:

"Da haben wir das Bild, ahbhh, sieht nicht so aus, wie wenn es Fasnacht wäre. Es siebt auch nicht so aus, wie wenn es eine 1.-Mai-Kundgebung wäre. (...)

Ich hab schon noch mal ein bisschen gespickt. Also es ist <Demonstration gegen die Teuerung auf dem Basler Marktplatz [...]>.» (P20, Absatz 9)

Der Befund erlaubt die Mutmassung, dass initiales Betrachten und eigenständiges Identifizieren möglicherweise vor allem dann als Weg gewählt wird, wenn auf der Fotografie genügend Elemente mit Wiedererkennungswert enthalten sind - wie im Fall der gezeigten Beispiele die Mittlere Rheinbrücke in Basel oder die Uniformen der französischen Sanitätsmannschaft.

Gerade im Bereich der militärischen Ausrüstungsgegenstände und Uniformen scheint P20 über Vorwissen zu verfügen, bilden diese doch einen thematischen Schwerpunkt der identifizierenden Tätigkeiten durch seinen oder ihren gesamten Besuchsverlauf hinweg und gehen die identifizierten Aspekte über das in den Bild- 
und Objektbeschriftungen Enthaltene hinaus. Zu diesem Eindruck passt, dass sich P20 gleich zu Beginn des Besuchs nach Lesen einer Bildquellenbeschriftung selbst als militärdienstkundige Person positioniert:

«[...] Die monatelangen ereignislosen Diensteinsätze, bei denen viel Wert auf Drill und Gehorsam gelegt worden ist, haben bei den Truppen zunehmend ein Gefühl von Sinnlosigkeit wach werden lassen.>

Kennen wir doch alles aus dem eigenen Militärdienst. Zwar zu einer anderen Zeit, aber (...) ja, damals schon so gewesen, heute auch noch immer so. (...)»(P20, Absatz 2)

Im Verlauf des Ausstellungsbesuchs bringt P20 immer wieder Wissen über das Militär ein, und zwar vornehmlich dann, wenn er oder sie die auf Bildquellen oder in Form von Dingquellen gesehenen Uniformen und Ausrüstungsgegenstände identifiziert, sowohl des schweizerischen Militärs als auch ausländischer Armeen, und die gesehenen Personen den jeweiligen Nationalitäten zuordnet. Auffällig ist zudem, dass P20 das Identifizieren von Ausrüstung und Kleidung vielfach kombiniert mit der Einordnung der Dienstgrade, die er oder sie vor sich zu haben glaubt. Einige ausgewählte Zitate verdeutlichen dies:

"Auf dem Bild, das ich jetzt anlï/, anschaue, sind Soldaten mit geschulterten Gewehren zu sehen, Patronentaschen um den Bauch. Also (...) ja, wie sie früher gewesen sind.»(P20, Absatz 15)

"Da haben wir eine Passkontrolle am Grenzwachtposten Tägerwilen, Konstanz'. (...) Ich weiss jetzt nicht, ob das (...), das sieht so nach deutschen Uniformen aus. (...) Also (...). Ja, ich kanns jetzt nicht genau (...) identifizieren, ob das Schweizer sind. (...) Könnte sein, aber dann haben die, die (...) die Hanben, die sie aufhaben, also nicht die Pickelhaube, die Tschakko, haben irgendeinen feldgranen Überzug, und das weiss ich nicht, ob die Schweizer das hatten.» (P20, Absatz 51)

"Da (...) auf dem Foto, ich, würd ich jetzt auch sagen, das sind (...) Franzosen. (...) Den Uniformen nach.» (P20, Absatz 90)

"Auf dem nächsten Bild sieht man (...) Schweizer Offiziere und Soldaten, und wenn ich das richtig anschaue, haben die alle so Rotkreuzarmbinden, aber den Uniformen nach wïrde ich jetzt mal irgendwie (...) auf französische Soldaten tippen.»(P20, Absatz 17) 
«Administration der französischen Internierten in der Schweiz〉. (...) Sind (...) Das könnten französische Uniformen sein, richtig. Wobei die (...) der Offiziere sicher nicht.» (P20, Absatz 76-77)

Die Fälle des Identifizierens von abgebildeten Uniformen und Ausrüstungsgegenständen ziehen sich wie ein roter Faden durch den Ausstellungsbesuch von P20. Identifizierendes Betrachten stellt den auffallendsten Modus im Umgang dieser Person mit (Bild-)Quellen dar. Eher selten bedient sich P20 der zugehörigen Beschriftungen, um das zu Sehende zu identifizieren. Vielmehr beschreibt er oder sie das Gesehene mit eigenen Worten und aus der eigenen Erfahrung.

Dies zeigt sich etwa auch in dem nachfolgenden Beispiel, in dem P20 sich mit militärischen Ausrüstungsgegenständen beschäftigt und diese identifiziert, die Objektbeschriftungen mutmasslich unberücksichtigt lassend, da die für die Beschreibung gebrauchten Begriffe nicht in der Beschriftung auftauchen.

"Da, da sieht man eine Munitionstasche, eine gefüllte. Dann (...) der (Horaff), sagt man zu dem Tornister, das ist bekannt gewesen, (Horaff), und (...) alte Gamelle, der Kaputt, der Mantel, überm Tornister gerollt. Das ist, ist, weiss ich von meinem Vater her noch, der hat auch so einen (Horaff) gehabt, und das ist genau festgelegt gewesen, wie, wie der musste, wie der gepackt werden musst auf den Tornister. (...)

Beim Gewehr dürfte es sich um ein Langgewehr handeln, also nicht um einen Karabiner, sondern eine etwas längere Variante, ein Langgewehr. (...) Dann (...) wie immer (...) Soldaten- (...) Soldatenspiele, Kartenspiele. Man sieht da einen Korporal, man siebt (...) Hauptmann mit seinen drei (Gallon), und eben - wie gesagt - die Reithosen und Reitstiefel, also wabrscheinlich aus besserem Haus.» (P20, Absatz 45-46)

Das Verhalten von P20 ist insofern auffällig und bemerkenswert, als sich bei ihm oder ihr während des Besuchsverlaufs immer wieder ein selbstständiges Beschreiben und Identifizieren des Dargestellten zeigt, ohne dass oder bevor zugehörige Bildbeschriftungen konsultiert werden. Regelmässiges selbstständiges Identifizieren als Muster zeigt sich neben P20 ausserdem bei P22, ${ }^{1388}$ wobei P22 auffallend

1388 Auch im Fall von P22 erstmalig im Eingangsbereich der Ausstellung bei der Beschäftigung mit den dort befindlichen Gemälden sowie den Klappkarten, denen sich P22 aber insgesamt deutlich kürzer als P20 widmet. Insgesamt beschäftigten sich überhaupt nur 
häufig vollständig auf die Lektüre von Objekt-/Bildbeschriftungen verzichtet. Dies führt dazu, dass P22 bisweilen zu eigenen, von den Bildbeschriftungen abweichenden Einschätzungen in Bezug auf das auf Bildern Dargestellte kommt.

Das nachfolgende Datenbeispiel verdeutlicht dies. Darin erkennt P22 auf einer Abbildung, die gemäss Beschriftung ein Lazarett für Grippekranke darstellt, stattdessen Soldatenschlafgemächer - obwohl er oder sie selbst vorher das Wort «Grippe» auf der Stellwand entdeckt hatte. Unmittelbar darauf identifiziert P22 eine Abbildung von Soldaten und Demonstranten im Kontext des Landesstreiks 1918 in Zürich sowie eine Versammlung anlässlich des Waffenstillstands 1918 in Lausanne als Szenen im Rahmen der Mobilmachung - dies, obwohl er oder sie offenbar mindestens einmal einen Blick auf eine Bildbeschriftung wirft ( ZZürich»):

"Da sieht man die (...) zum Teil Schlaf, 〈Grippe〉 heisst es da, aber die Schlafgemächer (...), wo es halt die Massen(...)Schlafgemächer gab, nicht einzeln oder zu zweit oder zu dritt (unv.), sondern eben wo alle einfach ibr Bett haben und vorne dran, das ist bei den Soldaten, das ist eigentlich normal, dass es so ist. (...) Da sieht man wieder etwas (...) auf der Strasse, wie sie sich auch wieder mobilmachen, ein Haufen Leute (...) Zürich (...).

[...]

Da sieht man (...) auch wieder (...) die Mobilmachung, >Papeterie fein und Tabak〉, hehe (lacht), lustig. (...)〈Chapellerie〉 (...)〈EOXE, Eloxe〉oder irgendso etwas, weiss nicht genau. (...)» (P22, Absatz 59-60 und 64)

Möglicherweise haben Militär, Soldaten und Mobilmachung für P22 eine besondere Bedeutung, was dazu führt, dass er oder sie diese Themen bereitwillig in die Abbildungen «hineinliest». ${ }^{1389}$ Auch bei der Abbildung des Schokoladeverpackens in einer Schokaladenfabrik und der daneben positionierten Kiste mit ausgestellten Schokoladentafeln stehend, kommt P22 zu einer militärbezogenen Einschätzung

4 von 18 Besuchenden mit diesem Stadtplan, mutmasslich deshalb, weil die Einweisung der Studienteilnehmenden erst räumlich hinter diesem Bereich stattfand (vgl. Fussnote 1019). Die übrigen zwei Besuchenden, P4 und P30, halten sich ebenfalls sehr kurz dort auf und wenden sich dabei gleich dem Lesen der Bildbeschriftungen zu, ohne wie P20 zuvor Vermutungen über das Dargestellte zu äussern.

1389 Auf Strategien des Umgangs mit nicht «den eigenen Deutungsmustern» entprechenden Informationen kommt auch Pampel zu sprechen, er spricht davon, dass diese «ignoriert, passend gemacht oder als nicht der Wahrheit entsprechend kritisiert» werden (Pampel 2007, S. 330). 
des Ausgestellten, wobei nicht eindeutig klar wird, ob er sich damit auf die Abbildung oder die Exponate in der Kiste bezieht, was insofern irrelevant ist, als aus keiner der jeweiligen Beschriftungen eine militärbezogene Konnotation hervorgeht.

"Das sind glaub Gutzli, die sie da verpacken, das typische, ah, Schokolade. (...) Und die typischen Gutzli, die man (...) im Militär bekommt.» (P22, Absatz 43)

Das Verhalten von P20 und P22 ist insofern auffällig und bemerkenswert, als sich bei ihnen während des Besuchsverlaufs immer wieder ein selbstständiges Beschreiben und Identifizieren des Dargestellten zeigt, bevor oder völlig ohne dass zugehörige Bildbeschriftungen konsultiert werden. Bei anderen Besuchenden entsteht umgekehrt oft der Eindruck, dass sie zügig Bild- oder Objektbeschriftungen zu Rate ziehen, statt sich zunächst ausführlicher auf das selbsttätige Identifizieren des Dargestellten einzulassen.

Oftmals kann allerdings auch gar nicht restlos geklärt werden, ob Besuchende bei der Benennung eines Ausstellungselements auf die zugehörigen Beschriftungen zurückgreifen oder dieses frei identifizieren. Hierauf habe ich bereits weiter oben im Zusammenhang mit den Abgrenzungsschwierigkeiten zwischen lesenden und freien Äusserungen hingewiesen. ${ }^{1390}$ Abgrenzungen sind dort verhältnismässig einfach, wo Besuchende sich beim Identifizieren Aspekten zuwenden, die gar nicht in den Beschriftungen erwähnt werden, wie im Fall von P20 teilweise für die Identifizierung von Militaria geltend. Abgrenzungen zwischen lesenden und freien Äusserungen sind auch in Bezug auf den im Eingang befindlichen Stadtplan gut sichtbar, wo das Konsultieren der Beschriftungen durch das Umdrehen der Kärtchen durch einen auf Video optisch sichtbaren Akt markiert wird. Das Verwenden einzelner Begriffe, die auch auf den zugehörigen Exponatbeschriftungen verwendet werden, lässt sich andernorts in der Ausstellung hingegen schwer kategorisieren. Zusammenfassend lässt sich jedoch, ungeachtet dieser Überlegungen zur Zuordnung, konstatieren, dass Identifizieren einen bedeutenden Bestandteil des Sich-Äusserns während des Ausstellungsbesuchs ausmacht, sei es, dass dies im Rahmen freier Äusserungen geschieht, oder sei es, dass Identifizieren schlicht auf dem Weg des Lesens von Exponatbeschriftungen durchgeführt wird.

1390 Vgl. Abschnitt 8.3.2. 


\subsection{4 Äusserungen der Besuchenden über Inhalt und Ästhetik der Ausstellung: Ästhetik als Deutungshilfe und strukturgebendes Element}

Zum Abschluss der Darstellung ausstellungsbezogener Äusserungen greife ich neben den identifizierenden Aktivitäten einen weiteren spezifischen Bereich detaillierter heraus. Es sind dies einerseits Äusserungen der Besuchenden zur ästhetischen Gestalt der Ausstellung, andererseits auch zu deren inhaltlicher Struktur. Ich widme mich nachfolgend dezidiert solchen Beispielen, in denen beide Aspekte Hand in Hand miteinander gehen und sich zeigen lässt, dass die Besuchenden vielfach die inhaltliche Struktur der Ausstellung nicht zuletzt auch aufgrund und anhand von ästhetischen Gliederungsmerkmalen erschliessen.

Beispielsweise erkennen vereinzelte Besuchende, dass die Ausstellung eine mit wachsender Zeit zunehmende soziale Spannung, eine fortschreitende «Erschütterung» ${ }^{1391}$ abbildet und dass dies unter anderem mittels zunehmender Schieflage der Stellwände symbolisiert wird. ${ }^{1392}$ So äussert eine Person:

"(Ja durch die) (...) Art, wie die Ausstellung hier gestaltet ist, (...) kann man sich vorstellen, wie da ein (...) ganz schönes Drunter und Drüber herrschte, (...) da gegen Kriegsende. Mit all den politischen Konflikten.» (P26, Absatz 52)

Eine andere Person bemerkt ebenfalls die szenografisch ausgedrückte Schieflage, beurteilt sie in einem ersten Schritt als bedeutungslos, formuliert gleich darauf jedoch eine mögliche Deutung:

"Auf die Nachricht des Waffenstillstands versammeln sich die Menschen auf dem Place Saint-François in Lausanne, um das Ende des Kriegs in Europa zu feiern, 1918.> (...) Lausanne, Saint-François, okay. (...)

Hmm (zustimmend). (...) Waffenstillstand. (...) Ja, es gibt viele ausstellungsarchitektonische Element drin, um den Raum wirklich auch zu füllen und (...). Im Endeffekt sind es Dekorationselemente, die sie da herstellen. (...) Die gar keine grosse Aussagekraft haben, aber (...). Ja, es wirkt, von der Raumgestaltung her wirkt es noch cool eigentlich. (...) Da (so) das Ganze symbolisiert so

1391 www.ersterweltkrieg.ch/hintergrund/ (25.8.2017).

1392 Vgl. zur Beschreibung der entsprechenden Architektur die Ausführungen in Abschnitt 7.3. 
ein bisschen auch ein, so einen Umbruch, so eine Unrube, so (...) so etwas Dramatisch-Hervorschnellendes. Ja, ist noch, ist effektvoll.»(P7, Absatz 37-38)

Explizit im Hinblick auf einen auf den Boden gezeichneten gespaltenen Rundkreis, der in einer von mir besuchten Ausstellungsführung als zerrissener Mantel von Helvetia gedeutet wurde und sich insofern vielleicht als Symbol für eine Spaltung der nationalen Einheit verstehen lässt, äussert eine Person:

"Hier finde ich auch sebr schön inszeniert, diese bedroblichen Reitertruppen, ja. Dann haben wir hier eine Spaltung der Gesellschaft. (...) Die Zeitungen sind ganz schöne Deko am Boden, aber lesen kann man die leider nicht.» (P8, Absatz 84)

Und wenig später äussert dieselbe Person mit ironischem Impetus:

"So (...). Hier haben wir noch schön (...) diese Spaltung und daneben dann dieses Ausgangsschild, womit man in die Einheit entlassen wird.» (P8, Absatz 97)

Demgegenüber kommentieren andere Besuchende zwar die auffallende Ausstellungsarchitektur, verbinden ihre Eindrücke dabei aber nicht explizit mit inhaltlichen Überlegungen:

"Die (...) dieses grosse Bild finde ich ein bisschen auseinandergerissen, aber das muss man sich vielleicht aus 'nem anderen Winkel anschauen, ah ja. (...) Gut, dann macht's wieder mehr Sinn.» (P4, Absatz 105)

"Okay, die ganze Sache wird immer wackeliger, da ist es schon schräg nach hinten (gekippt), jetzt kippt's vorne über.» (P6, Absatz 52)

«Kriegsende und Streik〉 (...) Ja ein bisschen VERWIRREND, die ganze Aufmachung. (...)» (P5, Absatz 25)

Nachfolgend gehe ich ausführlicher auf zwei bestimmte, ausstellungsarchitektonisch auffallende Ausstellungsteile ein, anhand deren sich ein Ineinander von ästhetischen und inhaltlichen Betrachtungsweisen der Besuchenden zeigen lässt. Es sind dies zum einen die wiederkehrenden und optisch von der übrigen Ausstellung 
abweichenden «Blick ins Ausland»-Elemente sowie die Schlussabteilung der Ausstellung zum Thema «Nach dem Krieg».

\subsubsection{Zum Umgang der Besuchenden mit den «Blick ins Ausland»- Elementen und der Struktur der Ausstellung}

Obwohl sich die Ausstellung mehrheitlich mit der Situation der Schweiz während des Ersten Weltkriegs beschäftigt, enthält sie doch auch Elemente, die unter dem Titel «Blick ins Ausland» das Geschehen bzw. den Kriegsverlauf ausserhalb der schweizerischen Grenzen thematisieren. Dies geschieht in Form von je dreiteiligen Stellwänden, die an mehreren Stellen des Ausstellungsverlaufs schlaglichtartig dazwischengeschoben werden und die durch ihre grüne Färbung von den übrigen, auf die Schweiz bezogenen Ausstellungsteilen mit roter Farbgebung abgegrenzt sind. Repräsentierter Inhalt und dafür gewählte Form korrespondieren also miteinander, wie auch in anderen Bereichen der Ausstellung.

Es gibt insgesamt fünf dieser Stationen, die sich je einem Kalenderjahr des Zeitraums von 1914 bis 1918 widmen und insofern einer chronologischen Struktur folgen. Eines der drei Teilelemente pro Station beinhaltet jeweils einen Ausstellungstext mit Überblick über das Geschehen im Ausland, ergänzt um eine Weltkarte, welche die zu der jeweiligen Zeit relevanten Schauplätze des Krieges verzeichnet. Hierbei handelt es sich um stillgestellte Ausschnitte aus einem zu Ausstellungsbeginn bereits gezeigten Film über die weltweite Entwicklung der Kriegsschauplätze im Zeitverlauf, den ich an dieser Stelle - obwohl von der Ausstellung selbst nicht explizit unter dem Titel «Blick ins Ausland» geführt - ebenfalls berücksichtige. In der Schlussabteilung «Nach dem Krieg» werden zudem historische Filmaufnahmen einer Schlachtfeldbegehung gezeigt und dort wiederum Bezug zu den kriegführenden Staaten genommen.

Über die fünf «Blick ins Ausland»-Stellwandeinheiten zieht sich jeweils eine grossformatige Fotografie, die aber Szenen aus dem schweizerischen Kontext abbildet und nur in manchen Fällen thematisch in Bezug zu diesem Blick ins Ausland steht. ${ }^{1393}$ Im Hintergrund der Elemente sind Zitatquellen angebracht, beispiels-

1393 Vereinzelt führt das zu Verwirrung. So glaubt P8 offenbar, auf einer Fotografie ausländische Soldaten vor sich zu haben, und nimmt auch die in einer Bildbeschriftung gefundenen Hinweise auf die Tätigkeit des Schwingens nicht zum Anlass, seiner Irritation Ausdruck zu geben: «Ja, also auch hier werden die Soldaten ähnlich wie die Schweizer dargestellt, wie sie mit Spass kämpfen, die Zeit vertreiben. (...) Oder mit Schwingen, Wrestling» (P8, Absatz 51). 
weise von Zeitzeugen des Kriegsgeschehens an der Front. Um diese Zitate lesen zu können, ist ein Blick durch die Schlitze zwischen den Stellwänden notwendig.

Wie gehen nun Besuchende mit diesen «Blick ins Ausland»-Elementen um? Reagieren sie auf die von der übrigen Ausstellung abweichende äussere Form? Welche Rolle schreiben sie den Blicken ins Ausland in Bezug auf die Gesamtausstellung zu? Ich schildere nachfolgend die zugehörigen Befunde und gehe dabei vom Groben zum Feinen und Tiefenstrukturellen vor.

Bei der Betrachtung der von den Besuchenden überhaupt behandelten Themen ${ }^{1394}$ fällt zunächst auf, dass die Teilnehmenden während ihrer Besuche im Vergleich doch häufig über das Thema Kriegsverlauf und (Kampf-)Geschehen im Ausland sprechen. Gemeinsam mit den Themen Güter/Prozesse/Import/Export innerhalb des Grossbereichs Wirtschaft sowie soziale Not/Ernährungskrise/Sozialhilfe innerhalb des Grossthemas Gesellschaft gehört es zu den meistbehandelten Themen, einerseits in der Hinsicht, dass alle oder fast alle Besuchenden sich überhaupt zu diesen Themen äussern, und andererseits in der Hinsicht, dass sie für viele von ihnen zu den persönlich oft behandelten Gegenständen gehören. Bei allen drei Themen handelt es sich zugleich um solche, die auch von der Ausstellung selbst ausführlich behandelt und jeweils an mehreren Stellen thematisiert werden - im Fall der Blicke ins Ausland wie geschildert an insgesamt sieben Stellen. Insofern ist die Bedeutung dieser Gegenstände in den Äusserungen der Besuchenden plausibel, auch wenn angesichts der Ausrichtung der Ausstellung «14/18» auf die Situation der Schweiz die Bedeutung des Themas Kriegsverlanf und (Kampf-) Geschehen im Ausland für die Besuchenden zunächst erstaunen mag.

Für eine differenzierte Betrachtung der Bedeutung dieses Themas ist auch ein Einbezug der Laufwege der Besuchenden aufschlussreich, um zu sehen, wie viele Besuchende die «Blick ins Ausland»-Elemente aufsuchen. Für die fünf «Blick ins Ausland»-Stellwandeinheiten finden sich jeweils Wortmeldungen von 13 bis $15 \mathrm{Be}$ suchenden. Zwar gibt es daneben andere Ausstellungseinheiten mit sogar bis zu 17 besuchenden Personen (siehe Abbildung 8 im digitalen Anhang), im Vergleich über die gesamte Ausstellung hinweg erscheinen die «Blick ins Ausland»-Elemente aber dennoch gut und vor allem konstant besucht, was umgekehrt wiederum auf eine Bedeutung hindeuten kann, die diese Elemente nicht nur aufgrund ihrer zahlenmässigen Häufigkeit, sondern auch thematisch für die Besuchenden haben. ${ }^{1395}$

1394 Vgl. Abschnitt 8.4 und Themenübersicht im Anhang.

1395 Einzig P27 lässt die «Blick ins Ausland»-Elemente weitgehend unbeachtet. Lediglich ein einziges Mal liest diese Person einen auf einem solchen Element befindlichen Ausstellungs- 
Meine Ausführungen zeigen die Problematiken und Deutungsschwierigkeiten, die mit einer quantifizierenden Betrachtung verbunden sein können, und unterstützen erneut das Anliegen, diese lediglich als sensibilisierende Instrumente für die folgende vertiefte, qualitative Analyse einzusetzen. Es gilt also zu erschliessen, worüber die Besuchenden genau sprechen, wenn sie sich mit diesen Elementen beschäftigen. Ich komme dabei in Kombination sowohl auf ausstellungs- als auch auf geschehensbezogene Aussagen der Besuchenden zu sprechen.

Zunächst lässt sich feststellen, dass die Besuchenden die von der Ausstellung gewählte Struktur erkennbar durchschauen und die Blicke ins Ausland als wiederkehrende Elemente identifizieren. Etliche Besuchende äussern sich etwa darüber, dass diese Elemente fortlaufend je einem Kriegsjahr gewidmet sind:

"Hier haben wir (wieder) den Blick ins Ausland, mit diesen Karten.» (P8, Absatz 71)

"Offenbar in chronologischer Jabresreibenfolge wird auch (...) der Blick ins Ausland (...) an verschiedenen Stationen der Ausstellung (...) thematisiert.» (P28, Absatz 110)

"Ah, hier ist (wieder) Blick ins Ausland, also das ist jetzt schon Ende 1916.»(P3, Absatz 55)

"'17, Blick ins Ausland> Das entwickelt sich jetzt chronologisch fort, das Ganze.» (P6, Absatz 41)

«Dann 1918, ein weiteres Jahr, Blick ins Ausland.»(P19, Absatz 91)

Sofern Besuchende sich über den Zweck der «Blick ins Ausland»-Elemente Gedanken machen, sehen sie diesen darin, in Bezug auf das Kriegsgeschehen "das Wichtigste» (P3, Absatz 72) in Kürze zusammenzufassen und «Überblickswissen» (P28, Absatz 111) oder «Kontext» (P12, Absatz 54) zu vermitteln. Entsprechende Äusserungen finden sich etwa in dieser Form:

text, freie Äusserungen finden sich in dem Zusammenhang jedoch nicht. Nichtsdestotrotz gehört aber auch für diese Person das Thema Kriegsverlauf und (Kampf-)Geschehen im Ausland zu den meistbehandelten Gegenständen. 
«Ja, kurz erklärt, wie es zum Kriegsausbruch gekommen ist.»(P19, Absatz 45)

«Was steht denn hier? <1914. Blick ins Ausland〉. Na, kommt jetzt ein bisschen Kontext.»(P12, Absatz 54)

"Dann 1917, Blick wieder ins Ausland. Das finde ich gut aufgemacht, so jedes Jahr, wo kurz dargestellt ist, was im Ausland passiert ist, oder?» (P19, Absatz 96)

«Der Begleittext vermittelt Überblickswissen über die Schlachten bei Verdun und an der Somme.» (P28, Absatz 111)

"Hier ist wieder ein internationaler Blick, so Zusammenfassung auf den Krieg, sehr gut gemacht.» (P3, Absatz 50)

"Also das ist sehr gut zusammengefasst, das Wichtigste (...) im Krieg mit den Karten dazu.» (P3, Absatz 72)

In eine ähnliche Richtung, aber ergänzt um eine zusätzliche Dimension, deuten die folgenden Äusserungen zweier Besuchenden:

«Blick ins Ausland». (...) Das ist die ganze Geschichte, da.»(P18, Absatz 44)

«Hier wird nochmals (...) diese Kriegserklärung von Österreich-Ungarn erklärt, also (...) eigentlich Geschichte.» (P3, Absatz 28)

Was genau von den Besuchenden an dieserStelle mit "ganz[er]»oder «eigentlich[er]» Geschichte gemeint ist, ist nicht eindeutig zu erschliessen. Insbesondere im ersten Beispiel scheint die Idee auf, dass ein Ausstellungselement diese «ganze» Geschichte überhaupt repräsentieren, quasi als Abbild derselben fungieren kann. Es handelt sich hier also erneut, wie weiter für den Fall von P19 dargestellt, um Aussagen über die Ausstellung bzw. die Darstellung in einzelnen darin befindlichen Elementen, in denen sich aber zugleich Vorstellungen über historische Wirklichkeit und deren Abbildbarkeit zeigen.

Möglicherweise manifestiert sich in den beiden Beispielen überdies ein Geschichtsverständnis, demzufolge die ausländische europäische oder Weltgeschichte als «eigentliche〉, 〈richtige> Geschichte zu betrachten sei und als Gegenpol zu 
der partikularen, in Bezug auf das Weltgeschehen womöglich irrelevanten oder maximal als Teilbereich anzusehenden Schweizer Geschichte. ${ }^{1396}$ Diese Deutung wird gestützt durch eine weitere Äusserung von P3, die sich an anderer Stelle des Besuchs im Zusammenhang mit der wirtschaftlichen Situation der Schweiz während des Krieges findet:

"Das ist interessant, das ist, das ist wirklich ein Thema, wie die Schweiz profitiert, das hab ich auch zu wenig (...). Ich hab bis jetzt Geschichte immer international angesehen, und hier wird jetzt auch sehr die Schweiz ins Zentrum gerückt, was die Schweiz gemacht hat. (...) Find ich interessant.» (P3, Absatz 48)

Auf eine Differenz zwischen Schweizer Geschichte und ausserschweizerischer Geschichte kommt auch P8 zu sprechen, ausgehend von der Konfrontation mit einer Zitatquelle, allerdings nimmt er oder sie dabei keine Abgrenzung zwischen einer schweizerischen Geschichte und einer <eigentlichen>, internationalen Geschichte vor:

«Was wird von allem übrig bleiben, wenn der Kampf zu Ende sein wird? Ein Leichenbaufen, ein Trümmerhaufen, ein Irrenbaus.> Ja, also bier (...) wird man jetzt tatsächlich mal angeregt, darüber nachzudenken, warum da überhaupt Krieg geführt wird, durch solche Zitate. Kommt in dieser Ausstellung relativ kurz, was aber (...) dem geschuldet ist, dass hier natürlich die Schweizer Perspektive eingenommen wird, die eben mit anderen Problemen zu kämpfen bat als eben die Frage nach dem Sinn dieses Krieges.» (P8, Absatz 72)

P8, weiter oben bereits als konstruktions- und deutungssensibel vorgestellt, ${ }^{1397}$ zeigt sich im hier zitierten Beispiel zugleich bewusst darüber, dass Ausstellungen perspektivisch sind und je nach Perspektive bestimmte Themen überhaupt zum Tragen kommen, andere wiederum nicht. Zugleich offenbart sich im Zitat auch ein Deutungsmuster von P8 selbst, nämlich dass die Situation in der Schweiz als verschieden zu der Situation in den kriegführenden Nationen zu betrachten sei.

\footnotetext{
1396 Diese Deutung ist angeregt durch eine Beobachtung, die Markus Furrer in Bezug auf schweizerische Geschichtslehrmittel formuliert hat, dass dort nämlich die Schweizer Geschichte bisweilen abgetrennt von der übrigen Geschichte dargestellt wird (Furrer 2004, S. 67; speziell für Lehrmitteldarstellungen zum Ersten und Zweiten Weltkrieg aufgegriffen und erneut festgestellt bei Thyroff 2017a, S. 169f.).

1397 Vgl. Abschnitt 8.6.2.
} 
Neben den Aussagen zur Struktur der Ausstellung und zur Funktion der «Blick ins Ausland»-Elemente innerhalb dieser sowie zu den von der Ausstellung vorgenommenen Deutungen finden sich auch ausstellungsbezogene Äusserungen, die eher die ästhetische Gestaltung der Elemente betreffen, so etwa die Farbgebung:

"Okay, also noch mal so zur Idee. Die Schweiz selber ist rot, und der Blick ins Ausland ist grün. So grafisch.» (P6, Absatz 55)

"Okay, (hier haben wir) wieder 1915, sind wir quasi ein Jabr weiter. (...) (Und wieder der grüne) (...) grüne Hintergrund, okay. (...) Der grüne Hintergrund (...) und wieder das Bild (...) vom Eingangsmonitor.» (P4, Absatz 53)

"Haben sie hier farblich ganz gut abgegrenzt, dass man sieht, jetzt geht es wieder in die Welt. (...)» (P8, Absatz 50)

"Jetzt (...) hab ich mich gerade gefragt, was denn eigentlich quasi (eher) um die Schweiz herum passiert, weil ja das vorher immer wieder gekommen ist quasi, dass immer wieder aufgenommen worden ist mit denen (...) mit den blauen Tafeln, wo der Blick ins Ausland ist.» (P13, Absatz 85)

Drei Personen kommen ausserdem auf die Kohärenz aus äusserer Form und Inhalt zu sprechen, die sich bei den «Blick ins Ausland»-Abteilungen manifestiert. So deutet P12 die grossformatigen Fotografien, die Szenen des soldatischen Alltags in den schweizerischen Grenzgebieten zeigen, als Versinnbildlichung eines Blicks über die Grenze:

"Also, nun denn, was ist denn hier? ‘Blick ins Ausland. Soldaten am Simplon vertreiben sich die Langeweile.> Das find ich jetzt schön, der Blick ins Ausland, und der Blick geht vom Simplon ins Ausland, nach Italien. Auch wenn hier urschweizerisch mit dem Schwingen Brauchtumsplege und, und Erholung zelebriert wird.» (P12, Absatz 137)

«Bick ins Ausland. Ein Beobachtungsposten am Splügen mit Sicht auf Italien.’ Das find ich jetzt sehr eindrücklich, wirklich. Wie die Blicke hier nach aussen gelenkt werden. Zugleich wird gezeigt, wie man hier die Wacht hielt. (...) So die Schweizer Antwort von der Wacht am Rhein. (...) Und gleichzeitig eben schon 
der Vorläufer des Réduits, schon damals, die Festung der Alpen und bier die Grenzübergänge, die Pässe, die bewaffnet werden.»(P12, Absatz 141)

Ähnlich äussert sich P8 zur Abbildung des Beobachtungspostens am Splügen:

"Wieder die Karte, ‘Blick ins Ausland〉, ‘Ein Beobachtungsposten am Splügen, Sicht aus [eigtl. auf] Italien.> Ja, (also) da wird diese Metapher >Blick ins Ausland> mit dem Bild sehr wörtlich genommen.» (P8, Absatz 55)

Umgekehrt kann dieselbe Person mit der Anbringung der Zitate im Hintergrund der Stellwände, die sich ebenfalls als versinnbildlichter Blick über die Grenzen deuten liessen, nichts anfangen:

"Ich frage mich gerade, warum diese Zitate immer so (...) nach hinten verlegt sind. (...) Irgendwie sieht das Ganze, wirkt (so) eher so, als wär, könnte man da was Geheimes entdecken, aber eigentlich muss man sich nur komisch vorbeugen, um sie lesen zu können. (...) Ganz nettes Spiel, aber so richtig den, ja, so richtig viel Sinn steckt glaube ich nicht dahinter.» (P8, Absatz 73)

Über eine mögliche Bedeutung der im Hintergrund angebrachten Zitate denken auch die folgenden beiden Personen nach und finden im Gegensatz zu P8 eine mögliche Deutung:

"Ah, die Quotes, da quasi immer der Hintergrund, so das, was im Hintergrund sich abspielt. Und vorne Zustände, die verschonte Schweiz. (...) Okay.»(P7, Absatz 92)

"Jetzt (swobbe) ich hier mal wieder rüber und wieder im Hintergrund die, also mittlerweile find ich diese Zitate richtig (...), wow, einfach so eine Hintergrund, der Hintergrundteppich.»(P12, Absatz 176)

Die Beispiele zeigen, dass viele Besuchende durchaus sensibel für die ästhetische Gestaltung der Ausstellung sind und über deren inhaltliche Bedeutung nachdenken, wobei sie sowohl über eine gelingende als auch bisweilen eine nichtgelingende Erschliessung sprechen. In etlichen gezeigten Beispielen finden sich zudem Bezüge zu einem Phänomen, das Susie Wise in ihrer Studie als «Embodied Interpretative Practices» beschrieben hat, als eine Form des Sense-Making, bei der «visitors use their bodies as tools to embody their thinking in the exhibition 
space». ${ }^{1398}$ Es geht bei diesem Phänomen darum, dass durch das Sich-Bewegen im Raum zugleich Deuten und Aneignen erfolgt, dass äusserer, physischer Raum der Ausstellung und die Bewegung darin einerseits und mentaler Raum, die Repräsentation historischen Geschehens in den Vorstellungen der Besuchenden andererseits, in einen inneren Zusammenhang treten. Allerdings beobachte ich nicht wie Wise auch nonverbal das Verhalten der Besuchenden, sondern beachte solche «Embodied Interpretative Practices» dann, wenn sie in den expliziten Äusserungen der Besuchenden selbst aufscheinen und reflektiert werden, etwa wenn P12 feststellt, er oder sie "(swobbe)»(P12, Absatz 176) in den Hintergrund und es würden sinnbildlich «die Blicke hier nach aussen gelenkt» (P12, Absatz 141), oder wenn P8 feststelllt, es gehe "wieder in die Welt» (P8, Absatz 50). Sinnbildlich für das beschriebene Phänomen steht auch die folgende Äusserung von P19:

"Ja, da sehe ich gerade schon wieder, dass die Exportindustrie Konjunktur hatte, und das ist jetzt ungefähr schon das dritte Mal. Da machts mich nicht unbedingt an, den Text noch zu lesen. (...) Darum gehen wir da lieber mal ins Ausland schauen.» (P19, Absatz 65-66)

Auch unabhängig von den chronologisch strukturierten «Blick ins Ausland»-Elementen finden sich im Material an einzelnen Stellen Äusserungen, in denen die Besuchenden ausdrücken, dass sie sich gleichsam selbst mit dem Geschehen bewegen, vor allem sich selbst mit der fortschreitenden Chronologie fortzubewegen.

"Jetzt kommen wir schon gegen Ende des Krieges, also anscheinend ist alles im Verlauf des Krieges dargestellt. (...) Es gibt viele Gefangene, heisst es hier, Millionen (...), und man ist nicht darauf vorbereitet.» (P3, Absatz 64)

«Die vom Bundesrat am/ abgelegte Neutralitätserklärung wird von den kriegfübrenden Ländern innerhalb weniger Wochen anerkannt.> (...) Das ist für mich jetzt chronologisch ein Bruch, weil das eigentlich etwas ist, das vorher kommt, weil wir jetzt im Prinzip schon (mitten) sind.» (P13, Absatz 56-57)

1398 Wise 2011, S. 74 f. Wise unterscheidet als vier Varianten: «leaning in to closely examine an object, juxtaposing objects with head turns, walking the path to connect objects, and adjusting vantage point» (ebd., S. 75, Kursivsetzung analog zum Original). Bei den für die Ausstellung «14/18» beschriebenen Fälle manifestiert sich dies als Hineinlehnen bzw. Hinausschauen, das zugleich den «Blick ins Ausland» symbolisiert. 
Neben diesen Äusserungen und den zu Beginn des Kapitels bereits gezeigten von P6 und P28, die im Zusammenhang mit den «Blick ins Ausland»-Elementen eine chronologische Struktur der Ausstellung feststellen, kommen mit P12 und P8 zwei weitere Besuchende auf einer Metaebene auf die Struktur der Ausstellung zu sprechen - nun unabhängig von den «Blick ins Ausland»-Elementen. Beide bezeichnen die Struktur der Ausstellung als chronologisch und stellen ihr eine thematische Struktur als alternative Variante gegenüber:

"Kriegsende und Streik. (...) Die Lebensmittel werden ständig knapper und teurer.> Ich find das so logisch wie eigentlich normal, dass die Ausstellung chronologisch verläuft, und nicht einfach nur thematisch. (...) Aber ja, find ich gut. Auf jeden Fall ist jetzt Kriegsende.»(P12, Absatz 185)

«Es wird chronologisch vorgegangen und hier erst mal die Situation vor dem Krieg dargestellt.» (P8, Absatz 9)

«Der Erste Weltkrieg und seine Folgen verändern die moderne Schweiz wie kaum ein anderes Ereignis.> Ja. Gut, das haben sie schon ganz gut herausgestellt. Ich frage mich nur, ob das eventuell in einem thematischen statt chronologischen Durchgang (...) noch besser gelungen wäre. Wobei natürlich beides Vorund Nachteile hat.» (P8, Absatz 92)

Bei sämtlichen Besuchenden, die sich in dieser Weise über die Struktur der Ausstellung Gedanken machen, handelt es sich um solche mit geschichtswissenschaftlichem (P6, P12, P13) oder überdies noch museumsbezogenem und/oder geschichtsdidaktischem Hintergrund (P3, P8, P28).

Andere Besuchende folgen dieser Struktur implizit, indem sie sich, wie oben dargestellt, an der linearen Struktur der Ausstellung entlangarbeiten. Inwiefern sie dies deshalb tun, weil es für ihre Aneignungsprozesse bedeutsam ist, der inhärenten chronologischen Struktur der Ausstellung zu folgen, oder inwiefern sie lineares Abarbeiten auch unabhängig von der damit verbundenen Chronologie als geboten für einen Ausstellungsbesuch erachten, ${ }^{1399}$ lässt sich letztlich nicht mit Bestimmtheit feststellen. Anhand der Äusserungen zu den wiederkehrenden

1399 Auch wenn andere Studien durchaus auch von diesem Prinzip abweichende Besuchertypen identifizieren (vgl. Abschnitt 5.3.1). 
«Blick ins Ausland»-Elementen lässt sich mindestens feststellen, dass die Besuchenden durchaus eine Sensibilität für die inhaltlich-ästhetische Struktur einer Ausstellung haben, selbst wenn sie diese nicht explizit als chronologische thematisieren, und diesen wiederkehrenden Elementen eine orientierende, kontextualisierende Funktion zuschreiben.

\subsubsection{Zum Umgang der Besuchenden mit in der Ausstellung angelegten Verknüpfungen von Zeitebenen und Gegenwartsbezügen}

Ich wende mich zum Abschluss des Abschnitts noch einem weiteren Bereich der Ausstellung zu, anhand dessen sich Äusserungen der Besuchende über die ästhetische Gestalt der Ausstellung und entsprechende Rückschlüsse auf inhaltliche Zugänge manifestieren. In Übereinstimmung mit dem Schwerpunkt meines Forschungsanliegens, der Erhellung von Gegenwartsbezügen, frage ich an dieser Stelle erneut nach selbigen, nun aber unter einer dezidiert anderen Perspektive. Während ich weiter oben die von den Besuchenden in der Fokussierung auf Geschehen erzählten und aktiv selbst hergestellten, konstruierten Gegenwartsbezüge in den Blick genommen habe, wechsle ich mit dem Schwerpunkt auf ausstellungsbezogene Äusserungen nun den Blickwinkel. Es geht nun darum, wie sich Besuchende in Bezug auf das äussern, was an physischer Umgebungsstruktur vorhanden ist. Im konkreten Fall lauten die Leitfragen also: Inwieweit erkennen die Besuchenden, dass die Ausstellung selbst Gegenwartsbezüge anbietet? Wie äussern sie sich über dieses Anliegen und die gemachten Bezüge? Schreiben sie der Ausstellung vielleicht auch Gegenwartsbezüge unabhängig von den konkreten genannten Räumen zu, und auf welche Weisen tun sie dies?

Bevor ich die von den Besuchenden erkannten bzw. zugeschriebenen Bezüge der Ausstellung zur Gegenwart differenzierter in den Blick nehme, ist es angebracht, das Angebot der Ausstellung für derartige Gegenwartsbezüge in den Blick zu nehmen. Die Ausstellung widmet sich grossmehrheitlich der Darstellung der Situation der Schweiz zur Zeit des Ersten Weltkriegs und behandelt daher die Phase der Kriegsjahre einschliesslich des Landesstreiks. Explizite Einbezüge späterer Zeiten bis hin zur jüngsten Vergangenheit und Gegenwart unternimmt die Ausstellung in den letzten beiden Räumlichkeiten. Einer der beiden Räume gehörte hierbei zum Kernbereich der Wanderausstellung und behandelt unter dem Titel «Nach dem Krieg» Entwicklungen bezogen auf die ganze Schweiz, konkret die folgenden Themen:

- 1939 Erinnerungskultur: Geistige Landesverteidigung,

- 1948 Sozialpolitik: Einführung der AHV, 
- 1970 Migration: Abstimmung zur Schwarzenbach-Initiative,

- 1971 politische Gleichstellung: Volksabstimmung zum Frauenstimmrecht,

- 1999 Landwirtschaft: Auflösung der Käseunion,

- 2002 Aussenpolitik: Volksabstimmung zum UNO-Beitritt.

Im zugehörigen einführenden Ausstellungstext wurde zusammenfassend die These vertreten, dass «[d]er Erste Weltkrieg und seine Folgen $[\ldots]$ die moderne Schweiz wie kaum ein anderes Ereignis [verändern]».

An diesen Raum anschliessend thematisiert ein zweiter Raum, im Rahmen des baselspezifischen Zusatzteils der Ausstellung konzipiert, die Relevanz des Ersten Weltkriegs in Bezug auf die Stadt Basel. Dort kommen folgende Themen zur Sprache:

- Messe Basel,

- Port of Switzerland,

- Life Science,

- Urban Farming,

- Mission 21.

Die beiden letzten Ausstellungsräume zeigten im Rahmen der genannten Themen auf, wie Entwicklungen, die zur Zeit des Ersten Weltkriegs ihren Ausgang genommen haben, in den folgenden Jahren weiter fortgeschritten sind und die Schweiz in ihrer heutigen Gestalt geprägt haben. In beiden Räumen wurden also Zeitebenen verknüpft und Verbindungslinien zwischen der Zeit des Ersten Weltkriegs und nachfolgenden Zeiten, teilweise bis hin zur Gegenwart, geknüpft.

Die ästhetische Gestaltung der Ausstellung der letzten beiden Räume wich von der zuvor gewählten Darstellungsform ab und suggerierte damit bereits auf optischem Weg einen veränderten inhaltlichen Zugang. So wurde für die Gestaltung dieser Räumlichkeiten nicht auf Stellwände, sondern auf Litfasssäulen zurückgegriffen, wobei jede der Litfasssäulen sich einem thematischen Bereich der Nachkriegsgeschichte zuwendete.

Abgesehen von den beiden Schlussräumlichkeiten gab es noch ein weiteres Ausstellungselement, in dem explizit die Gegenwart thematisiert wurde. So sprach ein Ausstellungstext davon, bei der zur Zeit des Ersten Weltkriegs eingeführten Kriegsgewinnsteuer handle es sich um die heutige direkte Bundessteuer.

Wie reagierten nun die Besuchenden auf das, was die Ausstellung in diesen Schlussräumlichkeiten anbot? Zwei Kategorien sind hierfür von Interesse: solche Äusserungen, in denen die Besuchenden explizit formulieren, die Ausstellung 
stelle Gegenwartsbezüge oder Bezüge zwischen Zeitebenen her oder rege diese an, und solche Äusserungen, in denen sie über Inhalt-Form-Zusammenhänge in der Ausstellung reflektieren, also darüber, dass sich in bestimmten ästhetischen Gestaltungsmitteln bestimmte zugehörige inhaltliche Zugangsweisen ausdrücken. In diesen zeigt sich, dass die oben beschriebene abweichende optische Gestaltung der Räume für die Besuchenden als Schlüssel zum Verständnis dienen konnte, um den auch inhaltlich veränderten Zugang dieser Räumlichkeiten zu durchschauen.

Es folgt eine vollständige Vorstellung all derjenigen Äusserungen, in denen die Besuchenden in irgendeiner Weise gesamthaft über das Anliegen der Schlussräumlichkeiten nachdenken. Zum Kontext sind sämtliche Aussagen der Besuchenden, während sie sich in diesen beiden Abteilungen befinden, im digitalen Anhang als ungekürzte Transkripte einsehbar.

Ein Zusammenhang zwischen der Sensibilität für die abweichende ästhetische und inhaltliche Darstellung geht etwa aus den nachfolgend zitierten Äusserungen von P4 hervor. Ich zeige eine längere Passage, um den sich darin abspielenden Prozess des Sinnverstehens abbilden zu können. Der Auszug startet mit dem Eintritt der Person in die Schlussräumlichkeiten, bei dem er oder sie sogleich einen «Bruch in der Darstellung» feststellt:

«Okay, da ist irgendwie (...) ein Bruch in der Darstellung, okay. (...) <(Sozial) politik 1948.> (...) 〈Nach dem Krieg (...). Der Erste Weltkrieg bringt (millionenfachen) Tod von Soldaten. (...) (Kriegführende) (...) Der Erste Weltkrieg und seine Folgen verändern die moderne Schweiz wie kaum ein anderes Ereignis.> (...)

Okay, ich bin irritiert. (schmunzelt) (...)〈Die Folgen des Ersten Weltkriegs〉. (...) Okay, hm. (...) Messe Basel, Hafenstandort, (...) chemische Firmen. (...) ¿Die Zeit des Ersten Weltkriegs brachte der Basler chemischen Industrie den eigentlichen Durchbruch.> Hm. (...)

‘Die schlechte Versorgungslage während des Ersten Weltkriegs führte in Basel zu einer steigenden Nachfrage nach Gartenland.〉 (...) 〈Bei Kriegsende gab es in Basel 8300 Kleingärten. (...) Während in den Freizeitgärten die Gemüseproduktion nicht mehr im Zentrum steht, (...) entwickeln sich anderswo newe Formen von städtischer Landwirtschaft.> (...) Okay, das ist (...) eigentlich ziemlich faszinierend. (...) (Ich finde dieses Gerät toll) (schmunzelt) [meint vmtl. Sitzgelegenheit aus Karton] (...)

‘Basler Mission. Während des Ersten Weltkriegs musste sie deshalb die französischen (...) Gebiete, Asien, (...) Afrika (...). 
Okay aber das hat mich erst irritiert, dass diese Darstellung komplett anders ist, aber (...) ïber die Texte (...) wird ja auch immer wieder der (...) Rückgriff auf den Evsten Weltkrieg gemacht, und das finde ich dann schon (...) faszinievend. (...) Wie diese Litfasssäulen dann so (...) anschlagen, wo die Wurzeln (...) von einigen (...) eigentlich modernen Sachen sind. (...) Diese kleineren Litfassäulen (...) gehen dagegen fast ein bisschen unter. (...)» (P4, Absatz 111-113)

Das gewählte Beispiel zeigt eine längere Phase des Ringens um Sinnverstehen, während der die Person durch die beiden Schlussräumlichkeiten wandert und schlaglichtartig und auszugsweise Ausstellungstexte liest. Ausgehend von einer Irritation durch die abweichende ästhetische Darstellung der Räumlichkeiten nähert er oder sie sich durch das Lesen der Ausstellungstexte schrittweise an das Thema der Räumlichkeiten an und kommt dann zu dem Schluss, dass es eine Korrespondenz zwischen Form und Inhalt gebe, nämlich dass die gewählten Litfasssäulen die Verbindung zwischen der Zeit des Ersten Weltkriegs und der Gegenwart versinnbildlichen und "anschlagen, wo die Wurzeln (...) von einigen (...) eigentlich modernen Sachen sind».

Vergleichbar dazu zeigt sich auch P12 beim Eintritt in die Schlussräumlichkeiten irritiert über die abweichende ästhetische Gestaltung ( Wieder bunte Stelen, hoppla») und begibt sich, ausgehend davon, auf die Suche danach, was das Thema der Räumlichkeiten sein könnte. Wie auch zuvor P4 wendet sich P12 relativ schnell dem übergreifenden Ausstellungstext «Nach dem Krieg» zu und beginnt im Anschluss an dessen Lektüre, durch die Abteilungen zu flanieren und einzelne Elemente schlaglichtartig zu betrachten bzw. anzulesen.

"Wieder bunte Stelen, hoppla. Äh, jetzt muss ich glaub ich doch lieber erst noch mal gucken, was es hier für ein Teil ist. ‘Nach dem Krieg. Der Erste Weltkrieg bringt millionenfachen Tod von Soldaten, Zivilisten sowie Hoffnungsund Orientierungslosigkeit für die Überlebenden mit sich. Er beendet das Zeitalter des Kräftegleichgewichts in Europa und führt in eine Phase von Krisen und Konflikten, die im Zweiten Weltkrieg gipfeln.> Genau, Krieg und Frieden.

〈Kriegführende wie auch neutrale Staaten sehen sich mit enormen Schuldenlasten und sozialen Problemen konfrontiert. Die von den Siegermächten diktierten Friedensbedingungen verschärfen diese zusätzlich. Der Weltkrieg beendet den Liberalismus der Belle Époque und die Phase des freien Personenverkehrs. Als 
neues System bildet sich ein zunehmender Wirtschaftsprotektionismus und Kulturnationalismus heraus. Der Erste Weltkrieg und seine Folgen verändern die moderne Schweiz wie kaum ein anderes Ereignis.>

Und ich glaub, GENAU das hat diese Ausstellung eigentlich sehr gut zeigen können. (...) Und zeigt auch wirklich, was es für eine Züsur ist, und man nicht nur das Gefühl hat, die Schweiz ist aussen vor geblieben oder war verschont oder. Also sie war verschont, aber doch auf, mit sehr vielen Einschränkungen und, und, und Leiden (...).

Diese Filmaufnabmen wären jetzt so spannend, aber ich bin einfach müde. Und mag eher noch diese, diese Plakate hier so ein bisschen angucken. (...) <Nach dem Ersten Weltkrieg> - das find ich jetzt aber sebr gut, dass sie hier eigentlich diesen Ausblick machen und die Verbindungslinien aufzeigen, auch wenn es nach ein bisschen viel aussiebt, im ersten Moment. Stichwort Migration, Schwarzenbach-Initiative. ‘Nach dem Ersten Weltkrieg beginnt eine neue Phase der Migrationspolitik. Kontrolle und (...).

[...]

'Aussenpolitik. Aufgrund der Erfahrungen während des Krieges strebt der Bundesrat 1919 rasch einen Beitritt zum Völkerbund an. Es gelingt ihm, die neutralitätspolitischen Bedenken auszuräumen. 1920 folgt das (unv.) Bundesrat mit klarer Mebrheit, aber knappem Ständemehr. In den 30er-Jahren geht die Schweiz zunehmend auf Distanz zum Völkerbund, und (nach) dem Zweiten Weltkrieg bleibt sie aus neutralitätspolitischen Gründen der UNO fern, nimmt allerdings Einsitz. Erst nach dem Ende des Kalten Kriegs stimmt das Volk im März 2002 dem UNO-Beitritt zu, und am 10. September 2002), ich mag mich sogar genau an den Tag erinnern, snimmt die UNO-Generalversammlung die Schweiz als 190. Mitglied auf.> (...)

Das find ich sebr gut, dass hier diese Verbindungen sind, weil man guckt die Stelen an und die bunten Plakate und bat das Gefübl, Moment, Moment, clash of times, wieso kommt hier diese Buntheit direkt hier nach (unv.) Ende des Ersten Weltkrieges. Aber es ist echt, in der Kürze, gut gemacht.» (P12, Absatz 196-197 und 200) 
Ebenso kommt P6 nach längerem Flanieren durch die Schlussräumlichkeiten ${ }^{1400}$ ebenfalls zu dem Befund, die Räume würden eine Thematisierung der "Jetzt-Zeit» darstellen:

"Okay, okay, also da geht's um die Auswirkungen bis heute, was das so alles bewirkt hat. (...) Andere Gestaltung (...), da drinnen ganz modern, da sind wir jetzt in der Jetzt-Zeit.» (P6, Absatz 68-69)

Auch P8 kommt zum Schluss, dass die abweichende ästhetische Gestaltung einen veränderten inhaltlichen Zugang widerspiegelt:

"Hier sieht man jetzt von der Inszenierung her einen deutlichen Bruch. Der Krieg ist vorbei, irgendwie dieser bedrückende Korridor endet auch, wenn man diesen Raum hier [zeigt auf vorletzten Säulenraum] betritt, füblt man sich schon so, als könnte man freier atmen.» (P8, Absatz 86)

Beim Eintritt in die Schlussräume irritiert bzw. fragend äussert sich P13, wobei hier allerdings die Unklarheit nicht wie bei den bislang zitierten Besuchenden unmittelbar an die Ästhetik der Räume zurückgebunden wird. P13 stellt die Frage, "was jetzt das da mit dem Krieg zu tu[n]» habe, ohne dass dabei explizit deutlich würde, welches Ausstellungselement diese Frage ausgelöst hat oder ob er oder sie sich auf die Gestaltung des gesamten Raums bezieht. Wie P4 und P12 wendet sich Pl3 jedoch nach Formulierung dieser Unklarheit unmittelbar dem übergeordneten Ausstellungstext zu. In diesen Beispielen zeigt sich, dass Besuchende auf Ausstellungstexte als Antwortgeber auf ihre Fragen vertrauen - ein Aspekt, den ich weiter unten noch differenzierter nachverfolgen werden.

"Frage mich gerade, was jetzt das da mit dem Krieg zu tu/, ah, da vorne, ‘Nach dem Krieg. Der Erste Weltkrieg bringt millionenfachen Tod von Soldaten, Zivilisten sowie Hoffnungs- und Orientierungslosigkeit für die Überlebenden mit sich.> (...)

Also die, ‘Der Erste Weltkrieg und seine Folgen verändern die moderne Schweiz wie kaum ein anderes Ereignis, wäre jetzt spannend gewesen, inwiefern, oder

1400 Die dabei formulierten Äusserungen können dem Transkriptauszug im digitalen Anhang entnommen werden. 
auf was da angesprochen wird? Oder ist das jetzt, sind das jetzt die Säulen, die das, die Veründerung zeigen?

[...]

Ist das quasi so ein, noch mal ein Ausblick? Ausblicksrunde? Ist mir jetzt nicht ganz klar.» (P13, Absatz 102-103 und 113)

Auch P13 stellt zum Ende des gezeigten Ausschnitts eine Verbindung zwischen inhaltlicher Ausrichtung der Räume und eingesetzten Gestaltungsmitteln dar, fragt sich nämlich, ob die im Text angekündigten Veränderungen auf den Säulen dargestellt seien.

Bei den gezeigten Beispielen handelt es sich um eine vollständige Darstellung derjenigen Textstellen, in denen Besuchende Zusammenhänge zwischen der ästhetischen Gestaltung der Schlussräumlichkeiten und dem darin repräsentierten inhaltlichen Zugang herstellen. Zwei Beispiele konnten dabei explizit zeigen, dass die ästhetische Gestaltung als Irritationsmoment beim Eintritt in die Räumlichkeiten fungieren kann, um ausgehend davon Suchbewegungen nach der inhaltlichen Ausrichtung der Räume bei den Besuchenden zu bewirken. Es zeigt sich somit, dass diese Besuchenden durchaus sensibel für die ästhetische Gestaltung einer Ausstellung sind und über ein Bewusstsein darüber verfügen, dass Gestaltungsmittel bewusst eingesetzt werden können, um Aussagen zu unterstreichen, Themen voneinander abzugrenzen usw.

Dass jede Säule Zeitdimensionen in Bezug auf ein anderes Thema verknüpft bzw. andere Beispiele darstellt, dazu äussert sich etwa auch P28, während er oder sie durch den Schlussraum der Kernausstellung wandert und nacheinander die darin befindlichen Säulen betrachtet bzw. deren Titel anliest:

"Ich schwenke auf die (...) Art Litfasssäulen. (...) Mit Gegenwartsbezügen (...) auf die (Einführung) einer Alters- und Hinterlassenen (...)versicherung, (...) auf die sogenannte Geistige Landesverteidigung 1939, (...) auf die Auflösung der Käseunion 1999, (...) die Abstimmung im Jahre 1970 zur Schwarzenbach-Initiative (...) oder zum Frauenstimmrecht im folgenden Jahr, (...) sowieso (...) zum UNO-Beitritt im Jahre 2002. (...)

$Z u$ diesen Volksabstimmungen sind hier einige (...) Plakate (...) aufgeklebt, (...) die (...) ibren eigenen Reiz haben. (...) Zum Beispiel ‘Frauenstimmrecht-nein! Lasst uns aus dem Spiel.> (...) 
Mit all diesen Beispielen soll offenbar die (...) Behauptung bestätigt werden [ab hier lesend:] 〈Der Erste Weltkrieg und seine Folgen verändern die moderne Schweiz wie kaum ein anderes Ereignis.»» (P28, Absatz 103-106)

Hingegen kommt P7 zu einer anderen Interpretation der Säulen, nämlich dass diese "Nationalismus, nationalistische Tendenzen und (...) Protektionismus symbolisieren oder thematisieren», eine Deutung, die so nur von P7 geäussert wird, aber auf Basis der von ihm zuvor betrachteten ausgewählten Ausstellungselemente durchaus ebenfalls schlüssig erscheint:

«Nach dem Krieg. Der Erste Weltkrieg bringt millionenfachen Tod von Soldaten und Zivilisten sowie Hoffnungs- und Orientierungslosigkeit über die Überlebenden. (unv.) beendet das Zeitalter des Kräftegleichgewichts in Europa und führt in eine Phase von Krisen und Konflikten. (unv.) Kriegführende wie auch neutrale Staaten sehen sich mit enormen Schuldenlasten und sozialen Problemen konfrontiert. Die von den Siegermächten diktierten Friedensbedingungen verschärfen diese zusätzlich. (...) Die Phasen des freien Personenverkehrs. Als neues System bildet sich ein zunehmender Wirtschaftsprotektionismus und Kulturnationalismus heraus.> (...) Ja. Ah, (...) Schwarzenbach-Initiative, aba. (...) Ist schon so, hm (lacht). (...) Okay, Imperial War Museum. (...)

Ja, das ist etwa da, die verschiedenen Säulen, die Nationalismus, nationalistische Tendenzen und (...) Protektionismus symbolisieren oder thematisieren (...). Hm (lacht). (...)» (P7, Absatz 32-33)

Auch ohne Verweis auf die damit verknüpfte ästhetische Darstellung erkennen andere Besuchende, dass in den Schlussräumlichkeiten zeitliche Verbindungslinien aufgespannt werden. Hierfür dienen die nächsten beiden Textpassagen als Beispiele:

« ¿Eine solide AHV〉. (...) 〈1948〉. (...) Das ist schon eindrucksvoll, das ist schon lange zurück. (...) Heute meint man, das sei normal. (...) (unv.) Vorher war die Unterstützung doch (...) vor allem von der Familie, von der Grossfamilie (kommend). Ich lese die Überschrift, hab mir die Bilder angeschaut. (...) Ich lese die Überschrift, die Bilder drunter (sind so ein bisschen durcheinander). (Da haben sie ein) Plakat (mit einer) Kuh. (...) 〈Frauenstimmrecht 1971〉, das ist aber nachber. (unv.) Dann 2002 〈Aussenpolitik. Volksabstimmung〉. Da wird (jetzt mal in gewissem Mass) über den (Zweiten?) Weltkrieg hinaus (gesponnen) (...) Ich lese da an der Wand 〈Nach dem Krieg〉. (...)» (P30, Absatz 83-89) 
"Abstimmung zu Schwarzenbach-Initiative. Nach dem Ersten Weltkrieg beginnt eine neue Phase der Migrationspolitik, die durch Kontrolle und Abwehr der Ausländer gekennzeichnet ist. Neben dem Bemühen, die Grenzen für Tourismus und Handel wieder vorsichtig zu öffnen, wird das Vorgehen der 1917 geschaffenen Fremdenpolizei weitgehend vom Verhindern einer Überfremdung bestimmt. Seit den 1960ern fordern [liest ab hier zusammenfassend] nicht mehr Verwaltung und Regierung restriktive Ausländer/, politische Bewegung.> Ja, also wird natïrlich auch deutlich Bezug auf (...) aktuelle Politik genommen.» (P8, Absatz 91)

Manche Besuchende stellen nicht nur hergestellte zeitliche Verbindungslinien fest, sondern kommentieren diese Versuche überdies und äussern Urteile, inwiefern dies ihrer Ansicht nach gut oder schlecht gelungen sei. So empfindet die soeben zitierte Person die Schlussabteilung als überdeutlich in ihrer Aussage:

"Was haben wir nun hier? (...) Ach, das kann man gar nicht drehen. (...)

‘Basler Mission war traditionell mit Deutschland verbunden. Wäbrend des Ersten Weltkriegs musste sie deshalb die französischen und britischen Kolonialgebiete in Asien und Afrika verlassen. Als die Missionare einige Jahre nach dem Krieg zurückkehren durften, stellten sie fest, dass viele der einheimischen Kirchen unterdessen ein gewisses Selbstbewusstsein erlangt hatten.> (...)

Ab ja. (...)

¿Die schlechte Versorgungslage während des [fehlt 〈Ersten Weltkriegs〉] führte (ïberall) [eigtl. «in Basel〉] zu einer steigenden Nachfrage (unv.) [eigtl. «nach Gartenland $>$.'

Aba, okay, das geht in diese Babn. (...) Lauter Verknüpfungen der Zeitdimensionen. (...) Kann man machen.

‘Während des Ersten Weltkriegs erzielten die chemischen Firmen in Basel (...) [liest ab hier teilw. unverständlich und bruchstückhaft] (unv.) Farbstoffproduktion (unv.) erbrachte Basler chemische Industrie. Im frühen wurden vermebrt pharmazeutische auf den Markt gebracht und so der Übergang Farbstoff Pharmaindustrie.

Ja, also. (...) Die Gegenwart ist geprägt von der Vergangenbeit des Ersten Weltkriegs. Na, haben sie hier etwas plump (...) an den Mann gebracht, diese Botschaft.» (P8, Absatz 93-95) 
Erfreut äussert sich demgegenüber die folgende Person:

"Das find ich jetzt aber sehr gut, dass sie hier eigentlich diesen Ausblick machen und die Verbindungslinien aufzeigen.»(P12, Absatz 197)

Zum Abschluss des Kapitels stelle ich im Überblick zusammen, mit welchem Vokabular die Besuchenden das benennen, was sie in den Schlussabteilungen der Ausstellung dargestellt zu sehen glauben, nämlich sehen sie, in der Reihenfolge der Auflistung nach Besuchenden gegliedert:

- "also eigentlich so: was ist nachber noch passiert» (P3, Absatz 81),

- "wie es nach dem Krieg, (...) welche Probleme nachber entstehen" (P3, Absatz 82),

- "Bruch in der Darstellung» (P4, Absatz 111),

- «Darstellung komplett anders» (P4, Absatz 113),

- «Wurzeln (...) von einigen (...) eigentlich modernen Sachen» (P4, Absatz 113),

- "Rückgriff auf den Ersten Weltkrieg» (P4, Absatz 113),

- "Auswirkungen bis heute» (P6, Absatz 68),

- «andere Gestaltung (...), da drinnen ganz modern» (P6, Absatz 69),

- «Jetzt-Zeit» (P6, Absatz 69),

- «pon der Inszenierung her einen deutlichen Bruch» (P8, Absatz 86),

- "Bezug auf (...) aktuelle Politik» (P8, Absatz 91),

- "lauter Verknüpfung der Zeitdimensionen» (P8, Absatz 94),

- "die Gegenwart (...) geprägt von der Vergangenheit des Ersten Weltkriegs» (P8, Absatz 95),

- «Ausblick» (P12, Absatz 197),

- «Verbindungslinien»(P12, Absatz 197),

- "clash of times» (P12, Absatz 200),

- "diese Buntheit direkt hier nach (unv.) Ende des Ersten Weltkrieges» (P12, Absatz 200),

- «Verbindungen»(P12, Absatz 200),

- «Säulen, die [...] die Veränderung zeigen?»(P13, Absatz 103),

- "[...] noch mal ein Ausblick? Ausblicksrunde?» (P13, Absatz 113),

- «neuere Geschichte» (P18, Absatz 139),

- «Wurzel»(P19, Absatz 142), 
- «Wurzeln» (P19, Absatz 148), ${ }^{1401}$

- «das (...) (äussere) vor dem Krieg hier und nach dem Krieg hier» (P21, Absatz 98),

- «in allgemeiner Form ein Ausblick»(P28, Absatz 100),

- «Gegenwartsbezüge[.]»(P28, Absatz 103),

- «die besonderen Bezüge (...) der Stadt Basel zum Ausstellungsthema» (P28, Absatz 104),

- «ist aber nachber» (P30, Absatz 68),

- «über den [...] Weltkrieg hinaus Gesponnenes» (P30, Absatz 89).

Insgesamt äussern sich zwei Drittel der beforschten Besuchenden - in unterschiedlichem Ausmass - in irgendeiner Weise über den veränderten inhaltlichen und/oder ästhetischen Zugang der Schlussräumlichkeiten. Die übrigen Besuchenden nehmen entweder die Räumlichkeiten vor allem lesend-rezeptiv zur Kenntnis (P5, P7, P22, P26) oder äussern sich zwar ausführlicher frei zu den einzelnen Elementen, formulieren aber keine Überlegungen, die sich als inhaltliche oder ästhetische Einordnung der Gesamtausrichtung der Schlussräume einordnen lassen (P25, P27).

Daneben gibt es Passagen, in denen zwar nicht explizit im Reden über die Ausstellung und ihre Elemente (Fokus II), wohl aber im Rahmen von geschehensbezogenen Äusserungen (Fokus I) die veränderte Ausrichtung der Räumlichkeiten implizit aufgegriffen wird. So schlussfolgert insbesondere P19 in verschiedenen Zusammenhängen, der Erste Weltkrieg habe «das Land verändert» (P19, Absatz 140), heute Bedeutsames habe zur Zeit des Ersten Weltkriegs seine "Wurzeln genommen» (P19, Absatz 148) oder etwas sei "auf den Ersten Weltkrieg zurückzufübren» (P19, Absatz 147, 149):

"Ja, ist ganz interessant, wie im Jurakonflikt da noch Sachen mitgespielt haben aus dem Ersten Weltkrieg und wie sebr der Erste Weltkrieg doch das Land veründert hat.» (P19, Absatz 140)

"Da gehts um Life Science. (...) und eben, dass die Exporte im Ersten Weltkrieg dazu geführt haben, dass heute Basel so eines von den absoluten Zentrum ist von

1401 P19 bezieht seine Feststellungen der Darstellung von «Wurzel(n)» je gesondert auf einzelne Themen innerhalb der Schlussräume, allerdings ergibt sich aus der Mehrfachverwendung implizit dennoch ein auf die Gesamtabteilung bezogenes Bild. 
Life Science, Biotech und Pharma (...) und heute noch wichtigste Export, also heute mit 30 Prozent zu den wichtigsten Exportschlager der Schweiz ist. Ja, da kann man sich Gedanken machen, dass das auf den Ersten Weltkrieg zurïckzufiibren ist [...]»(P19, Absatz 147)

"Find ich zum Beispiel ganz cool, dass die Muba, dass die auf den Ersten Weltkriegzurïckzufïhren ist, das hatte ich auch nicht gewusst.»(P19, Absatz 149)

Schwierigkeiten in der Zuordnung zwischen geschehens- und ausstellungsbezogenen Passagen bereitete die nachfolgend zitierte Äusserung von P20, eine Filmquelle betrachtend und das Dargestellte einordnend:

"Ja, das sieht so aus wie (...) wie umgepflügt, hm? (...) Dürfte Verdun sein, oder so irgendwo. (...) Sind das da Gasmasken, was die da umgehängt haben? Alle den gleichen Sack. (...) Aber das ist ja da eigentlich nach dem Krieg, oder? (...)»(P20, Absatz 121)

Die am Ende des Ausschnitts formulierte Frage gehört zu den zahlreichen Äusserungen, die sich im Zwischenraum zwischen geschehens- und ausstellungsbezogenen Äusserungen bewegen, weil sie sich einerseits auf das im Film repräsentierte historische Geschehen und dessen Aufnahmezeit beziehen oder aber auch stärker ausstellungsbezogen das Thema der Abteilung meinen können - vielleicht sogar eine Vermengung aus beidem. Im Verlauf der weiteren Darstellung werden immer wieder solche Grenzfälle auftauchen.

Die bisher gezeigten Beispiele entstanden in Auseinandersetzung der Besuchenden mit den beiden Schlussräumen der Ausstellung, die in ihrer Konzeption auf die Herstellung von Verbindungslinien zwischen der Zeit des Ersten Weltkriegs und dessen Nachgeschichte bis hin zur Gegenwart ausgerichtet sind. In diesen Fällen erkennen die Besuchenden also das Kernanliegen der besuchten Abteilung und äussern sich in Bezug auf dieses, vielfach unter Einbezug von ästhetischen Eindrücken.

Abgesehen davon glauben manche Besuchende vereinzelt auch in anderen Teilen der Ausstellung, intendierte Gegenwartsbezüge der Ausstellung zu erkennen, nun ausschliesslich aus der Rezeption von Ausstellungstexten resultierend und ohne Einbezug der ästhetischen Gestaltung der Ausstellung. So äussert etwa die für in der Ausstellung angelegte Gegenwartsbezüge sowieso sensible Person 
P8 beim Lesen eines Ausstellungstexts, in dem die heutige direkte Bundessteuer auf die damals eingeführte Kriegsgewinnsteuer zurückgeführt wird:

"Die kriegsbedingten neuen Bundesaufgaben fübren zu einem starken Anstieg der Staatsausgaben. Während der Kriegsjabre nimmt diese rund das Zweieinhalb/, rund das Zweieinhalbfache zu. Zur Finanzierung der (Kriegskosten fübrt der Bund eine) Kriegssteuer - die heutige direkte Bundesstener - ein. Zugleich tritt er als Akteur /> Hier werden wieder Verweise auf heute gemacht, (mit der) Kriegssteuer, Bundessteuer (...), (die dadurch) natürlich nicht besonders gut wegkommt.» (P8, Absatz 45)

Die Person erkennt hier also, dass im gelesenen Ausstellungstext Zeitebenen miteinander in Verbindung gebracht werden, und kommentiert zugleich dieses Ansinnen. Nämlich komme die Bundessteuer dabei «nicht besonders gut weg", womit P8 wohl darauf anspielt, dass hier eine Traditionslinie aufgezeigt wird und diese im konkreten Fall negativ konnotiert ist.

Abgesehen von dem soeben gezeigten Beispiel, entdecken Besuchende Gegenwartsbezüge ausserhalb der Schlussabteilungen überwiegend dann, wenn in der Ausstellung das Themenspektrum der ausländischen Arbeitskräfte, Migrationspolitik und Überfremdungsangst in der Schweiz zur Zeit des Weltkriegs thematisiert wird. Dabei handelt es sich im Gegensatz zu dem zuletzt gezeigten Beispiel durchwegs um Ausstellungsteile, in denen die Ausstellungselemente selbst nicht explizit die heutige Zeit thematisieren, die Besuchenden gleichwohl aber unterliegende Gegenwartsbezüge zu entdecken glauben. So äussert etwa die folgende Person, zunächst einen Ausstellungstext lesend:

«Rund 200000 Ausländer kehren zu Beginn des Krieges in ibre Heimatländer zurück, was zu chaotischen Zuständen in Zügen und Grenzbahnhöfen fübrt und die Schweizer Wirtschaft vor erhebliche Probleme stellt. Bereits damals ist die Wirtschaft auf ausländische Arbeitskräfte angewiesen.> (...) (Das ist natürlich auch) als kleine politische Anspielung aufaktuelle Fragen.»(P18, Absatz 17)

Gleich an mehreren Stellen des Besuchs unterstellt P19 intendierte Gegenwartsbezüge, jeweils im Zusammenhang mit der zur Zeit des Ersten Weltkriegs praktizierten Migrationspolitik. Hierbei handelt es sich teilweise um Textstellen, die 
weiter oben im Rahmen einer Brennpunktbetrachtung unter anderer Perspektive bereits einmal gezeigt wurden. ${ }^{1402}$

"Ja, da geht es etwas um Fremdenfeindlichkeit. (...) Wasein bisschen impliziert, ob man das nicht beute, auf eine beutige, man sollte das auf eine beutige Situation bezieben. (...) Weil begründet wird das da eigentlich nicht, ja. Es macht ein bisschen, argh. Es macht ein bisschen einen politisch gefärbten Eindruck auf mich.» (P19, Absatz 108)

Und wenig später, zunächst längere Zeit einen Ausstellungstext lesend:

"Ja. (...) Dann habe ich mich da (bingestellt): 〈Kriegsende und Streik〉, und da (...) da sehe ich, dass 'Zu Beginn des Krieges kehren Zehntausende von ausländischen Arbeitskräften in ihre Heimatländer zurück. Rasch schränkt die vom Bundesrat erlassene Grenzsperre den Personenverkehr ein. Medien und amtliche Texte zeichnen nach und nach ein kritischeres Bild von Ausländern. Sie unterscheiden vermehrt zwischen erwünschten und unerwünschten Personen. Woblhabende Touristen und internierte Militärpersonen sind willkommen, Deserteure, Kriegsgewinnler und Bolschewisten und Ostjuden werden als Unerwünschte bezeichnet. Während des Krieges verändert sich das Verhältnis zwischen In-und Ausländern nachbaltig. Der Begriff Überfremdung steigt zum beherrschenden Schlagwort auf. Die neu geschaffene Fremdenpolizei sieht ibre Hauptaufgabe in der Überfremdungsbekämpfung und verstebt es, den Anteil der Ausländer nach dem Krieg mit verschiedenen Mitteln zu senken. Zugleich schafft sie damit neue politische und humanitäre Probleme, die über Jahrzehnte nachwirken.> (...)

Ja, äbm (...), es ziebt natürlich eine Parallele zu einer beutigen Ausländerdiskussion. (...) wo, ja wo manchmal, wo mich manchmal dünkt, das hat so der, den, die Sachebene verlassen und wird sehr emotional, was offensichtlich damals schon emotional gewesen ist (dort) (...). Ich habe einfach immer so ein bisschen den Eindruck (als) (....), was ist, ist die historische Darstellung der Situation (denn) (unv.) politisch gefärbt mit der, mit der Brille aus der beutigen Situation. Und das gibt für mich halt immer so einen Touch von - argh - dass man mit, mit der Historie in der heutigen Zeit Politik machen will. Und das ist für mich hal-argh-(...) da vermisse ich dann doch manchmal die Sachebene.» (P19, Absatz 111-112)

1402 Vgl. Abschnitt 8.6.2. 
Aus Sicht von P19 beinhaltet die Ausstellung subtile Gegenwartsbezüge und ist gefärbt "mit der Brille aus der heutigen Situation", statt auf der aus seiner Sicht angemessenen «Sachebene» zu verbleiben. In diesen Aussagen manifestiert sich zugleich ein weiter oben im Rahmen der Brennpunktbetrachtung bereits dargelegtes spezifisches Geschichtsverständnis, demzufolge es überhaupt eine politisch ungefärbte Sachebene geben und gegenwärtige Perspektiven aus Darstellungen ausgeblendet werden können.

\subsection{5 Übergreifende Befunde, Zwischenfazit und Einordnung}

Im zurückliegenden Abschnitt wurde ein zweiter von drei Grossbereichen von Äusserungen während des Ausstellungsbesuchs vorgestellt: diejenigen Äusserungen, in denen die Besuchenden über die Ausstellung oder einzelne darin befindliche Elemente sprechen. In ihrer idealtypischen Ausprägung steht diese Dimension solchen Äusserungen diametral gegenüber, in denen Besuchende über Geschehen sprechen und die im Kapitel zuvor behandelt wurden. Auf einer Ebene geht es um das, was aus Sicht der Besuchenden war oder ist, geschehen ist oder geschieht, auf der anderen Ebene um die Art und Weise, wie die Ausstellung ist und dieses Geschehen darstellt.

Was sich idealtypisch und theoretisch in der beschriebenen Weise klar unterscheiden lässt, wird im konkreten Datenmaterial allerdings verwässert. Dies habe ich gezeigt anhand des Spektrums von Möglichkeiten, in denen Besuchende mit den in der Ausstellung enthaltenen Bildquellen umgehen und dabei von Fall zu Fall diese stärker als gestaltetes Bild, als Element innerhalb des Ausstellungsnarrativs oder als Abbild historischer Wirklichkeit hervorheben. Ebenfalls im Graubereich zwischen den beiden Fokussierungen bewegen sich mitunter Äusserungen, in denen Besuchende über Themen der Ausstellung sprechen. Auch hier fliessen Äusserungen über die Strukturierung historischen Geschehens und die Strukturierung von dessen Darstellung durch die Ausstellung, Äusserungen über den Verlauf historischen Geschehens und die Darstellung dieses Verlaufs in der Ausstellung bisweilen nahtlos ineinander. Auf dieses Feld von Schattierungen komme ich weiter unten im Zusammenhang mit der Beschreibung der durch die Besuchenden hergestellten persönlichen Relationen vertiefter zu sprechen, weil sich auch dort wieder ähnliche Grenzfälle manifestieren. ${ }^{1403}$

1403 Vgl. Abschnitt 8.7.2. 
Jenseits der im Material vorzufindenden Schattierungen konnte im Rahmen der Analyse dennoch festgestellt werden, dass es Unterschiede zwischen den Besuchenden mit Blick auf die Frage gibt, ob sie im Verlauf ihres Besuchs eher geschehens- oder ausstellungsbezogene Äusserungen formulieren. In dieser Hinsicht wurden stärker geschehensbezogene und stärker ausstellungsbezogene Besuchende identifiziert und ergänzt um eine dritte Gruppe von Besuchenden, die stärker ausgewogen zwischen beiden Bereichen hin und her wechseln. Sich ausschliesslich ausstellungs- oder geschehensbezogen äussernde Personen kommen allerdings nie vor - stets gibt es mindestens eine kleine Menge von Äusserungen, die sich auch dem jeweils anderen Bereich zuordnen lässt.

Neben der Differenzierung in geschehens- und ausstellungsbezogenen Äusserungen wurde parallel noch eine weitere Differenzierung vorgenommen, nämlich diejenige in stärker positivistisch und konstruktivistisch ausgerichtete Äusserungen, wobei ich dargelegt habe, dass Äusserungen im Fokus I keineswegs gleichbedeutend mit positivistischen, Äusserungen im Fokus II keineswegs gleichbedeutend mit konstruktivistischen Positionen sind, sondern dass sich innerhalb der Fokussierungen jeweils eine Bandbreite von Zugängen manifestiert. So umfassen Äusserungen $\ddot{u} b e r$ die Ausstellung Vorstellungen von der Existenz einer unzweifelhaft gültigen Wirklichkeit, die in der Ausstellung und ihren Elementen abbildhaft dargestellt werden kann, und Betrachtungen der Art und Weise, wie die Ausstellung gestaltet ist und erzählt, bis hin zu Einsichten in die deutende Rolle der Ausstellung und Reflexion über diese von der Ausstellung vorgenommenen Deutungen. Ein Spektrum von Zugangsweisen habe ich auch anhand von Äusserungen in Bezug auf Bildquellen bzw. die darin repräsentierten Bildinhalte dargestellt.

Am Beispiel von P19 wurde zudem deutlich, dass Sensibilität für die von der Ausstellung vorgenommenen Deutungen durchaus zusammen auftreten kann mit Vorstellungen von einer gültigen und angemessenen Repräsentation historischen Geschehens, nämlich dann, wenn abgeglichen wird, inwiefern die Ausstellung diese für angemessen gehaltene Darstellung liefert oder nicht. Reden über die Ausstellung und deren Erzählung von Geschichte muss somit keineswegs gleichbedeutend sein mit der Ablehnung der Idee einer Korrektheit der Darstellung.

Die geschilderten Befunde stellen dabei einerseits Bestätigungen, andererseits aber auch Differenzierungen des bestehenden Forschungsstands dar. Wie weiter oben bereits festgestellt, kommt Sharon Macdonald beispielsweise zu dem Schluss, Besuchende würden Museen «als autoritative Einrichtungen» betrachten, als Ort, 
der «ihnen neutrale, wertfreie Fakten präsentiert». ${ }^{1404}$ Christian Kohler bemerkt für Schüler und Schülerinnen, dass sich eine konstruktivistische Haltung, so sie denn überhaupt vorhanden ist, nicht zwingend im konkreten Umgang mit einer Ausstellung manifestiert. ${ }^{1405}$

Für die von mir beforschten Besuchenden lassen sich diese Befunde eines verbreiteten «Nicht-Konstruktivismus» im konkreten Umgang mit der Ausstellung höchstens in Teilen bestätigen. Vielmehr zeigt sich ein ambivalentes Nebeneinander aus stärker positivistischen und konstruktivistischen Zugängen, das, folgt man den Überlegungen Bärbel Völkels, keineswegs überrascht. Völkel stellt, wie bereits beschrieben, fest, dass menschlicher Lebensvollzug positivistischer Annahmen bedarf, damit Menschen überhaupt handlungsfähig werden. ${ }^{1406}$ Trotz des Wissens «um den Konstruktcharakter und die mögliche Vorläufigkeit unseres Wissens um die Welt» sei es im alltäglichen Lebensvollzug unumgänglich, «die Komplexität der vagen, vielfach konstruierten Welt zu reduzieren». ${ }^{1407}$ Diese Feststellung scheint auch auf die Situation eines Ausstellungsbesuchs unmittelbar übertragbar und eignet sich als Kontextualisierung sowohl für die genannten Befunde Kohlers ${ }^{1408}$ wie auch für diejenigen meiner Studie.

$\mathrm{Zu}$ bedenken gilt es allerdings, dass sich ein grosser Teil von ausstellungsbezogenen Äusserungen der Besuchenden gar nicht hinsichtlich einer möglichen dahinterstehenden geschichtstheoretischen Positionierung eindeutig deuten lässt. Dies gilt insbesondere für solche Äusserungen, mit denen die Besuchenden ausgestellte Elemente oder behandelte Themen identifizieren und die einen erheblichen Anteil innerhalb der ausstellungsbezogenen Äusserungen ausmachen, sich jedoch nicht schon zugleich als konstruktivistische Einsichten in die Gemachtheit von Geschichte interpretieren lassen. Identifizierende Aussagen können durchaus auf unterschiedlichen geschichtstheoretischen Überzeugungen basieren. So können von der Ausstellung behandelte Themen einerseits als Abbilder der thematischen Struktur historischer Wirklichkeit, andererseits die Themenwahl als interessen- und gegenwartsgeleitete Konstruktion angesehen werden. Aus der blossen Benennung der vorkommenden Themen oder Elemente sind zugehörige Sichtweisen der Besuchenden nicht zu identifizieren.

1404 Macdonald 2011, S. 246.

1405 Kohler 2016, S. 150, S. 193 ff., S. 226 ff.

1406 Völkel 2009, S. 723.

1407 Völkel 2009, S. 723.

1408 Kohler 2016, S. 150, S. 193 ff., S. $226 \mathrm{ff}$. 
Eindeutiger in dieser Hinsicht lassen sich solche Äusserungen interpretieren, in denen Besuchende sich über in der Ausstellung vorgenommene Deutungen äussern. Diese lassen sich dem Modus der De-Konstruktion zuordnen. Hier wird eine vorhandene Erzählung entschlüsselt und werden die ihr zugrunde liegenden Muster identifiziert. Bisweilen verbindet sich damit ein kritischer Impetus, wenn Erzählungen durch die Besuchenden infrage gestellt werden. Dies wurde insbesondere am Beispiel von Äusserungen von P8 aufgezeigt. In solchen Fällen lässt sich von Äusserungen im Modus einer kritischen Sinnbildung sprechen, die einerseits die Kritik an Deutungen, aber auch die Kritik an den Erzählungen zugrunde liegenden Deutungsmustern beinhalten kann. ${ }^{1409}$

Die Studie von Susie Wise sensibilisiert dafür, dass es möglicherweise Unterschiede in den erkenntnistheoretischen Zugängen gibt, je nachdem, über welche Hintergründe die Besuchenden verfügen. So kommt Wise zu dem Ergebnis, dass sich die Formen des Interpretierens zwischen den an ihrer Studie beteiligten Laien, Expertinnen und Experten auffällig unterscheiden.

«Whereas the tourists interpreted in order to understand what they were seeing in the first place, the historians, who were no more familiar with the exhibition's specific content, interpreted to create wider reaching narratives about what was happening either at the level of the object or the exhibition.» ${ }^{1410}$

Beispielsweise habe sich ein Tourist im Umgang mit Objekten auf das Identifizieren des Gesehenen beschränkt und darauf, herauszufinden, «what the museum wanted him to see». ${ }^{1411}$ Eine Historikerin habe stattdessen die Ausstellung betrachtet als «constructed space filled with objects that were chosen» und «revealed her knowledge that curators and designers created the exhibition and placed the objects, and that in so doing they also created potential meanings», ${ }^{1412}$ wobei Wise in Anlehnung an Wineburg überhaupt nur die zweite Form als Historical Thinking fasst. ${ }^{1413}$

1409 Zum Modus der kritischen Sinnbildung: Rüsen 2012, S. 175 ff.; Rüsen 2013, S. 213; zur Ausdifferenzierung der beiden Dimensionen kritischer Sinnbildung: Körber 2013, S. 3 ff.; Körber 2014. Vgl. hierzu die Ausführungen in Abschnitt 8.5.5.

1410 Wise 2011, S. 99.

1411 Wise 2011, S. 100 f., direktes Zitat S. 101.

1412 Wise 2011, S. 102, Kursivsetzungen analog zum Original.

1413 Wise 2011, S. 103 ff., sich beziehend auf Wineburg 1991 und 1998; vgl. zu Wineburg auch die Ausführungen in Abschnitt 2.6. 
Ähnlich unterscheidet auch Andreas Körber in seinem Graduierungsvorschlag in Bezug auf Museumsbesuchende unterschiedliche Grade der Einsicht in den Konstruktcharakter einer Ausstellung, die sich vor allem im Bereich der historischen Sach- und Methodenkompetenzen und dort wiederum im Bereich der DeKonstruktion manifestieren. So unterscheidet Körber im Bereich der historischen Sachkompetenzen Varianten von Vorstellungen über Museen bzw. Ausstellungen, die von einer Wahrnehmung als «Darstellung vergangener Wirklichkeit» über eine Einsicht in deren Bindung an Zeit und Forschungsstand bis hin zu einer Reflexion und Infragestellung der die Darstellung leitenden Sichtweisen reichen. ${ }^{1414}$ Für Vorstellungen über Objekte spricht er von einer Bandbreite, die von einer Wahrnehmung der «ausgestellten Objekte nur als «Gegenstände»» über deren Betrachtung «als Repräsentanten eines historischen Zusammenhangs» und Unterscheidung «zwischen 〈Original〉 und 〈Fälschung»» bis hin zu einer Reflexion des Originalitätskonzepts und der durch die Ausstellung getroffenen Objektauswahl reicht. ${ }^{1415}$ Strukturierungskompetenz reicht für Körber vom Wahrnehmen des Ausstellungsaufbaus als «nicht wahllos» mit zunehmender Fähigkeit zu deren Reflexion und Kommentierung bis hin zur Reflexion der Wirkung einer bestimmten Präsentationsweise. ${ }^{1416}$

Im Bereich der historischen Methodenkompetenzen und darin im Bereich der De-Konstruktion unterscheidet Körber eine Bandbreite, die damit beginnt, «überhaupt $[\ldots]$ das Dargestellte als eine heutige Aussage über Geschichte zu erkennen», die über die Verwendung hierfür «gängiger Konzepte und Begriffe ( $<$ Perspektive〉, 〈Interesse〉, 〈Inszenierung〉, 〈Auswahl〉, 〈Re-Kontextualisierung〉 ...)» führt, bis hin zu einer kritischen Reflexion vorhandener «Deutungs- und Erklärungsmuster». ${ }^{1417}$ Zunehmende Einsichten in die Konstruktivität einer Ausstellung gelten damit sowohl bei Wise als auch bei Körber als Merkmale elaborierterer Formen historischen Denkens oder gar überhaupt erst als Formen historischen Denkens.

Die Studie von Wise legt, wie geschildert, nahe, dass solche konstruktivistischen Zugänge mit den individuellen Hintergründen der Besuchenden zusammenhängen. $\mathrm{Ob}$ und inwiefern dies im Rahmen meiner Studie der Fall ist, kann zwar nicht exakt beziffert werden, jedoch sind tendenzielle Einschätzungen mög-

1414 Körber 2009, S. 63.

1415 Körber 2009, S. $66 \mathrm{f}$.

1416 Körber 2009, S. 67 f., direktes Zitat S. 67.

1417 Körber 2010a, S. 3 ff. 
lich, wobei angedeutete Zusammenhänge im Rahmen quantitativer Zugriffe differenzierter weiterzuverfolgen wären.

Wie dargelegt, besteht das von mir untersuchte Sample zur Hälfte aus Personen, die weder über einen geschichtswissenschaftlichen noch geschichtsdidaktischen oder museumsbezogenen Hintergrund verfügen, während die andere Hälfte solche geschichtswissenschaftlichen Hintergründe mitbringt, teilweise ergänzt um geschichtsdidaktische Hintergründe und/oder Erfahrungen in der Museumspraxis. ${ }^{1418}$ Auffallend ist dabei etwa, dass die genannten stark geschehensfokussierten Besuchenden (P5, P18, P20, P22, P25, P26, P27) mit einer Ausnahme über keinen geschichtswissenschaftlichen Hintergrund und nie über einen geschichtsdidaktischen und/oder museumsbezogenen Hintergrund verfügen, wohingegen die stark ausstellungsfokussierte Person (P4) über beide Hintergründe verfügt, ebenso wie P8, diejenige Person, die weiter oben als besonders sensibel für die von der Ausstellung vorgenommenen Deutungen beschrieben wurde.

Ausstellungsbezogene Äusserungen allein sind, wie oben geschildert, noch keineswegs ein Indiz für das Vorhandensein konstruktivistischer Zugänge. Namentlich die Gruppe der element- und themenidentifizierenden Äusserungen, die innerhalb der ausstellungsbezogenen Äusserungen stark vertreten sind, sind nicht ohne Weiteres erkenntnistheoretischen Zugängen zuordenbar.

Ebenso im Vergleich verhältnismässig häufig vorkommend und über nahezu alle Besuchenden vertreten sind Äusserungen über Elementauswabl und -prösentation, in denen sich nun bereits stärkere Anklänge von Einsichten in die Ausstellung als gestalteten, konstruierten Raum andeuten können. Äusserungen in diesem Spektrum finden sich auffallend bei P4, P8, P12, P19 und P28, mit Ausnahme von P19 alles Personen mit einem geschichtswissenschaftlichen oder sogar geschichtsdidaktischen/museumsbezogenen Hintergrund.

Alle übrigen ausstellungsbezogenen Kategorien sind je nur bei einem Teil der Besuchenden und dabei von Person zu Person in unterschiedlicher Kombination vertreten. Auffallend in der Hinsicht, dass sich bei ihnen jenseits identifizierender Tätigkeiten auch Äusserungen in den meisten anderen Bereichen innerhalb des Fokus II finden und sie insofern ein grosses Spektrum von Zugängen abdecken, sind die Besuchenden P8, P12 und P28, alle drei Personen mit geschichtswissenschaftlichem und in zwei Fällen überdies geschichtsdidaktischem und/oder museumsbezogenem Hintergrund.

$1418 \mathrm{Vgl}$. Abschnitt 6.2.3. 
Als tendenziell konstruktivistisch orientierte Zugänge lassen sich darunter insbesondere Äusserungen über Deutungen der Ausstellung und über in der Ausstellung angelegte Gegenwartsbezüge sowie über Leerstellen/Nicht-Themen der Ausstellung einschätzen. $\mathrm{Zu}$ diesen Bereichen äussern sich vor allem Personen, die über einen geschichtswissenschaftlichen Hintergrund verfügen, darunter in markanter Weise die bereits weiter oben vorgestellte Person P8, ${ }^{1419}$ sowie überdies P19, dessen/deren Äusserungen ebenfalls bereits in Form eines Brennpunkts vorgestellt wurden und der/die als einzige Person obne geschichtswissenschaftlichen Hintergrund ebenfalls in auffallendem Mass über Deutungen der Ausstellung und Leerstellen spricht, dabei nichtsdestotrotz zugleich Vorstellungen von historischer Wirklichkeit und Korrektheit formuliert.

In der Zusammenschau lässt sich feststellen, dass sich bisweilen einzelne Äusserungen als eher konstruktivistisch oder positivistisch einordnen lassen. Jedoch wäre es nicht adäquat, allein aus einzelnen Äusserungen Rückschlüsse auf insgesamt vorhandene Grundhaltungen der Besuchenden zu ziehen, da aufgrund der Anlage der Studie zum einen keine umfassenden Fallprofile entwickelt wurden und sich zum anderen eine grosse Zahl von Äusserungen im Fokus II überhaupt nicht in dieser Hinsicht eindeutig einschätzen lässt. Keinesfalls sollten etwa aus der Abwesenheit konstruktivistischer Äusserungen Rückschlüsse auf positivistische Grundhaltungen gezogen werden.

Nicht näher zuordenbar in dieser Hinsicht sind insbesondere die genannten identifizierenden Tätigkeiten, auf die ich zum Abschluss des Fazits nun noch genauer eingehe. Die von mir festgestellte Bedeutung identifizierender Aktivitäten beim Ausstellungsbesuch kann an diverse bereits erwähnte Studien anknüpfen. So weist auch Wise eine Kategorie «Identifying and describing» aus, die sie als Teilbereich innerhalb des «Interpreting» und dieses wiederum als eine der Strategien des «sense-making» einordnet. ${ }^{1420}$ Wise führt die Kategorie «Identifying and describing» abgesehen von der Nennung eines Textbeispiels ${ }^{1421}$ nicht weiter aus, und die Tragweite des Phänomens bleibt insofern unklar. Angesichts dessen, dass Wise den übergeordneten Bereich «interpreting» als «fundamental building block of the exhibition experience» und als die deutlich am häufigsten vorkommende

1419 Allerdings nicht bei P3 und P4, obwohl diese einen geschichtswissenschaftlichen und sogar geschichtsdidaktischen/museumsbezogenen Hintergrund haben.

1420 Wise 2011, S. 98.

1421 Wise 2011, S. 98. 
Form des sense-making vorstellt ${ }^{1422}$, lässt sich jedoch zumindest vermuten, dass das Identifizieren auch in ihrem Datenmaterial einen bedeutenden Stellenwert einnehmen dürfte.

Weiter können meine Befunde an Studien von Hannah Röttele, Gun-Brit Thoma, Heiner Treinen und Bernd Wagner anknüpfen, aus denen hervorgeht, dass sich Museumsbesuchende dem bereits Bekannten zuwenden, ${ }^{1423}$ wobei Treinen davon ausgeht, dass die Zuwendung zum Bekannten sogar den Hauptmodus während eines Ausstellungsbesuchs darstellt, ${ }^{1424}$ Röttele der Begegnung mit dem Bekannten als zweite Form die Zuwendung zu Irritierendem an die Seite stellt ${ }^{1425}$ und Wagner für Kinder zu erkennen glaubt, dass diejenigen Objekte besonders anziehend wirken, die gleichermassen Bekanntheit und Fremdheit in sich vereinigen. ${ }^{1426}$

Wie auch von Röttele festgestellt, zeigt sich in dem von mir analysierten Material, dass «[d]er Identifikation von 〈Bekanntem〉 $[\ldots]$ in vielen Fällen keine weitere Beschäftigung [folgt]». ${ }^{1427}$ Die Besuchenden bleiben beim Identifizieren eines Elements stehen oder stellen allenfalls noch eine knappe weiterführende Überlegung an. Dies entspricht auch den Befunden Thomas, die «kognitive[.] Prozesse eher in einfacher als in komplexer Form» in ihrem Material feststellt, ${ }^{1428}$ womit sich, wie ich weiter oben bereits ausgeführt habe und ohne dass Thoma selbst dies explizit ausführt, augenscheinlich identifizierende Aktivitäten verbinden. ${ }^{1429}$

Umgekehrt finden sich auch in meinem Material die von Röttele für die Begegnung mit nicht sofort Bekanntem und Einordenbarem beschriebenen Fälle, in denen aus einem Irritationsmoment eine vertieftere Beschäftigung resultiert. ${ }^{1430}$ Formulierte Irritationen der Besuchenden werden jedoch erst im weiteren Verlauf der Darstellung zum Gegenstand, wo ich erneut auf diese Überlegungen zu sprechen komme. ${ }^{1431}$

1422 Wise 2011, S. 95 und S. 98, direktes Zitat S. 98.

1423 Röttele 2017; Thoma 2009; Treinen 1988; Wagner 2013; wobei Thoma den geschilderten Zusammenhang nicht auf diese Weise selbst explizit herstellt; vgl. hierzu meine Ausführungen in Abschnitt 5.3.5.

1424 Treinen 1988, S. $33 \mathrm{f}$.

1425 Röttele 2017, S. 119.

1426 Wagner 2013, S. $213 \mathrm{ff}$.

1427 Röttele 2017, S. 119.

1428 Thoma 2009, S. 138.

1429 Vgl. hierzu Abschnitt 5.3.5 sowie die von Thoma angeführten Ankerbeispiele für ihre Kategorien (Thoma 2009, S. $221 \mathrm{ff}$.).

1430 Röttele 2017, S. 119.

1431 Vgl. Abschnitt 8.7.2.1. 
Ebenfalls Anknüpfungsmöglichkeiten an die vorliegende Theorie und Empirie eröffnen sich anhand der Befunde zum Umgang der Besuchenden mit den in der Ausstellung enthaltenen Bildquellen. Sie können an die in der Geschichtsdidaktik und ästhetischen Bildung virulente Diskussion über die Funktion von bildlichen Elementen innerhalb von Aneignungsprozessen, insbesondere innerhalb von Prozessen historischen Denkens und Lernens, anschliessen. ${ }^{1432}$ So deutet sich im Material eine Tendenz der Besuchenden an, Dargestelltes schlicht zu beschreiben und dabei als Abbilder bzw. als «Gucklöcher» auf historische Realität zu thematisieren, wohingegen die Konstruiertheit von Bildern, etwa die verwendete Bildsprache und Bildkomposition, ihre Intentionalität vor allem in Bezug auf die in der Ausstellung enthaltenen Karikaturen, im Vergleich dazu aber kaum einmal im Zusammenhang mit Fotografien und Filmen thematisiert wird. Besuchende scheinen Fotografien und Filmen einen vor allem wirklichkeitsabbildenden Charakter zuzuschreiben. Wie ich weiter unten noch näher beschreiben werde, nehmen Besuchende die Fotografien und Filme überdies zum Anlass, um sich Aspekte historischen Geschehens vorzustellen oder sich in diese hineinzuversetzen, ${ }^{1433}$ betrachten sie also als Wege eines unmittelbaren Zugangs zu historischem Geschehen.

Noch in einer weiteren Hinsicht eröffnen sich aus den Befunden Anknüpfungspunkte zur bestehenden Literatur, nämlich zeigte sich in der Analyse, dass die Erfahrung von Ästhetik und Raum beim Ausstellungsbesuch als Katalysator für die Beförderung von Erkenntnis fungieren kann, dass hier also kognitive und nicht-nur-kognitive Momente historischen Denkens und Aneignens in einen Zusammenhang treten. ${ }^{1434}$ Besuchende erweisen sich als sensibel für die ästhetische und räumliche Aufmachung der Ausstellung und auch für darin liegende Irritationsmomente, wie am Beispiel der abweichenden ästhetischen Gestaltung der Schlussabteilungen gezeigt.

Aus solchen Irritationen können Fragen nach möglichen auch inhaltlich veränderten Zugängen einer Abteilung erfolgen und damit die Auseinandersetzung mit Form und Inhalt in eine Wechselwirkung treten. Eine ähnliche Wechselwirkung habe ich ausserdem für den Umgang der Besuchenden mit den «Blick ins Ausland»Elementen und insgesamt der Struktur der Ausstellung festgestellt, wobei sich

1432 Vgl. Abschnitt 3.4.

1433 Vgl. Abschnitt 8.7.4.2.

1434 Vgl. Abschnitt 3.4. 
Anklänge an Wise' «Embodied Interpretive Practices» ${ }^{1435}$ zeigen und die Besuchenden mit der Bewegung im Raum zugleich inhaltliche Zugänge verknüpfen.

\section{7 Äusserungen im Fokus III: Die eigene Person und Lebenswelt}

\subsubsection{Varianten im Überblick}

Neben den Fokussierungen der Besuchenden auf das Geschehen (Fokus I) und die Ausstellung und ihre Elemente (Fokus II) habe ich eine dritte Fokussierung ausgemacht. In Anlehnung an das geschichtsdidaktische Prinzip Lebensweltbe$\operatorname{zug}^{1436}$ überschreibe ich diese Kateogorie als Fokussierung auf die eigene Person und Lebenswelt. ${ }^{1437}$ Beinhaltet sind in dieser Kategorie alle Textstellen, aus denen deutlich wird, dass sich beim Ausstellungsbesuch «persönliche Bedeutung» für die Besuchenden entfaltet, dass der Besuch und das Gesehene «etwas mit [ihrem] Leben zu tun» hat. ${ }^{1438}$ Anders als in der vorliegenden Literatur zum Lebensweltbezug als didaktisches Prinzip deute ich solche Bezüge allerdings nicht normativ als Zielgrösse, sondern beobachte deskriptiv ihr Vorkommen und systematisiere auftretende Formen.

Ich unterscheide drei Gruppen von Äusserungen mit Sichtbarmachung der eigenen Person und Lebenswelt und stelle sie in diesem Kapitel zunächst im Überblick, später differenzierter (Abschnitte 8.7.2, 8.7.3, 8.7.4) vor: Es sind dies Äusserungen, in denen die Besuchenden Bezüge zu ihrer «Erfahrungswelt», ${ }^{1439}$ ihrer Lebenswelt jenseits der Ausstellung herstellen, über ihre Rolle als Besuchende innerbalb der Ausstellung sprechen und reflektieren oder persönliche Relationen herstellen. Nachfolgend widme ich mich zunächst dem letztgenannten Aspekt, den Relationen. Was ist damit gemeint?

Ein zentraler Befund der Analyse besteht darin, dass sich Äusserungen der Besuchenden über die eigene Person häufig als ein Sich-in-Beziehung-Setzen manifestieren - nämlich zur Ausstellung oder zu Geschehen. ${ }^{1440}$ Beispiele hierfür

1435 Wise 2011, S. 74.

$1436 \mathrm{Vgl}$. Abschnitt 2.4.

1437 Knapp beschrieben und mit anderen Materialbeispielen veranschaulicht wird der Fokus III auch in Thyroff $2017 \mathrm{c}$, S. 4, S. 9 f.

1438 So von Buck allgemein als Merkmale von Lebensweltbezügen gefasst: Buck 2017, S. 293.

1439 Schörken 1997, S. 4.

1440 Dazu auch bereits Thyroff 2017c, S. 9. 
sind Formulierungen in der idealtypischen Struktur eines <ich finde interessant, dass $\mathrm{x}$ passiert ist〉, 〈 $\mathrm{x}$ ist spannend〉, <ich wusste bislang nicht, dass $\mathrm{y}$ war oder 〈schön, dass die Ausstellung z macht 〉. ${ }^{1441}$ Solche Äusserungen beinhalten einerseits Äusserungen über Geschehen oder die Ausstellung, gleichzeitig aber auch persönliche Bezüge, die Besuchende zu Geschehen oder der Ausstellung herstellen: beispielsweise als Interesse, neues Wissen oder Gefallen in Bezug auf die Ausstellung oder auf Geschehen. ${ }^{142}$ Abbildung E visualisiert diesen Zusammenhang zwischen den Fokussierungen.

Auf der Ebene der Codierungen habe ich derartige Textstellen als Überschneidungsbereiche von Kategorien betrachtet und systematisch mehreren Bereichen zugleich zugeordnet, nämlich einerseits die jeweilige Äusserung über Geschehen oder über die Ausstellung erfasst, andererseits auch festgehalten, inwiefern sich die Besuchenden darin als Person selbst sichtbar machen. Während ich für die Unterscheidung zwischen dem Fokus I und Fokus II im Codierprozess noch auf eine möglichst klare Abgrenzung der Kategorien achtete, nicht zuletzt angesichts der ursprünglichen Absicht, stärker geschehens- und ausstellungsfokussierte Besuchende unterscheiden zu können, sind also im Gegenteil für den Fokus III Doppelungen mit anderen Fokussierungen nicht nur möglich, sondern teilweise sogar durch die inhaltliche Struktur der Kategorien systematisch begründet.

$\mathrm{Zu}$ den Relationen zählen Äusserungen von

- Erstaunen und Eindruck,

- Interesse, Spannung und Faszination,

- Freude, Wohlgefühl, Dankbarkeit und positiver Bewegung,

- Belustigung, Schmunzeln, Spott und Ironie,

- Betroffenheit, Entsetzen, Beunruhigung und negativer Bewegung,

- Sättigung, Überdruss und Anstrengung,

- Desinteresse und Indifferenz,

1441 Wie im bisherigen Verlauf des Ergebniskapitels arbeite ich auch hier wieder mit idealtypischen Formulierungen und kennzeichne diese durch einfache Anführungs- und Schlusszeichen, um sie von den Zitaten aus dem Datenmaterial zu unterscheiden, die stets in Kursivschrift stehen und, wo nicht im Fliesstext eingebettet, eingerückt.

1442 «Ich» muss in solchen Formulierungen nicht zwingend vorkommen. Vielmehr gehe ich davon aus, dass sich in den Nennungen von Emotionen, Urteilen usw. auch ohne explizite Nennung der eigenen Person ein Bezug zu selbiger manifestiert. 
- Urteilen über Relevanz und Wichtigkeit, ergänzt um einen Exkurs zu impliziten Relevanzen und Bedeutungen,

- Urteilen über Schlüssigkeit, Erwartbarkeit und Nachvollziehbarkeit,

- positiven und negativen Urteilen,

- Vorwissen und neuem Wissen,

- Vermutungen,

- Fragen, Unklarheiten und Irritationen ${ }^{1443}$ sowie

- Sonstiges. ${ }^{1444}$

Ich übertitle diese Relationen präzisierend als kognitive und nicht-nur-kognitive Relationen, ${ }^{1445}$ bezugnehmend auf die weiter oben geschilderten Überlegungen, dass historisches Denken nicht allein eine kognitive Dimension hat, sondern sich darin auch eine Bandbreite weiterer Anteile manifestiert, ohne sich allerdings in einer reinen Dichotomie aus Kognition und Emotion zu erschöpfen. ${ }^{1446}$ Eine ursprünglich von mir angestrebte klare Trennung in kognitive Relationen auf der einen Seite sowie emotionale Relationen und Wertungen auf der anderen Seite habe ich hingegen aufgegeben, zugunsten einer Grosskategorie, die mehr oder weniger kognitive, mehr oder weniger emotionale Äusserungen umfasst, ohne dass ich diese dabei eindeutig klassifizieren muss. Die Reihenfolge der obigen Anordnung ist so gewählt, dass sie ein Kontinuum aus stärker emotional geprägten Zugängen tendenziell zu Beginn der Reihe und aus stärker kognitiv geprägten Zugängen tendenziell zum Schluss der Reihe abbildet, ohne aber eine klare Zuweisung vor-

1443 Einzelne Bereiche aus diesen Relationen wurden in Abschnitt 8.5 im Kontext der Äusserungen im Fokus I über das Geschehen bereits einmal ansatzweise thematisiert und werden hier nochmals systematisch aufgearbeitet, nun aber in neuem Kontext, nämlich aus Perspektive der Sichtbarmachung der Person der Besuchenden.

1444 Diese Kategorie fungiert als «Restekategorie» und beinhaltet weitere Äusserungen, in denen Besuchende das Geschehen oder die Ausstellung als in irgendeiner Weise ausserordentlich, auffällig, bemerkenswert einstufen, die ich aufgrund ihrer Diversität hier aber nicht weiter ausdifferenziere.

1445 Mich bedienend an der von Borries geprägten und bereits weiter oben von mir eingeführten Terminologie (Borries 2014, S. $167 \mathrm{ff}$.), insbesondere bei der bei Borries zu findenden Unterscheidung in kognitive und nicht-nur-kognitive Aspekte des historischen Lernens (Borries 2014, S. 169); vgl. zum Terminus die Ausführungen in Abschnitt 3.4.1.

1446 Zur nicht zielführenden Idee einer Gegensätzlichkeit: Gies 1994, S. 27 f. und S. 38 f; Brauer/Lücke 2013a, S. 15 ff., S. 18 ff.; Borries 2014, S. 168 f.; vgl. dazu ausserdem Abschnitt 3.4 . 
nehmen zu wollen. Insbesondere Äusserungen von Urteilen, ${ }^{1447}$ in der Mitte der Liste angesiedelt, stehen an der Schnittstelle von Emotion und Kognition. ${ }^{1448}$

1447 Mit dem Begriff «Urteile» können im Hinblick auf die Beurteilung historischen Geschehens (Fokus I) in Jeismann'schen Begriffen gesprochen sowobl Sach-als auch Werturteile gemeint sein, ohne den Versuch einer Unterscheidung im Datenmaterial unternehmen zu wollen. Folgt man Jeismann und seiner Rezeption bei Becker (Jeismann 2000, S. 63 f; Becker 2017, S. 319 f.), dann handelt es sich bei der bekannten Trias aus «Sachanalyse», «Sachurteil» und «Werturteil» (Jeismann 2000, S. 63 f.) um Kategorien, die «(nur) analytisch getrennt» sind (Becker 2017, S. 319; Kursivsetzung analog zum Original) und «die in historischen Vorstellungen sich gewöhnlich ununterscheidbar miteinander verbinden» (Jeismann 2000, S. 63).

Ich gehe deshalb von einem Kontinuum aus, in dem mehr oder weniger urteilsfreie Äusserungen über historisches Geschehen als Sachanalysen, d.h. als «Klärung[en] des historischen Sachverhaltes» (Jeismann 2000, S. 63), fliessend übergehen können in einerseits Sachurteile, verstanden als «historische Bedeutungszuweisung, d.h. die Einordnung dieses Faktums in einen grösseren Zusammenhang von Ursachen und Wirkungen und die $\mathrm{Zu}$ messung einer historischen Kraft - also ein Urteil über die Stellung dieses Faktums im Zusammenhang der Epoche oder der aufeinanderfolgenden Perioden der Geschichte» (ebd., S. 63 f.) - und andererseits auch Werturteile als «Herstellung einer Beziehung zwischen dem historischen Faktum und seiner geschichtlichen Bedeutung einerseits, einer persönlichen und sozialen Betroffenheit andererseits [...], die den unmittelbaren Lebensbezug historischer Erscheinungen betrifft» (ebd., S. 64).

Für die konkrete empirische Arbeit am Material stellt sich angesichts dieses Kontinuums jedoch die Frage, ob und wie überhaupt Urteile von Nicht-Urteilen unterschieden werden können. Eine solche Unterscheidung stellt meines Erachtens ein ähnlich komplexes Unterfangen dar wie der Versuch, Erzählen, Nacherzählen und Umerzählen (Pandel 2002, S. 49f.) oder Nacherzählungen von Interpretationen (Waldis et al. 2015, S. 77, S. 80 f.) unterscheiden zu wollen (siehe zu diesen Unterscheidungen auch Abschnitt 8.5.1). Derartige Differenzierungen sind theoretisch und analytisch äusserst aufschlussreich, aber wohl nur mit grossen Schwierigkeiten auf empirisches Material übertragbar, weil dort die Formen verfliessen.

Ein Abgleich zwischen den von mir am Material identifizierten Kategorien und der Jeismann'schen Trias ist teilweise möglich. Äusserungen, die nach Jeismann als Sachanalysen zu bezeichnen wären, sind in dem von mir verwendeten Kategoriensystem Bestandteil der Äusserungen über Geschehen (Fokus I). Äusserungen im Stil von Sach- und Werturteilen finden ebenfalls dort und/oder im Fokus III Platz, dort nämlich im Rahmen der Bezüge zur Lebenswelt (s.u.) und vor allem der kognitiven und nicht-nur-kognitiven Relationen, ohne dass allerdings in meinem Kategoriensystem explizit nach Sach- oder Werturteilen differenziert würde. Für die Betrachtung der Relationen einbezogen wurden vielmehr unterschiedslos all solche Äusserungen, in denen historisches Geschehen in irgendeiner Weise qualifiziert und dabei in irgendeiner Weise die Involvierung der eigenen Person sichtbar gemacht wird. Als ein zentraler, dabei auf empirischer Ebene auch zur Abgrenzung von Sachanalysen hilfreicher Indikator dient, wenn die Besuchenden Adjektive zur Beurteilung von Geschehen einsetzen.

1448 Urteile betrachte ich als unmittelbar verbunden mit Einstellungen bzw. Haltungen, die wiederum, folgt man Hasberg, ihrerseits emotionale und kognitive Elemente haben, wobei die jeweiligen Anteile schwerlich zu bestimmen seien (Hasberg 2013, S. 57). Für Hasberg «stellen sie Werthaltungen dar, die lebensgeschichtlich erworben, unweigerlich auch emo- 
Die oben aufgelisteten Aspekte wurden ausgehend vom Datenmaterial induktiv identifiziert und systematisiert. So orientieren sich die gewählten Emotionen nicht an einem vorab fixierten «Katalog mit distinkten Emotionen», sondern an den Verbalisierungen der Besuchenden, dem Hinweis Johannes Meyer-Hammes Rechnung tragend, «dass Emotionen immer sprachlich vermittelt sind, sie also nicht direkt, sondern immer nur durch diesen Filter erhoben werden können», was potenziell dazu führen kann, dass eine «Liste der möglichen Emotionsbegriffe sehr lang» wird. ${ }^{1449} \mathrm{Im}$ Sinne einer inhaltlich-strukturierenden Inhaltsanalyse strebte ich zwar eine Bündelung inhaltlich zusammengehöriger Emotionsbereiche an, allerdings vom Material ausgehend.

Teilweise spannen mehrere Kategorien verschiedene Dimensionen innerhalb eines ähnlichen Phänomens auf. So verweist der Bereich Erstaunen und Eindruck ebenso auf eine neue Erkennntis wie die explizite und stärker kognitive Thematisierung derselben als neues Wissen. Äusserungen von Interessen und Desinteressen haben kognitive und emotionale Elemente und sind als solche verwandt mit Äusserungen von Indifferenz auf der einen Seite, Spannung und Faszination auf der anderen Seite. Für die genannte Bandbreite erwies sich der Sammelname als kognitive und nicht-nur-kognitive Relationen als angemessen. Ausschlaggebend für die Zuordnung war jeweils die Art der Verbalisierung durch die Besuchenden selbst.

Kennzeichen der Relationen ist, dass sie sich auf etwas beziehen. Idealtypisch lassen sich querliegend zu der obigen Auflistung zwei Subgruppen unterscheiden, nämlich abhängig davon, ob Äusserungen in Bezug auf einen Aspekt des Geschehens (Fokus I) oder in Bezug auf die Ausstellung und ihre Elemente (Fokus II) formuliert werden. Für beide Varianten zeige ich nachfolgend ein Beispiel:

"Ja, ist ganz interessant, wie im Jurakonflikt da noch Sachen mitgespielt haben aus dem Ersten Weltkrieg und wie sehr der Erste Weltkrieg doch das Land verändert hat.» (P19, Absatz 140)

«Ich muss es noch mal sagen, die grossen Bilder sind schon beeindruckend.»(P4, Absatz 102)

tional konnotiert sind und als solche auf neue Erfahrungen, so auch auf den Umgang mit Vergangenheit/Geschichte zurückwirken. Es lässt sich indes kaum der emotionale Anteil bestimmen, der in Einstellungen und Haltungen eingeht, ebenso nicht der, der auf rational reflektierte Erfahrungen zurückgeht» (ebd., S. 57).

1449 Meyer-Hamme 2013, S. 128. 
Im ersten Fall wird ein Aspekt historischen Geschehens als «interessant» beurteilt (Fokus I), im zweiten Fall gilt die Einschätzung «beeindruckend» den in der Ausstellung enthaltenen Bildquellen als Elemente (Fokus II). Im digitalen Anhang der Arbeit sind alle Varianten von Relationen im Überblick, jeweils untergliedert nach Bezugspunkten und mit zugehörigen Beispielen, einsehbar.

Neben den geschehens- und ausstellungsbezogenen Varianten gibt es noch eine dritte Gruppe von Äusserungen, in denen die Relationen nicht eindeutig einem Bezugspunkt zugeordnet werden konnten bzw. unklar zwischen beiden Fokussierungen liegen und sich gleichermassen auf Geschehen oder die Ausstellung beziehen können. Dies ist etwa der Fall bei Äusserungen, in denen von den Besuchenden schlicht Adjektive eingeworfen werden (z. B. 〈interessant〉, 〈spannend〉), die mangels weiterer Präzisierung nicht zugeordnet werden konnten. Dies ist weiter der Fall bei doppelbödigen Formulierungen. So können sich Äusserungen bisweilen sowohl auf einen Aspekt des Geschehens, jedoch auch auf die Tatsache von dessen Darstellung/Thematisierung in der Ausstellung oder die Art und Weise dieser Thematisierung in der Ausstellung beziehen, ohne dass der Bezugspunkt jedoch in diesen Fällen präziser festzustellen wäre. Die nachfolgenden Beispiele verdeutlichen diese Graubereiche:

"Okay, was ist das, das finde ich interessant! (...) <Wirtschaften von Tag zu Tag. (...) (Mit) dem Krieg verändern sich die Rahmenbedingungen für die Wirtschaft. (...) Für die kriegführenden Länder ist die Schweiz mit ibrer hochentwickelten Industrie ein wichtiger Handelspartner.»» (P4, Absatz 43)

"Aber das ist ein wichtiger Aspekt finde ich auch zu seben, dass immer jemand ein Interesse hat, sonst müsste man ja sagen, warum gibt es überhaupt Krieg? Weil es ja, niemand will Krieg sozusagen.» (P3, Absatz 13)

"Gasmasken haben einen sehr bedroblichen (...) Eindruck auf mich.» (P21, Absatz 54)

"Hier steht jetzt im letzten Satz: ‘Entsprechend schlecht sind die kriegswirtschaftlichen Vorkehrungen.> Das stimmt.» (P12, Absatz 55)

Aus den Beispielen ist nicht eindeutig zu entnehmen, worauf sich die Relationen beziehen, ob also eher ein Aspekt des Geschehens als interessant, wichtig, bedrohlich eingestuft wird oder die Tatsache, dass, die Art und Weise, wie dieser Aspekt 
in der Ausstellung dargestellt wird. Eine Vielzahl von Passagen war in dieser Hinsicht schwer zuordenbar. Auch hierbei handelt es sich wiederum um einen der angekündigten Fälle, in denen sich das Datenmaterial einer eindeutigen Kategorisierung widersetzte bzw. bei welchen sich gerade aus Überschneidungen aufschlussreiche Befunde und Hypothesen ableiten lassen.

Die Beobachtung, dass die Besuchenden in vielen Fällen auf die genannte Weise unpräzis formulieren, lässt sich in mehrerlei Hinsicht einordnen. Die naheliegendsten Erklärungen sind, dass sich Besuchende in der Flüchtigkeit des Moments kurzfassen, dass sie einen weiteren Klärungsbedarf schlicht übersehen oder dass für sie selbst die Zuordnung einer Relation in diesem Moment derart selbstverständlich auf der Hand liegt, dass sie nicht versprachlicht werden muss.

Eine ebenfalls bedenkenswerte Hypothese unter erkenntnistheoretischem Blickwinkel könnte lauten, dass für die Besuchenden eine eindeutige Differenzierung zwischen Geschehen und der Art von dessen Darstellung in der Ausstellung gar nicht von derartiger Relevanz ist, dass sie versprachlicht werden müsste. Verbunden mit geschichtstheoretischen Überlegungen und der dort relevanten Differenzierung in Vergangenheit und Geschichte, ${ }^{1450}$ könnte dieser Befund dann auf zweierlei und dabei Widersprüchliches verweisen: einerseits auf die Möglichkeit, dass Besuchende die Ausstellung nicht als perspektivische Konstruktion, sondern als exaktes Abbild von Vergangenheit wahrnehmen und deshalb die Grenzen zwischen Geschehen und seiner Darstellung auflösen; zweitens und umgekehrt auf die Möglichkeit, dass die Besuchenden gerade aus dem Bewusstsein heraus, dass Vergangenheit überhaupt nur als Erzählung und in diesem Fall als Erzählung der Ausstellung zugänglich ist, eine gesonderte Erwähnung beider Dimensionen für obsolet halten. Mit dem vorliegenden Datenmaterial ist hier lediglich die Formulierung von Hypothesen, keine weitere Klärung möglich.

Neben dem zuletzt beschriebenen Bereich der nicht eindeutig einem Bezugspunkt zuordenbaren Äusserungen findet sich eine demgegenüber minime Menge von Äusserungen, in denen zwar Emotionen oder Kognitionen zur Sprache kommen, diese sich aber eindeutig weder auf Geschehen noch auf die Ausstellung beziehen und insofern gar keinem Bezugspunkt zugeordnet werden konnten:

1450 Vgl. zur Unterscheidung von Vergangenheit und Geschichte die Ausführungen in Fussnote 3. Zum Verhältnis von Vergangenheit, Geschichte, Fokus I und Fokus II siehe auch Abschnitt 8.2. 
"Ich lese wieder den Text. (...) Ich habe vor etwa einem Jahr nachgeschaut, was genau eine Garnisonsstadt ist, ich freue mich jetzt, dass ich das weiss beim Text. Ich weiss auch, was ein (Defilee) ist.» (P21, Absatz 10)

Während das von P21 geäusserte Wissen in Bezug auf Garnisonsstädte und Defilees formuliert ist, sich also auf etwas bezieht, ${ }^{1451}$ bezieht sich die in der Mitte der Passage geäusserte Freude rein auf die eigene Person und darauf, selbst etwas zu wissen, was im Datenmaterial äusserst selten vorkommt. In aller Regel ist ein Bezugspunkt ausserhalb der eigenen Person erkennbar, würde etwa Freude über einen Aspekt des Geschehens oder der Ausstellung geäussert.

Im Anschluss an die Darstellung der Relationen widme ich mich in Abschnitt 8.7.3 dem zweiten von insgesamt drei Äusserungsbereichen innerhalb des Fokus III: nämlich Äusserungen der Besuchenden über ihre eigene Lebenswelt jenseits der Ausstellung. Hier geht es um Bezüge, die die Besuchenden zu ihrem eigenen Alltag, zu ihrer «Erfahrungswelt» ${ }^{1452}$ ausserhalb der Ausstellung herstellen, etwa Bezüge zu ihrem sozialen, geografischen und materiellen Umfeld, zu ihrer eigenen Biografie und ihren gemachten Erfahrungen. Die Kategorie umfasst damit sowohl gegenwärtige als auch vergangene Lebenswelt.

Ich systematisiere Äusserungen über

- den eigenen Ort und Raum,

- das eigene Kollektiv,

- die eigene Familie,

- eigene Besitztümer,

- die eigene Militärzeit,

- die eigene Ausbildung,

- die eigene Berufstätigkeit- und Vermittlungstätigkeit,

- eigene Erfahrungen mit Geschichtskultur,

- sonstige biografische Bezüge,

- die Abwesenheit von persönlichen Bezügen.

Nicht immer handelt es sich dabei, wie in Lebensweltkonzepten eigentlich definiert, um «Lebenswelt [als] ein vorwissenschaftlicher Bereich menschlicher Praxis

1451 Wobei in beiden Fällen unentscheidbar zwischen dem Fokus I und Fokus II als Bezugspunkt liegend.

1452 Schörken 1997, S. 4. 
und menschlichen Lebensvollzugs». ${ }^{1453}$ Diejenigen unter den Besuchenden, die ausgebildete Historiker, Geschichtsdidaktikerinnen, Lehrpersonen oder Museumsmitarbeitende sind, verfügen im Hinblick auf Ausstellungsbesuch und -thema nämlich auch über eine professionelle, wissenschaftliche Lebenswelt, ${ }^{1454}$ in der sie sich in ihrem Alltag bewegen und die während des Ausstellungsbesuchs als Bezugspunkt relevant werden kann.

Im Gegensatz zu den weiter oben beschriebenen Relationen wurden Äusserungen über die eigene Lebenswelt jenseits der Ausstellung nicht grundsätzlich zugleich als Äusserungen im Fokus I oder II gewertet. Dies liegt in der unterschiedlichen Struktur der Kategorien begründet. Während sich relationale Äusserungen in der Regel zugleich auf etwas Drittes beziehen - das Geschehen oder die Ausstellung -, kommen andere Aussagen zur eigenen Person auf Ebene der einzelnen Texteinheit mitunter auch ohne diese unmittelbaren Bezüge aus. ${ }^{1455}$ Jedoch können durchaus auch hier Doppelungen vorkommen. Bezüge zur eigenen Lebenswelt können sich beispielsweise mit Äusserungen über Geschehen kombinieren. Die folgenden drei Äusserungen beinhalten einerseits Hinweise auf die Nutzung von Geschichtskultur als eine Form von Lebensweltbezug, nämlich den Konsum einer Radiosendung bzw. die Besuche von Ausstellungen. Im zweiten und dritten Beispiel kombinieren sich damit geschehensbezogene Äusserungen. So berichtet P21 zugleich über "eine Krankenschwester, die sich in den Dienst begab», P12 spricht über die schwierige Situation der Soldaten:

"Bei einer Ausstellung in Stuttgart konnte ich (...) eine Geruchsprobe von (...) der Luft in einem Schützengraben (...) riechen.» (P28, Absatz 57)

"Das erinnert mich an eine Sendung, die ich auf DRS 2 gehört habe über eine Krankenschwester, die sich in den Dienst begab.» (P21, Absatz 69)

1453 Im Abgleich mit den von Schörken zusammengetragenen Gemeinsamkeiten gängiger Lebensweltbegriffe (Schörken 1997, S. 4; direktes Zitat ebd.). Auf die Vorwissenschaftlichkeit des Lebensweltbegriffs verweist ausserdem Grunder (2011, S. 55).

1454 Genau genommen haben alle wissenschaftlich tätigen Personen neben ihrer vorwissenschaftlichen auch eine wissenschaftliche Lebenswelt. Als professionell im Hinblick auf den Besuch von historischen Ausstellungen stufe ich sie im Hinblick auf die genannten Personengruppen ein.

1455 Dies bedeutet nicht, dass derartige Äusserungen zur eigenen Person und Lebenswelt gänzlich von Bezügen auf Geschehen oder Ausstellung entkoppelt wären, nur, dass sie nicht grundsätzlich in derselben Texteinheit vorkommen. 
"Das erinnert mich jetzt an diese Tagebücher von Franzosen und Deutschen, wie sie im Museum in Lörrach gezeigt wurden und (...) die genau das gleich schildern, aus, ja, unter anderen Vorzeichen, aber eigentlich genau das Gleiche, das Elend und die, die Einsamkeit der Soldaten, und diese Sinnlosigkeit, der sie sich mehr und mehr wohl bewusst werden.» (P12, Absatz 113)

Im nächsten Beispiel verweist eine Person auf die eigene Militärzeit und stellt auch damit wiederum einen Lebensweltbezug her (Fokus III), gleichzeitig formuliert sie eine Aussage über Geschehen (Fokus I), nämlich hätten sich die Gasmasken zu den beiden genannten Zeiten nur «nur unwesentlich» unterschieden, womit überdies ein Bezug zwischen Zeitebenen hergestellt wird:

"Die Gasmasken, die damals gebraucht wurden, sind nur unwesentlich weniger modern gewesen als die, die ich 1969, mit denen ich durch den Wald habe joggen müssen.» (P25, Absatz 70)

In anderen Fällen wie dem folgenden habe ich Äusserungen hingegen ausschliesslich als Bezug zur eigenen Lebenswelt eingestuft:

"Das hatten wir alles im Gymnasium, als wir zusammen das Thema Farben besprochen hatten in Chemie.» (P21, Absatz 7)

Neben den Relationen und Sichtbarmachungen der eigenen Lebenswelt bilden einen dritten Bereich innerhalb des Fokus III solche Äusserungen über die eigene Person in der Ausstellung, in denen die Besuchenden sich selbst als Akteurinnen und Rezipienten innerhalb der Ausstellung thematisieren oder reflektieren (Abschnitt 8.7.4). Hierzu zählen Äusserungen über

- die eigene Rolle als Studienteilnehmende,

- eigene Geschichtsbilder und deren Bestätigung bzw. Revision durch die Ausstellung, ${ }^{1456}$

1456 Die Betrachtung dieses Aspekts und eine Differenzierung in zwei mögliche Umgangsweisen ist inspiriert durch die Studie von Pampel, der anhand von nachträglichen Befragungen und unter der Überschrift «Bekräftigung und Veränderung von historischen und politischen Einstellungen» feststellt, die beforschten Gedenkstättenbesuchenden sähen «sich durch den Besuch im Grossen und Ganzen in ihrer Deutung bzw. Bewertung des historischen Geschehens bestätigt» (Pampel 2007, S. 328 ff., direkte Zitate S. 328 u. S. 330), und der insgesamt schlussfolgert, die Besuchenden sähen «den Sinn ihres Aufenthalts eher 
- Sich-Hineinversetzen und -Vorstellen bzw. die eigene Nähe oder Ferne zum Geschehen,

- das eigene Verhalten in der Ausstellung, ${ }^{1457}$

- Pläne oder Massnahmen für eine über den Ausstellungsbesuch hinausreichende Weiterbeschäftigung. ${ }^{1458}$

In den nachfolgenden Abschnitten 8.7.2, 8.7.3 und 8.7.4 stelle ich die genannten drei Teilbereiche innerhalb des Fokus III näher vor und konkretisiere sie mit Beispielen aus dem Datenmaterial.

\subsubsection{Kognitive und nicht-nur-kognitive Relationen}

\subsubsection{Erstaunen und Eindruck}

In der nachfolgend zuerst beschriebenen Kategorie äussern Besuchende Erstaunen oder Eindruck - innerhalb der Relationen ein Bereich mit auffallend grosser Bedeutung. Als Äusserungen von Erstaunen oder Eindruck fasse ich zum einen explizit selbstreflektierende Formulierungen in der idealtypischen Struktur eines $<$ ich bin erstaunt, dass $\mathrm{x}$ > oder 〈ich bin beeindruckt von $\mathrm{x}$ 〉. Zur Kategorie zählen aber auch äquivalente Adjektive (<erstaunlich, dass〉), Ausrufe (etwa ein überraschtes $\langle\mathrm{Oh}$ !〉) sowie überrascht betonte Wörter, auch beim Lesen von Texten. Es handelt sich hierbei um eine positiv konnotierte Emotion.

Äusserungen von Erstaunen sind verwandt mit Äusserungen neuen Wissens in beiden Fällen liegt eine Konfrontation mit einem bislang nicht geläufigen

in einer Bestätigung des eigenen Geschichtsbildes als darin, es kritisch zu hinterfragen» (Pampel 2007, S. 348). Vgl. hierzu auch Abschnitt 5.3.6.

1457 Diesen Bereich nenne ich hier zwar als strukturell relevanten Bestandteil innerhalb dieser Gruppe von Äusserungen, betrachte ihn aber im Folgenden nicht gesondert. Beschreibungen des Verhaltens habe ich, wann immer möglich, für andere Kategorien nutzbar gemacht, beispielsweise darin zugleich enthaltene Benennungen von in der Ausstellung enthaltenen Elementen als identifizierende Tätigkeiten erfasst (z. B. "Ich schau mir die (Büchse) an, mit ‘Geigy〉 drauf geschrieben», P30, Absatz 44). Für diese Variante sowie für eine Sonderform, in der Besuchende den Umgang mit visuellen Eindrücken beschreiben und kommentieren (z. B. "Ich lass die Bilder mal auf mich einwirken», P25, Absatz 34), sind im digitalen Anhang Materialbeispiele einsehbar. Teilweise überschneiden sich diese Äusserungen auch mit solchen, die in Abschnitt 8.9.4.2. als Berichte über Sich-Hineinversetzen und Sich-Vorstellen thematisiert werden, was von den Besuchenden mitunter in Zusammenhang mit visuellen Eindrücken gebracht wird.

1458 Dieser Bereich wird in Form eines Exkurses im Zusammenhang mit Relationen in Abschnitt 8.7.2.3 behandelt. 
Sachverhalt zugrunde. Geäussertes neues Wissen wird weiter unten an anderer Stelle separat thematisiert. Für die Unterscheidung zwischen beiden Kategorien bzw. die Zuordnung von Äusserungen der Besuchenden war massgeblich, wie die Besuchenden selbst eine Neuigkeit einordnen, also ob sie eher darüber sprechen, etwas neu zu wissen, oder angeben, über etwas erstaunt bzw. von etwas beeindruckt zu sein.

Äusserungen von Erstaunen oder Eindruck tauchen bei allen untersuchten Personen auf, jedoch mit unterschiedlicher Relevanz. Während manche Besuchende eher vereinzelt Erstaunen und Eindruck formulieren, finden sich im Fall von P12 auffallende rund 70 Textstellen. Es muss hier jedoch wie für alle übrigen Relationsbereiche berücksichtigt werden, dass womöglich nicht alle Personen, selbst wenn sie beim Ausstellungsbesuch Emotionen wie Erstaunen und Eindruck empfinden sollten, diese im gleichen Masse unumwunden kundtun.

Äusserungen von Erstaunen und Eindruck kommen in der geschehens- und ausstellungsbezogenen Variante vor. Nachfolgend werden zunächst Varianten und Beispiele für geschehensbezogenes Erstaunen vorgestellt, ergänzt um eine Fallbeschreibung zu P12, anschliessend werden Ausprägungen ausstellungsbezogenen Erstaunens in den Blick genommen.

$\mathrm{Zu}$ den geschebensbezogenen Äusserungen von Erstaunen oder Eindruck zähle ich überraschte Betonungen oder Wiederholungen von gelesenen Passagen. So etwa im nächsten Beispiel:

«Am 5. November (...) bietet der Bundesrat 8000 Soldaten und Offiziere für die Besetzung Zürichs auf.> (...) Hui. (...) 〈(unv.) des Landesstreiks erhöht er das Truppenaufgebot auf insgesamt HUNDERTTAUSEND, HUNDERTZEHNTAUSEND MANN. Die Arbeiterschaft empfindet den Militäreinsatz gegen die eigene Bevölkerung als Provokation.»» (P27, Absatz 68)

Ich zähle solche und ähnliche Beispiele den geschehensbezogenen Äusserungen zu, in der Annahme, dass sich das Erstaunen der Besuchenden hier auf das durch den Text repräsentierte historische Geschehen bezieht und nicht auf die Art und Weise, wie der Text dieses Geschehen thematisiert, auch wenn die Besuchenden nicht im engeren Sinn explizit machen, worüber sie genau erstaunt sind. Auffallend ist, dass gewisse Texte oder Passagen gleich bei mehreren Besuchenden zur Äusserung von Erstaunen führen, wie etwa in den folgenden Textstellen: 
«Die Exportmenge von gesägtem Naturholz für den Bau von Schützengräben und Bunkern verDREISSIGfacht sich.> Das ist ja (...). 〈Herstellung von Munitionsbestandteilen der Firma (unv.)>. Das heisst, die Industrie wird relativ schnell umgestellt zu kriegsnotwendigen Produkten. (...) <Die Herstellung von Schusspatronen>. (...) Ja, geht aus dem Bild schön hervor, in welchen Mengen diese hergestellt wurden.» (P8, Absatz 37)

"'Exportmenge von gesägtem Nutzholz für den Bau von Schützengräben VERDREISSIG/, verdreissigfacht sich.»» (P20, Absatz 55)

«Die Exportmenge von gesägtem Nutzholz für den Bau von Schützengräben und Bunkern verdreissigfacht sich, VERDREISSIGFACHT sich bis 1916>ist ja toll. [〈toll〉 gemäss Intonation hier vmtl. im Sinn von 〈verrückt〉, 〈krass〉 o. ä. gebraucht]» (P5, Absatz 106)

Ähnliche Häufungen des Erstaunens lassen sich auch in der Konfrontation der Besuchenden mit den Erkrankungsraten zur Zeit der Spanischen Grippe beobachten:

"Spanische Grippe. [liest zusammenfassend] '18, '19, 50 Millionen zum Opfer. Sie fordert damit mehr Tote als der gesamte Krieg in der Schweiz. Erkrankt zwischen Mitte '18 bis Mitte '19 die HÄLFTE der Bevölkerung. (unv.) fordert in zwei Wellen 24500 Todesopfer, wobei Männer zwischen 20 und 40 Jabren besonders häufig tödlich erkranken.»» (P5, Absatz 30)

«Der sp/, die, der Spanischen Grippe von 1918/19 fallen weltweit über 50 Millionen Menschen zum Opfer. Sie fordert damit mehr Tote als der gesamte Krieg. In der Schweiz erkranken zwischen (Juli) 1918 und (Juni) 1919 die Hälfte> die HÄLFTE! 〈der Bevölkerung〉. Boab.» (P12, Absatz 188)

«Die Spanische Grippe». Da hab ich Leute, kenne ich Leute, die selber noch Angehörige verloren haben, und das interessiert mich jetzt sehr, weil es doch (...) eigentlich ein sehr heftiges Kapitel ist, das aber im Zug vom Ersten Weltkrieg irgendwo etwas den Tisch gefallen ist. (...) Eben, es sind mehr Opfer, hat es gegeben, als im ganzen Krieg. (...) Woah. In der Schweiz ist die Hälfte der Bevölkerung erkrankt. Das hab ich noch nie gehört im Leben, das ist wirklich sehr, sehr interessant.» (P19, Absatz 132) 
In anderen Fällen äussern Besuchende ihr Erstaunen, ihre Überraschung oder ihren Eindruck expliziter, indem sie darauf hinweisen, sie seien erstaunt oder überrascht, oder entsprechende Adjektive oder Substantive gebrauchen.

"Na ja, das mit dem Frauenstimmrecht, das weiss man ja, aber irgendwie ist es das immer wieder eine neue Überraschung, dass das so lang gedauert hat.» (P6, Absatz 67)

"Da sehe ich ein Bild (...) (von einer) Käserei, nehme ich an (...) und lese ‘Milch und Brot. Landwirtschaft im Umbruch.> (...)

Ich bin ERSTAUNT zu erfabren (...), dass (...) schon vor dem Krieg viel Käse in die ganze Welt exportiert hat, und frage mich, warum dass man dann in Basel viele Leute hatte, die gehungert haben.» (P25, Absatz 59-60)

In diesen Fällen finden sich dann vielfach, wie in den zuletzt gezeigten Beispielen, auch nähere Hinweise darauf, worüber die Besuchenden genau erstaunt sind. Eine Begründung für sein Erstaunen liefert etwa die nachfolgend zitierte Person im Anschluss an eine zunächst längere lesende Passage:

"Ich lese noch den Text da. 〈Die Schrecken des Krieges erreichen die Schweiz über Zeitungsberichte, Fotos und Filmaufnabmen sowie Augenzengenberichte. An einzelnen Grenzabschnitten, etwa im Raum Basel oder Münstertal, ist das Artilleriefeuer der Front zu hören und (nachts) zu sehen. (...) Das Wissen um das Leid führt in der Schweiz zu einem grossen humanitären Engagement. Das Internationale Komitee vom Roten Kreuz und der Bund bauen ibre Hilfe massiv aus. Tausende von Schweizerinnen und Schweizern melden sich freiwillig zu verschiedenen Diensten oder unterstützen die Hilfswerke finanziell. Andere begeben sich als Delegierte oder Krankenschwestern ins Ausland. Die humanitäre Hilfe erweitert den aussenpolitischen Handlungsspielraum der Schweiz und (stärkt) ihr Ansehen im Ausland.>

Eben, das ist beeindruckend, das Engagement, (wie/weil) man siebt, ja, dass die Bevölkerung sehr arm gewesen ist und sich trotzdem so engagiert hat, und man spïrt etwas von der Hilfsbereitschaft, wie die damals wirklich gross gewesen ist, und das finde ich beeindruckend.» (P19, Absatz 101-102) 


\section{Im Brennpunkt: P12}

\section{«jetzt bin ich aber platt» - Varianten des Eindrucks und Erstaunens}

Eine Person, die sowohl in der Häufigkeit als auch in der Qualität des geäusserten Eindrucks und Erstaunens auffallend ist, ist P12. Er oder sie lässt sich offenbar durch den Ausstellungsbesuch emotional stark beeindrucken - und tut dies auch unumwunden kund. Die Äusserungen von P12 sind durch eine Impulsivität und teilweise kräftige Rhetorik geprägt. Zum Ausdruck des Erstaunens gebraucht P12, teilweise auffallend gehäuft, die Ausdrücke

- «wow» (Absatz 31, 65, 72, 108, 131, 147, 148, 152, 154, 154, 157, 172, $176,177,185,186,188,190,191,219,221,226,228,229,231)$,

- etwas sei «Wahnsinn»/«wahnsinnig»(Absatz 53, 115, 116, 128, 157, 208),

- etwas sei «eindrücklich» (Absatz 23, 31, 39, 66, 76, 78, 85, 90, 96, 96, $108,131,132,139,141,147,147,169,172,203)$,

- er oder sie sei «total beeindruckt» (Absatz 115),

- er oder sie sei "platt» (Absatz 38),

- habe etwas «noch nie gehört» (Absatz 107, 115),

- hätte etwas «nicht gedacht» (Absatz 62, 157)

und ähnliche Formulierungen. In der Häufigkeit und Intensität solcher Äusserungen unterscheidet sich P12 deutlich von anderen Besuchenden. Nachfolgend werden einige Textbeispiele aufgelistet, die einen vertieften Eindruck von diesem Phänomen geben können. Die zitierten Passagen beinhalten jeweils zunächst das Lesen eines Ausstellungstextes. Im Anschluss an das Lesen oder auch schon währenddessen äussert P12 dann sein oder ihr Erstaunen.

"Mit Regulierung und Rationierung versucht der Staat gegen den zunehmenden Mangel anzukämpfen. Kriegswirtschaft und Wirtschaftskrieg. (...) Der Erste Weltkrieg ist nicht nur ein mit aller Härte geführter Stellungskrieg, sondern auch ein brutaler Wirtschaftskrieg. Die Kontrolle wirtschaftlicher Ressourcen wird rasch zu einer zentralen Aufgabe der Kriegführung. Seit 1915 wird der Warenverkehr der Schweiz mit den kriegfübrenden Ländern von Überwachungsgesellschaften beider Kriegsparteien kontrolliert.>

Das ist wabnsinnig, also, das bab ich noch nie gebört und bin total beeindruckt, welchen Zwängen da die Schweizzusätzlich oblag.»(P12, Absatz 115) 
"[liest paraphrasierend] Dass die Internierten, die in die Schweiz kommen, in Hotels, Pensionen und Sanatorien gebracht wurden, hat wiederum für einen Ersatz für den ausbleibenden Fremdenverkehrsdienst, Fremdenverkehrs, äh, Verdienstmöglichkeiten gesorgt〉. Das ist ja Wabnsinn. 〈Die Kosten von hund-, hundertvierzig Millionen Franken tragen die kriegführenden Staaten.> AACH so. Die durften, die durften da natürlich zur Kasse gebeten werden, okay. Das hätt ich jetzt nicht gedacht. Wow. (...) Hm.» (P12, Absatz 157)

«Der Bundesrat scheint zu Beginn auf einzelne Forderungen der Streikenden eingehen zu wollen, unter dem Druck des Parlaments und der Militärführung bleibt er aber hart. Die Kapitulation der Streikleitung um Robert Grimm>, der wurde ja auch vorhin schon vorgestellt, swurde indirekt angeführt, endet am 14. November 1918, ist für grosse Teile der Arbeiterschaft ein Schock.>

Das hätt ich jetzt nie gedacht, dass so wie es die Arbeiterunruben und revolutionären Umtriebe in Deutschland gab, im November 1918, dass es zwar unter anderen Vorzeichen, aber eine Entsprechung in der Schweiz gab.» (P12, Absatz 183)

«Wachsende Not. Der Schrecken des Kriegs erreicht die Schweiz über Zeitungsberichte, Fotos und Filmaufnahmen sowie Augenzengenberichte. An einzelnen Grenzabschnitten im Raum Basel im Münstertal ist das Artilleriefeuer der Front zu hören und nachts zu sehen.>

Wow. Das stimmt, das hört man und sieht man hier.» (P12, Absatz 148)

In den soeben gezeigten Passagen sind es jeweils Ausstellungstexte, beim Lesen deren P12 zu für sie oder ihn erstaunlichen Einsichten kommt. Gleichermassen gibt es jedoch auch Bildquellen, bei der Betrachtung deren Erstaunen und Eindruck formuliert wird, wie nachfolgend:

«Soldatenstube in einer Konditorei in Pontresina». Die ist eindrücklich, diese Soldatenstube, im hintersten Eck der Schweiz, in Pontresina, sehr nett gemacht, und fast schon Kaffeehausstimmung. Also, wow, man hat hier wirklich sich angestrengt.» (P12, Absatz 135)

"Ah, jetzt seh ich hier (...) auf diesem schwarz-weissen Foto hier, mit den italienischen Arbeitern an der Margarethenstrasse, da sieht man oben den Margarethenbügel und links die schönen Häuser, die da stehen, die zum Gundeldinger Quartier gebören. Und das ist wabrscheinlich ein Stück weit auch diese grosse Wiese, diese Matte, die da ist, wo es rechts zum Kreisel nach Binningen und Oberwil geht und zum Hintereingang vom Zolli. Das ist eine wahnsinnig grosse 
Zabl. (...) Dass es schon immer Arbeiter, halt auch Ausländer, also gerade ausländische Arbeiter in Basel gab, vor dem Krieg, das wusst ich, aber wenn man die, wenn man einfach nur mal schier die Menge hier an den italienischen Arbeitern in Basel sieht, die hier glaub ich eben zurïck mïssen oder wollen oder zwangsweise müssen, dann ist das echt beeindruckend. (...) Fällt mir ein, dass es ja zum Beispiel gerade (...). Ja, bätt ich jetzt nicht gedacht, dass es so viele italienische Arbeiter da gab.» (P12, Absatz 53)

"Hier ist ein schönes schwarz-weisses Wandbild. Was seh ich denn hier? ‘Provisorische Barrikaden am Zollposten`. Nein! - ‘zwischen Hegenheim und Allschwil 1914'. Das ist ja (...), jetzt bin ich aber platt. Weil ich fabre ja fast täglich an diesem Zollbäuschen hier vorbei.» (P12, Absatz 38)

"Was ist hier? <Urner Bataillon 87 beim Tell-Denkmal〉 (...). Das ist eindrïcklich, weil vor dem Denkmal stand ich schon.» (P66, Absatz 112)

In den letztgenannten beiden Beispielen manifestiert sich eine weitere Komponente des Erstaunens. Erstaunen entsteht dann, wenn P12 auf Abbildungen Orte wiedererkennt - hier aus der eigenen räumlichen Lebenswelt oder von einem eigenen Besuch. Das Wiedererkennen und Einordnen von Orten ist für P12 bedeutsam und kann sich, wie hier, an die Äusserung positiv konnotierter Emotionen knüpfen. Eine systematische Zusammenschau zur Bedeutung von räumlichen Lebensweltbezügen erfolgt weiter unten, wo ich erneut auf P12 zu sprechen komme.

Bei den bislang gezeigten Beispielen handelt es sich um Formen von Erstaunen, die sich auf Aspekte historischen Geschehens beziehen. Daneben finden sich auch Äusserungen des Eindrucks oder Erstaunens in Bezug auf die Ausstellung und ibre Elemente. Diese treten vornehmlich in Bezug auf bildliche Quellen auf. Vielfach bezieht sich der beschriebene Eindruck dann etwa darauf, dass der oder die Besuchende mit einem bestimmten Quellentyp konfrontiert wird, seien es "Filme", «bewegte Bilder» oder «Farbbild[er]»:

"Aber es ist eindrücklich, wenn auch Filme vorkommen. (...) Weil das ist ja eigentlich neu, dass man auch Geschichte, auch Originalfilme zeigen kann.»(P3, Absatz 23)

«Tja, bewegte Bilder sind schon immer sehr eindrücklich.»(P6, Absatz 17)

«Ah okay, Maggi-Flaschen. Ist ja abgefahren, Farbbild.» (P6, Absatz 29) 
Eindruck kann sich auch auf das Format der in der Ausstellung enthaltenen hochgezogenen Fotografien beziehen:

"Ah, das ist beeindruckend, wenn man dann so grosse Bilder hat.

[...]

Ich muss es noch mal sagen, die grossen Bilder sind schon beeindruckend.» (P4, Absatz 45 und 102)

In wieder anderen Fällen schildern Besuchende ihr Erstaunen oder ihren Eindruck darüber, was diese Fotografien mit ihnen als Besuchende machen, nämlich ihnen eine Vorstellung von vergangener Lebenswirklichkeit zu vermitteln und die Vorstellungskraft zu beflügeln.

"Die Bilder, die ich da sehe, sind sehr eindrücklich und (will) mir (...) eine Idee, Bild vermitteln vom damaligen Leben in der Schweiz.» (P25, Absatz 54)

"Also solche Schwarz-Weiss-Aufnahmen, echte Fotos, sind sicher eindrücklich, kann man auch sich mal vorstellen, wenn man selber dastehen würde, wie man sich da fühlt, wenn man weiss, dass jetzt Krieg ist, welche Gedanken einem da durch den Kopf gehen. Ist toll gemacht, dass von vorne auch die Leute dastehen und man sozusagen bei ihnen steht.» (P3, Absatz 25)

"Wenn man dieses Bild auf, vom Marktplatz und dem Rathaus sieht, dann ist es wirklich auch wieder so frappierend, weil, weil sich kaum was geändert hat und auch da ähnlich wie das Bild mit der, mit der Volksspeisung in der Dreirosenturnhalle, ja, man sich eigentlich sehr gut hineinversetzen kann und zurückversetzen kann.» (P12, Absatz 216)

"Ja, das ist cool. Echt da Bilder aus dem Alltag. (...) Von Regionen, die man, von denen man weiss, wie sie heute aussehen. (...) Da in Bern (...). Ist cool, das ist wirklich sehr gut (...). JA. Ja ist eindrücklich, ist wirklich, sind wirklich gute Bilder.» (P19, Absatz 60)

"Man könnte hier eigentlich länger bleiben, um sich das anzuschauen. Die grossen Bilder sind sehr eindrucksvoll. (...) Man (stellt) sich an ibre Position und fragt sich, was man gemacht hätte.» (P30, Absatz 31) 
Die mit den hier zitierten Textstellen angedeutete Thematik, nämlich das SichHineinversetzen der Besuchenden in historisches Geschehen, vielfach auf dem Weg der Bildbetrachtung, wird weiter unten noch systematisch behandelt. ${ }^{1459}$ An dieser Stelle gilt es zunächst festzuhalten, dass Äusserungen von Erstaunen und Eindruck nicht zuletzt in der Auseinandersetzung mit Bildquellen entstehen, etwa durch die in Bildquellen gesehene Möglichkeit des Sich-Hineinversetzens.

Jedoch kann Erstaunen auch in Bezug auf weitere Quellentypen oder die ästhetische Gestaltung der Ausstellung geäussert werden. So in nachfolgendem Beispiel, das bereits aus anderem Zusammenhang bekannt ist:

"Wieder bunte Stelen, hoppla. Äh, jetzt muss ich glaub ich doch lieber erst noch mal gucken, was es hier für ein Teil ist. 〈Nach dem Krieg [...]〉.» (P12, Absatz 195)

Ebenfalls findet sich Erstaunen in Bezug auf die thematische Gliederung der Ausstellung. In der nachfolgenden Textstelle äussert eine Person beispielsweise ihr Erstaunen darüber, dass es in der Ausstellung überhaupt um «Woblstand» und «reiche Leute» gehe, was er oder sie in einer Ausstellung über den Ersten Weltkrieg gar nicht erwartet habe:

"Also Woblstand, das erwart ich jetzt nicht, Erster Weltkrieg, dass da um Woblstand geht, aber natürlich, reiche Leute.» (P3, Absatz 12)

Aus dem Ausstellungsbesuch derselben Person entstammen auch die nachfolgenden zwei längeren Textstellen, in denen sich mehrere der bislang beschriebenen Varianten des Erstaunens und Eindrucks auf engem Raum nebeneinander vorfinden lassen und die deshalb den Abschluss der Darstellung zu diesem Emotionsbereich bilden. So tritt in der nachfolgenden Passage Erstaunen im Zusammenhang mit der Art des betrachteten Elements, einem grossen Film, und - mutmasslich - Erstaunen über das im Film repräsentierte historische Geschehen, nämlich das Einrücken von Pferden in die Armee und deren Einschätzung bzw. Selektion, auf:

"Also der Filmausschnitt aus der Armee schan ich noch etwas genaner hin. (...) Hm. (...)

1459 Vgl. Abschnitt 8.7.4.2. 
〈Mittagsverpflegung der Eingerückten durch das Platzkommando〉, dass man sieht, wie die gegessen haben. (...) Sebr eindrücklich, vor allem weil der Film so gross ist.

(...) Die Riesenpfannen. (...)

Jetzt müssen die Bauern noch die Pferde bringen, ist auch sebr eindriucklich. (...) Für den, also Krieg, für die Grenze. (...)» (P3, Absatz 36-39)

Auch in einem weiteren Beispiel aus dem Ausstellungsbesuch derselben Person kristallisieren sich mehrere Varianten des Erstaunens auf engem Raum. P3 befindet sich im Ausstellungsteil, der die Entwicklung von Importen und Exporten während der Zeit des Weltkriegs für diverse Wirtschaftsgüter vorstellt. Zunächst betrachtet er oder sie eine Fotografie, die Frauen beim Verpacken von Schokolade in einer Fabrik zeigt, wendet sich dann weiteren Exportgütern und -statistiken zu.

"Man sieht die Frauen bei der Arbeit, das heisst, weil ja die Männer gar nicht da sind, (...) was die da machen, seh ich gar nicht genau. Mal schau/ab Schokolade! Das ist toll gemacht. (...) Und noch nachgebaute, wie die Schokoladen Cailler ausgesehen haben (...) und dass alles Frauen in den Fabriken sind, ist interessant, ist (...) eindrücklich. Wo sind die Männer, ist die Frage. (...) Hm. (...) Also da wär natürlich grad Lust auf Schokolade. Hm. Ah ja, da sind noch Patronen, verschiedene Dinge. (...) Export (...).

Das ist auch ganz eindrïcklich wie da/ wie die Exporte ansteigen im Ersten Weltkrieg. Also Patronen (...), was heisst das? Ah, Kupferwaren. (...) Oh, Gasmaske(n). (...) Hier ist wieder ein internationaler Blick, so Zusammenfassung auf den Krieg, sehr gut gemacht. (...) Gasmasken, ganz neu, (...) dass es Gas gibt, sicher für die Schülerinnen und Schüler erstaunlich.» (P3, Absatz 49-50)

Im gezeigten Beispiel äussert P3 zunächst ausstellungsbezogenen Eindruck in Bezug auf die Art und Weise, wie in der Ausstellung das Exportgut Schokolade thematisiert wird. Eher geschehensbezogen formuliert er oder sie dann Eindruck über die Exportentwicklungen zu Kriegszeiten. Schliesslich denkt er oder sie noch potenzielles Erstaunen der eigenen Klasse als künftige Adressatinnen und Adressaten der Ausstellung mit, ein Zugang, der typisch für diese Person ist, wie weiter unten noch ausgeführt wird. ${ }^{1460}$

$1460 \mathrm{Vgl}$. Abschnitt 8.7.3.7. 


\subsubsection{Interesse, Spannung und Faszination}

Einen zweiten bedeutenden Relationsbereich bilden Äusserungen von Interesse, Spannung und Faszination. Hierunter fasse ich zum einen explizit selbstreflektierende Formulierungen in der idealtypischen Struktur eines «x interessiert mich» oder ich bin fasziniert von $\mathrm{x}$, daneben aber auch den Einsatz äquivalenter Adjektive (interessant, dass $\mathrm{x}$ ist`, ‘spannend ). Es handelt sich hierbei um eine positiv konnotierte Emotion. Solche Äusserungen von Interesse, Spannung und Faszination tauchen bei nahezu allen Personen auf, jedoch in unterschiedlichem Ausmass, von vereinzelten Nennungen bis hin zu mehreren Dutzend bei einzelnen Besuchenden.

Es finden sich darunter sowohl geschehens- als auch ausstellungsbezogene Äusserungen von Interesse, Spannung und Faszination. Ausstellungsbezogene Äusserungen beziehen sich im Wesentlichen auf die von der Ausstellung gewählte Art der Thematisierung und Präsentation, andererseits auf einzelne konkrete Elemente oder Elementtypen. Regelmässig werden insbesondere die bildlichen Elemente als interessant kommentiert. Auf Ebene der einzelnen, konkreten Elemente erweisen sich die Vorlieben jedoch als ausgesprochen divers, sodass sich kaum besonders geschätzte «Highlight-Exponate» identifizieren lassen.

Einige Äusserungen von Interesse, Spannung oder Faszination in Bezug auf einzelne Elemente werden nachfolgend gezeigt:

«Ist spannend, diese, diese Stimmen zu hören, aus verschiedenen Schweizer, ähm, Bevölkerungsteilen und den Intellektuellen, also.»(P12, Absatz 76)

«So Tonzengnisse sind sehr, sehr spannend.»(P18, Absatz 48)

«Tornister mit Vollpackung (...) und gerollter Kaputt〉. Das ist ja schon mal klasse.»(P12, Absatz 46)

«So Filmzengnisse faszinieren mich sehr. (...) Einfach wie es damals gewesen ist." (P18, Absatz 33)

«Faszinierend, so alte Bilder zu sehen.»(P18, Absatz 66)

Als sensibel für die Art der Darstellung und Strukturierung von Themen durch die Ausstellung und gleichzeitig interessiert daran und fasziniert, diese zu betrachten und analysieren, erweist sich P12. 
"Finde ich jetzt spannend, dass hier der Blick auf die Banern gelenkt wird, nachdem er in der anderen Stele auf die Soldaten gelenkt wird.» (P12, Absatz 26)

"Blick ins Ausland. Am 12. November 1918 weist der Bundesrat die Angehörigen der russischen Sowjet-Gesandtschaft aus Bern aus.> Unter anderem die Angelika Balabanoff, die Fran von der Stele vorbin. Das ist eigentlich sehr spannend zu sehen, wie die (...), wie die Ausstellung am Anfang so exemplarisch ein paar Sachen buchstäblich in den Raum stellt und an die Wand bängt und dann nach und nach die Ausstellung die Informationen gibt und unterfüttert und ergänzt und vertieft und man mehr und mehr wirklich so einen, ein, ein, ein, einen Setzkasten hat, das man mit hier mit Wissen, Informationen füllt.» (P12, Absatz 178)

«Was ist hier? ‘Erinnerungskultur〉, ob klasse, das wär jetzt ein super Thema an sich (...), für das ich gern mehr Zeit hätte.» (Pl2, Absatz 202)

Vielfach ist nicht eindeutig zu entscheiden, ob sich eine Äusserung von Interesse auf die Art der Thematisierung durch die Ausstellung oder das dargestellte historische Geschehen bezieht. Dieses Ineinanderfliessen scheint sogar geradezu ein symptomatisches Charakteristikum des Datenmaterials zu sein. Was aus Perspektive einer angestrebten Trennschärfe zwischen Kategorien beklagt werden könnte, lässt sich umgekehrt auch als eindrücklicher Hinweis darauf verstehen, dass aus Sicht der Besuchenden offenbar historisches Geschehen und dessen Darstellung in der Ausstellung nicht zwingend als getrennte Aspekte verbalisiert werden müssen.

Die nachfolgenden Beispiele geben einen Eindruck von diesem Spektrum. In manchen Fällen beziehen sich Aussagen deutlicher auf die Art der Thematisierung durch die Ausstellung:

"Ja, ich find's interessant, so Personen, die eigentlich heute in Vergessenheit geraten sind, die so herausgegriffen werden und ihre Leistungen oder ihr, ja ihr Wirken zu der Zeit erklärt wird.»(P19, Absatz 15)

"Das find ich auch spannend (...). Zuerst der kurze Blick ins Ausland und dann in die Schweiz.» (P19, Absatz 97) 
«Das ist sehr spannend, wie die ganze Schweizabgedeckt wird.»(P21, Absatz 63)

«Interessanter Hintergrund zum Thema Kriegsgewinnler.» (P6, Absatz 35 )

In anderen wiederum fliessen die Art der Thematisierung durch die Ausstellung und dem zugrunde liegendes historisches Geschehen als Dimensionen stärker ineinander:

"Hm, jetzt ist mir (...), ah, das ist doch noch spannend - <Neutral von Fall zu Fall), was dann EIGENTLICH Neutralität überhaupt bedeutet. (...) Hm.» (P13, Absatz 66)

"Hm, spannend, dass eben die (...) Zweiseitigkeit aufgezeigt wird, eigentlich von (...), dass es ein humanitärer Antrieb gewesen ist, die Hilfe zu leisten, aber gleichzeitig eben auch den Handlungsspielraum vergrössert hat und das Ansehen im Ausland, und weil das Ansehen im Ausland steigt, eben auch die Handlungsspielräume wieder.»(P13, Absatz 64)

"Das ist interessant, das ist, das ist wirklich ein Thema, wie die Schweiz profitiert, das hab ich auch zu wenig (...). Ich hab bis jetzt Geschichte immer international angesehen, und hier wird jetzt auch sehr die Schweiz ins Zentrum gerückt, was die Schweiz gemacht hat. (...) Find ich interessant.» (P3, Absatz 48)

"Das find ich auch spannend. (...) Zuerst der kurze Blick ins Ausland und dann in die Schweiz, wie die zunehmende Spannung in der Bevölkerung zunimmt. Etwas, wo ich auch nicht viel darüber gewusst habe, und ich merke gerade selber, dass mir so ein bisschen Pro- und Contrapositionen, wenn die etwas dargestellt werden, dass ich das, dass ich das sehr spannend finde, ja.» (P19, Absatz 97)

\subsubsection{Exkurs: Pläne und Massnahmen zur Weiterbeschäftigung}

Einige Teilnehmende äussern Ideen für eine weitere Auseinandersetzung mit der Thematik. Hierbei handelt es sich um Spielarten der Bekundung von Interesse, die in konkrete Handlungsvorhaben münden. So wird bisweilen geäussert, sich einen Teil der Ausstellung oder gar die ganze Ausstellung ein weiteres Mal ansehen zu wollen (P4, Absatz 13 und 17; P12, Absatz 199, P19, Absatz 151). Zudem äussern manche Besuchende, zu bestimmten Themen recherchieren zu wollen: 
"Muss ich nochmals anschanen, seit wann die Schweiz überhaupt neutral ist offiziell, ich glaube das ist seit 1815.» (P3, Absatz 60)

"Das interessiert mich sehr, dieser Artikel in der NZZ. Ich schreib mir das schnell auf, dass ich den zu Hause suchen möchte.» (P21, Absatz 57)

Notizen während des Ausstellungsbesuchs macht sich an etlichen Stellen auch P5 und kommentiert dieses. Auch diese Äusserungen wurden als Massnahmen zur Weiterbeschäftigung kategorisiert, auch wenn nicht explizit formuliert wird, dass aus den gemachten Notizen eine Weiterbeschäftigung resultieren soll.

"Das ist eine interessante Frau, die muss ich mir aufschreiben. (...) [nachfolgend parallel Notizen machend und langsam ablesend] 〈Balabanoff $>$ (...) ‘Sozialistin >. (P5, Absatz 13)

«Muss ich mir mal aufschreiben, Alfred Frey. (...) [nachfolgend parallel Notizen machend und langsam ablesend] 〈Wirtschaftspolitiker (...) und Präsident des Schweizerischen Handels- und Industrievereins.» (P5, Absatz 17)

Manche Besuchende geben auch an, sich mit anderen Personen zu bestimmten Themen austauschen zu wollen:

"Ich denk immer noch an das SSS, dass ich darüber nie etwas wusste, das möchte ich auch mit einem guten Freund von mir besprechen, ob er etwas davon weiss.» (P21, Absatz 61)

«Das Zitat muss ich mir merken für die [Name].»(P12, Absatz 161)

Einen Bestandteil der geplanten Weiterbeschäftigung machen auch Besuche in anderen Ausstellungen aus, um bestimmte Themenbereiche zu vertiefen, wie etwa im nächsten Beispiel das Spielzeugmuseum in Riehen bei Basel, um sich in der damaligen dortigen Sonderausstellung weiter mit der Thematik der Kriegsspielzeuge zu befassen:

«Was ist hier drin zu sehen? Spielkarten aus der Zeit. «Souvenir de l'occupation desfrontières. Weibnachten 1914'. Ja. Und das (hier das Spiel) auch dem gerecht. Da gibts doch diese Aufstellung im Riehener Museum, wo es um Spielzenge geht, 
das will ich mir auch angucken, wie diese ganze Kultur alle Bereiche durchdringt [...]» (P12, Absatz 42)

Diese Befunde schliessen an die Feststellung Doris Lewalters an, ein Museumsbesuch könne, «zumindest unmittelbar nach dem Besuch, die Weiterbildungsabsicht der BesucherInnen fördern». ${ }^{1461}$

\subsubsection{Freude, Wohlgefühl, Dankbarkeit und positive Bewegung}

Ein Emotionsbereich, der im Vergleich mit den bisher beschriebenen eher vereinzelt vorkommt, aber gleichwohl aufgrund seiner anders gearteten inhaltlichen Ausrichtung sinnvollerweise eine eigene Kategorie darstellt, umfasst Äusserungen von Freude, Wohlgefühl, Dankbarkeit oder Bewegung. Der Kategorie zugerechnet wurden einerseits explizite selbstbezogene Formulierungen im Stile eines ich fühle mich wohl> oder <ich bin dankbar, dass x>, aber auch entsprechender Adjektive ( es ist bewegend, dass $\mathrm{x}$ ). Es handelt sich hierbei um eine positiv konnotierte Emotion. Dieser Emotionsbereich kommt bei rund einem Drittel der Besuchenden und dort jeweils nur vereinzelt vor. Es finden sich sowohl ausstellungs- als auch geschehensbezogene Äusserungen.

In den folgenden vier beispielhaft angeführten ausstellungsbezogenen Äusserungen wird etwa Freude oder Wohlgefallen über die Gestaltung der Ausstellung oder das Vorhandensein bestimmter Exponate geäussert:

"Fühle mich sehr noh/, wohl, weil es sehr schön gestaltet ist. (...) (Das macht sehr Freude).»(P21, Absatz 62)

"Ja, sehr schön, aber so ein bisschen hier im Halbdunkel auch nicht ganz einfach zu sehen. Aber klasse, und vor allem diese Bilder sind so schön, auf diesem roten Untergrund oder in, in diesen Untergrund oder auf diesem Material appliziert. Das ist total schön, ich wïrd das am liebsten anfassen.» (P12, Absatz 104)

"Ich freue mich, gewisse Exponate zu sehen, zum Beispiel Essensrationenmarken hab ich noch nie in echt gesehen.» (P21, Absatz 9)

1461 Lewalter 2009, S. 54. 
Während die Besuchenden in Bezug auf die Ausstellung und ihre Elemente eher Freude oder Wohlgefühl äussern, ist in Bezug auf historisches Geschehen hingegen von Bewegung oder Dankbarkeit die Rede. Nahezu alle Äusserungen in diesem Bereich stammen von derselben Person, nämlich P19. So liest P19 im nachfolgenden Beispiel einen Text über die Rolle von Gustave Ador, Bundesrat und IKRKPräsident, und äussert anschliessend Bewegung über dessen Engagement:

«Gustave Ador. Bundesrat und Präsident des Internationalen Komitees vom Roten Kreuz. Der Genfer Anwalt und Politiker wird 1910 Präsident des Internationalen Komitees vom Roten Kreuz. Nach Kriegsausbruch setzt er sich mit grossem Engagement für humanitäre Belange ein und initiiert die Agence internationale des prisonniers de guerre. 1917 wird Ador zum Bundesrat gewählt. International hoch geachtet, stärkt er das Anseben der Schweiz im Ausland. Er tritt für eine aktive Aussenpolitik ein und ist massgeblich daran beteiligt, dass Genf 1920 Sitz des Völkerbundes wird.> (...) Ja, ist doch (...), von dem Mann hab ich noch nie etwas gehört, und ist bewegend, wie er durch seinen humanitären Einsatz der Schweiz zu gutem Ansehen verbilft.» (P19, Absatz 3)

An mehreren anderen Stellen bringt P19 zudem Dankbarkeit über historisches Geschehen zum Ausdruck.

\section{Im Brennpunkt: P19}

«ich bin doch sehr dankbar, dass wir von dem jetzt eigentlich nicht mebr betroffen sind» - Dankbarkeit über Geschehen

P19 ist die einzige Person unter den beforschten Besuchenden, die während des Besuchs explizit von Dankbarkeit spricht. Er oder sie tut dies an insgesamt fünf Punkten des Ausstellungsbesuchs. Die entsprechenden Passagen werden nachfolgend vollständig vorgestellt.

In zwei Fällen äussert P19 Dankbarkeit darüber, dass etwas heute anders sei als damals. So beschreibt er oder sie sich als dankbar darüber, dass Epidemien wie die grosse Grippewelle zumindest in der aktuellen Gegenwart nicht aufträten:

"Da überlegt man sich schon, ja, ob nicht auch heute wieder so eine Pandemie auftreten könnte und wie das heute wäre, weil wir uns eigentlich schon daran gewöhnt haben, dass es so etwas nicht mehr gibt, aber dass ja (...) das genau hundert Jahre oder nicht ganz hundert Jahre her ist, wo eine letzte grosse Pan- 
demie Zehntausende Todesopfer gefordert hat und (...) dass man irgendwo, man kann auch sagen, ja wir sind nicht von dem gefeit, und (...) man darf sich da nicht in einer falschen Sicherheit wiegen. Und ich denke, es ist gut, wenn man sich auch, $j a$, mit DEM auseinandersetzt und sich überlegt, wie sind die Leute damals damit umgegangen und was für Lehren kann man für heute ziehen. Aber (...) ich bin doch sebr dankbar, dass wir von dem jetzt eigentlich nicht mebr betroffen sind, oder im Moment nicht betroffen sind.»(P19, Absatz 135)

An anderer Stelle äussert P19 Dankbarkeit darüber, heute nicht mehr von starker Armut betroffen zu sein:

"Ja, es zeigt sich das doch, dass das Land sehr unvorbereitet in den Krieg gegangen ist und dass (...) der Krieg, auch wenn wir nicht direkt betroffen gewesen sind, zu einer starken Armut in der Bevölkerung geführt haben und (...), wo wir dankbar sein können, dass wir von dem verschont sind heute.» (P19, Absatz 8)

In den beiden genannten Beispielen ist es eine Differenz zwischen Vergangenheit und Gegenwart, über die sich P19 dankbar zeigt. Auch in den übrigen drei Textstellen resultiert die Dankbarkeit aus einem Bezug zwischen den Zeitebenen. Dort geht es aber darum, dass zur Zeit des Ersten Weltkriegs ein Grundstein für etwas gelegt oder etwas Entscheidendes geleistet wurde, von dem heute immer noch profitiert werden kann. Zum einen äussert P19 Dankbarkeit darüber, dass zur Zeit des Ersten Weltkrieg die Einigkeit der französisch- und deutschsprachigen Schweiz bewahrt werden konnte. Er oder sie tut dies sogar an zwei Stellen seines Ausstellungsbesuchs:

"Ja, ist krass, wie, wie (...) wie man damals eigentlich (...) den Febler gemacht hat, so ein bisschen, $j a$ (...) sich irgendwo angliedern zu wollen. (...) Und da bin ich eigentlich dankbar, dass, dass da, dass es da nicht, dass der Bundesrat da Gegensteuer gegeben hat und dass die Einheit der Schweiz ein Stück weit bewabrt geblieben ist, ja.» (P19, Absatz 51)

"Ja, Film und Tonanfnahme, vor allem die Tonaufnahmen sind in extrem guter Klangqualität, und das zeigt auch gut, wie (zur Aufnabmezeit) ein guter Gegensatz zwischen welscher und deutscher Schweiz und (...) ja (...). Finde ich eindrücklich, wie, wie das natürlich zu Spannungen gekommen ist, weil die Deutschschweiz mehr auf Deutschland und die Welschschweiz mehr natürlich zu den Franzosen gestanden ist und wie das zu einer echten Zerreissprobe für unser Land geworden ist, und ich bin wirklich da sebr dankbar, dass man, dass man 
die Einigkeit, den Weg gehen konnte, und macht einem auch bewusst, dass man, dass wir einfach in einem Land sind, wo, wo die Gegensätze sehr gross sind, und dass man durch Demokratie auch miteinander immer wieder einen Weg suchen muss. Aber immer auch dem anderen zubören muss und gemeinsam als Land den Weg finden muss.» (P19, Absatz 41)

Im weiteren Verlauf des Besuchs äussert P19 dann erneut Dankbarkeit über etwas, von dem in der Gegenwart dank einer vergangenen Entwicklung profitiert werden kann, hier nun der wirtschaftliche Erfolg und die Arbeitsplätze in der Life-ScienceBranche, deren Aufschwung P19 auf Basis der Darstellung der Ausstellung auf die Zeit des Ersten Weltkriegs zurückführt:

"Da geht's um Life Science. (...) und eben, dass die Exporte im Ersten Weltkrieg dazu geführt haben, dass heute Basel so eines von den absoluten Zentrum ist von Life Science, Biotech und Pharma (...) und heute noch wichtigste Export, also heute mit 30 Prozent zu den wichtigsten Exportschlager der Schweiz ist. Ja, da kann man sich Gedanken machen, dass das auf den Ersten Weltkrieg zurückzufuibren ist, und da kann man ja auch dankbar sein, weil beute haben so viele Leute da ibre Arbeit da. Und machen Riesengewinn damit, also (...) es gibt nicht nur schlechte Sachen im Krieg. (...) Ja.» (P19, Absatz 147)

In der Gesamtübersicht über die fünf Passagen, in denen P19 Dankbarkeit äussert, lässt sich also feststellen, dass diese Dankbarkeit stets aus einem Vergleich zwischen Vergangenheit und Gegenwart resultiert. Dabei äussert P19 sowohl Dankbarkeit darüber, dass etwas heute anders sei als damals (zwei Fälle), als auch darüber, dass heute von einer damaligen Leistung oder Entwicklung profitiert werden könne (drei Fälle). Dankbarkeit als Emotion tritt somit ausschliesslich dann auf, wenn die gegenwärtige Situation von P19 als angenehm empfunden wird und dies entweder in Abgrenzung zu oder aufgrund einer vergangenen Situation so ist. Dankbarkeit erweist sich bei P19 also als eine Emotion, die des Vergleichs von Zeitebenen und des Bezugs auf die eigene Gegenwart bedarf.

\subsubsection{Belustigung, Schmunzeln, Spott und Ironie}

In der nachfolgend beschriebenen Kategorie äussern die Besuchenden Belustigung, Schmunzeln, Spott oder Ironie. Dies kann durch explizite selbstbezogene Formulierungen erfolgen ( ich finde $\mathrm{x}$ lustig〉) oder auch durch den Einsatz entsprechender Adjektive ( $<$ das ist ja witzig, dass $\mathrm{x} 〉$ ), ausserdem durch in der Bedeutung äquivalente Ausrufe (〈haha〉), durch Lachen oder einen schmunzelnden, 
ironischen Tonfall. Es handelt sich hierbei um eine tendenziell positiv konnotierte Emotion. Dieser Emotionsbereich kommt bei mehr als zwei Dritteln der Teilnehmenden vor, wobei hierunter P27 durch zahlreiche Nennungen auffallend ist und weiter unten vorgestellt wird.

Auch in diesem Emotionsbereich manifestieren sich wieder Schwierigkeiten in der Zuordnung der geäusserten Relationen zu ihren Auslösern. Insbesondere Fälle von punktuellem Auflachen oder Einwürfe von Äusserungen im Stile eines 〈haha〉 oder lustig», die von den Besuchenden nicht weiter eingebettet werden, sind vielfach schwierig zu deuten. Beispielhaft hierfür steht das nachfolgende Beispiel. Darin äussert P20, eine Reihe von propagandistischen Karikaturen aus den kriegführenden Ländern betrachtend und lesend:

«Kriegsflugblätter vom Simplicissimus», ‘bumoristische Darstellung der Wappen unserer Feinde 1914'. (...) ‘Alles für den Geldsack> (...). Hm (schmunzelnd), lustig. (...) Die Japaner (...), Serbien (...), Belgien.» (P20, Absatz 58)

Die Belustigung kann sich hier auf mehrerlei beziehen: auf eine einzelne Bildkomposition, auf die gewählten Inschriften, auf die von der Ausstellung getroffene Bildauswahl, auf die Tatsache, dass solche Karikaturen zu Kriegszeiten im Einsatz waren usw. oder auf eine Kombination verschiedener Aspekte. Gerade bei der Betrachtung von Fotografien ist oft nicht einfach zu entscheiden, was genau die Belustigung auslöst: das Bild als Bild in seiner Komposition und die Tatsache des Vorhandensein des Bildes als Exponat in der Ausstellung oder das Bild als Abbild und als Repräsentant eines historischen Geschehens. ${ }^{1462}$ Im nachfolgenden Beispiel sind alle drei Varianten anzutreffen, weshalb anhand dieses Beispiels die Unterscheidung deutlich gemacht werden kann. Bei der Betrachtung einer Fotografie strickender Mädchen in Kamerun und beim Lesen der zugehörigen Bildbeschriftung äussert erneut P20:

«Ha (lacht). «Schulmädchen in der Missionsstation der Basler Mission in Kamerum stricken Socken für deutsche Soldaten.> (...) (lacht) (...) Siebt noch lustig aus, das Bild. (...) Mit einer Hingabe sind sie am Häkeln und Stricken. (...) (lacht) (...) Ja.» (P20, Absatz 117)

1462 Zur Differenzierung in «Bild» und «Abbild» siehe Hamann 2007, S. 65 f., direkte Zitate S. 65; vgl. zur Differenzierung der hier genannten Formen auch die Ausführungen in Abschnitt 8.6.2.3. 
Während der erste belustigte Ausruf «Ha» nicht eindeutig einem Bezugspunkt zugeordnet werden kann, bezieht sich P20 nach Lesen der Bildbeschriftung mit seiner oder ihrer Belustigung zunächst auf das Bild als Element, das lustig aussehe, und dann auf das darin abgebildete Geschehen, nämlich das mit «Hingabe» ausgeführte Handwerk des Häkelns und Strickens.

Ebenso fliessen im nachfolgenden Beispiel die Varianten ineinander. Hier betrachtet P19 die ausgestellten humoristischen Todesanzeigen für Lebensmittel, die auf den Mangel dieser Lebensmittel zu Kriegszeiten aufmerksam machen:

"Da, das ist jetzt lustig, S Satirische Todesanzeigen für verschiedenste Lebensmittel sind ein beliebtes Postkartensujet> (...). Ist eben spannend, wie man einen gewissen (lacht) (...) Galgenhumor man hat bebalten können damals. (...) Ja, das (...) ist wieder sebr ein (...) lustiger Einblick, aber doch ein sehr (...) in einem tragischen Umfeld, ja.» (P19, Absatz 109)

Auch hier fliessen wieder mehrere Perspektiven bei der Belustigung ineinander. Zunächst bleibt der Bezugspunkt noch uneindeutig ( «das ist jetzt lustig»), dann werden zweierlei verschiedene Perspektiven eingenommen, nämlich zunächst geschehensbezogene Belustigung darüber, dass man sich damals einen "Galgenhumor [...] hat behalten können» (Fokus I), und dann Belustigung über die Art des Einblicks, den die Ausstellung gewährt (Fokus II).

Eine Tendenz, Fotografien oder Filme als Abbilder historischer Wirklichkeit $\mathrm{zu}$ thematisieren, das darin repräsentierte historische Geschehen zu beschreiben und sich darüber zu belustigen, manifestiert sich auch bei P22:

"(...) und da sind recht viele Leute auf dem Marktplatz, mit einem Haufen Hüten (unv.), eigentlich fast alle, auch die Damen zum Teil. Vielleicht nicht ganz so viele Hüte. (...) Aber es ist unglaublich, behe (lacht), wirklich fast mit wenigen Ausnabmen, die keinen Hut haben.» (P22, Absatz 16)

"Da lacht mal einer, be (lacht), ein bisschen, also ich nebme es jetzt einmal an, dass jemand lacht, dass (...).» (P22, Absatz 38)

«Ha (lacht), und der kleine Bub, der auch mitläuft (...) und sich dann auch. Aber alle wieder mit dem Hut, das ist wieder ganz eindeutig. Aha, das sind verschiedene (...) Zünfte oder irgend so etwas, die da (...) sich präsentieren. (...) 
Frauen hat es sogar auch dabei. (...) Da hat es eine obne Hut, eieiei, (der Schreck), die hat (aber) (...) ein Tuch über dem Kopf. (...)»(P22, Absatz 56)

Umgekehrt gibt es auch Textstellen, in denen Besuchende Belustigung über ein Element der Ausstellung äussern, ohne auf das damit verbundene historische Geschehen zu sprechen zu kommen. Dies ist etwa im nachfolgenden Beispiel der Fall, in dem eine Person, wie weiter oben P19, über die satirischen Todesanzeigen spricht:

"Ja, mit Humor kann man manchmal auch Armut überwinden, ein Stück weit. (...) Ist auch lustig da, bm? (...) Die Todesanzeigen (...) von (kaputtigen) Lebensmitteln. (...) HUMOR. (...) Hm. (schmunzelnd) (...)» (P18, Absatz 115)

Selbiges gilt für Äusserungen im Stil der nachfolgenden:

«Was haben wir hier noch, Stricknadeln (schmunzelt).»(P3, Absatz 15)

"Ein Zierkissen aus Taschentuch, okay (schmunzelt). Das ist ja natürlich auch was.» (P4, Absatz 14)

Neben der Belustigung über einzelne Exponate finden sich auch Äusserungen von Belustigung, die sich beispielsweise auf die räumliche Gestaltung, Ästhetik, Einrichtungselemente oder Textgestaltung der Ausstellung richten.

«Die Lebensmittel werden ständig knapper», sie werden knapper und knapper und knapper und knapper, (kichert), wie sie das jetzt immer wieder hier gesagt baben. Ich glaube, man hat's wirklich kapiert. [...]» (P12, Absatz 185)

«ZZwischen 3. und 5. August rücken 220000 Mann und 45000 Pferde ein.〉 (...) Ja, nicht die Pferde vergessen (ironischer Tonfall).»(P27, Absatz 22)

"Okay, jetzt geh ich mal in die nächste (...) interaktive (schmunzelt) Sache, oder wie nennt man das (hier)?» (P4, Absatz 38)

«Aha, eine Vitrine (schmunzelt).»(P4, Absatz 103) 
Interessant ist zu betrachten, ob es bestimmte Themen oder Ausstellungselemente gibt, die bei mehreren Besuchenden Belustigung, Schmunzeln oder Spott auslösen. Dies sind zum einen die weiter oben bereits behandelten satirischen Todesanzeigen oder auch die in der Ausstellung enthaltenen Karikaturen, die als Elemente bereits inhärenten humoristischen Gehalt besitzen. Doch auch nüchternere Informationen über historisches Geschehen können bei Besuchenden für Belustigung sorgen. Gleich bei zwei Besuchenden entsteht beispielsweise Erheiterung beim Lesen der in einem Ausstellungstext enthaltenen Information, dass beim Landesstreik 1918 auch Bankangestellte gestreikt hätten:

"Dann wieder der Streik, hm? <Die Lebensbedingungen verschlechtern sich ständig, und die Proteste häufen sich. Im Oktober 1918 streiken die Zürcher Bankangestellten - behe (lacht) - 〈ein nie dagewesenes Ereignis.> Ja, das kann man sich heute auch nicht mehr vorstellen. Sind doch die Bankangestellten der Inbegriff vom Kapitalismus.» (P19, Absatz 129)

"(Ist ja) UNGLAUBLICH [ironischer Tonfall], dass die Zürcher Bankangestellten streiken.» (P26, Absatz 35)

Auch der in einem Text enthaltene Hinweis auf die eingeführte Kriegsgewinnsteuer löst bei einzelnen Besuchenden Belustigung aus:

"Die kriegsbedingten neuen Bundesaufgaben führen zu einem starken Anstieg der Staatsausgaben. Während - ist logisch, oder? - 〈während der Kriegsjabre nebmen diese um rund das Zweieinhalbfache zu. (...) Zur Finanzierung der Kriegskosten führt der Bund eine Kriegssteuer, die heutige direkte Bundessteuer, ein.> Hebe (schmunzelt), das ist auch noch interessant, dass die Steuer, die es beute noch gibt, auf damals, auf eine Kriegssteuer zurückgeht, und wabrscheinlich hat es geheissen, jaja, die wird dann wieder abgeschafft, aber (...) wir wissen ja alle, die gibts heute noch.»(P19, Absatz 33)

"Hehe, ২Zur Finanzierung der Kriegskosten führt der Bund eine Kriegsstemer, die heutige direkte Bundessteuer, ein.> (...) (Anleihen auf) (...) Tja, (...) Kriegssteuern einfübren (...) und dann behalten ist überall in Mode, bm?» (P27, Absatz 44) 


\section{Im Brennpunkt: P27}

\section{«Die Löbne wurden natürlich NICHT angepasst» - Varianten von Spott und Ironie}

Mit über einem Dutzend Äusserungen von Belustigung, Schmunzeln, Spott oder Ironie im Verlauf des Ausstellungsbesuchs ist P27 die auffallendste Person in diesem Bereich. Insbesondere Ironie ist ein Stilmittel, das bei P27 immer wieder auftaucht, kombiniert mit Spott, und dabei jeweils bezogen auf historisches Geschehen, kaum auf die Ausstellung und ihre Elemente.

Eine ganze Reihe von Äusserungen kommt bereits zu Beginn des Ausstellungsbesuchs zustande. Das nachfolgend zitierte längere Beispiel, das bereits einmal im Zusammenhang mit der Betrachtung von Äusserungen der Besuchenden über Überzeitliches und Allgemeingültiges vorgestellt wurde, entstammt dem Aufenthalt von P27 in der regionalspezifischen Eingangssequenz der Ausstellung. P27 liest, teilweise zusammenfassend, verkürzend bzw. paraphrasierend, die dortigen Texte zu den Themen «Wohlstand», «Profite» und «Not» und äussert sich dann jeweils dazu:

«Der Ausbruch des Ersten Weltkrieges bedeutete für die reichen Basler Familien noch nicht das Ende der Belle Époque. (...) Kriegsgewinne (...) und familiäres Vermögen ermöglichen der Oberschicht weiterhin ein (angenehmes) Leben.> (...) Tja, so ist das [ironischer/spöttischer Tonfall] (...)

‘Selbst als es (...) vermehrt zu Demonstrationen und Streiks kommt, konnte der Offizier und Geschäftsmann'. (...) Tja. (...) It's (...) the rich who fight war and the poor who die. (...)

‘Chemische Industrie zum DURCHBRUCH (überraschter Tonfall)! (...) Lieferungen an (Kriegs) (unv.) eröffnen Basler Firmen grosse nene Märkte. (...) Kriegsrelevanten Farbtöne FELDGRAU, FELDGRÜN und HECHTGRAU> [schmunzelt] (...)

'und eigene Pharmaforschung', ab! Die Pharmaforschung ging zum Ersten Weltkrieg los. (...) Tja. (...) Der Mensch war leider schon immer gut darin, (...) sich selbst umzubringen. (...)

Schön ist, dass damals selbst der Chemielaborant Krawatte trug. [spöttischer Tonfall] (...)

Ja, und f/, für die Massen gab's ‘Hunger, Not und Verarmung〉 (...). ‘Die fehlende Marktregulierung und die kriegsbedingten Importschwierigkeiten.> (...) Die Löhne wurden natürlich NICHT angepasst [ironischer Tonfall].» (P27, Absatz 2-5) 
Ein Thema, in Bezug auf das P27 in der Passage gleich mehrmals mit Ironie reagiert, ist der Gegensatz zwischen Arm und Reich bzw. zwischen denjenigen, die vom Krieg profitieren, und denjenigen, die darunter leiden. P27 bringt hier eine gewisse Bitterkeit über diese Situation zum Ausdruck und macht zugleich deutlich, dass es sich hierbei um ein aus seiner oder ihrer Sicht überzeitlich gültiges Phänomen handelt ("It's (...) the rich who fight war and the poor who die»). Ironische Bitterkeit über das Gewinnstreben der Wirtschaft kommt auch im nächsten Beispiel zum Ausdruck, wiederum beim Lesen eines Ausstellungstexts:

"Haha, die Wirtschaft fordert Demobilisierung", wabrscheinlich kann man sonst nicht vom Krieg genug gewinnen.» (P27, Absatz 23)

Spöttisches Unbehagen über die Rolle der Wirtschaft in Zeiten von Unruhen bringt P27 auch in der nachfolgenden Passage zum Ausdruck, in der er oder sie sich über den Einsatz und die Ausstattung von Bürgerwehren zur Zeit des Landesstreiks äussert. Dort kombiniert sich nun das Unbehagen mit einem ebensolchen in Bezug auf die Rolle der Armee. Wiederum wird, wie schon im weiter oben gezeigten Beispiel, der Befund als zeitübergreifendes, mindestens in der Gegenwart noch gültiges Phänomen eingeordnet:

«Grosse Teile des Bürgertums befürchten (...) die Revolution. (...) Bereits vor dem Landesstreik bilden sich bewaffnete Bürgerwehren. (...) (lacht) Finanziert von der Wirtschaft, (...) bewaffnet von der Armee [ironischer Tonfall].> (...) Macht man beute auch noch so.» (P27, Absatz 73)

Neben diesen Fällen, in denen sich bittere Ironie auf die Divergenzen zwischen Arm und Reich, zwischen Profiteuren und Verlierern des Krieges, zwischen Wirtschaft und Militär einerseits und der Gesellschaft andererseits richtet, finden sich ausserdem Beispiele, in denen P27 Belustigung und Spott über die zeitgenössische Kleidung und das Aussehen zum Ausdruck bringt. Dies geschieht in zwei Fällen bei der Betrachtung von Bildquellen. Und zwar äussert P27:

"Schön ist, dass damals selbst der Chemielaborant Krawatte trug [spöttischer Tonfall].» (P27, Absatz 5)

"Eine Schreibstube. (...) Und man trug SCHNURRBART ab einem gewissen Alter [ironischer Tonfall].»(P27, Absatz 46)

Somit manifestiert sich auch bei P27 in Momenten von Bildbetrachtung eine Aufmerksamkeit für zeitgenössisches Aussehen und Bekleidung, was weiter oben am Beispiel der militärischen Bekleidung bereits für P20 festgestellt wurde. In 
beiden Fällen handelt es sich um Beobachtungen, die nicht durch die Bildbeschriftungen der Ausstellung angeregt, sondern selbsttätig angestellt werden und die wegführen von der in den jeweiligen Ausstellungsteilen eigentlich behandelten Kernthemen, wobei sich diese Beobachtungen im Fall von P27 mit Momenten von Spott und Ironie verbinden.

\subsubsection{Betroffenheit, Entsetzen, Beunruhigung und negative Bewegung}

Einen nächsten Bereich bilden Äusserungen von Betroffenheit, Entsetzen, Beunruhigung und negativer Bewegung. Dies kann durch explizite selbstbezogene Formulierungen ( $<\mathrm{x}$ macht mich betroffen $>/<\mathrm{x}$ beunruhigt mich $>$ ) erfolgen oder aber auch durch den Einsatz entsprechender Adjektive («das ist ja fürchterlich, dass $\mathrm{X}\rangle$ ) oder äquivalenter Ausrufe ( $(\mathrm{Oh}$ mein Gott〉 oder ein betroffenes 〈Oh!〉). Es handelt sich hierbei um einen Bereich von negativ konnotierten Emotionen, die bei etwas mehr als der Hälfte der Besuchenden vorkommen und die vor allem auf Geschehen bezogen oder nicht eindeutig zuordenbar sind, hingegen kaum einmal auf die Ausstellung bezogen.

Ich beginne die Beschreibung von Varianten und Beispielen mit einer Brennpunktdarstellung. Darin werden Äusserungen von P19 vorgestellt, einer Person, die einerseits durch viele Aussagen in diesem Emotionsbereich auffallend, im Hinblick auf die angesprochenen Themenbereiche aber als stellvertretend für das gesamte Sample gelten kann.

\section{Im Brennpunkt: P19}

"Ja, das finde ich jetzt bewegend, weil sonst liest man immer nur über die militärische Seite des Kriegs, aber nie auch, dass es eben auch ein Wirtschaftskrieg gewesen ist.» - Äusserungen von Betroffenheit und Beunruhigung

P19 drückt während des Ausstellungsbesuchs auffallend häufig Betroffenheit, Entsetzen oder Beunruhigung aus. Nachfolgend werden einige längere Textpassagen gezeigt, um zu betrachten und nachzuvollziehen, wie diese Äusserungen zustande kommen. Es werden hierzu jeweils längere Kontexteinheiten gezeigt, zum einen, weil sich die Äusserungen von Betroffenheit zumeist auf etwas zuvor Gelesenes beziehen und auf diese Weise die Bezüge deutlich werden, zum anderen, weil P19 in Bezug auf manche Aspekte mehrfach in geringem Abstand Betroffenheit äussert und somit der Verlauf der Äusserungen deutlich wird. 
Zum ersten Mal Beunruhigung wird von P19 gleich zu Beginn des Besuchs geäussert, wo er oder sie sich im baselbezogenen Eingangsbereich der Ausstellung mit dem Themenbereich «Mobilisierung» beschäftigt. P19 liest in der nachfolgenden Textstelle zunächst den zugehörigen Ausstellungstext und äussert sich anschliessend sowohl in Bezug auf diesen Text als auch auf die im Hintergrund gezeigte Abbildung uniformierter Kadetten.

«Neben den Soldaten im Aktivdienst sollen auch Frauen und Kinder, vor allem aus den bürgerlichen Schichten, für das Vaterland mobilisiert werden. In der Garnisonsstadt Basel wurde die Verbindung zwischen Armee und Zivilbevölkerung über Defilees, Konzerte, Soldatenweihnachten und Regimentstage hergestellt. An diesen Anlässen wurden oft auch Taschentücher, Alben und Plaketten zum Andenken angeboten. Die Knaben wurden im Nacheifern der Soldaten gefördert und auf den Militürdienst vorbereitet, sei es im Kadettenkorps oder im privaten Spiel. Frawen und Mädchen erfüllten ibre Vaterlandspflichten, indem sie den Haushalt, allen Versorgungsengpässen zum Trotz, weiterführten, eifrig Socken und Bauchbinden für die Wehrmänner strickten, Samariterkurse besuchten oder sich in einem freiwilligen Hilfskomitee engagierten.> (...)

Ja, es ist (...) es ist interessant zu lesen, wie die ganze Gesellschaft in der, in den Krieg einbezogen gewesen ist, und irgendwie hat das, das etwas Unbeimliches, auch mit den Bildern da. Der kleine Bub mit den Waffen. Auf der anderen Seite (...) bat es auch etwas Melancholisches, wenn man doch irgendwie denkt, ja, man ist alle so aufs Gleiche ausgerichtet gewesen, man hat, es ist sicher ein $Z u$ sammenbalt da gewesen (...). Die Verbundenbeit untereinander wird sicher grösser gewesen sein als heute in unserer doch sehr individualistischen Gesellschaft. (...)» (P19, Absatz 6)

In der zitierten Passage bringt P19 zwei emotionale Relationen in Bezug auf historisches Geschehen zur Sprache. Aus dem gelesenen Ausstellungstext schlussfolgert er oder sie zunächst, dass "die ganze Gesellschaft [...] in den Krieg einbezogen gewesen» sei, und konstatiert zugleich, dass daran "etwas Unheimliches» sei. Für diese Deutung bezieht P19 neben den Informationen im Ausstellungstext auch die Bildquelle im Hintergrund ein ("auch mit den Bildern da. Der kleine Bub mit den Waffen»).

Inwiefern P19 die Involvierung der Gesellschaft als unheimlich empfindet, führt er oder sie nicht näher aus, bringt aber noch eine weitere emotionale Wertung ins Spiel, die er oder sie als konträr oder mindestens abweichend von diesem unheim- 
lichen Eindruck einführt, indem er oder sie die Aussage mit "Auf der anderen Seite» einleitet. Es liege nämlich auch «etwas Melancholisches» in dieser Situation. Und hier liefert P19 nun nähere Begründungen dafür, inwiefern er oder sie diesen Aspekt historischen Geschehens melancholisch empfindet. Vermutlich seien alle "aufs Gleiche ausgerichtet gewesen", habe es "Zusammenhalt» und "Verbundenheit untereinander» gegeben, und zwar mehr "als heute in unserer doch sehr individualistischen Gesellschaft».

Der letzte Satz liefert den Schlüssel zum Verständnis der Aussage, wird doch darin deutlich, dass P19 die emotionalen Wertungen aus einem Vergleich von Zeitebenen und aus der Feststellung einer Unterschiedlichkeit von Vergangenheit und Gegenwart gewinnt. Gewisse Aspekte der Vergangenheit würde er oder sie sich offenbar auch für die Gegenwart wünschen, nämlich «Zusammenhalt» und «Verbundenheit», gleichzeitig zeigt sich P19 abwägend und der beunruhigenden Kehrseite einer mobilisierten Gesellschaft bewusst, die er oder sie zugleich als unheimlich einordnet. Somit bringt P19 in der zitierten Passage ambivalente Deutungen und emotionale Zuschreibungen zur Sprache. Er oder sie zeigt sich selbst dieser Ambivalenz bewusst ("Auf der anderen Seite») und lässt beide Emotionen nebeneinanderstehen, ohne die Widersprüchlichkeit der Emotionen aufzulösen.

In Bezug auf andere Themen formuliert P19 hingegen eindeutig negative Emotionen und ablehnende Wertungen. Auch dort stehen wieder Aspekte historischen Geschehens und nicht die Ausstellung im Zentrum der Zuschreibungen. Im nachfolgenden Beispiel beschäftigt sich P19 mit dem Ausstellungstext einer der «Blick ins Ausland»-Stellwände und den darin enthaltenen Informationen über Aspekte des Gaskriegs und damit verbundenen Opferzahlen.

"Italien tritt an der Seite der Alliierten in den Krieg ein, sodass die Schweiz nun ganz von kriegführenden Ländern umgeben ist. Bei Ypern setzen die Deutschen mit Giftgas eine nene schreckliche Waffe ein, die im Verlauf des Krieges rund 90000 Tote fordern wird. Auch die Schweizer Armee bereitet sich auf einen möglichen Giftgaseinsatz vor. Ihre Bestände an Gasmasken bleiben aber bis zum Kriegsende bescheiden und reichen nicht für die gesamten Truppen.> (...) Ja, das ist furchtbar, wenn man sich das vorstellt, Giftgas. Und, ist auch übel, wenn man da liest, dass nicht einmal, sie nicht einmal für jeden Soldaten eine gegeben hat, geschweige denn für die Zivilbevölkerung. (...)

Finde ich aber einen guten Blick (...). So ein Jahr nach Kriegsbeginn, wie hat es ausgesehen rundum? (...) 
Ja und (...) verschiedene (...) ja, wie viele Leute da gestorben sind, bewegt einen, bewegt einen, wenn man das sieht, hm (seufzend). (...)» (P19, Absatz 69-70)

Gleich mehrere Aspekte im Zusammenhang mit dem Einsatz von Giftgas werden in der zitierten Passage zum Anlass für den Ausdruck von Betroffenheit und geradezu Entsetzen. Zum einen äussert P19 Bewegung über die Einsicht, "wie viele Leute da gestorben sind», zum anderen auch darüber, dass in der Schweiz kein genügender Bestand an Gasmasken vorhanden gewesen wäre, um für alle Soldaten, "geschweige denn für die Zivilbevölkerung» Schutz bieten zu können.

Die nachfolgend zitierte Textstelle schliesst sich im Transkript unmittelbar an. Nachdem P19 seine Bewegung über die vielen gasbedingten Toten zur Zeit des Ersten Weltkriegs zum Ausdruck gebracht hat, wendet er oder sie sich einem nächsten Ausstellungstext zu, der sich in der Abteilung «Wachsende Not» spezifischer mit dem Thema «Kriegswirtschaft und Wirtschaftskrieg» beschäftigt. Die daraus gewonnene Einsicht, dass es überhaupt einen Wirtschaftskrieg gegeben habe, ist dann auch Ausgangspunkt für eine im Anschluss an die Lektüre geäusserte emotionale Wertung.

"Wachsende Not (...) Kriegswirtschaft und Wirtschaftskrieg. Der Erste Weltkrieg ist nicht nur ein mit aller Härte geführter Stellungskrieg, sondern auch ein brutaler Wirtschaftskrieg. Die Kontrolle wirtschaftlicher Ressourcen wird rasch zu einer zentralen Aufgabe der Kriegsfübrung. Seit 1914 wird der Warenverkehr der Schweiz mit den kriegführenden Ländern von Überwachungsgesellschaften beider Kriegsparteien kontrolliert. Die Societé Suisse de Surveillance Économique mit Sitz in Bern und die Schweizerische Treuhandstelle in Zürich greifen immer tiefer in die wirtschaftliche Handlungsfreibeit des Landes ein. Parallel dazu steigt in der Bevölkerung der Unmut über Kriegsgewinnler, Schieber, Wucherer und Spekulanten.'

Ja, das finde ich jetzt bewegend, weil sonst liest man immer nur über die militärische Seite des Kriegs, aber nie auch, dass es eben auch ein Wirtschaftskrieg gewesen ist. (...)

Da würde mich jetzt noch mehr darüber interessieren. Und darum lesen wir jetzt mal, was da in dem Text steht, hm?» (P19, Absatz 71-72)

Im Anschluss folgt P19 der Ankündigung und wendet sich dem nächsten Ausstellungstext zu, der sich vertieft mit der genannten Überwachungsgesellschaft beschäftigt, es kommt jedoch unmittelbar zu keinen weiteren freien Äusserungen 
zum Thema, auch zu keinem Ausdruck von Betroffenheit mehr. Zu einem späteren Zeitpunkt des Ausstellungsbesuchs kommt P19 jedoch nochmals auf die Thematik des Wirtschaftskriegs zu sprechen. Ein dort befindliches «Blick ins Ausland»Element beinhaltet die Thematik, und P19 greift diese nach Lesen des Textes auf.

"Dann 1918, ein weiteres Jahr, ‘Blick ins Ausland. (...) Für wenige Kilometer Geländegewinn opfern die Generale in der Blutmüble von Verdun und an der Somme Millionen von Soldaten. In der Nordsee tobt vor dem Skagerrak die grösste Seeschlacht des gesamten Krieges, bringt aber keine Entscheidung. Grossbritannien bält die Seeblockade gegen Deutschland weiterbin aufrecht, was zum Tod Hunderttausender von Zivilisten führt. (...) Zugleich verschärft sich der Wirtschaftskrieg im Sommer 1916 noch einmal deutlich. Mit dem Hindenburgprogramm mobilisiert Deutschland sämtliche wirtschaftliche Ressourcen für den Krieg. Um die Materialschlachten weiterhin durchstehen zu können, soll die Produktion von Munition verdoppelt und die Herstellung von Geschützen verdreifacht werden. Der Wirtschaftskrieg führt in der Schweiz zu ersten Versorgungsengpässen. Ab 1916 wird der Druck auf das Land von beiden Kriegsparteien deutlich erhöht.>

Eben, das trifft mich jetzt, dass (...), über das redet ja keiner heute, dass die Wirtschaftsseeblockade von England zum Tod von Hunderttausenden von Zivilisten gefübrt hat. Ein Gedanke, der eigentlich (...) ja (...) der gar nicht diskutiert wird, wo ich mir auch nie Gedanken darüber gemacht habe. Und anf der anderen Seite die Blutmüble von Verdun, das kennt ja faktisch jeder, oder? Und das finde ich jetzt echt zum Nachdenken, wie sebr doch auch ein Wirtschaftskrieg zusammen mit dem Militärischen, (weil/wenn) das zusammen verlinkt ist, und eben auch ein Wirtschaftskrieg zum Tod von, von Hunderttausenden fübren kann. (...) Was aber kaum diskutiert und auch nicht irgendwo gross reflektiert oder, man hat auch nicht gross drüber nachgedacht, $j a$. Finde ich jetzt einen sebr spannenden Gedanken. (...)»(P19, Absatz 91-92)

Aus den beiden zitierten Passagen geht hervor, dass sich P19 bislang nicht über die Existenz eines Wirtschaftskriegs bewusst gewesen ist. Er oder sie erklärt und rechtfertigt dies damit, dass dieser Aspekt heute gar nicht diskutiert werde («über das redet ja keiner heute", "weil sonst liest man immer nur über die militärische Seite des Kriegs»), und macht zugleich deutlich, dass er oder sie durch die neue Erkenntnis über die Existenz eines Wirtschaftskriegs und die damit verbundenen zivilen Opfer berührt wird ("das finde ich jetzt bewegend", "das trifft mich jetzt», "das finde ich jetzt echt zum Nachdenken»). 
Auffallend ist, dass es nahezu ausschliesslich Ausstellungstexte sind, aus denen P19 als bewegend und beunruhigend eingestufte neue Erkenntnisse gewinnt. Auch im nachfolgenden und die Brennpunktdarstellung abschliessenden Beispiel ist dies wieder der Fall, und auch dort ist geäussertes Entsetzen wiederum geknüpft an die Menge von Toten - nun die Opfer der Spanischen Grippe. Die Konfrontation mit den durch die Spanische Grippe bedingten Opferzahlen scheint P19 an die Grenzen des Erklär- und Nachvollziehbaren zu bringen, führt er /sie doch Gott in seine/ihre Überlegungen ein und die Frage danach, wie dieser «so etwas zulässt». Im Verlauf wird das Beispiel dann ergänzt um gegenwartsbezogene Überlegungen, die weiter oben bereits einmal vorgestellt wurden.

«Die Spanische Grippe». Da hab ich Leute, kenne ich Leute, die selber noch Angehörige verloren haben, und das interessiert mich jetzt sehr, weil es doch (...) eigentlich ein sehr heftiges Kapitel ist, das aber im Zug vom Ersten Weltkrieg irgendwo etwas den Tisch gefallen ist. (...) Eben, es sind mehr Opfer, hat es gegeben, als im ganzen Krieg. (...) Woah. In der Schweiz ist die Hälfte der Bevölkerung erkrankt.> Das hab ich noch nie gehört im Leben, das ist wirklich sehr, sehr interessant. (...)

So viele Leute, die gestorben sind, hm. (...) Das ist krass, da fragt man sich, wie, ja wie Gott so etwas zulüsst. (...) Wie so viele Leute gestorben sind. Und erstaunlich, dass ja Männer zwischen 20 und 40 besonders häufig gestorben sind. Wo die eigentlich am resilienzfäbigsten täten (...). Dass die westlichen Landesteile stärker sind als die östlichen, dass die im Jura stationierten Truppen besonders heftig ist. (...) Haha (bitter) (...). Ist, ist krass, hm? Da fragt man sich, wieso dass das so ist, dass sogar geografisch stärker Zentren gegeben hat. (...)

$\mathrm{Ha}$ (bitter), dass man sich dann noch beschuldigt hat, mit den Truppenaufgeboten Grippetote in Kauf genommen zu h/, ist auch eine interessante (...) so ein interessanter Gedanke, den ich auch noch nie gehört haben vorher. Also interessante historische Tatsache, ist wirklich, ja (...) Die <Abdankung von einem Lieutnant, der gestorben ist.> (...)

Da überlegt man sich schon, ja, ob nicht auch heute wieder so eine Pandemie auftreten könnte und wie das heute wäre, weil wir uns eigentlich schon daran gewöhnt haben, dass es so etwas nicht mehr gibt, aber dass ja (...) das genau hundert Jahre oder nicht ganz hundert Jahre her ist, wo eine letzte grosse Pandemie Zehntausende Todesopfer gefordert hat und (...) dass man irgendwo, man kann auch sagen, ja wir sind nicht von dem gefeit, und (...) man darf sich da nicht in einer falschen Sicherheit wiegen. Und ich denke, es ist gut, wenn man sich auch, 
ja, mit DEM auseinandersetzt und sich überlegt, wie sind die Leute damals damit umgegangen und was für Lebren kann man für heute ziehen. Aber (...) ich bin doch sehr dankbar, dass wir von dem jetzt eigentlich nicht mehr betroffen sind, oder im Moment nicht betroffen sind. (...)»(P19, Absatz 132-135)

Nicht nur bei P19 löst insbesondere die Konfrontation mit Opferzahlen Äusserungen von Betroffenheit aus. Auch bei einigen weiteren Besuchenden finden sich vergleichbare Aussagen. So äussern sie einerseits in Bezug auf die durch die Spanische Grippe bedingten Opferzahlen:

"Die Spanische Grippe wird hier auch (...) in einem eigenen Text erläutert, (...) mit über 50 Millionen (...) Menschen weltweit, die ihr zum Opfer gefallen sind. (...) Und ich bin erschrocken, wenn ich lese, dass (...) die Hälfte der Schweizer Bevölkerung (...) von der Epidemie betroffen waren.» (P28, Absatz 93)

"Ah, hier wird jetzt noch von dieser Grippe geschrieben, ich weiss jetzt nicht mehr, (aber es) war bekannt, dass da sehr viele gestorben sind. (...) Sch/Ah, die Spanische Grippe, genau, das ist ja Wabnsinn. (...) Über 50 Millionen. (...) Mebr Tote als der gesamte Krieg. (...) Das ist ja wahnsinnig, (...) diese Epidemie.» (P3, Absatz 76)

"Da, das ist jetzt die Spanische Grippe <von 1918-19 fallen weltweit über FÜNFZIG MILLIONEN Menschen zum Opfer.> Das (...) hat epidemische Ausmasse angenommen (...). Sie fordert damit mehr Tote als der gesamte Krieg. (...) In der Schweiz erkrankt zwischen 18 und 19, also Juli 18 und Juli, die HÄLFTE der Bevölkerung. VIERUNDZWANZIGTAUSENDFÜNFHUNDERT Todesopfer . (...)»(P20, Absatz 112)

Und auch die durch Giftgas oder generell das Kriegsgeschehen bedingten Opferzahlen bewegen oder beunruhigen nicht nur P19, sondern auch weitere Besuchende:

"Das hat mich schon (...) durch den Sommer durch sebr beschäftigt (...), wenn man Dokumentarfilme zu sehen, wie da einfach Millionen von Menschen umgebracht werden. (...) Der Mensch, Kronik von, Krone der Schöpfung, sagt man, und sie bringen sich gegenseitig um. (...)»(P18, Absatz 35-36) 
«NEUNZIGTAUSEND TOTE〉. (...) Durch Giftgas. Schrecklich. (...) Und wo heute noch Giftgas gelagert ist, ist, weiss man ja nicht so genau.» (P18, Absatz 81)

Eine Person beschreibt ausserdem den Anblick der auf einer Fotografie zu sehenden Gasmasken als bedrohlich:

"Italien tritt an der Seite der Allierten in den Krieg ein, sodass die Schweiz nun ganz von kriegführenden Ländern umgeben ist. Bei Ypern setzen die Deutschen mit Giftgas eine neue schreckliche Waffe ein, die im Verlauf des Kriegs rund 90000 Tote fordern wird. Auch die Schweizer Armee bereitet sich auf einen möglichen Giftgaseinsatz vor. (Ihre) Bestände an Gasmasken bleiben aber bis zum Kriegsende bescheiden und reichen nicht für die gesamten Truppen.>

Dashab ich mir auch schon überlegt. Gasmasken haben einen sebr bedroblichen (...) Eindruck auf mich. (...)» (P21, Absatz 54)

In der zuletzt zitierten Textstelle wird nicht unmittelbar ersichtlich, ob sich die von P21 geschilderte Beunruhigung eher auf die Fotografie als ein Element der Ausstellung und damit eher auf den Fokus II oder das in seinen Augen in der Fotografie repräsentierte und zum Ausdruck kommende historische Geschehen und damit Fokus I bezieht. Eine Reihe von analogen Formulierungen war in dieser Hinsicht schwer zuzuordnen.

Als eindeutig ausstellungsbezogen wurde demgegenüber eine Aussage eingestuft, in der sich die Beunruhigung einer Person auf die Grösse der Ausstellung richtet.

"Also, jetzt bin ich ein bisschen nervös, weil ich nicht weiss, wie gross diese Ausstellung ist. Guck ich mir jetzt mal so ganz schnell im Überblick an, zwecks Orientierung. Ach du meine Güte, das gebt jetzt aber sehr lange. (...) Also, dann (...) beherze ich mich jetzt doch so ein bisschen und guck das ein bisschen zügiger durch.» (P12, Absatz 129)

Insgesamt wurden Äusserungen von Betroffenheit, Entsetzen und Beunruhigung jedoch schwergewichtig in Bezug auf Geschehen formuliert. 


\subsubsection{Sättigung, Überdruss und Anstrengung}

Bisweilen äussern Besuchende auch Sättigung, Überdruss oder Anstrengung. Zugeordnet wurden dieser Kategorie wiederum einerseits explizite selbstreflexive Formulierungen ( $<\mathrm{x}$ strengt mich an $>$ ) sowie entsprechende Adjektive ( $<\mathrm{x}$ ist anstrengend〉, ‘mühsam〉). Es handelt sich hierbei um eine negativ konnotierte Emotion. Dieser Emotionsbereich kommt bei der Hälfte der Besuchenden vor, in auffallender Häufigkeit erneut bei P12, der Person, die bereits durch ausgiebiges Äussern von Erstaunen und Eindruck aufgefallen war.

Dieser Emotionsbereich wird ausschliesslich ausstellungsbezogen geäussert, insbesondere in Zusammenhang mit Tonmedien. Besuchende äussern Anstrengung in Situationen, wenn sie mit mehreren Reizen gleichzeitig konfrontiert werden, wenn also beispielsweise Tonaufnahmen und Bildquellen sowie Ausstellungstexte auf engem Raum kombiniert werden. In solchen Situationen empfinden Besuchende offenbar insbesondere Tonaufnahmen als Überforderung.

"Aber irgendwie ist das doch anstrengend, diese, diese Zitate zu hören, wenn hier dieser Film läuft über die Schweizer Armee.» (P12, Absatz 77)

Aus Äusserungen von P12 geht hervor, dass er oder sie das Hören von Tonaufnahmen in der Kombination mit der Aufgabe des Lauten Denkens als «zu viel» empfindet:

"Ich glaub, das ist mir zu komplex, dadurch, dass ich ja selber reden darf, ist das mir irgendwie zu viel jetzt zu hören.» (P12, Absatz 128)

Möglicherweise müssen also die Äusserungen der Teilnehmenden über Audiomaterial auch im Kontext mit der Erhebungsmethode betrachtet werden, wobei sich die übrigen Besuchenden dahingehend nicht explizit äussern.

Insbesondere wird Missmut darüber geäussert, Tonmedien ausgesetzt zu sein und diese nicht abstellen zu können. Dies ist insbesondere in einer Ausstellungspassage der Fall, in der mit Ausstellungstexten, Bildquellen und einer permanent laufenden Tonspur verschiedene Schlaglichter auf ausländische und schweizerische Propagandaaktivitäten und die zu Kriegszeiten bestehenden divergierenden Haltungen der deutsch- und französischsprachigen Schweiz geworfen werden. P3 und P4 äussern dort: 
"Man kann hier aber nicht abstellen, es läuft einfach und (...) das ist etwas unangenehm.» (P3, Absatz 35)

"Also das stört ein bisschen, dass dieser Text einfach, immer läuft (...) und man ibn nicht abstellen kann.» (P3, Absatz 49)

"Die Hintergrundstimme (von diesen) (...) Propagandasachen, die stört mich ein bisschen, (...) weil ich da eigentlich immer (...) zuböre.» (P4, Absatz 46)

Mehrfach Anstrengung drückt in dem Zusammenhang auch P12 aus. In der nachfolgend zitierten Passage liest er oder sie zunächst den im Rundkreis befindlichen Ausstellungstext oder versucht dies zumindest, liest anschliessend Inschriften der gezeigten Bildpostkarten und äussert währenddessen wiederholt, sich von der parallel laufenden Tonquelle gestört zu fühlen, wiederum nicht zuletzt auch deshalb, weil er oder sie neben dem Lesen und Betrachten obendrein über die eigenen Gedanken Auskunft geben soll.

«Für die Kriegs». Das ist jetzt aber sebr mühsam, dass hier oben von der Decke dieser Text kommt, weil, ich muss hier lesen und soll hier auch noch berichten, was ich sebe und denke. (...) Das ist gut gemeint in dieser Ausstellung.

‘Damit der Graben zwischen den Sprachregionen nicht tiefer wird, versucht der Bundesrat, die äusserst beleidigende Auslandspropaganda einzuschränken. Verschiedene Schweizer Intellektuelle setzen sich für einen politischen Standpunkt ein, der Sprachbarrieren und unterschiedliche Sympathien zu überwinden sucht.> 〈Die Helvetia bewabrt ibre Neutralität〉, (...) 〈Schweiz, Grenzbesetzung 1914〉. (...) Das sind ja spannende Karten, aber es ist zu mühsam, die hier zu verfolgen, find ich, weil ja ich mit diesen Text hier oben hören muss. Ich geh also.» (P12, Absatz 79-80)

Einige Minuten später wendet sich P12 der Rückwand des zuvor von innen betrachteten Kreises zu und äussert dort:

"Jetzt guck ich noch mal auf die Seite hier, damit ich nicht immer vorbei laufe. Ich bin wieder hier im Propagandahafen. Ich hab glaub ich keine Lust mehr, diese vielen kleinen Dinge hier anzugucken, weil hier wieder dieser Mensch oben von der Decke spricht und mich total verwirrt. (...)»(P12, Absatz 96) 
Trotz der Ankündigung, jetzt weitergehen zu wollen, verbleibt P12 jedoch noch eine längere Zeit in der Abteilung und äussert sich eingehend zu den gezeigten Bildquellen, kommt im späteren Verlauf jedoch erneut und wiederholt darauf zu sprechen, dass er oder sie sich durch die parallel laufende Tonquelle angestrengt fühlt.

"Das ist total spannend, diese Sachen hier zu sehen, aber es ist wabnsinnig anstrengend mit dieser Stimme aus dem Off hier oben. <Illustrierter Kriegskurier. (Currira della guerra)〉, 〈Deutscher Teil. Import mit französischen Kindern〉. Ja das ist natürlich auch. 〈Deutsche Landstürmer, Landsturmmänner teilen ibr Brot mit französischen Kindern.> Das ist ja, bedarf keiner weiteren Worte. Hier, aber ach ja, die alte humoristische Karte von Europa im Jabr 1914. Die ist bekannt. Der deutsche Michel in der Mitte, der mit Wodka und Pulver behängte und bis zu den Zehen bewaffnete russische Bär. (...)

Österreich-Ungarn als Verbündete Richtung Osten ziehend. Der dazwischen eingeklemmte serbische Soldat. (...) Ja, sehr schön, aber so ein bisschen hier im Halbdunkel auch nicht ganz einfach zu sehen. Aber klasse, und vor allem diese Bilder sind so schön, auf diesem roten Untergrund oder in, in diesen Untergrund oder auf diesem Material appliziert. Das ist total schön, ich würd das am liebsten anfassen. ‘Ausländische Propagandapostkarte gegen die Zentralmächte〉. Aber jetzt muss ich geben, dieses, dieses, diese Texte hier von oben, ist zu anstrengend.» (P12, Absatz 103-104)

Andere Besuchende äussern Anstrengung weniger angesichts einer Unausweichlichkeit, sondern vielmehr aufgrund der Länge von - nun anderen - Tonaufnahmen:

"Okay, also der Text auf den Ohren, der (...) wird immer noch gesprochen, und da bin ich jetzt fast froh, dass ich sitzen kann. (Ja), ist doch relativ lange.» (P4, Absatz 121)

"So, ich beende das jetzt mit dem Kopfhörer. Find des, find die Hintergrundinformationen eigentlich sehr gut, aber mir geht das ehrlich, bin zu ungeduldig, das geht mir zu lang. (...) Ich geh weiter.» (P6, Absatz 20)

Neben Tonaufnahmen bilden einen weiteren schwerpunktmässigen Anlass für Überdruss und Anstrengung Ausstellungstexte und konkreter die Tatsache, dass 
innerhalb einer thematischen Abteilung die Übertitel und Einleitungsabschnitte von Ausstellungstexten wiederholt werden, was von etlichen Besuchenden bemerkt und mitunter als störend kommentiert wird:

"Ja, da sehe ich gerade schon wieder, dass die Exportindustrie Konjunktur hatte, und das ist jetzt ungefähr schon das dritte Mal. Da macht's mich nicht unbedingt an, den Text noch zu lesen.» (P19, Absatz 65)

« Wachsende Not». Den Titel haben wir glaube ich schon mal gehabt. (...) Darum macht es mich nicht unbedingt an, das jetzt zu lesen.» (P19, Absatz 105)

"Milch und Brot. Mitten im Krieg nach dem Schock des Kriegsbeginns hat die Schweizer Exportindustrie bald Hochkonjunktur.> Moment, das haben wir doch jetzt schon gelesen. Ich glaub, das sind immer wieder so Zusammenfassungen, die hier oben kommen. Das find ich nett, aber ist auch ein bisschen redundant hier. (...) Zumindest ist das praktisch, wenn man rechts wie links anfängt, hier durch die Ausstellung zu gehen. Ja. Nimmt man die Leute auch sicher mit hier mit diesen Übertiteln. Also, was steht denn hier? ‘Milch und Brot. Landwirtschaft im Umbruch $[\ldots]$ >

[...]

〈Die Lebensmittel werden ständig knapper〉, sie werden knapper und knapper und knapper und knapper, (kichert) wie sie das jetzt immer wieder hier gesagt baben. Ich glaube, man hat's wirklich kapiert, ‘und teurer, und die Verbitterung in der Bevölkerung zeigt sich in Demonstrationen und Streiks. Bürgertum und Arbeiterschaft stehen sich immer unversöhnlicher gegenüber.

[...]

〈Kriegsende und Streik. Die Lebensmittel werden ständig〉, ja schon wieder, also jetzt ist langsam wirklich sehr redundant hier.» (P12, Absatz 106-107, 185 und 194)

Neben den Tonquellen und sich wiederholenden Passagen in Ausstellungstexten ist es drittens auch generell die Fülle und Dichte der Ausstellung, die die Besuchenden als herausfordernd empfinden:

"Ich werd jetzt langsam müde, weil die Ausstellung ist eigentlich so dicht und so viel, und weiss manchmal gar nicht so genau gucken.» (P12, Absatz 166) 
"Es ist im Ganzen sehr detailliert, und irgendwann dann denkt man: Okay, ich glaub, ich habs jetzt gesehen.»(P3, Absatz 31)

"Also interessant sind die verschiedenen Ebenen, aber es ist fast etwas viel Flut, um, um die Übersicht zu behalten, (...) sind alles so Blitzlichter, hier noch mit dem Hintergrund, hat es noch (...) Zitate.» (P3, Absatz 56)

Gerade zu einem fortgeschrittenen Zeitpunkt ihres Ausstellungsbesuchs äussern die Besuchenden dann auch explizit Müdigkeit und nachlassende Konzentrationsfähigkeit:

"Das Einzige noch nur, entweder bin ich jetzt auch langsam müde, weil ich jetzt schon knapp zwei Stunden herumgucke und lese, oder es ist genau auch diese Dichte an Informationen langsam, diese Verdichtung (...), oder es ist eine Mischung aus beidem, die ich jetzt so langsam spïre» (P12, Absatz 179)

"Jetzt spüre ich, dass ich langsam müder werde. Konzentration lässt nach, und ich merke, dass ich ein bisschen schneller vorwärtsgehen muss im Rundgang durch die Ausstellung.» (P19, Absatz 81)

"Ja, das ist jetzt nemere Geschichte, das lassen wir aus. (...) Jetzt sind wir müde (lacht).»(P18, Absatz 139)

Diese Erschöpfung, die sich nach Aussage der Besuchenden mit fortschreitender Dauer des Museumsbesuchs einstellt, deckt sich mit den Befunden zahlreicher anderer, bei Annette Noschka-Roos zusammengetragener Museumsbesucherstudien, die «eine mit zunehmender Besichtigungsdauer nachlassende Intensität in der Betrachtung der Exponate und in der Lektüre der Texte» ausdrücken. ${ }^{1463}$

\subsubsection{Desinteresse und Indifferenz}

Bisweilen äussern Besuchende auch Desinteresse oder Indifferenz. Hierzu zähle ich explizit die eigene Person sichtbar machende Formulierungen ( $₫$ interessiert mich nicht $)$, die Verwendung entsprechender Adjektive ( $<$ ist uninteressant $>$, $x$ ist irrelevant>) oder aber auch die Ankündigung, sich mit etwas nicht näher be-

1463 Noschka-Roos 1994, S. 155, S. 159; vgl. hierzu Abschnitt 5.3.1. 
schäftigen zu wollen. Es handelt sich hierbei um eine tendenziell negative bzw. dem Titel entsprechend indifferente Emotion. Der genannte Bereich ist bei etwa zwei Dritteln der Besuchenden und jeweils nur mit vereinzelten Nennungen zu finden, kommt also eher selten vor.

Aufgrund einerseits der grossen thematischen Vielfalt und andererseits des Bezuges auf unterschiedlichste Ausstellungselemente lassen sich kaum Schwerpunkte innerhalb des Bereichs der geäusserten Desinteressen und Indifferenzen ausmachen. Die Aussagen der Besuchenden sind meist kurz und prägnant und beschränken sich darauf, nach der Zurkenntnisnahme eines Ausstellungselements oder behandelten Themas festzustellen, sich dafür nicht oder wenig zu interessieren oder sich nicht eingehender mit dem Element oder der Thematik beschäftigen zu wollen. Die nachfolgend zitierten Passagen verdeutlichen dies beispielhaft:

"Da stehe ich vor <Verfügung des schweizerischen Volkswirtschaftsdepartements betreffend die Milchversorgung des Landes>. Das interessiert mich eigentlich jetzt grad weniger, und ich gehe weiter.» (P25, Absatz 78)

«Gut, ist eine Suppenschale, reisst mich jetzt nicht so vom Hocker.»(P8, Absatz 4)

"Da die verschiedenen Bundesratsbeschlïsse und Verfügungen. Aber das schauen wir jetzt nicht alles an.» (P20, Absatz 71)

In dieser Explizitheit einmalig im Material bringt nachfolgend P19 Indifferenz zur Sprache:

"Ja (...), zunehmende Regulierung kann man sich irgendwo noch gut vorstellen (...) und kann man auch nachvollziehen (...), empfinde ich jetzt als sehv neutral, löst bei mir weder positive noch negative Emotionen aus.» (P19, Absatz 88)

Neben den expliziten Nennungen von eigenem Desinteresse und von Indifferenz wurden auch solche Äusserungen berücksichtigt, in denen die Besuchenden durch ihre Beschreibungen etwas als unwichtig, unauffällig oder irrelevant beurteilen. Etwa äussert eine Person geschehensbezogen, nach Konfrontation mit dem Speiseplan einer Basler Suppenküche: 
"Klingt jetzt nicht nach, nach einem herrlichen Festmabl, aber auch nicht nach grösster Hungersnot. (...)» (P8, Absatz 4)

In Bezug auf Elemente der Ausstellung äussert P30:

"Das Audiostation ist ausser Betrieb. (...) Das hilft nicht gerade, aber es stört nicht.»(P30, Absatz 52)

"Die Bilder geben einfach einen kurzen Blick, aber die sagen noch nicht viel aus. (...)» (P30, Absatz 70)

Die Beispiele in diesem Bereich verdeutlichen, dass der Grad an Explizitheit in der Sichtbarmachung der eigenen Person als emotional involvierte bzw. Geschehen oder die Ausstellung einschätzende Instanz variabel sein kann. Ebenso verfliessen die Grenzen zwischen dem Äussern von (Nicht-)Emotionen und dem Äussern von Bewertungen/Beurteilungen. Insofern erweist sich die auf Bodo von Borries zurückgehende Rede vom Nicht-nur-Kognitiven ${ }^{1464}$ als ausgesprochen praktikabel, um als Sammelbehältnis für dieses Spektrum an Äusserungen zu dienen.

Während ich mich auf dem Kontinuum zwischen emotionalen Relationen einerseits und kognitiven Relationen andererseits in den bisherigen Abschnitten vor allem im erstgenannten Bereich bewegt habe, fokussiere ich nachfolgend, bereits eingeleitet durch die zuletzt gezeigten Textbeispiele, nun auf einen Zwischenbereich, den Bereich der Urteile und Wertungen, ohne diese dabei freilich als emotionsfrei betrachten zu wollen.

\subsubsection{Urteile über Relevanz und Wichtigkeit}

Als Pendant zu den im letzten Abschnitt beschriebenen Äusserungen von Indifferenz lassen sich Bemerkungen der Besuchenden fassen, in denen sie auf Relevanz und Wichtigkeit zu sprechen kommen. Diese Kategorie taucht bei einem Drittel der Besuchenden auf und dort jeweils nur vereinzelt, insgesamt also eher selten.

Relevanz und Wichtigkeit wird in aller Regel bezogen auf die Behandlung eines Themas in der Ausstellung, wobei auch hier, wie schon an mehreren Stellen beschrieben, die Grenzen zwischen geschehens- und ausstellungsbezogenen Äusserungen verschwimmen und vielfach nicht eindeutig zu entscheiden ist, ob die

1464 Vgl. Abschnitt 3.4.1. 
Besuchenden eher einem Aspekt des Geschehens Wichtigkeit beimessen oder der Tatsache, dass dieser in der Ausstellung dargestellt wird. Vielfach, so lautet eine Hypothese, ist womöglich gleichermassen beides gemeint. Die folgenden Beispiele geben einen Eindruck:

"Also ich lese nur so grob, dass hier eben die Pharmaindustrie in dieser Zeit sehr gewachsen ist und dass ja die Schweiz eigentlich dann profitieren konnte, weil es Material brauchte. Sehr viel Gewinn, versechsfachst, versechsfacht, in dieser Zeit also fa/ färben und hat es schöne Beispiele mit Farbkarten von der Ciba-Geigy, die früher, also das war die frühere Chemie, die Namen baben ja immer gewechselt, und es ist, vielleicht wollen wir das nicht so gerne sehen, dass wir da profitiert haben vom Krieg. Aber das ist ein wichtiger Aspekt, finde ich, auch zu seben dass immer jemand ein Interesse hat, sonst müsste man ja sagen, warum gibt es ïberhaupt Krieg? Weil es ja, niemand will Krieg sozusagen.» (P3, Absatz 13)

"Der Bundesrat ist (...) von einer (...) kurzen Kriegsdauer ausgegangen, ja. (...) Das ist (immer) sebr wichtig, (...) das zu erwähnen, finde ich. (...) Okay.» (P4, Absatz 23)

"Ah okay, 〈Fremdenpolizei wird 1917 gegründet. (unv.)> Das ist relativ spannend, find ich wichtig.» (P6, Absatz 48)

"Also Stellungskrieg, Wirtschaftskrieg, zwei wichtige Wörter, sehr spannend, jedenfalls finde ich das.» (P3, Absatz 54)

"Ich lese den Text (...) zur (...) SSS. (...) Die Handlungsfreibeit der Unternehmen wird immer stärker eingeschränkt, (...) und (...) man kann es nicht oft genug wiederbolen, (...) seit 1916 gehen die Importe von Lebensmitteln und zentralen Robstoffen wie Koble und Eisen (...) deutlich zurïck.» (P28, Absatz 59)

Die in den Textbeispielen vorgenommenen Wertungen über Aussagen der Ausstellung bedürfen des mindestens impliziten Abgleichs mit einer angenommenen historischen Wirklichkeit. In den meisten Fällen kommen die Besuchenden offenbar zu dem Ergebnis, die Darstellung der Ausstellung trage der Bedeutung eines Aspekts historischen Geschehens Rechnung. 
Eine Abweichung konstatiert hingegen die nachfolgend zitierte Person, zumindest partikular bezogen auf eine Textquelle, wobei das darin vermisste Thema an anderen Stellen der Ausstellung durchaus aufgegriffen wird:

«Sehr relevant ist (...) die Frage der (...) Ernäbrungsgrundlagen, aber die (...) ausgestellten Thesen (...) nehmen darauf, (...) so weit ich sehe, (...) wenig Bezug.» (P28, Absatz 13)

Eine bemerkenswerte Facette in den Feststellungen von Wichtigkeit stellen vereinzelte Äusserungen dar, in denen Besuchende einen Zusammenhang zwischen der häufigen Erwähnung eines Aspekts in der Ausstellung und dessen Bedeutung als historisches Geschehen zu entdecken glauben.

"Ja, da kom/, dadurch dass das IKRK so oft erwähnt worden ist, sieht man auch, wie, wie die Bedeutung vom IKRK einfach wirklich enorm gewesen ist, ja es wird einem bewusst, was da, was da geleistet worden ist. Und es wächst einem echt auch der Respekt vor so einer Organisation.» (P19, Absatz 100)

"ZZwischen dem 3. und 7. August rücken 220000 Mann und 45000 Pferde ein.' Die 45000 Pferde scheinen wobl eine sebr grosse Bedeutung zu haben, da sie bier öfters auftauchen. Ist auch eine beeindruckende Zabl.» (P8, Absatz 20)

Anhand dieser Beispiele zeigt sich aufs Neue das Ineinandergreifen von Äusserungen über historisches Geschehen und über dessen Repräsentation in der Ausstellung. Aus Sicht der Besuchenden scheinen beide Aspekte vielmals ineinander zu greifen.

\subsubsection{Exkurs: Implizite Relevanzen und Bedeutungen}

Explizite Äusserungen über Relevanz und Wichtigkeit kommen im Datenmaterial selten vor. Dies bedeutet allerdings keineswegs, dass es für die Besuchenden keine bedeutsamen Themen gäbe. Vielfach äussert sich die Relevanz von Themen weniger in einer expliziten Benennung dieser Relevanz durch die Besuchenden als beispielsweise in einer wiederholten Beschäftigung mit einem Thema über den Besuchsverlauf hinweg oder in der Art und Weise dieser Beschäftigung.

Mit dem gewählten inhaltsanalytischen Vorgehen, das auf eine Systematisierung der expliziten Äusserungen abzielt, können diese Dimensionen von Relevanz allerdings nur bedingt eingefangen werden. Um ihnen gleichwohl beispielhaft 
Rechnung zu tragen, widme ich mich an dieser Stelle in Form eines Exkurses impliziten Relevanzen. Ich tue dies in Form einer Falldarstellung zu P20. Im Besuchsverlauf dieser Person erweist sich ein Thema, nämlich soziale Unterschiede und Spannungen zwischen Arm und Reich, als wiederholt vorkommend und offenbar für die Person bedeutsam, verbunden mit einer auffälligen Strukturierung geschehensbezogener Äusserungen nach sozialen Gegensatzpaaren.

\section{Im Brennpunkt: P20}

«dass es wirklich (...), ja, wie immer die Armen getroffen hat» - Unterschiede zwischen Arm und Reich als individuell bedeutsames Thema

Mehrfach wiederkehrendes Thema im Ausstellungsbesuch von P20 ist die während des Ersten Weltkriegs in der Schweiz bestehende soziale Not bzw. der Gegensatz zwischen Arm und Reich. Äusserungen zu diesem Thema stehen teilweise im Zusammenhang mit zuvor von P20 betrachteten Ausstellungselementen, werden aber auch losgelöst davon an mehreren Stellen zur Sprache gebracht.

Initial kommt das Thema bereits im Eingangsbereich der Ausstellung im Zusammenhang mit einem dort gezeigten Stadtplan Basels zur Sprache, wo sich eine Fotografie des Basler Marktplatzes befindet und die zugehörige Bildbeschriftung über steigende Nahrungsmittelpreise nach Kriegsbeginn Auskunft gibt. P20 äussert in Auseinandersetzung mit der Fotografie und teilweise die zugehörige Beschriftung lesend:

"Auf dem nächsten Bild, das (...) das könnte auf dem Fischmarkt sein, bin aber nicht sicher, muss dann mal spicken. (...) Es ist Markt, man siebt da Körbe mit Gemüse, dann (...) Frauen in langen Röcken natürlich. Wie immer. (...) Ah, nein, nicht auf dem Fischmarkt, sondern auf dem Marktplatz. (...)

‘Markt auf dem Basler Marktplatz. In den ersten Tagen nach Kriegsausbruch fand ein Ansturm auf die Geschäfte statt. Wer es sich leisten konnte, deckte sich mit Lebensmitteln ein.'

Also, hm, (unv.) damals schon Hamsterkäufe.

¿Die hohe Nachfrage fübrte zu höheren Preisen, vor allem die Kartoffeln waren vom Lebensmittelwucher betroffen. Sie waren begehrt und knapp, denn der Nachschub durch die Elsässer Bauern auf dem Basler Markt fehlte. Als die Vorratskammern der Vermögenden gefüllt waren, normalisierte sich die Lage wieder. 
Das heisst also, die Armen haben darben miissen, bis die Vermögenden ibre Vorratskammern gefüllt hatten, weil die das Geld hatten, die haben die Preise gezablt, die anderen vermutlich nicht. Und nachdem dass die Grenze natürlich zugegangen ist, ist ganz klar, dass der Nachschub von den Elsässer Gemüsefrawen, der Tradition hat in Basel, nicht mehr funktioniert hat. (...)» (P20, Absatz 10)

Auf die Tendenz von P20, Bildinhalte zu identifizieren und entsprechende Vermutungen zu äussern bzw. diese anschliessend mittels der Beschriftungen zu verifizieren oder falsifizieren, wurde an anderer Stelle bereits eingegangen. Nun stehen seine oder ihre Äusserungen unter neuer Perspektive im Fokus.

Interessant im zitierten Ausschnitt ist, dass die Bildbeschriftung zwar Auskunft über steigende Nahrungsmittelpreise und Einkäufe der Vermögenden gibt, dass die Gegenüberstellung mit der entsprechend schlechteren Situation der Armen aber selbsttätig durch P20 erfolgt. Selbiges geschieht erneut einige Minuten später, ebenfalls noch in der baselbezogenen Eingangszone der Ausstellung, wo eine Vitrine Exponate und zugehörigen Ausstellungstext zum Thema «Wohlstand» präsentiert. P20 wendet sich den ausgestellten Objekten zu, unter anderem etwa Kleidung und Toilettenartikeln von vermögenden Baslerinnen und Baslern, und konsultiert anschliessend den Ausstellungstext. Im folgenden Auszug liest P20 zunächst diesen Text und äussert sich dann dazu.

"Der Ausbruch des Ersten Weltkriegs ist für die reichen Basler Familien noch nicht das Ende der Belle Époque. Kriegsgewinne in einigen Industriezweigen und familiäres Vermögen ermöglichen der Oberschicht weiterhin ein angenehmes Leben. So konnte 1916 das Kaffeehaus Singer am Marktplatz eröffnet werden. Ein moderner Bau mit grossstädtisch-mondänem Interieur, wo sich die woblhabenden Familien an Kaffee, Tee, Süssigkeiten und Konzerten erfreuten.'

Also wir baben damals die einen, die um ibre Existenz bangen mïssen und jeden Rappen umkebren baben mïssen, weil der Mann, der Ernäbrer ist an der, an der, an der Grenze gewesen. Keinen (...) Lobnersatz bekommen hat. Haben die einen schauen müssen, und die anderen sitzen bei Kaffee, Kuchen und Konzert im Singerbaus. So GERECHT ist die Welt. (...)» (P20, Absatz 23)

Erneut ergänzt hier P20 ein Ausstellungselement, das explizit nur die Situation der Wohlhabenden thematisiert, um die entgegengesetzte Perspektive der Armen 
und bezieht hierzu ergänzend eine weiter vorn in der Ausstellung erhaltene Information über den Lohnausfall für wehrpflichtige Soldaten ein (P20, Absatz 9).

Das Bild der im Kaffeehaus Singer zusammenkommenden Reichen im Gegensatz zu den notleidenden Armen scheint für P20 sinnbildlich zu stehen für den konstatierten Arm-Reich-Gegensatz, greift er oder sie dieses Bild doch wenig später erneut auf, wenn er oder sie, immer noch in derselben Abteilung befindlich, nun zu einem Ausstellungstext zum Thema «Not» assoziiert:

"Die sozialen und politischen Spannungen stiegen und entluden sich in Demonstrationen und Streiks.'

Kein Wunder. Also wenn man jeden Tag um, um, drum bangen, ob man noch etwas für die Kinder auf den Tisch machen kann, und auf der anderen Seite dann über den Marktplatz läuft und beim Café Singer Musik hört, und die reichen Damen kommen heraus in ihren Oberkleidern, so wie man es da nebendran gesehen hat, das könnte ich mir jetzt noch vorstellen, dass das für die Ärmsten von den Armen nicht sebr einfach gewesen ist. Und dass sich da gewisse Frustration und Wut auch aufgebaut hat. (...)» (P20, Absatz 28)

Für Beschreibungen der sozialen Not verwendet P20 wie im genannten Beispiel zum Teil deutliche Formulierungen, etwa hätten die Armen "darben müssen» (Absatz 10), «bangen» (Absatz 28) oder «um ibre Existenz bangen» (Absatz 23) müssen, es sei zwischen Bürgertum und Arbeiterschaft «die Schere natürlich gross geworden» (Absatz 96), und es sei nicht verwunderlich, dass sich «Frustration und Wut» aufgebaut habe (Absatz 28). P20 thematisiert den Gegensatz zwischen Arm und Reich bzw. das Leid der Armen als universelles, immerwährendes Problem:

"Und ich kann mir schon vorstellen, dass in den Kriegsjahren der Verdienst nicht gross gewesen ist, eine grosse Arbeitslosigkeit geherrscht hat und, also dass es wirklich (...), ja, wie immer die Armen getroffen hat. (...)»(P20, Absatz 9)

Anhand der genannten und weiterer Beispiele lässt sich die soziale Not bzw. der Gegensatz zwischen Arm und Reich als für P20 relevantes Thema identifizieren, das er oder sie an mehreren Stellen bereitwillig aufgreift und sich dazu äussert, während andere in der Ausstellung angelegte Themen nicht in dem Mass rezipiert werden.

Das Aufgreifen des Arm-Reich-Gegensatzes geschieht dabei einerseits in Reaktion auf bestimmte Ausstellungsteile, die sich den sozialen Spannungen zuwenden, wird gleichzeitig aber auch manchenorts durch P20 in die Ausstellung hineinge- 
deutet. Beispielsweise deutet er oder sie einen Ausstellungstext um, der den im Militärdienst vorherrschenden Drill und die Langeweile und dadurch bedingte Spannungen zwischen Offizieren und Soldaten thematisiert, und deutet einen zumindest in der Form nicht explizit im Text enthaltenen - sozialen Unterschied hinzu:

«4200 Armeeangehörige kommen durch die Spanische Grippe» - hmpf, was immer das auch ist? - sandere Krankbeiten oder Unfülle ums Leben. Drill und Langeweile prägen den (...), den Webr/ (...) -aflikten - keine Abnung - «was verbreitet zu Missstimmung und Konflikten zwischen Offizieren und Soldaten fübrt>-

ja, das ist auch klar, weil die Offiziere, die sind natïrlich aus besserem Haus gewesen, Akademiker zum Teil, also das ist nicht wie heute, wo jeder Offizier werden kann, wenn er die Leistung bringt, sondern damals sind es noch die Herren in den Schaftstiefeln und den Reithosen gewesen, und Soldaten, das sind die Einfachen gewesen, und da ist schon eine ziemlich breite Kluft gewesen zwischen Offizieren und Soldaten. (...)»(P20, Absatz 41)

Der Arm-Reich-Gegensatz erweist sich anhand der Vielzahl genannter Beispiel als für P20 besonders relevantes und durch den gesamten Ausstellungsbesuch hindurchziehendes Querschnittsthema.

Damit verbindet sich eine weitere Auffälligkeit, nämlich ein generelles Sprechen in abstrakten Kollektiven bzw. in sozialen Kategorien, vielfach in Form von Gegensatzpaaren. Neben der im Rahmen der bereits gezeigten Beispiele erkennbaren Dichotomisierung von Armen und Reichen kommen folgende Gegensatzpaare in den Äusserungen von P20 vor:

- «Bürgertum und Arbeiterschaft» (P20, Absatz 108),

- «Arbeiterschaft links, Bürgerschaft rechts» (P20, Absatz 108),

- «Offiziere [...] aus besserem Hau» und «Soldaten» (P20, Absatz 41),

- «Lente [n], die an der Front gewesen sind, oder respektive im Aktivdienst» vs. «B̈̈rokraten» (P20, Absatz 73).

Das Beispiel von P20 macht deutlich, dass Themen für Besuchende bedeutsam sein können, dass diese Bedeutsamkeit aber nicht zwingend explizit als solche benannt werden muss. Es mag viele Fälle geben, in welchen den Besuchenden die 
Bedeutsamkeit eines Themas selbst nicht zwingend zu Bewusstsein gelangt und allein aus diesem Grund nicht verbalisiert wird. Solche impliziten Bedeutungen lassen sich wie im gezeigten Beispiel entdecken, wenn Besuchende während des Ausstellungsbesuchs wiederholt auf dieselben Themen zurückkommen - mit Anstoss durch Ausstellungselemente oder auch ohne, nämlich wenn Besuchende Ausstellungselemente selbstständig um weiterführende, ihnen offenbar wichtige Perspektiven ergänzen. Ein auf explizite Verbalisierungen fokussierendes Kategoriensystem, wie ich es im Rahmen meiner Arbeit entwickelt und eingesetzt habe, kann solche impliziten Bedeutungen allerdings nur bedingt einfangen. Zudem wären für deren Entschlüsselung vertieftere Einzelfallanalysen notwendig, die nicht im Zentrum der vorgenommenen Analyse standen.

\subsubsection{Urteile über Schlüssigkeit, Erwartbarkeit und Nachvollziehbarkeit}

Einen weiteren Bereich von Wertungen bilden solche, in denen die Besuchenden Aspekte des Geschehens oder der Ausstellung im Hinblick auf ihre Schlüssigkeit und Nachvollziehbarkeit bewerten und dabei in aller Regel in der positiven Form etwas als schlüssig, logisch, klar, einleuchtend oder nachvollziehbar beschreiben. Beurteilungen von Schlüssigkeit und Nachvollziehbarkeit kommen bei einem Grossteil der Besuchenden und eher in Bezug auf historisches Geschehen vor.

Zwei relativ häufig gebrauchte Adjektive, um die Schlüssigkeit historischen Geschehens zum Ausdruck zu bringen, sind «klar» und «natürlich», wie in den nachfolgenden Beispielen:

"Also das färbt auch auf die Kinder ab, jetzt hat's hier ein Zitat, dass schon ein Vierjühriger anfängt, Barrikaden zu bauen im, im Garten, also wie der Krieg dann auch die Kinder prägt und man natürlich ganz anders aufwächst.» (P3, Absatz 16)

«Mit der Schriftenreibe 〈Stimmen im Sturm〉-vom Bundesrat harsch kritisiert - verbreiten sie radikale deutschfreundliche sowie fremdenfeindliche und antisemitische Parolen. (...) Die Mittelmächte versuchen, den deutschen Standpunkt in der Schweiz mit Propagandafilmen, dem illustrierten Kriegskurier oder mit direkter Einflussnahme auf die Zürcher Post zu stärken.> (...)

Also hier versucht Deutschland, die Schweiz (...) auf seine Seite zu ziehen, was natürlich eine Herausforderung für Neutralität bedeutet.» (P8, Absatz 32) 
«Gegen Ende des Krieges setzt sich im Bundesrat die Idee einer aktiven Neutralitätspolitik im Rabmen internationaler Einko/, Übereinkommen durch. 1920 tritt die Schweiz dem Völkerbund bei.> Spannend, das heisst, der Erste Weltkrieg war so eine entscheidende Be/, also EINE von wabrscheinlich vielen, aber eine wichtige Bewährungsprobe für diese Neutralitätspolitik, womit man sich dann erst recht bestätigt füblte. Klar, wenn man diesem Wahnsinn doch entronnen war.» (P12, Absatz 139)

"Wachsende Not. Der Krieg wird zum Dauerzustand und die Versorgung der Bevölkerung immer schwieriger. Mit Regulierungen und Rationierung versucht der Staat gegen den zunehmenden Mangel anzukämpfen.> (...) Ist klar, es hat ja niemand mit so einem langen Krieg gerechnet. (...) Und da hat die Regierung schauen müssen, (...) dass das Volk trotzdem noch genug zu essen hat, und entsprechende Verfügungen erlassen.» (P25, Absatz 79)

«Die hobe Nachfrage führte zu höheren Preisen, vor allem die Kartoffeln waren vom Lebensmittelwucher betroffen. Sie waren begehrt und knapp, denn der Nachschub durch die Elsässer Bauern auf dem Basler Markt fehlte. Als die Vorratskammern der Vermögenden gefüllt waren, normalisierte sich die Lage wieder.

Das heisst also, die Armen haben darben müssen, bis die Vermögenden ibre Vorratskammern gefüllt hatten, weil die das Geld hatten, die haben die Preise gezahlt, die anderen vermutlich nicht. Und nachdem dass die Grenze natürlich zugegangen ist, ist ganz klar, dass der Nachschub von den Elsässer Gemüsefrauen, der Tradition hat in Basel, nicht mehr funktioniert hat.» (P20, Absatz 10)

«So, da stehen wir jetzt vor der Vitrine, die (...) scheinbar ein bisschen die Reicheren (...) mit ibren Accessoires vertreten sind. Also (...) wir baben da das Abendkleid (...) ja, ist wabrscheinlich damals Haute Couture gewesen. Damenschube (...), auch schon, würde ich sagen, sehr elegant. Dann die Toilettengarnitur mit Bürsten, mit, mit (...) verschiedenen Sachen. Und überall mit einem silbrigen Monogramm. (...) Ist, AHH! Klar, <Besitz von der, von der Fanny Clavell. Clavell-Wenkenhof, das ist ja eine von den reichsten Familien gewesen in Basel. Und man sieht da natürlich auch Elfenbein mit aufgelegtem Silbermonogramm 〈FC〉. Also das haben sich wirklich nur die Reichen leisten können.» (P20, Absatz 22) 
"Da (...) sind wir vorm Teil von der (...) von der Industrie, also von den Farbstoffen. (...) <In Basel verhalf der Erste Weltkrieg der chemischen Industrie zum Durchbruch. Vor 1914 wurden 85 Prozent der Farbstoffe für den globalen Markt in Deutschland hergestellt.> Also das ist sicher Bayer-Leverkusen und die grosse Chemiefirma BASF und so weiter, und die (...) sind dann natürlich alle, haben die Produktionen zum Teil kriegsbedingt einstellen müssen oder, oder wahrscheinlich auch (...) runterfahren. Und das ist natiurlich die Chance gewesen für die Schweiz, um die Produktion hochzufabren.» (P20, Absatz 25)

«4200 Armeeangehörige kommen durch die Spanische Grippe〉-hmpf, was immer das auch ist? - <andere Krankheiten oder Unfälle ums Leben. Drill und Langeweile prägen den (...), den Wehr/ (...) -aflikten〉 - keine Abnung - 〈was verbreitet zu Missstimmung und Konflikten zwischen Offizieren und Soldaten führt>-ja, das ist auch klar, weil die Offiziere, die sind natürlich aus besserem Haus gewesen, Akademiker zum Teil, also das ist nicht wie heute, wo jeder Offizier werden kann, wenn er die Leistung bringt, sondern damals sind es noch die Herren in den Schaftstiefeln und den Reithosen gewesen, und Soldaten, das sind die Einfachen gewesen, und da ist schon eine ziemlich breite Kluft gewesen zwischen Offizieren und Soldaten. (...)» (P20, Absatz 41)

«Streikende blockieren die Gleise beim Babnhof Grenchen.〉 (...) Ja (...), das ist natürlich die Folge vom, vom, von der Armut, Arbeitslosigkeit.» (P20, Absatz 101)

Bisweilen sprechen die Besuchenden ausserdem davon, etwas sei «logisch» oder «verständlich», wie in den nachfolgenden Beispielen:

«Die im Herbst 1916 eingeführte Kriegsgewinnsteuer bringt Bund und Kantonen 730 Millionen Franken ein.> (...) Ich könnte mir vorstellen, die Schweiz macht Gewinn mit dem Krieg, liefert einen Teil ab an den Bund, und der Bund setzt das Geld nachber wieder ein, um (...) sich besser verteidigen zu können gegen Kriegsgegner. (...) Das Ganze ist etwas paradox und trotzdem logisch.» (P25, Absatz 53)

"Die kriegsbedingten neuen Bundesaufgaben führen zu einem starken Anstieg der Staatsausgaben. Während - ist logisch, oder? - ‘wäbrend der Kriegsjabre nebmen diese um rund das Zweieinhalbfache zu. (...) Zur Finanzierung der 
Kriegskosten führt der Bund eine Kriegssteuer, die heutige direkte Bundessteuer, ein.»» (P19, Absatz 83)

«In den Deutschschweizer Industrieorten wird der Streik reger befolgt als in der Romandie. Auf dem Land wird kaum gestreikt.> Verständlich.» (P5, Absatz 37)

Hin und wieder gebrauchen Besuchende auch Negativformulierungen, um die Nachvollziehbarkeit historischen Geschehens zum Ausdruck zu bringen. Sie äussern dann, sie seien wenig oder nicht verwundert, erstaunt oder überrascht:

«Am Abend des 3. August wählt die (unv.) [vmtl. Vereinigte Bundesversammlung] Ulrich Wille zum General. Am folgenden Tag gibt der Bundesrat eine NEUTRALITÄTSERKLÄRUNG ab, die von den kriegfübrenden Staaten ANERKANNT wird.> Das (...) verwundert wenig.» (P8, Absatz 19)

«Nach dem Landesstreik beschuldigen sich die Konfliktparteien gegenseitig, mit dem Streikaufruf [fehlt: <und den Truppenaufgeboten〉] Grippetote in Kauf genommen zu haben.> Das überrascht mich relativ wenig, dass so eine Naturgewalt hier politisch ausgeschlachtet wird.» (P8, Absatz 78)

"Uns Frauen schaltet der Staat sonst von jedem aktiven Dienst aus, nun aber schien die grosse Zeit auch uns eine besondere Aufgabe bereithalten zu wollen. Zitat Else Spiller.>

Hm. Evstaunt mich überbaupt nicht und zeigt schön auf, wie (...) wie in der Schweiz und speziell die Frawen in der Schweiz ganz offensichtlich Bürger zweiter Klasse waren, und hier schreibt Frau Spiller eigentlich ganz eindrücklich, wie sich hier ein Betätigungs- findet, ein Betätigungsfeld findet für die Frauen, die ja eben vom aktiven Dienst im Militär ausgeschlossen sind, und gleichzeitig ist es natürlich vermeintlich zutiefst weiblich, sich hier irgendwie in der Fürsorge zu engagieren und die tapferen Männer zu pflegen, wenn sie zu Hause sind, bzw. sie zu unterstützen in diesen Soldatenstuben. Aber eben, was so glaube eigentlich auch so seine kritischen Aspekte hat, und seine, seine fast schon kitschigen Seiten, trägt ja eigentlich dazu bei, dass Frauen sich emanzipieren und (...), ja, feststellen, welchen Beitrag sie hier eigentlich leisten.»(P12, Absatz 23) 
Etliche der bislang zitierten Textstellen entstammen den Äusserungen der Besuchenden P8, P12 und P20, die durch verhältnismässig viele Äusserungen über die Schlüssigkeit und Nachvollziehbarkeit historischen Geschehens auffallen. Auffallend bei P20 ist ausserdem, dass er oder sie im Zusammenhang mit Feststellungen von Schlüssigkeit und Nachvollziehbarkeit einige Male auch davon spricht, sich etwas «porstellen» zu können:

"Auf dem nächsten Bild sieht man (...) Schweizer Offiziere und Soldaten, und wenn ich das richtig anschaue, haben die alle so Rotkreuzarmbinden, aber den Uniformen nach würde ich jetzt mal irgendwie (...) auf französische Soldaten tippen. (...) RICHTIG! <Französische Sanitätsmannschaft auf dem Weg zum Bundesbahnhof. Seit den ersten Kriegsmonaten wurden über die Transitstrecke Basel-Genf immer wieder deutsche und französische Sanitätstruppen ausgetauscht. Sie waren in Kriegsgefangenschaft geraten und durften gemäss Genfer Konvention in ibre Heimat zurückkehren. Während die Offiziere mit Autos chauffiert wurden, mussten die Truppen den Weg durch die Stadt zu Fuss gehen. Im September 1914 sorgte der Durchmarsch dieser fremden Soldaten in der Basler Bevölkerung für einiges Aufsehen.'

Ja, das ist mir schon klar, weil in der Zeit hat man natürlich noch kein Fernsehen gehabt, bestenfalls die, die ein bisschen Geld hatten, ein Radio. Aber wenn dann etwas in der Stadt gelaufen ist, gerade so etwas mit fremden Truppen, das sieht man ja in Basel nicht alle Tage, dann kann ich miv vorstellen, dass das wie ein Lauffeuer durch Basel durchgegangen ist, und alles, was irgendwie Zeit und Lust hatte, ist sich das Schauspiel anschauen gegangen.» (P20, Absatz 17)

"Die sozialen und politischen Spannungen stiegen und entluden sich in Demonstrationen und Streiks.> Kein Wunder. Also wenn man jeden Tag um, um, drum bangen, ob man noch etwas für die Kinder auf den Tisch machen kann, und auf der anderen Seite dann über den Marktplatz läuft und beim Café Singer Musik bört, und die reichen Damen kommen heraus in ibren Oberkleidern, so wie man es da nebendran gesehen hat, das könnte ich mir jetzt noch vorstellen, dass das für die Ärmsten von den Armen nicht sehr einfach gewesen ist. Und dass sich da gewisse Frustration und Wut auch aufgebaut hat.»(P20, Absatz 28)

Aus dem Kontext, in dem P20 den Begriff des Sich-Vorstellens gebraucht, namentlich in Kombination mit den Begriffen «klar», "natürlich» und "Kein Wunder», schliesse ich, dass damit ein historisches Geschehen als nachvollziehbar bzw. na- 
heliegend beschrieben werden soll, und weniger, dass das Sich-Vorstellen tatsächlich als ein Imaginieren gebraucht wird, wie dies bei anderen Besuchenden den Anschein macht und wie ich dies weiter unten noch behandeln werde.

Eine weitere Bedeutungsvariante des Sich-Vorstellens deutet sich im nachfolgenden Beispiel an, in dem der Begriff beim Versuch der Identifizierung des in einer Filmquelle Dargestellten auftritt und dort mutmasslich als Äussern einer Vermutung konnotiert ist, ein Bereich, der ebenfalls weiter unten noch thematisiert wird.

«Die Einschätzung der Pferde». (...) Ich kann mir vorstellen, die werden von einem Tierarzt untersucht (...) und dann bewertet (...). Aha, auf die Hufe wird eine Nummer (...) eingebrannt. Damit man siebt, dass (man) sie identifizieren kann. (...) Ich stelle mir vor, dass (...) nach Ende vom Krieg oder (...) bei (...) oder wenn die Tiere umkommen, die Landwirte entsprechend der Einschätzung entschädigt werden.»(P25, Absatz 38)

Am Beispiel des Begriffs des Sich-Vorstellens zeigt sich, dass Besuchende dieselben Wörter unter Umständen mit unterschiedlicher Aufladung gebrauchen können ${ }^{1465}$ und dass je nach Wortkontext die Zuordnung zu unterschiedlichen Kategorien sinnvoll sein kann, wobei die Grenzen zwischen diesen Kategorien fliessend sein können.

Die bislang gezeigten Materialbeispiele zeugen davon, dass die Besuchenden in vielerlei Hinsicht die Schlüssigkeit und Nachvollziehbarkeit historischen Geschehens konstatieren. Sehr vereinzelt formulieren sie strukturgleich wie in den oben gezeigten geschehensbezogenen Aussagen auch Schlüssigkeit und Nachvollziehbarkeit in Bezug auf die Ausstellung und ihre Elemente:

"Was wird von allem übrig bleiben, wenn der Kampf zu Ende sein wird? Ein Leichenhaufen, ein Trümmerhaufen, ein Irrenhaus.' Ja, also bier (...) wird man jetzt tatsächlich mal angeregt, darüber nachzudenken, warum da überhaupt Krieg geführt wird, durch solche Zitate. Kommt in dieser Ausstellung relativ kurz, was aber (...) dem geschuldet ist, dass hier natiurlich die Schweizer Perspektive eingenommen wird, die eben mit anderen Problemen zu kämpfen hat als eben die Frage nach dem Sinn dieses Krieges.» (P8, Absatz 72)

1465 Schröder hat dies in ihrer Studie für den Begriff der «Chronologie» aufgezeigt (Schröder 2013, S. 204). 
«Kadettengewehr, gut, das darf natürlich nicht fehlen, wenn es darum geht, das Militär darzustellen.» (P8, Absatz 5)

"Und ich bin gevade überhaupt nicht erstaunt, dass hier Friedensorganisationen genannt werden zusammen mit Frauenorganisationen.»(P12, Absatz 138)

Im Gesamtüberblick über alle Äusserungen in dieser Kategorie scheinen Schlüssigkeit, Erwartbarkeit und Nachvollziehbarkeit allerdings Kriterien zu sein, die die Besuchenden vor allem auf historisches Geschehen beziehen.

Ebenfalls lediglich vereinzelt habe ich Textstellen identifiziert, in denen die Besuchenden explizit eine Nicht-Schlüssigkeit bzw. Nicht-Nachvollziehbarkeit konstatieren, etwa die nachfolgende Äusserung von P18:

«Für mich (...) nicht verständlich, dass die Deutschschweizer sich viel mehr zu Deutschland hingezogen gefühlt haben (...) als in der eigenen Schweiz. (...) Und umgekehrt dann auch die Welschen (...) mehr für die Franzosen Sympathie hatten. (...) Es ist ein Wunder, dass da die Schweiz nicht auseinandergebrochen ist.» (P18, Absatz 49)

Eine weitgehende Abwesenheit entsprechender Adjektive bedeutet allerdings nicht, dass die Besuchenden generell keine Verständnishürden oder kein Unverständnis formulieren würden. Derartige Äusserungen gehen allerdings in einer Reihe von andernorts beschriebenen Kategorien auf. So gehen sie bisweilen fliessend in den Bereich der negativen Urteile über, dem ich mich im nächsten Abschnitt zuwende, oder werden formuliert in Form von Fragen oder Irritationen, ein Bereich, dem ich ebenfalls weiter unten noch eine gesonderte Darstellung widme. Des Weiteren lassen sich auch die bereits vorgestellten Äusserungen von Erstaunen als Gegenpol zu den hier gezeigten Feststellungen von Schlüssigkeit und Erwartbarkeit verstehen.

\subsubsection{Positive und negative Urteile}

Neben den soeben betrachteten Urteilen in Bezug auf Schlüssigkeit, Erwartbarkeit und Nachvollziehbarkeit sowie den weiter oben bereits beschriebenen Urteilen über Wichtigkeit und Relevanz gibt es einen dritten Grossbereich von Urteilen, den ich verallgemeinernd als positive und negative Urteile überschreibe und der unter den beobachteten Urteilen den weitaus bedeutendsten Stellenwert im Datenmaterial ausmacht. $\mathrm{Zu}$ den positiven Urteilen zähle ich solche, mit denen die 
Besuchenden Aspekte des Geschehens oder der Ausstellung als gut, schön, richtig oder in irgendeiner anderen Weise positiv konnotiert einstufen. Negative Urteile sind umgekehrt solche, mit denen Geschehen oder Ausstellung als nicht gut, nicht richtig oder in anderer Weise negativ konnotiert eingeschätzt werden.

Derartige Urteile kommen bei allen 18 Besuchenden und in Bezug auf beide Fokussierungen als Bezugspunkt vor. Wenn ich weiter oben festgestellt habe, dass Besuchende im Hinblick auf Schlüssigkeit, Erwartbarkeit und Nachvollziehbarkeit vor allem historisches Geschehen beurteilen, bedeutet dies also nicht generell, dass nicht auch die Ausstellung und ihre Elemente zum Gegenstand von Urteilen würden.

Eine thematische Häufung von Urteilen findet sich im Zusammenhang mit dem Gegenstand «Kriegsverlauf/(Kampf-)Geschehen im Ausland», weshalb ich diesem Bereich nachfolgend eine differenziertere Betrachtung widme, und auch deshalb, weil sich in Bezug auf diesen Gegenstand gleichermassen positive und negative, gleichermassen geschehensbezogene und ausstellungsbezogene Urteile illustrieren lassen.

Bei den nachfolgenden Zitaten handelt es sich um Äusserungen der Besuchenden, die im Zusammenhang mit den in regelmässigen Abständen wiederkehrenden «Blick ins Ausland»-Elementen zustande gekommen sind. Dass die Besuchenden ein verhältnismässig reges Interesse für diese Elemente haben und sensibel sind für die wiederkehrende, chronologische Struktur und die ästhetisch abweichende Gestaltung dieser Elemente, habe ich weiter oben bereits dargestellt. ${ }^{1466}$ Nun geht es spezifischer darum, im Zusammenhang mit diesen Elementen geäusserte Urteile der Besuchenden in den Blick zu nehmen, und zwar einerseits in Bezug auf historisches Geschehen und andererseits in Bezug auf die Ausstellung und ihre Elemente, wobei ich einige Textstellen exemplarisch herausgreife.

Gleich zu Beginn der Kernausstellung enthält ein Film einen Einführungstext zum Kriegsausbruch und zeigt die geografische Ausdehnung des Ersten Weltkriegs im Zeitverlauf. Ich stelle nachfolgend vergleichend einige Äusserungen der Besuchenden zu diesem Film zusammen, die positive und negative Urteile enthalten, wobei ich, wo für das Verständnis nötig, längere Kontexteinheiten zeige.

1466 Vgl. Abschnitt 8.6.4. 
"Hier quasi die Zeitleiste, hier am Bildschirm. (...) 4. August, Dezember (...) okay, Entente ist grün, Mittelmächte (...) (unv.). (...) Okay, quasi einmal der Verlauf weltweit. Ab, das finde ich ganz gut, weil da kann man (...) (Moment), fängt an. (schmunzelt) (...) Ah, okay. <Weltenbrand. Das Attentat von Sarajevo entwickelt eine Dynamik, die schon bald (...) (zu einem) alle Lebensbereiche umfassenden Krieg führt.> (...)

Also auch hier wieder (unv.) zweisprachig (unv.) finde ich echt sehr gut. (...) Okay, das ist jetzt erst der Anfang. (...) Ah, klar. (...) Das finde ich faszinierend, weil (...) man zwar immer Weltkrieg sagt, aber (...) das mal so gebannt auf eine Karte, finde ich echt nicht schlecht (...) (von dev Idee). (...) (unv.) (kichert). (...)»(P4, Absatz 19-20)

"Ein weiteres, technisches Medium (...) erregt meine Aufmerksamkeit, eine Weltkarte, (...) die als Zeittafel (...) arrangiert ist (...) und mich informiert (...) über das Ausmass, globale Ausmass mit 70 Millionen Soldaten in 40 Ländern, (...)

wobei es etwas irrefübrend ist, wenn ganze Kontinente gefärbt werden, (...) so, als ob dort überall und zu jeder Zeit gekämpft werden würde. (...)» (P28, Absatz 17-20)

"Weltenbrand 1914 bis 18. Das Attentat entwickelt eine Dynamik, die schon bald zu einem alle Lebensbereiche umfassenden Krieg führt. So wird aus einem militärischen Mord der (zuerst) totale Krieg.>

Ist für mich eine etwas zu simple Sinnbildung bier. (...) Vom Attentat die Dynamik abzuleiten, die zu einem Weltkrieg fübrt. Da seh ich doch auch andere Entwicklungen, die da eine wichtige Rolle spielten. (...) Hier mit der Zeitleiste, mal schauen, ob man da irgendwas machen kann. Nee, dasscheint (...) nicht interaktiv zu sein. (...)

Die Karte zeigt das sebr, sebr ïbersichtlich. Zum einen, dass es sich hier um einen Weltkrieg handelt und nicht, wie er oft gesehen wird, als zentraleuropäischer Krieg, bei dem es vor allem um die Westfront geht, sondern (...) wie viel Länder der Welt beteiligt waren. (...) Und dass auf verschiedenen Kontinenten gekämpft wurde. (...) Ich denke, das wird für viele Besucher ziemlich spannend sein, da man das meistens nicht so berücksichtigt. (...)

Hier siebt man auch relativ deutlich, wie die Entente wächst und die Mittelmächte zurückgedrängt werden.» (P8, Absatz 7-9) 
"Ich finde es gut gestaltet, mit einem Bildschirm, das erleichtert es einem auch, und man muss nicht mehrere Karten nebeneinander anschauen.» (P21, Absatz 19)

"Ah, hier ist noch eine Karte, das ist jetzt interessant. Mit den Bündnissen und die Schweiz. (...) Mal schauen, wie des da mit der, wie des wechselt. (...) 〈4. August〉. (...) Also die Schweiz ist gut eingezeichne/ ah jetzt geht das so langsam vorwärts, die Zeitleiste, wie sich das verändert mit den verschiedenen, mit den Mittelmächten, das ist eine sehr interessante Grafik, die Schweiz rot, neutral, und die grauen Länder, die auch neutral sind. Also diese Begriffe, die werd ich vorher auch einfübren.

[kurzer Unterbruch durch Gespräch mit JT zu Aufnahmetechnik]

Die Farben, das werd ich sicher vorher auch mit ibnen [den Schülerinnen und Schülern von P3, Anm. JT] anschauen. Da ist das mit dem Attentat beschrieben, gut. Ich weiss nicht, wie viel sie dann lesen, ausser sie müssen etwas finden. Also die Geduld ist ja bei den Schülerinnen und Schülern nicht immer so wahnsinnig, aber (...) wenn ich ihnen dann Aufträge gebe schon.

Ab, jetzt sieht man noch was von Anfang an, die Karte mit der Schweiz schön rot, dann diese (...) wie das anfängt mit (...) Serbien, Österreich-Ungarn, wie die anderen Länder dazukommen, das ist toll gemacht. Das passt dann auch zum Imperialismus, haben wir auch schon Afrika und so, die verschiedenen, welche/ welches Land hat welche Kolonien, haben sie schon (...) eingezeichnet, und dann verstehen sie das auch besser, wie das mit dieser Karte ist. (Im Schnellzugstempo) ändert das ja da, dass Länder wieder aussteigen oder Kriegsschauplätze ist auch interessant, ist gut gemacht. (...) Toll. (...) Die Schweiz immer noch ganz schön brav rot (schmunzelt), neutral, was ist jetzt mit Russland passiert, aha. Das ist ja mit der Russischen Revolution dann am Ende, das g/ das kann man natürlich ohne Hintergrundwissen irgendwie nicht versteben, wieso jetzt da plötzlich Russland zum Beispiel aussteigt und solche Dinge. Aber ich schau dann mal, was ich vorbearbeite mit ibnen.» (P3, Absatz 20-22)

Die Zitate zeigen, dass sich die Besuchenden mehrheitlich positiv über die Art der Darstellung in Form einer sich verändernden Karte äussern. Die Karte führe die geografische Ausdehnung des Krieges und seine globale Dimension bildlich vor Augen, sei «gut gestaltet» (P21, Absatz 19) und «sehr, sehr übersichtlich» (P8, Absatz 8), wohingegen P28 die Einfärbung «ganze[r] Kontinente» (P28, Absatz 20) offenbar als zu pauschalisierend empfindet und P8 eine "etwas zu simple Sinnbil- 
dung» (P8, Absatz 7) bemängelt. Bei diesen Äusserungen handelt es sich jeweils um Urteile in Bezug auf die Ausstellung bzw. konkreter in Bezug auf ein darin befindliches Element und die Art der erzählten Geschichte. Sämtliche derartigen Äusserungen haben als Bezugspunkt den Fokus II, die Ausstellung.

Ein geschehensbezogenes, negatives Urteil äussert hingegen P25, wenn er oder sie von einem «schlimmen Krieg» spricht:

"Da steh ich, steh ich vor der Tafel 〈Der Weltenbrand. 1914 1918〉, (...) von meinem Verständnis her (...) ist, sind die Schüsse von Sarajevo (...) nur noch der Auslöser vom Ersten Weltkrieg gewesen (...), aber (...) die Zeit ist bereit gewesen für den schlimmen Krieg, und wenn es nicht Sara/, Sarajevo gewesen wäre, wäre irgendein anderer Ort gesucht worden. Und die Vernetzung der verschiedenen Staaten (...) untereinander und gegeneinander (...) hat bedeutet, dass ja der Krieg fast programmiert gewesen ist.»(P25, Absatz 23)

Ähnlich negativ konnotiert äussert sich P18:

"Ich schaue da die Weltkarte an. (...) Aha, wie es so im Jahr ist. (...) Jetzt schau ich noch mal von vorne. (...) Ich persönlich finde das immer noch sebr frag/, fragwiurdig (...), dass einfach so ein Attentat so eine Dynamik entwickelt hat, in dem Krieg, zu einem Weltkrieg. (...)

Eigentlich lokal, Serbien (...) mit Österreich-Ungarn (...), und dann, ja da kommt mir schon in den Sinn, könnte heute auch wieder so sein. Russland, Serbien. (...) Plötzlich in, innert einem Jahr so eine (...) Ausdehnung, das ist extrem. (...)

Da hoffe ich schon auch, dass der Ukraine-Konflikt nicht so etwas auch wieder auswirken kann. Dann ist es dann noch viel grösser und umfassender. (...)

Unverständlich. (...) Ich sehe da viele Parallelen auch zu heute. (...)» (P18, Absatz 14-18)

In dieser Textstelle zeigen sich Anklänge an diejenigen Urteile, die im vorigen Kapitel bereits thematisiert wurden, nämlich Urteile über Schlüssigkeit und Nachvollziehbarkeit. An diesem Beispiel lässt sich deshalb erneut das im Verlauf der Darstellung mehrfach erwähnte inhaltliche Ineinandergreifen verschiedener Kategorien, das sich in der konkreten Auseinandersetzung mit dem Datenmaterial zeigt, auf besonders augenfällige Weise illustrieren. 
Ähnliches zeigt sich bei P25, der/die im vorletzten Beispiel noch einen «schlimmen Krieg» (P25, Absatz 23) konstatiert hatte. Einige Minuten nach dieser Äusserung knüpft P25 daran an und bezeichnet das Kriegsgeschehen als "[u]nglaublich»:

«1914. Blick ins Ausland.> Was ist im Ausland passiert? Ich lese. (...)

Ah so, wie ich schon früher gesagt habe, die verschiedenen Staaten, die sind so miteinander verbandelt gewesen mit Bündnisverpflichtungen (...), dass ja fast (...) klar gewesen ist, dass da ein grosser Krieg daraus hat werden müssen. (...) Unglaublich.» (P25, Absatz 40-41)

Die beschriebenen Einschätzungen als «[u]nverständlich»(P18, Absatz 18) und «[u]nglaublich» (P25, Absatz 41) wurden in diesem Fall als negative Urteile gewertet, fallen aber in den im vorigen Kapitel beschriebenen Grenzbereich, in denen Äusserungen von Unverständnis und weitere negative Urteile unmittelbar ineinanderfliessen und nicht immer trennscharf zu unterscheiden sind. Sich auf denselben Text beziehend, äussert P19:

"Ja, kurz erklärt, wie es zum Kriegsausbruch gekommen ist. (...) Ja, es ist ganz kurz dargestellt, auch da auf der Weltkarte, wer zu wem gehört hat. Finde ich jetzt, ja, ist ein bisschen dïrftig, weil doch noch sebr viele andere Faktoren mitgespielt haben, aber so für einen guten $\ddot{U} /$, kurzen Überblick langt es sicher mal. Da fehlt es ein bisschen, dass, Deutschland hat ja Belgien überfallen, und das ist ja der ganz grosse (...), das ist ja der ganz grosse Skandal gewesen, auch weil die Bibliothek in Leu, Leuwen ja Raub von Flammen geworden ist. [...]»(P19, Absatz 45)

Mit dieser Aussage äussert P19 ein ausstellungsbezogenes sowohl zunächst negatives als auch dann positives Urteil, wobei zugleich deutlich wird, dass in sein Urteil über die Darstellung der Ausstellung auch Wissen über historisches Geschehen einfliesst, mit dem er die Darstellung der Ausstellung in Abgleich bringt. Es hätten, so P19, «doch noch sehr viele andere Faktoren» beim Kriegsausbruch eine Rolle gespielt, als dies von der Ausstellung dargestellt werde, wobei gerade der von P19 vermisste Überfall Deutschlands auf Belgien vom Ausstellungstext sogar angesprochen wird.

Einen in Bezug auf die Darstellung des Kriegsausbruchs bestehenden Mangel empfindet offenbar auch P27, allerdings ohne zu diesem Zeitpunkt bereits die 
Filminstallation oder den gezeigten Überblickstext zum Kriegsverlauf des Jahres 1914 überhaupt nachweisbar zur Kenntnis genommen zu haben.

"Also was ein bisschen feblt, ist der Hergang, (...) [geht zurück in den Vorraum und schaut sich um] (und) der ganze Hintergrund, WARUM es zum Krieg (kam). (...) Daswar in London ein bisschen (...), das war in London ein bisschen besser dargestellt.» (P27, Absatz 21)

Auffallend an dieser Äusserung ist, dass P27 eine weitere besuchte Ausstellung zum Ersten Weltkrieg, nämlich im Imperial War Museum in London, zur Sprache bringt und die beiden Ausstellungen miteinander vergleicht. Dass die Ausstellung «14/18» mit ihrer Perspektive auf die Situation der Schweiz während des Kriegs ein anderes Anliegen verfolgt und insofern die Betrachtungen des Kriegsgeschehens im Ausland notwendigerweise und absichtsvoll knapp gehalten werden, darauf kommen die zuletzt zitierten beiden Besuchenden nicht zu sprechen. Sensibel für die entsprechenden Konstruktionsbedingungen erweist sich hingegen P8, die/ der, wie weiter oben bereits zitiert, bereits eine «etwas zu simple Sinnbildung» (P8, Absatz 7) in der Darstellung der Kriegsursachen bemängelt hatte. ${ }^{1467}$

"Ah, das (...) ist hier relativ stringent durchgezogen, dieses Thema der sozialen Spaltung. Zum einen kulturell und zum anderen eher wirtschaftlich. Finde ich überzengend gemacht, wie da immer wieder darauf gewiesen wird. Im Grossen und Ganzen find ich auch schön den Schwerpunkt auf die Schweiz gesetzt und trotzdem immer (...) ein Blick auf das Globale, der natürlich stark vereinfacht sein muss in diesem Fall. Solange er nicht ganz so stark vereinfacht ist wie eben zu Beginn der Ausstellung, wenn es um die Kriegsursachen geht.» (P8, Absatz 57)

Nur ein Teil der Besuchenden reflektiert wie P8 explizit darüber, dass in Abhängigkeit von der Ausrichtung der Ausstellung bestimmte Themen ausführlicher thematisiert werden, andere wiederum notwendigerweise zu kurz kommen. Eine entsprechend sensible Aussage, verbunden mit einem positiven Urteil, findet sich auch bei P12:

1467 Siehe generell zur Sensibilität dieser Person für die der Ausstellung zugrunde liegenden Narrative auch die Brennpunktdarstellung in Abschnitt 8.6.2.1. 
"Das find ich auch noch gut, dass beschrieben wird, dass Italien an die, an der Seite der Alliierten in den Krieg eintritt und die Schweiz nun völlig von kriegfübrenden Ländern umgeben ist. Das ist eigentlich so ein kleiner Nebensatz, der eben, ja, wabrscheinlich so in einem anderen ausländischen Bericht nicht steben wïrde, aber eben für die Schweiz dieses Gefühl von Umzingeltsein.»(P12, Absatz 111)

Generell scheinen die regelmässigen «Blick ins Ausland»-Elemente bei den Besuchenden auf Wohlwollen zu stossen und als orientierende Hilfestellung aufgefasst zu werden. ${ }^{1468}$ Zugehörige Urteile fallen, abgesehen von den zuweilen als zu knapp bemängelten Darstellungen, überwiegend positiv aus, wohingegen das darin beschriebene historische Geschehen von den Besuchenden umgekehrt negativ beurteilt wird, teilweise auch unter Äusserung der weiter oben bereits behandelten negativen Emotionen, wie beispielsweise Betroffenheit und Entsetzen. Die nachfolgenden Beispiele aus den Besuchsverläufen von P19, P3 und P12 geben von dieser Bandbreite einen Eindruck.

"Italien tritt an der Seite der Alliierten in den Krieg ein, sodass die Schweiz nun ganz von kriegführenden Ländern umgeben ist. Bei Ypern setzen die Deutschen mit Giftgas eine neue schreckliche Waffe ein, die im Verlauf des Krieges rund 90000 Tote fordern wird. Auch die Schweizer Armee bereitet sich aufeinen möglichen Giftgaseinsatz vor. Ibre Bestände an Gasmasken bleiben aber bis zum Kriegsende bescheiden und reichen nicht für die gesamten Truppen.> (...)

Ja, das ist furchtbar, wenn man sich das vorstellt, Giftgas. Und, ist auch übel, wenn man da liest, dass nicht einmal, sie nicht einmal für jeden Soldaten eine gegeben hat, geschweige denn für die Zivilbevölkerung. (...)

Finde ich aber einen guten Blick. (...) So ein Jabr nach Kriegsbeginn, wie bat es ausgesehen rundum? (...) Ja und (...) verschiedene (...) ja, wie viele Leute da gestorben sind, bewegt einen, bewegt einen, wenn man das siebt, bm (seufzend).»(P19, Absatz 69-70)

"Dann 1917, Blick wieder ins Ausland. Das finde ich gut aufgemacht, so jedes Jabr, wo kurz dargestellt ist, was im Ausland passiert ist, oder?» (P19, Absatz 96)

1468 Vgl. hierzu auch Abschnitt 8.6.4. 
"Also Informationen kommen mehrfach vor, das beisst, das ist noch gut, dann kann man das auch in Rube zum Beispiel (...) die Karte nochmals ansehen, obne dass sie sich bewegt, das ist gut. Und hier ist eine gute Zusammenfassung über den Ersten Weltkrieg.» (P3, Absatz 29)

"Hier ist wieder ein internationaler Blick, so Zusammenfassung auf den Krieg, sebr gut gemacht.» (P3, Absatz 50)

"Ah, hier ist (wieder) Blick ins Ausland, also das ist jetzt schon Ende 1916. (...) Verdun ist hier erwähnt, mit diesen furchtbaren Stellungskriegen. (...) Die Seeblockade, es wird hier alles nochmals erwähnt. (...) Versorgungsengpässe auch in der Schweiz. (...)» (P3, Absatz 55)

"Also, nun denn, was ist denn hier? ‘Blick ins Ausland. Soldaten am Simplon vertreiben sich die Langeweile.> Das find ich jetzt schön, der Blick ins Ausland und der Blick gebt vom Simplon ins Ausland, nach Italien. Auch wenn hier urschweizerisch mit dem Schwingen Brauchtumspflege und, und Erholung zelebriert wird.» (P12, Absatz 137)

"Jetzt (swobbe) ich hier mal wieder rüber und wieder im Hintergrund die, also mittlerweile find ich diese Zitate richtig (...), wow, einfach so eine Hintergrund, der Hintergrundteppich. 〈Heimkehr im Oktober 1918. Die Läuse krochen noch an mir herum, und die Zivilisten ekelten sich vor mir. Ich war wie geläbmt vor Scham, und nun sab ich, dass auch andere Menschen micht anstarrten. Alfred (Kantorovicz)»» (P12, Absatz 176)

\subsubsection{Vorwissen und neues Wissen}

Einen Bereich im stärker kognitiv orientierten Spektrum von Relationen machen explizite Benennungen von Vorwissen oder neuem Wissen aus. Idealtypische Formulierungen für diese Kategorie lauten <ich wusste nicht, dass $\mathrm{x}$ ist〉, 〈ich weiss jetzt, dass $\mathrm{x}$ 〉, 〈mir ist $\mathrm{x}$ neu $>$ oder umgekehrt 〈ich wusste schon $\mathrm{x}\rangle,\langle\mathrm{x}$ ist bekannt〉, 〈x kennt man〉. Ebenso erfasst wurden Vorwissen verdeutlichende Kurzausdrücke im Stil eines 〈Ja genau〉 oder 〈eben〉. ${ }^{1469}$ Implizites Einbringen von Vorwissens-

1469 Abgrenzungsschwierigkeiten ergeben sich bei Kurzausdrücken wie «oh〉 oder «aha〉, die gleichermassen auf neues Wissen, aber auch auf Überraschung hindeuten können. Derartige Textstellen wurden gesamthaft dem Bereich Erstaunen und Eindruck zugerechnet und 
beständen ist in dieser Kategorie hingegen nicht beinhaltet, da die Systematisierung auf expliziten Verbalisierungen der Besuchenden fusst. Würde implizites Vorwissen erfasst, könnten beispielsweise auch sämtliche Bezüge auf die eigene Lebenswelt jenseits der Ausstellung, die die Besuchenden herstellen, ${ }^{1470}$ als Einbringen von Vorwissensbeständen aufgefasst werden.

Doch auch explizit im Sinn der oben genannten Varianten wird von nahezu allen Teilnehmenden während ihres Besuchsverlaufs Vorwissen und/oder neues Wissen genannt - bei manchen Besuchenden lediglich vereinzelt, bei anderen etliche Male. Zu den Besuchenden, die im Vergleich häufig eigenes Vorwissen oder Neuwissen thematisieren, gehören P18 und P21, deren Charakteristika ich im Rahmen von zwei Fallbetrachtungen darstelle.

\section{Im Brennpunkt: P18}

«Und da, das hab ich gewusst da von der chemischen Industrie (...), wie sie viel Farbstoffe produziert haben.» - Varianten von Vorwissen und neuem Wissen

P18 stellt während des Ausstellungsbesuchs immer wieder Bezüge zwischen den in der Ausstellung enthaltenen Informationen und eigenem Wissen her. Mit insgesamt einem Dutzend Nennungen gehört P18 neben P19 und P21 zu den Besuchenden mit relativ vielen expliziten Bezugnahmen auf ihre Wissensbestände.

Die von P18 hierfür gebrauchten Formulierungen sind im gesamten Besuchsverlauf auffallend einheitlich und folgen dem idealtypischen Muster ich habe gewusst, dass > oder ‘mir ist neu, dass`. Die folgenden Materialauszüge illustrieren diesen Befund. Angesichts der insgesamt doch überschaubaren Anzahl von Äusserungen zum Thema und mit dem Ziel, einen Eindruck vom thematischen Gesamtspektrum und der Struktur der Aussagen geben zu können, werden nachfolgend alle von mir gefundenen Äusserungen von P18 über eigenes Vorwissen und neues Wissen in der Reihenfolge ihres Vorkommens im Besuchsverlauf aufgelistet.

"Ja, das ist für mich neu (...), der Erste Weltkrieg habe ich im Sommer einige Filme gele/, gesehen und die Schrecken vom Krieg gesehen, und jetzt sehe ich da. (...) EBEN. Belle Époque, Woblstand, Ballettschuhe.»(P18, Absatz 4)

somit nicht als Ausdruck neuen Wissens erfasst. Siehe für derartige Abgrenzungen auch die jeweiligen Kategorienbeschreibungen im Anhang.

1470 Vgl. Abschnitt 8.7.3. 
"Und da, das hab ich gewusst, da von der chemischen Industrie (...), wie sie viel Farbstoffe produziert haben.» (P18, Absatz 5)

"Das hab ich da auch, das ist da für mich neu. (...) Dass eine Absistenz, eine Abstinentenbewegung im Ersten Weltkrieg entstanden ist. Soldatenstuben. (...) Das hab ich gewusst, da, der Schweizerische Verband Volksdienst, gibt's ja heute noch.» (P18, Absatz 20)

"Aber das ist für mich neu, dass doch schon im Dezember 1914 hunderttausend Soldaten wieder entlassen worden sind.»(P18, Absatz 26)

"Das hab ich auch nicht gewusst, dass die Wehrmänner erst 1918 Stablhelme bekommen haben.» (P18, Absatz 39)

«Hab ich nicht gewusst, dass da (...) schon den 〈Nebelspalter〉 gegeben hat.» (P18, Absatz 48)

"Aber da kommen mir die Bilder noch sebr bekannt vor! Aber, vor 50 Jahren, später, hat das bei meinen Grosseltern auf dem Bauernhof nicht viel anders ausgesehen.

Obwobl ich ja noch nicht so alt bin, aber das kommt mir noch sebr bekannt vor. (...) Auch noch in den 50er-Jabren hat es solche Pflüge gegeben mit einem Pferd.» (P18, Absatz 59-60)

"Ja, das ist mir neu, dass die Schweiz auch so viel Kriegsgewinnlerin gewesen ist, durch die Produktion.» (P18, Absatz 83)

"Das hab ich auch nicht gewusst, dass eigentlich die direkte Bundessteuer eigentlich eine Kriegssteuer gewesen ist.» (P18, Absatz 89)

"Das hab ich auch nicht gewusst, dass da Gemüsegärten entstanden sind aus (...) $\operatorname{der}($...) Not vom Ersten Weltkrieg.» (P18, Absatz 136)

Die Textstellen verdeutlichen, dass Vorwissen und neues Wissen von P18 in den allermeisten Fällen in Bezug auf historisches Geschehen geäussert wird, wie es sich auch generell bei P18 um eine stärker geschehens- als ausstellungsfokussierte Person handelt. Thematisch sind die Äusserungen dabei breit gestreut und weisen keine auffallenden gegenstandsbezogenen Häufungen auf. P18 erweist sich somit themenunabhängig als stark wissensorientiert. Er oder sie scheint den Ausstellungsbesuch als eine Gelegenheit zu verstehen, in der es um den Erwerb von neuem Wissen oder die Bestätigung von Vorwissen geht. 
Die Äusserungen folgen, wie eingangs angedeutet, einer ähnlichen Struktur. P18 entnimmt der Ausstellung eine Information, beispielsweise wie im letzten Beispiel einem Ausstellungstext die Information über Selbstversorgungsstrategien während des Ersten Weltkriegs, und konstatiert anschliessend, diesen Aspekt historischen Geschehens bereits gewusst zu haben oder nun zu wissen. Diese Struktur des Zustandekommens von Äusserungen über Vorwissen und neues Wissen ist typisch für das gesamte Datenmaterial und unterstreicht erneut die weiter oben bereits beschriebene Kleinschrittigkeit und Momentbezogenheit der Äusserungen beim Ausstellungsbesuch.

\section{Im Brennpunkt: P21}

\section{«Ich ïberleg mir, ob ich das alles schon wusste.» - Zur subjektiven Bedeutung von Wissensbeständen}

Auch P21 legt augenscheinlich viel Wert darauf, das in der Ausstellung Gezeigte in Abgleich mit dem eigenen Wissen zu bringen. Auch er oder sie spricht dann entweder davon, etwas bereits gewusst oder umgekehrt bislang noch nicht gewusst zu haben, jetzt aber zu wissen. Wie im Fall von P18 manifestieren sich diese Äusserungen auch bei P21 in Form von kleinen, satzweisen Einschüben, wie etwa in den folgenden zwei Beispielen, jeweils nach dem Lesen von Bildquellenbeschriftungen oder Ausstellungstexten:

«Banernbuben mit Zaumtieren vor der Käserei in Ursenbach». Ich weiss nicht, wo Ursenbach ist. 'Armee-Käselager in Sursee'. Ich wusst' nicht, dass es ein Armeeküselager der/.»(P21, Absatz 50)

«Skagerrak», das kannte ich nicht.» (P21, Absatz 63)

Im Gegensatz zu P1 8 gehen Bezüge zu Wissensbeständen bei P2 1 allerdings nicht mit einer fast ausschliesslichen Geschehensfokussierung einher. Vielmehr finden sich bei P2l auch ausstellungsbezogene Wissensäusserungen. So bezieht sich ein Teil der Äusserungen von Vorwissen und neuem Wissen auch auf die in der Ausstellung gezeigten Quellenbestände. P21 äussert sich dann dazu, bestimmte Elemente bereits einmal oder umgekehrt noch nicht gesehen zu haben:

"Grenzposten auf dem Umbrailpass . Ich denke, dass ich dieses Bild schon einmal gesehen habe.» (P21, Absatz 40) 
"Solche Gegenstände hab ich dort in meinem, in dem Elternhaus meiner Mutter auch schon gesehen.» (P21, Absatz 6)

"Ich freue mich, gewisse Exponate zu sehen. Zum Beispiel Essensrationenmarken hab ich noch nie in echt gesehen.» (P21, Absatz 9)

Über Wissen zu verfügen, scheint für P21 bedeutsam zu sein, wie im zuletzt genannten Beispiel und auch in weiteren Passagen zum Ausdruck kommt. So formuliert P21 an einer Stelle Freude darüber, Fachbegriffe aus einem Ausstellungstext zu kennen:

"Ich lese wieder den Text. (...) Ich habe vor etwa einem Jahr nachgeschaut, was genau eine Garnisonsstadt ist, ich freue mich jetzt, dass ich das weiss beim Text. Ich weiss auch, was ein Defilee ist.» (P21, Absatz 10)

Darüber zu reflektieren, ob er oder sie etwas weiss oder nicht, erweist sich als bedeutsam für P21:

"Ich lese hier den Text. (...) <Mit der Unterzeichnung des Waffenstillstandes vom Compiègne am 11. November 1918 endet in Europa ein Krieg, der die Welt grundlegend verändert.> (...) Ich ïberleg mir, ob ich das alles schon wusste.» (P21, Absatz 97)

Eigenes Nichtwissen ist für P21 hingegen offenbar irritierend. So beunruhigt sie oder ihn die Feststellung eigenen Nichtwissens an einer Stelle offenbar derart, dass er oder sie ein Thema einige Momente später nochmals aufgreift und dann äussert, einen Freund nach dessen Wissen zum Thema befragen zu wollen:

"Ich lese hier über die SSS. ‘Für die im Herbst gegründete Überwachungsgesellschaft der Entente bald mit souverainété suisse suspendue gleichgesetzt.> (...) Zwangssyndikate (...) SSS, da bab ich noch nie etwas davon gehört. (...) [...]

Ich denk immer noch an das SSS, dass ich darïber nie etwas wusste, das möchte ich auch mit einem guten Freund von mir besprechen, ob er etwas davon weiss.» (P21, Absatz 59 und 61)

In der derart hohen individuellen Bedeutung, die er oder sie dem eigenen Wissen zuschreibt, erscheint P21 damit im Kreis der untersuchten Personen auffällig. 


\subsubsection{Vermutungen}

Eine andere Möglichkeit, sich in Relationen zu historischem Geschehen oder der Ausstellung zu setzen, stellen Vermutungen dar. In den Äusserungen drückt sich dann aus, dass sich die Besuchenden in irgendeiner Weise über die Gültigkeit einer von ihnen gemachten Aussage im Unklaren sind oder diese lediglich annehmen bzw. für wahrscheinlich halten. Idealtypische Formulierungen für diese Kategorie lauten 〈ich vermute, dass $\mathrm{x}$ ist〉, 〈wahrscheinlich gilt $\mathrm{x}\rangle$, 〈vielleicht ist $\mathrm{x}\rangle$, 〈x könnte sein〉. Auch Adverbien wie 〈offenbar〉 oder 〈vermutlich〉 betrachte ich als Indikatoren für Vermutungen. Vermutungen kommen vor allem im Hinblick auf historisches Geschehen vor, jedoch auch in Bezug auf die Ausstellung und ihre Elemente. Nahezu alle Besuchenden äussern im Verlauf ihres Ausstellungsbesuchs Vermutungen, wobei auch hier individuelle Unterschiede bestehen und manche Besuchende lediglich vereinzelt, andere gar bis zu einige Dutzend Male Vermutungen im Verlauf ihres Besuchs äussern.

Wie gestaltet sich nun genau das Äussern von Vermutungen? Nachfolgend werden Textbeispiele gezeigt und gedeutet. Im Bereich der ausstellungsbezogenen Vermutungen äussern die Besuchenden beispielsweise Einschätzungen darüber, welche Rolle und Bedeutung bestimmte Elemente innerhalb der Ausstellung erfüllen, welches übergeordnete Themen sein könnten oder wie einzelne Ausstellungselemente miteinander in Verbindung stehen könnten:

"Aber gut, vielleicht kann man ja auch, ist das ja auch eine erste Irritation oder ein erster Überraschungsmoment.» (P12, Absatz 21)

«Da (...) sehr, sehr cool gestaltet, rund herum, wo es offenbar um Propaganda geht.» (P19, Absatz 46)

"Dann gibt's hier ja so einen Kreis, der vermutlich auf Nationalismus zielen wird, (wenn das) (...) wenn das Element so fortgefübrt wird.» (P8, Absatz 45)

"Ja, ‘238000 Soldaten im August 1914〉. [...] Ja ich nehme an, das bezieht sich auf die Soldaten, die damals gesamthaft im Dienst gewesen sind.» (P19, Absatz 19)

"Ich glaub hier ist der Hinweis, von wann die Quelle ist.» (P12, Absatz 32) 
Geschehensbezogene Vermutungen äussern die Besuchenden beispielsweise dann, wenn sie versuchen, Aspekte zu erklären oder zu begründen, die sie nicht durch die Ausstellung selbst erklärt finden. Ein Ausstellungselement, im Zusammenhang mit dem gleich mehrere Besuchende Vermutungen anstellen, ist ein Ausstellungstext zur Spanischen Grippe in der Schweiz, genauer die darin enthaltene Aussage, Männer im Alter von 20 bis 40 Jahren sowie die sich im Jura aufhaltenden Soldaten seien besonders stark von der Grippe betroffen gewesen. Diese Aussage veranlasst gleich drei Besuchende dazu, Vermutungen über mögliche Gründe hierfür zu äussern:

«Die Epidemie fordert in zwei Wellen 24500 Todesopfer, wobei Männer zwischen 20 und 40 besonders häuf/, häufig tödlich erkrankten.> (...) Warum das wobl? Vielleicht weil die am mobilsten waren in dem Alter und viel unterwegs und sowieso beim Dienst und viel ausser Haus. Nun denn.» (P12, Absatz 189)

"[...] Im Sommer 1918 sind die westlichen Landesteile stärker betroffen als die östlichen, die Grippe grassiert bei den im Jura stationierten Truppen besonders heftig.> (...) Wabrscheinlich wegen mangelnder Hygiene.» (P8, Absatz 78)

«Die Grippe grassiert bei den im Jura stationierten Truppen besonders heftig." Wabrscheinlich sind da die sanitärischen Gegebenheiten eben auch nicht so optimal gewesen, bei den Truppen, oder, die Unterkünfte einfach, ein Haufen Soldaten auf einem Fleck.» (P20, Absatz 113)

Eine weitere, nachfolgend zitierte Person beschäftigt sich ebenfalls mit den Opferzahlen, äussert allerdings keine zugehörigen Vermutungen, sondern stattdessen Irritationen und Fragen - ein Bereich, dem ich mich im nächsten Kapitel noch zuwenden werde:

"So viele Leute, die gestorben sind, hm. (...) Das ist krass, da fragt man sich, wie, ja wie Gott so etwas zulässt. (...) Wie so viele Leute gestorben sind. Und erstaunlich, dass ja Männer zwischen 20 und 40 besonders häufig gestorben sind. Wo die eigentlich am resilienzfühigsten täten (...).

Dass die westlichen Landesteile stärker sind als die östlichen, dass die im Jura stationierten Truppen besonders heftig ist. (...) Haha. (bitter) (...) Ist, ist krass, hm? Da fragt man sich, wieso dass das so ist, dass sogar geografisch stärker Zentren gegeben hat. (...)»(P19, Absatz 133) 
Einen Bereich von Vermutungen stellen auch Mutmassungen über in Bildquellen Abgebildetes und zugehörige historische Kontexte dar. Vermutungen über Bildinhalte finden sich etwa bei P20, wie weiter oben im Zusammenhang mit dem Identifizieren von bildlich Dargestelltem bereits eingehender vorgestellt. Auffällig an dieser Person ist, dass sich der Versuch des Identifizierens von Dargestelltem verknüpft mit dem anschliessenden Verifizieren oder Falsifizieren von Vermutungen durch Beiziehung von Bildbeschriftungen. Im nachfolgenden Beispiel zeigt sich dieses Muster. Für weitere Manifestationen des Musters verweise ich auf die erwähnte Falldarstellung. ${ }^{1471}$

"Auf dem nächsten Bild, das (...) das könnte auf dem Fischmarkt sein, bin aber nicht sicher, muss dann mal spicken. (...) Es ist Markt, man sieht da Körbe mit Gemüse, dann (...) Frauen in langen Röcken natürlich. Wie immer. (...)

Ab, nein, nicht auf dem Fischmarkt, sondern auf dem Marktplatz. (...) ‘Markt auf dem Basler Marktplatz. In den ersten Tagen nach Kriegsausbruch fand ein Ansturm auf die Geschäfte statt. Wer es sich leisten konnte, deckte sich mit Lebensmitteln ein.»» (P20, Absatz 10)

P20 behandelt somit Bildbeschriftungen als den Ort, der Auskunft darüber gibt, was auf einer Abbildung «tatsächlich» dargestellt ist, und insofern die zuvor geäusserten Vermutungen verifizieren oder falsifizieren kann.

Neben dem Identifizieren von bildlich Dargestelltem beziehen sich geschehensbezogene Vermutungen bisweilen auch darauf, ob ein für die Vergangenheit beschriebenes Geschehen wohl in der Gegenwart noch Gültigkeit hat, oder sie beziehen sich auf Unterschiede und Gemeinsamkeiten zwischen den Zeitebenen sowie auf überzeitlich Gültiges:

«1917 beschäftigt die Schweizer Industrie mehr als 30000 Personen für die Herstellung von Munition.> Da wird wabrscheinlich auch beute noch so, gell, mit Munition und Rïstungsindustrie.» (P12, Absatz 93)

«'Pikettstellung der Armee, der Pferde, Maultiere und Motorwagen». Also Motorwagen hat es dort sicher noch sebr, sebr wenige gegeben.» (P22, Absatz 19)

1471 Vgl. Abschnitt 8.6.3. 
"Ein Foto fällt mir auf, zum Teil ein bisschen unscharf, aber das wird (...) an den langen Belichtungszeiten gelegen sein, die man damals immer batte. Man hat mit den Holzkasten mit den Platten, (immer) abdecken, freigeben, wieder zudecken, hat man den Film belichtet. Und wenn sich halt da jemand auf dem Film, auf den Fotos bewegt hat, ist das natürlich auch unscharf geworden.» (P20, Absatz 18)

"Ja wabrscheinlich ist es auch dort wieder, dass (...) nicht (...) der streikt, der am Boden liegt, sondern dass der streikt, der von besseren Zeiten träumt.» (P5, Absatz 29)

\subsubsection{Fragen, Unklarheiten und Irritationen}

Eng verwandt und teilweise ineinander übergehend sind Äusserungen von Vermutungen auf der einen Seite, von Fragen, Unklarheiten und Irritationen auf der anderen Seite. Diese betrachte ich nun als letzten Teilbereich von Relationen. Diesem Bereich zugezählt habe ich explizite Formulierungen im Stil eines <ich

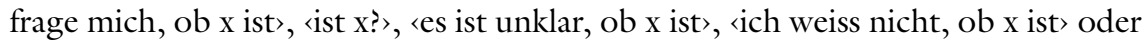
$\langle$ mich irritiert $x 〉$. Ebenfalls unter dieser Kategorie subsumiert wurden ausgedrückte Erwartungen bzw. Hoffnungen ( IIch hoffe, ich seh noch mehr von diesen Bildern", P12, Absatz 39).

Äusserungen von Fragen, Unklarheiten und Irritationen kommen im Datenmaterial ausgesprochen häufig vor. Im Vergleich mit den anderen kognitionslastigen Relationen, den Äusserungen von Vermutungen, Vorwissen und neuem Wissen, bilden sie den bei Weitem am häufigsten vorkommenden Modus und finden sich bei nahezu allen Besuchenden. In einem ersten, allgemeinen Eindruck lässt sich also festhalten, dass offenbar während des Ausstellungsbesuchs vielfach Unklarheiten, Irritationen und offene Fragen auftreten und dass die Besuchenden bereitwillig darauf zu sprechen kommen. Im Hinblick auf den zentralen Stellenwert, den das Fragen in Modellierungen historischen Lernens und Denkens ausmacht, ist dieser Befund anknüpfungsfähig, erschliesst sich aufgrund der Häufigkeit des Vorkommens gleichwohl aber noch nicht die Rolle von Fragen, die diese im Verlauf eines Ausstellungsbesuchs einnehmen und ob sie beispielsweise, wie theoretisch angenommen, als Ausgangspunkt oder Triebkraft historischen Denkens fungieren. ${ }^{1472}$

1472 Vgl. Abschnitt 2.2 und 2.5. 
In welchen Varianten treten nun Äusserungen von Fragen, Irritationen und Unklarheiten auf? Sie finden sich zahlreich sowohl in Bezug auf historisches Geschehen wie in Bezug auf die Ausstellung und ihre Elemente. In beiden Fällen lässt sich, wie bereits an mehreren Orten meiner Ergebnisdarstellung aufgezeigt, eine ausgesprochene Kleinschrittigkeit und Kurzlebigkeit des Sich-Äusserns konstatieren. Auch hier lassen sich die Besuchenden wieder überwiegend leiten von dem, was aktuell ins Blickfeld rückt oder gelesen wird, äussern sich dann knapp dazu hier nun im fragenden Stil - und gehen anschliessend zum nächsten Element über. Ich zeige nachfolgend einige Textbeispiele, die diese Knappheit der Beschäftigung verdeutlichen. Das Ende eines Zitats bedeutet hier zugleich das Ende der Beschäftigung mit der aufgeworfenen Frage bzw. den Übergang zu einem neuen Element.

«Kriegsfürsorgeamt Basel 1919〉. Wo ist denn das gewesen?» (P7, Absatz 88)

"'Bis Kriegsende beschafft die Armee zudem 100000 Gasmasken.〉 (...) Warum Gasmasken? Haben die Angst gehabt, dass (...)? Hm hm.» (P5, Absatz 24)

"Das ist schon interessant zu sehen, wie sich das entwickelt hat. (...) Da merkt man, dass eben nach Osten, oder (unv.) Afrika involviert war. (...) (Das Attentat von Sarajevo>, das weiss ich nicht so genau, bin mit der Geschichte nicht gut bekannt. (...) Das war dann einfach der, der Anfang.»(P30, Absatz 102)

«4200 Armeeangehörige kommen durch die Spanische Grippe»-hmpf, was immer das auch ist? - <andere Krankheiten oder Unfälle ums Leben [...])» (P20, Absatz 41)

"Neue Familiengärten an der Ache/, Ackerstrasse in Basel. Juli 1950, 15». Ackerstrasse, keine Abnung, wo das ist.» (P22, Absatz 84)

«Während Milch zu Beginn des Krieges noch im Überfluss produziert wird, besteht beim Brotgetreide von Anfang an ein krasses Missverbältnis zwischen Bedarf und Produktion. Nach Schätzungen des Bauernsekretariats deckt die Schweizer Produktion nur 16 Prozent des inländischen Getreidebedarfs. Im Krieg fallen mit den Zentral(städten) [eigtl. -staaten] zudem die Hauptlieferanten weg. Der Import beschränkt sich auf Getreide aus den USA. Die prekäre Importabhängigkeit fübrt zu Diskussionen über die Versorgungssicherheit des Landes. Man will die Milchbauern vermebrt zum Getreideanbau bewegen. Die 
Produktionsumstellung gestaltet sich jedoch schwierig. Das agrarische Wissen ist verloren gegangen.> Ich frage mich wobin? (...) Oder wer das genau verloren bat?» (P21, Absatz 55)

«5282 Handelsschiffe werden im Verlauf des Krieges versenkt und 10000 von Seemännern mit ihnen.> Ich frag mich eben, ob die Schweizer eben Handelsschiffe hatten, weil die Basler und der Rhein und die Handelstradition könnten ja nabelegen, dass sie schon welche hatten. Und was das wobl für sie bedeutete, das ist ja vielleicht, falls dem so wäre, wär das ja ein bisschen so wie diese Grenzverletzungen und Überflugmissachtung, die da weiter vorhin beschrieben worden waren.»(P12, Absatz 113)

«Tornister mit Vollpackung〉, 〈Gerollter Kaputt〉. (...) Was ist ein Kaputt?. (...) Gut, nebendran ist ein Bajonett.»(P27, Absatz 18)

«Der sogenannten Käseunion wird das Monopol im Käseexport sowie das Aushandeln und Festsetzen des Milchpreises übertragen. Das halbstaatliche Gremium versucht, die unterschiedlichen Preisvorstellungen der Milch- und Käseproduzenten, Händler und Konsumenten in Einklang zu bringen und die Milchkriege zu beenden. Die Käseunion ist die erste grosse kriegswirtschaftliche Massnahme der Schweiz, besteht bis Ende der 1990er-Jahre in leicht veränderter Form weiter.> Das ist ja (...) klasse, warum nur bis Ende der 90er-Jabre? Das wär jetzt noch nett gewesen zu erfabren.» (P12, Absatz 109)

Gelegentlich kommt es vor, dass mehrere Besuchende dieselben Unklarheiten in Bezug auf ein Element formulieren, wie nachfolgend P3 und P18 in Bezug auf eine Filmquelle, in der die Bereitstellung von Pferden durch Bauern und die Aufnahme dieser Pferde in die Armee darstellt:

"Jetzt müssen die Bauern noch die Pferde bringen, ist auch sehr eindrücklich. (...) Für den, also Krieg, für die Grenze. (...)

Also, ob die jetzt das freiwillig machen oder die einfach bringen müssen, das weiss man jetzt nicht so genau.» (P3, Absatz 39-40)

"Da ist mir nicht klar, haben da die Bauern einfach die, ibre Pferde abgeben müssen, obne Entschädigung, oder? Dann haben sie sie ja nicht mehr gehabt für (...) ibre, ibren Bauernhof, Landwirtschaftsbetriebe.» (P18, Absatz 31) 
Ebenso äussern sich zwei Besuchende ähnlich in Bezug auf eine Abbildung von Grenzbarrikaden:

«(Provisorische) Barrikaden am Zollposten zwischen Hegenheim und Allschwil». (...) Hm, ob das (gebalten) hat?» (P7, Absatz 14)

"'Provisorische Barrikaden.> (...) Na ja, sehr provisorisch. (...) Also ob das irgendjemand lang aufgehalten bätte. (...) Man weiss es nicht.» (P27, Absatz 17)

Im nachfolgenden Beispiel äussert P12 gleich mehrere Fragen in Bezug auf denselben Gegenstand in kurzer Folge. Zudem zeige ich das Beispiel deshalb, weil sich darin das Entstehen einer Unklarheit aus einem für P12 zunächst kurz klar erscheinenden Sachverhalt beobachten lässt:

«Was ist hier? 〈Der, der Zeit nachempfunden mit Dank an Herrn Dudler〉. Die erinnert mich an meine Schweizer Medizin, Sanitätskiste. Die ist ein bisschen gröber, diese hier, und viel kleiner. 〈Schwarze Gazebinde〉. Wieso ist denn die schwarz? Aus Schaffhausen. (...) Verband. Baumwollgewebe. Ja, davon hat's auch viel gebraucht, aber eigentlich, ich weiss gar nicht, haben die Schweizer denn überhauptgrosse Verwendung für Gazebinden haben müssen? Sie haben die Leute ja nicht wirklich zuhauf hoffentlich verpfle/, ähm, pflegen müssen.» (P12, Absatz 91)

Im Stil der bislang gezeigten Beispiele werden vielmals Fragen formuliert und in den Raum gestellt, ohne dass sie beantwortet würden. Werden hingegen Antworten gegeben, so geschieht dies auf mehrerlei Wegen. Bisweilen äussern die Besuchenden eigene Vermutungen - diesen Bereich habe ich im vorigen Kapitel bereits dargestellt. Häufig kommt ausserdem der Fall vor, dass die Besuchenden sich auf der Suche nach einer Antwort einem Text zuwenden, beispielsweise einer Exponatbeschriftung.

"da haben wir noch mal ein Foto, das zeigt uns was? (Maultierkolonne zieht durch das Wal/ ein Walliser Dorf. '14-'18>.»(P6, Absatz 15)

«Was sehen wir da? Da ist irgendeine Abbildung. Was zeigt das? (...) Ich les den Text: <Provisorische Barrikaden am Zollposten zwischen Hegenbeim und Allschwil. 1914. Bundesarchiv Bern.»» (P6, Absatz 10) 
"Ein grosses Bild von einer Fabrik (...) im Hintergrund (...). Was ist da bergestellt worden? Geben wir mal zu der Beschreibung.» (P25, Absatz 65)

«1914. Blick ins Ausland.> Was ist im Ausland passiert? Ich lese.» (P25, Absatz 40)

"Man muss den Frieden wollen, nicht nur mit Worten, sondern mit Taten und einem festen Willen.> Wer ist das gewesen? (...) Der GUSTAVE ADOR. (...) Aba. (...). Okay.» (P18, Absatz 12)

«Was haben wir hier? ‘Armee-Käselager in Sursee〉.»(P12, Absatz 108)

"Auf dem Bild sieht man ein Brotlager. Was hat es aufsich? (...) <Wäbrend Milch zu Beginn des Kriegs noch im Überfluss produziert wird, besteht beim Brotgetreide von Anfang ein krasses Missverhältnis.»» (P25, Absatz 71)

"Was sieht man hier? 'Auf die Nachricht des Waffenstillstandes versammeln sich die Menschen auf dem Platz (Saint François) in Lausanne, um das Ende des Kriegs in Europa zu feiern.' Ach klasse, Fabnen werden aus dem Fenster gehängt, die Masse ist da. Feblt nur noch, dass man irgendwelche Hüte in die Luft fliegen sieht.» (P12, Absatz 194)

Hin und wieder wird die Suche nach einer passenden Beschriftung zunächst fehlgeleitet, etwa in folgenden zwei Situationen des Ausstellungsbesuchs von P6:

«was zeigt denn das Foto? (...) 〈Das Album〉 (unv.), wo kann man denn hiev entnebmen, was das für ein Foto ist? 〈Koblekessel〉, 〈Hintergrund〉, ab ja, 〈Teuerungsdemonstration>, okay.» (P6, Absatz 4)

"Was haben wir da für ein Foto? Wo ist das? Ist das in Basel? (unv.) Ich lese den Text. 〈Mobilisierungsplakat zum Aufge/> Nö, das ist das. Das bezieht sich da drauf. Ach da ist die Beschriftung. <Urner Bataillon 87 beim Teilden/, beim Telldenkmal in Altdorf . Okay.»(P6, Absatz 15)

In beiden Fällen konsultiert P6 zunächst eine Beschriftung, die er oder sie jedoch als unpassend bzw. zu einem anderen Element gehörig einschätzt, und findet schliesslich eine für sie oder ihn passende Beschriftung. Vielmals dient das Aufsu- 
chen von Beschriftungen dem Identifizieren des Abgebildeten oder des Exponats, das sich vor dem/der Besuchenden befindet. Identifizieren scheint generell der Grundmodus zu sein, in dem sich geäusserte Fragen und Unklarheiten bewegen.

«So, was haben wir da? Ab〈Nebelspalter〉. Satiremagazin.»(P6, Absatz 22)

«Okay, was haben wir da? Verbandsstoffe.» (P6, Absatz 29)

«OHH, was ist das da? 〈Mission 21〉.» (P18, Absatz 135)

«Was haben wir da oben? Ah okay, Maggi-Flaschen.» (P6, Absatz 29)

"Was hab'n wir hier noch, ein Zierkissen. 〈Eine Erinnerung an die Grenzbesetzung Weihnachten 1914'. Sehr eindrücklich mit dem Baslerstab.» (P3, Absatz 15)

«Oh, was ist das? (...) Ah, Patronen. Schoki und Patronen.» (P18, Absatz 74)

Immer wieder zeigt sich hier ein Muster, in dem Besuchende Fragen stellen und die Ausstellungstexte und Exponatbeschriftungen offenbar als diejenigen Instanzen einschätzen, die Antworten auf diese Fragen geben können. Den Besuchenden gilt, so lässt sich feststellen, die Ausstellung bzw. gelten vielmehr die in ihr befindlichen Texte als diejenige Instanz und Autorität, die Aufschluss darüber geben kann, was man vor sich hat und wie etwas gewesen ist $\mathrm{t}^{1473}$ - dies, obschon in vielen Äusserungen, wie weiter oben dargelegt, durchaus auch eine Sensibilität für die Ausstellung als konstruierte Geschichte zum Ausdruck kommt.

$\mathrm{Zu}$ den Varianten, in denen aufgeworfene Fragen beantwortet werden, gehört auch, dass die Besuchenden beim Weiterlesen eher zufällig eine Antwort auf ihre Frage in der Ausstellung finden, ohne unbedingt danach gesucht zu haben:

1473 Diese Beobachtung ist inspiriert durch Befunde von Kohler in Bezug auf Texte (Kohler 2016, S. 208f.) und Maconald in Bezug auf Museen als Ganzes, die von Besuchenden als «autoritative Einrichtungen» betrachtet würden (Macdonald 2011, S. 246, darin Bezug nehmend auf «verschiedene Studien», namentlich genannt Usherwood et al. 2004, mir als Usherwood et al. o. J. vorliegend). 
«Farbmuster für (Ichio)chrom für den britischen Markt von der Firma Geigy». Ja (...) ob das wohl für, für die Militärfarben war, wabrscheinlich schon, John Geigy (...), Coronation edition, aniline color〉. 〈Farbmuster zur Prüfung der Farbechtheit〉. 〈Farbmuster〉. Das wär natürlich klasse jetzt noch hier zu erfahren, 〈für Sport und Militärtuche〉, genau, da baben wir ja die Erklärung (...) für die Militärfarben, und die ist vom, von, von der Firma bzw. von Geigy, CibaGeigy, also Novartis, Basel, und dann (unv.) in Grenzach in Deutschland.» (P12, Absatz 218)

"Ist das ein Spiel? (...) Weiss man nicht. (...) Doch 〈Quartettspiel〉.» (P27, Absatz 19)

Im folgenden Beispiel formuliert P2 1 zunächst die Frage, ob der Bestand an Gasmasken in der Schweiz ausreichend gewesen wäre. Einige Minuten später beinhaltet ein Ausstellungstext die Antwort auf diese Frage, und P21 nimmt dies zur Kenntnis:

«(Bis) Kriegsende beschafft die Armee zudem 100000 Gasmasken.> (...) Ob das genug wäre, frage ich mich. (...)

[...]

$<$ Italien tritt an der Seite der Alliierten in den Krieg ein, sodass die Schweiz nun ganz von kriegfübrenden Ländern umgeben ist. Bei Ypern setzen die Deutschen mit Giftgas eine neue schreckliche Waffe ein, die im Verlauf des Kriegs rund 90000 Tote fordern wird. Auch die Schweizer Armee bereitet sich auf einen möglichen Giftgaseinsatz vor. (Ihre) Bestände an Gasmasken bleiben aber bis zum Kriegsende bescheiden und reichen nicht für die gesamten Truppen.> Das bab ich mir auch schon ïberlegt. Gasmasken haben einen sehr bedroblichen (...) Eindruck auf mich. (...)» (P21, Absatz 40 und 54)

P12, P27 und P21 machen in diesen Beispielen deutlich, nun doch noch die Antwort auf eine aufgeworfene Unklarheit gefunden zu haben. Im Gegensatz dazu formuliert im nächsten Auszug P25 eine Erklärung auf eine zuvor von ihm oder ihr aufgeworfene Frage, ohne diese Erklärung explizit mit der vorherigen Frage in Bezug zu setzen. Im Beispiel äussert P25 beim Lesen eines Ausstellungstexts zum Thema «Milch und Brot. Landwirtschaft im Umbruch» Erstaunen über den Käseexport der Schweiz in der Vorkriegszeit und fragt sich dann, warum man unter diesen Umständen überhaupt in Basel Hunger gelitten habe. Im gelesenen Text 
findet sich eine mögliche Antwort mit dem Hinweis, dass «[d]iese Import-ExportAbhängigkeit mit dem Kriegsausbruch zu einem Problem» wird, die P25 offenbar auch aufgreift und in freier Formulierung weiterführt, aber dabei nicht darüber reflektiert, dass es sich hierbei um eine mögliche Antwort auf die zuvor aufgeworfene Frage handelt.

«Ich bin ERSTAUNT zu erfabren (...), dass (...) schon vor dem Krieg viel Käse in die ganze Welt exportiert hat, und frage mich, warum dass man dann in Basel viele Leute hatte, die gehungert haben. (...) Mit dem Ausdruch, Ausbruch vom Ersten Ersten Weltkrieg ist natürlich (...) der Import und der Export weitgehend zum Erliegen gekommen. (...) Was andere Probleme gebracht hat. (...)» (P25, Absatz 60)

Die bislang gezeigten Beispiele lassen sich mehrheitlich dem geschehensbezogenen Spektrum von Äusserungen zuordnen. Vereinzelt war bislang zudem das Identifizieren von in der Ausstellung befindlichen Elementen sichtbar. Daneben werden im Bereich der ausstellungsbezogenen Äusserungen noch weitere Aspekte zum Gegenstand von Fragen. Etwa gilt dies für das Identifizieren von Ausstellungsthemen oder das Erschliessen von thematischen Zusammenhängen und Kohärenzen. Ich zeige nachfolgend eine kleine Anzahl zugehöriger Beispiele:

"Gut, (wie ist) das ist hier einsortiert, weil Pazifismus haben wir ja auch schon an anderen Stellen. (...) Gut, das ist wabrscheinlich, hm. (...) Einlüutung des Kriegsendes. Aber die Stimmen gegen den Krieg, die gabs eigentlich auch schon früher, also das versteh ich jetzt nicht ganz, warum das hier bei Kriegsende und Streik. Gut, Streik, da kann das schon irgendwie (...) dazu passen.» (P8, Absatz 64)

"Koblekessel mit einer kleinen Schaufel. Okay, da seb ich jetzt nicht ganz, wie das in die Narration passt.» (P8, Absatz 5)

«Da wird mir auch nicht ganz klar, warum jetzt dieses Bild an dieser Stelle bier ist. Neutralität wird ja an anderer Stelle eigentlich schon thematisiert.» (P8, Absatz 66)

"Auf Anbieb erschliesst sich mir jetzt nicht irgendwie, was es da für Themen gibt, so zumindest nicht auf den ersten Blick. Okay, das war, das waren die 
Frauen da drüben. Was haben wir denn da? Na ja, okay, das waren die (unv.) Arbeiter, glaub ich mal.» (P6, Absatz 13)

Für manche Elemente der Ausstellung fällt auf, dass dort gleich mehrere Besuchende Irritationen äussern. Dies gilt beispielsweise für zwei in der Ausstellung befindliche begehbare Rondelle, jeweils auf der Innen- und Aussenseite mit Ausstellungstexten und Bildquellen versehen.

Das erste der beiden Rondelle beinhaltete einen Ausstellungstext zum Thema «Propaganda und der Wille zur Einigkeit», der sich über die in die Schweiz gelangende ausländische Propaganda äussert. Im nachfolgenden Beispiel macht sich P19 Gedanken darüber, wie Ausstellungstext und die daneben befindlichen Abbildungen, schweizerische Propagandapostkarten, zusammengehören, und stellt eine mangelnde Kohärenz fest:

"Ja, (komm) vom Text her hab ich mir jetzt die Bilder da, die man da sieht, eigentlich, sagen wir mal, krasser vorgestellt. (...) Ja, Helvetia, die einigermassen wehrhaft da steht, empfinde ich jetzt nicht unbedingt als massive Propaganda. (...) Ja, Postkarte, die irgendwo die Wehrhaftigkeit symbolisiert. (...) Ja. (...) Da wird jetzt schon wieder so ein bisschen der Wehrwille motiviert, aber (...). Die Bilder zeigen jetzt nicht unbedingt das, was der Text vorher gezeigt hat, finde ich.» (P19, Absatz 48)

Hingegen bemerkt zum Vergleich P8, nun ohne explizite Formulierung einer Irritation, dass die in der Innenseite des Rondells vom Text angekündigten ausländischen Propagandapostkarten erst auf der Aussenseite des Rondells zu finden sind:

"Ach, das sind jetzt die ausländischen Propagandapostkarten, von denen drüben die Rede war (...), die die Neutralität stören sollten. 〈Hilfsbund für deutsche Kriegsfürsorge in der Schweiz〉 (...), 〈Verhöhnung der britischen Kolonialtruppen> (...). Das sind die klassischen Bilder, die dann wohl auch in der Schweiz verbreitet wurden. (...) Ah schön gemischt, die verschiedenen Propagandakarten, die ein relativ umfassendes Bild malen. (...)» (P8, Absatz 35)

Schwierigkeiten bzw. Irritationen bei der Einordnung dieses Rondells zeigen sich auch in den Äusserungen von P4, und auch diese Person stellt nachträglich fest, dass sich die Darstellung auf der Aussenseite des Rondells fortsetzt. 
"Ok, jetzt geh ich mal in die nächste (...) interaktive (schmunzelt) Sache, (oder wie nennt man das hier)? (...) [ab hier Neben-/Störgeräusche durch parallel laufendes Audiomaterial der Ausstellung] (...)

‘(Mit Kriegsbeginn werden die) Grenzen geschlossen.> (...) Okay, das (haben wir) schon gehabt. (...) 〈Propaganda〉. (...) 〈Die Mittelmächte (und die Entente) nutzen die Kriegspropaganda (...) und die damit verbundene Beeinflussung wie nie zuvor in einem militärischen Konflikt. (...) Neben Plakaten (und der Literatur) werden erstmals auch Filme eingesetzt.> (...)

〈Stark und frei in Not und Gefahr〉 ab okay, 〈Postkarten zur Grenzbesetzung〉. (...) Okay, mir ist es jetzt nicht ganz klar, warum das in so 'nem besondereren Raum (...) dargestellt wird. (...) Bei den (...). Beim Eingang hat mich das irgendwie (...) das hat mich gleich gepackt, aber hier (...) finde ich die Darstellung ein bisschen (...) zu überladen (...) für den Inbalt, oder? (...)

Ach so okay, das gebt draussen noch weiter. (...) Auch noch eine Propagandapostkarte. (...) 〈Gegen die zentralen Mächte. (...) Ausländische Propagandapostkarte.> (...) 〈Deutsche Propagandazeitschrift, (...) französische Propagandazeitschrift, (...) humoristische Karte von Europa.> (...) (schmunzelt) (...)» (P4, Absatz 38-42)

Wie für den Fall des ersten Rondells bereits von P19 geäussert, zeigen sich auch im Fall des zweiten Rondells Besuchende irritiert über eine aus ihrer Sicht fehlende Kohärenz zwischen Ausstellungstexten und Abbildungen. Im Rondell befindlich, wo in einem Ausstellungstext von der zunehmenden staatlichen Einflussnahme auf wirtschaftliche Prozesse die Rede ist, während die nebenstehenden Bildquellen Szenerien der Soldatenhilfe zeigen, äussert etwa erneut P19:

"Da frage ich mich, wie, wie genau die Bilder, was genau der Zusammenbang ist mit den Bildern, zwischen Bilder und Text. Im Text ist es ja mehr um die verschiedenen Ämter gegangen. Und da (...) hat man das Gefübl, ja, die Bilder betreffen mehr so Hilfsorganisationen. Und ich frage mich, ob das dann auch Frauen von, gewesen sind, die zum Beispiel für ein Amt gearbeitet haben oder ob (...), weil da heisst es ja, für ein Hilfswerk, oder, ja, frage ich mich, wie die Sachen zusammengehören.» (P19, Absatz 86) 
Ähnlich zeigen sich auch P8 und P13 irritiert:

"Frauen betreiben Soldatenstuben, Frauen waschen und flicken. (...) Wie jetzt diese Bilder zu dem Text passen, leuchtet mir jetzt erst mal nicht ein. (...) Ist das nur meiner Müdigkeit geschuldet, oder, nee. (...) Eigenartig, gut.» (P8, Absatz 46)

"Das sind eigentlich alles Frauen praktisch. (...) Ist jetzt nicht ganz klar, was die Bilder mit dem Text zu tun haben, der mehr Zentralisierung und mebr Verwaltungstätigkeit. (...) Weil das jetzt Hilfswerke, die privat sind.» (P13, Absatz 49)

Auch hier befinden sich zugehörige Materialien und Texte teilweise wiederum auf der Aussenseite der Installation, wie etwa P28 nach Betrachtung der ebenfalls im Rondell hängenden Bundesratsbeschlüsse bemerkt:

"Und in der Installation mit (...) Bundesratsbeschlüssen zu allem Möglichen wird gut verdeutlicht, (...) dass (...) Kriegszeiten die Jabre der Exekutive sind. (...) und das kann ich nacblesen leider erst auf der Rückseite der Installation mit der Überschrift <Der Krieg zeigt Wirkung. (...) Das Parlament erteilt dem Bundesrat umfassende Vollmachten (...) mit rund 1000 Verordnungen (...) zur Einschränkung der Handels- und Gewerbefreibeit (...) und auch zur Einschränkung der Meinungsfreibeit.»»(P28, Absatz 69)

Ähnlich stellen auch P8 und P12 nach Verlassen des Rondells fest, dass der auf der Aussenseite befindliche Text zum darin Gezeigten passt:

«Der Krieg zeigt Wirkung. Wachsende Not. [fehlt: 〈um die〉] Kriegsbedingte Probleme bewältigen zu können, erteilt das Parlament dem Bundesrat gleich zu Beginn des Krieges umfassende Vollmachten. Je länger der Krieg dauert, desto mehr macht er davon Gebrauch.' Ja, das passt zu dem, was man da auf der anderen Seite siebt.» (P8, Absatz 50)

"Ja. Also, dass so die Bundesaufgaben sich weiterentwickeln. Das muss jetzt eigentlich reichen. Was ist denn hier zu sehen? Ach hier wär ja der Text gewesen. Das war jetzt auch nicht so sichtbar.» (P12, Absatz 134) 
Generell bekunden mehrere Besuchende Irritationen bzw. Fragen dahingehend, die Themen der beiden Rondelle zu identifizieren und einzuordnen:

"Ich stehe jetzt in der (...) rollenförmigen Installation, (...) zu welchem Thema kann ich nicht auf den ersten Blick erkennen, aber ich lese den Text <Die kriegsbedingten neuen Bundesaufgaben fübrten zu einem starken Anstieg (...) der Staatsausgaben.» (P28, Absatz 66)

"Okay, mir ist es jetzt nicht ganz klar, warum das in so 'nem besonderen Raum (...) dargestellt wird.» (P4, Absatz 41)

P8 schlussfolgert aus seinen Eindrücken mit dem ersten Rondell vermutend auf das zweite:

"Dann gibts hier ja so einen Kreis, der vermutlich auf Nationalismus zielen wird, (wenn das) (...) wenn das Element so fortgeführt wird.» (P8, Absatz 45)

Damit macht P8 deutlich, dass er oder sie eine mit der von der restlichen Ausstellung abweichenden ästhetischen Gestaltung der Rondelle zugleich eine abweichende inhaltliche Ausrichtung verbindet. ${ }^{1474}$ Auch P12 weist dem Rondell, nun dem ersten der beiden, eine eigene inhaltliche Bedeutung zu:

«Ich bin wieder hier im Propagandahafen.»(P12, Absatz 96)

Die Beispiele zeigen, dass die Besuchenden sensibel für die ästhetisch-inhaltliche Gliederung der Ausstellung und für Kohärenzen sind. Sie tun ihre Irritationen darüber kund, wenn Ausstellungstexte und zugeordnete Materialien aus ihrer Sicht nicht zusammenpassen.

Ein weiteres Beispiel dafür, dass mehrere Besuchende im Zusammenhang mit demselben Ausstellungselement Irritationen äussern, stellt die in der Abteilung «Vor dem Krieg» gezeigte Filminstallation mit den Filmen «Métamorphoses» und «La Peine du talion» aus dem frühen 20. Jahrhundert dar. Darin sind als Schmetterlinge kostümierte Balletttänzerinnen zu sehen. In diesem Zusammenhang beziehen sich geäusserte Irritationen nun darauf, dass die Besuchenden

1474 Vgl. zu diesem Phänomen auch Abschnitt 8.6.4. 
über den Sinn, Zweck und Stellenwert des dort gezeigten Films im Kontext der gesamten Ausstellung ins Nachdenken geraten. Manche Besuchenden beschränke sich entweder auf das Identifizieren oder äussern eher knapp die eigene Irritation:

"Okay. (...) So, was siebt man denn da an der Wand? (...) Keine Abnung. Ein Schmetterling.»(P6, Absatz 10)

"Ich lese 〈Vor dem Krieg〉. (...) Ich versuche herauszufinden, was es mit den Bildern von (...) einer Oper, oder was es dort hinten auf sich hat.»(P30, Absatz 100)

"Ein Metterschling. ${ }^{1475}$ (...) Hm. (...) Eigenartige Mode, oder ist das Kunst. (...) [betrachtet die Beschriftung] $\mathrm{Hm}$.

[...]

Das mit den Schmetterlingen versteh ich immer noch nicht.» (P27, Absatz 15 und 21)

Deutlich ausführlicher äussert sich hingegen P3 und denkt über den möglichen Zusammenhang der Quelle an dieser Stelle der Ausstellung nach:

"Ah, das ist schön, ein Filmchen. Ich schau mal einfach, Schmetterlinge, das passt nicht so ganz zum Ersten Weltkrieg irgendwie. (...) Es ist wie ein Gegensatz zwischen Krieg und (...) und Friede, aber ich schau mal noch genauer, um was es da geht, um Seidenraupen oder. (...) Ah das ist die Belle Époque, also (...) also la Belle Époque, Schmetterlinge, es hat hier jetzt gar keine Jahreszabl, und der Zusammenhang ist mir jetzt im Moment nicht ganz klar, aber es ist herzig gemacht mit de/ wie eine Raupe dann zum Schmetterling wird. Ah, hier steht vielleicht etwas.

Aha, vor dem Ersten Weltkrieg, genau (...) was da alles für ein Aufschwung ist, Verbesserung in Medizin und Hygiene, das hab ich grad beim letzten Test gefragt, warum die Bevölkerungsentwicklung so, also dass die Kurve so in die Höhe schnellt, wie's jetzt hier auch alles gezeigt, geschrieben (...) Eigentlich ist es ja schade, dass der Erste Weltkrieg da so ein' abrupten Stopp gemacht hat, dass

1475 Ein in einem Gedicht von Mira Lobe vorkommender Ausdruck für Schmetterling: Lobe/ Kaufmann 1996, ohne Seitenangabe. 
diese Belle Époque dann so abrupt aufhört. Was sie [die Schülerinnen und Schüler von P3, Anm. JT] sicher auch wissen ist, dass die Titanic vorher a/ da/ dazugehört zur Belle Époque. Das muss ich sicher vorher noch erwähnen, sonst wird das sehr seltsam, wenn da plötzlich Erster Weltkrieg so Schmetterlinge rumbüpfen. Warum da Schmetterlinge (schmunzelt), aber lustig gemacht, sehr lustig. Es ist schön wenn nicht alles nur so schwer ist.» (P3, Absatz 17-18)

Ebenso beschäftigt sich eine weitere Person, P12, eingehender mit dem Schmetterlingsfilm, dieser beschäftigt sie oder ihn sogar über den Verlauf des Ausstellungsbesuchs hin mehrfach. Obwohl das Formulieren von Fragen und Irritationen und zugehörige Antwortsuchen, wie oben geschildert, zumeist sehr kleinschrittig erfolgt, kommt es doch auch vor, dass Besuchende Fragen, Irritationen und Unklarheiten über den Ausstellungsbesuch hinweg mitnehmen und zu einem späteren Zeitpunkt oder gar an verschiedenen Stellen des Besuchs immer wieder auf ein Thema zu sprechen kommen. Um dies zu verdeutlichen gehe ich nachfolgend in einem Brennpunkt näher auf die Äusserungen von P12 ein. Das Beispiel ist überdies gut dazu geeignet, um ein Ineinandergreifen von geschehens- und ausstellungsbezogenen Irritationen und Unklarheiten aufzuzeigen.

\section{Im Brennpunkt: P12}

"Indirekt wird hier [...] eigentlich der Bogen geschlagen zu diesem immer noch ein bisschen kryptischen Schmetterlingsauftakt» - Aufgreifen von Irritationen und thematische Querverbindungen durch den Besuchsverlauf

Typisch für den Ausstellungsbesuch von P12 ist das Herstellen zahlreicher inhaltlicher Querverbindungen über die gesamte Ausstellung und Besuchsdauer hinweg. In der Häufigkeit und auch der Detailliertheit der bei diesen Querverbindungen angestellten Überlegungen ist P12 unter den 18 Besuchenden äusserst auffallend. Mitunter stehen die formulierten Querverbindungen im Zeichen einer Klärung von zunächst noch bestehenden Irritationen und Vermutungen - sowohl in Bezug auf bestimmte Ausstellungselemente als auch beschriebenes Geschehen.

Ein Querschnittsthema, auf das P12 während des Besuchs immer wieder zu sprechen kommt, ist die Emanzipation von Frauen während des Ersten Weltkriegs. Erstmals kommt P12 beim Aufenthalt in der Abteilung «Vor dem Krieg» darauf zu sprechen, wo er oder sie sich unter anderem mit dem dort projizierten Film «Métamorphoses» und einer Stele mit Informationen zu Else Züblin-Spiller beschäftigt. 
Über den Film zeigt sich P12 anfänglich irritiert und macht sich Gedanken zu dessen Funktion im Ausstellungsnarrativ. Über die anschliessende Beschäftigung mit der Figur von Else Züblin-Spiller und deren Wirken kommt er oder sie anschliessend jedoch zu einer Deutung in Bezug auf die Funktion des Films. Ich zeige nachfolgende eine längere Passage aus dem Datenmaterial, die diesen Prozess abbildet:

"Hm. Steh jetzt hier ein bisschen ratlos vor diesem Film, diesem Schmetterlings-, Metamorphose, weil ich mich eigentlich frage, was das jetzt hier so soll. Find ich zwar echt gut gemacht, wenn man so Tricks verwendete und optische Täuschungen hinkriegte, aber der Einstieg ist jetzt ein bisschen in medias res. Aber gut, vielleicht kann man ja auch, ist das ja auch 'ne erste Irritation oder ein erster Überraschungsmoment.

Ich kuck mir mal die Stelen hier an, konkret von der Else Züblin-Spiller, mit dem Text ‘Nach Kriegsausbruch fehlt es in der Schweiz an Massnahmen.> (...) <Uns Frauen schaltet der Staat sonst von jedem aktiven Dienst aus, nun aber schien die grosse Zeit auch uns eine besondere Aufgabe bereithalten zu wollen. Zitat Else Spiller.>

Hm. Erstaunt mich überhaupt nicht und zeigt schön auf, wie (...) wie in der Schweiz und speziell die Frauen in der Schweiz ganz offensichtlich Bürger zweiter Klasse waren, und hier schreibt Frau Spiller eigentlich ganz eindrücklich, wie sich hier ein Betätigungs- findet, ein Betätigungsfeld findet für die Frauen, die ja eben vom aktiven Dienst im Militär ausgeschlossen sind, und gleichzeitig ist es natürlich vermeintlich zutiefst weiblich, sich hier irgendwie in der Fürsorge zu engagieren und die tapferen Männer zu pllegen, wenn sie zu Hause sind, bzw. sie zu unterstützen in diesen Soldatenstuben. Aber eben, was so glaube eigentlich auch so seine kritischen Aspekte hat, und seine, seine fast schon kitschigen Seiten, trägt ja eigentlich dazu bei, dass Frauen sich emanzipieren und (...), ja, feststellen, welchen Beitrag sie hier eigentlich leisten.»(P12, Absatz 21-23)

Im Anschluss an diese Passage wendet sich P12 einigen anderen in der Abteilung befindlichen Elementen zu, unter anderem einer weiteren, dem Agronomen Ernst Laur gewidmeten Stele, und äussert dann:

"Finde ich jetzt spannend, dass hier der Blick auf die Bauern gelenkt wird, nachdem er in der anderen Stele auf die Soldaten gelenkt wird. Und irgendwie gucke ich immer noch rüber zu diesem Schmetterlingsfilm. Vielleicht sind die Schmetterlingsfrauen und diese Metamorphose, die da anklingt, ja auch gerade der Hinweis darauf, dass es der Krieg ist, der ein Riesenmeilenstein ist für die 
Emanzipation der Franen, weil sie zu Hause ihre Männer vertreten mussten, im Haushalt wohl weniger, aber eben bei den Kindern, und eben auch fürs Einkommen sorgen mussten, sowobl als Arbeiter rekrutiert, und mussten da buchstäblich ihren Mann stehen, und wie schwierig es dann für viele war, für viele Männer vor allen Dingen, von (...) jetzt nicht in der Schweiz (...) aber von der Front zu kommen und dann eine selbstbewusste Frau zu sehen, vielleicht gerade auch, jetzt in Zeiten nach dem Krieg, mit kurzen Haaren, und (...) und und und weniger üppiger, frauenbetonter Mode, die ein ganz nenes Selbstbewusstsein hatten und in Berufe drängten und das Wablrecht forderten und und und, und vielleicht vor diesem Hintergrund machen diese Metamorphosen Richtung Schmetterling Sinn. Auch wenn sie hier dann doch mit ibrem Auftreten, so ein bisschen Theaterbïhne und, ja, Konkonstil und Musical, doch eher dem traditionellen Bild entsprechen, aber ja, die Raupe zeigt sich wieder auf ibrem Blatt. Vielleicht, je länger, je mehr, könnte das vielleicht eine Erklärung sein.»(P12, Absatz 26)

P12 zeigt starkes Interesse für die Situation der Frauen sowie Emanzipationsmöglichkeiten während des Krieges und erweist sich als sensibel für genderbezogene Fragestellungen, wie beispielsweise aus der folgenden Äusserung hervorgeht, ebenfalls noch auf die Eingangsabteilung «Vor dem Krieg» bezogen:

«Fällt mir grad auf, dass es in diesen Stelen zwei Männer und zwei Franen sind. Das gefällt mir spontan sehr gut, wenn ich dran denke, wie das Schweizer Fernsehen im Sommer diese Serie und diesen Schwerpunkt zur schweizerischen Geschichte der letzten Jahrhunderte gemacht hat und dabei skandalöserweise einfach komplett die Frauen aussen vor liess. Ist das hier einfach schon mal sehr down to earth und schon mal sehr realistisch.»(P12, Absatz 36)

In dem Ausmass, in dem P12 eigene, freie Überlegungen zu den in der Ausstellung befindlichen Elementen anstellt, sie in den Ausstellungskontext und in ihren historischen und geschichtskulturellen Kontext einbettet, hierzu auf eigenes geschichtswissenschaftliches Wissen zurückgreift, ist er oder sie im analysierten Sample einmalig.

Oft greift P12 Themen im Verlauf des Ausstellungsbesuchs häufiger auf. So zieht sich das Interesse für die Situation der Frauen und deren Emanzipationsmöglichkeiten während des Ersten Weltkriegs wie ein roter Faden durch den Besuchsverlauf, und auch auf den irritierenden Schmetterlingsfilm kommt P12 in diesen Zusammenhängen noch mehrfach zu sprechen. Ich zeige nachfolgend solche Rückbezüge. Einen Ausstellungstext lesend, äussert P12: 
«Den Familien fehlt oft der Ernährer, denn die Webrmänner erhalten nur einen Franken dreissig Sold.> Also sie haben den Lobnausfall, der Mann ist nicht da, und der Sold ist auch noch jämmerlich. Hier kommt's. ‘Den wirtschaftlichen und sozialen Aspekten schenken sie jedoch kaum Beobachtung.> Das erinnert mich jetzt eben genau an diesen Auftakt mit diesen Stelen und auch diesen FrauenSchmetterlingen. (...)» (P12, Absatz 69-70)

Später nimmt P12 eine Bildquelle zum Anlass, um eine thematische Querverbindung zurück zum Eingangsbereich der Ausstellung zu schlagen, obwohl dieser Bezug durch die Bildbeschriftung gar nicht explizit angeregt wird:

"Und hier sieht man die <Verpackung von Schokolade bei Peter und Kohler in Arb'. Man sieht hier das Glitzerpapier, Papierverpackung von Nestlé. Dass das alles Frauen sind, die hier arbeiten. Das war ja genau eben dieses Thema, dass die Frauen sich hier eigentlich mit emanzipieren.» (P12, Absatz 94)

Und auch noch in weiteren Situationen stellt P12 Rückbezüge zur Eingangsabteilung her, erkennt nämlich, dass die dort vorgestellten Personen im weiteren Ausstellungsverlauf nochmals auftauchen.

«Frauen nähen Wäsche für Internierte in der Armee. Sanitätsanstalt Luzern. Der von Else Spiller〉, jetzt kommt unseve Frau aus der Stele wieder, 〈Der von Else Spiller bereits 1914 gegründete Verband Soldatenwobl betreibt während des Krieges Hunderte von Soldatenstuben. (unv.) Frauen verpacken für das Hilfswerk (pain quotidien) von Madame (Medwed)>, klasse, scheint auch eine russische Emigrantin zu sein, ‘Brot für Bedürftige in Genf. Soldatenstube in einer Konditorei in Pontresina〉. Die ist eindrücklich, diese Soldatenstube, im hintersten Eck der Schweiz, in Pontresina, sehr nett gemacht, und fast schon Kaffeehausstimmung. Also, wow, man hat hier wirklich sich angestrengt.» (P12, Absatz 131)

«Blick ins Ausland. Am 12. November 1918 weist der Bundesrat die Angehörigen der russischen Sowjet-Gesandtschaft aus Bern aus.> Unter anderem die Angelika Balabanoff, die Frau von der Stele vorbin.

Das ist eigentlich sehr spannend zu sehen, wie die (...), wie die Ausstellung am Anfang so exemplarisch in paar Sachen buchstäblich in den Raum stellt und an die Wand bängt, und dann nach und nach die Ausstellung die Informationen gibt und unterfüttert und ergänzt und vertieft und man mebr und mehr wirklich so einen, ein, ein, ein, einen Setzkasten hat, das man mit hier mit Wissen, Informationen füllt.» (P12, Absatz 178) 
P12 erweist sich durch diese Äusserungen einerseits als sensibel dafür, dass die Ausstellung solche inhaltlichen Querverbindungen herstellt, stellt aber auch selbst solche Querbezüge in Vielzahl her.

Schliesslich wird die Thematik der Frauenemanzipation von P12 nochmals ganz zum Ende des Ausstellungsverlaufs aufgegriffen. In der Abteilung «Nach dem Krieg» befindlich und sich dort mit der Stele zum Thema Frauenstimmrecht beschäftigend, stellt P12 fest, die Ausstellung schlage einen Bogen zurück zum Beginn, wodurch auch P12 selbst wiederum diesen inhaltlichen Bogen herstellt:

"Indirekt wird hier bei dem, bei der Stele zur Volksabstimmung, zum Frauenstimmrecht eigentlich der Bogen geschlagen zu diesem immer noch ein bisschen kryptischen Schmetterlingsauftakt zu Beginn der Ausstellung. (...)

Weil hier eben steht, vom gemeinnützigen Einsatz im Krieg erhoffen, eben genan diese Soldatenheime und, und, und ‘vom gemeinnützigen Einsatz im Krieg erhoffen sich die Franenrechtlerinnen die Anerkennung als Staatsbïrgerin. Die Linke forderte das Frauenstimmrecht im Landesstreik von 1918.> Und während in Deutschland in der Weimarer Republik die Franen sie auch bekamen, ging es hier eben noch lange, lange, und wurde na, na, na, was stebt hier? <alles verworfen', genau. (...) Und dann' '7l finalement. (...) Die Plakate sind, sind, sind (...) fast nicht zu glauben. ¿Überfremdungsinitiative. Unsere Franen, ein herzliches Ja am 7. Februar. Lasst uns aus dem Spiel. NEIN! Das glaub ich ja nicht. ¿Lasst uns aus dem Spiel. Man sieht hier die manikürten Finger von dieser Frau, Franenstimmrechtlerin. Das ist einfach. Muss man sich noch mal mit Musse glaub ich angucken.» (P12, Absatz 198-199)

In den vorgestellten Äusserungen von P12 vermischen sich geschehens- und ausstellungsbezogene Feststellungen. P12 nimmt einerseits Einbettungen historischen Geschehens vor, indem er oder sie über historische und geschichtskulturelle Hintergründe von Phänomenen spricht, diese miteinander vernetzt und Bezüge herstellt. Gleichzeitig ist P12 im selben Zug auch sensibel für die inhaltliche Struktur der Ausstellung und die darin befindlichen Kohärenzen, stellt nämlich auch fest, dass die Ausstellung ihrerseits solche Bezüge herstellt, indem sie

"am Anfang so exemplarisch ein paar Sachen buchstäblich in den Raum stellt und an die Wand hängt, und dann nach und nach [...] die Informationen gibt und unterfüttert und ergänzt und vertieft.»(P12, Absatz 178). 
Der Besuchsverlauf von P12 ist ein besonders auffälliges Beispiel dafür, dass Äusserungen von Besuchenden nicht in allen Fällen dem Prinzip des kleinschrittigen Abarbeitens folgen, sondern dass es durchaus auch Fälle geben kann, in denen Themen über den Verlauf des Besuchs mitgenommen und immer wieder aufgegriffen werden. Als Beispiel hiefür können auch die weiter oben vorgestellten Äusserungen von P20 dienen, der/die im Ausstellungsverlauf immer wieder selbsttätig auf Divergenzen zwischen Arm und Reich zu sprechen kommt. ${ }^{1476}$

\subsubsection{Die eigene Lebenswelt}

Im vorigen Abschnitt wurden Relationen behandelt, also Äusserungen, in denen die Besuchenden ihre Person in Bezug auf etwas sichtbar machen - Geschehen oder die Ausstellung - und die in der Logik des Kategoriensystems Überschneidungsbereiche zwischen zwei Fokussierungen darstellen. Nun wende ich mich einem anderen, genuin zum Fokus III gehörigen Bereich zu: denjenigen Äusserungen, in denen die Lebenswelt der Besuchenden sichtbar wird.

Alle Besuchenden machen im Verlauf ihres Besuchs ihre Lebenswelt sichtbar, jedoch auch hier wieder mit individuellen Unterschieden. Bei den meisten Besuchenden finden sich vereinzelte bis um ein Dutzend Lebensweltbezüge während ihres Besuchs, bei einzelnen Besuchenden allerdings auch zwei Dutzend oder gar mehr Lebensweltbezüge. Es muss in Betracht gezogen werden, dass Besuchende Lebensweltbezüge, selbst wenn ihnen diese in den Sinn gekommen sind, womöglich nicht grundsätzlich geäussert haben. Obwohl ich die Besuchenden dazu aufforderte, möglichst alles mitzuteilen, was ihnen während des Besuchs in den Sinn kommen würde, gibt es in den Äusserungen von P13 einen Hinweis darauf, dass er oder sie einen solchen Bezug womöglich nicht für mitteilenswert oder nicht zur Sache gehörig erachtet hat, eine begonnene Erzählung jedenfalls abgebrochen hat:

"Hm, spannend, dass eben die (...) Zweiseitigkeit aufgezeigt wird, eigentlich von (...) dass es ein humanitärer Antrieb gewesen ist, die Hilfe zu leisten, aber gleichzeitig eben auch den Handlungsspielraum vergrössert hat und das Ansehen im Ausland, und weil das Ansehen im Ausland steigt, eben auch die Handlungs-

1476 Vgl. Abschnitt 8.7.2.10. Ein weiteres Beispiel für die Wiederkehr eines Themas, die mehrfache Beschäftigung von P19 mit wirtschaftlichen Verflechtungen der Schweiz und deren Darstellung durch die Ausstellung, habe ich andernorts vorgestellt (Thyroff 2017b, S. 116, und Thyroff 2017c, S. 10). 
spielräume wieder (...) Mir kommt da in den Sinn, dass ich auch mal mit Leuten. (...) Ah, nein.» (P13, Absatz 64)

Tatsächlich gehört P13 zu den Personen mit den wenigsten sichtbaren Lebensweltbezügen. Im Gegensatz dazu entsteht der Eindruck, dass viele andere Besuchenden solche Bezüge durchaus bereitwillig äussern.

\subsubsection{Eigener Ort und Raum}

Eine häufig vorkommende Form der Lebensweltbezüge bilden Bezüge zum eigenen Ort bzw. Raum der Besuchenden. Als Raumbezüge wurden all diejenigen Äusserungen gewertet, in denen Besuchende über einen Raum sprechen und dabei deutlich wird oder bekannt ist, dass sie diesen selbst kennen. Oft sind dies Räume, in denen die Besuchenden aktuell leben, die sie aber mindestens im Lauf ihrer Biografie einmal kennengelernt haben. Beispielsweise äussern sie dann, dass sie einen in der Ausstellung vorkommenden Ort selbst kennen oder dass sie an einen eigenen Raum erinnert werden. Solche raumbezogenen Äusserungen finden sich bei mehr als der Hälfte der Besuchenden.

Was kennzeichnet diese Raumbezüge? Auffallend ist die folgende Äusserung von P30, weil er oder sie in dieser nicht nur einen Bezug zur Lebenswelt herstellt, sondern diesen Bezug auf einer Metaebene sogar selbst als «Bezug zum Alltag» identifiziert:

"Messe Basel. (...) Die Muba geht jetzt heute zu Ende. Da (merkt) man den Bezug zum Alltag. (...) (unv.) abgesehen, aber dieses schöne alte Gebäude ist nicht mehr da, zumindest nicht in der Form.» (P30, Absatz 91)

Häufig findet sich der Fall, dass Besuchende Orte entweder auf Bildquellen abgebildet oder in einem Text erwähnt finden und ausgehend davon feststellen, einen Ort zu kennen bzw. bereits dort gewesen zu sein. Insbesondere die Bildquellen der Ausstellung erweisen sich als Katalysatoren für das Herstellen räumlicher Lebensweltbezüge.

"Ich betrachte die Fotografien. (...) Hegenbeim und Allschwil, da war ich auch schon.» (P21, Absatz 28)

"Das ist zwischen Hegenheim und Allschwil, aber welcher der beiden Zollposten? Das sieht aus wie das (...). Klar, das ist, das ist der, an dem ich vorbeifabre.» (P12, Absatz 38) 
Viele Äusserungen beschränken sich, wie in den zuletzt angeführten Beispielen, darauf festzustellen, dass man einen bestimmten Ort kenne. Gelegentlich kombinieren sich die Aussagen damit, dass eine Relation zwischen Vergangenheit und Gegenwart vorgenommen und beispielsweise festgestellt wird, dass ein Ort ähnlich oder umgekehrt ganz anders ausgesehen habe, als man dies von heute kennt.

"Der Babnhof von Zürich sah noch ganz anders aus, als ich ibn heute kenne.» (P21, Absatz 33)

Auch im nächsten Beispiel wird eine Zeitdifferenz zum Ausdruck gebracht. P19 liest darin zunächst einen Ausstellungstext und äussert sich dann zu der darin erwähnten Befestigungsanlage auf dem Hauenstein, feststellend, dass heute noch «Reste davon» übrig seien, dass sie sich heute also in einem anderen Zustand als damals befindet.

"Mit Kriegsbeginn verschärft die Armee die Grenzkontrollen für Personen und Güter. Grenzübergänge werden mit improvisierten Barrikaden gesichert. Die Truppenaufstellung wird als Grenzbesetzung in das kollektive Gedächtnis eingeben. Sie besteht aus Überwachungstruppen im Grenzraum und Truppen in den Befestigungen Murten, Hauenstein und Bellinzona.> - Ja, Hauenstein kennt man beute noch Reste davon, die hab ich auch schon mal geseben - <die im Lauf des Krieges stark ausgebaut werden. [...].»» (P19, Absatz 37)

In den bislang angeführten Beispielen sind es jeweils sehr konkrete Orte, auf welche die Besuchenden Bezug nehmen, etwa Ortschaften rund um Basel, Städte oder bestimmte Bauten. Unspezifischer stellt sich der Raumbezug hingegen im folgenden Beispiel dar:

"Ja, das ist cool. Echt da Bilder aus dem Alltag. (...) Von Regionen, die man, von denen man weiss, wie sie heute ausseben.» (P19, Absatz 60)

Äusserungen der Besuchenden darüber, bestimmte abgebildete oder erwähnte Orte zu kennen, bilden einen wesentlichen Teil innerhalb der Bezüge zum eigenen Raum. Daneben gibt es Äusserungen, in denen die Besuchenden auch auf einen eigenen Ort Bezug nehmen, aber dessen Vergangenheit thematisieren. 
"Auf den Strassen wimmelt es von Reisenden und Soldaten.» Das erinnert mich an die Situation in [eigener Ort], da war das genauso.» (P6, Absatz 14)

Die Äusserungen innerhalb der Kategorie der räumlichen Lebensweltbezüge unterscheiden sich also dahingehend, wie explizit darin Bezüge zwischen verschiedenen Zeitebenen hergestellt werden und welche Zeitebenen dies sind. Ein weiteres Unterscheidungskriterium besteht darin, wie stark die Besuchenden explizit über die Bedeutung dieser räumlichen Lebensweltbezüge für sich selbst reflektieren oder diese eher implizit vornehmen. Die bereits gezeigten Beispiele stehen für eine Thematisierung von Raumbezügen ohne Reflexion über deren Bedeutung, die im Datenmaterial den überwiegenden Anteil ausmacht. Vereinzelt wird auch über die Bedeutung dieser Raumbezüge nachgedacht. So äussert eine Person, die Thematisierung von bekannten Orten «por der Tür» helfe ihm oder ihr dabei, "Kontext herzustellen»:

"Das ist schön, dass man den Marktplatz jetzt wieder sieht, um den Kontext herzustellen, vor allem (...) weil es ja vor der Tür liegt.» (P30, Absatz 11)

Nachdenken über die Bedeutung von räumlichen Bezügen findet sich des Weiteren auch bei P12. Dieser Person wird angesichts zahlreicher hergestellter räumlicher Bezüge nachfolgend eine Einzelfalldarstellung gewidmet.

\section{Im Brennpunkt: P12}

«Weil da macht's wirklich Geschichte noch mal evlebbarer, wenn ich dann an diesen Gebäuden oder, oder Zolliubergängen vorbeikäme heute und mich dann zurïckerinnere und so eine kleine Zeitreise machen kann»-Zur Bedeutung von Verortung und räumlichen Lebensweltbezügen

P12 interessiert sich in auffallender Weise für Orte, sowohl im Rahmen geschehensbezogener Aussagen (Fokus I) als auch im Rahmen der Bezüge zur eigenen Person (Fokus III). Erstens scheint P12 daran gelegen zu sein, historisches Geschehen zu verorten, also zu wissen, wo etwas gewesen ist und stattgefunden hat. Sofern er oder sie in der Ausstellung selbst nicht die gewünschte Angabe findet, äussert er oder sie entsprechende Fragen oder den Wunsch danach, gerne mehr zu erfahren. So finden sich etliche Passagen wie die folgenden: 
«Bauernbuben mit Saumtieren vor der Käserei in Ursenbach〉. (...) Das fänd ich jetzt noch nett, wenn hier noch stehen würde, wo dieses Ursenbach ist, zum Beispiel mit so einer kleinen Kantonsbezeichnung hinten dran. (...) Auf dem Bild selber seh ich das nicht. (...) Vielleicht ist das ja im Ursachental, und dann ist das irgendwie im Kanton Uri.» (P12, Absatz 108)

"Und was heisst's hier? ‘Aufmarsch zu einer Kundgebung während des Landesstreiks in Basel 1918>. (...) Das wär jetzt spannend zu sehen, wo, wo das jetzt in Basel ist. Beziehungsweise wenn ich genau hingucken würde, könnt ich's vielleicht, nee, ich erkenn's nicht. (...) Ich weiss nicht, wo es ist.» (P12, Absatz 181)

"Wo das wohl ist, das Hauptzollamt in Basel? Vielleicht beim SBB irgendwo, SNCF.» (P12, Absatz 51)

In diesen Textstellen, insbesondere der letztgenannten, manifestiert sich eine zweite Auffälligkeit in der Art und Weise, wie P12 über die Orte historischen Geschehens spricht, nämlich taucht Raum dabei auch als überzeitliche Grösse und als Parameter auf, bei dessen Thematisierung Grenzen zwischen den Zeitebenen verschwimmen, geradezu aufgelöst werden. Dieses Phänomen wurde weiter oben bereits beschrieben.

Die Bedeutung von Räumen und Verortung manifestiert sich bei P12 drittens auch in einer Vielzahl räumlicher Lebensweltbezüge. In der nächsten Passage, die bereits aus einem früheren Abschnitt bekannt ist, erkennt P12 einen in einer Bildquelle abgebildeten Zollübergang (vgl. Umschlagbild) als denjenigen, an dem er oder sie heute täglich vorbeifährt:

"Hier ist ein schönes schwarz-weisses Wandbild. Was seh ich denn hier? <Provisorische Barrikaden am Zollposten - Nein! - «zwischen Hegenheim und Allschwil 1914.

Das ist ja (...), jetzt bin ich aber platt. Weil ich fabre ja fast täglich an diesem Zollhäuschen hier vorbei. Ich versuch mich gerade zu orientieren. Das ist zwischen Hegenheim und Allschwil, aber welcher der beiden Zollposten? Das sieht aus wie das (...). Klar, das ist, das ist der, an dem ich vorbeifabre. Muss ich gerade am Wochenende mal gucken. Das Haus rechts scheint noch das gleiche zu sein. Die Bäume scheinen alle gefällt worden zu sein. Die Strasse ist breiter. Und ich frag mich, ob diese, dieses Gutshaus, diese Villa da rechts auf Allschwiler Seite, ja, was da wohl ist. Ich glaub, da ist heute alles Industrie und Wobngebiet.

(unv.) wohl da von der französischen Seite zu. (...) Das ist ja eindrücklich. Ich hoffe, ich seh noch mehr von diesen Bildern.» (P12, Absatz 38-39) 
Ausgehend von der eigenen lebensweltlichen Kenntnis des Ortes beginnt P12 in dieser Passage, anhand des Ortes über Unterschiede und Gemeinsamkeiten zwischen Vergangenheit und Gegenwart nachzudenken. Gewisse Elemente fänden sich auch heute noch, anderes wiederum sehe inzwischen anders aus. Zum Ende der Passage bezeichnet P12 das Bild als eindrücklich und äussert den Wunsch, mehr derartige Bilder zu sehen. Hier deutet sich bereits an, dass er oder sie die Möglichkeit zum Verorten historischen Geschehens und Verknüpfen mit der eigenen Lebenswelt schätzt, ohne an der Stelle weitere Ausführungen anzuschliessen.

Eine weitere Passage unterstützt diese Deutung. Dort führt P12 aus, dass Geschichte «erlebbarer» werde in dem Moment, wo er oder sie Orte aus der eigenen Lebenswelt wiedererkennt, was es ermögliche, «eine kleine Zeitreise» zu machen:

«Ist ein ‘Warenlager des Kriegsfürsorgeamts in Basel>. Wo das wohl war? ‘Staatsarchiv〉. Das wär noch nett gewesen, wenn irgendwo, das ist wahrscheinlich, $j a$ wenn irgendwo stehen würde, wo das, welcher Ort das ist, welche Adresse. Wabrscheinlich war das dieser Stadtplan, den ich da im Erdgeschoss beim Hinuntergehen noch mit einem Blick erhascht hatte, wo man glaub ich die Dinge so ein bisschen lozieren kann. Das fänd ich noch spannend heute, weil da macht's wirklich Geschichte nochmal erlebbarer, wenn ich dann an diesen Gebäuden oder, oder Zollübergängen vorbeikäme heute und mich dann zurückerinnere und so eine kleine Zeitreise machen kann.»(P12, Absatz 136)

\section{Im Brennpunkt: P6}

\section{«Brutal starke Parallele zu Deutschland» - Bezüge zum eigenen Raum}

Ebenfalls eine Reihe von räumlichen Bezügen findet sich bei P6. Auch hier betrifft die Bedeutung räumlicher Bezüge wie bei P1 2 sowohl die von der eigenen Person losgelösten, geschehensbezogenen Äusserungen als auch die Thematisierungen der eigenen Lebenswelt. Bei P6 handelt es sich um eine Person mit geschichtswissenschaftlichem Hintergrund, die in der süddeutschen Region Baden historisch tätig ist. Auffallend ist, dass P6 während des gesamten Ausstellungsbesuchs immer wieder Vergleiche zwischen der Situation in der Schweiz und der ihm/ihr bekannten Gegend in Süddeutschland oder allgemeiner Deutschland herstellt.

Die Äusserungen folgen stets einer ähnlichen Struktur: Ausgelöst von der Konfrontation mit einem in der Ausstellung befindlichen Exponat oder Text, formuliert P6 
einen Vergleich zum eigenen Raum und stellt fest, dass etwas dort gleich, ähnlich oder anders gewesen sei. Die folgenden Beispiele verdeutlichen dieses Muster:

«Lebensmittelmarken», ja die sehen sehr ähnlich aus wie die bei uns in [Ort].» (P6, Absatz 4)

"Nähstube für arbeitslose Frau, das ist ganz interessant, gab's in [Ort] auch.» (P6, Absatz 5)

« Auf den Strassen wimmelt es von Reisenden und Soldaten. ' Das erinnert mich an die Situation in [Ort], da war das genauso.» (P6, Absatz 14)

«Frauen nähen Wüsche für Internierte. In $\operatorname{der} A n /$, in der Armeesanitätsanstalt Luzern〉. Ach das evinnert mich an Deutschland. SSoldatenwobl betreibt Soldatenstuben', na das ja (dann) auch.» (P6, Absatz 37)

Im Stil der gezeigten Beispiele geht P6 mit der überwiegenden Anzahl der Äusserungen auf Gemeinsamkeiten bzw. Ähnlichkeiten zwischen der Schweiz und Deutschland respektive dem eigenen Ort ein. Feststellungen von Unterschieden tauchen demgegenüber kaum im Datenmaterial auf. P6 thematisiert diese als Unterschiede trotz Ähnlichkeit, bezogen auf eine in der Schweiz aus seiner oder ihrer Sicht insgesamt weniger gravierende Betroffenheit durch den Krieg:

« Wachsende Not> Brutal starke Parallele zu Deutschland. Die Not wird grösser, allerdings ist's natürlich anders, den Text hab ich da nebenher schon gelesen, während ich die Tonstation gehört hab.» (P6, Absatz 35)

Und vor einer Reihe von Fotografien stehend, möglicherweise unter Bezug auf die dort zu sehende Abbildung des Aushebens eines Schützengrabens durch Schweizer Soldaten, formuliert P6:

"Sebr äbnlich die Bilder wie bei uns. Nur dass das da in einem lauwarmeren Stadium blieb.» (P6, Absatz 17)

Die in der zuletzt zitierten Textstelle gebrauchte Formulierung «bei uns» leitet über zu einer weiteren Form der Lebensweltbezüge, nämlich der Bezüge auf ein 〈Wir〉 bzw. 〈Uns〉 und damit ein eigenes Kollektiv. Dieser Variante von Bezügen gehe ich im nächsten Abschnitt nach. 


\subsubsection{Eigenes Kollektiv}

Einen weiteren stark vertretenen Teilbereich innerhalb der Bezüge zur Lebenswelt bilden neben den Bezügen zum eigenen Ort und Raum auch Bezüge zum eigenen Kollektiv. Als Indikator für die Zuordnung zu dieser Kategorie wurde die Formulierung ‘wir` oder «uns` verwendet, mit der sich Besuchende einem wie auch immer verstandenen Kollektiv zuordnen. Diese Form des Lebensweltbezugs ist im Vergleich zu den übrigen anders gelagert, weil Bezugsgrösse nicht die Besuchenden als einzelnes Subjekt sind, sondern sie sich vielmehr als Teil einer Gemeinschaft thematisieren und Bezüge zu diesem Kollektiv herstellen. ${ }^{1477}$ Mehr als ein Drittel der Besuchenden gebraucht derartige Wir-Formulierungen, teilweise nur vereinzelt, in auffallendem Mass demgegenüber P5. Eine Feinanalyse dieser Bezüge auf Kollektive hat im Wesentlichen drei verschiedene Varianten von Kollektiven ergeben, ${ }^{1478}$ zu denen sich die Besuchenden als zugehörig beschreiben, nämlich

a) ein überzeitliches, nicht schweizerisches, räumlich-abgrenzendes «Wir anderen dort>,

b) ein überzeitliches schweizerisches und teilweise räumlich-abgrenzendes «Wir in diesem Land,

c) ein zeitlich-abgrenzendes ‘Wir heute Lebenden`.

Diese drei Formen werden nachfolgend näher beschrieben und mit Beispielen veranschaulicht.

\section{Zu a) Wir als röumlich abgrenzende Grösse: 〈Wir anderen dort〉}

Eine erste Kategorie von Wir-Formulierungen bilden Äusserungen über ein Wir jenseits der schweizerischen Grenzen, konkret entweder ein badisches, deutsches oder konkret ortsbezogenes Wir. Diese räumliche Variante des Wir findet sich in den Äusserungen von P5 und P6, darunter überwiegend bei P5. Es handelt sich hierbei um zwei aus Deutschland angereiste Besuchende, die beide in einem badischen Ort in einem geschichtswissenschaftlichen Feld tätig sind.

1477 Für einzelne Passagen erscheint es möglich, dass dort «Wir» schlicht im Sinn eines Pluralis Majestatis eingesetzt wird, so etwa: "Kennen wir doch alles aus dem eigenen Militärdienst. Zwar zu einer anderen Zeit, aber (...) ja, damals schon so gewesen, heute auch noch immer so.» (P20, Absatz 2). Diese vereinzelten Fälle wurden mangels eindeutiger Einordenbarkeit ebenfalls als Bezüge zum eigenen Kollektiv erfasst.

1478 Neben vereinzelten Textstellen, die nicht zufriedenstellend zugeordnet werden konnten, weil die Konnotation des dabei verwendeten «Wir» nicht deutlich wurde. 
Die hier beschriebene Form eines Wir hat vergleichende Funktion. Die Besuchenden gehen von der schweizerischen oder Basler Situation während des Ersten Weltkriegs aus und äussern sich dazu, ob und inwiefern dies «bei uns» (P6, Absatz 4 ) genauso oder anders gewesen sei. Sich selbst positionieren die Besuchenden durch das Wir als 〈Wir andere dort〉. Das Wir hat in diesem Fall eine örtlichräumliche oder gar national-räumliche Distinktions- und Abgrenzungsfunktion. Diese Form des Wir ist verwandt mit den im vorigen Kapitel vorgestellten Bezügen zum eigenen Ort und Raum. Wenn neben den Wir-Formulierungen zudem der damit gemeinte Raum expliziert wurde, wurden entsprechend Doppelcodierungen von Passagen vorgenommen.

\section{Im Brennpunkt: P5}

\section{«Bei uns in Baden» - Bezüge zum eigenen Kollektiv}

Auffallend häufig finden sich Wir-Formulierungen bei P5, und zwar ausschliesslich in der Variante eines 〈Wir anderen dort). Sie tauchen auf, wenn P5 Vergleiche zwischen der Situation der Schweiz im Ersten Weltkrieg und der Situation in Deutschland, Baden oder dem eigenen Ort herstellt. P5 erweist sich als gut (lokal-) geschichtlich informiert und kann in etlichen Situationen und für etliche Themenbereiche selbsttätig Vergleiche herstellen.

Die folgende Textstelle entstammt der Anfangsphase des Ausstellungsbesuchs, in der sich P5 mit den in der Abteilung «Vor dem Krieg» porträtierten Personen, im konkreten Fall mit Else Züblin-Spiller, beschäftigt, und äussert:

"Spiller, den Namen kennt man. (...)<Nach Kriegsausbruch fehlt es in der Schweiz an Massnahmen, um den sozialen Folgen des Krieges und des Truppenaufgebotes zu begegnen. Diesem Missstand wirkt Spiller als Mitinitiantin und Leiterin des '14 gegründeten Schweizer Verbands Soldatenwohl entgegen. Die Soldatenstuben sorgen für eine alkoholfreie Truppenverpflegung. Die Wehrmannsfürsorge unterstützt die Familien armer Soldaten. Durch die Professionalisierung weiblicher Fürsorgetätigkeit erweist sich Spiller als Pionierin der Sozialen Arbeit. (unv.) Der Schweizer Verband Volksdienst umbenannte Organisation entwickelt sich zum grössten Anbieter im Bereich Betriebskantinen.> (...)

Bei uns gab es ja die zwei Richtungen der (...) Friedensbewegung (...) unter den Frauen. Die einen (...) die Bürgerlichen, die das Wobl der Soldaten im Auge batten und sie versorgten und schauten, dass sie wieder (...) Soldaten wer/ äh 
bleiben können, und die anderen, die das ablehnen, (die lehnten), zu denen auch die sozialistischen Frauen gehören, und die (eben) solchen Dienst am Soldaten ablehnen. Die Soldaten sollten nicht wiederhergestellt werden, um weiter ihren Kriegsdienst tun zu können. (...) Da hat's die Spiller einfacher. (...) Die braucht nicht zu unterscheiden.» (P5, Absatz 10-11)

Im zitierten Beispiel vergleicht P5 also Friedensbewegungen bzw. Initiativen zur Soldatenhilfe und berichtet, dass es im eigenen Kollektiv ( «Bei uns») zwei Varianten gegeben habe, während die Situation in der Schweiz bzw. konkret für Else Züblin-Spiller eindeutiger gewesen sei. P5 stellt also eine Unterschiedlichkeit der Situationen fest. Auch an anderer Stelle vergleicht P5 die Formen von Soldatenhilfe, ausgehend von einer Bildbeschriftung:

«Bürgerliche Franen verpacken für das Hilfswerk Pain quotidien Brot für Bedürftige in Genfs (...) (Die unseren) waschen und flicken und schicken's an die Soldaten.»(P5, Absatz 91)

Auf welches Kollektiv P5 mit «(Die unseren)» Bezug nimmt, ob es in diesem Fall ein nations-, regions- oder ortsbezogenes Kollektiv ist, geht aus der genannten Textstelle nicht eindeutig hervor. Ähnlich ist dies im folgenden Beispiel:

"Aus Angst vor bolschewistischen Umtrieben weist der Bundesrat im November die Mitglieder der sowjetischen GESANDTSCHAFT aus (...) und setzt mit dieser Massnabme ein deutliches Zeichen nach innen.> Aha? (...) Ist ja kaum zu glauben. (...) Die haben Angst vor ihren eigenen Demonstrationen. Aber der bolschewistische Sozialismus bat ja nie eine grosse Rolle gespielt, auch bei uns nicht.» (P5, Absatz 47)

An anderen Stellen lässt sich das Kollektiv, auf das P5 Bezug nimmt, eindeutiger erschliessen. Dabei wird deutlich, dass es nicht immer dasselbe Kollektiv ist. Vielmehr finden sich mindestens drei Varianten von Kollektiven, denen sich P5 zuordnet.

Zum einen spricht P5 von der Region Baden und gebraucht Formulierungen wie «bei uns in Baden» (P5, Absatz 59) oder «in unserem Baden» (P5, Absatz 21), nämlich hier:

"Angeblich ist ja im Zweiten Weltkrieg die Arbeitslosigkeit wenigstens in unserem Baden NICHT wesentlich angehoben worden.» (P5, Absatz 21) 
In einer anderen Textstelle steht dann mutmasslich ein nationales Kollektiv im Zentrum, wie sich implizit aus der Äusserung erschliessen lässt, Kolonien hätten "wir auch gehabt» (P5, Absatz 105):

"Das ist (...)<kriegführende Staaten Ende '15〉. Aufseiten der Mittelmächte Österreich-Ungarn (...). Was ist mit der Türkei? Ach ja, die haben ja grosse Anteile vom Sinai gehabt, osmanisch (...). Na und ein paar Kolonien baben wir auch gehabt.» (P5, Absatz 105)

Eine dritte Form von Bezugskollektiv bildet die städtische Gemeinschaft. Dies zeigt sich in einer Textstelle, in der P5 von einem spezifischen Geschehen «bei uns (...) um das Rathaus» (P5, Absatz 44) berichtet.

Es lässt sich somit festhalten, dass P5 wechselweise auf mindestens drei verschiedene Kollektive Bezug nimmt, die mit einem wechselnden Grad von Explizitheit umgrenzt werden. Diese Kollektivformulierungen treten dann auf, wenn P5 räumliche Vergleiche anstellt und ausgehend von einer Beschäftigung mit der Situation der Schweiz oder Basels im Ersten Weltkrieg berichtet, dass etwas «[b]ei uns» (P5, Absatz 11) genauso oder anders gewesen sei.

Keineswegs immer dienen die in dieser Kategorie beschriebenen Wir-Formulierungen der Feststellung von Unterschieden. Ganz im Gegenteil werden von P5 und P6 in vielen Fällen Parallelen und Ähnlichkeiten zwischen den Situationen konstatiert. So äussern etwa beide ganz ähnlich in Bezug auf die in der Ausstellung gezeigten Lebensmittelmarken:

"Lebensmittelmarken», ja die seben sehr ähnlich aus wie die bei uns in [Ortsname].» (P6, Absatz 4)

"Ach die Marken, die Essensmarken, ja, die hat es bei uns in Deutschland auch gegeben.» (P5, Absatz 6)

Ähnlichkeiten und Gemeinsamkeiten werden auch in den folgenden Beispielen festgestellt:

"Jawoll, das Giftgas. (Ne) das wird auch bei uns produziert. (...)» (P5, Absatz 101) 
«Kriegsende und Streik. (...) Die Lebensmittel werden ständig knapper und teurer, und die Verbitterung in der Bevölkerung zeigt sich in Demonstrationen und Streiks. Bürgertum und Arbeiterschaft stehen sich immer unversöbnlicher gegenüber.>

Es ist ja auch so (...), dass das Bürgertum eigentlich (...) bei uns (...) der ideologische Träger war. (...) Die Avbeiterschaft will eigentlich das Gegenteil (...), die waren mit der SPD verbunden, die sie (innen) rubig gehalten haben.» (P5, Absatz 27)

«Die Arbeiterschaft empfindet diesen Militäreinsatz gegen die eigene Bevölkerung als Provokation> - wie die unserigen auch, das ist defätistisch [...]» (P5, Absatz 35)

Jedoch stellen die Besuchenden, wie oben gezeigt, durchaus auch Unterschiede fest bzw. wägen die Situationen ab:

"Sehr ähnlich die Bilder wie bei uns. Nur dass das da in einem lauwarmeren Stadium blieb.» (P6, Absatz 17)

Unabhängig davon, ob letztlich Unterschiede oder Gemeinsamkeiten festgestellt werden, drückt diese Form des Wir eine Unterscheidung von räumlich abgegrenzten Kollektiven aus.

\section{Zu b) Wir als überzeitliches, schweizerisches Kollektiv}

Die zweite Variante ist ein Wir, das ein schweizerisches Kollektiv bezeichnet und dabei ein vergangenes und gegenwärtiges Wir integriert, also ein überzeitliches schweizerisches Wir meint. ${ }^{1479}$ Die nachfolgende Formulierung von P3 steht nahezu idealtypisch für dieses Phänomen. Er oder sie äussert, konfrontiert mit den in einem Ausstellungstext geschilderten Gewinnen von Schweizer Unternehmen durch sich neu erschliessende Märkte:

1479 Eine Spielart des überzeitlichen «Wir» findet sich auch in den weiter oben gezeigten Äusserungen von P5, dort allerdings bezogen auf ein ausserschweizerisches, überzeitliches «Wir». So spricht auch P5 von einem «Wir» und «Uns» zur Zeit des Ersten Weltkriegs (z. B. P5, Absatz 47, 105), also von einem «Wir» zu einer Zeit, als er/sie selbst von Alters wegen nicht lebender Teil dieses Kollektivs gewesen sein kann. 
«Vielleicht wollen wir das nicht so gerne sehen, dass wir da profitiert haben vom Krieg.»(P3, Absatz 13)

Die zitierte Textstelle vereint implizit zwei Wir-Konstrukte: ein vergangenes und ein gegenwärtiges Wir, wobei Ersteres vom Krieg "profitiert» hat, das jetzige dies «nicht so gerne sehen» will. Indem P3 in beiden Fällen von «wir» spricht, zeichnet er oder sie das Bild einer zeitüberschreitenden Gemeinschaft, die damals schon und heute immer noch existiert. Dabei stellt er oder sie durchaus eine Zeitdifferenz und eine Entwicklung zwischen beiden fest, wenn er oder sie bemerkt, dass ein heutiges Wir möglicherweise Schwierigkeiten im Umgang mit dem Handeln des vergangenen Wir hat. Indem P3 in beiden Fällen von einem «wir» spricht, entwirft er oder sie gleichwohl das Bild eines zeitübergreifenden Wir und schreibt sich selbst als Teil dieses Kollektivs ein.

Einer ganz ähnlichen Struktur folgt eine Äusserung von P19:

"Ja, es zeigt sich das doch, dass das Land sehr unvorbereitet in den Krieg gegangen ist und dass (...) der Krieg, auch wenn wir nicht direkt betroffen gewesen sind, zu einer starken Armut in der Bevölkerung geführt haben und (...), wo wir dankbar sein können, dass wir von dem verschont sind heute.» (P19, Absatz 8)

Auch in diesem Beispiel ist an zwei Stellen von «wir» die Rede, wobei das erstgenannte ein vergangenes, das zweitgenannte ein heutiges Wir bezeichnet. Auch hier wird eine Zeitdifferenz festgestellt. So sei das vergangene Wir von «einer starken Armut» betroffen gewesen, und das heutige Wir könne froh darüber sein, "pon dem verschont» zu sein. Gleichwohl spricht auch diese Person für beide Zeitebenen von einem «wir» und erzeugt damit das Bild eines zeitüberschreitenden, überzeitlichen Kollektivs.

In beiden zitierten Beispielen sprechen die Besuchenden von einem vergangenen Wir, ohne von Alters wegen selbst Teil desselben gewesen zu sein, imaginieren sich aber sprachlich als Teil dieser Gemeinschaft. Beispielhaft dafür steht auch die folgende, strukturähnliche Äusserung einer weiteren Person:

"Menschen kehrten heim mit stillen, staunenden Augen, in denen der Tod sich noch spiegelt.> (...) Ja (...). Können wir froh sein, dass wir von dem Krieg verschont worden sind.» (P20, Absatz 81) 
Gerade das letztgenannte Beispiel legt den Schluss nahe, dass hier ein schweizerisches Kollektiv gemeint ist, auf das Bezug genommen wird, nämlich ein Kollektiv, das "pon dem Krieg verschont» worden ist. Auch im nächsten Beispiel wird deutlich, dass hier von einem schweizerischen Kollektiv die Rede ist, dort als ein Kollektiv, das durch grosse Gegensätze zwischen Deutsch- und Westschweiz geprägt ist:

"Finde ich eindrücklich, wie, wie das natürlich zu Spannungen gekommen ist, weil die Deutschschweiz mehr auf Deutschland und die Welschschweiz mehr natürlich zu den Franzosen gestanden ist, und wie das zu einer echten Zerreissprobe für unser Land geworden ist, und ich bin wirklich da sehr dankbar, dass man, dass man die Einigkeit, den Weg gehen konnte, und macht einem auch bewusst, dass man, dass wir einfach in einem Land sind, wo, wo die Gegensätze sehr gross sind, und dass man durch Demokratie auch miteinander immer wieder einen Weg suchen muss. Aber immer auch dem anderen zuhören muss und gemeinsam als Land den Weg finden muss.»(P19, Absatz 41)

\section{Zu c) Wir als zeitlich-abgrenzende Grösse: ‘Wir heute Lebenden〉}

Neben den zwei Varianten eines Wir als überzeitlich schweizerisches Wir und eines räumlich abgrenzenden Wir findet sich im Material noch eine dritte Variante. Dabei handelt es sich um eine Form des Kollektivs, die im Gegensatz zu den anderen beiden Varianten nicht räumlich (als schweizerisch oder ausserschweizerisch), sondern zeitlich begründet ist. Wir wird hier verwendet im Sinn eines «Wir heute Lebenden` im Gegensatz zu den während des Ersten Weltkriegs Lebenden.

Diese dritte Form des Wir kommt bei P3 und P19 vor und steht in inhaltlichem Kontrast zu Äusserungen eines überzeitlichen, schweizerischen Wir. Interessant ist insofern die Beobachtung, dass bei beiden Besuchenden beide Varianten auftreten, wodurch sich ein insgesamt disparates Gesamtbild ergibt.

Von den insgesamt sehr wenigen Textstellen in diesem Bereich entstammt die Mehrheit den Äusserungen von P3 und geht dort einher mit Äusserungen darüber, dass aus heutiger Perspektive ein Sich-Hineinversetzen und -Vorstellen von vergangenen Gegebenheiten nicht möglich sei. ${ }^{1480}$ Stellenweise bringt P3 die dabei ausgedrückte unüberbrückbare Differenz zwischen Gegenwart und Vergangen-

1480 Der Aspekt des Sich-Vorstellens und -Hineinversetzens wird weiter unten in Abschnitt 8.7.4.2 differenzierter behandelt. 
heit dadurch zum Ausdruck, dass er oder sie von "wir» als den heute Lebenden spricht, umgekehrt die damals lebende Generation mit einem distanzierenden «man» beschreibt. Ich liste diese Äusserungen aus dem Besuch von P3 auf, um das beschriebene Phänomen zu veranschaulichen:

"Ja, alles, wie sich das jetzt steigert, wie die Not langsam schlimmer wird, (...) weil der Krieg zum Dauerzustand wird, und man weiss ja gar nicht, wie lange der geht. Jetzt im Rückblick wissen wir ja, wie lange der Krieg gedauert hat, aber mitten nach drei Jahren, was man da fübl, wenn man nicht weisst, wann das endlich vorbei ist, das können wir uns auch ïberbaupt nicht vorstellen.» (P3, Absatz 65)

"Wir können einfach in den Laden gehen und etwas kaufen, und dort musste man Vorräte ansammeln (...) für den Winter, Einmachgläser, ich weiss nicht, wie viele das überhaupt noch kennen, dass man mit diesen Einmachgläsern für den Winter Früchte und Gemüse sterilisiert.»(P3, Absatz 66)

"Für uns ist es unvorstellbar, überhaupt Hunger zu haben, (...) dass wir irgendwo nach Essen bitte/ um Essen bitten müssen, oder eine Frühstückssuppe, oder anstehen für eine Brotkarte, (...) damit wir etwas zu essen haben.» (P3, Absatz 70)

Strukturgleich, wenn auch mit abgewandelter Wortwahl, ist auch die folgende Äusserung aufgebaut. P19 verwendet darin für die Beschreibung der Gegenwart die Formulierungen "wir» und «man», im Kontrast dazu für die Vergangenheit den Ausdruck «die Leute damals».

"Da ïberlegt man sich schon, ja, ob nicht auch heute wieder so eine Pandemie auftreten könnte und wie das heute wäre, weil wir uns eigentlich schon daran gewöhnt haben, dass es so etwas nicht mehr gibt, aber dass ja (...) das genau hundert Jahre oder nicht ganz hundert Jahre her ist, wo eine letzte grosse Pandemie Zehntausende Todesopfer gefordert hat, und (...) dass man irgendwo, man kann auch sagen, ja wir sind nicht von dem gefeit, und (...) man darf sich da nicht in einer falschen Sicherheit wiegen. Und ich denke, es ist gut, wenn man sich auch, ja, mit DEM auseinandersetzt und sich überlegt, wie sind die Leute damals damit umgegangen und was für Lehren kann man für heute zieben. Aber (...) 
ich bin doch sehr dankbar, dass wir von dem jetzt eigentlich nicht mehr betroffen sind, oder im Moment nicht betroffen sind.» (P19, Absatz 135)

Auch P19 drückt hier einen Kontrast zwischen Vergangenheit und Gegenwart aus, wobei lediglich für ein gegenwärtiges Kollektiv von «wir» die Rede ist und diesem "die Leute damals» gegenübergestellt werden. Auch hier liegt also eine zeitlich abgrenzende Wir-Verwendung vor.

\subsubsection{Eigene Familie}

Eine nächste Form von Lebensweltbezügen bilden Äusserungen, in denen die Besuchenden auf ihre eigenen Familienmitglieder zu sprechen kommen. Im Vergleich mit den Bezügen zur eigenen Stadt und Region und zum eigenen Kollektiv kommen diese allerdings deutlich seltener vor und finden sich mit je vereinzelten Nennungen bei etwas mehr als der Hälfte der Besuchenden. Einmalig ist die folgende Äusserung von P25, in der er oder sie den Bezug zu seiner eigenen Familiengeschichte sogar als Grund dafür benennt, überhaupt die Ausstellung «14/18» zu besuchen:

"Der Grund, warum ich die, überhaupt in die Ausstellung gekommen bin, ist, weil mein Vater Jahrgang 1914 hat und ich über die damalige Zeit und den Krieg etwas erfahren möchte.» (P25, Absatz 5)

Die soeben zitierte Textstelle ist auch insofern interessant, als sie das einzige Beispiel dafür darstellt, dass während des Besuchs explizit ein Besuchsanlass thematisiert wird.

Den Hauptanteil an Familienbezügen bilden kurze Erzählungen zu Familienmitgliedern, die zur Zeit des Ersten Weltkriegs gelebt haben. Je nach Alter der Besuchenden ist dies entweder die Eltern- oder bereits die Grosselterngeneration. Die Besuchenden berichten dann darüber, was ihre Familienangehörigen zur Zeit des Ersten Weltkriegs getan oder erlebt haben, oder mutmassen über deren Situation. So äussert etwa eine Person bei Betrachtung einer Fotografie von Schweizer Soldaten:

"Wenn ich da diese Bilder anschaue (...), kommt mir auch in den Sinn, was mein Grossvater erzählt hat. Der ist eben als 20-Jähriger, 18-Jähriger damals (...) ausgehoben worden und (...) hat da den Ersten Weltkrieg erlebt in der Schweiz. (...)» (P18, Absatz 21) 
Eine andere Person sieht sich ebenfalls an ihren Grossvater erinnert - nun nach Lesen einer Textquelle:

" Andreas Latzko, Menschen im Krieg, Menschen kehren heim mit stillen, staunenden Augen, in denen der Tod sich noch spiegelt.>

Ja und mein, erinnert mich an meinen Grossvater, der als ganz junger Mann, oder Jüngling, sich als Deutscher mit Begeisterung für den Krieg gemeldet hat und dann sein Augenlicht in Galizien verloren hat und von da an eigentlich immer noch als sehr junger Mann, na ja, noch irgendeine Art von Leben hatte, bis er dann starb, in den dreissiger Jahren.» (P12, Absatz 143)

Eine Person mutmasst nach Lesen eines Ausstellungstextes über die Lebensumstände ihres Vaters zu Kriegszeiten:

«Der Tisch bleibt leer. Im Sommer 1918 sind schweizweit schwe/, schweizweit rund 700000 Personen auf die Zuteilung verbilligter Milch-und Brotrationen angewiesen.> (...)

Mein Vater ist 1914 geboren, der hat also als, als Baby, als Kind (...) (ein gefährliches) Leben gehabt. (...) Da er aber auf dem Land aufgewachsen ist, hat er sicher nicht Hunger leiden müssen. (...)» (P25, Absatz 97)

Eine weitere Person wird nach Lektüre eines Ausstellungstexts sowie Betrachtung von zugehörigen Dingquellen an den Haushalt der eigenen Grosseltern erinnert:

«Der Ausbruch des Ersten Weltkriegs bedeutete für die reichen Basler Familien noch nicht das Ende der Belle Époque. Kriegsgewinne in einigen Industriezweigen und familiäres Vermögen ermöglichten der Oberschicht weiterhin ein angenehmes Leben.> (...)

Ich denke, dass meine Grosseltern auch zu dieser Schicht gehörten. Solche Gegenstände hab ich dort in meinem, in dem Elternhaus meiner Mutter auch schon geseben. (...) Wobei sie natürlich auch dann einfach Kind waren und dann später erst ihre Blüte erlebten und nicht im Ersten Weltkrieg lebten, sondern das waren dann eher ibre Eltern.» (P21, Absatz 6)

In der zitierten Textstelle reflektiert P21 darüber, inwiefern die eigenen Verwandten die Zeit des Ersten Weltkriegs überhaupt miterlebt haben, inwiefern also die Ausstellung überhaupt einen Eindruck von ihrer Lebenswirklichkeit geben kann. 
Analog findet sich ein Nachdenken darüber, inwiefern eigene Familienmitglieder die Zeit des Ersten Weltkriegs überhaupt miterlebt haben, auch bei der folgenden Person:

"Ja, hier sieht man auch noch einen Film, mit der Armee, also ich habe ein Foto von meinem Grossvater, der auch in der Kavallerie war (...) und ganz stolz mit seinem eigenen Pferd. Aber er war, bei Ausbruch des Ersten Weltkriegs war er zwölf und am Ende war er sechzehn, also er ist erst nachber dann in die Kavallerie.» (P3, Absatz 23)

In beiden Fällen sehen sich die Besuchenden beim Ausstellungsbesuch ausgehend von Objekten oder Fotografien an ihre eigene Familie erinnert, erkennen aber zugleich die Ungleichzeitigkeit zwischen ihrer eigenen Familiengeschichte und den Geschehnissen zur Zeit des Ersten Weltkriegs, benennen also eine Zeitdifferenz.

Und obwohl sie diese Zeitdifferenz erkennen, glauben manche Besuchende doch, Ähnlichkeiten zwischen der Zeit des Ersten Weltkriegs und Episoden aus ihrer eigenen, späteren Familiengeschichte zu erkennen. So fühlen sich zwei Besuchende durch Fotografien von Wohn- und Arbeitssituationen aus der Zeit des Ersten Weltkriegs erinnert an Szenerien, die sie aus ihrer Familiengeschichte der 1950er- oder 1960er-Jahre kennen. Sie unterstellen somit, dass es in der dazwischenliegenden Zeit seit dem Ersten Weltkrieg wenig Veränderung gegeben hat:

"Aber da kommen mir die Bilder noch sebr bekannt vor! Aber, vor 50 Jabren, später, hat das bei meinen Grosseltern auf dem Bauernhof nicht viel anders ausgesehen.» (P18, Absatz 59)

"'Mittagstisch, Backstube». Witzig, da fällt mir mein Vater ein, die Bilder aus den 50er-Jahren von ihm sehr ähnlich aus (unv.).» (P6, Absatz 34)

Teilweise sind es Objekte, die bis in spätere Zeiten überdauert haben, den Besuchenden bekannt sind und Erinnerungen auslösen. So etwa auch im nachfolgenden Beispiel, in dem eine Person die ausgestellten historischen Diplome zur Erinnerung an die Kriegsmobilmachung wiedererkennt:

"Historische Diplome erfrewen sich grosser Beliebtheit während und kurz nach dem Krieg. Trotz ibrer Aufmachung sind sie nicht offizielle Dokumente, sondern 
Teil einer Erinnerungsindustrie, zusammen mit einer grossen Zabl von Postkarten.> (...)

Ja, so eine (...), so ein Dokument ist auch bei meinem Grossvater gehangen. (...) Was natürlich eine gewisse Verbundenheit auslöst und Erinnerungen an meine eigene Familie.»(P19, Absatz 20)

\subsubsection{Eigene Besitztümer}

Das Beispiel berührt bereits eine weitere Gruppe von Lebensweltbezügen, in der es um Bezüge der Besuchenden zu eigenen Besitztümern geht und die lediglich sehr vereinzelt im Datenmaterial vorkommt. Wenn Besuchende eigene Besitztümer ins Spiel bringen, dann tun sie dies, um Vergleiche zwischen den in der Ausstellung gezeigten oder erwähnten Objekten und ihren eigenen Objekten anzustellen. Vorzugsweise werden dabei Ähnlichkeiten festgestellt, wie in den folgenden Beispielen:

«Die erinnert mich an meine Schweizer Medizin, Sanitätskiste. Die ist ein bisschen gröber, diese hier, und viel kleiner.»(P12, Absatz 91)

"Jaja (zustimmend), der Tornister, Gamellen, das hat sich ja nicht verändert eigentlich, haben wir heute noch daheim, so eine Gamelle.» (P18, Absatz 22)

\subsubsection{Eigene Militärzeit}

Eine ebenfalls in geringem Mass vertretene Kategorie bilden Bezüge der Besuchenden zur eigenen Militärzeit. Ich zeige nachfolgend alle gefundenen Textstellen. Hierbei werden durchweg Parallelen zwischen der eigenen Erfahrung im Militär und der Zeit des Ersten Weltkriegs festgestellt oder gar vermeintlich überzeitlich gültige Phänomene entdeckt.

"[...] Die monatelangen ereignislosen Diensteinsätze, bei denen viel Wert auf Drill und Gehorsam gelegt worden ist, haben bei den Truppen zunehmend ein Gefübl von Sinnlosigkeit wach werden lassen.> Kennen wir doch alles aus dem eigenen Militärdienst. Zwar zu einer anderen Zeit, aber (...) ja, damals schon so gewesen, heute auch noch immer so.» (P20, Absatz 2) 
An anderer Stelle der Ausstellung, aber inhaltlich ganz ähnlich, äussert sich eine Person, zunächst längere Zeit einen Ausstellungstext lesend:

"Zwischen dem 3. und 7. August 1914 rücken 220000 Mann und 45000 Pferde ein. Der durchschnittliche Mannschaftsbestand wäbrend des Kriegs beträgt jedoch nur 70000, bei Kriegsende sind noch 12000 Mann im Aktivdienst. (...) Im Schnitt leistet, leisten die Armeeangehörigen 500 Diensttage, meist weit entfernt von ibren Wohnorten. 4200 Armeeangehörige kommen durch die Spanische Grippe, andere Krankbeiten oder Unfälle ums Leben. Drill und Langeweile prägen den Wehr/ (...) aflikten, was verbreitet zu Misstimmung>

(lacht), das ist da noch umkreist mit einem Fragezeichen, ${ }^{1481}$ kann ich gut nachvollzieben (...)

'was verbreitet zu Missstimmung und Konflikten zwischen Offizieren und Soldaten führt. (...) Die Mobilmachung hat tief greifende Veränderungen in Wirtschaft und Gesellschaft zur Folge. Die Arbeitskräfte in der Industrie werden knapp, weshalb die Wirtschaft schon bald eine zumeist teilweise Demobilisierung fordert. Bereits im Dezember 1914 werden 100000 Soldaten aus dem Dienst entlassen. Der Familie fehlt oft der Ernährer, denn die Wehrmänner erhalten nur ein Franken dreissig Sold pro Tag. Den wirtschaftlichen und sozialen Aspekten der Mobilmachung schenkt man zunächst jedoch kaum Beachtung.>

Ja, das ist interessant, dass man sich mal ein Bild machen kann, wie viele Soldaten dass da im Dienst gewesen sind, und 500 Diensttage (...). Ja wenn man denkt, vier Jahre, vier mal 360 Tage, und davon hat man doch nur im Durchschnitt 500 Diensttage gemacht. Das zeigt doch, wie anders man sich das vielleicht vorstellt, dass man eigentlich nur sehr punktuell im Dienst gestanden ist und (...) der Soldat eigentlich doch grossmehrheitlich hat zu Hause sein können. (...)

Und eben es zeigt einmal mehr, dass, dass man wirtschaftlich gar nicht auf den Krieg vorbereitet gewesen ist. Und, ja, und dass, wenn man selber ja auch Militürerfabrung hat, dass es oft eben langweilig ist und (...) und das Militär eigentlich grundsätzlich eine äusserst langweilige Sache ist und nichts mit irgendwelchen heroischen Vorstellungen zu tun hat.» (P19, Absatz 35-36)

1481 Der hier von P19 gelesene Ausstellungstext enthielt den Begriff «Wehraflikten», versehen mit einer Kritzelei, vermutlich von einem/einer Besucher/in. Der Begriff sorgte auch bei mehreren der von mir beforschten Besuchenden für Irritationen. 
Bei Betrachtung einer Fotografie von schweizerischen Soldaten mit Gasmasken äussert eine Person:

"Die Gasmasken, die damals gebraucht wurden, sind nur unwesentlich weniger modern gewesen als die, die ich 1969, mit denen ich durch den Wald habe joggen müssen.» (P25, Absatz 70)

Und die ausgestellten Schokoladentafeln veranlassen eine Person zu der Feststellung:

"Aha, ich stehe vor einer Kiste mit Cailler-Schokolade. Das erinnert mich an meine Militärzeit (...), wo man also im, mit dem Notvorrat der Soldaten ebenfalls Cailler-Schokolade bekommen hat.»(P25, Absatz 63)

\subsubsection{Eigene Ausbildung}

Eine lediglich vereinzelt vertretene Kategorie innerhalb der Lebensweltbezüge stellen solche Äusserungen dar, in denen Besuchende Bezüge zu ihrer eigenen Ausbildung herstellen, mehrheitlich Bezüge zur eigenen Schulzeit und den dort behandelten oder umgekehrt gerade nicht behandelten Themen. In einem Fall stellt eine Person fest, sie habe in der Schule die Zeit der Weltkriege für ihren Geschmack zu wenig behandelt. Dies kann implizit auch als Ausdruck der Hoffnung gedeutet werden, die Ausstellung möge für diese Wissenslücke Abhilfe schaffen, wäre insofern ein weiterer Fall der Nennung einer Besuchsmotivation.

"Mich interessiert die Geschichte vom Ersten und vom Zweiten Weltkrieg, weil man das eigentlich nie, in der Schule hab ich das noch nicht ausfübrlich ein/, behandelt. (...) Sind wir viel zu lang bei den Römern und im Mittelalter gewesen.» (P18, Absatz 23)

Zwei andere Besuchende fühlen sich durch Elemente der Ausstellung an Lerngegenstände aus ihrer eigenen Schulzeit erinnert. So äussert eine Person, nachdem sie zuvor einen längeren Ausstellungstext über Exportgewinne von Basler Chemieunternehmen im Ersten Weltkrieg gelesen hat:

"Das hatten wir alles im Gymnasium, als wir zusammen das Thema Farben besprochen hatten in Chemie.» (P21, Absatz 7) 
Eine andere Person betrachtet die Gemälde von Basler Künstlern aus der Zeit des Ersten Weltkriegs, versucht, diese stilistisch einzuordnen, und macht schliesslich deutlich, dass sie das zugehörige Wissen im Kunstunterricht erworben habe bzw. dass sie sich von den Abbildungen an den Kunstunterricht erinnert fühlt.

"Ah ja, gut also dann geh ich grad nochmals die Jahreszabl schauen von diesem Bild. Ich habe vorher das Bild nur knapp angeschaut, und jetzt geh ich nochmals, das Bild ist Ende Erster Weltkrieg 1918, Kubismus, hab ich gedacht, vielleicht's sei von Picasso, sieht so nach eben kubistischen Bildern aus, ich nehme an, das ist alles diese Zeit. Es sind keine echten Bilder, seh ich hier, aber vielleicht alles aus dem Kunstmuseum, oder von Basel. Düstere Bilder, man erkennt nicht mehr recht, und es erinnert mich an meine Kunstbetrachtung am Gymnasium, wo wir Bilder auseinandergenommen baben, stundenlang, und Kubismus ist mir noch sebr in Evinnerung.» (P3, Absatz 12)

\subsubsection{Eigene Berufs- und Vermittlungstätigkeit}

Eine weitere Kategorie von Lebensweltbezügen stellen Äusserungen dar, in denen Besuchende Bezüge zu ihrer eigenen Berufstätigkeit herstellen. Bei einem knappen Drittel der Besuchenden finden sich derartige Hinweise. Aus Gründen der Anonymisierung der Teilnehmenden werden an dieser Stelle nur wenige Beispiele aus dem Datenmaterial angeführt, da sich aus anderen Äusserungen teilweise unmittelbare Rückschlüsse auf die Tätigkeit oder den Tätigkeitsort der Besuchenden ziehen lassen.

Aussergewöhnlich im Sample der beforschten Besuchenden ist P3. Er oder sie nutzt den Durchgang durch die Ausstellung zugleich zur Vorbereitung eines geplanten Besuchs mit der eigenen Schulklasse und geht in diesem Kontext an etlichen Stellen auf die eigene erlebte oder geplante Vermittlungstätigkeit als Lehrperson ein, überlegt beispielsweise, wie sich bestimmte Elemente der Ausstellung für den Besuch mit der Klasse nutzbar machen lassen. Des Weiteren spricht P3 an etlichen Stellen über die (potenzielle) Lebenswelt der Schüler und Schülerinnen als Adressaten und Adressatinnen der Ausstellung, was ich an dieser Stelle als Lebensweltbezüge auf einer Metaebene verstehe. 


\section{Im Brennpunkt: P3}

"Also ich nebme auch an, dass die Schülevinnen und Schüler diesen Platz dann erkennen.» - Bezüge zur eigenen Vermittlungstätigkeit und zur Lebenswelt von Schülerinnen und Schülern

Bei P3 handelt es sich um eine Geschichtslehrperson, die einen Besuch mit ihrer Schulklasse in der Ausstellung plant. Diese besondere Konstellation prägt in einem erheblichen Mass den Ausstellungsbesuch bzw. die gemachten Äusserungen. Insofern ist die inhaltliche Ausrichtung des Besuchs von P3 im Vergleich mit den übrigen Teilnehmenden merklich verschieden.

Zum einen spricht P3 an vielen Stellen des Besuchs über ihre geplante Vermittlungstätigkeit, identifiziert beispielsweise für den Klassenbesuch interessante Themen oder Elemente innerhalb der Ausstellung und erläutert, wie er oder sie damit umgehen möchte. Die nächsten Textbeispiele stehen stellvertretend für die erste Gruppe von Äusserungen:

"Ah Rationierung ist hier noch mit diesen Marken, da werd ich sicher die Schülerinnen und Schüler darauf aufmerksam machen, ein Essnapf, wo man da ansteht, um Essen zu bekommen, und diese Marken, was man da bekommt, dass sie da mal lesen, heisst es zum Beispiel <1 Kilo Kartoffeln〉.»(P3, Absatz 14)

"Jetzt steht da, wie viele Pferde gebraucht werden, ist jetzt nicht ganz klar, wahrscheinlich ist das in der Schweiz. Wie viele Soldaten im August schon (...) losziehen, das ist wabrscheinlich auch in der Schweiz, ist eine beeindruckende Zabl, 238000 Soldaten. Ein paar Dinge könnte man auch vorber als Schätzfrage nehmen.» (P3, Absatz 23)

"Also die humanitäre Hilfe ist ein Thema hier, Menschlichkeit und auch (...) das Anseben im Ausland von der Rolle der Schweiz. (...) Vielleicht wär es gut, das IKRK vorher nochmals genauer anzusehen.» (P3, Absatz 62)

Neben den Äusserungen über geplantes Lehrverhalten findet sich eine zweite Gruppe von Äusserungen, in denen P3 über seine oder ihre Schülerinnen und Schüler als künftige Adressatinnen und Adressaten der Ausstellung spricht, beispielsweise über mögliche Wirkungen der Ausstellung auf diese nachdenkt, ihre Interessen und Lebenswelt antizipiert. Eine Äusserung nach Konfrontation mit in der Eingangszone projizierten Tagebuchauszügen aus Kriegszeiten kann dies verdeutlichen: 
"Also das färbt auch auf die Kinder ab, jetzt hat's hier ein Zitat, dass schon ein Vierjähriger anfüngt, Barrikaden zu bauen im, im Garten, also wie der Krieg dann auch die Kinder prägt und man natürlich ganz anders aufwächst. Hier ist nochmals das Thema Kadetten. Auch der Stolz, dass man eine Uniform bekommt, dass man das gerne macht, das können sich wabrscheinlich die Schülerinnen und Schüler beute auch nicht mebr vorstellen, dass man stolz ist, dass man jetzt mitmachen darf und in Uniform fast wie ein anderer Mensch wird.» (P3, Absatz 16)

Nachfolgend werden einige weitere Beispiele aufgelistet, die deutlich machen, dass P3 immer wieder über die Interessen und Lebenswelt der Schüler und Schülerinnen spricht und sich Gedanken darüber macht, welche Themen oder Elemente der Ausstellung für die eigene Klasse von Interesse sein könnten, bei welchen Themen sich Bezüge zur Lebenswelt eröffnen oder auch Verständnishürden bestehen könnten:

"Aber eben, hier ist wieder ein Bild von Basel, schön, die fr/ Marktplatz, also ich nehme auch an, dass die Schïlerinnen und Schüler diesen Platz dann erkennen.» (P3, Absatz 13)

"Es hat einige sehr Pferdenärrinnen in der Schulklasse, und vielleicht werden sie auch ein bisschen empört sein, dass die Pferde da für den Krieg eingesetzt werden.» (P3, Absatz 23)

"Der Nebelspalter ist wahrscheinlich den Kindern kein Begriff.»(P3, Absatz 43)

«Dass Europa sich völlig verändert, steht jetzt hier noch. (...) Da ist dann auch das Problem mit dem (...) Balkan, das wird jetzt hier, (...) osmanische Reich und so. (...) Das wäre interessant, weil es auch ein paar Schüler von der Türkei und von (...) Albanien hat.» (P3, Absatz 78)

"Ich sehe da, dass es bis nach Life Science jetzt die nachfolgenden Wirkungen der (...) chemischen Firmen, was ganz am Anfang ja auch stand, dass es ein Profit für die Schweiz ist, und das hat sich alles weiterentwickelt mit erfolgreichen Unternehmen. Ich denke, dass da auch die Einzelnen, einige Eltern (...) in der Novartis, Sandoz oder so arbeiten.» (P3, Absatz 84)

"Also hier sind noch Themen wie, (...) dass an Grippe gestorbene Soldaten Kriegsopfer werden, aber dami/ das hat ja eigentlich gar nichts miteinander zu tun. (...) Aber beute jetzt mit Ebola, ist das sicher wieder etwas, was die Schülerinnen auch interessiert. (...) Wenn man das alles noch liest.» (P3, Absatz 77) 
P3 nimmt also vielfach die Schülerinnen und Schüler als künftige Besuchende der Ausstellung in den Blick. Sich selbst als Person macht P3 dabei von Situation zu Situation mehr oder weniger explizit sichtbar. Selten lässt sich zweifelsfrei unterscheiden, welche Themen und Elemente P3 für sich selbst als Person als interessant oder relevant erachtet und welche er oder sie im Hinblick auf den Besuch mit der Klasse als bemerkenswert empfindet. Häufig fliessen beide Perspektiven ineinander. Die folgenden Beispiele verdeutlichen die genannten Abgrenzungsschwierigkeiten:

"Hier heisst es jetzt (unv.) von dieser Doppelmoral, Waffenexporte und humanitäres Engagement, das ist sebr spannend, das werde ich auch (...) ansprechen.» (P3, Absatz 53)

Bei der gezeigten Äusserung bleibt letztlich unklar, inwiefern P3 die genannten Themen auch persönlich «spannend» findet oder als spannend für die Thematisierung im Unterricht einstuft. Auch im nächsten Beispiel vermengen sich die beiden Perspektiven:

"Die Zusammenfassung, ich denke, ich werde vorher schon einiges Hintergrundwissen über (...) den Krieg machen mit der Seeblockade, (U-Boot-Krieg) und so. Jetzt seh ich, dass der Zeitraffer, der vorne als Ganzes gezeigt ist, jetzt hier in (Detail) wiederkommt (...) mit den verschiedenen Ländern. (...) Das ist auch interessant, (...) das nochmals nachber zu seben, zuerst im Ganzen und nachber noch einzeln.» (P3, Absatz 51)

Lebensweltbezüge weisen also im Fall von P3 eine doppelbödige Struktur auf. Es werden Bezüge zu sich selbst und potenzielle Bezüge zu den Schülern und Schülerinnen vermengt thematisiert, weshalb der Ausstellungsbesuch der hier beschriebenen Person im Vergleich mit den übrigen Besuchenden eine auffallende eigene Prägung erhält.

\subsubsection{Eigene Erfahrungen mit Geschichtskultur}

Einen weiteren, im Vergleich verhältnismässig häufig vorkommenden Bereich von Lebensweltbezügen bilden Äusserungen, in denen Besuchende über ihren eigenen Kontakt mit Geschichtskultur und ihre Nutzung derselben sprechen - sei es, dass sie bereits gemachte Erfahrungen thematisieren, sei es, dass sie in Einzelfällen auch Pläne für eine Nutzung formulieren. Geschichtskultur bezeichnet hier, wie in der Geschichtsdidaktik gängig, «die Art und Weise, wie eine Gesellschaft mit 
Vergangenheit und Geschichte umgeht» ${ }^{1482}$ einschliesslich der dabei entstehenden Formen bzw. Manifestationen. ${ }^{1483}$

Die Äusserungen der Besuchenden über eigene Erfahrungen mit Geschichtskultur können teilweise im Kontext der einhundertsten Jährung des Ersten Weltkriegs im Zeitraum zwischen 2014 und 2018 gesehen werden, in den einerseits die Ausstellung «14/18» fiel, in dem aber auch insgesamt eine auffällige geschichtskulturelle Behandlung des Ersten Weltkriegs zu verzeichnen war. ${ }^{1484}$

Punktuell werden von Besuchenden gelesene geschichtswissenschaftliche $\mathrm{Pu}$ blikationen zum Thema (P7, Absatz 51 und 55) oder auch Besuche von Denkmälern oder Gedenkorten erwähnt (P25, Absatz 69; P28, Absatz 55), so etwa:

"Ich babe mit meinen Kindern und mit meiner Frau den Hartmannsweilerkopfbesucht, wo (...) Deutschland und Franzosen in Schützengräben ein paar Meter voneinander (...) gewesen sind (...) und sich bekämpft haben. (...) Weiss nicht mehr, wie viel Soldaten dort umgekommen sind, aber sehr viele (...), und kürzlich ist ja dort eine Erinnerungsfeier (...) gewesen.»(P25, Absatz 69)

Daneben sprechen Besuchende über geschichtliche Dokumentationen in Radio und Fernsehen sowie überdies und insbesondere über andere Museen und Ausstellungen, die sie besucht haben oder noch besuchen wollen und die sie teilweise mit der Ausstellung «14/18» in Bezug setzen. Sie tun dies entweder auf einer inhaltlichen Ebene und gleichen die Informationen bzw. Aussagen über historisches Geschehen ab, die sie an beiden Orten erhalten. Oder sie tun es auf einer konzeptionellen Ebene und sprechen über die Art und Weise, wie in den Ausstellungen das Thema behandelt wird. Vielfach treten also bei diesen Passagen zwei, wenn nicht gar drei Fokussierungen in Zusammenhang auf, nämlich einerseits Äusserungen über die eigene Nutzung von Geschichtskultur und damit die eigene Person (Fokus III) und andererseits Aussagen über historisches Geschehen (Fokus I) und/oder die Ausstellung und ihre Elemente (Fokus II). Die folgenden Zitate geben einen Eindruck davon, wie die Besuchenden andere Ausstellungen thematisieren und dabei wechselweise eher geschehens- oder ausstellungsfokussierte Bezüge herstellen und Vergleiche vornehmen.

1482 Pandel 2009, S. 86. Vgl. zum Begriff und Konzept der Geschichtskultur ausserdem Rüsen 1994, Rüsen 1997, Schönemann 2002 sowie die Ausführungen in Fussnote 2 und 5.

1483 Zum Manifestationsbegriff vgl. Fussnote 5.

1484 Vgl. Kapitel 7. 
"Hier sind einige Zitate versteckt! (...) <Das Schlachtfeld ist furchtbar, ein ganz eigentümlicher, (...) säuerlicher (...) Leichengeruch.> (...) Das hat man allerdings nicht (...) nachempfunden. (...)

Bei einer Ausstellung in Stuttgart konnte ich (...) eine Geruchsprobe von (...) der Luft in einem Schützengraben (...) riechen.» (P28, Absatz 56-57)

"Ja, aber da steht's (auch wieder). 90000 Tote, für Giftgas (ist das) nicht besonders (...) effektiv, das war in London [meint Imperial War Museum; Anm. JT] auch schon so beschrieben. Die Schreckungswirkung zwar schon, (...) aber die effektive Wirkung nicht.» (P27, Absatz 35)

"Kennt man so eigentlich auch aus deutschen Ausstellungen, dass auch die Kinder früh vom Militär begeistert werden sollten.»(P8, Absatz 5)

"Da gibts doch im (...) Museum für (...), wie heisst es? Am Münsterplatz oben. (...) Museum für Kultur. Dort gibt es doch auch eine Ausstellung über, über (...) eben so (...) Ersten Weltkrieg, Soldatenstuben. Was der Sinn dabinter gewesen ist, dass die Soldaten, die natürlich da im Feld gewesen sind, das Geld nicht hatten, um in irgendein öffentliches Restaurant zu gehen, mit ibrem Sold von, was haben wir gesehen? gehört oder gesehen? I Franken 70. Also sind die darauf angewiesen gewesen, aufgünstige (...) Lokalitäten. Und da in den Soldatenstuben haben sie für wenig Geld etwas konsumieren können. (...)»(P20, Absatz 71)

Neben anderen Ausstellungen nennen Besuchende als zweiten grossen Bereich auch konsumierte Radio- und Fernsehdokumentationen zum Ersten Weltkrieg. Nach Lesen eines Ausstellungstexts zur humanitären Hilfe und der Rolle von schweizerischen Krankenschwestern erinnert sich etwa folgende Person an einen gehörten Radiobeitrag:

"[...] Tausende von Schweizerinnen und Schweizern melden sich freiwillig zu verschiedenen Diensten oder unterstützen die Hilfswerke finanziell. Andere begeben sich als Delegierte oder Krankenschwestern ins Ausland. Die humanitäre Hilfe erweitert den aussenpolitischen Handlungsspielraum der Schweiz und stärkt ihr Ansehen im Ausland.> Das erinnert mich an eine Sendung, die ich auf DRS 2 gehört habe über eine Krankenschwester, die sich in den Dienst begab.» (P21, Absatz 69) 
Sogar zweifach auf Fernsehdokumentationen zu sprechen kommt Pl8, der/die davon berichtet, im Sommer 2014 mehrfach Filme zum Ersten Weltkrieg gesehen zu haben

"Der Erste Weltkrieg, habe ich im Sommer einige Filme gele/, gesehen und die Schrecken vom Krieg gesehen und jetzt sehe ich da (...). EBEN, Belle Époque, Woblstand, Ballettschuhe.»(P18, Absatz 4)

Im gezeigten Beispiel deutet sich implizit eine Irritation darüber an, dass angesichts von «Schrecken vom Krieg» in der Ausstellung auch «Belle Époque, Woblstand, Ballettschuhe» thematisiert würden, allerdings führt P18 diesen Kontrast nicht näher aus.

Die Grausamkeiten des Kriegsgeschehens, die P18 den gesehenen Filmen entnommen hat, scheinen in besonderer Erinnerung geblieben zu sein, kommt er oder sie doch an anderer Stelle erneut darauf zu sprechen. Im Vorfeld der nachfolgenden Passage betrachtet Pl8 eine Filmquelle, die Aktivitäten rund um die Mobilmachung in der Schweiz behandelt, konkret das «Einrücken» von Pferden in die schweizerische Armee. Ausgehend von diesem Film und im Vergleich mit den von ihm im Sommer gesehenen Filmen über das Kriegsgeschehen, kommt P18 zu dem Schluss, die Lage sei in den kriegführenden Nachbarländern schlimmer gewesen:

«So Filmzengnisse faszinieren mich sehr (...). Einfach wie es damals gewesen ist. (...)

Und wenn man noch bedenkt, wie das noch VIEL, VIEL mächtiger und grösser gewesen ist in Deutschland oder in Frankreich. (...)

Das hat mich schon (...) durch den Sommer durch sehr beschäftigt (...), wenn man Dokumentarfilme zu sehen, wie da einfach Millionen von Menschen umgebracht werden. (...)

Der Mensch, Kronik von, Krone der Schöpfung, sagt man, und sie bringen sich gegenseitig um.» (P18, Absatz 33-36)

Ähnlich wie P18 kommt auch P12 im Verlauf des Ausstellungsbesuchs mehrmals auf dieselben gesehenen oder besuchten geschichtskulturellen Manifestationen zurück. Die Äusserungen dieser Person werden nachfolgend gesondert vorgestellt. 


\section{Im Brennpunkt: P12}

"Das erinnert mich jetzt an diese Tagebücher von Franzosen und Deutschen, wie sie im Museum in Lörrach gezeigt wurden» - Vergleiche mit anderen Museen und Ausstellungen

Eine Person, die gleich an mehreren Stellen auf eigene Erfahrungen mit Geschichtskultur zu sprechen kommt, insbesondere auf Besuche in anderen Ausstellungen, ist P12. So spricht P12 an drei Stellen über eine Ausstellung des Dreiländermuseums in Lörrach und vergleicht beide Orte miteinander, so etwa die gezeigten Textquellen:

"Das erinnert mich jetzt an diese Tagebücher von Franzosen und Deutschen, wie sie im Museum in Lörrach gezeigt wurden und (...) die genau das Gleich schildern, aus, ja, unter anderen Vorzeichen, aber eigentlich genau das Gleiche, das Elend und die, die Einsamkeit der Soldaten, und diese Sinnlosigkeit, der sie sich mehr und mehr wohl bewusst werden.» (P12, Absatz 112-113)

Im nächsten Beispiel kommt P12 auf die Zweisprachigkeit der Ausstellung «14/18» zu sprechen und geht, eigene Erfahrungen mit dem Museum in Lörrach in die Überlegungen einbeziehend, auf die in der Region Basel und dem Dreiländereck generell verbreitete Zweisprachigkeit ein, die dazu beitrage, dass auch die beiden kriegführenden Nationen Deutschland und Frankreich in den Ausstellungen "sprachlich wiedergefunden werden»:

"So toll, dass diese Ausstellung zweisprachig ist, wobei das ja eigentlich in der Schweiz normal ist, zumindest als Wanderausstellung in den zwei grösseren Landessprachen macht das Sinn. Aber in Lörrach, wo ich die Ausstellung schon geseben hab, da fällt es eigentlich auf, wie sehr diesem Charakter hier in der Region, und gerade Deutsch und Französisch für die zwei grössten, oder zwei der grössten Kriegsparteien, dass die hier sprachlich wiedergefunden werden, oder, oder einfach gezeigt werden.» (P12, Absatz 34)

An anderer Stelle bezieht P12 ein in einer anderen Ausstellung erworbenes Wissen ein:

"Spannend zu sehen, wie, wie wirtschaftspolitisch achtsam man hier war und in Zeiten, ja, wo man vielleicht auch gröbere Ängste hätte. Hm. Gleichzeitig ist ja gerade die Angst durch die Verpflichtung, die es damals schon gab mit den Nachbarstaaten hier, gerade wirtschaftlich noch mehr geschwächt zu sein. Ich glaube, ich hab in irgendeiner Ausstellung, in Lörrach wabrscheinlich, gelesen, dass 
die Schweiz eben hart getroffen war von den Kriegswirren, weil es eben so viel importierte aus dem Ausland, möglicherweise auch exportierte, und ähm, und dass die Not gross war, auch wenn es von aussen schien, das sei eine Oase im Frieden.»(P12, Absatz 37)

Weiter erwähnt P12 einen Besuch in «im IKRK-Museum»- gemeint ist wohl das Musée international de la Croix-Rouge et du Croissant-Rouge in Genf - und stellt fest, die Ausstellung «14/18» trage zu einer inhaltlichen «Ergänzung» des dortigen, früheren Besuchs bei:

"(Obwobl ich im IKRK-Museum war, ist das) eine wirklich gute Ergänzung hier.» (P12, Absatz 135)

Wie die genannten Beispiele zeigen, beziehen sich vier Äusserungen über eigene Erfahrungen mit Geschichtskultur konkret auf Erfahrungen mit besuchten Museen. Mit einer weiteren, fünften Aussage geht P12 hingegen auf eine Dokumentationsreihe des Schweizer Fernsehens ein, die im Sommer 2014 unter dem Titel «Die Schweizer» ausgestrahlt wurde und dafür in die Kritik geriet, lediglich männliche Schweizer Persönlichkeiten porträtiert zu haben. ${ }^{1485}$ P12 vergleicht die Auswahl der in der Ausstellung porträtierten Personen damit und konstatiert seine oder ihre Freude darüber, dass das Geschlechterverhältnis dort ausgewogen sei:

«Fällt mir grad auf, dass es in diesen Stelen zwei Männer und zwei Franen sind. Das gefällt mir spontan sehr gut, wenn ich dran denke, wie das Schweizer Fernsehen im Sommer diese Serie und diesen Schwerpunkt zur schweizerischen Geschichte der letzten Jahrhunderte gemacht hat und dabei skandalöserweise einfach komplett die Frauen aussen vor liess. Ist das hier einfach schon mal sehr down to earth und schon mal sehr realistisch.»(P12, Absatz 36)

In dieser Textstelle deutet sich erneut das besondere Interesse von P12 für genderbezogene Fragestellungen an, das weiter oben bereits thematisiert wurde. ${ }^{1486}$

1485 Siehe z.B. entsprechende Medienberichte zum Thema: https://bazonline.ch/digital/ social-media/schweizerinnen--welche-Frauen-fuer-die-SRFDoku-vorgeschlagen-werden/ story/11336839 (Zugriff am 21.4.2018); www.schweizamwochenende.ch/aktuell/frauenaufstand-gegen-srg-131052265 (Zugriff am 21.4.2018).

1486 Vgl. Abschnitt 8.7.2.15. 


\subsubsection{Sonstige biografische Bezüge}

Neben den in den letzten Kapiteln behandelten Varianten von Lebensweltbezügen findet sich eine ganze Reihe von weiteren hergestellten biografischen Bezügen, die vereinzelt auftreten und im Rahmen einer Sammelkategorie zusammengefasst werden. Die Beispiele variieren dahingehend, auf welche Zeiten ihrer Biografie die Besuchenden Bezug nehmen. So bringen sie Erinnerungen an frühere Phasen ihrer Biografie ein, etwa ihre Kindheit, oder sie beschreiben sich selbst in ihrer gegenwärtigen Lebenssituation. Über die eigene Kindheit äussert sich nachfolgend P20, zunächst einen Ausstellungstext lesend und ausgehend davon sich erinnernd:

«Basel (war) mit seiner Kaserne eine Garnisonsstadt und diente verschiedenen Truppen als Ausgangspunkt für ibre Verschiebung an die Grenze im Jura. Die Defilees, die Fahnenübergaben, die Konzert der Armeemusik und die Festtage des Basler Regiments stellten für die Basler Bevölkerung eine willkommene Abwechslung dar. Gleichzeitig sollten sie die Verbundenheit mit der Armee stärken und patriotische Gefüble wecken. Oft wurden an solchen Anlässen auch Geld für notlen/, notleidende Soldaten gesammelt.>

Ja, da kommt mir da in den Sinn, wir baben natürlich in Basel, in der Kaserne ist lange Zeit, wo ich (...) Schuljunge gewesen bin, lange Zeit noch Sanitätssoldaten als (...) dauernde Einvichtung dort einquartiert gebabt.» (P20, Absatz 6)

Erlebnisse in der (mutmasslich) jüngeren Vergangenheit werden etwa von den folgenden Besuchenden thematisiert:

"Für uns ist es unvorstellbar, überhaupt Hunger zu haben, (...) dass wir irgendwo nach Essen bitte/ um Essen bitten müssen, oder eine Frühstückssuppe, oder anstehen für eine Brotkarte, (...) damit wir etwas zu essen haben. (...) Ich habe mal ein Kind erlebt, (im) Coop, das seine Mutter gefragt hat, ob denn dieser Laden nie leer wird, (...) und ich fand das eine sehr interessante Frage, das Kind war etwa sechs oder sieben, (...) wird denn dieser Laden NIE leer.» (P3, Absatz 70)

"Was ich jetzt nicht realisiert habe, von wem dann Lebensmittelmarken und -karten ausgegeben worden sind. (...) Notabene, ich bin vor zwei Jabren in Kuba gewesen, und dort werden immer noch Lebensmittelmarken ausgegeben und verwendet (...), und das seit 1959.» (P25, Absatz 80) 
Die bislang angeführten Textstellen sind Beispiele dafür, wie Besuchende in relativ freier Assoziation auf Episoden aus ihrer eigenen Biografie zu sprechen kommen und diese erzählend ausschmücken. Umgekehrt beschränken sich andere Lebensweltbezüge auch auf die schlichte und knappe Feststellung, ein von der Ausstellung erwähntes Ereignis selbst miterlebt zu haben und sich erinnern zu können:

«Da kann ich mich noch erinnern, Abstimmung zu der Schwarzenbach-Initiative.» (P25, Absatz 107)

«Erst nach dem Ende des Kalten Kriegs stimmt das Volk im März 2002 dem UNO-Beitritt zu, und am 10. September 2002> - ich mag mich sogar genau an den Tagerinnern-snimmt die UNO-Generalversammlung die Schweiz als 190. Mitglied auf.» (P12, Absatz 200)

In aller Regel thematisieren die Besuchenden bei diesen Bezügen zu ihrer eigenen Biografie eine Zeitebene innerhalb dieser Biografie. Passagen, in denen Besuchende Lebensweltbezüge herstellen und dabei zugleich Zeitebenen in ihrer eigenen Lebenswelt verknüpfen, kommen demgegenüber nur vereinzelt vor, jedoch in den folgenden zwei Äusserungen von P25:

«1948. Sozialpolitik. Einfübrung der AHV'. Genau, dann bin ich auf die Welt gekommen und kann jetzt profitieren von dieser Institution, indem dass ich eine AHV-Rente bekomme.» (P25, Absatz 104)

"Life Science, da stehe ich vor einer Säule betreffend Novartis. Mit der Geschichte von Geigy, Ciba und dann Novartis. (...)

1996 baben Ciba, Geigy und Sandoz zu Novartis fusioniert. Damals bab ich Aktien besessen von Ciba-Geigy und hab hübschen Gewinn gemacht bei der Fusion. Muss ich da jetzt ein schlechtes Gewissen haben?» (P25, Absatz 110-111)

Das zweitgenannte Beispiel ist zugleich eine der sehr selten vorkommenden Textstellen, in denen Besuchende Schlussfolgerungen für mögliche Handlungen ab- 
leiten, im konkreten Fall auf moralischer Ebene und in Bezug auf die eigene Person ("Muss ich da jetzt ein schlechtes Gewissen haben?»). ${ }^{1487}$

\subsubsection{Abwesenheit von persönlichen Bezügen}

Sehr vereinzelt kommt es vor, dass die Besuchenden über die Abwesenheit von persönlichen Bezügen sprechen und damit feststellen, dass das soeben Gesehene für sie lebensweltlich nicht relevant oder nicht bekannt ist. Beispielswese äussern zwei Besuchende in Bezug auf ausgestellte Sachquellen, dass sie für diese in ihrer eigenen Lebenswelt keine Verwendung hätten. Eine Person bemerkt etwa bei Betrachtung eines Damenoberkleids aus der Basler Oberschicht zur Zeit des Ersten Weltkriegs:

"Das Kleid würd ich auch nicht unbedingt so an meine Frau verschenken.» (P8, Absatz 2)

Ein anderer Besucher bemerkt in Konfrontation mit der ebenfalls im Basler Regionalteil gezeigten Kinderuniform:

«Würde mir keinen Spass machen.» (P26, Absatz 4)

Eine dritte Person stellt ausserdem fest, die ausgestellten Jasskarten bzw. die darauf abgebildete Motivik sei ihm oder ihr in der Form teilweise aus heutiger Zeit nicht mehr geläufig.

"Jasskarten, die ich (...) nicht mehr kenne, die sind heute anders (...). Also die (Schaufel) (...) und (die Eichel) und (...) ja, die anderen sind mir (...) nicht so bekannt, nein.» (P22, Absatz 33)

1487 Auf die kleine Anzahl von Beispielen, in denen Besuchende Lehren formulieren, die sich aus der Geschichte ziehen lassen, dort allerdings ohne unmittelbaren Bezug zur eigenen Person, bin ich weiter oben bereits eingegangen (vgl. Abschnitt 8.5.4). 


\subsubsection{Die eigene Person in der Ausstellung}

Neben den Relationen und geäusserten Lebensweltbezügen bilden einen dritten Bereich von Äusserungen im Fokus III solche, in denen die Besuchenden über sich als Person in der Ausstellung sprechen und ihre Rolle bzw. Erfahrungen dort in den Blick nehmen. Daraus greife ich drei, sich teilweise gegenseitig überlappende Bereiche heraus und stelle sie näher vor.

\subsubsection{Die eigene Rolle als Studienteilnehmende}

Vereinzelt finden sich Äusserungen zur eigenen Rolle als Studienteilnehmende, beispielsweise über die damit verbundenen Besonderheiten des Ausstellungsbesuchs. Eine Gruppe von Äusserungen sind solche, in denen die Besuchenden eine Veränderung ihrer Laufwege kommentieren, verursacht durch weitere in der Ausstellung befindliche Personen, die sie nicht stören wollen. ${ }^{1488}$

"Ich tu jetzt, damit ich die anderen nicht störe, von hinten anfangen.» (P7, Absatz 24)

«Ich gehe einfach vorbei, weil ich die Leute nicht stören will.»(P30, Absatz 48)

"Ich geh etwas nach vorne, damit ich die anderen Leute nicht störe, wenn ich spreche.» (P21, Absatz 49)

Zweitens äussern die Besuchenden punktuell auch Unbehagen über ihre Aufgabe des Lauten Denkens in der Nähe anderer Besuchender:

«Das ist dann unbequem, wenn andere Leute herumstehen.»(P30, Absatz 4)

«Ich hoff, ich stör hier niemand, das ist mir wirklich ein bisschen unangenehm.» (P12, Absatz 36)

Vereinzelt wird auch von Anstrengung berichtet, insbesondere im Zusammenhang mit der Gleichzeitigkeit von Tonquellen und Lautem Denken. ${ }^{1489}$ 
"Das ist jetzt aber sehr mühsam, dass hier oben von der Decke dieser Text kommt, weil, ich muss hier lesen und soll hier auch noch berichten, was ich sebe und denke.» (P12, Absatz 79)

"Ich glaub, das ist mir zu komplex, dadurch, dass ich ja selber reden darf, ist das mir irgendwie zu viel jetzt zu hören, aber dafür studier ich schon während des Hörens hier diese Tafel [...]»(P12, Absatz 28)

Eine Person berichtet zudem am Ende ihres Rundgangs von einer erlebten erhöhten Notwendigkeit zur Konzentration im Vergleich zu einem üblichen Besuch:

"Ist sicher speziell, mit einem Mikrofon durch eine Ausstellung zu laufen und alles so zu komm/, zu kommentieren. Ist manchmal einfacher, wenn man seinen Gedanken einfach so freien Lauflassen kann und sich nicht so sehr konzentrieren muss.» (P19, Absatz 151)

Ein Drittel der Besuchenden berichtet in dieser Weise während des Ausstellungsbesuchs vereinzelt von Störungen oder Anstrengungen. In der Summe erscheint dies erfreulich wenig angesichts der doch herausfordernden Aufgabe des besuchsbegleitenden Lauten Denkens.

\subsubsection{Sich-Vorstellen und -Hineinversetzen, Nähe und Ferne zum Geschehen}

Einen weiteren Bereich stellen Äusserungen dar, in denen Besuchende über SichVorstellen und -Hineinversetzen sprechen, ${ }^{1490}$ über ihre eigene Nähe bzw. auch Ferne zum Geschehen und die Rolle der Ausstellung und ihrer Elemente als Beförderer dieser Zugänge. Besuchende sprechen dann beispielsweise darüber, sich damalige Situationen und das Befinden der damals lebenden Menschen vorzustellen, sich hineinzuversetzen oder, umgekehrt und seltener, sich etwas gerade nicht vorstellen zu können. ${ }^{1491}$ Äusserungen in dieser Kategorie finden sich bei der Hälfte der Besuchenden, dabei vermehrt in Zusammenhang mit der Beschäftigung mit

1490 Vgl. für entsprechende Differenzierungen auf theoretischer Ebene, dort u.a. unter den Begriffen «Imagination» und «Empathie», stellvertretend Brauer 2013, insb. S. 84 ff., sowie die Ausführungen und Literaturbezüge in Abschnitt 3.4.2. Ich beziehe die erzielten Befunde weiter unten noch auf die vorhandenen theoretischen Überlegungen.

1491 Die Unterscheidung dieser zwei Varianten ist inspiriert durch eine entsprechende Unterscheidung bei Bert Pampel (2007, S. 257 ff.). 
Bildquellen und in Zusammenhang mit Themen, die den Alltag und die Lebenswirklichkeit der damals lebenden Menschen betreffen.

Ich nehme nun zunächst Äusserungen über ein gelungenes Sich-Vorstellen und -Hineinversetzen in den Blick und systematisiere diese. Beispielsweise lassen sich gewisse Abstufungen dahingehend erkennen, wie stark der Grad der persönlichen Involvierung ist, der von den Besuchenden thematisiert wird, ob sie beispielsweise eher von einem abstrakten Sich-Vorstellen oder von einer stärker emotionalen Involvierung im Sinne eines Sich-Hineinfüblens oder -Hineinversetzens sprechen. Auch sind die Übergänge fliessend hin zu Textstellen, in denen Besuchende zwar den Ausdruck des Sich-Vorstellens gebrauchen, damit aber mutmasslich etwas anderes meinen, beispielsweise einen Sachverhalt als logisch oder nachvollziehbar beschreiben. ${ }^{1492}$ An dieser Stelle beziehe ich mich nur auf diejenigen Textstellen, in welchen es mutmasslich um Sich-Vorstellen im Sinn eines Imaginierens geht.

Die folgenden Zitate machen die Bandbreite an Äusserungen deutlich. Von einem Vorstellen-Können spricht P21:

"Mir gefällt die Auswabl der Objekte, sie ist ziemlich stimmig und vermittelt auch noch ein gutes Bild. (...) Und womit dem man sich ein bisschen besser vorstellen kann, (mit den ganzen) Gegenständen, damals die durchschnittlichen Wohnzimmer ausgerïstet waren.»(P21, Absatz 9)

Im Kontrast dazu spricht P19 von einem Nachspürenkönnen und damit von einer stärkeren persönlichen emotionalen Involvierung:

"Da wieder das übergrosse Bild mit Zivilisten und Soldaten. (...) Ich glaube, man spïrtein bisschen von der Stimmung damals, wie (...) wie allesso in einen Strudel von dem Krieg hineingezogen gewesen ist und (...) aber doch auch Wehrbereitschaft, Nationalsymbole und Gemeinsamkeiten beschworen worden sind zu der Zeit, ja.» (P19, Absatz 34)

Andernorts thematisiert P19 noch expliziter eine Emotion, die sich mit dem SichVorstellen verbindet:

«Ja, das ist furchtbar, wenn man sich das vorstellt, Giftgas.» (P19, Absatz 39)

1492 Vgl. Abschnitt 8.7.2.11. 
Einen Schritt weiter als Sich-Vorstellen und Nachspüren geht P30, der oder die davon spricht, sich an die Stelle historischer Akteure und Akteurinnen zu stellen:

"Die grossen Bilder sind sehr eindrucksvoll. (...) Man (stellt) sich an ibre Position und fragt sich, was man gemacht hätte.» (P30, Absatz 31)

Inwiefern diese Äusserung tatsächlich wörtlich zu nehmen ist, ist allerdings unklar, weil P30 nicht muttersprachlich Deutsch spricht. Im wörtlichen Sinn würde sie eine vollständige Perspektivübernahme ausdrücken, also die Annahme, dass ein Sich-an-ihre-Position-Stellen überhaupt möglich ist.

Ähnlich äussert auch in der folgenden Textstelle P12 bei Betrachtung einer Bildquelle zunächst das Gefühl, direkt im Geschehen zu stehen. Kurz darauf relativiert er oder sie jedoch die Aussage und bringt ein Bewusstsein für die Unmöglichkeit dieses Ansinnens zum Ausdruck:

"Oh, diese Bilder sind e/, die sind eindrücklich. Grad hier hab ich das Gefübl, ich steh hier mitten in diesem, in dieser Kantine, oder eigentlich in dieser Turnballe, besser gesagt, gell, die zu einem, zu irgendsoeiner Volksspeisung hier. <Ein Esslokal der Volksküche des Kriegsfürsorgeamtes in der Turnhalle des Schulhauses〉 - wow - 〈Dreirosen in Basel> (...). Und die Gesichter sehen echt aus, wie, wär, wär, wär die Schnurrbartmode nicht, und die Haarschnitte, und die (...) Hemdenkragen, bätte man das Gefübl, das sind heutige Basler, die da sitzen. (...) Und eben, das ist die Turnballe, die Dreirosen.»(P12, Absatz 172-173)

In dieser Passage wird Andersartigkeit zweier Zeitebenen ausgedrückt, die sich für P12 anhand der Kleidung und Haarmode zeigt.

Generell scheinen sich die Besuchenden durchaus darüber bewusst zu sein, es mit einer anderen Zeit und anderen Umständen zu tun zu haben, die sie sich vorzustellen oder in die sie sich hineinzuversetzen versuchen. Formulierungen wie «Stimmung damals» (P19, Absatz 34) oder "damals die durchschnittlichen Wohnzimmer» (P21, Absatz 9) machen dies erkennbar. Dennoch halten die Besuchenden es offenbar für möglich, sich diese Bedingungen vorzustellen oder sich hineinzuversetzen.

Ungewöhnlich ist in diesem Zusammenhang die zuletzt von P12 gewählte Formulierung: Er oder sie schildert, die Kleidung und Haare hielten davon ab, die abgebildeten Personen für «hentige Basler» zu halten. Hier geht es also nicht um 
das Sich-Hineindenken der eigenen Person in historisches Geschehen, sondern umgekehrt den Transfer historischer Personen in die Gegenwart.

An anderen Stellen spricht P12 umgekehrt wieder davon, sich «bineinversetzen» und «zurückversetzen» zu können und selbst «eine kleine Zeitreise» zu unternehmen:

"Wenn man dieses Bild auf, vom Marktplatz und dem Rathaus sieht, dann ist es wirklich auch wieder so frappierend, weil, weil sich kaum was geändert hat und auch da ähnlich wie das Bild mit der, mit der Volksspeisung in der Dreirosenturnballe, ja, man sich eigentlich sehr gut hineinversetzen kann und zurückversetzen kann.» (P12, Absatz 216)

"Ist ein ‘Warenlager des Kriegsfürsogeamts in Basel〉. Wo das wohl war? ‘Staatsarchiv'. Das wär noch nett gewesen, wenn irgendwo, das ist wahrscheinlich, ja wenn irgendwo stehen würde, wo das, welcher Ort das ist, welche Adresse. Wabrscheinlich war das dieser Stadtplan, den ich da im Erdgeschoss beim Hinuntergehen noch mit einem Blick erhascht hatte, wo man glaub ich die Dinge so ein bisschen lozieren kann. Das fänd ich noch spannend heute, weil da machts wirklich Geschichte noch mal erlebbarer, wenn ich dann an diesen Gebäuden oder, oder Zollübergängen vorbeikäme heute und mich dann zuriuckerinnere und so eine kleine Zeitreise machen kann.» (P12, Absatz 136)

Auffällig an den bislang zitierten Textstellen ist, dass die Besuchenden vielfach nicht explizit von «ich〉 sprechen, sondern davon, dass «man〉 sich etwas vorstellen, etwas nachspüren könne. Hierfür sind mindestens zwei Deutungen denkbar. Zum einen dient das Sprechen mit 〈man〉-Formulierungen der Distanzierung. Aus sprachlicher Sicht bleibt auf diese Weise unklar, ob es tatsächlich die eigene Person ist, die sich in etwas hineinversetzt und etwas vorstellt. Die eigene Person erscheint also auf diesem Weg nicht explizit als emotional involviert.

Umgekehrt kann eine gewählte ‘man〉-Formulierung auch darauf hindeuten, dass in den Äusserungen Wirkungen auf andere Besuchende bereits mitgedacht werden. Dies kann vor allem dann der Fall sein, wenn die Besuchenden darüber sprechen, dass es bestimmte Elemente der Ausstellung sind, die aus ihrer Sicht die Möglichkeiten für ein Sich-Vorstellen oder -Hineinversetzen eröffnen, was dann aus ihrer Sicht vielleicht nicht mehr allein auf die eigene Person beschränkt wäre. 
Im Datenmaterial finden sich neben dem Grad der Involvierung auch Unterschiede dahingehend, wie stark die Besuchenden explizit eine Verknüpfung herstellen zwischen einerseits ihrer eigenen Wahrnehmung und andererseits der Ausstellung als Auslöser für bestimmte Wahrnehmungen. P4 spricht beispielsweise eher nüchtern über die Gestaltung der Ausstellung, lässt aber im Unklaren, inwieweit diese die eigene Rezeption beeinflusst:

"Also ich find's gut, dass (...) der Film so gross gezeigt wird, (...) weil man teilweise die Leute lebensgross, also, oder fast lebensgross vor sich hat. (Finde ich) nicht schlecht.»(P4, Absatz 120)

P4 stellt hier zwar fest, die abgebildeten Personen seien «lebensgross» zu sehen, und lobt dies, gleichzeitig äussert er oder sie sich nicht dazu, inwiefern diese Darstellung in Lebensgrösse bedeutsam sein könnte.

In zahlreichen Äusserungen kombinieren sich Aussagen über das SichVorstellen-Können mit der Feststellung, dass es die Elemente in der Ausstellung seien, die diese Möglichkeit eröffnen. Zumeist sind es Bildquellen, genauer Fotografien, denen die Besuchenden das Potenzial zuschreiben, Vorstellungen und Sich-Hineinversetzen zu ermöglichen. So kommt auch ein bemerkenswerter Teil der Äusserungen in der hier beschriebenen Kategorie im Zusammenhang mit einer Auseinandersetzung mit Bildquellen zustande.

Die folgenden Beispiele enthalten, neben den bereits gezeigten Materialauszügen, weitere Hinweise auf die Bedeutung von Bildquellen, teilweise verbunden mit der Feststellung, dass Bilder Aufschluss über die alltägliche Lebenssituation geben, teilweise explizit verknüpft mit dem Hinweis, dass mithilfe der Bilder SichVorstellen möglich werde:

"Die Bilder, die ich da sehe, sind sehr eindrücklich und (will) mir (...) eine Idee, Bild vermitteln vom damaligen Leben in der Schweiz.» (P25, Absatz 54)

"Das ist sehr eindrücklich, ein Bild, was ich da sehe (...) (und das) einen allgemeinen Einblick gibt, wie man damals gelebt hat.» (P25, Absatz 56)

"Also solche Schwarz-Weiss-Aufnabmen, echte Fotos, sind sicher eindrücklich, kann man auch sich mal vorstellen, wenn man selber dasteben wïrde, wie man sich da fühlt, wenn man weiss, dass jetzt Krieg ist, welche Gedanken einem 
da durch den Kopf gehen. Ist toll gemacht, dass von vorne auch die Leute dastehen und man sozusagen bei ibnen stebt.» (P3, Absatz 25)

"Ich glaube, das ist in Bern (...), wo die Armee antritt. (...) Man kann sich das so mit dem Film super vorstellen.» (P3, Absatz 45)

Jedoch wird durchaus auch anderen Elementen der Ausstellung ein die Vorstellungskraft beflügelndes Potenzial zugeschrieben. So P21 in Bezug auf Alltagsgegenstände aus reichen Basler Familien:

"Mir gefällt die Auswabl der Objekte, sie ist ziemlich stimmig und vermittelt auch noch ein gutes Bild. (...) Und womit dem man sich ein bisschen besser vorstellen kann, (mit den ganzen) Gegenständen, damals die durchschnittlichen Wohnzimmer ausgerïstet waren.» (P21, Absatz 9)

P26 spricht auch dem Layout der Ausstellung die Kraft zu, Vorstellungen zu wecken. Er oder sie bezieht sich hier mutmasslich auf die im zunehmenden Verlauf der Ausstellung immmer stärker in Schieflage stehenden, versatzstückhaft angeordneten Stellwände:

"(Ja durch die) (...) Art, wie die Ausstellung hier gestaltet ist, (...) kann man sich vorstellen, wie da ein (...) ganz schönes Drunter und Drüber herrschte, (...) da gegen Kriegsende. Mit all den politischen Konflikten.»(P26, Absatz 52)

Für P19 erweist sich hingegen der in der Ausstellung teilweise enthaltene biografische Zugang zu einzelnen Personen als bedeutsam, wie aus der nachfolgenden Falldarstellung hervorgeht.

\section{Im Brennpunkt: P19}

«direkt aus dem Leben gegriffen» - Ausstellungselemente als Zugang zu alltäglichen Erfahrungen

Eine Person, die sich stark mit Fragen der Elementauswahl in der Ausstellung beschäftigt und zugehörige Überlegungen zu den Möglichkeiten eines SichHineinversetzens anstellt, ist P19. An mehreren Stellen des Besuchs finden sich Äusserungen, in denen sich P19 erfreut über die Möglichkeit zeigt, Einblicke in 
das Leben und die alltäglichen Erfahrungen historischer Personen zu erhalten, sich in diese hineinzuversetzen. So etwa:

"Ich komm jetzt rein in die Ausstellung (...) und kann gleich mal die grossen Bilder da bestaunen. (...) ähm (...) in Übergrösse. Sujets von der damaligen Zeit da. (...) Wo ich wirklich sehr gelungen finde (...). Also direkt so aus dem Alltag gegriffen (lacht) der (...) paar Kinder auf dem Wagen hinten, auf dem Heuwagen, vorne die Soldaten, die sich (angelehnt) finden. Es kommt wirklich sehr realistisch rüber.» (P19, Absatz 13)

Beim Lesen projizierter Tagebucheinträge aus der Zeit des Ersten Weltkriegs kommt P19 zu ähnlichen Feststellungen:

«Morgens Spaziergang mit Papa. Münchenstein - Schönmatt-Pratteln. Unterredung über Berufswahl und Seidenbandgeschäft. (Starkes Schiessen) aus dem Elsass.> (...)

$A$ h, das find ich sebr gelungen, die verschiedenen Zitate, direkt aus dem Leben gegriffen (...), dass man sich einen Eindruck machen kann, was die Leute gefüblt und gedacht haben, gevade in der Zeit, wo sie damals unterwegs gewesen sind.

<Oft schreckte man in der Nacht auf durch das Schiesser/, Schiessen, bei (Pfetterhausen) oder Hartmannsweilerkopf. (...) Eröffnung des Singer-Kaffeehaus am Markt, wozu Peter und ich feierlich eingeladen sind. Es ist ein ganz normaler, moderner Bau mit lauschigen Ecken und Nischen. Ob Basel grossstädtisch genug ist dafür, wird sich zeigen.> (...) Eben, inmitten von einem tobenden Krieg, so ganz alltägliche Situationen. (...)» (P19, Absatz 4-5)

Etliche Elemente der Ausstellung veranlassen P19 zu strukturgleichen Äusserungen darüber, dass darin der Alltag und das Leben dargestellt werde oder dass man sich ausgehend von Elementen in vergangenes Geschehen hineinversetzen könne. Mit solchen Äusserungen bezieht sich P19 einerseits auf Fotografien:

"Ja, das ist cool. Echt da Bilder aus dem Alltag. (...) Von Regionen, die man, von denen man weiss, wie sie heute aussehen. (...) Da in Bern (...). Ist cool, das ist wirklich sehr gut. (...) JA. Ja ist eindrücklich, ist wirklich, sind wirklich gute Bilder.» (P19, Absatz 60)

"Die Bilder finde ich gelungen, so die kleinen Bilder und nebendran die grossen. Weil es wirklich auch einen guten Einblick in den Alltag gibt von den Soldaten damals.» (P19, Absatz 39) 
Jedoch hält P19 auch weitere Elementtypen für geeignet, um einen direkten $\mathrm{Zu}$ gang zu vergangener Lebenswirklichkeit zu erhalten. Hierzu zählen Textquellen wie die weiter oben bereits vorkommenden Tagebucheinträge oder auch Lebensmittelmarken:

"Man sieht auch Lebensmittelmarken, wo man sich gut vorstellen kann, wie das da alles rationiert gewesen ist.» (P19, Absatz 110)

Abgesehen von den in der Ausstellung befindlichen einzelnen Quellen ist P19 auch in Bezug auf die punktuell vorkommende Vorstellung von Einzelpersonen der Meinung, diese gewährten Einblicke in Lebenswelten und ermöglichten es, «sich dann so hinein $[z u]$ denken»:

«Der Ernst Laur, Agronom, Direktor des Schweizerischen Bauernverbandes. Der in Leipzig promovierte Agronom ist über 40 Jahre lang Direktor des 1870 gegrïndeten Banernverbandes und Dozent an der ETH Zürich. Laur gilt als achter Bundesrat. Er führt betriebswirtschaftliche Grundsätze in die Landwirtschaft ein und profiliert sich als Modernisiever. Unter seiner Führung wird die Position der Bauernorganisation wäbrend des Krieges markant gestärkt und das Einkommen der Bauern erhöbt.> (...)

Ja, ich find's interessant, so Personen, die eigentlich beute in Vergessenbeit geraten sind, die so herausgegriffen werden und ibre Leistungen oder ibr, ja ibr Wirken zu der Zeit erklärt wird. Find ich (...) find ich interessant, weil man kann sich dann so hineindenken, wie, wie die politischen Gegebenheiten in der damaligen Zeit gewesen sind.

[...]

-Angelika Balabanoff. Immigrantin und russische Sozialistin. Die Tochter eines reichen russischen Grundbesitzers studiert an verschiedenen Universitäten, engagiert sich ab 1902 in der sozialistischen Bewegung in der Schweiz und setzt sich für italienische Arbeiter ein. Sie nimmt aktiv an der Oktoberrevolution teil, kehrt als russische Rotkreuz-Vertretung in die Schweiz zurück und wird 1918 ausgewiesen. 1921 bricht sie mit dem Bolschewismus, lebt in Frankreich und später in Italien, wo sie fübrendes Mitglied der sozialdemokratischen Partei wird.> (...)

‘Wenn ich abends mit den italienischen Genossen einen Spaziergang mache oder wir in ein Lokal einkehrten, gab es immer eine kleine Gruppe, die sich über die chaibe Tschinken oder über die chaibe Bolschewiki lustig machte.> (...) 


\section{Ja, das ist wirklich direkt aus dem Leben gegriffen. Einzelne Biograf/,} Biografien in einen grossen Gesamtkontext hineingesetzt, was ich wirklich sehr interessant finde, weil jetzt auch gerade von ihr, da bab ich noch nie etwas gehört gehabt.» (P19, Absatz 14-15 und 22-24)

P19 scheint in diesen Beispielen die Auffassung zu vertreten, dass Sich-Hineindenken und -Hineinversetzen in den Alltag historischer Personen prinzipiell möglich sei und einzelne Exponate oder Darstellungen in der Ausstellung hierfür eine Brückenfunktion bieten. Dass ein Sich-Hineinversetzen aus der eigenen, gegenwärtigen Perspektive heraus auch an Grenzen gelangen könnte, darüber reflektiert P19 in diesen Situationen nicht, was auch für die übrigen bislang zitierten Äusserungen der Besuchenden in diesem Bereich gilt.

Solche Überlegungen finden sich hingegen, neben der weiter oben zitierten Äusserung von P12, insbesondere bei P3. Der folgende Brennpunkt widmet sich daher dieser Person und stellt ihre Überlegungen zu Möglichkeiten und Grenzen des Vorstellbaren zusammen.

\section{Im Brennpunkt: P3}

"Für uns istes unvorstellbar, überbaupt Hunger zu haben»-Möglichkeiten und Grenzen des Sich-Vorstellens

In etlichen Situationen spricht P3 über mögliches Sich-Hineinversetzen in historische Gegebenheiten, stellt jedoch in gleichem Masse immer wieder auch die Unmöglichkeit dieses Sich-Hineinversetzens fest.

Gelingendes Sich-Hineinversetzen stellt P3 in Bezug auf ausgestellte Fotografien fest:

"Also solche Schwarz-Weiss-Aufnahmen, echte Fotos, sind sicher eindrücklich, kann man auch sich mal vorstellen, wenn man selber dastehen wïrde, wie man sich da füblt, wenn man weiss, dass jetzt Krieg ist, welche Gedanken einem da durch den Kopf gehen. Ist toll gemacht, dass von vorne auch die Leute dastehen und man sozusagen bei ihnen steht.» (P3, Absatz 25)

Jedoch spricht P3 auch davon, dass Sich-Vorstellen und -Hineinversetzen nicht möglich sei. Die im Zusammenhang mit dem wiederkehrenden «Blick ins Ausland»-Elementen gezeigten Zitatquellen von der Front veranlassen P3 zu der Feststellung: 
"Dann wieder die Ebenen mit den Te/Quellen. (...) Ah, von den Menschen, die in den Armen von einer Krankenschwester, nehm ich jetzt mal an, gestorben sind. 〈Kriegstagebuch〉, (...) das glaub ich, das können wir uns nicht vorstellen, was das heisst. (...) Von den Menschen, die zurückkehren (...) und alle (...) gezeichnet sind. Ich glaube, auch das können wir uns wirklich nicht vorstellen, (...) was es heisst, nach diesem Stellungskrieg zurïckzukommen.» (P3, Absatz 60)

In anderen Momenten äussert P3 ähnlich:

«Für uns ist es unvorstellbar, überhaupt Hunger zu haben, (...) dass wir irgendwo nach Essen bitte/ um Essen bitten müssen, oder eine Frühstückssuppe, oder anstehen für eine Brotkarte, (...) damit wir etwas zu essen haben.» (P3, Absatz 70)

"Hier gibt es einen Landesstreik, also Militär gegen die Bevölkerung, (...) das ist auch etwas, was wir uns nicht so vorstellen können.» (P3, Absatz 73)

P3 gebraucht in diesen Fällen Wir-Formulierungen, wodurch sich Überschneidungen mit einer weiter oben bereits geschilderten Kategorie eröffnen: den Bezügen zum eigenen Kollektiv und dort wiederum der spezifischen Form eines zeitlich abgrenzenden ‘Wir heute Lebenden〉. Die Unfähigkeit, sich hineinversetzen zu können, scheint sich für P3 aus einer zeitlichen Differenz zu ergeben. Gleichzeitig lässt diese Differenz im Rückblick Dinge klarer erscheinen und erlaubt einen distanzierteren Blick:

"Ja, alles, wie sich das jetzt steigert, wie die Not langsam schlimmer wird, (...) weil der Krieg zum Dauerzustand wird, und man weiss ja gar nicht, wie lange der geht. Jetzt im Rïckblick wissen wir ja, wie lange der Krieg gedauert hat, aber mitten nach drei Jabren, was man da füblt, wenn man nicht weiss, wann das endlich vorbei ist, das können wir uns auch überbaupt nicht vorstellen. (...) Die Spannungen, die das dann auch gibt, (...) mit der Armut, Mangel.»(P3, Absatz 65)

P3 ist die einzige Person, die mehrfach explizit über Schwierigkeiten spricht, sich historische Gegebenheiten vorstellen zu können. Im zuletzt gezeigten Beispiel finden sich Ansätze einer Reflexion über mögliche Gründe für dieses Sich-NichtVorstellen-Können. Nämlich bringt P3 im zuletzt gezeigten Beispiel eine Zeitdifferenz ins Spiel und die Einsicht, dass «im Rückblick» Dinge anders bewertet werden können. 
Die Gründe, die Besuchende annehmen, wenn sie über ein Nicht-Gelingen des Sich-Vorstellens und -Hineinversetzens sprechen, werden insgesamt eher schemenhaft sichtbar. ${ }^{1493}$ Für P12 steht, wie weiter oben dargestellt, die veränderte Haarmode und Kleidung im Zentrum:

"[...] wär die Schnurbartmode nicht, und die Haarschnitte, und die (...) Hemdenkragen [...]»(P12, Absatz 173)

Die von P3 gewählte Formulierung «im Rückblick wissen wir ja» deutet an, dass er oder sie ein Nicht-Gelingen des Sich-Vorstellens womöglich mit einer grundsätzlichen Alterität begründet, die zwischen sich selbst und den historischen Subjekten und deren unmittelbarer Lebenssituation besteht, allerdings werden auch dort die Überlegungen nicht weiter ausgeführt. Die anderen bei P3 zu findenden Passagen lassen insgesamt im Unklaren, ob das Nichtgelingen «wahrnehmungstheoretisch» und "geschichtstheoretisch» begründet wird oder vielmehr eher situativ in Bezug auf spezielle Gegebenheiten, die Schrecken des Krieges und Nöte der Bevölkerung. ${ }^{1494}$

\subsubsection{Eigene Geschichtsbilder und deren Bestätigung oder Revision}

Einen weiteren Bereich von Äusserungen, mit denen Besuchende über sich selbst als Besuchende reflektieren, bilden solche über eigene Geschichtsbilder und die Art und Weise, wie diese durch den Ausstellungsbesuch bestätigt oder revidiert werden. Unter Geschichtsbildern fasse ich mit Marko Demantowsky

1493 Meine Beobachtungen in Bezug auf das Nichtgelingen von Sich-Vorstellen und -Hineinversetzen und die Strukturierung der durch die Besuchenden hierfür angeführten Gründe sind inspiriert durch die Studie von Pampel (2007). Pampel differenziert für Gedenkstättenbesuchende nach angeführten Gründen für ein Nichtgelingen von Imagination und Empathie und kommt, wie oben bereits geschildert (vgl. Abschnitt 5.3.4), zu dem Befund, dass ein Nicht-Gelingen des Sich-Vorstellens oder -Einfühlens von den Besuchenden vor allem auf örtliche Gegebenheiten oder auf einen «Mangel an Anschaulichkeit oder an Information» zurückgeführt wird, in beiden Fällen also «praktisch» begründet werde, hingegen nur selten «wahrnehmungstheoretisch» oder «geschichtstheoretisch - mit der unaufhebbaren Distanz zwischen Vergangenheit und Gegenwart - oder psychologisch - mit der unüberwindlichen Differenz zwischen Subjekten» (Pampel 2007, S. 257 ff.; direkte Zitate S. 258, S. 264). Ich greife die hier angedeuteten Überlegungen weiter unten im Zwischenfazit auf (vgl. Abschnitt 8.7.5).

1494 Die Unterscheidung ist angeregt durch Pampel 2007, S. 258, S. 264. 
«stabilisierte Gefüge der historischen Vorstellungen einer Person [...]. Ein Geschichtsbild ist inhaltlich konkret und narrativ abrufbar. [...] Während das Geschichtsbewusstsein sich in den komplexen mentalen Operationen der Vergangenheitsdeutung, Gegenwartserfahrung und Zukunftserwartung manifestiert, zeigt sich das Geschichtsbild als ein mehr oder minder fixer Bestand vermeintlich sicheren historischen Wissens.» ${ }^{1495}$

Ausgehend davon können im Prinzip alle Äusserungen der Besuchenden, die diese innerhalb des Fokus I als unhinterfragt gültige Annahmen über historisches Sein und Werden formulieren, als Ausdruck von Geschichtsbildern betrachtet werden. An dieser Stelle geht es nun allerdings spezieller um explizite Äusserungen über die eigenen Geschichtsbilder, in denen die Besuchenden ihre eigenen Vorstellungen als Vorstellungen thematisieren und damit einen reflektierenden Blick auf sich selbst als Person und die eigenen Geschichtsbilder werfen. Implizit in ihren Äusserungen enthaltene und durchscheinende Geschichtsbilder wurden hingegen nicht systematisch erfasst und untersucht, da die Analyse darauf zielt, worauf die Besuchenden auf einer expliziten Ebene zu sprechen kommen, wie sie sich als Person explizit selbst sichtbar machen.

Ich habe dabei zwei Arten von Äusserungen unterschieden: die Fälle, in denen sich die Besuchenden als bestätigt in ihren Vorstellungen beschreiben, und die, in denen sie explizit angeben, bisherige Blickwinkel zu verändern, oder zumindest deren Infragestellung thematisieren. ${ }^{1496}$ Solche Äusserungen sind ähnlich mit einigen weiter oben bereits beschriebenen Relationen, etwa, wenn die Besuchenden Erstaunen oder Irritation formulieren oder konstatieren, dass sie etwas neu gelernt haben, bzw. umgekehrt, dass sie etwas bereits gewusst haben, wenig überraschend oder erwartbar finden. ${ }^{1497}$ Solcherlei Äusserungen tauchen im Datenmaterial vielfach auf, wurden jedoch nicht per se auch als Äusserungen über Geschichtsbilder

1495 Demantowsky 2009, S. 82.

1496 Diese Differenzierung in zwei mögliche Umgangsweisen ist inspiriert durch die Studie von Pampel, der anhand von nachträglichen Befragungen und unter der Überschrift «Bekräftigung und Veränderung von historischen und politischen Einstellungen» feststellt, die beforschten Gedenkstättenbesuchenden sähen «sich durch den Besuch im Grossen und Ganzen in ihrer Deutung bzw. Bewertung des historischen Geschehens bestätigt» (Pampel 2007, S. 328 ff., direkte Zitate S. 328 u. S. 330), und der insgesamt schlussfolgert, die Besuchenden sähen «den Sinn ihres Aufenthalts eher in einer Bestätigung des eigenen Geschichtsbildes als darin, es kritisch zu hinterfragen» (Pampel 2007, S. 348). Vgl. hierzu auch Abschnitt 5.3.6.

1497 Vgl. Abschnitt 8.7.2. 
eingestuft. Denn Relationen beziehen sich häufig auf singuläre Aspekte des historischen Geschehens und Wissensbestandteile der Besuchenden in Bezug auf diese, während ich Geschichtsbilder eher als diese singuläre Ebene übergreifende, grundsätzlichere und verdichtete Vorstellungen von vergangener Wirklichkeit verstehe und nach Äusserungen der Besuchenden über diese suche. Auf dieser abstrakten, übergreifenden und explizit-reflektierenden Ebene habe ich lediglich eine kleine Anzahl von Äusserungen identifiziert, die ich nachfolgend gesamthaft vorstelle.

Zunächst betrachte ich den Bereich von Äusserungen, in denen Besuchende vorhandene Geschichtsbilder als bestätigt beschreiben. In der geschilderten stark verdichteten Form finden sich diese bei P8 und werden nachfolgend in einer Fallbetrachtung näher beleuchtet:

\section{Im Brennpunkt: P8}

\section{«Insgesamt so, wie ich mir die Schweiz vorstelle»-Das eigene Schweizbild im} Visier

Bei P8 handelt es sich um eine Person aus Deutschland, die sich während des Besuchs wiederholt mit dem eigenen Schweizbild beschäftigt, und zwar unter mindestens dreierlei Perspektiven: erstens in Bezug auf das zur Zeit des Ersten Weltkriegs bestehende Selbstverständnis der Schweiz, zweitens in Bezug auf das von der Ausstellung vermittelte Schweizbild sowie drittens auch in Bezug auf das eigene Bild der Schweiz, über dessen Bestätigung oder Modifizierung P8 an manchen Stellen des Ausstellungsbesuchs nachdenkt. Äusserungen über eigene Geschichtsbilder sind im Fall von P8 stets Äusserungen über das eigene Schweizbild oder einzelne Facetten daraus. Nachfolgend steht dieser drittgenannte Bereich im Fokus der Darstellung, wobei sich in vielen Textstellen alle drei Perspektiven vermengen.

Bei Betrachtung eines Zierkissens, das der Erinnerung an die Grenzbefestigung diente und in der Mitte mit einem Schweizerkreuz und der Aufschrift «Grenzbesetzung Weihnachten 1914» versehen ist, äussert P8 etwa:

"Dann wird's jetzt hier sehr nationalistisch, da (wohl) ein klassisches Exponat. Schweizer Kreuz. ‘Grenzbesetzung Weihnachten 1914〉.

Wirkt auf mich irgendwie ein bisschen lächerlich, dass man eine Grenzbesetzung, die militärisch relativ unspektakulär ist, durch solche Trophäen feiern muss. (...) Passt aber irgendwie in das Bild des Schweizer Militarismus, das ich so habe.» (P8, Absatz 5) 
P8 spricht hier von seinem bzw. ihrem «Bild des Schweizer Militarismus» und davon, dass sich das gezeigte Objekt in eigene Vorstellungen von diesem Schweizer Militarismus einfüge, in dem eigentlich «unspektakulär[e]» Ereignisse wie die Grenzbesetzung zur Zeit des Ersten Weltkriegs gefeiert würden. Auffällig ist in der zitierten Passage die Formulierung «feiern muss». Warum P8 von einem Müssen spricht, kann aus dem Kontext nicht zweifelsfrei erschlossen werden. Denkbar ist, dass er oder sie mit dieser Formulierung Ideen von einer Funktionalisierbarkeit historischen Geschehens ausdrückt. Das Feiern militärischer Ereignisse würde dann einen Zweck für die Gemeinschaft erfüllen, etwa ein identitätsstiftendes Moment darstellen, das mangels ernsthafter Gefährdungslagen und feierbarer Kampferfolge auf Umwegen konstruiert werden «muss». Das Feiern der Grenzbesetzung passe jedenfalls in das eigene "Bild des Schweizer Militarismus", so konstatiert P8, und macht damit deutlich, dass er oder sie einen solchen Umgang mit militärischen Ereignissen für sinnbildlich und typisch schweizerisch hält.

Dass P8 die militärische Lage der Schweiz während des Ersten Weltkriegs für gefährdungsarm hält, kommt auch in einer zweiten Passage zum Ausdruck, in der ebenfalls das eigene Geschichtsbild in Bezug auf die militärische Situation der Schweiz während des Krieges reflektiert wird. So äussert P8 bei Betrachtung der Abbildung von Grenzbarrikaden (vgl. Umschlagbild):

"Hier (...) wird das romantische Soldatenleben dargestellt. Muntere Soldaten, die sich auf ibren Karren stützen, martialische Symbole auf der Mütze. Kinder, die sich des Anblicks erfreuen. Insgesamt so, wie ich mir die Schweiz vorstelle. Ein ruhiges Bild. (...) Eine Idylle.»(P8, Absatz 12)

P8 spricht hier über eigene Vorstellungen von der Schweiz, die er oder sie sich demzufolge ruhig und idyllisch vorstellt, verbunden mit einem unaufgeregten und unbedrohten Soldatenalltag. Die Bildinhalte scheinen für P8 dieses Bild zu bestätigen. Aufschlussreich ist jedoch, welche Elemente des Bildes P8 überhaupt für diese Bestätigung herausgreift. Es sind dies die Soldaten, ihre Mützen und die im Hintergrund schemenhaft zu erkennenden Kinder, die auf einem Wagen sitzend die Szenerie beobachten. Zwar trügen die abgebildeten Soldaten «martialische Symbole auf der Mütze» - diese Äusserung kann zugleich als Wiederaufgreifen des im vorigen Beispiel behandelten Themas eines «lächerlich[en]» Militarismus gedeutet werden -, seien aber "[m] unter[.]", insofern also heiter und weder verletzt noch akut bedroht. Auf eine ruhige Lage deutet für P8 wohl auch die Anwesenheit von Kindern in der Szene hin. Es ist auffallend, dass er oder sie überhaupt auf die 
im Hintergrund positionierten Kinder hinweist, während dem zentralen Bildelement im Vordergrund, der Verbarrikadierung einer Strasse, keine Aufmerksamkeit gewidmet wird. P8 deutet insofern das Bild mit anderen inhaltlichen Schwerpunkten, als dies die Bildkomposition selbst und die Ausstellungsmachenden mit ihrer Bildbeschriftung ( «Provisorische Barrikaden am Zollposten zwischen Hegenheim und Allschwil 1914») nahelegen. P8 liest weder die Beschriftung, noch geht er oder sie auf die abgebildeten Barrikaden näher ein, greift vielmehr diejenigen Bildelemente heraus, die sich für die Konstruktion bzw. Bestätigung eines spezifischen Schweizbildes eignen.

Die dritte von drei Passagen, in denen P8 im Verlauf des Ausstellungsbesuchs auf die Bestätigung von vorhandenen Vorstellungen eingeht, bezieht sich dann nicht mehr auf die militärische Situation und eine vorgestellte Abwesenheit von Bedrohung in der Schweiz, sondern auf den wirtschaftlichen Bereich und konkreter die Produktion von Käse zu Kriegszeiten. Nach Betrachtung zweier zugehöriger Bildquellen äussert P8:

«Exponate zeigen, oder die Bilder zeigen eigentlich relativ deutlich, wie viel Küse (bier) produziert wird. (...) So stellt man sich das vor. (...)»(P8, Absatz 38)

Für P8 erweisen sich die Abbildungen demnach als erwartungskonform. Durch den Einsatz der Formulierung «man» wird allerdings, im Vergleich zu den vorigen Passagen, nicht deutlich, ob P8 tatsächlich von einem eigenen Schweizbild spricht oder vielmehr von einem Schweizbild, das gängig ist, das «man» hat und das hier bestätigt wird.

Angesichts dessen, dass es sich bei P8, wie bereits dargelegt, um eine Person mit hoher Bewusstheit für die Konstruiertheit von Geschichte handelt, ist es möglich, dass sich in dieser Passage Ironie ausdrückt, wobei sich diese Ironie dann entweder belustigend auf das eigene Schweizbild oder aber auch auf ein allgemein gängiges, klischeehaftes Schweizbild beziehen kann - möglicherweise eine Kombination aus beiden. Generell bewegen sich die gezeigten Äusserungen von P8 bisweilen im Graubereich zwischen der Reproduktion, De-Konstruktion und Verspottung von Geschichtsbildern.

Im Überblick über die drei zitierten Passagen lässt sich feststellen, dass P8 klischeehafte Vorstellungen von einer Schweiz als einem trotz Krieg idyllischen, friedliches und Käse produzierenden Land aufgreift, solche Vorstellungen im Ausstellungsverlauf auch explizit als Vorstellungen benennt und sich fragt, ob und inwiefern die in der Ausstellung befindlichen Elemente zur Bestätigung dieser Vorstellungen 
beitragen können. Vereinzelt werden Ausstellungselemente darauf hin «zugedeutet», dass sie sich in vorhandene Vorstellungen nahtlos einfügen lassen.

Bestätigung von Geschichtsbildern ist allerdings durchaus nicht der alleinige Modus, in dem sich P8 durch die Ausstellung bewegt, vielmehr kommt es auch zur Revision eines Bildes. So äussert P8 bei Lektüre eines Ausstellungstexts zum Landesstreik, der über das Truppenaufgebot zur Niederschlagung des Landesstreiks berichtet:

«Am 5. November bietet der Bundesrat 800 Soldaten [eigtl. 8000] und Offiziere für die Besetzung Zürichs anf.> Okay, jetzt scheint sich hier die Situation tatsächlich noch mehr zuzuspitzen.

¿Zu Beginn des Landesstreiks erhöht er das Truppenaufgebot auf insgesamt 110000 Mann.> Überrascht jetzt, so hätte ich die Schweiz gar nicht eingeschätzt.» (P8, Absatz 75)

Hier reflektiert P8 darüber, dass historisches Geschehen nicht mit vorhandenen Vorstellungen in Einklang zu bringen sei. P8 führt die Gedanken nicht weiter, weshalb lediglich Vermutungen darüber angestellt werden können, in welcher Hinsicht genau die Schweiz bislang anders eingeschätzt wurde. Die Überraschung kann sich, in Analogie zu den in den vorigen Beispielen zum Ausdruck gekommenen Vorstellungen über eine ruhige und idyllische Schweiz, beispielsweise auf das hohe Militäraufkommen beziehen oder auf die damit entstehende Unruhe und somit Nicht-Idylle innerhalb des Landes oder aber auf die Rolle des Bundesrats als Akteur im Landesstreik u.v.m.

Das in der Fallbeschreibung zu P8 zuletzt genannte Beispiel fällt - unabhängig von seiner nicht bis ins Detail zu ergründenden Stossrichtung - unter die Kategorie der Revision von Geschichtsbildern, die neben der Bestätigung von Geschichtsbildern den zweiten Bereich von expliziten Äusserungen der Besuchenden über ihre eigenen Vorstellungen und Geschichtsbilder darstellt. Der nachfolgende Abschnitt stellt die entsprechenden Äusserungen zusammen.

Zum Bereich der Infragestellung und Revision von vorhandenen Geschichtsbildern finden sich im Datenmaterial einige wenige weitere Textstellen. Ebenfalls Vorstellungen von der Schweiz, nun im Verhältnis zum Ausland, werden tangiert im Fall von P3. Im Zusammenhang mit einem Ausstellungstext zur wirtschaftlichen Situation der Schweiz während des Krieges stellt diese Person fest: 
"Aha, hier kommt jetzt nochmals das, der Gewinn mit dem Krieg, Hochkonjunktur in der Schweiz, weil die Schweiz ist ja (eben) (...) eigentlich gar nicht divekt betroffen. (...)

Das ist interessant, das ist, das ist wirklich ein Thema, wie die Schweiz profitiert, das hab ich auch zu wenig (...). Ich hab bis jetzt Geschichte immer international angesehen, und hier wird jetzt auch sehr die Schweiz ins Zentrum gerückt, was die Schweiz gemacht hat. (...) Find ich interessant.» (P3, Absatz 47-48)

Die ausgewählte Textstelle ist in zweierlei Hinsicht aussergewöhnlich. Zum einen handelt es sich hier um die einzige Fundstelle, in der in derartiger Explizitheit darüber reflektiert wird, durch die Ausstellung zu einem neuen Blick auf die Rolle der Schweiz im Weltgeschehen angeregt zu werden. Nämlich bekundet P3, die Schweiz nun überhaupt erstmals als beachtenswerte Akteurin innerhalb des kriegführenden Staatengefüges zu begreifen.

Zum anderen ist die Textstelle auch deshalb eindrücklich, weil P3 nicht nur auf einer Metaebene über den erfolgten Blickwechsel reflektiert, sondern weil dieser Blickwechsel überdies unmittelbar zuvor im Prozess sichtbar wird. Beginnt P3 das Lesen des Textes noch mit der Vorstellung, die Schweiz sei «eigentlich gar nicht direkt betroffen", kommt er oder sie unmittelbar während des Lesens offensichtlich zu der Einsicht, dass die Schweiz «profitiert» habe und überhaupt eine nennenswerte Akteurin des Geschehens sei.

Bei den zitierten Äusserungen der Besuchenden P8 und P3 handelt es sich um diejenigen, in denen einerseits mit dem höchsten Grad an Explizitheit über eigene Geschichtsbilder reflektiert wird, andererseits diese Bilder, von denen die Rede ist, mit gewisser Verdichtung und gewissem Abstraktionsgrad («das Bild der Schweiz >) vorliegen.

Als weniger expliziter und weitreichender Vergleich hierzu kann die bereits bekannte Äusserung von P18 dienen, darüber, dass in der Ausstellung «14/18» entgegen dem aus gesehenen Filmen Bekannten nicht die "Schrecken vom Krieg», sondern «Belle Époque, Woblstand, Ballettschuhe» gezeigt werden:

«Der Erste Weltkrieg, habe ich im Sommer einige Filme gele/, gesehen und die Schrecken vom Krieg gesehen und jetzt sehe ich da (...), EBEN, Belle Époque, Woblstand, Ballettschuhe.»(P18, Absatz 4) 
Ein weiteres Beispiel für die Revision einer Vorstellung mit etwas geringerer Reichweite stellt etwa auch die folgende Äusserung von P19 dar, zunächst einen Ausstellungstext lesend und sich anschliessend dazu frei äussernd:

"Zwischen dem 3. und 7. August 1914 rücken 220000 Mann und 45000 Pferde ein. Der durchschnittliche Mannschaftsbestand während des Kriegs betrügt jedoch nur 70000, bei Kriegsende sind noch 12000 Mann im Aktivdienst. (...) Im Schnitt leistet, leisten die Armeeangehörigen 500 Diensttage, meist weit entfernt von ibren Wohnorten.'

[liest Text weiter und äussert sich zu anderen Aspekten des Textes, dann:] Ja, das ist interessant, dass man sich mal ein Bild machen kann, wie viele Soldaten dass da im Dienst gewesen sind, und 500 Diensttage (...). Ja wenn man denkt, vier Jahre, vier mal 360 Tage, und davon hat man doch nur im Durchschnitt 500 Diensttage gemacht. Das zeigt doch, wie anders man sich das vielleicht vorstellt, dass man eigentlich nur sebr punktuell im Dienst gestanden ist und (...) der Soldat eigentlich doch grossmebrheitlich hat zu Hause sein können. (...)»(P19, Absatz 35-36)

In der hier zitierten Passage bezieht sich die Irritation auf die Dienstzeit schweizerischer Soldaten, die entgegen den Vorstellungen «eigentlich nur sehr punktuell» gewesen sei. Auch hier reflektiert die Person darüber, dass etwas anders sei als eigentlich vorgestellt, begibt sich also auf eine Metaebene zu den eigenen Vorstellungen bzw. den Vorstellungen, die «man» haben könne. Jedoch geht es dabei stärker um die Revision einzelner Vergangenheitspartikel.

Die Spannbreite an Äusserungen zwischen der Bestätigung und Revision verdichteter Geschichtsbilder und der Bestätigung und Revision singulärer Vorstellungen über Vergangenheitspartikel erweist sich im Datenmaterial insgesamt als ausgesprochen weit und fliessend. Auf einzelne Aspekte historischen Geschehens bezogene Äusserungen bilden im Datenmaterial eher den Normalfall. Solche Äusserungen von Irritationen, Bestätigungen, Ergänzungen von partikularen Vorstellungen waren weiter oben im Rahmen der Darstellung von Relationen bereits Gegenstand. Bezüge zu abstrakten Geschichtsbildern, wie sie in den weiter oben vorgestellten Äusserungen von P8 und P3 zu finden sind, kommen im Vergleich eher selten vor.

Selbstverständlich gilt auch in diesem Bereich, was analog bereits weiter oben für Benennungen von Relevanz und Wichtigkeit durch die Besuchenden festgestellt wurde: Ebenso, wie sich die Relevanz von Themen nicht zwingend in einer 
expliziten Benennung dieser Relevanz durch die Besuchenden äussern muss, sondern implizit in einer wiederholten Beschäftigung mit einem Thema über den Besuchsverlauf hinweg oder in der Art und Weise dieser Beschäftigung zum Ausdruck kommen kann, bedeutet auch die weitgehende Abwesenheit von expliziten Reflexionen über eigene Geschichtsbilder nicht, dass die Besuchenden nicht über solche Geschichtsbilder verfügen würden oder dass es nicht zur Bestätigung oder Revision solcher Geschichtsbilder während des Ausstellungsbesuchs käme. Das von mir eingesetzte Kategoriensystem zielt jedoch auf die Strukturierung der expliziten Verbalisierungen, kann insofern implizit aufscheinende Geschichtsbilder und deren Entwicklung im Besuchsverlauf nicht systematisch einfangen. Hierfür wären beispielsweise Einzelfallbetrachtungen eine geeignete Form, bei denen die Behandlung eines Themas durch eine Person über den gesamten Besuchsverlauf hinweg systematisch betrachtet wird. ${ }^{1498}$

\subsection{5 Übergreifende Befunde, Zwischenfazit und Einordnung}

Auf den vorangegangenen Seiten wurden drei Bereiche vorgestellt, innerhalb deren Besuchende während des Ausstellungsbesuchs ihre eigene Person und Lebenswelt sichtbar machen. Ich fasse diese drei Bereiche nachfolgend zunächst zusammen und formuliere dann, beginnend mit dem dritten Bereich und die Überlegungen anschliessend auf die anderen beiden Bereiche ausdehnend, übergreifende Befunde und Bezüge zu vorhandenen empirischen Studien sowie zu theoretischen Überlegungen.

Ein erster Bereich wurde als Relationen überschrieben (Abschnitt 8.7.2). Versammelt wurde dort eine umfangreiche Gruppe von Äusserungen, im Rahmen deren Besuchende sich in Bezug zu etwas setzen. Eine grosse Bandbreite möglicher Relationen wurde dort identifiziert, die ein Spektrum aus stärker kognitiven Zugängen, beispielsweise Nennungen von Vorwissen oder Fragen, und nicht-nurkognitiven Zugängen, darin Äusserungen von Emotionen wie Irritationen und Betroffenheit, versammeln und innerhalb dieses Spektrums auch Urteile beinhalten. Es wurde aufgezeigt, dass sich diese Äusserungen in der Regel einem Bezugspunkt zuordnen lassen, was durch die Wahl des Begriffs Relationen verdeutlicht wird. Nämlich beziehen sich derartige Äusserungen entweder auf einen Aspekt des

1498 In sehr knapper Form habe ich einen solchen Vergleich über den Besuchsverlauf hinweg andernorts für P19 und dessen Äusserungen über wirtschaftliche Verflechtungen der Schweiz dargestellt (Thyroff 2017b, S. 116, sowie Thyroff 2017c, S. 10). 
Geschehens (Fokus I) oder auf einen Aspekt der Ausstellung und ihrer Elemente (Fokus II). Vielfach liegt der Bezugspunkt auch unentscheidbar zwischen beiden Bereichen, so etwa bei Einflechtungen von Adjektiven ( interessant〉, 〈spannend〉) oder wenn die Grenzen zwischen historischem Geschehen und der Art von dessen Darstellung in den Äusserungen der Besuchenden verfliessen.

«1921〉, heisst es hier, 〈bricht sie mit dem Bolschewismus, lebt in Frankreich und später in Italien, wo sie führendes Mitglied der sozialdemokratischen Partei wird.> Angelica Balabanoff. Spannend.» (P12, Absatz 33)

Selbst wenn Bezugspunkte nicht explizit gemacht werden, drücken sich in solchen Äusserungen implizite Relationen aus: Irgendetwas ist es, das P12 hier spannend findet, wobei sich die geäusserte Spannung in diesem Fall zum Beispiel auf die Biografie Angelica Balabanoffs beziehen kann und damit einen Aspekt des Geschehens (Fokus I) oder aber auf die Art und Weise, wie Angelica Balabanoff in der Ausstellung «14/18» porträtiert wird (Fokus II) - mutmasslich beide Aspekte in Vermengung.

Einen zweiten Bereich stellten die Bezüge zur eigenen Lebenswelt dar (Abschnitt 8.7.3). Auch dort wurde ein breites Spektrum von Formen identifiziert, nämlich Bezüge zum eigenen Ort und Raum, zum eigenen Kollektiv, zur eigenen Familie, zu eigenen Besitztümern, zur eigenen Militärzeit, zur eigenen Ausbildung, zur eigenen Berufs- und Vermittlungstätigkeit, zu eigenen Erfahrungen mit Geschichtskultur sowie weitere biografische Bezüge und im Umkehrschluss auch Feststellungen zur Abwesenheit von Bezügen.

Als dritter Bereich innerhalb der Bezüge zur eigenen Person und Lebenswelt wurden diejenigen Äusserungen identifiziert, in denen Besuchende über ibre eigene Person und Rolle in der Ausstellung reflektieren (Abschnitt 8.7.4), sich also beispielsweise über ihre eigenen Geschichtsbilder und deren Bestätigung und Revision durch die Ausstellung äussern oder über ihre eigene Nähe und Ferne zum vergangenen Geschehen nachdenken und dort über Möglichkeiten des Sich-Vorstellens und -Hineinversetzens sprechen. Dort zeigte sich, dass die Besuchenden mehrheitlich von einem gelingenden Sich-Vorstellen und -Hineinversetzen ausgehen. Insbesondere die in der Ausstellung enthaltenen Fotografien scheinen von den Besuchenden als Hilfsmittel verstanden zu werden, um Sich-Vorstellen und -Hineinversetzen zu ermöglichen.

Dieser Befund ist anschlussfähig an Ergebnisse weiterer Studien zu Museums-/Ausstellungsbesuchenden, die die Bedeutung von Sich-Vorstellen/Imagi- 
nation und Sich-Hineinversetzen/Empathie hervorgehoben haben. Wie im Rahmen des Forschungsüberblicks bereits dargelegt, zeigt eine Reihe von Studien, dass sich Besuchende während ihres Besuchs solche Erlebnisse entweder erhoffen und erwarten oder als erlebt berichten, ${ }^{1499}$ wobei Studien für den Bereich der Empathie von Fall zu Fall stärker von einem Sich-Hineinversetzen sprechen oder auch das Erkennen von Alterität im Sinne des Empathiebegriffs Juliane Brauers mitdenken und beobachten. ${ }^{1500}$ Nicht nur die geschichtsdidaktische Theorie, sondern auch diese Besucherstudien verorten dabei Imagination und Empathie an der Schnittstelle zwischen Emotion und Kognition und schreiben ihr Potenzial im Zusammenhang mit historischer Erkenntnis zu. ${ }^{1501}$

Eine differenzierte Betrachtung zu diesem Phänomen findet sich bei Bert Pampel, dessen Befunde sich zur Kontextualisierung der meinigen anbieten. Pampel stellte in seiner Analyse der Besuchsmotive von Gedenkstättenbesuchenden fest, Letztere erhofften sich «von ihrem Aufenthalt in Gedenkstätten eine Vorstellung davon, «wie es früher war〉, den Nachvollzug des historischen Geschehens oder sogar eine Zeitreise in die Vergangenheit». ${ }^{1502}$ Gemachte Erfahrungen gliedert Pampel unter anderem in «Vorstellungen (Imaginative Erfahrungen)» und «Einfühlung (Empathische Erfahrungen)». Besuchende hätten sowohl gelingende Fälle des Sich-Vorstellens und -Einfühlens, aber auch Schwierigkeiten berichtet, sowohl dahingehend, sich den «Ort des Geschehens» vorzustellen, als auch, «sich in die Opfer hineinzuversetzen». ${ }^{1503}$ Darin unterscheiden sich die Befunde Pampels von den meinigen, wo die Besuchenden Sich-Vorstellen und -Hineinversetzen meistens als gelingend behandeln, demgegenüber seltener auf dessen Grenzen zu sprechen kommen. Es ist naheliegend, diese Differenz mit der unterschiedlichen historischen Thematik zu begründen, die im Fall von Gedenkstätten zu ehemaligen Konzentrationslagern besondere Hürden des Sich-Einfühlens und Nachvollziehens bereithält.

1499 Pekarik et al. 1999, S. 152 u. 155.; Höge 2006, S. 215, S. 218 f.; Pampel 2007, S. 245 ff.; Pleitner 2008, S. 108 f.; Pleitner 2011, S. 39; Kohler 2016, S. 230 ff. Die Differenzierung nach erwarteten und tatsächlich erlebten Aspekten ist angeregt durch Pekarik et al., die danach fragen, "what visitors look forward to and find satisfying» (Pekarik et al. 1999, S. 152). Vgl. hierzu ausserdem die Ausführungen in Abschnitt 5.3.4.

1500 Brauer 2013, insb. S. 84 ff.; vgl. für eine entsprechende Einordnung der genannten Studien die Ausführungen in Abschnitt 5.3.4.

1501 Pleitner 2008, S. 110; Kohler 2016, S. 164, S. 203. Für Ausführungen zur geschichtsdidaktischen Theorie zum Thema siehe Abschnitt 3.4.

1502 Pampel 2007, S. 257.

1503 Pampel 2007, S. 257 ff.; direkte Zitate S. 257, S. 258, S. 262, S. 263. 
Interessante Bezüge zeigen sich allerdings in der Art und Weise, wie NichtGelingen eines Sich-Vorstellens und -Einfühlens begründet wird. Ersteres werde von den Besuchenden, so Pampel, vor allem auf die örtlichen Gegebenheiten zurückgeführt, nämlich auf das inzwischen veränderte Aussehen des Ortes, im zweiten Fall unter anderem auf einen «Mangel an Anschaulichkeit oder an Information», in beiden Fällen also «praktisch» begründet, hingegen nur selten «wahrnehmungstheoretisch» oder «geschichtstheoretisch - mit der unaufhebbaren Distanz zwischen Vergangenheit und Gegenwart - oder psychologisch - mit der unüberwindlichen Differenz zwischen Subjekten». ${ }^{1504}$

Diese weitgehende Abwesenheit von Reflexionen über wahrnehmungsoder erkenntnistheoretisch begründbare Hürden des Sich-Hineinversetzens und -Vorstellens lässt sich ebenso in dem von mir analysierten Material feststellen. Ansätze finden sich in folgender Äusserung von P3:

"Ja, alles, wie sich das jetzt steigert, wie die Not langsam schlimmer wird, (...) weil der Krieg zum Dauerzustand wird, und man weiss ja gar nicht, wie lange der geht. Jetzt im Rückblick wissen wir ja, wie lange der Krieg gedauert hat, aber mitten nach drei Jabren, was man da füblt, wenn man nicht weiss, wann das endlich vorbei ist, das können wir uns auch ïberbaupt nicht vorstellen. (...) Die Spannungen, die das dann auch gibt, (...) mit der Armut, Mangel.»(P3, Absatz 65)

In anderen gezeigten Beispielen wird die Unmöglichkeit eines Sich-Vorstellens und -Hineinversetzens, sofern sie überhaupt festgestellt wird, von den Besuchenden eher situativ mit der veränderten Alltags- und Lebenssituation, konkreter Haarmode und Ernährungslage (P12, Absatz 173; P3, Absatz 70) in Verbindung gebracht, also, ähnlich zu den Befunden Pampels eher auf praktischer Ebene behandelt, aber nicht erkenntnistheoretisch eingebettet.

Wenn Pampel feststellt, dass Besuchende Nicht-Gelingen des Sich-Hineinversetzens auf einen «Mangel an Anschaulichkeit oder an Information» zurückführen, ${ }^{1505}$ so lässt sich dieser Befund «umgepolt» auch auf die Äusserungen der von mir beforschten Besuchenden übertragen, nämlich wird dort gelingendes Sich-Vorstellen und -Hineinversetzen mit der in der Ausstellung gefundenen

1504 Pampel 2007, S. 258, S. 264.

1505 Pampel 2007, S. 264. 
Alltags-/Lebensnähe und Anschaulichkeit in Verbindung gebracht. Das Phänomen des Sich-Vorstellens und -Hineinversetzens verknüpft sich mit dem Medium Fotografie, kommen doch zahlreiche Äusserungen der Besuchenden im Zusammenhang mit diesen zustande oder schreiben sie Fotografien sogar explizit das Potenzial zu, vergangenen Alltag sichtbar zu machen oder Vorstellungen und Sich-Hineinversetzen zu evozieren. ${ }^{1506}$

Dabei drücken Besuchende durchaus ein Bewusstsein für die zeitliche Differenz und Andersartigkeit zwischen dem Abgebildeten und der Gegenwart aus. Sie sprechen zum Beispiel davon, sich die «Stimmung damals» (P19, Absatz 34) vorzustellen oder wie "damals die durchschnittlichen Wohnzimmer ausgerïstet waren» (P21, Absatz 9). In einem früheren Abschnitt (Fokus I) zeigte sich, dass Besuchende nicht zuletzt im Zusammenhang mit Fotografien auf eine Unterschiedlichkeit zwischen Vergangenheit und Gegenwart zu sprechen kommen, etwa im Hinblick auf das veränderte Aussehen von Orten, technische Belange und Fortbewegungsmittel, im Hinblick auf Fragen des Alltagslebens der Bevölkerung wie soziale Not und Sozialhilfe, Kleidung, Aussehen, Alltagspraktiken. ${ }^{1507}$ Offenbar gehen sie jedoch neben oder trotz dieser Feststellungen von Unterschiedlichkeit auch und dennoch von Möglichkeiten des Sich-Vorstellens und -Hineinversetzens aus.

Die geschilderten Befunde lassen sich verbinden mit geschichtsdidaktischen Überlegungen zu den medienspezifischen Stärken und Schwächen von Bildquellen. Wie weiter oben bereits ausgeführt, wird Bildern in der didaktischen Literatur einerseits Anschaulichkeit und imaginatives Potenzial zugeschrieben, wird umgekehrt auf ihre Subjektivität und Ausschnitthaftigkeit hingewiesen. ${ }^{1508}$ Darunter sind es nun gerade die erstgenannten Aspekte, die Anschaulichkeit und das imaginative Potenzial, die sich auch in den Äusserungen einiger Besuchender widerspiegeln. Jedoch zeigt sich auch ein Potenzial von Fotografien dahingehend, auf die Andersartigkeit zwischen Vergangenheit und Gegenwart zu verweisen. Die Rolle von Fotografien in der konkreten Ausstellung erweist sich insofern als mehrschichtig.

Diese Mehrschichtigkeit entspricht der Mehrschichtigkeit des Empathiebegriffs, zumindest in der Konzeption Juliane Brauers, wo Empathie eine inhärente Gleichzeitigkeit und Widersprüchlichkeit aus Nähe und Ferne beinhaltet und

1506 Jedoch durchaus auch in Bezug auf andere Ausstellungselemente. Vgl. hierzu die differenzierte Darstellung in Abschnitt 8.7.2.4.

$1507 \mathrm{Vgl}$. Abschnitt 8.5.4.3 und 8.5.5.

1508 So etwa bei Pandel 201la, S. 13 ff., insb. S. 13, S. $24 \mathrm{ff}$. 
gerade aus dieser Kombination «produktive Irritation» entstehen soll. ${ }^{1509}$ Jedoch lässt sich in den Verbalisierungen der Besuchenden gerade eine solche irritierende Gleichzeitigkeit wenig bis gar nicht beobachten. In der Regel bringen die Besuchenden beide Aspekte nicht systematisch zusammen, sprechen vielmehr situativ entweder über die Unterschiedlichkeit von Situationen oder berichten von SichVorstellen und -Hineinversetzen, oder sogar beides in Kombination, schlussfolgern jedoch dennoch nur begrenzt Limiten eines Sich-Vorstellens und -Hineinversetzens, vor allem nicht erkenntnistheoretisch eingebettet und als Reflexion über einen «Unterschied zwischen dem Selbst und dem Anderen». ${ }^{1510}$ Inwiefern tatsächlich Irritation bewirkt wird, lässt sich anhand der momentbezogenen Verbalisierungen der Besuchenden nicht befriedigend nachvollziehen.

In der Logik des Kompetenz-Strukturmodells historischen Denkens ${ }^{1511}$ berührt der zuletzt geschilderte Bereich mehrere Kompetenzbereiche. Sich-Hineinversetzen und -Vorstellen liesse sich einerseits den Methodenkompetenzen zuordnen, ${ }^{1512}$ jedoch auch als Teilbereich von historischer Orientierung verstehen und dort wiederum dem Bereich «des Welt- und Fremdverstehens» zuweisen. ${ }^{1513}$ Der letztgenannte Bereich stellt den Bezugsmassstab für meine nachfolgenden Überlegungen dar, und dabei spezifischer die durch Andreas Körbers bereits erfolgte theoretische Wendung des Bereichs in Bezug auf Ausstellungs-/Museumsbesuchende (siehe Tabelle A). ${ }^{1514}$

Beim Versuch der Zuordnung meiner Befunde zu diesem Bereich ergeben sich Anknüpfungspunkte, aber auch Passungsschwierigkeiten.

Für Körber beinhaltet das basale Niveau im Bereich des Welt- und Fremdverstehens, «in irgendeiner Weise zu kommunizieren, dass die Ausstellung etwas an

1509 Brauer 2013, insb. S. 84 ff., direktes Zitat S. 88. Vgl. zum Empathiebegriff auch die Ausführungen in Abschnitt 3.4.2.

1510 Brauer 2013, S. 86.

1511 Schreiber et al. 2007.

1512 So bei Johannes Meyer-Hamme, der den Bereich von «Perspektivwechsel» und «Empathieversuchen» unter «Methoden- und Sachkompetenzen» behandelt (Meyer-Hamme 2013, S. 134).

$1513 \mathrm{Zu}$ diesem Bereich: Schreiber et al. 2007, S. 30. Historische Orientierung lässt sich, dem genannten Modell folgend, in vier Bereiche aufgliedern, nämlich erstens, «das eigene Geschichtsbwusstsein zu re-organisieren», sowie zweitens den Bereich der «Reflexion und Erweiterung des Welt- und Fremdverstehens», drittens den Bereich der «Reflexion und Erweiterung des Selbstverstehens» und viertens den Bereich der «Reflexion und Erweiterung der Handlungsdispositionen» (Schreiber et al. 2007, S. 29 ff., direkte Zitate S. 29, S. 30, S. 31).

1514 Körber 2010a und 2010b; siehe hierzu ausserdem die Ausführungen in Abschnitt 3.3. sowie Körber 2009. 
ihren [der Besuchenden, Anm. JT] vorherigen Vorstellungen über den ausgestellten Zusammenhang, die fragliche Zeit, die damaligen Menschen geändert hat». ${ }^{1515}$ Für die höheren Niveaus bringt Körber weiter die allmähliche Einsicht in die Alterität zwischen Vergangenheit und Gegenwart ins Spiel, bis hin zum elaborierten Niveau, in dem Besuchende «in der Lage [sind], ihre eigenen Bemühungen um das Verständnis der dargestellten Menschen, Lebensverhältnisse als perspektivische Versuche und als nie ganz gelingend anzuerkennen». ${ }^{1516}$ Körbers Entwurf vermengt also mehrere Ebenen: zum einen eine zunehmende Einsicht in Alterität und schliesslich in die Unmöglichkeit einer vollständigen Einsicht in historisches Geschehen, zum anderen eine Veränderung von Sichtweisen auf vergangenes Geschehen und die zunehmende Fähigkeit, diese neuen Einsichten auf den Begriff zu bringen.

Beim Sich-Hineinversetzen und-Vorstellen, so wie es die hier beforschten Besuchenden thematisieren, geht es hingegen zumeist schlicht um eine Einsicht in historisches Geschehen, was insofern stärkere Passung mit dem Bereich der Methodenkompetenzen ${ }^{1517}$ aufweist. Ob mit dem Sich-Hineinversetzen und -Vorstellen tatsächlich nicht nur ein Versuch der Einsicht, sondern zugleich auch schon eine Veränderung von «Vorstellungen über den ausgestellten Zusammenhang» verbunden ist, die Körber zum Konstitutiv des basalen Niveaus im Bereich des Welt- und Fremdverstehens erklärt, ${ }^{1518}$ lässt sich aus den Äusserungen der Besuchenden in den Momenten, in denen sie Sich-Vorstellen und -Hineinversetzen schildern, nicht erschliessen.

Tatsächliche Veränderungen von Sichtweisen werden zum Gegenstand in einer Reihe der anderen von mir identifizierten Kategorien. Zum einen werden sie dort sichtbar, wo Besuchende ihre eigenen Geschichtsbilder explizit zum Thema machen und über Bestätigungen, durchaus aber auch über Revisionen berichten. ${ }^{1519}$ Auch hier finden sich somit wieder Abweichungen zwischen den Ergebnissen meiner Studie und denjenigen Pampels. Nämlich stellt Pampel fest, dass Besuchende den Sinn eines Gedenkstättenbesuchs «eher in einer Bestätigung des eigenen Geschichtsbildes [sehen] als darin, es kritisch zu hinterfragen ${ }^{1520}$ - wobei er durchaus

1515 Körber 2010a, S. 5.

1516 Körber 2010a, S. 3 ff., direktes Zitat S. 5.

1517 Meyer-Hamme 2013, S. 134.

1518 Körber 2010a, S. 5.

1519 Vgl. Abschnitt 8.7.4.3.

1520 Pampel 2007, S. 348; viertiefend hierzu unter der Überschrift «Bekräftigung und Veränderung von historischen und politischen Einstellungen» auch Pampel 2007, S. $328 \mathrm{ff}$., direktes Zitat S. 328. 
einen Methodeneffekt mitdenkt, der auch für meine Studie zu berücksichtigen ist, nämlich, «[d]ass es keine Selbstverständlichkeit ist, die Korrektur eigener Ansichten offen zu bekennen». ${ }^{1521}$ Weiter gilt es in meinem Fall zu bedenken, dass die gewählte Erhebungsmethode einer momentbezogenen Logik folgt und Reflexionen von Geschichtsbildern mutmasslich eher mit Distanz zum Besuch und auf Nachfrage zur Sprache kommen, wie dies bei Pampel mittels Fragebogen und fokussiertem Interview ${ }^{1522}$ der Fall ist. Für die dennoch zu findenden Äusserungen der Besuchenden lässt sich das von Pampel festgestellte Übergewicht geschichtsbildbestätigender Äusserungen indes gar nicht feststellen. Vielmehr finden sich einige Hinweise darauf, dass Besuchende «das eigene Geschichtsbild infrage stellen und durch neue Erkenntnisse verändern», ${ }^{1523}$ was für Schreiber et al. explizit als Komponente der «Reflexion und Erweiterung des Welt- und Fremdverstehens» gilt.

Und auch für den grossen Bereich der geäusserten Relationen, die ebenfalls unter der hier verfolgten Perspektive mitzudenken sind, weil sich darin wenn auch keine verdichteten Geschichtsbilder, so doch mindestens Facetten bzw. Bausteine von Geschichtsbildern zeigen, finden sich nicht nur Hinweise auf Bestätigungen, sondern gleichermassen auch auf Veränderungen von Sichtweisen. Zu erstgenanntem Bereich, den Bestätigungen, lassen sich Bezugnahmen der Besuchenden auf bereits Gewusstes zählen, ${ }^{1524}$ ebenso Beurteilungen von Sachverhalten als schlüssig oder erwartbar, ${ }^{1525}$ die alle als ein Aufgreifen von bereits Vorhandenem und sowieso Gedachtem gedeutet werden können. Veränderungen zeigen sich in einer Vielzahl von Bereichen: So wird deutlich, dass Besuchende den Ausstellungsbesuch durchaus in starkem Masse als Ort erleben, bei dem sie sich im positiven Sinn erstaunen und beeindrucken lassen, ${ }^{1526}$ im negativen Sinn betroffen sind und entsetzen lassen, ${ }^{1527}$ neues Wissen erwerben, ${ }^{1528}$ bei dem sie Irritationen, Fragen und Unklarheiten erleben. ${ }^{1529}$ All diese, teilweise zahlreich vertretenen Formen können als Ausdruck dafür gelten, dass der Ausstellungsbesuch mannigfach Veränderungen anstösst.

1521 Pampel 2007, S. 330.

1522 Pampel 2007, S. $162 \mathrm{ff}$.

1523 Schreiber et al. 2007, S. 30.

1524 Vgl. Abschnitt 8.7.2.13.

1525 Vgl. Abschnitt 8.7.2.11.

1526 Vgl. Abschnitt 8.7.2.1.

1527 Vgl. Abschnitt 8.7.2.6.

1528 Vgl. Abschnitt 8.7.2.13.

1529 Vgl. Abschnitt 8.7.2.15. 
In der Gesamtschau über alle Kategorien im Fokus III hinweg sollte der Ausstellungsbesuch wohl am ehesten als ein Nebeneinander aus Gleichbleibendem und SichVeränderndem verstanden werden, in dem sich bereits Bekanntes und Gewusstes mit Neuem trifft und ergänzt, wodurch sowohl Bestätigungen als auch Ergänzungen, Differenzierungen und Modifizierungen stattfinden. Dieser Befund ist unmittelbar anschlussfähig an theoretische Konzeptionen des Lernens bzw. Aneignens bei Museums-/Ausstellungsbesuchenden, die dieses als aktiven und individuellen Konstruktionsprozess verstehen und dabei einerseits auf ausstellungsseitig vorhandene Faktoren, aber andererseits auch auf die individuellen Voraussetzungen aufseiten der besuchenden Individuen als Teil eines komplexen Bedingungsgefüges verweisen. ${ }^{1530}$

Äusserungen der Besuchenden im Fokus III tangieren indes nicht nur den Bereich des Welt- und Fremdverstehens, sondern auch weitere Komponenten von Orientierungskompetenz. Anknüpfungspunkte eröffnen sich auch im Bereich der Lebensweltbezüge, deren sich ein breites Spektrum in den Äusserungen der Besuchenden findet. Diese lassen sich in der Logik des Kompetenz-Strukturmodells als Beiträge zum Bereich «des Selbstverstehens» ${ }^{1531}$ begreifen. Zu diesem Bereich gehören - der Stufung Körbers folgend - zunächst überhaupt Hinweise darauf, dass Besuchende «das [G] esehene auf sich und die eigene Zeit beziehen», ${ }^{1532}$ weiter dass sich Besuchende «zum Gegenstand in eine Beziehung setzen und ihre eigene Perspektive $[\ldots]$ reflektieren ${ }^{1533}$ oder schliesslich auf elaboriertem Niveau gar in der Lage sind, "die ihnen in der Ausstellung angebotenen Deutungsmuster des eigenen Verhältnisses zur dargebotenen Geschichte kritisch zu reflektieren». ${ }^{1534}$

Dass die Besuchenden Bezüge zu sich selbst herstellen, dies ist der Kern aller im Fokus III betrachteten Äusserungen. Insofern lassen sich in einem weiten Verständnis sämtliche in diesem Abschnitt betrachteten Kategorien diesem Teilbereich von Orientierung zuordnen. In engerem Sinn lässt sich beispielsweise das Spektrum von Lebensweltbezügen diesem Bereich zuweisen. Explizite Reflexionen über die eigene Perspektive finden sich insbesondere dann, wenn Besuchende, namentlich P3, im Zusammenhang mit der Unmöglichkeit eines Sich-Vorstellens oder im Zusammenhang mit dem Gebrauch eines zeitlich abgrenzenden 〈Wir〉 auch die eigene Standortgebundenheit ausdrücken.

1530 Stellvertretend: Falk/Dierking 2000, Noschka-Roos/Lewalter 2013, Kohler 2016, sowie differenzierter die Ausführungen in Abschnitt 2.3.

1531 Schreiber et al. 2007, S. 30.

1532 Körber 2010a, S. 5.

1533 Körber 2010a, S. 4.

1534 Körber 2010a, S. 3. 
Dass die Ausstellung ihnen eine Deutung in Bezug auf das eigene Verhältnis zur Geschichte anbieten würde, darauf kommen die Besuchenden nicht zu sprechen, wohl aber in umfangreicher Weise darauf, dass die Ausstellung Bezüge zur Gegenwart herstellt. Diese Bezüge werden teilweise benannt oder auch kommentiert, mitunter sogar kritisch reflektiert, wobei Äusserungen über die von der Ausstellung hergestellten Gegenwartsbezüge in der Logik des von mir verwendeten dreigliedrigen Kategoriensystems dem Fokus II, den Äusserungen über die Ausstellung und ihre Elemente, zugehören und dort bereits vorgestellt wurden. ${ }^{1535}$

Was insgesamt lediglich vereinzelt formuliert wird, sind explizite Äusserungen in Bezug auf den vierten Teilbereich historischer Orientierung, die "Handlungsdispositionen ${ }^{1536}$. Rüsen zufolge kann Orientierung eine handlungsleitende Komponente aufweisen, ohne aber bereits die Handlung selbst zu beinhalten. ${ }^{1537}$ Für Museums-/Ausstellungsbesuchende zählt hierzu nach Körber auf basalem Niveau, «in irgendeiner Weise zu kommunizieren, dass das Gesehene oder der Besuch sie zu einem bestimmten Verhalten anregt, auffordert», ${ }^{1538}$ darüber hinaus dann, «eine von der Ausstellung empfangene Anregung zu einem bestimmten Verhalten zu benennen», ${ }_{1539}$ und schliesslich, «angebotene oder präsentierte Handlungsoptionen kritisch zu reflektieren». ${ }^{1540}$

Die letztgenannten Bereiche, Benennung und Reflexion einer in der Ausstellung enthaltenen Handlungsempfehlung, finden sich in folgendem Beispiel. Auch dieses wurde in der Logik meines Kategoriensystems als Äusserung über die Ausstellung und ihre Elemente (Fokus II) klassifiziert, überdies jedoch auch als Relation zwischen der eigenen Person und der Ausstellung, nämlich als negatives Urteil von P19 in Bezug auf die in der Ausstellung entdeckte Deutung:

"Ja, da geht es etwas um Fremdenfeindlichkeit. (...) Wasein bisschen impliziert, ob man das nicht beute, auf eine heutige, man sollte das auf eine heutige Situation beziehen (...). Weil begründet wird das da eigentlich nicht, ja. Es macht ein bisschen, argh. Es macht ein bisschen einen politisch gefärbten Eindruck auf mich. (...)» (P19, Absatz 108)

\footnotetext{
1535 Vgl. Abschnitt 8.6.4.2.

1536 Schreiber et al. 2007, S. 31.

1537 Rüsen 2013, S. $42 \mathrm{f}$.

1538 Körber 2010a, S. 5.

1539 Körber 2010a, S. 4.

1540 Körber 2010a, S. 3.
} 
Formulierungen von Handlungsempfehlungen finden sich auch dort, wo Besuchende Lehren aus der Vergangenheit für die Gegenwart ziehen, ${ }^{1541}$ wobei diese Lehren abstrakt für die Gegenwart und nicht als Handlungsorientierungen für die eigene Person formuliert sind und somit als Äusserungen im Fokus I gefasst wurden. Ein Beispiel hierfür ist die Äusserung von P25:

"Also mir geht so durch den Kopf (...), dass (...), damit Frieden berrscht, eine Balance muss finde/, gefunden werden (...) zwischen den woblbabenden Leuten und den arbeitenden, nicht so woblbabenden Leuten. Das Schlimmste ist (...), wenn die einen viel und die anderen nichts baben.» (P25, Absatz 20)

Eine auf die eigene Person bezogene Konsequenz wird in einer anderen Äusserung von P25 angedeutet:

"Life Science, da stehe ich vor einer Säule betreffend Novartis. Mit der Geschichte von Geigy, Ciba und dann Novartis. (...) 1996 baben Ciba, Geigy und Sandoz zu Novartis fusioniert. Damals hab ich Aktien besessen von Ciba-Geigy und hab hübschen Gewinn gemacht bei der Fusion. Muss ich da jetzt ein schlechtes Gewissen haben?» (P25, Absatz 110-111)

Handlungsdispositionen im weiteren Sinn finden sich ausserdem dort, wo die Besuchenden Pläne zur Weiterbeschäftigung mit einem Thema äussern. ${ }^{1542}$ Angesichts der insgesamt wenigen Textstellen stellt sich auch in diesem Bereich erneut die Frage, ob solche Reorganisationen von Handlungsdispositionen mit anderen Formen der Datenerhebung besser einzufangen wären. Selbst falls sie durch den Ausstellungsbesuch angeregt werden, geraten sie offensichtlich wäbrend des Besuchs (noch) nicht derart zu Bewusstsein, dass sie im Rahmen des Lauten Denkens geäussert würden.

Während ich mich im Rahmen dieses Zwischenfazits bislang zu Bezügen zwischen den gemachten Befunden und dem Bereich der historischen Orientierung geäussert habe, beziehe ich nun noch Überlegungen zu einem zweiten Bereich historischen Denkens ein, den historischen Fragen, die eng mit dem Bereich der 
Orientierung verknüpft sind, ausgehend von der Annahme, dass Fragen aus lebensweltlichen «Orientierungsbedürfnisse[n]» erwachsen können. ${ }^{1543}$

Dass ein Interesse am Besuch der Ausstellung bei den beforschten Besuchenden überhaupt vorhanden war, sollte bereits durch die Akquisestrategie sichergestellt werden. Explizit äusserte allerdings nur eine Person während ihres Ausstellungsbesuchs ein lebensweltlich begründetes Orientierungsbedürfnis, das zum Besuch der Ausstellung geführt habe. Die Rede ist von der bereits vorgestellten Äusserung von erneut P25, der oder die angibt, Einblicke mit Bezug zur eigenen Familiengeschichte erhalten zu wollen:

"Der Grund, warum ich die, überbaupt in die Ausstellung gekommen bin, ist, weil mein Vater Jahrgang 1914 hat und ich über die damalige Zeit und den Krieg etwas erfahren möchte.» (P25, Absatz 5)

Ebenfalls zumindest angedeutet ist eine Besuchsmotivation in der folgenden Äusserung von Pl8, der oder die berichtet, in der eigenen Schulzeit wenig über den Ersten Weltkrieg erfahren zu haben:

"Mich interessiert die Geschichte vom Ersten und vom Zweiten Weltkrieg, weil man das eigentlich nie, in der Schule hab ich das noch nicht ausfübrlich ein/, behandelt. (...) Sind wir viel zu lang bei den Römern und im Mittelalter gewesen.» (P18, Absatz 23)

Deutlicher formulieren die Besuchenden nicht, was sie zum Besuch der Ausstellung bewogen habe. Dies bedeutet allerdings keineswegs, dass solche Orientierungsbedürfnisse nicht vorhanden wären, vielmehr muss auch in diesem Fall wiederum ein Einfluss der gewählten Methode in Erwägung gezogen werden. Möglicherweise ist es für die Besuchenden schlicht nicht naheliegend, im Rahmen des Lauten Denkens während des Ausstellungsbesuchs über ihre Besuchsmotivation zu sprechen. Durchaus denkbar ist hingegen, dass in pro- oder auch retrospektiven Befragungen solche Orientierungsbedürfnisse zutage treten würden.

Zudem gilt es, den Hinweis Körbers ernst zu nehmen, dass es womöglich doch nicht persönliche, eigene Orientierungsbedürfnisse sind, die zum Besuch einer

1543 Schreiber et al. 2007, insb. S. 24f., direktes Zitat S. 24; Schreiber 2007a; vgl. ausserdem Abschnitt 2.2 und Abschnitt 2.5. 
historischen Ausstellung führen, sondern dass dort das Fragen vielmehr von den Ausstellungsmachenden übernommen wird, indem sie mit einer Ausstellung gesellschaftliche Orientierungsbedürfnisse aufgreifen:

«Anders als es der Regelkreis auf den ersten Blick suggeriert, nimmt das historische Denken hier nur im Ausnahmefall den Ausgang bei einer gegenwärtigen Verunsicherung über die Bedeutung eines Phänomens oder Phänomenkomplexes der Vergangenheit für die eigene lebensweltliche Gegenwart. Ein derartiges Orientierungsbedürfnis, auf das das Geschichtsbewusstsein mit der Erstellung einer narrativen historischen Aussage antwortet, ist zunächst nur auf Seiten der Ausstellungsmacher, ihrer Auftraggeber und Berater aktiv, auch bei ihnen allerdings in der vermittelten Form, dass sie nicht nur ihre persönlichen Bedürfnisse einfliessen lassen, sondern die von ihnen wahrgenommenen Bedürfnisse der 〈Gesellschaft〉 (oder relevanter Teile von ihr). [...] Für die Masse der Besucher wird gelten, dass ihr Interesse an der Ausstellung, wenn es denn eine derartige lebensweltliche Verunsicherung über den Gegenstand ist, sich nur partiell mit demjenigen der Ausstellungsmacher überschneidet.» ${ }^{1544}$

Selbst falls keine eigenen Orientierungsbedürfnisse initialer Bestandteil des Ausstellungsbesuchs sein sollten, so zeigt sich doch im Datenmaterial, dass während des Besuchs eine ganze Reihe von Fragen und Irritationen ausgelöst und diese auch von den Besuchenden verbalisiert werden. ${ }^{1545}$ Allerdings sind die aus Fragen und Irritationen resultierenden Beschäftigungseinheiten zumeist eher kurz, beschränken sich oft auf das Formulieren einer Frage, oft auf die Identifizierung eines Ausstellungselements zielend, ohne dass daraus zwangsläufig längere Prozesse des Suchens nach Antworten und längerfristige Prozesse historischen Denkens resultieren würden. Bisweilen kommt es aber dennoch vor, dass, wie von Hannah Röttele beschrieben, aus der Begegnung mit Irritierendem, mit nicht sofort Bekanntem und Einordenbarem, eine tiefergehende Beschäftigung resultiert. ${ }^{1546}$ Dies habe ich am Beispiel von P12 und seiner bzw. ihrer wiederholten Auseinandersetzung mit dem «Métamorphoses»-Film und der zugehörigen Frage nach Emanzipationsmöglichkeiten für Frauen aufgezeigt. ${ }^{1547}$

1544 Körber 2009, S. 68.

1545 Vgl. Abschnitt 8.7.2.1 und 8.7.2.15.

1546 Röttele 2017, S. 119.

1547 Vgl. Abschnitt 8.7.2.15. 


\section{Synthese und Fazit}

Zum Abschluss meiner Darstellungen führe ich das Festgestellte in einer Synthese zusammen und ziehe ein Fazit. Dabei verzichte ich darauf, akribisch alle Befunde zu repetieren, die im Rahmen der Zwischenfazits bereits dargelegt wurden. ${ }^{1548}$ Vielmehr geht es darum, partikulare Eindrücke in einen grösseren Gesamtzusammenhang einzuordnen. Hierzu führe ich zunächst die Befunde zu den drei Fokussierungen zusammen und unterbreite auf deren Basis einen Modellvorschlag (Abschnitt 9.1). Im Anschluss daran gleiche ich das Fokussierungsmodell mit vorhandenen theoretischen Überlegungen $\mathrm{zu}$ historischem Denken ab (Abschnitt 9.2) und denke abschliessend darüber nach, worin die spezifischen Prägungen historischen Denkens, spezifischer «Lauten historischen Denkens» in der Manifestation historische Ausstellung bestehen (Abschnitt 9.3).

\subsection{Dreierlei Fokussierungen: Zusammenfassung und Modell}

Im Verlauf der Ergebnisdarstellung habe ich drei Fokussierungen unterschieden. Es sind dies erstens Äusserungen der Besuchenden über Geschehen (Fokus I), zweitens Äusserungen über die Ausstellung und ibre Elemente (Fokus II) und drittens Äusserungen, in denen die eigene Person und Lebenswelt der Besuchenden sichtbar werden (Fokus III).

Bei Äusserungen im Fokus I berichten Besuchende darüber, was ihrer Ansicht nach war oder ist, sich ereignet hat oder ereignet, über das, was als gegeben angenommen wird und ihrer Meinung nach Gültigkeit hat. Die typische Grundstruktur von Äusserungen im Fokus I lautet $\langle\mathrm{x}$ war so $>/ \mathrm{x}$ ist passiert $>$ oder auch $<\mathrm{y}$ ist so / $/ y$ passiert`. Äusserungen im Fokus I können unterschiedliche Zeitebenen betreffen und diese entweder einzeln behandeln oder auch mehrere von ihnen zueinander in Bezug setzen. Die idealtypische Ausprägung dieses Fokus ist das Berichten über eine angenommene Wirklichkeit, sei diese vergangen oder gegenwärtig.

1548 Für einen Gesamteindruck auch von den Teilbefunden der Studie empfiehlt sich insofern neben der Lektüre des aktuellen Kapitels auch diejenige der vier Zwischenfazits (Abschnitt 8.3.3, 8.5.5, 8.6.5, 8.7.5). 
Hingegen beinhaltet der Fokus II Äusserungen über die Ausstellung und ihre Elemente, entweder in ihrer Gesamtheit oder über einzelne in der Ausstellung befindliche Bausteine. In unterschiedlichen Ausprägungsgraden wird im Fokus II die Ausstellung als ein gemachter Ort sichtbar und nehmen die Besuchenden einen konstruktionssensiblen Blickwinkel ein. Sie äussern sich dazu, wie die Ausstellung ist und über Geschehen berichtet. Allerdings sind die Fokussierungen auf Geschehen und Ausstellung keineswegs deckungsgleich mit Differenzierungen in positivistische und konstruktivistische Zugänge, da sich auch bei Äusserungen über die Ausstellung durchaus solche finden, die die Ausstellung oder einzelne ihrer Elemente stärker als Abbild vergangener Wirklichkeit denn als konstruierte Darstellung dieser Wirklichkeit thematisieren.

Neben den Fokussierungen auf das Geschehen und die Ausstellung bilden den Fokus III solche Äusserungen, in denen die eigene Person und Lebenswelt der Besuchenden sichtbar wird. Hier thematisieren sie sich selbst als Besuchende, ihre Erfahrungswelt jenseits der Ausstellung, und stellen Relationen zwischen sich selbst und dem Geschehen oder der Ausstellung her.

Diese drei Fokussierungen werden in Abbildung F in einem Modell zusammengeführt, das ich als Fokussierungsmodell der beim Ausstellungsbesuch gemachten Äusserungen bezeichne. Das Modell drückt aus, worüber die Besuchenden sprechen, während sie sich auf ihrem Weg durch die Ausstellung befinden, systematisiert also die Äusserungsebene. Umgekehrt drückt das Modell nicht aus, in welchem Modus sich die Besuchenden zu welcher Zeit befinden, also beispielsweise, ob sie bei ihren Äusserungen über Geschehen am «Erzählen», «Nacherzählen» oder «Umerzählen» sind, ${ }^{1549}$ ob sie gerade implizites Vorwissen aktivieren, auf ihnen implizit verfügbare, geschichtskulturell virulente Deutungen zurückgreifen usw.

In theoretischer Hinsicht bildet Geschichtskultur freilich die Hintergrundfolie, auf der sich das gesamte Phänomen des Ausstellungsbesuchs abspielt. Historische Ausstellungen werden verstanden als geschichtskulturelle Manifestationen, und auch die Besuchenden sind Akteurinnen und Akteure innerhalb dieser Geschichtskultur. Weil das Modell aber dem Fokus auf die explizite Äusserungsebene verpflichtet ist, taucht Geschichtskultur darin gleichwohl nicht auf. Eine Berücksichtigung wäre dann gerechtfertigt, wenn die Besuchenden selbst mit nennenswertem Anteil über Geschichtskultur sprechen, sich selbst explizit und konstant als

1549 Pandel 2002, S. 49 f.; siehe hierzu auch Abschnitt 8.5.1. 
Teil eines grösseren Systems, des gesamtgesellschaftlichen Umgangs mit Geschichte, thematisieren würden. Jedoch stellen sie Verknüpfungen zu geschichtskulturellen Phänomenen im Vergleich mit den drei grundsätzlichen Fokussierungen auf Geschehen, die Ausstellung und die eigene Person, lediglich vereinzelt her und wurden diese daher als eine unter vielen Formen von Lebensweltbezügen im Fokus III klassifiziert.

Das gezeigte dreipolige Modell stellt ein Kondensat der Analyseergebnisse dar, wobei empirische Wirklichkeit selbstredend sehr viel komplexer ist, als sie durch eine Modellierung abgebildet werden kann. Dass es zum Beispiel Grauzonen und Abgrenzungsschwierigkeiten zwischen diversen Kategorien gibt, hierauf habe ich im Verlauf der Ergebnisdarstellung an etlichen Stellen hingewiesen. Aus dem Anliegen heraus, der Komplexität des empirischen Feldes zumindest näberungsweise gerecht zu werden, wurde vor bzw. parallel zur Reduktion auf Kernelemente auch eine Modellierung mit sehr viel höherem Differenzierungsgrad angefertigt. Abbildung $G$ enthält diese differenziertere Variante in ihrer Fassung zum Ende des Analyseprozesses. Die Abbildungen F und G ergänzen und klären einander insofern wechselseitig, sorgen in der einen Richtung für Detaillierung, Präzisierung und Bezug zur empirischen Basis, in der umgekehrten Richtung für Reduktion.

Die im Verlauf der Arbeit immer wieder angesprochenen Überschneidungsbereiche zwischen den Fokussierungen werden in Abbildung $G$ durch die sich überlappenden Ellipsen und richtungsweisenden Pfeile angedeutet. Im Zentrum der Überschneidungszone zwischen dem Fokus I und Fokus II steht ein Bereich, der während der Analyse immer wieder zum Gegenstand von Abgrenzungsüberlegungen wurde. So werden Ausstellungselemente mal mehr als Hinweisgeber auf Geschehen, mal mehr in ihrer Rolle als Exponate innerhalb der Ausstellung thematisiert. Konkrete Bildquellen dienen Besuchenden oft in ihrer Abbildfunktion als Spiegel von Geschehen, umgekehrt werden sie jedoch auch als Ausstellungselemente sichtbar gemacht. Und auch wenn die Besuchenden Relationen formulieren, wird nicht immer klar, ob sie sich mit ihrer Einschätzung auf Geschehen oder vielmehr auf die Art von dessen Darstellung durch die Ausstellung beziehen, ob sie beispielsweise einen Aspekt des Geschehens interessant finden oder vielmehr die Tatsache, dass, und die Art und Weise, wie dieser in der Ausstellung behandelt wird. Vielmehr fliessen beide Bereiche bisweilen nahtlos ineinander.

Für die Besuchenden, so lautet die Schlussfolgerung aus diesen Abgrenzungsschwierigkeiten, sind die theoretisch klar trennbaren Pole «Geschehen» und «Ausstellung» nicht immer in dieser Weise klar voneinander getrennt, sondern vermen- 
gen sich in den konkreten Äusserungen. Gleichwohl erscheint eine zumindest theoretische Unterscheidung dieser Pole und entsprechender Bezugnahmen der Besuchenden aufschlussreich.

Als Überschneidungen systematisch im Modell angelegt ist der Bereich der Relationen. Diese kognitiven und nicht-nur-kognitiven Relationen beziehen sich, wie ich dargelegt habe, systematisch auf etwas, nämlich auf Aspekte des Geschehens und auf Aspekte der Ausstellung. Im Modell werden diese Bezüge mittels Pfeilen ausgedrückt.

Nicht im Fokussierungsmodell optisch dargestellt sind die ebenfalls betrachteten Themen, über die sich die Besuchenden äussern. Diese können als zu den Fokussierungen quer stehende Ebene gedacht werden, da theoretisch Paarungen zwischen allen möglichen Fokussierungen und Themenbereichen denkbar sind. Selbiges gilt für den Bereich der Elementbezüge und Aktivitätsformen, die eine weitere quer zu den Fokussierungen liegende Ebene darstellen (siehe Abbildung 2 im digitalen Anhang).

Die vorgelegte Modellierung in ihrer Gesamtheit entspricht der ersten Forschungsfrage meiner Arbeit, die darauf zielte, Elemente und Strukturen des Denkens beim Besuch einer historischen Ausstellung in ihrer Gesamtheit zu identifizieren und zu systematisieren. Die zweite Forschungsfrage bezog sich spezifischer auf die Art und Weise, wie Besuchende während des Besuchs ihre eigene Person und Gegenwart in ihren Überlegungen sichtbar machen.

Bezüge zur eigenen Person sind identisch mit allen Äusserungen, die dem Fokus III zugeordnet wurden. Bezüge zur Gegenwart verteilen sich hingegen auf mehrere Bereiche der vorgelegten Modellierung, sie tauchen in dreierlei Gewand auf. Die Gegenwart taucht erstens als Zeitebene in Äusserungen über Geschehen auf, wobei dort überdies die Person der Besuchenden nicht zwingend sichtbar werden muss, aber es kann. Oft stellen Besuchende auch Bezüge zwischen der Vergangenheit und einer abstrakten Gegenwart her, in dem Sinn, dass sie sich nicht selbst als Teil dieser Gegenwart explizit positionieren. Derartige Äusserungen fallen im Rahmen des hier ausgearbeiteten Kategoriensystems idealtypisch in den Bereich des Fokus I.

Zweitens ist die Gegenwart selbstredend auch Gegenstand der bereits erwähnten Fokussierung III, in dem die Besuchenden sich selbst als Person in ibrer Gegenwart und Lebenswelt sichtbar machen, wobei es Überschneidungen zwischen Fokus I und Fokus III geben kann. Drittens gibt es Gegenwartsbezüge schliesslich auch in de-konstruktiver Form im Fokus II. Dort sprechen Besuchende darüber, dass und wie die Ausstellung die Gegenwart thematisiert und Verknüpfungen 
zwischen Zeitebenen herstellt. In diesem Bereich geht es also nicht um das aktive Generieren von Gegenwartsbezügen, sondern um das Zur-Kenntnisnehmen vorhandener Bezüge. Abbildung 9 im digitalen Anhang weist diesen drei Varianten ihren Platz in der Modellierung zu.

\subsection{Theoretische Bezüge: Das Fokussierungsmodell im Verhältnis zur "Sechs-Felder-Matrix»}

In welchem Verhältnis stehen nun diese Befunde zu bereits existierenden Theorien und Modellierungen historischen Denkens? Es liegt nahe, in den beiden Fokussierungen auf einerseits das Geschehen und andererseits die Ausstellung und ihre Elemente Parallelen zu den zwei Modi der Re-Konstruktion und De-Konstruktion zu entdecken. ${ }^{1550}$ Im Fokus I entsteht eine Erzählung über Geschehen, wobei ich absichtlich vorläufig noch nicht von einer historischen Erzählung spreche und weiter unten auf diesen Aspekt zurückkomme. Im Fokus II äussern sich die Besuchenden über einen Ort, an dem eine Erzählung oder gar mehrere Erzählungen bereits «fertig» vorliegen, mit denen die Besuchenden in Kontakt kommen, wobei de-konstruktive Operationen denkbar werden.

Um dem Verhältnis meiner Modellierung mit vorhandenen Konzeptionen historischen Denkens weiter nachzugehen, wende ich mich den Übereinstimmungen und Abweichungen mit der Sechs-Felder-Matrix ${ }^{1551}$ des historischen Denkens zu (siehe Abbildung 10 im digitalen Anhang). Ich greife aus mehreren Gründen auf diese Matrix und nicht beispielsweise auf das Kompetenz-Strukturmodell historischen Denkens zurück, das konzeptionell an die Sechsermatrix anknüpft. ${ }^{1552}$ Ein Grund für die Wahl ist, dass in der Sechsermatrix durch die Anordnung in zwei Zeilen und sechs Feldern die beiden Operationen Re-Konstruktion und DeKonstruktion optisch klarer voneinander getrennt sind, als dies im KompetenzStrukturmodell der Fall ist. Dort gehen sie visuell, wenn auch keineswegs konzeptionell, unterschiedslos in den Kompetenzbereichen auf.

Zweitens favorisiere ich die Sechsermatrix auch deshalb, weil sie durch ihre Spalten einen expliziten Bezug zu den unterschiedlichen Zeitebenen herstellt,

1550 Stellvertretend: Schreiber et al. 2007, S. 28 f.; vgl. hierzu die Ausführungen in Abschnitt 2.5. 1551 Zabold/Schreiber 2004, S. 206; Körber et al. 2007, S. 863.

1552 Zum FUER-Modell: Körber et al. 2007 und Ausführungen in Abschnitt 2.5. Für Bezüge zwischen Kompetenz-Strukturmodell und Sechs-Felder-Matrix stellvertretend: Schreiber et al. 2007, S. $27 \mathrm{ff}$. 
wohingegen deren Differenzierung im Kompetenz-Strukturmodell zwar implizit hinter der Modellierung steht, aber nicht visuell ausgedrückt wird. Problematisch an der Sechs-Felder-Matrix erscheint mir in diesem Zusammenhang allerdings, dass sie die «Fokussierung auf Vergangenheit» und «Fokussierung auf Gegenwart / Zukunft» einerseits und die «Fokussierung auf Geschichte» andererseits in dieselbe Ebene legt und damit strukturgleich behandelt, ${ }^{1553}$ obwohl es sich bei den erstgenannten um Bezüge auf Zeitebenen, bei der anderen um einen Darstellungsmodus handelt. Ungeachtet dieser strukturellen Inkohärenz, erscheint mir die Differenzierung nach drei Fokussierungen gleichwohl für meine Zwecke hilfreich.

Drittens, dies wurde soeben deutlich, operiert die Sechsermatrix ebenso wie ich mit dem Begriff der Fokussierungen, meint damit aber, wie weiter oben bereits einmal dargelegt, teilweise anderes. Durch den Abgleich lassen sich die unterschiedlichen Verwendungsweisen aufzeigen und nachvollziehen.

Die Sechsermatrix ist in Abbildung 10 im digitalen Anhang einsehbar, in Abbildung 11 wurde sie von mir ergänzt und überlagert mit den drei von mir identifizierten Fokussierungsbereichen. Dabei kommt es zu Überlappungen, aber auch zu Abweichungen. Ich gehe darunter nachfolgend auf drei Aspekte näher ein und beginne mit dem optisch augenscheinlichsten.

\subsubsection{Historisches vs. ahistorisches Denken}

Erstens gehen alle drei Fokussierungen visuell über die Bereiche hinaus, die von der Sechsermatrix abgedeckt werden. Anlass für diese Darstellung ist, dass es engere und weitere Verständnisse davon gibt, was als historisches Denken und Erzählen zu fassen sei. Wie bereits dargelegt, wird bisweilen all denjenigen Erzählungen, in denen nicht mehrere Zeitpunkte zueinander in Bezug gebracht werden, «das Attribut 〈historisch»» aberkannt. ${ }^{1554}$ Auch wenn die Sechsermatrix sich selbst nicht in dieser Hinsicht deutlich positioniert, sondern beispielsweise eine «Fokussierung auf Vergangenheit» oder «synchrone Kontextualisierungen» als mögliche Bausteine historischen Denkens vorsieht, ${ }^{1555}$ soll durch die über die Felder der Matrix hinausgehende Darstellung angedeutet werden, dass die von

1553 Zabold/Schreiber 2004, S. 206. Vgl. Abb 12.

1554 So festgestellt bei Schreiber 2007c, S. 244. Diese Feststellung lässt sich übertragen zum Beispiel auf Pandel 2002, S. 41; Rüsen 2013, S. 76; vgl. zur Bedeutung der Verknüpfung von Zeitebenen die Ausführungen in Abschnitt 2.3.

1555 Zabold/Schreiber 2004, S. 206; vgl. Abb. 10. 
mir gewählten Fokussierungen auch Bereiche von Äusserungen abdecken, die je nach beigezogener Theorie jenseits der Grenze dessen liegen können, was noch als historisch eingestuft wird. ${ }^{1556}$

Auf Ebene des Sich-Äusserns über Geschehen (Fokus I) betrifft dies all diejenigen Passagen, in denen die Besuchenden nicht mehrere Zeitpunkte zueinander in Bezug setzen, sondern über eine Zeitebene berichten. Wie erwähnt, stellt dies den Hauptmodus des Sich-Äusserns im Fokus I dar. Dort geht es um Zustandsbzw. Situationsbeschreibungen, vielfach bezogen auf die Zeit des Ersten Weltkriegs, es geht um das Feststellen von «Vergangenheitspartikeln» ${ }^{1557}$ und allenfalls damit verbundene synchrone Verknüpfungen, ohne dass diachrone Verknüpfungen vorgenommen würden. ${ }^{1558}$

Diese Beobachtung einer teilweisen Abwesenheit von zeitlichen Bezügen gilt wohlgemerkt nicht nur für die Äusserungen der beforschten Besuchenden, sondern gleichermassen auch für Geschichtslehrmittel und Geschichtsunterricht, ${ }^{1559}$ die Abwesenheit von Zeitbezügen bis in die Gegenwart auch für viele historiografische Werke. ${ }^{1560}$ Bezüge zwischen Zeitebenen scheinen also durchaus nicht selbstverständlich, wenn in lebensweltlichen oder auch historiografischen Zusammenhängen ein historischer Gegenstand dargestellt wird, weshalb auch ihre nachrangige Bedeutung im vorliegenden Datenmaterial keineswegs überrascht. Umgekehrt liefert meine Studie einmal mehr Argumente dafür, dass Bezüge zwischen mehreren Zeitebenen keineswegs als alleiniges Konstitutiv einer Auseinandersetzung mit einem historischen Gegenstand betrachtet werden sollten, wenn sich die Theoriebildung nicht von ihrem zugehörigen empirischen Feld entfernen möchte.

Auf Ebene des Sich-Äusserns über die Ausstellung und ihre Elemente (Fokus II) könnten nach strenger Auslegung beispielsweise solche Äusserungen als unhistorisch eingestuft werden, in denen Besuchende schlicht die Elemente identifizieren und benennen, die sie in der Ausstellung vorfinden. Dieser Bereich

1556 Die Grösse der über die Felder der Sechsermatrix hinausreichenden Fläche hat dabei keinerlei tiefere Bedeutung.

1557 Schreiber 2007b, S. 207.

1558 Vgl. zur Idee der synchronen und diachronen Kontextualisierungen z. B. Schöner 2013b, S. 109, sowie die Ausführungen in Abschnitt 2.3.

1559 Pandel 2002, S. 47. Dies schlussfolgert Pandel aus Ergebnissen einer Studie von Magull (2000, zit. n. Pandel 2002, S. 46 f.).

1560 Schreiber 2007c, S. 244. 
macht, wie ich gezeigt habe, einen wichtigen Bestandteil innerhalb der ausstellungsbezogenen Äusserungen aus.

Als verhältnismässig eindeutig historisch nach engem Verständnis können diejenigen Äusserungen eingestuft werden, in denen Besuchende Bezüge zu ihrer eigenen Person und Lebenswelt herstellen (Fokus III). Diese sind in der Regel inhaltlich angebunden an einen Aspekt des Geschehens oder der Ausstellung, mit dem sich die Besuchenden in diesem Moment beschäftigen. Damit liegt mindestens implizit ein historischer Vergleichshorizont vor, ausgehend von dem die Besuchenden Bezüge zu sich selbst und ihrer eigenen Zeit herstellen. Aber auch hier werden durchaus nicht immer explizit mehrere Zeitebenen miteinander in Beziehung gesetzt.

Im Mindesten lassen sich all diese beschriebenen Ausprägungen als «Teil- und Protoformen» ${ }^{1561}$ historischen Denkens fassen, um eine Terminologie Körbers aufzugreifen. Sie fungieren sämtlich als wichtige Bausteine innerhalb der Prozesse, mit denen sich Besuchende eine historische Ausstellung und die darin erzählte Geschichte aneignen. Beispielsweise kann das Identifizieren eines Elements Ausgangspunkt dafür sein, sich anschliessend zu fragen, welche Rolle dieses spezifische Element in der Erzählung der Ausstellung spielt. Feststellen von Vergangenheitspartikeln kann hingegen als Ausgangslage dafür gelten, um anschliessend überhaupt diese Partikel in Zeitverlaufsvorstellungen einfügen zu können. ${ }^{1562}$ Bei all diesen Formen handelt es sich um notwendige Bausteine historischen Denkens in seinem theoretisch konzipierten Sinn. Inwiefern sie allein bereits als historisches Denken benennbar sind, wird je nach Bezugstheorie unterschiedlich zu beantworten sein. ${ }^{1563}$

\subsubsection{Re-konstruktive und de-konstruktive Elemente}

Eine zweite Beobachtung betrifft den angekündigten Abgleich zwischen den Operationen Re-Konstruktion und De-Konstruktion auf der einen Seite und den Fokussierungen auf Geschehen und die Ausstellung auf der anderen Seite. Wie Abbildung 11 im digitalen Anhang zeigt, gibt es Gemeinsamkeiten zwischen dem

1561 Körber 2006, S. 193.

1562 Körber unterstreicht etwa die Bedeutung des Feststellens von Vergangenheitspartikeln als Grundlage jeglicher Sinnbildungsformen (Körber 2016, S. 32).

1563 Eine enge Auslegung findet sich etwa mit der Prämisse Rüsens, dass alle Teilschritte des Regelkreises historischen Denkens «notwendig» sind, um überhaupt von historischem Denken sprechen zu können (Rüsen 2013, S. 68). 
Modus der Re-Konstruktion und dem Fokus auf Geschehen, umgekehrt auch Gemeinsamkeiten zwischen dem Modus der De-Konstruktion und dem Fokus auf die Ausstellung und ihre Elemente. Jedoch besteht keine Deckungsgleichheit.

Grund dafür ist einerseits, dass für das Fokussierungsmodell die Äusserungen der Besuchenden systematisiert wurden und nicht die zugrunde liegenden Operationen. Ob die Besuchenden zu einer Äusserung über Geschehen tatsächlich dadurch gelangen, dass sie dieses aus einer Quelle re-konstruieren, wie dies für die Basisoperation Re-Konstruktion zumindest idealtypisch angedacht wäre, ${ }^{1564}$ spielt für die Zuordnung einer Äusserung zum Fokus I keine Rolle.

Ganz im Gegenteil zeigt sich, dass Äusserungen über Geschehen neben der Beschäftigung mit Quellen auf vielerlei Wegen zustande kommen können. Rückgriffe auf Vorwissensbestände oder das Aufgreifen und die Wiedergabe von Aussagen über Geschehen, die die Besuchenden in Ausstellungstexten oder Quellenbeschriftungen vorfinden, spielen hierfür ebenfalls eine Rolle. Vielmehr zeigt sich sogar, dass all diese möglichen «Quellen» im erweiterten Sinn gleichermassen und strukturgleich von den Besuchenden verwendet werden, um aus ihnen heraus Berichte über Geschehen zu generieren. Diese Beobachtung fügt sich zu der bereits bei Waltraud Schreiber zu findenden Feststellung, «dass kaum einmal ausschliesslich aus Quellen 〈rekonstruiert〉 wird». ${ }^{1565}$

Bisweilen machen die Besuchenden explizit die Ausstellung als Herkunft einer Aussage über Geschehen sichtbar. Sie äussern dann beispielsweise, aus einem Text gehe hervor, dass etwas gewesen sei. Derartige Äusserungen habe ich, wie bei der Betrachtung des Fokus I ausgeführt, den Äusserungen über Geschehen zugeordnet, auch wenn darin bis zu einem gewissen Grad auch die Ausstellung bzw. eines ihrer Elemente explizit sichtbar gemacht wird. Derartige Äusserungen bilden in der Logik der Sechsermatrix Grenzfälle zwischen dem Modus der De-Konstruktion und dem der Re-Konstruktion. Die Besuchenden erkennen darin, dass die Ausstellung eine bestimmte Aussage über Geschehen macht, de-konstruieren also bis zu einem gewissen Grad die Erzählung der Ausstellung, formulieren aus der Aussage der Ausstellung heraus aber im selben Atemzug selbst eine Aussage über Geschehen und befinden sich damit im re-konstruierenden Modus.

Solche Textstellen, in denen Äusserungen der Ausstellung zwar als solche benannt, aber schlicht nacherzählt und als Äusserungen über Geschehen wieder-

1564 Schreiber 2007b, S. 200 ff.; zu Differenzierungen siehe unten.

1565 Schreiber 2007b, S. 198. 
gegeben werden, habe ich dem Fokus I zugerechnet. Um dies optisch darzustellen, reicht in Abbildung 11 der Fokus I in den Bereich der De-Konstruktion hinein. Sich-Äussern $\ddot{u b e r}$ die Erzählung einer Ausstellung, das nicht zugleich in eine eigene Äusserung über Geschehen überführt wird, sondern auf die Ausstellung als erzählte Geschichte fokussiert, wäre demgegenüber in der Logik des Fokussierungsmodells Bestandteil des Fokus II.

Anhand des empirischen Materials zeigt sich also, dass de-konstruktive und re-konstruktive Elemente bisweilen ineinanderfliessen, nämlich im Fall meiner Studie dahingehend, dass das Erkennen der Aussage einer Ausstellung unmittelbar in das Wiedergeben und Nacherzählen dieser Aussage übergehen kann, ohne dass die Ausstellung selbst in dem Moment tiefergehend zum Gegenstand der Betrachtung würde. Während die Trennung in die Operationen Re-Konstruktion und De-Konstruktion auf theoretischer und analytischer Ebene überzeugt, scheinen die beiden Bereiche auf empirischer Ebene also bisweilen ineinanderzufliessen oder mindestens miteinander in Bezug zu stehen. ${ }^{1566}$ Bereits Schreiber spricht von einer «Durchglitterung» zwischen den beiden Basisoperationen», die «offen zu Tage» liege ${ }^{1567}$, und führt den Zusammenhang näher aus, wobei sie offensichtlich professionelles geschichtswissenschaftliches Arbeiten im Blick hat, ihre Überlegungen allerdings auch der Kontextualisierung der in meiner Studie gemachten Befunde dienen können:

«Im konkreten Vollzug historischen Denkens überlappen sich die beiden Basisoperationen. Wer aufgrund einer historischen Frage eine vergangene Entwicklung rekonstruieren und seine Ergebnisse in einer historischen Narration darstellen will, arbeitet mit Quellen - damit ist eine klassische Teilkompetenz der Re-Konstruktion benannt, die ihrerseits in weitere Kompetenzen untergliedert werden kann [...]. Der historisch Denkende analysiert aber auch einschlägige Literatur, mit dem Ziel, aus vorliegenden historischen Narrationen 〈Vergangenheitspartikel〉, die für die eigene Fragestellung relevant scheinen,

1566 Empirische Hinweise auf einen Bezug zwischen den beiden Operationen finden sich bei Monika Waldis und Martin Nitsche, die in einem Tagungsbeitrag zum Thema «Epistemological Beliefs Matter: Investigating Pre-Service History Teachers' Narrative Competence» von einer leicht positiven Korrelation (.37) zwischen re-konstruktiven und de-konstruktiven Komponenten narrativer Kompetenz berichteten (Waldis/Nitsche 2017, S. 10). Für diesen Hinweis danke ich M. Nitsche.

1567 Schreiber 2007b, S. 198 
zu erschliessen - und das ist ein Akt der De-Konstruktion. Die aus Quellen und Darstellungen erarbeiteten Vergangenheitspartikel werden dann für die Re-Konstruktion genutzt $[\ldots] .{ }^{1568}$

«Indem aber für die folgende eigene Re-Konstruktion viele Vergangenheitspartikel nicht mehr aus Quellen erarbeitet werden, sondern (vor allem im Randbereich der eigenen Fragestellung) aus den Vorarbeiten anderer übernommen werden, konstituiert sich eine Verbindung zwischen diesem de- und dem re-konstruktiven Vorgehen. Das ist arbeitsökonomisch notwendig, muss aber reflektiert werden». ${ }^{1569}$

Empiriebasierte Konzeptionen historischen Denkens wie diejenigen von Drie und Boxtel oder Wineburg tragen dem geschilderten Ineinanderfliessen Rechnung, indem sie gar nicht systematisch nach den Operationen Re-Konstruktion und De-Konstruktion unterscheiden, ${ }^{1570}$ verwässern dabei aber gleichzeitig auf theoretischer Ebene die unterschiedlichen Logiken eines re-konstruktiven und de-konstruktiven Modus.

Die weiter oben angesichts von Befunden aus einer Studie von Andreas Körber ${ }^{1571}$ von mir formulierte Frage, ob und inwiefern der theoretisch modellierte de-konstruktive Modus überhaupt empirisch relevant ist oder ob sich das von Körber für Schüler und Schüleinnen festgestellte Übergewicht re-konstruktiven Denkens vielleicht auch bei Ausstellungsbesuchenden manifestiert, wobei dann womöglich eine von Körber zunächst nicht in Erwägung gezogene «anthropologische Ursache» ${ }^{1572}$ als Erklärung in Betracht $\mathrm{zu}$ ziehen gewesen wäre, lässt sich allerdings dahingehend beantworten, dass sich in den Äusserungen der Besuchenden durchaus auch de-konstruktive Elemente finden. Allerdings sind diese, wie bereits mehrfach betont, nicht gleichzusetzen mit der Gesamtheit von ausstellungsbezogenen Äusserungen im Fokus II. Sie machen vielmehr einen Teilbereich innerhalb dieser aus und umfassen beispielsweise diejenigen Äusserungen, in denen Besuchende über Deutungen der Ausstellung und intendierte Gegenwartsbezüge sprechen, wobei die genannten Kategorien, mit Ausnahme von P19, vornehmlich bei Personen mit geschichtswissenschaftlichemund/odergeschichtsdidaktischem/museumsbezogenem

1568 Schreiber 2007b, S. $194 \mathrm{f}$.

1569 Schreiber 2007b, S. $198 \mathrm{f}$.

1570 Wineburg 1991; Wineburg 1998; Wineburg 2001; Drie/Boxtel 2008; vgl. hierzu die Ausführungen in Abschnitt 2.6.

1571 Körber 2006; vgl. hierzu die Ausführungen in Abschnitt 2.5.2.

1572 Körber 2006, S. 211. 
Hintergrund vorkommen, insofern also nicht grundsätzlich für alle Besuchenden angenommen werden können.

\subsubsection{Stellung von eigener Person und Gegenwart}

Ein dritter und letzter Beobachtungsbereich im Abgleich zwischen Fokussierungsmodell und Sechsermatrix betrifft die Stellung und Rolle der eigenen Person sowie der (abstrakten) Gegenwart. Die Sechsermatrix unterscheidet nicht systematisch zwischen einerseits der Gegenwart als abstrakter Zeitebene und andererseits der eigenen Gegenwart und Lebenswelt des denkenden Individuums - ebenso wie diese Differenzierung in der oben vorgestellten diaktischen Literatur zu Gegenwartsbezug- und Lebensweltbezug als normative didaktische Prinzipien tendenziell abwesend ist. ${ }^{1573}$ Bei Rüsen ist die genannte Unterscheidung hingegen angelegt, unterscheidet er doch einerseits in eine «Historische Deutung», in der mehrere Zeitebenen in Bezug gesetzt werden, und andererseits eine «Historische Orientierung», in der dann spezifischer ein Bezug zur «Lebenspraxis» hergestellt wird. ${ }^{1574}$ Mit der in der Sechsermatrix ausgewiesenen «Fokussierung auf Gegenwart/Zukunft» werden diese beiden Aspekte verwässert.

In meinem Datenmaterial zeigt sich, dass die Besuchenden durchaus nicht immer und zwangsläufig über sich selbst sprechen, wenn sie die Gegenwart thematisieren. Vielmehr finden sich auch zahlreiche Äusserungen, in denen sie die Gegenwart ohne expliziten Bezug auf ihre eigene Person behandeln. Diese Äusserungen habe ich dem Fokus I auf Geschehen zugerechnet, während explizite Sichtbarmachungen der eigenen Person stattdessen oder zusätzlich als Äusserungen im Fokus III klassifiziert wurden. Im Abgleich der beiden Modelle findet dies visuell seinen Niederschlag, indem die besagte «Fokussierung auf Gegenwart/ Zukunft» als sowohl dem Fokus I wie auch Fokus III zugehörig dargestellt wird. In analytischer Hinsicht halte ich es, ausgehend von den Befunden meiner Studie, für bedeutsam, nach der Gegenwart als behandelter Zeitebene und den überdies erfolgenden Bezügen zur eigenen Person zu unterscheiden, da Erstes nicht zwingend auch Zweites beinhalten muss.

1573 Heuer 2009; Bergmann 2008; Bergmann 2016; Gautschi 2015, S. 36; Buck 2017; hingegen mit Differenzierung bei Baumgartner 2015, S. 68. vgl. hierzu die Ausführungen in Abschnitt 2.4.

1574 Rüsen 2013, S. 40 f., direkte Zitate S. 40 u. S. 41; vgl. zu Rüsen die Ausführungen in Abschnitt 2.2. 


\subsection{Aneignen in einer historischen Ausstellung: Überlegungen zu manifestations- und methoden- spezifischen Prägungen historischen Denkens}

Ich trage nachfolgend noch einige weitere Beobachtungen zusammen, die ebenfalls die Anknüpfung meiner Befunde an existierende Theorien historischen Denkens betreffen, nun aber über den formalen Abgleich des entwickelten Modells mit der Sechsermatrix hinausführen. Vielmehr geht es nun um eine Zusammenstellung von Beobachtungen, die Hinweise auf manifestationsspezfische Prägungen historischen Denkens in einer historischen Ausstellung bzw. vielmehr in der konkreten gewählten Ausstellung «14/18» geben können, gleichzeitig aber auch Hinweise auf methodenbedingte Ausprägungen eines «Lauten historischen Denkens».

Die beiden Aspekte isoliert voneinander zu betrachten, ist aufgrund der Anlage meiner Studie unmöglich, da beobachtetes historisches Denken in diesem Fall immer zugleich auch «Lautes historisches Denken» ist, wohingegen für eine getrennte Betrachtung einerseits der vergleichende Einbezug weiterer Manifestationen, andererseits der Einsatz weiterer Erhebungsmethoden notwendig wäre. Reflexionen über mögliche spezifische Einflüsse von Manifestation und Methode sind gleichwohl auch ohne ein vergleichendes Setting möglich, so etwa im Abgleich mit weiteren bereits vorliegenden empirischen Studien zu Besuchenden und theoretischen Überlegungen. Zu den relevanten theoretischen Vorarbeiten, auf die es Bezug zu nehmen gilt, zähle ich neben weiteren ${ }^{1575}$ insbesondere das von Kohler entwickelte «domänenspezifische Modell des musealen Lernen[s]» ${ }^{1576}$ und Körbers Vorschlag zur Spezifizierung von Kompetenzen historischen Denkens für den Fall des historischen Denkens im Museum. ${ }^{1577}$ Meine eigene Studie verstehe ich hierzu als empirische Ergänzung und Differenzierung.

\subsubsection{Kleinschrittigkeit und Momentbezogenheit des Denkens}

Im Verlauf meiner Darstellung habe ich immer wieder auf die Kleinschrittigkeit und Momentbezogenheit des Sich-Äusserns im Museum hingewiesen. Die Besuchenden äussern sich in der Regel in Bezug auf das oder ausgehend von dem, was

1575 Vgl. hierzu insb. die Abschnitte 3.3. und 3.4.

1576 Kohler 2016, S. 70.

1577 Körber 2009; Körber 2010a; Körber 2010b. 
sie aktuell vor sich sehen und mit dem sie sich beschäftigen, seien es Ausstellungstexte, Exponate usw., womit ein permanentes Wechseln der Aktivitätsformen verbunden ist. Einzelne Elemente werden im Normalfall der Reihe nach abgehandelt, ${ }^{1578}$ Rück- und Querbezüge zu deutlich früher betrachteten Elementen finden tendenziell eher selten statt. Auf diese Weise entstehen zahlreiche Kleinstnarrationen, oder mit Rüsen gesprochen «narrative Abbreviaturen», die Rüsen selbst durchaus für den Regelfall im Umgang mit Historischem hält, ${ }^{1579}$ die insofern wenig überraschen.

Etwa wird ein Objekt betrachtet und ausgehend davon ein Bezug zur eigenen Lebenswelt formuliert, übergreifende, den gesamten Ausstellungsbesuch überspannende Erzähllinien tauchen demgegenüber eher selten auf - dies, obwohl eine für die Erhebung solcher zusammenhängender Prozesse als unmittelbar geeignet eingestufte ${ }^{1580}$ prozessbezogene Erhebungsmethode gewählt wurde. Ein Beispiel für gleichwohl auftretende, über den Besuchsverlauf hinweg vernetzte Erzähllinien liefert exemplarisch P12 mit dem mehrmaligen Zurückkommen auf den anfänglich irritierenden «Métamorphoses»-Film und die Frage der Emanzipationsmöglichkeiten für Frauen während des Ersten Weltkriegs.

Mehrheitlich funktioniert der Ausstellungsbesuch jedoch kleinschrittig und momentbezogen. Inwieweit Befunde konstitutiv durch die eingesetzte Methode mitbestimmt werden, lässt sich nicht mit Gewissheit beurteilen. Die These liegt nahe, dass übergreifende Deutungen und grössere Erzähllinien womöglich eher mit Abstand zum Ausstellungsbesuch entstehen.

Umgekehrt birgt die Methode des Prozessbegleitenden Lauten Denkens unschätzbare Vorteile, wenn es darum geht, genau die geschilderte Momentbezogenheit der Äusserungen der Besuchenden einzufangen. Sie ermöglicht, festzustellen, welche Exponate und sonstigen Ausstellungselemente genau es sind, in Bezug auf die Überlegungen angestossen werden. Mit Prozessbegleitendem Lauten Denken ist ein unmittelbarer Rückbezug der Äusserungen auf die räumliche Struktur und Erzählung der Ausstellung möglich ${ }^{1581}$ - vor allem dann, wenn nicht nur Audioaufnahmen des Lauten Denkens, sondern ergänzend auch Videoaufnahmen angefertigt werden, die eine Zuordnung von Äusserungen zu Elementen in

1578 Treinen 1988, S. $33 \mathrm{f}$

1579 Rüsen 2008, S. 19 f.

1580 Dazu auch bereits Thyroff 2017c, S. 11.

1581 Vgl. hierzu differenzierter Abschnitt 6.1.5 und die dortigen Literaturverweise, insbesondere auf Wise 2011. 
vielen Fällen überhaupt erst möglich machten oder mindestens erheblich erleichterten.

\subsubsection{Nicht-nur-kognitive Elemente}

Meine Arbeit erlaubt weiter Schlussfolgerungen in Bezug auf das, was ich oben unter Rückgriff auf eine Terminologie Bodo von Borries' als die bisweilen vernachlässigten nicht-nur-kognitiven, ${ }^{1582}$ etwa ästhetischen, emotionalen und räumlichen Komponenten von Aneignungsvorgängen und Prozessen historischen Denkens thematisiert habe. ${ }^{1583}$ Derartige Komponenten werden, so stellt Borries für das Kompetenz-Strukturmodell fest, in bislang vorliegenden Modellierungen zwar nicht verneint, aber auch bis anhin «nicht explizit» als Bestandteile historischen Denkens ausgewiesen. ${ }^{1584}$ Sogar lässt sich in Spezifizierungen für Museums-/ Ausstellungsbesuchende eine teilweise Unsichtbarkeit der Ausstellung und ihrer gestalterischen Prinzipien als Ort der zu beobachtenden Aneignungsvorgänge verzeichnen. ${ }^{1585} \mathrm{Um}$ dies zu ändern, nimmt Borries, wie geschildert, explizit die Beschäftigung mit Museen/Ausstellungen in den Blick:

«Ist das Geschichtslernen im Museum geeignet, das Kompetenzkonzept auf Verkürzungen zu überprüfen und solche gegebenenfalls abzustellen? Gab es z.B. bisher eine Verengung auf blosse Kognition? Fehlte die Einbeziehung der ästhetischen und politischen Dimension [...]? Im Museum ist ein sinnlichästhetischer Überschuss unverkennbar - aber im Kompetenzmodell?» 1586

Eine Modellierung, die diesen Komponenten ihren systematischen Platz beim historischen Denken und Lernen zuweist, steht bislang noch aus. ${ }^{1587}$ Zarte Ansätze finden sich in Kohlers «domänenspezifische[m] Modell des musealen Lernens», in dem er eine «Ästhetische Dimension», «Emotionale Dimension», «Kommuni-

1582 Borries 2014, S. $170 \mathrm{f}$.

1583 Vgl. hierzu die Ausführungen in Abschnitt 3.4.

1584 Borries 2014, S. 232 f., direktes Zitat S. 233. Meyer-Hamme stellt fest, Emotionen könnten «im Bereich der Frage- und Orientierungskompetenzen eingegliedert werden» (Meyer-Hamme 2013, S. 127).

1585 Vgl. die Abschnitte 3.3 und 3.4.; dort festgestellt beispielsweise in Bezug auf Körber 2009 und 2010.

1586 Borries 2009, S. 117.

1587 Hasberg 2013, S. 65; Meyer-Hamme 2013, S. 127; Borries 2014, S. 232 f. 
kative Dimension» und eine «Kognitive Dimension» ausweist, aber nicht weiter ausdifferenziert oder in ihren Bezügen zum dargestellten Lernprozess entfaltet. ${ }^{1588}$ Eine daran anknüpfende Modellierung mit holistischem Anspruch kann auch im Rahmen meiner Arbeit nicht entwickelt werden. Gedankenanstösse für eine weitere Erhellung des Feldes sind, dem oben genannten Hinweis Borries' folgend, am Beispiel des Aneignens in einer historischen Ausstellung gleichwohl möglich.

Die Herausforderung bei der Integration derartiger Komponenten in Modelle historischen Denkens besteht darin, dass sich nicht-nur-kognitive Dimensionen strukturell in mehreren Ebenen niederschlagen. Hierauf weisen Borries und weitere Autorinnen und Autoren hin, wenn sie in Bezug auf Emotionen von deren Subjekt- und Objektseite sprechen. ${ }^{1589}$

Diese Unterscheidung lässt sich gleichermassen auf die ästhetische, räumliche und weitere Dimensionen übertragen. Sie sind einerseits Merkmale der Objektseite, wobei es, wie Wolfgang Hasberg für den Fall der Emotionen präzisiert, um «Emotionen in Vergangenheit/Geschichte» geht. ${ }^{1590}$ Durch die von Hasberg gewählte Schrägstrich-Variante deutet sich bereits an, dass eine weitere, zumindest idealtypische Differenzierung sinnvoll und notwendig ist, nämlich in den betrachteten historischen Gegenstand (in meinem Fall: «Geschehen», Fokus I) einerseits und die Form, in der dieser Gegenstand dargestellt wird (in meinem Fall: die Ausstellung und ihre Elemente, Fokus II) andererseits, wobei der Gegenstand überhaupt nur noch über seine Darstellung vermittelt zugänglich ist, und beide Perspektiven in den Äusserungen der Besuchenden, wie bereits mehrfach dargestellt, mitunter verwässern.

Nicht-nur-kognitive Dimensionen manifestieren sich aber auch in der Wahrnehmung und Einschätzung eines Gegenstands bzw. seiner Darstellung durch das denkende Individuum und damit in der Subjektseite. Dass in Bewertungen eines Gegenstands immer zugleich auch die eigene Person sichtbar wird, beide Dimensionen also ineinanderfliessen, habe ich mit dem Begriff der Relationen zum Ausdruck zu bringen versucht. Sofern davon ausgegangen wird, dass eine historische Darstellung, hier eine Ausstellung, in ihrer Ästhetik, Räumlichkeit, Emotionalität usw. überhaupt ausserbalb der Wahrnehmung des Subjekts existiert, wäre für die Erforschung von Aneignungsvorgängen beispielsweise zu fragen, ob

1588 Kohler 2016, S. 70.

1589 Borries 2014, S. 162; Brauer/Lücke 2013a, S. 14; Gies 1994, S. 35; Hasberg 2013, S. 49; vgl. hierzu auch Abschnitt 3.4.1.

1590 Hasberg 2013, S. 49. 
und inwiefern Subjekte vorliegende nicht-nur-kognitive Dimensionen eines Gegenstands bzw. seiner Darstellung wahrnehmen, sich zu eigen machen, kommentieren, reflektieren, individuell umdeuten, durch andere, kognitive oder nichtnur-kognitive Komponenten ersetzen. Umgekehrt wäre natürlich auch zu fragen, inwiefern auf der Subjektseite unabhängig von der Objektseite individuell und aktiv nicht-nur-kognitive Komponenten mitgebracht und eingebracht werden, die Denkprozesse prägen, die in einen Gegenstand und seine Darstellung hineingelesen und auf diesen bezogen werden, inwieweit einem Gegenstand nicht-nurkognitive Aspekte zugewiesen oder bei der Auseinandersetzung selbst empfunden werden usw.

Unter geschichtsdidaktischer Perspektive wären all diese denkbaren Aktivitäten ${ }^{1591}$ wiederum auf Elemente und Prozesse historischen Denkens und Lernens zu beziehen. Im Brennpunkt steht dabei das Verhältnis von nicht-nur-kognitiven Elementen - sowohl objekt- als auch subjektseitig - und historischer Erkenntnis. In diesem Zusammenhang erscheint mir die Frage zentral, inwieweit es für Erkenntnis tatsächlich einer kognitiven Kontrolle und Reflexion solcher nicht-nurkognitiven Momente braucht, was in aktuellen geschichtsdidaktischen Publikationen zum Thema als idealerweise angestrebte Form des Umgangs mit Emotionen nahegelegt wird. ${ }^{1592}$

Etwa benennen Bodo von Borries und Johannes Meyer-Hamme als basales Niveau im Umgang mit Emotionen, «intuitiv seine eigenen Emotionen [auszuleben $]{ }^{1593}$ bzw. ein «[n]aives «Zu-Hause-Sein in den eigenen Empfindungen». ${ }^{1594}$ Ein höheres Niveau umfasst dann eine noch unreflektierte Übernahme von «gesellschaftlichen Konventionen» im Fall von Meyer-Hamme, ${ }^{1595}$ eine «Distanzierung> von den eigenen Emotionen» im Fall von Borries. ${ }^{1596}$ Letztliche Zielgrösse für Meyer-Hamme ist im Umgang mit Emotionen, eigene Emotionen aus einer «analytische[n] Distanz» zu betrachten und ihr Verhältnis zu «gesellschaftlich konventionellen Emotionen» zu reflektieren; ${ }^{1597}$ Borries nennt ähnlich die «Selbstreflexive 〈Wieder-Annäherung a a - u.U. revidierte, gewandelte - eigene Emotio-

1591 Eine grosse Bandbreite, in der Emotionen im Zusammenhang mit historischem Lernen und Denken auftreten können, wird auch aufgezeigt bei Hasberg 2013.

$1592 \mathrm{Vgl}$. dazu auch die Ausführungen in Abschnitt 3.4.

1593 Meyer-Hamme 2013, S. 133.

1594 Borries 2014, S. 234.

1595 Meyer-Hamme 2013, S. 133.

1596 Borries 2014, S. 234.

1597 Meyer-Hamme 2013, S. 133 f. 
nen (〈Selbst-Versöhnung〉) unter Abgleich mit den gesellschaftlich dominanten Affekten». ${ }^{1598}$

Anknüpfend an Meyer-Hamme und Borries wäre zu fragen, ob Emotionen möglicherweise selbst dann eine Bedeutung im Zusammenhang mit Erkenntnis haben, wenn sie nicht explizit zum Gegenstand von Reflexion werden. Weiter wäre in dem Zusammenhang auch zu differenzieren, ob von Emotionen als Voraussetzung für Erkenntnis die Rede ist, so etwa bei Meyer-Hamme, wenn er Emotionen bzw. vielmehr deren Irritation als mögliche Auslöser für historisches Fragen darstellt, ${ }^{1599}$ oder ob umgekehrt Emotionen als Folge von Erkenntnis im Zusammenhang mit historischem Denken ebenfalls bedacht werden. ${ }^{1600}$

Wird zum Beispiel Erstaunen und Überraschung geäussert, ein Emotionsbereich, der in den von mir analysierten Daten einen bemerkenswerten Anteil ausmacht, so ist dies eine Emotion, die überhaupt nur denkbar ist im Zusammenhang mit neuen Einsichten, also Folge von Erkenntnis ist bzw. zeitgleich mit dieser einhergeht, aber nicht zwingend auch Ausgangspunkt für weiteres Fragen sein muss. Selbiges gilt für Äusserungen von Betroffenheit und Entsetzen, die ebenfalls ihrem Wesen nach situativ im Zusammenhang mit einer neuen Einsicht entstehen.

Angesichts der oben skizzierten Komplexität und Mehrschichtigkeit des Verhältnisses von nicht-nur-kognitiven Momenten und historischem Denken, sowohl auf theoretischer als auch empirischer Ebene, ${ }^{1601}$ wird offenkundig, dass im Rahmen meiner Studie lediglich Denkanstösse in Bezug auf einzelne Bereiche des aufgezeigten Feldes möglich sind.

Generell entsteht der Eindruck, dass die Besuchenden Emotionen vor allem als Reaktion auf etwas bzw. in Bezug auf etwas thematisieren, das ihnen beim Ausstellungsbesuch begegnet, sei es ein Aspekt historischen Geschehens oder der Ausstellung. Äusserungen über Emotionen beinhalten das deskriptive Feststellen des Vorhandenseins eigener Emotionen, wobei mitunter auch die zugehörigen Gründe bzw. Auslöser explizit benannt werden. Eine tiefergehende Reflexion und Hinterfragung der eigenen Emotionen in dem von Meyer-Hamme und Borries geschilderten Sinn, etwa im Abgleich mit im Hinblick auf Emotionen bestehenden

1598 Borries 2014, S. 234.

1599 Meyer-Hamme 2013, S. 132.

1600 Hasberg thematisiert diese Unterscheidung im Zusammenhang mit Einstellungen, die «nicht allein Voraussetzungen», sondern auch «Effekte[.] historischen Lernens» seien (Hasberg 2013, S. 58).

1601 Ein Überblick über die Vielfalt von relevanten Forschungsfeldern in der deutsch- und englischsprachigen Literatur findet sich bei Hasberg (Hasberg 2013, S. 50 ff.). 
gesellschaftlichen Konventionen, findet hingegen in dem von mir untersuchten Datenmaterial keine Entsprechung.

Und dennoch zeigt sich, dass Emotionen und Erkenntnis gemeinsam auftreten. Integral verwoben sind sie in Äusserungen von Erstaunen und Eindruck, aber auch Betroffenheit und Entsetzen, für die die Konfrontation mit etwas bislang nicht Gedachtem oder Gewusstem konstitutiv ist, auch wenn die Besuchenden die Erkenntnis in dem Moment stärker emotional als kognitiv konnotieren mögen. ${ }^{1602}$

Hinsichtlich der Bedeutung von Ästhetik und Raum zeigt sich im Rahmen meiner Studie, dass die ästhetische und räumliche Gestaltung der Ausstellung inhaltliche Bedeutungen transportieren kann und von den Besuchenden durchaus auch als solches wahrgenommen wird. Dies habe ich insbesondere am Beispiel der Äusserungen der Besuchenden zu den wiederkehrenden «Blick ins Ausland»-Elementen sowie zu den Schlussräumlichkeiten «Nach dem Krieg» dargelegt. ${ }^{1603}$ Die abweichende ästhetische Gestaltung dieser Elemente kann Besuchende dafür sensibilisieren, es darin auch mit veränderten inhaltlichen Zugängen zu tun zu haben. Am Beispiel der Schlussabteilung zeigte sich, dass deren Gestaltung bei mehreren Besuchenden anfänglich Irritation auslöste und sie anschliessend dazu neigten, über die Bedeutung dieser Räume nachzudenken. Ästhetik verfügt also über ein Potenzial als Irritationsmoment und kann ausstellungsbezogene und de-konstruktive, geschehensbezogene und re-konstruktive Überlegungen anstossen.

Eine ähnliche Wechselwirkung aus Form und Inhalt zeigte sich beim Umgang der Besuchenden mit den «Blick ins Ausland»-Elementen und insgesamt der Struktur der Ausstellung, wobei die Äusserungen auf Zusammenhänge zwischen Bewegung im Raum und inhaltlichen Zugängen hindeuten, sich also Anklänge an Wise' «embodied interpretive Practices» ${ }^{604}$ zeigen. Raum erweist sich dabei, ganz im Sinn jüngerer raumtheoretischer Zugänge, ${ }^{1605}$ nicht einfach als physikalischer Behälter, sondern gleichermassen als Akteur und prägende Instanz, die in Wechselwirkung mit den dargestellten Inhalten und der individuellen Aneignung dieser Inhalte durch die Besuchenden tritt.

In der Zusammenschau lässt sich feststellen, dass die ästhetische und die räumliche Gestaltung einer Ausstellung eine Katalysatorfunktion in der Beförderung

1602 Auf die hier angedeutete Verwandtschaft zwischen Äusserungen von Erstaunen und Eindruck einerseits und neuem Wissen andererseits habe ich bereits hingewiesen.

1603 Vgl. Abschnitt 8.6.5.

1604 Wise 2011, S. 74.

$1605 \mathrm{Vgl}$. Abschnitt 3.4.3. 
von Erkenntnis einnehmen können und dass beim Ausstellungsbesuch kognitive und nicht-nur-kognitive Momente historischen Denkens und Aneignens in einen Zusammenhang treten.

Auch singuläre gezeigte Elemente können solche Irritationen auslösen. So führte der zu Beginn der Ausstellung gezeigte Film «Métamorphoses» beispielsweise bei P12 einerseits zu ausstellungsbezogener Irritation hinsichtlich der Frage, wie sich dieser Film in die Erzählung der Ausstellung einfügt. Gleichzeitig wurde er aber auch zum Ausgangspunkt für sich durch den ganzen Ausstellungsbesuch ziehende geschehensbezogene Überlegungen in Bezug auf die Rolle schweizerischer Frauen während des Ersten Weltkriegs und ihrer Emanzipationsmöglichkeiten. Drittens regte er ausstellungsbezogene Feststellungen in der Hinsicht an, dass P12 die von der Ausstellung angebotenen thematischen Verknüpfungen im Hinblick auf dieses Thema beachtete und kommentierte.

Eine besondere und auch mehrschichtige Bedeutung lässt sich zudem für die in der Ausstellung enthaltenen Bildquellen beobachten. So zeigte sich, dass Besuchende dazu neigen, Fotografien und Filme tendenziell als Spiegel historischen Geschehens zu thematisieren und dass Auseinandersetzungen mit ihrem Charakter als konstruiertes Bild demgegenüber selten vorkommen - wohingegen dieser Charakter im Zusammenhang mit den ebenfalls in der Ausstellung gezeigten Karikaturen durchaus in den Blick gerät.

Etliche Besuchende äussern zudem im Zusammenhang mit Fotografien, sich Vergangenes vorstellen oder sich in dieses hineinversetzen zu können, und sprechen teilweise explizit den Bildern das Potenzial zu, dieses zu bewirken. Demgegenüber kaum einmal kommt es in diesem Zusammenhang zu Reflexionen über die Unmöglichkeit eines Sich-Hineinversetzens. Hingegen wurde für die im Fokus I hergestellten Bezüge zwischen Vergangenheit und Gegenwart festgestellt, dass Besuchende dort gerade im Zusammenhang mit Bildquellen dazu tendieren, auf eine Unterschiedlichkeit zwischen den Zeitebenen zu sprechen kommen, zum Beispiel indem sie Unterschiede in Bekleidung, Alltagspraktiken oder Fortbewegungsmitteln feststellen. ${ }^{1606}$

In diesem Bereich zeigt sich also eine Mehrschichtigkeit des Datenmaterials, die nicht völlig aufgelöst werden kann, und auch ein mehrschichtiges Potenzial von Fotografien, nämlich dahingehend, dass sie offenbar sowobl Andersartigkeit zu zeigen imstande sind als auch die Möglichkeit eines Sich-Hineinversetzens in

1606 Vgl. Abschnitt 8.5.4, insb. 8.5.4.3. 
dieses andere suggerieren, dabei aber nicht zwingend auch Reflexionen über die Grenzen eines Sich-Hineinversetzens anstossen. Diese Mehrschichtigkeit deckt sich, wie bereits dargestellt, mit der Mehrschichtigkeit eines geschichtsdidaktischen Empathiebegriffs, zumindest in der Konzeption Juliane Brauers, die für Empathie eine inhärente Gleichzeitigkeit von Nähe und Ferne und ein darin liegendes Potenzial für Erkenntnis annimmt. ${ }^{1607}$ Jedoch fehlt in den Verbalisierungen der Besuchenden, dies wurde ebenfalls dargestellt, gerade diese Gleichzeitigkeit. In der Regel sprechen Besuchende situativ entweder über die aus den Fotografien zu entnehmende Unterschiedlichkeit zwischen Vergangenheit und Gegenwart oder berichten von Sich-Vorstellen und -Hineinversetzen, stolpern jedoch nicht erkennbar über Widersprüche zwischen beiden Dimensionen.

Falls aufseiten von Ausstellungsmachenden, Geschichtsdidaktikern und -didaktikerinnen der Wunsch besteht, bei den Besuchenden noch weniger den Eindruck eines möglichen Sich-Hineinversetzens auszulösen, sondern darüber hinaus die Besuchenden auch dazu anzuregen, die letztliche Unmöglichkeit eines solchen Sich-Hineinversetzens zu erkennen und «produktive Irritation» ${ }^{1608}$ zu bewirken, gilt es zu überlegen, ob und wie sich Bildquellen auf andere und für dieses Anliegen noch stärker förderliche Weise kontextualisieren liessen. In dem Zusammenhang wäre weiter zu überlegen, ob Besuchende überdies stärker dazu angeregt werden sollen, Bilder auch als Konstruktionen wahrzunehmen, um den in der Wahrnehmung der Besuchenden offenbar stark manifestierten Eindruck ihrer Abbildhaftigkeit aufzubrechen.

Insgesamt scheinen sich im Umgang mit Fotografien ästhetische und emotionale Momente historischen Denkens zu kondensieren. Jenseits der bereits geschilderten Anregung zum Sich-Hineinversetzen haben Bildquellen generell ein Potenzial zur Beförderung von Emotionen, worauf auch Wise in ihrer Studie hinweist. Als eine von vier Sinnbildungsformen identifiziert sie das «emoting» als Empfinden bzw. Äussern von Emotionen ${ }^{1609}$ und stellt fest, dass dieses vor allem durch einen bestimmten Objekttyp, nämlich Fotografien, ausgelöst wird. ${ }^{1610}$ Ein Vergleich der Wirkungen unterschiedlicher Exponattypen hinsichtlich der Beförderung von Emotionen ist im Kontext meiner Studie kaum möglich, auch deshalb,

1607 Brauer 2013, insb. S. 84 ff., direktes Zitat S. 88. Vgl. zum Empathiebegriff auch die Ausführungen in Abschnitt 3.4.2.

1608 Brauer 2013, S. 88.

1609 Wise 2011, S. 123 ff., direktes Zitat S. 123.

1610 Wise 2011, S. 125. 
weil Bildquellen den deutlich grössten Anteil der in der Ausstellung «14/18» vorhandenen Quellentypen ausmachen und es insofern an einer Vergleichbarkeit mit anderen Exponattypen mangelt. Jedoch zeigt sich auch hier, dass in Auseinandersetzung der Besuchenden mit Bildquellen mannigfach Emotionen und überdies in einer grossen Bandbreite auftreten.

Was sich demgegenüber im Rahmen meiner Studie kaum erschliessen lässt, ist die Bedeutung, die originale Objekte in musealen Aneignungsvorgängen einnehmen. Wie ich weiter oben dargelegt habe, gilt das originale Exponat in museumstheoretischen Zugängen als zentrales Element historischer Ausstellungen und wird seine Bedeutung im Zusammenhang mit Konzepten wie Aura oder Authentizität diskutiert. ${ }^{1611}$ In der meiner Studie zugrunde liegenden Ausstellung «14/18» wird nur zurückhaltend mit originalen Exponaten gearbeitet, stattdessen verstärkt mit reproduzierten, grossformatigen Fotografien. Es bieten sich also verhältnismässig wenige Anknüpfungspunkte, um den Umgang der Besuchenden mit solchen Originalen bzw. überhaupt ihre Ideen von «Originalität» oder «Authentizität» zu beforschen.

Vereinzelt wird Freude darüber geäussert, in der Ausstellung auch Originalen zu begegnen, ohne dass die mit Originalen verbundene Bedeutung aber weiter expliziert würde. ${ }^{1612}$ Für eine tiefergehende Verfolgung derartiger Forschungsinteressen wäre einerseits verstärkt die Begegnung von Besuchenden mit originalen Objekten herbeizuführen und wären womöglich auch weitere Formen der Datenerhebung zu erproben. Nämlich ist zu vermuten, dass auch die mit dem Lauten Denken gewählte, sehr momentbezogene äussere Form des Besuchs die Teilnehmenden davon abhält, sich differenzierter über eigene Originalitätsvorstellungen zu äussern.

\subsubsection{Zur Einschätzung der Ausstellung und ihrer Elemente zwischen Abbild historischer Wirklichkeit und konstruiertem Raum}

In etlichen der weiter oben vorgestellten empirischen Studien zu Museums-/Ausstellungsbesuchenden finden sich Überlegungen dazu, inwieweit Besuchende das Dargestellte als Abbild historischer Wirklichkeit oder als Konstruktion wahrneh-

1611 Vgl. Abschnitt 3.1.

1612 Dies gilt namentlich für P4; vgl. die zugehörige Brennpunktdarstellung in Abschnitt 8.6.3.1. 
men. ${ }^{1613}$ Bei Andreas Körber entspricht dies dem Bereich der Sachkompetenzen. ${ }^{1614}$ Er formuliert zugehörige Niveauvorstellungen, nämlich differenziert er zwischen einer Wahrnehmung von Museen/Ausstellungen als «Darstellung vergangener Wirklichkeit» über eine Einsicht in deren Bindung an Zeit und Forschungsstand bis hin zu einer Reflexion und Hinterfragung der «in einer Ausstellung verwendeten Kategorien», ${ }^{1615}$ zwischen einem Wahrnehmen des Ausstellungsaufbaus als «nicht wahllos» mit zunehmender Fähigkeit zu dessen Reflexion und Kommentierung bis hin zur Reflexion der Effekte einer bestimmten Präsentationsweise. ${ }^{1616}$

Vorstellungen über Objekte reichen für Körber von einer Wahrnehmung der «ausgestellten Objekte nur als «Gegenstände» über deren Betrachtung «als Repräsentanten eines historischen Zusammenhangs» und Unterscheidung "Zwischen 〈Original〉 und 〈Fälschung»» bis hin zu einer Reflexion des Originalitätskonzepts und der durch die Ausstellung getroffenen Objektauswahl. ${ }^{1617}$

Sharon Macdonald kommt zu dem radikalen Schluss, Museen insgesamt würden «verbreitet als autoritative Einrichtungen» betrachtet und Besuchende neigten dazu, «eine Einrichtung zu sehen, die ihnen neutrale, wertfreie Fakten präsentiert». ${ }^{1618}$ Dass sich diese Einschätzung auf die für meine Studie vorliegenden Daten nur in eingeschränktem Mass übertragen lässt, habe ich weiter oben anhand der Äusserungen von Besuchenden im Fokus II dargelegt, ${ }^{1619}$ zeigt sich doch in vielen Äusserungen der Besuchenden durchaus eine Sensibilität für den Konstruktcharakter einer historischen Ausstellung und findet sich in dem von mir analysierten Datenmaterial, mit Ausnahme einer expliziten Reflexion der Idee von Originalität, deren Abwesenheit auch ausstellungsseitig begründet sein kann, das gesamte Spektrum der von Körber auf theoretischer Ebene ausgefalteten Zugangsweisen. Allerdings gilt es auch daran zu erinnern, dass sich zahlreiche Äusserungen, vor allem die element- und themenidentifizierenden Tätigkeiten, gar nicht eindeutig hinsichtlich einer dahinterstehenden erkenntnistheoretischen Position einordnen lassen. Rückschlüsse auf posistivistische oder konstruktivistische Grundhaltungen werden insofern in weiten Teilen des Datenmaterials verwehrt.

1613 Pleitner 2008; Pleitner 2011; Macdonald 2011; Kohler 2016. Vgl. dazu auch Abschnitt 5.3.3.

1614 Körber 2009, S. 65 ff.

1615 Körber 2009, S. 65. Vgl. dazu auch Abschnitt 3.3.

1616 Körber 2009, S. 67 f., direktes Zitat S. 67.

1617 Körber 2009, S. 66 f.

1618 Macdonald 2011, S. 246.

1619 Vgl. Abschnitt 8.6. 
Sofern die Daten Rückschlüsse erlauben, stellt sich die Lage insgesamt differenziert bis ambivalent dar. Im Kontrast zu den geschilderten konstruktivistischen Zugängen zeigt sich beispielsweise auch, dass sich Besuchende in Fällen von auftretenden Fragen und Irritationen den Ausstellungstexten und Exponatbeschriftungen zuwenden und offensichtlich auf die «Richtigkeit» der in der Ausstellung zur Verfügung gestellten Informationen vertrauen, sie als Antwortgeber auf entstandene Fragen und Vermutungen wahrnehmen. Dies entspricht den Befunden Kohlers, der für Schülerinnen und Schüler feststellte, dass diese insbesondere den in der Ausstellung enthaltenen Texten Glaubwürdigkeit attestieren und deren Inhalte als «Verständnishilfen» oder gar als «gesichertes Wissen» betrachten. ${ }^{1620}$

Im Gesamtblick über alle vorliegenden Daten erscheint es mir als angemessen, von einem ambivalenten Nebeneinander aus stärker positivistischen und konstruktivistischen Zugängen auszugehen, das Bärbel Völkel folgend kaum überraschen dürfte. So hält Völkel fest, dass es trotz des Wissens «um den Konstruktcharakter und die mögliche Vorläufigkeit unseres Wissens um die Welt» im alltäglichen Lebensvollzug unumgänglich ist, «die Komplexität der vagen, vielfach konstruierten Welt zu reduzieren». ${ }^{1621}$ Selbst wenn auf theoretischer Ebene Einsichten in den Konstruktcharakter von Geschichte vorhanden sind, kann es folglich notwendig sein, diese in der Lebenspraxis, also auch während des Besuchs einer historischen Ausstellung, immer wieder auszublenden. Dies wäre wiederum anschlussfähig an die Studie Kohlers, hält dieser doch, allerdings in Bezug auf die Vorstellungen bei Schülerinnen und Schülern, fest, dass «[d]as Vorhandensein entsprechend ausgeprägter Meta-Konzepte [...] nicht automatisch [bedeutet], dass sie auf die museale Präsentation von Geschichte angewandt werden». ${ }^{1622}$

Einzelne beforschte Besuchende dabei exakt auf diesem Spektrum aus konstruktivistischen und positivistischen Zugängen zu verorten, verbietet sich anhand der Anlage der Datenanalyse, die auf eine inhaltlich strukturierende Inventarisierung der Gesamtheit der Äusserungen zielte, wobei zwar immer wieder auch auf personenbezogene Befunde eingegangen wurde, umfassende Fallprofile zu einzelnen Besuchenden demgegenüber aber nicht das Ziel der Analyse bildeten. ${ }^{1623}$

1620 Kohler 2016, S. 208 f.

1621 Völkel 2009, S. 723.

1622 Kohler 2016, S. 228.

$1623 \mathrm{Vgl}$. Abschnitt 6.4.2. 


\subsubsection{Bezüge zur eigenen Person und Gegenwart und Rolle des Erhebungsortes}

Im Rahmen meiner Datenanalyse habe ich gezeigt, dass während des Ausstellungsbesuchs die Besuchenden auf vielerlei Weisen Bezüge zu ihrer eigenen Person und Gegenwart herstellten. Eine wesentliche Einsicht meiner Studie besteht also darin, dass solche Bezüge überhaupt vorkommen und durch die Besuchenden geleistet werden, wenn sie, sich selbst überlassen, eine historische Ausstellung besuchen und dabei ihre Gedanken äussern. Bei allen 18 Besuchenden tauchen im Verlauf des Besuchs in irgendeiner Weise solche Bezüge auf. Sie erscheinen insofern durchaus «anthropologisch» bedeutsam, nicht nur als normativ gesetzte Zielgrösse historischen Denkens und Lernens. ${ }^{1624}$

Dieser Befund ist vor allem auch deshalb aufschlussreich, weil es sich bei der Ausstellung «14/18» um eine Ausstellung zu einem Thema handelt, mit dem die Besuchenden zwar mitunter die Familiengeschichte, aber keine eigene biografische Erinnerung verbindet. Darin unterscheidet sich meine Studienanlage von derjenigen Wise', die mit 9/11 ein Thema der unmittelbaren Zeitgeschichte wählte, an das alle Probandinnen und Probanden, mindestens vermittelt durch Medien, eine persönliche Erinnerung haben, zum Teil auch selbst unmittelbar von den Ereignissen betroffen waren. ${ }^{1625}$ Dass unter diesen Umständen der Besuch einer Ausstellung autobiografische Erinnerungen anregen und Emotionen hervorrufen kann, wurde von Wise aufgezeigt. ${ }^{1626}$

Im Rahmen meiner Studie lässt sich zeigen, dass auch in Auseinandersetzung mit einer Thematik jenseits der Spannbreite der eigenen biografischen Erinnerung emotionale Reaktionen hervorgerufen werden und die Besuchenden Bezüge zu Gegenwart und eigener Lebenswelt herstellen. In diesem Zusammenhang ist besonders aufschlussreich, dass die Besuchenden dies auch ausserhalb der Ausstellungsabteilung «Nach dem Krieg» tun, in der Bezüge des Ersten Weltkriegs zur heutigen Schweiz durch die Ausstellung selbst nahegelegt werden. Es lässt sich also schlussfolgern, dass die Besuchenden nicht zwingend explizite Angebote durch die Ausstellungsstruktur selbst brauchen, um entsprechende Verknüpfungen von Zeitebenen und Bezüge zur eigenen Person herzustellen.

$1624 \mathrm{Vgl}$. für entsprechende theoretische Hintergründe die Ausführungen in Kapitel 2.

1625 Wise 2011, S. 34.

1626 Wise 2011, S. $113 \mathrm{ff}$. 
Abschliessend stellt sich in diesem Zusammenhang die Frage, inwieweit die erzielten Befunde und die beobachteten Aneignungsweisen abhängig oder unabhängig von dem konkreten Erhebungsort sind, der Ausstellung «14/18». Ich habe bereits darauf hingewiesen, dass Befunde, die anhand einer spezifischen Einrichtung gewonnen wurden, als nur eingeschränkt übertragbar gelten. ${ }^{1627}$ Hierbei sollte nicht nur die Ausstellung selbst als prägender Faktor angenommen werden sollte. Theoretische Konzeptionen des Lernens im Museum betonen neben dem Einfluss von «Physical Context» bzw. «Ausstellungskontext» gleichberechtigt die Bedeutung weiterer Faktoren wie «Personal Context»/«Individuelle Lernvoraussetzungen» und «Sociocultural Context»/ «Soziale Besuchs- und Vermittlungssituation». ${ }^{1628}$

Dass es nicht der Ausstellungskontext allein ist, der die darin stattfindenden Prozesse prägt, dass also Lern- und Aneignungsvorgänge nicht allein instruktionsseitig beeinflusst sind, wird von der Museumsbesucherforschung bereits seit ihrer konstruktivistischen Wendung nicht mehr bestritten, ${ }^{1629}$ und auch die Befunde meiner eigenen Studie fügen sich angesichts der hohen Individualität von Besuchsverläufen in dieses Paradigma ein. Umgekehrt zeigen sich durchaus auch Muster, die über viele Besuchende hinweg generalisierbar sind und durch Befunde weiterer Studien bestätigt werden, wie etwa die Tendenz des Abarbeitens beim Ausstellungsbesuch oder die für mehrere Besuchende feststellbare Bedeutung eines SichHineinversetzens in vergangenes Geschehen.

Wie gross genau dabei der Einfluss ist, den ein spezifischer Erhebungsort und seine einzelnen Elemente auf diese Aneignungsweisen haben, lässt sich unter den gegebenen Bedingungen nicht exakt beziffern. Vergleichende Erhebungsdesigns unter Einbezug Besuchender mehrerer historischer Ausstellungen und Beobachtung derselben Besuchenden in unterschiedlichen Ausstellungen wären zur weiteren Aufklärung eines solchen Verhältnisses sicherlich empfehlenswert. Umgekehrt leisten aber auch Studien wie die meinige, die Besuchende einer einzigen Ausstellung in den Blick nehmen und im Gegenzug die Chance haben, die gemachten Äusserungen detailliert bis in Tiefenstrukturen hinein zu ergründen, zu strukturieren und systematisieren, zur Erhellung des individuellen und aktiven historischen Denkens und Aneignens bei Ausstellungsbesuchenden einen Beitrag.

1627 Höge 2009, S. 208; Noschka-Roos 1994, S. 160; vgl. hierzu Abschnitt 5.3.

1628 Falk/Dierking 2000, S. 53 ff.; Kohler 2016, S. 70.

1629 Vgl. hierzu Abschnitt 3.2; stellvertretend: Falk/Dierking/Adams 2006; Hooper-Greenhill 2006; Noschka-Roos/Lewalter 2013. 


\section{Literaturverzeichnis}

\subsection{Artikel, Monografien, Sammelbände, Zeitschriften}

Alavi, Bettina (2009). Kompetenzen historischen Denkens im Museum. Ein geschichtsdidaktischer Blick auf die Museumspädagogik, dargestellt am Beispiel der Rulaman-Ausstellung im Kurpfälzischen Museum Heidelberg. In Susanne Popp \& Bernd Schönemann (Hrsg.), Historische Kompetenzen und Museen (S. 237-250). Idstein: Schulz-Kirchner.

Alkemeyer, Thomas \& Brümmer, Kristina (2016). Körper und informelles Lernen. In Marius Harring, Matthias D. Witte \& Timo Burger (Hrsg.), Handbuch informelles Lernen. Interdisziplinäre und internationale Perspektiven (S. 493-509). Weinheim: Beltz Juventa.

Ameln-Haffke, Hildegard \& Schuster, Martin (2006). Der Museumsbesuch als emotionales Erlebnis - Erlebnisverläufe im Kunstmuseum Bonn. In Martin Schuster \& Hildegard AmelnHaffke (Hrsg.), Museumspsychologie. Erleben im Kunstmuseum (S. 227-259). Göttingen: Hogrefe.

Andermann, Jens \& Arnold-de Simine, Silke (2012). Introduction. Museums and the Educational Turn: History, Memory, Inclusivity. Journal of Educational Media, Memory, and Society, $4(2)$, S. $1-7$.

Arand, Tobias (2006). Geschichtskultur des Ersten Weltkriegs - Prolegomena zu einer Systematik. In Tobias Arand (Hrsg.), Die «Urkatastrophe» als Erinnerung - Geschichtskultur des Ersten Weltkriegs (S. 1-14). Münster: ZfL.

Arand, Tobias \& Seidenfuss, Manfred (Hrsg.) (2014). Neue Wege-neue Themen-neue Methoden? Ein Querschnitt aus der geschichtsdidaktischen Forschung des wissenschaftlichen Nachwuchses. Göttingen: V\&R unipress.

Artelt, Cordula \& Moschner, Barbara (Hrsg.) (2005). Lernstrategien und Metakognition. Implikationen für Forschung und Praxis. Münster: Waxmann.

Assmann, Aleida (1988). Die Sprache der Dinge. Der lange Blick und die wilde Semiose. In Hans Ulrich Gumbrecht \& K. Ludwig Pfeiffer (Hrsg.), Materialität der Kommunikation (S. 237251). Frankfurt am Main: Suhrkamp.

Assmann, Aleida (1997). Gedächtnis, Erinnerung. In Klaus Bergmann, Klaus Fröhlich, Annette Kuhn, Jörn Rüsen \& Gerhard Schneider (Hrsg.), Handbuch der Geschichtsdidaktik (5. Aufl., S. 33-37). Seelze-Velber: Kallmeyer.

Assmann, Jan (2007). Das kulturelle Gedächtnis. Schrift, Erinnerung und politische Identität in frühen Hochkulturen (6. Aufl.). München: C. H. Beck.

Atkinson, R. C. \& Shiffrin, R. M. (1968). Human memory: A proposed system and its control. In K. W. Spence \& J. T. Spence (Hrsg.), The psychology of learning and motivation (Bd. 2, S. 89-105). New York: Academic Press.

Bannert, Maria (2007). Metakognition beim Lernen mit Hypermedien. Erfassung, Beschreibung und Vermittlung wirksamer metakognitiver Strategien und Regulationsaktivitäten. Münster: Waxmann.

Baring, Frank (2009). Empathie. In Ulrich Mayer, Hans-Jürgen Pandel, Gerhard Schneider \& Bernd Schönemann (Hrsg.), Wörterbuch Geschichtsdidaktik (2. Aufl., S. 51-52). Schwalbach/Ts.: Wochenschau. 
Baring, Frank (2011). Empathie und historisches Lernen. Eine Untersuchung zur theoretischen Begründung und Ausformung in Schulgeschichtsbüchern. Frankfurt am Main: Peter Lang.

Barricelli, Michele (2005). Schüler erzählen Geschichte. Narrative Kompetenz im Geschichtsunterricht. Schwalbach/Ts.: Wochenschau.

Barricelli, Michele (2008). Rezension zu Andreas Körber/Waltraud Schreiber/Alexander Schöner (Hrsg.): Kompetenzen historischen Denkens. Ein Strukturmodell als Beitrag zur Kompetenzorientierung in der Geschichtsdidaktik. In Wolfgang Hasberg (Hrsg.), Epoche als geschichtsdidaktische Grösse (= Zeitschrift für Geschichtsdidaktik. Jahresband 2008, S. 234-238). Schwalbach/Ts.: Wochenschau.

Barricelli, Michele \& Lücke, Martin (Hrsg.) (2017). Handbuch Praxis des Geschichtsunterrichts (2. Aufl.). Schwalbach/Ts.: Wochenschau.

Barton, Keith C. (2001). A Sociocultural Perspective on Children's Understanding of Historical Change: Comparative Findings From Northern Ireland and the United States. American Educational Research Journal, 38(4), S. 881-913.

Baumgartner, Hans Michael (1997). Narrativität. In Klaus Bergmann, Klaus Fröhlich, Annette Kuhn, Jörn Rüsen \& Gerhard Schneider (Hrsg.), Handbuch der Geschichtsdidaktik (5. Aufl., S. 157-159). Seelze-Velber: Kallmeyer.

Baumgärtner, Ulrich (2015). Wegweiser Geschichtsdidaktik. Historisches Lernen in der Schule. Paderborn: Schöningh (UTB).

Baur, Joachim (Hrsg.) (2010). Museumsanalyse. Methoden und Konturen eines neuen Forschungsfeldes. Bielefeld: Transcript.

Becker, Axel (2017). Historische Urteilsbildung. In Michele Barricelli \& Martin Lücke (Hrsg.), Handbuch Praxis des Geschichtsunterrichts (2. Aufl., S. 316-325). Schwalbach/Ts.: Wochenschau.

Bender, Saskia (2011). Empirische Zugriffe auf ästhetische Erfahrungen bei Kindern durch Materialtriangulation. In Jutta Ecarius \& Ingrid Miethe (Hrsg.), Methodentriangulation in der qualitativen Bildungsforschung (S. 321-335). Opladen: Barbara Budrich.

Benjamin, Walter (1996). Das Kunstwerk im Zeitalter seiner technischen Reproduzierbarkeit. In Michael Opitz (Hrsg.), Walter Benjamin. Ein Lesebuch (S. 313-347). Frankfurt am Main: Suhrkamp.

Berg, Alena (2016). Qualitative Bildungsforschung und informelles Lernen. In Marius Harring, Matthias D. Witte \& Timo Burger (Hrsg.), Handbuch informelles Lernen. Interdisziplinäre und internationale Perspektiven (S. 710-723). Weinheim: Beltz Juventa.

Bergmann, Klaus (1998). «So viel Geschichte wie heute war nie» - historische Bildung angesichts der Allgegenwart von Geschichte. In Ulrich Mayer, Hans-Jürgen Pandel \& Gerhard Schneider (Hrsg.), Geschichtsdidaktik. Beiträge zu einer Theorie historischen Lernens (S. 13-31). Schwalbach/Ts.: Wochenschau.

Bergmann, Klaus (2002). «... so ist das Bild immer notwendig ein beschränktes» - historisches Denken durch Bilder. In Gerhard Schneider (Hrsg.), Die visuelle Dimension des Historischen. Hans-Jürgen Pandel zum 60. Geburtstag (S. 9-20). Schwalbach/Ts.: Wochenschau.

Bergmann, Klaus (2008). Der Gegenwartsbezug im Geschichtsunterricht (2. Aufl.). Schwalbach/ Ts.: Wochenschau.

Bergmann, Klaus (2016). Gegenwarts- und Zukunftsbezug. In Ulrich Mayer, Hans-Jürgen Pandel \& Gerhard Schneider (Hrsg.), Handbuch Methoden im Geschichtsunterricht: Klaus Bergmann zum Gedächtnis (5. Aufl., S. 91-112). Schwalbach/Ts.: Wochenschau. 
Bergmann, Klaus, Fröhlich, Klaus, Kuhn, Annette, Rüsen, Jörn \& Schneider, Gerhard (Hrsg.) (1997). Handbuch der Geschichtsdidaktik (5. Aufl.). Seelze-Velber: Kallmeyer.

Bernhardt, Markus (2011). «Ich sehe was, was du nicht siehst!». Überlegungen zur Kompetenzentwicklung im Geschichtsunterricht am Beispiel der Bildwahrnehmung. In Saskia Handro \& Bernd Schönemann (Hrsg.), Visualität und Geschichte (S. 37-53). Berlin: LIT.

Bernhardt, Markus (2015). Wahrnehmungskompetenz im ausserschulischen Umgang mit Geschichte. In Dietrich Karpa, Bernd Overwien \& Oliver Plessow (Hrsg.), Ausserschulische Lernorte in der politischen und historischen Bildung (S. 33-44). Immenhausen bei Kassel: Prolog.

Binnenkade, Alexandra (2008). Lehrmittel gestalten, Lernprozesse anregen. Bilder und Emotionen. In Werner Dreier, Eduard Fuchs, Verena Radkau \& Hans Utz (Hrsg.), Schliusselbilder des Nationalsozialismus. Fotohistorische und didaktische Überlegungen (S. 101-112). Wien: Studienverlag.

Bishop Kendzia, Victoria (2011). Visitor Experience and Learning. The case of the Jewish Museum Berlin. In Jan Hodel \& Béatrice Ziegler (Hrsg.), Forschungswerkstatt Geschichtsdidaktik 09. Beiträge zur Tagung "geschichtsdidaktik empirisch 09»(S. 51-61). Bern: hep.

Blumer, Herbert (1954). What is wrong with social theory? American Sociological Review, 19, S. 3-10.

Boehm, Gottfried (2001). Die Wiederkehr der Bilder. In Gottfried Boehm (Hrsg.), Was ist ein Bild? (3. Aufl., S. 11-38). München: Fink.

Bohnsack, Ralf(1999). Rekonstruktive Sozialforschung. Einfübrung in die Methodologie und Praxis qualitativer Forschung (3. Aufl.). Opladen: Leske + Budrich.

Bohnsack, Ralf (2010). Rekonstruktive Sozialforschung. Einführung in qualitative Methoden (8. Aufl.). Opladen: Barbara Budrich.

Borries, Bodo von (1988). Geschichtslernen und Geschichtsbewusstsein. Empirische Erkundungen zu Erwerb und Gebrauch von Historie. Stuttgart: Klett.

Borries, Bodo von (1994). Von gesinnungsbildenden Erlebnissen zur Kultivierung der Affekte? Über Ziele und Wirkungen von Geschichtslernen in Deutschland. In Bernd Mütter \& Uwe Uffelmann (Hrsg.), Emotionen und historisches Lernen: Forschung, Vermittlung, Rezeption (2. Aufl., S. 67-92). Frankfurt am Main: Diesterweg.

Borries, Bodo von (2003). Historisches Lernen im Kunstmuseum? Das Beispiel der Hamburger Kunsthalle. In Wolfgang Hasberg (Hrsg.), Erinnern - Gedenken - Historisches Lernen. Symposium zum 65. Geburtstag von Karl Filser (S. 107-139). München: Ernst Vögel.

Borries, Bodo von (2009). Lernende in Historischen Museen und Ausstellungen. Erhoffter Kompetenzerwerb und kritische Rückfragen. In Susanne Popp \& Bernd Schönemann (Hrsg.), Historische Kompetenzen und Museen (S. 100-120). Idstein: Schulz-Kirchner.

Borries, Bodo von (2012). Historische Kenntnisse - historische Kategorien - historische Kompetenzen? In Christoph Kühberger (Hrsg.), Historisches Wissen. Geschichtsdidaktische Erkundungen zu Art, Tiefe und Umfang für das historische Lernen (S. 9-31). Schwalbach/Ts.: Wochenschau.

Borries, Bodo von (2014). Zwischen «Genuss» und «Ekel»: Ästhetik und Emotionalität als konstitutive Momente historischen Lernens (mit Beiträgen von Jobannes Meyer-Hamme). Schwalbach/Ts.: Wochenschau. 
Borries, Bodo von (2016). Ästhetisches Vergnügen an und emotionale Verarbeitung von Historie. Ein vernachlässigtes Problem der geschichtsdidaktischen Kompetenzdebatte? In Saskia Handro \& Bernd Schönemann (Hrsg.), Aus der Geschichte lernen? Weisse Flecken der Kompetenzdebatte (S. 53-76). Berlin: LIT.

Borsdorf, Ulrich \& Grütter, Heinrich Theodor (1999). Einleitung. In Ulrich Borsdorf \& Heinrich Theodor Grütter (Hrsg.), Orte der Erinnerung. Denkmal, Gedenkstätte, Museum (S. 1-10). Frankfurt am Main: Campus.

Borsdorf, Ulrich, Grütter, Heinrich Theodor \& Rüsen, Jörn (Hrsg.) (2004a). Die Aneignung der Vergangenheit. Musealisierung und Geschichte. Bielefeld: Transcript.

Borsdorf, Ulrich, Grütter, Heinrich Theodor \& Rüsen, Jörn (2004b). Einleitung. In Ulrich Borsdorf, Heinrich Theodor Grütter \& Jörn Rüsen (Hrsg.), Die Aneignung der Vergangenheit. Musealisierung und Geschichte (S. 7-11). Bielefeld: Transcript.

Borun, Minda \& Miller, Maryanne (1980). What's in a name? A study of the effectiveness of explanatory labels in a science museum. Philadelphia: Franklin Institute.

Brandt, Susanne (2008). Reisen zu den Schlachtfeldern des Ersten Weltkriegs. In Barbara Korte, Sylvia Paletschek \& Wolfgang Hochbruck (Hrsg.), Der Erste Weltkrieg in der populären Erinnerungskultur (S. 201-212). Essen: Klartext.

Brauer, Juliane (2013). Empathie und historische Alteritätserfahrung. In Juliane Brauer \& Martin Lücke (Hrsg.), Emotionen, Geschichte und historisches Lernen: geschichtsdidaktische und geschichtskulturelle Perspektiven (S. 75-92). Göttingen: V\&R.

Brauer, Juliane \& Lücke, Martin (2013a). Emotionen, Geschichte und historisches Lernen. Einführende Überlegungen. In Juliane Brauer \& Martin Lücke (Hrsg.), Emotionen, Geschichte und historisches Lernen. Geschichtsdidaktische und geschichtskulturelle Perspektiven (S. 11-26). Göttingen: V\&R.

Brauer, Juliane \& Lücke, Martin (Hrsg.) (2013b). Emotionen, Geschichte und historisches Lernen. Geschichtsdidaktische und geschichtskulturelle Perspektiven. Göttingen: V\&R.

Brehm, Thomas (2004). Museumspädagogen, Besucher und Ausstellungen. In Waltraud Schreiber, Katja Lehmann, Simone Unger \& Stefanie Zabold (Hrsg.), Ausstellungen anders anpacken. Event und Bildung für Besucher - ein Handbuch (S. 181-195). Neuried: Ars Una.

Buck, Thomas Martin (2017). Lebenswelt- und Gegenwartsbezug. In Michele Barricelli \& Martin Lücke (Hrsg.), Handbuch Praxis des Geschichtsunterrichts (2. Aufl., S. 289-301). Schwalbach/Ts.: Wochenschau.

Bührmann, Andrea D. \& Schneider, Werner (2008). Vom Diskurs zum Dispositiv. Eine Einführung in die Dispositivanalyse. Bielefeld: Transcript.

Bundesamt für Statistik (o. J.). Bildungsstand und Kompetenzen. Abgerufen von: www.bfs. admin.ch/bfs/de/home/statistiken/bildung-wissenschaft/bildungsstand-kompetenzen.html [18.8.2017].

Buschkühle, Carl-Peter (2015). Bildet das Ästhetische? Überlegungen zu einer ästhetischen und künstlerischen Bildung. Pädagogische Rundschau, 69(5), S. 467-486.

Buschmann, Heike (2010). Erzähltheorie als Museumsanalyse. In Joachim Baur (Hrsg.), Museumsanalyse. Methoden und Konturen eines neuen Forschungsfeldes (S. 149-184). Bielefeld: Transcript.

Buttkereit, Florence-Aline, Heinrich, Horst-Alfred, Reithmayr, Lorenz, Watmann, Alice \& Weyland, Verena (2014). Prozessbegleitendes lautes Denken im Museum: Methodenbericht und 
Ergebnisdokumentation. Abgerufen von: https://opus4.kobv.de/opus4-uni-passau/frontdoor/index/index/docId/229 [14.6.2017]

Cerutti, Mauro (2015). Weltkrieg, Erster. Innenpolitik. (Historisches Lexikon der Schweiz. Version vom 11.1.2015, Hrsg.). Abgerufen von: www.hls-dhs-dss.ch/textes/d/D8926.php [24.8.2017].

Christmeier, Martina (2011). Wahrnehmung eines authentischen Ortes. Jugendliche Besucher im Dokumentationszentrum Reichsparteitagsgelände in Nürnberg. In Bert Pampel (Hrsg.), Erschrecken - Mitgefühl - Distanz. Empirische Befunde über Schülerinnen und Schüler in Gedenkstätten und zeitgeschichtlichen Ausstellungen (S. 307-327). Leipzig: Leipziger Universitätsverlag.

Christmeier, Martina \& Reither, Ingmar (2009). Fragestellungen, Interessen und Deutungsansätze von jugendlichen Besuchern des Dokumentationszentrums Reichsparteitagsgelände. In Susanne Popp \& Bernd Schönemann (Hrsg.), Historische Kompetenzen und Museen (S. 133-140). Idstein: Schulz-Kirchner.

Cornelissen, Christoph (2003). Was heisst Erinnerungskultur? Begriffe - Methoden - Perspektiven. Geschichte in Wissenschaft und Unterricht, 54, S. 548-563.

Danker, Uwe \& Schwabe, Astrid (2011). Empirische Besucherforschung in einem regionalhistorischen Virtuellen Museum. In Jan Hodel \& Béatrice Ziegler (Hrsg.), Forschungswerkstatt Geschichtsdidaktik 09: Beiträge zur Tagung "geschichtsdidaktik empirisch 09» (S. 25-34). Bern: hep.

Deffner, Gerhard (1984). Lautes Denken. Untersuchung zur Qualität eines Datenerhebungsverfahrens. Frankfurt am Main: Peter Lang.

Deffner, Gerhard (1989). Interaktion zwischen Lautem Denken, Bearbeitungszeiten und Aufgabenmerkmalen: Eine experimentelle Prüfung des Modells von Ericsson und Simon. Sprache und Kognition, 8, S. 98-111.

Demantowsky, Marko (2009). Geschichtsbild. In Ulrich Mayer, Hans-Jürgen Pandel, Gerhard Schneider \& Bernd Schönemann (Hrsg.), Wörterbuch Geschichtsdidaktik (2. Aufl., S. 82-83). Schwalbach/Ts.: Wochenschau.

Deutsche Forschungsgemeinschaft (Hrsg.) (1974). Denkschrift Museen. Zur Lage der Museen in der Bundesrepublik Deutschland und Berlin (West). Boppard.

Deutscher Museumsbund e. V. gemeinsam mit ICOM-Deutschland (2006). Standards für Museen (2. Aufl.). Kassel: Deutscher Museumsbund e. V. gemeinsam mit ICOM-Deutschland.

Diamond, Judy (1986). The behavior of family groups in science museums. Curator, 29, S. 139154.

Dilthey, Wilhelm (1924). Die Entstehung der Hermeneutik. In Die geistige Welt. Einleitung in die Philosophie des Lebens. Erste Hälfte. Abhandlungen zur Grundlegung der Geisteswissenschaften (S. 317-338). Leipzig: Teubner.

Dinkelaker, Jörg (2011). Lernen. In Jochen Kade, Werner Helsper, Christian Lüders, Birte Egloff, Frank-Olaf Radtke \& Werner Thole (Hrsg.), Pädagogisches Wissen: Erziehungswissenschaft in Grundbegriffen (S. 133-139). Stuttgart: Kohlhammer.

Dresing, Thorsten \& Pehl, Thorsten (2013). Praxisbuch Interview, Transkription \& Analyse. Anleitungen und Regelsysteme für qualitativ Forschende(5. Aufl.). Marburg: Dr. Dresing und Pehl GmbH. 
Dressler, Jens (2012). Vom Sinn des Lernens an der Geschichte: Historische Bildung in schultheoretischer Sicht. Stuttgart: Kohlhammer. Abgerufen von http://shop2.kohlhammer.de/shopX/ shops/kohlhammer/data/pdf/978-3-17-022327-1_L.pdf

Drie, Jannet van \& Boxtel, Carla van (2008). Historical Reasoning: Towards a Framework for Analyzing Students' Reasoning about the past. Educational Psychology Review, 20(2), S. 87110.

DuBois, Pierre (1983). Mythe et réalité du fossé pendant la Première Guerre Mondiale. In Pierre DuBois (Hrsg.), Union et Division des Suisses. Les Relations entre Alémaniques, Romands et Tessinois aux XIX ${ }^{e}$ et $X X^{e}$ siècles (S. 65-91). Lausanne: Editions de l'Aire.

Dufresne-Tassé, Colette (1995). Andragogy (adult education) in the museum: a critical analysis and new formulation. In Eilean Hooper-Greenhill (Hrsg.), Museum, Media, Message (S. 245-259). London: Routledge.

Dufresne-Tassé, Colette \& Lefebvre, A. (1994). The Museum in Adult Education: A Psychological Study of Visitor Reactions. Review of Education, 40(6), S. 469-484.

Duncker, Ludwig \& Niesseler, Andreas (2015). Ästhetische Bildung - Lernkulturen in neuer Sicht. Pädagogische Rundschau, 69(5), S. 461-465.

Eghbal-Azar, Kira \& Widlok, Thomas (2013). Potentials and Limitations of Mobile Eye Tracking in Visitor Studies: Evidence from Field Research at Two Museum Exhibitions in Germany. Social Science Computer Review, 31(1), S. 103-118.

Ekman, Paul (2007). Gefüble lesen. Wie Sie Emotionen erkennen und richtig interpretieren. Heidelberg: Spektrum Akademischer Verlag.

Elsig, Alexandre (2014). Zwischen Zwietracht und Eintracht. Propaganda als Bewährungsprobe für die nationale Kohäsion. In Roman Rossfeld, Thomas Buomberger \& Patrick Kury (Hrsg.), 14/18. Die Schweiz und der Grosse Krieg (S. 72-101). Baden: Hier + Jetzt.

Elsig, Alexandre (2017). Les shrapnels du mensonge. La Suisse face à la propagande allemande de la Grande Guerre. Lausanne: Editions Antipodes.

Erdmann, Elisabeth (1994). Treppensteigen in der Toga. Sinnlich-emotionale Erfahrungen im Museum. In Bernd Mütter \& Uwe Uffelmann (Hrsg.), Emotionen und historisches Lernen: Forschung, Vermittlung, Rezeption (2. Aufl., S. 153-163). Frankfurt am Main: Diesterweg.

Erdmann, Elisabeth \& Virta, Arja (2016). Introduction: The Pain and Lightness of Nostalgia. In Susanne Popp, Markus Furrer, Katja Gorbahn, Harry Haue, Terry Haydn, Elize van Eeden \& Joanna Wojdon (Hrsg.), Nostalgia in Historical Consciousness and Culture (S. 13-17). Schwalbach/Ts.: Wochenschau.

Ericsson, K. Anders \& Simon, Herbert A. (1980). Verbal Reports as Data. Psychological Review, $87(3)$, S. $215-251$.

Ericsson, K. Anders \& Simon, Herbert A. (1984). Protocol analysis. Verbal reports as data. Cambridge, MA: MIT.

Ericsson, K. Anders \& Simon, Herbert A. (1993). Protocol analysis. Verbal reports as data. Cambridge, MA: MIT.

Erll, Astrid (2005). Kollektives Gedüchtnis und Erinnerungskulturen: eine Einführung. Stuttgart: Metzler.

Eurostat (2016). Classification of learning activities (CLA) - Manual. 2016 edition. European Union. Abgerufen von: http://ec.europa.eu/eurostat/documents/3859598/7659750/ KS-GQ-15-011-EN-N.pdf/978de2eb-5fc9-4447-84d6-d0b5f7bee723 [7.7.2017]. 
Falk, John H. (2006). An Identity-Centered Approach to Understanding Museum Learning. Curator, 49(2), S. 151-166. [DOI: https://doi.org/10.1111/j.2151-6952.2006.tb00209.x].

Falk, John H. \& Dierking, Lynn D. (1997). The Museum Experience (3. Aufl.). Washington D.C.: Whalesback Books.

Falk, John H. \& Dierking, Lynn D. (2000). Learning from museums. Visitor Experiences and the Making of Meaning. Lanham, MD: AltaMira.

Falk, John H., Dierking, Lynn D. \& Adams, Marianna. (2006). Living in a Learning Society: Museums and Free-choice Learning. In Sharon Macdonald (Hrsg.), A Companion to Museum Studies (S. 323-339). Malden, MA: Blackwell.

Fenn, Monika (2015). Beeinflusst geschichtsdidaktische Lehre die subjektiven Theorien von Studierenden zu Lehren und Lernen im Geschichtsunterricht? Ergebnisse einer empirischen Interventionsstudie. Geschichte in Wissenschaft und Unterricht, 66(9/10), S. 515-538.

Flöter, Jonas (2009). Aus der (Bildungs-)Geschichte lernen?! Gerhard Kluchert zum 60. Geburtstag. Zeitschrift für pädagogische Historiographie, 15(2), S. 71-72.

Foucault, Michel (1981). Archäologie des Wissens. Frankfurt am Main: Suhrkamp.

François, Etienne \& Schulze, Hagen (Hrsg.) (2005). Deutsche Erinnerungsorte. Eine Auswabl. Bonn: Bpb.

Franz, Julia, Siegele, Patrick \& Warmbold, Nicole (2011). Lebensweltorientierungen in der historisch-politischen Jugendbildungsarbeit. Evaluation und Weiterentwicklung der pädagogischen Arbeit in der Ausstellung «Anne Frank. hier \& heute». In Bert Pampel (Hrsg.), Erschrecken - Mitgefühl - Distanz: Empirische Befunde über Schülerinnen und Schüler in Gedenkstätten und zeitgeschichtlichen Ausstellungen (S. 329-346). Leipzig: Leipziger Universitätsverlag.

Frei, Norbert (2012). Vergangenheitspolitik. Die Anfünge der Bundesrepublik und die NS-Vergangenheit. München: C. H. Beck.

Furrer, Markus (2004). Die Nation im Schulbuch-zwischen Überhöhung und Verdrängung. Leitbilder der Schweizer Nationalgeschichte in Schweizer Geschichtslehrmitteln der Nachkriegszeit und Gegenwart. Hannover: Hahnsche Buchhandlung.

Furrer, Markus (2009). Die Weltkriege des 20. Jahrhunderts und ihre Funktion im nationalen Narrativ von Schweizer Geschichtslehrmitteln. In Markus Furrer \& Kurt Messmer (Hrsg.), Kriegsnarrative in Geschichtslehrmitteln. Brennpunkte nationaler Diskurse (S. 149-165). Schwalbach/Ts.: Wochenschau.

Gautschi, Peter (2009a). Guter Geschichtsunterricht. Grundlagen, Erkenntnisse, Hinweise. Schwalbach/Ts.: Wochenschau.

Gautschi, Peter (2009b). Vom «Hinschauen und Nachfragen» zu Sachanalyse, Sachurteil und Werturteil. In Susanne Popp \& Bernd Schönemann (Hrsg.), Historische Kompetenzen und Museen (S. 48-61). Idstein: Schulz-Kirchner.

Gautschi, Peter (2015). Geschichte lehren. Lernwege und Lernsituationen für Jugendliche (6. Aufl.). o. O.: schulverlag plus.

Geering, Traugott (1928). Handel und Industrie der Schweiz unter dem Einfluss des Weltkriegs. Basel. 
Gies, Horst (1994). Emotionalität versus Rationalität? In Bernd Mütter \& Uwe Uffelmann (Hrsg.), Emotionen und historisches Lernen: Forschung, Vermittlung, Rezeption (2. Aufl., S. 27-40). Frankfurt am Main: Diesterweg.

Glaser, Barney G. \& Strauss, Anselm L. (2010). Grounded Theory. Strategien qualitativer Forschung (3. Aufl.). Bern: Huber.

Glaser, Edith (2009). Aus Bildungsgeschichte(n) lernen? Zeitschrift für pädagogische Historiographie, 15(2), S. 74-75.

Graf, Bernhard \& Treinen, Heiner (1983). Besucher im Technischen Museum. Zum Besucherverbalten im Deutschen Museum München. München: Gebr. Mann.

Groppe, Carola (2009). Vom Bildungswert der (Bildungs-)Geschichte. Zeitschrift für pädagogische Historiographie, 15(2), S. 75-76.

Grosch, Waldemar (2014). Schriftliche Quellen und Darstellungen. In Hilke Günther-Arndt \& Meik Zülsdorf-Kersting (Hrsg.), Geschichts-Didaktik. Praxishandbuch für die Sekundarstufe I und II (6. Aufl., S. 74-99). Berlin: Cornelsen Scriptor.

Gross, Jorge (2011). Orte zum Lernen - Ein kritischer Blick auf ausserschulische Lehr-/Lernprozesse. In Kurt Messmer, Raffael Niederhäusern, Armin Rempfler \& Markus Wilhelm (Hrsg.), Ausserschulische Lernorte - Positionen aus Geographie, Geschichte und Naturwissenschaften (S. 25-49). Wien: LIT.

Grunder, Hans-Ulrich (2001). Schule und Lebenswelt: Ein Studienbuch. Münster: Waxmann.

Grunder, Hans-Ulrich (Hrsg.) (2011). Aus der Geschichte lernen. Die historische Perspektive in der Ausbildung von Lehrerinnen und Lehrern. Baltmannsweiler: Schneider.

Grütter, Heinrich Theodor (1997a). Aspekte der Geschichtskultur. In Klaus Bergmann, Klaus Fröhlich, Annette Kuhn, Jörn Rüsen \& Gerhard Schneider (Hrsg.), Handbuch der Geschichtsdidaktik (5. Aufl., S. 601-611). Seelze-Velber: Kallmeyer.

Grütter, Heinrich Theodor (1997b). Die historische Ausstellung. In Klaus Bergmann (Hrsg.), Handbuch der Geschichtsdidaktik (5. Aufl., S. 668-674). Seelze-Velber: Kallmeyer.

Grütter, Heinrich Theodor (1997c). Geschichte im Museum. In Klaus Bergmann (Hrsg.), Handbuch der Geschichtsdidaktik (5. Aufl., S. 707-713). Seelze-Velber: Kallmeyer.

Grütter, Heinrich Theodor \& Kuhn, Bärbel (2014). Geschichte erfahren im Museum. Zur Einführung. In Bärbel Kuhn, Susanne Popp, Jutta Schumann \& Astrid Windus (Hrsg.), Geschichte erfahren im Museum (S. 11-12). St. Ingbert: Röhrig.

Günther-Arndt, Hilke (2014). Methodik des Geschichtsunterrichts. In Hilke Günther-Arndt \& Meik Zülsdorf-Kersting (Hrsg.), Geschichts-Didaktik. Praxishandbuch für die Sekundarstufe I und II (6. Aufl., S. 158-204). Berlin: Cornelsen Scriptor.

Günther-Arndt, Hilke \& Zülsdorf-Kersting, Meik (Hrsg.) (2014). Geschichts-Didaktik. Praxishandbuch für die Sekundarstufe I und II (6. Aufl.). Berlin: Cornelsen Scriptor.

Hamann, Christoph (2007). Visual History und Geschichtsdidaktik. Bildkompetenz in der historisch-politischen Bildung. Herbolzheim: Centaurus.

Hamann, Christoph (2008). Wechselrahmen. Narrativierungen von Schlüsselbildern - das Beispiel vom Foto des kleinen Jungen aus dem Warschauer Ghetto. In Werner Dreier, Eduard Fuchs, Verena Radkau \& Hans Utz (Hrsg.), Schlüsselbilder des Nationalsozialismus. Fotohistorische und didaktische Überlegungen (S. 28-42). Wien: Studienverlag.

Hamann, Christoph (2011). Zum Eigensinn der Fotografie. In Saskia Handro \& Bernd Schönemann (Hrsg.), Visualität und Geschichte (S. 23-35). Berlin: LIT. 
Hamel, Ronald (1990). Over het denken van de architect (on the thought processes of architects). Amsterdam: AHA books.

Handro, Saskia \& Schönemann, Bernd (Hrsg.) (2008). Orte historischen Lernens. Berlin: LIT.

Handro, Saskia \& Schönemann, Bernd (Hrsg.) (201la). Visualität und Geschichte. Berlin: LIT.

Handro, Saskia \& Schönemann, Bernd (2011b). Zur Einleitung. In Saskia Handro \& Bernd Schönemann (Hrsg.), Geschichtsdidaktische Schulbuchforschung (2. Aufl., S. 3-12). Berlin: LIT.

Handro, Saskia \& Schönemann, Bernd (2014). Einleitung. In Saskia Handro \& Bernd Schönemann (Hrsg.), Raum und Sinn. Die räumliche Dimension der Geschichtskultur (S. 1-4). Berlin: LIT.

Hartung, Olaf (Hrsg.) (2006). Museum und Geschichtskultur. Ästhetik-Politik - Wissenschaft. Bielefeld: Verlag für Regionalgeschichte.

Hartung, Olaf (2009). Aktuelle Trends in der Museumsdidaktik und ihre Bedeutung für das historische Lernen. In Vadim Oswalt \& Hans-Jürgen Pandel (Hrsg.), Geschichtskultur: Die Anwesenheit von Vergangenheit in der Gegenwart (S. 153-173). Schwalbach/Ts.: Wochenschau.

Hasberg, Wolfgang (2006). Erinnerungs- oder Geschichtskultur? Überlegungen zu zwei (un-) vereinbaren Konzeptionen zum Umgang mit Gedächtnis und Geschichte. In Olaf Hartung (Hrsg.), Museum und Geschichtskultur. Ästhetik-Politik-Wissenschaft (S. 32-59). Bielefeld: Verlag für Regionalgeschichte.

Hasberg, Wolfgang (2009). Vermittlung geschichtskultureller Kompetenzen in historischen Ausstellungen. In Susanne Popp \& Bernd Schönemann (Hrsg.), Historische Kompetenzen und Museen (S. 211-236). Idstein: Schulz-Kirchner.

Hasberg, Wolfgang (2012). Analytische Wege zu besserem Geschichtsunterricht. Historisches Denken im Handlungszusammenhang Geschichtsunterricht. In Johannes Meyer-Hamme, Holger Thünemann \& Meik Zülsdorf-Kersting (Hrsg.), Was heisst guter Geschichtsunterricht? Perspektiven im Vergleich (S. 137-160). Schwalbach/Ts.: Wochenschau.

Hasberg, Wolfgang (2013). Emotionalität historischen Lernens. Einblicke in und Ausblicke auf empirische Forschung. In Juliane Brauer \& Martin Lücke (Hrsg.), Emotionen, Geschichte und historisches Lernen: geschichtsdidaktische und geschichtskulturelle Perspektiven (S. 47-73). Göttingen: V\&R.

Hasberg, Wolfgang \& Körber, Andreas (2003). Geschichtsbewusstsein dynamisch. In Andreas Körber (Hrsg.), Geschichte - Leben - Lernen: Bodo von Borries zum 60. Geburtstag (S. 177200). Schwalbach/Ts: Wochenschau.

Hass, Matthias (2002). Gestaltetes Gedenken. Yad Vashem, das U. S. Holocaust Memorial Museum und die Stiftung Topographie des Terrors. Frankfurt am Main: Campus.

Heese, Thorsten (2014). Außerschulische Lernorte im Geschichtsunterricht: Das Museum. In Bärbel Kuhn, Susanne Popp, Jutta Schumann \& Astrid Windus (Hrsg.), Geschichte erfahren im Museum (S. 13-21). St. Ingbert: Röhrig.

Heikkilä, Tomi, Jaatinen, Carina, Kyllönen, Eeva \& Tornberg, Leena (2011). How to access the experiences of museum visitors? The Thinking Aloud method in the evaluation workshop of the exhibition Ötzi - Iceman of the Alps. Abgerufen von: www.museoliitto.fi/doc/How to_access_experiences_of_Museum_visitors.pdf [14.1.2018]. 
Hein, Georg E. (2006). Museum Education. In Sharon Macdonald (Hrsg.), A Companion to Museum Studies (S. 340-352). Malden, MA: Blackwell.

Hein, George E. (1988). Learning in the Museum. London: Routledge.

Hellmuth, Thomas \& Klepp, Cornelia (2010). Politische Bildung. Geschichte, Modelle, Praxisbeispiele. Wien: Böhlau.

Helmke, Andreas (2015). Unterrichtsqualität und Lehrerprofessionalität. Diagnose, Evaluation und Verbesserung des Unterrichts (6. Aufl.). Seelze-Velber: Klett u. Kallmeyer.

Heuer, Christian (2009). Gegenwartsbezug. In Ulrich Mayer, Hans-Jürgen Pandel, Gerhard Schneider \& Bernd Schönemann (Hrsg.), Wörterbuch Geschichtsdidaktik (2. Aufl., S. 76-77). Schwalbach/Ts.: Wochenschau.

Heuer, Christian (2011). Historisches Lernen vor Ort - Skizze für ein zeitgenössisches Bild vom ausserschulischen historischen Lernen. In Kurt Messmer, Raffael Niederhäusern, Armin Rempfler \& Markus Wilhelm (Hrsg.), Ausserschulische Lernorte - Positionen aus Geographie, Geschichte und Naturwissenschaften (S. 50-81). Wien: LIT.

Hodel, Jan (2013). Verkürzen und Verknüpfen. Geschichte als Netz narrativer Fragmente: Wie Jugendliche digitale Netzmedien für die Erstellung von Referaten im Geschichtsunterricht verwenden. Bern: hep.

Hodel, Jan (2014). Narrative Bricolage. Jugendlicher Umgang mit digitalen Netzmedien zur Bewältigung des «narrativen Paradox» von Neu-Nacherzählungen. In Marko Demantowsky \& Christoph Pallaske (Hrsg.), Geschichte lernen im digitalen Wandel (S. 17-33). Berlin: De Gruyter.

Hoffrichter, Horst (1998). Besucherforschung an den Museen der Stadt Köln. In Museumspädagogik in Köln. Konzepte - Angebote - Themen (S. 108-121). Köln: Museumsdient Köln.

Höge, Holger (2006). Empirische Befunde zum musealen Erleben populärer Ästhetik. In Martin Schuster \& Hildegard Ameln-Haffke (Hrsg.), Museumspsychologie. Erleben im Kunstmuseum (S. 204-225). Göttingen: Hogrefe.

Hooper-Greenhill, Eilean (2006). Studying Visitors. In Sharon Macdonald (Hrsg.), A Companion to Museum Studies (S. 362-376). Malden, MA: Blackwell.

Hooper-Greenhill, Eilean (2007). Museums and Education. Purpose, Pedagogy, Performance. London: Routledge.

Hooper-Greenhill, Eilean \& Moussouri, Theano (2001). Making Meaning in Art Museums 2: Visitors' Interpretative Strategies at Nottingham Castle Museum and Art Gallery. Research Centre for Museums and Galleries. Abgerufen von: www2.le.ac.uk/departments/ museumstudies/rcmg/projects/making-meaning-in-art-museums-2-1/Making\%20Meaning \%202.pdf [14.1.2018].

Hooper-Greenhill, Eilean, Moussouri, Theano, Hawthorne, Emma \& Riley, Rowena (2001). Making Meaning in Art Museums 1: Visitors' Interpretative Strategies at Wolverhampton Art Gallery. Research Centre for Museums and Galleries. Abgerufen von: www2.le.ac.uk/ departments/museumstudies/rcmg/projects/making-meaning-in-art-museums-1/Making $\% 20$ meaning\%201.pdf [14.1.2018].

Hopf, Christel (2009). Qualitative Interviews - ein Überblick. In Uwe Flick, Ernst von Kardorff \& Ines Steinke (Hrsg.), Qualitative Forschung. Ein Handbuch (7. Aufl., S. 349-360). Reinbek bei Hamburg: Rowohlt. 
Hopf, Christel \& Weingarten, Elmar (Hrsg.) (1993). Qualitative Sozialforschung (3. Aufl.). Stuttgart: Klett-Cotta.

Huber, Günter L. \& Mandl, Heinz (1982). Verbalisierungsmethoden zur Erfassung von Kognitionen im Handlungszusammenhang. In Günter L. Huber \& Heinz Mandl (Hrsg.), Verbale Daten: Eine Einführung in die Grundlagen und Methoden der Erbebung und Auswertung (S. 11-42). Weinheim: Beltz.

International Council of Museums (2017). ICOM Code of Ethics for Museums. Abgerufen von: http://icom.museum/fileadmin/user_upload/pdf/Codes/ICOM-code-En-web.pdf [17.7.2017].

Jeismann, Karl-Ernst (1985). Verlust der Geschichte? Zur gesellschaftlichen und anthropologischen Funktion des Geschichtsbewusstseins in der gegenwärtigen Situation. In Wolfgang Jacobmeyer \& Erich Kosthorst (Hrsg.), Geschichte als Horizont der Gegenwart: über den Zusammenhang von Vergangenheitsdeutung, Gegenwartsverständnis und Zukunftsperspektive (S. 11-25). Paderborn: Schöningh.

Jeismann, Karl-Ernst (1988). Geschichtsbewußtsein als zentrale Kategorie der Geschichtsdidaktik. In Gerhard Schneider (Hrsg.), Geschichtsbewusstsein und historisch-politisches Lernen (S. 1-24). Pfaffenweiler: Centaurus.

Jeismann, Karl-Ernst (1997). Geschichtsbewusstsein-Theorie. In Klaus Bergmann, Klaus Fröhlich, Annette Kuhn, Jörn Rüsen \& Gerhard Schneider (Hrsg.), Handbuch der Geschichtsdidaktik (5. Aufl., S. 42-44). Seelze-Velber: Kallmeyer.

Jeismann, Karl-Ernst (2000). "Geschichtsbewusstsein» als zentrale Kategorie der Didaktik des Geschichtsunterrichts. In Wolfgang Jacobmeyer \& Bernd Schönemann (Hrsg.), Karl-Ernst Jeismann. Geschichte und Bildung. Beiträge zur Geschichtsdidaktik und zur Historischen Bildungsforschung (S. 46-72). Paderborn: Schöningh.

Jost, Hans Ulrich (1983). Bedrohung und Enge (1914-45). In Geschichte der Schweiz und der Schweizer. Band III (S. 101-189). Basel: Helbing \& Lichtenhahn.

Kahnwald, Nina (2016). Informelles Lernen im Erwachsenenalter. In Marius Harring, Matthias D. Witte \& Timo Burger (Hrsg.), Handbuch informelles Lernen. Interdisziplinäre und internationale Perspektiven (S. 344-358). Weinheim: Beltz Juventa.

Kelle, Udo (1994). Empirisch begrïndete Theoriebildung. Zur Logik und Methodologie interpretativer Sozialforschung. Weinheim: Deutscher Studienverlag.

Kelle, Udo \& Kluge, Susann (2010). Vom Einzelfall zum Typus. Fallvergleich und Fallkontrastierung in der qualitativen Sozialforschung (2. Aufl.). Wiesbaden: VS Verlag für Sozialwissenschaften.

Kessl, Fabian (2016). Erziehungswissenschaftliche Forschung zu Raum und Räumlichkeit. Eine Verortung des Thementeils «Raum und Räumlichkeit in der erziehungswissenschaftlichen Forschung». Zeitschrift für Pädagogik, 62(1), S. 5-19.

Kessl, Fabian, Reh, Sabine, Glaser, Edith \& Thole, Werner (2016). Raum und Räumlichkeit in der erziehungswissenschaftlichen Forschung. Zeitschrift für Pädagogik, 62(1), S. 1-4.

Klein, Hans-Joachim \& Wüsthoff-Schäfer, Barbara (1990). Inszenierungen an Museen und ibre Wirkung auf Besucher. Berlin: Institut für Museumskunde.

Klein, Marion (2012). Schülerinnen und Schüler am Denkmal für die ermordeten Juden Europas. Eine empirisch-rekonstruktive Studie. Wiesbaden: Springer VS. 
Klieme, Eckard, Artelt, Cordula \& Stanat, Petra (2001). Fächerübergreifende Kompetenzen: Konzepte und Indikatoren. In Franz E. Weinert (Hrsg.), Leistungsmessungen in Schulen (S. 203-218). Weinheim: Beltz.

Klingler, Felicitas Iris (2017). Die Relevanz «authentischer Objekte» in der museumspädagogischen Geschichtsvermittlung. In Monika Waldis \& Béatrice Ziegler (Hrsg.), Forschungswerkstatt Geschichtsdidaktik 15. Beiträge zur Tagung "geschichtsdidaktik empirisch 15»(S. 72-86). Bern: hep.

Knigge, Volkhard (2004). Museum oder Schädelstätte? Gedenkstätten als multiple Institutionen. In Stiftung Haus der Geschichte der Bundesrepublik Deutschland (Hrsg.), Gedenkstätten und Besucherforschung (S. 17-33). Bonn: Stiftung Haus der Geschichte der Bundesrepublik Deutschland.

Kohler, Christian (2014). «Wo Geschichte näherrückt» - Schülervorstellungen über die Konstruktion von Geschichte im Museum. In Tobias Arand \& Manfred Seidenfuss (Hrsg.), Neue Wege - neue Themen - neue Methoden? Ein Querschnitt aus der geschichtsdidaktischen Forschung des wissenschaftlichen Nachwuchses (S. 83-97). Göttingen: V\&R unipress.

Kohler, Christian (2015). «Es ist halt mehr so da»-Schülervorstellungen über die Darstellung von Geschichte im Museum. In Monika Waldis \& Béatrice Ziegler (Hrsg.), Forschungswerkstatt Geschichtsdidaktik 13. Beiträge zur Tagung «geschichtsdidakik empirisch 13»(S. 63-73). Bern: hep.

Kohler, Christian (2016). Schülervorstellungen über die Präsentation von Geschichte im Museum. Eine empirische Studie zum historischen Lernen im Museum. Berlin: LIT.

Köhr, Katja (2012). Die vielen Gesichter des Holocaust. Museale Repräsentationen zwischen Individualisierung, Universalisierung und Nationalisierung. Göttingen: V\&R unipress.

Koinzer, Thomas \& Loeffelmeier, Rüdiger (Hrsg.) (2009). Aus der (Bildungs-)Geschichte lernen?! Gerhard Kluchert zum 60. Geburtstag. Zeitschrift für pädagogische Historiographie, 15(2), S. 68-88.

Kolb, Barbara \& Murr, Karl Borromäus (2009). Über den Erwerb historischer Kompetenzen im Museum. Überlegungen aus der Planungspraxis des Bayerischen Textil- und Industriemuseums in Augsburg. In Susanne Popp \& Bernd Schönemann (Hrsg.), Historische Kompetenzen und Museen (S. 141-164). Idstein: Schulz-Kirchner.

Konrad, Klaus (1998). Kooperatives Lernen bei Studierenden. Explorative Analyse selbstregulativer Lernstrategien. Zeitschrift für Pädagogische Psychologie, 12(1), S. 25-37.

Konrad, Klaus (2010). Lautes Denken. In Günter Mey \& Katja Mruck (Hrsg.), Handbuch Qualitative Forschung in der Psychologie (S. 476-490). Wiesbaden: VS Verlag für Sozialwissenschaften.

Körber, Andreas (2006). Hinreichende Transparenz der Operationen und Modi des historischen Denkens im Unterricht? Erste Befunde einer Einzelfallanalyse im Projekt «FUER Geschichtsbewusstsein». In Hilke Günther-Arndt \& Michael Sauer (Hrsg.), Geschichtsdidaktik empirisch. Untersuchungen zum historischen Denken und Lernen (S. 189-214). Berlin: LIT.

Körber, Andreas (2007). Die Dimensionen des Kompetenzmodells «Historisches Denken». In Andreas Körber, Waltraud Schreiber \& Alexander Schöner (Hrsg.), Kompetenzen historischen Denkens. Ein Strukturmodell als Beitrag zur Kompetenzorientierung in der Geschichtsdidaktik (S. 89-154). Neuried: Ars Una. 
Körber, Andreas (2009). Kompetenzorientiertes historisches Lernen im Museum? Eine Skizze auf der Basis des Kompetenzmodells «Historisches Denken». In Susanne Popp \& Bernd Schönemann (Hrsg.), Historische Kompetenzen und Museen (S. 62-80). Idstein: SchulzKirchner.

Körber, Andreas (2010a). Anhang zu Andreas Körber (2010): «Historisches Denken zwischen Museum und Schule.» In Christoph, Barbar \& Günter Dippold (Hrsg.). Museum und Schule - erfolgreiche Partner? Bayreuth. Bezirk Oberfranken: Beratungsstelle für Museen (Banzer Museumsgespräche; 2), S. 23-47. Bezirk Oberfranken. Servicestelle für Museen. Abgerufen von: http://koerber2005.erzwiss.uni-hamburg.de/wordpress-mu/historisch denkenlernen/files/2010/06/2009_10_28_Banz_Museum_K\%C3\%B6rber_Graduierungsanhang_2.pdf [9.6.2017].

[Hinweis: In dieser Publikation sind keine durch den Autor selbst vergebenen Seitenzahlen enthalten, ich beziehe mich daher mit Referenzen auf die Seiten der PDF-Datei, S. 1-5.]

Körber, Andreas (2010b). Historisches Denken zwischen Museum und Schule. In Barbara Christoph \& Günter Dippold (Hrsg.), Museum und Schule - Erfolgreiche Partner? (S. 23-46). Bayreuth: Bezirk Oberfranken. Servicestelle für Museen.

Körber, Andreas (2013). Historische Sinnbildungstypen: Weitere Differenzierung. pedocs. Open Access Erziehungswissenschaften. Abgerufen von: https://www.pedocs.de/volltexte/2013/ 7264/pdf/Koerber_2013_Sinnbildungen_Differenzierung.pdf [4.1.2018].

Körber, Andreas (2016). Sinnbildungstypen als Graduierungen? Versuch einer Klärung am Beispiel der historischen Fragekompetenz. In Katja Lehmann, Michael Werner \& Stefanie Zabold (Hrsg.), Historisches Denken jetzt und in Zukunft. Wege zu einem theoretisch fundierten und evidenzbasierten Umgang mit Geschichte (S. 27-41). Münster: LIT.

Körber, Andreas, Schreiber, Waltraud \& Schöner, Alexander (Hrsg.) (2007). Kompetenzen historischen Denkens. Ein Strukturmodell als Beitrag zur Kompetenzorientierung in der Geschichtsdidaktik. Neuried: Ars Una.

Korff, Gottfried (2002). Zur Eigenart der Museumsdinge (1992). In Gottfried Korff, Martina Eberspächer, Gudrun M. König, Bernhard Tschofen \& Bodo M. Baumunk (Hrsg.), Museumsdinge: deponieren - exponieren (S. 140-145). Köln: Böhlau.

Korff, Gottfried (2004). Einleitung. In Ulrich Borsdorf, Heinrich Theodor Grütter \& Jörn Rüsen (Hrsg.), Die Aneignung der Vergangenheit. Musealisierung und Geschichte (S. 81-103). Bielefeld: Transcript.

Koselleck, Reinhart (1989). Vergangene Zukunft. Zur Semantik geschichtlicher Zeiten. Frankfurt am Main: Suhrkamp.

Koselleck, Reinhart (2003). Die Zeiten der Geschichtsschreibung. In Reinhart Koselleck, Zeitschichten. Studien zur Historik (S. 287-297). Frankfurt am Main: Suhrkamp.

Krammer, Reinhard (2006). Historische Kompetenzen erwerben - durch das Arbeiten mit Bildern? In Reinhard Krammer \& Heinricht Ammerer (Hrsg.), Mit Bildern arbeiten. Historische Kompetenzen erwerben (S. 21-37). Neuried: Ars Una.

Krammer, Reinhard (2008). Historisches Lernen mit Bildern. In Werner Dreier, Eduard Fuchs, Verena Radkau \& Hans Utz (Hrsg.), Schlïsselbilder des Nationalsozialismus. Fotohistorische und didaktische Überlegungen (S. 43-56). Wien: Studienverlag.

Kraus, Katrin, Schmid, Martin \& Thyroff, Julia (2013). Validierung als Weg in die Erwachsenenbildung. Eine empirische Analyse von Lebenslaufdokumenten. Forschungsbericht. Basel: Fach- 
hochschule Nordwestschweiz, Pädagogische Hochschule, Institut Weiterbildung und Beratung.

Kreis, Georg (2008). Zeitzeichen für die Ewigkeit. 300 Jahre schweizerische Denkmaltopographie. Zürich: Verlag Neue Zürcher Zeitung.

Kreis, Georg (2010). Schweizer Erinnerungsorte. Aus dem Speicher der Swissness. Zürich: Verlag Neue Zürcher Zeitung.

Krüger, Dirk, Parchmann, Ilka \& Schecker, Horst (Hrsg.) (2014). Methoden in der naturwissenschaftsdidaktischen Forschung. Berlin: Springer Spektrum.

Kruse, Jan (2014). Qualitative Interviewforschung: ein integrativer Ansatz. Weinheim: Beltz Juventa.

Kuckartz, Udo (2014b). Qualitative Inhaltsanalyse. Methoden, Praxis, Computerunterstützung (2. Aufl.). Weinheim: Beltz Juventa.

Kuckartz, Udo (2016). Qualitative Inhaltsanalyse. Methoden, Praxis, Computerunterstïtzung (3. Aufl.). Weinheim: Beltz Juventa.

Kühberger, Christoph (2015). Kompetenzorientiertes historisches und politisches Lernen. Methodische und didaktische Annäherungen für Geschichte, Sozialkunde und Politische Bildung (3. Aufl.). Innsbruck: Studienverlag.

Kuhn, Bärbel, Popp, Susanne, Schumann, Jutta \& Windus, Astrid (2014). Vorwort. In Bärbel Kuhn, Susanne Popp, Jutta Schumann \& Astrid Windus (Hrsg.), Geschichte erfahren im Museum (S. 9). St. Ingbert: Röhrig.

Kuhn, Konrad J. \& Ziegler, Béatrice (2011). Dominantes Narrativ und drängende Forschungsfragen. Zur Geschichte der Schweiz im Ersten Weltkrieg. Traverse. Zeitschrift für Geschichte/ Revue d'histoire, 18(3), S. 123-141.

Kuhn, Konrad J. \& Ziegler, Béatrice (2013). Tradierungen zur Schweiz im Ersten Weltkrieg: Geschichtskulturelle Prägungen der Geschichtswissenschaft und ihre Folgen. Schweizerische Zeitschrift für Geschichte, 63(3), S. 505-526.

Kuhn, Konrad J. \& Ziegler, Béatrice (Hrsg.) (2014a). Der vergessene Krieg. Spuren und Traditionen zur Schweiz im Ersten Weltkrieg. Baden: Hier + Jetzt.

Kuhn, Konrad J. \& Ziegler, Béatrice (2014b). Eine vergessene Zeit? Zur geschichtskulturellen Präsenz des Ersten Weltkriegs in der Schweiz. In Roman Rossfeld, Thomas Buomberger \& Patrick Kury (Hrsg.), 14/18. Die Schweiz und der Grosse Krieg (S. 367-387). Baden: Hier + Jetzt.

Kuhn, Konrad J. \& Ziegler, Béatrice (2014c). Vom Krieg im Frieden. Zur Geschichtskultur des Ersten Weltkriegs in der Schweiz - eine Einleitung. In Konrad J. Kuhn \& Béatrice Ziegler (Hrsg.), Der vergessene Krieg. Spuren und Traditionen zur Schweiz im Ersten Weltkrieg (S. 7-21). Baden: Hier + Jetzt.

Kuhn, Konrad J. \& Ziegler, Béatrice (2015). Der «Hype» um den Ersten Weltkrieg. Ausgangspunkt eines neuen Narrativs über die Schweiz im Grossen Krieg? Didacta Historica, 1, S. 51-56.

Kuhn, Konrad J. \& Ziegler, Béatrice (2016). Commemoration (Switzerland). In Ute Daniel, Peter Gatrell, Oliver Janz, Heather Jones, Jennifer Keene, Alan Kramer \& Bill Nasson (Hrsg.), 1914-1918-online. International Encyclopedia of the First World War. Berlin: Freie Universität Berlin. Abgerufen von: https://encyclopedia.1914-1918-online.net/pdf/19141918-Online-commemoration_switzerland-2016-01-29.pdf [16.3.2018]. 
Kunz-Ott, Hannelore, Kudorfer, Susanne \& Weber, Traudel (Hrsg.) (2009). Kulturelle Bildung im Museum. Aneignungsprozesse - Vermittlungsformen-Praxisbeispiele. Bielefeld: Transcript.

Kury, Patrick (2014). Der Erste Weltkrieg als Wendepunkt in der Ausländerpolitik. Von der Freizügigkeit zu Kontrolle und Abwehr. In Roman Rossfeld, Thomas Buomberger \& Patrick Kury (Hrsg.), 14/18. Die Schweiz und der Grosse Krieg (S. 290-313). Baden: Hier + Jetzt.

Lange, Dirk (2004). Historisch-politische Didaktik. Zur Begründung historisch-politischen Lernens. Schwalbach/Ts.: Wochenschau.

Lässig, Simone (2006). Vom historischen Fluchtpunkt zur transnationalen Metapher. HolocaustErinnerung in Museen zwischen Geschichte und Moral. In Olaf Hartung (Hrsg.), Museum und Geschichtskultur. Ästhetik - Politik - Wissenschaft (S. 184-210). Bielefeld: Verlag für Regionalgeschichte.

Lefebvre, Henri (2004). The Production of Space. Malden MA: Blackwell.

Lenz, Claudia \& Talsnes, Anne (2014). Stimulated Recall. Tracing Learning Narratives and Reinforcing Historical Competence. In Helle Bjerg, Andreas Körber, Claudia Lenz \& Oliver Wrochem (Hrsg.), Teaching Historical Memories in an Intercultural Perspective: Concepts and Methods: Experiences and Results from the TeacMem Project (S. 97-114). Berlin: Metropol.

Lewalter, Doris (2009). Bedingungen und Effekte von Museumsbesuchen. In Hannelore KunzOtt, Susanne Kudorfer \& Traudel Weber (Hrsg.), Kulturelle Bildung im Museum. Aneignungsprozesse - Vermittlungsformen - Praxisbeispiele (S. 45-56). Bielefeld: Transcript.

Lewalter, Doris \& Noschka-Roos, Annette (2009). Museum und Erwachsenenbildung. In Rudolf Tippelt \& Aiga von Hippel (Hrsg.), Handbuch Erwachsenenbildung/Weiterbildung (3. Aufl., S. 527-541). Wiesbaden: VS Verlag für Sozialwissenschaften.

Liebau, Eckart (2012). Ich-Bildung und Welt-Bildung von Kindern und Jugendlichen im Museum. In Gisela Staupe (Hrsg.), Das Museum als Lern- und Erfahrungsraum. Grundlagen und Praxisbeispiele (S. 39-45). Wien: Böhlau.

Litten, Katharina (2013). "Geschichte zum Thema machen». Eine empirische Studie zum Planungsverhalten von Geschichtslehrkräften. In Jan Hodel, Monika Waldis \& Béatrice Ziegler (Hrsg.), Forschungswerkstatt Geschichtsdidaktik 12: Beitrüge zur Tagung "geschichtsdidaktik empirisch 12» (S. 84-94). Bern: hep.

Litten, Katharina (2017). Wie planen Geschichtslehrkräfte ibren Unterricht? Eine empirische Untersuchung der Unterrichtsvorbereitung von Geschichtslehrpersonen an Gymnasien und Hauptschulen. Göttingen: V\&R unipress.

Lobe, Mira \& Kaufmann, Angelika (1996). Zwei Elefanten, die sich gut kannten. Wien: Jungbrunnen.

Lorenz, Chris (1997). Konstruktion der Vergangenheit. Eine Einführung in die Geschichtstheorie. Köln: Böhlau.

Lotz, Miriam, Gabriel, Katrin \& Lipowsky, Frank (2013). Niedrig und hoch inferente Verfahren der Unterrichtsbeobachtung. Analysen zu deren gegenseitiger Validierung. Zeitschrift für Pädagogik, 59(3), S. 357-380.

Löw, Martina, Steets, Silke \& Stoetzer, Sergej (2008). Einfübrung in die Stadt-und Raumsoziologie (2. Aufl.). Opladen: Barbara Budrich.

Macdonald, Sharon (1992). Cultural imagining among museum visitors: a case study. International Journal of Museum Management and Curatorship, 11(4), S. 401-409. 
Macdonald, Sharon (2000). Nationale, postnationale, transkulturelle Identitäten und das Museum. In Rosemarie Beier (Hrsg.), Geschichtskultur in der Zweiten Moderne (S. 123-148). Frankfurt: Campus.

Macdonald, Sharon (2006). Introduction to Part IV. In Sharon Macdonald (Hrsg.), A Companion to Museum Studies (S. 320-322). Malden, MA: Blackwell Publishing.

Macdonald, Sharon (2011). Museumsbesuch und Ausstellungsdesign. Wechselseitige Verbindung und Austausch. In Doris Harrasser, Karin Harrasser, Stephanie Kiessling, Karin Schneider, Sabine Sölkner \& Veronika Wöhrer (Hrsg.), Wissen Spielen. Untersuchungen zur Wissensaneignung von Kindern im Museum (S. 237-259). Bielefeld: Transcript.

Magull, Gabriele (2000). Sprache oder Bild. Unterrichtsforschung zur Entwicklung von Geschichtsbewusstsein. Schwalbach/Ts.: Wochenschau.

Maissen, Thomas (2015). Schweizer Heldengeschichten - und was dabintersteckt (2. Aufl.). Baden: Hier + Jetzt.

Marx, Alexandra \& Sauer, Michael (2011). Historisch-politisches Lernen in Gedenkstätten. Ergebnisse einer empirischen Studie. In Jan Hodel \& Béatrice Ziegler (Hrsg.), Forschungswerkstatt Geschichtsdidaktik 09: Beiträge zur Tagung "geschichtsdidaktik empirisch 09» (S. 62-75). Bern: hep.

Matthes, Eva (2009). Gedanken zum Stellenwert und zur Situation der Historischen Bildungsforschung im universitären Alltag. Zeitschrift für pädagogische Historiographie, 15(2), S. 8081 .

Mayer, Ulrich (2009). Ausserschulische Lernorte. In Ulrich Mayer, Hans-Jürgen Pandel, Gerhard Schneider \& Bernd Schönemann (Hrsg.), Wörterbuch Geschichtsdidaktik (2. Aufl., S. 27-29). Schwalbach/Ts.: Wochenschau.

Mayring, Philipp (2009). Qualitative Inhaltsanalyse. In Uwe Flick, Ernst von Kardorff \& Ines Steinke (Hrsg.), Qualitative Forschung. Ein Handbuch (7. Aufl., S. 468-475). Reinbek bei Hamburg: Rowohlt.

Mayring, Philipp (2010). Qualitative Inbaltsanalyse. Grundlagen und Techniken (11. Aufl.). Weinheim: Beltz.

Merkens, Hans (2009). Auswahlverfahren, Sampling, Fallkonstruktion. In Uwe Flick, Ernst von Kardorff \& Ines Steinke (Hrsg.), Qualitative Forschung: Ein Handbuch (7. Aufl., S. 286299). Reinbek bei Hamburg: Rowohlt-Taschenbuch.

Merton, Robert K. \& Kendall, Patricia L. (1993). Das fokussierte Interview. In Christel Hopf \& Elmar Weingarten (Hrsg.), Qualitative Sozialforschung (3. Aufl., S. 171-204). Stuttgart: Klett-Cotta.

Meseth, Wolfgang (2005). Aus der Geschichte lernen. Über die Rolle der Erziehung in der bundesdeutschen Erinnerungskultur. Frankfurt am Main: Books on Demand GmbH.

Messmer, Kurt, Niederhäusern, Raffael von, Rempfler, Armin \& Wilhelm, Markus (Hrsg.) (2011). Definition Ausserschulische Lernorte. In Kurt Messmer, Raffael von Niederhäusern, Armin Rempfler \& Markus Wilhelm (Hrsg.), Ausserschulische Lernorte - Positionen aus Geographie, Geschichte und Naturwissenschaften (S. 7). Wien: LIT.

Messmer, Kurt, Rempfler, Armin \& Wilhelm, Markus (2011). Lehren und Lernen an Ausserschulischen Lernorten - 10 Thesen. In Kurt Messmer, Raffael von Niederhäusern, Armin Rempfler \& Markus Wilhelm (Hrsg.), Ausserschulische Lernorte - Positionen aus Geographie, Geschichte und Naturwissenschaften (S. 135-152). Wien: LIT. 
Messmer, Roland (2015). Stimulated Recall als fokussierter Zugang zu Handlungs- und Denkprozessen von Lehrpersonen. Forum Qualitative Sozialforschung / Forum: Qualitative Social Research, 16(1), Art. 3. DOI: http://dx.doi.org/10.17169/fqs-16.1.2051.

Meyer-Hamme, Johannes (2013). «I never liked history at school.» Identitäten und Emotionen beim historischen Lernen. In Juliane Brauer \& Martin Lücke (Hrsg.), Emotionen, Geschichte und historisches Lernen. geschichtsdidaktische und geschichtskulturelle Perspektiven (S. 125137). Göttingen: V\&R.

Michler, Andreas (2004). Museum und Ausstellung. In Waltraud Schreiber (Hrsg.), Erste Begegnungen mit Geschichte. Grundlagen historischen Lernens (S. 597-614). Neuried: Ars Una.

Mkayton, Noa (2011). «... the great danger is tears ...»- Die Bedeutung von Empathie und Emotionen im Holocaustunterricht. Zeitschrift für Didaktik der Gesellschaftswissenschaften, 2(1), S. $28-48$.

Moehring, Markus (Hrsg.) (2014). Der Erste Welthrieg am Oberrhein. La Grande Guerre dans le Rhin Supérieur. Lörrach: Waldemar Lutz.

Abgerufen von: www.dreilaendermuseum.eu/de/Infos\%2BService/Publikationen [21.2.2018].

Moos, Carlo (2014). Schweizer Neutralität(en) zur Zeit des Ersten Weltkriegs. Von der schwierigen Umsetzung eines umstrittenen Konzepts. In Roman Rossfeld, Thomas Buomberger \& Patrick Kury (Hrsg.), 14/18. Die Schweiz und der Grosse Krieg (S. 214-239). Baden: Hier + Jetzt.

Morgenthaler, Jonas (2009). «Gleich einer Insel im wogenden Meere ...». Das Bild der Schweiz im Ersten Weltkrieg in Schweizer Geschichtsbüchern von 1917 bis heute. In Markus Furrer \& Kurt Messmer (Hrsg.), Kriegsnarrative in Geschichtslehrmitteln. Brennpunkte nationaler Diskurse (S. 45-63). Schwalbach/Ts.: Wochenschau.

Morrissey, Kristine A. (2002). Pathways Among Objects and Museum Visitors. In Scott G. Paris (Hrsg.), Perspectives on Object-Centered Learning in Museums (S. 285-299). Mahwah, NJ: Lawrence Erlbaum.

Morse, Janice M. (1994). Designing Funded Qualitative Research. In Norman K. Denzin \& Yvonna S. Lincoln (Hrsg.), Handbook of Qualitative Research(S. 220-235). Thousand Oaks: Sage.

Mütter, Bernd \& Uffelmann, Uwe (1994a). Einleitung: Emotionen - Eine neue Debatte der Geschichtsdidaktik? In Bernd Mütter \& Uwe Uffelmann (Hrsg.), Emotionen und historisches Lernen: Forschung, Vermittlung, Rezeption (2. Aufl., S. 11-24). Frankfurt am Main: Diesterweg.

Mütter, Bernd \& Uffelmann, Uwe (Hrsg.) (1994b). Emotionen und historisches Lernen: Forschung, Vermittlung, Rezeption (2. Aufl.). Frankfurt am Main: Diesterweg.

Nater Cartier, Carol (2014). Vom Schulbuch an der Wand zum emotionalen Erlebnis. Der Erste Weltkrieg in den historischen Museen der Schweiz. In Konrad J. Kuhn \& Béatrice Ziegler (Hrsg.), Der vergessene Krieg. Spuren und Traditionen zur Schweiz im Ersten Weltkrieg (S. 307-329). Baden: Hier + Jetzt.

Nieke, Wolfgang (2016). Erziehung, Bildung, Lernen. In Marius Harring, Matthias D. Witte \& Timo Burger (Hrsg.), Handbuch informelles Lernen. Interdisziplinäre und internationale Perspektiven (S. 26-39). Weinheim: Beltz Juventa. 
Nipperdey, Thomas (1986). Neugier, Skepsis und das Erbe. Vom Nutzen und Nachteil der Geschichte für das Leben. In Thomas Nipperdey, Nachdenken über die deutsche Geschichte. Essays (S. 7-20). München: C. H. Beck.

Nitsche, Martin (2016). Geschichtstheoretische und -didaktische Überzeugungen von Lehrpersonen. Begriffliche und empirische Annäherungen an ein Fallbeispiel. In Martin Buchsteiner \& Martin Nitsche (Hrsg.), Historisches Erzäblen und Lernen. Historische, theoretische, empirische und pragmatische Erkundungen (S. 159-196). Wiesbaden: Springer VS.

Nohl, Arnd-Michael (2012). Interview und dokumentarische Methode: Anleitungen für die Forschungspraxis (4. Aufl.). Wiesbaden: Springer VS.

Nora, Pierre (1990). Zwischen Geschichte und Gedächtnis. Aus dem Französischen von Wolfgang Kaiser. Berlin: Klaus Wagenbach.

Nora, Pierre (1995). Das Abenteuer der Lieux de mémoire. In Étienne François, Hannes Siegrist \& Jakob Vogel (Hrsg.), Nation und Emotion. Deutschland und Frankreich im Vergleich. 19. und 20. Jahrbundert (S. 83-92). Göttingen: Vandenhoeck \& Ruprecht.

Nora, Pierre (Hrsg.) (2005). Erinnerungsorte Frankreichs. München: C. H. Beck.

Noschka-Roos, Annette (1994). Besucherforschung und Didaktik. Opladen: Leske + Budrich.

Noschka-Roos, Annette (2001). Bausteine eines besucherorientierten Informationskonzepts. In Ulrich Schwarz \& Philipp Teufel (Hrsg.), Museografie und Ausstellungsgestaltung (S. 88113). Ludwigsburg: avedition.

Noschka-Roos, Annette \& Lewalter, Doris (2013). Lernen im Museum - theoretische Perspektiven und empirische Befunde. Zeitschrift für Erziehungswissenschaft, 16(3), S. 199-215. DOI: https://doi.org/10.1007/s11618-013-0434-9.

Pampel, Bert (2007). "Mit eigenen Augen sehen, wozu der Mensch fühig ist». Zur Wirkung von Gedenkstätten auf ibre Besucher. Frankfurt am Main: Campus.

Pampel, Bert (2011). Gedenkstätten als «ausserschulische Lernorte». Theoretische Aspekte empirische Befunde - praktische Herausforderungen. In Bert Pampel (Hrsg.), Erschrecken - Mitgefühl - Distanz. Empirische Befunde über Schülerinnen und Schüler in Gedenkstätten und zeitgeschichtlichen Ausstellungen (S. 11-58). Leipzig: Leipziger Universitätsverlag.

Pandel, Hans-Jürgen (2002). Erzählen und Erzählakte. Neuere Entwicklungen in der didaktischen Erzähltheorie. In Marko Demantowsky \& Bernd Schönemann (Hrsg.), Neue geschichtsdidaktische Positionen (S. 39-55). Bochum: projekt.

Pandel, Hans-Jürgen (2005). Geschichtsunterricht nach PISA. Kompetenzen, Bildungsstandards und Kerncurricula. Schwalbach/Ts.: Wochenschau.

Pandel, Hans-Jürgen (2009). Geschichtskultur. In Ulrich Mayer, Hans-Jürgen Pandel, Gerhard Schneider \& Bernd Schönemann (Hrsg.), Wörterbuch Geschichtsdidaktik (2. Aufl., S. 86-87). Schwalbach/Ts.: Wochenschau.

Pandel, Hans-Jürgen (2011a). Bildinterpretation. Die Bildquelle im Geschichtsunterricht. Bildinterpretation I (2. Aufl.). Schwalbach/Ts.: Wochenschau.

Pandel, Hans-Jürgen (2011b). Bildinterpretation. Zum Stand der geschichtsdidaktischen Bildinterpretation. In Saskia Handro \& Bernd Schönemann (Hrsg.), Visualität und Geschichte (S. 69-87). Berlin: LIT. 
Pandel, Hans-Jürgen (2013). Geschichtsdidaktik. Eine Theorie für die Praxis. Schwalbach/Ts.: Wochenschau.

Pandel, Hans-Jürgen \& Land, Kristin (2009). Bildinterpretation praktisch. Bildgeschichten und verfilmte Bilder. Bildinterpretation II. Schwalbach/Ts.: Wochenschau.

Pandel, Hans-Jürgen \& Schneider, Gerhard (Hrsg.) (2017a). Einführung. In Handbuch Medien im Geschichtsunterricht (7. Aufl., S. 7-12). Schwalbach/Ts.: Wochenschau.

Pandel, Hans-Jürgen \& Schneider, Gerhard (Hrsg.) (2017b). Handbuch Medien im Geschichtsunterricht (7. Aufl.). Schwalbach/Ts.: Wochenschau.

Panofsky, Erwin (1991). Zum Problem der Beschreibung und Inhaltsdeutung von Werken der bildenden Kunst. In Ekkehard Kaemmerling (Hrsg.), Bildende Kunst als Zeichensystem 1. Ikonographie und Ikonologie. Theorien-Entwicklung-Probleme (5. Aufl., S. 185-206). Köln: DuMont.

Parmentier, Michael (2013). Freiheit in der Erscheinung. Zum «Zweck» ästhetischer Bildung heute, hier und überhaupt. Pädagogische Korrespondenz, (48), S. 461-465.

Paufler-Gerlach, Stefanie (2014). «So nah und doch so fern: Schülervorstellungen zum (Lernort) Museum». Methodologische Überlegungen und ausgewählte Beispiele zum Dissertationsprojekt. In Tobias Arand \& Manfred Seidenfuss (Hrsg.), Neue Wege - neue Themen - neue Methoden? Ein Querschnitt aus der geschichtsdidaktischen Forschung des wissenschaftlichen Nachwuchses (S. 99-115). Göttingen: V\&R unipress.

Paul, Gerhard (2011). Die (Zeit-)Historiker und die Bilder. Plädoyer für eine Visual History. In Saskia Handro \& Bernd Schönemann (Hrsg.), Visualität und Geschichte (S. 7-21). Berlin: LIT.

Pekarik, Andrew J., Doering, Zahava D. \& Karns, David A. (1999). Exploring Satisfying Experiences in Museums. Curator, 42(2),S. 152-173. [DOI:https://doi.org/10.1111/j.2151-6952.1999. tb01137.x

Peter, Nicole \& Burgermeister, Nicole (2012). Der Holocaust und die Schweiz. Konkurrierende Erinnerungen im intergenerationellen Dialog. In Béatrice Ziegler, Bernhard C. Schär, Peter Gautschi \& Claudia Schneider (Hrsg.), Die Schweiz und die Shoa. Von Kontroversen zu neuen Fragen (S. 19-28). Zürich: Chronos.

Pethes, Nicolas (2008). Kulturwissenschaftliche Gedächtnistheorien zur Einführung. Hamburg: Junius.

Pieper, Kathrin (2006). Die Musealisierung des Holocaust. Das Jüdische Museum Berlin und das U. S. Holocaust Memorial Museum in Washington D. C. Köln: Böhlau.

Pieper, Katrin (2010). Resonanzräume. Das Museum im Forschungsfeld Erinnerungskultur. In Joachim Baur (Hrsg.), Museumsanalyse. Methoden und Konturen eines neuen Forschungsfeldes (S. 187-212). Bielefeld: Transcript.

Pilarczyk, Ulrike (2009). Bildungshistorisches Orientierungswissen. Zeitschrift für pädagogische Historiographie, 15(2), S. 81-82.

Pleitner, Berit (2008). Living History an britischen Museen. Eine empirische Studie mit Grundschülern. In Saskia Handro \& Bernd Schönemann (Hrsg.), Orte historischen Lernens (S. 99113). Berlin: LIT. 
Pleitner, Berit (2011). Historisches Lernen im Museum. In Jan Hodel \& Béatrice Ziegler (Hrsg.), Forschungswerkstatt Geschichtsdidaktik 09: Beiträge zur Tagung "geschichtsdidaktik empirisch 09»(S. 35-44). Bern: hep.

Plessow, Oliver (2015). «Ausserschulisch» - zur Bedeutung eines Begriffs aus geschichtsdidaktischer Sicht. In Dietrich Karpa, Bernd Overwien \& Oliver Plessow (Hrsg.), Ausserschulische Lernorte in der politischen und historischen Bildung (S. 17-32). Immenhausen bei Kassel: Prolog.

Pohl, Karl Heinrich (2013). Der kritische Museumsführer. Neun Historische Museen im Fokus. Schwalbach/Ts.: Wochenschau.

Popp, Susanne (2009). Historische Bildung und Kompetenzmodelle. Überlegungen zu einer aktuellen Debatte. In Susanne Popp \& Bernd Schönemann (Hrsg.), Historische Kompetenzen und Museen (S. 24-37). Idstein: Schulz-Kirchner.

Popp, Susanne, Furrer, Markus, Gorbahn, Katja, Haue, Harry, Haydn, Terry, Eeden, Elize van \& Wojdon, Joanna (Hrsg.) (2016). Nostalgia in Historical Consciousness and Culture. Schwalbach/Ts.: Wochenschau.

Popp, Susanne \& Schönemann, Bernd (Hrsg.) (2009). Historische Kompetenzen und Museen. Idstein: Schulz-Kirchner.

Prenzel, Manfred (2009). Was man alles im Museum lernen kann: Lernvoraussetzungen, Prozesse und Ergebnisse. In ICOM Deutschland, ICOM Frankreich \& Deutsches Technikmuseum Berlin (Hrsg.), Wissenschaftskommunikation. Perspektiven der Ausbildung. Lernen im Museum. (S. 137-142). Frankfurt am Main: Peter Lang.

Pressley, Michael \& Afflerbach, Peter (1995). Verbal protocols of reading. The nature of constructively responsive reading. Hillsdale, NJ: Erlbaum.

Priem, Karin (2009). Aus Geschichte lernen? Zeitschrift für pädagogische Historiographie, 15(2), S. 82.

Prondczynsky, Andreas von (2009). Inwieweit kann Historische (Bildungs-)Forschung zur Orientierung (noch) beitragen? Zeitschrift für pädagogische Historiographie, 15(2), S. 82-83.

Rau, Caroline \& Welser, Stephanie (2017). Informelles Lernen - «Ordnungen des Wissens» im Vergleich. Sammelrezension zu Harring et al. (Hrsg.), Handbuch informelles Lernen, und Rohs (Hrsg.), Handbuch Informelles Lernen. Zeitschrift für Erziehungswissenschaft, 19(1), S. 141-148. Abgerufen von: https://link.springer.com/content/pdf/10.1007/s11618017-0723-9.pdf [28.3.2018].

Rayner, Ann (1998). Access in Mind: Towards the Inclusive Museum. Edinburgh: Intact.

Research Centre for Museums and Galleries (2003). Measuring the Outcomes and Impact of Learning in Museums, Archives and Libraries. The Learning Impact Research Project. End of Project Paper. Leicester: Research Centre for Museums and Galleries.

Abgerufen von: www2.le.ac.uk/departments/museumstudies/rcmg/projects/lirp-1-2/ LIRP\%20end\%20of\%20project\%20paper.pdf [03.08.2017].

Ricœur, Paul (2004). Gedächtnis, Geschichte, Vergessen. Aus dem Französischen von Hans-Dieter Gondek, Heinz Jatho und Markus Sedlaczek. München: Fink.

Rohs, Matthias (Hrsg.) (2016). Handbuch Informelles Lernen. Wiesbaden: Springer VS.

Rossfeld, Roman, Buomberger, Thomas \& Kury, Patrick (Hrsg.) (2014). 14/18. Die Schweiz und der Grosse Krieg. Baden: Hier + Jetzt. 
Röttele, Hannah (2017). Mensch, Objekt, Objektbegegnung. Eine empirische Studie zum Wahrnehmungsverhalten von Schülerinnen und Schülern bei einem Besuch im Historischen Museum. In Monika Waldis \& Béatrice Ziegler (Hrsg.), Forschungswerkstatt Geschichtsdidaktik 15. Beiträge zur Tagung "geschichtsdidaktik empirisch 15» (S. 111-123). Bern: hep.

Rounds, Jay (2004). Strategies for the Curiosity-Driven Museum Visitor. Curator, 47(4), S. 389412. DOI: https://doi.org/10.1111/j.2151-6952.2004.tb00135.x.

Rowe, Shawn (2002). The Role of Objects in Active, Distributed Meaning-Making. In Scott G. Paris (Hrsg.), Perspectives on Object-Centered Learning in Museums (S. 19-35). Mahwah, NJ: Lawrence Erlbaum.

Rüsen, Jörn (1982). Geschichtsdidaktische Konsequenzen aus einer erzähltheoretischen Historik. In Siegfried Quandt \& Hans Süssmuth (Hrsg.), Historisches Erzäblen. Formen und Funktionen (S. 129-170). Göttingen: Vandenhoeck \& Ruprecht.

Rüsen, Jörn (1983). Historische Vernunft. Grundzüge einer Historik I: Die Grundlagen der Geschichtswissenschaft. Göttingen: Vandenhoeck \& Ruprecht.

Rüsen, Jörn (1994). Was ist Geschichtskultur? Überlegungen zu einer neuen Art, über Geschichte nachzudenken. In Klaus Füssmann, Heinrich Theodor Grütter \& Jörn Rüsen (Hrsg.), Historische Faszination. Geschichtskultur heute (S. 3-26). Köln: Böhlau.

Rüsen, Jörn (1997a). Geschichtskultur. In Klaus Bergmann, Klaus Fröhlich, Annette Kuhn, Jörn Rüsen \& Gerhard Schneider (Hrsg.), Handbuch der Geschichtsdidaktik (5. Aufl., S. 38-41). Seelze-Velber: Kallmeyer.

Rüsen, Jörn (1997b). Historisches Erzählen. In Klaus Bergmann, Klaus Fröhlich, Annette Kuhn, Jörn Rüsen \& Gerhard Schneider (Hrsg.), Handbuch der Geschichtsdidaktik (5. Aufl., S. 5763). Seelze-Velber: Kallmeyer.

Rüsen, Jörn (2001). Holocaust, Erinnerung, Identität. Drei Formen generationeller Praktiken des Erinnerns. In Harald Welzer (Hrsg.), Das soziale Gedächtnis. Geschichte, Erinnerung, Tradierung (S. 243-259). Hamburg: Hamburger Edition.

Rüsen, Jörn (2003). Kann gestern besser werden? Über die Verwandlung der Vergangenheit in Geschichte. In Jörn Rüsen, Kann gestern besser werden? Zum Bedenken der Geschichte (S. 1744). Berlin: Kadmos.

Rüsen, Jörn (2006). Kultur macht Sinn. Orientierung zwischen Gestern und Morgen. Köln: Böhlau.

Rüsen, Jörn (2008). Historische Orientierung. Über die Arbeit des Geschichtsbewusstseins, sich in der Zeit zurechtzufinden (2. Aufl.). Schwalbach/Ts.: Wochenschau.

Rüsen, Jörn (2012). Zeit und Sinn. Strategien historischen Denkens. Frankfurt am Main: Humanities Online.

Rüsen, Jörn (2013). Historik. Theorie der Geschichtswissenschaft. Köln: Böhlau.

Russo, Joseph E., Johnson, Eric J. \& Stephens, Debra L. (1989). The Validity of Verbal Protocols. Memory and Cognition, 17, S. 759-769.

Saaman, Dörte (2001). Kognitive Prozessvariablen und Lautes Denken: Individuelle Unterschiede in der Verbalisierung. In Johann F. Schneider (Hrsg.), Lautes Denken. Prozessanalysen bei Selbst- und Fremdeinschätzungen (S. 125-141). Weimar: Rita Dadder.

Sander, Wolfgang (2014). Kompetenzorientierung als Forschungs- und Konfliktfeld der Didaktik der politischen Bildung. In Wolfgang Sander (Hrsg.), Handbuch politische Bildung (S. 113124). Schwalbach/Ts.: Wochenschau. 
Sauer, Michael (2009). Historisches Lernen in Ausstellungen. Kompetenzen im Umgang mit Geschichte als Ziel und Voraussetzung. In Susanne Popp \& Bernd Schönemann (Hrsg.), Historische Kompetenzen und Museen (S. 81-93). Idstein: Schulz-Kirchner.

Sauerborn, Petra \& Brühne, Thomas (2007). Didaktik des ausserschulischen Lernens. Baltmannsweiler: Schneider Verlag Hohengehren.

Schäfer, Hermann (2004). Besucherorientierung durch Besucherforschung. In Waltraud Schreiber, Katja Lehmann, Simone Unger \& Stefanie Zabold (Hrsg.), Ausstellungen anders anpacken. Event und Bildung für Besucher - ein Handbuch (S. 159-180). Neuried: Ars Una.

Schmid, Harald (2008). Konstruktion, Bedeutung, Macht. Zum kulturwissenschaftlichen Profil einer Analyse von Geschichtspolitik. In Horst-Alfred Heinrich \& Michael Kohlstruck (Hrsg.), Geschichtspolitik und sozialwissenschaftliche Theorie(S. 75-98). Stuttgart: Franz Steiner.

Schneider, Gerhard (Hrsg.) (2002). Die visuelle Dimension des Historischen. Hans-Jürgen Pandel zum 60. Geburtstag. Schwalbach/Ts.: Wochenschau.

Schneider, Johann F. (Hrsg.) (2001). Lautes Denken. Prozessanalysen bei Selbst- und Fremdeinschätzungen. Weimar: Rita Dadder.

Scholze, Jana (2010). Kultursemiotik. Zeichenlesen in Ausstellungen. In Joachim Baur (Hrsg.), Museumsanalyse. Methoden und Konturen eines neuen Forschungsfeldes (S. 121-148). Bielefeld: Transcript.

Schönemann, Bernd (2000). Geschichtsdidaktik und Geschichtskultur. In Bernd Mütter, Bernd Schönemann \& Uwe Uffelmann (Hrsg.), Geschichtskultur. Theorie - Empirie - Pragmatik (S. 26-58). Weinheim: Deutscher Studienverlag.

Schönemann, Bernd (2002a). Geschichtskultur als Forschungskonzept der Geschichtsdidaktik. In Bernd Schönemann, Waltraud Schreiber \& Hartmut Voit (Hrsg.), Grundfragen - Forschungsergebnisse - Perspektiven (= Zeitschrift für Geschichtsdidaktik. Jahresband 2002, S. 78-86). Schwalbach/Ts.: Wochenschau.

Schönemann, Bernd (2002b). Visualität als Lernfalle? Vom Nutzen und Nachteil der Bilder beim Aufbau von Geschichtsbewusstsein. In Gerhard Schneider (Hrsg.), Die visuelle Dimension des Historischen. Hans-Jürgen Pandel zum 60. Geburtstag (S. 21-31). Schwalbach/Ts.: Wochenschau.

Schönemann, Bernd (2006). Museum als Institution der Geschichtskultur. In Olaf Hartung (Hrsg.), Museum und Geschichtskultur. Ästhetik - Politik - Wissenschaft. Bielefeld: Verlag für Regionalgeschichte.

Schönemann, Bernd (2014). Geschichtsdidaktik, Geschichtskultur, Geschichtswissenschaft. In Hilke Günther-Arndt \& Meik Zülsdorf-Kersting (Hrsg.), Geschichts-Didaktik. Praxishandbuch für die Sekundarstufe I und II (6. Aufl., S. 11-23). Berlin: Cornelsen Scriptor.

Schöner, Alexander (2007). Kompetenzbereich historische Sachkompetenzen. In Andreas Körber, Waltraud Schreiber \& Alexander Schöner (Hrsg.), Kompetenzen historischen Denkens. Ein Strukturmodell als Beitrag zur Kompetenzorientierung in der Geschichtsdidaktik (S. 265314). Neuried: Ars Una.

Schöner, Alexander (2013a). Die Eichstätter Schulbuchanalysen. Zur Methode kategorialer Inhalts- und Strukturanalysen. In Waltraud Schreiber, Alexander Schöner \& Florian Sochatzy, Analyse von Schulbüchern als Grundlage empirischer Geschichtsdidaktik (S. 66-90). Stuttgart: Kohlhammer. 
Schöner, Alexander (2013b). Die «Sprache der Geschichte» - Skizze einer «Histo-Linguistik». In Waltraud Schreiber, Alexander Schöner \& Florian Sochatzy, Analyse von Schulbüchern als Grundlage empirischer Geschichtsdidaktik (S. 102-115). Stuttgart: Kohlhammer.

Schöner, Alexander (2013c). Inhaltsbezogene Kategorien als «Grammatik historischen Denkens» und «inhaltliches Strickmuster» historischer Narrationen. In Waltraud Schreiber, Alexander Schöner \& Florian Sochatzy, Analyse von Schulbüchern als Grundlage empirischer Geschichtsdidaktik (S. 91-101). Stuttgart: Kohlhammer.

Schönert, Volker \& Weckwerth, Susanne (2011). Emotionale Überwältigung durch Inszenierung? Ergebnisse einer Schülerbefragung am Deutschen Hygiene-Museum Dresden in der Ausstellung «Tödliche Medizin. Rassenwahn im Nationalsozialismus». In Bert Pampel (Hrsg.), Erschrecken - Mitgefübl-Distanz. Empirische Befunde über Schülerinnen und Schüler in Gedenkstätten und zeitgeschichtlichen Ausstellungen (S. 283-305). Leipzig: Leipziger Universitätsverlag.

Schorb, Bernd (2009). Medienaneignung. In Bernd Schorb, Günther Anfang \& Kathrin Demmler (Hrsg.), Grundbegriffe Medienpädagogik Praxis (S. 182-186). München: kopaed.

Schörken, Rolf(1981). Geschichte in der Alltagswelt. Wie uns Geschichte begegnet und was wir mit ibr machen. Stuttgart: Klett-Cotta.

Schörken, Rolf (1994). Historische Imagination und Geschichtsdidaktik. Paderborn: Schöningh.

Schörken, Rolf (1995). Begegnungen mit Geschichte. Vom ausserwissenschaftlichen Umgang mit der Historie in Literatur und Medien. Stuttgart: Klett-Cotta.

Schörken, Rolf (1997). Geschichte als Lebenswelt. In Klaus Bergmann, Klaus Fröhlich, Annette Kuhn, Jörn Rüsen \& Gerhard Schneider (Hrsg.), Handbuch der Geschichtsdidaktik (5. Aufl., S. 3-9). Seelze-Velber: Kallmeyer.

Sommer, Barbara (2016). Aneignungspraktiken an ausserschulischen Lernorten, 10.06.2017 Luzern. In H-Soz-Kult, 25.7.2016.

Abgerufen von: www.hsozkult.de/event/id/termine-31579 [23.4.2018].

Schrammel, Sabrina (2008). Überlegungen zur räumlichen Analyse von Bildungs- und Erziehungsprozessen. In Rudolf Egger, Regina Mikula, Sol Haring, Andrea Felbinger \& Angela Pilch-Ortega (Hrsg.), Orte des Lernens. Lernwelten und ibre biographische Aneignung (S. 9299). Wiesbaden: VS Verlag für Sozialwissenschaften.

Schreiber, Waltraud (2005). Historisches Lernen und Lebenswelt. In Barbara Weber (Hrsg.), Phänomenologische Dimensionen der Bildungsanthropologie: Interdisziplinäre Forschungsbeiträge im Fokus ethischer Verantwortlichkeit (S. 311-323). Regensburg: Roderer.

Schreiber, Waltraud (2007a). Kompetenzbereich historische Fragekompetenzen. In Andreas Körber, Waltraud Schreiber \& Alexander Schöner (Hrsg.), Kompetenzen historischen Denkens. Ein Strukturmodell als Beitrag zur Kompetenzorientierung in der Geschichtsdidaktik (S. 155193). Neuried: Ars Una.

Schreiber, Waltraud (2007b). Kompetenzbereich historische Methodenkompetenzen. In Andreas Körber, Waltraud Schreiber \& Alexander Schöner (Hrsg.), Kompetenzen historischen Denkens. Ein Strukturmodell als Beitrag zur Kompetenzorientierung in der Geschichtsdidaktik (S. 194-235). Neuried: Ars Una.

Schreiber, Waltraud (2007c). Kompetenzbereich historische Orientierungskompetenzen. In Andreas Körber, Waltraud Schreiber \& Alexander Schöner (Hrsg.), Kompetenzen historischen Denkens. Ein Strukturmodell als Beitrag zur Kompetenzorientierung in der Geschichtsdidaktik (S. 236-264). Neuried: Ars Una. 
Schreiber, Waltraud (2009). Sektion 1. «Kompetenzmodelle der Geschichtsdidaktik und ihre Erklärungsleistung für das historische Lernen in Museen und Ausstellungen». Zur Einordnung der Sektion. In Susanne Popp \& Bernd Schönemann (Hrsg.), Historische Kompetenzen und Museen (S. 39-47). Idstein: Schulz-Kirchner.

Schreiber, Waltraud (2012). Zum Verhältnis zwischen Wissen und Kompetenzen. Ein Essay. In Christoph Kühberger (Hrsg.), Historisches Wissen. Geschichtsdidaktische Erkundungen zu Art, Tiefe und Umfang für das historische Lernen (S. 119-134). Schwalbach/Ts.: Wochenschau.

Schreiber, Waltraud (2017). Raum - vernachlässigte Kategorie der Geschichtskultur. Zeitschrift für Geschichtsdidaktik, 16, S. 48-66.

Schreiber, Waltraud, Körber, Andreas, Borries, Bodo, Krammer, Reinhard, Leutner-Ramme, Sibylla, Mebus, Sylvia, ... \& Ziegler, Béatrice (2007). Historisches Denken. Ein KompetenzStrukturmodell (Basisbeitrag). In Andreas Körber, Waltraud Schreiber \& Alexander Schöner (Hrsg.), Kompetenzen historischen Denkens. Ein Strukturmodell als Beitrag zur Kompetenzorientierung in der Geschichtsdidaktik (S. 17-53). Neuried: Ars Una.

Schreiber, Waltraud, Kraus, Annemarie, Lehmann, Katja \& Zabold, Stefanie (2015). Empirische Erforschung von Ausprägungen historischer Kompetenzen in museumspädagogischen Programmen - Die Fallstudie «Erinnern und Gedenken» zur Europaratsausstellung «Verführung Freiheit» am Deutschen Historischen Museum in Berlin. In Monika Waldis \& Béatrice Ziegler (Hrsg.), Forschungswerkstatt Geschichtsdidaktik 13. Beiträge zur Tagung "geschichtsdidakik empirisch 13» (S. 182-192). Bern: hep.

Schreiber, Waltraud, Lehmann, Katja, Unger, Simone \& Zabold, Stefanie (Hrsg.) (2004). Ausstellungen anders anpacken. Event und Bildung für Besucher - ein Handbuch. Neuried: Ars Una.

Schröder, Vanessa (2013). Geschichte ausstellen. Geschichte verstehen. Wie Besucher im Museum Geschichte und historische Zeit deuten. Bielefeld: Transcript.

Schultheiss, Michel \& Thyroff, Julia (2014a). Der Krieg als Bewährungsprobe - Der Erste Weltkrieg in aktuellen Geschichtslehrmitteln. In Roman Rossfeld, Thomas Buomberger \& Patrick Kury (Hrsg.), 14/18. Die Schweiz und der Grosse Krieg (S. 384-385). Baden: Hier + Jetzt.

Schultheiss, Michel \& Thyroff, Julia (2014b). «Friedensinsel» in der «Einigkeitsprobe». Eine Untersuchung von aktuellen Geschichtslehrmitteln zur Schweiz im Ersten Weltkrieg. In Konrad J. Kuhn \& Béatrice Ziegler (Hrsg.) (S. 291-306). Baden: Hier + Jetzt.

Schulze, Christa (1994). Besucherinteressen und Besucherverhalten im Museum. In Hildegard Vieregg, Marie-Louise Schmeer-Sturm, Jutta Thinesse-Demel \& Kurt Ulbricht (Hrsg.), Museumspädagogik in neuer Sicht. Erwachsenenbildung im Museum (S. 108-114). Baltmannsweiler: Schneider Verlag Hohengehren.

Schuster, Martin \& Ameln-Haffke, Hildegard (2006). Der Museumsbesuch als emotionales Erlebnis - Erlebnisverläufe im Kunstmuseum Bonn. In Martin Schuster \& Hildegard AmelnHaffke (Hrsg.), Museumspsychologie. Erleben im Kunstmuseum (S. 280-289). Göttingen: Hogrefe.

Schwan, Stephan (2009). Lernen und Wissenserwerb im Museum. In Hannelore Kunz-Ott, Susanne Kudorfer \& Traudel Weber (Hrsg.), Kulturelle Bildung im Museum. Aneignungsprozesse - Vermittlungsformen - Praxisbeispiele (S. 33-43). Bielefeld: Transcript. 
Schwan, Stephan (2012). Lernpsychologische Grundlagen zum Wissenserwerb im Museum. In Gisela Staupe (Hrsg.), Das Museum als Lern- und Erfahrungsraum. Grundlagen und Praxisbeispiele (S. 46-50). Wien: Böhlau.

Seidenfuss, Manfred (2002). Was denken erfolgreiche Geschichtslehrer bei der Unterrichtsplanung? Expertiseansatz und empirische Forschung in der Didaktik der Geschichte. In Saskia Handro \& Bernd Schönemann (Hrsg.), Methoden geschichtsdidaktischer Forschung (S. 6171). Münster: LIT.

Seixas, Peter (1998). Student Teachers Thinking Historically. Social Education, 26(3), 310-341.

Seixas, Peter \& Morton, Tom (2013). The Big Six Historical Thinking Concepts. Toronto: Nelson Education.

Serrell, Beverly (1980). Looking at zoo and aquarium visitors. Museum News, 59(3), S. 36-41.

Serrell, Beverly (1998). Paying Attention: Visitors and Museum Exhibitions. Washington D. C.: American Association of Museums.

Serrell, Beverly (2010, ed. 2016). Paying more Attention to Paying Attention. Chicago: Serrell \& Associates. Abgerufen von: www.informalscience.org/sites/default/files/S\%26A.PA2. FinalDforCAISE2016.pdf [28.3.2018].

Soja, Ed (2003). Thirdspace - Die Erweiterung des Geographischen Blicks. In Hans Gebhardt, Paul Reuber \& Günter Wolkersdorfer (Hrsg.), Kulturgeographie. Aktuelle Ansätze und Entwicklungen (S. 269-288). Heidelberg: Spektrum Akademischer Verlag.

Someren, Maarten W. van/Barnard, Yvonne F. \& Sandberg, Jacobijn A. C. (1994). The think aloud method. A practical guide to modelling cognitive processes. London: Academic Press.

Steinke, Ines (2009). Gütekriterien qualitativer Forschung. In Uwe Flick, Ernst von Kardorff \& Ines Steinke (Hrsg.), Qualitative Forschung. Ein Handbuch (7. Aufl., S. 319-331). Reinbek bei Hamburg: Rowohlt.

Strauss, Anselm L. \& Corbin, Juliet M. (1996). Grounded Theory. Grundlagen Qualitativer Sozialforschung. Weinheim: Beltz. Psychologie Verlags Union.

Strübing, Jörg (2014). Grounded Theory. Zur sozialtheoretischen und epistemologischen Fundierung eines pragmatistischen Forschungsstils (3. Aufl.). Wiesbaden: Springer VS.

Tanner, Jakob (1999). Die Krise der Gedächtnisorte und die Havarie der Erinnerungspolitik. Zur Diskussion um das kollektive Gedächtnis und die Rolle der Schweiz während des Zweiten Weltkriegs. Traverse. Zeitschrift für Geschichte/Revue d'histoire, 6(1), S. 16-38.

Tanner, Jakob (2011). Lehren aus der Geschichte - Lernen aus der Vergangenheit? In HansUlrich Grunder (Hrsg.), Aus der Geschichte lernen. Die historische Perspektive in der Ausbildung von Lehrerinnen und Lehrern (S. 271-277). Baltmannsweiler: Schneider Verlag Hohengehren.

Tanner, Jakob (2015). Geschichte der Schweiz im 20. Jahrhundert. München: C. H. Beck.

Tenorth, Heinz-Elmar (2009). Aus der Geschichte lernen? Sicher, aber wie? Zeitschrift für pädagogische Historiographie, 15(2), S. 84-85.

Tergan, Sigmar-Olaf (1988). Qualitative Wissensdiagnose: Methodologische Grundlagen. In Heinz Mandl \& Hans Spada (Hrsg.), Wissenspsycholgogie (S. 400-422). München: Psychologie Verlags-Union. 
Thamer, Hans-Ulrich (2006). Krieg im Museum. Konzepte und Präsentationsformen von Militär und Gewalt in historischen Ausstellungen. In Bernd Schönemann, Waltraud Schreiber \& Hartmut Voit (Hrsg.), Museum und historisches Lernen (S. 33-43). Schwalbach/Ts.: Wochenschau.

Thiemeyer, Thomas (2012). Die Sprache der Dinge. Museumsobjekte zwischen Zeichen und Erscheinung. In Gisela Staupe (Hrsg.), Das Museum als Lern- und Erfahrungsraum. Grundlagen und Praxisbeispiele (S. 51-59). Wien: Böhlau.

Thoma, Gun-Brit (2009). Was lernen Besucherinnen und Besucher im Museum? Eine Untersuchung von Lerngelegenheiten einer Museumsausstellung und ihrer Nutzung. Kiel (= Dissertation an der Christian-Albrechts-Universität zu Kiel). Abgerufen von: http://macau. uni-kiel.de/servlets/MCRFileNodeServlet/dissertation_derivate_00002960/dissertation_ gun-brit_thoma.pdf [14.1.2018].

Thomas, Bernd (2009). Lernorte ausserhalb der Schule. In Handbuch Unterricht (2. Aufl., S. 283-287). Bad Heilbrunn: Klinkhardt.

Thünemann, Holger (2005). Holocaust-Rezeption und Geschichtskultur. Zentrale Holocaust-Denkmäler in der Kontroverse. Ein deutsch-österreichischer Vergleich. Idstein: Schulz-Kirchner.

Thünemann, Holger (2011). Visualität als Chance. Denkmäler und historisches Lernen. In Saskia Handro \& Bernd Schönemann (Hrsg.), Visualität und Geschichte (S. 89-108). Berlin: LIT.

Thyroff, Julia (2012). Museale Perspektiven auf den Holocaust zwischen Ästhetik, Politik und Wissenschaft. Das Holocaust History Museum Yad Vashem in Jerusalem, der Ort der Information des Denkmals für die ermordeten Juden Europas in Berlin und die Ausstellung "Faszination und Gewalt» des Dokumentationszentrums Reichsparteitagsgelände in Nürnberg [unveröffentlichte Masterarbeit]

Thyroff, Julia (2017a). Die Rolle der Schweiz in den Weltkriegen. Aktuelle Geschichtslehrmittel zwischen Mythos und Dekonstruktion. In Roland Bernhard, Susanne Grindel, Felix Hinz \& Christoph Kühberger (Hrsg.), Mythen in deutschsprachigen Geschichtsschulbüchern (S. 159-183). Göttingen: V\&R.

Thyroff, Julia (2017b). Facetten des Denkens im Museum - Aneignungsweisen bei Besuchenden der Ausstellung «14/18. Die Schweiz und der Grosse Krieg». Didacta Historica, 3, 111117. Zusammengehörig mit:

Thyroff, Julia (2017c). Facetten des Denkens im Museum - methodischer Zugang, empirische Befunde. Didacta Historica, 3 [Onlineversion] [= längere Version zu Thyroff 2017b], S. 1-11. Abgerufen von: www.alphil.com/freedownload.php?sku=Didactica\%20Historica\% 203,\%20Le\%20documentaire\%20en\%20histoire,\%20article\%207 [16.3.2018].

Thyroff, Julia (2017d). Rezension zu Christian Kohler: Schülervorstellungen über die Präsentation von Geschichte im Museum. Eine empirische Studie zum historischen Lernen im $\mathrm{Mu}$ seum. Zeitschrift für Geschichtsdidaktik, 16, S. 285-288.

Tosch, Frank (2009). Lernfeld Bildungsgeschichte. Zeitschrift für pädagogische Historiographie, 15(2), S. 85-86.

Trautwein, Ulrich, Bertram, Christiane, Borries, Bodo von, Brauch, Nicola, Hirsch, Matthias, Klausmeier, Kathrin, ... \& Zuckowski, Andreas (2017). Kompetenzen historischen Denkens erfassen. Konzeption, Operationalisierung und Befunde des Projekts "Historical Thinking Competencies in History (HiTCH)». Münster: Waxmann.

Treinen, Heiner (1988). Was sucht der Besucher im Museum? Massenmediale Aspekte des Museumswesens. In Gottfried Fliedl (Hrsg.), Museum als soziales Gedächtnis? Kritische Beiträge 
zur Museumswissenschaft und Museumspädagogik (S. 24-41). Klagenfurt: Kärtner Druckund Verlagsgesellschaft.

Usherwood, Bob, Wilson Kerry \& Bryson, Jared (o. J.). Relevant repositories of public knowledge? Perceptions of archives libraries and museums in modern Britain. University of Sheffield: The Centre for the Public Library and Information in Society.

Abgerufen von: www.sheffield.ac.uk/polopoly_fs/1.128102!/file/CPLIS---Repositoriesof-Public-Knowledge.pdf [4.8.2017].

VanSledright, Bruce \& Limón, Margarita (2006). Learning and Teaching Social Studies: A Review of Cognitive Research in History and Geography. In Patricia A. Alexander \& Philip H. Winne (Hrsg.), Handbook of Educational Psychology (2. Aufl., S. 545-570). New York: Lawrence Erlbaum.

Veenman, Marcel V. J. (2005). The assessment of Metacognitive Skills: What can be learned from multi-method designs? In Cordula Artelt \& Barbara Moschner (Hrsg.), Lernstrategien und Metakognition: Implikationen für Forschung und Praxis (S. 77-99). Münster: Waxmann.

Verband der Geschichtslehrer Deutschlands (Hrsg.) (2006). Bildungsstandards Geschichte. Rahmenmodell Gymnasium 5.-10. Jahrgangsstufe. Schwalbach/Ts.: Wochenschau.

VERBI Software. Consult. Sozialforschung. GmbH (2014). MAXQDA. The Art of Data Analysis. Einführung. Windows-Version. Abgerufen von: www.maxqda.de/download/manuals/ maxl1_intro_ger.pdf [16.9.2017].

Verein «Die Schweiz im Ersten Weltkrieg» (Hrsg.) (2012). 14/18. Die Schweiz und der Grosse Krieg. Eine Wanderausstellung thematisiert die Bedeutung des Ersten Weltkriegs für die Schweiz. o. O. Abgerufen von: www.fsw.uzh.ch/static/medien/ausstellung_schweiz weltkriegl.pdf [6.4.2018].

Verein «Die Schweiz im Ersten Weltkrieg» (2014). Medieninformation zum Projekt. Abgerufen von: www.ersterweltkrieg.ch/fileadmin/user_upload/140822_Pressetext.pdf [16.3.2018].

Vieregg, Hildegard (2008). Geschichte des Museums. Eine Einführung. München: Fink.

Völkel, Barbara (2009). «Was war, ist doch wahr, oder!?» Geschichte(n) im Spannungsfeld zwischen Positivismus und Konstruktivismus. Geschichte in Wissenschaft und Unterricht, 12, S. 720-733.

Wagner, Bernd (2013). Informelles Sachlernen von Kindern im Museum der Dinge. Zeitschrift für Erziehungswissenschaft, 16(2), S. 203-218. DOI: https://doi.org/10.1007/s11618-0130422-0.

Waldis, Monika (2016). Unterrichtsvideografie im Fach Geschichte. In Holger Thünemann \& Meik Zülsdorf-Kersting (Hrsg.), Methoden geschichtsdidaktischer Unterrichtsforschung (S. 114-148). Schwalbach/Ts.: Wochenschau.

Waldis, Monika, Marti, Philipp \& Nitsche, Martin (2015). Angehende Geschichtslehrpersonen schreiben Geschichte(n). Zeitschrift für Geschichtsdidaktik, 14, S. 63-86.

Waldis, Monika \& Nitsche, Martin (2017). Epistemological Beliefs Matter: Investigating PreService Teachers Narrative Competence. Präsentation am SIG-Teaching History Symposium «Teaching and Assessing Historical Thinking: New Approaches and Empirical Results» auf der AERA, San Antonio 2017 [der Beitrag wurde mir von den Autor/innen zur Verfügung gestellt]. 
Wallach, Dieter \& Wolf, Christiane (2001). Das prozessbegleitende Laute Denken. Grundlagen und Perspektiven. In Johann F. Schneider (Hrsg.), Lautes Denken. Prozessanalysen bei Selbstund Fremdeinschätzungen (S. 9-29). Weimar: Rita Dadder.

Weber, Florian (2016). Die amerikanische Verheissung. Schweizer Aussenpolitik im Wirtschaftskrieg 1917/18. Zürich: Chronos.

Wehler, Hans-Ulrich (1988). Aus der Geschichte lernen? In Aus der Geschichte lernen? Essays (S. 11-18). München: C. H. Beck.

Weidle, Renate \& Wagner, Angelika C. (1982). Die Methode des Lauten Denkens. In Günter L. Huber \& Heinz Mandl (Hrsg.), Verbale Daten: Eine Einführung in die Grundlagen und Methoden der Erhebung und Auswertung (S. 81-103). Weinheim: Beltz.

Welzer, Harald (2008). Das kommunikative Gedächtnis. Eine Theorie der Erinnerung (2. Aufl.). München: C. H. Beck.

Wiegmann, Ulrich (2009). Vom Lernen aus der Geschichte der Erziehungsgeschichten. Zeitschrift für pädagogische Historiographie, 15(2), S. 86-87.

Wineburg, Samuel S. (1991). Historical Problem Solving: A Study of the Cognitive Processes Used in the Evaluation of Documentary and Pictorial Evidence. Journal of Educational Psychology, 83(1), S. 73-87.

Wineburg, Samuel S. (1998). Reading Abraham Lincoln: An Expert/Expert Study in the Interpretation of Historical Texts. Cognitive Science, 22(3), S. 319-346.

Wineburg, Samuel S. (2001). Historical Thinking and Other Unnatural Acts. Charting the future of teaching the past. Philadelphia: Temple University Press.

Wise, Susie (2011). Visitors encounter the dust: How People think with objects in a history museum exhibition. o.O. (= Dissertation an der Stanford University). Abgerufen von: https://purl.stanford.edu/zs034ry4864 [16.3.2018].

Witcomb, Andrea (2006). Interactivity: Thinking Beyond. In Sharon Macdonald (Hrsg.), A Companion to Museum Studies (S. 353-361). Malden, MA: Blackwell.

Wolf, Robert L. (1980). A naturalistic view of evaluation. Museum News, 58(1), S. 39-45.

Yalowitz, Steven S. \& Bronnenkant, Kerry (2009). Timing and Tracking: Unlocking Visitor Behavior. Visitor Studies, 12(1), S. 47-64.

Yi, Byung Jun (2013). Museum, Artefakte und informelles Lernen: Eine Herausforderung für die Erwachsenenbildung. Zeitschrift für Erziehungswissenschaft, 16(2), S. 219-228.

DOI: https://doi.org/10.1007/s11618-013-0414-0.

Zabold, Stefanie \& Schreiber, Waltraud (2004). Mit Geschichte in Ausstellungen umgehen lernen. In Waltraud Schreiber, Katja Lehmann, Simone Unger \& Stefanie Zabold (Hrsg.), Ausstellungen anders anpacken. Event und Bildung für Besucher - ein Handbuch (S. 197224). Neuried: Ars Una.

Zacharias, Wolfgang (2010). Kulturell-ästhetische Medienbildung 2.0. Sinne. Künste. Cyber. München: kopaed.

Ziegler, Béatrice (2012). Historische Konzepte und Kompetenzmodelle - ein empirischer Zugang zur Bedeutung von Wissen für Kompetenzen. In Christoph Kühberger (Hrsg.), Historisches Wissen. Geschichtsdidaktische Erkundungen zu Art, Tiefe und Umfang für das historische Lernen (S. 135-151). Schwalbach/Ts.: Wochenschau.

Ziegler, Béatrice (2017a). Einleitung. Zeitschrift für Geschichtsdidaktik, 16, S. 5-16. 
Ziegler, Béatrice (2017b). Rezension zu: Elsig, Alexandre: Les shrapnels du mensonge. La Suisse face à la propagande allemande de la Grande Guerre. Lausanne 2017. In H-Soz-Kult, 27.7.2017. Abgerufen von: www.hsozkult.de/publicationreview/id/rezbuecher-27406 [21.12.2017].

Ziegler, Béatrice (2017c). Rezension zu Weber, Florian: Die amerikanische Verheissung. Schweizer Aussenpolitik im Wirtschaftskrieg 1917/18. Zürich 2016. In H-Soz-Kult, 7.6.2017. Abgerufen von: www.hsozkult.de/publicationreview/id/rezbuecher-26965 [21.12.2017]. Zülsdorf-Kersting, Meik (2007). Sechzig Jahre danach: Jugendliche und Holocaust. Eine Studie zur geschichtskulturellen Sozialisation. Berlin: LIT.

\subsection{Websites}

Hinweis: Einzelnen Autorinnen und Autoren zugeordnete, online publizierte Artikel, Monografien, Rezensionen, Dokumente usw. sind im vorigen Abschnitt aufgeführt. Sie werden in den Fussnoten unter Angabe von Name und Jahreszahl zitiert. Die nachfolgend aufgeführten Websites werden in den Fussnoten unter Angabe der URL zitiert.

Basler Zeitung / bazonline (14.10.2013):

\#schweizerinnen - welche Frawen für die SRF-Doku vorgeschlagen werden.

Abgerufen von: https://bazonline.ch/digital/social-media/schweizerinnen-welche-Frauen-fuer-die-SRFDoku-vorgeschlagen-werden/story/11336839 [21.4.2018].

Dreiländermuseum Lörrach:

23. Juni-23. November 2014. Der Erste Weltkrieg - die zerrissene Region.

Abgerufen von: www.dreilaendermuseum.eu/de/Ausstellungen/Sonderausstel lungen/Erster-Weltkrieg [21.2.2018].

Historisches Lexikon der Schweiz (HLS) (Version vom 11.1.2015):

Weltkrieg, Erster.

Abgerufen von: www.hls-dhs-dss.ch/textes/d/D8926.php [21.2.2018].

Historisches Museum Basel:

14/18. Die Schweiz und der Grosse Krieg.

Abgerufen von: www.hmb.ch/14/18.html [21.2.2018]. 
Landesmuseum Zürich:

1900-1914. Expedition ins Glück. 28.3.-13.7.2014.

Abgerufen von: http://1914.landesmuseum.ch/[21.2.2018].

University of Leicester:

Museum Studies at Leicester.

Abgerufen von: www2.le.ac.uk/uol/departments/museumstudies/ [27.3.2018].

Schweiz am Wochenende (12.10.2013):

Frauen-Aufstand gegen SRG.

Abgerufen von: www.schweizamwochenende.ch/aktuell/frauen-aufstand-gegensrg-131052265 [21.4.2018].

Schweizerischer Nationalfonds zur Förderung der wissenschaftlichen Forschung $(\mathrm{SNF})$ :

Projekt Die Schweiz im Ersten Weltkrieg: Transnationale Perspektiven auf einen Kleinstaat im totalen Krieg.

Abgerufen von: http://p3.snf.ch/Project-141906 [21.2.2018].

Spielzeugmuseum Riehen:

Krieg im Kinderzimmer. spielen kämpfen träumen. 28.8.2014-1.3.2015.

Abgerufen von: www.spielzeugmuseumriehen.ch/Ausstellungen/Sonderausstel lungen2014/\$/Krieg-im-Kinderzimmer/209 [21.2.2018].

Verein «Die Schweiz im Ersten Weltkrieg»:

Ausstellung.

Abgerufen von: www.ersterweltkrieg.ch/ausstellung/ [21.2.2018].

Verein «Die Schweiz im Ersten Weltkrieg»:

Die Ausstellung.

Abgerufen von: www.ersterweltkrieg.ch/[21.2.2018].

Verein «Die Schweiz im Ersten Weltkrieg»:

Hintergrund.

Abgerufen von: www.ersterweltkrieg.ch/hintergrund/ [21.2.2018]. 


\section{Anhang}

\subsection{Hinweise zum Anhang und zur digitalen Ergänzung des Anhangs}

Der Anhang der Druckfassung der Dissertation stellt nur einen Teilbereich des Anhangs dar.

Er enthält die Abbildungen $A-G$ und die Tabellen A-F. Ein ergänzender Anhang ist online unter mehr.hep-verlag.ch/geschichtsdidaktik-12 verfügbar und enthält folgende Bestandteile:

- Abbildungen 1-13

- Tabellen 1-6

- Ausschreibungstext

- Hauptschritte und Prinzipien der Inhaltsanalyse im Überblick

- Kategorien der Inhaltsanalyse und Beispiele

- Prinzipien der Transkription und Transkriptdarstellung

- Transkriptauszüge

- Übersicht der kategorienbezogenen Falldarstellungen

Fotografien aus der Ausstellung «14/18. Die Schweiz und der Grosse Krieg» liegen dem Anhang nicht bei. In diese kann zum Beleg meiner Aussagen über die Ausstellung bei Bedarf bei mir Einsicht genommen werden. 


\subsection{Abbildungen A-G ${ }^{1630}$}

\section{Transkripte des Lauten Denkens von 18 Besuchenden}

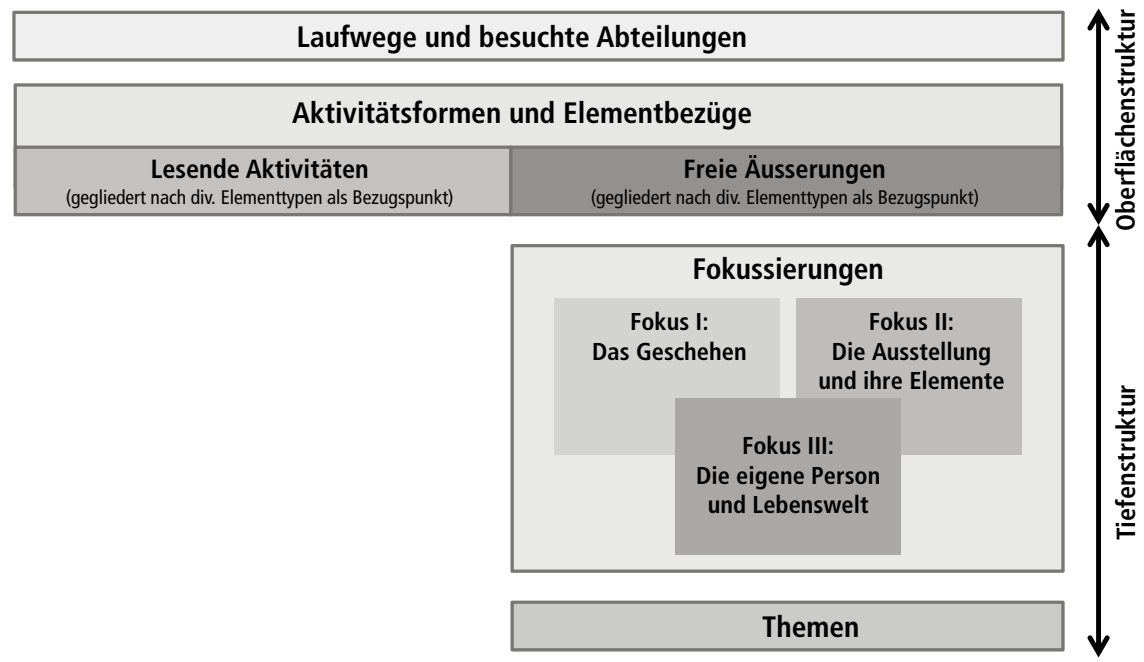

Abbildung A: Struktur der Analysekategorien

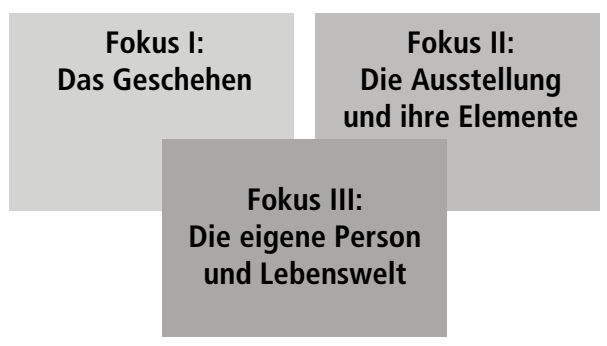

Abbildung B: Die drei Fokussierungen in vereinfachter Darstellung

1630 Die Abbildungen A - G wurden selbst erstellt. Eine frühere Form des Fokussierungsmodells ist publiziert in Thyroff 2017b, S. 112, und Thyroff 2017c, S. 4. Die in der aktuellen Fassung gebrauchte Bezeichnung als «nicht-nur-kognitive» Relationen geht zurück auf einen Terminus von Borries (2014, S. 167 ff.; vgl. zu dessen Einführung Abschnitt 3.4.2). 


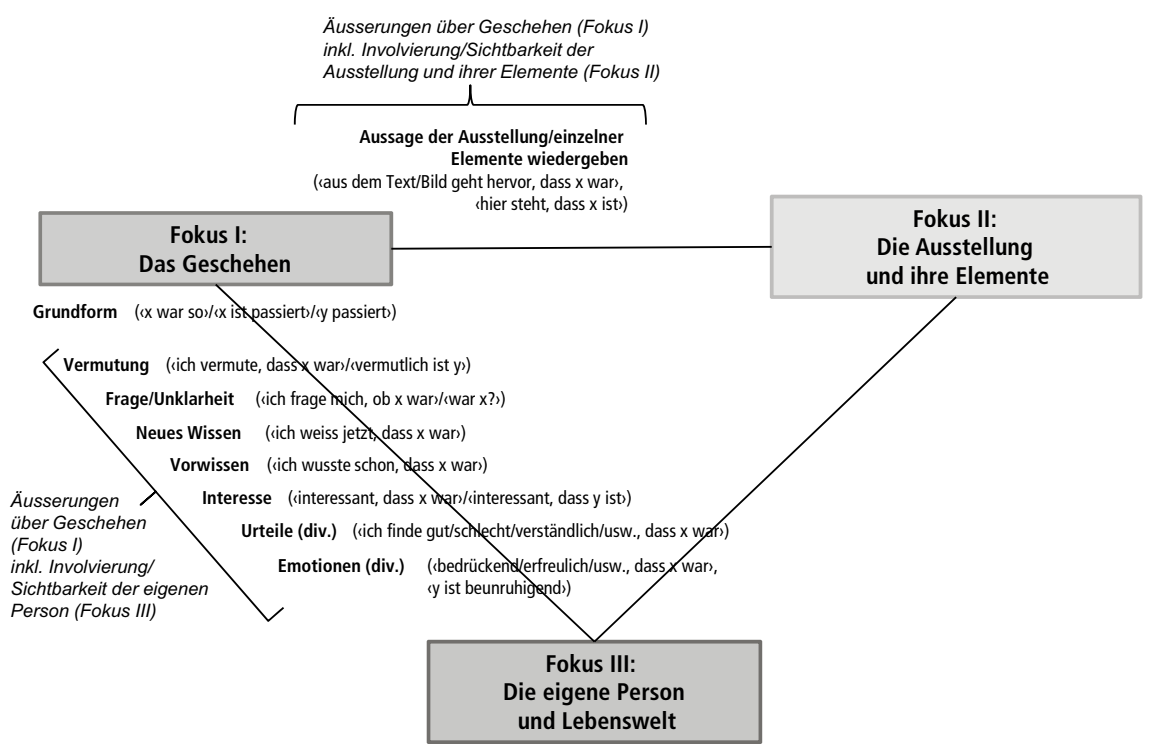

Abbildung C: Ausgewählte Überschneidungsbereiche zwischen Äusserungen im Fokus I und anderen Fokussierungen

Bild als konstruiertes «Bild» mit Intentionen thematisieren («das Bild ist nach Prinzip x gestaltet)/ (es soll y ausdrücken))

Abgebildetes räumlich und zeitlich einordnen (res ist dann/dort))

Bildinhalt als "Abbild» behandeln und dabei zugleich in Spuren als Element sichtbar machen ((das Bild zeigt $\mathrm{x}$ )/(auf dem Bild sieht man y)/ (das Bild zeigt, dass $\mathrm{x}$ ist))

Bildinhalt als «Abbild" behandeln («es passiert $\mathrm{x}$ )/(es ist $\mathrm{y}$ )
Bild als Element der Ausstellung thematisieren ('hier ist eine Fotografie))

Bild als Quelle/Beleg/Exponat usw. thematisieren ((hier sind wieder Filmquellen))

Bildauswahl/-präsentation durch die Ausstellung und deren Funktionen/Intentionen kommentieren ('die Bilder haben Eigenschaft $x$ ), (die Bilder sollen y zeigenı, (die Bilder sind nach Prinzip z ausgewähltı)

\section{Fokus I: Das Geschehen}

Äusserungen
im Umgang
mit Bildern

Fokus II: Die Ausstellung und ihre Elemente

Abbildung D: Äusserungen im Umgang mit Bildern an der Schnittstelle zwischen Fokus I und Fokus II 


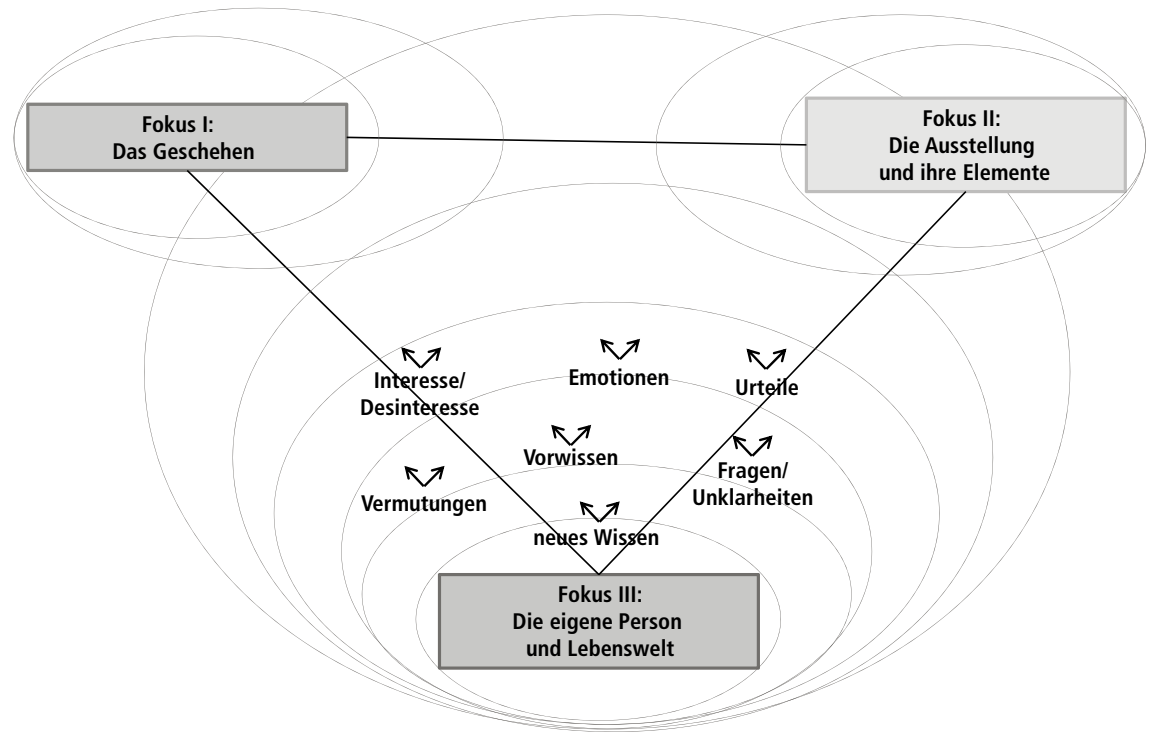

Abbildung E: Relationen zwischen der eigenen Person (Fokus III) und Geschehen (Fokus I) oder der Ausstellung und ihren Elementen (Fokus II)

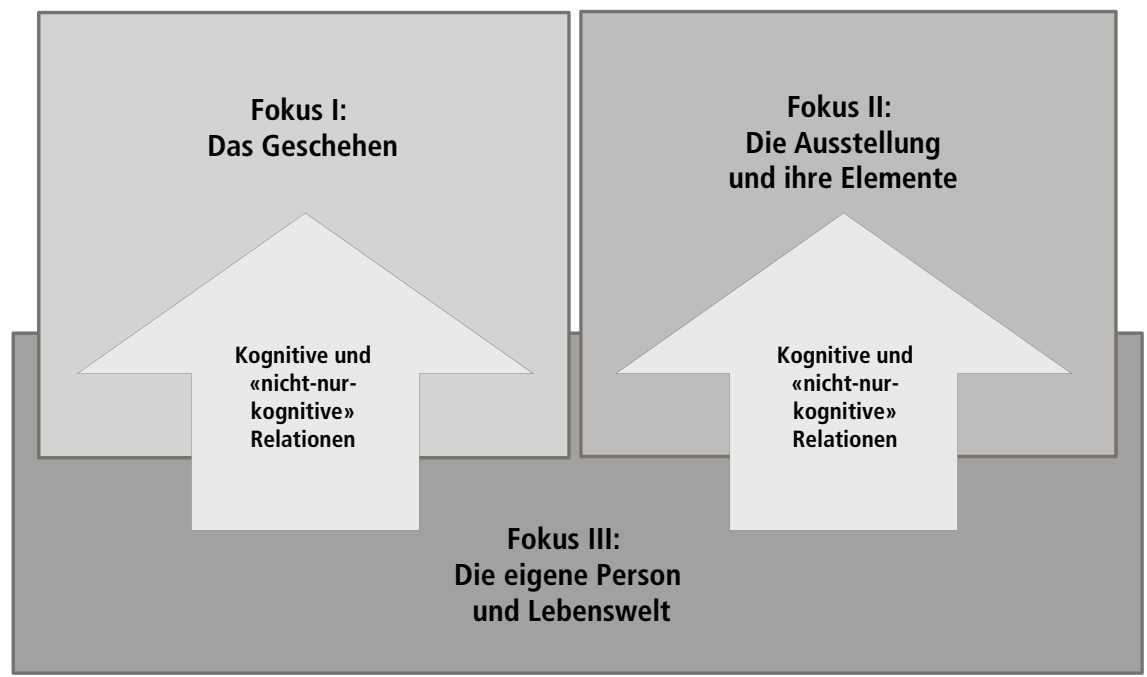

Abbildung F: Das Fokussierungsmodell 


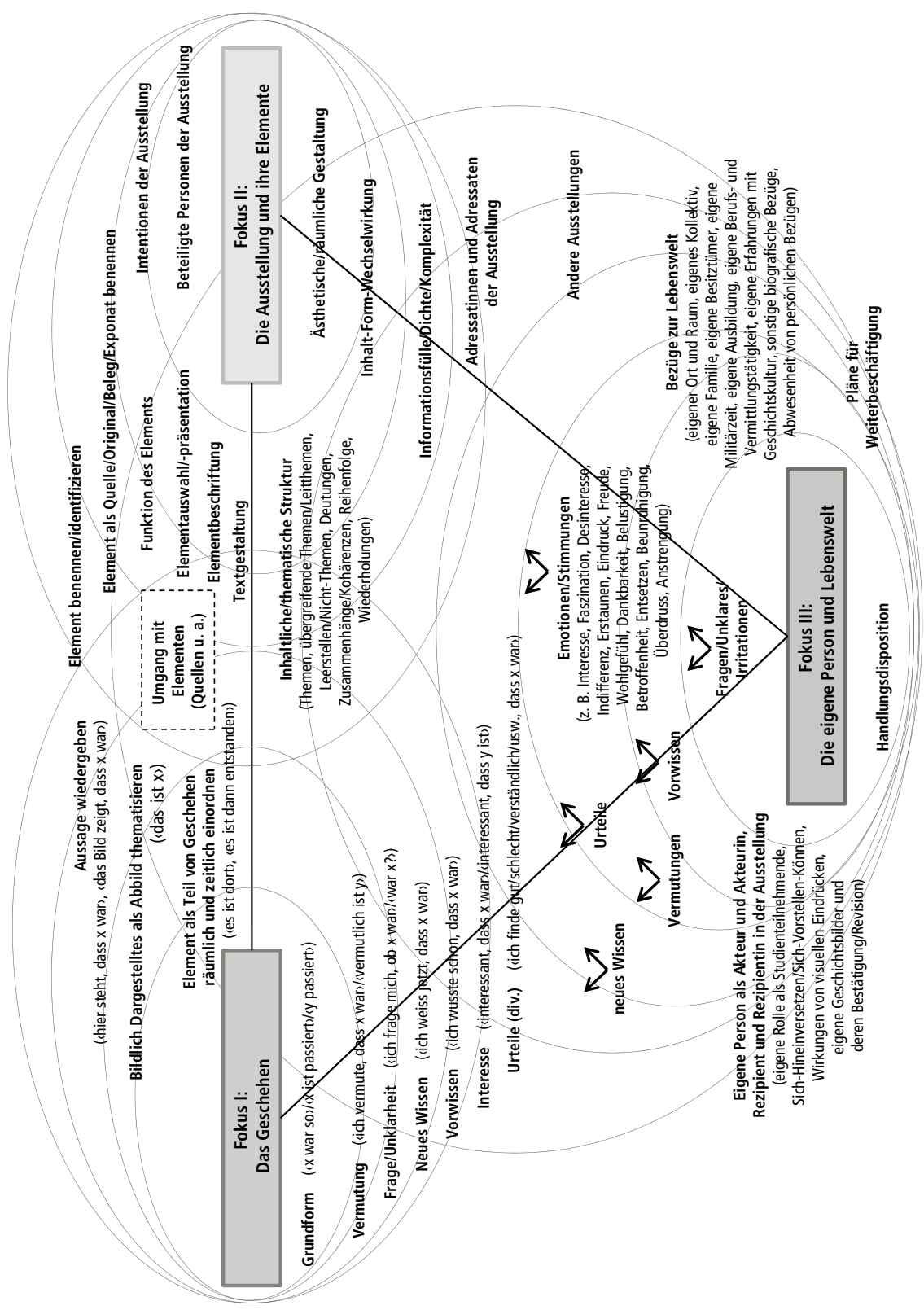

Abbildung G: Das Fokussierungsmodell in differenzierter Form 


\subsection{Tabellen A-F}

Tabelle A: Komponenten von Orientierungskompetenz bei Museums-/Ausstellungsbesuchenden bei Andreas Körber (gekürzt) ${ }^{1631}$

\begin{tabular}{|c|c|c|}
\hline $\begin{array}{l}\text { Kern- } \\
\text { kompetenz }\end{array}$ & $\begin{array}{l}\text { Niveau- } \\
\text { stufe }\end{array}$ & Beschreibung \\
\hline \multirow{3}{*}{$\begin{array}{l}\text { Reflexion und } \\
\text { Erweiterung } \\
\text { des Ge- } \\
\text { schichts- } \\
\text { bewusstseins }\end{array}$} & Basal & $\begin{array}{l}\text { Die Besuchenden sind in der Lage zu «irgendwelche[n] } \\
\text { Veränderungen ihrer Konzepte zu Geschichte, Museum, } \\
\text { Präsentation etc». }{ }^{1632}\end{array}$ \\
\hline & $\begin{array}{l}\text { Inter- } \\
\text { mediär }\end{array}$ & $\begin{array}{l}\text { Die Besuchenden sind «in der Lage, ihre Vorstellung vom } \\
\text { ausgestellten Sachverhalt, den relevanten Kategorien etc. mit } \\
\text { Hilfe der in der Ausstellung und ihren Zusätzen üblichen } \\
\text { Verfahren selbstständig zu verändern». }{ }^{.633} \\
\text { Die Besuchenden können «die Informationstafeln selbstständig } \\
\text { auswerten» und «in den Texten verwendete Kategorien auf } \\
\text { ihnen bekannte beziehen und diese so verändern». } .^{634}\end{array}$ \\
\hline & $\begin{array}{l}\text { Elabo- } \\
\text { riert }\end{array}$ & $\begin{array}{l}\text { Die Besuchenden sind «in der Lage, die Konzepte, die sie beim } \\
\text { historischen Denken einsetzen, in Auseinandersetzung mit der } \\
\text { Ausstellung selbstständig zu verändern und innovativ zu } \\
\text { erweitern». }{ }^{1635}\end{array}$ \\
\hline $\begin{array}{l}\text { Reflexion und } \\
\text { Erweiterung } \\
\text { des Welt- und } \\
\text { Fremdverste- } \\
\text { hens }\end{array}$ & Basal & $\begin{array}{l}\text { Die Besuchenden sind «in der Lage, in irgendeiner Weise zu } \\
\text { kommunizieren, dass die Ausstellung etwas an ihren vorherigen } \\
\text { Vorstellungen über den ausgestellten Zusammenhang, die } \\
\text { fragliche Zeit, die damaligen Menschen geändert hat». }{ }^{1636}\end{array}$ \\
\hline
\end{tabular}

1631 Für die Zusammenstellung der Komponenten historischer Orientierungskompetenz beziehe ich mich ausschliesslich auf Körber 2010a, dort wiederum auf den Bereich «Fragen zur Kompetenzdiagnostik» (Körber 2010a S. 3 ff.) und übernehme daraus eine gekürzte Auswahl.

1632 Körber 2010a, S. 5.

1633 Körber 2010a, S. 4.

1634 Körber 2010a, S. 4.

1635 Körber 2010a, S. 3.

1636 Körber 2010a, S. 5. 


\begin{tabular}{|c|c|c|}
\hline $\begin{array}{l}\text { Kern- } \\
\text { kompetenz }\end{array}$ & $\begin{array}{l}\text { Niveau- } \\
\text { stufe }\end{array}$ & Beschreibung \\
\hline \multirow[t]{2}{*}{$\begin{array}{l}\text { Reflexion und } \\
\text { Erweiterung } \\
\text { des Welt- und } \\
\text { Fremdverste- } \\
\text { hens (Forts.) }\end{array}$} & $\begin{array}{l}\text { Inter- } \\
\text { mediär }\end{array}$ & $\begin{array}{l}\text { Die Besuchenden können «das in der Ausstellung [...] } \\
\text { Ausgestellte als Dokumente aus einer bzw. Aussagen über eine } \\
\text { Lebenswirklichkeit [...] erkennen, die sich von ihrer } \\
\text { unterscheidet». }{ }^{1637} \\
\text { Die Besuchenden können «die für sie neuen Erkenntnisse über } \\
\text { den dargestellten Zusammenhang begrifflich [...] fassen». }{ }^{1638} \\
\text { Die Besuchenden sind «in der Lage und bereit, andere } \\
\text { Lebens- und Denkweisen probehalber zu durchdenken, und } \\
\text { können [...] dabei auf gängige Konzepte zurückgreifen } \\
\text { (ıanders, nicht rückständig;; (primitiv), (zwar damals - heute } \\
\text { aber», (damals noch))». }{ }^{1639}\end{array}$ \\
\hline & $\begin{array}{l}\text { Elabo- } \\
\text { riert }\end{array}$ & $\begin{array}{l}\text { Die Besuchenden sind «in der Lage, ihre eigenen Bemühungen } \\
\text { um das Verständnis der dargestellten Menschen, Lebensverhält- } \\
\text { nisse als perspektivische Versuche und als nie ganz gelingend } \\
\text { anzuerkennen». } 1640\end{array}$ \\
\hline \multirow[t]{3}{*}{$\begin{array}{l}\text { Reflexion des } \\
\text { Selbst- } \\
\text { verstehens }^{1641}\end{array}$} & Basal & $\begin{array}{l}\text { Die Besuchenden können «irgendwelche Aussagen darüber } \\
\text { [machen], dass sie das gesehene [sic] auf sich und die eigene } \\
\text { Zeit beziehen». }{ }^{1642}\end{array}$ \\
\hline & $\begin{array}{l}\text { Inter- } \\
\text { mediär }\end{array}$ & $\begin{array}{l}\text { Die Besuchenden sind «in der Lage, sich selbst unter Rückgriff } \\
\text { auf bekannte Kategorien zum Gegenstand in eine Beziehung zu } \\
\text { setzen und ihre eigene Perspektive unter Rückgriff auf diese } \\
\text { Kategorien zu definieren und zu reflektieren», zum Beispiel } \\
\text { «ılch als Nachgeborener»». }{ }^{1643}\end{array}$ \\
\hline & $\begin{array}{l}\text { Elabo- } \\
\text { riert }\end{array}$ & $\begin{array}{l}\text { Die Besuchenden können «die ihnen in der Ausstellung } \\
\text { angebotenen Deutungsmuster des eigenen Verhältnisses zur } \\
\text { dargebotenen Geschichte kritisch reflektieren». }{ }^{1644} \\
\text { Die Besuchenden sind «in der Lage, die eigenen Denk- und } \\
\text { Urteilsmuster als solche zu erkennen». }{ }^{1645}\end{array}$ \\
\hline
\end{tabular}

1637 Körber 2010a, S. 4.

1638 Körber 2010a, S. 4.

1639 Körber 2010a, S. 4.

1640 Körber 2010a, S. 3

1641 Körber benennt diese Kategorie als «Reflexion», nicht aber als «Erweiterung», obwohl dies im Kompetenz-Strukturmodell so vorgesehen wäre (Körber et al. 2007, S. 253). Inwiefern es sich hierbei um ein Versehen handelt oder bewusst gesetzt wurde, ist unklar.

1642 Körber 2010a, S. 5.

1643 Körber 2010a, S. 4.

1644 Körber 2010a, S. 3

1645 Körber 2010a, S. 3. 


\begin{tabular}{|c|c|c|}
\hline $\begin{array}{l}\text { Kern- } \\
\text { kompetenz }\end{array}$ & $\begin{array}{l}\text { Niveau- } \\
\text { stufe }\end{array}$ & Beschreibung \\
\hline \multirow{3}{*}{$\begin{array}{l}\text { Reflexion und } \\
\text { Erweiterung } \\
\text { der Handlungs- } \\
\text { disposition }\end{array}$} & Basal & $\begin{array}{l}\text { Die Besuchenden sind «in der Lage, in irgendeiner Weise zu } \\
\text { kommunizieren, dass das Gesehene oder der Besuch sie zu } \\
\text { einem bestimmten Verhalten anregt, auffordert». }{ }^{1646}\end{array}$ \\
\hline & $\begin{array}{l}\text { Inter- } \\
\text { mediär }\end{array}$ & $\begin{array}{l}\text { Die Besuchenden können «eine von der Ausstellung empfange- } \\
\text { ne Anregung zu einem bestimmten Verhalten [...] } \\
\text { benennen». }{ }^{1647} \\
\text { Die Besuchenden sind «in der Lage, untereinander anschlussfähig, } \\
\text { mit gemeinsam akzeptierten Begriffen über Handlungsoptionen zu } \\
\text { sprechen, die ihnen in der Gesellschaft angeboten werden». }{ }^{1648} \\
\text { Die Besuchenden können «zwischen gesellschaftlich diskutier- } \\
\text { ten Handlungsoptionen abwägen». }{ }^{1649}\end{array}$ \\
\hline & $\begin{array}{l}\text { Elabo- } \\
\text { riert }\end{array}$ & $\begin{array}{l}\text { Die Besuchenden sind «in der Lage, ıgesellschaftlich» (bzw.: in } \\
\text { der Ausstellung [...]) angebotene Handlungsoptionen kritisch } \\
\text { zu reflektieren». }{ }^{1650} \\
\text { Die Besuchenden sind «in der Lage, etwaige Parallelisierungen } \\
\text { zu Heute bzw. Weiterentwicklungen abwägend zu } \\
\text { reflektieren». }{ }^{1651}\end{array}$ \\
\hline
\end{tabular}

Tabelle B: Die Altersverteilung der Teilnehmenden

\begin{tabular}{l|c|c}
\hline Altersgruppe & $\begin{array}{l}\text { Anzahl } \\
\text { Teilnehmende } \\
(\mathrm{N})\end{array}$ & $\begin{array}{l}\text { Anteil } \\
\text { Teilnehmende } \\
(\%)\end{array}$ \\
\hline $20-29$ Jahre & 2 & 11.1 \\
\hline $30-39$ Jahre & 6 & 33.3 \\
\hline $40-49$ Jahre & 3 & 16.7 \\
\hline $50-59$ Jahre & 1 & 5.6 \\
\hline $60-69$ Jahre & 5 & 27.8 \\
\hline$\geq 70$ Jahre & 1 & 5.6 \\
\hline Summe & 18 & 100.0 \\
\hline
\end{tabular}

1646 Körber 2010a, S. 5.

1647 Körber 2010a, S. 4.

1648 Körber 2010a, S. 4.

1649 Körber 2010a, S. 4.

1650 Körber 2010a, S. 3.

1651 Körber 2010a, S. 3. 
Tabelle C: Die Bildungsabschlüsse der Teilnehmenden

\begin{tabular}{|c|c|c|}
\hline Höchster Bildungsabschluss & $\begin{array}{l}\text { Anzahl } \\
\text { Teilnehmende } \\
\text { (N) }\end{array}$ & $\begin{array}{l}\text { Anteil } \\
\text { Teilnehmende } \\
(\%)\end{array}$ \\
\hline $\begin{array}{l}\text { Hochschulabschluss (Tertiär A), } \\
\text { teilweise inkl. abgeschlossenem Doktorat ( } 2 \text { Personen) } \\
\text { oder laufendem Doktorat (4 Personen) }\end{array}$ & 11 & 61.1 \\
\hline Lehrerseminar & 1 & 5.6 \\
\hline $\begin{array}{l}\text { Maturität/Abitur und/oder Berufsbildung } \\
\text { (Sekundarstufe II, ggf. Tertiär B }{ }^{1652} \text { ), } \\
\text { davon teilweise aktuell studierend (2 Personen) }\end{array}$ & 6 & 33.3 \\
\hline Obligatorische Schulzeit (Sekundarstufe I) & 0 & 0.0 \\
\hline Summe & 18 & 100.0 \\
\hline
\end{tabular}

Tabelle D: Die fachlichen Hintergründe der Teilnehmenden

\begin{tabular}{l|c|c|l}
\hline Person & $\begin{array}{l}\text { Geschichts- } \\
\text { wissenschaftlicher } \\
\text { Hintergrund }\end{array}$ & $\begin{array}{l}\text { Geschichtsdidaktischer und/ } \\
\text { oder museumsbezogener } \\
\text { Hintergrund }\end{array}$ & $\begin{array}{l}\text { Keines von } \\
\text { beiden }\end{array}$ \\
\hline P3 & $x$ & $x$ & \\
\hline P4 & $x$ & $x$ & \\
\hline P5 & $x$ & $x$ & \\
\hline P6 & $x$ & $x$ & \\
\hline P7 & $x$ & & \\
\hline P8 & $x$ & $x$ & \\
\hline P12 & $x$ & & \\
\hline
\end{tabular}

1652 Berufsbildungsabschlüsse haben unter anderem drei der älteren Teilnehmenden erworben. Der Erwerb dieser Abschlüsse fällt insofern mutmasslich eher in die Zeit vor der verstärkten Einführung von Abschlüssen der höheren Berufsbildung (Tertiär B). Die von mir verwendete Einteilung verfolgt das Ziel, Abschlüsse gemäss ihrer Wertigkeit zum Zeitpunkt der Diplomausstellung zu klassifizieren (in Anlehnung an die gewählte Vorgehensweise bei Kraus/Schmid/Thyroff 2013, S. 19). Allerdings habe ich bei den Teilnehmenden meiner Studie nicht explizit das Datum ihres Abschlusses und den zugehörigen Status erfragt. Es ist deshalb nicht völlig auszuschliessen, dass ein Teil der Teilnehmenden über Abschlüsse auch auf Ebene Tertiär B verfügt.

$\mathrm{Zu}$ Schwierigkeiten in der Klassifizierung von Abschlüssen im Zusammenhang mit der Tertiarisierung der Berufsbildung siehe beispielhaft auch: Kraus/Schmid/Thyroff 2013, S. 19. 


\begin{tabular}{l|l|l|l}
\hline Person & $\begin{array}{l}\text { Geschichts- } \\
\text { wissenschaftlicher } \\
\text { Hintergrund }\end{array}$ & $\begin{array}{l}\text { Geschichtsdidaktischer und/ } \\
\text { oder museumsbezogener } \\
\text { Hintergrund }\end{array}$ & $\begin{array}{l}\text { Keines von } \\
\text { beiden }\end{array}$ \\
\hline P13 & $\mathrm{x}$ & & $\mathrm{x}$ \\
\hline P18 & & & $\mathrm{x}$ \\
\hline P19 & & & $\mathrm{x}$ \\
\hline P20 & & & $\mathrm{x}$ \\
\hline P21 & & & $\mathrm{x}$ \\
\hline P22 & & $\mathrm{x}$ & $\mathrm{x}$ \\
\hline P25 & & & $\mathrm{x}$ \\
\hline P26 & & & $\mathrm{x}$ \\
\hline P27 & & & 9 \\
\hline P28 & 9 & & \\
\hline P30 & & & \\
\hline Summe & & & \\
\hline
\end{tabular}

Tabelle E: Die inhaltliche Gliederung der Ausstellung am Standort in Basel

\begin{tabular}{|c|c|c|c|}
\hline $\begin{array}{l}\text { Ausstellungs- } \\
\text { teil }\end{array}$ & \multicolumn{2}{|c|}{ Textüberschriften (Gliederungsebene 1 und 2) } & Ort \\
\hline \multirow{6}{*}{$\begin{array}{l}\text { Regional- } \\
\text { spezifische } \\
\text { Ergänzung }\end{array}$} & \multicolumn{2}{|c|}{$\begin{array}{l}\text {-ohne Überschrift- (Basler Stadtplan mit historischen } \\
\text { Fotografien) }\end{array}$} & EG \\
\hline & \multicolumn{2}{|c|}{ Basler Künstler 1914-1919 } & EG und Treppe \\
\hline & \multicolumn{2}{|l|}{ Mobilisierung } & UG Vorraum \\
\hline & \multicolumn{2}{|l|}{ Not } & UG Vorraum \\
\hline & \multicolumn{2}{|l|}{ Profite } & UG Vorraum \\
\hline & \multicolumn{2}{|l|}{ Wohlstand } & UG Vorraum \\
\hline \multirow{5}{*}{$\begin{array}{l}\text { Kern- } \\
\text { ausstellung } \\
\text { «14/18» }\end{array}$} & \multirow[t]{5}{*}{ Vor dem Krieg } & Gustave Ador & \multirow{5}{*}{$\begin{array}{l}\text { UG Vorraum } \\
\text { und innen }\end{array}$} \\
\hline & & Ernst Laur & \\
\hline & & Else Züblin-Spiller & \\
\hline & & Angelika Balabanoff & \\
\hline & & Alfred Frey & \\
\hline
\end{tabular}




\begin{tabular}{|c|c|c|c|}
\hline Ausstellungs- & \multicolumn{2}{|c|}{ Textüberschriften (Gliederungsebene 1 und 2) } & Ort \\
\hline \multirow{14}{*}{$\begin{array}{l}\text { Kern- } \\
\text { ausstellung } \\
\text { «14/18» Forts.) }\end{array}$} & \multirow[t]{4}{*}{ Krieg! } & $\begin{array}{l}\text { Mobilisierung und Grenz- } \\
\text { besetzung }\end{array}$ & \multirow[t]{4}{*}{ UG innen } \\
\hline & & Sympathien und Widerstreit & \\
\hline & & $\begin{array}{l}\text { Propaganda und der Wille zur } \\
\text { Einigkeit }\end{array}$ & \\
\hline & & Blick ins Ausland 1915 & \\
\hline & \multirow[t]{3}{*}{ Mitten im Krieg } & Wirtschaften von Tag zu Tag & \multirow[t]{3}{*}{ UG innen } \\
\hline & & $\begin{array}{l}\text { Milch und Brot: Landwirtschaft } \\
\text { im Umbruch }\end{array}$ & \\
\hline & & Blick ins Ausland 1916 & \\
\hline & \multirow[t]{7}{*}{ Wachsende Not } & Der Krieg zeigt Wirkung & \multirow[t]{7}{*}{ UG innen } \\
\hline & & $\begin{array}{l}\text { Kriegswirtschaft und Wirt- } \\
\text { schaftskrieg }\end{array}$ & \\
\hline & & Neutral von Fall zu Fall & \\
\hline & & Menschlichkeit und Kalkül & \\
\hline & & Fremde unter Beobachtung & \\
\hline & & Nicht arm und doch nicht satt & \\
\hline & & Blick ins Ausland 1917 & \\
\hline & \multirow{5}{*}{$\begin{array}{l}\text { Kriegsende } \\
\text { und Streik }\end{array}$} & Stimmen gegen den Krieg & \multirow[t]{5}{*}{ UG innen } \\
\hline & & Der Tisch bleibt leer & \\
\hline & & Streik! & \\
\hline & & 11.11.18 & \\
\hline & & Blick ins Ausland 1918 & \\
\hline & \multirow[t]{4}{*}{ Nach dem Krieg } & $\begin{array}{l}1948 \text { Sozialpolitik: Einführung } \\
\text { der AHV }\end{array}$ & \multirow[t]{4}{*}{ UG inner } \\
\hline & & $\begin{array}{l}1939 \text { Erinnerungskultur: Geistige } \\
\text { Landesverteidigung }\end{array}$ & \\
\hline & & $\begin{array}{l}1970 \text { Migration: Abstimmung zur } \\
\text { Schwarzenbach-Initiative }\end{array}$ & \\
\hline & & $\begin{array}{l}1999 \text { Landwirtschaft: Auflösung } \\
\text { der Käseunion }\end{array}$ & \\
\hline
\end{tabular}




\begin{tabular}{l|l|l|l}
\hline $\begin{array}{l}\text { Ausstellungs- } \\
\text { teil }\end{array}$ & \multicolumn{2}{|l|}{ Textüberschriften (Gliederungsebene 1 und 2) } & Ort \\
\hline $\begin{array}{l}\text { Kern- } \\
\text { ausstellung } \\
\text { «14/18» Forts.) }\end{array}$ & $\begin{array}{l}\text { Nach dem Krieg } \\
\text { (Forts.) }\end{array}$ & $\begin{array}{l}\text { 1971 Politische Gleichstellung: } \\
\text { Volksabstimmung zum } \\
\text { Frauenstimmrecht }\end{array}$ & \\
\cline { 2 - 3 } & $\begin{array}{l}\text { 2002 Aussenpolitik: Abstimmung } \\
\text { zum UNO-Beitritt }\end{array}$ & \\
\hline \multirow{2}{*}{$\begin{array}{l}\text { Regional- } \\
\text { spezifische } \\
\text { Ergänzung }\end{array}$} & Messe Basel & \multirow{2}{*}{ UG innen } \\
\cline { 2 - 3 } & Life Science & \\
\cline { 2 - 3 } & Port of Switzerland & \\
\cline { 2 - 3 } & Urban Farming & \\
\cline { 2 - 3 } & Messe 21 & \\
\hline
\end{tabular}

Tabelle F: Aktivitätsformen und Elementbezüge im Überblick

\begin{tabular}{l|l}
\hline Aktivitätstyp & Elementtyp \\
\hline $\begin{array}{l}\text { Freies Äussern } \\
\text { in Bezug auf oder } \\
\text { ausgehend von: }\end{array}$ & Bildquelle und deren Beschriftung ${ }^{1653}$ \\
\cline { 2 - 2 } & Textquelle und deren Beschriftung \\
\cline { 2 - 2 } & Dingquelle und deren Beschriftung \\
\cline { 2 - 2 } & Tonaufnahme \\
\cline { 2 - 2 } & Ausstellungstexte \\
\cline { 2 - 2 } & Sonstige Elemente \\
\cline { 2 - 2 } & Abteilungsebene \\
\cline { 2 - 2 } & Ausstellungsebene \\
\cline { 2 - 2 } & Ohne erkennbaren Bezug/Rest \\
\hline
\end{tabular}

1653 Bei den freien Äusserungen im Zusammenhang mit Quellen wurde nicht weiter dahingehend differenziert, ob freie Äusserungen im Zusammenhang mit der eigentlichen Quelle oder ihrer Beschriftung zustande kommen, da die beiden Aspekte im Material nicht sinnvoll $\mathrm{zu}$ trennen sind. 


\begin{tabular}{l|l}
\hline Aktivitätstyp & Elementtyp \\
\hline Lesen von: & Bildquellenbeschriftung \\
\cline { 2 - 2 } & Text in Bildquelle \\
\cline { 2 - 2 } & Textquelle \\
\cline { 2 - 2 } & Textquellenbeschriftung \\
\cline { 2 - 2 } & Dingquellenbeschriftung \\
\cline { 2 - 2 } & Text in Dingquelle \\
\cline { 2 - 2 } & Ausstellungstexte \\
\cline { 2 - 2 } & Sonstige Elemente \\
\hline
\end{tabular}




\section{Monika Waldis, Béatrice Ziegler (Hrsg.)}

\section{Forschungswerkstatt Geschichtsdidaktik 17}

\section{Beiträge zur Tagung »geschichtsdidaktik
empirisch $17 \ll$}

$\frac{\text { Oh }}{11}$ Geschichtsdidaktik heut

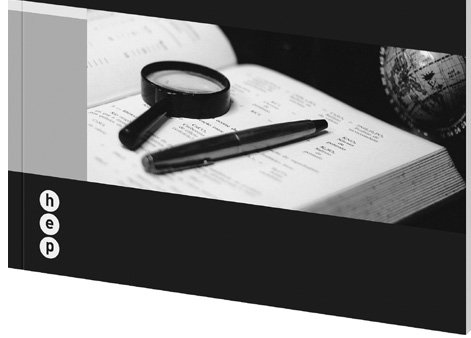

\section{Forschungs-} werkstatt

\section{Geschichts-}

didaktik 17

Beiträge zur Tagung «geschichtsdidaktik empirisch 17»

Der Band «Forschungswerkstatt Geschichtsdidaktik 17» versammelt verschiedene Beiträge der sechsten Ausgabe der Tagung «geschichtsdidaktik empirisch». Sie decken einerseits die drei Themenfelder ab, mit der sich die empirische Geschichtsdidaktik intensiv befasst. Im Blick sind die historischen Kompetenzen der Schülerinnen und Schüler und deren Messung, Fragen der Lehrerprofessionalität sowie das Verstehen von Lehr-Lern-Vorgängen im geschichtskulturellen Kontext. Darüber hinaus führen die Beiträge die Diskussionen über einen virulenten Forschungsaspekt weiter, der an der Tagung im Rahmen der Keynotes aufgegriffen wurde: die «Übersetzung» zwischen Theorie und Empirie. 


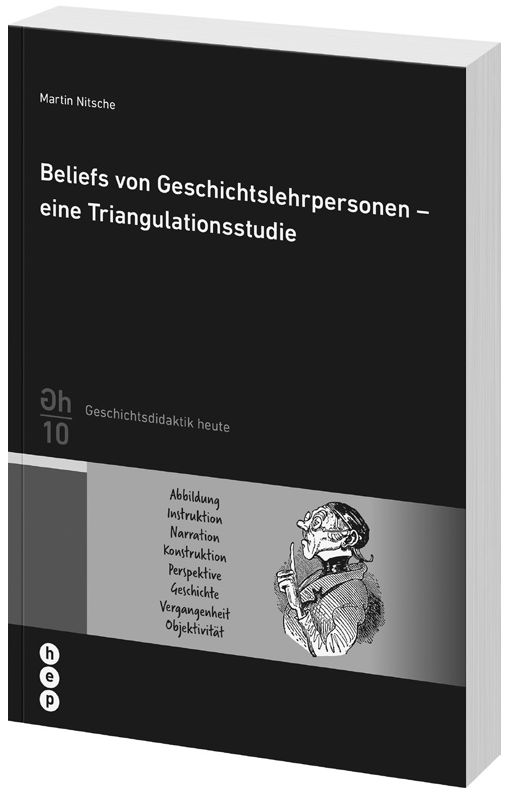

\section{Martin Nitsche}

\section{Beliefs von}

Geschichts-

lehrpersonen -

eine Triangulationsstudie

Angehende Geschichtslehrpersonen müssen sich während ihrer Professionalisierung mit geschichtstheoretischen und geschichts-

didaktischen Beliefs (Überzeugungen) beschäftigen. Welches sind aber diese Beliefs, und wie kommen sie zustande? Die quantitativ und qualitativ angelegte Studie liefert einen Einblick in die Wirksamkeit des Studiums und macht unter anderem deutlich, dass dort auch Annahmen evoziert werden, die nicht zum eigentlichen Ausbildungsziel gehören. Der Autor zeigt auf, inwiefern die Unterrichtspraxis der Lehrenden von bewussten und unbewussten Beliefs geprägt ist und dass eine verstärkte Auseinandersetzung mit der Ausbildungsgestaltung nötig ist. 


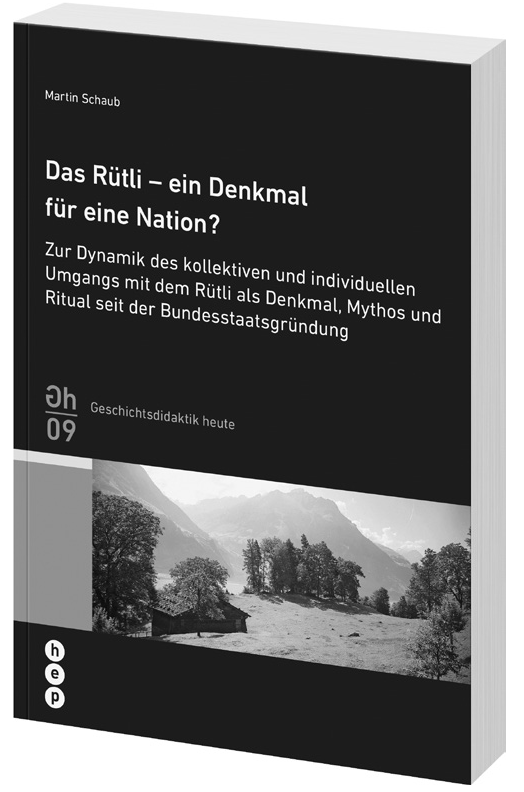

\section{Martin Schaub}

\section{Das Rütli - ein Denkmal für eine Nation?}

Zur Dynamik des kollektiven und individuellen Umgangs mit dem Rütli als Denkmal, Mythos und Ritual seit der Bundesstaatsgründung

Inwiefern sind Denkmäler Orte des informellen Geschichts-Erlebens und -Lernens? Konkret: Welches Wissen, welche Vorstellungen bringen Besucherinnen und Besucher mit? Wie nehmen sie das Denkmal wahr? Wie eignen sie sich den Ort an? Was nehmen sie mit? Die vorliegende Untersuchung fragt - am Beispiel des Rütlis nach dem individuellen und kollektiven Umgang mit einem Denkmal und zugleich nach dessen Gebrauch und Instrumentalisierung. Die im chronologischen Längsschnitt beobachtbare geschichtskulturelle Dynamik prägt auch die Denkmalgestaltung. Deren detaillierte Analyse und Deutung zeigt, wie und mit welcher Wirkungsabsicht der Schauplatz des Gründungsmythos inszeniert wurde und wird, und wie sich Gestaltung und Gebrauch gegenseitig beeinflussen.

Das Rütli, eines der wenigen Schweizer Nationaldenkmäler, bietet sich als Untersuchungsgegenstand ganz besonders an. Dies nicht nur wegen seiner isolierten Lage am See und seiner besonderen Beschaffenheit als begehbares Landschaftsdenkmal ohne (offensichtliches) Denkmalobjekt, sondern auch wegen seiner noch - grossen politisch-ideologische Strahlkraft als nationaler Mythos. 